\title{
FACULTAD DE BIOLOGIAA
}

Departamento de Biología Animal, Parasitologia, Ecologia,

Edafologia y Química Agrícola

(Área de Zoología)

EFECTO DE LOS INCENDIOS FORESTALES SOBRE LA DMERSIDAD Y ESTRUCTURA DE LA COMUNIDAD DE AVSPAS SPHECIFORMES EN EL P.N. DFARRIBES DEL DUERO QESTE ESTANOL)

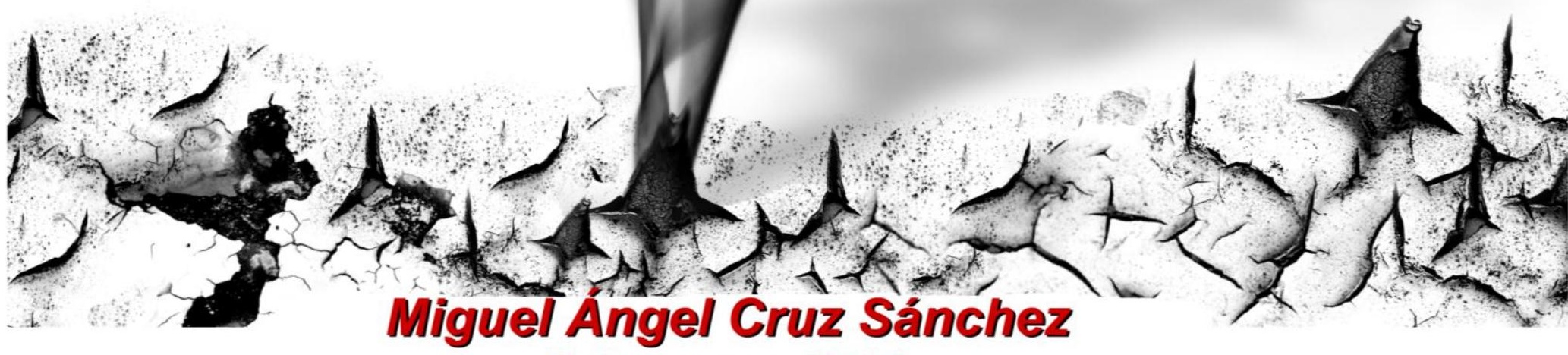
Salamanca, 2009 


\section{FACULTAD DE BIOLOGÍA}

Departamento de Biología Animal, Parasitología, Ecología, Edafología y Química Agrícola. (Área de Zoología)

EFECTO DE LOS INCENDIOS FORESTALES

SOBRE LA DIVERSIDAD Y ESTRUCTURA DE LA COMUNIDAD DE AVISPAS SPHECIFORMES, EN EL PARQUE NATURAL DE ARRIBES DEL DUERO (OESTE ESPAÑOL)

El doctorando, 
A mis padres, con amor y agradecimiento eternos. 
"La naturaleza no es frágil.. . Lo que es frágil son los servicios prestados por los ecosistemas, de los cuales dependen los humanos."

LEVIN, 1999 


\section{ÍNDICE}

\section{Agradecimientos}

1.- INTRODUCCIÓN

1.1. El fuego: función en los ecosistemas mediterráneos ............................. 9

1.1.1. Presencia histórica del fuego y acción antrópica ............................ 10

1.1.2. Susceptibilidad de los ecosistemas mediterráneos al fuego ............... 11

1.1.2.1. Factores climatológicos .......................................................... 12

1.1.2.2. Tipo de vegetación ........................................................... 12

1.1.2.3. Factores socio-económicos .............................................. 14

1.2. Régimen de incendios.................................................................................... 15

1.3. Tipos de incendios ................................................................................... 19

1.4. Efectos del fuego sobre las poblaciones animales .................................. 20

1.4.1. Respuesta de los artrópodos en general, y de los insectos en particular al fuego .................................................................... 21

1.4.1.1. Mortalidad o lesiones ......................................................... 22

1.4.1.2. Emigración e inmigración ................................................... 27

1.5. Bibliografía ........................................................................................................... 37

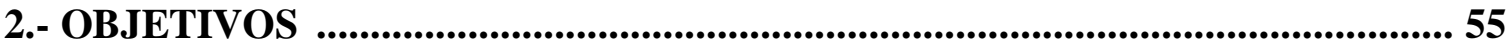

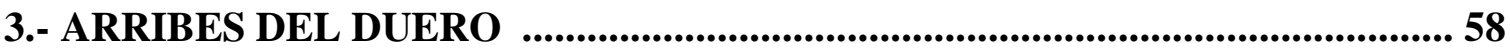

3.1. Introducción ......................................................................................................... 59

3.2. Situación geográfica ..................................................................................6 60

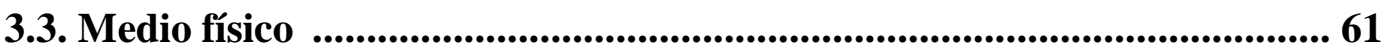

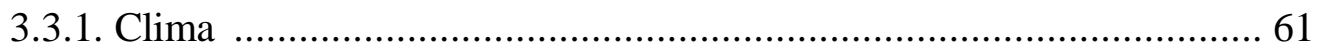

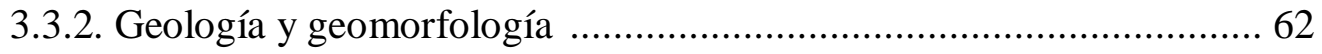

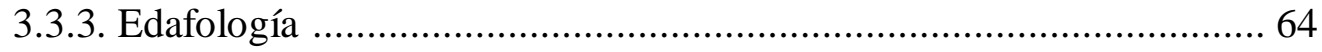

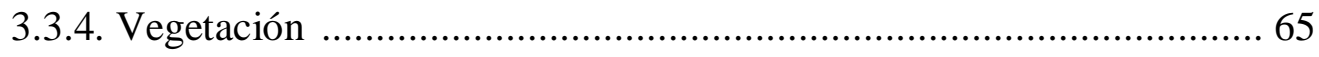

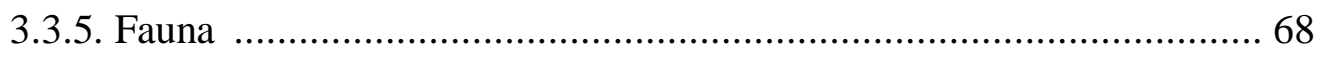

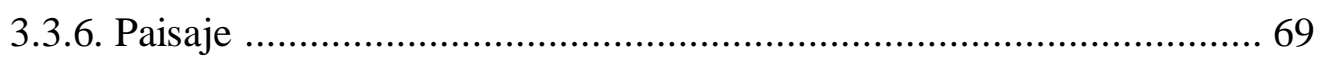

3.4. Medio socio-económico ....................................................................................... 70

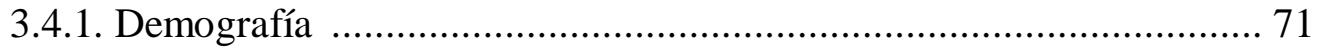

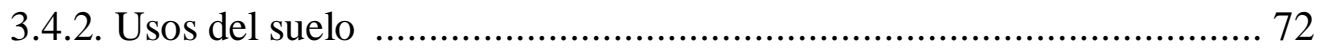

3.5. Relación con el fuego ............................................................................ 73

3.5.1. Análisis de riesgos y motivaciones sociales ................................. 75 


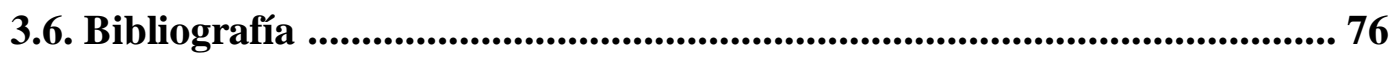

4.- SPHECIFORMES. ................................................................................................ 80

4.1. Avispas Spheciformes ................................................................ 81

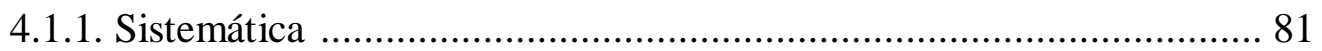

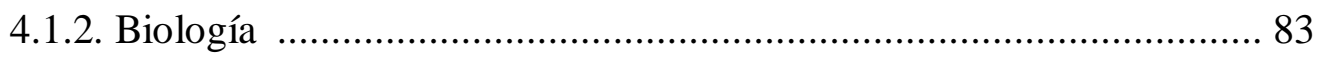

4.2. Protección y conservación de himenópteros aculeados ............................. 88

4.3. Bibliografía ............................................................................................... 91

5.- MATERIAL Y MÉTODOS............................................................................... 96

5.1. Descripción del área de estudio ............................................................... 97

5.2. Recolección de ejemplares .............................................................. 99

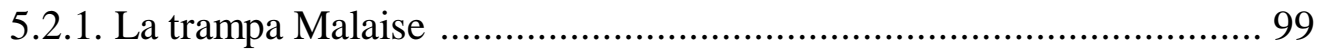

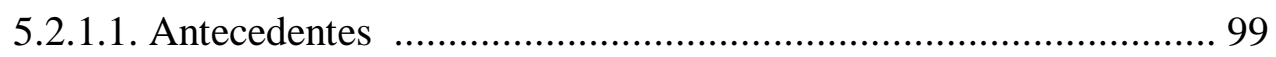

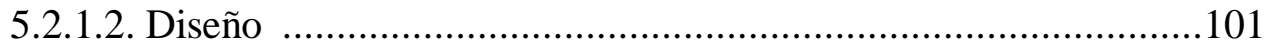

5.2.2. Platos de color amarillo (Yellow pan traps) ..................................103

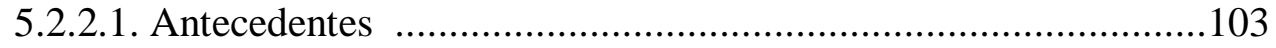

5.2.2.2. Descripción ................................................................... 104

5.3. Trabajo de campo ...............................................................................106

METOdOLOGÍA CORRESPONDIENTE AL APARTADO 6.1 .....................................108

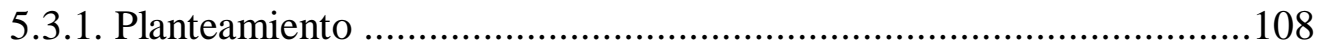

METODOLOGÍA CORRESPONDIENTE A LOS APARTADOS 6.2, 6.3 y $\underline{6.4}$................115

5.3.2. Planteamiento: sustitución de espacio por tiempo ...........................115

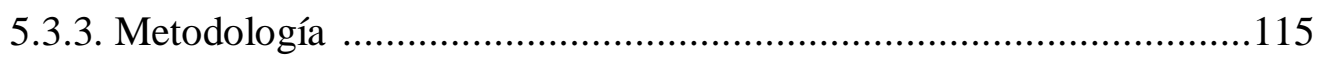

5.3.3.1. Muestreo de Spheciformes .................................................116

5.3.3.1.1. Metodología empleada con la trampa Malaise .................116

5.3.3.1.2. Metodología empleada con los platos amarillos ................117

5.3.3.2. Muestreo de la vegetación ......................................................119

5.4. Trabajo de laboratorio .................................................................134

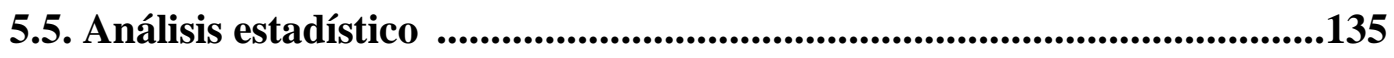

5.5.1. Diversidad y perturbación ............................................................135

5.5.2. Medición de la diversidad Alfa .....................................................138

5.5.3. Medición de la diversidad Beta ....................................................143

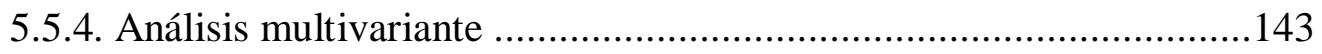

5.5.4.1. Análisis de Escalamiento Multidimensional (MDS) ................144 
5.5.4.3. Análisis de Componentes Principales (PCA)

5.6. Análisis de la composición gremial de la comunidad

6.1. Response of Spheciformes wasps communities (Hymenoptera: Apoidea) to wildfire in a Mediterranean ecosystem (Arribes del Duero Natural Park, western Spain).

6.2. Effects of wildfire on Spheciformes wasp diversity (Hymenoptera: Apoidea) in a Mediterranean agroecosystem of European interest .

6.3. Efecto de los incendios forestales sobre la estructura de la comunidad de avispas Spheciformes: importancia de las condiciones locales del hábitat.

6.4. Fuego vs. condiciones ambientales: influencia en la estructuración de comunidades de insectos depredadores. 


\section{INTRODUCCIÓN}

"Si toda la humanidad desapareciera, el mundo se regeneraría de nuevo hasta el rico estado de equilibrio existente hace diez mil años. Si los insectos desaparecieran, el medio ambiente se sumiría en el caos."

E. O.Wilson (1985)

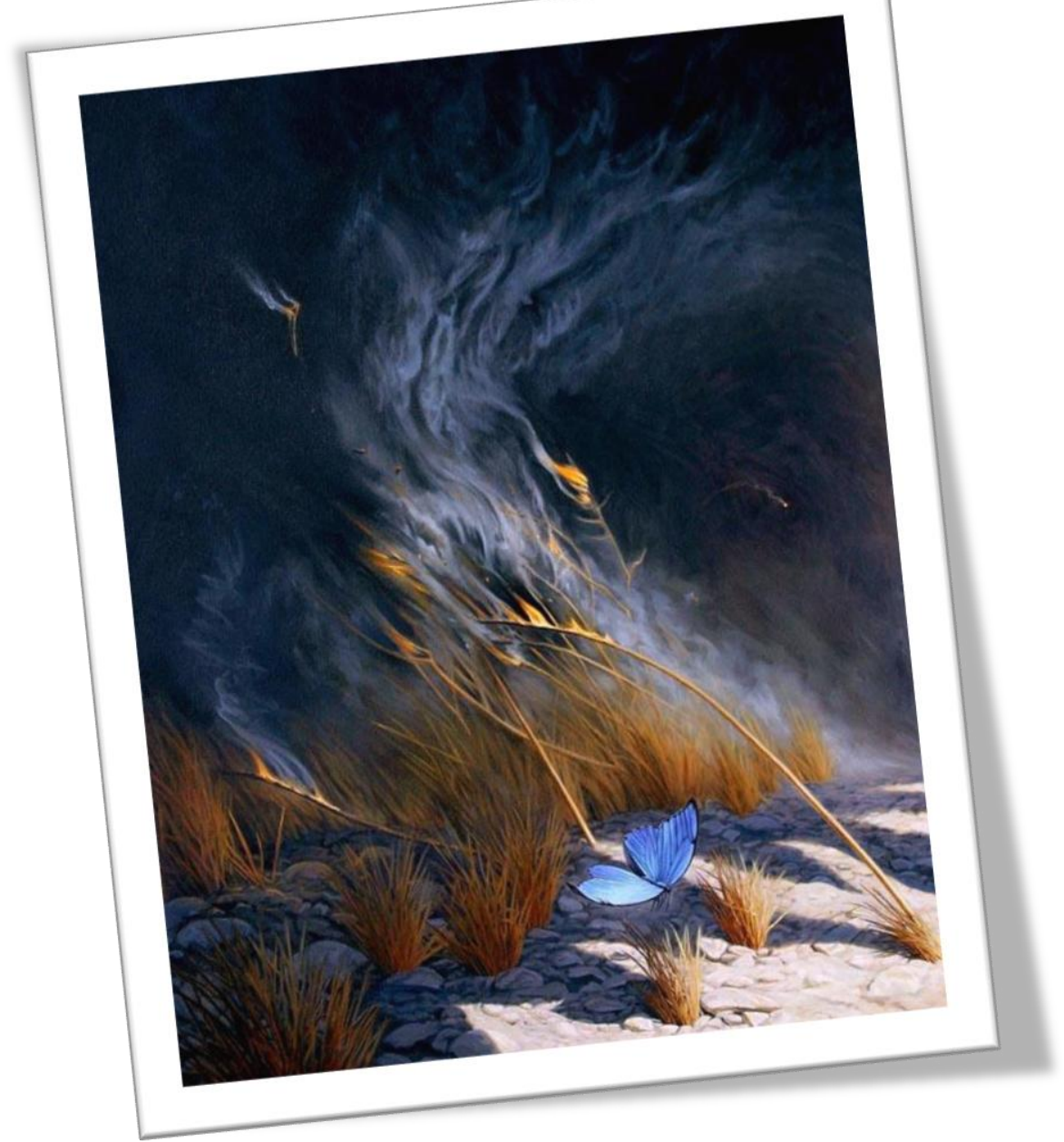

"La Teoría del Caos II" (Chris Jones) 
Los incendios forestales han estado presentes y forman parte de la historia del planeta desde el momento en el que aparece la vegetación (PAUSAS \& KEELEY, 2009). Es por ello que son fundamentales y característicos de un gran número de ecosistemas terrestres cuya composición y distribución está ligada al fuego en mayor o menor medida (WHELAN, 1995; PYNE et al., 1996; BOND \& VAN WILGEN, 1996; BOND et al., 2005; SHLISKY et al., 2007) (Figura 1). Entre ellos destacan los ecosistemas mediterráneos, especialmente afectados y ligados al fuego (NAVEH, 1975, 1995; Trabaud, 1981, 1998; Trabaud \& Prodon, 1993; Moreno \& OeChel, 1994; PAUSAS \& VALLEJO, 1999), dadas las características intrínsecas del clima y del tipo de vegetación que poseen, entre otras.

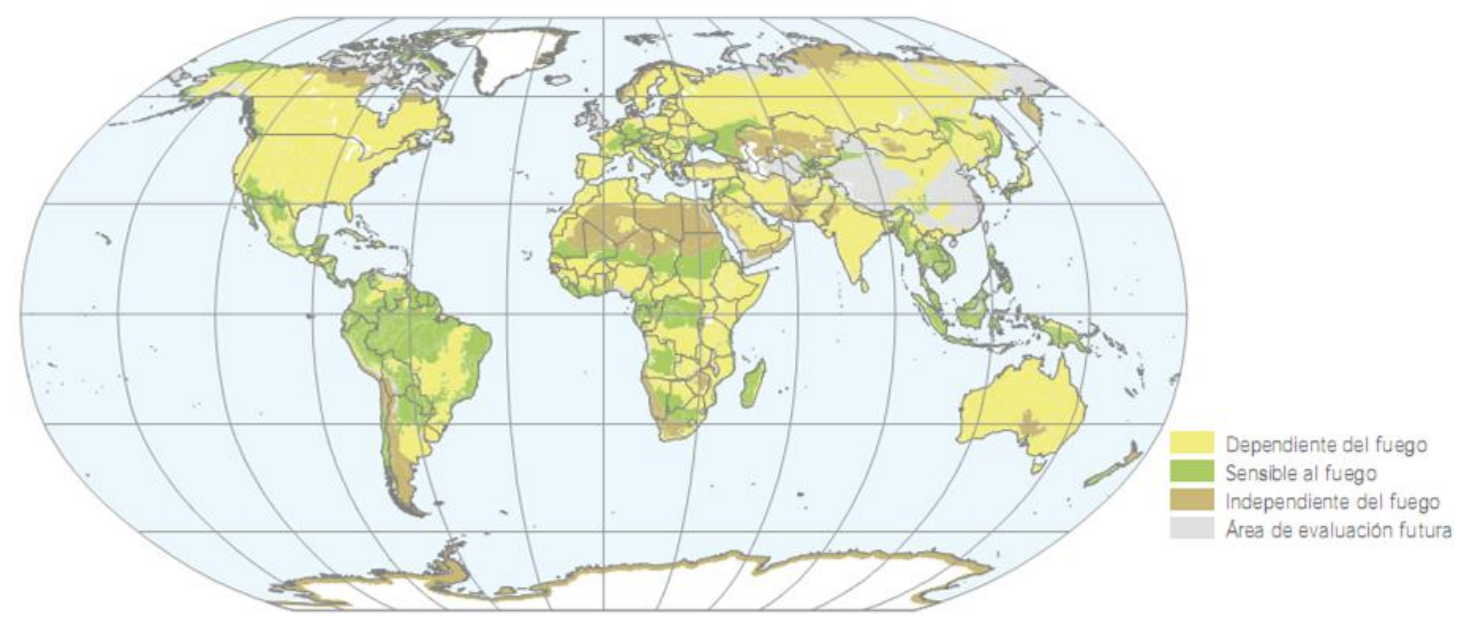

Figura 1: Distribución mundial de los tipos de regímenes de fuego. Imagen extraída y modificada de Shlisky et al., 2007.

Los incendios forestales son considerados por la sociedad como sucesos catastróficos que degradan y eliminan la vegetación natural, además de provocar cuantiosas pérdidas económicas y, en ocasiones, pérdida de vidas humanas. Sin embargo, resulta erróneo considerar el fuego como un agente de destrucción de la naturaleza (TRABAUD, 1998). A pesar de su papel destructor, también constituye un factor ecológico fundamental de la dinámica de muchos ecosistemas (NAVEH, 1975; RUNDEL, 1981; WHELAN, 1995; BOND \& VAN WILGEN, 1996; LLORET, 2003, 2004). El fuego, provoca la pérdida de individuos o biomasa y crea espacios y recursos que pueden ser colonizados por los individuos supervivientes, de la misma o de otras especies colonizadoras, ahora favorecidas por la aparición de nuevas condiciones 
ecológicas, o por la eliminación de la competencia ejercida por otras especies (Noble \& Slatyer, 1981; PicketT \& White, 1985; HobbS \& Gimmincham, 1987; PANZER, 2003; MoreTti et al., 2004, 2006). Es por todo ello, que el papel del fuego es reinterpretado desde el punto de vista de perturbación ecológica y conservación biológica (NAVEh, 1975; AtTiWILl, 1994; Whelan, 1995; BOND \& VAN WiLGEN, 1996; DeBANO et al., 1998; TRABAUd, 1998; DiAdEMA et al., 2007) reconociéndose su labor como participante activo en la formación, composición y estructura de los paisajes y bosques, en la evolución de especies y en la diversificación y mantenimiento de las comunidades vegetales y animales (TRABAUD \& PRODON, 1993; MoReno \& OeChel, 1994; BOND \& VAN WILGEN, 1996; VÁzQueZ \& RoDRíGUEZ, 2008). Tanto es así, que muchas de estas comunidades dependen de su existencia periódica para sobrevivir (WHELAN, 1995; BOND \& VAN WILGEN, 1996; SMITH, 2000) al ejercer este un papel beneficioso y actuar como un agente selectivo y regulador de las mismas (NAVEH, 1990; MORGAN \& LUNT, 1999; OESTERHELD et al., 1999; DIADEMA et al., 2007).

La "reciente" visión del fuego como un componente natural de los ecosistemas coincide con el estudio del papel que desempeña en la alteración de las comunidades vegetales, la confirmación de su capacidad resiliente, el estudio de los mecanismos de regeneración de la vegetación (NAVEH, 1975; 1995; TRABAUD, 1994; BOND \& VAN WILGEN, 1996) y el condicionamiento en la ecología humana (CALDARARO, 2002). Sin embargo, el estudio de los factores que determinan la respuesta regenerativa ha puesto también de relieve la existencia de límites en la capacidad de resiliencia (tiempo necesario para que la composición de especies de un lugar vuelva a ser la misma que antes del fuego), lo que sin duda afecta al funcionamiento de los ecosistemas. Estos límites están asociados a las características del régimen de incendios, del entorno físico y biológico, así como de las prácticas de manejo forestal llevadas a cabo. Por lo tanto, los efectos desfavorables del fuego sobre los ecosistemas forestales, dependen en gran medida de la alteración actual, por parte del hombre, del régimen de incendios, es decir, de su intensidad, frecuencia, estacionalidad o época en que tienen lugar, y extensión, así como de la existencia de diversos condicionantes (circunstancias locales del hábitat, clima, topografía...) que determinan la magnitud de su efecto (WHELAN, 1995; BOND \& VAN WILGEN, 1996) y su actuación como agente destructor (fuegos muy frecuentes, 
extensos y de gran intensidad), o creador de diversidad (menor frecuencia, intensidad y extensión). En este último caso, el paisaje resultante tras el paso del fuego es un paisaje compuesto por un complejo y heterogéneo mosaico de vegetación en regeneración (ver definiciones de mosaico en WHELAN, 2006) y fauna asociada, que favorece el mantenimiento y conservación de la riqueza y diversidad de especies (Whelan, 1995; BAILEy \& WhithaM, 2002; MoretTI \& BARbalat, 2004; SWENGEL \& SWENGEL, 2007).

Actualmente existe una gran cantidad de estudios relacionados con los efectos y respuestas de las comunidades vegetales al fuego (Ej. CALvo et al., 1991; LuISCalabuig \& TÁrRega, 1993; Ne’eman et al., 1993; Bond \& VAn Wilgen, 1996; Ojeda-Copete, 2001; TÁrrega et al., 1996, 2001; DíAZ-Delgado, 2003; HAUGAASEN et al., 2003; FERNÁNDEZ-SANTOS et al., 2004; FYNN et al., 2004; Rodrigo et al., 2004; DE LUIS et al., 2006; CAPITANIO \& CARCAILlET, 2008; PAULA et al., 2009 y bibliografía contenida en ella). Sin embargo, son escasos los trabajos referidos a los efectos del fuego sobre la fauna, dirigiéndose la mayoría de ellos a los vertebrados, y de manera especial a las aves (IZHAKI, 1993; PONS \& PRODON, 1996; IZHAKI \& ADAR, 1997; PONS, 1998; HOBSON, \& SCHIECK, 1999; DAVIS et al., 2000; HERRANDO \& Brotons, 2002; HERRANDO et al., 2003; MOREIRA et al, 2003; PONS et al., 2003; BROTONS et al., 2005; VALENTINE et al., 2007) y mamíferos (Ej. FONS et al., 1993; Monimeau et al., 2002; LeTNIC, 2003; PEEN et al., 2003; BRIANI et al., 2004; KopRoski et al., 2006; MATTHEWs et al., 2009) y, en menor medida, a anfibios y reptiles (CLIVILlé et al., 1997; BRISSON et al., 2003; PENN et al., 2003; GREENBERG \& WALDROP, 2008) y peces (FERNÁNDEZ \& SÁNCHEZ, 1996).

Menos frecuentes que los estudios sobre vertebrados, son los que tienen como objeto de análisis la respuesta de los artrópodos en general, y de los insectos en particular (ver NUNES et al., 2000 y SWENGEL, 2001 para una revisión; MORETTI et al., 2002a, 2002b, 2004, 2006; NIWA \& PECK, 2002; POTTs et al., 2003, 2005; MoretTi \& BARBALAT, 2004; SAINT-GERMAin et al., 2004; KNIGHT \& Holt, 2005; NUNES et al., 2006; CAMPBELl et al., 2007; GIBB \& HJÄLtÉN, 2007; HiROWATARI et al., 2007; BREECE et al., 2008; MÖLLENBECK et al., 2009; UNDERWOOD \& Christian, 2009; ANTUNES et al., 2009), siendo extremadamente escaso el número de los realizados en España, (GARCíA-VILLANUEVA et al., 1995, 1998; URONES \& 
MAJADAS, 2002; FERNÁNDEZ \& SALGADO, 2002, 2004; ARNAN et al., 2006; RODRIGO \& RETANA, 2006; RODRIGO et al., 2008), a pesar de la gran transcendencia e impacto que tiene este tipo de perturbación sobre nuestros bosques.

Los insectos, como el grupo de animales más diverso que existe en el planeta con más del $80 \%$ de las especies descritas, tanto a nivel mundial (WILSON, 1992; FoOTTIT \& ADLER, 2009) como en la Península Ibérica (RAMOS et al., 2001), son un componente fundamental de la biodiversidad en todos los ecosistemas terrestres (OlEMBO, 1991; KIM, 1993; SAMWAYS, 1990, 1994) y realizan una labor fundamental e imprescindible en el mantenimiento y desarrollo de los ecosistemas forestales (DAJOZ, 2001; ScHOWALTER, 2006; SCUDDER, 2009). Por este motivo, la pérdida y alteraciones sufridas por las masas forestales amenazan la supervivencia de muchas de sus especies que se ven sometidas a distintos tipos de impactos y, al consiguiente peligro de extinción (BROOK et al., 2003; DunN, 2005; SAMWAYS, 2006, 2007; HANSKI et al., 2007; SODHI et al., 2009).

Los insectos, gracias a sus cortos ciclos biológicos, elevado tamaño de sus poblaciones, rápida respuesta a las perturbaciones ambientales y facilidad de captura, pueden actuar como buenos indicadores del estado de conservación de los ecosistemas, de la sostenibilidad de un paisaje determinado o de cambios en la diversidad general de un territorio debidos al impacto humano (SAMWAYS, 1989; Holloway \& Stork, 1991; Kremen et al., 1993, 1994; SAmWAys, 1994; LufF \& WoiWod, 1995; Finnamore, 1996; TscharntKe et al., 1998; PAOletTI, 1999). Actualmente no existe ninguna duda acerca de la importancia que tiene la preservación de los hábitats para conservar los insectos (COLLINS \& THOMAS, 1991; GASTON et al., 1993; SAMWAYS, 1994; MATHESON et al., 1996; KIRBY, 2001; SAMWAYS, 2007).

Las respuestas ofrecidas por los distintos grupos de insectos al fuego varía mucho de unos estudios a otros (SWENGEL, 2001) en función de distintos parámetros (especies, hábitat analizado, régimen de fuego, etc.) que se detallarán más adelante, y que complican en gran manera la comparación entre ellos y la extracción de unos resultados "generales" para cada grupo y hábitat particular (WHELAN, 1995; NUNES et al., 2000; SwENGEL, 2001; MORETTI et al., 2004). Sus respuestas, reguladas por factores intrínsecos y específicos de cada especie (Ej. BUDDLE et al., 2000; HANULA 
\& WADE, 2003; MORETTI et al., 2004, 2006; HiROWATARI et al., 2007), están principalmente relacionadas con el grado de exposición a temperaturas letales, y al estrés experimentado en el medio después del fuego. Se pueden citar así casos tan dispares como aquellos en los que las especies presentan una gran resiliencia a las modificaciones sufridas por el hábitat (WIKARS, 2002; HANULA \& WADE, 2003; PARR et al., 2004), otros en los que la recuperación es más lenta (NE’EMAN et al., 2000; POTTS et al. 2003; MORETTI et al., 2006), y algunos en los que las especies se ven favorecidas por la presencia de este tipo de perturbaciones y las alteraciones que provoca en el hábitat (HOLLIDAY, 1991; KAILA et al., 1997; ANDERSEN \& YEN, 1985; PORTER \& REDACK, 1996; WIKARS, 2002; SAINT-GERMAIN et al., 2004; CAMPBELL et $a l .$, 2007; HiROWATARI et al., 2007), y otros en los que se ven perjudicadas (Hermann et al., 1998; Swengel, 1998a; PotTs et al., 2001; PANZer, 2003; PANZER \& SchWARTZ, 2000; York, 1999; CleAry \& Grill, 2004; MORETTI et al., 2004) o inalteradas (Bock \& Bock, 1991; Collett \& Neumann, 1995; SiEmann et al., 1997; ANDERSEN \& MÜLLER, 2000). Se pueden citar también muchos casos en los que determinadas especies características de espacios abiertos aumentan tras el fuego, mientras que otras especies pertenecientes a bosques cerrados disminuyen en zonas quemadas (LOCKWOOD et al., 1996; BudDLE et al., 2000; FERNÁNDEZ \& SALGADO, 2004; MORETTI et al., 2004, 2006; RodRIGO \& RETANA, 2006; RODRIGO et al., 2008). Otros estudios indican que especies escasas o amenazadas se ven favorecidas (SIMILÄ et al., 2002; MORETTI et al., 2004) o perjudicadas (SPRINGETT, 1976; ØKLAND, 1994; YANOVSKY \& KISELEV, 1996; YORK, 1998), por los efectos del fuego.

La gran mayoría de este tipo de estudios se ha basado en el uso del fuego como herramienta de manejo forestal, principalmente con fines conservacionistas y preventivos ante sucesos incendiarios potencialmente desastrosos, o como método para favorecer la presencia de determinadas especies (NUNES et al., 2006). Para ello se emplean quemas controladas (prescritas) de parcelas previamente delimitadas, y con los diferentes parámetros que definen el régimen de incendios bajo control (generalmente basados en quemas de baja intensidad y extensión del fuego, realizadas en épocas relativamente húmedas) y que poco o nada tienen que ver con los derivados de un suceso de origen natural. Este tipo de análisis, aunque fundamentales allí donde el fuego constituye una herramienta de conservación, no 
reflejan el verdadero efecto del fuego en áreas dominadas por los incendios (cada vez más frecuentes, intensos, extensos y originados en la época seca) en las que su utilización, incluso con fines conservacionistas no está permitida, bien sea por motivos políticos, ecológicos o sociales. Por esta causa las comparaciones establecidas con ellos deben tomarse con precaución. Este es el caso de España, donde la creciente frecuencia y magnitud de los incendios, mantiene una política de lucha contra el fuego basada en la supresión. Así, pocos son los estudios que como el que se presenta en esta memoria, analizan la respuesta de los insectos ante incendios forestales no controlados (Ej. LOCKWOOD et al., 1996; BOCK \& BOCK, 1991; MORETTI \& BARBALAT, 2004; MORETTI et al., 2006).

El escenario creado por el gran número de especies conocidas ha conducido a que la mayoría de los estudios se hayan focalizado hacia grupos que reaccionan sensiblemente ante este tipo de perturbación, y que pueden utilizarse como indicadores ecológicos, como son los escarabajos, hormigas, colémbolos y mariposas (revisado por NUNES et al., 2000). Sin embargo, para alcanzar un mayor grado de conocimiento de cómo actúa el fuego sobre las poblaciones de insectos, y dada la heterogeneidad de los resultados obtenidos hasta ahora (SWENGEL, 2001), se hace necesario ampliar el análisis a otros grupos que también sean indicadores del estado de los ecosistemas, que estén sujetos a peligro de extinción por ocupar un nivel trófico elevado, que sean indicadores del estado de la diversidad local, tengan una influencia significativa sobre la diversidad de otros organismos y permitan a su vez un mejor seguimiento y predicción de los efectos que este tipo de perturbaciones ejercen sobre diferentes tipos de hábitats. Entre los grupos que cumplen estas características se encuentra el formado por los himenópteros aculeados (Aculeata). Estos himenópteros son vitales en los ecosistemas terrestres y especialmente sensibles a ciertas formas de perturbación, (GAULD et al., 1990; DAY, 1991; LASALLE \& GAULD, 1993) convirtiéndose en indicadores biológicos particularmente importantes (DAY, 1991).

Dentro de los Aculeata, los Spheciformes, ya propuestos como grupo indicador de biodiversidad (ver GAYUBO et al., 2005), mantienen una estrecha relación con la estructura del medio (STEFFAN-DEWENTER, 2002; STEFFANDEWENTER \& LeSChKe, 2003; PotTS et al., 2005; TAKi et al., 2008; SOBEK et al., 
2009), manifestada por la necesidad de vegetación florecida por parte de los individuos adultos para alimentarse y sustratos viables para nidificar, así como por la presencia de insectos (arañas en algunos casos), sobre los que depredan las hembras para alimentar a sus larvas (O’NeILL, 2001); todo esto los hace especialmente sensibles a las transformaciones provocadas por el fuego $\mathrm{u}$ otros tipos de perturbaciones. Del mismo modo, considerando su comportamiento depredador con fines pedotróficos y la cantidad de presas capturadas (O’NeILL, 2001), podrían reflejar a su vez la recuperación de otros grupos de insectos tras la perturbación e incluso vertebrados como las aves insectívoras.

Entre los estudios existentes (ver las revisiones realizadas por NUNES et al., 2000; SwEngEL, 2001), apenas se analiza la respuesta al fuego por parte de los Hymenoptera (excluyendo a las hormigas que es uno de los grupos más estudiados y con una respuesta más favorable ante este tipo de perturbación, por su adaptación a condiciones xéricas fundamentalmente), centrándose la mayoría de ellos sobre abejas y su papel como polinizadores (Ej. LOCKWOOD et al., 1996; NE'EMAN et al., 2000; PotTs et al., 2001, 2003, 2005; MoretTI et al., 2004, 2006; CAMPBELL, 2007). No existe, por tanto, ningún trabajo específico sobre las avispas Spheciformes, si bien en alguno de ellos aparecen recogidas ciertas especies, de manera casi testimonial (Ej. LOCKWOOD et al., 1996; MoRETTI et al., 2004; 2006; CAMPBELl et al., 2007), manifestando generalmente una respuesta positiva al impacto provocado por el fuego.

Dada la inexistencia de información disponible, este trabajo no solamente basa su relevancia en ser el primer análisis llevado a cabo de la respuesta de las avispas Spheciformes ante el impacto provocado por el fuego, en un enclave natural especialmente afectado por este tipo de perturbaciones dentro de la Península Ibérica, como es el Parque Natural de Arribes del Duero (oeste español), sino en su posible papel como indicador de la respuesta de otros grupos de insectos. Este Espacio Protegido se caracteriza por su gran diversidad entomológica y significado biogeográfico (GONZÁLEZ, 2002; GONZÁLEZ et al., 2009), lo que le confiere una extraordinaria importancia ante una gran amenaza ambiental de nuestros días, a la que contribuyen los grandes incendios forestales que provocan la fragmentación de los ecosistemas en pequeños islotes de difícil comunicación entre sí. 


\section{1.- EL FUEGO: FUNCIÓN EN LOS ECOSISTEMAS MEDITERRÁNEOS}

Los incendios forestales constituyen el tipo de perturbación natural más importante que soportan los ecosistemas mediterráneos (NAVEH, 1975; TRABAUD, 1981; Moreno \& Oechel, 1994; Bond \& VAN Wilgen, 1996; Trabaud, 1998). Cuando estos incendios son provocados por el hombre, de manera incontrolada, se consideran como uno de los principales problemas de bosques y matorrales (SCARASCIA-MugNOZZA et al., 2000) ya que se altera el régimen natural de perturbación, transformándose los efectos ecológicamente beneficiosos del mismo en algo potencialmente dañino y perjudicial.

Esto cobra una especial relevancia debido a que la Cuenca Mediterránea está considerada como uno de los puntos calientes ("hotspots") de la diversidad global (MYERS et al., 2000), contando además con un gran número de endemismos y especies relictas como valor añadido (Ej. MÉDAIL \& QuÉZEL, 1999; BALLETO \& CASAle, 1991; RAMOS et al., 2001). Además de la elevada cantidad de especies que posee, la Cuenca Mediterránea cuenta también con una alta diversidad de unidades de paisaje, modos de vida y aspectos socio-económicos de las poblaciones humanas (BLONDEL \& ARONSON, 1999) que la dotan de unas características particulares frente al resto de regiones con clima mediterráneo.

Muchas de estas actividades humanas, y sus efectos sobre el medio, suponen un grave riesgo para la conservación y mantenimiento de esta elevada diversidad (SALA et al., 2000), si bien, debido a la gran presencia y alteración ejercida por parte del hombre en estos ecosistemas desde hace miles de años, esta diversidad es difícil de entender y conservar sin un cierto grado de intervención antropogénica en ellos (BENGTSSON et al., 2000; VALLADARES, 2004, 2007; VALLADARES et al., 2008).

Actualmente, se puede afirmar que las diferentes formas de exceso de explotación por parte del hombre (tala de árboles, agricultura, etc.) y sus rebaños de animales domésticos, ha contribuido a modelar los paisajes que existen hoy en día en los países de la Cuenca Mediterránea. Esto ha provocado la virtual desaparición de la mayoría de los bosques clímax en dicha región, de manera que los remanentes, llamados bosques naturales, son bosque alterados, más o menos intensamente 
manejados por el hombre, que generalmente se corresponden con estados sucesionales regresivos de los bosques originales (SCARASCIA-MUGNOZZA, et al., 2000; VALLADARES, 2007). A este tipo de impactos, hay que sumar el provocado por los incendios forestales, que han contribuido también a crear los diferentes tipos de vegetación y a configurar el paisaje existente en el entorno mediterráneo, jugando a su vez un importante papel en el mantenimiento de la diversidad biológica de las comunidades mediterráneas, ya sean vegetales (TRABAUd \& PRODON, 1993; PAUSAS \& VAllejo, 1999; PAusAs et al., 2008) o animales (ProdON \& ATHIAS-BrinCHE, 1987; IZHAKI, 1993). Es por ello que un conocimiento de la antigua dinámica de perturbaciones y cómo están relacionadas con las originadas por el hombre, es esencial para preservar y manejar la biodiversidad así como las funciones de los ecosistemas en estos bosques, actualmente dominados por el hombre (NILSSON \& ERICSSON, 1997; CONEDERA et al., 2009).

\subsection{1.- PRESENCIA HISTÓRICA DEL FUEGO Y ACCIÓN ANTRÓPICA}

Al principio el fuego era un agente que se manifestaba más o menos regularmente en el ciclo natural de la dinámica de los ecosistemas. Su acción promovía la renovación de ciertas poblaciones vegetales y creaba un mosaico de comunidades en diferentes estados sucesionales; la aparición del hombre perturbó el equilibrio natural sustituyéndolo por una situación artificial y trastocando todo el orden original. Se ha sugerido la utilización del fuego por parte del hombre desde el Paleolítico (BIRD et al., 2008), pero no hay evidencia clara de su utilización en la Cuenca Mediterránea hasta el Neolítico (NAVEH, 1975; VAlladAres et al., 2008; PAUSAS \& KEELEY, 2009).

La utilización tradicional del fuego como una herramienta para favorecer las prácticas de caza, agrícolas y ganaderas por parte del hombre, ha sido frecuente en las diferentes culturas que se han desarrollado en la Cuenca a lo largo de su historia, lo que unido a la tala de árboles, a la creación de pastos para los animales domésticos y a una agricultura extensiva muy agresiva (caracterizada por la eliminación de plantas competidoras y el arranque de sus raíces), ha contribuido a modelar los paisajes que existen hoy en día en los países Mediterráneos (TRABAUD, 1998), 
convirtiendo a su vez al fuego en un importante factor ecológico en sus ecosistemas (Naveh, 1975, 1990; Trabaud \& Prodon, 1993; Moreno \& Oechel, 1994).

A pesar de esta existencia del fuego en la Península en periodos anteriores a la romanización (RIERA-MORA \& ESTEBAN-AMAT, 1994; CARRIÓN \& VAN GEEL, 1999) y de la constancia de un pico de actividad de incendios durante la Edad Media, coincidiendo con la expansión ganadera, el mayor registro de incendios se produce en la actualidad, ligado a los grandes cambios socio-económicos experimentados en la Península Ibérica en general, y en España en particular, especialmente en las últimas décadas del siglo $\mathrm{XX}$, y al aumento de temperaturas derivado del cambio climático actual (MORENO, 2007).

Aunque la presencia del fuego por causas naturales, y sus efectos sobre la vegetación mediterránea de la Cuenca a lo largo de la historia podrían ser bastante importantes, como apunta OJEDA-COPETE (2001), hoy día, el fuego no puede calificarse exclusivamente como un fenómeno natural, de modo que el elevado riesgo de incendios forestales actual es considerado por algunos autores como un fenómeno relativamente reciente, asociado principalmente a la actividad humana (Millán et al., 1998; VÁZQUEZ \& MoRENO, 1998), y, además, muy ligado a las condiciones intrínsecas de los paisajes mediterráneos.

\subsection{2.- SUSCEPTIBILIDAD DE LOS ECOSISTEMAS MEDITERRÁNEOS AL FUEGO}

Hay varias características que diferencian a los paisajes de la Cuenca Mediterránea del resto de paisajes europeos. Estas diferencias están principalmente relacionadas con el clima, el gran e intenso impacto humano que han sufrido durante siglos de historia, y el papel ejercido por el fuego (muy influido por los otros dos) sobre ellos, su estructura y desarrollo. Todas estas características, y su interacción con diferentes factores geológicos, biogeográficos, topográficos y edáficos, dan lugar a comunidades muy complejas. Asimismo, todos esos factores son responsables de la generación y el mantenimiento de la diversidad biológica (BLONDEL \& ARANSON, 1999; GROVE \& RACKHAM, 2001).

Por otro lado, los ecosistemas mediterráneos se caracterizan por una excepcional heterogeneidad espacial y temporal, facilitada en gran medida por la 
acción del fuego (DíAZ-DELGADO, 2003), que da como resultado un paisaje formado por un complejo y dinámico mosaico de vegetación en regeneración y fauna asociada (RUNDEL et al., 1998).

1.1.2.1.- Factores climatológicos: El clima mediterráneo, comienza a establecerse en la Cuenca del Mediterráneo hace más de tres millones de años, apareciendo hace unos dos millones de años los primeros indicios de una vegetación mediterránea típica (GROVE \& RACKHAM, 2001; VALLADARES, et al., 2008). Se caracteriza por una marcada estacionalidad, generalmente con inviernos húmedos y fríos y veranos largos, secos y calurosos, con un determinado grado de aridez y en los que tienen lugar episodios de sequía relativamente frecuentes, si bien estos episodios pueden presentarse en cualquier época del año. Otra de las características del clima mediterráneo es su impredecible variación intra e interanual, sobre todo en lo que respecta a la distribución de las temperaturas y las precipitaciones, que en muchos casos marcará la diferencia entre el éxito o el fracaso en la recuperación de determinadas comunidades vegetales al fuego (OJEDA-COPETE, 2001). La escasez de agua es por tanto el factor limitante, tanto para el crecimiento vegetal y animal, como para las sociedades humanas.

Ante la actual tendencia de aumento de temperaturas y descenso de las precipitaciones, casi todas las predicciones auguran un incremento de los episodios de sequía, lo que contribuirá a un mayor desecado de la vegetación, elevando así el riesgo de incendios (VÉLEZ, 1995; Pĩ̃ol et al., 1998; Williams et al., 2001, Mouillot et al., 2002, PAuSAS, 2004a, 2004b; CASTro et al., 2005; BRUnET et al., 2006; MORENO, 2007).

1.1.2.2.- Tipo de vegetación: Las condiciones tan particulares mencionadas anteriormente (climatológicas, presión humana, fuego...), contribuyen también de manera muy importante en la evolución de la vegetación mediterránea (TRABAUD, 1981; VALLADARES, 2004; VALLADARES et al., 2008).

El fuego necesita de tres elementos para tener lugar: Oxígeno, combustible y una fuente de calor o ignición. Las dos primeras son proporcionadas por la vegetación, ligando el origen del fuego a su aparición sobre el planeta (PAUSAS \& KeEley, 2009). Por tanto, dada la ilimitada disponibilidad de oxígeno en la 
atmósfera actual y la existencia de fuentes o causas de ignición de origen natural o antrópico (tratadas más adelante), las características del combustible, unido al clima preponderante en la zona, son claves a la hora de proporcionar una explicación a la existencia frecuente de incendios en la Región Mediterránea (NAVEH, 1975; PAUSAS, 2003; LLORET, 2004).

Una de las características de los ecosistemas mediterráneos es la acumulación en la planta y en el suelo de una cantidad importante de biomasa muerta -ramas, brotes y hojas-, lo que hace de ésta una vegetación muy propensa a quemarse (PAUSAS et al., 1999; LLORET, 2004; DE LUIS et al., 2006; ARNAN et al., 2007). A esto contribuye el clima, con veranos secos, calurosos y con una humedad relativa del aire bajas, que facilita la desecación de esa materia vegetal y reduce la tasa de descomposición de la misma durante una parte del año, incrementando así el riesgo de incendios en la zona (VÉLEZ, 1995).

La presencia de condiciones tan adversas (sequías, incendios, pastoreo, ramoneo...), ha provocado que la capacidad de regeneración tras los incendios sea otra de las principales características de las comunidades vegetales mediterráneas (Bond \& VAN Wilgen, 1996; LAVOREL, 1999; OJEDA-Copete, 2001; PAUSAS, 2001; LLORET, 2004).

La capacidad de las comunidades vegetales de recuperarse después del incendio se fundamenta en la respuesta individualizada de las especies. De manera resumida se puede decir, que la regeneración de la cubierta vegetal se producirá a partir de las poblaciones de las especies capaces de sobrevivir y volver a crecer tras el fuego -especies rebrotadoras-, y de las que establecen nuevas poblaciones especies germinadoras-, ya sea a partir de semillas que se mantienen en las plantas quemadas, que están almacenadas en bancos de semillas del suelo o copas, o que llegan posteriormente al área incendiada (PAUSAS, 1999a, 1999b; OJEDA-COPETE, 2001; PAusas, 2001; Lloret, 2004; PAUSAS et al., 2004; Rodrigo et al., 2004; PAUla \& PAUSAS, 2008). El éxito en la regeneración, dependerá del tipo de la estrategia regenerativa empleada por las especies afectadas, de las características del medio -particularmente en el período posterior al incendio-, y de las perturbaciones que pudieran ocurrir posteriormente (WHELAN, 1995; BOND \& VAN WILGEN, 1996; QUINTANA et al., 2004; ARNAN et al., 2006). 
Aunque tradicionalmente este tipo de respuestas se han asociado al papel jugado por el clima (especialmente por los períodos de sequía) o el fuego en la evolución de la vegetación mediterránea (NAVEH, 1975; ZEDLER, 1995; TAPIAS et al., 2001), hoy día, son muchos los autores que ponen en duda estas afirmaciones ya que la capacidad de rebrote existía antes de que el clima mediterráneo apareciera como tal (Grove \& RACKHAM, 2001; OJEDA-COPETE, 2001; Verdú et al., 2003) y por lo tanto antes de que los incendios forestales interviniesen activamente sobre el ecosistema. Como norma general, se puede concluir que, el comportamiento rebrotador o germinador de nuestras plantas mediterráneas no debe calificarse estrictamente como una adaptación al fuego sino como una "exaptación" (OJEDACOPETE, 2001), es decir, una respuesta de las plantas al incendio equivalente a la que tendrían por la acción del ramoneo del ganado, o de la sequía...

1.1.2.3.- Factores socioeconómicos: A parte de las causas y factores naturales mencionadas anteriormente (los incendios producidos por rayos raramente superan el $10 \%$ ), los principales motivos que han generado el aumento de los incendios desde las últimas décadas del siglo $\mathrm{XX}$ son los múltiples factores sociales y económicos que han transformado la relación del hombre con los bosques, y las acciones antrópicas, deliberadas o no (VÉLEZ, 1990, 1991, 1993; MORENO et al., 1998; LLORET \& Vilà, 2003; Pausas, 2004b; Viedma et al., 2006; Moreno, 2007). Los principales cambios socioeconómicos que aumentan la probabilidad de incendios forestales son:

1) Cambio de los usos del suelo: La pérdida de valor económico del monte y sus productos lleva a la población rural a emigrar a las ciudades, lo que origina a su vez un abandono de grandes superficies de cultivo y una pérdida de los usos tradicionales empleados en la explotación del mismo. Todo ello conlleva cambios evidentes en la fisionomía de nuestros paisajes, pasando de tener poca cubierta arbolada o vegetal en general, a paisajes que poco a poco se han ido cubriendo de vegetación arbórea o arbustiva, en un claro aumento de la superficie forestal y una acumulación y continuidad de combustible como resultado de los procesos de sucesión secundaria (GARCÍA-RUíz et al., 1996; Pausas \& VAllejo, 1999; Vilà et al., 2001; LloRet \& Vilà, 2003; VALLADARES, 2007). No hay duda de que esta acumulación de combustible 
provoca más probabilidades de ignición, más facilidades para la propagación y altas intensidades del fuego, y la alteración de la dinámica de paisajes forestales y cambios en la diversidad de las comunidades animales como consecuencia de ello (SIRAMI et al., 2008; VÁZQUEZ \& RoDRÍGUEZ, 2008).

2) Crecimiento continuo de la interfaz monte-terreno urbano: $\mathrm{Al}$ mismo tiempo que se ha producido una despoblación de las zonas rurales, se ha experimentado un incremento de las residencias existentes en ellas (población que no vive del campo) y un aumento de la presión turística; el campo adquiere ahora valor como lugar de distensión y recreo, aumentando así las probabilidades de ignición y el número de incendios.

En este sentido, son varios los autores que hallan una relación directa entre la densidad de la población y la frecuencia del fuego en áreas de la Península Ibérica (Terradas et al., 1998; PAUSAS \& VAllejo, 1999).

En resumen, se puede afirmar que los incendios tienden a concentrarse en aquellas áreas donde los factores sociales -frecuentación, pastoreo- favorecen las igniciones, en áreas donde se ha acumulado el combustible y en áreas en las que las condiciones meteorológicas (ausencia de precipitaciones, altas temperaturas, vientos fuertes, etc.) y topográficas son particularmente apropiadas para la ignición y la propagación (Millán et al., 1998; VÁZQUEZ \& MORENO, 2001; VILÀ et al., 2001; DíAZ-DELGADo et al., 2004). En estas zonas se produce una alta frecuencia de incendios y un periodo de recurrencia corto, es decir, una repetición de incendios en el mismo punto en periodos muy cortos de tiempo.

La combinación de todos estos factores climáticos, tipo de vegetación y socio-económicos, entre otros, contribuyen de manera activa a la creación del régimen de incendios de un área determinada.

\section{2.- RÉGIMEN DE INCENDIOS}

La definición más clásica de régimen de incendios/fuego, en sentido estricto, engloba a todas aquellas características ecológicamente relevantes que definen a un incendio en un área determinada o en un ecosistema específico durante un periodo 
concreto de tiempo (GILL, 1975). Por lo tanto, el fuego, al igual que otros agentes de perturbación, tiene una incidencia variable sobre la vegetación y las distintas comunidades de animales asociadas a esta, dependiendo de los condicionantes espaciales y temporales que definen el régimen de incendios y determinan la magnitud de su efecto (GILL, 1975; WHELAN, 1995; BOND \& VAN WILGEN, 1996). Estos condicionantes, altamente interrelacionados entre sí, con el tipo de vegetación, clima y factores socio-económicos son: Frecuencia, intensidad, estacionalidad, extensión y recurrencia.

- Frecuencia: Número de perturbaciones que se producen en un área concreta a lo largo de un periodo determinado.

Las variaciones en la frecuencia de los incendios producen efectos marcadamente distintos sobre las plantas (TRABAUD, 1991; OJEDA-COPETE, 2001; Díaz-Delgado et al., 2002), fauna (SMith, 2000, SwENGEL, 2001) y sobre la estructura y organización de la vegetación (KEELEY, 1992; PAUSAS, 1999a; DíAZ-DELGAdo et al., 2004), de la que dependerán las distintas poblaciones y comunidades animales.

Aparte del gran incremento de incendios provocados por el hombre, el cambio climático, y las previsiones existentes al respecto, indican un claro aumento en la frecuencia y el alcance de los incendios (PIÑOL et al., 1998; Williams et al., 2001; Mouillot et al., 2002; PAUSAS 2004a, 2004b) mediante la alteración de factores clave que controlan el fuego: temperatura, precipitación, humedad, viento, ignición, biomasa, materia orgánica muerta, composición de las especies y estructura de la vegetación y humedad del suelo (IPCC, 2007; PAUSAS, 2004a; SHLISKY et al., 2007). Estos cambios amenazan el funcionamiento adecuado del ecosistema y el suministro de sus servicios (IPCC, 2007) pudiendo determinar su estructura y funcionamiento (NAVEH, 1990). Por lo tanto, sobrepasar un ciclo óptimo de perturbación puede causar la interrupción de algunas de sus propiedades básicas (Ej. Ciclo de nutrientes y reservorio de energía), lo cual podría llevar a su destrucción o alteración.

En casos extremos, una alta frecuencia de incendios favorece la invasión por parte de especies vegetales altamente susceptibles al fuego y que 
pueden dar lugar a un cambio en las propiedades del combustible, aumentando su inflamabilidad y alterando de esta manera el régimen del fuego (BROOKS et al., 2004; VELDMAN et al., 2009), al incrementar la intensidad y frecuencia del mismo.

- Intensidad: Mide la magnitud física de la perturbación (Ej. Temperaturas alcanzadas en el incendio, longitud de llama, tamaño del frente de llama, altura de la columna de humo...). La intensidad de un fuego depende de las condiciones climatológicas específicas, topografía (pendiente y exposición), cantidad, tipo y distribución (vertical y horizontal) del combustible (WHELAN, 1995; VILÁ et al., 2001), pudiendo tener un marcado impacto en las comunidades animales y vegetales (FLORENCE, 1996; YORK, 1998; SWENGEL, 2001; SMITH, 2000).

- Estacionalidad: Época del año en que se produce la perturbación. Es sobradamente conocido que las condiciones climatológicas influyen en la susceptibilidad que un área determinada presenta frente al fuego; factores como la temperatura, la humedad y la pluviosidad determinan la velocidad y el grado al que se seca el material inflamable, y por lo tanto, la combustibilidad del bosque (SMITH, 2000; LlORET \& VILÁ, 2003; LlORET, 2004). Asimismo, el viento tiende a acelerar la desecación y a aumentar la gravedad de los incendios, avivando la combustión. La unión de todos estos factores hace que la mayoría de los incendios forestales que tienen lugar en la península ibérica se produzcan en la época estival.

La época del año en que tenga lugar el incendio, se corresponderá a su vez con una determinada fase del ciclo vital en que se hallen las especies afectadas, tanto vegetales como animales. Este hecho marcará considerablemente la afectación sobre los individuos al presentar estos una mayor capacidad o habilidad para huir de las llamas (en el caso de los animales, que veremos más adelante), o reducir el impacto de las mismas manteniendo su capacidad de rebrote y germinación (en el caso de la vegetación). 
- Extensión: Superficie afectada. La topografía y heterogeneidad del paisaje y de la vegetación influirán sobre este factor, en la medida en que determinados elementos pueden actuar como cortafuegos naturales impidiendo el avance de las llamas. Los incendios de gran tamaño suelen ser también incendios de alta intensidad (Huston, 1994), ya que suelen ir unidos a una cubierta forestal continua y extensa (Huston, 1994; TURNER et al., 1994; PIÑOL et al., 1998), y a determinadas condiciones meteorológicas caracterizadas por largos periodos de sequía y fuertes vientos (TURNER et al., 1997).

Los grandes incendios pueden tener un doble efecto sobre el paisaje: Por un lado, pueden tener un papel homogeneizador, ya que el fuego normalmente arrasa la vegetación, sincronizando en grandes áreas la sucesión de la misma y eliminando la heterogeneidad generada por estadios más avanzados de la misma (HuSTON, 1994). Por otro lado, también pueden tener un efecto heterogeneizador que depende de la escala a la que se observan (TURNER et al., 1994): a nivel de paisaje se origina un mosaico de áreas quemadas y no quemadas, mientras que a nivel de zona quemada, la heterogeneidad espacial es el resultado del mosaico generado por las diferentes severidades con que se quema la vegetación (TURNER et al., 1994).

- Recurrencia: Tiempo necesario para que un área vuelva a ser afectada por el fuego. Una recurrencia elevada puede poner en peligro a las comunidades vegetales al impedir que alcancen un alto grado de madurez, manteniéndolas siempre en un estado de recuperación inicial e impidiendo su capacidad de rebrote y de producción de semillas (ENRIGHT, et al., 1998a; 1998b; CANAdell \& LÓPeZ-SORIA, 1998; PAUSAS, 2001; DíAZ-Delgado et al., 2002; SAlvador et al., 2005), lo que a su vez se transformará en una des/ventaja para determinados grupos animales.

Una elevada recurrencia de incendios puede alterar la dinámica espacial y temporal de procesos clave en los ecosistemas, como puede ser la pérdida de biodiversidad, un incremento de los procesos erosivos y una pérdida de paisajes (Menges \& HAwKES, 1998; PAUSAS, 2004b) o de resiliencia (DíAZ-DELGAdo et al., 2002; DíAZ-DELGADO, 2003). 
Actualmente el concepto Régimen de fuego está enmarcado por una generalizada y estructurada descripción del papel del fuego en los ecosistemas (WHELAN, 1995; CONEDERA et al., 2009).

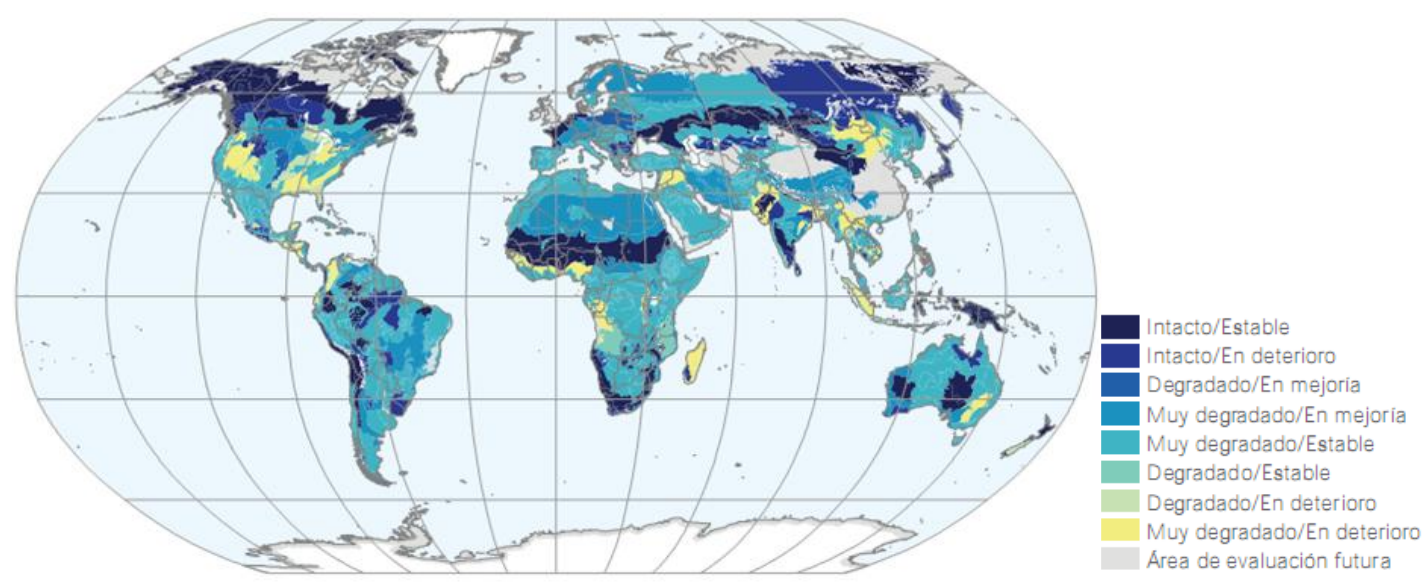

Figura 2: Distribución de las condiciones de los regímenes del fuego en todo el mundo. Imágen extraída de Shlisky et al., 2007

En la Cuenca Mediterránea, la historia del fuego ha interactuado tan estrechamente con la transformación de las comunidades vegetales y las sociedades humanas que intentar definir cuál sería su régimen natural de incendios es muy complicado (Figura 2).

\section{3.- TIPOS DE INCENDIOS}

Se diferencian diversos tipos de incendios según dónde se localicen dentro del bosque:

1. Incendio superficial: Se extienden por la superficie de monte, quemando los combustibles ligeros, esto es: vegetación herbácea, matorrales y arbolado de poco porte, así como los restos vegetales que se encuentran en la superficie, hojaraca, leñas... También pueden producir heridas en la base de los troncos y en las raíces de las especies de mayor porte. Dependiendo de la cantidad y calidad del material existente en el área, de la topografía y de las condiciones atmosféricas imperantes, estos fuegos se pueden transformar en incendios de copas o incendios subterráneos. 
2. Incendio de copas: Aquellos que queman las copas de los árboles hiriendo sus ramas y llegando incluso a matarlos. Es necesario que el estrato arbóreo sea suficientemente denso y se dé un viento importante o pendientes muy pronunciadas. Son de gran intensidad y muy complicados de extinguir. Su origen puede ser un fuego superficial, excepcionalmente un rayo sobre un árbol dominante puede ser factor desencadenante de un fuego de copa.

3. Incendio subterráneo o de subsuelo: Es el que se propaga bajo la superficie. Generalmente se da en lugares de mucha acumulación de materia orgánica, combinado generalmente con el superficial. Quema la capa de materia orgánica acumulada en el suelo y las raíces. Son poco frecuentes y su peligro radica en la dificultad de detección y extinción que conllevan y en que apenas dan señales de su existencia al no producir llamas ni apenas humo. Su velocidad de propagación es muy lenta, sin embargo son muy perjudiciales al quemar las partes subterráneas de las plantas impidiendo así su rebrote.

El tipo de incendios que tenga lugar en un área determinada también jugará un papel fundamental en el grado de impacto que producirá sobre las especies, tanto vegetales como animales, en el modo en que afectará a los individuos y especies por desigual, y provocará un cambio más o menos intenso en el hábitat post-fuego.

\section{4.- EFECTOS DEL FUEGO SOBRE LAS POBLACIONES ANIMALES}

Los estudios sobre los efectos del fuego en las poblaciones animales son muy escasos. La mayoría de los autores han limitado la discusión de este problema sólo a unos pocos grupos de vertebrados, zonas (provincias) bióticas concretas o a capítulos y reseñas en libros generales (WHELAN, 1995; SMITH, 2000). Dichos estudios muestran que el fuego tiene importantes efectos sobre la fauna, ya sea porque sus poblaciones se ven directamente afectadas, o porque deben ajustarse a un nuevo escenario de disponibilidad de recursos y de actividad de los depredadores tras la actuación del mismo (Whelan, 1995; SMith, 2000; HANUla \& WAdE, 2003; KNIGHT \& HOLT, 2005). 
Se puede decir que los incendios forestales, como cualquier otra perturbación, afectan a la fauna matando parte de las poblaciones existentes, reduciendo los nichos utilizados por las especies o creando nuevos nichos para los taxones supervivientes o colonizadores (WHELAN, 1995). Asimismo, bajo un régimen natural de fuego, aumenta la heterogeneidad del paisaje mediante la formación de un complejo mosaico de clases de tamaño, estructura de vegetación y ocurrencia de especies de plantas, lo que produce una profunda influencia sobre las comunidades animales dado que la estructura espacial de la vegetación les provee de recursos necesarios para vivir y reproducirse, incluyendo la comida, refugio y protección (WHELAN, 1995; YORK, 1996; SMITH, 2000). En el siguiente apartado, referente al efecto del fuego sobre los insectos, se reflejarán los distintos aspectos que influyen en el grado de influencia de este tipo de perturbación sobre los mismos, y que son, en gran medida, extrapolables al resto de grupos faunísticos.

Como se verá, las comunidades animales que se han desarrollado en el contexto de un régimen particular de incendios, muestran modelos de respuesta a ese mismo régimen (SMITH 2000). Así, las especies animales nativas de áreas con siglos de historia sometidas al fuego pueden persistir en hábitats modelados por el fuego. Muchas especies actualmente prosperan gracias a la influencia del fuego (FROST, 1984; WARREN et al., 1987; WHELAN, 1995; REED, 1997; SMITH, 2000). Es por esto, que grandes cambios en el régimen del fuego alteran el modelo del paisaje, los procesos ecológicos y los corredores o uniones funcionales entre los distintos hábitats o ecosistemas, afectando al hábitat de los animales y produciendo a menudo grandes cambios en la composición de sus comunidades (WHELAN, 1995; SMITH, 2000).

\subsection{1.- RESPUESTA DE LOS ARTRÓPODOS EN GENERAL, Y DE LOS INSECTOS EN PARTICULAR, AL FUEGO}

Los efectos del fuego sobre la fauna en general, y sobre los insectos en particular, muestran una amplia variedad. Por tanto, el análisis de las respuestas ofrecidas por los distintos grupos de insectos presenta resultados variables de unos estudios a otros. Dichos resultados se ven alterados tanto por el tipo de hábitat en el que se realizó el estudio, como por los diferentes componentes del régimen de incendios bajo los que actuó el fuego (intensidad, frecuencia, estacionalidad, 
extensión y recurrencia), las condiciones ambientales previas y posteriores al fuego, el grupo analizado y la metodología empleada (NuNES et al., 2000; SWENGEL, 2001). A esto hay que añadir el hecho de que las poblaciones de insectos, generalmente difieren temporal y espacialmente en relación a factores ambientales relacionados con el clima y las características del hábitat (SCHOwALTER, 2006). Por tanto, entraña bastante dificultad, establecer una clasificación unánime de los efectos del fuego y respuestas ofrecidas por cada especie, dada la singularidad de cada una de ellas y de los grupos a los que pertenecen.

No obstante, se puede establecer una clasificación con los tipos de respuestas individuales más comunes de estos animales ante el fuego, y la de sus poblaciones y comunidades en función del tiempo transcurrido tras la perturbación, es decir, la de sus variaciones a corto, medio y largo plazo.

En términos generales, la respuesta de los insectos al fuego está relacionada con el grado de exposición a temperaturas letales, al estrés experimentado en el medio después del incendio y antes del rebrote de la vegetación, al tipo de vegetación (previa al incendio y post-fuego) y de recursos proporcionados por ésta (indispensable para su supervivencia tras el incendio) y a la capacidad de las especies para sobrevivir y/o recuperar su abundancia en el área quemada. A su vez, todos esos factores y la respuesta inmediata de los insectos al fuego, están condicionados por los distintos componentes del régimen de incendios y por las características intrínsecas y adaptaciones de cada una de las especies afectadas.

Con todo ello, las respuestas de los insectos a los incendios forestales son básicamente las siguientes: mortalidad o lesiones, emigración e inmigración.

1.4.1.1.- Mortalidad o lesiones: La mortalidad de los insectos por acción del fuego se origina fundamentalmente por su exposición directa a las llamas, al calor producido por las altas temperaturas experimentadas durante el incendio (altamente influenciado por el tipo, estado y cantidad de vegetación quemada -intensidad del incendio-) y al humo generado por la combustión de la vegetación.

Los animales, al contrario que la vegetación, generalmente mueren si se quema gravemente cualquier parte de su cuerpo. Según WHELAN (1995), los animales de mayor tamaño resistirán mejor las altas temperaturas que los de tamaños 
inferiores, por lo que un menor tamaño corporal en los insectos supone una desventaja.

A pesar de haber pruebas directas que demuestran la muerte de insectos por la acción del fuego (Figura 3) (obs. pers.; FAY \& SAMENUS, 1993; WHELAN, 1995), la mayor evidencia está implícita en la ausencia o descenso de estos tras el impacto (irreconocibles entre las cenizas). Sin embargo, la reducción de las poblaciones

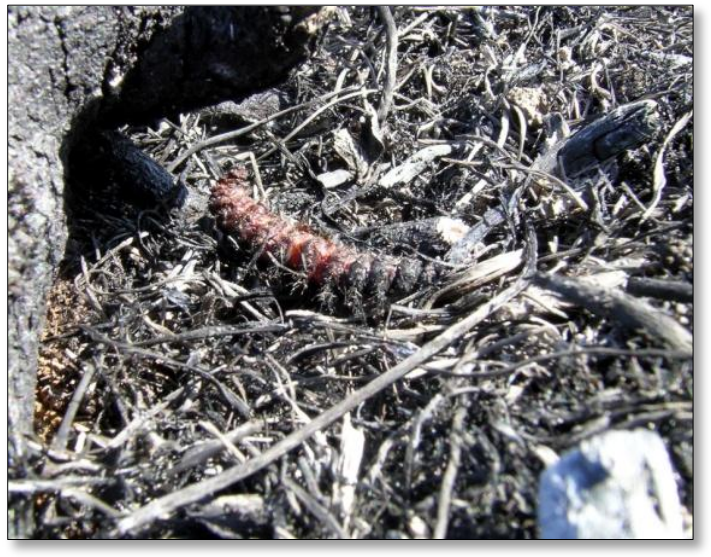
puede no alcanzar el $100 \%$, incluso con una exposición aparentemente total al fuego (PANZER, 1988; SWENGEL, 2001; TOOKER \& HANKS, 2004).

El declive de los insectos puede continuar durante semanas después del fuego, ya que la mortalidad puede ocurrir no sólo durante el incendio, sino también durante una "fase de shock" después de éste, en la que morirían por inanición (RICE, 1932; LamotTe, 1975; Morris, 1975; Frost, 1984; WARREN et al., 1987). No obstante, las poblaciones rara vez son erradicadas por un único episodio incendiario (ANDERSON et al., 1989; FAY \& SAMENUS, 1993; SwENGEL, 2001).

La tasa de mortalidad vendrá determinada a su vez por varios factores, entre los que destacan:

I. La localización y exposición de los individuos en el momento en el que tiene lugar el fuego (Evans, 1984; SiEMANN et al., 1997; SWENGEL, 2001; TOOKER \& HANKS, 2004). De ello dependerá su mayor o menor grado de exposición a las llamas y a las altas temperaturas.

El fuego teóricamente se extendería como un modelo elíptico, pero la forma de las áreas quemadas y de la severidad en ellas está influenciada por las fluctuaciones del tiempo durante el fuego, los cambios diurnos en las condiciones de quema, la variación en la topografía, el combustible y las 
estructuras de defensa o resistencia de la vegetación afectada (WHELAN, 1995). Una topografía variable y abrupta, con combustible esparcido, es más propensa a formar parches de quema, donde permanezcan zonas sin quemar dentro del propio área incendiada (obs. pers.), mientras que paisajes con poco relieve y combustible homogéneo puede quemarse más uniformemente. No sorprende entonces que el fuego forme un complejo mosaico de clases de tamaño, estructura de vegetación y ocurrencia de especies de plantas a través del paisaje (WHELAN, 1995; BOND \& VAN WILGEN, 1996), y que esta variedad tenga una profunda influencia sobre los animales que allí viven, tanto antes, como durante y después del incendio, permitiendo la supervivencia de determinadas especies.

Los individuos que se hallen más cercanos a las llamas, y en las zonas más intensamente quemadas, tendrán más probabilidades de morir que los que se hallen más alejados, cuyo tiempo de reacción será mayor, o los que se hallen en zonas donde la intensidad de la quema es baja, o nula (mayor humedad, combustible menos inflamable...) dentro del propio área incendiada. De este modo, las áreas de vegetación no quemada cobran especial valor desde el punto de vista conservacionista al proporcionar protección y refugio a los individuos que huyen del fuego (LAmotte 1975; RobBins \& MYers, 1992; Swengel, 1998b; ANDREW et al., 2000; HARPER et al., 2000; NE'EMAN et al., 2000; GANDHI et al., 2001; NeKOlA, 2002; PANZER, 2003; CleARY \& GRILl, 2004; KNIGHT \& Holt, 2005; HirowATARI et al., 2007; SWENGEL \& SWENGEL, 2007), actuando, a su vez, como fuente de especies a la hora de recolonizar el área afectada. Cobran en este punto gran relevancia las áreas labradas, que por carecer de combustible no son quemadas y pueden actuar a su vez de cortafuegos ante el avance de las llamas (obs. pers.) y como refugio para las especies que huyen de las mismas.

Dado que no todos los individuos están capacitados o pueden huir de las llamas a tiempo, otro factor de protección importante lo constituye la localización específica de esos organismos en el momento del incendio, el hábitat particular ocupado por cada especie y en el que desarrollen su actividad. Así, se verán afectados de manera muy diferente los insectos que vivan bajo la superficie del suelo (DEBANO et al., 1998; BROSA, 2000) -generalmente poco 
afectados-, en la capa de hojarasca existente sobre el suelo (SGARDELLIS et al., 1995; YORK, 1999) -muy afectados-, o en los distintos estratos vegetales (herbáceo, arbustivo, arbóreo) (Ej. TOOKER \& HANKS, 2004) -afectados en función del tipo e intensidad del fuego (RODRIGO et al., 2008)-, como norma general.

Muchos autores han demostrado la capacidad aislante ejercida por el suelo frente a las elevadas temperaturas provocadas por las llamas (CHRISTENSEN, 1994; MARXER \& CONEDERA, 2000). Según Christensen (1994), los efectos del calor en los incendios forestales más intensos de matorrales mediterráneos, están generalmente confinados a los primeros $10-20 \mathrm{~cm}$ de profundidad del suelo. Sin embargo, las altas temperaturas generalmente permanecen poco tiempo. Es esta capacidad aislante del suelo la que permite que numerosas especies que viven, o desarrollan alguna parte de su ciclo biológico enterradas o en galerías, sobrevivan a este tipo de impactos (EvANS, 1988; BocK \& BocK, 1991; DeBAnO et al., 1998; Harper et al., 2000; Swengel, 2000; MoRetTi et al., 2002a; PotTs et al., 2003; GiBB \& HJÄLtÉN, 2007).

En otros casos, es la capacidad de resistencia de la vegetación o de alguna de sus estructuras, e incluso la mala combustibilidad de la misma, la que impide el avance del fuego y proporciona protección a los insectos, permitiendo así su supervivencia (MAKIHARA et al., 2000; MÖLLENBECK et al., 2009).

Nuevamente la intensidad y tipo de fuego (subsuelo, superficie, de copas) marcarán sobremanera el grado de afectación y mortalidad de los individuos y poblaciones de insectos frente al fuego, al someterlos a temperaturas elevadas, para las que quizá el grado de protección que poseen, ejercido por el suelo o distintas estructuras vegetales en las desarrollen su actividad, no sean suficientes.

II. La movilidad y capacidad de huída de las especies. Esta característica está directamente relacionada con la fase del ciclo biológico en la que se encuentren los individuos, esto es: Huevo, larva, ninfa, pupa... Así, etapas inmaduras, adultos de taxones con una baja capacidad dispersiva, se verán afectados en un grado mucho mayor que los individuos más móviles, adultos alados, 
excavadores o con una gran capacidad de movimiento, y por lo tanto de huída ante las llamas PANZER, 1988; Ditlhogo et al., 1992; HAll \& SchWEITZER, 1992; PIPPIN \& NiCHOLS, 1996; CHAMBERS \& SAMwAYS, 1998; ZIMMER \& Parmenter, 1998; Swengel \& Swengel, 1999; Kalisz \& Powell, 2000; Swengel, 2001; Niwa \& PeCK, 2002; HoffmanN, 2003. En este sentido, cobra gran relevancia la intensidad, velocidad y extensión del fuego, ya que estos factores pueden limitar en cierto modo la posibilidad de huida de las especies y aumentar así su mortalidad.

Esta misma capacidad de movimiento cobrará posteriormente gran importancia a la hora de colonizar o regresar al área quemada (SWENGEL, 2001; POTTS et al., 2003).

La estacionalidad está estrechamente relacionada con la fenología de las especies, y, en consecuencia, con su grado de actividad o de latencia. Así, la época del año en que tenga lugar el episodio incendiario tendrá reflejo en una mayor o menor mortalidad de insectos (EvANS, 1988; CHAMBERS \& SAMways, 1998; MAKIHARA et al., 2000; POTTS et al., 2001; NE’EMAN et al., 2000; RIESKE-KINNEY, 2006). Si los individuos menos móviles, en el momento del fuego permanecen en diapausa, o en fase de huevo o pupa enterrados en el suelo o protegidos por estructuras vegetales resistentes al calor, estarán más protegidos que si se encuentran activos.

Del mismo modo, un incendio producido fuera de la época seca (otoñoinvierno), contará con menor carga de combustible y más húmedo, y con unas condiciones climatológicas que lo harán menos intenso y, probablemente, menos extenso, lo que supondrá una ventaja para la supervivencia de gran cantidad de especies (CHAMBER \& SAMWAYS, 1998). Es por este motivo, que la mayoría de las quemas prescritas enfocadas a la limpieza del monte y reducción de combustible se aconseja llevarlas a cabo fuera de la estación seca o con condiciones climatológicas favorables (baja temperatura, alta humedad relativa...). 


\subsubsection{2.- Emigración e inmigración.}

- Respuestas de los Insectos en Función del Tiempo Transcurrido después del Fuego

$\mathrm{Si}$ algo caracteriza a los insectos, es su elevado número de especies. La enorme variedad de comportamientos y biología que presentan hace que sus respuestas, evidentemente individuales, estén reguladas por factores intrínsecos y específicos de cada especie. De ahí la inexistencia de una respuesta única para todos y cada uno de los grupos de insectos después de un periodo incendiario (MORETTI et al., 2004, 2006). Por este motivo, la clasificación mostrada a continuación intenta resumir las respuestas más frecuentes de las poblaciones de insectos a corto, medio y largo plazo después del fuego, según los periodos de tiempo tomados por SWENGEL (2001), y en comparación con las mismas áreas antes del fuego o con áreas control no quemadas. Estas respuestas dependen, en la mayoría de los casos, del grado de alteración o simplificación experimentado por el medio, de la resistencia y de la resiliencia del mismo, así como de las especies que lo componen y su capacidad de supervivencia, recolonización y adaptación a los nuevos recursos disponibles a lo largo de sus diferentes etapas sucesionales.

\section{RESPUESTAS A CORTO PLAZO (0 a 1-2 meses después del fuego)}

\section{a) Descenso de las poblaciones}

Inmediatamente después de un incendio, de forma general, se produce un descenso en el número de especies y en la abundancia relativa de éstas, así como un empobrecimiento de las condiciones favorables del hábitat para las especies establecidas antes del incendio (ANDERSON et al., 1989; SAMWAYS, 1990; BocK \& Bock, 1991; PiPPIN \& Nichols, 1996; PAQuin \& CODERRE, 1997; SiEMANN et al., 1997; DIETRICH et al., 1998; PANZER, 2002; IZHAKY et al., 2003; POTTS et al., 2003; TOOKER \& HANKS, 2004; MORETTI et al., 2006).

Una de las respuestas comunes de casi todos los grupos animales al fuego es el abandono del lugar tan pronto como es detectado. Este tipo de respuesta, está muy relacionada con la movilidad que poseen los individuos. 
Varios de los motivos para emigrar, aparte de huir de las llamas, pueden estar originados por los efectos del fuego sobre el medio. La consecuencia inmediata más aparente es la pérdida o alteración de la cobertura vegetal, lo que da lugar a una liberación de espacio y aumento del paso de luz solar por una parte, pero también a la pérdida de recursos tróficos para numerosas especies herbívoras, y la desaparición de sustratos de nidificación y refugio para otras muchas (WHELAN, 1995; BOND \& VAN WiLgEN, 1996; SMITH, 2000). Esta pérdida de cobertura vegetal puede originar también una alteración de la eficiencia de caza de los depredadores (ANDOW, 1991; HANULA \& WADE, 2003) y un cambio posterior en la composición de la comunidad vegetal (Lawton, 1983; Evans, 1984; Mitchell, 1990; Whelan, 1995; Bond \& VAN WILGEN, 1996), si bien, esto no es muy común en los ecosistemas mediterráneos donde la regeneración, generalmente rápida, suele estar marcada por la autosucesión (TRABAUD, 1998) (aparecen las mismas especies que existían antes de la perturbación debido a los diferentes mecanismos de regeneración que poseen).

Otras alteraciones o modificaciones del medio consisten en una reducción de la capa de materia orgánica superficial, modificación de la humedad, temperatura y $\mathrm{pH}$ del suelo, lo que en muchas ocasiones elimina o disminuye las poblaciones que viven sobre ella (LUSSENHOP, 1976; VAN AMBURG et al., 1981; SEASTEDT, 1984; Collet \& NeumanN, 1995; SGardelis et al., 1995; Whelan, 1995; Bond \& VAN WILGEN, 1996; COLLET, 1998; HAIMI et al., 2000).

En vista de todas las alteraciones posibles sufridas por el medio tras un incendio, se puede determinar que el tiempo que tarden en regresar muchas de las especies afectadas dependerá de cómo se haya alterado la estructura del hábitat y de los recursos alimenticios disponibles (WHELAN, 1995; SMITH, 2000; FARJI-BRENER et al., 2002; POTTS et al., 2003).

Varios son los factores que pueden alargar este descenso generalizado de las poblaciones en el tiempo después del fuego, entre los que destacan: a) baja tasa reproductiva debido a la alteración de la estructura de las poblaciones (mortandad diferencial entre ambos sexos, muerte de los estadios más inmaduros...); b) condiciones climatológicas desfavorables (Ej. Escasez de lluvias, altas temperaturas) que retrasan el periodo de recuperación, mantienen una baja cobertura forestal y elevan la temperatura de la superficie del suelo, lo que puede llevar a un c) 
incremento de la mortalidad y tasa de emigración; d) alta tasa de depredación al disminuir los refugios disponibles y aumentar la exposición de las presas.

Todos estos factores ambientales se pueden traducir en una modificación de la composición de especies de insectos y en una redistribución de las especies dominantes entre los grupos de la comunidad (LOCKWOOD et al., 1996; CoOK \& HOLT, 2006; MORETTI et al., 2006; RodRIGO et al., 2008), donde algunos teóricos competidores menores lleguen a ser dominantes.

\section{b) Aumento de las poblaciones}

Este modelo representa un aumento en la abundancia, especialmente de las especies oportunistas. El cambio súbito producido en el hábitat tras un incendio puede suponer también un aumento de las especies invasoras y/o de las respuestas explosivas por parte de las especies colonizadoras o supervivientes (AMMAN \& RYAN, 1991; FERNÁNDEZ \& SALGADO, 2004; BREECE et al., 2008).

Algunas especies de insectos son atraídas por el fuego, el humo, $\mathrm{CO}_{2} \mathrm{o}$ compuestos volátiles liberados por las plantas, hacia zonas recién quemadas para alimentarse o para ovipositar sobre la madera calcinada (FROST, 1984; WARREN et al., 1987; ReED, 1997; HART, 1998; MCCUllough et al., 1998; Millius, 2001; SUCKLING et al., 2001; WiKARS, 2002; SULLIVAN et al., 2003; SAINT-GERMAIN et al., 2004; SIX \& SKOV, 2009), encontrándose algunas de ellas exclusivamente confinadas a dichas áreas (WIKARS, 1994). A estos insectos se les conoce como insectos pirófilos y se caracterizan porque al menos alguna parte de su ciclo de vida está ligada a la existencia de madera recién quemada, por lo que es esencial para ellos localizar las áreas incendiadas y desplazarse a través de ellas de forma segura. Para ello, en muchos casos, cuentan con órganos especiales de recepción de la radiación infrarroja producida por el fuego (SCHMITZ et al., 1997; SCHMITZ et al., 2000), o de $\mathrm{CO}_{2}$ en las especies atraídas por el humo (KLOCKE et al., 2009), además de glándulas que les protegen de la desecación provocada por las altas temperaturas.

Por lo general, la mayoría de estas especies son coleópteros, pero también existen especies pertenecientes a otros grupos, como dípteros o himenópteros. La mayoría son especies que necesitan sustratos quemados, restos de madera muerta, 
vegetación debilitada o los hongos que crecen en ella, pero también las hay que se benefician de los insectos atraídos por dichos recursos. Según Evans (1980), existen alrededor de cuarenta especies pirófilas en Europa. Sin embargo, no se puede asumir que la atracción de las especies por el fuego sea un comportamiento relativamente común (SWENGEL, 2001).

La presencia de áreas no quemadas (alrededor o en el interior de la zona expuesta a las llamas) sirven, además de como refugio o sumideros de especies en el momento del incendio, como fuentes de poblaciones en el modelo de inmigración y colonización de las áreas afectadas por el fuego (PULLIAM, 1988; SAINT-GERMAIN et al., 2004; CLEARY et al., 2006; ANTUNES et al., 2009).

Mientras que la mortalidad causada por el fuego puede ser verdaderamente elevada, la vegetación "post-fuego", y los recursos que esta supone (cobijo, alimento, cobertura, etc.), pueden ser también bastante atractivos para algunos insectos recolonizadores, si bien su presencia estará marcada por el tipo de vegetación, la intensidad y la época en que se produzca el fuego. El grado en el cual se incrementa el número de especies de insectos en un área determinada, después del fuego, muestra la capacidad que tienen dichas especies para acceder a dicha vegetación rebrotante, en el caso de especies herbívoras o a estas por parte de las depredadoras ForCE, 1981; Evans, 1988; Fellows \& Newton, 1999; Ne’EMAn et al., 2000; POTTS et al., 2003, 2005; MORETTI et al., 2006). De la misma manera, las especies supervivientes, o los inmigrantes más rápidos (generalmente alados), son los que poseen mayor ventaja en los estados tempranos de la sucesión post-fuego (LAMOTTE, 1975; Holliday, 1991, MORETI et al. 2002a, 2002b, 2006; POTTS et al., 2003, 2005).

La simplificación del medio y la pérdida inicial de recursos, incrementa la actividad y distancias de forrajeo de la mayor parte de los grupos animales supervivientes o colonizadores. Este es el caso de las hormigas (ANDERSON et al., 1989; YorK, 1996; ANDERSEN \& MÜlLER, 2000; PARR et al., 2007. Estos himenópteros, que se benefician del recurso aportado por los cuerpos calcinados de otros invertebrados (obs. pers.) (Figura 4), se ven ahora obligados a aumentar la distancia recorrida hasta alcanzar el alimento existente en zonas no quemadas. A pesar de ello, según algunos autores, el aumento de temperatura de la superficie del suelo, y la propia simplificación del medio, favorecen su desplazamiento al contar 
con menos obstáculos, y hace que el balance energético sea positivo (NIELSEN, 2001), viéndose así favorecidos por dicha perturbación, salvo excepciones achacadas a temperaturas extremas (RodRIGO \& RETANA, 2006). El número de capturas, generalmente depende de la densidad de individuos y del grado de actividad de los mismos (SPEnCE \& Niemela, 1994; NiWA \& PeCK, 2002). Es por esto que el incremento en la actividad de las hormigas y su mayor exposición, ha propiciado que determinados autores hallen en la facilidad de su captura la explicación a la alta frecuencia con que se observan tras el fuego (ANDERSEN, 1991; MELbOURne, 1999; GIBB \& HJÄLTÉN, 2007), y que puede no ser un reflejo exacto de la realidad, ya que en otros estudios, realizados a largo plazo, se muestra un descenso en la riqueza de especies al aumentar el tiempo tras el incendio (YORK, 1996).

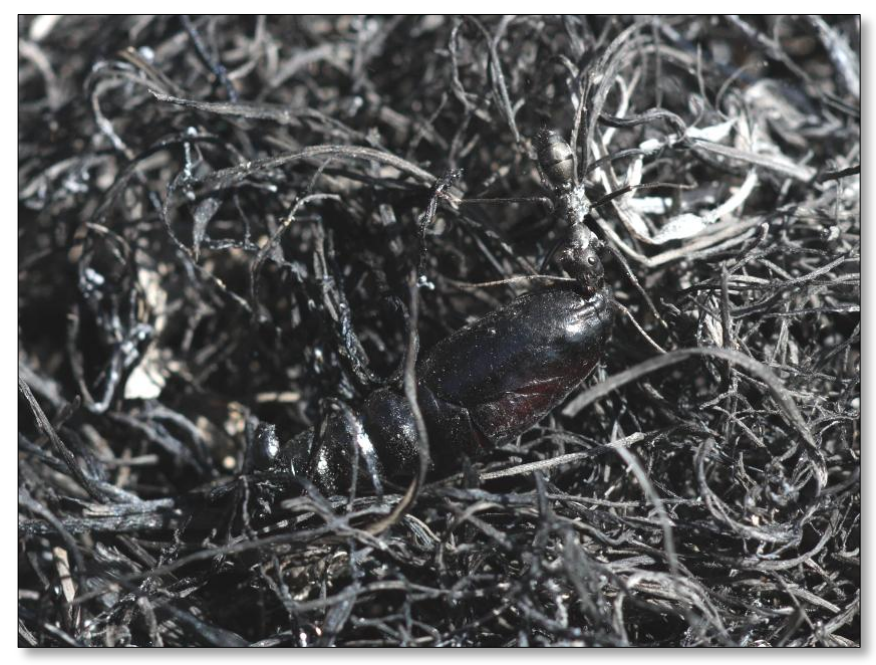

Figura 4: Hormiga arrastrando una pupa de lepidóptero. Imagen tomada en Villarino de los Aires (Salamanca) 24 h. después de un incendio forestal.

II. RESPUESTAS A MEDIO-LARGO PLAZO (> 1-2 meses después del fuego)

A medio plazo (> 1-2 a 12 meses) el ambiente post-fuego favorece a la entomofauna dependiente del sol (heliófila) y habitante de zonas con condiciones xéricas, espacios abiertos o pastos (LAMOTTE, 1975; YORK, 1996; BUDDLE et al., 2000; Blanche et al., 2001; MoretTI et al., 2002a, 2002b, 2004, 2006; NiWA \& PECK, 2002; FERNÁNDEZ \& SALGADO, 2004; ClEARY et al., 2006), pero perjudica -o elimina- a otras especies de áreas más boscosas y de mayor densidad vegetal (BudDle et al., 2000; PotTs et al., 2003; FERnÁNDEZ \& SAlGAdO, 2004; MoRETTI 
et al., 2004; APIGIAN et al., 2006; CleARY et al., 2006; RodRigO \& RETANA, 2006; RODRIGO et al., 2008), dado que el hábitat recién quemado se habría simplificado, es decir, se habrían reducido los nichos y la riqueza vegetal (según BULAN \& BARRETT, 1971).

Por otro lado, la disminución de la competencia vegetativa y la combustión de la capa superficial de materia orgánica, proporciona un flujo de nutrientes para el suelo de los bosques, lo que puede aumentar la calidad nutricional de la vegetación y la magnitud de su crecimiento, floración, volumen, concentración y calidad del néctar en los primeros meses de la recuperación (REICH et al., 1990; BOND \& VAN Wilgen, 1996; KRUGer \& ReICH, 1997; ARTHUR et al., 1998; RHADO-TOLy et al., 2001; Rieske, 2002; MoretTi et al., 2002b; PotTs et al., 2003), si bien hay excepciones en las que el fuego disminuye características como la cantidad de néctar (PotTs et al., 2001) o de frutos (debido a la menor presencia de polinizadores) en el área quemada, respecto a las áreas circundantes no afectadas por el fuego (NE’EMAN et al., 2000). Todos estos cambios en la calidad de la vegetación pueden alterar las pautas de alimentación de los herbívoros, de manera que se produzcan aumentos de sus poblaciones tanto en el interior de las áreas incendiadas, si las condiciones meteorológicas son favorables y la recuperación es rápida, como en las áreas marginales no quemadas, donde la presión ejercida por los herbívoros sobre la vegetación puede alcanzar cuotas muy elevadas debido al desplazamiento hacia estas de las poblaciones de las áreas quemadas, ahora sin alimento (RIESKE 2002; RIESKE et al., 2002; ADAMS \& RieSKE, 2003; KNIGHT \& Holt, 2005). Los cambios provocados por los incendios en la química foliar no son plenamente previsibles y pueden ser específicos de cada especie.

El desplazamiento por parte de los herbívoros puede conllevar igualmente al desplazamiento de sus depredadores (WHELAN, 1995; CAMPBELl et al., 2007).

Debido a todos estos factores, los efectos sufridos por las poblaciones de insectos a medio plazo son muy variados (SWENGEL, 2001). Así, existen estudios en los que las poblaciones:

a) Mantienen un número bajo de especies y/o individuos (Ej. Bulan \& BARRETT, 1971; ANDERSON et al., 1989; NEWMAN \& TOLHURST, 1991; 
SiEMAN et al., 1997; SWENGEL, 1998b; ANDERSEN \& MülleR, 2000; NE'EMAN et al., 2000; MORETTI et al., 2004; IZHAKI et al., 2003; MORETTI \& BARBALAT, 2004; TOOKER \& HANKS, 2004).

b) Llegan a ser similares a las existentes en áreas control/no quemadas, o permanecen inalterables (Ej. BULAN \& BARRETT, 1971; ANDERSON et al., 1989; Collett \& Neumann, 1995; ANDERSEN \& Müller, 2000; PANZER, 2002; MORETTI et al., 2004).

c) Presentan una mayor abundancia (especialmente en el caso de ortópteros y depredadores) (Ej. HollidAY, 1992; MuONA \& RUTANEN, 1994; REED, 1997; Bock \& BocK, 1991; Galley \& Flowers, 1998; Buddle et al., 2000; CAllaham et al., 2002; POTTS et al., 2003, 2005; MoRetTI et al., 2004, 2006).

En el desarrollo de estas respuestas cobra gran relevancia la intensidad del fuego, ya que si es elevada, además de provocar la muerte directa de muchos individuos, puede limitar la capacidad de rebrote y germinación de la vegetación, restringiendo a su vez la aparición de los recursos necesarios para la recuperación y supervivencia de las especies animales previamente existentes en el área afectada, o de los nuevos colonizadores (WHELAN, 1995).

Al igual que en los casos anteriores, las respuestas de las poblaciones y comunidades a largo plazo, muestran signos muy variados. En este caso son mucho más dependientes, si cabe, de la capacidad de recuperación del medio, de modo que la composición de insectos y sus respuestas vendrán nuevamente determinadas por los cambios producidos en la estructura del hábitat y por la mayor o menor capacidad de resiliencia mostrada por el mismo (WHELAN, 1995). La capacidad de regeneración de la cobertura vegetal y su estructura, muestran gran relevancia, tanto para los insectos que sobrevivieron in situ al paso del fuego, como para las especies colonizadoras, que hallarán en ella los recursos tróficos, de refugio y/o nidificación necesarios para su supervivencia, garantizando así el éxito de su colonización. Tal es la importancia de la estructura del hábitat post-fuego, que muchos autores la consideran aún más relevante para el desarrollo de las comunidades de insectos que 
el efecto del propio fuego (CHAMBERs \& SAMWAYS, 1998; FARJI-BRENER et al., 2002; POTTS et al 2003; PARR et al., 2004).

Conforme se recupera el área incendiada y aumenta la heterogeneidad estructural del medio, la diversidad de plantas y los recursos alimenticios y de nidificación, se incrementa la riqueza de especies (HAYSOM \& COULSON, 1998; POTTS et al., 2005). De esta manera, los modelos de floración y fructificación de las diferentes especies de plantas a través de los años determinarán el modelo en el que los recursos estarán disponibles para una amplia selección de especies animales (RODRIGO \& RETANA, 2006).

Nuevamente se han publicado estudios en los que se mantiene un número bajo de especies y/o individuos con el transcurso de los años post-fuego (Ej. Holliday, 1992; LOCKWOOD et al., 1996; PORTER \& REDACK, 1996; SWENGEL, 1998b, 2001; Swengel, 2001; MORETTI et al., 2004, 2006; IZHAKI et al., 2003; POTTS et al., 2003, 2005; MORETTI \& BARBALAT, 2004), otros, con mayor grado de recuperación, en los que llegan a ser similares a los existentes en áreas control o no quemadas (Ej. ANDERSON et al., 1989; SwEngel, 2001; PANZER, 2002; PARR et al., 2004) y otros en los que la abundancia es superior, debido a una mayor recuperación o a la presencia de especies favorecidas por las nuevas condiciones ambientales (Ej. Reed, 1997; Galley \& Flowers, 1998; Orgeas \& Andersen, 2001; Swengel, 2001; MoretTi et al., 2006). Para especies dependientes de estructuras de la vegetación (flores, frutos, etc.) que no reaparezcan en un área quemada durante uno o más años, los fuegos de gran extensión podrían interrumpir la viabilidad del biotopo durante una o más generaciones (SWENGEL, 2001).

En esta ocasión, la recuperación de los insectos está muy influida por la mayor o menor frecuencia y/o recurrencia con que tiene lugar el fuego en un mismo lugar, hecho que determinará la velocidad de recuperación de la vegetación hasta alcanzar un estado maduro semejante al existente antes del impacto. Esta diferencia de frecuencias y recurrencia favorecerá o perjudicará, una vez más, a unas especies frente a otras (NUNES et al., 2000; SWENGEL, 2001). En el caso de los insectos, existen muchas especies favorecidas, o con mayor capacidad de recuperación ante un único episodio incendiario (SWENGEL, 1998b; MORETTI et al., 2006), mientras que otras se ven beneficiadas (SIEMAN et al., 1997; CHAMBERS \& SAMWAYS, 1998; 
CAllaham et al., 2002; MoRetTi et al., 2004; ANDERSEN et al., 2009), o no especialmente afectadas con el aumento de estos (MORETTI et al., 2004; COLLET \& NeumanN, 1995; CoOK \& Holt, 2006), o perjudicadas (COLlet \& NeUMANN, 1995; Sieman et al., 1997; Chambers \& SAmways, 1998; HANula \& WADE, 2003; MORETTI et al., 2004), pudiendo desaparecer si la frecuencia es muy elevada (WRIGHT \& SAMWAYS, 1998, 1999). Las especies favorecidas, generalmente lo son como adaptación ante la existencia periódica del fuego en su hábitat.

A pesar de la gran variedad de comportamientos y respuestas existentes para los distintos grupos, varias son las conclusiones generales que se pueden extraer del análisis de los diferentes estudios llevados a cabo sobre el impacto del fuego en los insectos:

1.- Las respuestas tienden a ser específicas de cada especie (ANDERSON et al., 1989; Buddle et al., 2000; Swengel, 2001; CAllaham et al., 2002; Niwa \& PeCK, 2002; MORETTI et al., 2004).

2.- Los resultados de muchos estudios de campo evidencian que la variación de especies y el cambio del medio físico tras un fuego tiene como resultado la formación o desarrollo de comunidades diferentes en zonas quemadas, comparadas con zonas sin quemar (NunES et al., 2000; PANZER \& SCHWARTZ, 2000; SwENGEL, 2001; FARJi-BRENER et al., 2002; FernÁNDEZ \& SALGADO, 2004; PARR et al., 2004; SAINT-GERMAIN et al., 2004; KNIGHT \& HOLT, 2005; RATCHFORD et al., 2005; UNDERWOOD \& CHRISTIAN, 2009).

3.- Hay un complejo grupo de factores que influyen en los patrones de respuesta, de manera que mientras que unos grupos incrementan su abundancia otros la disminuyen o no se ven afectados. La variabilidad de los resultados obtenidos en los diferentes estudios se debe al hecho de que las poblaciones de insectos difieren en tiempo y espacio en una amplia escala, estando ampliamente condicionadas por factores ambientales relacionados con el clima y las características del hábitat (NunEs et al., 2000; SWEnGEL, 2001; PARR et al., 2004). Esto hace que sus modificaciones no puedan ser atribuidas de una manera concluyente al efecto del fuego, cuyo impacto es casi imposible de predecir. 
4.- Hay una amplia variedad de métodos y situaciones, diseños experimentales, duración de los estudios y grupos analizados, lo que hace muy complicado saber si las respuestas son características de los insectos son debidas realmente a la acción del fuego (NUNES et al., 2000; SWENGEL, 2001).

5.- La mayoría de los impactos sobre las poblaciones duran relativamente poco tiempo (3-4 años) (SWENGEL, 2001).

6.- Los fuegos de gran intensidad tienen efectos mucho mayores que los de baja intensidad, lo que hace frecuente la propuesta de quemas prescritas de baja intensidad como método de conservación de determinadas especies de insectos (NUNES et al., 2006).

7.- Quemas en primavera (época de crecimiento y mayor movilidad de los insectos) tienen más efecto que las quemas en otoño-invierno (EvANS, 1988; COLLET, 1998; NUNES et al., 2000).

8.- La mayoría de estudios evidencian que los fuegos muy frecuentes (equivalente a recurrentes en la mayoría de los estudios) eliminan o dañan de manera grave las poblaciones de insectos, a pesar de que algunos se vean favorecidos o beneficiadas (MORETTI et al., 2004).

9.- Los insectos con mayor movilidad tienen más probabilidades de sobrevivir a un fuego y son los primeros colonizadores de las áreas quemadas (LAMOTTE, 1975; POTTS et al., 2003; MORETTI et al., 2004).

10.- El estado de desarrollo y el microhábitat en el que los insectos lleven a cabo su actividad pueden ser muy relevantes para su supervivencia.

11.- Las adaptaciones y habilidades competitivas mostradas por cada especie pueden derivarse de la historia y régimen de fuegos de la zona, al que han estado expuestas estas especies a lo largo de los años. Esto se traduce en que las especies que viven en hábitats sometidos a la acción del fuego a lo largo de la historia, serán más resistentes ante este tipo de perturbación (ANDERSON et al., 1989; BENGTSSON et al., 2000; MoReTTI et al., 2002a, 2002b, 2004, 2006) que las que lo hacen en hábitats menos o nada afectados por el fuego. 
12.- Es posible predecir la respuesta de las comunidades, o de ciertas especies de insectos a una quema prescrita o a una serie de fuegos si se conoce la historia de fuegos del lugar, la tolerancia a la quema, la capacidad de colonización y la biología de las especies estudiadas.

13.- En ocasiones, estudios diferentes del mismo grupo producen resultados distintos (SWENGEL, 2001).

14.- La mayoría de los estudios trabajan a nivel de familia u orden, de manera que sólo se pueden establecer diferencias muy generales entre dichos niveles taxonómicos elevados, persistiendo dichas diferencias a corto-medio plazo.

\subsection{BIBLIOGRAFÍA}

AdAMS, A. S. \& RIESKE, L. K. 2003. Prescribed fire affects white oak seedling phytochemistry: implications for insect herbivory. Forest Ecol Manag. 176: 37-47.

Amman, G. D. \& RyAN, K. C. 1991. Insect infestation of Fire-Injured Trees in the Greater Yellowstone Area. United States Departament o Agriculture. Intermountain Research Station Sept. http://www.fs.fed.us/rm/publications/titles/int_research_notes.html INT-RN-398

ANDERSEN, A. N. 1991. Sampling communities of ground-foraging ants: pitfall catches compared with quadrat counts in an Australian tropical savanna. Aust. J. Ecol. 16:273-279.

Andersen, A. N. \& MÜLleR, W. J. 2000. Arthropod responses to experimental fire regimes in an Australian tropical savannah: ordinal-level analysis. Austral Ecology 25: 199-209.

ANDERSEN, A. N. \& Yen, A., 1985. Immediate effect on ants in the semiarid mallee region of Northwestern Victoria. Aust. J. Ecol. 10: 25-30.

Andersen, A. N, Penman, T. D., Debas, N. \& Houadria, M. 2009. Ant community responses to experimental fire and logging in a eucalypt forest of south-eastern Australia. Forest Ecol Manag. 258: 188-197.

ANDERSON, R. C., LEAHY, T. \& DhiLlion, S. S. 1989. Numbers and biomass of selected insect groups on burned and unburned sand prairie. Am. Midl. Nat.122 (1): 151-162.

ANDow, D. A. 1991. Vegetation diversity and arthropod population response. Annu. Rev. Entomol. 36: 561-586.

ANDREw, N., Rodgerson, L. \& York, A. 2000. Frequent fuel-reduction burning: the role of logs and associated leaf litter in the conservation of ant biodiversity. Austral Ecology 25 (1): 99-107.

Antunes, S. C., Curado, N. \& Castro, B. B. 2009. Short-term recovery of soil functional paramenters and edaphic macro-arthropod community after forest fire. J. Soils Sediments 9: 267-278.

Apigian, K., Dahlsten, D. \& Stephens, L. 2006. Fire and fire surrogate treatments effects on leaf litter arthropods in a western Sierra Nevada mixed-conifer forest. Forest Ecol Manag 221: 110-124.

Arnan, X., Rodrigo, A. \& Retana, J., 2006. Post-fire recovery of Mediterranean ground ant communities follows vegetation and dryness gradients. J. Biogeogr.33 (7): 1246-1258. 
ARnAN, X., Rodrigo, A. \& RETANA, J., 2007. Uncoupling the effects of shade and food resources of vegetation on Mediterranean ants: an experimental approach at the community level. Ecography 30: 161-172.

Arthur, M. A., Paratley, R. D. \& Blakenship, B. A. 1998. Single and repeated fires affect survival and regeneration of woody and herbaceous species in an oak-pine forest. J. Torrey Botanical Society. 125: 225-236.

AtTiwiLl, P. M. 1994. The disturbance of forest ecosystems: the ecological basis for conservative management. Forest Ecol Manag. 63: 247-300.

BAILEY, J. K. \& Whitham, T. G. 2002. Interactions among fire, aspen, and elk affect insect diversity: Reversal of a community response. Ecology 83 (6): 1701-12.

Balleto, E. \& CASAle, A. 1991. Mediterranean Insect Conservation. En: Collins, N. M. \& Thomas, J. A. (eds.) The Conservation of Insects and Their Habitats. Pp 121-142. Academic Press, London.

Bengtsson, J., Nilsson, S. G., Franc, A. \& Menozzi, P. 2000. Biodiversity, disturbances, ecosystem function and management of European forests. Forest Ecol Manag. 132: 39-50.

Bird, R. B., Bird, D. W., Codding, B. F., Parker, C. H. \& Jones, J. H. 2008. The "fire stick farming" hypothesis: Australian Aboriginal foraging strategies, biodiversity, and anthropogenic fire mosaic. Proceedings of the National Academy of Sciences 105: 14796-14801.

Blanche, K. R., Andersen, A. N. \& Ludwig. J. A. 2001. Rainfall-contingent detection of fire impacts: Responses of beetles to experimental fire regimes. Ecological Applications 11 (1): 86-96.

Blondel, J. \& Aronson, J. 1999. Biology and Wildlife of the Mediterranean Region. OxfordUniversity Press. New York.). 328 pp.

Bоск, C. \& Bоск, J., 1991. Response of grassoppers (Orthoptera:Acrididae) to wildfire in a Southeastern Arizona Grassland. Notes and Discussion, Am. Midl. Nat.125: 162-167.

Bond, W. J. \& VAN WiLgen, B. W. 1996. Fire and Plants. Chapman \& Hall, London. 263 pp.

Bond, W. J., Woodward, F. I. \& Midgley, G. F. 2005. The global distribution of ecosystems in a world without fire. New Phytologist 165: 525-538.

Breece, C. R., Kolb, T. E., Dickson, B. G., McMillin, J. D. \& Clancy, K. M. 2008. Prescribed fire effects on bark beetle activity and tree mortality in southwestern ponderosa pine forests. Forest Ecol Manag. 255: 119-128.

Briani, D. C., Palma, A. R. T., Vieira, E. M. \& Henriques, R. P. B. 2004. Post-fire succession of small mammals in the Cerrado of central Brazil. Biodivers. Conserv. 13: 1023-37.

Brisson, J. A., Strasburg, J. L. \& Templeton, A. R. 2003. Impact of fire management on the ecology, of collared lizard (Crotaphytus collaris) populations living on the ozark plateau. Animal Conservation 6: 247-254.

BrooK, B. W., SodhI, N. S., NG, P. K. L. 2003. Catastrophic extinctions follow deforestation in Singapore. Nature 424: 420-423.

Brooks, M. L., D’Antonio, C. M., Richardson, D. M., Grace, J. B., Keeley, J. E., Ditomaso, J. M., Hobbs, R. J., Pellant, M. \& Pyke, D. 2004. Effects of Invasive Alien Plants on Fire Regimes. BioScience 54 (7): 677-688.

Brosa, M. 2000. Soil arthropods in east Mediterranean Pinus halepensis forests. - En: NE'EMAN, G. \& TRABAUD, L. (eds). Ecology, biogeography and management of Pinus halepensis and P. brutia forest ecosystems in the Mediterranean basin. pp. 203-216. Backhuys Publishers,

Brotons, L., Pons, P. \& HerRando, S. 2005. Colonisation of dynamic Mediterranean landscapes: where do birds come from after fire?. J. Biogeogr., 32: 789-798. 
Brunet, M., Saladié, O., Jones, P.D., Sigró, J., Moberg, A., Aguilar, E., Walther, A., Lister, D. \& LÓPEZ, D. 2006. The development of a new daily adjusted temperature dataset for Spain (1850-2003). Inter. J. Climatology 26: 1777-1802.

Buddle, C. M., Spence, J. R. \& LANGOR, D. W. 2000. Succession of boreal forest spider assemblages following wildfire and harvesting. Ecography 23 (4): 424-436.

Bulan, C. A. \& BARrett, G. W. 1971. The effects of two acute stresses on the arthropod component of an experimental grassland ecosystem. Ecology 52: 597-605.

CALDARARO, N. 2002. Human ecological intervention and the role of forest fires in human ecology. Sci. Total Environ. 292: 141-165.

Callaham, M. A., Whiles, M. R. \& Blair, J. M. 2002. Annual fire, mowing and fertilization effects on two cicada species (Homoptera: Cicadidae) in Tallgrass prairie. Am. Midl. Nat. 148 (1): $90-101$.

Calvo, L., Tárrega, R. \& Luis-Calabuig, E. 1991. Regeneration in Quercus pyrenaica ecosystems after surface fires. Int. J. Wildland Fire 1 (4): 205-210.

Calvo, L., Tárrega, R. \& Luis-Calabuig, E. 1999. Post-fire sucesion in two Quercus pyrenaica communities with different disturbance histories. Ann. For. Sci. 56: 441-447.

CAmpbell, J. W, Hanula, J. L., WAldrop, T. A. 2007. Effects of prescribed fire and fire surrogates on floral visiting insects of the blue ridge province in North Carolina. Biolog Conserv 134: 393-494.

CAnadell, J. \& LóPez-SoRia, L. 1998, Lignotuber Reserves Support Regrowth Following Clipping of Two Mediterranean Shrubs. Func. Ecol. 12: 31-38.

CAPITANio, R. \& CARCAILlET, C. 2008. Post-fire Mediterranean vegetation dynamics and diversity: A discussion of succession models. Forest Ecol Manag 255: 431-439.

CARrión, J.S. \& B. VAN GeEL. 1999. Fine-resolution Upper Weichselian and Holocene palynological record from Navarrés (Valencia, Spain) and a discussion about factors of Mediterranean forest succession. Rev. Palaeobotany \& Palynology 106: 209-236.

Castro, M., Martín-Vide, J. \& Alonso, S. 2005. El clima de España: Pasado, presente y escenarios de clima para el siglo XXI. En: Moreno, J. M. (Coord./Ed.). Evaluación Preliminar de los Impactos en España por Efecto del Cambio Climático. pp. 1-64. Ministerio de Medio Ambiente, Madrid.

Chambers, B. Q. \& SAmways, M. J. 1998. Grasshopper response to a 40-year experimental burning and mowing regime, with recommendations for invertebrate conservation management. Biodiver. Conserv. 7: 985-1012.

Christensen, N. L. 1994. The effects of fire on physical and chemical properties of soil in Mediterranea-climate shrub-lands. En: Moreno, J. M. \& OECHEL, W. C. (eds.). The role of fire in Mediterranean-type ecosystems. pp.79-95.Springer.

Cleary, D. F. R. \& GRILl, A. 2004. Butterfly response to severe ENSO-induced forest fires in Borneo. Ecol. Entomol. 29: 666-676.

Cleary, D. F. R., Priadjati, A., Suryokusumo, B. K. \& Menkem, S. B. J. 2006. Butterfly, seedling, sapling and tree diversity and composition in a fire-affected Bornean rainforest. Austral Ecology 31 (1): 46-57.

Clivillé, S., Montori, A., Llorente, G. A., Santos, X. \& Carretero, M. A. 1997. El impacto de los incendios forestales sobre los anfibios. Quercus 138: 10-13.

Collett, N. G. 1998. Effects of two short rotation prescribed fires in autumn on surface-active arthropods in dry sclerophyll eucalypt forest of west-central Victoria. Forest Ecol Manag. 107 (1-3): 253-73. 
Collett, N. G. \& Neumann, F. G. 1995. Effects of two Spring Prescribed Fires on Epigeal Coleoptera in Dry Sclerophyll Eucalypt Forest in Victoria, Australia. Forest Ecol Manag. 76 (1-3): 69-85.

Collins, N. M. \& Thomas, J. A. (eds.) 1991. The Conservation of Insects and Their Habitats. Academic Press, Londres. 432 pp.

Conedera, M., Tinner, W., NefF, C., Meurer, M., Dickens, A. F. \& Krebs, P. 2009. Reconstructing past fire regimes: methods, applications, and relevance to fire management and conservation. Quaternary Science Rev.s 28: 555-576.

CoOK, W. M. \& HOLT, R. D. 2006. Fire frequency and mosaic burning effects on a tallgrass prairie ground beetle assemblage. Biodivers. Conserv. 15: 2301-2323.

DAJOZ, 2001. Entomología Forestal. Los Insectos y el Bosque. Editorial Mundi-Prensa. Madrid. 550 pp.

Davis, M. A., Peterson, D. W., Reich, P. B., Crozier, M., Query, T., Mitchell, E., Huntington, J. \& BAZAKAS, P. 2000. Restoring savanna using fire: impact on the breeding bird community. Restor. Ecol. 8: 30-40.

DAY, M. C. 1991. Towards the conservation of aculeate Hymenoptera in Europe. Nature and Environment Series, $\mathrm{n}^{\circ}$ 51. Ediciones del Consejo de Europa, Estrasburgo. $80 \mathrm{pp}$.

De Luis, M., Raventós, J. \& González-Hidalgo, J. C. 2006. Post-fire vegetation succession in Mediterranean gorse shrublands. Acta Oecologica 30: 54-61.

DeBano, L. F., Neary, D. G. \& Ffolliott, P. F. 1998. Fire's effects on ecosystems. Wiley. New York. $352 \mathrm{pp}$.

Diadema, K., MÉdAil, F. \& Bretagnolle, F. 2007. Fire as a control agent of demographic structure and plant performance of a rare Mediterranean endemic geophyte. C. R. Biologies 330: 691700 .

DíAZ-DELGADO, R. 2003. Efecto de la recurrencia de los incendios sobre la resiliencia post-incendio de las comunidades vegetales de Cataluña a partir de imágenes de satélite. Ecosistemas Año XII. No 3/ 2003 SEPT-DIC.

Díaz-Delgado, R., Lloret, F. \& Pons, F. X. 2002. Satellite evidence of decreasing resilience in Mediterranean plant communities after recurrent wildfires. Ecology 83: 2293-2303.

DíAZ-Delgado, R., LloRET, F. \& Pons, X. 2004. Spatial patterns of fire occurrence in Catalonia, NE Spain. Landscape Ecology 19: 731-745.

Dietrich, C. H., Harper, M. G., Larimore, R. L. \& Tessene, P. A. 1998. Insects and fire: too much of a good thing? Illinois Nat. Hist. Survey Reports 349: 4.

Ditlhogo, M. K. M., James, R., Laurence, B. R. \& Sutherland, W. J. 1992. The effects of conservation management of reed beds. I. The invertebrates. J. Applied Ecology 29: 265-276.

DunN, R. R. 2005. Modern insect extinctions, the neglected majority. Conserv. Biol. 19: 1030-1036.

Enright, N. J., Marsula, R., Lamont, B. B., \& Wissel. C. 1998a. The ecological signficance of canopy seed storage in Fire-prone environments: a model for non-resprouting shrubs. $J$. Ecology 86: 946-959.

ENRIGHT, N. J., R. MARSUla, B. B. LAMONT, AND C. Wissel. 1998b. The ecological significance of canopy seed storage in fire-prone environments: a model for resprouting shrubs. J. Ecology 86: 960-973.

Evans, E. W. 1984. Fire as a natural disturbance to grasshopper assemblages of tallgrass praire. Oikos 43: 9-16.

Evans, E. W. 1988. Grasshopper (Insecta: Orthoptera: Acrididae) assemblages of tallgrass prairie: influences of fire frequency, topography, and vegetation. Canadian J. Zoology 66: 14951501. 
Evans, W. G. \& Kurster, A. G. 1980. The infrared receptive fields for Melanophila acuminata (Coleoptera, Buprestidae). Can. Entomol. 112: 211-216.

Farji-Brener, A. G., Corley, J. C. \& Bettinelli, J. 2002. The effects of fire on ant communities in north-western Patagonia: the importance of habitat structure and regional context. Divers. Distr. 8: 235-243.

FAY, P. A. \& SAmenus, R. J. JR. 1993. Gall wasp (Hymenoptera: Cynipidae) mortality in a spring tallgrass prairie fire. Environ. Entomol 22: 1333-1337.

Fellows, D. P. \& Newton, W. E. 1999. Prescribed fire effects on biological control of leafy spurge. J. Range Management 52: 489-493.

FERNÁNDEZ, C. \& SÁNCHEZ, F. J. 1996. Efectos del fuego sobre los ecosistemas acuáticos y las comunidades de peces. Quercus 126: 26-29.

FERnÁndez, M. M. \& SAlgado J. M. 2002. Recolonization of a burnt pine tree forest (Pinus pinaster) by edaphic coleoptera. Entomol. Gen. 26 (1):17-28.

FERnÁndeZ, M. M. \& SAlgado J. M. 2004. Recolonization of a burn pine forest (Pinus pinaster) by Carabidae (Coleoptera). Eur J. Soil Biol. 40: 47-53.

Fernández-Santos, B., Martínez, C., García, J. A. \& Puerto, A. 2004. Postfire regeneration in Cytisus oromediterraneus: sources of variation and morphology of the below-ground parts. Acta Oecologica 26: 149-156.

FINNAMORE, A. T. 1996. The advantages of using arthropods in ecosystem management. Biological Survey of Canada (Terrestrial Arthropods), Canadian Museum of Nature, Ottawa. 11 pp.

FloRENCE, R. G. 1996. Ecology and Eucalipt Forests. CSIRO. Australia. 413 pp.

Fons, R., Grabulosa, I., Feliu, C., Mas-Coma, S., Galan-Puchades, M. T. \& Comes, A. M. 1993. Postfire dynamics of a small mammal community in a mediterranean forest (Quercus suber). En: Trabaud, L. \& Prodon, R. (eds.). Fire in Mediterranean Ecosystems. Ecosystems Research Report, 5. Commission of the European Communities, Bruxelles. Pp. 259-270.

Foottit, R. G. \& Adler, P. H. (eds.) 2009. Insects Biodiversity. Science and Society. Blackwell Publishing. $642 \mathrm{pp}$.

FORCE, D. C. 1981. Post-fire insect succession in Southern California chaparral. The American Naturalist, 117: 575-582.

Frost, P. G. H. 1984. The responses and survival of organisms in fire-prone environments. En: Ecological Effects of Fire in South African Ecosystems (BoOYSEN, P. V. \& TAINTON, N. M. eds.), pp. 274-309. Springer-Verlag, Berlin.

Fynn, R. W. S., Morris, C. D. \& EDWARDS, T. J. 2004. Effect of burning and mowing on grass and forb diversity in a long-term grassland experiment. Applied Vegetation Science 7 (1): 1-10.

GALlEy, K. E. M. \& FlowERS, R. W. 1998. Rediscovery of a springtail and a grasshopper in Florida. Florida Entomologist 81: 544-546.

GAndhi, K. J. K., Spence, J. R., LAngor, D. W. \& Morgantini, L. E. 2001. Fire residuals as habitat reserves for epigaeic beetles (Coleoptera: Carabidae and Staphylinidae). BiologConserv 102: 131-141.

García-Ruiz, J. M., Lasanta, T., Ruiz-Flano, P., Ortigosa, L., White, S., González, C. \& MARTí, C. 1996. Land-use changes and sustainable development in mountain areas: A case study in the Spanish Pyrenees. Landscape Ecol. 11: 267-277.

García-Villanueva, J., Ena, V. Mediavilla, TáRrega, R. 1995. Explotación post-fuego por hormigas de Quercus pyrenaica. Avances Ent. Ib. 91-100.

García-Villanueva, J., Ena, V., Tárrega, R. \& Mediavilla, G. 1998. Recolonization of two burned Quercus pyrenaica ecosystems by Coleoptera. Int. J. Wildland Fire 8: 21-27. 
Gaston, K. J., New, T. R. \& Samways, M. J. (eds.) 1993. Perspectives on Insect Conservation. Intercept Ltd., Andover, UK. 420 pp.

Gauld, I. D., Collins, N. M. \& FitTon, M. G. 1990. The biological significance and conservation of Hymenoptera in Europe. Nature and Environment Series, $\mathrm{n}^{\circ}$ 44. Consejo de Europa, Estrasburgo. $47 \mathrm{pp}$.

Gayubo, S. F., González, J. A., Asís, J. D. \& Tormos, J. 2005. Conservation of European environments: The Spheciformes wasp as biodiversity indicators (Hymenoptera: Apoidea: Ampulicidae, Sphecidae and Crabronidae). J. Natural History 39 (29): 2705-2714.

GIBB, H. \& HJÄLTÉN, J. 2007. Effects of low severity burning after clear-cutting on mid-boreal ant communities in the two years after fire. J. Insect Conservation 11: 169-175.

GILL, A. M. 1975. Fire and the Australian flora: a review. Australian Forestry 38: 4-25.

GONZÁleZ, J. A. 2002. Estudio sobre la biodiversidad de avispas "esfeciformes" (Hymenoptera: Apoidea: Ampulicidae, Sphecidae t Crabronidae) een el Espacio Natural de Arribes del Duero. Tesis doctoral. Universidad de Salamanca. Salamanca. 305 pp.

GonzÁlez, J. A., Gayubo, S. F., Asís, J. D. \& Tormos, J. 2009. Diversity and Biogeographical Significance of Solitary wasp (Chrysididae, Eumeninae and Spheciformes) at the Arribes del Duero Natural Park, Spain: Their Importance for Insects Diversity Conservation in the Mediterranean Region. Environ. Entomol. 38 (3): 608-626.

GREENBERG, C. H. \& WALDROP, T. A. 2008. Short-term response of reptiles and amphibians to prescribed fire and mechanical fuel reduction in a southern Appalachian upland hardwood forest. Forest Ecol Manag. 255: 2883-2893.

Grove, A. T. \& Rackham, O. 2001. The Nature of Mediterranean Europe. An Ecological History. Yale University Press. New Haven. 384 pp.

Haimi, J., Fritze, H., MoIlanen, P. 2000. Response of soil decomposer animals to wood-ash fertilization and burning in a coniferous forest stand. Forest Ecol Manag. 129: 53-61.

HALl, S. P. \& SCHWEITZER, D. F. 1992. A survey of the moths, butterflies, and grasshoppers of four Nature Conservancy preserves in southeastern North Carolina. Rept. to Nature Conservancy, North Carolina Chapter, Carrboro, NC 122 pp.

Hanski, I., Koivulehto, H., Cameron, A., Rahagalala, P. 2007. Deforestation and apparent extinctions of endemic forest beetles in Madagascar. Biol. Lett. 3: 344-347.

HANUlA, J. L. \& WADE, D. D. 2003. Influence of long-term dormant-season burning and fire exclusion on ground-dwelling arthropod populations in longleaf pine flatwoods ecosystems. Forest Ecol Manag. 175: 163-184.

Harper, M. G., Dietrich, C. H., Larimore, R. L. \& Tessene, P. A. 2000. Effects of prescribed fire on prairie arthropods: An enclosure study. Natural Areas J. 20 (4): 325-335.

HART, S. 1998. Beetle Mania: an Attraction to Fire. BioScience 48:3-5.

Haugaasen T., Barlow, J. \& Peres, C. A. 2003. Surface wildfires in central Amazonia: short-term impact on forest and carbon loss. Forest Ecol Manag. 179: 321-31.

Haysom, K. A. \& Coulson, J. C. 1998. The Lepidoptera fauna associated with Calluna vulgaris: effects of plant architecture on abundance and diversity. Ecol. Entomol. 23: 377-385.

Hermann, S. M., Hook, T. V., Flowers, R. W., Brennan, L. A., Glitzenstein, J. S., Streng, D. R., WAlker, J. L., MYers, R. L., 1998. Fire and biodiversity: Studies of vegetation and arthropods. Trans. 63rd North Am. Wildl. Nat. Res. Conf. 63: 384-401.

Herrando, S. \& Brotons, L. 2002. Forest bird diversity in Mediterranean areas affected by wildfires: A Multi-scale approach. Ecography 25: 161-172.

Herrando, S., Brotons, L. \& Llacuna, S. 2003. Does fire increase the spatial heterogeneity of bird communities in Mediterranean landscapes? Ibis 145: 307-317. 
Hirowatari, T., Makihara, H. \& Sugiarto, 2007. Effects of fires on butterfly assemblages in lowland dipterocarp forest in East Kalimantan. Entomological Science 10 (2): 113-127.

HobBs, R. J. \& Gimmingham, C. H. 1987. Vegetation, fire and herbivore interactions in heathland. Adv. Ecol. Res. 16: 18-173.

Hobson, K. A., \& J. SCHIECK. 1999. Changes in bird communities in boreal mixedwood forest: harvest and wildfire effects over 30 years. Ecological. Applications 9: 849-863.

HofFMANN, B. D. 2003. Responses of ant communities to experimental fire regimes on rangelands in the Victoria River District of the Northern Territory. Austral Ecology. 28: 182-195.

Holliday, N. J. 1991. Species responses of carabid beetles (Coleoptera: Carabidae) during post-fire regeneration of boreal forest. Can. Entomol. 123: 1369-1389.

Holliday, N. J. 1992. The carabid fauna (Coleoptera: Carabidae) during post-fire regeneration of a boreal forest: Properties and dynamics of species assemblages. Can. Jour. Zool. 70: 796-808.

Holloway, J. D. \& StORK, N. E. 1991. The dimensions of biodiversity: the use of invertebrates as indicators of human impact. En: The biodiversity of microorganisms and invertebrates: Its role in sustainable agriculture (ed. HAWKSWORTH, D. L.), pp. 37-62. CAB-International, Wallingford.

Huston, M. A, 1994. Biological diversity: The coexistence of species changing landscapes. Cambridge University Press, Cambridge. 681 pp.

IPCC, 2007. Climate Change 2007: Climate Change Impacts, Adaptation and Vulnerability. Working Group II Contribution to the Intergovernmental Panel on Climate Change Fourth Assessment Report. Cambridge University Press, Cambridge, UK.

IZHAKI, I. 1993. The resilience to fire of passerine birds in an east-Mediterranean pine forest on Mount Carmel, Israel: The effects of post-fire management. En: TrABAUD, L. \& PRODON, R. (eds.). Fire in Mediterranean Ecosystems. ECSC-EEC-EAEC, Brussels-Luxenburg, pp. 303-314.

IZHAKI, I. \& ADAR, M. 1997. The effects of post-fire management on bird community succession. Int. J. Wildland Fire 7: 335-342.

IZHAKI, I., LEVEY, D. J. \& Silva, W. R. 2003. Effects of prescribed fire on an ant community in Florida pine savanna. Ecol. Entomol. 28 (4): 439-48.

Kaila, L., Martikainen, P. \& Punttila, P. 1997. Dead trees left in clear-cuts benefit saproxylic Coleoptera adapted to natural disturbances in boreal forest. Biodivers. Conserv. 6: 1-18.

KAlisZ, P. J. \& Powell, J. E. 2000. Effects of prescribed fire on soil invertebrates in upland forests on the Cumberland Plateau of Kentucky, USA. Natural Areas J. 20: 336-341.

KeEley, J. E. 1992. Demographic structure of California chaparral in long-term absence of fire. $J$. Vegetation Science 3: 79-90.

KIM, K. C. 1993. Biodiversity, conservation and inventory: why insects matter. Biodivers. Conserv. 2: 191-214.

KIRBY, P. 2001. Habitat Management for Invertebrates: A practical handbook. National Power, JNCC \& RSPB. viii + 150 pp.

Klocke, D., Schmitz, A. \& Schmitz, H. I. 2009. Native flies attracted to bushfires. Information Sheet 15 / 2009. Science Division, Department of Environment and Conservation, Western Australia, Locked Bag 104, Bentley Delivery Centre, WA 6983 nstitut für Zoologie, Universität Bonn.

Knight, T. M. \& Holt, R. D. 2005 Fire Generates Spatial Gradients in Herbivory: An Example from a Florida Sandhill Ecosystem. Ecology 86 (3): 587-593.

Koproski, L., Mangini, P. R., Pachaly, J. R., Soares, R. V. \& Batista, A. C.2006. Fire effects on reptiles and mammals in Ilha Grande National Park (PR/MS), Brazil. Forest Ecol Manag. 234: $1 \mathrm{~S} 180$. 
Kremen, C., Colwell, R. K., Erwin, T. L., Murphy, D. D., Noss, R. F. \& Sanjayan, M. A. 1993. Terrestrial arthropod assemblages: their use in conservation planning. Conservation Biology 7 (4): 796-808.

Kremen, C., Merenlender, A. M. \& Murphy, D. D. 1994. Ecological monitoring: a vital need for integrated conservation and development programs in the tropics. Conserv Biolog 8 (2): 388397.

KRUGeR, E. L. \& ReICH, P. B. 1997. Responses of hardwood regeneration to fire in mesic forest openings. II. Leaf gas exchange, nitrogen concentration, and water status. Canadian J. Forest Research.27: 1832-1840.

Lamotte, M. 1975. The structure and function of a tropical savanna ecosystem. En: Tropical Ecological Systems: Trends in Terrestrial and Aquatic Research. Golley, F. B. \& MedinA, E. (eds.), pp 179-222. Springer-Verlag, Berlin.

LaSAlle, J. \& Gauld, I. D. (eds.) 1993. Hymenoptera and Biodiversity. CAB International. The Natural History Museum, Wallingford, UK. xi + 348 pp.

LAVOREL, S. 1999. Ecological diversity and resilience of Mediterranean vegetation to disturbance. Divers. Distr. 5: 3-13.

Lawton, J. H. 1983. Plant architecture and the diversity of phytophagous insects. Annu. Rev. Entomology 28: 23-39.

LETNIC, M. 2003. The effects of experimental patch burning and rainfall on small mammals in the Simpson Desert, Queensland. Wildlife Research 30 (6): 547-63.

LlORET, F. 2003. Gestión del fuego y conservación en ecosistemas mediterráneos. Ecosistemas, $2003 / 2$

LlORET, F. 2004. Régimen de incendios y regeneración. En: VAlladARES F. (ed.) Ecología del bosque mediterráneo en un mundo cambiante. pp 101-126. Ministerio de Medio Ambiente O. A. Parques Nacionales, Madrid

LLORET, F. \& M. VILÀ. 2003. Diversity patterns of plant functional types in relation to fire regime and previous land use in Mediterranean woodlands. J. Vegetation Science 14: 387-398.

Lockwood, J. A., Shaw, S. R. \& Struttmann, J. M. 1996. Biodiversity of wasp species (Insecta: Hymenoptera) in burned and unburned habitats of Yellowstone National Park, Wyoming, USA. J. Hymenopt. Res. 5: 1-15

LUFF, M. L. \& WOIWOD, I. P. 1995. Insects as indicators of land-use change: a European perspective, focusing on moths and ground beetles. En: Insects in a Changing Environment (eds. HARrintong, R. \& StORK, N. E.), pp. 400-424. Academic Press, Londres.

Luis-Calabuig, E. \& TÁrrega, R. 1993. Studies on post-fire regeneration in Quercus pyrenaica ecosystems in Leon Province (NW Spain). Pp 209-219. En: TrABAUd, L. \& Prodon, R. (eds.). Fire in Mediterranean Ecosystems. ECSC-EEC-EAEC, Brussels-Luxembourg.

LuSSENHOP, J. 1976. Soil arthropod response to prairie burning. Ecology 57: 88-98.

Makihara, H., KinuUra, H., Yahiro, K. \& Soeyamto, C. 2000. The effects of droughts and fires on Coleopteran insects in lowland dipterocarp forests in Bukit Soeharto, East Kalimantan. En: Guhardua, E., Futawi, M., Sutisna, M. \& OHTA, S. (eds.) Rainforest Ecosystems of East Kalimantan. Ecological Studies, 140, pp 153-163. Springer, Tokyo.

MarXer, P. \& CONEDera, M. 2000. Experimental fire in Switzerland. Final report of the Prometheus system validation project. EU project no. PL971037. Swiss Federal Research Institute, Sottostazione Sud delle Alpi, Bellinzona, Switzerland.

Matheson, A., Buchmann, S. L., O'toole, C., Westrich, P. \& Williams, I. H. (eds.) 1996. The Conservation of Bees. Academic Press, Londres. 254 pp. 
Matthews, C. E., Moorman, C. E., Greenberg, C. H. \& Waldrop, T. A. 2009 Response of soricid populations to repeated fire and fuel reduction treatments in the southern Appalachian Mountains. Forest Ecol Manag. 257: 1939-1944.

McCullough, D. G., Werner, R. A. \& Neumann, D. 1998. Fire and insects in northern and boreal forest ecosystems of North America. Annu. Rev. Entomology 43: 107-127.

MÉDAIL, F. \& QuÉZEL, P. 1999. Biodiversity hotspots in the Mediterranean Basin: setting global conservation priorities. Conserv Biolog 13: 1510-1513.

Melbourne, B. A. 1999. Bias in the effect of habitat structure on pitfall traps: An experimental evaluation. Aust. J. Ecol. 24:228-239

MENGES, E. S. \& HAWKES, C. V. 1998. Interactive effects of fire and microhabitat on plants of Florida scrub. Ecological Applications 8: 935-946.

Milius, S. 2001. Why Fly into a Forest Fire?. Science News 159 (9): 140-141.

Millán, M., Estrela, M. J. \& BÁdenAs, C. 1998. Meteorological processes relevant to forest fire dynamics on the Spanish Mediterranean Coast. J. Applied Meteorology 37: 83-100.

Mitchell, R. G. 1990. Effects of prescribed fire on insect pests. En: WALSTAD, J. D., RADOSEVICH, S. R., SAndberg, D. V. (eds.). Natural and prescribed fires in Pacific Northwest forests. Corvallis, OR: Oregon State University Press: 111-121.

Möllenbeck, V., Hermann, G. \& Fartmann, T. 2009. Does prescribed burning mean a threat to the rare satyrine butterfly Hipparchia fagi? Larval-habitat preferences give the answer. J. Insect Conservation, 13 (1): 77-87.

Monimeau, L., Moulllot, D., Fons, R., Prodon, R. \& Marchand, B. 2002. Impact of prescribed burning on the survival rates of the wood mouse (Apodemus sylvaticus). Acta Oecologica 23: 51-58.

Moreira, F., Delgado, A., Ferreira, S., Borralho, R., Oliveira, N., Inacio, M., Silva, J.S. \& REGO, F. 2003. Effects of prescribed fire on vegetation structure and breeding birds in young Pinus pinaster stands of northern Portugal. Forest Ecol. Manag. 184: 225-237.

Moreno, J. M. 2007. Cambio Global e Incendios Forestales: Una Visión desde España. $4^{\mathrm{a}}$ Conferencia Internacional sobre Incendios Forestales. Sevilla. España. 13-17 Mayo de 2007.

Moreno, J. M. \& Oechel, W. C. 1994. The role of fire in Mediterranean type ecosystems. SpringerVerlag, New York. 215 pp.

Moreno, J. M., VÁzquez, A. \& VÉlez, R. 1998. Recent history of forest fires in Spain. En: Moreno, J. M. (Ed.) Large Fires. Pp.: 159-185. Backhuys Publishers, Leiden.

Moretti, M. \& S. Barbalat. 2004. The effects of wildfires on wood-eating beetles in deciduous forests on the southern slope of the Swiss Alps. Forest Ecol Manag. 187 (1): 85-103.

Moretti, M., ConederA, M., Duelli, P. \& Edwards, P. J. 2002a. The effects of wildfire on groundactive spiders in deciduous forests on the Swiss Southern slope of the Alps. J. of Applied Ecology 39 (2): 321-336.

Moretti, M., Duelli, P. \& OBRist, M. K. 2006. Biodiversity and resilience of arthropod communities after fire disturbance in temperate forests. Oecología 149: 312-327

Moretti, M., OBRIST, M. K. \& Duelli, P. 2004. Arthropod biodiversity after forest fires: winners and losers in the winter fire regime of the Southern Alps. Ecography 27 (2): 173-186.

Moretti, M., Zanini, M. \& Conedera, M. 2002b. Faunistic and floristic post-fire succession in southern Switzerland: an integrated analysis with regard to fire frequency and time since the last fire. In: Wiegas, D. X. (ed.), Forest Fire Research and Wildland Fire Safety. Millpress, Rotterdam. CD-Rom.

Morgan, J. W. \& LunT, I. D. 1999. Effect of time-since fire on the tussock dynamics of a dominant grass (Themeda triandra) in a temperate Australian grassland. Biolog Conserv 88: 379-386. 
MoRRIS, M. G. 1975. Preliminary observations on the effects of burning on the Hemiptera (Heteroptera and Auchenorrhyncha) of limestone grassland. Biological Conservation 7: 311319.

Mouillot, F., RAmbal, S. \& JoffRe, R. 2002. Simulating climate change impacts on fire frequency and vegetation dynamics in a Mediterranean-type ecosystem. Global Change Biology 8: 423437.

MuOnA, J. \& RutANEn, I. 1994. The short-term impact of fire on the beetle fauna in boreal coniferous forest. Ann. Zool. Fenn. 31: 109-121.

Myers, N., Mittermeier, R. A., Mittermeier, C. G., Da Fonseca, G. A. B., \& Kent, J. 2000. Biodiversity hotspots for conservation priorities. Nature 403: 853-858.

NAVEH, Z. 1975. The evolutionary significance of fire in the Mediterranean region. Vegetatio 29: 199208.

NAVEH, Z. 1990. Fire in the Mediterranean- A landscape ecological perspective. En: GolDAMMER, J. G. \& Jenkins, M. J. (eds) Fire in Ecosystems Dynamics. Pp. 1-20. Proceedings of the Third International Symposium in Freiburg, FRG, May 1989. SPB Academic Publishing by, The Hague, the Netherlands,

NaveH, Z., 1995. The role of fire and its management in the conservation of mediterranean ecosystems and landscapes. En: Moreno, J. M., Oechel, W. C. (Eds.). The Role of Fire in Mediterranean-Type Ecosystems. pp. 163-185. Springer-Verlag, New York, USA,

Ne'eman, G., Dafni, A. \& PotTs, S. G. 2000. The effect of fire on flower visitation rate and fruit set in four core-species in east Mediterranean scrubland. Plant Ecol. 146: 97-104.

Ne'eman, G., Lahav, H. \& Izhaki, I. 1993. The resilience of vegetation to fire in an eastMediterranean pine forest on Mount Carmel, Israel: The effects of post-fire management regimes. En: Trabaud, L. \& Prodon, R. (eds.), Fire in Mediterranean Ecosystems. Pp. 127140. ECSC-EEC-EAEC, Brussels-Luxenburg,

NeKola, J. 2002. Effects of fire management on the richness and abundance of central North American grassland land snail faunas. Anim. Biodiv. Conserv. 25 (2): 53-66.

Newman, F. \& TolhuRst, K., 1991. Effect of fuel reduction burning on epigeal arthropods and earthworms in dry sclerophyl eucalypt forest of west-central Victoria. Aust. Jour. Ecol. 16: 315-330.

Nielsen, M. G. 2001. Energetic costs of foraging in the ant Rhytidoponera aurata in tropical Australia. Physiol Entomol. 26: 248-253.

NilsSON, S. G. \& ERICSON, L., 1997. Conservation of plant and animal populations in theory and practice. Ecol. Bull. 46: 117-139.

NiWA, C. G. \& PECK, R. W. 2002. Influence of prescribed fire on carabid beetle (Carabidae) and spider (Araneae) assemblages in forest litter in southwestern Oregon. Environ. Entomol. 31: 785796.

Noble, I. R. \& Slatyer, R. O. 1981. Concepts and models of succession in vascular plant communities subject to recurrent fire. En: Gill, A. M., Groves, R. H. \& Noble, I. R. (eds) Fire and the Australian Biota

NunES, L., Leather, S. \& REGO, F. 2000. Effects of fire on insects and other invertebrates. A review with particular reference to fire indicator species. Silva Lusitana 8 (1): 15-32.

Nunes, L., Silva, I., Pité, M., Rego, F., Leather, S. \&Serrano, A. 2006. Carabid (Coleoptera) Community changes following prescribed burning and the potencial use of carabids as indicatrs species to evaluate the effects of FIRE management in Mediterraneans Reginon. Silva Lusitana 14 (1): 85-100. 
O’NeILL, K. M. 2001. Solitary wasps: behavior and natural history. Cornell University Press, Ithaca. xiii +406 pp.

Oesterheld, M., Loreti, J., Semmartin, M. \& Paruelo, J. M. 1999. Grazing, fire and climate effects on primary productivity of grasslands and savannas. En: WALKER, L. R. (ed.), Ecosystems of the World 16. Ecosystems of Disturbed Ground. Elsevier, Amsterdam.

OJEDA-COPETE, F. 2001. El fuego como factor clave en la evolución de plantas mediterráneas. En: Ecosistemas Mediterráneos. Análisis funcional. ZAMORA RodRÍGUEZ, R. \& PUGNAIRE DE IRAOLA, F. I. (eds.). Textos Universitarios. CSIC. Asociación Española de Ecología Terrestre. Pp. 319-349.

ØKLAND, B. 1994. Mycetophilidae (Diptera), an insect group vulnerable to forestry? A comparison of clearcut, manager and semi-natural spruce forests in southern Norway. Biodivers. Conserv. 3: 68-85.

OLEMBO, R. 1991. Importance of microorganisms and invertebrates as components of biodiversity. En: The biodiversity of microorganisms and invertebrates: Its role in sustainable agriculture (ed. HAWKSWORTH, D. L.), pp. 7-15. CAB-International, Wallingford.

Orgeas, J. \& Andersen, A. N.. 2001. Fire and biodiversity: responses of grass-layer beetles to experimental fire regimes in an Australian tropical savanna. J. Applied Ecology 38 (1): 49-62.

PANZER, R. 1988. Managing prairie remnants for insect conservation. Natural Areas J. 8: 83-90.

PANZER, R. 2002. Compatibility of prescribed burning with the conservation of insects in small, isolated prairie reserves. Conserv Biolog 16 (5): 1296-1307.

PANZER, R. 2003. Importance of in situ survival, recolonization, and habitat gaps in the postfire recovery of fire-sensitive prairie insect species. Nat. Areas J. 23: 14-21.

PANZER, R. \& SCHWARTZ, M. 2000. Effects of management burning on prairie insect species richness within a system of small, highly fragmented reserves. Biological Conservation 96 (3): 363369.

PAoletti, M. G. 1999. Using bioindicators based on biodiversity to assess landscape sustainability. Agriculture, Ecosystems and Environment 74: 1-18.

Paquin, P. \& Coderre, D. 1997. Deforestation and fire impact on edaphic insect larvae and other macroarthropods. Environ. Entomol. 26: 21-30.

Parr, C. L., Andersen, A. N., Chastagnol, C. \& Duffaud, C. 2007, Savanna Fires increase rates and distances of seed dispersal by ants. Oecologia 151: 33-41.

Parr, C. L., Robertson, H. G., Biggs, H. C. \& Chown, S. L., 2004. Response of African savanna ants to long-term fire regimes. J. Appl. Ecol. 41: 630-642.

PAula, S. \& PAuSAS, J. G. 2008. Burning seeds: germinative response to heat treatments in relation to resprouting ability. J. Ecology 96: 543-552.

Paula, S., Arianoutsou, M., Kazanis, D., Tavsanoglu, Ç., Lloret, F., Buhk, C., Ojeda, F., Luna, B., Moreno, J. M., Rodrigo, A., Espelta, J. M., Palacio, S., Fernández-Santos, B., Fernandes, P. M., \& PausAs, J. G. 2009. Fire-related traits for plant species of the Mediterranean Basin. Ecology 90: 1420.

PAUSAS, J. G. 1999a. Mediterranean vegetation dynamics: modelling problems and functional types. Plant Ecology 140: 27-39.

PAusas, J. G. 1999b Post-fire regeneration patterns in the eastern Iberian Peninsula. Acta Oecologica 499-508.

PAuSAS, J. G. 2001. Resprouting vs seeding- a Mediterranean perspective. Oikos 94:193-194.

Pausas, J. G. 2003. The effect of landscape pattern on Mediterranean vegetation dynamics: a modelling approach using functional types. J. Vegetation Science 14: 365-374. 
Pausas, J. G. 2004a. Changes in fire and climate in the eastern Iberian Peninsula (Mediterranean basin). Climatic Change 63: 337-350.

Pausas, J. G. 2004b. La recurrencia de incendios en el monte Mediterráneo. Págs. 47-64. En: Vallejo, V. R. \& Alloza J. A. (eds). Avances en el estudio de la gestión del monte mediterráneo. Fundación CEAM.

Pausas, J. G. \& Keeley, J. E. 2009. A Burning Story: The Role of Fire in the History of Life. BioScience 59 (7): 593-601.

Pausas, J. G., Vallejo, R. 1999. The role of fire in European Mediterranean ecosystems. En: Chuvieco, E. (ed.), Remote Sensing of Large Forest Fires in the European Mediterranean Basin. Springer.

Pausas, J. G., Bradstock, R. A., Keith, D. A., Keeley, J. E. \& the GCTE Fire Network 2004. Plant functional traits in relation to fire in crown-fire ecosystems. Ecology 85: 1085-1100

Pausas, J. G., Carbó, E., Caturla, R. N., Gil, J. M. \& Vallejo, R. 1999. Post-fire regeneration patterns in the eastern Iberian Peninsula. Acta Oecologica 20 (5): 499-508.

Pausas, J. G., Llovet, J., Rodrigo, A. \& Vallejo, R. 2008. Are wildfires a disaster in the Mediterranean Basin?- A review. Int. J. Wildland Fire 17: 713-723.

Penn, A. M., Sherwin, W. B., Lunney, D. \&, BAnks, P. B. 2003. The effects of a low-intensity fire on small mammals and lizards in a logged, burnt forest. Wildlife Research 30 (5): 477-86.

PicketT, S. T. A. \& White, P.S. 1985. Patch dynamics: a synthesis. En: PICKETT, S. T. A. \& WHITE, P. (eds.) Pp: 371-385. The ecology of natural disturbance and patch dynamics. New York: Academic Press

Piñol, J., TerRADAS, J. \& LlORET, F. 1998. Climate warming, wildfire hazard, and wildfire occurrence in coastal eastern Spain. Climate Change 38: 345-357.

PIPPIN, W. F. \& NichOLS, B. 1996. Observations of arthropod populations following the La Mesa Fire of 1977. En: Allen C. D. (ed.). Fire effects in Southwestern Forests. Pp. 161-165. Proceedings of the Second La Mesa Fire Symposium, General Technical Report RM-GTR286, USDA Rocky Mountain Forest and Range Experiment Station, Fort Collins.

Pons, P. 1998. Bird site tenacity after prescribed burning in a Mediterranean shrubland. En: Trabaud, L. (ed.). Fire Management and Landscape Ecology. Pp. 261-270.International Association of Wildland Fire, Washington.

Pons, P. \& PRODON, R. 1996. Short-term temporal patterns in a Mediterranean shrubland bird community after wildfire. Acta Oecologica., 17: 29-41.

Pons, P., Lambert, B., Rigolot, E. \& Prodon, R. 2003. The effects of grassland management using fire on habitat occupancy and conservation of birds at a mosaic landscape. Biodivers. Conserv. 12: 1843-1860.

PORTER, E. \& REDACK, R. 1996. Short-term recovery of the grasshopper communities (Orthoptera. Acrididae) of a California native grassland after prescribed burning. Environ. Entomol. 25: 987-998.

Potts, S. G., DafnI, A. \& Ne'eman, G. 2001. Pollination of a core flowering shrub species in Mediterranean phrygana: variation in pollinator diversity, abundance and effectiveness in response to fire. Oikos 92: 71-80.

Potts, S. G., Vulliamy, B., Dafni, A., Ne'eman, G., O’Toole, C., Roberts, S. \& Willmer, P. 2003. Response of plant-pollinator communities to fire: changes in diversity, abundance and floral reward structure. Oikos 101 (1): 103-112.

Potts, S. G., Vulliamy, B., Roberts, S., Roberts, S., O’Toole, C., Dafni, A., Ne'eman, G. \& WILLMER, P., 2005. Role of nesting resources in organising diverse bee communities in a Mediterranean landscape. Ecol. Entomol. 30: 78-85. 
Prodon, R. \& Athias-Brinche, F. 1987. The impact of fire on animal communities in Mediterranean area. En: Trabaud, L. (ed.), pp. 121-157. The role of fire in ecological systems. SPB. Academic Publishing, Den Haag.

Pulliam, H. R. 1988. Sources, sinks, and population regulation. The American Naturalist 132: 652669.

Pyne, S. J., Andrews, P. L. \& Laven, R. D. 1996. Introduction to Wildland Fire. Wiley \& Sons, Inc. New York. 808 pp.

Quintana, J. R., Cruz, A., Fernández-González, F., Moreno, J. M., 2004. Time of germination and establishment success after fire of three obligate seeders in a Mediterranean shrubland of Central Spain. J. Biogeogr.31: 241-249.

RAdho-Toly, S., Majer, J. D. \& YATES, C. 2001. Impact of fire on leaf nutrients, arthropod fauna and herbivory of native and exotic eucalypts in Kings Park, Perth, Western Australia. Austral Ecology 26: 500-506.

Ramos, M. A., Lobo, J. M. \& EstebAn, M. 2001. Ten years inventorying the Iberian fauna: results and perspectives. Biodivers. Conserv. 10: 19-28.

Ratchford, J. S., Wittman, S. E., Jules, E. S., Ellison, A. M., Gotelli, N. J. \& Sanders, N. J. 2005 The effects of fire, local environment and time on ant assemblages in fens and forests. Divers. Distr. 11: 487-497.

REED, C. C. 1997. Responses of prairie insects and other arthropods to prescription burns. Natural Areas J. 17: 380-385.

Reich, P. B., Abrams, M. D., Ellsworth, D. S., Kruger, E. L., Tabone, T. J. 1990. Fire effects ecophysiology and community dynamics of a central Wisconsin oak forest regeneration. Ecology 71: 513-518.

RICE, L. 1932. Effect of fire on the prairie animal communities. Ecology. 13: 392-401.

RIERA-MORA, S. \& ESTEBAN-AMAT, A. 1994. Vegetation history and human activity during the last 6000 years on the central Catalan coast (northeastern Iberian Peninsula). Veg. Hist. Archaeobot. 3: 7-23.

RIESKE, L. K. 2002. Wildfire alters oak growth, foliar chemistry, and herbivory. Forest Ecol Manag. 168: 91-99.

Rieske, L. K., Housman, H. H, Arthur, M. A. 2002. Effects of prescribed fire on canopy foliar chemistry and suitability for an insect herbivore. Forest Ecol Manag. 160: 177-187.

RiESKE-KinneY, L. K. 2006. Do fire and insects interact in eastern forests? En: Dickinson, M. B. (ed.). Fire in eastern oak forests: delivering science to land managers. Proceedings of a conference; 2005 November 15-17; Columbus, OH. Gen. Tech. Rep. NRS-P-1. Newtown Square, PA: U.S. Department of Agriculture, Forest Service, Northern Research Station: 152157.

Robbins, L. E. \& Myers, R. L. 1992. Seasonal effects of prescribed burning in Florida: a review. Misc. Pub. no. 8. Tallahassee, FL: Tall Timbers Research, Inc. 96 pp.

Rodrigo, A. \& RetanA, J. 2006. Post-fire recovery of ant communities in Submediterranean Pinus nigra forests. Ecography 29: 231-239.

Rodrigo, A., Retana, J. \& Pico, F. X. 2004. Direct regeneration is not the only response of Mediterranean forests to large fires. Ecology 85 (3): 716-729.

Rodrigo, A., Sardá-Palomera, F., Bosch, J. \& Retana, J. 2008. Changes of dominant ground beteles in black pine forest with fire severity and sucesional age. EcoScience 15 (4): 442-452.

Rundel, P. W. 1981. Fire as an ecological factor. Pp. 501-538. En: LANGe, O. L., Nobel, P. S., Osmond, C. B. \& Ziegler, H. (eds.), Physiological Plant Ecology I: Responses to the Physical Environment. Springer-Verlag, Berlin. 
Rundel, P. W., Montenegro, G. \& JAKsic, F. 1998. Landscape disturbance and biodiversity in Mediterranean ecosystems. Ecological Studies 136. Springer-Verlag, Berlin, Heidelberg, New York.

Saint-Germain, M., Drapeau, P. \& HéBert, C. 2004. Comparison of Coleoptera assemblages from a recently burned and unburned black spruce forests of northeastern North America. Biological Conservation 118: 583-592.

Sala, O. E., Chapin, F. S., Armesto, J. J., Berlow, E., Bloomfield, J., Dirzo, R., HuberSanwald, E., Huenneke, L. F., Jackson, R. B., Kinzig, A., Leemans, R., Lodge, D. M., Mooney, H. A., Oesterheld, M., Poff, N. L., Sykes, M. T., WAlker, B. H., WAlker, M. \& WALL, D. H. 2000. Biodiversity - Global biodiversity scenarios for the year 2100. Science 287: $1770-1774$.

SAlvador, R., Lloret, F., Pons, X. \& PiÑOL, J. 2005. Does fire occurrence modify the probability of being burned again? A null hypothesis test from Mediterranean ecosystems in NE Spain. Ecological Modelling 188: 461-469.

SAmways, M. J. 1989. Insect conservation and the disturbance landscape. Agriculture, Ecosystems and Environment 27: 183-194.

Samways, M. J. 1990. Insect conservation ethics. Environ. Conserv. 17: 7-8.

SAmways, M. J. 1994. Insect Conservation Biology. Chapman \& Hall Ltd., Londres. xiii + 358 pp.

SAMWAYS, M. J. 2006. Insect extinctions and insect survival. Conservation Biology. 20: 245-246.

SAmways, M. J. 2007. Insect Conservation: A Synthetic Management Approach. Ann. Rev. Entomol. 52: 465-487.

Scarascia-Mugnozza, G., Oswald, H., Piussi, P. \& Radoglou, K. 2000. Forests of the Mediterranean region: gaps in knowledge and research needs. Forest Ecol Manag. 132: 97109.

Schmitz, H., Bleckmann, H. \& MuRTz, M. 1997. Infrared Detection in a Beetle. Nature 386: 773774.

Schmitz, H., Schmitz, A. \& BleckmanN, H., 2000. A new type of infrared organ in the Australian "fire-beetle" Merimna atrata (Coleoptera: Buprestidae). Naturwissenschaften 87: 542-545.

SCHOwAlter, T. D. 2006. Insect Ecology. An ecosystem approach. Academic Press. London. 574 pp.

Scudder, G. G. E. 2009. The Importance of Insects. En: Foottit, R. G. \& AdLer, P. H. (eds.) 2009. Insects Biodiversity. Science and Society. Blackwell Publishing. 642 pp.

SEASTEDT, T. R. 1984. Microarthropods of burned and unburned tallgrass prairie. J. Kansas Entomological Society 57: 468-476.

Sgardelis, S. P., Pantis, J. D., Argyropoulou, M. D. \& Stamou, G. P. 1995. Effects of fire on soil macroinvertebrates in a Mediterranean Phryganic ecosystem. International J. Wildland Fire 5: 129-136.

Shlisky, A., Waugh, J., González, P., González, M., Manta, M., Santoso, H., Alvarado, E., Ainuddin Nuruddin, A., Rodríguez-Trejo, D. A., Swaty, R., Schmidt, D., Kaufmann, M., Myers, R., Alencar, A., Kearns, F., Johnson, D., Smith, J., Zollner, D. \& Fulks, W. 2007. El Fuego, los Ecosistemas y la Gente: Amenazas y estrategias para la conservación global de la biodiversidad. Informe Técnico de la Iniciativa Global para el Manejo del Fuego 2007-2. The Nature Conservancy. Arlington, VA.

Siemann, E., HaARSTAD, J. \& Tilman, D. 1997. Short-term and long-term effects of burning on oak savanna arthropods. Am. Midl. Natur., 137 (2): 349-361.

Similä, M. Kouki, J., Martikainen, P. \& Uotila, A. 2002. Conservation of beetles in boreal pine forests: the effects of forest age and naturalness on species assemblages. Biological Conservation 106: 19-27. 
Sirami, C., Brotons, L., Burfield, I., Fonderflick, J. \& Martin, J. L. 2008. Is land abandonment having an impact on biodiversity? A meta-analytical approach to bird distribution changes in the north-western Mediterranean. Biological Conservation 141: 450-459.

SiX, D. L. \& Skov, K., 2009. Response of bark beetles and their natural enemies to fire and fire surrogate treatments in mixed-conifer forests in western Montana. Forest Ecol Manag., doi:10.1016/j.foreco.2009.05.016

SMITH, J. K., (ed.) 2000. Wildland fire in ecosystems: effects of fire on fauna. Gen. Tech. Rep. RMRSGTR-42-vol. 1. Ogden, UT: U.S. Department of Agriculture, Forest Service, Rocky Mountain Research Station. 83 pp.

Sobek, S., Tscharntke, T., Scherber, C., Schiele, S., \& Steffan-Dewenter, I. 2009. Canopy vs. understory: Does tree diversity affect bee and wasp communities and their natural enemies across forest strata?. Forest Ecol Manag. 258: 609-615.

Sodhi, N. S., Wilcove, D. S., Subaraj, R. Yong, D. L., Lee, T. M., Bernard, H. \& Lim, S. L. H. 2009. Insect extinctions on a small denuded Bornean island. Biodiversity and Conservation Publicado on line 04/02/2009. http://www.springerlink.com/content/uOh2623712228468/fulltext.pdf

SPENCE, J. R. \& J. K. NiEMELA. 1994. Sampling carabid assemblages with pitfall traps: the madness and the method. Can. Entomol. 126: 881-894.

SPRINGETT, J. A. 1976. The effect of prescribed burning on the soil fauna and on litter decomposition in western Australian forests. Aust. J. Ecol. 1: 77-82.

STEFFAN-DEWENTER, I. \& LESCHKE, K. 2003. Effects of habitat management on vegetation and above-ground nesting bees and wasps of orchard meadows in Central Europe. Biodivers. Conserv. 12: 1953-1968.

STEFFAN-DEWENTER, I., 2002, Landscape context affects trap-nesting bees, wasp, and their natural enemies. Ecol. Entomol. 27: 631-637.

Suckling, D. M., Gibb, A. R., Daly, J. M., Chen, D. \& Brockerhoff, E. G. 2001. Behavioral and electrophysiological responses of Arthopalus tristis to burnt pine and other stimuli. J.Chemical Ecology, 27: 1091-1104.

Sullivan, B. T., Fettig, C. B., Otrosina, W. J., Dalusky, M. J. \& Berisford, C. W. 2003. Association between severity of prescribed burns and subsequent activity of conifer-infesting beetles in stands of longleaf pine. Forest Ecol Manag. 185: 327-340.

Swengel A. B. 1998a. Comparisons of butterfly richness and abundance measures in prairie and barrens. Biodivers. Conserv. 7: 1639-1659

SwENGEL, A. B. 1998b. Effects of management on butterfly abundance in tallgrass prairie and pine barrens. Biological Conservation 83: 77-89.

Swengel, A. B. 2001. A literature review of insect responses to fire, compared to other conservation managements of open habitat. Biodivers. Conserv. 10 (7): 1141-1169.

Swengel, A. B. \& Swengel, S. R. 1999. Observations on Schinia indiana and S. lucens (Lepidoptera: Noctuidae) in the Midwest USA. Holarctic Lepidoptera 6: 11-21.

Swengel, A. B. \& SwENGEL, S.R. 2007. Benefit of permanent non-fire refugia for Lepidoptera conservation in fire-managed sites. J. Insect. Conservation 11: 263-279.

Taki, H., Viana, B. F., Kevan, P. G., Silva, F. O., \& Buck, M. 2008. Does forest loss affect the communities of trap-nesting wasps (Hymenoptera: Aculeata) in forests? Landscape vs. local habitat conditions. J. Insect Conservation 12 (1): 15-21.

Tapias, R., Gil, L., Fuentes-Utrilla, P., \& Pardos J. A. 2001. Canopy seed banks in Mediterranean pines of south-eastern Spain: a comparison between Pinus halepensis Mill., P. pinaster Ait., P. nigra Arn. and P. pinea L. J. Ecology 89 (4): 629-638. 
TÁRrega, R., Luis-Calabuig, E. \& Marcos, E. 1996. Relationship between soil changes and plant succession in postfire regeneration of Quercus pyrenaica ecosystems. Arid Soil Res. Rehab. 10: 85-93.

TárRega, R., Luis-Calabuig, E. \& Valbuena, L. 2001 Eleven years of recovery dynamic after experimental burning and cutting in two Cistus communities. Acta Oecologica 22: 277-283.

TERRADAS, J., PiÑoL, J. \& LlORET, F. 1998. Risk factors in wildfires along the Mediterranean coast of Iberian Peninsula. Pages 297-304. En: Trabaud, L. (ed.). Fire Management and Landscape Ecology. Internat. Ass. Wildland Fire, Washington.

TOOKER, J. F. \& HANKS, L. M. 2004. Impact of prescribed burning on endophytic insect communities of prairie perennials (Asteraceae: Silphium spp.). Biodivers. Conserv. 13: 1875-1988.

Trabaud, L. 1981. Man and Fire: Impacts on Mediterranean vegetation. En: Di CastRI, F., GOODALL, W. \& SPECHT, R. L. (eds.) Mediterranean-type shrublands. Elsevier. Amsterdam. Pp. 523-537.

TRABAUD, L. 1991. Fires regimes and phytomass growth dynamics in a Quercus coccifera garrigue. $J$. Vegetation Science 2: 307-314.

Trabaud, L. 1994. Post fire plant community dynamics in the Mediterranean basin.. En: MorenO, J. M. \& OeChel, W. C. (eds.). The Role of Fire in Mediterranean-Type Ecosystems. Pp. 1-15. Springer-Verlag, New York.

TRABAUD, L. 1998. Recuperación y regeneración de los ecosistemas mediterráneos incendiados. Serie Geográfica 7: 37-47.

Trabaud, L. \& Prodon, R. 1993. Fire in Mediterranean ecosystems. - ECSC-EEC-EAEC, BrusselsLuxembourg. 333 pp.

TscharntKe, T., Gathmann, A. \& Steffan-Dewenter, I. 1998. Bioindication using trap-nesting bees and wasps and their natural enemies: community structure and interactions. J. Applied Ecology 35: 708-719.

Turner, M. G., Dale V. H. \& Everham E. H. 1997. Fires, hurricanes, and volcanoes: Comparing large disturbances. BioScience 47 (11): 758-68.

Turner, M. G., Hargrove, W. W., Gardner, R. H. \& Romme, W. H. 1994. Effects of fire on landscape heterogeneity in Yellowstone National Park, Wyoming. J. Veg. Sci. 5: 731-742.

Underwood, E. C. \& Christian, C. E. 2009. Consequences of prescribed fire and grazing on grassland ant communities. Environ. Entomol. 38 (2): 325-332.

URONES, C. \& MAJADAS, A. 2002. Cambios en la comunidad de Araneae durante la sucesión post-fire en matorrales mediterráneos de montaña. Revista Ibérica de Aracnología 5: 19-28.

Valentine, L. E., Schwarzkopf, L., Johnson, C. N. \& Grice, A. C. 2007. Burning season influences the response of bird assemblages to fire in tropical savannas. Biological Conservation 137: 90-101.

VAlladares, F. 2004. El bosque mediterráneo, un sistema antropizado y cambiante. En: VALLADARES, F. (ed.): Ecología del bosque mediterráneo en un mundo cambiante, pp. 1326. Organismo Autónomo de Parques Nacionales (Ministerio de Medio Ambiente). Madrid.

VALLADARES, F. 2007. El hábitat mediterráneo continental: un sistema humanizado, cambiante y vulnerable. En: Paracuellos, M. (Coord.) Ambientes mediterráneos. Funcionamiento, biodiversidad y conservación de los ecosistemas mediterráneos. Colección Medio Ambiente, 2. Instituto de Estudios Almerienses (Diputación de Almería). Almería.

Valladares, F., Camarero, J. J. Pulido, F. \& Gil-Pelegrín, E. 2008. El Bosque mediterráneo, un sistema humanizado y dinámico. En: Ecología del bosque mediterráneo en un mundo cambiante. Segunda Edición (Valladares, F. ed.), pp. 15-28. Ministerio de Medio Ambiente EGRAF, S. A. Madrid. 
VAn Amburg, G. L., Swaby, J. A. \& Pemble, R. H. 1981. Response of arthropod to a spring burn of a tallgrass prairie in Northwestern Minnesota. Ohio Biol. Surv. Biol. Notes 15: 240-243.

VÁzQuez, A. \& Moreno, M. 1998. Patterns of lightning, and people-caused fires in peninsular Spain. Inter J. Wild Fire 8: 103-115.

VÁzQuez, A. \& Moreno, M. 2001. Spatial distribution of forest fires in Sierra de Gredos (Central Spain). Forest Ecol Manag 147: 55-65.

VAZQuEZ, A. \& RodrígueZ, J. A. 2008. Dinámica de paisajes forestales en relación a la incidencia del fuego en España peninsular: 1987 - 2000. Investigación Agraria: Sistemas y Recursos Forestales 17 (2): 143-154.

Veldman, J. W., Mostacedo, B., Peña-Claros, M. \& Putz, F. E. 2009. Selective logging and fire as drivers of alien grass invasion in a Bolivian tropical dry forest. Forest Ecol Manag 258: 1643-1649.

VÉLEZ, R. 1990. Los incendios forestales en España. Ecología 1: 213-221.

VÉLEZ, R. 1991. Los incendios forestales y la política forestal. Revista de Estudios Agro-Sociales 158: 83-104.

VÉLEZ, R. 1993. High intensity forest fires in the Mediterranean Basin: Natural and socioeconomic causes. Disaster Management 5: 16-20.

VÉLEZ, R. 1995. El peligro de los incendios forestales derivado de la sequía. Cuadernos Sociedad Española Ciencias Forestales 2: 99-109.

Verdú, M., Dávila, P., García-Fayos, P., Fernández-Flores, N. \& Valiente-Banuet, A. 2003. "Convergent" traits of Mediterranean woody plants belong to pre-Mediterranean lineages. Biological J. Linnean Society 78: 415-427.

VIEDMA O., RIEIRO I. \& MORENO, J. M. 2006. Interactions between land use/land cover change, forest fires and landscape structure in Sierra de Gredos (Central Spain). Environment International 33 (3): 1-11.

Vilà, M., Lloret, F., Ogheri, E. \& Terradas, J. 2001. Positive fire-grass feedback in Mediterranean Basin woodlands. Forest Ecol Manag. 147 (1): 3-14.

WARren, S. D., ScIFres, C. J. \& TeEl, P. D. 1987. Response of grassland arthropods to burning: a review. Agriculture, Ecosystems and Environment, 19: 105-130.

Whelan, R. J. 1995. The Ecology of Fire. Cambridge University Press, Cambridge. 346 pp.

Whelan, R. J. 2006. The ecology of fire-Developments since 1995 and outstanding questions. Proceeding of Bushfire 2006 - Life in a Fire-Prone Environment: Translating Science into Practice conference, Griffith University, Brisbane, 69. June 2006. http://ro.uow.edu.au/scipapers/46

WIKARS, 2002. Dependence on fire in wood-living insects: An experiment with burned and unburned spruce and birch logs. J. Insect Conservation 6: 1-12.

WIKARS, L. O. 1994. Effects of fire and Ecology of fire-adapted insects. Introductory Research Essay $\mathrm{n}^{\mathrm{o}}$ 12. Dep. Zool., Univ. Uppsala, Sweden.

Williams, A. A. J., Karoly, D. J. \& TapPer, N. 2001. The sensitivity of Australian fire danger to climate change. Climatic Change 49: 171-191.

WILSON, E. O. 1992. The diversity of life. Harvard Univesity Press, Cambridge. 410 pp.

Wright, M. G. \& SAMWAYS, M. J. 1998. Insect species richness tracking plant species richness in a diverse flora: gall-insects in the Cape Floristic Region, South Africa. Oecologia 115: 427433.

Wright, M. G. \& SAMWAYS, M. J. 1999. Plant characteristics determine insect borer assemblages on Protea species in the Cape Fynbos, and importance for conservation management. Biodivers. Conserv. 8: 1089-1100. 
Yanovsky, V. M. \& Kiselev, V. V. 1996. Response of the endemic insect fauna to fire damage. En: Goldammer, J. G. (ed.), Fire in ecosystems of boreal Eurasia. Kluwer, pp. 409-413.

YORK, A. 1996. Long-term effect of repeated prescribed burning on forest invertebrates: Management implications for the conservation of biodiversity. Consultancy report to the Department of the Environment and Heritage. Final report. April.

YORK, A. 1998. Managing for biodiversity: what are the longterm implications of frequent fuelreduction burning for the conservation of forest invertebrates? En: WIEGAS, D. X. (ed.), III International Conference on Forest Fire Research. ADAI Univ. of Coimbra, pp. 1435-1445.

YORK, A. 1999. Long-term effects of frequent low-intensity burning on the abundance of litterdwelling invertebrates in coastal blackbutt forests of southeastern Australia. J. Insect Conservation 3: 191-199.

ZEDLER, P. 1995. Are some plants born to burn? Trends in Ecology and Evolution 10: 393-395.

ZimMER, K. \& PARMENTER, R. R. 1998. Harvester ants and fire in a desert grassland: ecological responses of Pogonomyrmex rugosus (Hymenoptera: Formicidae) to experimental wildfires in Central New Mexico. Environ. Entomol. 27: 282-287. 


\section{OBJETIVOS}

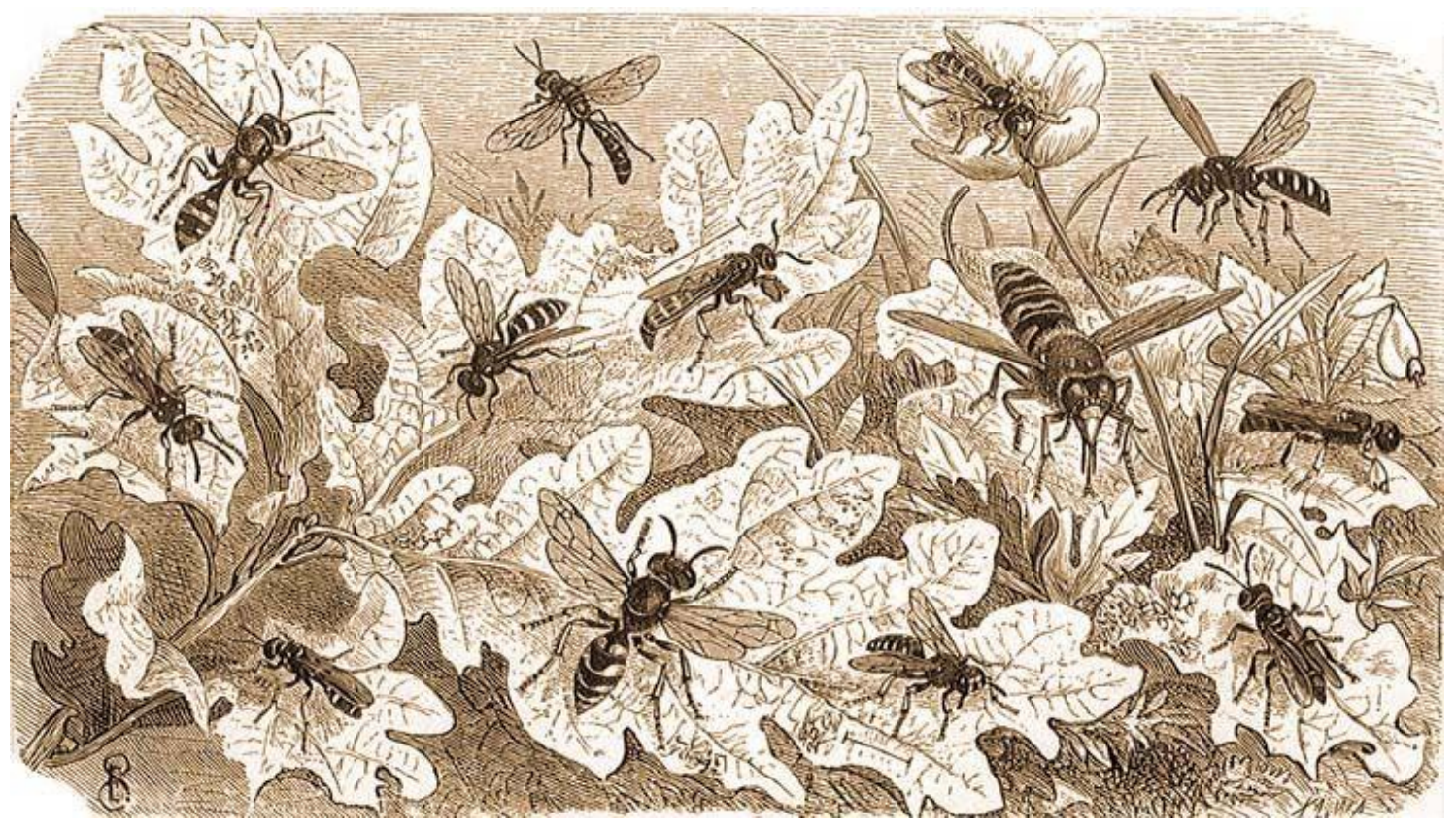


- PRIMERO: Analizar y comparar la abundancia, riqueza, diversidad, dominancia y uniformidad de las comunidades de Spheciformes tras la acción de un incendio forestal en áreas pertenecientes al Parque Natural Arribes del Duero, a lo largo del periodo de recuperación de las mismas y en comparación con áreas Control, ya recuperadas.

- SEGUNDO: Catalogar las especies de avispas entomófagas Spheciformes presentes en el ecosistema elegido, después de la perturbación, y analizar la variación de sus abundancias relativas con el transcurso de los años tras el fuego.

El conocimiento de las especies de avispas entomófagas permitirá valorar cuáles son las que exhiben una mejor adaptación a los ecosistemas estudiados y una mayor resistencia o capacidad de recuperación tras la perturbación provocada por el fuego, considerando fundamentalmente su comportamiento nidificador y los requerimientos pedotróficos de las mismas.

- TERCERO: Analizar la influencia de la cobertura vegetal y de su recuperación (diversidad estructural), en cada una de las zonas estudiadas, sobre las comunidades de Spheciformes, basándose en el análisis de las diversidades alfa y beta, y sus cambios tras el incendio. Analizar también la influencia ejercida por la cantidad de suelo desnudo disponible, como recurso necesario para la nidificación de muchas especies de Spheciformes.

Se llevará a cabo un estudio y valoración de la estructura vegetal de cada zona (altura y cobertura) y de la cantidad de suelo desnudo disponible, para posteriormente analizar su influencia en la recuperación y composición de las comunidades de Spheciformes tras la perturbación.

- CUARTO: Analizar la estructura poblacional de la comunidad de avispas Spheciformes tras el incendio, en función del comportamiento nidificador y los requerimientos pedotróficos de las mismas.

El análisis del comportamiento nidificador y requerimientos pedotróficos de las especies supervivientes, o colonizadoras, tras el fuego, permitirá conocer la influencia de las modificaciones en el hábitat producidas tras el episodio incendiario y valorar el reparto y ocupación de los nichos resultantes tras el impacto. 
- QUINTO: Contrastar la información obtenida sobre las comunidades mediante el empleo de dos métodos de muestreo diferentes: trampas Malaise y platos amarillos, así como analizar la complementariedad existente entre las capturas procedentes de cada uno de estos métodos, para valorar si ofrecen una visión diferente sobre la respuesta de las comunidades de Spheciformes a la acción del fuego.

OBJETIVO GENERAL: El objetivo general es llevar a cabo un seguimiento de la recuperación de las poblaciones de Spheciformes en el área de estudio, tras la acción de un incendio forestal, caracterizar sus comunidades y determinar las variables ambientales que más contribuyen a la estructura de dicha comunidad y en qué medida lo hacen.

De este modo se podrá conocer el efecto real de este tipo de perturbación sobre las comunidades de insectos en el Parque Natural Arribes del Duero. Ello podría permitir el planteamiento de métodos de gestión -con criterios ecológicos- para la correcta recuperación de los ecosistemas estudiados, en relación con el uso de los propios recursos naturales que proporcionan las zonas de estudio. 


\section{ARRIBES DEL DUERO}

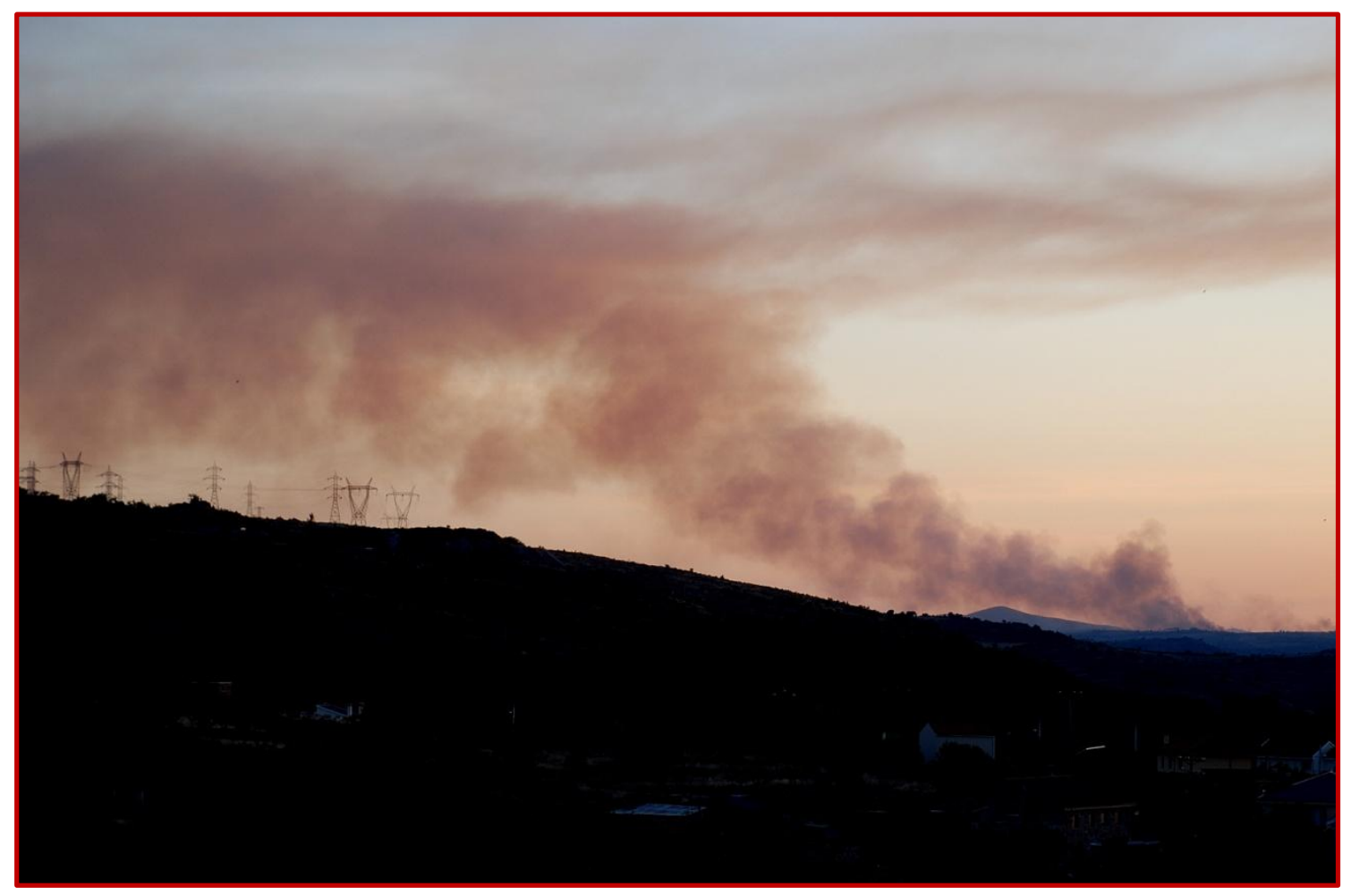




\section{1.- INTRODUCCIÓN}

Las Arribes de Duero constituyen un Espacio Natural Protegido de alta calidad, perfectamente caracterizable con criterios geográficos (LLORENTE-MALDONADO, 1980) y que ofrece rasgos ecológicos, climatológicos y geomorfológicos singulares (CABERODIÉGUEZ, 1982, 1987). La homogeneidad morfológica de la penillanura se ve interrumpida hacia el oeste por las angosturas de esta comarca, creando un extraordinario laberinto de cañones y gargantas, que introduce matices de diferenciación paisajística, en función de los distintos gradientes topográficos y bioclimáticos (CABERO-DiÉGueZ, 1987), y que ha permitido la permanencia de comunidades vegetales relictas y altamente significativas, caracterizadas por la abundancia de especies típicamente mediterráneas (NAVARRO \& VALLE, 1987; SANTOS et al., 2006; Luis-CAlABUig, 2008).

Para todas las formas de vida, las Arribes constituyen un gran corredor ecológico que une el sur con el norte, el Sistema Central con la Cordillera Cantábrica, permitiendo la comunicación de las diferentes poblaciones (GONZÁLEZ et al., 2009) y la existencia de hábitats de gran superficie, y que cobra una extraordinaria importancia ante una gran amenaza ambiental de nuestros días: la fragmentación de los ecosistemas.

La gran riqueza ecológica que concentra este enclave orográfico, no ha pasado desapercibida. La idea firme de declararlo como Parque Natural se empieza a gestar en 1989, viendo la necesidad de darle un carácter internacional mediante algún tipo de convenio o figura jurídica de protección en colaboración con Portugal. En el año 1990 fue declarado Zona de Especial Protección para las Aves (ZEPA), siguiendo la Directiva 79/409/CEE del Consejo de Europa relativa a la conservación de las aves silvestres, al cumplir hasta ocho especies los criterios de selección.

Sobre la base de un gran valor natural, paisajístico y faunístico, en el BOCyL de 22 de mayo de 1992 se publicó la Orden, de 30 de abril, de Iniciación del Plan de Ordenación de los Recursos Naturales de este espacio, PORN que fue aprobado en 2001. Ya en el año 2002 tuvo lugar la declaración del Parque Natural de Arribes del Duero en España (Ley 5/2002, de 11 de abril; BOCyL nº 79, de 26 de abril de 2002). 
Previamente, en enero de 1998 se creó el "Parque Natural do Douro Internacional" en Portugal. A nivel europeo, la parte portuguesa fue declarada como ZEPA en 1999; este hecho implica que ambas zonas formen parte de la "Red NATURA 2000", red que engloba las áreas de mayor valor ecológico de toda Europa Occidental. Por su parte, la zona española recibió en 1997 una línea de ayudas a través del Programa LIFE de la Unión Europea. Entre otras actuaciones, se destinó una parte de los fondos para la conservación y recuperación de palomares, charcas, pequeñas presas y pesqueras tradicionales; actividades humanas ligadas a la conservación de ciertas especies amenazadas, concretamente del águila perdicera y la cigüeña negra.

\section{2.- SITUACIÓN GEOGRÁFICA}

Con una superficie total aproximada de 106.105 ha, el Parque Natural Arribes del Duero está situado en el extremo occidental de la Submeseta Norte, en el límite SO

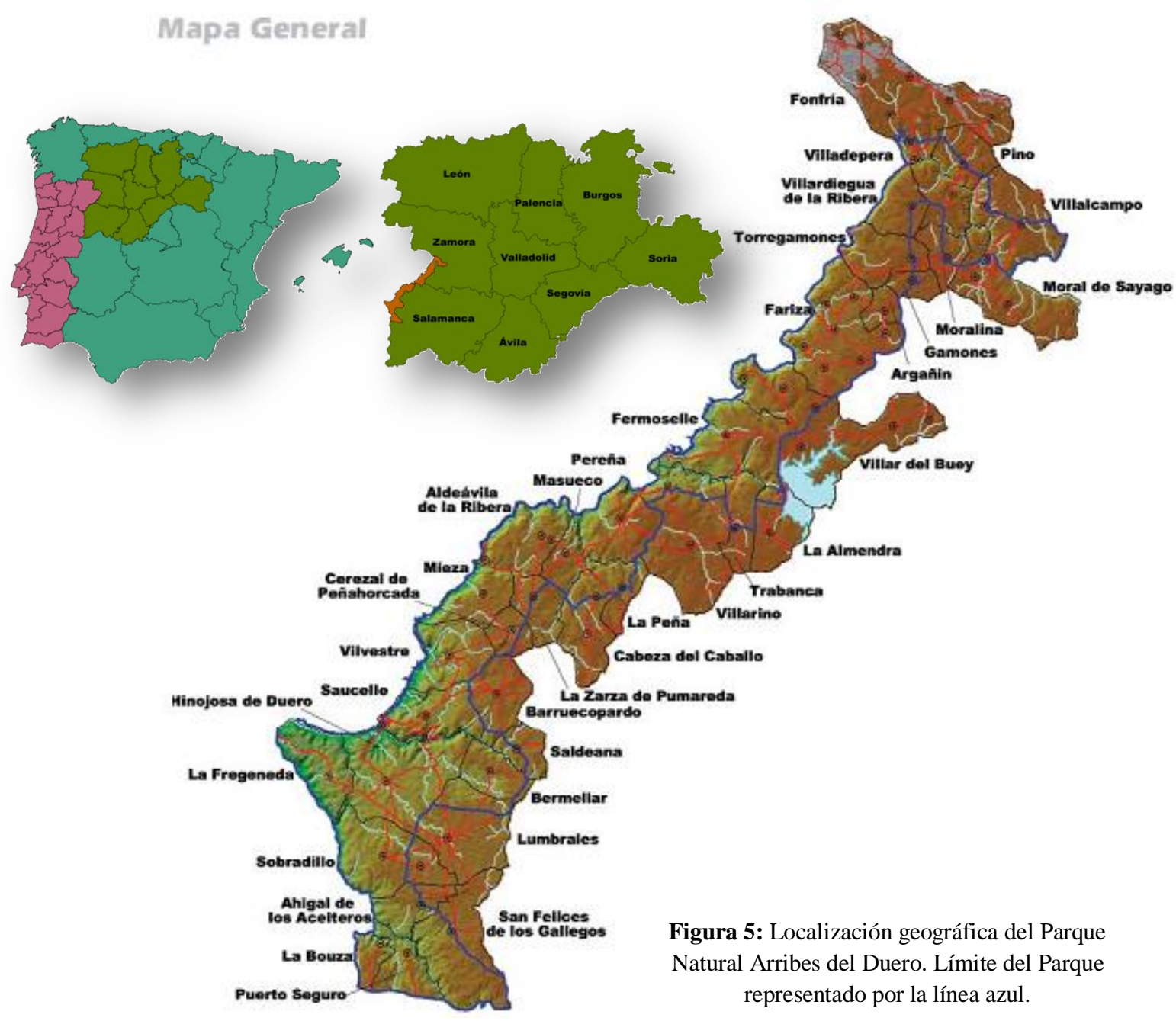


de la provincia de Zamora y NO de Salamanca $\left(40^{\circ} 50^{\prime}-41^{\circ} 35^{\prime}\right.$ N, 6 $00^{\prime}-6^{\circ} 41^{\prime}$ O) (Figura 5), en las tradicionales comarcas de Sayago (Zamora), las Arribes y el Abadengo (Salamanca) y en su simétrico portugués (el Planalto), que sirven de frontera a España y Portugal, países que separa el propio cañón que forma el Duero en todo su tramo internacional.

\section{3.- MEDIO FÍSICO}

\subsection{1.- CLIMA}

Los rasgos del clima también se ven modificados por el encajamiento de la red fluvial. En la climatología de las Arribes se diferencian claramente dos zonas: por un lado, la correspondiente al propio valle del río, con un clima suave y atenuado, caracterizado por tener inviernos cortos ( $\approx 2$ meses), suaves y húmedos, lo que conlleva la práctica inexistencia de heladas, y veranos largos y calurosos (CALONGE-CANO, 1990); por otro, la cresta de la penillanura, con valores de temperaturas y precipitaciones más continentales y rigurosos, con grandes diferencias de temperatura entre estaciones; inviernos largos y crudos $(\approx 5$ meses $)$, con presencia de heladas, $\mathrm{y}$ veranos cortos y relativamente calurosos (LUIS-CALABUIG, 2008).

La temperatura media del conjunto se fija en $11^{\circ} \mathrm{C}$, notándose mayor suavidad en las proximidades del cañón, con una variación térmica de aproximadamente medio grado en la mayoría de los meses, acrecentada en las zonas de bancales y al nivel del río. En las Arribes, cuatro meses superan $\operatorname{los} 20^{\circ} \mathrm{C}$, de junio a septiembre, constatándose una marcada aridez estival.

Los meses de mayores precipitaciones (precipitación media en torno a los 700 mm/año), se sitúan entre octubre y febrero, produciéndose las máximas en noviembre. Las precipitaciones son claramente superiores en las Arribes que en la zona continental, debido a la proximidad atlántica, con borrascas que provocan condiciones de humedad.

Hay que destacar la escasez de datos climatológicos concretos en este Espacio Protegido, y más concretamente en las áreas de muestreo. Únicamente se cuenta con los datos de precipitación recogidos por la estación meteorológica de Villarino de los Aires 
y facilitados por el Centro Nacional de Meteorología. Las precipitaciones medias registradas los años de muestreo 2005, 2006 y 2007 se muestran en la Tabla I.

Tabla I: Precipitaciones medias anuales, registradas en Villarino de los Aires durante los años 2005, 2006 y 2007 (en $\mathrm{mm}$.).

\begin{tabular}{ccc}
\hline \multicolumn{3}{c}{ PRECIPITACIÓN MEDIA ANUAL } \\
(mm.) & \\
\hline Año 2005 & Año 2006 & Año 2007 \\
\hline 345,67 & 714,83 & 426,17 \\
\hline
\end{tabular}

\subsection{2.- GEOLOGÍA Y GEOMORFOLOGÍA}

Al final de la era Primaria se produce la Orogenia Hercínica (350 millones de años), a la que pertenece la Meseta española. Durante esta orogenia los materiales sedimentados fueron comprimidos, provocando más tarde la emergencia en grandes cantidades de magma que, tras su posterior enfriamiento, formará las cadenas montañosas del centro y oeste peninsular. Las profundas capas graníticas, al contactar con los sedimentos paleozoicos, originaron en algunos puntos rocas metamórficas (micacitas y gneis). A partir de ese momento, la Orogenia Hercínica pierde fuerza, dando paso a una erosión intensa del zócalo recién formado, y a un allanamiento de la protopenínsula ibérica. Las cumbres paleozoicas son limadas poco a poco, dando como resultado el actual paisaje de la penillanura salmantino-zamorana, salpicada por los afloramientos graníticos que han resistido la erosión (CASCOS-MORAÑA, 1987; JUNTA DE CASTILLA Y LEÓN, 1988).

El inicio de la era Terciaria coincide con los primeros movimientos que provocaron el basculamiento de la penillanura ibérica causado por la Orogenia Alpina. La intensa reestructuración deja más o menos intactos los materiales de las Arribes, los cuales continúan acusando la erosión y, sobre todo, la fracturación, con orientación predominantemente noreste, iniciada en la era Primaria.

Las Arribes se encuentran por lo tanto, dentro del dominio del Macizo Hespérico, formado por materiales de la era Paleozoica o Primaria. Desde el punto de vista morfológico constituyen una extensa penillanura evolucionada, puesto que desde el Mesozoico han actuado fenómenos erosivos hasta hacer aflorar los materiales del 
zócalo paleozoico (MolinA et al., 1990; MoLinA, 1991), formado esencialmente por rocas ígneas (granitos de diversos tipos, granodiorita y algunos enclaves sieníticos), acompañadas por algunas incisiones de rocas metamórficas (gneis y pizarras) (MARTíneZ-FERnÁNDEZ， 1974; Llorente-PinTO， 1985; CASCOS-MoraÑA， 1987; BlANCO-SÁNCHEZ, 1992; RodRÍGUEZ-MuÑOZ, 1994; MARTíN, 1995, 1996). En esta penillanura destaca el accidente topográfico producido por el profundo encajamiento del río Duero y su red de afluentes, que siguiendo fallas tardihercínicas y las grandes diaclasas existentes en la roca han labrado gargantas de paredes subverticales de varios centenares de metros. Toda la penillanura, cuya altitud oscila entre los 700 y $800 \mathrm{~m}$, se encuentra retocada por la incisión cuaternaria del Duero y sus afluentes. Los tajos fluviales son el resultado de los últimos movimientos orogénicos alpinos. Hasta entonces, el roquedo componía un amplio farallón que se orientaba al este, obligando a la cuenca hidrográfica a desaguar hacia el Mediterráneo.

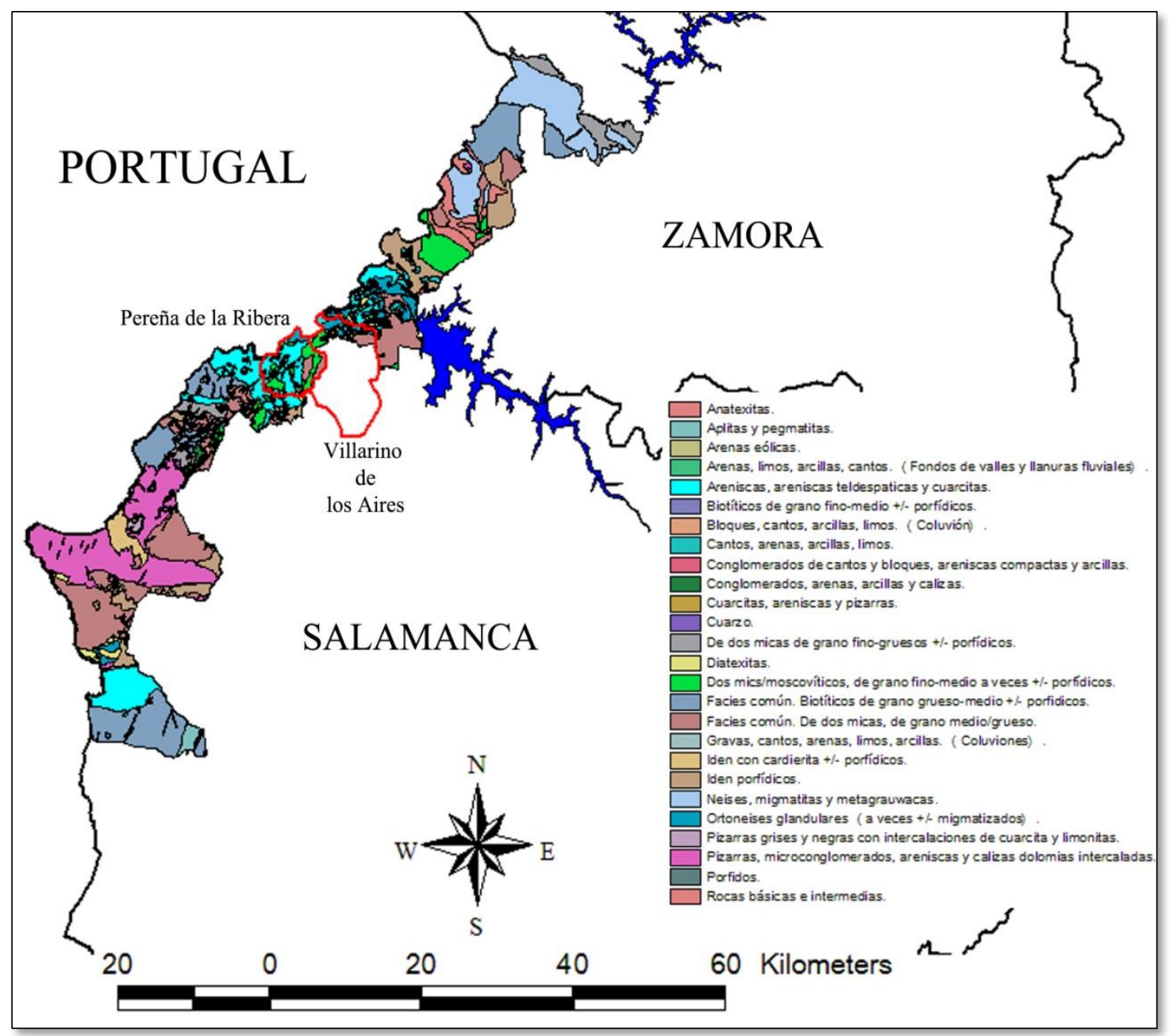

Figura 6: Mapa geológico del Parque Natural Arribes del Duero. 
La Orogenia Alpina (Cenozoico) elevó drásticamente el levante peninsular, provocando que el Duero tuviera que buscar una nueva salida hacia el Océano Atlántico, y obligando a la cuenca a invertir su orientación y a aprovechar las fallas hercínicas para salvar el desnivel existente entre la meseta castellana y las llanuras portuguesas (RODRÍGUEZ-MUÑOZ, 1994; MARTíN, 1995, 1996; LUIS-CALABUIG, 2008).

En lo referente a la litología, predomina el granito, salvo algunos islotes o franjas de gneis, pizarras y cuarcitas (Figura 6). Al sur del Tormes, la penillanura alterna las áreas graníticas con las pizarreñas. Las pizarras aparecen sobre todo en la zona sur, Vilvestre-Saucelle y al sur del Huebra (La Fregeneda-Bermellar-Cerralbo), en una dirección O-E. Además destaca una importante isla de gneis en la zona del Salto de Aldeadávila, y pequeñas manchas de diques de cuarzo, en pueblos concretos como La Zarza de Pumareda o Cerezal de Peñahorcada (CASCOS-MorañA, 1987; BlancoSÁNCHEZ, 1992). En el SO, a partir de Saucelle, así como en otros lugares puntuales, los materiales ígneos dan paso a las pizarras, las cuarcitas y las grauvacas del Cámbrico.

\subsection{3.- EDAFOLOGÍA}

Son muchos los factores que influyen en la formación del suelo: clima, organismos, relieve, tiempo y tipo de roca madre. En las Arribes predomina el granito; pero, como se ya ha comentado, se observa en ciertas zonas, pizarras y cuarcitas, formando en su conjunto un complejo esquisto-grauváquico.

Sobre granito, y como resultado de su descomposición in situ, los suelos predominantes, fundamentalmente en la penillanura, son una asociación de cambisoles y regosoles dístricos (DORRONSORO, 1992). Se trata de suelos con estructura poco desarrollada y escasa profundidad $(30-60 \mathrm{~cm})$, con un horizonte A de un espesor medio de $25 \mathrm{~cm}$ y color pardo oscuro. Predomina la textura gruesa, generalmente francoarenosa, con un elevado porcentaje de arena (> 60\%), lo que confiere un escasa capacidad de retención de agua, que drena con facilidad y propicia un escaso desarrollo de la cubierta vegetal (JUNTA DE CASTILLA Y LEÓN, 1988). Son suelos ácidos (pH de 4 a 6) y con deficiencia en calcio y fósforo, por lo que, añadido lo anterior, resultan mediocres o malos para el cultivo cerealista, teniendo un uso eminentemente forestal y ganadero. 
Respecto a los suelos sobre pizarra, abundan las antiguamente llamadas "tierras pardas sobre pizarras", que muestran parecidas cualidades negativas que los suelos formados en roca madre granítica; si bien, gozan de las ventajas de una estructura menos suelta y un valor de $\mathrm{pH}$ menos ácido o neutro (de 6 a 7,5). Aparecerán: leptosoles líticos $(10 \mathrm{~cm}$ de profundidad), regosoles $(20 \mathrm{~cm})$ y cambisoles, predominando las subunidades eútricas frente a las dístricas. El horizonte A de los suelos de esta zona es de colores claros, estructura tipo granular de débil grado de desarrollo y consistencia suelta. La composición granulométrica destaca por presentar un importante contenido en limos -textura franco-limosa-. Los contenidos en materia orgánica son bajos $(<2 \%)$.

Para finalizar, decir que predomina la clase agrológica IV, suelos con capacidad de uso para pastos y bosques (DORRONSORO, 1992), y en los que la erosión es considerada grande, con una pérdida de suelo de entre 100 y 300 t/ha/año; fenómeno que se acentúa por las elevadas pendientes.

\subsection{4.- VEGETACIÓN}

Las dilatadas dimensiones de este Espacio Natural, junto con su clara orientación norte-sur, propician la existencia de una elevada diversidad vegetal, aumentada, si cabe, por las diferencias altitudinales existentes.

El valle encajado, con sus peculiares características topográficas, resguardado de los vientos y con mucha insolación, da lugar a una riquísima comunidad vegetal, caracterizada por la gran abundancia de especies típicamente mediterráneas (NAVARRO \& VAlle, 1987; SANTOS et al., 2006; LuIS-CALABUiG, 2008), donde destacan cultivos impropios para esta latitud como: el olivo, la vid y el almendro. También encontramos en la comarca higueras subespontáneas, que como las chumberas crecen asilvestradas, confirmando el carácter mediterráneo del mesoclima (LUIS-CALABUIG, 2008). Ya en los siglos XV y XVI se ha señalado la existencia de caña de azúcar, al igual que otros cultivos subtropicales como la pita. Asimismo, como reliquia de antiguos cultivos, en los ribazos y laderas pedregosas quedan ejemplares arbustivos de zumaque (Rhus coriaria $\mathrm{L})$. 
Las diferentes exposiciones respecto al sol, alturas y pendientes de los recovecos de las laderas de los ríos, permiten una gran diversidad de comunidades vegetales, a la que contribuye, además, la presencia de un paisaje agrario muy poco homogéneo, todavía con pastizales, cultivos y bosques.

En el fondo de los cañones alternan especies claramente mediterráneas con otras más atlánticas, según la orientación de la ladera. En la solana dominan la encina y el enebro, resistentes a la fuerte insolación estival, donde conviven con jaras, olivillas, jaguarzos y cornicabras. La umbría es ocupada bien por el alcornoque y el almez u hojaranzo, bien por el roble melojo, que se alterna con arces, endrinos, madreselvas, madroños y perales silvestres (RIVAS-MARTínEZ, 1987). En las cercanías de arroyos y charcas crecen fresnos y olmos, y aunque se puede afirmar que las Arribes carecen de bosques de ribera, en algunos puntos del tramo final del Tormes aún existe una rica representación.

Hasta casi la masiva emigración de los años sesenta, el paisaje del arribe está conformado por cultivos agrícolas de gran variedad, bancales donde sustentarlos, y cercados para asegurar el mantenimiento ganadero; pero el desarrollo de la zona condujo a un abandono paulatino del aprovechamiento y cultivo de las áreas más inaccesibles y alejadas. Éstas, han sido ahora recolonizadas por la vegetación autóctona, formando grandes y espesas masas de vegetación natural, a menudo pasto de las llamas, y que contrastan con la ladera portuguesa, fuertemente intervenida y dominada por cultivos de olivos, almendros y cítricos (GARCÍA-FECED et al., 2007; LUIS-CALABUiG, 2008).

En la penillanura, por su modelo de utilización principalmente ganadero, las prácticas agrícolas han reducido la biodiversidad, transformando el bosque primitivo en un paisaje que se podría describir como un mosaico de dehesas de roble y encina, fuertemente intervenidas por el hombre, con monocultivos de cereal o con amplias extensiones de matorral más o menos desarrollado. Los matorrales, cada vez más abundantes, son los típicos de las series previas a los melojares o los encinares, invadidos por el abrojo (Genista hystrix Lange), acompañado por la escoba blanca (Cytisus multiflorus L'Hér.) y la retama negra (Cytisus scoparius L.), sobre todo en montes adehesados de baja intensidad (LLORENTE-PINTO, 1985; CABERO-DiÉGUEZ et al., 
1987; TARAZOnA, 2000; Amich \& Bernardos, 2008; Escudero AlCÁNTARA et al., 2008; Luis-CALABUiG, 2008).

Desde el punto de vista de la Corología Vegetal, los territorios de las Arribes responderían al siguiente encuadre biogeográfico:

\author{
Reino: HOLÁRTICO \\ Región: MEDITERRÁNEA \\ Subregión: MEDITERRÁNEA OCCIDENTAL \\ Provincia: MEDITERRÁNEA IBÉRICA OCCIDENTAL \\ Subprovincia: CARPETANO-LEONESA \\ Sectores: LUSITANO DURIENSE y SALMANTINO
}

Estos territorios del arribe presentan una serie de vegetación característica de los mismos, los bosques de alcornoques con oxicedros (Juniperus oxycedrus L.) y, aunque no es de los sectores peninsulares mejor caracterizados desde el punto de vista florístico, sí cuenta con algunos elementos endémicos, como el "dragón de las Arribes" (Antirrhinum lopesianum Rothm., Scrophulariaceae) (GONZÁLEZ TALAVÁn et al., 2003) o la "chupera" (Scrophularia valdesii O. A. Ortega \& Devesa); o taxones que presentan aquí su óptimo, por ejemplo Isatis platyloba Link ex Steud, o Arabis lusitánica Boiss.

En los territorios situados en el ombroclima seco, el dominio vegetal está marcado por los bosques esclerófilos mediterráneos por excelencia, es decir, encinares. En aquellos que pertenecen al ombroclima subhúmedo destaca la presencia frecuente de marcescentes (quejigos) y caducifolios (melojos y hojaranzos) (RIVAS-MARTínEZ, 1987; COSTA-TENORIO et al., 2005); los encinares ocupan aquí situaciones topográficas desfavorables, como crestas, laderas, etc., aunque tampoco es infrecuente que se presenten en etapa climácica, sobre todo cuando los suelos retienen muy poco la humedad (por ejemplo suelos arenosos) y no pueden asentarse sobre ellos árboles que no soportan una acusada sequía.

Prácticamente todo el límite del espacio de Arribes del Duero en su zona española está limitado por masas de roble melojo o rebollo (Quercus pyrenaica Willd.) formando masas adehesadas, extensas y abiertas, sobre todo en Salamanca, o como manchas más pequeñas y cerradas en el Sayago zamorano, mezclado con alcornoques y 
fresnos. Cuanto más cerca se halle del Arribe, es más frecuente encontrarlo como masas más cerradas y con mayor cantidad de individuos jóvenes formando bardales.

\subsection{5.- FAUNA}

La gran variedad de vegetación, hábitats, usos del suelo y condiciones climatológicas mostrada hasta ahora, transforman a este Espacio Protegido en un paisaje en mosaico, altamente heterogéneo, vital para albergar una gran riqueza y diversidad de fauna asociada a él (TARAZONA, 2000; SANZ-ZUASTI et al., 2001; LUIS-CALABUIG, 2008; GONZÁLEZ et al., 2009). En la alternancia de hábitats reside su riqueza zoológica, al producirse numerosas condiciones favorables para la supervivencia de distintas especies.

Además de la previsiblemente elevada riqueza de insectos, consecuencia de la diversidad de la vegetación y de la relativa escasez de plaguicidas, hay que destacar el importante número (unas 230) de especies de vertebrados. En este Parque Natural están representadas: unas 20 especies piscícolas, un 44,44\% (12 de 27) de las especies de anfibios presentes en España (VELASCO-MARCOS et al., 1997) -datos que se pueden extrapolar a la totalidad de la Península Ibérica- y un 46,34\% (19 de 41) de las especies de reptiles (PlegueZuelos et al., 2002), un 51,24\% (124 de 242) de las especies de aves reproductoras (MARTí \& DEL MORAL, 2003) y un 51,13\% de las especies de mamíferos terrestres (PALOMO et al., 2007). Igualmente constituye un punto importantísimo de cría de algunas especies relevantes (VIADA, 1998; VICENTEGONZÁLEZ et al., 2000) y con poblaciones muy reducidas, como el lince ibérico (si bien la última cita fiable data de comienzos de los 90), el gato montés, la nutria, la cigüeña negra, el águila real, el águila perdicera o la collalba negra entre otras. Aunque en muy raras ocasiones, hay que citar la presencia del lobo.

Los cortados y las formaciones de roquedos de las márgenes fluviales resultan el biotopo más característico de este Parque Natural, donde se localizan notables poblaciones de ciertas especies de aves: cigüeña negra, águila perdicera, buitre leonado, águila real, alimoche, halcón peregrino; sin olvidar otras especies de interés faunístico como el águila culebrera, el águila calzada, el búho real, la chova piquirroja, el vencejo real, el roquero solitario o la collalba

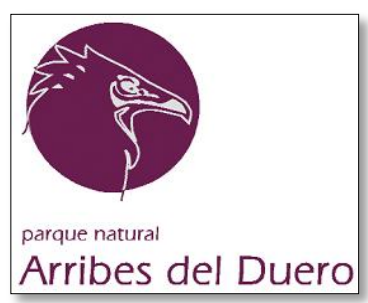

Figura 7: Logotipo del Parque Natural de Arribes del Duero. 
negra. La importancia de este grupo tiene su reflejo en la elección del alimoche como imagen del Parque Natural (Figura 7).

Presumiblemente elevada, pero notablemente menos conocida que la del resto de grupos, la entomofauna de Arribes del Duero comienza a despertar el interés de los expertos. Así, comienzan a surgir estudios al respecto con resultados que apuntan hacia esa gran riqueza y diversidad. La fauna de mariposas ha sido razonablemente bien muestreada, pero a pesar de ello no se dispone de información a una escala precisa (ROMO \& GARCÍA-BARROS, 2005). Existen seis publicaciones sobre comunidades de insectos (GONZÁLEZ et al., 1998, 2002; 2009; GAYUBO et al., 2000, BASELGA \& NOVOA 2003; DE LA NuEZ et al., 2003), además de una tesis doctoral (GONZÁLEZ, 2002) sobre el grupo de las avispas Spheciformes.

GONZALEZ et al. (2009) proponen este Parque Natural como un área prioritaria de conservación de insectos en función de su papel como corredor entre el norte y el sur peninsular, sirviendo de unión entre comunidades pertenecientes a las regiones biogeográficas Eurosiberiana y Mediterránea, así como de su buena representación de la biodiversidad europea, entre otras características.

\subsection{6.- PAISAJE}

A escala de paisaje [entendido como "un territorio heterogéneo compuesto por un grupo de ecosistemas que interactúan y se repiten de forma similar por todo él" según FORMAN \& GODRON (1986)], la biodiversidad es el resultado de procesos ecológicos que se producen en periodos de tiempo breves, y evolutivos y biogeográficos que ocurren en tiempos mucho mayores. Las actividades humanas tienen gran influencia sobre la configuración del paisaje, en lo referente al tipo e intensidad de la modificación o al grado de heterogeneidad, perturbación o fragmentación. Por todo ello, el paisaje es el nivel en el cual debe enfocarse la conservación, particularmente en regiones altamente heterogéneas como Arribes del Duero.

Para el territorio de Arribes del Duero se han definido cinco unidades de paisaje (Luis-CALABUig, 2008): 
1. Valle y arribe (cañón del río). Fuertes pendientes. Aparecen matorral y masas de bosque natural.

2. A medida que disminuye la pendiente se hacen dominantes los cultivos leñosos (aterrazamiento) y aumenta la diversidad de ocupaciones del suelo.

3. Zona de transición entre el arribe y la penillanura. Toman importancia los cultivos herbáceos y la ocupación forestal. Zona cercana a los núcleos de población.

4. Caracterizada por cultivos herbáceos. Localizada en los mejores suelos, con ausencia de pendiente y afloramientos rocosos.

5. Dominio de la asociación pastizal y afloramientos rocosos. Unidad más alejada de los núcleos urbanos.

La zona de penillanura se caracteriza por un paisaje matorralizado agrícola (32\% de matorral) significativamente más diverso que el del arribe que, con un $35 \%$ de bosque, se define por su naturalidad (solo un $1 \%$ de cultivos), y estructura significativamente más fragmentada que los de las penillanuras (GARCÍA-FECED, et al., 2007).

\section{4.- MEDIO SOCIO-ECONÓMICO}

El tratamiento de este apartado es clave para entender la gran incidencia que los fuegos presentan en esta zona, a pesar de ser un espacio protegido .

Como se ha constatado en muchos trabajos, el mayor o menor grado de incidencia del fuego está estrechamente relacionado con las características tanto demográficas, como socioeconómicas y culturales de una determinada zona (PAUSAS, 2004).

\subsubsection{DEMOGRAFÍA}

El parque natural de Arribes del Duero está constituido por 37 municipios (24 salmantinos y 13 zamoranos). 
De ellos, 23 tienen una población inferior a los 500 habitantes (entre los que se halla Pereña de la Ribera), y nueve cuentan con poblaciones que oscilan entre 500 y 1.000 habitantes. Se trata de núcleos con características eminentemente rurales, que tan sólo difieren de los anteriores en la cuantía de la población empadronada. Solamente existen 5 municipios incluidos en el Espacio Natural cuya población supera los 1.000 habitantes (entre ellos Villarino de los Aires), configurándose en determinados aspectos como centros comarcales de servicios.

La característica fundamental que define a todos estos municipios es la posesión de una población muy envejecida (con una edad media de 52,6 años y una Tasa de vejez del 39,65\% (JUNTA DE CASTILLA Y LEÓN, 2003), aspecto este que influirá de una manera muy relevante en el abandono de cultivos y la pérdida de los usos tradicionales del suelo. Este hecho, a la larga, repercutirá en la virulencia de los incendios producidos en este espacio natural, dada la recuperación existente de la vegetación natural, y la gran proliferación del matorral (LUIS-CALABUIG, 2008).

A lo largo de la historia se han intentado aprovechar las ventajas medioambientales de este enclave con rasgos bioclimáticos mediterráneos, mencionadas en los anteriores apartados. El inconveniente de un relieve abrupto, con fuertes pendientes, y la presencia de suelos raquíticos se ha salvado aterrazando las laderas. Los bancales fueron una necesidad imperiosa en la lucha contra la erosión y en la creación del terrazgo. Sin embargo, hoy, el descenso de la presión demográfica, la pérdida de rentabilidad de los cultivos y el abandono del terreno labrado han provocado que, en las zonas más alejadas de los pueblos, los bancales se hayan desmoronado y arruinado.

La emigración rural y la crisis de la agricultura tradicional han llevado al progresivo abandono de las tierras cultivadas, ahora tomadas por el matorral. Además, la actividad agraria conserva acusados rasgos de arcaísmo, debido en parte, a las dificultades de mecanización de un terreno abrupto y con un elevado grado de parcelación. De hecho, aún no es raro ver a los burros y los mulos tirar del arado romano. Estas formas de vida seculares contrastan con la intensa explotación hidroeléctrica que coloca a la comarca en el ámbito más avanzado de la economía nacional, a pesar de que los habitantes de Arribes apenas han participado de esta moderna y rentable actividad; las empresas tienen su sede en tierras lejanas y la mano de obra que emplean es mínima y muy cualificada. 
El proceso emigratorio iniciado a principios de siglo continúa, tras un paréntesis ocurrido en los años cincuenta con motivo de la construcción de las grandes centrales hidroeléctricas. La emigración de los jóvenes, unida a la reducción de la natalidad, han socavado las bases demográficas de la comarca $\mathrm{y}$, consecuentemente, se ha incrementado el envejecimiento. El poblamiento oscila entre los 10 y 25 hab./ $\mathrm{Km}^{2}$ (MARTín, 1996).

\subsubsection{USOS DEL SUELO}

En las Arribes se alternan tierras de secano, masa de matorral, pastos de aprovechamiento temporal y viñedos, así como olivos en las zonas de valle, más abrigadas de los fríos.

En el arribe, con mayor pluviosidad y temperaturas más elevadas, predomina el cultivo del olivo, almendro, vides y cítricos, fundamentalmente del lado portugués, actualmente más antropizado e intervenido que el lado español (GARCíA-FECED et al., 2007; LuIS-CAlABUig, 2008; SIERRA-PUPARELli et al., 2009). En la actualidad, la vid, el olivo y los almendros suman casi la mitad del espacio labrado. El viñedo, domina en los municipios más septentrionales y determina una cierta especialización vitivinícola, mientras que el olivar se halla, mayoritariamente, intercalado entre las viñas en la mitad norte, o entre los almendros en el Sur.

Sin embargo, en las zonas de penillanura, las condiciones climáticas más extremas, los afloramientos rocosos y los suelos esqueléticos no favorecen el desarrollo de la agricultura y los cultivos arriba descritos. La tierra, más fácil de labrar, es utilizada ahora para el cultivo de cereal, principalmente cebada, y en menor medida trigo y centeno. En las proximidades de los pueblos, son frecuentes los huertos mantenidos en minifundismo, casi de subsistencia y para el consumo familiar (HERNÁNDEZ \& PÉREZ DE ANA, 1999; JuÁREZ-AlCALde, 2000; LuiS-CALABuig, 2008; Sierra-PuPARElli $e t$ al., 2009).

Las tierras labradas suponen sólo el 23\% del total, cantidad ligeramente superior a la mitad de la superficie que ocupan los pastizales, y también inferior al terreno improductivo. Los cultivos forrajeros son los que más superficie ocupan, en los municipios que disponen de terreno para ello. 
La ganadería (ovina, vacuna y porcina), explotada en régimen extensivo, ha sido la base del soporte económico en la mayor parte de los municipios (RODRÍGUEZMuÑoZ, 1994; Martín, 1995; JuÁREZ-AlCALDE, 2000, LuIS-CALABUiG, 2008), sobre todo en los de la penillanura, en cuyo caso el abandono de las prácticas agrícolas ha incrementado la superficie dedicada a pastos, excepto en las zonas más pobres donde ahora domina el matorral. El matorral retorna a su potencial nicho ecológico tan pronto como cesa la presión ganadera o la intervención humana.

Esta forma de aprovechamiento agrícola y ganadero, ha reducido las zonas susceptibles de aprovechamiento forestal. La mayor parte de la superficie forestal está constituida por monte abierto, sin aprovechamiento maderero o leñoso.

\section{5.- RELACIÓN CON EL FUEGO}

El problema de los incendios forestales en Castilla y León, al igual que en el resto de la Península Ibérica, guarda una estrecha relación con el ámbito socioeconómico en que se producen y con la necesidad de mejorar las relaciones, tanto económicas como afectivas de la población con sus montes. Entre las causas que dan lugar a los incendios, están la existencia de una arraigada tradición en el uso del fuego como herramienta de gestión del matorral (ya sea relacionada con actividades agroganaderas o, simplemente, con la "limpieza" del monte), y la falta de valor de los montes (VÉlEZ-MuÑOZ, 1986, 1991; PAUSAS, 2004). No existe una tradición cultural forestal, llevando a que la única relación económica con el monte se base en el aprovechamiento ganadero extensivo. La falta de interés económico que los montes tienen para las poblaciones locales propicia también un contexto social en que los incendios no se perciben como un problema importante por las poblaciones que los sufren. Estas situaciones, son generalizables tanto a nivel nacional como mundial (FAO, 2005).

Todos estos problemas y situaciones se hacen extensibles a Arribes del Duero, donde la importancia y el impacto del fuego es indudable. Tanto es así, que la mayoría de los municipios que componen este Parque Natural, especialmente los salmantinos, están recogidos en lo que la Junta de Castilla y León ha denominado Plan 42: una estrategia de intervención para contribuir a reducir el problema de los incendios en las 
comarcas más afectadas de la región. Aprobado en enero de 2002, y ampliado en el año 2005, el Plan 42, centra una buena parte de sus esfuerzos en la intervención social (educación, formación, comunicación y participación), sin olvidar las medidas relacionadas con la prevención clásica, orientadas más al corto plazo (infraestructuras, cortafuegos, selvicultura, etc.). Fue en este año 2005 cuando se dio cabida en él a los municipios salmantinos integrados en Arribes del Duero, entre los que se encuentran las localidades estudiadas en este trabajo, junto con algunos más del resto de la provincia y de la Comunidad en general (BOLECín, 2002; JunTA DE CASTILlA Y LEÓN, 2007).

Para acotar el problema, y siguiendo los intereses del presente trabajo, este apartado se centrará en una de las localidades en las que se ha llevado a cabo, Villarino de los Aires (Salamanca), por ser una de las más afectadas, y con mayor frecuencia, por este tipo de perturbación (generalmente de carácter intencionado), como lo demuestra el hecho de que fuese una de las zonas con mayor número de siniestros (Figura 8) y superficie quemada (Figura 9), durante el decenio 1996-2005 (MINISTERIO DE MEDIO AMBIENTE, 2006), año este último en que comenzó el presente estudio. Dada la vecindad de este municipio con la otra localidad analizada (Pereña de la Ribera), no es raro que una gran parte de los incendios afecte a ambas localidades al mismo tiempo.

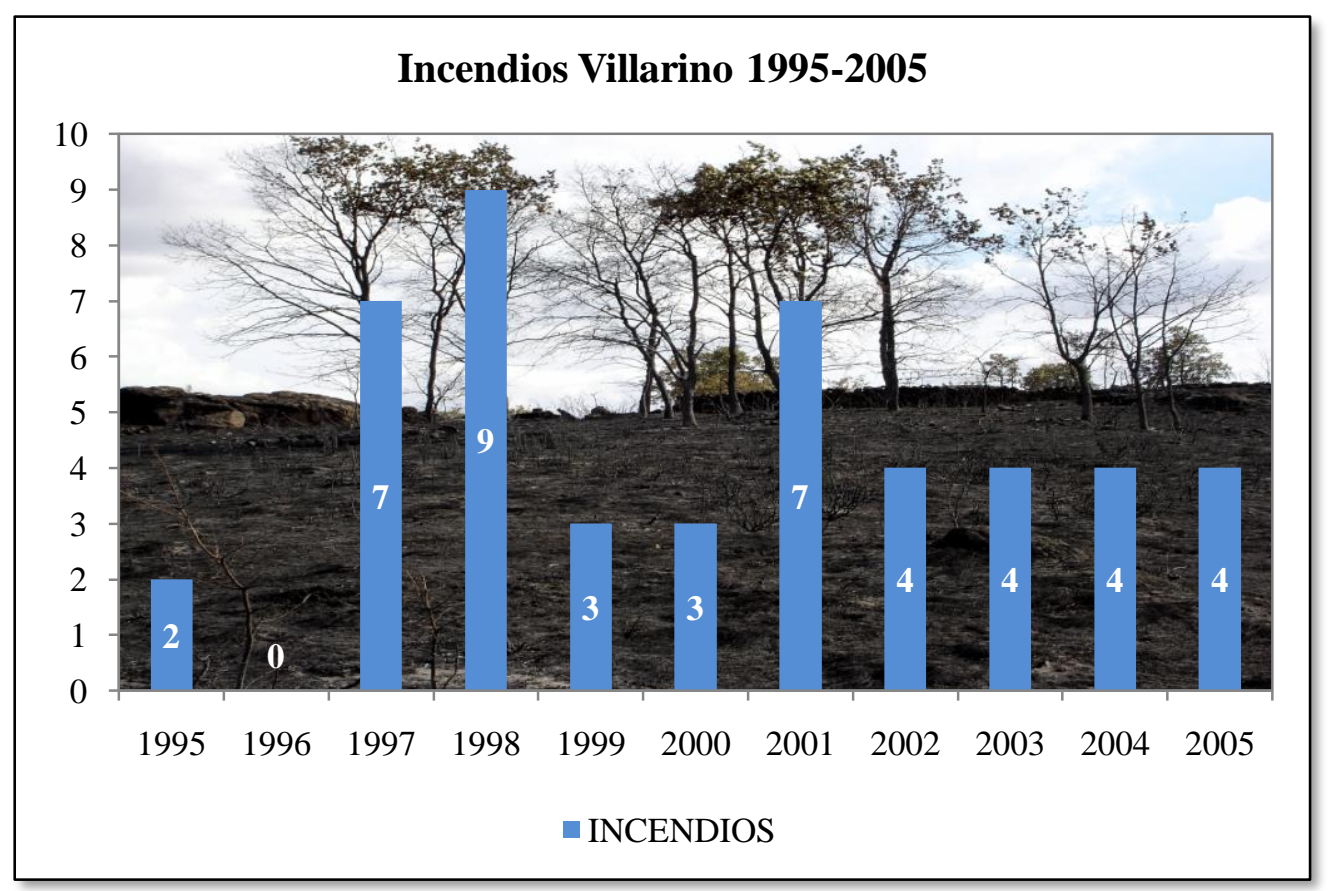

Figura 8: Número de incendios ocurrido en Villarino de los Aires durante el decenio 1996-2005*. 


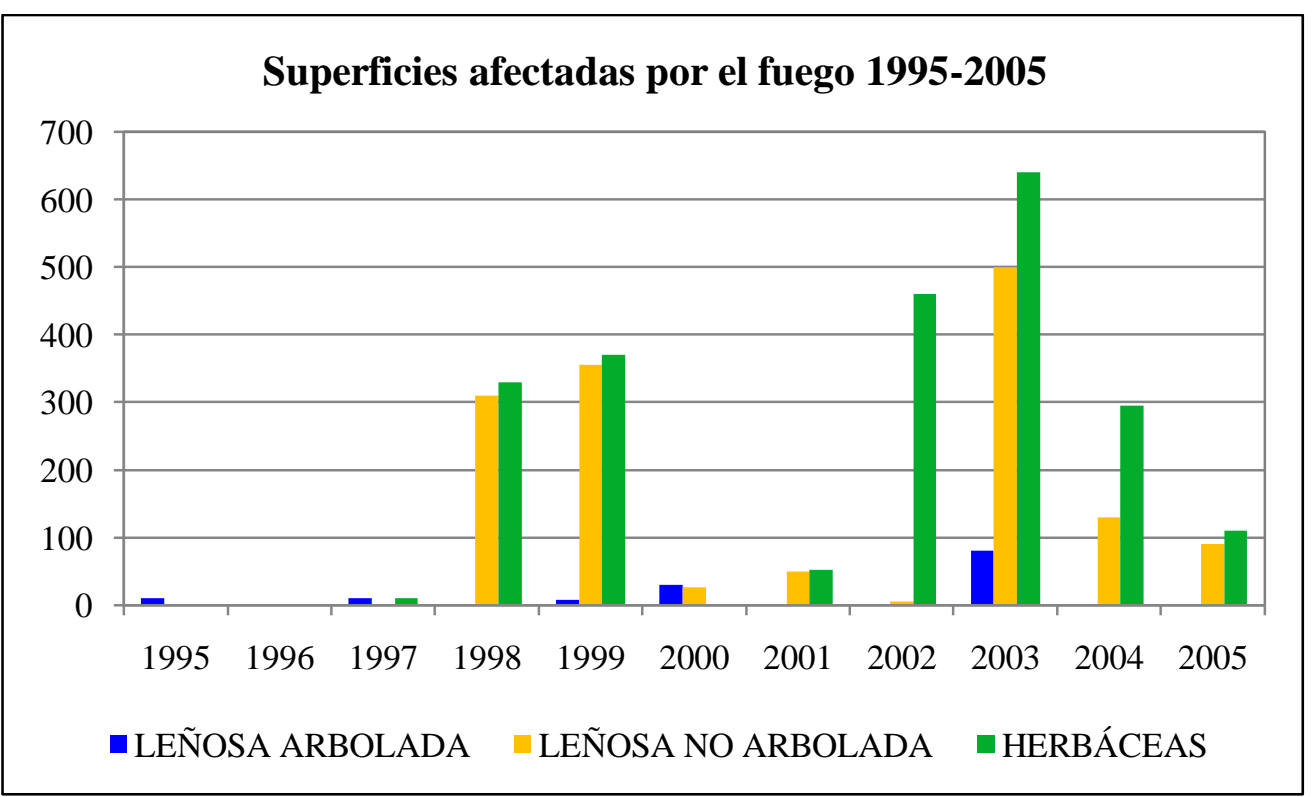

Figura 9: Superficie (en hectáreas), y tipo de vegetación quemada en Villarino de los Aires durante el decenio 19962005*.

\subsection{1.- ANÁLISIS DE RIESGOS Y MOTIVACIONES SOCIALES}

El riesgo de incendios, definido como la probabilidad de que se produzca un incendio en una zona y en un intervalo de tiempo determinados, varía en función del combustible vegetal existente en el monte, de la probabilidad de que se presente alguna de las causas típicas de incendio y las condiciones meteorológicas.

En Villarino de los Aires, el abandono de las prácticas agrícolas (actualmente solamente el 10,8\% de la superficie total del municipio se considera agrícola), forestales y ganaderas tradicionales, sumado a la reincidencia de incendios en la misma zona, ha provocado una notable degradación de la vegetación, fundamentalmente arbórea.

Estas prácticas mantenían hasta hace unas décadas el monte limpio de maleza y restos de poda, pero la falta de rentabilidad de los usos agrarios tradicionales ha motivado el abandono del campo y la emigración de la población más joven, aumentando de esta manera el envejecimiento de los residentes en el municipio. La dinámica ecológica tras los incendios ha transformado a gran parte de este espacio en zona de pasto, acompañado de vegetación arbustiva de porte bajo, con continuidad de combustible horizontal. Estas grandes masas de matorral (67,5\% del municipio), antes escasas por el labrado del terreno, han alentado la ya de por sí arraigada y tradicional cultura del fuego, para "limpiar" las fincas, convirtiendo a esta en una práctica de alto 
riesgo. La suma de todos estos factores, se traduce en fuegos de superficie, de intensidad (longitud de llama) baja a moderada, pero con una alta velocidad de propagación, favorecida por la pendiente y la orografía del terreno, lo que dificulta su extinción e incrementa su peligrosidad. El verano es la época de mayor índice de ocurrencia histórica.

Otros factores, como la excesiva rigurosidad de determinadas normas legales, motivaciones de índole personal o profesional, pérdida de terrenos para la caza, la falta de cultura ecológica, o la escasa dotación de medios de protección, han convertido a este en uno de los municipios más afectados por los incendios de carácter intencionado (Figura 10).

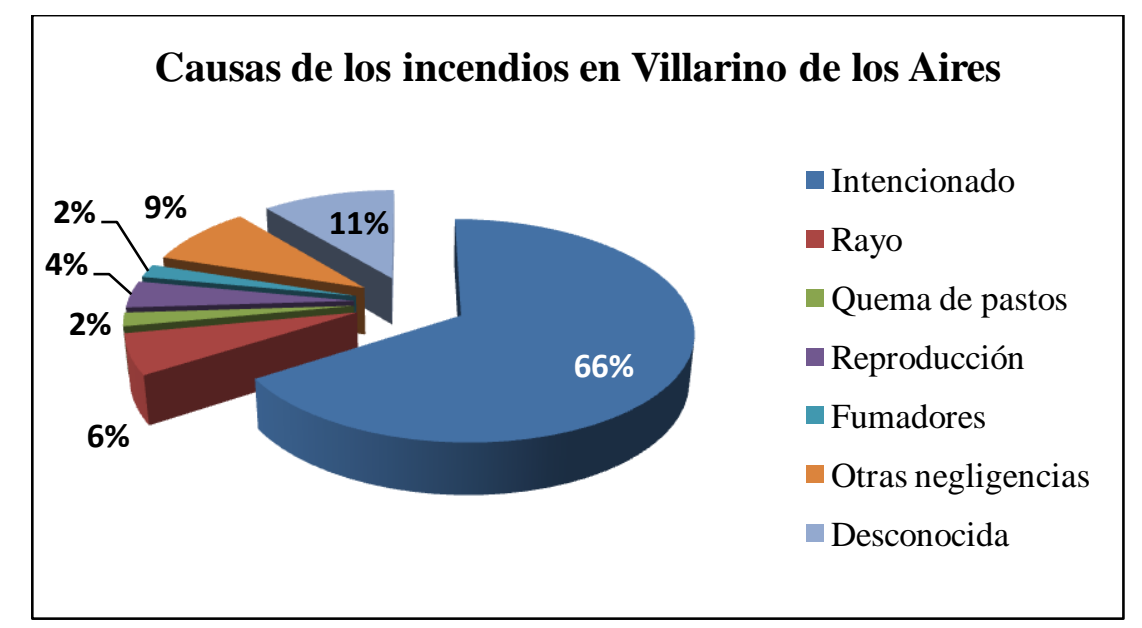

Figura 10: Principales causas de incendio en Villarino de los Aires durante el decenio 1996-2005*.

*Datos extraídos del Plan Municipal de prevención de los incendios forestales en Villarino de los Aires (Salamanca)

\section{6.- BIBLIOGRAFÍA}

Bartolomé, C., Álvarez Jiménez, J., Vaquero, J., Costa, M., CAsermeiro, M. A., Giraldo, J. \& ZAMORA, J. 2005. Los tipos de hábitats de interés comunitario de España. Guía Básica. Ministerio de Medio Ambiente. Dirección General para la Biodiversidad. 287 pp.

Baselga, A. \& Novoa, F. 2003. Los Chrysomelidae de los Arribes del Duero, noroeste de la Península Ibérica (Coleoptera). Nouv. Rev. Entomol. 20: 117-131.

BLANCO-SÁNChEZ, J. A. 1992. Rasgos geomorfológicos. El marco geológico. En: El libro de las dehesas salmantinas (coord. GÓMEZ-GUTIÉRREZ, J. M.), pp. 33-69. Junta de Castilla y León, Consejería de Medio Ambiente y O.T., Salamanca. 947 pp.

Bolecín: Boletín del Centro de InTERPRetación de la NATURAleza de Valladolid. 2002. Plan 42, más medidas preventivas contra los incendios forestales en Castilla y León. 58: 3-6. 
CABero-DiÉGueZ, V. 1982. El espacio geográfico castellano-leones. Ámbito Ediciones, S.A., Valladolid. $142 \mathrm{pp}$.

CABERO-DiÉGueZ, V. 1987. Los espacios naturales de alta calidad ecológica y ambiental. En: Geografía de Castilla y León. Tomo 3: Los Espacios Naturales (dirección de la obra CABO, A. \& MANERO, F.), pp. 132-152. Ámbito Ediciones, S.A., Valladolid.

Cabero-Diéguez, V., CAscos-Moraña, C. \& CALONGE-CANO, G. 1987. Estructura y dinámica de los paisajes vegetales. En: Geografía de Castilla y León. Tomo 3: Los Espacios Naturales (dirección de la obra CABO, A. \& MANERO, F.), pp. 76-115. Ámbito Ediciones, S.A., Valladolid.

Calonge-Cano, G. 1990. La excepcionalidad climática de los Arribes del Duero. ERIA, 21: 45-59.

CAlvo, L., TÁrrega, R. \& Luis-CAlABUig, E. 1991. Regeneration in Quercus pyrenaica ecosystems after surface fires. Int. J. Wildland Fire 1 (4): 205-210.

Calvo, L., Tárrega, R., \& Luis-Calabuig, E. 1999. Post-fire succesion in two Quercus pyrenaica communities with different disturbance histories. Ann. For. Sci. 56: 441-447.

Cascos-Moraña, C. 1987. La compleja y variada configuración del relieve. En: Geografía de Castilla y León. Tomo 3: Los Espacios Naturales (dirección de la obra CABO, A. \& MANERO, F.), pp. 8-43. Ámbito Ediciones, S.A., Valladolid.

Costa-Tenorio, M., Morla-Juaristi, C. \& Sainz-Ollero, H. (eds.) 2005. Los bosques ibéricos. Una interpretación geobotánica. $4^{\mathrm{a}}$ edición. Editorial Planeta, Barcelona. 598 pp.

De la Nuez, A., González, J. A., Gayubo, S. F. \& Torres. F. 2003. Abundancia y diversidad de avispas sociales (Hymenoptera: Vespidae) en el Parque Natural de "Arribes del Duero" (Oeste español). Bol. SEA 32: 87-93.

Dorronsoro, C. 1992. Suelos. En: GómeZ-Gutiérrez, J. M. (coord.)El libro de las dehesas salmantinas. Pp. 71-124. Junta de Castilla y León, Consejería de Medio Ambiente y O.T., Salamanca.

Escudero Alcántara, A., Olano, J. M., García, R., Bariego, P., Molina, C., Arranz, J. A., Molina, J. I. \& EzQuerRA, F. J. 2008. Guía básica para la interpretación de los hábitats de interés comunitario de Castilla y León. Junta de Castilla y León. Consejería de Medio Ambiente. Valladolid. $432 \mathrm{pp}$.

FAO. 2005. Global Forest Resources Assesment - Progress towards sustainable forest management. FAO Forestry Paper 147, Food and Agricultura Organisation, United Nations, Rome.

Forman, R. T. T. \& Godron, M. 1986. Landscape Ecology. John Wiley \& Sons. New York. 619 pp.

García-Feced, C., Escribano, R. \& Elena, R. 2007. Comparación de la estructura de los paisajes en Parques Naturales fronterizos: Arribes del Duero versus Douro Internacional. Montes 91: 8-14.

Gayubo, S. F., J. A. GonzÁlez, \& F. Torres. 2000. Estudio de una comunidad de esfécidos en la zona natural de "Las Arribes del Duero" (Salamanca, Oeste español) (Hymenoptera, Sphecidae). Fragm. Entomol. 32: 181-209.

GONZÁlEZ, J. A. 2002. Estudio sobre la biodiversidad de avispas "esfeciformes" (Hymenoptera: Apoidea: Ampulicidae, Sphecidae t Crabronidae) en el Espacio Natural de Arribes del Duero. Tesis doctoral. Universidad de Salamanca. Salamanca. 305 pp.

GonzÁlez, J. A., Gayubo, S. F. \& Strumia, F. 1998. Biodiversità dei Crisididi di un ambiente orticolo del territorio "Las Arribes del Duero" (provincia di Salamanca, Spagna Occidentale) (Hymenoptera, Chrysididae). Frustula entomologica n. s., XXI (XXXIV): 26-41.

González, J. A., Gayubo, S. F. \& TorRes, F. 2002. Diversidad, conservación e importancia en la gestión de los himenópteros megaquílidos (Insecta, Hymenoptera, Megachilidae) como agentes polinizadores en el Espacio Natural de Arribes del Duero, pp. 53-78. En: WAVES (eds.), Master Universitario Internacional en Gestión y Conservación de la Fauna Salvaje Euromediterránea: Estudios y Proyectos. WAVES-Caja España, Zamora, Spain. 
González, J. A., Gayubo, S. F., Asís, J. D. \& Tormos, J. 2009. Diversity and Biogeographical Significance of Solitary wasp (Chrysididae, Eumeninae and Spheciformes) at the Arribes del Duero Natural Park, Spain: Their Importance for Insects Diversity Conservation in the Mediterranean Region. Environ. Entomol. 38 (3): 608-626.

González talaván, A., Bernardos, S. \& Amich, F. 2003. Antirrhinum lopesianum Rothm. En: Bañares, A., Blanca, G., Güemes, J., Moreno, J. C. \& Ortiz, S. (eds.). Atlas y Libro Rojo de la Flora Vascular Amenazada de España. Pp: 586-587. Dirección General de Conservación de la Naturaleza, Madrid.

HernándeZ, J. A. \& PÉRez de AnA, J. M. 1999. Arribes del Duero: el gran cañón ibérico. Quercus 158: 26-30.

JuÁreZ-AlCAlde, J. 2000. El hombre y el medio: actividades tradicionales. En: Arribes del Duero: el hogar del águila perdicera y de la cigüeña negra (eds. ViCENTE-GonZÁLEZ, J. L., PALACIOSAlberti, J., Martínez-Fernández, A. \& Rodríguez-Alonso, M.), pp. 53-63. Consejería de Medio Ambiente. Junta de Castilla y León, Valladolid.

Junta de CAStilla y León (ed.) 1988. Análisis del medio físico de Salamanca. Delimitación de unidades y estructura territorial. Junta de Castilla y León, Consejería de Fomento, Valladolid. 79 pp.

Junta de Castilla y León, 2003. Libro del Parque Natural de Arribes del Duero. Programa Parques Naturales de Castilla y León. Servicio de Espacios Naturales (Coord.). 67 pp.

JunTA DE CASTILLA Y LEÓN, 2007. http:// www.jcyl.es

LLORENTE-MALDONADO, A. 1980. Las comarcas históricas y actuales de la provincia de Salamanca. $2^{\mathrm{a}}$ edición. Centro de Estudios Salmantinos, CSIC, Salamanca. 160 pp.

Llorente-Pinto, J. M. 1985. Los paisajes adehesados salmantinos. Publicaciones del Centro de Estudios Salmantinos n. ${ }^{\circ}$ 42, Salamanca. 265 pp.

Luis-Calabuig, E. (Coord.) 2008. Arribes del Duero. Guía de la Naturaleza. Edilesa. León. 224 pp.

Luis-Calabuig, E. \& TÁrrega, R. 1993. Studies on post-fire regeneration in Quercus pyrenaica ecosystems in Leon Province (NW Spain). Pages 209-219. En: TrabAUd L. \& ProdOn, R. (eds.) Fire in mediterranean ecosystems. ECSC-EEC-EAEC, Brussels-Luxembourg.

Luis-Calabuig, E., Tárrega, R., Calvo, L., Valbuena, L. \& Marcos, E. 2001. Fuego y paisaje en áreas de dominio del Roble Rebollo. Ecosistemas X (1).

Martí, R. \& Del Moral, J. C. (eds.) 2003. Atlas de las Aves Reproductoras de España. Dirección General de Conservación de la Naturaleza - SEO, Madrid. 733 pp.

Martín, F. 1995. Paseos por Las Arribes del Duero (España-Portugal). Amarú Ediciones, Salamanca. $202 \mathrm{pp}$.

Martín, F. 1996. Arribes del Duero. A caballo entre Zamora y Salamanca. Artec Impresiones, Segovia. $191 \mathrm{pp}$.

MARTíneZ-FERnÁndeZ, F. J. 1974. Estudio del área metamórfica y granítica de los Arribes del Duero (provincias de Salamanca y Zamora). Tesis Doctoral (inédita). Facultad de Geología, Universidad de Salamanca. Salamanca. 286 pp.

MMA. 2006. Los incendios forestales en España. Decenio 1996-2005. Centro de Coordinación de la información nacional sobre incendios forestales. Dirección General para la Biodiversidad. Madrid. 106 pp.

Molina, E. 1991. Geomorfología y Geoquímica del paisaje. Edic. Univ. Salamanca. 156 pp.

Molina, E., García, M. P., CAnTANo, M., \& Vicente, M. A. 1990. Some aspects of paleoweathering in the Iberian Hercynian Massif. Catena 17: 333-346.

Navarro, F. \& Valle, C. J. 1987. Castilla y León. En: Peinado, M. \& Rivas-Martínez, S. (eds.). La Vegetación de España. pp. 117-161Universidad de Alcalá de Henares, Madrid, Spain. 
Palomo, L. J., Gisbert, J., \& Blanco, J. C. (eds.). 2007. Atlas y Libro Rojo de los Mamíferos Terrestres de España. Dirección General para la Biodiversidad-SECEM-SECEMU, Madrid, España. 586 pp.

PAUSAS, J. G. 2004. La recurrencia de incendios forestales en el monte mediterráneo. En: VALLEJO, V. R. \& Alloza, J. A. (eds.) Avances en el estudio de la gestión del monte mediterráneo. Fundacion CEAM. Pp: 47-64.

Pleguezuelos, J. M.; Márquez, R. \& Lizana, M. (eds.) 2002. Atlas y Libro Rojo de los Anfibios y Reptiles de España. Dirección General de Conservación de la Naturaleza - Asociación Herpetológica Española (AHE), Madrid. 587 pp.

RIVAS-MaRTíneZ, S. 1987. Memoria del mapa de series de vegetación de España. ICONA. Ministerio de Agricultura, Pesca y Alimentación, Madrid. 268 pp.

Rodríguez-Muñoz, N. P. 1994. Arribes del Duero. Colección “El Viajero Independiente”. Ediciones Júcar, Madrid. 192 pp.

Romo, H. \& García-Barros. E. 2005. Distribucion e intensidad de los estudios faunísticos sobre mariposas diurnas en la Península Ibérica e Islas Baleares (Lepidoptera, Papilionoidea y Hesperioidea). Graellsia 61: 37-50.

Santos, M., Delgado, L. \& Bariego, P. 2006. Guía de las plantas silvestres de los Arribes del Duero zamoranos y su entorno. Náyade, Medina del Campo (VA). 450 pp.

SAnZ-ZuAsti, J. \& FERnÁndeZ-GutiérReZ, J. 2001. Guía de la fauna vertebrada de los Arribes del Duero zamoranos y su entorno. Náyade, Medina del Campo (VA). 205 pp.

Sierra-Puparelli, V., Colinas, A., Pascual, J. A. \& Blanco, J. F. 2009. Arribes del Duero. Tierra de límites. Ediciones de la Diputación de Salamanca. Serie PAISAJES SALMANTINOS nº 1. 232 pp.

TARAZOnA, T. 2000. Una vegetación singular. En: (Vicente-GonZÁlez, J. L., Palacios-Alberti, J., Martínez-Fernández, A. \& RodrígueZ-Alonso, M. Arribes del Duero: el hogar del águila perdicera y de la cigüeña negra (eds.). Pp. 29-36. Consejería de Medio Ambiente. Junta de Castilla y León, Valladolid.

TÁRregA, R. \& Luis-CAlABUig, E. 1989. Sucesión post-fuego y mecanismos de supervivencia en comunidades de Quercus pyrenaica de la provincia de León. Options Mediterraneénnes- Serie Seminaires 3: 137-140.

Tárrega, R., Calvo, L., Marcos, E. \& Taboada, A. 2006. Forest structure and understory in Quercus pyrenaica communities with different human uses and disturbances. Forest Ecol Manag 227: 5058.

TrabAud, L. 1987. Fire and survival traits of plants. En: The role of fire in ecological systems. SPB Academic Publishing. The Hague. Pp. 65-89.

Velasco-Marcos, J. C., Peris, S. J., Pollo-Mateos, C. J. \& GonzÁlez-Sánchez, N. 1997. Los peces de la provincia de Salamanca. Atlas de distribución. Ediciones Universidad de Salamanca Iberdrola, Salamanca. 172 pp.

VÉLEZ-MuÑoz, R. 1986. Incendios forestales y su relación con el medio rural. Revista de Estudios AgroSociales 136: 195-224.

VÉLEZ-MUÑOZ, R. 1991. Los incendios forestales y la política forestal. Revista de Estudios Agro-Sociales 158: 83-105.

ViadA, C. (ed.) 1998. Áreas importantes para las aves en España. $2^{\mathrm{a}}$ edición. Monografía n. ${ }^{\circ}$, SEO/BirdLife, Madrid. 398 pp.

Vicente-González, J. L., Palacios-Alberti, J., Martínez-Fernández, A. \& Rodríguez-Alonso, M. (eds.) 2000. Arribes del Duero: el hogar del águila perdicera y de la cigüeña negra. Consejería de Medio Ambiente. Junta de Castilla y León, Valladolid. 190 pp. 


\section{SPHECIFORMES}

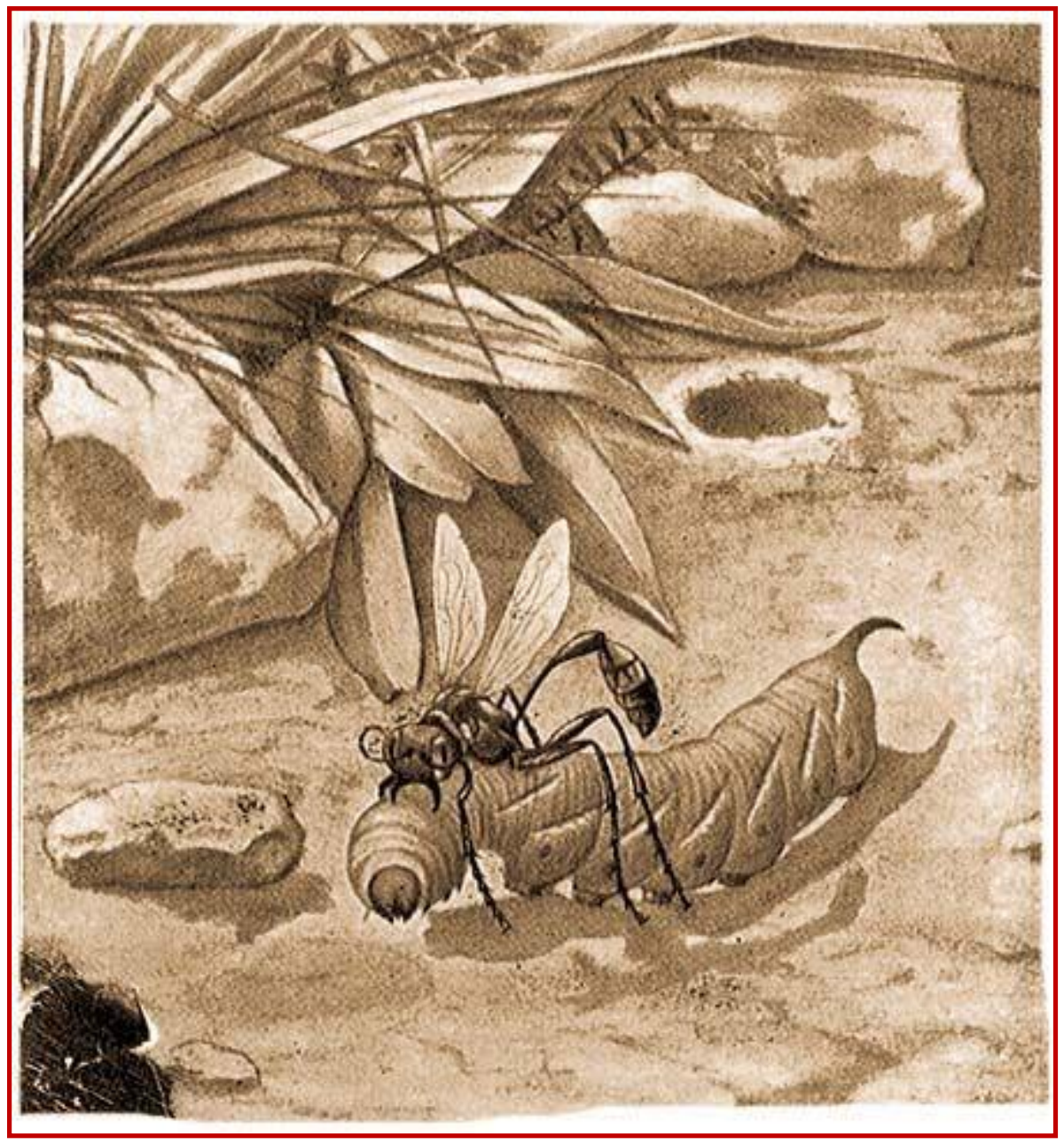

Armmophila sabulosa (Linnaeus, 1758) 


\section{1.- AVISPAS SPHECIFORMES}

\subsection{1.- SISTEMÁTICA}

Las relaciones filogenéticas de los diferentes grupos que componen los himenópteros aculeados han sido modificadas a partir de la década de 1990. Aunque el número de superfamilias consideradas tradicionalmente en la sección Aculeata ha sido de siete, la tendencia surgida tras el estudio filogenético de BROTHERS (1975) es considerar solamente tres. De acuerdo a GAULD \& BOLTON (1988) éstas son: Chrysidoidea, Vespoidea y Apoidea.

El grupo tratado en el presente estudio se consideraba como monofilético, ya fuese con la categoría taxonómica de familia (Sphecidae sensu BoHART \& MENKE, 1976) o superfamilia (Sphecoidea sensu KROMBEIN et al., 1979), si bien durante estos años BROTHERS (1975) ya indicó que los "esfécidos" no podían ser considerados como un grupo natural (proponiendo el término Spheciformes para denominarlos). En esta línea, ya más recientemente, MELO (1999) confirmó que el conjunto de los esfécidos corresponde en realidad a tres familias: Ampulicidae, Sphecidae y Crabronidae, opinión reiterada por el propio BROTHERS (1999). Otros autores señalan modificaciones y cambios en lo que respecta a subfamilias y tribus: MENKE \& FERNÁNDEZ (1996) y MENKE (1997).

Aunque no se han publicado los resultados, una obra fundamental a la hora de considerar el status de los "esfécidos" es la tesis doctoral realizada por PRENTICE (1998), quien además de tratar todas las tribus y subtribus de los Sphecidae (sensu BoHART \& MEnKE, 1976), incluye en su estudio el género Heterogyna (Heterogynaidae), así como varios representantes de Apidae y de otros aculeados.

Todos estos estudios filogenéticos recientes coinciden en considerar a los Apidae en sentido clásico, más los Sphecidae sensu BOHART \& MENKE (1976), como un conjunto monofilético bajo la denominación del término Apoidea (propuesto por la ley de prioridad frente a Sphecoidea) (ver MiCHENER, 2007), siendo los "esfécidos" un grupo parafilético, por lo que no se puede mantener el status de familia para este grupo. En este sentido, y considerando todo lo anteriormente expuesto, se denominará al grupo objeto de estudio como Spheciformes, al igual que otros autores en trabajos recientes 
(Ej. Fernández, 2000a, 2000b; GAYUBO et al., 2000, 2004a, 2004b, 2005, 2007; ZETTEl et al., 2001; GONZÁLEZ et al., 2003; 2009; BAÑOs-PiCÓN et al., 2007, 2009). Aún así, en la literatura actual pueden encontrarse denominaciones como avispas apoideas ("apoid wasps") o Spheciformes apoideos (VEPREK D. \& STRAKA J., 2007).

Si se compara la concepción clásica de los esfécidos como grupo monofilético en el sentido de Bohart \& MEnke (1976) y la actual de considerar el conjunto monofilético de los Apoidea (según se comenta en el párrafo anterior), los Spheciformes estarían formados por las siguientes familias:

- Ampulicidae: Grupo monofilético que aparece en la base de los Apoidea y que se corresponde con subfamilia Ampulicinae de BoHART \& MENKE (1976).

- Sphecidae: Clado en el que se incluyen fundamentalmente las tribus Sceliphrini, Sphecini y Ammophilini. Se corresponde con subfamilia Sphecinae de BOHART \& MENKE (1976).

- Crabronidae: Clado que incluye el resto de subfamilias de BOHART \& MENKE (1976), y difiere de la concepción, mucho más restringida, de la subfamilia Crabroninae de BOHART \& MENKE (1976).

- Heterogynaidae: La posición de esta familia en el actual conjunto de los Apoidea es controvertida. Se consideraba como grupo hermano de Ampulicidae (Ej. PrentiCE, 1998), pero los recientes análisis cladísticos, basados en datos moleculares, de OHL \& BLEIDORN (2006) la sitúan dentro de los Crabronidae. En cualquier caso, esta familia aún no se ha citado en España, por lo que no se menciona en el presente estudio.

Las diferentes subfamilias y tribus que se recogen en el listado de especies, están basadas en las modificaciones propuestas por los autores mencionados anteriormente que cambian el concepto clásico de considerar a los esfécidos como un grupo monofilético -familia Sphecidae sensu BOHART \& MENKE (1976), o superfamilia Sphecoidea, sensu KrombeIN et al. (1979)-. Todo ello es recogido en la clasificación $\begin{array}{lllll}\text { reflejada } & \text { por } & \text { Pulawski } & \text { Catálogo }\end{array}$ (www.calcademy.com/research/entomolgy/Entomology_Resources/Hymenoptera/sphecidae.) 


\subsection{2.- BIOLOGÍA}

Los imagos necesitan de un elevado grado de insolación para estar activos, por lo que son considerados insectos heliófilos por excelencia (O’NEILL, 2001). Su dieta es preferentemente nectarófaga, mostrando preferencia por las umbelíferas (BOHART \& MENKE, 1976; BITSCH \& LECLERCQ, 1993; BITSCH et al., 1997, 2007).

En las regiones templadas, la mayoría de las especies pasan el invierno como larvas en diapausa, pupando en primavera y apareciendo los imagos durante los meses de mayo o junio. Muchas especies son univoltinas, presentando una sola generación al año, aunque otras pueden dar lugar a dos o tres generaciones anuales, sobre todo en las zonas más meridionales (Figura 11).

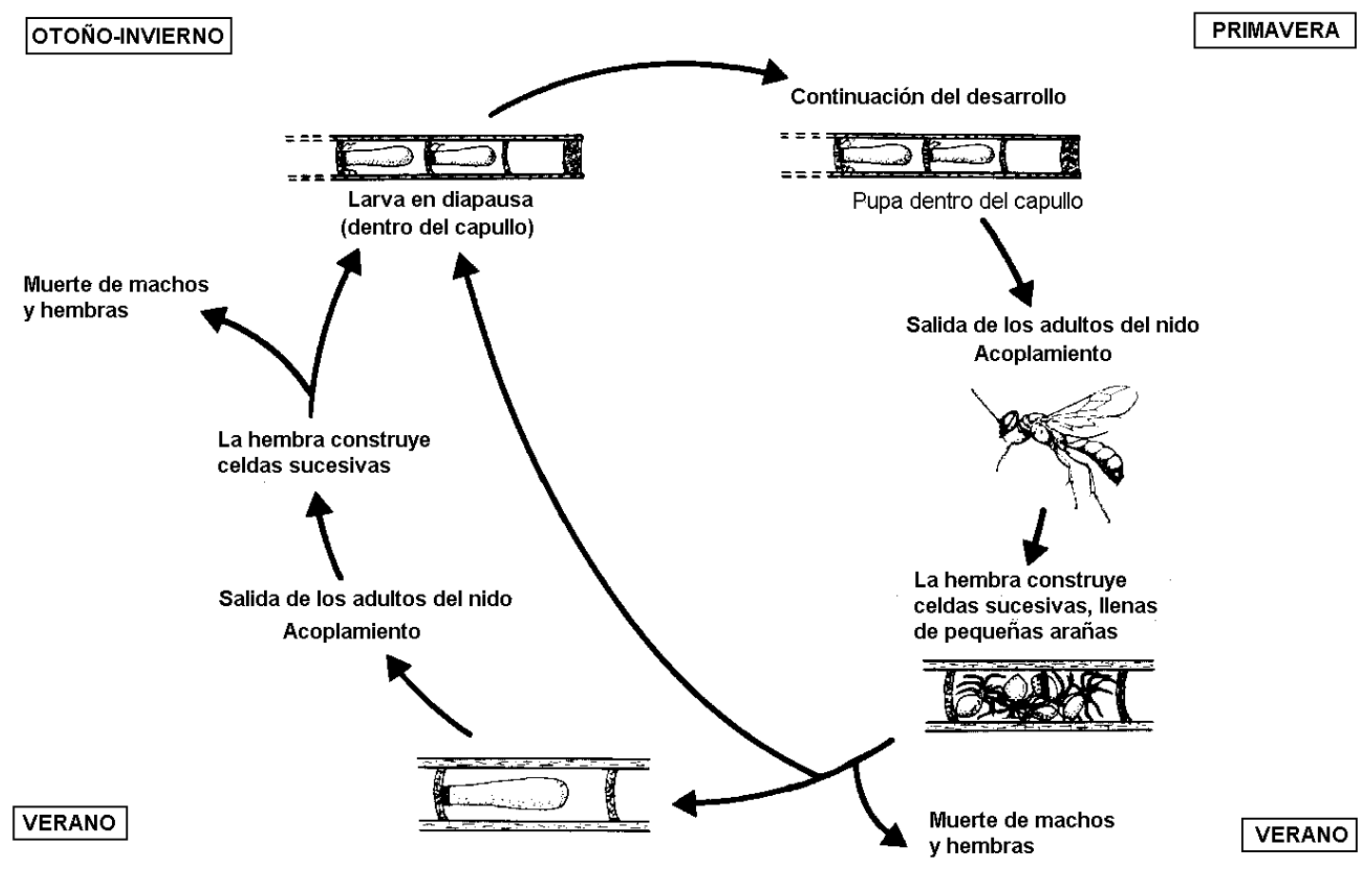

Figura 11: Ciclo biológico de una especie bivoltina, Trypoxylon figulus Linnaeus, 1758. (Crabronidae). La segunda generación es facultativa. Modificado de JACOB-REMACLE (1989).

Los machos, que emergen unos días antes que las hembras, sobrevuelan las áreas de nidificación o se posan en el suelo o sobre diversas plantas, acudiendo a las flores en busca de néctar. Los de algunas especies establecen territorios en áreas frecuentadas por las hembras (zonas de nidificación, plantas especialmente atractivas...) para aumentar 
así sus posibilidades de apareamiento. Pasan la noche en cortas galerías excavadas en el suelo por ellos mismos, o sobre plantas.

Las hembras, que generalmente se aparean una sola vez durante el transcurso de su vida (salvo algunas excepciones que lo hacen varias veces), son fecundadas poco después de su emergencia. Tras ello, inician su actividad nidificadora, que se desarrollará durante los meses de verano.

Se trata de un grupo muy diversificado y presente en una gran cantidad de hábitats, debido fundamentalmente a lo variado de su morfología y comportamiento, tanto en lo referido a la nidificación (sustrato utilizado, construcción del nido, estructura del mismo...) como a la captura y transporte de presas con fines pedotróficos.

La mayoría de las especies son de hábitos solitarios y depredadores, con la excepción de las de la tribu Nyssonini, que son cleptoparasitoides de otros Spheciformes, es decir, que no construyen nidos, sino que aprovechan los nidos y provisiones de otras especies para efectuar la puesta de sus huevos.

Por lo que respecta al sustrato empleado en la construcción del nido existen cuatro categorías de especies:

1. Amasadoras (nidos libres): Construyen nidos con barro o fibras de determinadas plantas. Son pocas especies las que se incluyen en esta categoría (Figura 12).

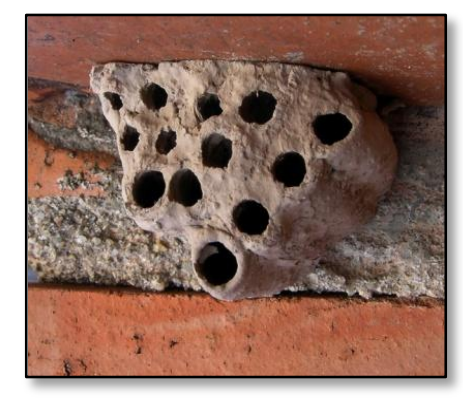

Figura 12: Nido de Sceliphron, Klug, 1801, construido con barro.

2. Terrícolas (nidos establecidos en el suelo): Realizan nidos, en distintos tipos de terreno, preferentemente arenoso, formados por galerías que desembocan en una o varias celdas; utilizan para su construcción las mandíbulas y patas anteriores (Figura 13). Un gran número de especies son terrícolas.

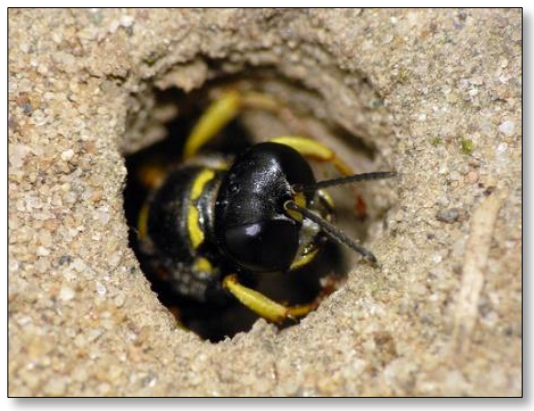

Figura 13: Hembra de Crabro (Fabricius, 1775), en su nido. construido 
3. Xilícolas-Rubícolas (nidos establecidos en tallos y troncos): Construyen nidos en madera muerta o médula de troncos y ramas. Los nidos establecidos en tallos de médula blanda pueden tener sus celdas dispuestas linealmente, una a continuación de otra, o de forma ramificada a partir de la galería principal. Las celdas se encuentran separadas entre ellas por tabiques, constituidos por distintos materiales (barro, resina, serrín, etc.) según la especie de que se trate (Figura

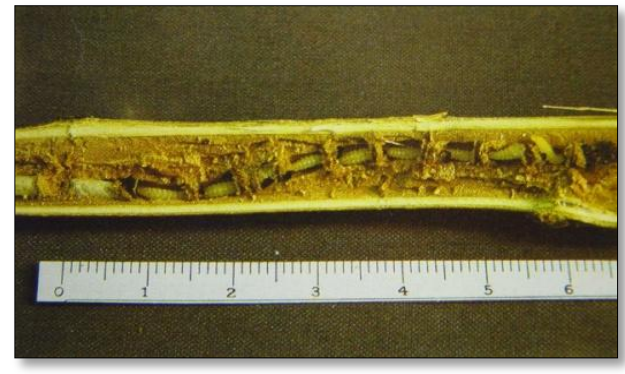

Figura 14: Nido de Trypoxylon attenuatum Smith, 1851, realizado en el interior de una caña.
14). En el caso de los nidos construidos en madera, la mayor parte de ellos presentan una estructura ramificada. Son numerosos los Spheciformes que emplean esta estrategia.

4. Ocupantes de cavidades preexistentes: Dentro de esta categoría se establecieron tres subcategorías, a las que se les concedió entidad propia en el análisis de la comunidad. Dado que todas ellas nidifican en galerías naturales o confeccionadas por otros artrópodos, esta diferenciación está motivada por el comportamiento exhibido a la hora de finalizar el nido en el primero de los casos, y por el tipo de sustrato en el que se hallan esos huecos o galerías, en los otros dos. Así distinguimos:

I. Ocupantes de cavidades-amasadoras: Cierran el nido mediante el amasado de barro o fibras vegetales. Sólo especies del género Chalybion.

II. Ocupantes de cavidades preexistentes-terrícolas: Los huecos o galerías ocupados están establecidos en el suelo, muros, o grietas en las rocas. Este método es utilizado por muchas especies.

III. Ocupantes de cavidades preexistentes-vegetales: En esta ocasión, los huecos ocupados se hallan construidos en sustratos vegetales (madera muerta, tallos con médula...).

Depredan sobre insectos en cualquier estado de desarrollo, incluidos -en determinados casos- los propios Spheciformes, si bien algunos capturan arañas 
(Sceliphron Klug, Miscophus Jurine, Pison Jurine, Trypoxylon Latreille). Una vez capturadas, las presas son paralizadas mediante el veneno inyectado a través del aguijón, lo que las mantendrá vivas y permitirá conservar mejor sus tejidos durante más tiempo, para posteriormente ser transportadas al nido, donde servirán de alimento a las larvas.

El transporte de las presas muestra una gran variabilidad en el conjunto de los Spheciformes. Siguiendo la terminología propuesta por GENISE en 1980 (basada en Evans, 1966), existen hasta cinco tipos diferentes:
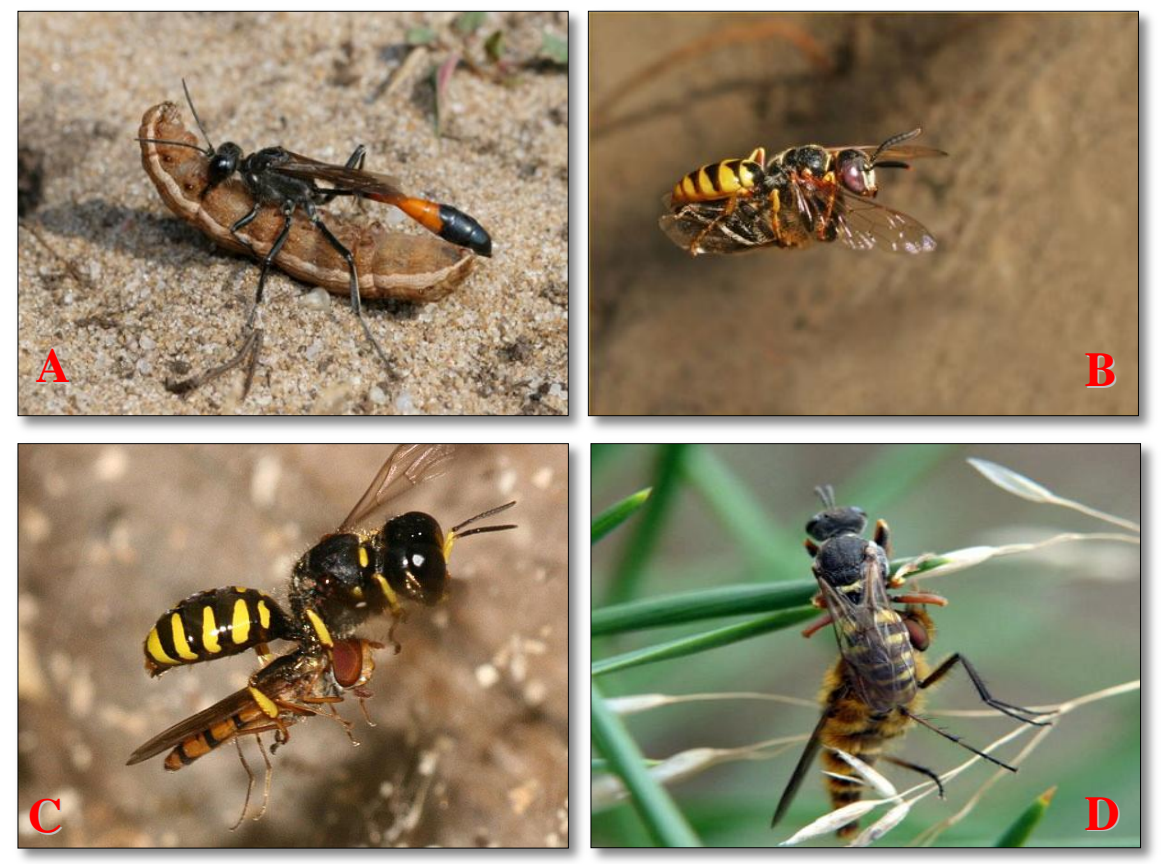

Figura 15: A) Transporte mandibular. Hembra de Ammophila sabulosa (Linnaeus, 1758) transportando una larva de lepidóptero hacia su nido (excavado en el suelo). B) Transporte Pedal 1: Hembra de Philanthus transportando una abeja en vuelo. C) Transporte Pedal 2: Hembra de Ectemnius transportando a un díptero en vuelo. D) Transporte Abdominal 1: Hembra de Oxybelus transportando un díptero.

I. Mandibular (M): La hembra sujeta con las mandíbulas a la presa, que puede ser transportada tanto en vuelo como arrastrándola por el suelo (Figura 15A).

II. Pedal 1 (P1): La presa, sujeta con las patas intermedias, es transportada en vuelo (Figura 15B).

III. Pedal 2 (P2): La presa también es transportada en vuelo, esta vez sujeta con las patas posteriores. Es el menos común (Figura 15C). 
IV. Abdominal 1 (A1): La presa es clavada en el aguijón y transportada en vuelo (Figura 15D).

V. Abdominal 2 (A2): El transporte es realizado también en vuelo, y la presa va sujeta al gáster mediante una modificación de los escleritos del último segmento de éste.

Muchas especies depositan varias presas en cada celda hasta completar la cantidad necesaria para el desarrollo de la larva. El aporte de presas puede ser, o continuo y rápido, o discontinuo y más lento. La larva, que puede nacer antes de que se haya completado el aprovisionamiento, consume las presas almacenadas por la madre, pasando por diferentes estados (habitualmente cinco) hasta llegar al de la larva madura. Una vez alcanzado dicho estado, construye un capullo, en donde pasa el invierno.

En función del modelo de aporte de presas, se distinguen varios tipos de aprovisionamiento. Según la clasificación propuesta por EvANS (1966), y teniendo en cuenta las modificaciones sugeridas por GENISE (1982), se distinguen dos tipos principales, en función de la existencia o no de contacto entre la hembra y la larva:

I. Masivo: no existe contacto entre ambas. La hembra aporta presas sin esperar el nacimiento de la larva.

II. Progresivo: La hembra no aporta presas -o aporta exclusivamente aquella sobre la cual depositará el huevo- hasta que se produce el nacimiento de la larva. Existen por tanto contactos frecuentes entre esta y la hembra.

El comportamiento nidificador mostrado por las hembras puede ser considerado como una compleja cadena de pautas comportamentales, cuyo objetivo final es asegurar la supervivencia de sus descendientes hasta alcanzar el estado adulto. Las pautas principales en este proceso son la puesta, el aporte de las presas y la construcción del nido, pautas que se realizan en un orden determinado, dependiendo de la especie de que se trate. Si utilizamos la terminología propuesta por IWATA (1976) y representamos con ella el comportamiento nidificador de una especie, obtendremos la denominada fórmula comportamental. 
La diversidad observada en el comportamiento nidificador de las diferentes especies de Spheciformes hace que este grupo muestre el mayor número de fórmulas comportamentales distintas, dentro del grupo de aculeados. Las consideradas como más primitivas son aquellas en las que la captura de la presa precede a la construcción del nido y ovoposición, mientras que en las más evolucionadas, esas dos tareas son anteriores a la captura de las presas.

\section{2.- PROTECCIÓN Y CONSERVACIÓN DE HIMENÓPTEROS ACULEADOS}

Todos los himenópteros aculeados desempeñan una función insustituible en la mayoría de los ecosistemas terrestres (GAULD \& BOLTON, 1988; GAULD et al., 1990; SAMWAYS, 1990; DAY, 1991; LASALlE \& GAULD, 1993), bien sea como polinizadores, favoreciendo la fructificación de las plantas (PRIMACK \& SILANDER, 1975; SPEARS, 1983; NEEF \& SiMPSON, 1993; O TOOLE, 1993; HEARD, 1999), bien como depredadores, o parásitos controlando de esta manera las poblaciones de otras especies, lo que posibilita incluso su utilización en el control biológico de plagas (FLANDERS, 1953; SMiley \& RANK, 1986; Collins \& JenningS, 1987; UnRUH \& MESSING, 1993; BLOMMERS, 1994; GREATHEAD, 1994; KIDD \& JERVIS, 1997; HARRIS, 1994; HILL, 1997; SÁNCHEZ - RUIZ et al., 1997; SEARS et al., 2001). Otros, como es el caso de las abejas melíferas, deben su importancia a que de ellas se obtienen productos de gran interés comercial.

Es por tanto, la relevancia de los procesos económicos y ecológicos en los que participan los aculeados, sumado al hecho de que algunos de ellos sean propuestos como indicadores de diversidad (TSCHARNTKE et al., 1998; GAYUBO et al., 2005), o como bioindicadores sensibles a los cambios ambientales (TSCHARNTKE et al., 1998), lo que indica que deben ser tenidos en cuenta a la hora de planificar prácticas dirigidas a promover la conservación de la biodiversidad y asegurar la salud y el buen estado de conservación del medio (GAULD et al., 1990; DAY, 1991; LASALlE \& GAULD, 1993; MARTínEZ DE MuRGuía et al., 2002).

La causa principal de la extinción o disminución de sus poblaciones se debe a la destrucción o alteración de sus hábitats o de las condiciones locales de los mismos 
(PYle et al., 1981; GAUld et al., 1990; DAY, 1991; GESS \& GESS, 1993; BANASZAK, 1995; FERnÁNDEZ, 1995; LAWTON et al., 1998; STEFFAn-DEWENTER, 2002, 2003; TAKI et al., 2007, 2008), causada de manera directa o indirecta por las actividades del hombre.

Los principales factores que afectan a la conservación de los aculeados en los ambientes gestionados, son los que están relacionados con las prácticas llevadas a cabo sobre la vegetación, particularmente sobre su floración, y la pérdida de los recursos clave como son zonas o lugares aptos para su nidificación, como las manchas arenosas soleadas, los bancos de arena y la vegetación de las orillas de los ríos, los senderos o los restos de madera muerta (DAY, 1991; ARCHER, 1998).

La configuración de las plantaciones, estructura y técnicas de cosecha, deben ser lo menos dañinas posibles para la biodiversidad nativa (EHRLICH, 1996; HARTLEY, 2002). Además, se ha de favorecer el uso tradicional del suelo, formando mosaicos de bosques autóctonos, huertas, campos de cereal y repoblaciones forestales, donde predominen los policultivos, siempre que sea posible con especies autóctonas o propias del lugar donde se va a llevar a cabo (HUMPHREY et al., 1999; HARTLEY, 2002).

Los claros del bosque cobran gran importancia, al favorecer la presencia de vegetación, que además de servir de alimento para muchos himenópteros, también crea suelos con las características esenciales para la construcción de nidos por parte de muchas especies (ShlyakHTENOK, 1995; Martínez De Murguía et al., 2002). Debido a esto, una medida para promover la diversidad de muchas de estas especies, y la de otros insectos, sería favorecer la práctica de dejar espacios abiertos. El aclaramiento y mantenimiento de claros del bosque y setos, o creación de zonas arenosas soleadas deberán ser prácticas forestales comunes para crear o recrear hábitats esenciales para la conservación de muchas de las especies estos artrópodos (KIRBY, 2001). En relación a esto, sería de esperar que la actuación de los incendios forestales beneficiase en cierta manera a estas especies.

Otro recurso importante para algunas especies de aculeados, lo constituye la presencia de restos de madera muerta, ya que les proporciona un lugar de nidificación (MARTínEZ DE MurGuía et al., 2002). En esta ocasión, el efecto del fuego sobre este recurso presumiblemente ejerza dos efectos contrapuestos, por un lado calcinando los 
restos de vegetación y madera muerta, matando así a los individuos que se encuentren en los nidos en el momento del fuego, y aumentando o creando nuevos recursos al matar parte del arbolado, que se transformará ahora en sustrato potencialmente útil para nidificar.

La despoblación del medio rural y el abandono de prácticas agrícolas tradicionales tienen consecuencias muy negativas en las poblaciones debido a la homogeneización del medio con la eliminación de setos y otros ecotonos.

Por último, los tratamientos con biocidas son, al menos, un elemento degradante del medio natural y, en ciertos casos, pueden acabar con especies que se encuentran ya muy mermadas (PYLE et al., 1981; SAMWAYS, 1993; DUELLI et al., 1999).

La conservación de estos himenópteros tiene una indudable repercusión ecológica, económica y cultural, por lo que su diversidad debe ser tenida en cuenta a la hora de proyectar las prácticas de manejo forestal y evaluar la conservación de la biodiversidad en los bosques.

La Unión Mundial para la Conservación de la Naturaleza (UICN) tiene registradas más de un millar de especies de himenópteros que presentan problemas de supervivencia en al menos un país de Europa (DAY, 1991), lo que representa, aún sin conocimiento preciso, cerca del $10 \%$ de la himenopterofauna europea (NIEVES-ALDREY \& FONTAL - CAZALLA, 1999; UlRICH, 1999). La protección legal de los himenópteros está contemplada en Bélgica, donde veintitrés especies están amparadas por la ley, seguida de Finlandia con siete. En España únicamente cinco especies de hormigas se incluyen en los Convenios Internacionales ratificados (RoSAS et al., 1992).

GAULD et al. (1990) citan el número de especies de aculeados recogidas en Listas Rojas nacionales e internacionales europeas. En cuanto a los Spheciformes se refiere, destacan 126 especies incluidas en Alemania, 74 en Austria y 34 en el Reino Unido. Por su parte, DAY (1991), en su anexo, relaciona el total de especies de aculeados incluidas en las citadas listas, añadiendo la categoría de protección (según la UICN) asignada y el autor de la lista concreta. 


\section{3.- BIBLIOGRAFÍA}

ARCHER, M. E. 1998. Threatened wasps, ants and bees (Hymenoptera Aculeata) En: Watsonian Yorkshire. A red Data book. PLACE Research Centre. University College of Ripon and York St. John. Occasional paper $\mathrm{n}^{\circ}$ 2: $68 \mathrm{pp}$

BanaszaK, J. (ed.) 1995. Changes in Fauna of Wild Bees in Europe. Pedagogical University, Bydgoszcz. 220 pp.

Baños-Picón, L., Asis, J. D., GAyubo, S. F., \& ToRmos, J. 2009. Analyzing Insect Community Structure through the Application of Taxonomic Distinctness Measures. Zoological Studies 48 (3): 298314.

Baños-Picon L., Gayubo S. F., Asis J. D., Tormos J. \& Gonzalez J. A. 2007. Diversidad de la comunidad de avispas Spheciformes de una zona agricola abondonada del oeste español (Hymenoptera: Apoidea: Ampulicidae, Sphecidae y Crabronidae). Nouvelle Revue d'Entomologie, (n. s.), 23: 249-266.

Bitsch, J. \& LECLERCQ, J. 1993. Hyménoptères Sphecidae d'Europe Occidentale vol. 1. Faune de France 79. Fédération Française des Sociétés de Sciences Naturelles, París. 325 pp.

Bitsch, J., Barbier, Y., Gayubo, S. F., Schmidt, K. \& Ohl, M. 1997. Hyménoptères Sphecidae d'Europe Occidentale vol. 2. Faune de France 82. Fédération Française des Sociétés de Sciences Naturelles, París. 429 pp.

Bitsch, J., Dollfuss, H., Boucek, Z., Schmidt, K., Schmid-Egger, C., Gayubo, S. F., Antropov, A. V., BARBIER, Y. 2007. Hyménoptéres Sphecidae D’Europe Occidentale. Volume 3 (seconde édition). Faune de France 86. Fédération Française des Sociétés de Sciences Naturelles. París. $459 \mathrm{pp}$.

Blommers, L. H. M. 1994. Integrated pest management in European apple orchards. Annu. Rev. Entomology 39: 213-241.

Bohart, R. M. \& Menke, A. S. 1976. Sphecid Wasps of the World, a Generic Revision. University of California Press, Berkeley. ix + 695 pp.

Brothers, D. J. 1975. Phylogeny and classification of the aculeate Hymenoptera, with special reference to the Mutillidae. University of Kansas Science Bulletin 50: 483-648.

Brothers, D. J. 1999. Phylogeny and evolution of wasps, ants and bees (Hymenoptera, Chrysidoidea, Vespoidea and Apoidea). Zoologica Scripta 28: 233-249.

Collins J. A., JENnings D.T. 1987. Spruce budworm and other lepidopterous prey of Eumenid wasps (Hymenoptera: Eumenidae) in spruce-fir forests of Maine. The Great Lakes Entomologist, 20: 127-133.

DAY, M. C. 1991. Towards the conservation of aculeate Hymenoptera in Europe. Nature and Environment Series, $\mathrm{n}^{\circ}$ 51. Ediciones del Consejo de Europa, Estrasburgo. 80 pp.

Duelli, P., ObRist, M. K. \& Schmatz, D. R. 1999. Biodiversity evaluation in agricultural landscapes: above-ground insects. Agriculture, Ecosystems and Environment 74: 33-64.

Evans, H. E. 1966. The comparative ethology and evolution of the sand wasps. Harvard University Press, Cambridge, MA. 526 pp.

FERNÁNDEZ F. 1995. La diversidad de los himenópteros en Colombia. En: RANGEL, J. O (ed.), Colombia. Diversidad Biótica I. Pp. 373-442. Universidad Nacional de Colombia, Santafé de Bogotá D.C. 442 pp.

FERnÁNDEZ, F. 2000a. Sistemática y filogenia de los himenópteros de la región neotropical: estado del conocimiento y perspectivas. En: Hacia un Proyecto CYTED para el Inventario y Estimación de la Diversidad Entomológica en Iberoamérica: PrIBES 2000 (eds. MARTÍN-PIERA, F; 
MORRONE, J. J. \& MELIC, A.), pp. 211-231. m3m-Monografías Tercer Milenio vol. 1, Sociedad Entomológica Aragonesa (SEA), Zaragoza.

FERnÁndeZ, F. 2000b. Sistemática de los himenópteros de Colombia: estado del conocimiento y perspectivas. En: Martín-Piera, F, Morrone, J. J. \& Melic, A. (eds.). Hacia un Proyecto CYTED para el Inventario y Estimación de la Diversidad Entomológica en Iberoamérica: PrIBES 2000. pp. 233-243. m3m-Monografías Tercer Milenio vol. 1, Sociedad Entomológica Aragonesa (SEA), Zaragoza.

FLANDERS, S. E. 1953. Predatism by the adult hymenopterous parasite and its role in biological control. $J$. of Economical Entomology 46: 541-544.

Gauld, I. D. \& Bolton, B. (eds.) 1988. The Hymenoptera. British Museum (Natural History). Oxford University Press, Nueva York. xi +332 pp.

Gauld, I. D., Collins, N. M. \& FitTon, M. G. 1990. The biological significance and conservation of Hymenoptera in Europe. Nature and Environment Series, n. ${ }^{\circ}$ 44. Consejo de Europa, Estrasburgo. $47 \mathrm{pp}$.

Gayubo, S. F., GonzÁlez, J. A. \& Torres, F. 2000. Estudio de una comunidad de esfécidos en la zona natural de "Las Arribes del Duero" (Salamanca, Oeste español) (Hymenoptera, Sphecidae). Fragmenta entomologica, 32 (1): 181-209.

Gayubo, S. F., Nieves-Aldrey, J. L., GonzÁlez J. A., Asis, J. D., Rey del Castillo C. \& Tormos, J. 2004a. La communidad de avisas esfeciformes de la estación biogeológica de El Ventorillo (Sector Medio de la Sierra de Guadarrama Madrid, España) (Hymenoptera, Apoidea, Ampulicidae, Sphecidae y Crabronidae). Nouvelle Revue d'Entomologie (n.s.), 21: 125-156.

Gayubo, S. F., Nieves-Aldrey, J. L., GonzÁlez, J. A., Tormos, J., Rey del Castillo, C. \& Asis, J. D., 2004b. Diversidad de avispas spheciformes (Hymenoptera, Apoidea, Ampulicidae, Sphecidae y Crabronidae) colectas mediante trampa Malaise en el Monte Pardo (Madrid, España). Boletín de la Real Sociedad española de Historia natural, Sección Biologica, 99: 105-113.

GAyubo, S. F., GonzÁlez, J. A., Asís, J. D. \& Tormos, J. 2005. Conservation of European environments: The Spheciformes wasp as biodiversity indicators (Hymenoptera: Apoidea: Ampulicidae, Sphecidae and Crabronidae). J. of Natural History, 39 (29): 2705-2714.

Gayubo, S. F., GonzÁlez, J. A., Asís, J. D. \& Tormos, J. 2007. Diversidad de avispas Sphceciformes en el Parque Natural de Las Batuecas-Sierra de Francia (Salamanca, España) (Hynemnoptera: Ampulicidae, Sphecidae y Crabronidae). Nouvelle Revue d'Entomologie (n.s.), 24: 131-147.

GENISE, J. F. 1980. Evolución de los tipos de transporte de presas de avispas. Reclasificación de los tipos mandibulares y esquema evolutivo general. Revista de la Sociedad Entomológica Argentina 39 (1-2): 19-36.

GENISE, J. F. 1982. Estudios sobre el comportamiento de Bembicini neotropicales I. Bicyrtes simillima (Smith) y Bicyrtes discisa (Tasch.) (Hymenoptera, Sphecidae), con una revisión de los tipos de aprovisionamiento en Bembicini. Physis, sec.C, 40 (99): 93-99.

GESS, F. W. \& GESS, S. K. 1993. Effects of increasing land utilization on species representation and diversity of aculeate wasps and bees in the semi-arid areas of Southern Africa. En: LASALLE, J. \& GAUlD, I. D (eds.)Hymenoptera and Biodiversity, pp. 83-113. CAB International. The Natural History Museum, Wallingford, UK. xi + 348 pp.

González, J. A., Gayubo, S. F., Asís, J. D. \& Tormos, J. 2009. Diversity and Biogeographical Significance of Solitary wasp (Chrysididae, Eumeninae and Spheciformes) at the Arribes del Duero Natural Park, Spain: Their Importance for Insects Diversity Conservation in the Mediterranean Region. Environ Entomol 38 (3): 608-626.

González, J. A., Gayubo, S. F., Asís, J. D., Tormos, J, \& García, C. 2003. Estructura y dinámica temporal de la comunidad de avispas esfeciformes (Hymenoptera: Apidea: Ampulicidae, 
Sphecidae y Crabronidae) en un pastizal de la Cuenca Alta del Duero (España). Boletín de la Real Sociedad Entomológica Aragonesa 32: 59-65.

GreatheAD, D. 1994. History of Biological Control. Antenna, Bulletin of the Royal Entomological Society 18 (4): 187-199.

Ehrlich, P. R. 1996. Conservation in temperate forests: what do we need to know and do? Forest Ecol Manag. 85: 9-19

HARrIS, A. C. 1994. Ancistrocerus Gazella (Hymenoptera: Vespoidea: Eumenidae): A Potentially Useful Biological Control Agent for Leafrollers Plantortix Octo, P. Excessana, Ctenopseustis Obliqua,

C, Herana, and Epiphyas Postvittana (Lepidoptera: Tortricidae) In New Zealand. New Zealand J. Crop Horticultural Science 22: 235-238.

HaRtLey, M. J. 2002. Rationale and methods for conserving biodiversity in plantation forests. Forest Ecol Manag. 155: 81-95

HEARD, T. A. 1999. The role of stingless bees in crop pollination. Annu. Rev. Entomology 44: 183-206.

HiLL, D. S. 1997. The Economic Importance of Insects. Chapman \& Hall, Londres. $\mathrm{x}+395$ pp.

Humphrey, J. W., Hawes, C., Peace, A. J., Ferris-KaAn, R. \& Jukes, M. R. 1999 Relationships between insect diversity and habitat characteristics in plantation forests. Forest Ecol Manag. 113: 11-21.

IwatA, K. 1976. Evolution of instinct. Comparative ethology of Hymenoptera. Amerind Publishing Co., Nueva Delhi. ix +535 pp.

JACOB-REMACLE, A. 1989. Abeilles et Guêpes de nos jardins. Unité de Zoologie générale et appliquée de la Faculté des Sciences agronomiques de Gembloux. Nouvelle Imprimerie Duculot s.a., Gembloux. 48 pp.

KIDD, N. \& JERVIS, M. A. 1997. The impact of parasitoids and predators on forest insect populations. En: Watt, A. D., Stork, N. E. \& Hunter, M. D (eds.). Forests and Insects. Pp. 49-68. Chapman \& Hall Ltd., Londres.

KIRBY, P. 2001. Habitat Management for Invertebrates: A practical handbook. National Power, JNCC \& RSPB. viii + 150 pp.

Krombein, K. V., Hurd, P. D. Jr., Smith, D. R. \& BurKs, B. D. 1979. Catalog of Hymenoptera in America North of Mexico. Smithsonian Institution Press, Washington, D.C. 2.735 pp. (3 vols.).

Lasalle, J. \& GAUld, I. D. (eds.) 1993. Hymenoptera and Biodiversity. CAB International. The Natural History Museum, Wallingford, UK. xi + 348 pp.

Lawton, J. H., Bignell, D. E., Bolton, B., Bloemers, G. F., Eggleton, P., Hammond, P. M., Hodda, M., Holt, R. D., Larsen, T. B., Mawdsley, N. A., Stork, N. E., Srivastava, D. S. \& Watt, A. D. 1998. Biodiversity inventories, indicator taxa and effects of habitat modification in tropical forest. Nature, 391: 72-76.

Martínez De Murguía L., VÁzQuez, M. A., Nieves-Aldrey, J. L. 2002. Distributions of sawflies and aculeates in a heterogeneous secondary acid forest in Artikutza (Navarre) (Insecta: Hymenoptera). Munibe (Ciencias Naturales-Natur-Zientziak) 53: 183-204.

Melo, G. A. R. 1999. Phylogenetic relationships and classification of the major lineages of Apoidea (Hymenoptera), with emphasis on the crabronid wasps. Scientific Papers, Natural History Museum, The University of Kansas, 14: 1-55.

MEnKE, A. S. 1997. Family-group names in Sphecidae (Hymenoptera: Apoidea). J. Hymenoptera Research 6 (2): 243-255.

Menke, A. S. \& FernándeZ, F. 1996. Claves ilustradas para las subfamilias, tribus y géneros de esfécidos neotropicales (Apoidea: Sphecidae). Revista de Biología Tropical, 44 (suplemento 2): $1-68$.

MichenER, C. D. 2007. The Bees of the World. Second Edition. John Hopkins University Press. 953 pp. 
NefF, J. L. \& Simpson, B. B. 1993. Bees, pollination systems and plant diversity. En: LASALLE, J. \& GAULD, I. D. (eds.), Hymenoptera and Biodiversity pp. 143-167. CAB International. The Natural History Museum, Wallingford, UK.

Nieves-Aldrey, J. L. \& Fontal-CaZalla, F. M. 1999. Filogenia y evolución del orden Hymenoptera. Boletín de la Sociedad Entomológica Aragonesa 26: 459-474.

OHL, M. \& BleIDORN, C. 2006. The phylogenetic position of the enigmatic wasp family Heterogynaidae based on molecular data, with description of a new, nocturnal species (Hymenoptera: Apoidea). Systematic Entomology, 31: 321-337.

O’NeILL, K. M. 2001. Solitary wasps: behavior and natural history. Cornell University Press, Ithaca. xiii $+406 \mathrm{pp}$.

O’ToOle, C. 1993. Diversity of native bees and agroecosystems. En: LASALlE, J. \& GAUlD, I. D. (eds.), Hymenoptera and Biodiversity. Pp. 169-196. CAB International. The Natural History Museum, Wallingford, UK.

PRENTICE, M. A. 1998. The comparative morphology and phylogeny of apoid wasps (Hymenoptera: Apoidea). Dissertation Thesis. University of California, Berkeley, 1439 pp.

Primack, R. B. \& Silander, J. A. 1975. Measuring the relative importance of different pollinators to plants. Nature, 225: 143-144.

Pyle, R., Bentzein M. \& Opler, P. 1981. Insect conservation. Annu. Rev. Entomology, 26: 233-258.

Rosas, G., Ramos, M. A. \& García-VAldecAsas, A. 1992. Invertebrados españoles protegidos por Convenios Internacionales. Colección Técnica del ICONA. Ministerio de Agricultura, Pesca y Alimentación, Madrid. 250 pp.

SAMways, M. J. 1990. Insect conservation ethics. Environ. Conserv. 17: 7-8.

SAMWAYS, M. J. 1993. Insects in biodiversity conservation: some perspectives and directives. Biodivers. Conserv. 2: 258-282.

SÁnchez-Ruiz, M., Fontal-Cazalla, F. M., SÁnchez-Ruiz, A. \& LóPEZ-Colón, J. I. 1997. El uso de insectos depredadores en el control biológico aplicado. Boletín de la Sociedad Entomológica Aragonesa 20: 141-149.

Sears A.L.W., Smiley J.T., Hilker M., Muller F. \& Rank, N.E. 2001. Nesting behavior and prey use in two geographically separated populations of the specialist wasp Symmorphus cristatus (Vespidae: Eumeninae). Amer. Midl. Natur. 145: 233-246.

ShlyAKHTENoK, A. S. 1995. Distribution of spider and digger wasps (Hymenoptera, Pompilidae, Sphecidae) in a mossy pine forest (Pinetum pleurosum) in the Berezinsky Biosphere Reserve. Fragmenta faunistica 38: 191-195.

Smiley, J. T., RANK, N. E. 1986. Predator protection versus rapid growth in a montane leaf beetle. Oecologia 76: 106-112.

SPEARS, E. E. J. 1983. A direct measure of pollinator effectiveness. Oecologia, 57: 196-199.

STEFFAN-DEwENTER, I. 2002. Landscape context affects trap-nesting bees, wasps, and their natural enemies. Ecol. Entomol. 27: 631-637

STEFFAN-DEWENTER, I. 2003. Importance of habitat area and landscape context for species richness of bees and wasps in fragmented orchard meadows. Conservation Biology. 17: 1036-1044.

TAKI, H., KeVAn, P. G. \& Ascher, J. S., 2007. Landscape effects of forest loss in a pollination system. Landscape Ecology 22: 1575-1587.

Taki H., Viana, B. F., Kevan, P. G., Silva, F. O. \& Buck, M. 2008. Does forest loss affect the communities of trap-nesting wasps (Hymenoptera: Aculeata) in forests? Landscape vs. local habitat conditions. J. Insect Conservation 12 (1): 15-21. 
Tscharntke T., Gathmann A. \& Steffan-Dewenter, I. 1998. Bioindication using trap-nesting bees and wasps and their natural enemies: community structure and interactions. J. Applied Ecology 35: 708-719.

UlRICH, W. 1999. The number of species of Hymenoptera in Europe and assessment of the total number of Hymenoptera in the world. Polskie Pismo Entomologiczne 68: 151-164.

UnRUh, T. R. \& Messing, R. H. 1993. Intraspecific biodiversity in Hymenoptera: Implications for conservation and biological control. En: LASAlle, J. \& GAUlD, I. D. (eds.). Hymenoptera and Biodiversity. Pp. 27-52. CAB International. The Natural History Museum, Wallingford, UK.

VepreK, D. \& StraKa, J., 2007. Apoidea Spheciformes (Kutilky). En: Bogusch, Straka \& KMEnT (eds.). Annotated checklist of the Aculeata (Hymenoptera) of the Czech Republik and Slovakia. Acta Entomologica Musei nationalis Pragae, Suppl. 11[Crabronidae: p. 118-232].

Zettel, H., Gross, H. \& MAZZucco K. 2001. Liste der Grabwespen-Arten (Hymenoptera: Spheciformes) Wiens, Österreich. Beiträge zur Entomofaunistik 2: 61-86. 


\section{MATERIAL Y MÉTODOS}

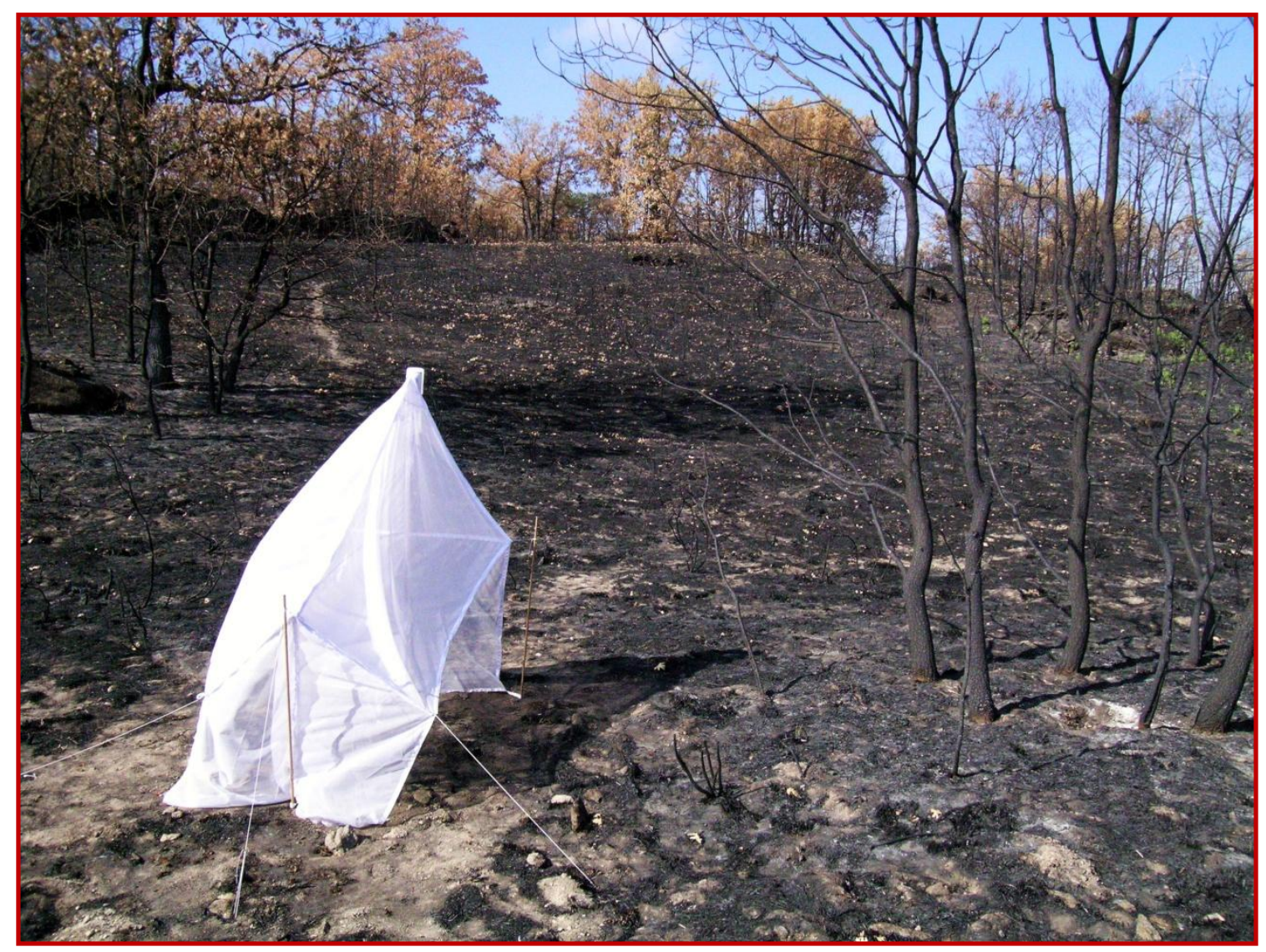




\section{1.- DESCRIPCIÓN DEL ÁREA DE ESTUDIO}

De entre los Hábitats de Interés Comunitario representados en Arribes del Duero, el área de estudio constituye una buena representación de los "Bosques galaicoportugueses con Quercus robur y Quercus pyrenaica" (código 9230), definidos como “robledales marcescentes mediterráneos o submediterráneos dominados por el melojo (Quercus pyrenaica), a veces en mezcla con el carballo (Q. robur L.)" (BARTOLOMÉ et al., 2005: 230-231; ESCUDERO ALCÁNTARA et al., 2008: 362-369).

Dentro de la tipología reconocida (ESCUDERO AlCÁNTARA et al, 2008: 369) para estos "Bosques mediterráneos caducifolios", el área de estudio se corresponde con los "Melojares subhúmedos en mosaico con escobonales blancos" del Genisto falcataeQuercetum pyrenaicae (Figura 16). Estas formaciones vegetales se caracterizan por el dominio del roble melojo (Quercus pyrenaica, que presenta una cobertura arbórea entre el 20\% y el 70\%), acompañado de escobonales blancos, vegetación de orla y mosaico de pastizales anuales y vivaces, en el ámbito meso- y supramediterráneo y sobre sustrato silíceo (o descarbonatado). El matorral suele adscribirse a la asociación Lavandulo sampaioanae-Cytisetum multiflori, participando fundamentalmente Cytisus multiflorus, Lavandula stoechas subsp. sampaioana, Daphne gnidium, Cistus salviifolius y $C$. psilosepalus. Las comunidades de orla de bosque caducifolio del Geranion sanguinei se encuentran bastante empobrecidas respecto a las que presentan los melojares húmedos o subhúmedos más densos; son comunes: Campanula rapunculus, Legousia scabra, Silene latifolia, Origanum vulgare subsp. virens y Satureja vulgaris.

Acerca del estrato herbáceo que ocupa los claros del escobonal hay que advertir que, aunque las comunidades presentes son comunes con los pastizales que aparecen en zonas de encinar (Tuberarietalia y Agrostio-Stipion gigantae, principalmente), su diversidad específica es mucho menor; entre las plantas más comunes encontramos: Tuberaria guttata, Aira caryophyllea, Cynosurus echinatus, Trifolium arvense, Arrhenatherum album y Agrostis castellana. Además, en las zonas más umbrosas, hallamos en ocasiones restos de praderas del Cynosurion cristatae, con Cynosurus cristatus, Plantago media o Trifolium pratense, entre otras.

Los melojares subhúmedos con cobertura arbórea del 20-70\% constituyen una etapa de degradación de los melojares subhúmedos con arbolado denso que se disponen 
en ambientes continentales, generalmente en laderas sobre afloramientos graníticos o en zonas llanas alejadas del "arribe". Debido a la xericidad de estos bosques, no se crea el ambiente umbrío propicio para el desarrollo de plantas nemorales típicas y se asientan los pastizales mediterráneos de Tuberarietalia y Agrostio-Stipion gigantae. El aclarado de estas comunidades por acción antrópica permite en un primer momento la colonización de los claros por parte de los escobonales blancos y el pastizal; si la alteración cesa, el bosque se regenerará debido a que Quercus pyrenaica rebrota muy bien de raíz, dando lugar a unas formaciones densas de individuos jóvenes conocidos como "bardales".

Los melojares subhúmedos en el P.N. Arribes del Duero están muy alterados por la acción antrópica. Frecuentemente se ven sometidos a fuegos intencionados con el fin de obtener pastos aprovechables por el ganado y sufren talas para la obtención de leña. Diferentes estudios sobre el efecto del fuego en las comunidades de $Q$. pyrenaica revelan una elevada capacidad de recuperación y resistencia (TÁRREGA \& LUISCalabuig, 1989; Calvo et al., 1991, 1999; Luis-Calabuig et al., 1993, 2001; TÁRREGA et al., 2006), si bien estas adaptaciones no tienen por qué haberse desarrollado como una respuesta selectiva frente al fuego de manera exclusiva, ya que las estrategias desarrolladas frente la tala, corta y pastoreo, también se manifiestan eficaces ante los incendios (TRABAUD, 1987). Debido a la alta capacidad de regeneración de los melojares, si cesa la presión sobre los mismos, podrían recuperarse en un tiempo razonable.

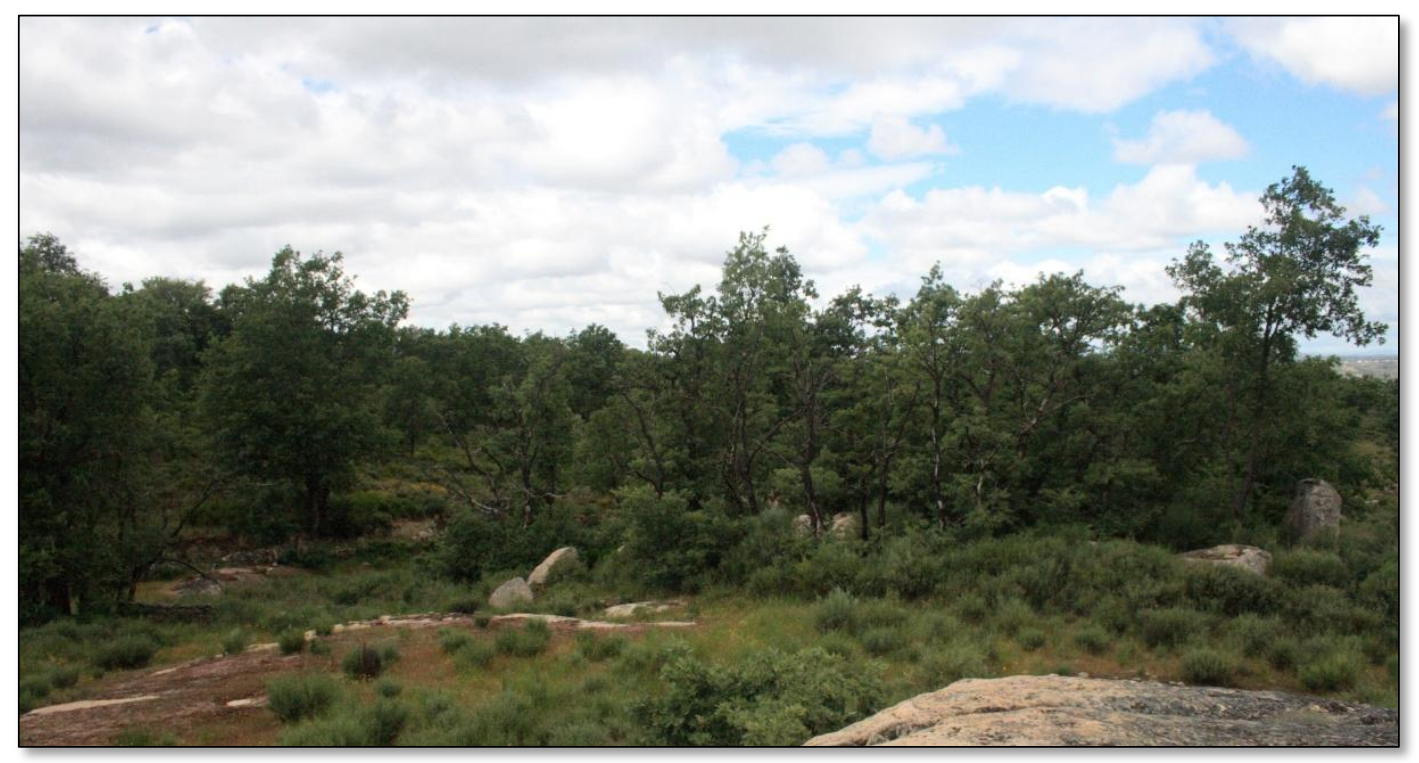

Figura 16: Imagen representativa de los robledales estudiados. 


\section{2.- RECOLECCIÓN DE EJEMPLARES}

Son múltiples los métodos de captura de insectos, pero casi todos ellos, ya sea para atraerlos, o para atraparlos, se basan en algún aspecto comportamental de los mismos, tanto del estado adulto como del larvario. Como consecuencia, existe una gran cantidad de métodos de captura, y bibliografía científica que los describe (Ej. HubBEL, 1956; Peterson, 1964; Masner, 1976; MASner \& Goulet, 1981; MuirheadThomson, 1991; Basset et al., 1997; Southwood \& HeNderson, 2000; MarcosGARCíA, 2004; SCHAUFF, 2005).

Habitualmente estos métodos de captura se clasifican en activos (empleados manualmente por la persona que los colecta, o que ejercen algún tipo de atracción, ya sea debida al color, olor, forma, etc.) y pasivos (basados en la interceptación aleatoria de los insectos). En el presente estudio se ha utilizado un método de cada tipo. Ordenados en función del esfuerzo de muestreo empleado son, de mayor a menor: La Trampa Malaise (modelo ligero de Townes) (Townes, 1972), como método pasivo de interceptación aérea y los platos de color amarillo (yellow pan traps) (MASNER, 1976; MoERICKE 1951, 1955) como método activo que ejerce su atracción debida al color de los mismos.

\subsection{1.- LA TRAMPA MALAISE}

\subsubsection{1.- Antecedentes}

Entre las trampas de interceptación aérea, y que no utilizan atrayentes, la trampa Malaise se ha mostrado particularmente eficaz para la captura de insectos voladores. Concebida y diseñada por el entomólogo sueco René MALAISE en 1937 ha sido modificada por diferentes autores (BUTLER, 1965; CHANTER, 1965; BLUME et al., 1972; DUfour, 1980; BASSET, 1988; ROBERT, 1992, 1996; CAMPOS et al., 2000) con el fin de hacerla más eficaz, más manejable, o mejor adaptada a la captura de un grupo en particular, o un biotopo determinado, e incluso para abaratar su coste (HUTCHESON, 1991; PLATT et al., 1999). Las variaciones tienen lugar tanto en el color y forma de la trampa como en el modelo del recipiente colector.

Sin embargo, el auténtico divulgador de esta trampa fue Henry Townes, que reformó y perfeccionó el diseño original de Malaise (TowNES, 1962) (advirtió incluso 
que variaciones en el color de las diferentes partes de la misma podían mejorar su rendimiento) modificándolo a su vez en un nuevo modelo más ligero (TOWNES, 1972) (tampoco exento de posteriores modificaciones llevadas a cabo por diversos autores). Es a partir de este trabajo cuando el empleo de este modelo de trampa se fue generalizando entre los entomólogos como un instrumento muy valioso en los estudios faunísticos y ecológicos de insectos voladores (MATTHEWS \& MATTHEWS, 1970; GonZÁLEZ et al., 2000a, 2000b; VAS et al., 2001; CRUZ-SÁNCHEZ et al., 2004; MAKINO et al., 2006; FRASER et al., 2008; ROHRIG et al., 2008).

La utilidad y potencial recolector de este tipo de trampa ha sido revisado por diversos autores, entre los que podemos destacar DISNEY et al., (1982); MATTHEWS \& Matthews, (1983); OWEn, (1983, 1991); DARLing \& PACKer, (1988); Brown \& FeEner, (1995); ShlyakhtenoK, (2000), CAMPBell \& Hanula, (2007) y MAzón \& BORDERA, (2008).

Destaca la extraordinaria eficiencia recolectora de la trampa: instalada a lo largo de un año, captura cifras que oscilan entre 30.000 y 120.000 ejemplares.

Varias son las características que podemos destacar y que hacen ventajosa su utilización frente a otros tipos de trampas:

- Fácil montaje y mantenimiento.

- Operatividad ininterrumpida: Actúa, tanto de día como de noche y durante largos períodos de tiempo si fuera necesario.

- Actúa bajo diferentes condiciones meteorológicas (MATTHEWS \& MATTHEWS, 1970, 1971), si bien no es recomendable su utilización en lugares sometidos a fuertes rachas de viento.

- Descarta la variación debida a la atracción, no utiliza cebo o atrayente alguno, lo que evita la variación debida a la atracción química.

- Las muestras, generalmente, son recogidas en alcohol: Proporciona así un material íntegro, limpio y perfectamente conservado. Esto permite un tratamiento numérico que lo hace idóneo para el estudio cuantitativo de poblaciones y comunidades de insectos voladores. 
Entre sus desventajas, sobresale su selectividad de especie, sexo o casta (Southwood, 1978; Masner \& Goulet, 1981; Owen, 1991; Kulhmann, 1994), causada por respuesta fototrópica. Asimismo, la ubicación, luz de malla y color de la trampa parecen influir en la eficacia de captura de distintos grupos (DARLING \& PACKER, 1988; NieVES-AldREY, 1995; GAYUBO et al., 2000; GONZÁLEZ et al., 2000a, 2000b, 2000c, 2003; DE LA NuEZ et al., 2003; CRUZ-SÁNCHEZ et al., 2004; CAMPBELL \& HANUla, 2007). A pesar de ello, es considerada un excelente método de muestreo del tamaño de las poblaciones, particularmente interesante de cara a estudios de tipo faunístico, de distribución espacial y temporal, y ecológicos en general.

Para optimizar su rendimiento, la trampa se coloca en zonas de paso de insectos voladores (HARRIS, 1982; MATTHEWS \& MATTHEWS, 1983), no siendo recomendable su uso en lugares sometidos a fuertes vientos.

Siempre que el emplazamiento sea adecuado y la operatividad se prolongue durante un tiempo suficiente, las cifras pueden ser consideradas como una buena aproximación a la composición de la biocenosis local de insectos voladores (Ej. Canaday, 1987; DeCleer, 1990; Kuhlmann, 1994; Precht \& Cölln, 1996).

Para el estudio a gran escala de la diversidad de artrópodos terrestres, y en concreto de poblaciones y comunidades de insectos voladores, constituye un método idóneo y recomendado (Ej. LONGINO \& COLWELL, 1997; CANOVAI et al., 2000; CAMPOS \& FERNÁNDEZ, 2002; NOGUERA et al., 2002; MAKINO, et al., 2006).

Este modelo se ha mostrado eficaz en la captura de avispas Spheciformes en los estudios llevados a cabo en la Submeseta Norte (GoNZÁLEZ et al., 1998a, 1998b, 2003; GAYUBO et al., 2000; CRUZ-SÁNCHEZ et al., 2004), al igual que para otras zonas de la Península Ibérica (GONZÁLEZ et al., 2000a, b; GAYUBO et al., 2004a, 2004b y de Europa (ARCher, 1988, 1990, PAUly, 1989; SORG \& CÖlln, 1992; PAPP \& JóZAN, 1995; SHLYAKHTENOK, 1995; KUHLMANN, 2002).

\subsubsection{2.- Diseño}

La trampa Malaise aprovecha dos tropismos que afectan a un amplio porcentaje de las especies de insectos: geotropismo negativo y fototropismo positivo. Dichos tropismos provocan que los insectos que, caminando o volando, chocan o se encuentran con una barrera se dirijan hacia arriba, hacia la luz solar. El diseño de una de estas 
trampas consiste básicamente en una estructura rectangular $(203 \mathrm{~cm}$ de mayor altura y $112 \mathrm{~cm}$ la menor, y $122 \mathrm{~cm}$ de ancho por $183 \mathrm{~cm}$ de largo) (Figura 17) con una malla central dispuesta verticalmente sobre el suelo, interceptando el paso y dirigiendo a los individuos hacia el polo colector. Las paredes laterales son de malla negra o blanca.
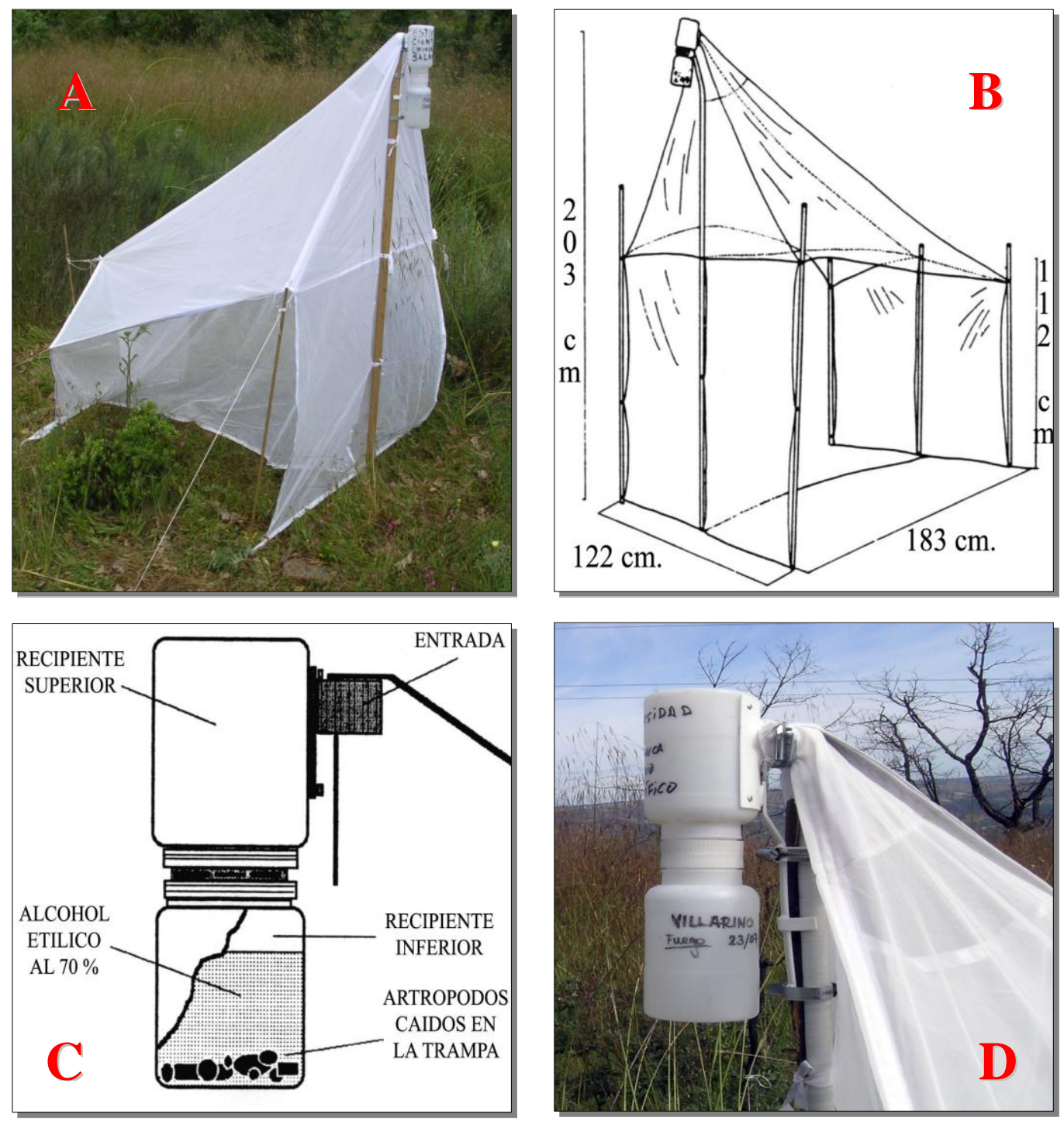

Figura 17: A y B: Esquema y aspecto general de una trampa Malaise blanca, modelo ligero de Townes. C y D: Detalle del bote recolector.

En el extremo situado a mayor altura se coloca el recipiente recolector que consta de dos botes de PVC, de aproximadamente $13 \mathrm{~cm}$ de altura por $8 \mathrm{~cm}$ de anchura, ensamblados entre sí por medio de una rosca (Figura $17 \mathrm{C} \mathrm{y} \mathrm{D).} \mathrm{El} \mathrm{bote} \mathrm{inferior} \mathrm{se}$ llena de alcohol etílico al $70 \%$, que matará y actuará como conservante de los artrópodos que caen en el mismo. 
El incremento actual en el empleo de la trampa Malaise ha elevado el número de diferentes objetivos; así, además de utilizarse en trabajos de tipo faunístico, se utiliza para otras aplicaciones, entre las que se encuentra el estudio del efecto provocado por el fuego sobre un hábitat y las poblaciones de insectos que en él habitan, así como la posterior recuperación de la mismas, (Ej. CANCELADO \& YONKE, 1970; HANSEN, 1986, 1988; LocKWOOD et al., 1996; MAKIHARA et al., 2000; CAMPBell et al., 2007; HIROWATARI \& MAKIHARA, 2007).

Las trampas Malaise empleadas en este estudio se corresponden al modelo ligero de Townes, (1972), de color blanco y luz de malla muy fina $(0,1 \mathrm{~mm})$, de origen comercial (MARRIS HOUSE NETS, 54 Richmond Park Avenue, Bournemouth, BH8 9DR, UK).

\subsection{2.- PLATOS DE COLOR AMARILLO (Yellow pan traps)}

\subsubsection{1.- Antecedentes}

Este método, ampliamente utilizado en la captura de insectos, está basado en los diferentes mecanismos (fisiológicos, neuronales y moleculares) que estos poseen para percibir los colores, y en la diferente atracción que sienten por determinadas coloraciones (KIRK, 1984; BRISCOE \& CHITTKA, 2001; NATION, 2008).

TOLER et al. (2005) concluyeron que el color predominante de las flores, en la comunidad de plantas, no influía en la atracción relativa ejercida por un color particular de platos. Sin embargo, no analizaron el efecto ejercido por la abundancia floral en sí misma, y quizá es por ello por lo que las coloraciones de los platos se eligen generalmente por parecerse a las de las flores existentes en la zona a muestrear, y de las que se alimentan los insectos objeto de estudio (CAMPBELl \& HANULA, 2007; CAMPBELl et al., 2007; WESTPHAL et al., 2008), obteniéndose resultados satisfactorios.

Los colores más empleados, por ser los que más eficaces se han mostrado, son el amarillo, blanco y azul, pudiéndose utilizar platos de estos tres colores en un mismo estudio. Algunos autores, aunque no es frecuente, emplean las tres coloraciones en un mismo recipiente, de manera que este posee franjas azules, blancas y amarillas (LARSSON, 2008) con el fin de acceder a un espectro más amplio de especies. Esta atracción por determinados colores es, en muchas ocasiones, diferente para distintos 
grupos, especies, e incluso sexos dentro de una misma especie (DE BARRO, 1991; Aguiar \& Sharkov, 1997; CAmpbell \& Hanula, 2007; LeOng \& ThorP, 1999; PUCCI, 2008). De todos ellos, el amarillo parece ser el mejor color -siendo más eficaces los amarillos más intensos y brillantes a la luz ultravioleta (STEPHEN \& RAO, 2005, DROEGE, 2006), principalmente entre los insectos voladores. Con el fin de demostrar la atracción ejercida por dicho color, algunos autores los han empleado junto con otros de color verde (más parecido al color de la vegetación, y por lo tanto menos llamativo), o combinaciones de este con el amarillo (LAUBERTIE, et al., 2006).

Este método, utilizado en el muestreo de diferentes grupos, como coleópteros (LEKSONO et al., 2006), áfidos (MOERICKE, 1951, 1955; HALBERT et al., 1986; LAZZARI \& LazarotTo, 2005) o dípteros (Delettre et al, 1998; Moreno \& Carles-Tolrá, 2004; LAUBERTIE, et al., 2006), se muestra especialmente eficaz en el muestreo de himenópteros, principalmente polinizadores y Parasitica, existiendo múltiples estudios que lo refrendan (KIRK 1984; LEONG \& THORP 1999, NoYES, 1989; DELFín \& BuRGOS, 2000; GibB \& Hochuli, 2002; Toler et al., 2005, CAmpbell \& Hanula, 2007; LeIRANA-AlCOCER \& GONZÁlEZ-MORENO, 2007; RoulSTON et al., 2007; TAKI et al., 2007; SouZa \& CAMPOS, 2008; WeStPhal et al., 2008). ORTIZ-SÁNCHEZ \& AGUIRRESEGURA (1993), tras utilizar cinco colores diferentes para capturar Apoidea (Hymenoptera), verificaron que el color amarillo era el que el mayor número de capturaba.

\subsubsection{2.- Descripción}

Como su propio nombre indica, este método consiste en un plato, bandeja o recipiente de color amarillo, relleno casi en su totalidad de agua a la que se le añaden unas gotas de jabón líquido que rompe la tensión superficial de la misma, e impide la huida de los insectos que entran en contacto con ella. De este modo, los insectos quedan atrapados y perecen ahogados en el interior del plato. De manera adicional, se añade sal que actuará como conservante de la muestra. El uso de la sal, vendrá condicionado por el tiempo que vaya a permanecer sin recogerse la muestra -siendo recomendable hacerlo en un plazo máximo de 48 horas desde el momento en que se coloquen los platos- y por las temperaturas máximas alcanzadas en el área estudiada, ya que temperaturas muy elevadas incrementan el riesgo de putrefacción de los individuos capturados. 
Su principal ventaja es su bajo coste económico y fácil y rápida colocación. $\mathrm{Su}$ pequeño tamaño y portabilidad hacen que puedan ser utilizados en casi cualquier hábitat terrestre, incluyendo humedales, o superficies acuáticas como estanques, ríos o lagos (floating pan traps) (WIPFLI, 1997; ALLAN et al., 2003; GREENWOOD et al., 2004), o suspendidos de las copas de los árboles (MAZÓN \& BORDERA, 2008; PUCCI, 2008; StiREMAN, 2008), si bien su aplicación más común es sobre la superficie del suelo. Cuando su colocación tiene lugar en el suelo, se recomienda enterrar el plato hasta el borde superior del mismo para obtener un rendimiento óptimo.

Los platos también son una herramienta muy valiosa a la hora de aumentar las capturas obtenidas por otros métodos de muestreo (CANE et al., 2000; ROULSTON et al., 2007; MAZÓN \& BORDERA, 2008), especialmente cuando existen muy pocas plantas hospedadoras (ROULSTON et al., 2007).

Al igual que cualquier otro tipo de trampa, para la realización de estudios sobre riqueza y diversidad de especies, es conveniente colocarlos en la mayor cantidad de microhábitats posible, con el fin de obtener el mayor número de especies representativas del área estudiada (STIREMAN, 2008). La posibilidad de utilizar distintas coloraciones posibilitará a su vez un mejor resultado en función del grupo a analizar.

Los platos pueden ser empleados en conjunción con la trampa Malaise para proporcionar más información, sobre una comunidad de insectos determinada, en estudios ecológicos y faunísticos (NOYES, 1989; GARCíA, 2003; CAMPBELl \& HANUlA, 2007; LEIRANA-AlCOCER \& GONZÁlEZ-MORENO, 2007; MAZÓN \& BORDERA, 2008; QUINTERO et al., 2008), ya que existen grupos o especies que son capturadas por estos pero que no lo son por la trampa, y viceversa.

Algunos autores los han empleado igualmente para analizar los efectos de la perturbación provocada por el fuego y otras prácticas de manejo de los ecosistemas, sobre determinadas poblaciones de insectos, como CAMPBELL et al. (2007), quienes los emplearon en combinación con la trampa Malaise, a su vez con diferentes colores para incrementar su poder recolector.

Entre sus desventajas se cuentan: 
- Fácilmente alterables, bien sea por el impacto de las condiciones meteorológicas extremas (viento, lluvia, granizo...), humano, o por la fauna salvaje o doméstica.

- Necesidad de llevar importantes cantidades de agua cuando su colocación está distante.

- Poder de atracción dependiente de las condiciones del hábitat. Ej. En zonas con vegetación elevada que impida su visibilidad por parte de los insectos.

- Necesidad de recoger las muestras en un periodo máximo $48 \mathrm{~h}$.

\section{3.- TRABAJO DE CAMPO}

En este apartado se reflejará de manera independiente el trabajo de campo correspondiente al subapartado 6.1 por un lado, y a los Subapartados 6.2, 6.3 y 6.4 por otro, correspondientes a Resultados y Discusión. Esta separación está motivada por la distinta metodología empleada en cada uno de ellos. En ambos casos, tras la explicación de la misma, se expondrá una breve descripción de las áreas analizadas (quemadas o no) que incluirá la siguiente información:

- Localidad/ municipio al que pertenece el incendio analizado

- Fecha del incendio

- Extensión del área quemada

- Fecha de colocación de las trampas (año/s)

- Periodo de muestreo: meses de actuación

- Número y tipo de trampas utilizadas

- Coordenadas X e Y de colocación de las trampas Malaise y altura (en metros s.n.m).

- Distancia de cada trampa Malaise al borde sin quemar más cercano

- Edad o número de años post-fuego representada por la localidad muestreada, a lo largo del periodo de muestreo. 
Esta información se complementará con imágenes de las trampas empleadas en el muestreo, así como de la propia zona analizada, en diferente fase de recuperación en el caso de las afectadas por el fuego.

Debe tenerse en cuenta que siempre se muestreó el interior de las áreas quemadas y en áreas denominadas Control (no quemadas), con el fin de establecer comparaciones entre ellas.

Los datos relativos a la fecha en que se produjeron los incendios, y su extensión, han sido proporcionados por la Consejería de Medio Ambiente de Salamanca. 


\section{METODOLOGÍA CORRESPONDIENTE AL SUBAPARTADO 6.1}

\subsection{1.- PLANTEAMIENTO}

Se empleó como único método de captura la trampa Malaise. El muestreo se basó en la colocación de una trampa en el interior de cada zona quemada analizada, y otra en dos zonas sin quemar que actuaron como controles.

Con la intención de comprobar qué especies resistían al paso de las llamas, o eran pioneras a la hora de acceder a un área recién quemada, y compararlas con los registros de meses posteriores, se colocó una trampa en una zona recién quemada (un día antes).

Las capturas obtenidas en las áreas incendiadas se compararon con las obtenidas por las otras dos trampas, situadas en dos zonas distintas entre sí en cuanto al grado de desarrollo de la vegetación, pero similares a la zona de estudio y que no habían sido quemadas desde hacía más de diez años.

Las muestras pertenecientes a cada trampa se recogieron quincenalmente, procediéndose entonces a una revisión exhaustiva de su estado de conservación para asegurar su eficiencia recolectora. Posteriormente, todas las muestras eran trasladadas al laboratorio, donde permanecerían hasta el momento de su preparación.

Las características de cada uno de los incendios y las localidades muestreadas se resumen en la Tabla II.

Tabla II: Resumen de las principales características de las localidades de estudio.

\begin{tabular}{|c|c|c|c|c|c|c|}
\hline & \multirow{2}{*}{ Localidad } & \multicolumn{3}{|c|}{ INCENDIO } & \multirow{2}{*}{$\begin{array}{c}\text { Años de } \\
\text { muestreo } \\
\text { (Jun-Sept.) }\end{array}$} & \multirow{2}{*}{$\begin{array}{l}\text { Años } \\
\text { post- } \\
\text { fuego } \\
\end{array}$} \\
\hline & & Año & Fecha & Extensión & & \\
\hline \multirow{2}{*}{ FUEGO } & 1 "Cenizas" & 2005 & Julio & 175 ha & 2005, 2006, 2007 & $<1,1,2$ \\
\hline & 2 "Fuente Lurde" & 2003 & Sept. & 38,36 ha & 2006, 2007 & 1,2 \\
\hline \multirow{2}{*}{ CONTROL } & $\begin{array}{l}3 \text { (Control 1 } \\
\text { "El Franco") }\end{array}$ & $\cdots$ & $\ldots$ & $\cdots$ & 2005, 2006, 2007 & \multirow{2}{*}{$>10$} \\
\hline & $\begin{array}{l}4 \text { (Control } 2 \text { "La } \\
\text { Mata de Arriba") }\end{array}$ & $\cdots$ & $\cdots$ & $\cdots$ & 2005, 2006, 2007 & \\
\hline
\end{tabular}




\section{INCENDIOS ANALIZADOS}

\section{- LOCALIDAD No 1: "Cenizas" -}

(Figuras 19, 21, 22, 23)

Localidad/municipio: Villarino de los Aires.

a Fecha del incendio: 24-07-2005.

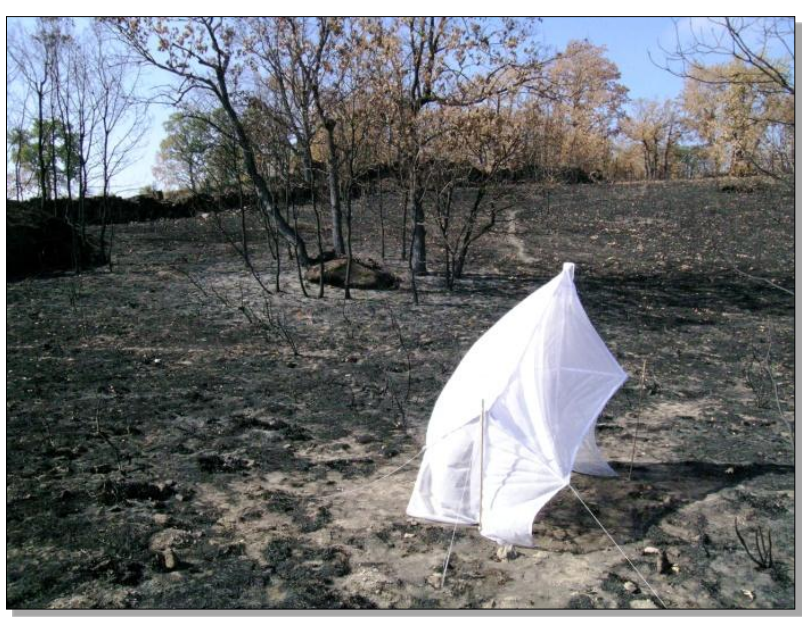

Figura 19: Trampa Malaise colocada el día posterior al incendio de 24-07-2005.
- Extensión: 175 ha.

- Fecha y periodos de muestreo: Año 2005 (25/07/2005 - 15/10/2005); años 2006 y 2007 (01/junio-30/sept.).

- $\mathbf{N}^{0}$ de trampas/año de muestreo: 1

- Coordenadas: $\mathrm{X}=210.087,49 ; \mathrm{Y}$ $=4.573 .600,59$.

- Altura:

- Distancia al borde más próximo: $130 \mathrm{~m}$.

- Edad post-fuego representada: $<1,1$ y 2 años.

\section{- LOCALIDAD No 2: "La Fuente Lurde" -}

(Figuras 20, 24, 25, 26)

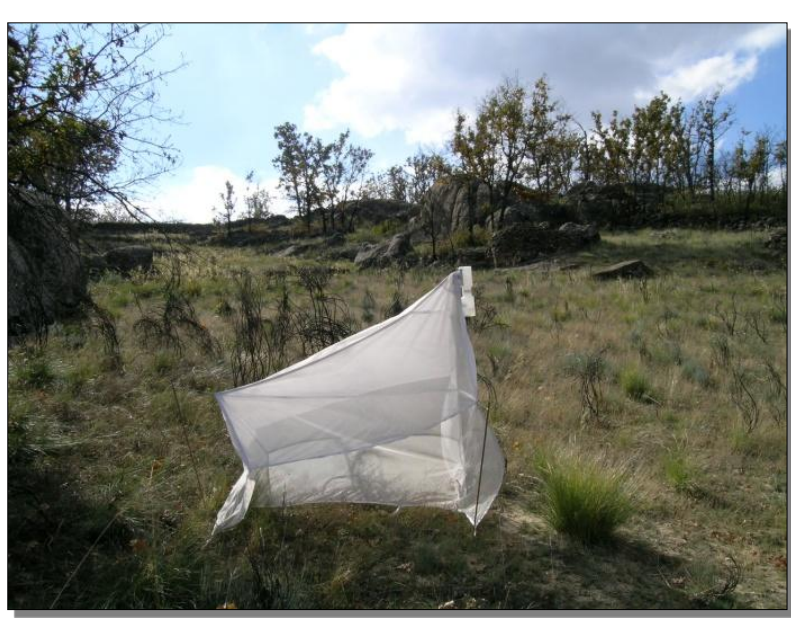

Figura 20: Trampa Malaise colocada en el área quemada en Sept./2003, un año después del fuego.
Localidad/municipio: Villarino de los Aires

- Fecha del incendio: Sept./2003

- Extensión: 38,36 ha.

- Fecha y periodos de muestreo: Años 2004 y 2005 (16/Mayo-31/Oct.).

- $\mathrm{N}^{\circ}$ de trampas/año de muestreo: 1

Coordenadas: $\mathrm{X}=711.521,0 ; \mathrm{Y}=$ 4.570.621,5. Altura: $690 \mathrm{~m}$.

Distancia al borde más próximo: $240 \mathrm{~m}$.

- Edad post-fuego representada: 1 y 2 años. 


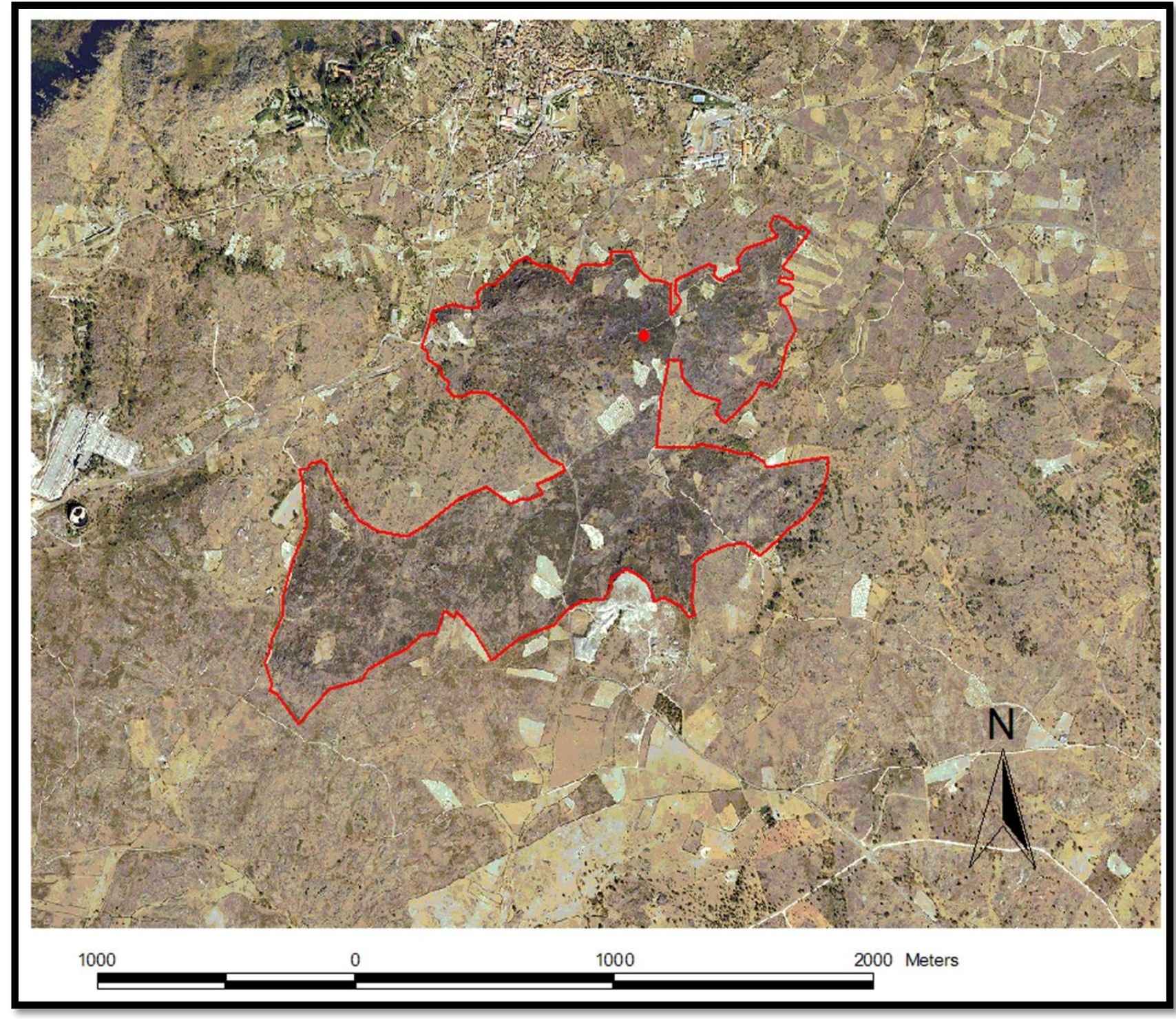

Distancia de la

trampa Malaise al

borde más cercano

sin quemar: $116 \mathrm{~m}$.

Figura 21: Ortofotografia de la Localidad $N^{\circ} 1$ “Cenizas”. Punto rojo: Ubicación de la trampa Malaise. Línea continua: Perímetro del área incendidada 

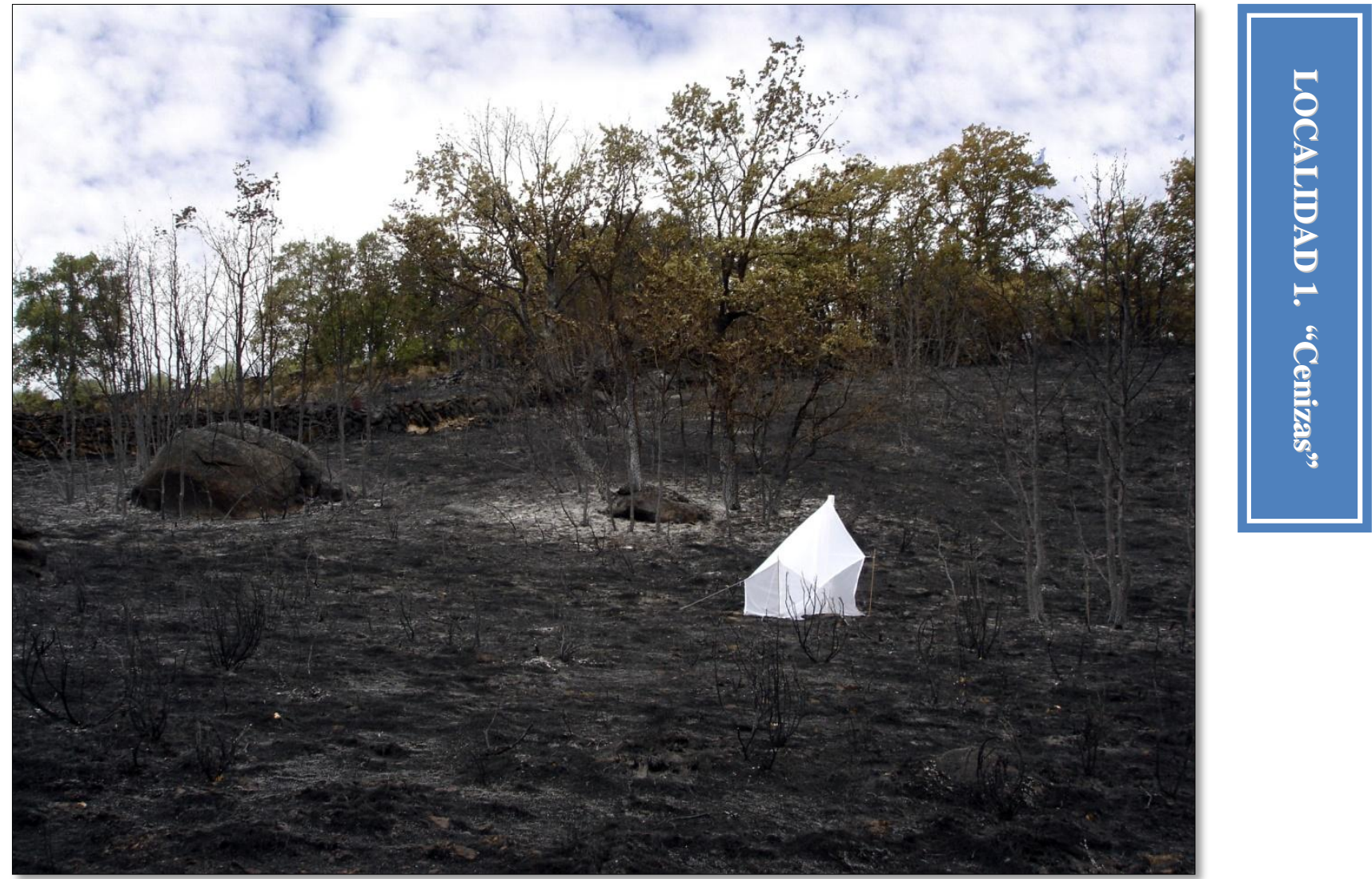

Figura 22: Aspecto del área incendiada el 24-07-2005, un día después del incendio.

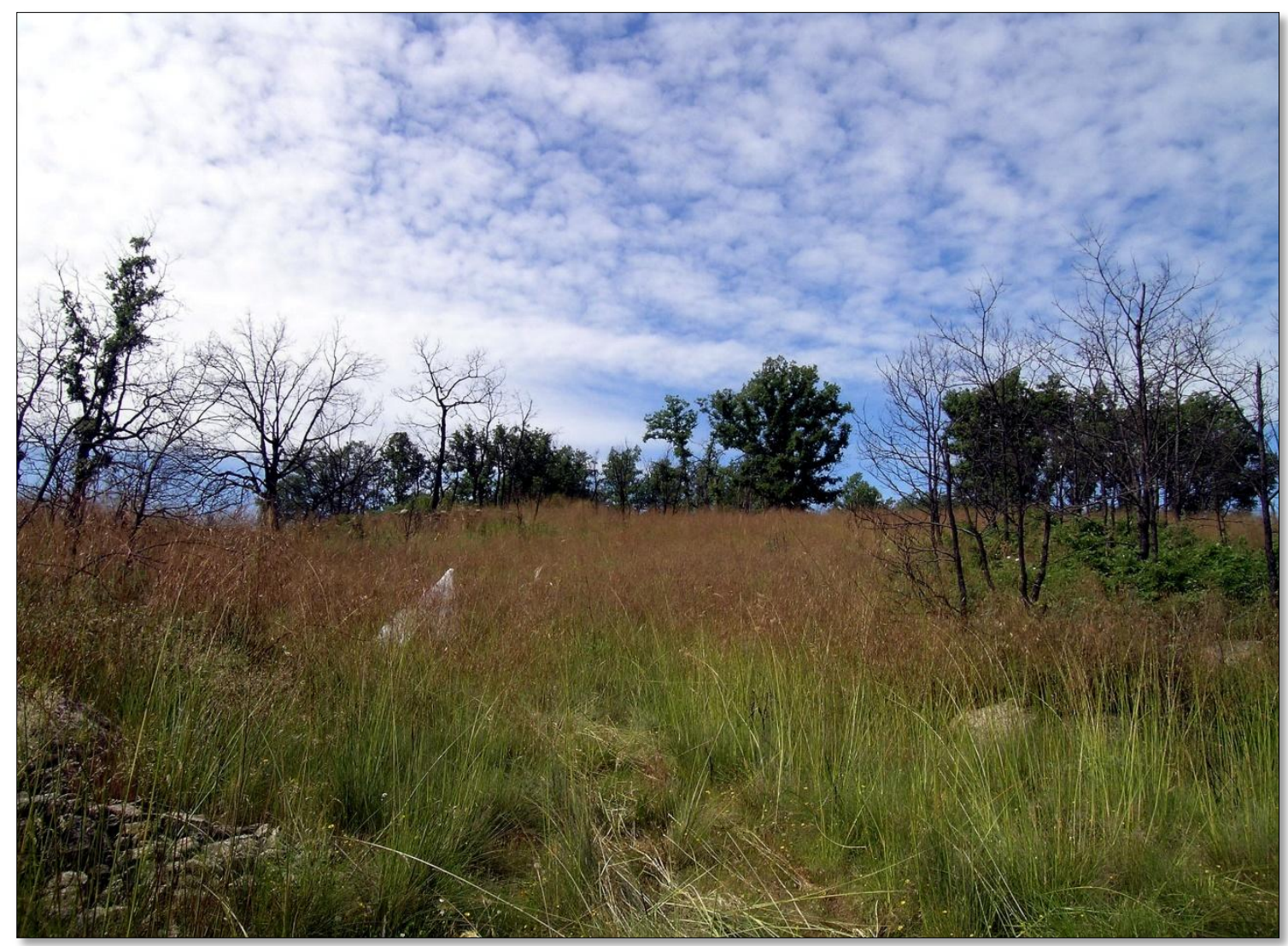

Figura 23: Aspecto de la zona incendiada el 24-07-2005, dos años después del incendio. 


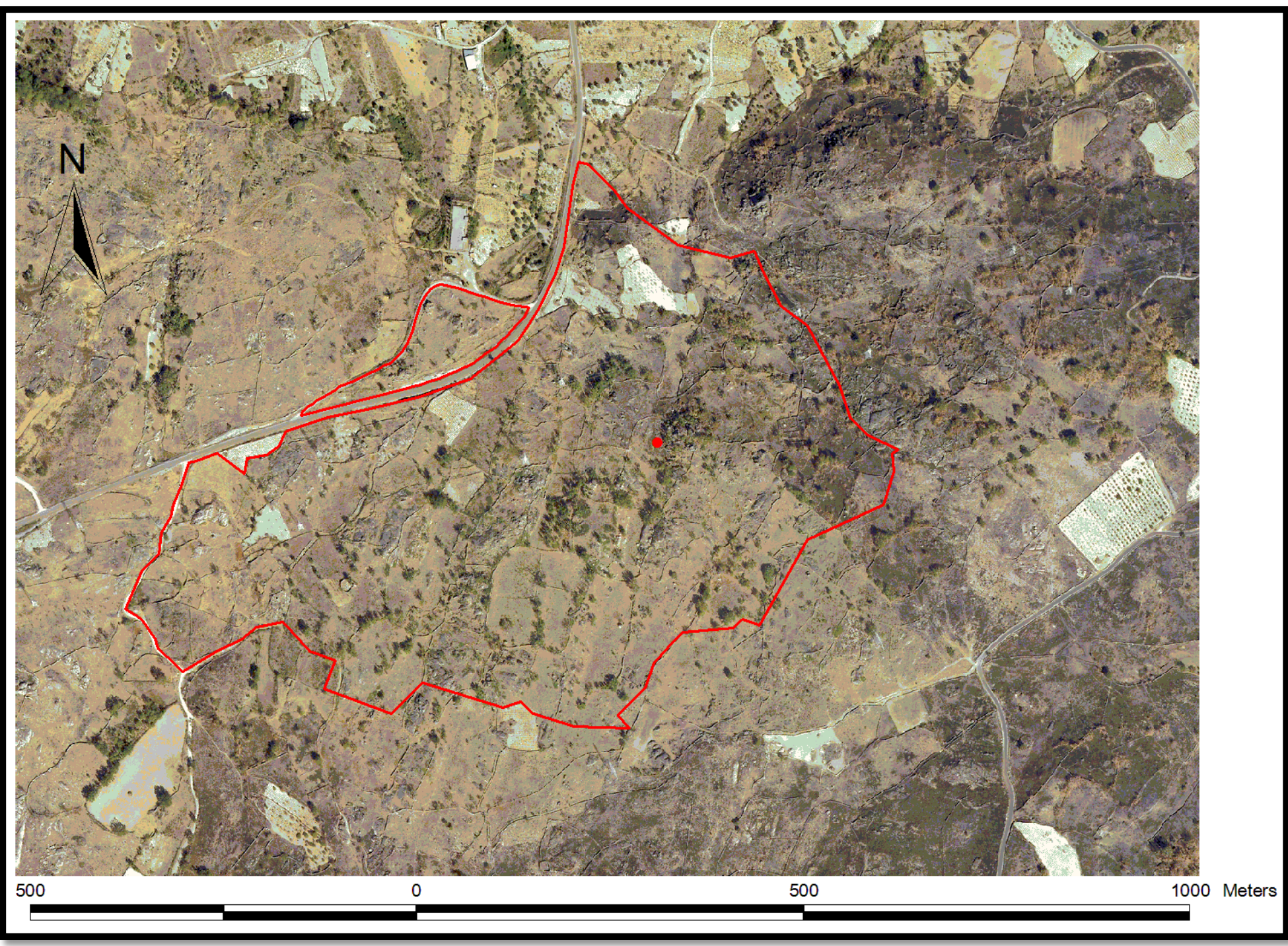

Distancia de la

trampa Malaise al

borde más cercano

sin quemar: $228,5 \mathrm{~m}$.

Figura 24: Ortofotografia de la Localidad N² "La Fuente Lurde". Punto rojo: Ubicación de la trampa Malaise. Línea continua: Perímetro del área incendidada 

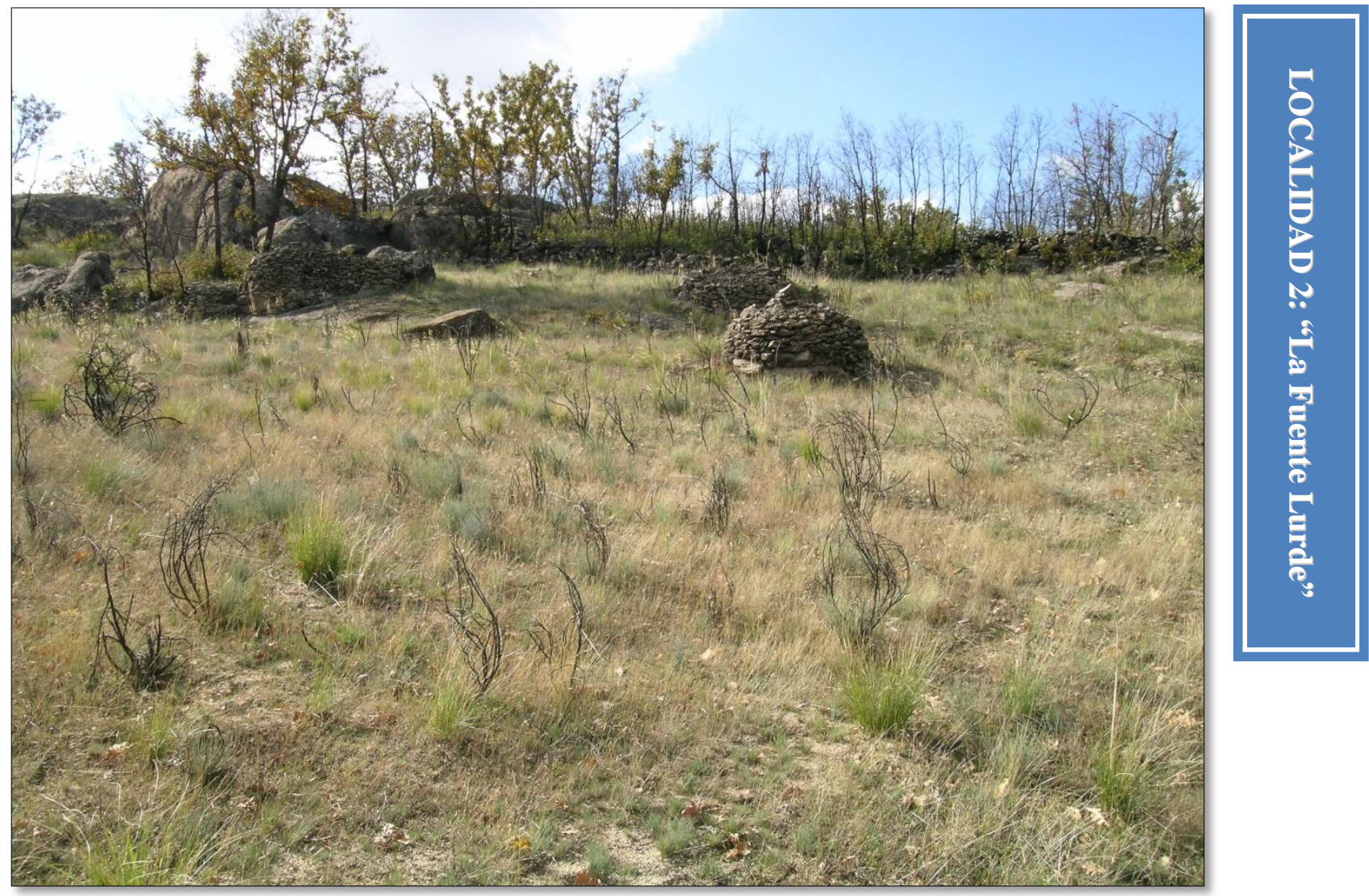

Figura 25: Aspecto del área incendiada en 2003, un año después del incendio

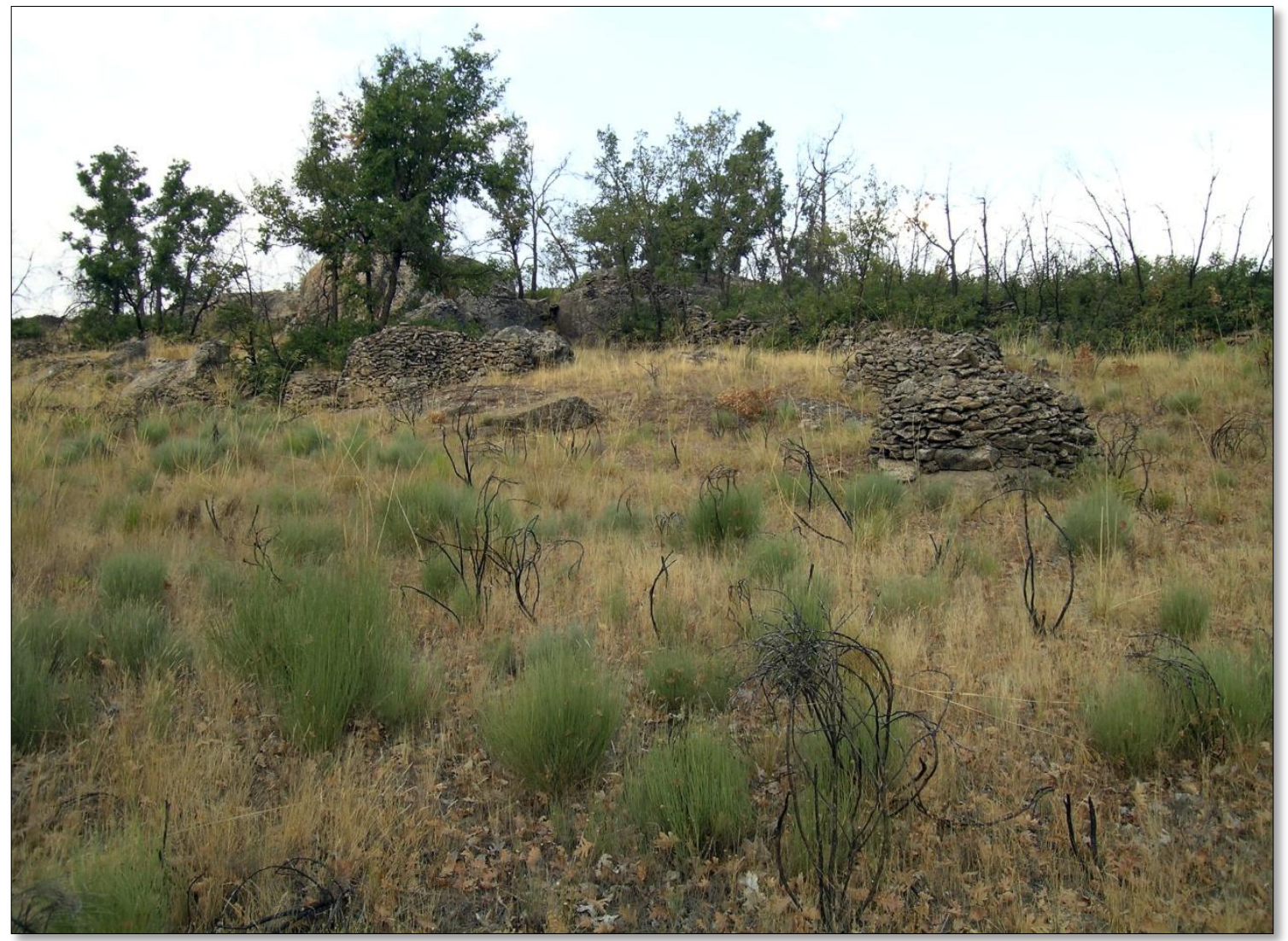

Figura 26: Aspecto del área incendiada en 2003, dos años después del incendio. 


\section{ZONAS CONTROL}

\section{- LOCALIDAD N 3: CONTROL 1 "El Franco"-}

(Figura 27)

Representativo de un estado sucesional intermedio y no plenamente maduro del área de estudio, sin quemar.

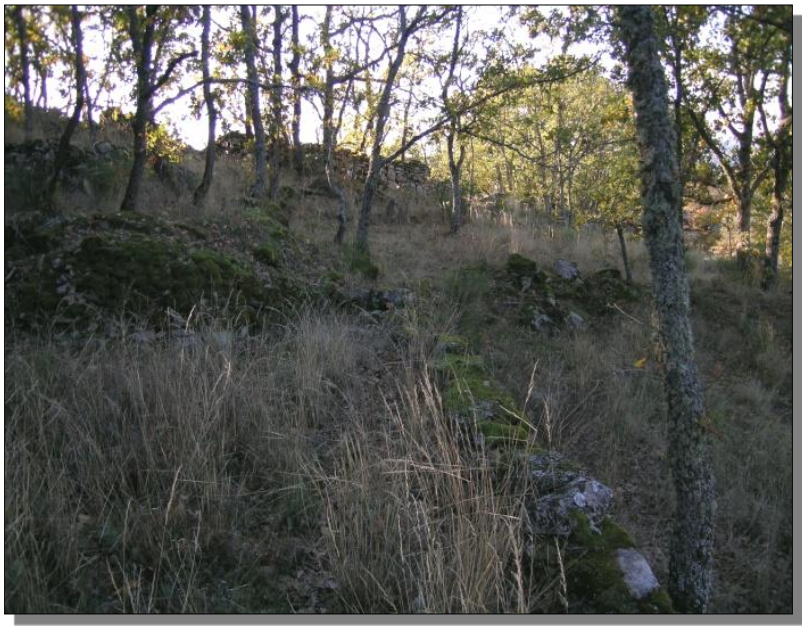

- Localidad: Villarino de los Aires

- Fecha y periodos de muestreo: Año 2004 (01/Mayo-31/Oct.).

- $\mathbf{N}^{0}$ de tramp/ año de muestreo: 1

- Coordenadas: $X=711,011.8$ $\mathrm{Y}=4.570 .621,5$.

- Altura: 630 m.

- Edad post-fuego representada: $>10$ años.

Figura 27: Aspecto del Control 1 (Año 2004).

\section{- LOCALIDAD No 4: CONTROL 2 "La Mata de Arriba"}

(Figura 28)

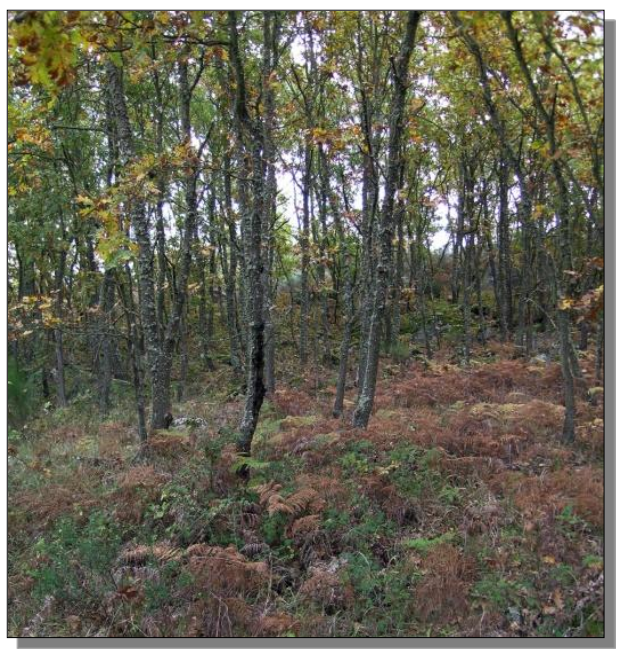

- Localidad: Pereña de la Ribera

- Fecha y periodo de muestreo: Año 2005 (01/Mayo-31/Oct.).

- $\mathbf{N}^{0}$ de trampas Malaise/año de muestreo: 1

n Coordenadas: $X=704.638,1 ; Y=4.565 .231,9$

- Altura: $640 \mathrm{~m}$.

- Edad post-fuego representada: > 10 años.

Figura 28: Aspecto del Control 2 (año 2005). 


\section{METODOLOGÍA CORRESPONDIENTE A LOS SUBAPARTADOS $6.2,6.3$ Y 6.4}

\subsection{2.- PLANTEAMIENTO: SUSTITUCIÓN DE ESPACIO POR TIEMPO}

Para la realización de esta "fase" del estudio, se siguió la teoría de "sustitución de espacio por tiempo" o "cronosecuencia" propuesta por PICKET (1989) como una alternativa a los estudios ecológicos a largo plazo. Esta teoría, asume que para el estudio de la sucesión de una determinada comunidad, la suma de localidades separadas en el espacio, pero semejantes en sus características y rasgos físicos, y que han sufrido un mismo impacto a edades diferentes, reflejarán la secuencia de cambios ocurridos a lo largo del tiempo en una única localidad sometida a ese mismo impacto.

El gran coste y lentitud que supondría llevar a cabo estudios a largo plazo son los que han popularizado el uso de esta técnica. Frecuente en estudios sobre la sucesión de comunidades vegetales (Ej. AIDE et al., 2000; CHINEA, 2002), también es empleada en el análisis de la recuperación de insectos tras sufrir un incendio (Ej. MoretTI, 2000; BIERINGER, 2002; MORETTI et al., 2002; 2006; POTTS et al., 2003; MoRetTI \& BARBALAT, 2004). Entre sus posibles desventajas destaca el hecho de que las localidades son susceptibles de variar en sus condiciones bióticas, abióticas y meteorológicas. Por este motivo, se hace necesaria la utilización de áreas lo más semejantes posible, tanto en condiciones bióticas y abióticas, como en su historia de uso del paisaje.

\subsection{3.- METODOLOGÍA}

Se muestrearon tres incendios de características semejantes ocurridos en los años 2004, 2002 y 1998, es decir, uno, tres y siete años antes del comienzo del estudio, en 2005. Las zonas muestreadas, próximas entre sí, pertenecen a áreas de composición vegetal y características físicas y geológicas semejantes. Su muestreo sucesivo permite establecer una sucesión cronológica que comprende el periodo de 
recuperación que va de uno a cinco años, siete y nueve años tras el incendio (Tabla III).

Las características de cada una de los incendios y las localidades muestreadas se resumen en la Tabla III.

Tabla III: Resumen de las principales características de las localidades de estudio. TM = Trampa Malaise; PL= Platos amarillos; $\mathrm{F}=$ Fuego; $\mathrm{C}=\mathrm{Control}$. * Nótese que en las localidades $2 \mathrm{~F}$ y $3 \mathrm{~F}$ sólo se muestrearon 2 años.

\begin{tabular}{|c|c|c|c|c|c|c|}
\hline & \multirow{2}{*}{ Localidad } & \multicolumn{3}{|c|}{ INCENDIO } & \multirow{2}{*}{$\begin{array}{l}\text { Años de muestreo } \\
\text { (Jun-Sept.) }\end{array}$} & \multirow{2}{*}{$\begin{array}{c}\text { Años } \\
\text { post-fuego }\end{array}$} \\
\hline & & Año & Fecha & Extensión & & \\
\hline \multirow{3}{*}{ FUEGO } & $1 \mathrm{~F}$ & 2004 & Agosto & 120 ha & 2005, 2006, 2007 & $1,2,3$ \\
\hline & $2 \mathrm{~F}$ & 2002 & Octubre & 452 ha & 2006,2007 & 4,5 \\
\hline & $3 \mathrm{~F}$ & 1998 & Agosto & 110 ha & 2005,2007 & 7,9 \\
\hline \multirow{2}{*}{ CONTROL } & $1 \mathrm{C}$ & $\ldots$ & $\ldots$ & $\ldots$ & 2005, 2006, 2007 & \multirow{2}{*}{$13,14,15$} \\
\hline & $2 \mathrm{C}$ & $\ldots$ & $\ldots$ & $\ldots$ & 2005, 2006, 2007 & \\
\hline
\end{tabular}

\subsubsection{1.- Muestreo de Spheciformes}

La recolección de ejemplares se llevó a cabo mediante trampa Malaise y platos amarillos.

5.3.3.1.1.- Metodología empleada en la recolección con trampa Malaise: Para el muestreo de cada una de las localidades incendiadas se emplearon tres trampas Malaise, situadas a diferentes distancias del borde más cercano sin quemar. La separación entre ellas fue lo suficientemente grande, como para considerar inexistentes las interferencias ejercidas por cada una de ellas sobre las demás.

Las muestras pertenecientes a cada trampa se recogieron quincenalmente. En el momento de la recogida se procedió a una revisión exhaustiva del estado de conservación de cada trampa, para asegurar su eficiencia recolectora. Posteriormente, cada una de las muestras era 
trasladada al laboratorio, donde permanecerían hasta el momento de su preparación.

\subsubsection{2.- Metodología empleada en la recolección con platos amarillos:}

Alrededor de cada trampa Malaise se delimitó una parcela de 10m x 10m, en la que se colocaron 20 platos de plástico amarillo $(22 \mathrm{~cm}$ de diámetro por $3 \mathrm{~cm}$ de profundidad), cinco en cada lateral (Figura 29). La separación entre cada uno de ellos fue de $2 \mathrm{~m}$ aproximadamente, si bien estuvo condicionada por la existencia o no de vegetación y sustrato adecuado para su colocación. Los platos fueron enterrados en el suelo hasta su borde superior y rellenados, casi en su totalidad, con agua jabonosa.

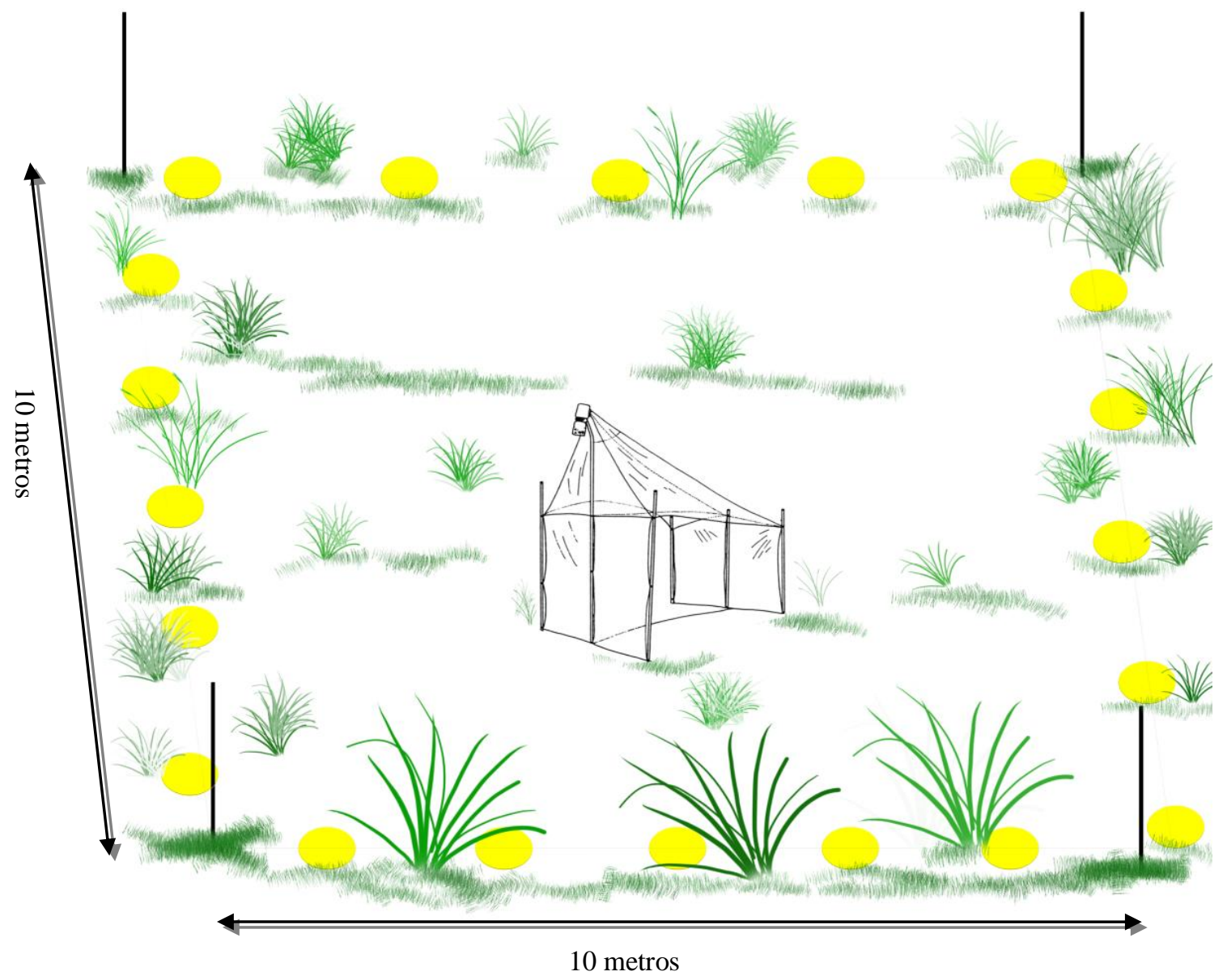

Figura 29: Representación esquemática de la parcela de muestreo delimitada alrededor de cada trampa Malaise y situación de los platos amarillos respecto a esta. 
Adicionalmente se añadió sal que actuó como conservante. Su posición fue señalada con una estaca de color anaranjado (Figura 30) para facilitar

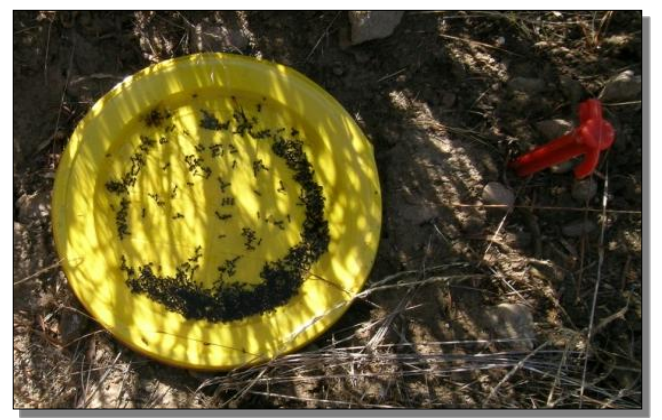
su localización a la hora de la recogida de las muestras, dificultada por la frondosidad vegetal existente en alguna de las localidades de muestreo.

Figura 30: Plato amarillo empleado en el muestreo y estaca anaranjada marcando su posición.

Las muestras se recogieron mensualmente, tras permanecer activos los platos durante 48 horas. Posteriormente se trasladaron al laboratorio, donde eran traspasadas a un recipiente relleno de etanol al $70 \%$ para garantizar su conservación hasta el momento de su preparación y montaje.

En los casos en que parte de la muestra se perdió debido a la climatología desfavorable, el muestreo se repitió dos días más tarde, hasta obtener una muestra de platos por mes y área muestreada. A pesar de ello, la muestra correspondiente al mes de junio de 2005 no pudo obtenerse debido a las condiciones climatológicas adversas en unas zonas, y al impacto provocado por rebaños de ganado doméstico y/o de la fauna de mamíferos salvajes en otras.

Tabla IV: Resumen del esfuerzo de muestreo realizado en las localidades de estudio por cada año de muestreo. F $=$ Fuego $\mathrm{C}=$ Control. $*$ Nótese que en las localidades $2 \mathrm{~F}$ y $3 \mathrm{~F}$ sólo se muestrearon 2 años.

\begin{tabular}{|c|c|c|c|c|c|c|}
\hline \multirow[b]{2}{*}{ Localidad } & \multicolumn{3}{|c|}{ TRAMPA MALAISE } & \multicolumn{3}{|c|}{ PLATOS AMARILLOS } \\
\hline & 2005 & 2006 & 2007 & 2005 & 2006 & 2007 \\
\hline $\mathbf{1 F}$ & 3 & 3 & 3 & 240 & 240 & 240 \\
\hline $2 F$ & - & 3 & 3 & - & 240 & 240 \\
\hline $3 F$ & 3 & - & 3 & 240 & - & 240 \\
\hline $1 \mathrm{C}+2 \mathrm{C}$ & 3 & 3 & 3 & 240 & 240 & 240 \\
\hline Total/Año de muestreo & 9 & 9 & 12 & 720 & 720 & 960 \\
\hline Trampas totales & & 30 & & & 400 & \\
\hline
\end{tabular}


El esfuerzo de muestreo llevado a cabo por localidad y año, con cada uno los métodos de muestreo, se resume en la Tabla IV.

\subsubsection{2.- Muestreo de la vegetación}

Cada uno de los tres años de estudio, se llevó a cabo un muestreo de la vegetación existente en las áreas analizadas, quemadas y no quemadas. Dicho muestreo tuvo lugar a finales del mes de mayo, previo a la colocación de las trampas. En ellos se calculó, mediante estimación visual, el porcentaje de cobertura arbórea, arbustiva, y de herbáceas. Se midió también la altura de los arbustos, por ser este estrato el principal causante de variación estructural a lo largo del periodo de sucesión posterior al fuego, entre las distintas localidades analizadas (Figura 31). Adicionalmente, se calculó, también mediante estimación visual, el porcentaje de suelo descubierto/desnudo, dada la gran importancia que tiene la disponibilidad de este recurso para la nidificación de muchas especies de Spheciformes

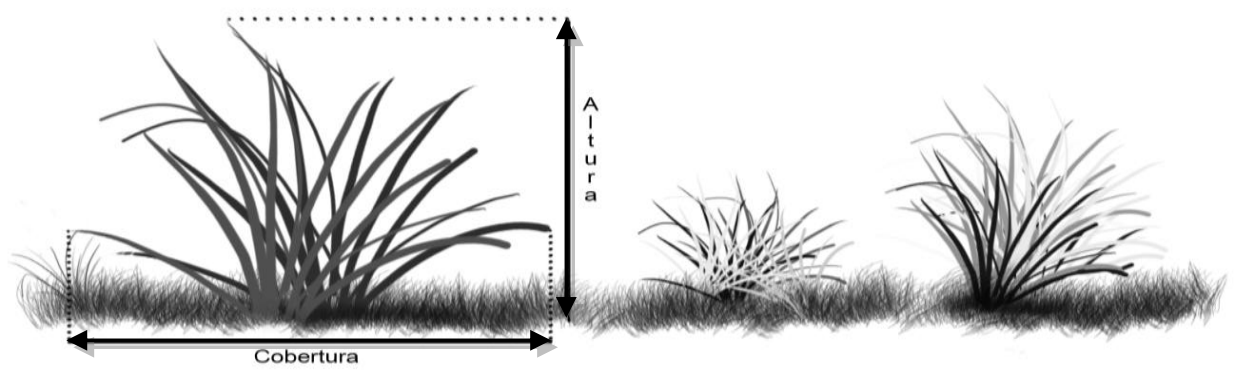

Figura 31: Esquema representativo de las mediciones realizadas en cada uno de los transectos.

Cada muestreo consistió en la creación de cinco grupos formados por cinco transectos paralelos, de $5 \mathrm{~m}$ cada uno, y con una separación de $5 \mathrm{~m}$ entre uno y otro (Figura 32).

Cada grupo de transectos ocupó una superficie global de $100 \mathrm{~m}^{2}$, por lo que el

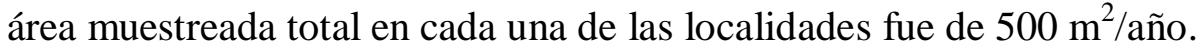

Los diferentes transectos fueron realizados en diferentes áreas, representativas de la vegetación existente en cada una de las localidades analizadas, alrededor de las trampas Malaise. 


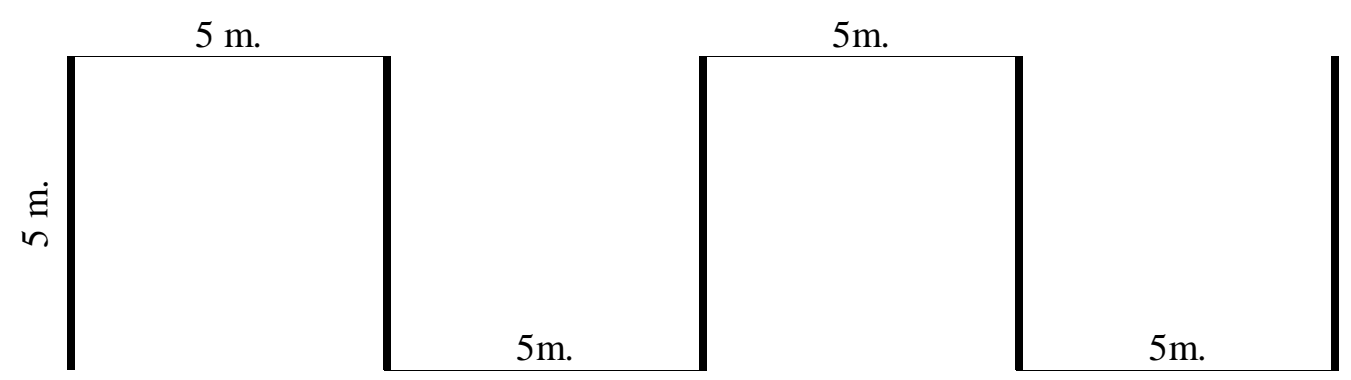

Figura 32: Esquema representativo del muestreo mediante transectos, empleado en el análisis de la vegetación.

Los valores medios de cada una de las variables analizadas, las localidades y años en que fueron obtenidas y la edad post-fuego representada por cada una de ellas, se muestran en la Tabla V.

Tabla V: Valores medios de cobertura, en porcentaje, para los diferentes estratos vegetales y suelo desnudo, en los diferentes años de muestreo. Altura media del estrato arbustivo $(\mathrm{cm}$.), en porcentaje. $\mathrm{F}=$ Fuego; $\mathrm{C}=\mathrm{Control}$.

\begin{tabular}{|c|c|c|c|c|c|c|c|}
\hline \multirow{2}{*}{ Localidad } & \multirow{2}{*}{$\begin{array}{c}\text { Años } \\
\text { post-fuego }\end{array}$} & \multirow{2}{*}{$\begin{array}{c}\text { Año de } \\
\text { muestreo }\end{array}$} & \multicolumn{3}{|c|}{ COBERTURA } & \multirow{2}{*}{$\begin{array}{c}\text { Suelo } \\
\text { desnudo }\end{array}$} & \multirow{2}{*}{$\begin{array}{c}\text { Altura } \\
\text { arbustiva }\end{array}$} \\
\hline & & & Arbórea & Arbustiva & Herbácea & & \\
\hline $\mathbf{1 F}$ & 1 & 2005 & 7,24 & 4,68 & 44,28 & 69,88 & 31,24 \\
\hline $1 F$ & 2 & 2006 & 3,08 & 2,2 & 68,68 & 38,24 & 30,88 \\
\hline $\mathbf{1 F}$ & 3 & 2007 & 14,76 & 16,36 & 40,36 & 36,6 & 36,54 \\
\hline $2 F$ & 4 & 2006 & 8,8 & 16,44 & 32,72 & 43,48 & 36,86 \\
\hline $2 F$ & 5 & 2007 & 12,64 & 34,6 & 51,16 & 31,12 & 57,7 \\
\hline $3 F$ & 7 & 2005 & 14,8 & 48,72 & 46,32 & 2,88 & 97 \\
\hline $3 F$ & 9 & 2007 & 8,8 & 46,12 & 65,6 & 0,56 & 106,85 \\
\hline $1 \mathrm{C}+2 \mathrm{C}$ & 13 & 2005 & 34,52 & 57,56 & 37,64 & 8 & 124,54 \\
\hline $1 \mathrm{C}+2 \mathrm{C}$ & 14 & 2006 & 21,48 & 63,48 & 41,76 & 4,92 & 91,77 \\
\hline $1 \mathrm{C}+2 \mathrm{C}$ & 15 & 2007 & 21,36 & 52,84 & 29 & 9,08 & 86,43 \\
\hline
\end{tabular}




\section{INCENDIOS ANALIZADOS}

\section{LOCALIDAD 1 F (Figuras 33, 34, 35)}

- Localidad/ municipio: Pereña de la Ribera

- Fecha del incendio: 8/10/2004.

- Extensión: 120 ha.

- Fecha y de periodo de muestreo: Años 2005, 2006 y 2007 (01/Jun.-30/Sept.).

- $\mathbf{N}^{\mathbf{0}}$ de trampas /año de muestreo: 3 Trampas Malaise y 240 platos amarillos.

- Coordenadas / Altura: Sobre las fotografías

- Edad post-fuego representada: 1, 2 y 3 años.
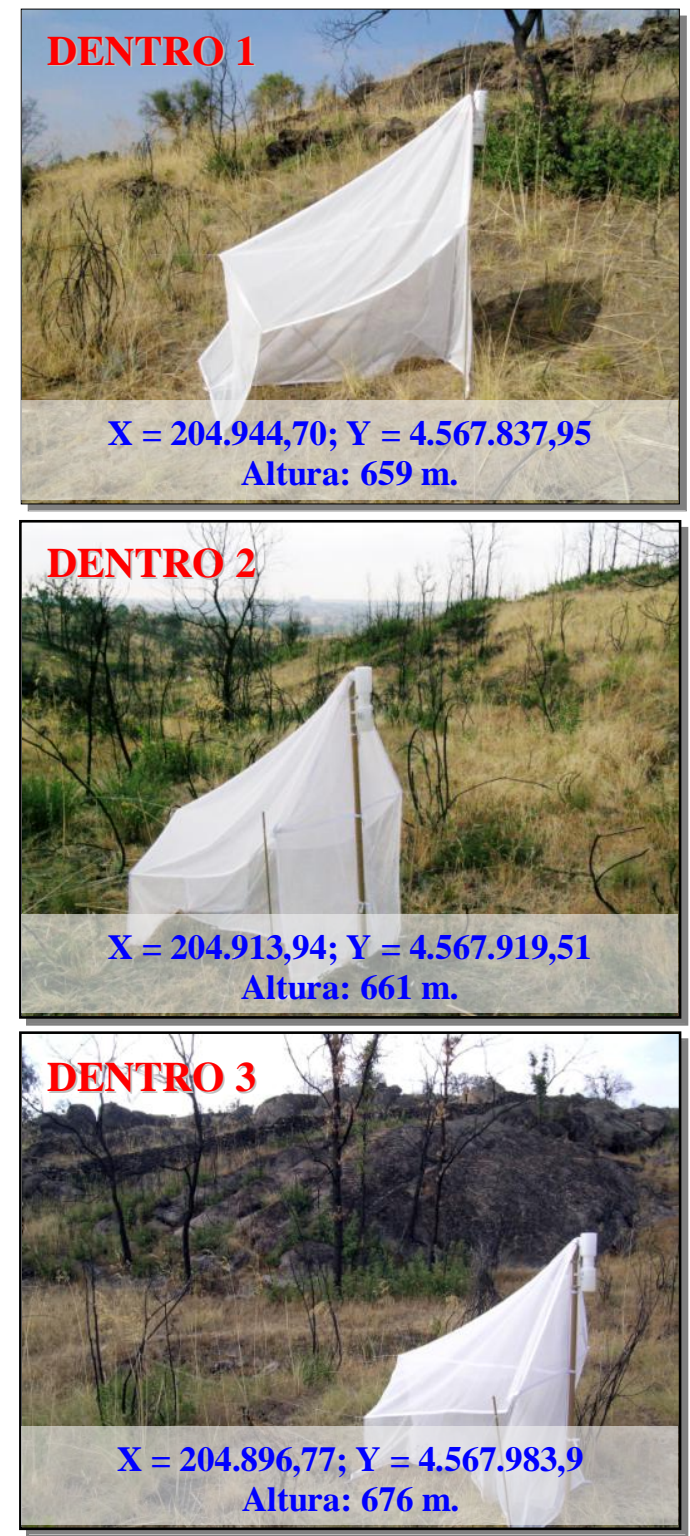
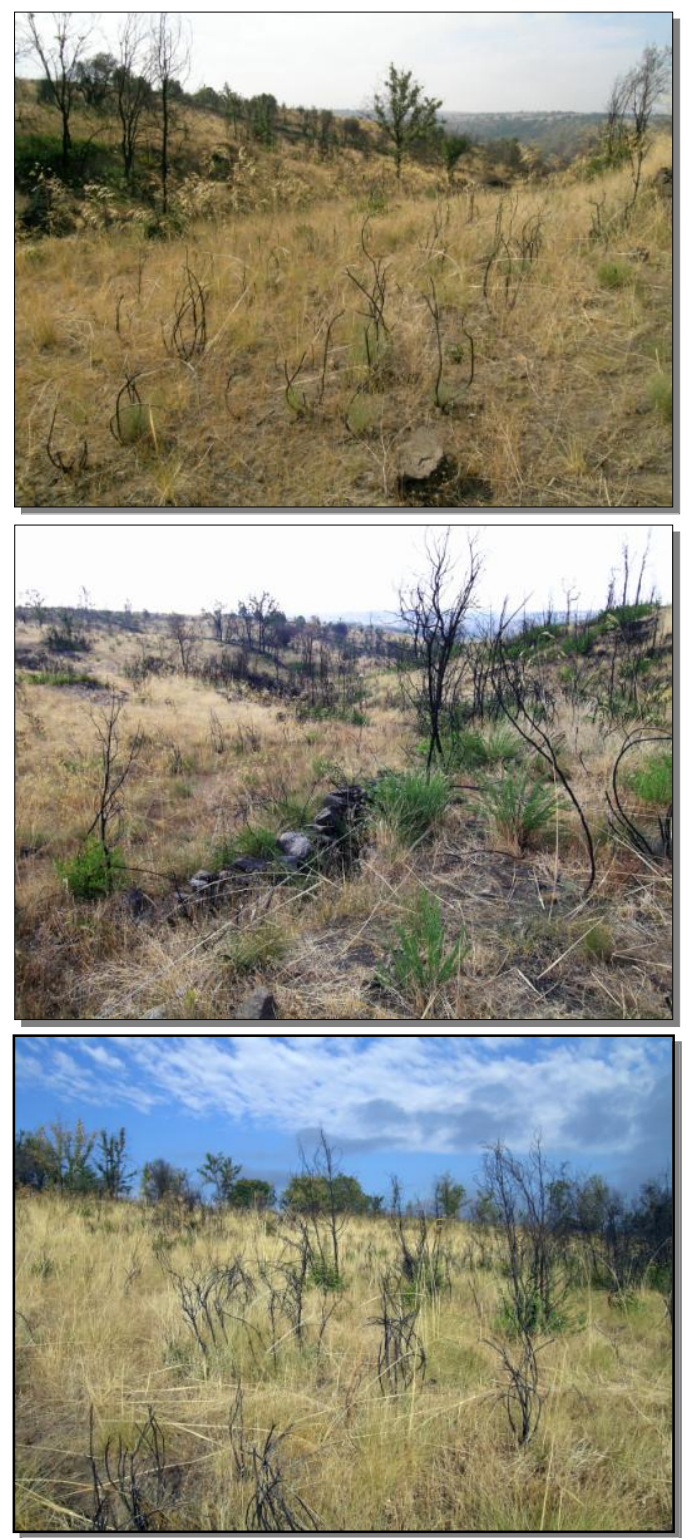

Figura 33: Izquierda: Trampas Malaise ubicadas en el área incendiada en el año 2004, un año después del incendio. Derecha: Aspecto del área circundante a cada una de ellas en 2005 (1 año post-fuego). 


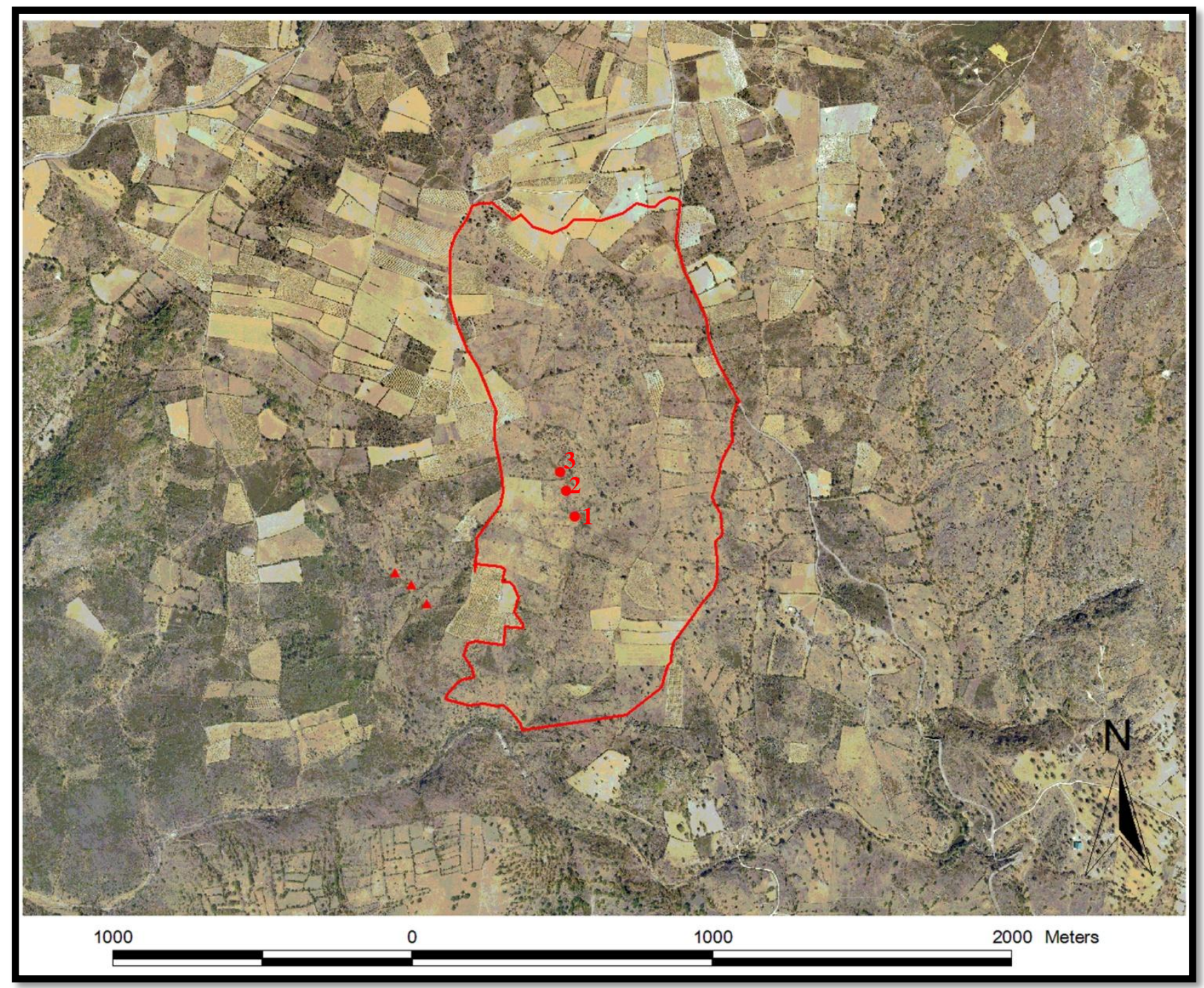

Distancias de las trampas

Malaise al borde más

cercano sin quemar:

DENTRO 1: $250 \mathrm{~m}$.

DENTRO 2: 214,6 m.

DENTRO 3: 198,93 m.

Figura 34: Ortofotografia de la Localidad 1F, área incendiada en el año 2004. Puntos rojos: Ubicación de las trampas Malaise. Línea continua: Perímetro del área incendidada. Triángulos rojos: Ubicación de las trampas correspondientes a la localidad 3F, incendiada en 1998. 

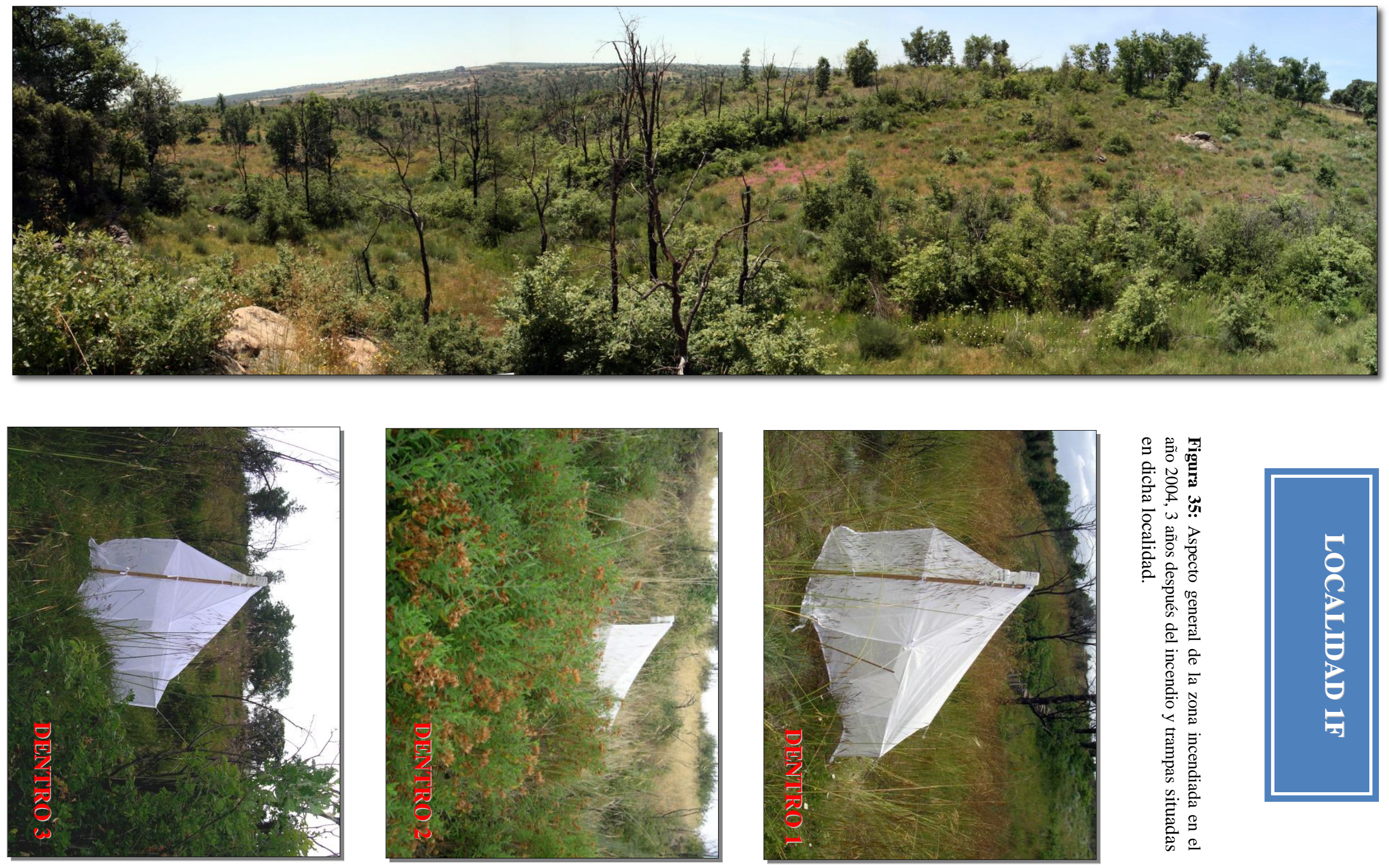


\section{LOCALIDAD 2 F (Figuras 36, 37, 38)}

- Localidad/ municipio: Villarino de los Aires (y la pedanía Cabeza de Framontanos).

- Fecha del incendio: 01/08/2002.

- Extensión: 452 ha.

- Fecha de muestreo: Años 2006 y 2007.

- Periodo de muestreo: 01/Junio-30/septiembre.

- $\mathbf{N}^{\mathbf{0}}$ de trampas /año de muestreo: 3 Trampas Malaise y 240 platos amarillos

- Coordenadas / Altura: Sobre las fotografías

- Edad post-fuego representada: 4 y 5 años post-fuego.
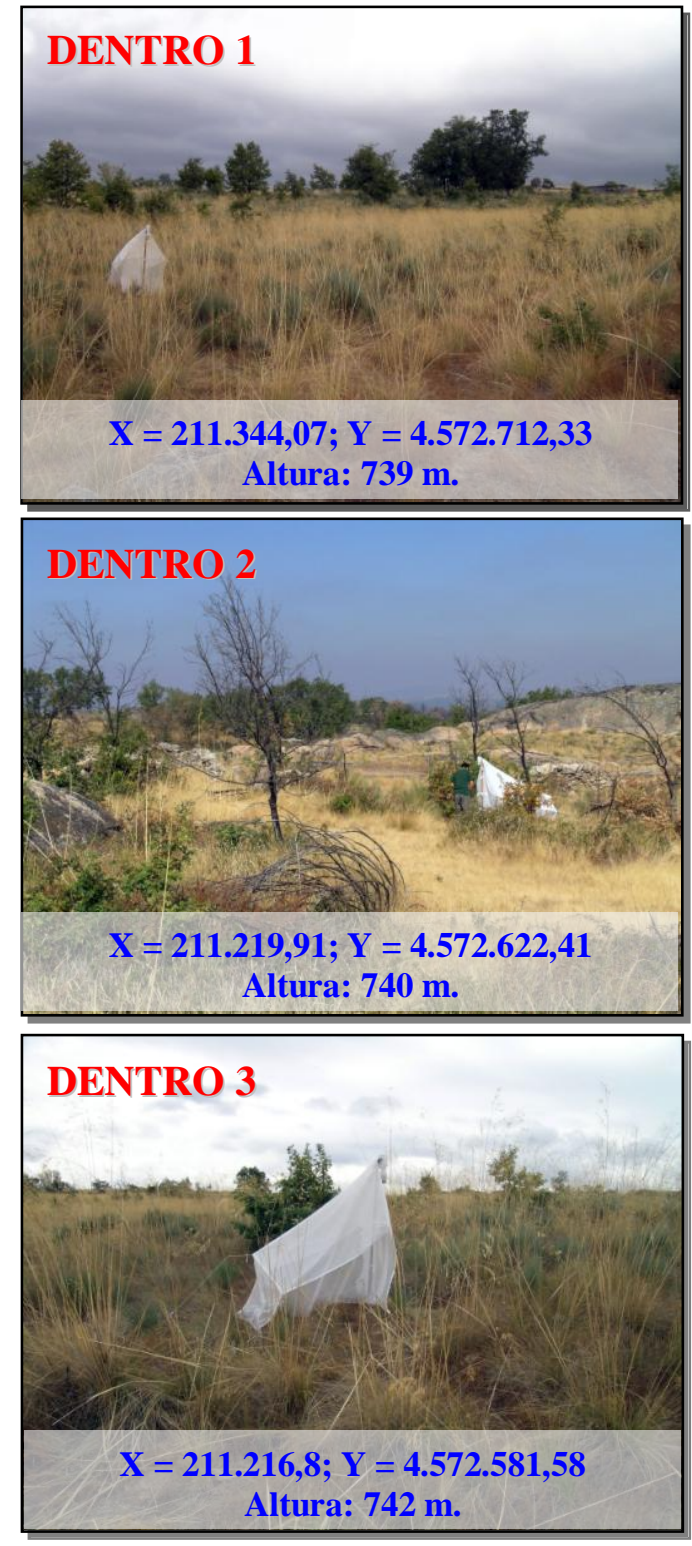
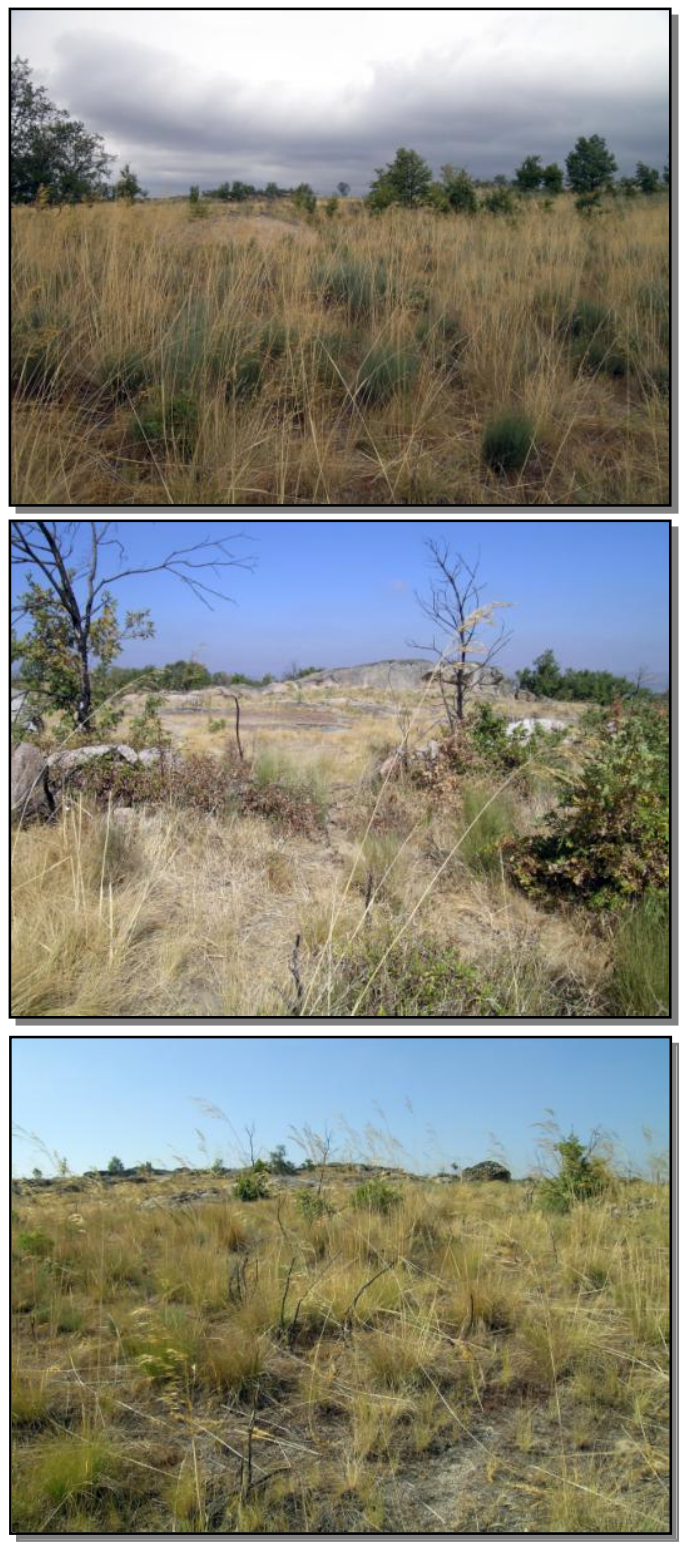

Figura 36: Izquierda: Trampas Malaise ubicadas en el área incendiada en el año 2002, 4 años después del incendio. Derecha: Aspecto del área circundante a cada una de ellas 

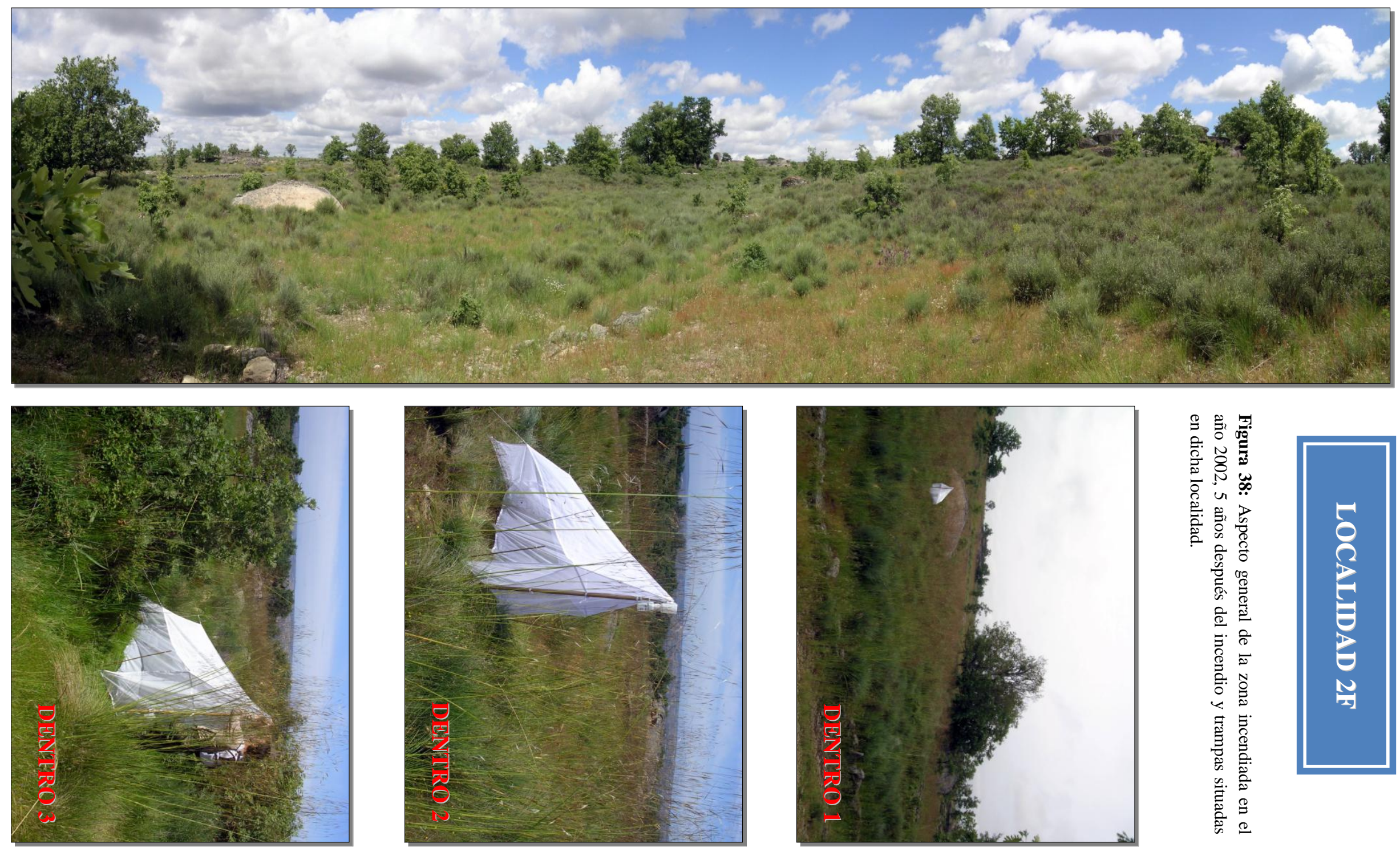


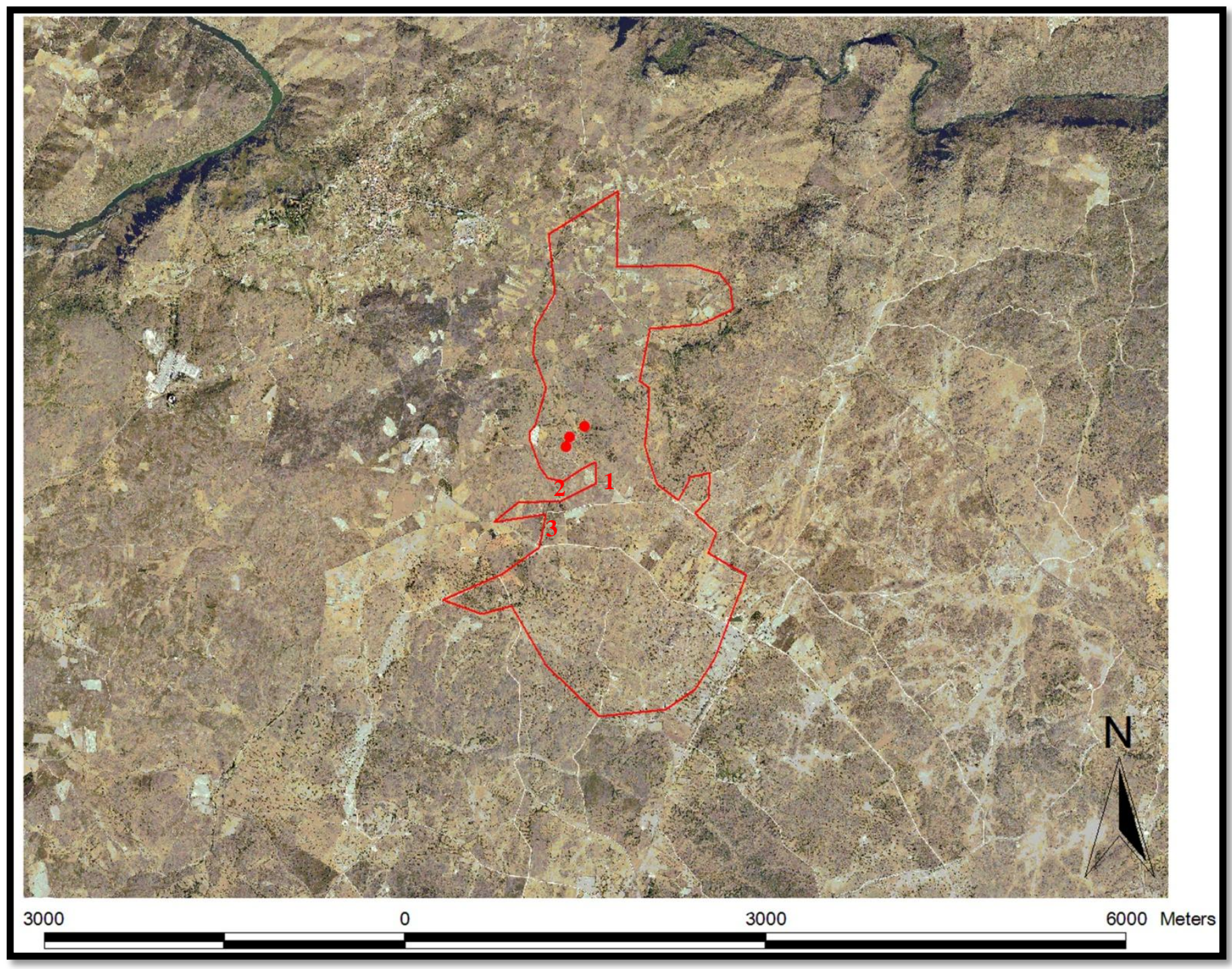

Distancias de las trampas al borde más cercano sin quemar:

DENTRO 1: 400 m.

DENTRO 2: 349,9 m.

DENTRO 3: $289 \mathrm{~m}$.

Figura 37: Ortofotografia de la Localidad 2F, área incendiada en el año 2002. Puntos rojos: Ubicación de las trampas Malaise. Línea continua: Perímetro del área incendidada. 


\section{LOCALIDAD 3F (Figuras 39, 40, 41)}

- Localidad/ municipio: Pereña de la Ribera.

- Fecha del incendio: 10/08/1998.

- Extensión: 110 ha.

- Fecha de muestreo: Años 2005 y 2007.

- Periodo de muestreo: 01/Junio-30/septiembre.

- $\mathbf{N}^{\mathbf{0}}$ de trampas/ año de muestreo: 3 Trampas Malaise y 240 platos amarillos.

- Coordenadas / Altura: Sobre las fotografías

- Edad post-fuego representada: 7 y 9 años post-fuego.
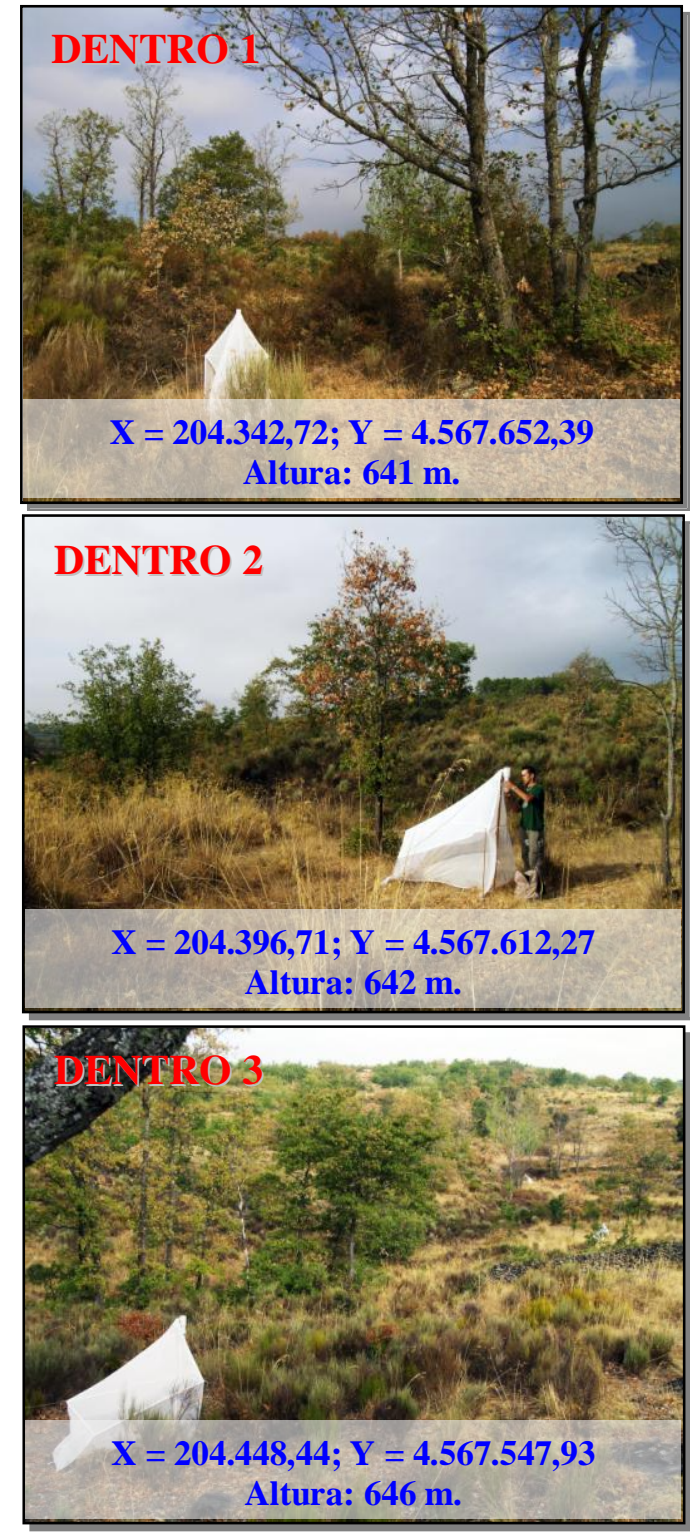
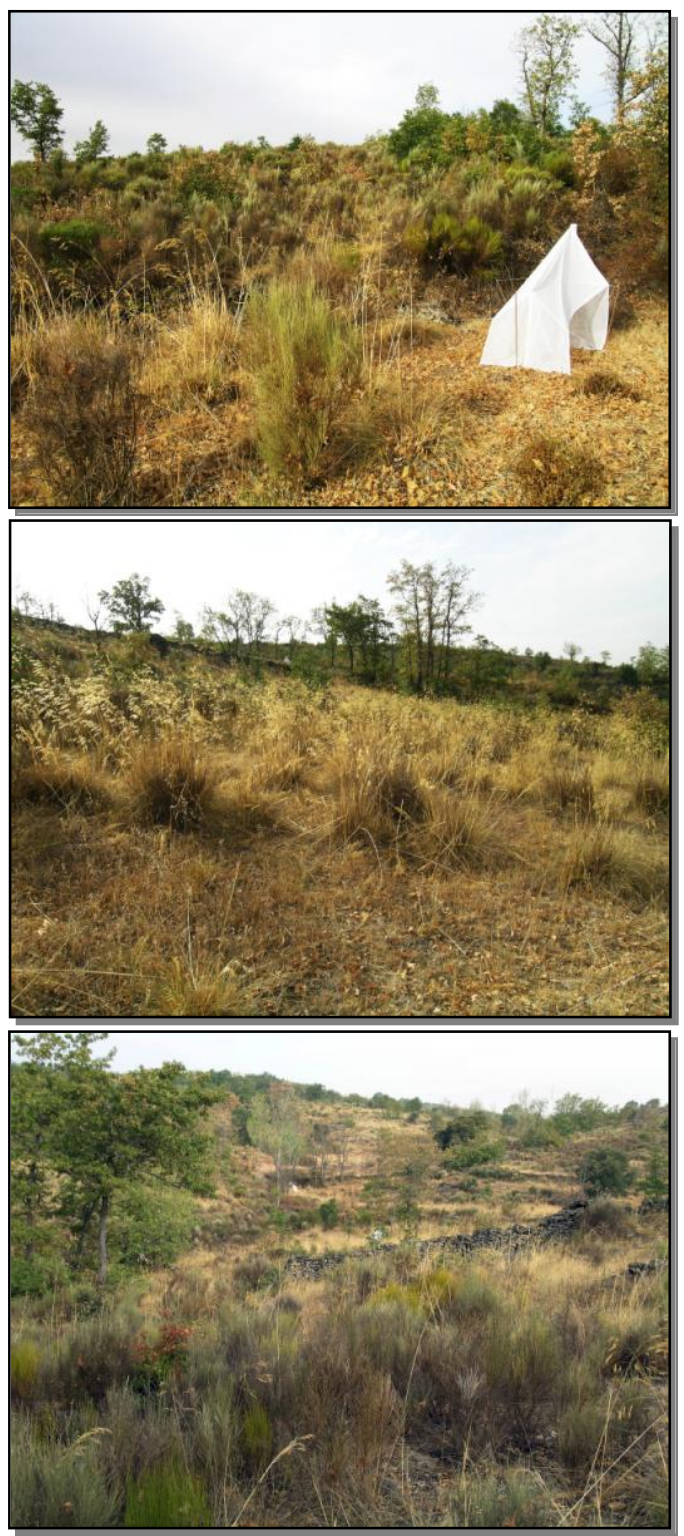

Figura 39: Izquierda: Trampas Malaise ubicadas en el área incendiada en el año 1998, 7 años después del incendio. Derecha: Aspecto del área circundante a cada una de ellas 


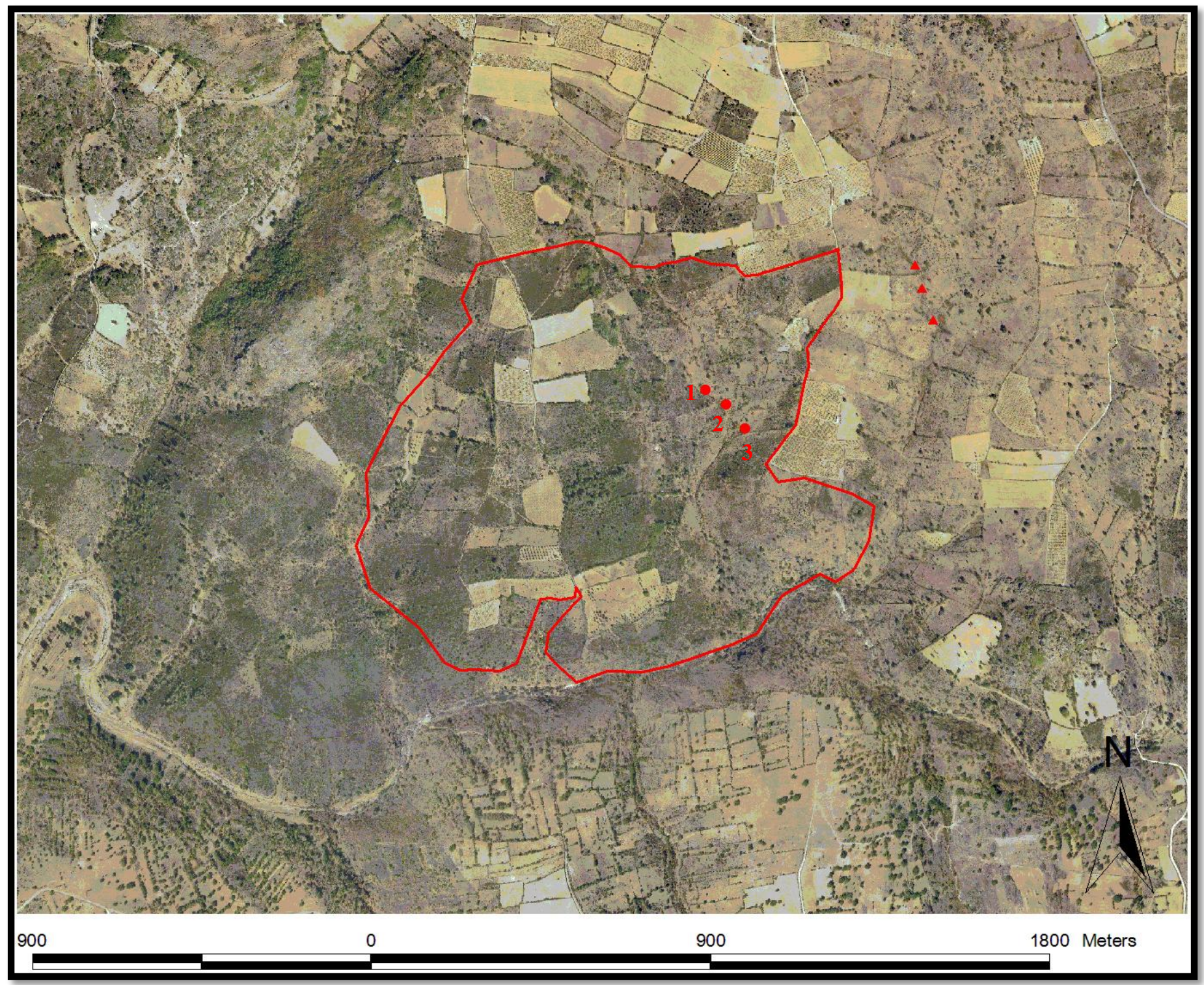

Distancia de las trampas al borde más cercano sin quemar:

DENTRO 1: 255,8 m.

DENTRO 2: 203,2 m.

DENTRO 3: 102,5 m.

Figura 40: Ortofotografia de la Localidad 3F, área incendiada en el año 1998. Puntos rojos: Ubicación de las trampas Malaise. Línea continua: Perímetro del área incendidada. Triángulos rojos: Ubicación de las trampas correspondientes a la localidad 1F, incendiada en 2004. 

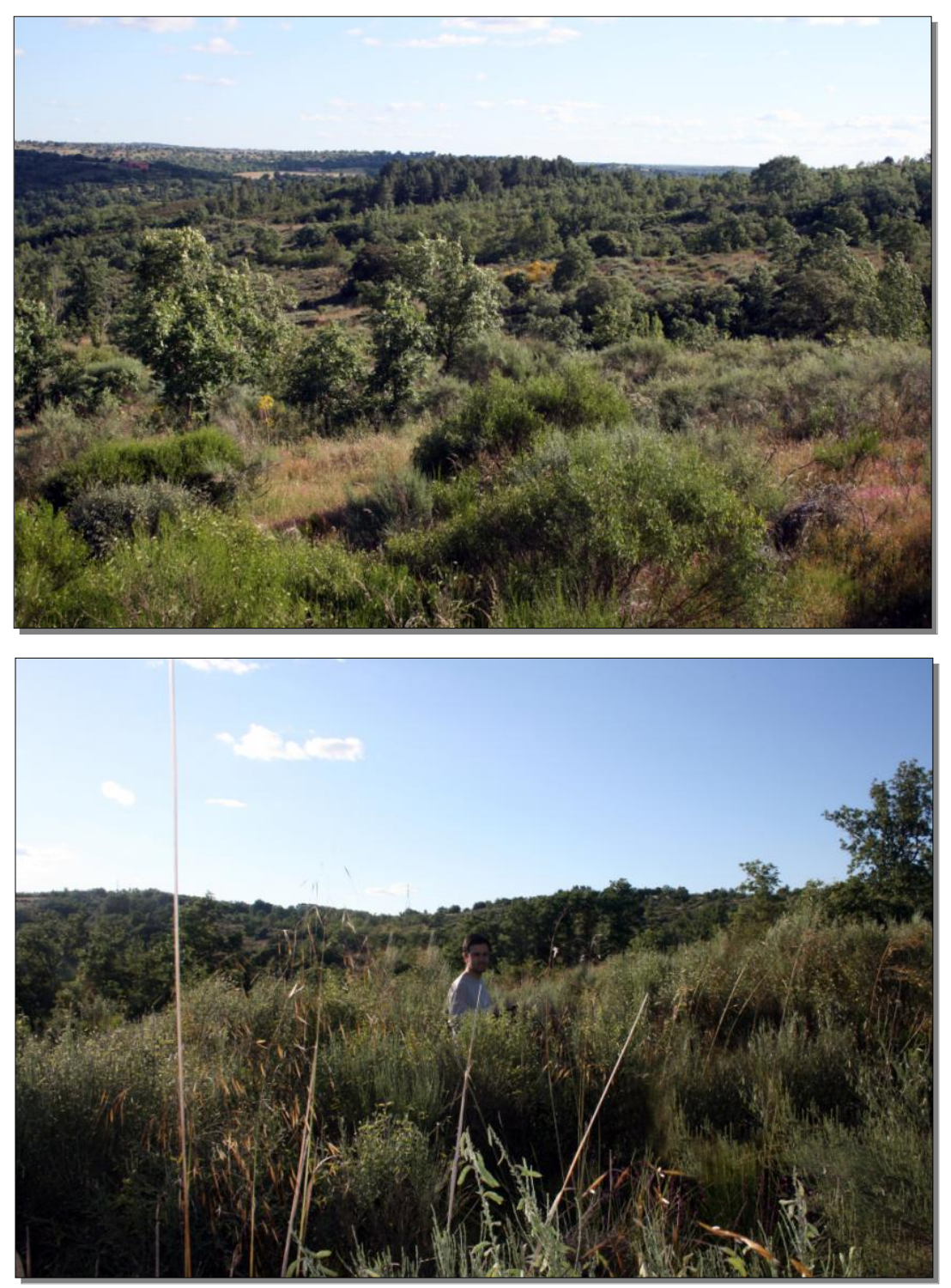
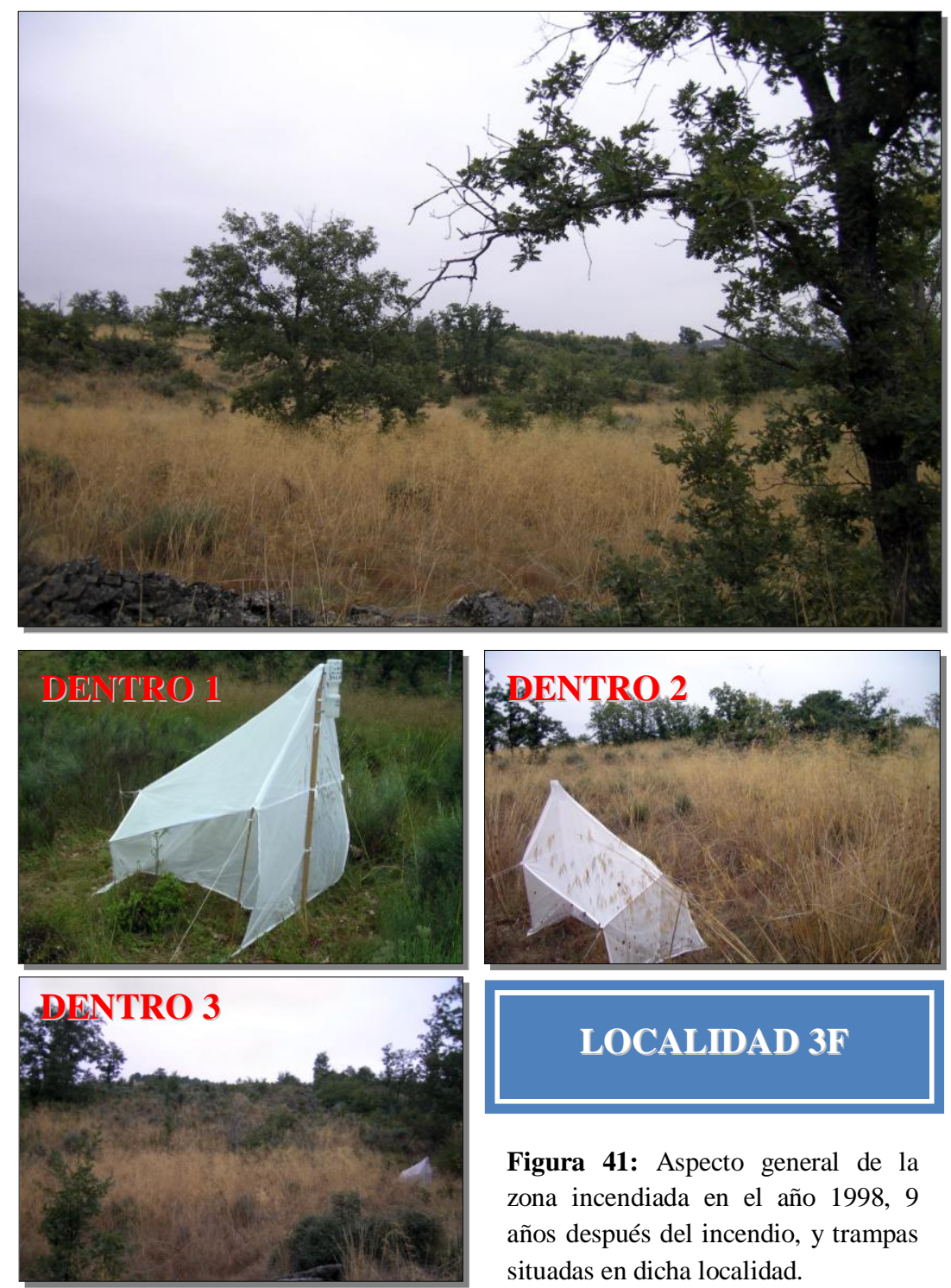

LOCALIDAD 3F

Figura 41: Aspecto general de la zona incendiada en el año 1998, 9 años después del incendio, y trampas situadas en dicha localidad. 


\section{ZONAS CONTROL}

Paralelamente a las zonas incendiadas se muestrearon otras dos, denominadas CONTROL, consideradas recuperadas y representativas del área de estudio. No obstante, y debido a la presencia histórica del fuego en la misma, estas áreas no son controles estrictos.

\section{LOCALIDAD 1C (Figuras 42, 43)}

- Localidad/ municipio: Pereña de la Ribera

- Fecha de muestreo: Años 2005, 2006 y 2007

- Periodo de muestreo: 01/Junio - 30/septiembre.

- $\mathbf{N}^{\circ}$ de trampas empleadas/ año de muestreo: 2 trampas Malaise y 160 platos amarillos.

- Coordenadas - Altura: Sobre las fotografías.

- Edad post-fuego representada: 13,14 y 15 años post-fuego.
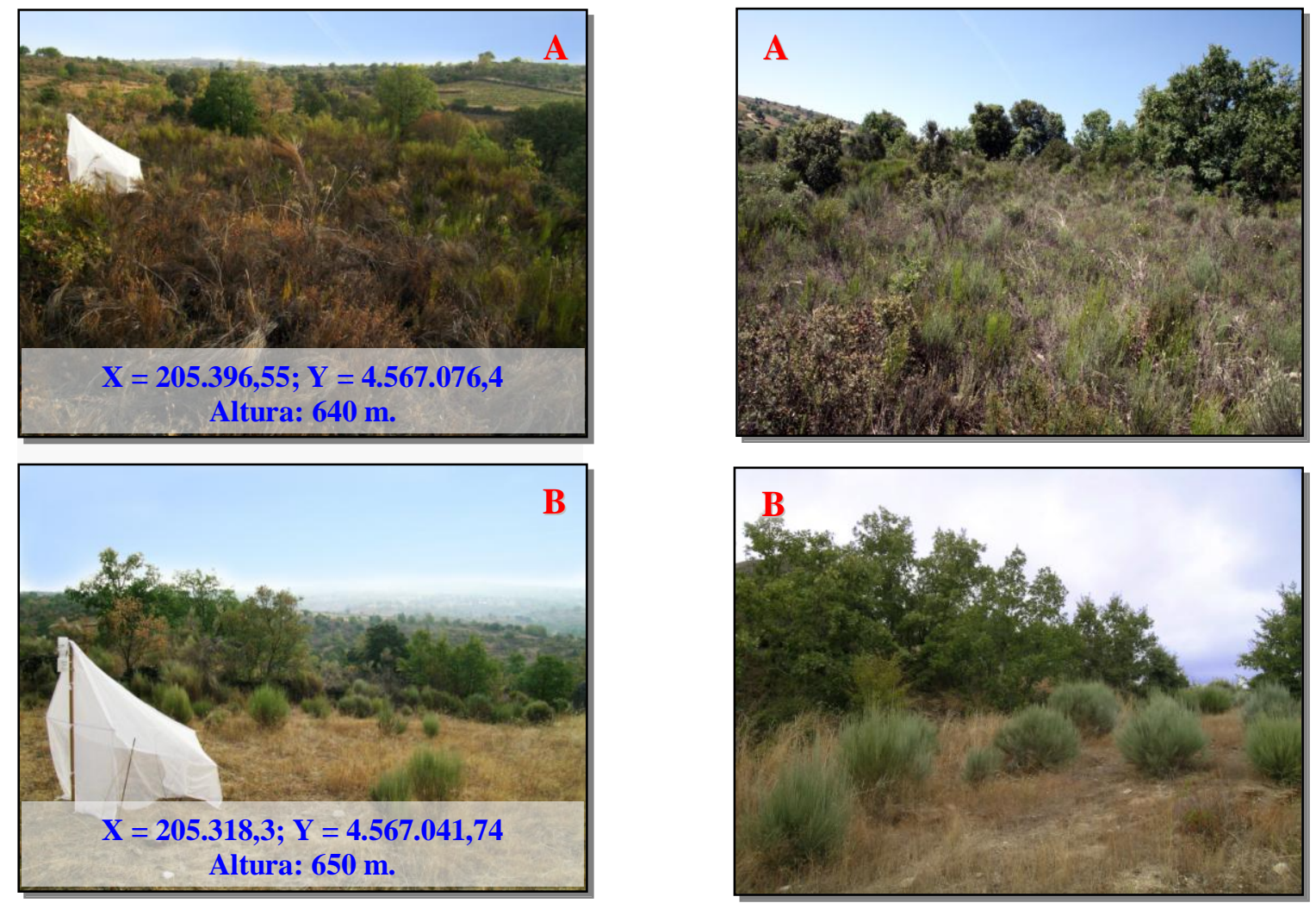

Figura 42: Trampas Malaise ubicadas en la zona Control de Pereña de la Ribera en el año 2005 y aspecto del área circundante a cada una de ellas. A = Control "Escobas"; $\mathbf{B}=$ Control "Prado" 

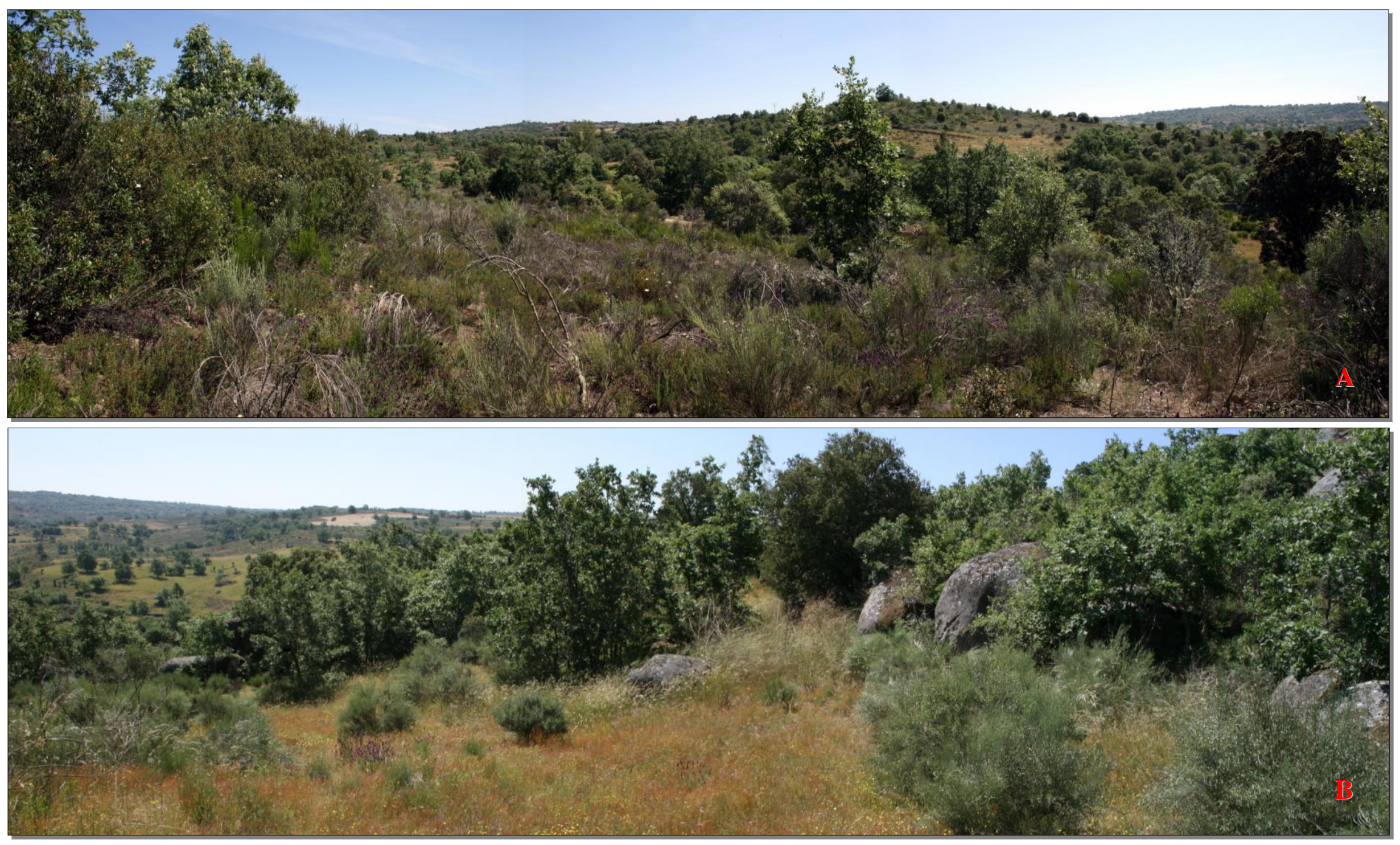

Figura 43: Aspecto de la zona Control 1 (Pereña de la Ribera) en el año 2007. A = Control "Escobas"; B = Control "Prado". 


\section{LOCALIDAD 2C (Figuras 44, 45, 46)}

- Localidad/ municipio: Cabeza de Framontanos (Villarino de los Aires).

- Fecha de muestreo: Año 2005, 2006 y 2007.

- Periodo de muestreo: 01/Junio - 30/Septiembre.

- $\mathbf{N}^{\mathbf{0}}$ de trampas empleadas/ año de muestreo: 3 trampas Malaise y 80 platos amarillos.

- Coordenadas - Altura: Sobre fotografía (Figura 42).

- Edad post-fuego representada: Años 13, 14 y 15 post-fuego.

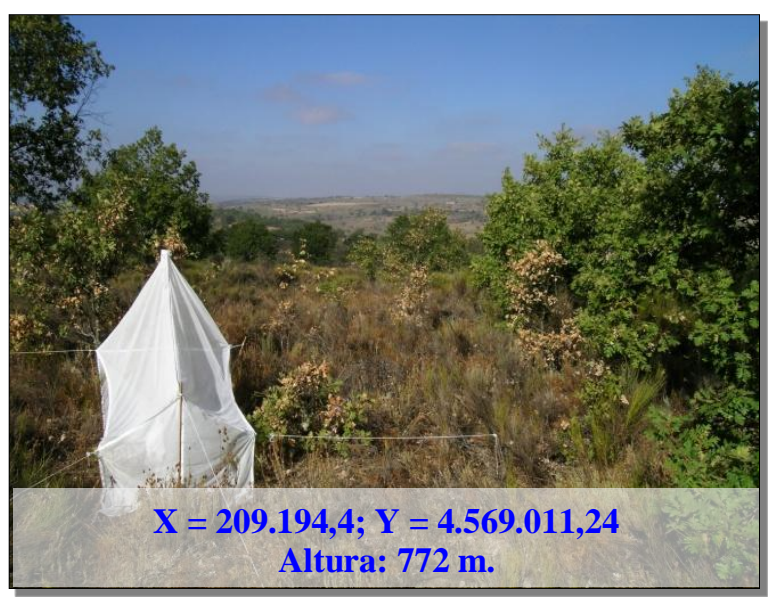

Figura 44: Trampa Malaise colocada en la zona Control 2 (Cabeza de Framontanos -Villarino de los Aires-) en el año 2005.
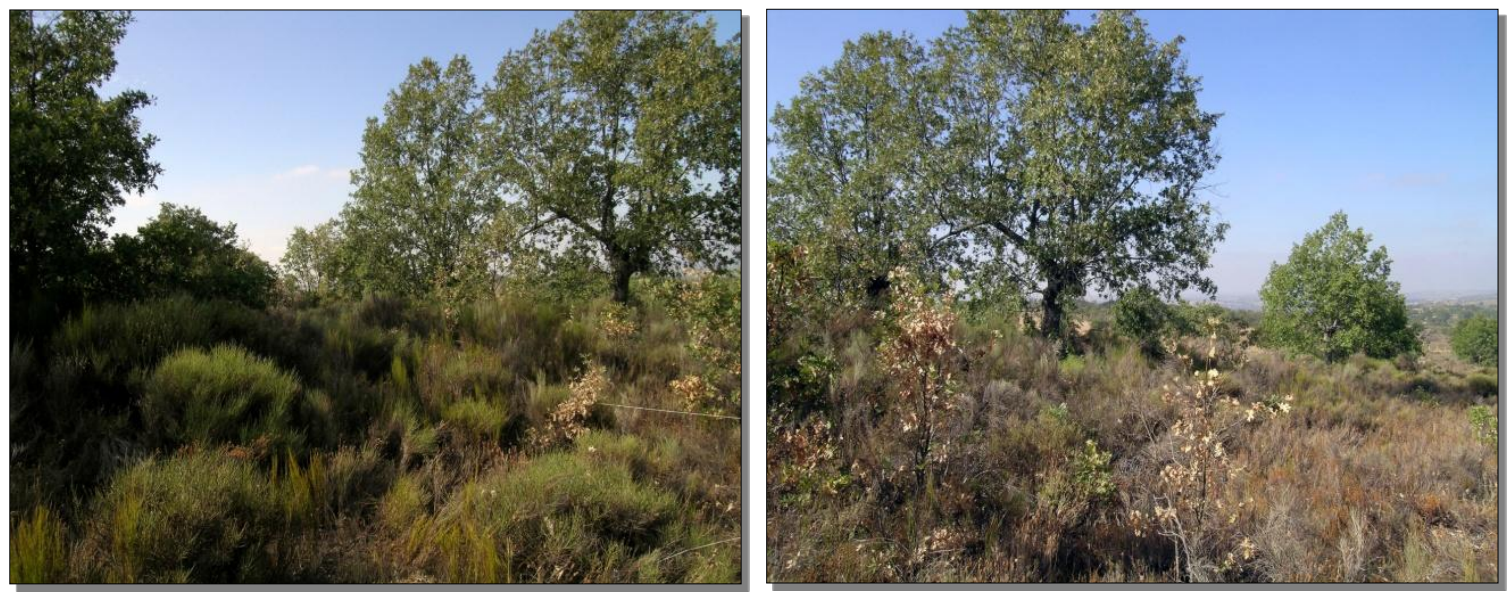

Figura 45: Aspecto de la zona Control 2 (Cabeza de Framontanos -Villarino de los Aires-) en el año 2005. 


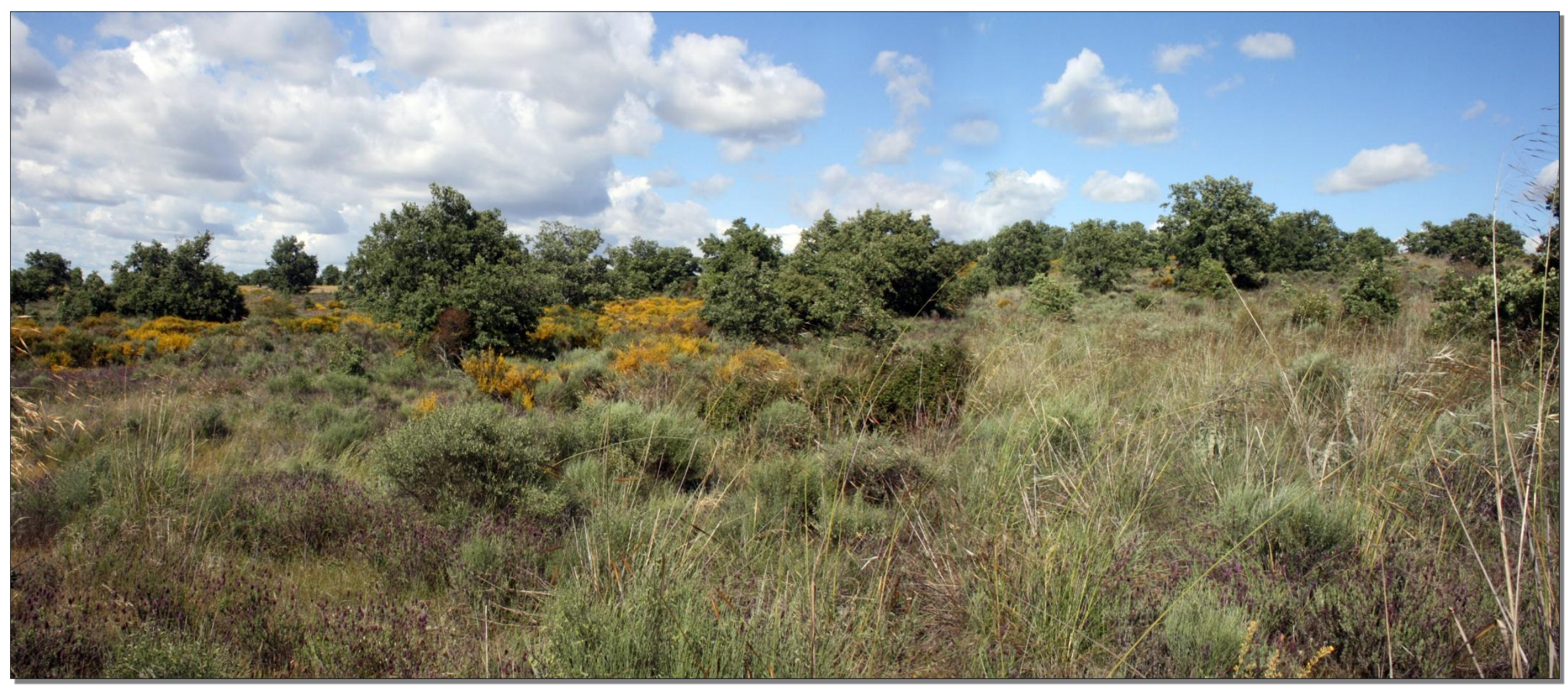

Figura 46: Aspecto de la zona Control 2 (Cabeza de Framontanos -Villarino de los Aires-) en el año 2007. 


\section{4.- TRABAJO DE LABORATORIO}

Como ya se ha señalado en los apartados anteriores, la totalidad de las muestras obtenidas se trasladaron al laboratorio para su análisis cuantitativo y cualitativo. Para ello se depositaba el contenido de los botes recolectores en una bandeja de plástico blanca (Figura 47A) y se procedía a la separación exhaustiva de los ejemplares. Para garantizar su conservación, éstos eran introducidos en recipientes apropiados de plástico (Figura 47B), que contenían como medio conservante etanol al 70\%.
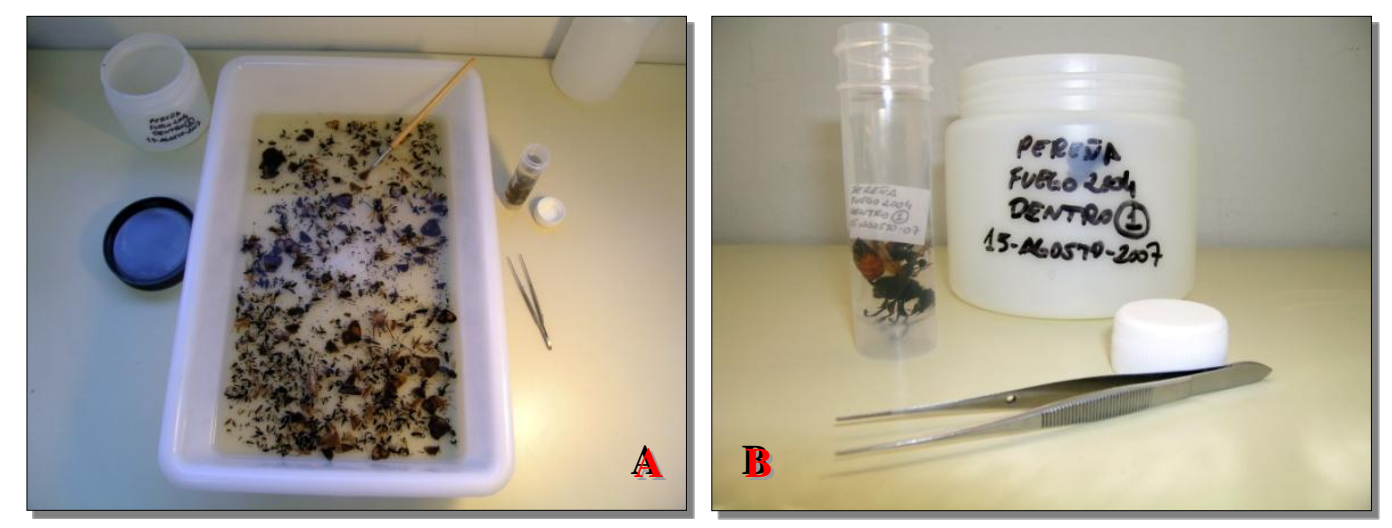

Figura 47: A) Bandeja de plástico y material empleado para la separación del material procedente de las trampas.

B) Detalle del recipiente de plástico en el que era guardado el material separado, hasta el momento de su preparación.

Una vez separados, se procedió al montaje y preparación de todos los ejemplares pertenecientes al grupo en estudio. Para ello, una vez secados, se montaron mediante la utilización de alfileres entomológicos, de distinto grosor, y minucias, en función del tamaño del ejemplar. Para algunos individuos, en los que el estudio de la genitalia resulta imprescindible para llevar a cabo su correcta determinación, se procedió a su reblandecimiento en una cámara al efecto para la extracción de la misma mediante agujas o pinzas finas.

Seguidamente se etiquetó cada ejemplar, se colocaron en cajas entomológicas y se procedió a su separación por familias, subfamilias, tribus y géneros para identificarlos posteriormente hasta nivel específico.

Sin embargo, en tres casos se ha diferenciado como Género sp. y en otros dos casos como Género sp. aff. Estos individuos han sido considerados para realizar el 
análisis de la comunidad, pero excluidos para el tratamiento estadístico de los datos.

Todo el material recogido se halla depositado en la colección entomológica del Área de Zoología del Departamento de Biología Animal, Parasitología, Ecología, Edafología y Química Agrícola de la Universidad de Salamanca.

\section{5.- ANÁLISIS ESTADÍSTICO}

\subsection{1.- DIVERSIDAD Y PERTURBACIÓN}

En los últimos años, la diversidad biológica se ha convertido en un tema de debate fundamental, tanto en el plano político como en el plano social, llegando a convertirse en un asunto de interés prioritario en materia de conservación. Este interés está motivado por la existencia de datos que sugieren una pérdida de especies sin precedentes e irreversible (WILSON, 1988, 1992; ELDREDGE, 1998), debida fundamentalmente a la actividad humana (HEYWOOD, 1995; LAWTON \& MAY, 1995; PURVIS et al., 2000).

La mayoría de los ecosistemas están sujetos a regímenes de perturbación que operan a través de rangos de escala temporal y espacial. Las perturbaciones naturales suelen ser puntuales, con una magnitud y distribución de frecuencias características (White \& PicketT, 1985). No obstante, las actividades humanas tienden a transformar esas perturbaciones puntuales en perturbaciones crónicas, constituyendo una fuerte presión y generando una influencia negativa sobre los ecosistemas y las especies que contienen (PAINE et al., 1998; BENGTSSON et al., 2003).

El mantenimiento del estado deseable de un ecosistema, de cara a las perturbaciones, exige que los grupos funcionales de especies que lo componen sigan estando disponibles para la renovación y reorganización del mismo, una vez sufrida la perturbación (LUNDBERG \& MOBERG, 2003). Sin embargo, ante la actual simplificación humana de la biosfera, la sobreexplotación de sus recursos y la consiguiente pérdida de especies -ya existen algunos ejemplos de reducción de la capacidad de los ecosistemas para hacer frente a las perturbaciones y al cambio (JACKSON et al., 2001; SCHEFFER et al., 2001)- son varios los autores que manifiestan sus dudas sobre la capacidad de 
renovación y reorganización de los ecosistemas (CHAPIN et al., 2000; ELMQVIST et al., 2003).

La diversidad biológica puede mantener también la estabilidad ecológica y es un componente vital para la sostenibilidad de los ecosistemas (CHAPIN et al., 2000). Por ello, conservarla puede ser necesario para mantener su estabilidad, asegurar su resistencia y resiliencia a las perturbaciones y garantizar sus funciones y sostenibilidad a largo plazo (TILMAN et al., 1996; NAEEM, 1998; PETERSON et al., 1998; Duelli et al., 1999; BENGTSSON et al., 2000). La diversidad biológica es especialmente importante durante la sucesión y fases de reorganización de los ecosistemas, porque una alta diversidad regional significa que existirá un pool de especies apropiado para continuar el ciclo. De este modo, los sistemas más diversos y ricos en especies pueden ser más resistentes a las perturbaciones y más resilientes que los sistemas pobres en especies (McNaughton, 1993; Tilman \& Downing, 1994; MCGRADY-SteEd et al., 1997; NAEEM \& LI, 1997; ELMQVIST et al., 2003).

En la medida en que el funcionamiento de un ecosistema está sujeto a una variedad de estrés o perturbaciones ambientales, de origen natural o humano, el tener una diversidad de especies, que abarquen una variedad de tipos de respuestas funcionales, debería reducir la probabilidad de pérdida de todas las especies capaces de desempeñar procesos ecológicos particulares, siempre que las características de las respuestas no sean las mismas (NAEEM, 1998; BENGTSSON, 1998; YACHI \& LOREAU 1999; HOOPER et al., 2005).

Un patrón observado a menudo es una relación unimodal, en la cual la riqueza de especies es mayor a niveles intermedios de perturbación. Es la conocida como hipótesis de perturbación intermedia (HUSTON, 1979, 1994), según la cual, en zonas con niveles intermedios de frecuencia de perturbación moderada, se produce un incremento de la diversidad, al relajarse la competencia entre especies que existe en lugares donde la perturbación es mínima, y al no verse eliminadas dichas especies por el estrés provocado por la perturbación, como ocurre en zonas con perturbaciones muy frecuentes (WALKER, 1995; BENGTSSON, 1998). En este sentido y de acuerdo a dicha hipótesis de perturbación intermedia, algunos estudios enfatizan el papel positivo del fuego como una importante fuerza evolutiva para el mantenimiento de la riqueza de especies (BENGTSSON et al., 2000; SimiLÄ, et al., 2002; SiPPOLA et al., 2002). 
Actualmente, el significado y la importancia de la biodiversidad no están en duda y se ha desarrollado una gran cantidad de parámetros para medirla como un indicador del estado de los sistemas ecológicos, con aplicación práctica para fines de conservación, manejo y monitoreo ambiental (WARWICK \& CLARKE, 1995, 1998; IZSÁK \& PAPP, 2000; ClARKE \& WARWICK, 2001a, 2001b; MAGURRAN, 2004).

Uno de los principales objetivos de medir la diversidad biológica es contar con parámetros que permitan tomar decisiones, o emitir recomendaciones a favor de la conservación de especies o áreas amenazadas, así como monitorizar el efecto de las perturbaciones en el ambiente (MORENO, 2001; MAGURRAN, 2004), propósito de este trabajo. Para ello no basta con conocer cuántas especies hay (riqueza específica), sino sus abundancias relativas y absolutas, las densidades y el espacio que ocupan (estructura de la comunidad).

La alteración de las comunidades bióticas debidas a un mayor estrés antropogénico, no sólo altera el número de especies en la mayoría de los ecosistemas, sino también sus abundancias relativas y por ello la dominancia o uniformidad (HILlebrand et al., 2008). Medir la diversidad relativa de cada especie permite identificar aquellas que por su escasa representatividad en la comunidad son más sensibles a las perturbaciones ambientales. Además, identificar un cambio en la diversidad, ya sea en el número de especies, en la distribución de sus abundancias, o en la dominancia, nos alerta acerca de procesos empobrecedores (MAGURRAN, 2004).

El índice de diversidad, en cualquiera de sus versiones, proporciona una idea cuantitativa de la complejidad y la forma de organización de los ecosistemas (COUSINS, 1991; HALFFTER \& EzCURRA, 1992; HuMPHRIES et al., 1995; DÍAZ-PinEDA, 1998; MAGURRAN, 2004), siendo además uno de los parámetros que más claramente detecta la existencia de actividad humana (DíAz-PinEdA et al., 1991; MAGURRAN, 2004). En lo que a componentes vivos se refiere, ello puede explicarse por la abundancia y distribución de las especies de una zona, cuya cantidad puede variar desde unas pocas a un número muy elevado de ellas, siendo de mayor complejidad la organización que presente el número de especies más alto, especialmente si ninguna de ellas es mucho más abundante que las restantes. Por tanto, debe diferenciarse el número de especies presentes en un lugar (la riqueza biológica del sitio) de la proporción del reparto de los individuos de cada una, la equitatividad o uniformidad (CAMARGO, 1995; SMITH \& 
WILSON, 1996), ya que esta última a veces responde más rápidamente a las perturbaciones que la propia riqueza de especies (CHAPIN et al., 2000).

Según HiLlebrand et al. (2008), los efectos de la riqueza de especies en la resistencia de una comunidad son menos predecibles porque la mayor riqueza de especies incrementa la probabilidad de que la comunidad pueda contener especies muy resistentes, pero también altamente susceptibles a las perturbaciones. Así, la resistencia está más conectada a la dominancia (e inversamente a la uniformidad) que a la riqueza de especies, dependiendo el resultado de la identidad de las especies dominantes y de la importancia de las interacciones sinérgicas interespecíficas. En resumen, si la especie (o especies) dominante es susceptible a la perturbación, su comunidad tendrá menor resistencia que las comunidades con más uniformidad en la distribución de las funciones que estas ejercen en el ecosistema. Sin embargo, esas comunidades también obtienen uniformidad después de la perturbación, debido a la sustracción de especies altamente dominantes que no sobreviven a la misma.

Por el contrario, en comunidades donde el dominio se debe a las especies altamente resistentes a las perturbaciones, un aumento de la uniformidad reducirá la resistencia de la comunidad (HILLEBRAND et al., 2008).

Para entender los cambios en la diversidad biológica en relación con la estructura del paisaje, suelen analizarse los componentes alfa, beta y gamma de una comunidad. Así, la diversidad alfa sería la riqueza de especies de una comunidad en particular (ver HALFFTER et al., 2005 para más detalles), a la que se le considera homogénea, la diversidad beta el grado de cambio o reemplazo en la composición de especies entre diferentes comunidades en un paisaje y la diversidad gamma la riqueza de especies del conjunto de comunidades que integran un paisaje, esto como resultado de las diversidades alfa y beta (MORENO 2001; MAGURRAN 2004).

\subsection{2.- MEDICIÓN DE LA DIVERSIDAD ALFA}

La gran mayoría de los métodos propuestos para evaluar la diversidad de especies se refieren a la que existe dentro de las comunidades (alfa). Para medirla se debe definir el aspecto biológico que se quiere describir: el número de especies o la estructura de la comunidad. 
Hasta ahora la diversidad se ha medido registrando el número de especies (riqueza), y/o la estructura de la comunidad (describiendo su abundancia relativadominancia, equitatividad, o riqueza y equitatividad en conjunto) o usando una medida que combine los dos componentes. En este trabajo, para el análisis matemático del componente alfa de la diversidad de avispas Spheciformes en el territorio quemado objeto de este estudio, se han utilizado los índices y parámetros más comúnmente empleados en la definición y análisis de biocenosis (MAGURRAN, 2004). Estos índices y parámetros son:

- Abundancia $(N)$ : Número de ejemplares de la muestra.

- Riqueza específica $(\boldsymbol{S})$ : Número de especies de la muestra. Es la forma más sencilla de medir la biodiversidad, ya que se basa únicamente en el número de especies presentes, sin tener en cuenta la importancia de las mismas. Las medidas de riqueza de especies tienen un gran atractivo intuitivo y evitan muchos problemas a la hora de utilizar modelos e índices (BALTANÁs, 1992). Asegurando la fiabilidad en el tamaño de las muestras, estas medidas proporcionan una expresión comprensible e instantánea de la biodiversidad (MAGURRAN, 2004; IZSÁK \& PAPP, 2000).

- Índice de diversidad de Shannon $\left(H^{\prime}\right)$ : Expresado por la siguiente fórmula:

$$
H^{\prime}=-\Sigma\left(p_{i} \ln p_{i}\right)
$$

siendo $\boldsymbol{p}_{\boldsymbol{i}}$ la proporción de individuos hallados en la especie $i$-ésima, calculada mediante la fórmula $\boldsymbol{n}_{\boldsymbol{i}} / \boldsymbol{n}$ (donde $\boldsymbol{n}_{\boldsymbol{i}}$ es igual al número de ejemplares de $i$ y $n$ el número total de individuos de la muestra). Varía entre cero (para una sola especie) y $\log S$ (cuando todas las especies están representadas por el mismo número de individuos) (MAGURRAN, 2004).

Derivado de la Teoría de la Información (MagurRan, 2004; BEgON et al., 2006), trata de predecir a qué especie pertenecerá un individuo extraído al azar de una muestra. Asume que los individuos son seleccionados al azar, que 
todos tienen la misma probabilidad de ser extraídos y que todas las especies presentes en la comunidad se hallan en la muestra (MAGURRAN, 2004).

El índice crece a medida que aumenta la heterogeneidad de la comunidad, pero en la práctica, para la comunidades biológicas, $\boldsymbol{H}^{\prime}$ no excede el valor de 5 (KREBS, 1989; MAGURRAN, 2004).

- Uniformidad de Pielou ( $\left.J^{\prime}\right)$ : Expresado por la fórmula:

$$
J^{\prime}=H^{\prime} / H^{\prime}{ }_{\max }=H^{\prime} / \ln S
$$

La diversidad máxima $\left(\boldsymbol{H}^{\prime}{ }_{\max }\right)$ aparece cuando todas las especies son igualmente abundantes, es decir, si $\boldsymbol{H}^{\prime}=\boldsymbol{H}^{\prime}{ }_{\max }=\ln \boldsymbol{S}$. El valor de $\boldsymbol{J}^{\prime}$ está acotado entre 0 y 1 , donde 1 representa la situación en la que todas las especies son igualmente abundantes (KrEBS, 1989; MORENO, 2001; MAGURRAN, 2004). Este índice también considera que todas las especies presentes en la comunidad están representadas en la muestra.

- Índice de dominancia de Simpson $(\lambda)$ : Expresado por la fórmula:

$$
\lambda=\Sigma p_{i}^{2}
$$

donde $\boldsymbol{p}_{\boldsymbol{i}}$ es la abundancia proporcional de la especie $i$-ésima, es decir, el número de individuos de la especie $i$ dividido entre el número total de individuos de la muestra (MORENO, 2001). Expresa la importancia proporcional de las especies más abundantes (MAGURRAN, 2004). Traduce el concepto opuesto al de uniformidad, reflejando la mayor o menor predominancia, en cuanto a su abundancia, de unas especies sobre otras (MAGURRAN, 2004; MORENO, 2001).

Dado que, a medida que $\lambda$ se incrementa, la dominancia es mayor, es habitual emplear la forma $1-\lambda$ (o $1 / \lambda$ ) para expresar el índice, de manera que a dominancias mayores (que aparecerían en comunidades menos equilibradas) se obtengan valores inferiores del índice. En este trabajo se ha empleado la expresión 1 - $\lambda$ ', una corrección de la expresión original para tamaños muestrales 
reducidos (que corresponde a una extracción de los individuos sin reemplazo en lugar de con reemplazo).

Sin embargo, estos análisis no realizan ninguna evaluación de la diversidad filogenética o taxonómica de los individuos de una muestra. De este modo, dos comunidades que presenten igual número de especies y patrones equivalentes de abundancia, pero que difieran en cuanto a la distribución de sus especies en las categorías taxonómicas superiores, mostrarán similares valores de diversidad. Sin embargo, y sobre todo en el contexto de la biología de la conservación, parece apropiado considerar que las comunidades más variadas taxonómicamente deben considerarse más diversas (MAGURRAN, 2004). De este modo, las medidas de diversidad taxonómica podrían emplearse conjuntamente con las de riqueza y dominancia como indicadores del estado de conservación de un área determinada (CLARKE \& WARWICK, 2001a). Aunque para su medición se hace necesario conocer con detalle la filogenia del grupo estudiado (MAGURRAN, 2004), en grupos en los que ese conocimiento existe pueden constituir un aliado valioso en la valoración del estado de las comunidades y en el establecimiento de prioridades de conservación.

En nuestro estudio se han calculado dos de los índices de diversidad taxonómica desarrollados por K. R. Clarke y R. M. Warwick (CLARKE \& WARWICK, 2001a, 2001b): Índice de Distancia Taxonómica Media $(\Delta+)$ e Índice de Variación de la Distancia Taxonómica Media $\left(\Lambda^{+}\right)$. La elección de los mismos está motivada porque muestran ciertas ventajas sobre los índices clásicos de diversidad, entre las que destacan: (1) su independencia respecto del tamaño de muestra; (2) su relación monotónica con el grado de perturbación (aumentando o disminuyendo, pero no ambos); (3) su menor sensibilidad a las diferencias en las variables ambientales, pero con respuesta a las perturbaciones antropogénicas; y (4) su capacidad para reflejar las relaciones genéticas, filogenéticas o taxonómicas de los individuos de la muestra (CLARKE \& WARWICK, 2001a, 2001b).

Estos dos nuevos índices, con propiedades interesantes, han sido aplicados casi exclusivamente en estudios de comunidades marinas (CLARKE \& WARWICK, 1999; Hall \& Greenstreet, 1998; PiePenburg et al., 1997; Price et al., 1999, Heino et al., 2005), y se han utilizado recientemente en el análisis de la estructura de comunidades de insectos (ANU \& SABU, 2006 -hormigas-; BAÑOS-PICÓN et al., 2009 -avispas 
Spheciformes-; DARDón et al., 2009 -abejas-, en revisión), si bien en ningún caso para valorar los efectos de perturbaciones sobre las mismas.

- Índice de Distancia Taxonómica Media $(\Delta+)$ : Expresado por la fórmula:

$$
\Delta+==\left[\sum \sum \mathbf{i}<\mathbf{j} \omega \mathbf{i j}\right] /[\mathbf{S}(\mathbf{S}-\mathbf{1}) / 2]
$$

donde $S$ es el número de especies observadas en la muestra y el doble sumatorio abarca todos los pares $i$ y $j$ de estas especies $(i<j)$. Expresa la distancia taxonómica media entre todos los pares de especies de una lista (CLARKE \& WARWICK, 2001a) y considera únicamente datos de presencia - ausencia.

$\mathrm{Su}$ valor se reduce generalmente para hábitats degradados, en comparación con otros mejor conservados y, según CLARKE \& WARWICK (2001 a) presenta menor sensibilidad a las diferencias en las variables ambientales y a las diferencias entre hábitats, aunque responde a las perturbaciones antropogénicas.

- Índice de Variación en la Distancia Taxonómica $(\Lambda+)$, expresado como:

$$
\Lambda+=\left[\sum \sum \mathbf{i}<\mathbf{j}(\omega \mathbf{i j}-\Delta+)^{2}\right] /[\mathbf{S}(\mathbf{S}-1) / 2]
$$

Complementa a la Distancia Taxonómica Media $(\Delta+)$, representando la variación en las distancias entre cada par de especies y reflejando la inequitabilidad del árbol taxonómico.

La combinación de ambos índices proporciona un resumen estadístico robusto de los patrones de relación taxonómica (o filogenética) dentro de una muestra (CLARKE \& WARWICK, 2001b). Recientemente, MouIllot et al. (2005) han propuesto que valores bajos de distancia taxonómica media estarían relacionados con la presencia de impactos de origen antropogénico (y valores elevados de $\Delta+$ con ausencia de impacto antropogénico), mientras que valores altos de variación en la distancia taxonómica podrían asociarse con una elevada variabilidad ambiental. 
Todos los índices han sido calculados mediante la aplicación informática PRIMER $v 5$ (PRIMER-E Ltd).

\subsection{3.- MEDICIÓN DE LA DIVERSIDAD BETA}

Para analizar el efecto de los cambios en el ambiente se hace necesario disponer de información tanto sobre la diversidad biológica en comunidades naturales y modificadas (diversidad alfa) como acerca de su tasa de cambio entre distintas comunidades (diversidad beta). Con ello, se conocerá su contribución a nivel regional y se podrán diseñar estrategias de conservación coherentes, así como llevar a cabo acciones concretas (BISBY, 1995; HALFFTER, 1998; HALFFTER et al., 2001).

MAGURRAN (2004) define la diversidad beta (término acuñado por WHITTAKER en 1960) como "una medida de cuán diferentes (o similares) son una serie de hábitats o muestras en términos de variación de las especies encontradas en ellos".

En el presente estudio, para el cálculo de la diversidad beta se emplea el índice de complementariedad de Colwell y Coddington (COLWELl \& CODDINGTON, 1994), que establece el grado de diferencia entre dos comunidades y que viene dado por la fórmula:

$$
C J K=U J K / S J K
$$

donde: $U j k=S j+S k-2 V j k$ y $S j k=S j+S k-V j k$. La riqueza de ambas comunidades está representada por $S j$ y $S k$ respectivamente, mientras que $V j k$ indica el número de especies comunes.

\subsection{4.- ANÁLISIS MULTIVARIANTE}

El análisis multivariante surge como una necesidad para explicar fenómenos complejos para los que la utilización de métodos univariantes y bivariantes son inadecuados o excesivamente simplistas y comprende un conjunto de técnicas dedicadas al análisis de grupos de datos con múltiples variables.

Un grupo de métodos de análisis multivariante se basa en las similitudes entre pares de muestras, lo que permitirá agruparlas en función de su proximidad, o construir 
un diagrama de ordenación, en el cual las distancias entre pares de muestras reflejan sus similitudes en cuanto a la composición de especies.

\subsubsection{1.- Análisis de Escalamiento Multidimensional (MDS)}

Para analizar la relación entre las distintas muestras se generaron representaciones en dos (o tres) dimensiones mediante la realización Análisis de Escalamiento Multidimensional (MDS), utilizando como medida de proximidad el coeficiente de Bray-Curtis.

El punto de partida para llevar a cabo este análisis es construir una matriz de disimilitud entre las muestras, entre pares de muestras a partir de los coeficientes de similitud. Puede llevarse a cabo con cualquiera de los múltiples índices de similitud existentes, aunque en este trabajo se empleó el de Bray-Curtis (BRAY \& CURTIS, 1957) por ser uno de los más utilizados en estudios ecológicos (CLARKE \& WARWICK, 2001a). Su valor se sitúa entre 0 (cuando las dos muestras no tienen especies en común) y 100 (cuando las muestras son idénticas).

El objetivo del MDS es construir un "mapa", en un determinado número de dimensiones (por lo general en dos), que intenta satisfacer las condiciones impuestas por el rango de la matriz de similitud (o disimilitud) (ej. si la muestra 1 tiene mayor similitud con la muestra 3 que con la muestra 2, se representará más próxima a aquélla que a ésta).

La fidelidad de la representación se mide en función de su "stress", una medida de la desviación de una relación linear entre la distancia en la matriz original de datos y la distancia en el espacio de ordenamiento. Según Clarke \& WARWICK (2001a), valores de stress:

- $\quad$ 0,05 indican una muy buena representación de los datos en el gráfico.

- < 0,1 indican una buena representación; la agregación de un tercer eje aportará escasa información adicional.

- > $\mathbf{0 , 2}$ revelan que el gráfico en dos dimensiones es potencialmente útil, aunque no ofrece mucha confianza. 
- > 0,3, llevarían a considerar que la distribución de los puntos es casi al azar.

Por el modo de funcionamiento del análisis, este método permite trabajar con matrices con diferentes abundancias (ej. especies muy abundantes y especies raras) ya que en el análisis se reduce el peso de las especies raras. El MDS es un método adecuado cuando los datos no son normales o cuando se dispone de variables en escalas discontinuas o arbitrarias, por lo que su uso con datos ecológicos es frecuente (HoLlAN, 2008).

Sus principales ventajas (CLARKE \& WARWICK, 2001a) radican en que:

I. Es de comprensión simple: las distancias entre muestras en el mapa de ordenación reflejan la disimilitud de las mismas en la matriz de disimilitudes, de manera que cuanto más cercanas se muestren unas de otras, más similares serán.

II. Se basa en la información relevante de las muestras: trabaja sobre la matriz de disimilitudes (no sobre los datos originales), de manera que cuenta con total libertad para definir la similitud en la composición de la comunidad de lo que sería en términos biológicamente significativos.

III. Hace innecesaria la eliminación de especies: al llevar a cabo el cálculo desde la matriz de disimilitudes, el número de especies en el cual se basa es irrelevante para la realización de los cálculos requeridos. Normalmente, la medida de similitud disminuirá automáticamente el peso de las especies raras.

IV. El MDS es generalmente aplicable: puede aplicarse en una amplia variedad de situaciones.

\subsubsection{2.- Análisis de Similitud (ANOSIM) (ClARKE, 1993)}

El análisis de similitudes es un procedimiento de permutación no paramétrico que permite probar estadísticamente si existen diferencias significativas entre dos o más grupos o unidades de muestreo. Opera directamente sobre la matriz de disimilitud (la 
misma que la empleada para el análisis MDS), previa creación o asignación de las muestras a grupos, en función de lo que se pretenda analizar (p.e. muestras obtenidas en zonas perturbadas o no perturbadas). Si dos grupos de muestras son muy diferentes en su composición de especies, las diferencias de la composición entre grupos de muestras serán mayores que dentro de las muestras de cada grupo.

Produce un estadístico $R$, una medida absoluta de distancia entre los grupos, basado en la diferencia de los rangos medios de similitud de todos los pares de réplicas entre los diferentes grupos $\left(r_{-} B\right)$ y la media de todos los rangos de similitud de las réplicas dentro de los grupos $\left(r_{-} W\right)$ :

$$
R=\left(r_{-} B-r_{-} W\right) / 1 / 2 M
$$

donde $\boldsymbol{M}=(\boldsymbol{n}(\boldsymbol{n}-\mathbf{1}) / 2)$, siendo $\boldsymbol{n}$ es el número total de muestras analizadas.

Partiendo de la hipótesis nula de que no hay diferencias en la composición de la comunidad entre los sitios, valores positivos y elevados (hasta 1) de $R$, indican baja similitud entre los grupos; mientras que valores bajos (hasta 0 ) indican alta similitud entre grupos y un agrupamiento completamente al azar. Es en este último caso cuando la hipótesis nula es cierta, de modo que las similitudes entre y dentro de los grupos de muestras es la misma. El nivel de significación se calcula mediante permutaciones de las localidades, entre los diferentes grupos asignados.

\subsubsection{3.- Análisis de Componentes Principales (PCA)}

Estas técnicas fueron inicialmente creadas por PEARSON (1901) y posteriormente desarrolladas por Hotelling (1933), aunque su uso no se popularizó hasta la aparición de los ordenadores, debido a su dificultad de cálculo.

Los objetivos principales de un PCA son reducir la dimensionalidad del conjunto de datos e identificar nuevas variables subyacentes.

En los sistemas naturales, muchas de las variables que se recogen entre los individuos de una comunidad están correlacionadas, por lo que la información es 
redundante. Interesa, por tanto, reducir el número de variables, resumiendo adecuadamente la información y con la menor pérdida posible (MCGARIGAL et al., 2000; LEPŠ \& ŠMILAUER, 2003). En este sentido, la técnica consiste en crear "artificialmente" unas pocas variables "nuevas" (componentes principales), que retengan una parte significativa de la información proporcionada por los datos. Los nuevos componentes principales (o factores) serán una combinación lineal de las variables originales y estarán altamente correlacionados con ellas. Estos componentes se van seleccionando según su importancia en cuanto a la variabilidad total que recogen de la muestra, siendo además independientes entre sí (no están correlacionados) (LEGENDRE \& LEGENDRE, 1998).

El punto de partida es la matriz original de datos, a partir de la cual se obtendrá una matriz de covarianza o matriz de coeficientes de correlación. El PCA construye una transformación lineal que define un nuevo sistema de coordenadas para el conjunto original de datos, en el cual la mayor varianza en el conjunto de datos es capturada en el primer eje (llamado el Primer Componente Principal), la segunda varianza en el segundo eje, y así sucesivamente (LEGENDRE \& LEGENDRE, 1998).

El PCA es una técnica adecuada cuando existe una relación aproximadamente lineal entre las variables. Al realizar un PCA, además del gráfico, se obtiene una tabla con los datos relativos a cada eje, siendo sobre todo importante conocer el porcentaje de varianza explicada por cada eje para poder evaluar si los dos o tres primeros ejes proporcionan una buena representación de los datos. Otra información relevante son los eigenvalores y los eigenvectores. Los eigenvalores son la cantidad de varianza explicada por los componentes y los eigenvectores son los coeficientes de la combinación lineal (componentes principales) que permiten explicar dicha cantidad de varianza.

\subsubsection{4.- Análisis de Redundancia (RDA)}

Con el fin de conocer qué variables ambientales, medidas en las localidades de muestreo, podían explicar la variación en la composición de especies, se llevaron a cabo análisis de redundancia (RDA). 
El análisis de redundancia (RDA) fue propuesto por RAO (1964) y desarrollado por VAN DEN WOLLENBERG (1977) como alternativa al análisis canónico de correlación (CCorA). Se trata de la forma canónica del método de ordenación lineal PCA, pudiendo considerarse como una extensión constreñida (limitada) del mismo, que identifica las tendencias en la dispersión de puntos de datos, que están máxima y linealmente relacionadas, con un conjunto de variables explicativas constreñidas (LEGENDRE \& LEGENDRE, 1998; LEPŠ \& ŠMILAUER, 2003).

RDA es una extensión directa de la regresión lineal múltiple para el modelado de una respuesta multivariada de datos, siendo Redundancia sinónimo de varianza explicada (LEGENDRE \& LEGENDRE, 1998). El RDA asume una relación directa entre las variables dependientes e independientes. Una de sus principales utilidades es examinar la relación entre los dos grupos de variables, que en este caso será la relación entre la composición de especies de una comunidad, medida como las abundancias de cada una de las $n$ especies (variables dependientes, respuesta), y las características ambientales (variables independientes, predictoras), medidas como un conjunto de $m$ variables ambientales (LEGENDRE \& LEGENDRE, 1998).

RDA es un análisis asimétrico, donde $\mathbf{Y}$ es la tabla de variables respuesta y $\mathbf{X}$ es la tabla de variables explicativas. Cuando la tabla $\mathbf{Y}$ contiene datos de abundancia de especies, el componente de los ejes resultantes del RDA se pueden interpretar en términos de diferencias en las abundancias de las especies.

Su resultado se presenta habitualmente como un biplot (diagrama de ordenación compuesto por las especies y las variables ambientales), en el que los ejes de componentes representan los gradientes de abundancia absoluta de especies, constreñidos por las variables explicativas (variables ambientales). Los ángulos entre las especies y las variables ambientales reflejan su correlación (LEGENDRE \& LEGENDRE, 1998)

Los resultados del RDA pueden analizarse para conocer su significación estadística mediante el uso de un test de permutación de Monte Carlo, siendo la hipótesis nula que no existe relación entre las variables ambientales y la composición de especies (ver TER BRAACK \& ŠMILAUER, 1998, pág.: 41-43). 


\section{6.- ANÁLISIS DE LA COMPOSICIÓN GREMIAL DE LA COMUNIDAD}

Entendemos por gremios (del inglés "guilds"), aquellas categorías funcionales que contienen conjuntos de especies que presentan similares nichos, un mismo comportamiento o están adscritas a idéntico nivel trófico (JAKSIC, 1981; TERBOUGH, \& Robinson, 1986; HAWKins \& MCMAHON, 1989; SimberlofF \& DAYAN, 1991; RoOT, 2001; CAPINERA, 2008). Con el fin de reducir la aparente complejidad de una comunidad y comparar distintas comunidades con pocas especies en común, es muy frecuente, en estudios sobre ecología de comunidades, clasificar las especies en gremios o grupos funcionales a través de los cuales reconocer el papel ecológico de estas especies, así como su afinidad taxonómica (TERBOUGH \& RoBInson, 1986; DidHAM et al., 1996; ANDERSEN, 1995).

Son muchos los estudios ecológicos que emplean la clasificación de insectos en gremios como uno de los medios para obtener patrones de distribución de estos organismos en la naturaleza (BASSET, 1999; FIELD, 1992; STEFFAN-DEWENTER, 2002; TYLIANAKIS et al., 2005; SOBEK et al., 2009). Asimismo, este tipo de clasificaciones también ha sido empleado para estimar la recuperación de comunidades de artrópodos y/o la variación de su estructura ante la fragmentación del medio o ante perturbaciones tales como el fuego (GOLDEN \& CRIST, 1999; NIWA \& PECK, 2002; WiKARS, 2002; PotTs et al., 2003; MORETTI et al., 2004, 2006; ARNAN et al., 2006; RODRIGO \& RETANA, 2006; LARRIVEÉ et al., 2008).

Para el estudio de la composición gremial de la comunidad se ha establecido una diferenciación en categorías en cuanto al tipo de dieta pedotrófica (presas capturadas para alimentar a las larvas) y al tipo de sustrato utilizado en la nidificación. En el primer caso se han establecido 7 categorías diferentes, atendiendo, como ya hiciese DELARZE (1990), al grupo taxonómico a que pertenecen las presas (en insectos se consideran los órdenes). Las categorías establecidas fueron: 1) Araneida; 2) Orthoptera; 3) Homoptera; 4) Heteroptera; 5) Larvas de Lepidoptera ; 6) Diptera; 7) Otros (Blattodea, Mantodea, Psocoptera, Thysanoptera, Coleoptera e Hymenoptera -adultos y larvas-).

Según la clasificación propuesta por ROTH (1994), se ha utilizado como una categoría de presas potenciales de Spheciformes el orden Blattodea, ya que a pesar de 
que algunos autores los reúnen con los Mantodea en el orden Dictyoptera, las acusadas diferencias en cuanto a historia natural y comportamiento de estos dos grupos aconsejan su separación (GILLOTT, 1995).

Respecto a los hemípteros, algunos autores establecen dos grupos: Homoptera y Heteroptera, tanto como órdenes distintos o como subórdenes dentro de Hemiptera, mientras que otros consideran que los homópteros forman dos grupos con la misma categoría taxonómica que éste: Sternorrhyncha y Auchenorrhyncha (CARVER et al., 1994; NiETO-NAFRÍA, 1999). En el presente estudio, se consideran los dos grandes grupos inicialmente citados, independientemente de su categoría taxonómica, en consonancia con el tipo de presas capturadas por los Spheciformes, fundamentalmente áfidos y chinches de campo, que pertenecen a los grupos homópteros y heterópteros respectivamente.

En lo que se refiere al sustrato utilizado en la nidificación, se han definido gremios según el comportamiento de las hembras: 1) Parasitoides (que no construyen nidos y aprovechan los nidos y provisiones de otras avispas Spheciformes para efectuar la puesta de sus huevos); 2) Amasadoras (que realizan nidos con barro); 3) Terrícolas (que realizan nidos en distintos tipos de terreno, preferentemente arenoso); 4) Xilícolasrubícolas (en madera muerta o en médula de ramas); 5) Nidificantes en cavidades preexistentes (ver apartado 4.1.2).

\section{7.- BIBLIOGRAFÍA}

Aguiar, A. P. \& Sharkov, A. 1997. Blue Pan Traps as a Potential Method for Collecting Stephanidae (Hymenoptera). J. Hymenoptera Research 6: 422-423.

Aide, T. M., Zimmerman, J. K., Pascarella, J. B., Rivera, L. \& Marcano Vega, H. 2000. Forest regeneration in a chronosequence of tropical abandoned pastures: Implications for restoration ecology. Restoration Ecology 8: 328-338.

Allan, J. D., WiPfli, M. S., Caouette, J. P., Prussian, A. \& Rodgers, J. 2003 Influence of streamside vegetation on inputs of terrestrial invertebrates to salmonid food webs. Can. J. Fish. Aquat. Sci. 60 (3): 309-320.

ANDERSEN, A. N. 1995. A classification of Australian ant communities, based on functional groups which parallel plant life-forms in relation to stress and disturbance. J. Biogeogr. 22 15-29.

ANU, A, \& SABU, T. K. 2006. Biodiversity analysis of forest litter ant assemblages in the Wayanad region of Western Ghats using taxonomic and conventional diversity measures. 13pp. J. Insect Science 7.06, available online: insectscience.org/7.06.

ARCHER, M. E. 1988. The aculeate wasp and bee assemblage (Hymenoptera: Aculeata) of a woodland: Bernwood Forest in the English Midlands. The Entomologist 107 (1): 24-33. 
ARCHER, M. E. 1990. The solitary aculeate wasps and bees (Hymenoptera: Aculeata) of an English suburban garden. Entomologist's Gazette 41 (3): 129-142.

Arnan, X., Rodrigo, A. \& Retana, J., 2006. Post-fire recovery of Mediterranean ground ant communities follows vegetation and dryness gradients. J. Biogeography 33 (7): 1246-1258.

BaltanÁs, A. 1992. On the use of some methods for the estimation of species richness. Oikos 65 (3): 484-492.

Baños-Picón, L., Asís, J. D., Gayubo, S. F., \& Tormos, J. 2009. Analyzing Insect Community Structure through the Application of Taxonomic Distinctness Measures. Zoological Studies 48 (3): 298314.

BASSET, Y. 1988. A composite interception trap for sampling arthropods in tree canopies. J. Australian Entomological Society 27: 213-219.

BASSET, Y. 1999. Diversity and abundance of insect herbivores foraging on seedlings in a rainforest in Guyana. Ecol. Entomol., 24: 245-259

Basset, Y., Springate, N. D., Aberlenc, H. P. \& Delvare, G. 1997. A review of methods for sampling arthropods in tree canopies. En: STORK, N. E., AdIS, J. \& DidHAM, R. K. (eds.). Canopy Arthropods. Pp. 27-52. Chapman \& Hall, Londres.

Begon, M., Townsend, C. R. \& HARPER, J. L. 2006. Ecology: from individuals to ecosystems. Blackwell Publishing. Oxford. 738 pp.

Bengtsson, J. 1998. Which species? What kind of diversity? Which ecosystem function? Some problems in studies of relations between biodiversity and ecosystem function. Appl. Soil Ecol. 10: 191199.

Bengtsson, J., Nilsson, S. G., Franc, A. \& Menozzi, P. 2000. Biodiversity, disturbances, ecosystem function and management of European forests. Forest Ecol Manag 132: 39-50.

Bengtsson J, Angelstam P, Elmqvist T, Emanuelsson, U., Folke, C., Ihse, M., Moberg, F D. \& NyströM, M. 2003. Reserves, resilience, and dynamic landscapes. Ambio 32: 389-96.

BIERINGER, G. 2002. Response of Orthoptera species (Tettigoniidae and Acrididae) to wildfires in a Central European dry grassland. J. Orthoptera Research 11 (2): 237-242.

BISBY, F. A. 1995. Characterization of biodiversity. En: Global Biodiversity Assessment (eds.) HEYWOOD, V. H. \& WATSON, R. T.). Pp. 21-106. UNEP-Cambridge University Press, Cambridge.

Blume, R. R., Miller, H. A., Eschle, J. L. \& Matter, J. J. 1972. Trapping tabanids with modified Malaise traps baited with $\mathrm{CO}_{2}$. Mosquito News 32: 90-95.

BRAY, J. R. \& CURTIS, J. T. 1957. An ordination of the upland forest communities of Southern Wisconsin. Ecolog. Monogr. 27: 325-349

Briscoe, A. D. \& ChitTKa, L. 2001. The Evolution of Color Vision in Insects. Annu. Rev.Entomology 46: 471-510.

BRown, B. V. \& FEENER, D. H. Jr. 1995. Efficiency of two mass sampling methods for sampling phorid flies (Diptera: Phoridae) in a tropical biodiversity survey. Contributions in Science 459: 1-10.

Butler, G. D. Jr. 1965. A modified Malaise insect trap. The Pan-Pacific Entomologist 41 (1): 51-53.

CAMARGO, J. A. 1995. On measuring species evenness and other associated parameters of community structure. Oikos 74: 538-542.

Campbell, J. W. \& Hanula, J. L. 2007. Efficiency of malaise traps and colored pan traps for collecting flower visiting insects from three forested ecosystems. J. Insect Conserv. 11: 399-408.

Campbell, J. W., Hanula J. L, Waldrop, T. A. 2007. Effects of prescribed fire and fire surrogates on floral visiting insects of the blue ridge province in North Carolina. Biological Conservation 134: 393-494. 
Campos, D. F. \& Fernández, F. 2002. El Proyecto "Divesidad de Insectos en Colombia". En: Costa, C., Vanin, S. A., Lobo, J. M. \& Melic, A. (eds.). Proyecto de Red Iberoamericana de Biogeografía y Entomología Sistemática PrIBES 2002 pp. 297-300. m3m-Monografías Tercer Milenio, vol. 2. Sociedad Entomológica Aragonesa (SEA) y CYTED, Zaragoza.

Campos, W. G., Pereira, D. B.S. \& Schoereder, J. H. 2000. Comparison of the Efficiency of FlightInterception Trap Models for Sampling Hymenoptera and Other Insects. An. Soc. Entomol. Brasil 29 (3). Sept. 2000

CANADAy, C. L. 1987. Comparison of insect fauna captured in six different trap types in a Douglas-fir forest. The Canadian Entomoligist 119: 1101-1108.

CAnCElado, R. \& Yonke, T. R. 1970. Effects of prairie burning on insects populations. J. Kansas Entomological Society 43: 274-281.

Cane, J. H., Minckley, R. L. \& Kervin, L. J. 2000. Sampling bees (Hymenoptera: Apiformes) for pollinator community studies: pitfalls of pan-trapping. J. Kansas Entomological Society 73: 225231.

Canovai, R., Giannotti, P., Giannetti, S., Loni, A., Raspi, A., Santini, L., Dellacasa, M., Generani, M., Pagliano, G., Strumia, F., Scaramozzino, P. L., Zuffi, M., Baldaccini, N. E., Puglisi, L., Battesti, M. J. \& Brocard, E. 2000. Biodiversità: compilazione delle specie dell'entomofauna e dei piccoli vertebrati della Corsica e della Toscana Marittima. En: Progetto INTERREG II Toscana-Corsica. L'attività scientifica delle Università di Pisa e Corte (ed. Strumia, F.), pp. 75-86. Unión Europea. Edizioni ETS, Pisa.

CAPINERA, J. L. (ed.). 2008. Encyclopedia of Entomology, 2nd Edition. Springer. 4411 pp.

Carver, M., Gross, G. F. \& Woodward, T. E. 1994. Hemiptera. En: NAumann, I. D. (ed.). Systematic and Applied Entomology Pp: 316-329. Melbourne University Press, Carlton.

Chanter, D. O. 1965. The Malaise trap. Entomological Record 77: 224-226.

Chapin, F. S., Zavaleta, E. S., Eviner, V. T., Naylor, R. L., Vitousek, P. M., Reynolds, H. L., Hooper, D. U., Lavorel, S., Sala, O. E., Hobbie, S. E., Mack, M. C. \& Diaz. S. 2000. Consequences of changing biodiversity. Nature 405: 234-242.

ChineA, J. D. 2002. Tropical forest succession on abandoned farms in the Humacao Municipality of eastern Puerto Rico. Forest Ecol Manag. 167: 195-207.

Clarke, K. R., 1993. Non-parametric multivariate analyses of changes in community structure. Australian J. Ecology 18: 117-143.

ClARKE, K. R. \& WARWICK, R. M. 1999. The taxonomic distinctness measure of biodiversity: weighting of step lengths between hierarchical levels. Marine Ecology Progress Series 184: 21-29.

Clarke, K. R. \& WARWick, R. M. 2001a. Change in marine communities: An Approach to Statistical Analysis and Interpretation. $2^{\text {nd }}$ edition. PRIMER-E, Plymouth. $171 \mathrm{pp}$.

Clarke, K. R. \& WARWICK, R. M. 2001b. A further biodiversity index applicable to species list: variation in taxonomic distinctness. Marine Ecology Progress Series 216: 265-278.

Colwell, R. K. \& Coddington, J. A. 1994. Estimating terrestrial biodiversity through extrapolation. Philosophical Transactions of the Royal Society of London, Series B 345: 101-118.

Cousins, S. H. 1991. Species diversity measurement: choosing the right index. Trends Ecol. Evolution 6: 190-192.

Cruz-Sánchez, M. A., Gayubo, S. F., GonzÁlez, J. A. \& Torres, F. 2004 La comunidad de avispas Spheciformes de un melojar del oeste español: diversidad y dinámica temporal (Hymenoptera, Apoidea: Ampulicidae, Sphecidae y Crabronidae). Nouvelle Revue d'Entomologie (N.S.), 21 (3): 213-238.

Dardón, M. J., Torres, F. \& Asís, J. D. 2009 Analysis of the diversity of Megachilidae bees on the northern subplateau of the Iberian Peninsula. J. Insect Science En revision. 
DARling, D. C. \& PACKER, L. 1988. Effectiveness of Malaise traps in collecting Hymenoptera: The influence of trap desing, mesh size, and location. The Canadian Entomologist 120: 787-796.

De Barro, P. J. 1991. Attractiveness of Four Colours of Traps to Cereal Aphids (Hemiptera: Aphididae) in South Australia. J. Aust. Ent. Soc. 30: 263-264.

De la Nuez, A., González, J. A., Gayubo, S. F. \& Torres, F. 2003. Abundancia y diversidad de avispas sociales (Hymenoptera: Vespidae) en el Parque Natural de "Arribes del Duero" (oeste español). Boletín de la Sociedad Entomológica Aragonesa 32: 87-93.

DECLEER, K. 1990. Faunistich-ecologische studie van de ongerwervelde fauna in het natuur reservaat (De Gulke Putten" (West-Vlaanderen, Wingene). I. Zweefvliegen (Diptera: Syrphidae) en een bespreking van de malaiseval als bemonsteringstechniek. Phegea 18 (2): 71-88.

DELARZE, R. 1990. L'intérêt des guildes trophiques dans la comparaison de listes faunistiques qualitatives. Mitteilungen der Schweizerischen entomologischen Gesellschaft 63: 25-32.

Delettre, Y. R., Morvan, N., Trehen, P. \& Grootaert, P., 1998. Local biodiversity and multi-habitat use in empidois flies (Insecta: Diptera, Empidoidea) Biodivers. Conserv. 7: 9-25.

Delfín H. \& Burgos D. 2000: Los Bracónidos (Hymenoptera: Braconidae) como grupo parámetro de biodiversidad en las selvas deciduas del trópico: una discusión acerca de su posible uso. Acta Zool. Mex. 79: 43-56.

DíAZ-PinEDA, F. 1998. Diversidad biológica y conservación de la biodiversidad. En: Diversidad biológica y cultural rural en la gestión ambiental del desarrollo (coords. DíAZ-PINEDA, F., DE Miguel, J. M. \& CASAdo, M. A.). Pp. 41-55. Ediciones Mundi-Prensa, Madrid.

Díaz-Pineda, F., CASAdo, M. A., DE Miguel, J. M. \& Montalvo, J. (eds.) (1991). Diversidad Biológica/Biological Diversity. Fundación Ramón Areces, ADENA-WWF, SCOPE, Madrid. 300 pp.

Didham, R. K., Ghazoul, J., Stork, N. E., Davis, A. J. 1996. Insects in fragmented forests: a functional approach. Trends in Ecology and Evolution 11: 255-260.

Disney, R. H. L., Erzinçlioglu, Y. Z., Henshaw, D. J. De C., Howse, D., Unwin, D. M., Withers, P. $\&$ Woods, A. 1982. Collecting methods and the adequacy of attempted fauna surveys, with reference to the Diptera. Field Studies 5: 607-621.

DROEGE, S. 2006. Impact of color and size of bowl trap on numbers of bees captured. hhttp://online.sfsu.edu/,beeplot/pdfs/color\%20and\%20size.pdf i

Duelli, P, OBRIST, M. \& Schmatz, D. 1999. Biodiversity evaluation in agricultural landscapes: aboveground insects. Agriculture, Ecosystems and Environment 74: 33-64.

Dufour, C. 1980. Un nouveau piège lumineux pour la capture des Tipulidae et autres Diptères Nématocères: une tente Malaise lumineuse. Bulletin de la Société entomologique Suisse 53: 313320 .

Eldredge, N. 1998. Life in the Balance. Humanity and the Biodiversity Crisis. Princeton University Press, Princeton. 224 pp.

Elmqvist, T., Folke, C., Nystro, M., Peterson, G., Bengtsson, J., Walker, B. \& Norberg, J. 2003. Response diversity, ecosystem change, and resilience. Frontiers in Ecology and the Environment 1: 488-494.

FIELD, J. 1992. Guild structure in solitary spider-hunting wasps (Hymenoptera: Pompilidae) compared with null model predictions. Ecol. Entomol., 17: 198-208

Fraser, S. E. M., Dytham, C. \& Mayhew, P. J. 2008. The effectiveness and optimal use of Malaise traps for monitoring parasitoid wasps. Insect Conserv. Divers. 1: 22-31

GARCÍA, J. L. 2003. Comparación de la captura de Hymenoptera (Insecta) mediante cuatro métodos de muestreo, en los cerros Yaví y Yutajé del Pantepui venezolano. Entomotropica 18 (1): 27-35. 
GAyubo, S. F., GonzÁlez, J. A. \& Torres, F. 2000. Estudio de una comunidad de esfécidos en la zona natural de "Las Arribes del Duero" (Salamanca, Oeste español) (Hymenoptera, Sphecidae). Fragmenta entomologica 32 (1): 181-209.

Gayubo, S. F., Nieves-Aldrey, J. L., GonzÁlez, J. A., Asis, J. D., Rey del Castillo, C. \& Tormos, J. 2004a. La communidad de avisas esfeciformes de la estación biogeológica de El Ventorillo (Sector Medio de la Sierra de Guadarrama Madrid, España) (Hymenoptera, Apoidea, Ampulicidae, Sphecidae y Crabronidae). Nouvelle Revue d'Entomologie (n.s.) 21: 125-156.

Gayubo, S. F., Nieves-Aldrey, J. L., GonzÁlez, J. A., Tormos, J., Rey del Castillo, C. \& Asis, J. D., 2004b. Diversidad de avispas spheciformes (Hymenoptera, Apoidea, Ampulicidae, Sphecidae y Crabronidae) colectas mediante trampa Malaise en el Monte Pardo (Madrid, España). Boletín de la Real Sociedad española de Historia natural, Sección Biologica 99: 105-113.

GiBB, H. \& Hochuli, D. F. 2002. Habitat fragmentation in an urban environment: large and small fragments support different arthropod assemblages. Biological Conservation 106 (1): 91-100.

Gillot, C. 1995. Entomology. $2^{\mathrm{a}}$ edición. Plenum Press, Nueva York. xviii +798 pp.

Golden, D. M. \& CRIST, T. O. 1999. Experimental effects of habitat fragmentation on old-field canopy insects: community, guild and species responses. Oecologia 118: 371-380.

GonzÁlez, J. A., Gayubo, S. F. \& Strumia, F. 1998a. Biodiversità dei Crisididi di un ambiente orticolo del territorio "Las Arribes del Duero" (provincia di Salamanca, Spagna Occidentale) (Hymenoptera, Chrysididae). Frustula Entomologica n. s., XXI (XXXIV): 26-41

González, J. A., Gayubo, S. F. \& Torres, F. 1998b. Diversidad y abundancia de esfécidos (Hymenoptera, Sphecidae) en un sector arenoso de la Submeseta Norte (España). Boletín de la Real Sociedad Española de Historia Natural (Sec. Biol.) 94 (3-4): 71-85.

González, J. A., Gayubo, S. F., De La Nuez, A. \& Blasco-Zumeta, J. 2000a. Estudio de la comunidad de esfécidos (Hymenoptera, Sphecidae) colectados mediante trampas Malaise en un sabinar de Los Monegros (Zaragoza, España). IX Congreso Ibérico de Entomología (Zaragoza, 2000). Libro de resúmenes pág. 104.

GonzÁlez, J. A., GAyubo, S. F. \& Torres, F. 2000b. Diversidad y abundancia de esfécidos en una zona pirenaica con influencia mediterránea. Nouvelle Revue d'Entomologie (N.S.) 17 (1): 13-33.

González, J. A., Tomé, M. A. M., Gayubo, S. F. \& Torres, F. 2000c. Himenópteros aculeados capturados mediante trampas Malaise en un sector arenoso de la Submeseta Norte (España) (Hymenoptera, Aculeata). Nouvelle Revue d'Entomologie (N.S.) 17 (4): 337-353.

González, J. A., Gayubo, S. F., Asís, J. D., Tormos, J, \& García, C. 2003. Estructura y dinámica temporal de la comunidad de avispas esfeciformes (Hymenoptera: Apidea: Ampulicidae, Sphecidae y Crabronidae) en un pastizal de la Cuenca Alta del Duero (España). Boletín de la Real Sociedad Entomológica Aragonesa 32: 59-65.

GreEnwood, H., O'Dowd, D. J. \& LAKE, P. S. 2004. Willow (Salix x rubens) invasion of the riparian zone in south-eastern Australia: reduced abundance and altered composition of terrestrial arthropods. Divers. Distribut. 10 (5-6): 485-492.

HAlbert, S.E., Zhang, G. X. \& PU, Z. Q. 1986. Comparison of sampling methods for alate aphids and observations on epidemiology of soybean mosaic virus in Nanjing, China. Annals of Applied Biology 109: 473-483.

HALFFTER, G. 1998. A strategy for measuring landscape biodiversity. Biology International 36: 3-17.

HAlfFter, G. \& EzCURRA, E. 1992. ¿Qué es la biodiversidad?. En: La Diversidad Biológica en Iberoamérica (compilador HALFFTER, G.), pp. 3-24. Acta Biológica Mexicana (n.s.), volumen especial de 1992. CYTED, México D.F

Halffter, G., Moreno, C. E. \& Pineda, E. O. 2001. Manual para evaluación de la biodiversidad en Reservas de la Biosfera. M\&T - Manuales y Tesis SEA vol. 2, Zaragoza. 80 pp. 
Halffter, G., Soberón, J., Koleff, P. \& Melic, A (eds.). 2005. Sobre Diversidad Biológica: El significado de las Diversidades Alfa, Beta y Gamma. M3m-Monografías 3ercer Milenio, vol. 4. S.E.A., CONABIO, Grupo DIVERSITAS \& CONACYT, Zaragoza. IV + 242 pp.

Hall S. J. \& Greenstreet, S. P. 1998. Taxonomic distinctness and diversity measures, responses in marine fish communities. Mar. Ecol. Prog. Ser. 166: 227-229.

HANSEN, J. D. 1986. Comparison of insects from burned and unburned areas after a range fire. Great Basin Naturalist 46 (4): 721-727.

HANSEN, J. D. 1988. Trapping methods for rangeland insects in burned and unburned sites: A comparison. Great Basin Naturalist 48 (3): 383-387

HARris, A. 1982. On Malaise traps and collecting bags. Sphecos 5: 10-12.

Hawkins, C. P. \& McMahon, J. A. 1989. Guilds: The multiple concept meaning. Annu. Rev. Entomology 34: 423-451.

Heino, J., Soinien, J., Lappalainen, J. \& ViRTanen, R. 2005. The relationship between species richness and taxonomic distinctness in freshwater organisms. Limnol. Oceanogr. 50: 978-986

HeYwood, V. H. 1995. Global Biodiversity Assessment. UNEP. Cambridge University Press, Cambridge, $1140 \mathrm{pp}$.

Hillebrand, H., Bennett, D. M. \& Cadotte, M. W. 2008. Consequences of Dominance: A Review of Evenness Effects on Local and Regional Ecosystem Processes. Ecology 89 (6): 1510-1520

HirowatARI, T. \& MAKIHARA, H. 2007. Effects of fires on butterfly assemblages in lowland dipterocarp forest in East Kalimantan. Entomological Science 10 (2): 113-127.

Holland, S. M. 2008. Non-Metric Multidimensional Scaling. URL: http://www.uga.edu/strata/software/pdf/mdsTutorial.pdf

Hooper, D. U., Chapin, F. S., III, Ewel, J. J., Hector, A., Inchausti, P., Lavorel, S., Lawton, J. H., Lodge, D. M., Loreau, M., NAEem, S., Schmid, B., Setälä, H., Symstad, A. J., VAndermeEr, J. \& Wardle, D. A. 2005. Effects of Biodiversity on Ecosystem Functioning: A Consensus of Current Knowledge. Ecological Monographs 75 (1): 3-35

Hotelling, H. 1933. Analysis of a complex of statistical variables into principal components. J.Educational Psychology, 24: 417-441, 498-520.

Hubbell, T. H. 1956. A new collecting method: The oatmeal trail. Entomol. News 67:49-51.

Humphries, C. J., Williams, P. H. \& vane-Wright, R. I. 1995. Measuring biodiversity value for conservation. Annu. Rev. Ecol System 26: 93-111.

Huston, M. 1979. A general hypothesis of species diversity. American Naturalist 113: 81-101.

Huston, M. A. 1994. Biological diversity: the coexistence of species on changing landscapes. Cambridge University Press, Cambridge, UK.

HutCHESON, J. 1991. Malaise trap collection jar: a cheap simple modification. New Zealand Entomologist 14: 48-49.

IZSÁK, J. \& PAPP, L. 2000. A link between ecological diversity indices and measures of biodiversity. Ecological Modelling 130: 151-156.

Jackson, J. B. C., Kirby, M. X., Berger, W.H., Jeremy B. C. Jackson, Bjorndal, K. A., Botsford, L. W., Bourque, B. J., Bradbury, R. H., Cooke, R., Erlandson, J., Estes, J. A., Hughes, T. P., Kidwell, S., Lange, C. B., Lenihan, H. S., Pandolfi, J.M., Peterson, C. H., Steneck, R. S., TEGner, M. J., WARnER, R. R. 2001. Historical overfishing and recent collapse of coastal ecosystems. Science 293: 629-638.

JAKSIC, F. M. 1981. Abuse and misuse of the term "guild" in ecological studies. Oikos 37: 397-400.

KIRK, W. D. J. 1984. Ecologically selective colored traps. Ecol. Entomol. 9: 35-41.

KREBS, C. J. 1989. Ecological Methodology. Harper Collins Publishers Inc., Nueva York. xii + 654 pp. 
Kuhlmann, M. 1994. Die Malaise-Falle asl Instrument der faunistisch-ökologischen Arbeit. Erfahrungen-Probleme- Für und Wider. bembiX 3: 27-34.

KuhlmanN, M. 2002. Struktur der Wildbienen- und Wespenzönosen ausgewählter Waldstandorte im Nationalpark Bayerischer Wald (Hymenoptera, aculeata) NachrichtenBlatt der Bayerischen Entomologen 51 (3-4): 61-74.

LARrivÉE, M., Drapeau, P. \& FAHRig, L. 2008. Edge effects created by wildfire and clear-cutting on boreal forest ground-dwelling spiders. Forest Ecol Manag 255: 1434-1445.

LARSSON, M. 2008 VILDBIN I DALARNAS ODLINGSLANDSKAP En inventering med fokus på åtgärdsprogrammet för bevarande av vildbin på ängsmarker Rapport 2008: 18. http://www.w.lst.se/upload/12261/08_18.pdf

LAUBERTIE, WrATtEN \& SEDCOLE, 2006. The role of odour and visual cues in the pan-trap catching of hoverflies (Diptera: Syrphidae) Annals Applied Biology 148 (2): 173-178 (6).

Lawton, J. H. \& May, R. M. (eds.) 1995. Extinction Rates. Oxford University Press, Oxford. 256 pp.

LAZZARI, S. G. M. \& LAZArotto, C. M., 2005 Distribuic̃ao actitudinal e sazonal de afídeos (Hemiptera, Aphididae) na Serra do Mar, Paraná, Brasil. Revista Brasileira de Zoología 22 (4): 891-897

Legendre, P. \& Legendre, L. 1998. Numerical ecology. 2nd English edition. Elsevier Science BV, Amsterdam. $\mathrm{xv}+853 \mathrm{pp}$.

LeiranA-Alcocer, J. \& GonzÁlez-Moreno, A. 2007: Comparación de dos tipos de trampas en estudios de diversidad de Bracónidos (Hymenoptera: Braconidae) de Yucatán. Entomol. Mex. 6: 332-336

Leksono, A., TAKada, K., NAKagoshi, N \& NaKamura, K. 2006 Species composition of Modellidae and Cerambycidae (Coleoptera) in a coppice woodland. J For Res 11: 61-64.

LEONG, J. M.\& THORP, R. W. 1999. Colour-coded sampling: the pan trap colour preferences of oligolectic and nonoligolectic bees associated with a vernal pool plant. Ecological Eentomology 24 (3): 329335 .

LEPŠ, J. \& ŠMILAUER, P. 2003. Multivariate analysis of ecological data using CANOCO. Cambridge University Press, Cambridge, United King-dom. 269 pp.

Lockwood, J. A., Shaw, S. R. \& Struttmann, J. M. 1996. Biodiversity of wasp species (Insecta: Hymenoptera) in burned and unburned habitats of Yellowstone National Park, Wyoming, USA. J. Hymenopt. Res. 5: 1-15.

Longino, J. T. \& Colwell, R. K. 1997. Biodiversity assessment using structured inventory: capturing the ant fauna of a tropical rain forest. Ecological Applications 7 (4): 1263-1277.

LundBerg J. \& Moberg F. 2003. Mobile link organisms and ecosystem functioning: implications for ecosystem resilience and management. Ecosystems 6: 87-98.

MagurRan, A. E. 2004. Measuring Biological Diversity. Blackwell Science Publishing. Oxford.

Makihara, H., KinuUra, H., Yahiro, K. \& Soeyamto, C. 2000. The effects of droughts and fires on Coleopteran insects in lowland dipterocarp forests in Bukit Soeharto, East Kalimantan. En: Guhardja, E., Futawi, M., Sutisna, M. \& Ohta, S. (eds.) Rainforest Ecosystems of East Kalimantan. Ecological Studies, 140: 153-163. Springer, Tokyo.

Makino, S., Goto, H., Inoue, T.,Sueyoshi, M., OKabe, K., Hasegawa, M., Hamaguchi, K., Tanaka, H. \& Окосні, I. 2006 The Monitoring of Insects to Maintain Biodiversity in Ogawa Forest Reserve. Environ. Monitoring and Assessment 120: 477-485.

Marcos-García M. A. 2004. Métodos de captura. En: Barrientos, J. A. (ed.): Curso Práctico de Entomología. Asociación Española de Entomología; CIBIO Centro Iberoamericano de la Biodiversidad, Universidad de Alicante; Universitat Autònoma de Barcelona, Servei de publicacions, pp. 27-45.

MASNER, L., 1976. Yellow pan traps (Moericke traps, Assiettes jaunes). Proctos 2 (2): 2. 
MASNer, L. \& Goulet, H. 1981. A new model of flight-interception trap for some hymenopterous insects. Entomological News 92 (5): 199-202.

Matthews, R. W. \& Matthews, J. R. 1970. Malaise trap studies of flying insects in a New York Mesic Forest I. Ordinal composition and seasonal abundance. N. Y. Entomol. Soc. 78: 52-60.

Matthews, R. W. \& Matthews, J. R. 1971. The Malaise trap: its utility and potential for sampling insect populations. The Michigan Entomologist 4 (4): 117-122.

Matthews, R. W. \& Matthews, J. R. 1983. Malaise traps: the Townes model catches more insects. Contributions of the American Entomological Institute 20: 428-432.

MAZÓN, M. \& BORDERA, S. 2008. Effectiveness of two sampling methods used for collecting Ichneumonidae (Hymenoptera) in the Cabañeros National Park (Spain). Eur. J. Entomol. 105: 879-888.

McGarigal, K., Cushman, S. \& Stafford, S. 2000. Multivariate Statistics for Wildlife and Ecology Research. Springer-Verlag New York, Inc. 283 pp.

McGrady-SteEd, J., HARRIS, P. M. \& Morin, P. J. 1997. Biodiversity regulates ecosystem predictability. Nature 390: 162-165.

McNaughton, S. J. 1993. Biodiversity and function of grazing ecosystems. En: Schultze, E. D., MoOney, H. A. (eds.). Biodiversity and Ecosystem Function. pp. 361-383. Springer.

MoERICKE, V. 1951. Eine farbefalle zür kontrolle des fluges von blattlausen, insbesondere der pfirsichblattlaus, Myzodes persicae (Sulz.). Nachrichtenblatt der deutschen pflanzenschutz dienst (Braunschweig) 3: 23-24.

MOERICKE, V. 1995. Über die lebensgewohnheiten der geflugelten blattlause (Aphidina) under besonderer berucksichtigung des verhaltens beim landen. Zietschrift für Angewandte Entomologie 37: 29-91.

Moreno, C. E. 2001. Métodos para medir la biodiversidad. M\&T-Manuales y Tesis SEA vol.1, Zaragoza. 84 pp.

Moreno, J. O. \& CARles-Tolrá, M. 2004. Calliopum tripodium Carles-Tolrá, 2001: nuevo lauxánido para España (Diptera, Lauxaniidae) Bol. S.E.A. 34: 222.

MoretTi, M. 2000. Effects of winter fire on spiders. Proceedings of the 19th European Colloquium of Arachnology, Århus 17-22 July 2000. European Arachnology 2000 (S. Toft \& N. Scharff eds.), pp. 183-190

Moretti, M. \& S. Barbalat. 2004. The effects of wildfires on wood-eating beetles in deciduous forests on the southern slope of the Swiss Alps. Forest Ecol Manag 187 (1): 85-103.

Moretti, M., Duelli, P. \& OBrist, M. K. 2006. Biodiversity and resilience of arthropod communities after fire disturbance in temperate forests. Oecología 149: 312-327.

Moretti, M., Obrist, M. K. \& Duelli, P. 2004. Arthropod biodiversity after forest fires: winners and losers in the winter fire regime of the Southern Alps. Ecography 27 (2): 173-186.

Moretti, M., Conedera, M., Duelli, P. \&Edwards, P. J. 2002. The effects of wildfire on ground-active spiders in deciduous forests on the Swiss Southern slope of the Alps. J. Applied Ecology 39 (2): 321-336.

Mouillot, D., Gaillard, S., Aliaume, C., Verlaque, M., Belsher, T., Troussellier, M. \& Do Chi, T. 2005. Ability of taxonomic diversity indices to discriminate coastal lagoon environments based on macrophyte communities. Ecol. Indicat. 5: 1-17.

MuirheAd-Thomson, R. C. 1991. Trap responses of flying insects. The influence of trap desing on capture efficiency. Academic Press, Londres. 304 pp.

NAEEM, S. \& LI, S. B. 1997. Biodiversity enhances ecosystem reliability. Nature 390: 507-509.

NAEEM, S. 1998. Species redundancy and ecosystem reliability. Conserv. Biol. 12: 39-45. 
NAtion, J. L. 2008. Eyes and Vision. Pp: 1381-1392. En: CAPInERA, J. L. (ed.). Encyclopedia of Entomology, 2nd Edition. Springer. 4411 pp.

NiETO-NAFRíA, J. M. 1999. Filogenia y posición taxonómica de los "homópteros" y de sus principales grupos. Boletín de la Sociedad Entomológica Aragonesa 26: 421-426.

NiEVES-AlDREY, J. L. 1995. Abundancia, diversidad y dinámica temporal de cinípidos en dos hábitats del centro de España (Hymenoptera: Cynipidae). En: Avances en Entomología Ibérica (eds. Comité Editorial del VI Congreso Ibérico de Entomología), pp. 113-136. Museo Nacional de Ciencias Naturales (CSIC) y Universidad Autónoma de Madrid. 502 pp.

NIWA, C. G. \&PECK, R. W. 2002. Influence of prescribed fire on carabid beetle (Carabidae) and spider (Araneae) assemblages in forest litter in southwestern Oregon. Environ. Entomol. 31: 785-796.

Noguera, F. A., Zaragoza-Caballero, S. Chemsak, J. A., Rodríguez-Palafox, A., Ramírez, E., GonZÁleZ-Soriano, E. \& AyAlA, R. 2002. Diversity of the family Cerambycidae (Coleoptera) of the tropical dry forest of Mexico, I. Sierra de Huautla, Morelos. Annals Entomol. Soc. America 95 (5): 617-627.

NOYES, J. S., 1989. The study of five methods of Sampling Hymenoptera (Insecta) in a tropical rainforest, with special reference to the Parasitica. J. Natural History 23: 285-298.

Ortiz-SAnchez, F.J. \& Aguirre-Segura, A. 1993. Efecto del color sobre las capturas de abejas mediante trampas Moericke en el sur de España (Hymenoptera, Apoidea). Graellsia 49: 63-71.

OWEN, D. F. 1983. A hole in a tent or how to explore insect abundance and diversity. Contributions of the American Entomological Institute 20: 32-46.

OwEN, J. 1991. The Ecology of a Garden: The first fifteen years. Cambridge University Press, Cambridge, UK. 403 pp.

Paine, R. T, Tegner, M. J. \& Johnson E. A. 1998. Compounded perturbations yield ecological surprises. Ecosystems 1: 535-45.

PAPP, J. \& JóZAN, Z. 1995. The dispersion and phenology of sawflies and aculeate wasps in the Síkfókút oak forest, Hungary (Hymenoptera). Folia Entomologica Hungarica 56: 133-152.

PAuly, A. 1989. Hyménoptères Aculéates récoltés dans un réseau de 15 pièges Malaise en Hesbaye (Belgique). Bulletin et Annales de la Société royale belge d'Entomologie 125: 140-146.

PeArson, K. 1901. On Lines and Planes of Closest Fit to Systems of Points in Space. Philosophical Magazine 2 (6): 559-572.

PETERSON, A. 1964. Entomological techniques. How to work with insects. Edwards Brothers Ed., Michigan. $435 \mathrm{pp}$.

Peterson, G., Allen, C. R. \& Holling, C. S. 1998. Ecological resilience, biodiversity and scale. Ecosystems 1: 6-18.

PICKETT, S. T.A. 1989. Space-for-time substitution as an alternative to long-term studies. Likens GE (ed) Long-term studies in ecology: approaches and alternatives. Springer, Berlin Heidelberg New York.

PiepenburG, D., Vob, J. \& GuTt, J. 1997. Assemblages of sea stars (Echinodermata: Asteroidea) and brittle stars (Echinodermata: Ophiuroidea) in the Weddel 1 Sea (Antarctica) and off Northeast Greenland (Artic): a comparison of diversity and abundance. Polar Biol. 17: 305-322.

Platt, J., Caldwell, J. S. \& KoK, L. T. 1999. An easily replicated, inexpensive Malaise-type trap desing. J. Entomological Science 34 (1): 154-157.

Potts, S. G., Vulliamy, B., Dafni, A., Ne’eman, G., O’Toole, C., Roberts, S. \& Willmer, P.G. 2003. Response of plant-pollinator communities to fire: changes in diversity, abundance and floral reward structure. Oikos 101 (1): 103-12.

Precht, A. \& Cölln, K. 1996. Zum Standorbezug von Malaise-Fallen. Eine Untersuchung am Beispiel der Schwebfliegen (Diptera: Sirphidae). Fauna und Flora in Rheinland-Pfalz. 8 (2): 449-508 
Price, A. R. G., Keeling, M. J. \& O’CAllaghan, C. J. O. 1999. Ocean-scale patterns of 'biodiversity' of Atlantic asteroids determined from taxonomic distinctness and other measures. Biol. J. Linn. Soc. 66: 187-203.

PuCCI, T., 2008. A Comparison of the Parasitic Wasps (Hymenoptera) at Elevated Versus Ground Yellow Pan Traps in a Beech-Maple Forest J. HYM. RES. 17 (1): 116-123.

Purvis, A., Aapow, P. M., Gittleman, J. L. \& MACE, G. M. 2000. Nonrandom extinction risk and the loss of evolutionary hystori. Science 228: 328-330.

Quintero D., Cambra, R. A., Santos A. \& Miranda. R. J. 2008 Biodiversidad De Insectos En La Reserva Forestal La Tronosa (Rflt), Azuero, Panamá. http://probio-panama.org/resinsectos.htm

RAO, C. R., 1964. The use and interpretation of principal components analysis in applied research. Sankhya A 26: 329-358.

RoBert, J. C. 1992. Le piège Entomologique Composite (P.E.C.): une technique d'échantillonage à large spectre de l'entomofaune terrestre circulante. Bulletin de la Société Entomologique Suisse 65: 395-411.

Robert, J. Y. 1996. Evaluation d'une technique d'échantillonage à large spectre de l'entomofaune terrestre circulante: le piège Entomologique Composite (P.E.C.). Annales scientifiques de l'Université de Franche-Comté, Besançon, Biologie-Ecologie, 5: 13-28.

Rodrigo, A., \& Retana, J. 2006. Post-fire recovery of ant communities in Submediterranean Pinus nigra forests. Ecography 29: 231-239.

Rohrig, E., Sivinski, J. \& Wharton, R. 2008. Comparison of Parasitic Hymenoptera Captured in Malaise Traps Baited with two Flowering Plants Lobularia maritima (Brassicales: Brassicaceae) and Spermacoce verticillata (Gentianales: Rubiaceae). Florida Entomologist 91 (4): 621-627.

Root, R. B. 2001. Guilds. En: Levin, S. A. (ed.). Encyclopedia of Biodiversity. Pp: 295-302. Academic Press, San Diego.

Roth, L. M. 1994. Blattodea. En: Naumann, I. D. (ed.) Systematic and Applied Entomology. Pp: 266270. Melbourne University Press, Carlton.

Roulston, T. H., Smith, A. S. \& Brewster, A. L. 2007. A Comparison of Pan Trap and -Intensive Net Sampling Techniques for Documenting a Bee (Hymenoptera: Apiformes) Fauna. J.Kansas Entomological Society 80 (2): 179-181.

Schauff, M. E. (ed.). 2005. Collecting And Preserving Insects And Mites: Techniques And Tools. Systematic Entomology Laboratory, USDA. National Museum of Natural History, NHB 168. Washington, $\quad$ D.C. $20560 . \quad 68$ pp. http://www.ars.usda.gov/Main/site_main.htm?docid=10141\&page $=1$

Scheffer, M., Carpenter, S. R., Foley, J., Folke, C. \& Walker, B. 2001. Catastrophic shifts in ecosystems. Nature 413: 591-696.

ShlyakHTENOK, A. S. 1995. Distribution of spider and digger wasps (Hymenoptera, Pompilidae, Sphecidae) in a mossy pine forest (Pinetum pleurosum) in the Berezinsky Biosphere Reserve. Fragmenta faunistica 38: 191-195.

ShlyAKHTENOK, A. S. 2000. Effectiveness of Malaise traps for collection of wasps (Hymenoptera: Aculeata). Pakistan J. Zoology 32 (1): 45-47.

SimberlofF, D. \& DAYAN, T. 1991. The guild concept and the structure of ecological comunities. Annu. Rev. Ecology Systemat 22: 115-143.

Similä, M., Kouki J., Martikainen, P. \& Uotila, A. 2002. Conservation of beetles in boreal pine forests: the effects of forest age and naturalness on species assemblages. Biol. Conserv. 106: 1927.

Sippola, A. L., SitTonen, J. \& PuntTila, P. 2002. Beetle diversity in timberline forests: a comparison between old-growth and regeneration areas in Finnish Lapland. Ann. Zool. Fenn. 39: 69-86 
Smith, B. \& Wilson, J. B. 1996. A consumer's guide to evenness indices. Oikos 76: 70-82.

Sobek, S., Tscharntke, T., Scherber, C., Schiele, S. \& Steffan-Dewenter, I. 2009. Canopy vs. understory: Does tree diversity affect bee an d wasp communities and their natural enemies across forest strata? Forest Ecol Manag 258: 609-615.

SoRG, M. \& Cölln, K. 1992. Die Grabwespen (Hymenoptera, Sphecidae) von Gönnersdorf (Kr. Daun). Beiträge zur Insektenfauna der Eifeldörfer VI. Dendrocopos 19: 126-142.

Southwood, T. R. E. 1978. Ecological Methods. With particular reference to the study of insect populations. Chapman \& Hall Ltd., Londres. xxiii +524 pp.

SOuthwood, T. R. E. \& Hernderson, P. A. 2000. Ecological Methods. With particular reference to the study of insect populations. 3th Edition. Blackwell Science Ltd, Oxford. 575 pp.

SouzA, L. \& CAmpos, M. J. O. 2008. Composition and diversity of bees (Hymenoptera) attracted by Moericke traps in an agricultural area in Rio Claro, state of Sao Paulo, Brasil. Iheringia (Zool.) 98: 236-243.

Steffan-Dewenter, I., Münzenberg, U., Bürger, C., Carsten, T. \& Tscharntke, T. 2002. Scale dependent effects of landscape context on three pollinator guilds. Ecology 83: 1421-1432.

StePhen, W. P., \& RAO. S. 2005. Unscented color traps for non-Apis bees (Hymenoptera: Apiformes). J.Kansas Entomological Society 78: 373-380.

Stireman, J. O. 2008. Diversity of a Tachinid Parasitoid Community over Space and Time. Ann. Entomol. Soc. Am. 101 (2): 362-370.

TAKI, H., KeVAn, P. G. \& Ascher, J. S. 2007. Landscape effects of forest loss in a pollination system. Landscape Ecol. 22: 1575-1587.

Ter BraACK, C. J. F. \& Šmilauer, P. 1998. CANOCO Reference Manual and User's Guide to Canoco for Windows: Software for Canonical Community Ordination (version 4). Microcomputer Power, Ithaca, NY. 352 pp.

Terbough, J. \& Robinson, S., 1986. Guilds and their utility in ecology. En: KikKawa, J., Anderson, D. J. (eds.), Community Ecology: Patterns and Processes. Pp. 65-90.Blackwell Scientific Publications, Melbourne, Australia.

Tilman, D. \& Downing, J. A., 1994. Biodiversity and stability in grasslands. Nature 367: 363-365.

Tilman, D., Wedin, D. \& KNOPS, J., 1996. Productivity and sustainability influenced by biodiversity in grassland ecosystems. Nature 379: 718-720.

Toler, T. R., Evans, E. W. \& TePedino. V. J. 2005. Pan-trapping for bees (Hymenoptera: Apiformes) in Utah's West Desert: the importance of color diversity. Pan-Pacific Entomologist 81: 103-113

Townes, H. 1962. Design for a Malaise trap. Proceedings of the Entomological Society of Washington, 64: $253-262$.

TownEs, H. 1972. A light-weight Malaise trap. Entomological News 83: 239-247

Tylianakis, J. M., Klein, A. M. \& TscharntKe, T. 2005. Spatiotemporal variation in the diversity of Hymenoptera across a tropical habitat gradient. Ecology 86 (12): 3296-3302

VAN DEN WOLLENBERG, A. L. 1977. Redundancy analysis. An alternative for canonical correlation analysis. Psychometrika, 42: 207-219

VAS, J., MARKó V., ÁbrahÁM L. \& MÉSZÁRos Z. 2001: Study of Neuropteroidea (Raphidioptera, Neuroptera) communities by using Malaise traps in an untreated orchard and its environment. Acta Phytopathol. Entomol. Hungar. 36: 115-122

WALKER, B. 1995. Conserving biological diversity through ecosystem resilience. Conserv. Biol. 9:747752.

WARWICK, R. M. \& ClaRke, K. R. 1995 New 'biodiversity' measures reveal a decrease in taxonomic distinctness with increasing stress. Mar. Ecol.-Prog. Ser. 129: 301-305 
Warwick, R. M. \& Clarke, K. R. 1998. Taxonomic distinctness and environmental assessment. J. Appl. Ecol. 35: 532-543.

Westphal, C., Bommarco, R., Carre, G., Lamborn, E., Morison, N., Petanidou, T., Potts, S. G., Roberts, S. P. M., Szentgyorgyi, H., Tscheulin, T., VAissiere, B. E., Woyciechowski, M., Biesmeijer, J. C., Kunin, W. E., Settele, T. \& Steffan-Dewenter, I., 2008. Measuring Bee Diversity in Different European Habitats. Ecological Monographs 78 (4): 653-671.

White, P. S. \& PicketT, S. T. A. 1985. Natural disturbance and patch dynamics: An introduction. In: The Ecology of Natural Disturbance and Patch Dynamics. WhiTE, P.S \& PICKETT, S.T.A. (eds). Academic Press, New York, pp. 3-13.

Whittaker, R. H. 1960. Vegetation of the Siskiyou Mountains, Oregon and California. Ecological Monographs 30: 279-338.

WIKARS, L. O. 2002. Dependence on fire in wood-living insects: An experiment with burned and unburned spruce and birch logs. J. Insect Conserv 6: 1-12.

Wilson, E. O. 1988. The current state of biological diversity. En: (WILSON, E. O. \& PETER, F. M (eds.), Biodiversity pp. 3-18. National Academy Press, Washington D. C.

WiLson, E. O. 1992. The diversity of life. Harvard Univesity Press, Cambridge. 410 pp.

WIPFLI, M. S. 1997. Terrestrial invertebrates as salmonid prey and nitrogen sources in streams: contrasting old-growth and young-growth riparian forests in southeastern Alaska, U.S.A. Canadian J. Fisheries and Aquatic Sciences 54: 1259-1269.

YACHI, S. \& LOREAU, M. 1999. Biodiversity and ecosystem productivity in a fluctuating environment: the insurance hypothesis. Proceeding of the National Academy of Sciences USA 96: 1463-1468. 


\section{RESULTADOS Y DISCUSIÓN}

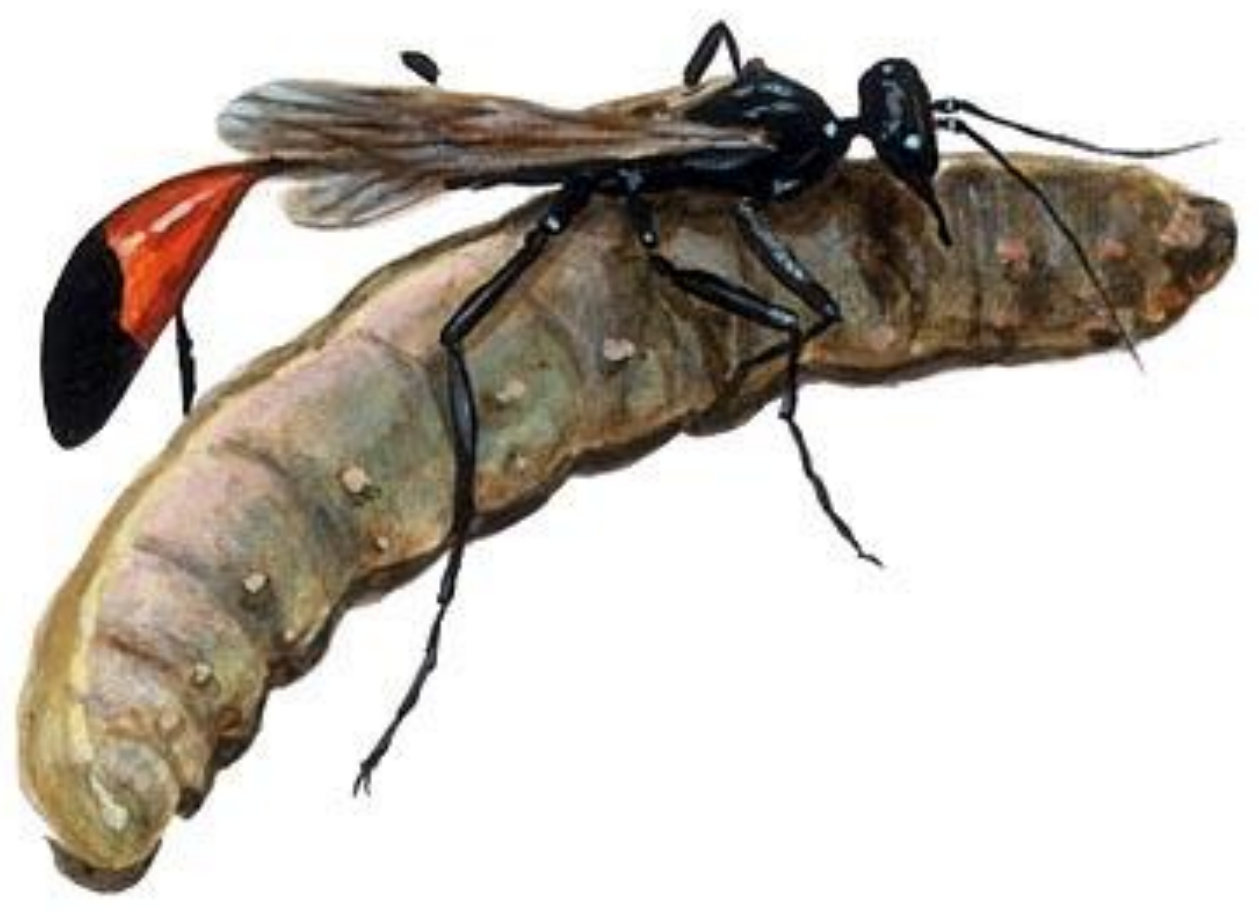


Ante la falta de información disponible, se planteó un primer análisis, recogido en el subapartado 6.1 con el objetivo de obtener una idea preliminar de la posible respuesta a corto-medio plazo (2 años) del grupo analizado, y establecer la metodología a seguir en su análisis.

Tras este primer trabajo, y en vista de los datos obtenidos, se analizaron áreas quemadas más extensas y utilizando un mayor esfuerzo de muestreo, cuyos resultados se recogen en los subapartados 6.2, 6.3 y 6.4. En ellos, se analiza la recuperación de las comunidades de Spheciformes a lo largo de los 15 años posteriores a un incendio forestal, empleando el método de la sustitución de espacio por tiempo (PICKET, 1989).

En el subapartado 6.2, se analiza cómo varían las comunidades de Spheciformes en sus diferentes componentes de diversidad, a través de la utilización de Modelos Lineales Generales (GLMs), y si existen diferencias en dichos análisis en función del tipo de trampa empleada. En el subapartado 6.3, y mediante el empleo de análisis multivariantes, se estudia la influencia de la estructura de la vegetación (cobertura y altura) y de la cantidad de suelo desnudo disponible para la nidificación, a lo largo del periodo de recuperación, así como su papel en la estructuración de la comunidad de Spheciformes y en la composición gremial de la misma, con el transcurso de los años post-fuego (a medida que avanza el periodo de recuperación del hábitat). El subapartado 4 se centra en la comparación de los resultados obtenidos en función de los años post-fuego, los años de muestreo, presencia o no de perturbación y tipo de trampa empleado en la captura de los individuos, utilizando el Índice de Complementariedad de Colwell y Coddington, técnicas de Escalamiento Multidimensional (MDS) y Análisis de Similitud (ANOSIMs). El subapartado 5 recoge una serie de especies encontradas por primera vez en Arribes del Duero, junto con las citas de las especies más interesantes recogidas en este estudio, desde el punto de vista faunístico, además de una actualización de su distribución peninsular. 


\section{1}

* Response of Spheciformes wasps communities (Hymenoptera: Apoidea) to wildfire in a Mediterranean ecosystem (Arribes del Duero

Natural Park, western Spain).

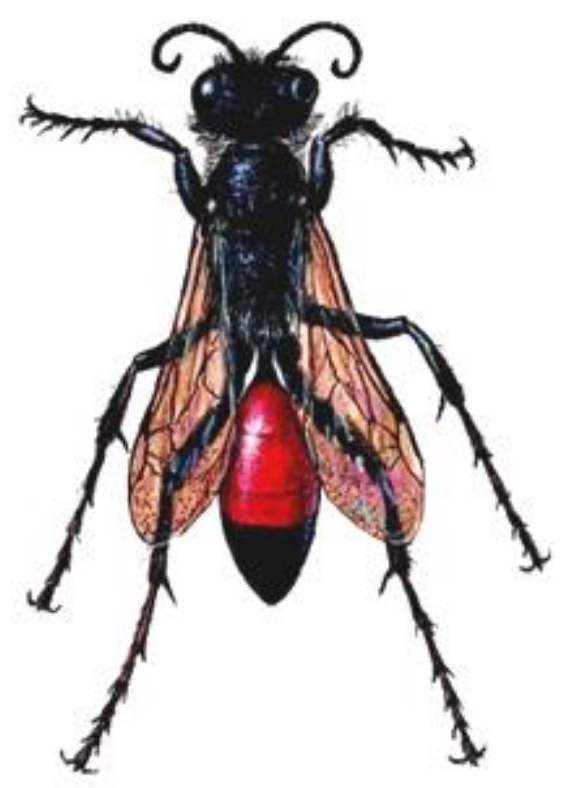




\title{
* Response of Spheciformes wasps communities (Hymenoptera: Apoidea) to wildfire in a Mediterranean ecosystem (Arribes del Duero Natural Park, western Spain).
}

\begin{abstract}
In a study carried out over three years in a Mediterranean ecosystem (Arribes del Duero Natural Park, western Spain), the response of Spheciformes wasps (Hymenoptera: Apoidea) communities to a wildfire (superficial, fast and of lowmedium intensity) that occurred towards the end of a summer was addressed for the first time using Malaise trapping. The populations of Spheciformes seem to have survived the direct impact of the fire and were initially favoured by the post-fire environmental conditions, as reflected in the increases observed in abundance and species richness. Despite this, these populations have undergone an important degree of "destructuring", which takes years to be corrected and which would be directly related to the modifications undergone by the habitat structure, this pointing to its strong influence on these insects. Additionally, the changes observed after the perturbation and those occurring between the two controls used in the study suggest the preference of the group for cleared habitats. The presence of 30 exclusive species was observed in the burnt areas in comparison with 9 in unburnt areas. The differences obtained between the dominant species at the different sites, perturbed or not, are important, there being cases of displacement, within the same genus, of some species by others after the fire.
\end{abstract}

Keywords: Diversity, Malaise trap, Quercus pyrenaica forests, Spheciformes, Wildfire. 


\section{Introduction}

Forest fires are one of the most important and active agents of perturbation in forested areas and one of the main causes of habitat fragmentation. However, they constitute an ecological factor that contributes strongly to the diversification and maintenance of plant communities, and hence of the animal communities dependent upon these, and to determining the temperature, rainfall and water balance of many biomes (Bond et al. 2005). At the same time, they are an essential component of the dynamics of many ecosystems (Whelan 1995; Bond and van Wilgen 1996; Lloret 2003, 2004), where they even have a beneficial effect (Morgan and Lunt 1999; Oesterheld 1999; Diadema et al. 2007), resulting in a landscape composed of a complex and heterogeneous mosaic of regenerating vegetation that favours the maintenance and conservation of species richness and diversity (Bailey and Whitham 2002; Moretti et al. 2002a; Moretti and Barbalat 2004; Swengel and Swengel 2007). Accordingly, it is mistaken to consider fires as mere agents of the destruction. In this sense, the role of fire has been interpreted from the ecological point of view (Naveh 1975; Debano et al. 1998; Ojeda-Copete 2001). Fire is a factor leading to the loss of individuals or biomass in a sudden or episodic way, but at the same time it creates spaces that can be colonized by the individuals that survive it or other colonising species, favoured by the appearance of new environmental conditions or by the removal of the competition exerted by other species (Noble and Slatyer 1981; Pickett and White 1985; Hobbs and Gimmincham 1987; Panzer 2003; Moretti et al. 2004, 2006). This means that many species, of both plants and animals, depend on the existence of such periodic disturbances for their survival (Smith 2000).

Mediterranean forests are especially affected by and dependent on fires (Naveh 1975, 1995; Moreno and Oechel 1995; Pausas and Vallejo 1999) owing to the nature of their vegetation, one of the most susceptible and best adapted to this kind of perturbation in the world (e.g. Pausas et al. 1999; de Luis et al. 2006, Arnán et al. 2007). Owing to its ecological and demographic conditions, the Iberian Peninsula in general, and Spain in particular, represent one of the most outstanding cases in the Mediterranean region $(\approx 8,200$ fires/year, Spanish Ministry of Environment, and Rural and Marine Affairs). 
The increased risk of fire is mainly due to a combination of climatic factors (Pausas 2004), such as the elevated temperatures, the natural susceptibility of the vegetation to ignition and its inflammable nature (Naveh 1975, 1995; Ojeda-Copete 2001; Pausas 2003), and human factors, such as changes in land use, the abandonment of old agricultural and livestock-rearing exploitations (Espelta et al. 2002; Viedma et al. 2006; Moreira and Russo 2007), and the many human activities liable to start fires in areas close to forests (Vélez 1990, 1999; Moreno et al. 1998; Badia-Perpinya and Pallares-Barbera 2006). The presence of these factors is particularly prominent in the Arribes del Duero Natural Park (western Spain), which together with its enormous importance as a Protected Landscape is particularly vulnerable to this type of impact.

Biodiversity conservation, threatened by disturbances or impacts due to human activity, is considered a vital part of the management of natural resources (Humphries et al. 1995; Tilman 2000) since it plays an important role in the resilience of ecosystems and the maintenance of their status with respect to change, because conservation guarantees the production of the benefits provided by ecosystems (Peterson et al. 1998; Elmqvist et al. 2003; Luck et al. 2003).

The species diversity represented at a locality after a fire, or post-fire succession, depends on the new environmental conditions (Pyne et al. 1996; Moretti et al. 2002a; Hirowatari and Makihara 2007), on the degree to which different competitive skills are expressed in space and over time (Huston 1994), on the potential for immigration (Steffan-Dewenter et al. 2001, 2002; Potts et al. 2001; Gathmann and Tscharntke 2002; Knight and Holt 2005), and on the composition and structure of the surrounding habitat that has not been affected by the fire (Bengtsson et al. 2003; Ratchford et al. 2005). In light of all this, it is crucial to know the time taken by an ecosystem to recover after a forest fire.

Species richness is a common indicator of change and is used to monitor the disturbances caused by a given impact (e.g. Kremen 1992; York 1996). Insects, as representatives of $80 \%$ of species described both world-wide (Wilson 1992) and on the Iberian Peninsula (Ramos et al. 2001), play many roles of vital importance in forest ecosystems. Owing to their short generation periods, large population sizes, rapid responses to environmental disturbances and ease of capture, they are good indicators of the state of ecosystems, the sustainability of a given landscape, and of changes in the 
general diversity of the territory owing to the impact of human activities (Samways 2005). Nevertheless, the paucity of available data and the large number of species suggest that priority should be given to groups of insects that -playing a primary ecological role- are indicators of the state of local diversity, have a significant influence on the diversity of other organisms, and are subject to the risk of extinction because they occupy a high trophic level (Fisher 1998).

Despite the importance of forest fires on the Iberian Peninsula, few studies have addressed their effects on insect populations (e.g. García-Villanueva et al. 1995 and Arnán et al. 2006 -ants-; García-Villanueva et al. 1998; Nunes et al. 2006 and Fernández and Salgado 2004 -Coleoptera-), and these have mainly addressed groups considered to be good indicators of fire because they show a consistent response to this kind of disturbance (Nunes et al. 2000). To gain further insight into how fire affects insect populations, it is necessary to broaden to scope of analysis to other groups, with different types of behaviour and biology, that can be considered indicators of the state of ecosystems and that allow a better follow-up and prediction of the effects of this type of perturbation on different types of habitat. Owing to their complex biology, the Hymenoptera Aculeata are considered to be vital in all terrestrial ecosystems (Huber 2009) and highly sensitive to certain forms of environmental disturbance, such that they can be considered to be extremely important biological indicators (LaSalle and Gauld 1993). In view of the intimate relationship between them and the structure of the environment, within the aculeates, the Spheciformes wasps (Apoidea) -already proposed as a biodiversity indicator group (see Gayubo et al. 2005)- could also be proposed as ecological indicators of fire. Likewise, considering their predatory behaviour and the amount of prey captured (Evans and O’Neill 2007) they could in turn reflect the recovery of other groups of insects after the disturbance.

The aim of the present work is to determine how wildfire affects the populations of Spheciformes in a highly heterogeneous Mediterranean ecosystem along two years after a forest fire, and to characterise their communities. 


\section{Methods}

\section{Study zone}

The study was carried out at the Arribes del Duero Natural Park (Villarino de los Aires, province of Salamanca, Spain) in an area that was burnt towards the end of September $2003\left(41^{\circ} 15^{\prime} 27^{\prime \prime}-41^{\circ} 15^{\prime} 37^{\prime \prime}\right.$ N and 6 $\left.27^{\prime} 41^{\prime \prime}-6^{\circ} 28^{\prime} 36^{\prime \prime} \mathrm{W}\right)$. Villarino de los Aires is a municipality especially affected by forest fires (mainly of human origin), whose Local Risk Index (LRI) and Fire Frequency Index (FFI) are the highest in the territory (Municipal Plan for Forest Fire Prevention of Villarino de los Aires, Salamanca- Plan 42 Junta Castilla y León, http://www.jcyl.es). Likewise, this municipality is of great interest owing to its entomological diversity and biogeographic significance, not only on the Iberian Peninsula but also at European level (González et al. 2009).

The affected area belongs to the peniplain zone, is characterised by its wildness propitiated by the abandonment of intensive agricultural practices and a greater trend towards livestock rearing- and because it has a high percentage of shrub vegetation (García-Feced et al. 2007). With an extension of $c a .38 .36$ ha, from the botanical point of view thisarea corresponds to subhumid oak woods of Quercus pyrenaica Willd. (from the Genisto falcatae-Quercetum pyrenaicae association), characteristic of the central and north-western zone of the Iberian Peninsula at heights equal to or greater than $700 \mathrm{~m}$ a.s.l, although always depending on the different microtopographic conditions.

These forests, which are floristically impoverished, have been more or less converted into savannah-like "dehesas" and have to a large extent been cleared-felled (Romero and Velasco 1997; Luis-Calabuig 2008). Owing to the constant pressure to which these plant formations have been subjected through fires, felling, and grazing, Quercus pyrenaica has become a very resistant species, and its communities contain many species that resprout from underground parts, endowing them with great resilience (Luis-Calabuig and Tárrega 1993; Calvo et al. 1991, 1999).

The only representative soils are leptosols, and there are broad swathes of bare rock and some vineyards dispersed throughout the area. The zone is characterised by a mean annual temperature (mean $11^{\circ} \mathrm{C}$ for the overall area) and by its rainfall regime 
(precipitation along the year around $700 \mathrm{~mm}$ ) (Calonge-Cano 1990), conferring it a Mediterranean mesoclimate nature.

\section{Sampling protocol}

In this study, Malaise traps (light model of Townes) were used as the capture method. This type of trap has been satisfactorily used for the study of the effects caused by fire on insect populations in different types of habitat and the later recovery of these (e.g. Lockwood et al. 1996; Makihara et al. 2000; Hirowatari and Makihara 2007). The following traps were set up in the area studied:

- BURNT 04 (1-B04). This was set up in May 2004 at $240 \mathrm{~m}$ from the edge of an area burnt in 2003, where it remained until November of the same year. Thus, this trap would be measuring a community one year after the fire.

- BURNT 05 (2-B05). Set up in 2005, at the same site as that occupied by 1-B04 and during the same time period (May to November). This would be sampling a community two years after the fire.

The captures were compared with those obtained with another two traps situated in two zones differing from each other (with two different types of habitat), but that were similar to the study zone and that had not been burnt for more than 10 years.

- CONTROL 1 (C1) (Villarino de los Aires, "El Franco"). This was set up at a subhumid oak stand, whose only crops were vines and olives, all of them on small plots. During 2004, the control remained installed inside a patch of $Q$. pyrenaica. The vegetation was representative of an intermediate successional and not fully mature state of the study area, but had not been burnt.

- CONTROL 2 (C2) (Pereña de la Ribera, "Mata de Arriba"). This was set up close to the River Uces, on a $Q$. pyrenaica forest with the typical nemoral flora of such emplacements. The vegetation represented a later successional state of the study area that could be considered fully mature, although it had not been burnt either. The trap remained in place throughout 2005. 
In order to determine which species survived the fire, or were pioneers in accessing a recently burnt area, and to compare them with the recordings made in ensuing months a further three traps were set up:

- ASH 05 (0-ASH05). This was placed at a distance of $130 \mathrm{~m}$ from the edge of the burnt area, in a zone with characteristics similar to the previous ones. The trap, installed on the day after the fire (25.07.05) and left there until 30 September of the same year, would be sampling a community immediately after the fire. In the two ensuing years a new trap was set up at the same site, remaining active from 1st June to 30th September of 2006 and 2007, respectively. These samples were designated 1ASH06 and 2-ASH07 (these would be measuring a community at one year and at two years, respectively, after the fire).

The samples were collected fortnightly and were taken to the laboratory for specimen preparation. They were then subjected to qualitative and quantitative analyses, identifying the specimens down to species level.

\section{Data analysis}

For mathematical analysis of the alpha component of Spheciformes wasps diversity, the indices and parameters most commonly used in the definition and analysis of biocenoses were employed (Magurran 2004): abundance $(N)$, the number of specimens in each sample; species richness $(S)$, the number of species appearing in each of the samplings; the Shannon diversity index ( $H^{\prime}$, in base e); the Simpson diversity index $\left(D=1-\lambda^{\prime}\right)$, and the evenness index of Pielou $\left(J^{\prime}\right)$. Likewise, two of the taxonomic distinctness indices developed by Clarke and Warwick (Clarke and Warwick 2001) were used: average taxonomic distinctness $(\Delta+)$, the mean taxonomic distance of all the pairs of species in a list, and variation in taxonomic distinctness $\left(\Lambda^{+}\right)$, the variation in the phylogenetic distances between each pair of species. The combination of the $\Delta+$ and $\Lambda+$ indices provides a robust statistical summary of the patterns of taxonomic, or phylogenetic, relationship within a sample. Construction of the two taxonomic distinctness indices requires a "master list" or inventory of species, within which taxonomic boundaries are defined. In the present case, we used a list of 462 species with

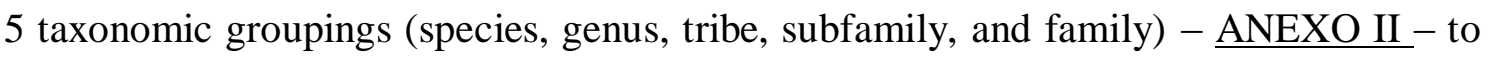
which equal step-lengths were assigned. Samples obtained were compared to the master 
list to analyze whether the observed subset of species was representative of the biodiversity expressed in the full species inventory. In the comparison, we plotted values obtained for each of the indices in each sample against the number of species in the sample. The use of both indices allows a bivariate approach to be obtained, in which their values are jointly considered in terms of both observed outcomes from real datasets and their expected values under subsampling from a master species inventory (Clarke and Warwick 2001). Elliptical plots were generated by simulation, formed by $95 \%$ probability contours for sample size ranges of $\mathrm{S}$ of $<50$ species.

In the comparison of the results obtained during the different sampling years, Colwell and Coddington's complementarity index (Colwell and Coddington 1994) was used, considering each of the traps used in the study separately.

To assess the dominance of species in the community, the criterion of Haeseler (1972) was used, cataloguing the species as: eudominant (represented by more than $15 \%$ of all captures), dominant (between $5 \%$ and 15\%), subdominant (from $1 \%$ to $5 \%$ of captures), and subordinate (the remaining species).

In the study of the beta diversity for all the samples, the data were square-root transformed to reduce the effect of the most abundant species; to limit the effect of "tourist" species, those represented at less than $2 \%$ of the total number of individuals collected by sample, were removed. A Mutidimensional Scaling Analysis (MDS) was performed, generating a plot in two dimensions and using the Bray-Curtis coefficient as measure of similarity. All analyses were carried out using the PRIMER v5 program (see Clarke and Warwick 2001).

To analyse the possible variations in community structure, for each of the samples obtained an analysis was made of the dominance of the species, following the criterion of Haeseler (1972), and the guild composition of the community was studied, establishing several categories as a function of (1) the type of substrate used for nesting, and (2) the type of paedotrophic diet (preys captured to feed the larvae). In the first case, a differentiation was made between the terrestrial and plant substrates, such that the resulting clusters would come from the sum of terricolous species (TE) (which excavate nests in different types of soil, mainly sandy) and squatters (SQt) (which occupy nests in hollows and in galleries excavated by other arthropods in soil), on one hand, and the sum of squatters (SQv) (which nest in hollows and in galleries excavated by other 
arthropods in plant substrates) and xylicolous-rubicolous species (XR) (which excavate their nests in dead wood or hollow branches), on the other. Parasitoid and mud dauber species, with very low frequencies, were removed. Second, attending to the order to which the prey captured by each wasp species belonged, seven different categories were established (Appendix 1); owing to the low number of captures of hunting species of Blattodea, Psocoptera, Thysanoptera, Coleoptera, Hymenoptera (adults and larvae) and Mantodea, some orders were grouped attending to their ecological characteristics. The categories established were 1) Araneida; 2) Orthoptera, Blattodea and Mantodea; 3) Homoptera; 4) Heteroptera; 5) Diptera; 6) Larvae of Lepidoptera and Hymenoptera; and 7) "Others" (with Psocoptera, Thysanoptera, Coleoptera and Hymenoptera). The resulting percentage is above 100 owing to the existence of species that belonged to several categories at once (Appendix 1).

\section{Results}

\section{Alpha diversity and Taxonomic Distinctness}

Among the values obtained for the different diversity indices analysed (Table 1), the low values recorded for sample C2 are striking. Also important are the differences between the two zones affected by the fire, higher values being seen for the BURNT samples, especially 2-B05, with the highest values for $N$ and $S$ for the overall sample.

Table 1: Results, by traps, of the indices and parameters used in the community analysis.

\begin{tabular}{lccccccc}
\hline Samples & S & N & H' $^{\prime}$ & J' & D & Delta+ & Lambda+ \\
\hline 1-B04 & 45 & 245 & 3.26 & 0.86 & 0.95 & 82.24 & 405.88 \\
2-B05 & 49 & 255 & 3.33 & 0.86 & 0.95 & 75.10 & 484.85 \\
0-ASH05 & 23 & 62 & 2.89 & 0.92 & 0.95 & 73.75 & 588.67 \\
1-ASH06 & 36 & 103 & 3.17 & 0.88 & 0.95 & 78.51 & 400.95 \\
2-ASH07 & 31 & 143 & 2.73 & 0.79 & 0.90 & 81.89 & 369.75 \\
C1 & 42 & 111 & 3.35 & 0.90 & 0.96 & 75.87 & 413.10 \\
C2 & 15 & 44 & 2.27 & 0.84 & 0.86 & 71.43 & 303.67 \\
\hline
\end{tabular}

The highest diversity was obtained for $\mathrm{C}$, although with values very close to those recorded for 2-B05. The Simpson and Pielou indices reflected few differences 
among the samples, although sample 0 -ASH05, with a value very close to $\mathrm{C} 1$, reached the highest value as regards evenness.

In the ellipse generated by simulation for the whole sample set (Fig. 1), in which the values of $\Delta^{+}$are plotted against $\Lambda+$ for each sample, a striking observation is that three samples (0-ASH05, 1-B04 and 2-B05) are situated outside the ellipses, together with the fact that $\mathrm{C} 2$, despite the low values seen as regards diversity indices (Table 1), appears inside the ellipse.

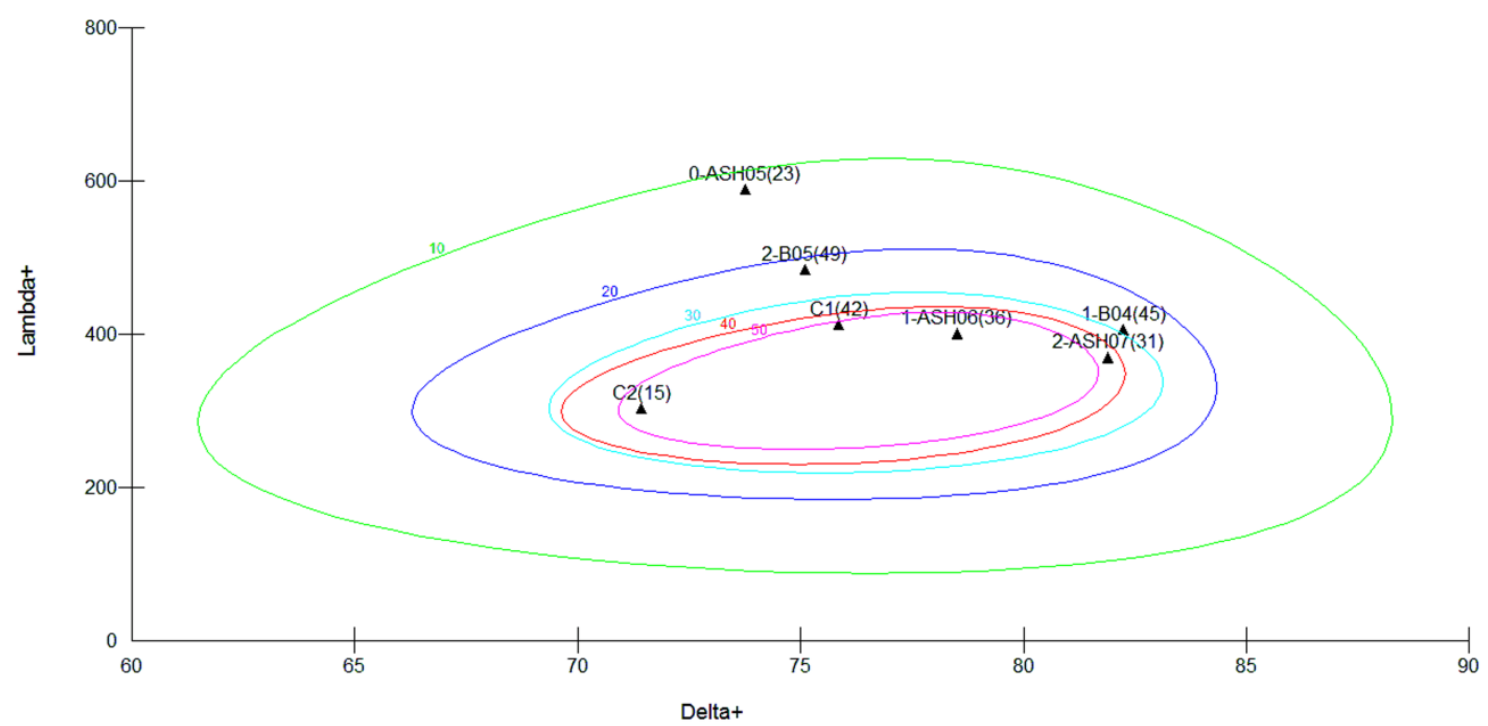

Fig. 1: Elliptical plot of 95\% probability areas for Average Taxonomic Distinctness (Delta+) and Variation in Average Taxonomic Distinctness (Lambda+) pairs, separated by sublist sample sizes: $\mathrm{S}<50$.

\section{Beta diversity}

In general, the complementarity values between pairs of samples (Table 2) reveal few species in common, there being noteworthy differences among the samples analyzed. The samples with a higher complementarity index are C2 and 0-ASH05.

In the MDS plot obtained with the seven samples studied (Fig. 2) the clear separation (although in opposite directions) of $\mathrm{C} 2$ and 0-ASH05 from the rest of the samples is striking. 
Table 2: Results, in percentages, obtained for the complementarity index. In brackets: number of species in common.

\begin{tabular}{lccccccc}
\hline Samples & 1-B04 & 2-B05 & 0-ASH05 & 1-ASH06 & 2-ASH07 & C1 & C2 \\
\hline 1-B04 & $\ldots$ & & & & & & \\
2-B05 & $50.8(31)$ & $\ldots$ & & & & & \\
0-ASH05 & $74.1(14)$ & $69.1(17)$ & $\ldots$ & & & & \\
1-ASH06 & $52.7(26)$ & $60.7(24)$ & $71.7(13)$ & $\ldots$ & & & \\
2-ASH07 & $71.2(17)$ & $73(17)$ & $77.3(10)$ & $57.4(20)$ & $\ldots$ & & \\
C1 & $55(27)$ & $40.4(35)$ & $72.5(14)$ & $65.5(20)$ & $67.3(18)$ & $\ldots$ & \\
C2 & $88.9(6)$ & $85.7(8)$ & $88.2(4)$ & $81.4(8)$ & $82.1(7)$ & $88.2(6)$ & $\ldots$ \\
\hline
\end{tabular}

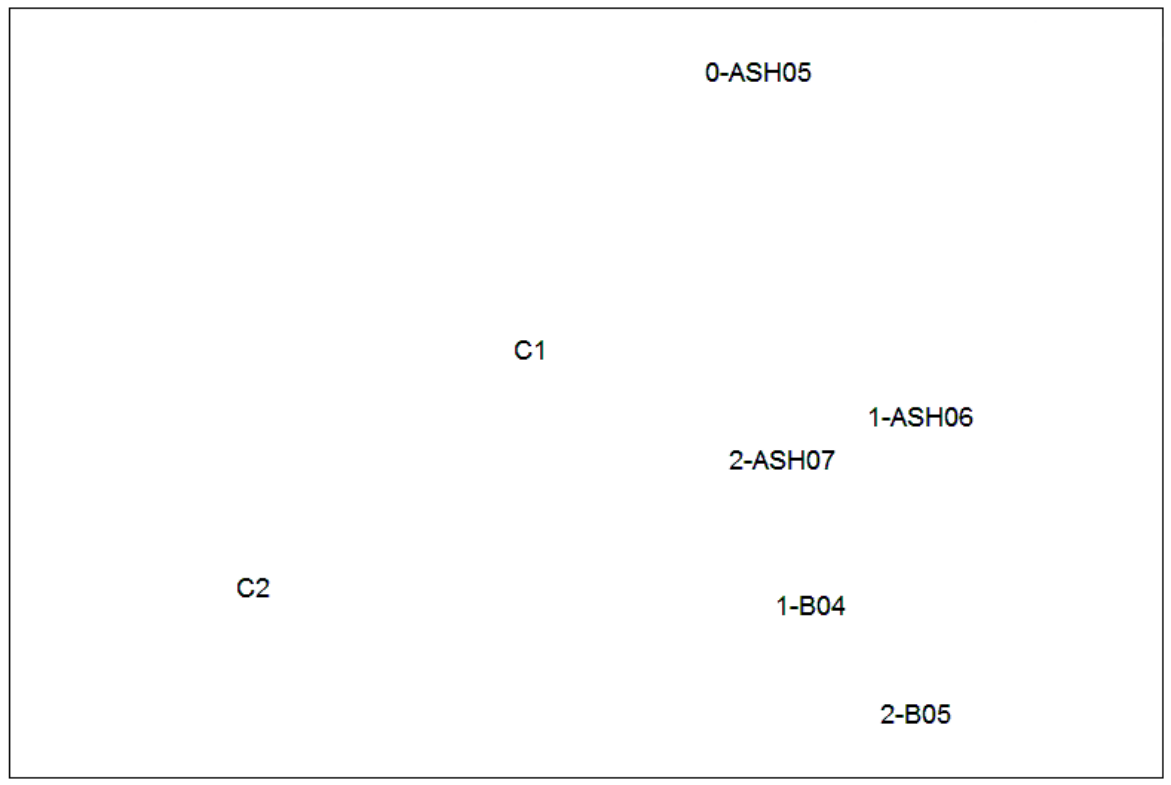

Fig. 2: MDS plot for the seven samples analysed, based on Bray-Curtis similarities. Stress $=0.02$

\section{Species dominance}

The eudominant and dominant species of the community are listed in Table 3. Trypoxylon attenuatum, eudominant or dominant in the CONTROLS, disappeared immediately after the fire (0-ASH05), although it returned to being well represented two years later (2-ASH07, 2-B05). However, Trypoxylon scutatum, subdominant in the CONTROLS, became dominant two years after the fire (1-B04, 2-B05, 1-ASH06, 2ASH07). Sphex leuconotus, which was absent after the fire (0-ASH05), was dominant one year after it (1-B04, 1-ASH06), although its presence decreased again in the second year, thereafter disappearing or being minimally represented in the CONTROLS. In 
contrast, Sphex funerarius, also absent in C2, appeared within the dominant species inside the burnt zone (except 2-B05, subordinate), and also in $\mathrm{C} 1$. The presence of Ammophila hungarica was clearly different between both disturbed zones since it only appeared in one of them (1-B04, 2-B05), under the category of dominant; in C1, only one individual was collected, in contrast with C2, with none. Solierella compedita, which was initially absent after the fire and in $\mathrm{C} 2$, became eudominant two years after it (except in 2-B05), divergences between both zones analysed (ASH and BURNT) also appearing. As in the case of A. hungarica, only one individual was captured in C1.

In an analysis of both disturbed zones, a marked difference was observed among the species that were dominant in the first and second years post-fire for each of them (Table 3, Appendix 1). Thus, for both zones sampled one year after the fire, four of the seven dominant species summed for both samples coincided. In contrast, between the two representative samples of the second year post-fire, only two of the six dominant species accumulated between both samples coincided.

Table 3: List of eudominant (>15\%) and dominant (5-15\%) species in percentages and number of individuals of such species (in brackets) captured per trap. Also shown are the percentages and number of singletons (species with only one individual) per sample.

\begin{tabular}{|c|c|c|c|c|c|c|c|}
\hline Species & 0-ASH05 & 1-ASH06 & 2-ASH07 & 1-B04 & 2-B05 & C1 & $\mathbf{C 2}$ \\
\hline Sphex funerarius & $6.45(4)$ & $5.82(6)$ & $7.58(11)$ & $9.8(24)$ & $0.76(2)$ & $5.35(6)$ & $\ldots$ \\
\hline Sphex leuconotus & $\ldots$ & $5.82(6)$ & $3.45(5)$ & $7.35(18)$ & $1.15(3)$ & $0.9(1)$ & $\ldots$ \\
\hline Ammophila campestris & $\ldots$ & $3.88(4)$ & $2.06(3)$ & $3.27(8)$ & $9.6(25)$ & $\ldots$ & $\ldots$ \\
\hline Ammophila hungarica & $\ldots$ & $\ldots$ & $\ldots$ & $6.12(15)$ & $6.51(17)$ & $0.9(1)$ & $\ldots$ \\
\hline Diodontus insidiosus & $14.52(9)$ & $4.85(5)$ & $10.34(15)$ & $3.83(10)$ & $11.9(31)$ & $0.9(1)$ & $\ldots$ \\
\hline Pemphredon lethifer & $3.23(2)$ & $1.94(2)$ & $6.9(10)$ & $0.41(1)$ & $1.92(5)$ & $0.9(1)$ & $2.27(1)$ \\
\hline Ammoplanus ceballosi & $\ldots$ & $1.94(2)$ & $0.67(1)$ & $7.35(18)$ & $0.76(2)$ & $1.79(2)$ & $\ldots$ \\
\hline Larra anathema & $\ldots$ & $\ldots$ & $\ldots$ & $\ldots$ & $\ldots$ & $\ldots$ & $11.36(5)$ \\
\hline Tachysphex incertus & $11.3(7)$ & $6.8(7)$ & $\ldots$ & $1.63(4)$ & $1.92(5)$ & $1.79(2)$ & $\ldots$ \\
\hline Tachysphex obscuripennis & $8.06(5)$ & $\ldots$ & $\ldots$ & $\ldots$ & $0.38(1)$ & $3.57(4)$ & $\cdots$ \\
\hline Solierella compedita & $\ldots$ & $17.47(18)$ & $23.45(34)$ & $14.3(35)$ & $4.21(11)$ & $0.9(1)$ & $\ldots$ \\
\hline Miscophus bicolor & $1.61(1)$ & $0.97(1)$ & $\ldots$ & $2.85(7)$ & $7.66(20)$ & $2.67(3)$ & $\ldots$ \\
\hline Miscophus nicolai & $6.45(4)$ & $0.97(1)$ & $\ldots$ & $\ldots$ & $2.68(7)$ & $\ldots$ & $\ldots$ \\
\hline Trypoxylon attenuatum & $\ldots$ & $1.94(2)$ & $6.2(9)$ & $3.26(8)$ & $4.98(13)$ & $9.82(11)$ & $34.09(15)$ \\
\hline Trypoxylon scutatum & $1.61(1)$ & $9.7(10)$ & $13.1(19)$ & $5.31(13)$ & $6.9(18)$ & $3.57(4)$ & $4.55(2)$ \\
\hline Oxybelus quattuordecimnotatus & $6.45(4)$ & $2.91(3)$ & $2.76(4)$ & $2.04(5)$ & $\ldots$ & $13.4(15)$ & $\ldots$ \\
\hline Oxybelus subspinosus & $6.45(4)$ & $\ldots$ & $\ldots$ & $\ldots$ & $\ldots$ & $\ldots$ & $\ldots$ \\
\hline Oxybelus uniglumis & $\ldots$ & $\ldots$ & $\ldots$ & $\ldots$ & $\ldots$ & $5.35(6)$ & $\ldots$ \\
\hline Gorytes sulcifrons & $\ldots$ & $0.97(1)$ & $2.07(3)$ & $2.45(6)$ & $0.38(1)$ & $7.14(8)$ & $9.09(4)$ \\
\hline Bembix bidentata & $\ldots$ & $0.97(1)$ & $0.67(1)$ & $\ldots$ & $\ldots$ & $\ldots$ & $9.09(4)$ \\
\hline singletons & $34.78(8)$ & $15.53(16)$ & $11.03(16)$ & $26.7(12)$ & $30(15)$ & $48.83(21)$ & $40(6)$ \\
\hline
\end{tabular}


For the samples obtained in ASH, the observation that Oxybelus subspinosus, exclusive and dominant immediately after the fire, disappeared from the remaining samples is striking. With the exception of Sphex funerarius, Oxybelus quattuordecimnotatus and Trypoxylon attenuatum, none of the dominant species in zones affected by the fire was dominant in the control zones. Also, the CONTROLS only shared two of the seven dominant species appearing in them.

Appendix 2 shows the species collected exclusively by each of the traps, the number of individuals collected at each of them, and the nesting patterns and type of prey captured by the females. Of the whole sample analysed, 30 species exclusive to the burnt areas were found, as compared with the 9 species in unburnt zones. Of all these, the species Larra anathema, Oxybelus subspinosus and O. uniglumis are outstanding because they were dominant in $\mathrm{C} 2,0-\mathrm{ASH} 05$ and $\mathrm{C} 1$ respectively.

\section{Guild composition of the community}

To assess possible deviations in the guild composition of the community, the values obtained for each trap were compared with the global pattern of the species found on the Iberian Peninsula (Table 4).

Considering the number of species belonging to the different guilds, no significant differences were found either for the type of nesting substrate (Chi-square test, $\chi_{6}^{2}=10.6, p=0.102$ ) or for the type of prey captured to feed the progeny (Chisquare test, $\left.\chi_{36}^{2}=14.8, \mathrm{p}=0.99\right)$.

Regarding the number of individuals, the following were observed: 1) a greater abundance of those nesting in the vegetation in unburnt zones (Chi-square test, $\chi^{2}{ }_{6}=$ 67.10, p < 0.0001) (Table 4a), and 2) a greater predominance of individuals belonging to species preying on spiders and dipterans in $\mathrm{C} 2$ and $\mathrm{C} 1$, respectively (Chi-square test, $\left.\chi_{36}^{2}=241.30, \mathrm{p}<0.0001\right)$ (Table $4 \mathrm{~b}$ ). 
Table 4: Results, by trap, of the Chi-square analysis of the type of nesting substrate and prey captured (NS: nonsignificant; (-): less than expected; (+): more than expected; *p< 0.05 , **p< 0.01 , ***p $<0.001$; critical $\mathrm{z}$ values corrected following Legendre and Legendre (1998) to avoid the problem of multiple simultaneous comparisons).

a) No. of individuals and nesting type

\begin{tabular}{lcc}
\hline \multicolumn{1}{c}{ Samples } & TE+SQt & SQv+XR \\
\hline 1-B04 & NS & NS \\
2-B05 & NS & NS \\
0-ASH05 & NS & NS \\
1-ASH06 & NS & NS \\
2-ASH07 & NS & $(+)^{* * *}$ \\
C1 & NS & NS \\
C2 & NS & $(+)^{* *}$ \\
\hline
\end{tabular}

TE: terriculous; SQt: squatters t; SQv: squatters v; XR: xylicolous-rubiculous

b) No. of individuals and type of prey captured

\begin{tabular}{lccccccc}
\hline Samples & Ar & Or+Bl+Man & Ho & He & Di & Lel+Hyl & $\begin{array}{c}\text { Others } \\
\text { (Ps+Th+Co+Hy) }\end{array}$ \\
\hline $\mathbf{1 - B 0 4}$ & NS & NS & NS & NS & NS & NS & $(+)^{*}$ \\
$\mathbf{2 - B 0 5}$ & NS & NS & NS & NS & $(-)^{*}$ & $(+)^{* * *}$ & NS \\
$\mathbf{0 - A S H 0 5 ~}$ & NS & NS & NS & NS & NS & NS & NS \\
$\mathbf{1 - A S H 0 6 ~}$ & NS & NS & NS & NS & NS & NS & NS \\
$\mathbf{2 - A S H 0 7 ~}$ & NS & NS & NS & $(+)^{* * *}$ & NS & NS & NS \\
C1 & NS & NS & NS & NS & $(+)^{* * *}$ & NS & NS \\
C2 & $(+)^{*}$ & NS & NS & NS & NS & NS & NS \\
\hline
\end{tabular}

Ar: Araneida; Or: Orthoptera; Bl: Blattodea; Man: nymphs of Mantodea; Ps: Psocoptera; Ho: Homoptera; He: Heteroptera; Th: Thysanoptera; Co: Coleoptera; Hy.- Hymenoptera, Hyl.- larvae of Hymenoptera, Lel.- larvae of Lepidoptera, Di.- Diptera

\section{Discussion}

Although the literature contains works in which references are only made to the response of certain species of solitary wasps to the effects of fire (e.g. Lockwood et al. 1996; Moretti et al. 2004, 2006; Campbell et al. 2007), as far as we are aware the present work is the first to address this type of perturbation in Spheciformes communities.

The recovery of the insect populations after a wildfire depends on both their capacity to survive the flames and their colonizing capacity (Swengel 2001; Panzer 2003; Potts et al. 2003; Moretti et al. 2004). The results obtained are consistent with those reported by Moretti et al. (2006), who in Castanea sativa forests observed that 
after a single fire the richness of flying zoophagous and flying phytophagous species increased in the three years after the fire, these species showing the greatest resistance and resilience. In our case, the greatest abundance and richness were also recorded inside the burnt area, with a tendency to increase during the second year after the fire. The same response has been described by other authors for different insect groups, such as Coleoptera (Saint-Germain et al. 2004), Carabidae, Aculeata and Syrphidae (Moretti et al. 2002, 2004), and Apidae (Potts et al. 2003), among others.

Potts et al. (2003) observed a very marked decrease in bee species immediately after a fire, followed by a rapid recovery and maximum diversity during the second year after the impact, and then followed by a progressive decrease over time. Something akin to this was observed in the present study, where after an important decrease in richness immediately after the fire (0-ASH05), the highest value was recorded inside the burnt area two years after it (2-B05), together with one of the highest diversity values. This suggests a considerable presence of surviving and/or colonizing species of the newly created environment and available resources (trophic, spatial, or light) after the fire. These resources derive from a weakening or elimination of the tree and shrub cover and from the increase in the diversity of herbaceous species (Harper et al. 2000; Panzer 2003; Campbell et al. 2007; Breece 2008) and the quality of the nutritional resources offered by them (Potts et al. 2003), from which the imagos of the group analysed could benefit.

The season in which fires occur is very important in the determination of the number and composition of insect species in different ecosystems (Swengel 2001). The fact that the fire addressed here took place at the end of summer (the end of September) probably affected species survival, since the timing implies that most of them were in the adult phase and were approaching the end of their life cycles, as happens for other groups such as moths, butterflies, and grasshoppers (Hall and Schweitzer 1992), and hence nest construction and provisioning would have been completed. This implies that owing to their considerable ability to fly (Steffan-Dewenter et al. 2001, 2002; Gathmann and Tscharntke 2002) the imagos could have fled to neighbouring zones not affected by the fire or towards unburnt patches within the burnt zone itself -since this did not burn uniformly (pers. obs.)- and there were some small vineyards scattered and fairly large areas occupied by outcrops of bare granite- where in turn there would have been already completed nests that were not affected by the fire. These areas that are 
unaffected by fire and that serve as refuges later become the sources for species that will eventually colonize the affected area (Panzer 1988; Hall and Schweitzer 1992; Niwa and Peck 2002; Hoffmann 2003; Saint-Germain et al. 2004; Swengel and Swengel 2007).

The nature of the wildfires that generally occur in the study area (superficial, fast and low-medium intensity (Plan 42, JCyL) means that the high temperatures generated do not persist for very long. Since most of the species sampled nest below ground level (see Appendix 1), it could be assumed that they would show a high survival rate thanks to the insulation from the flames exerted by the soil layers (Evans 1988; Christensen 1994; DeBano et al. 1998), unlike species that nest in plant substrates, which -with few exceptions (Möllenbeck et al. 2009)- are more vulnerable to fire.

The lower values of abundance, richness and diversity obtained in C2 (Table 1, Appendix 1), in fact surpassed by 0 -ASH05, could be attributed to the special characteristics of this sampling site: a closed habitat, little sunlight, and a greater degree of maturity than the other zones analysed. This would support the proposal of Lamotte (1975), who suggested that winged species are the first to recover after a disturbance (see Moretti et al. 2006) and that post-fire environments would favour sun-dependent entomofauna -heliophilous and floricolous insects (Moretti et al. 2002b, 2004)-, as is the case of Spheciformes wasps, which require a high degree of insolation for their survival (Evans and O'Neill 2007). They could also be favoured by the existence of dry conditions, as is the case of many species of ants (e.g. York 1996; Andersen and Müller 2000), which are protected from flames by their nests (Gibb and Hjältén 2007) and are favoured by the immediate simplification of their environment, although the response does vary from one species to another (Izhaki et al. 2003) depending on their ecology (Moretti et al. 2006). According to Fye (1972), the abundance of wasps is greater in perturbed forests, where there is more light and cover from the lower strata, which would afford this insects many trophic resources, such as nectar and prey for feeding their larvae (Taki et al. 2008). None of these characteristics is shared by C2, suggesting that this emplacement is not the most suitable one for Spheciformes and that only a few specialists would occupy the existing niches.

High species diversity provides greater stability to ecosystems, endowing them with greater resistance and resilience against disturbances, biological diversity being 
important in the processes of succession and reorganization of such ecosystems (Tilman and Downing 1994; McGrady-Steed et al. 1997; Naeem and Li 1997; Naeem 1998). In the present case, the highest value for the Shannon index $\left(H^{\prime}\right)$ was obtained for $\mathrm{C} 1$, while the values obtained in the burnt areas were contradictory; this could have been due both to the difference in local habitat conditions between both sites and to the marked influence that a low number of species exerts on this index (Magurran 2004). It is known that the captures recorded may represent both the relative activity of the taxa captured (Niwa and Peck 2002) and their population density, or a combination of both (Spence and Niemela 1994). Thus, the number of captures obtained with Malaise traps is directly related to the abundance and mobility of individuals. This mobility, as in the case of most insects, is affected by insolation and temperature (Evans and O'Neill 2007). Since the climatic characteristics of the zone studied seem to be favourable for this groups of insects (see Materials and Methods), the observed differences in the parameters analysed between the two perturbed areas could be due to the hindrance to mobility exerted by the high density of Stipa gigantea, a vivaceous grass reaching up to $2 \mathrm{~m}$ in height present in the ASH zone, for certain species, and the local differences in habitat deriving from its presence with respect to the other zone (BURNT) analyzed.

In the ellipses generated by simulation for the whole sample set (Fig. 1), in which the values of $\Delta+$ are plotted against those of $\Lambda+$ for each sample, 0-ASH05 has abnormally high values of $\Lambda+$. These could be the result of the destructuring of the community brought about by the fire. Thus, after the impact, this community would show a poor, simple, and less "compact" structure than the rest, perhaps due to the presence of pioneer species from different higher-level taxa, taking advantage of the resources or niches available to them through the new open zones. 2-B05 and 1-B04 also show abnormally high values of $\Lambda+$ and $\Delta+$ respectively, significantly different from what is expected from the simulation. To a certain extent this contrasts with the location of the two controls ( $\mathrm{C} 1$ and $\mathrm{C} 2)$, which exhibit structured communities, in agreement with the pattern observed for the Iberian Peninsula (as is reflected in their emplacement within the corresponding simulation ellipses). Even $\mathrm{C} 2$, despite its having lower richness and abundance values, has a relatively "well structured" community. All the foregoing suggests that the perturbation caused an important community destructuring that was not corrected until well after the fire and that could be more 
evident with the use of taxonomic distinctness indices than with the classic indices of diversity.

The observed separation in the MDS plot for 0-ASH05, C2, and to a lesser extent $\mathrm{C} 1$, from the rest of the samples (Fig. 2) is confirmed by the values of the complementarity indices (Table 2). These results reveal, on the one hand, the important changes that occurred in the communities owing to the fire (the 0-ASH05 community is clearly separated from the others) and, on the other hand, the importance of the local differences between the zones analyzed. Thus, the habitat structure play a fundamental role in the distribution of insect communities, and on certain occasions they may be a more important factor than the fire itself (Ratchford et al. 2005). In the case of ants, when the differences in the structure of the vegetation between the burnt and unburnt zones are small, the effects of fire are less pronounced (Parr et al. 2004). In this study, the fact that both the controls appear clearly separated reflects a contrast that could be due to the marked structural differences. Also, the greater proximity between the group of samples affected by the fire (except the one collected immediately after it, 0-ASH05) and $\mathrm{C} 1$ suggests that the recovery of Spheciformes populations after a fire is relatively fast when the zones affected correspond to cleared habitats (such as C1) instead of closed ones (such as $\mathrm{C} 2$ ).

The differences obtained between the dominant species at the different localities, perturbed or not, were very large. There were hardly any common dominant species, either at spatial scale (among localities) or temporal scale (among the different periods post-fire) (Table 3). This again shows the importance of habitat structure for these insects (see Taki et al. 2008), which is even greater than that of the effects of the fire.

The extent to which insect richness increases in a given area after a fire points to their ability to access resprouting vegetation, with greater nutrient quality (in the case of herbivorous species) and access to those herbivores by predatory species (Evans 1988; Fellows and Newton 1999; Ne'eman et al. 2000; Underwood et al 2009). Thus, $S$. funerarius, which is not present in closed forest, could have benefited to a certain extent from the post-fire conditions, when the amount of bare soil potentially suitable for nest building and the availability of orthopterans, attracted by the better quality of the resprouting herbaceous vegetation, are greater, allowing it to become dominant in both the burnt areas (with the exception of 2-B05) and in $\mathrm{C} 1$ (unburnt). It thus emerges as the 
species that is most resistant to the habitat conditions brought about by the fire in open and cleared zones, in detriment to S. leuconotus.

After the disturbance, the species Trypoxylon attenuatum (eudominant in mature habitats, C2) was displaced by T. scutatum, which despite having similar ecological requirements, seemed to acquire a certain advantage over the former species and achieve greater growth thanks to the simplification of the habitat and the capacity of $T$. scutatum to nest in both plant hollows and in the ground.

Despite the existence of a greater number of species exclusive to disturbed areas, only Oxybelus subspinosus was dominant at 0-ASH05, pointing to its greater preference for post-fire conditions, since it was not recorded in the rest of the samples. In contrast, the fact that Larra anathema and Oxybeluus uniglumis were dominant and exclusive to $\mathrm{C} 2$ and $\mathrm{C} 1$ respectively shows that the two species have very special habitat requirements and are thus highly sensitive to this type of disturbance.

The available resources for nesting, very important in the case of Spheciformes, and the guild structure, vary markedly in the habitat in different post-fire regeneration phases, which will undoubtedly influence community structure and the relative abundance of the dominant species, as reported by Potts et al. (2005) for bees. In light of the data obtained for the guild composition of the community, the low number of captures of individuals nesting on plant substrates in most of the samples from the disturbed areas would partly support the results of Potts et al. (2005), since those substrates, initially eliminated by the fire, increased along the recovery period and increased in habitat complexity, which was simplified after the fire. An example of this is $\mathrm{C} 2$, where the presence of a large number of species and spider-hunting individuals, among which $T$. attenuatum (eudominant in that community) is included, corroborates the significance of the individuals occupying plant cavities (including xylicolousrubicolous species), since most of them belong to spider-hunting species, and it reinforces the importance of habitat as regards the abundance of these species. The fact that 2-ASH07 also had a higher number of individuals with this nesting pattern, in detriment to those that nest in the ground, to a certain extent would support the notion that some of the species existing in that zone would have been favoured by the presence of Stipa gigantea, although the absence of references or direct observations regarding this mean that caution should be exercised with regard to this possibility. 


\section{Conclusions}

Populations of Spheciformes wasps seem to survive the direct impact of the flames in superficial, rapid and low-medium intensity wildfires occurring towards the end of summer, probably owing to their good flying ability and the protection exerted by the soil substrate for the nests of many species. Likewise, their populations seem to be favoured by post-fire environmental conditions; this is reflected in an increase in abundance and species richness. Despite this, however, and as shown by the taxonomic distinctness indices, these populations do undergo an important degree of "destructuring", which is not corrected until a considerable time after the disturbance. This would be directly related to the modifications undergone by the habitat structure, pointing to the strong influence of habitat on these insects and the preference of the group for cleared habitats.

In spite of the foregoing, the low number of samples used in the present study suggests that it would be risky to advance a definitive statement about the recovery capacity of Spheciformes wasps when challenged by this type of disturbance. It would therefore seem advisable to complete this study with others spanning longer periods of time and with a greater sampling effort in order to confirm or rebut the results obtained. Likewise, it would be indispensable to follow up the recovery and/or evolution of the community over time in areas with a high tree density after the impact of a highintensity forest fire up to the recovery of the conditions prevailing prior to the disturbance. 
Appendix 1. Abundances of the species collected. Classificatión acording to Pulawski, 2009: www.calcademy.com/research/entomolgy/Entomology_Resources/Hymenoptera/sphecidae.

Species

0-ASH05

1-ASH06

2-ASH07

C1 C2

TOTAL

Nesting/ Prey

AMPULICIDAE Shuckard, 1840

Ampulicinae Shuckard, 1840

Ampulicini Shuckard, 1840

Dolichurus corniculus (Spinola, 1808)

Dolichurus haemorrhous A. Costa, 1886

SPHECIDAE Latreille, 1802

Sceliphrinae Ashmead, 1899

Sceliphrini Ashmead, 1899

Sceliphron destillatorium (Illiger, 1807)

Sphecinae Latreille, 1802

Sphecini Latreille, 1802

Sphex atropilosus Kohl, 1885

Sphex flavipennis Fabricius, 1793

Sphex funerarius Gussakovskij, 1934

Sphex leuconotus Brullé, 1833

Pryonichini Bohart \& Menke, 1963

Palmodes melanarius (Mocsáry, 1883)

Palmodes occitanicus (Roth, 1963)

Chilosphex argyrius (Brullé, 1833)

Prionyx viduatus (Christ, 1791)

Ammophilinae André, 1886

Ammophilini André, 1886

Ammophila campestris Latreille, 1809

Ammophila heydeni Dahlbom, 1845

Ammophila hungarica Mocsáry, 1883

Ammophila sabulosa (Linnaeus, 1758)

Podalonia hirsuta (Scopoli, 1763)

CRABRONIDAE Latreille, 1802

Pemphredoninae Dahlbom, 1835

Psenini Costa, 1858

Psenulus fuscipennis (Dahlbom, 1843)

Mimesa grandii Maidl, 1933

Pemphredonini Dahlbom, 1835

Diodontus insidiosus Spooner, 1938

Pemphredon lethifer (Shuckard, 1837)

Passaloecus pictus Ribaut, 1952

Passaloecus vandeli Ribaut, 1952

Spilomena troglodytes (Van der Linden, 1829)

Ammoplanus bischoffi Maréchal, 1938

Ammoplanus ceballosi Giner Marí, 1943

Ammoplanus perrisi Giraud, 1869

Astatinae Lepeletier, 1845

Astatini Lepeletier, 1845

Astata cobosi Giner Marí, 1946

Dryudella tricolor (Van der Linden, 1829)

Dinetinae Fox, 1895

Dinetini Fox, 1895

Dinetus pictus (Fabricius, 1793)

Crabroninae Latreille, 1802

Larrini Latreille, 1810

Larra anathema (Rossi, 1790)

Larropsis punctulata (Kohl, 1884)

Tachytes panzeri (Dufour, 1841)

Tachysphex adjunctus Kohl, 1885

Tachysphex consocius Kohl, 1892

Tachysphex denisi Beaumont, 1936

Tachysphex fulvitarsis (A. Costa, 1867)

Tachysphex incertus (Radoszkowski, 1877)

Tachysphex julliani Kohl, 1883

Tachysphex nitidior Beaumont, 1940

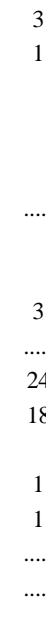

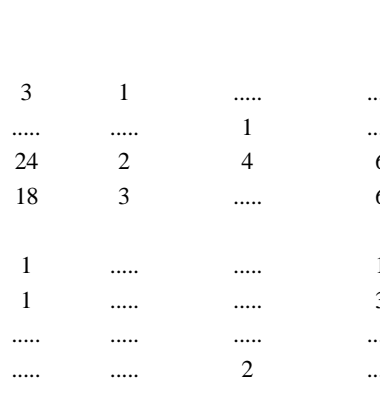

$\cdots$.

$\cdots .$.
$\cdots .$.
6
6
1
3
$\cdots .$.
$\cdots$.

\begin{tabular}{|c|c|c|c|c|}
\hline 1 & $\ldots$. & $\ldots .$. & 1 & $\mathrm{MD} / \mathrm{Ar}$ \\
\hline$\ldots$. & $\ldots$. & $\ldots .$. & 4 & TE/Or \\
\hline 1 & $\ldots .$. & $\ldots .$. & 2 & TE/Or \\
\hline 11 & 6 & $\ldots .$. & 53 & TE/Or \\
\hline 5 & 1 & $\ldots .$. & 33 & TE/Or \\
\hline ..... & $\ldots$. & $\ldots .$. & 2 & TE/Or \\
\hline 1 & $\ldots .$. & $\ldots .$. & 5 & TE/Or \\
\hline 2 & $\ldots .$. & $\ldots .$. & 2 & SQt/Or \\
\hline ..... & $\ldots .$. & $\ldots .$. & 2 & $\mathrm{TE} / \mathrm{Or}$ \\
\hline
\end{tabular}

$\begin{array}{ccc}8 & 25 & \ldots . \\ 1 & 2 & 3 \\ 15 & 17 & \ldots . . \\ 1 & \ldots . & \ldots . . \\ 1 & \cdots . & \ldots . .\end{array}$

4
1
$\cdots$
$\cdots$.
1

$\begin{array}{cccc} & & & \\ 3 & \ldots . & \ldots . & 40 \\ 3 & 2 & \ldots . . & 12 \\ \ldots . & 1 & \ldots . . & 33 \\ \ldots . & \ldots . . & \ldots . . & 1 \\ \ldots . & \ldots . . & \ldots . . & 2\end{array}$

TE/Lel-HyL

TE/Lel

TE/Lel

TE/Lel

TE/Lel

TE/Bl

TE/Bl

Qt/Or 


\begin{tabular}{|c|c|c|c|c|c|c|c|c|c|}
\hline Species & 1-B04 & 2-B05 & 0-ASH05 & 1-ASH06 & 2-ASH07 & C1 & $\mathrm{C2}$ & $\begin{array}{c}\text { TOTAL } \\
\mathbf{N}\end{array}$ & Nesting/ Prey \\
\hline Tachysphex obscuripennis (Schenck, 1857) & $\ldots .$. & 1 & 5 & $\ldots .$. & $\ldots .$. & 4 & ...... & 10 & $\mathrm{TE} / \mathrm{Bl}$ \\
\hline Tachysphex panzeri (Van der Linden, 1829) & 1 & 4 & 2 & 1 & $\ldots .$. & $\ldots .$. & $\ldots .$. & 8 & $\mathrm{TE} / \mathrm{Or}$ \\
\hline Tachysphex pompiliformis (Panzer, 1805) & $\ldots .$. & 5 & $\ldots .$. & $\ldots .$. & $\ldots .$. & 1 & $\ldots .$. & 6 & TE/Or \\
\hline Tachysphex psammobius (Kohl, 1880) & $\ldots .$. & 1 & $\ldots .$. & $\ldots .$. & $\ldots .$. & 1 & $\ldots .$. & 2 & $\mathrm{TE} / \mathrm{Or}$ \\
\hline Tachysphex pseudopanzeri Beaumont, 1955 & 3 & $\ldots .$. & $\ldots .$. & $\ldots .$. & $\ldots .$. & $\ldots .$. & $\ldots .$. & 3 & TE/Or \\
\hline Tachysphex tarsinus (Lepeletier, 1845) & $\ldots .$. & 2 & 1 & $\ldots .$. & $\ldots .$. & $\ldots .$. & $\ldots .$. & 3 & TE/Or \\
\hline Tachysphex unicolor (Panzer, 1809) & 2 & 1 & 2 & $\ldots$. & $\ldots .$. & $\ldots .$. & $\ldots .$. & 5 & $\mathrm{TE} / \mathrm{Or}$ \\
\hline Prosopigastra kohli Mercet, 1907 & $\ldots$. & $\ldots .$. & $\ldots .$. & 1 & $\ldots$. & ..... & ..... & 1 & TE/Ho \\
\hline Prosopigastra punctatissima A. Costa, 1867 & $\ldots .$. & $\ldots .$. & $\ldots .$. & 1 & $\ldots .$. & $\ldots .$. & $\ldots .$. & 1 & TE/Ho \\
\hline \multicolumn{10}{|l|}{ Miscophini Fox, 1895} \\
\hline Solierella compedita (Piccioli, 1869) & 35 & 11 & $\ldots .$. & 18 & 34 & 1 & $\ldots .$. & 99 & TE-SQt-SQv/He \\
\hline Solierella pisonoides (Saunders, 1873) & $\ldots .$. & 1 & $\ldots .$. & $\ldots .$. & $\ldots .$. & 1 & $\ldots .$. & 2 & TE-SQt-SQv/He \\
\hline Solierella seabrai Andrade, 1950 & $\ldots .$. & $\ldots .$. & $\ldots .$. & $\ldots .$. & 1 & $\ldots .$. & $\ldots .$. & 1 & SQt-SQv/He \\
\hline Miscophus ater Lepeletier, 1845 & $\ldots .$. & 1 & $\ldots .$. & $\ldots \ldots$ & ..... & $\ldots .$. & $\ldots .$. & 1 & $\mathrm{TE} / \mathrm{Ar}$ \\
\hline Miscophus bicolor Jurine, 1807 & 7 & 20 & 1 & 1 & $\ldots .$. & 3 & $\ldots .$. & 32 & $\mathrm{TE} / \mathrm{Ar}$ \\
\hline Miscophus eatoni Saunders, 1903 & 2 & 3 & $\ldots .$. & 2 & 2 & 1 & $\ldots .$. & 10 & $\mathrm{TE} / \mathrm{Ar}$ \\
\hline Miscophus nicolai Ferton, 1896 & $\ldots .$. & 7 & 4 & 1 & $\ldots .$. & $\ldots .$. & $\ldots .$. & 12 & $\mathrm{TE} / \mathrm{Ar}$ \\
\hline Nitela lucens Gayubo \& Felton, 2000 & 2 & 1 & 1 & 1 & $\ldots .$. & $\ldots .$. & 1 & 6 & SQv/PAs \\
\hline \multicolumn{10}{|l|}{ Trypoxylini Lepeletier, 1845} \\
\hline Pison atrum (Spinola, 1808) & $\ldots .$. & $\ldots .$. & $\ldots .$. & $\ldots .$. & 1 & $\ldots .$. & $\ldots .$. & 1 & $\mathrm{SQv} / \mathrm{Ar}$ \\
\hline Trypoxylon attenuatum $\mathrm{F}$. Smith, 1851 & 8 & 13 & $\ldots .$. & 2 & 9 & 11 & 15 & 58 & $\mathrm{SQv} / \mathrm{Ar}$ \\
\hline Trypoxylon clavicerum Lepeletier \& Serville, 1828 & 4 & 2 & 2 & 2 & 2 & 5 & 2 & 19 & SQv/Ar \\
\hline Trypoxylon figulus (Linnaeus, 1758) & $\ldots .$. & $\ldots .$. & $\ldots .$. & $\ldots .$. & $\ldots .$. & $\ldots .$. & 1 & 1 & SQv/Ar \\
\hline Trypoxylon minus Beaumont, 1945 & $\ldots .$. & $\ldots .$. & $\ldots .$. & $\ldots .$. & 2 & $\ldots .$. & $\ldots .$. & 2 & SQv/Ar \\
\hline Trypoxylon scutatum Chevrier, 1867 & 13 & 18 & 1 & 10 & 19 & 4 & 2 & 67 & SQv-SQt/Ar \\
\hline \multicolumn{10}{|l|}{ Oxybelini Leach, 1815} \\
\hline Oxybelomorpha steckii (Kohl, 1923) & 2 & 3 & $\ldots .$. & 1 & $\ldots .$. & $\ldots .$. & $\ldots .$. & 6 & TE/He-Co \\
\hline Oxybelus quattuordecimnotatus Jurine, 1807 & 5 & $\ldots .$. & 4 & 3 & 4 & 15 & $\ldots .$. & 31 & TE/Dip \\
\hline Oxybelus subspinosus Klug, 1835 & $\ldots .$. & $\ldots .$. & 4 & $\ldots .$. & $\ldots .$. & $\ldots .$. & $\ldots .$. & 4 & TE/Dip \\
\hline Oxybelus uniglumis (Linnaeus, 1758) & $\ldots .$. & $\ldots .$. & $\ldots .$. & $\ldots .$. & $\ldots .$. & 6 & $\ldots .$. & 6 & TE/Dip \\
\hline \multicolumn{10}{|l|}{ Crabronini Latreille, 1802} \\
\hline Encopognathus braunsi Mercet, 1915 & 1 & $\ldots .$. & $\ldots .$. & $\ldots .$. & ..... & ..... & $\ldots .$. & 1 & $\mathrm{TE} / \mathrm{He}$ \\
\hline Lindenius ibericus Kohl, 1905 & $\ldots .$. & $\ldots .$. & $\ldots .$. & 1 & $\ldots .$. & $\ldots .$. & $\ldots .$. & 1 & TE/He-Dip \\
\hline Tracheliodes quinquenotatus (Jurine, 1807) & $\ldots .$. & 2 & $\ldots .$. & $\ldots .$. & $\ldots .$. & $\ldots .$. & $\ldots .$. & 2 & TE/Hy \\
\hline Ectemnius cephalotes (Olivier, 1792) & $\ldots$. & 1 & $\ldots .$. & $\ldots$. & $\ldots .$. & $\ldots .$. & $\ldots .$. & 1 & XR/Dip \\
\hline Ectemnius crassicornis (Spinola, 1808) & $\ldots .$. & $\ldots .$. & $\ldots .$. & $\ldots .$. & 1 & $\ldots .$. & $\ldots .$. & 1 & SQv-XR/Dip \\
\hline \multicolumn{10}{|l|}{ Mellininae Latreille, 1802} \\
\hline \multicolumn{10}{|l|}{ Mellinini Latreille, 1802} \\
\hline Mellinus arvensis (Linnaeus, 1758) & ..... & $\ldots .$. & $\ldots .$. & $\ldots .$. & $\ldots .$. & 1 & 1 & 2 & TE/Dip \\
\hline \multicolumn{10}{|l|}{ Bembicinae Latreille, 1802} \\
\hline \multicolumn{10}{|l|}{ Nyssonini Latreille, 1804} \\
\hline Nysson interruptus (Fabricius, 1798) & 6 & 1 & $\ldots .$. & $\ldots .$. & $\ldots .$. & 1 & $\ldots .$. & 8 & PA \\
\hline Nysson maculosus (Gmelin, 1790) & $\ldots .$. & $\ldots .$. & $\ldots .$. & $\ldots .$. & 1 & $\ldots .$. & $\ldots .$. & 1 & PA \\
\hline Nysson pratensis Mercet, 1909 & $\ldots .$. & 1 & $\ldots .$. & & & 1 & $\ldots$. & 2 & PA \\
\hline \multicolumn{10}{|l|}{ Bembicini Latreille, 1802} \\
\hline Argogorytes fargeii (Shuckard, 1837) & $\ldots .$. & 3 & $\ldots .$. & $\ldots .$. & $\ldots .$. & $\ldots .$. & 1 & 4 & TE/Ho \\
\hline Gorytes quinquefasciatus (Panzer, 1798) & $\ldots .$. & 1 & $\ldots .$. & $\ldots .$. & $\ldots .$. & 2 & $\ldots .$. & 3 & TE/Ho \\
\hline Gorytes sulcifrons (A. Costa, 1869) & 6 & 1 & $\ldots .$. & 1 & 3 & 8 & 4 & 23 & TE/Ho \\
\hline Harpactus alvaroi Gayubo, 1992 & 1 & $\ldots .$. & 2 & $\ldots .$. & $\ldots .$. & 2 & $\ldots .$. & 5 & TE/Ho \\
\hline Harpactus formosus (Jurine, 1807) & 2 & 3 & 1 & $\ldots .$. & 1 & 3 & $\ldots .$. & 10 & TE/Ho \\
\hline Harpactus laevis (Latreille, 1792) & 4 & 11 & $\ldots .$. & $\ldots .$. & $\ldots .$. & $\ldots .$. & $\ldots .$. & 15 & TE/Ho \\
\hline Lestiphorus bicinctus (Rossi, 1794) & $\ldots .$. & $\ldots .$. & $\ldots .$. & 1 & 1 & $\ldots .$. & 2 & 4 & TE/Ho \\
\hline Bembecinus carpetanus (Mercet, 1906) & ..... & $\ldots .$. & $\ldots .$. & ..... & $\ldots .$. & 1 & $\ldots$. & 1 & TE/Ho \\
\hline Bembecinus tridens (Fabricius, 1781) & $\ldots .$. & $\ldots .$. & 1 & $\ldots$. & $\ldots .$. & $\ldots .$. & $\ldots$. & 1 & TE/Ho \\
\hline Bembix bidentata Van der Linden, 1829 & $\ldots .$. & $\ldots .$. & $\ldots .$. & 1 & 1 & $\ldots .$. & 4 & 6 & TE/Dip \\
\hline Bembix oculata Panzer, 1801 & $\ldots .$. & $\ldots .$. & $\ldots .$. & 2 & $\ldots .$. & $\ldots .$. & $\ldots .$. & 2 & TE/Dip \\
\hline Bembix zonata Klug, 1835 & 4 & 1 & $\ldots .$. & 2 & $\ldots .$. & 1 & $\ldots$. & 8 & TE/Dip \\
\hline \multicolumn{10}{|l|}{ Philanthinae Latreille, 1802} \\
\hline \multicolumn{10}{|l|}{ Cercerini Lepeletier, 1845} \\
\hline Cerceris arenaria (Linnaeus, 1758) & 2 & 2 & $\ldots .$. & $\ldots .$. & $\ldots .$. & 2 & $\ldots .$. & 6 & TE/Co \\
\hline Cerceris quadricincta (Panzer, 1799) & $\ldots$. & 1 & ..... & ..... & $\ldots$. & $\ldots .$. & 2 & 3 & TE/Co \\
\hline Cerceris sabulosa (Panzer, 1799) & 2 & $\ldots .$. & $\ldots .$. & 1 & $\ldots .$. & $\ldots$. & $\ldots .$. & 3 & TE/Hy \\
\hline $\begin{array}{ll}\text { TOTAL INDIVIDUALS } \\
\end{array}$ & 241 & 253 & 62 & 103 & 143 & 110 & 44 & 956 & \\
\hline TOTAL SPECIES & 45 & 49 & 23 & 36 & 31 & 42 & 15 & 98 & \\
\hline
\end{tabular}


Appendix 2. Exclusive species of burnt and Control (unburnt) areas.

\begin{tabular}{|c|c|c|c|c|c|}
\hline \multicolumn{6}{|c|}{ BURNT AREAS } \\
\hline & 0-ASH05 & 1-ASH06 & 2-ASH07 & 1-B04 & 2-B05 \\
\hline Sceliphron destillatorium & & & 1 & & \\
\hline Sphex flavipennis & 1 & & 1 & & \\
\hline Palmodes melanarius & & 1 & & 1 & \\
\hline Palmodes occitanius & & 3 & 1 & 1 & \\
\hline Chilosphex argyrius & & & 2 & & \\
\hline Prionyx viduatus & 2 & & & & \\
\hline Ammophila campestris & & 4 & 3 & 8 & 25 \\
\hline Ammophila sabulosa & & & & 1 & \\
\hline Podalonia hirsuta & & 1 & & 1 & \\
\hline Mimesa grandii & & & & 1 & \\
\hline Passaloecus pictus & & & 1 & & \\
\hline Passaloecus vandeli & & & & & 1 \\
\hline Tachysphex denisi & & & & 2 & \\
\hline Tachysphex panzeri & 2 & 1 & & 1 & 4 \\
\hline Tachysphex tarsinus & & & & & 2 \\
\hline Prosopigastra kohli & & 1 & & & \\
\hline Prosopigastra punctatissima & & 1 & & & \\
\hline Solierella seabrai & & & 1 & & \\
\hline Miscophus ater & & & & & 1 \\
\hline Pison atrum & & & 1 & & \\
\hline Trypoxylon minus & & & 2 & & \\
\hline Oxybelomorpha steckii & & 1 & & 2 & 3 \\
\hline Oxybelus subspinosus & 4 & & & & \\
\hline Encopognathus braunsi & & & & 1 & \\
\hline Lindenius ibericus & & 1 & & & \\
\hline Ectemnius cephalotes & & & & & 1 \\
\hline Ectemnius crassicornis & & & 1 & & \\
\hline Nysson maculosus & & & 1 & & \\
\hline Bembecinus tridens & 1 & & & & \\
\hline Cereris sabulosa & & 1 & & 2 & \\
\hline \multicolumn{6}{|c|}{ CONTROLS } \\
\hline & & $\mathrm{C1}$ & & \multicolumn{2}{|c|}{ C2 } \\
\hline Bembecinus carpetanus & & 1 & & & \\
\hline Larropsis punctulata & & 1 & & & \\
\hline Larra anathema & & & & \multicolumn{2}{|c|}{5} \\
\hline Oxybelus uniglumis & & 6 & & & \\
\hline Trypoxylon figulus & & & & \multicolumn{2}{|c|}{1} \\
\hline Mellinus arvensis & & 1 & & \multicolumn{2}{|c|}{1} \\
\hline Ammoplanus bischoffi & & & & \multicolumn{2}{|c|}{1} \\
\hline Ammoplanus perrisi & & 2 & & & \\
\hline Spylomena troglodytes & & & & \multicolumn{2}{|c|}{2} \\
\hline
\end{tabular}




\section{References}

Andersen, A. \& Müller, W. J. 2000 Arthropod responses to experimental fire regimes in an Australian tropical savannah: ordinal-level analysis. Austral Ecol 25: 199-209.

Arnan, X., Rodrigo, A. \& Retana, J. 2006. Post-fire recovery of Mediterranean ground ant communities follows vegetation and dryness gradients. J Biogeogr 33 (7): 1246-1258.

Arnan, X., Rodrigo, A.\& Retana, J. 2007. Post-fire regeneration of Mediterranean plant communities at a regional scale is dependent on vegetation type and dryness. J Veget Science 18 (1): 111-122.

Badia-Perpinya, A. \& Pallares-Barbera, M. 2006. Spatial distribution of ignitions in Mediterranean periurban and rural areas: the case of Catalonia. Int J Wildland Fire 15: 187-196.

Bailey, J. K. \& Whitham, T. G. 2002. Interactions among fire, aspen, and elk affect insect diversity: Reversal of a community response. Ecology 83 (6): 1701-1712.

Bengtsson, J., Angelstam, P., Elmqvist, T., Emanuelsson, U., Folke, C., Ihse, M., Moberg, F. \& d Nyström, M. 2003. Reserves, resilience, and dynamic landscapes. Ambio 32: 389-96.

Bond, W. J. \& van Wilgen, B. W. 1996. Fire and Plants. Chapman and Hall, Londres. 263 pp.

Bond, W. J., Woodward, F. I. \& Midgley, G. F. 2005. The global distribution of ecosystems in a world without fire. New Phytol 165: 525-538.

Breece, C. R., Kolb, T. E., Dickson, B. G., McMillin, J. D. \& Clancy, K. M. 2008. Prescribed fire effects on bark beetle activity and tree mortality in southwestern ponderosa pine forests. Forest Ecol Manag 255: 119-128.

Calonge-Cano, G. 1990. La excepcionalidad climática de los Arribes del Duero. ERIA.

Calvo, L., Tárrega, R. \& Luis-Calabuig, E. 1991. Regeneration in Quercus pyrenaica ecosystems after surface fires. Int J Wildland Fire 1 (4): 205-210.

Calvo, L., Tárrega, R. \& Luis-Calabuig, E. 1999. Post-fire succesion in two Quercus pyrenaica communities with different disturbance histories. Ann For Sci 56: 441-447.

Campbell, J. W., Hanula, J. L. \& Waldrop, T. A. 2007. Effects of prescribed fire and fire surrogates on floral visiting insects of the blue ridge province in North Carolina. Biol Conserv 134: 393-494

Christensen, N. L. 1994. The effects of fire on physical and chemical properties of soil in Mediterraneanclimate shrublands. - In: Moreno, JM, Oechel WC. (eds), The role of fire in Mediterranean-type ecosystems. Pp. 79-95. Springer-Verlag. New York.

Clarke, K. R. \& Warwick, R. M. 2001. Change in marine communities: An Approach to Statistical Analysis and Interpretation. $2^{\text {nd }}$ edition. PRIMER-E, Plymouth. $171 \mathrm{pp}$.

Colwell, R. K. \& Coddington, J. A. 1994. Estimating terrestrial biodiversity through extrapolation. Philosophical Transactions of the Royal Society of London, Series B 345: 101-118

De Luis, M., Raventós, J. \& González-Hidalgo, J. C. 2006. Post-fire vegetation succession in Mediterranean gorse shrublands. Acta Oecol 30: 54-61

DeBano, L. F., Neary, D. G. \& Ffolliott, P. F. 1998. Fire's effects on ecosystems. Wiley. New York. 352 pp.

Diadema, K., Médail, F. \& Bretagnolle, F. 2007. Fire as a control agent of demographic structure and plant performance of a rare Mediterranean endemic geophyte. C. R. Biologies 330: 691-700

Elmqvist, T., Folke1, C., Nyström, M., Peterson, G., Bengtsson, J., Walker, B. \& Norberg, J. 2003. Response diversity, ecosystem change, and resilience. Front Ecol Environ 1 (9): 488-494

Espelta, J. M., Rodrigo, A., Habrouk, A., Meghelli, N., Ordonez, J. L. \& Retana J 2002. Land use changes, natural regeneration patterns, and restoration practices after a large wildlife in NE Spain: challenges for fire ecology and landscape restoration. In: Traubaud, L., Rrodon, P. (Eds.), Fire and Biological Processes. pp. 315-324. Backhurys Publishers, Leiden, The Netherlands. 
Evans, E. W. 1988. Grasshopper (Insecta: Orthoptera: Acrididae) assemblages of tallgrass prairie: influences of fire frequency, topography, and vegetation. Can J Zool 66: 1495-1501

Evans, H. E. \& O’Neill, K. M. 2007. The Sand Wasps: Natural History and Behavior. Harvard University Press, Cambridge, Massachusetts

Fellows, D. P. \& Newton, W. E. 1999. Prescribed fire effects on biological control of leafy spurge. $J$ Range Manage 52: 489-493

Fernández, M. M \& Salgado, J. M 2004. Recolonization of a burn pine forest (Pinus pinaster) by Carabidae (Coleoptera). Eur J Soil Biol 40: 47-53

Fisher, B. L. 1998. Insect behaviour and Ecology in Conservation: Preserving functional species interactions. Ann Entomol Soc Am 91 (2): 155-158

Fye, R. E. 1972. The effect of forest disturbances on populations of wasps and bees in northwestern Ontario (Hymenoptera: Aculeata). Can Entomol 104: 1623-1633

García-Feced, C., Escribano, R. \& Elena, R. 2007. Comparación de la estructura de los paisajes en Parques Naturales fronterizos: Arribes del Duero versus Douro Internacional. Montes 91: 8-14

García-Villanueva, J., Ena, V., Mediavilla, G. \& Tárrega, R. 1995. Explotación post-fuego por hormigas de Quercus pyrenaica. Avances Ent Ib.: 91-00.

García-Villanueva, J., Ena, V., Tárrega, R. \& Mediavilla, G., 1998. Recolonization of two burned Quercus pyrenaica ecosystems by Coleoptera. Int J Wildland Fire 8: 21-27

Gathmann, A. \&Tscharntke, T. 2002. Foraging ranges of solitary bees. J Anim Ecol 71: 757-764

Gayubo, S. F., González, J. A., Asís, J. D. \& Tormos, J. 2005. Conservation of European environments: The Spheciformes wasp as biodiversity indicators (Hymenoptera: Apoidea: Ampulicidae, Sphecidae and Crabronidae). J Nat Hist 39 (29): 2705-2714.

Gibb, H. \& Hjältén, J. 2007. Effects of low severity burning after clear-cutting on mid-boreal ant communities in the two years after fire. J Insect Conserv 11: 169-175

González, J. A., Gayubo, S. F., Asís, J. D. \& Tormos, J, 2009. Diversity and Biogeographical Significance of Solitary wasp (Chrysididae, Eumeninae and Spheciformes) at the Arribes del Duero Natural Park, Spain: Their Importance for Insects Diversity Conservation in the Mediterranean Region. Environ Entomol 38 (3): 608-626

Haeseler, V. 1972. Anthropogene Biotope (Kahlschlag, Kiesgrube, Stadtgärten) als Refugien für Insekten, untersucht am Beispiel der Hymenoptera Aculeata. Zoologische Jahrbücher (Systematik) 99: $133-212$

Hall, S. P. \& Schweitzer, D. F. 1992. A survey of the moths, butterflies, and grasshoppers of four Nature Conservancy preserves in southeastern North Carolina. Rept. to Nature Conservancy, North Carolina Chapter, Carrboro, NC $122 \mathrm{pp}$.

Harper, M. G., Dietrich, C. H., Larimore, R. L. \& Tessene, P. A. 2000. Effects of prescribed fire on prairie arthropods: an enclosure study. Nat Area J 20: 325-335

Hirowatari, T. \& Makihara, H. 2007. Effects of fires on butterfly assemblages in lowland dipterocarp forest in East Kalimantan. Entomol Sci 10 (2): 113-127

Hobbs, R. J. \& Gimmingham, C. H. 1987. Vegetation, fire and herbivore interactions in heathland. $A d v$ Ecol Res 16: 18-173

Hoffmann, B. D. 2003. Responses of ant communities to experimental fire regimes on rangelands in the Victoria River District of the Northern Territory. Austral Ecol 28: 182-195

Huber, J. T. 2009. Biodiversity of Hymenoptera. In: Foottit RG, Adler PH, (eds.) Insect Biodiversity: Science and Society. Blackwell Publishing Ltd, Oxford, UK

Humphries, C. J., Williams, P. H. \& Vane-Wright, R. I. 1995. Measuring biodiversity value for conservation. Annu Rev Ecol Syst 26: 93-111 
Huston, M. 1994. Biological diversity: The coexistence of species changing landscapes. Cambridge University Press, Cambridge. 681 pp.

Izhaki, I., Levey, D., Silva, W. 2003. Effects of prescribed fire on an ant community in Florida pine savanna. Ecol Entomol 28: 439-448

Knight, T. M., Holt, R. D. 2005. Fire Generates Spatial Gradients in Herbivory: An Example from a Florida Sandhill Ecosystem. Ecology 86 (3): 587-593

Kremen, C. 1992. Assessing the indicator properties of species assemblages for natural areas monitoring. Ecol Appl 2: 203-217

Lamotte, M. 1975. The structure and function of a tropical savannah ecosystem. In: Golley FB, Medina E (eds.), Tropical Ecological Systems: Trends in Terrestrial and Aquatic Research. pp 179-222. Springer-Verlag, Berlin

LaSalle, J. \& Gauld, I. D. (eds.) 1993. Hymenoptera and Biodiversity. CAB International. The Natural History Museum, Wallingford, UK. xi +348 pp.

Legendre, P. \& Legendre, L. 1998. Numerical Ecology. Elsevier Science. 2 Edition. Amsterdam. 870 pp.

Lloret, F. 2003. Gestión del fuego y conservación en ecosistemas mediterráneos. Ecosistemas 2003/2

Lloret, F. 2004. Régimen de incendios y regeneración. In: Valladares F. (ed.) Ecología del bosque mediterráneo en un mundo cambiante. pp. 101-126. Ministerio de Medio Ambiente - O. A. Parques Nacionales, Madrid.

Lockwood, J. A., Shaw, S. R. \& Struttmann J. M. 1996. Biodiversity of wasp species (Insecta: Hymenoptera) in burned and unburned habitats of Yellowstone National Park, Wyoming, USA. J Hymenopt Res 5: 1-15.

Luck, G. W., Daily, G. C. \& Ehrlich, P. R. 2003. Population diversity and ecosystem services. Trends Ecol Evol 18: 331-36

Luis-Calabuig, E. (Coord.) 2008. Arribes del Duero. Guía de la Naturaleza. Edilesa. León. 224 pp.

Luis-Calabuig, E. \& Tárrega, R. 1993. Studies on post-fire regeneration in Quercus pyrenaica ecosystems in Leon Province (NW Spain.. In: Trabaud L., Prodon R., (eds.) Fire in mediterranean ecosystems. Pp 209-219. ECSC-EEC-EAEC, Brussels-Luxembourg.

Magurran, A. E. 2004. Measuring Biological Diversity. Osford. Blackwell Science Publishing.

Makihara, H., Kinuura, H., Yahiro, K. \& Soeyamto, C. 2000. The effect of droughts and fires on coleopteran insects in lowland dipterocarp forests in Bukit Soeharto, East Kalimantan. In: Guhardja E, Fatawi M, Sutisna M, Mori T and Ohta S (eds.) Rainforest ecosystems of East Kalimantan: El Niño, drought, fire and human impacts. Ecological Studies vol. 140. SpringerVerlag, Tokyo

McGrady-Steed, J., Harris, P. M. \& Morin, P. J. 1997. Biodiversity regulates ecosystem predictability. Nature 390: 162-165

Ministerio de Medio Ambiente, medio Rural y Marino 2009. www.marm.es

Möllenbeck, V., Hermann, G. \& Fartmann, T. 2009. Does prescribed burning mean a threat to the rare satyrine butterfly Hipparchia fagi? Larval-habitat preferences give the answer. $J$ Insect Conserv 13 (1): 77-87

Moreira, F. \& Russo, D. 2007. Modelling the impact of agricultural abandonment and wildfires on vertebrate diversity in Mediterranean Europe. Landscape Ecol 22: 1461-1476

Moreno, J. M. \& Oechel, W. C. 1995. The role of fire in Mediterranean type ecosystems. SpringerVerlag, New York. 215 pp.

Moreno, J. M., Vázquez, A., Vélez, R. 1998. Recent history of forest fires in Spain. In: Moreno JM (ed.) Large Forest Fires. Pp: 159-181. Backhuys, Leiden 
Moretti, M. \& Barbalat, S. 2004. The effects of wildfires on wood-eating beetles in deciduous forests on the southern slope of the Swiss Alps. Forest Ecol Manag 187 (1): 85-103.

Moretti, M., Conedera, M., Duelli, P. \& Edwards, P. J. 2002. The effects of wildfire on ground-active spiders in deciduous forests on the Swiss Southern slope of the Alps. J Appl Ecol 39 (2): 321336

Moretti, M., Duelli, P. \& Obrist, M. K. 2006. Biodiversity and resilience of arthropod communities after fire disturbance in temperate forests. Oecologia 149: 312-327

Moretti, M, Obrist, M. K, \& Duelli, P. 2004. Arthropod biodiversity after forest fires: winners and losers in the winter fire regime of the Southern Alps. Ecography 27 (2): 173-186

Morgan, J. W. \& Lunt, I. D. 1999. Effect of time-since fire on the tussock dynamics of a dominant grass (Themeda triandra) in a temperate Australian grassland. Biol Conserv 88: 379-386

Naeem, S. 1998. Species redundancy and ecosystem reliability. Conserv Biol 12: 39- 45

Naeem, S. \& Li, S. B. 1997. Biodiversity enhances ecosystem reliability. Nature 390: 507-509

Naveh, Z. 1975. The evolutionary significance of fire in the Mediterranean region. Vegetatio 29: 199-208

Naveh, Z. 1995. The role of fire and its management in the conservation of Mediterranean ecosystems and landscapes. In: Moreno, J.M., Oechel, W.C. (eds) The Role of Fire in Mediterranean-Type Ecosystems. Pp: 163-185.Springer-Verlag, New York, USA

Ne'eman, G., Dafni, A. \& Potts, S. G. 2000. The effect of fire on flower visitation rate and fruit set four core-species in east Mediterranean scrubland. Plant Ecol 146: 97-104

Niwa, C. G. \& Peck, R. W. 2002. Influence of prescribed fire on carabid beetle (Carabidae) and spider (Araneae) assemblages in forest litter in southwestern Oregon. Environ Entomol 31: 785-796

Noble, I. R. \& Slatyer, R. O. 1981. Concepts and models of succession in vascular plant communities subject to recurrent fire. In: Gill AM, Groves RH, Noble IR (eds) Fire and the Australian Biota. pp. 311-315.

Nunes, L., Leather, S. \& Rego, F. 2000. Effects of fire on insects and other invertebrates. A review with particular reference to fire indicator species. Silva Lusitana 8 (1): 15-32

Nunes, L., Silva, I., Pité, M., Rego, F., Leather, S. \& Serrano, A. 2006. Carabid (Coleoptera) Community changes following prescribed burning and the potential use of carabids as indicators species to evaluate the effects of FIRE management in Mediterraneans Region. Silva Lusitana 14 (1): 85100

Oesterheld, M., Loreti, J., Semmartin, M. \& Paruelo, J. M. 1999. Grazing, fire and climate effects on primary productivity of grasslands and savannas. In: Walker LR (ed), Ecosystems of the World 16. pp. 287-306. Ecosystems of Disturbed Ground. Elsevier, Amsterdam

Ojeda-Copete, F. 2001. El fuego como factor clave en la evolución de plantas mediterráneas. In: Zamora Rodríguez R, Pugnaire de Iraola FI (eds) Ecosistemas Mediterráneos. Análisis funcional. Pp: 319-349. Textos Universitarios. CSIC. Asociación Española de Ecología Terrestre

Panzer, R. 1988. Managing prairie remnants for insect conservation. Nat Areas J 8: 83-90

Panzer, R. 2003. Importance of in situ survival, recolonization, and habitat gaps in the postfire recovery of fire-sensitive prairie insects species. Nat Areas $J$ 23: 14-21

Parr, C. L., Robertson, H. G., Biggs, H. C. \& Chown, S. L. 2004. Response of African savannah ants to long-term fire regimes. J Appl Ecol 41: 630-642

Pausas, J. G. \& Vallejo, R. 1999. The role of fire in European Mediterranean ecosystems. In: Chuvieco E (ed), Remote Sensing of Large Forest Fires in the European Mediterranean Basin. Pp. 3-16. Springer.

Pausas, J. G. 2003. The effect of landscape pattern on Mediterranean vegetation dynamics: a modelling approach using functional types. J Veget Scienc 14: 365-374 
Pausas, J. G. 2004. Changes in fire and climate in the eastern Iberian Peninsula (Mediterranean basin). Climatic Change 63: 337-350

Pausas, J. G., Carbo, E., Caturla, R. N., Gil, J. M. \& Vallejo, R. 1999. Post-fire regeneration patterns in the eastern Iberian Peninsula. Acta Oecol 20 (5): 499-508

Peterson, G., Allen, C. R., \& Holling, C. S. 1998. Ecological resilience, biodiversity, and scale. Ecosystems 1: 6-18

Pickett, S. T. A., \& White, P. S. 1985. Patch dynamics: a synthesis. In: Pickett STA and P. White (eds) The ecology of natural disturbance and patch dynamics. Pp: 371-384. New York: Academic Press

Potts, S. G., Dafni, A., Ne'eman, G. 2001. Pollination of a core flowering shrub species in Mediterranean phrygana: variation in pollinator diversity, abundance and effectiveness in response to fire. Oikos 92: $71-80$

Potts, S. G., Vulliamy, B., Dafni, A., O’Toole, C., Roberts, S. \& Willmer, P. 2003. Response of plantpollinator communities to fire: changes in diversity, abundance and floral structure. Oikos 101: $103-112$

Potts, S. G., Vulliamy, B., Roberts, S., O'Toole, C., Dafni, A., Ne'eman, G. \& Willmer, P. 2005. Role of nesting resources in organising diverse bee communities in a Mediterranean landscape. Ecol Entomol 30: 78-85

Pyne, S. J., Andrews, P. L. \& Laven, R D. 1996. Introduction to Wildland Fire, 2nd edn. John Wiley and Sons, New York, NY. 808 pp.

Ramos, M. A., Lobo, J. M. \& Esteban, M. 2001. Ten years inventorying the Iberian fauna: results and perspectives. Biodivers Conserv 10: 19-28

Ratchford, J. S., Wittman, S. E., Jules, E. S., Ellison, A. M., Gotelli, N. J. \& Sanders, N. J. 2005. The effects of fire, local environment and time on ant assemblages in fens and forests. Divers Distr 11: $487-497$

Saint-Germain, M., Drapeau, P. \& Hébert, C. 2004. Comparison of Coleoptera assemblages from a recently burned and unburned black spruce forests of northeastern North America. Biol Conserv 118: 583-592

Samways, M. J. 2005. Insect Diversity Conservation. Cambridge University Press, Cambridge

Smith, J. K. 2000. Wildland fire in ecosystems: Effects of fire on fauna. Gen. Tech. Rep. RMRS-GTR-42Vol. 1. ODGEN, UT: U.S. Department of Agriculture, Forest Service, Rocky Mountain Research Station

Spence, J. R. \& Niemela, J. K 1994. Sampling carabid assemblages with pitfall traps: the madness and the method. Can Entomol 126: 881-894

Steffan-Dewenter, I., Münzenberg, U. \& Tscharntke, T. 2001. Pollination, seed set and seed predation on a landscape scale. Proc $R$ Soc Lond B 268: 1685-1690

Steffan-Dewenter, I., Münzenberg, U., Bürger, C., Thies, C. \& Tscharntke, T. 2002. Scale-dependent effects of landscape context on three pollinator guilds. Ecology 83:1421-1432

Swengel, A. B. 2001. A literature review of insect responses to fire, compared to other conservation managements of open habitat. Biodiver Conserv 10 (7): 1141-1169

Swengel, A. B. \& Swengel, S. R. 2007. Benefit of permanent non-fire refugia for Lepidoptera conservation in fire-managed sites. J Insect Conserv 11: 263-279

Taki, H., Viana, B. F., Kevan, P. G., Silva, F. O. \& Buck, M. 2008. Does forest loss affect the communities of trap-nesting wasps (Hymenoptera: Aculeata) in forests? Landscape vs. local habitat conditions. J Insect Conserv 12 (1): 15-21

Tilman, D. 2000. Causes, consequences and ethics of biodiversity. Nature 405: 208-211 
Tilman, D. \& Downing, J. A. 1994. Biodiversity and stability in grasslands. Nature 367: 363-365

Underwood, E. C. \& Christian, C. E. 2009. Consequences of prescribed fire and grazing on grassland ant Communities. Environ Entomol 38 (2): 325-332

Vélez, R. 1990. Los incendios forestales en España. Ecología 1: 213-221

Vélez, R. 1999. Perspectiva global de los incendios forestales en el mundo al final del siglo XX. In: Araque, E (ed) Incendios Históricos. Una aproximación multidisciplinar. Pp: 411-422. Universidad Internacional de Andalucía, Baeza, España.

Viedma, O., Moreno, J. M. \& Rieiro, I. 2006. Interactions between land use/land cover change, forest fires and landscape structure in Sierra de Gredos (Central Spain). Environ Conserv 33: 212-222

Whelan, R. J. 1995. The Ecology of Fire. Cambridge University Press, Cambridge. 346 pp.

Wilson, E. O. 1992. The diversity of life. Harvard Univesity Press, Cambridge.

York, A. 1996. Long-term effect of repeated prescribed burning on forest invertebrates: Management implications for the conservation of biodiversity. Consultancy report to the Department of the Environment and Heritage. Final report. April 1996. 


\section{2}

*Effects of wildfire on Spheciformes wasp

diversity (Hymenoptera: Apoidea) in a

Mediterranean agroecosystem of European interest

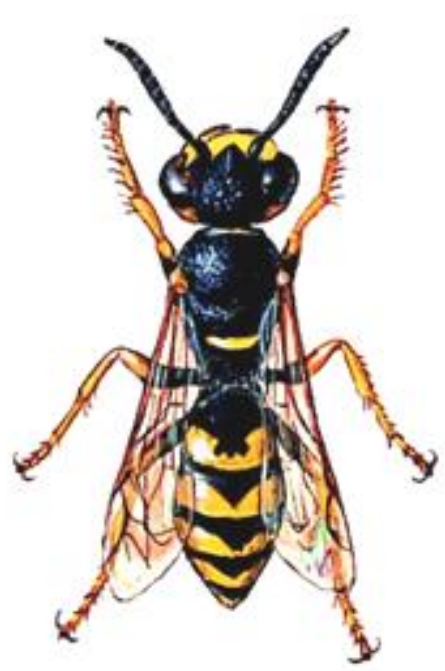




\title{
Effects of wildfire on Spheciformes wasp diversity (Hymenoptera: Apoidea) in a Mediterranean agroecosystem of European interest
}

\begin{abstract}
In a study conducted in a Mediterranean agroecosystem (Arribes del Duero Natural Park, western Spain), a "space-for-time substitution" was used to analyze how the communities of Spheciformes wasps varied in their different diversity components along the 15 years elapsed after the occurrence of a wildfire in summer. Both the habitat and the particular environmental conditions marking the interannual variations in the populations of the communities of the groups analyzed seemed to exert a greater influence than that due to the fire itself. The time elapsed after the wildfire was a specially important factor to the recovery of the richness and species diversity after the disturbance. The existence of unburnt patches, deriving from traditional land use and the presence of bare rock, was seen to be important because they served as refuges for the populations of these insects during the fire. The differences between the analyses performed with the samples obtained with the two capture methods employed (Malaise and yellow pan traps) pointed to differences in their mode of action and in the information they provided about the communities, highlighting the need to use them jointly in order to reflect more precisely the responses to the fire and the composition of the Spheciformes wasps communities, which would otherwise have remained hidden.
\end{abstract}

Keywords: Spheciformes; wildfire; diversity; Quercus pyrenaica forests; Malaise and yellow pan traps; Mediterranean agroecosystem. 


\section{Introduction}

Fire is the most frequent natural type of perturbation affecting Mediterranean ecosystems (Naveh, 1975; Trabaud and Prodon, 1993), and it acts not only as a destructive force against such ecosystems but also as an important ecological factor that seems to be a selective and regulatory agent (Naveh, 1990). Like other agents of disturbance, its effect on the vegetation and the different communities of animals associated with this varies. Different determinants (intensity, frequency, seasonality, local habitat conditions, climate, topography...) govern the magnitude of the effect of fire (Whelan, 1995; Bond and van Wilgen, 1996), resulting in a landscape composed of a complex and heterogeneous mosaic of regenerating vegetation that favours the maintenance and conservation of species richness and diversity (Moretti and Barbalat, 2004; Swengel and Swengel, 2007).

Owing to its ecological and demographic conditions, within the Mediterranean region the Iberian Peninsula, in general, and Spain in particular, is an area with a particularly severe problem with forest fires. Currently, fire cannot be considered merely as a natural phenomenon since the current fire regime is to a large extent governed by social factors, stemming from the profound transformations that the territory has undergone in the past century (Pausas, 2004; Moreno et al., 1998; Moreno, 2007). A good example of a mosaic-patterned and highly heterogeneous landscape that has not escaped such transformations is the Arribes del Duero Natural Park (PNAD). This is of great importance owing to its entomological diversity and biogeographic significance (González et al., 2009) and it has often been subjected to wildfires deriving from human activity owing to the entrenched culture of the use of fire in the zone (Plan 42 Junta Castilla y León, http://www.jcyl.es).

Insects, with more than $80 \%$ of the species described, both at world level (Wilson, 1992) and on the Iberian Peninsula (Ramos et al., 2001), perform a crucial task in the maintenance and development of forest ecosystems (Schoonhoven et al., 2005). Despite this, however, studies addressing the effects of fire on their populations are relatively scarce and have usually aimed at groups that react in a sensitive way to this type of disturbance and that can be used as ecological indicators (reviewed by Nunes et al., 2000). In this sense, Spain is no exception (e.g. García-Villanueva et al., 1998; Arnán et al., 2006; Rodrigo et al., 2008). 
Nevertheless, it is necessary to expand such studies to other groups that because of their characteristics could be vital in terrestrial ecosystems (Huber, 2009) and especially sensitive to certain forms of perturbation, such as the Hymenoptera Aculeata (LaSalle and Gauld, 1993). Within the Aculeata, the Spheciformes, which have been proposed as a biodiversity indicator group (see Gayubo et al., 2005), maintain a close relationship with the structure of the environment (Steffan-Dewenter and Leschke, 2003; Potts et al., 2005; Taki et al., 2008), which would make them especially sensitive to the transformation brought about by fire (Cruz-Sánchez et al., in prep.) or other types of impact. At the same time, considering their predatory behaviour and the variety of preys captured (Evans and O'Neill, 2007), they could in turn reflect the recovery of other groups of insects after the disturbance.

Forest fires affect insect communities directly, damaging part of the existing populations, eliminating them, or leading them to emigrate, or indirectly, by modifying the structure of the environment and reducing the niches used or creating other new ones for surviving or colonizing species (Whelan, 1995; Swengel, 2001; Andersen and Müller, 2000; Potts et al., 2005; Knight and Holt, 2005; Rodrigo et al., 2008). The recovery of animal species to a large extent depends on the resilience of the habitat in which they live and on the time that it takes to recover. Thus, insect communities will vary in the parameters of abundance, richness and diversity as a function of the degree of habitat recovery.

To properly assess the response of insect communities to a fire it is necessary to study and follow up their evolution during the post-fire recovery period. This was the main aim of the present study, which had three specific objectives: (1) to analyze the variations in Spheciformes wasps communities in their different diversity components along 15 years after a summer forest fire; (2) to determine whether, as reported by different authors for other groups (Moretti et al., 2002a; Izhaki et al., 2003), the Spheciformes, as a group "adapted" to the action of fire, are able to recover positively after the action of fire, and (3) to check whether the use of different capture methods (Malaise traps and yellow pan traps) might offer a different view of the response of Spheciformes communities to the action of fire. 


\section{Material and Methods}

\section{Study area}

The study was carried out at two localities (Villarino de los Aires and Pereña de la Ribera) located in the PNAD (Province of Salamanca, western Spain), in the zone most affected by wildfire (see Municipal Plan for Fighting Forest Fires at Villarino de los Aires and Plan 42-JCyL, http://www.jcyl.es).

The area affected, a zone of peniplain, is characterized by its wildness, propitiated by the abandonment of intensive agricultural practices and a greater tendency for the land to be used for live-stock rearing, together with the presence of a high percentage of shrubby vegetation (García-Feced et al., 2007), with small, scattered cereal plots and small vineyards. All these aspects make this area a clear example of a Mediterranean agroecosystem. This is the greatest zone of the territory harbouring Galicio-Portuguese oak woods with Quercus pyrenaica, characteristic of the central and northwestern zone of the Iberian Peninsula at altitudes equal to or higher than 700 m.s.a.1. (Costa Tenorio et al., 2005). These Mediterranean deciduous forests have been included in the list of habitats of community interest of the EU (Bartolomé et al., 2005: 230-231). To a large extent clear-felled by humans, they are a fine example of agroecosystems, and they have developed into savannah-like areas (“dehesas") and are floristically impoverished (Escudero Alcántara et al., 2008: 366; Luis-Calabuig, 2008). The constant pressure undergone by these plant formations along time owing to fire, felling and grazing, have led Quercus pyrenaica to become a very resistant species, whose communities contain many species able to resprout from under the ground, endowing them with great resilience (Calvo et al., 1991, 1999; Luis-Calabuig and Tárrega, 1993).

The zone is characterized by having a gentle mean annual temperature (mean 11 ${ }^{\circ} \mathrm{C}$ for the whole area) and certain moisture conditions (mean precipitation around 700 $\mathrm{mm} /$ year), that confer the region a Mediterranean mesoclime character (Calonge-Cano, 1990). The only representative soils are leptosols.

The fires typical of the zone analyzed are superficial, rapid and of low-to medium intensity, in most cases of anthropic origin -mainly arson- and occurring during the summer (Plan 42, JCyL). Generally, the fires do not burn the substrate in a uniform 
fashion, since the disperse presence of large bare surfaces of rock, small tilled vineyards and fields delimited by stone walls act as fire barriers, allowing the existence of unburnt zones within the area affected by the fire.

\section{Sampling techniques}

Specimen collection was carried out using Malaise traps (henceforth MT) and yellow pan traps (YPT) $(22 \mathrm{~cm}$ diameter; $3 \mathrm{~cm}$ depth). The study was based on a "space-for-time substitution" (Picket, 1989) through the analysis of three fires that occurred in 2004, 2002 and 1998; ej., 1, 3 and 7 years before the start of the study (2005). A sampling performed along 3 years (see Table 1) allowed us to establish a chronological succession that encompassed the recovery period, which was from 1 to 3 years for the first fire (2004); 5 to 6 for the second one (2002) and 7 to 9 for the third one (1998). All the zones sampled were close to one another and belonged to areas with similar plant compositions and physical, geological and soil characteristics. The characteristics of the localities sampled: the year of the wildfires, their extent and time of occurrence, the sampling year of each wildfire, the number of MT and YPT used at each of them and the time elapsed since the wildfire are shown in Table 1.

Table 1: Summary of the main characteristics of the study sites. SY: Sampling year: MT: Malaise Trap; YPT:

Yellow Pan Traps; F: Fire; C: Control. * Note that at sites 2F and 3F only two years were sampled.

\begin{tabular}{|c|c|c|c|c|c|c|c|c|}
\hline & Site & $\begin{array}{l}\text { Year of } \\
\text { wildfire }\end{array}$ & Extension & $\begin{array}{l}\text { Date of } \\
\text { wildfire }\end{array}$ & $\begin{array}{l}\text { SY (June- } \\
\text { September) }\end{array}$ & MT/SY & YPT/SY & $\begin{array}{c}\text { Age (years } \\
\text { post-fire) }\end{array}$ \\
\hline \multirow{3}{*}{ 舆 } & $1 \mathrm{~F}$ & 2004 & 120 ha & August & $\begin{array}{c}2005,2006, \\
2007\end{array}$ & 3 & 240 & $1,2,3$ \\
\hline & $2 \mathrm{~F}$ & 2002 & 452 ha & October & 2006, 2007 & 3 & 240 & 4,5 \\
\hline & $3 \mathrm{~F}$ & 1998 & 110 ha & August & 2005,2007 & 3 & 240 & 7,9 \\
\hline \multirow{2}{*}{$\begin{array}{l}0 \\
0 \\
\\
0 \\
0 \\
0\end{array}$} & $1 \mathrm{C}$ & $\cdots$ & $\cdots$ & $\ldots$ & $\begin{array}{c}2005,2006 \\
2007\end{array}$ & 2 & 160 & \multirow{2}{*}{$13,14,15$} \\
\hline & $2 \mathrm{C}$ & $\ldots$ & $\ldots$ & $\ldots$ & $\begin{array}{c}2005,2006 \\
2007\end{array}$ & 1 & 80 & \\
\hline
\end{tabular}

The control zones were recovered zones and were representative of the areas studied, although owing to the historical presence of fire in the area analyzed they were considered to be representative of a fire that occurred 13 years before the start of the study. 
In each sampling year three MT were installed inside each of the three burnt zones and in the two controls (Table 1). The traps were set at a minimum distance of $150 \mathrm{~m}$ and a maximum of $320 \mathrm{~m}$ from the closest unburnt edge. The traps set in the same zone were sufficiently distant from one another (mean $80 \mathrm{~m}$ ) for no interferences with one another during the sampling to be suspected. Around each MT, a plot of $10 \mathrm{x}$ $10 \mathrm{~m}$ was established, in which 20 YPT were installed, five on each side. The separation between the YPT was approximately $2 \mathrm{~m}$, depending on the presence of vegetation and a suitable substrate for their installation. The YPT were buried in the ground up to the top lip, and were filled almost completely with soapy water plus salt, which acted as a preservative. To facilitate their location, hindered by plant overgrowth in certain zones, their position was signalled with a small orange-painted stake. The choice of yellow for the pans was mainly for the following reasons: 1) yellow is the colour that offers the best results for Hymenoptera and, in particular, for the superfamily Apoidea (OrtizSánchez and Aguirre-Segura, 1993), and 2) it is the most common colour among the flowers growing in the study area on which the imagos of the group analyzed feed, such that their result must be optimum (Campbell et al., 2007; Westphal et al., 2008). Both capture methods have already been used satisfactorily, independently or both at the same time, in the analysis of insect communities affected by fire (e.g. Hansen, 1988; Lockwood et al., 1996; Makihara et al., 2000; Campbell et al., 2007; Hirowatari et al., 2007).

Sampling was carried out from June to September (both inclusive) along the three consecutive years of the sampling period. The captures belonging to each MT were collected fortnightly, while those taken from the YPT (installed on day 15 of each month) were collected monthly, after remaining active for $48 \mathrm{~h}$. In cases in which part of the sample was lost owing to unfavourable climate, the sampling was repeated two days later until one YPT sample per month and area sampled had been obtained. Despite this, the sample corresponding to June 2005 could not be collected because of adverse climate conditions and the impact of the presence of domestic animals in some zones and wild mammalian fauna in others. The samples were taken to the laboratory for appropriate preparation of the individuals collected, after which the specimens were identified up to species level and analyzed. The material collected has been deposited at the Department of Animal Biology, Ecology, Parasitology, and Agricultural Chemistry of the University of Salamanca. 


\section{Statistical analyses}

Statistical analyses of the data were performed using PRIMER v5 (PRIMER-E Ltd) and XLSTAT 2009. For mathematical analysis of the alpha diversity component, the indices and parameters most commonly used for the definition and analysis of biocenoses were used (Magurran, 2004): abundance (N), number of specimens in each sample; species richness (S), number of species appearing in each of the samples; the Shannon index of diversity ( $H^{\prime}$, loge $)$, the Simpson index of diversity $\left(D=1-\lambda{ }^{\prime}\right)$ and the Pielou evenness index (J'). Likewise, two of the taxonomic distinctness indices developed by Clarke and Warwick (Clarke and Warwick 2001a) were used: Average taxonomic distinctness $\left(\Delta^{+}\right)$, the mean taxonomic distance of all the pairs of species in a list, and Variation in taxonomic distinctness $(\Lambda+)$, the variation in the phylogenetic distances between each pair of species. These indices are non-parametric measures based on presence/absence data. In response to environmental degradation, $\Delta^{+}$appears to decline monotonically, generally being lower for degraded habitats compared to better-conserved zones. Further, it is relatively insensitive to major habitat differences. The combination of $\Delta+$ and $\Lambda+$ provides a robust statistical summary of the patterns of taxonomic, or phylogenetic, relationships within a sample (Clarke \& Warwick, 2001b). Construction of the two taxonomic distinctness indices requires a "master list" or inventory of species, within which taxonomic boundaries are defined. We used a list with the 462 species cited in the Iberian peninsula, with 5 taxonomic levels (species,

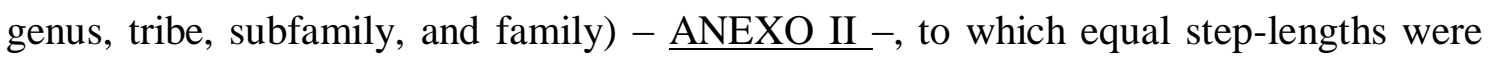
assigned. The samples obtained were compared with a simulation obtained from the master list (10,000 restarts) to analyze whether the observed subset of species was representative of the diversity expressed in the full species inventory. The use of both indices allows a bivariate approach to be obtained, in which their values are jointly considered in terms of both observed outcomes from real datasets and their expected values under subsampling from a master species inventory (Clarke and Warwick 2001b). Data points outside the relevant $95 \%$ contour or ellipse plots imply statistical evidence of "departure from expectation" for those samples (Clarke and Warwick 2001b).

To determine the most influential factors in the response of the communities to the disturbance caused by the fire, general linear models (GLMs) were performed using 
the different estimators of diversity separately as dependent variables and the following variables as explanatory:

- AGE (years since fire): This is a quantitative variable that would explain the variation in the index as the study zone recovered from the effects of the fire. This provides an idea of the resilience or time taken by the wasp community to recover from the disturbance and return to the conditions before the impact, and of the variation in the composition of the community along the recovery period. Since the response to this variable was often unimodal, and even bimodal, the quadratic and/or cubic variable was introduced into the model.

- Sampling Year (SY) (2005, 2006, and 2007): This is a qualitative variable related to the year of sampling. It determines the incidence of the interannual variation in the Spheciformes populations in the response variable.

- Trap LOCATION: A qualitative variable with two categories:

a) F = FIRE, for traps situated inside the burnt zone.

b) $\mathrm{C}=\mathrm{CONTROL}$, for traps situated outside the burnt zone.

The GLM model chosen was usually the minimal adequate model (see Grafen and Hails, 2002), in which all the variables were significant at a probability level of 0.05 , although in some cases the variables with submarginal significance were retained when their presence led to reasonable increases in the percentage of variation explained (estimated by the value of $\mathrm{R}^{2}$ adjusted).

In view of the large amount of samples available (from both MT and YPT) and the quantitative differences observed between them, and in order to obtain the maximum amount of information possible, several analyses were conducted using different groupings of MT and YPT. To accomplish this we followed homogeneity criteria, consistently assessing the differences between the sampling effort made by each of the capture methods and the dependence of some of the indices used on this sampling effort.

The analyses carried out with the samples used for each of them were as follows (see Table 2): 
1. Malaise traps individually: Using the samples from the $30 \mathrm{MT}$ used during the sampling period

2. Malaise traps grouped by site and sampling year: Using the 10 samples obtained upon grouping the three MT installed each year at each of the sites analyzed (FIRE and CONTROL) $(1$ sample $=3 \mathrm{MT})$

3. Yellow pan traps grouped by site and sampling year: Using the 10 samples obtained upon grouping the YPT installed each year at each of the sites analyzed $($ FIRE and CONTROL $)(1$ sample $=240$ YPT $)$

4. Malaise traps + Yellow pan traps: With the samples grouped by locality and sampling year (total, 10 samples; 1 sample $=3 \mathrm{MT}+240 \mathrm{YPT}$ ).

Table 2: Global and partial number of traps used in the study by site and sampling year MT = Malaise Trap; YPT= Yellow Pan Traps; F= Fire; C= Control.

\begin{tabular}{|c|c|c|c|c|c|c|}
\hline \multirow[b]{3}{*}{ SITE } & \multicolumn{6}{|c|}{ Sampling Year \& Trap Method } \\
\hline & \multicolumn{3}{|c|}{ MT } & \multicolumn{3}{|c|}{ YPT } \\
\hline & 2005 & 2006 & 2007 & 2005 & 2006 & 2007 \\
\hline $\mathbf{1 F}$ & 3 & 3 & 3 & 240 & 240 & 240 \\
\hline $2 \mathbf{F}$ & $\cdots$ & 3 & 3 & .. & 240 & 240 \\
\hline $3 \mathbf{F}$ & 3 & $\cdots$ & 3 & 240 & $\cdots$ & 240 \\
\hline $1 C+2 C$ & 3 & 3 & 3 & 240 & 240 & 240 \\
\hline Total MT/SY & 9 & 9 & 12 & 720 & 720 & 960 \\
\hline Total traps & & 30 & & & 2400 & \\
\hline
\end{tabular}

\section{Results}

The values obtained for the different indices and parameters analyzed are shown in Appendix A.

1.- Malaise traps individually: The $30 \mathrm{MT}$ used in this analysis collected a total of 8,290 specimens, belonging to 129 species, of which 49 species were exclusive to the MT (Appendices A, B and C).

The GLM results for the indices and variables described in the Materials and Methods section are detailed in Table 3. 
Table 3: Results of the GLM for the Malaise trap samples. SY: Sampling year.

\begin{tabular}{|c|c|c|c|c|c|c|c|c|c|}
\hline \multirow{2}{*}{ INDEX } & \multirow{2}{*}{$\begin{array}{c}\mathbf{R}^{2} \\
\text { adjusted }\end{array}$} & \multicolumn{3}{|c|}{ Analysis of variance } & \multicolumn{5}{|c|}{ Model parameters } \\
\hline & & df & $\mathbf{F}$ & $\operatorname{Pr}>\mathbf{F}$ & Parameter & Value & SD & $\mathbf{t}$ & $\operatorname{Pr}>|t|$ \\
\hline \multirow{8}{*}{$\mathbf{N}$} & \multirow{8}{*}{0.509} & \multirow{5}{*}{5} & \multirow{8}{*}{7.015} & \multirow{8}{*}{0.000} & Intercept & 626.977 & 80.872 & 7.753 & $<0.0001$ \\
\hline & & & & & Age & -83.215 & 27.090 & -3.072 & 0.005 \\
\hline & & & & & $\mathrm{Age}^{2}$ & 8.191 & 2.455 & 3.336 & 0.003 \\
\hline & & & & & SY - 2005 & 0.000 & 0.000 & & \\
\hline & & & & & SY - 2006 & -218.436 & 56.719 & -3.851 & 0.001 \\
\hline & & \multirow{3}{*}{24} & & & S Y - 2007 & -316.091 & 59.762 & -5.289 & 0.000 \\
\hline & & & & & Fire & 0.000 & 0.000 & & \\
\hline & & & & & Control & -619.866 & 216.104 & -2.868 & 0.008 \\
\hline \multirow{8}{*}{$\mathbf{S}$} & \multirow{8}{*}{0.427} & \multirow{5}{*}{5} & \multirow{8}{*}{5.316} & \multirow{8}{*}{0.002} & Intercept & 49.205 & 4.923 & 9.996 & $<0.0001$ \\
\hline & & & & & Age & -4.935 & 1.649 & -2.993 & 0.006 \\
\hline & & & & & $\mathrm{Age}^{2}$ & 0.619 & 0.149 & 4.141 & 0.000 \\
\hline & & & & & SY - 2005 & 0.000 & 0.000 & & \\
\hline & & & & & SY - 2006 & -3.248 & 3.452 & -0.941 & 0.356 \\
\hline & & \multirow{3}{*}{24} & & & SY - 2007 & -9.698 & 3.638 & -2.666 & 0.014 \\
\hline & & & & & Fire & 0.000 & 0.000 & & \\
\hline & & & & & Control & -52.494 & 13.154 & -3.991 & 0.001 \\
\hline \multirow{5}{*}{$\mathbf{H}^{\prime}$} & \multirow{5}{*}{0.377} & \multirow{3}{*}{3} & \multirow{5}{*}{6.841} & \multirow{5}{*}{0.002} & Intercept & 2.933 & 0.153 & 19.178 & $<0.0001$ \\
\hline & & & & & Age & -0.100 & 0.058 & -1.717 & 0.098 \\
\hline & & & & & $\mathrm{Age}^{2}$ & 0.013 & 0.005 & 2.629 & 0.014 \\
\hline & & \multirow{2}{*}{26} & & & Fire & 0.000 & 0.000 & & \\
\hline & & & & & Control & -0.975 & 0.409 & -2.382 & $\mathbf{0 . 0 2 5}$ \\
\hline \multirow{3}{*}{$D=1-\lambda^{\prime}$} & & & & & Intercept & 0.900 & 0.010 & 90.623 & $<0.0001$ \\
\hline & 0.102 & 1 & 4.303 & 0.047 & Fire & 0.000 & 0.000 & & \\
\hline & & 28 & & & Control & 0.038 & 0.018 & 2.074 & 0.047 \\
\hline & & & & & Intercept & 0.758 & 0.020 & 37.529 & $<0.0001$ \\
\hline & & 3 & & & SY - 2005 & 0.000 & 0.000 & & \\
\hline $\mathbf{I}^{\prime}$ & 034 & & 5969 & 0,003 & SY - 2006 & -0.009 & 0.027 & -0.351 & 0.729 \\
\hline $\boldsymbol{J}$ & 0.34 & & 5.909 & 0.000 & SY - 2007 & 0.072 & 0.025 & 2.877 & 0.008 \\
\hline & & 26 & & & Fire & 0.000 & 0.000 & & \\
\hline & & & & & Control & 0.056 & 0.023 & 2.475 & 0.020 \\
\hline & & & & & Intercept & 87.188 & 2.433 & 35.832 & $<0.0001$ \\
\hline & & & & & Age & -0.637 & 0.152 & -4.184 & 0.000 \\
\hline & & 4 & & & SY - 2005 & -2.675 & 0.789 & -3.390 & 0.002 \\
\hline$\Delta^{+}$ & 0.502 & & 8.304 & 0.000 & SY - 2006 & -0.391 & 0.808 & -0.483 & 0.633 \\
\hline & & & & & SY - 2007 & 0.000 & 0.000 & & \\
\hline & & 25 & & & Fire & -4.681 & 1.629 & -2.873 & 0.008 \\
\hline & & & & & Control & 0.000 & 0.000 & & \\
\hline & & & & & Intercept & 440.716 & 15.593 & 28.263 & $<0.0001$ \\
\hline$\Delta+$ & 0.200 & & 4626 & 0019 & SY - 2005 & 72.260 & 23.819 & 3.034 & 0.005 \\
\hline 27 & & 27 & $4.0 \angle 0$ & 0.013 & SY - 2006 & 35.726 & 23.819 & 1.500 & 0.145 \\
\hline & & 21 & & & SY- 2007 & 0.000 & 0.000 & & \\
\hline
\end{tabular}

In general, it was observed that (1) all the indices analyzed reached significant values for one or several variables; (2) N, S and H' revealed a model of unimodal response, that reflected a negative effect as from the second year after the wildfire; this effect increased gradually up to the fourth-fifth year post-fire, the time at which 
recovery began, after which it surpassed the initial values as from years ninth, seventh and eighth post-fire for N, S and H' respectively; (3) LOCATION (Fire and Control) was the only significant variable shared by all the parameters analyzed (except for $\Lambda^{+}$), although without a uniform response. Thus, N, S and H' attained higher values in the disturbed zones in comparison with the control ones, while these latter showed higher values of D, J' y $\Delta+$; (4) AGE (years since fire) acted by increasing the value of the indices with a significant response as the recovery period progressed, except for $\Lambda^{+}$, while SY displayed different responses, depending on the parameter analyzed, 2007 being usually the main cause of variation.

2.- Malaise traps by site and sampling year: This case involved the same traps as the previous one (see Table 2), the number of species and individuals captured being the same (Appendices A, B and C).

Table 4: GLM results for the Malaise trap samples grouped by site and sampling year. SY: Sampling year.

\begin{tabular}{|c|c|c|c|c|c|c|c|c|c|}
\hline \multirow{2}{*}{ INDEX } & \multirow{2}{*}{$\underset{\text { adjusted }}{\mathbf{R}^{2}}$} & \multicolumn{3}{|c|}{ Analysis of variance } & \multicolumn{5}{|c|}{ Model parameters } \\
\hline & & df & $\mathbf{F}$ & $\operatorname{Pr}>\mathbf{F}$ & Parameter & Value & SD & $\mathbf{t}$ & $\operatorname{Pr}>|t|$ \\
\hline \multirow{4}{*}{$\mathbf{N}$} & \multirow{4}{*}{0.456} & \multirow{2}{*}{2} & \multirow{4}{*}{4.780} & \multirow{4}{*}{0.049} & Intercept & 559.250 & 163.210 & 3.427 & 0.011 \\
\hline & & & & & SY - 2005 & 747.750 & 249.307 & 2.999 & 0.020 \\
\hline & & 7 & & & SY - 2006 & 151.417 & 249.307 & 0.607 & 0.563 \\
\hline & & & & & SY - 2007 & 0.000 & 0.000 & & \\
\hline \multirow{5}{*}{$\mathbf{S}$} & \multirow{5}{*}{0.716} & & \multirow{5}{*}{8.558} & \multirow{5}{*}{0.014} & Intercept & 4.182 & 14.992 & 0.279 & 0.790 \\
\hline & & 3 & & & Age & -5.582 & 2.241 & -2.491 & 0.047 \\
\hline & & & & & $\mathrm{Age}^{2}$ & 0.725 & 0.194 & 3.734 & 0.010 \\
\hline & & \multirow{2}{*}{6} & & & Fire & 61.513 & 15.802 & 3.893 & 0.008 \\
\hline & & & & & Control & 0.000 & 0.000 & & \\
\hline \multirow{2}{*}{$\mathbf{H}^{\prime}$} & \multirow{2}{*}{0.363} & 1 & \multirow{2}{*}{6.128} & \multirow{2}{*}{0.038} & Intercept & 2.857 & 0.145 & 19.760 & $<0.0001$ \\
\hline & & 8 & & & Age & 0.041 & 0.016 & 2.475 & $\mathbf{0 . 0 3 8}$ \\
\hline \multirow{2}{*}{$\mathbf{D}=1-\lambda^{\prime}$} & \multirow{2}{*}{0.128} & 3 & \multirow{2}{*}{2.317} & \multirow{2}{*}{0.166} & Intercept & 0.889 & 0.025 & 35.137 & $<0.0001$ \\
\hline & & 6 & & & Age & 0.004 & 0.003 & 1.522 & 0.166 \\
\hline \multirow{2}{*}{$\mathbf{J}^{\prime}$} & \multirow{2}{*}{0.157} & 1 & \multirow{2}{*}{2.672} & \multirow{2}{*}{0.141} & Intercept & 0.717 & 0.035 & 20.780 & $<0.0001$ \\
\hline & & 8 & & & Age & 0.006 & 0.004 & 1.635 & 0.141 \\
\hline \multirow{3}{*}{$\Delta+$} & \multirow{3}{*}{0.139} & & \multirow{3}{*}{1.725} & \multirow{3}{*}{0.246} & Intercept & 80.622 & 1.359 & 59.319 & $<0.0001$ \\
\hline & & 2 & & & Age & -0.796 & 0.440 & -1.808 & 0.114 \\
\hline & & 7 & & & $\mathrm{Age}^{2}$ & 0.044 & 0.026 & 1.682 & 0.136 \\
\hline \multirow{4}{*}{$\Lambda+$} & \multirow{4}{*}{0.225} & 2 & & & Intercept & 423.116 & 19.067 & 22.191 & $<0.0001$ \\
\hline & & 2 & 2302 & 0170 & SY - 2005 & 62.387 & 29.126 & 2.142 & 0.069 \\
\hline & & & 2.303 & $0.1 / 0$ & SY - 2006 & 30.306 & 29.126 & 1.041 & 0.333 \\
\hline & & 7 & & & SY - 2007 & 0.000 & 0.000 & & \\
\hline
\end{tabular}

The results obtained after calculating the GLMs (Table 4) revealed the following: (1) significant responses only for N, S and H'; (2) a clear difference among 
the sampling years as regards the number of specimens captured; (3) the AGE variable was the only one found to influence species diversity (H'), although unlike what occurred on analyzing all the Malaise traps individually, LOCATION did not show significant values for this index, and the model obtained reflected a continuing increase in $\mathrm{H}^{\prime}$ with the passing of time (in the analysis of the traps separately, diversity decreased but later recovered as from the fourth year post-fire); (4) according to the GLM, none of the variables considered had a significant effect on D, J', $\Delta+$ or $\Lambda+$.

3.- Yellow pan traps grouped by site and sampling year: A total of 2,606 specimens, belonging to 92 species, were captured by 2,400 YPT. Thirteen species were exclusive to this method of capture (Appendices A, B and C).

Table 5: GLM results for the YPT sample grouped by site and sampling year

\begin{tabular}{|c|c|c|c|c|c|c|c|c|c|}
\hline \multirow{2}{*}{ INDEX } & \multirow{2}{*}{$\begin{array}{c}\mathbf{R}^{2} \\
\text { adjusted }\end{array}$} & \multicolumn{3}{|c|}{ Analysis of variance } & \multicolumn{5}{|c|}{ Model parameters } \\
\hline & & df & $\mathbf{F}$ & $\operatorname{Pr}>\mathbf{F}$ & Parameter & Value & SD & $\mathbf{t}$ & $\operatorname{Pr}>|t|$ \\
\hline \multirow{6}{*}{$\mathbf{N}$} & \multirow{6}{*}{0.865} & \multirow{4}{*}{4} & \multirow{6}{*}{15.407} & \multirow{6}{*}{0.005} & Intercept & 442.764 & 36.835 & 12.020 & $<0.0001$ \\
\hline & & & & & Age & -141.781 & 21.528 & -6.586 & 0.001 \\
\hline & & & & & $\mathrm{Age}^{2}$ & 23.520 & 3.229 & 7.283 & 0.001 \\
\hline & & & & & $\mathrm{Age}^{3}$ & -0.935 & 0.131 & -7.148 & 0.001 \\
\hline & & \multirow[t]{2}{*}{5} & & & Fire & 0.000 & 0.000 & & \\
\hline & & & & & Control & -238.043 & 65.548 & -3.632 & 0.015 \\
\hline \multirow{4}{*}{$\mathbf{S}$} & \multirow{4}{*}{0.566} & \multirow{2}{*}{2} & \multirow{4}{*}{6.880} & \multirow{4}{*}{0.022} & Intercept & 36.333 & 2.640 & 13.764 & $<0.0001$ \\
\hline & & & & & SY - 2005 & 0.000 & 0.000 & & \\
\hline & & \multirow{2}{*}{7} & & & SY - 2006 & -2.000 & 3.733 & -0.536 & 0.609 \\
\hline & & & & & SY - 2007 & -11.833 & 3.492 & -3.389 & 0.012 \\
\hline \multirow{4}{*}{$\mathbf{H}^{\prime}$} & \multirow{4}{*}{0.601} & \multirow{3}{*}{2} & \multirow{4}{*}{7.770} & \multirow{4}{*}{0.017} & Intercept & 2.094 & 0.095 & 22.123 & $<0.0001$ \\
\hline & & & & & SY - 2005 & 0.496 & 0.145 & 3.428 & 0.011 \\
\hline & & & & & SY - 2006 & 0.467 & 0.145 & 3.227 & 0.015 \\
\hline & & 7 & & & SY - 2007 & 0.000 & 0.000 & & \\
\hline \multirow{4}{*}{$D=1-\lambda^{\prime}$} & \multirow{4}{*}{0.368} & \multirow{2}{*}{2} & \multirow{4}{*}{3.618} & \multirow{4}{*}{0.083} & Intercept & 0.890 & 0.033 & 26.839 & $<0.0001$ \\
\hline & & & & & Age & -0.014 & 0.006 & -2.230 & 0.061 \\
\hline & & \multirow{2}{*}{7} & & & Fire & 0.000 & 0.000 & & \\
\hline & & & & & Control & 0.184 & 0.069 & 2.670 & 0.032 \\
\hline \multirow{4}{*}{$\mathbf{J}^{\prime}$} & & & & & Intercept & 0.768 & 0.033 & 22.925 & $<0.0001$ \\
\hline & 0425 & 2 & 4150 & 0056 & Age & -0.018 & 0.006 & -2.766 & 0.028 \\
\hline & 0.453 & 7 & 4.458 & 0.050 & Fire & 0.000 & 0.000 & & \\
\hline & & I & & & Control & 0.207 & 0.070 & 2.976 & 0.021 \\
\hline & & 2 & & & Intercept & 70.634 & 2.293 & 30.805 & $<0.0001$ \\
\hline$\Delta+$ & 0045 & 2 & (2) 212 & 0353 & SY - 2005 & -3.830 & 3.502 & -1.093 & 0.310 \\
\hline$\Delta+$ & 0.045 & 7 & 0.212 & 0.353 & SY - 2006 & 1.867 & 3.502 & 0.533 & 0.611 \\
\hline & & I & & & SY - 2007 & 0.000 & 0.000 & & \\
\hline & & 1 & & & Intercept & 617.045 & 48.159 & 12.813 & $<0.0001$ \\
\hline$\Lambda+$ & 0.562 & 1 & 12.560 & 0.008 & Fire & -203.998 & 57.561 & -3.544 & 0.008 \\
\hline & & 8 & & & Control & 0.000 & 0.000 & & \\
\hline
\end{tabular}


The GLM results for the indices and variables analyzed are detailed in Table 5 and show the following: (1) $\mathrm{N}$ showed a bimodal response to the AGE variable (the model predicts a continuing decrease in $\mathrm{N}$ from the second to the fourth year after the fire, after which a recovery would occur until a point of inflection would be reached at thirteen years post-fire). A significant effect of LOCATION is also seen (the number of individuals captured is significantly greater in the burnt zones than in the unburnt ones); (2) the variations in both richness $(\mathrm{S})$ and in the Shannon index of diversity $\left(\mathrm{H}^{\prime}\right)$ were determined by SY, with the observation of very similar values between the first two years of sampling $(2005,2006)$ and considerably lower values for both parameters in 2007; (3) none of the variables considered significantly affected D, J' (only a submarginal effect being observed) or $\Delta+; 4$ ) higher $\Lambda+$ values were observed for the control areas than the burnt ones.

4.- Malaise traps + Yellow Pan Traps: The sum of captures made by the $30 \mathrm{MT}$ and the 2,400 YPT was 141 species and 10,896 individuals (Appendices A and B).

The GLM results are shown in Table 6 and show that (1) none of the variables analyzed was able to explain the variance of $\mathrm{N}$ and $\Delta+$ in the communities studied, although a submarginal value was obtained, with SY as the only explanatory variable; (2) the value of $S$ was determined by AGE, SY and LOCATION; (3) the number of species is higher in the disturbed zones than in the Controls, with an also noteworthy difference among the SY. Despite this, a negative response of S and $\mathrm{H}^{\prime}$ to fire was noted, its value decreasing again as from the second year after the impact until a recovery as from the fourth-fifth years post-fire; (4) LOCATION was the only variable able to account for the variation in D and the evenness ( $\mathrm{J}$ '), the values being higher in the control zones than in those affected by the fire; 5) SY affected $\Lambda+$ values.

In the ellipse generated by simulation for the whole sample set (Fig. 1), in which the values of $\Delta+$ are plotted against $\Lambda+$ for each sample, only the samples of the third, fifth, and ninth years postfire do not depart significantly from what was obtained with the simulation (Fig. 1). $\Lambda+$, with very elevated values for most of the samples, was the main parameter responsible for this behaviour. To a certain extent, the samples are distributed as a function of the SY, in agreement with the results also obtained in the GLM. 
Table 6: GLM results for the MT + YPT sample grouped by Site and Sampling Year

\begin{tabular}{|c|c|c|c|c|c|c|c|c|c|}
\hline \multirow{2}{*}{ INDEX } & \multirow{2}{*}{$\begin{array}{c}\mathbf{R}^{2} \\
\text { adjusted }\end{array}$} & \multicolumn{3}{|c|}{ Analysis of variance } & \multicolumn{5}{|c|}{ Model parameters } \\
\hline & & df & $\mathbf{F}$ & $\operatorname{Pr}>F$ & Parameter & Value & SD & $\mathbf{t}$ & $\operatorname{Pr}>|\mathbf{t}|$ \\
\hline \multirow{4}{*}{$\mathbf{N}$} & \multirow{4}{*}{0.395} & \multirow{3}{*}{2} & \multirow{4}{*}{3.935} & \multirow{4}{*}{0.072} & Intercept & 815.500 & 186.817 & 4.365 & 0.003 \\
\hline & & & & & SY - 2005 & 772.500 & 285.368 & 2.707 & 0.030 \\
\hline & & & & & SY - 2006 & 141.167 & 285.368 & 0.495 & 0.636 \\
\hline & & 7 & & & SY - 2007 & 0.000 & 0.000 & & \\
\hline \multirow{9}{*}{$\mathbf{S}$} & \multirow{9}{*}{0.903} & \multirow{5}{*}{6} & \multirow{9}{*}{14.923} & \multirow{9}{*}{0.025} & Intercept & 17.312 & 14.584 & 1.187 & 0.321 \\
\hline & & & & & Age & -20.339 & 3.907 & -5.206 & 0.014 \\
\hline & & & & & $\mathrm{Age}^{2}$ & 3.035 & 0.599 & 5.062 & 0.015 \\
\hline & & & & & $\mathrm{Age}^{3}$ & -0.092 & 0.026 & -3.595 & 0.037 \\
\hline & & & & & SY - 2005 & 3.793 & 3.975 & 0.954 & 0.410 \\
\hline & & \multirow{4}{*}{3} & & & SY - 2006 & 11.171 & 3.267 & 3.420 & 0.042 \\
\hline & & & & & SY - 2007 & 0.000 & 0.000 & & \\
\hline & & & & & Fire & 74.804 & 11.807 & 6.336 & 0.008 \\
\hline & & & & & Control & 0.000 & 0.000 & & \\
\hline \multirow{3}{*}{$\mathbf{H}^{\prime}$} & \multirow{3}{*}{0.805} & \multirow[b]{3}{*}{7} & \multirow{3}{*}{19.548} & \multirow{3}{*}{0.001} & Intercept & 3.134 & 0.100 & 31.295 & $<0.0001$ \\
\hline & & & & & Age & -0.056 & 0.032 & -1.711 & 0.131 \\
\hline & & & & & $\mathrm{Age}^{2}$ & 0.006 & 0.002 & 2.912 & 0.023 \\
\hline \multirow{3}{*}{$D=1-\lambda^{\prime}$} & \multirow{3}{*}{0.517} & \multirow[b]{3}{*}{8} & \multirow{3}{*}{10.623} & \multirow{3}{*}{0.012} & Intercept & 0.951 & 0.011 & 84.727 & $<0.0001$ \\
\hline & & & & & Fire & -0.044 & 0.013 & -3.259 & 0.012 \\
\hline & & & & & Control & 0.000 & 0.000 & & \\
\hline \multirow{3}{*}{$\mathbf{J}^{\prime}$} & \multirow{3}{*}{0.535} & \multirow[b]{3}{*}{8} & & & Intercept & 0.792 & 0.018 & 44.742 & $<0.0001$ \\
\hline & & & 11.364 & 0.010 & Fire & -0.071 & 0.021 & -3.371 & 0.010 \\
\hline & & & & & Control & 0.000 & 0.000 & & \\
\hline & & & & & Intercept & 78.735 & 0.669 & 117.749 & $<0.0001$ \\
\hline 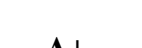 & 0260 & 2 & 2550 & & SY - 2005 & -2.657 & 1.021 & -2.601 & 0.035 \\
\hline$\Delta+$ & 0.362 & 7 & 3.558 & 0.086 & SY - 2006 & -0.594 & 1.021 & -0.581 & 0.579 \\
\hline & & 1 & & & SY - 2007 & 0.000 & 0.000 & & \\
\hline & & 2 & & & Intercept & 409.258 & 10.962 & 37.335 & $<0.0001$ \\
\hline$\Delta+$ & 0695 & & & & SY - 2005 & 79.073 & 16.744 & 4.722 & 0.002 \\
\hline$\Lambda+$ & 0.695 & & 11.243 & 0.007 & SY - 2006 & 27.380 & 16.744 & 1.635 & 0.146 \\
\hline & & 7 & & & SY - 2007 & 0.000 & 0.000 & & \\
\hline
\end{tabular}

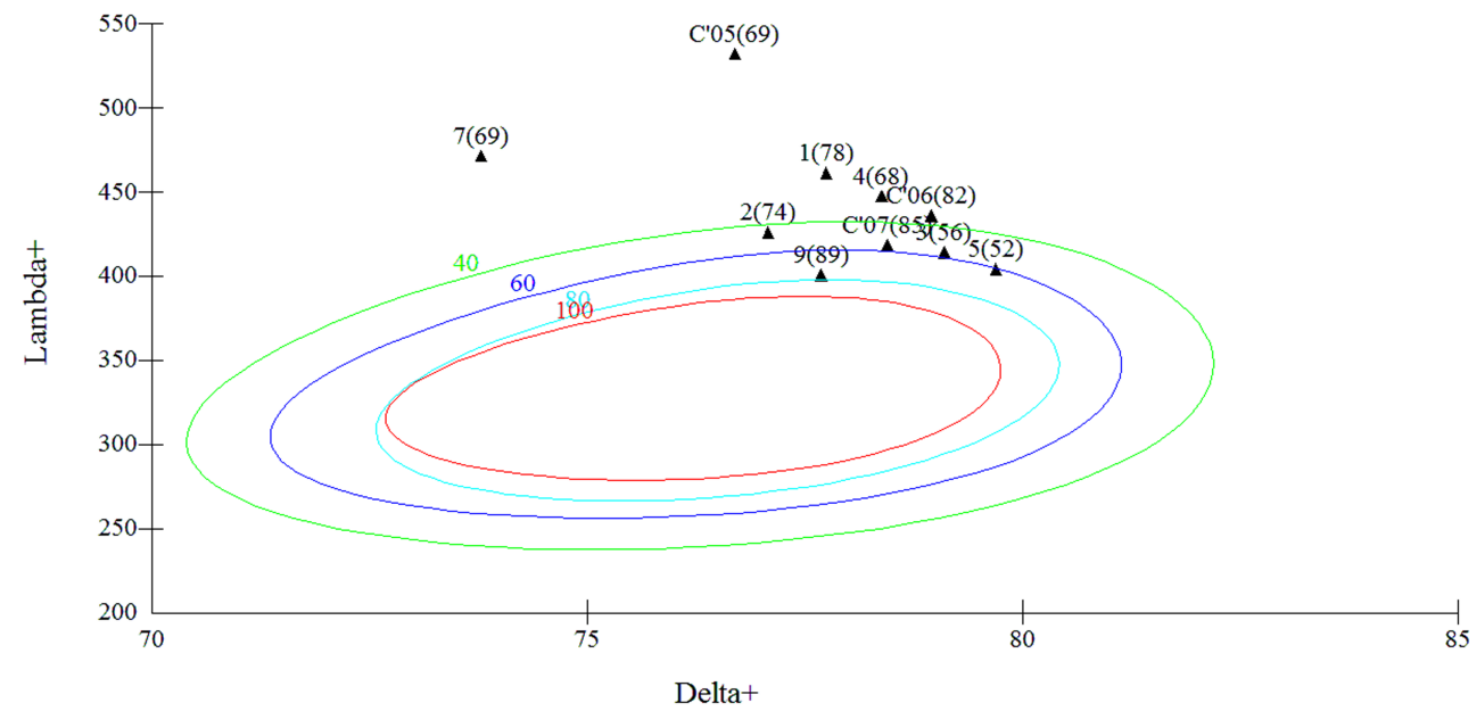

Fig. 1: Elliptical plot of 95\% probability areas for Average Taxonomic Distinctness (Delta+) and Variation in Average Taxonomic Distinctness (Lambda+) pairs, separated by sublist sample sizes: $\mathrm{S}<100$. 


\section{Discussion}

The results obtained in the present study reveal differences in the models derived from the GMLs as regards the influence of the variables analyzed on the diversity parameters $\left(\mathrm{N}, \mathrm{S}, \mathrm{H}^{\prime}, \mathrm{D}, \mathrm{J}, \Delta+\right.$ and $\left.\Lambda+\right)$ of the Spheciformes wasps communities as a function of the capture method employed and the samples used. This could be due, at least in part, to the bias introduced in the samples by the capture method employed (MT and YPT) or the influence of the microhabitat on the Spheciformes communities. Thus, in the analysis performed with all the traps separately (Table 3), a significant effect was detected for all the parameters studied, while the analyses with groups of MT or YPT only revealed changes in the number of individuals (N) and richness (S), Shannon index of diversity (H') and the $\Lambda+$ (Tables 4 and 5). These differences deriving from the capture method have been reported in other studies and for different groups, among them the Spheciformes (Baños-Picón et al., 2009). Analysis of the global sample (MT + YPT) did not unveil any significant influence of any of the factors analysed concerning abundance (Table 6), unlike the case of the samples obtained only with MT (grouped or not) and with YPT, for which a higher value of $\mathrm{N}$ was obtained in the disturbed zones than in the control zones, in agreement with Cruz-Sánchez et al. (in prep.) The same finding was reported by Moretti et al., (2006), who attributed the temporal increase in the number of individuals and flying polinophagous, phytophagous and zoophagous species to their high mobility and capacity for opportunistic exploitation of resources across a large spatial scale. Despite the collection of a greater number of individuals in the first year post-fire, the number tended to decrease along the ensuing 4-5 years, thereafter increasing. Additionally, according to the samples obtained with the MT (grouped or not), the captures made in 2005 surpassed those made in 2006, and the latter those of 2007, pointing to the interannual variation among the populations of these insects, and the probable influence of the particular climatological conditions during each of the three sampling years. Thus, 2005 and 2007 could be said to have been dry, especially the former (preceded by a drought that persisted for a large part of that year), while 2006 was a "typical" year as regards the precipitation recorded in the zone analyzed $(\approx 700 \mathrm{~mm} /$ year$)$.

The fact that the model obtained for $\mathrm{S}$ and $\mathrm{H}^{\prime}$ following analysis of the YPT samples was different from those obtained for both the global model of the community and for those involving TM, in which the AGE variable (the years of recovery after the 
fire) was particularly important, would on the one hand emphasize the strong relationship between $\mathrm{S}$ and $\mathrm{H}^{\prime}$ and, on the other, the bias introduced by the sampling method used (MT and YPT) and the greater weight of MT (which captured a much higher number of individuals than the YPT) in the global analysis of the community.

The fact that the passage of time (AGE) was the only factor, shared with $\mathrm{S}$, that seemed to affect the variation in $\mathrm{H}^{\prime}$, for all the captures in the community, points to the importance of habitat structure, which changes along the recovery period, for these insects (Steffan-Dewenter, 2002; Lassau and Hochuli, 2005; Taki et al., 2008; CruzSánchez et al., in prep.). This importance is also patent in higher number of species present in the burnt zones as compared with those that were not.

The recovery of insect populations after a fire depends both on their survival capacity and their colonizing skills and on their ability to adapt to new surroundings and access the new resources provided by the environment (Swengel, 2001; Panzer, 2003; Potts et al., 2003; Moretti et al., 2004). Despite the exceptions, the trend generally followed by $\mathrm{N}, \mathrm{S}$ and $\mathrm{H}^{\prime}$ plots as a curvilinear response, displaying an increase during the first year post-fire, a decrease in the intermediate stages of recovery (between the second and fourth-fifth years), and a new increase as the burnt area acquired characteristics similar to those present pre-fire (the eighth-ninth year after the fire). This response is similar to that reported by Potts et al. (2003) for the richness of Apidae and Andrenidae, and by Potts et al. (2005) for the richness of bees in Israel, although in this latter case the mature communities had lower values than those of recently burnt zones. All the foregoing data suggest a good capacity for survival and/or colonization of the new environment and a good use of the existing resources (trophic, spatial and sunlight) by the groups of insects analyzed after the action of fire.

Insect survival after a fire is intimately linked to the parameters defining its regime (Whelan, 1995; Bond and van Wilgen, 1996), to the location where the individuals are at the time the disturbance occurs, and to their mobility, which depends on their developmental stage (egg, larva or nymph, pupa, adult) (Swengel, 2001; Nunes et al., 2000 for a review). In the case of the communities analyzed here, several factors could account for this high survival rate:

1) The season in which the fires occurred implies that the species were in the mobile phase (as winged adults) and that many of them were fully devoted to nest construction 
and provisioning (or nest completion). According to Lamotte (1975) and Moretti et al. (2004, 2006), winged animals are the first to recover after fire owing to their good mobility (Steffan-Dewenter et al., 2001, 2002; Gathmann and Tscharntke, 2002). This would have allowed the imagos to escape the flames by flying away and heading for neighbouring areas unaffected by fire, towards patches within the zone of impact that were not affected (ones that did not burn uniformly; pers.obs), or towards one of the abundant islands formed by small tilled vineyards or large areas of bare rock characteristic of the area. These unburnt areas, serving as refuges, later become the source of species that will eventually colonize the affected area (Hall and Schweitzer, 1992; Niwa and Peck, 2002; Saint-Germain et al., 2004; Swengel and Swengel, 2007).

2) The type of fire typical of the area analysed (see Materials and Methods) means that the high temperatures caused are only present for a short time. Many authors have shown that the isolating capacity of the soil against high temperatures caused by flames allows many species to survive this type of impact (Evans, 1988; DeBano et al., 1998; Potts et al., 2003; Gibb and Hjältén, 2007). Accordingly, similar to what has been observed by Cruz-Sánchez et al., (in prep.), it would be possible to envisage a high survival rate in the Spheciformes wasps communities analyzed, because most of the species captured nest below the ground, and some of them may not even have laid eggs before the fire started. The nests of species who build them in plants would evidently have undergone the opposite fate, with a few exceptions, such as the species Trypoxylon scutatum and T. attenuatum, which were well represented one year after the fire. This could have been due to the greater presence of spiders on which they predate for their offspring since. As reported by different authors, spiders can survive the fire and/or can increase rapidly in numbers owing to the greater presence of food in the new habitat of mosaics created by the fire (Moretti et al., 2002a).

Haydon et al. (2000) and Moretti et al. (2006) report that such perturbations promotes species richness in forest habitats. This was also observed by Fye (1972), who reported greater abundances of wasps in disturbed forests, where there is more light and plant cover in the lower strata, which perhaps provided the wasps with trophic resources (pollen and nectar) and prey to feed their larvae (Taki et al., 2008). In the present case, owing to the characteristics typical of the habitat analyzed (open, cleared and with small groups of more or less dispersed oaks), the negative effect exerted by the crowns of trees on the passage of light to lower strata does not seem relevant. Accordingly, the 
variation in the amount of species and specimens of Spheciformes wasps could have been governed by the variation in the structure, richness and diversity of species in the herbaceous strata and bushes (Brown, 1991; Parr et al., 2004; Taki et al., 2008), together with the ecological and microclimatic conditions, imposed by the greater or lesser degree of development, and by the degree of simplification (Andersen and Müller, 2000) undergone in the zone affected by the fire and its/their influence on the different species. In this case, both the shrub and the herbaceous strata were almost completely destroyed by the fire. This was not the case of the trees, dominated by Quercus pyrenaica, because only the young, short specimens died, while the crown, branches and trunks of the larger individuals were merely blackened with soot.

At the start of the present study, after one growth season the tree cover showed a large number of resproutings (of roots, trunk and branches) and the herbaceous layer had already returned, although it was less well developed than in successive years, in part owing to the drought. However, the shrub stratum was almost absent, becoming the main differentiating trait between the burnt and control zones; in the latter it was very abundant and dense. Thus, after the fire the new availability of resources would be due to a weakening and/or destruction of the tree and shrub cover and, to the increase in the diversity of herbaceous species (Harper et al., 2000; Panzer, 2003; Campbell et al., 2007; Breece, 2008) and the greater nutrient quality of these and of the resources they produce (Potts et al., 2003), which could be beneficial for the imagos of the group analyzed. This initial absence of shrub stratum and the increase in the quality, diversity or contents of plant nutrients can facilitate access to certain species that benefit from this situation (Stein et al., 1992; Moretti et al., 2002b; Potts et al., 2003) and even alter feeding habits and create spatial variations in the trophic interactions (Knight and Holt, 2005).

The degree to which the number of insect species increases within a given area after a fire points to the capacity of such species to access the resprouting vegetation, in the case of herbivorous species, or to those herbivores in the case of predatory species (Evans, 1988; Fellows and Newton, 1999; Ne'eman et al., 2000). From the data it can be seen that in the case of the Spheciformes this degree of access to resprouting vegetation and preys could be high, in light of the greater presence of species in the burnt zones than in the control areas. However, this potential increase is moderated by the ability to prosper in the altered, and often simplified, habitat structure after the fire. 
The low shrub cover present in the first years after the fire could have meant that the xeric conditions imposed by the perturbation persisted for longer (Whelan, 1995), further increasing the already high temperatures reached in the study area. The sum of these environmental conditions after the fire and the existence of a greater number of species in the burnt areas would support the thesis of Lamotte (1975), according to which post-fire environments would favour the fauna dependent upon the sun, heliophilous and floricolous (Moretti et al., 2004), as is the case of the Spheciformes, which need a high degree of insolation to survive (Evans and O'Neill, 2007). The same is the case of many species of ants (York, 1996; Andersen and Müller, 2000; Nunes et al., 2000), which survive the flames thanks to the refuge of their nests (Gibb and Hjältén, 2007) and are later favoured by the existence of xeric conditions (York, 1996; Gibb and Hjältén, 2007) and the simplification of the environment.

These positive data of post-fire conditions contrast with those reported by Ne'eman et al. (2000) and Potts et al. (2001), who observed negative effects of fire on flower-visiting insects in Israel, where fires occur in summer when the insects are still active, as in the present case. Accordingly, response varies as a function of species, their ecology and the characteristics of the fire regime in the specific study zone (Swengel, 2001; Izhaki et al., 2003; Moretti et al., 2004, 2006; Hirowatari et al., 2007).

In light of what has been discussed above, and in view of the negative response of S and H' obtained as from the second year after the fire for the overall community, it could be speculated that the effect of fire on the nutritional content of the plants or of the food resources provided by them would be ephemeral, as suggested by Smith (2000), being manifested only during a single growth season or only during the first years after the fire (Potts et al., 2003). In turn, this would lead to a loss of quality of the vegetation, on which the adults (which are floricolous) of these wasps feed, and a decrease in the quantity and quality of the prey captured to provision their nests. Another possible cause of the later decrease in Spheciformes could be the modification undergone by the plant cover, which would affect the hunting efficiency of the predators (Harmon et al., 2003). All these factors could lead to a decrease in reproductive efficiency or to a process of migration towards closer areas that are more suitable for the wasps' ecological needs. The time taken by these species to return to the original site will depend on the degree of alteration of the habitat and of the available food or nesting resources (Wright and Samways, 1998; Potts et al., 2003). Thus, even though a positive 
response is obtained in the short-term, favoured by the resources available in the first year (trophic, spatial, or light) and the new environmental conditions created by the fire (temperature, solar radiation, moisture, etc), this could not be maintained owing to the simplification of the habitat (loss of ecological niches, a decrease in numbers of prey, changes in food quality owing to the alteration of the plant growth pattern, etc). This again points to the importance of the degree of complexity of the habitat for this group of insects (Cruz-Sánchez et al., in prep.).

As mentioned at the beginning of this section, it is striking that for the samples obtained with YPT the variation in species number $(\mathrm{S})$ and diversity $\left(\mathrm{H}^{\prime}\right)$ were explained only by SY, again showing a great difference between 2005 and 2006 (with almost identical values) and 2007, which exhibited a sharp decrease in both parameters. This observation, which highlights the considerable influence of the climatological conditions on insect populations and the interannual variations in the size of these, contrasts with the fact that the most numerous captures were recorded in 2007 at global and individual level (for the ninth year after the fire). The zone representative of the ninth year post-fire was characterized by a high density of Stipa gigantea (Gramineae), a tall species that reaches up to $2 \mathrm{~m}$ in height (the density of this grass hindered the detection of some of the MT at relatively short distances and the emplacement and later localization of the YPT for sample collection by the authors). Considering that the captures obtained may represent both the relative activity of the taxa captured (Niwa and Peck, 2002) and the density of their populations, or a combination of both factors, as indicated by Spence and Niemela (1994) for pitfall traps, the density of this grass could hamper the displacement of different species and could decrease the power of attraction exerted by the YPT, which are almost invisible for species that do not circulate in their neighbourhood. Only certain species would be favoured by the physical and microclimatic conditions imposed by Stipa and by the potential food resources offered by its flowering stage (end of spring-summer), or its hollow stems, which could be used as a nesting substrate by some species. In the present study, the greatest number of captures nine years after the fire was due to the high number of individuals belonging to two specific species, both of which nest in plant cavities: namely, Solierella compedita and Trypoxylon attenuatum $(\approx 50 \%$ and $15 \%$, respectively, of the total number of captures made in that year -2007-), in agreement with the results obtained by Cruz-Sánchez et al. (in prep.). 
Regarding the Simpson dominance index $\left(\mathrm{D}=1-\lambda^{\prime}\right)$ and Pielou evenness index $(\mathrm{J} ')$, the community showed higher values for the Control areas than for those affected by the fire, probably a reflection of more structured communities. These communities, which would be more mature, would exhibit higher values of uniformity as the habitat is recovered and the particular post-fire conditions gradually disappear.

Regarding the taxonomic distinctness indices employed, $\Delta^{+}$shows average values that are in general very similar for all the samples (both in disturbed and control areas), most of them lying within the limits of likelihood (Fig. 1). However the $\Lambda+$ values are in general clearly higher than those expected with simulation from the master list (Fig. 1), revealing communities with some particularly well diversified genera as compared with others represented by a single (or only a few) species; only the samples of the third, fifth, and ninth years post-fire were located inside the ellipse. The GLM analysis carried out for $\Lambda+$ revealed a significant effect of the SY (Table 6), reflected by the position of the samples in the probability elipse (Fig. 1), in which they are also disposed across SY (those belonging to the same SY have approximately the same $\Lambda+$ values). Mouillot et al. (2005) suggested that zones with high $\Lambda+$ values could correspond to areas with high environmental variability, whereas the areas subjected to human impact would have low $\Lambda+$ values. However, in the present study we were unable to find a relationship between the disturbance (fire) and either of the two taxonomic distinctness indices used. Thus, it would appear that these indices are not efficient when attempting to analyze the impact caused by fire on the Spheciform communities. Another possible explanation, apart from the strong effect that the sampling year (SY) seems to exert, would be that the indices might be only sparingly sensitive in the analysis of communities when low (lower than family) taxonomic levels are used.

In conclusion, the results of the present study point to the high resistance of Spheciformes wasps communities challenged by this type of fire occurring in the summer (superficial, low-medium intensity) in cleared habitats of Mediterranean deciduous forests. Another relevant observation is the importance of the habitat and the particular environmental conditions that cause the interannual variations in the populations in the communities of the group analyzed, which could have an even greater effect than that produced by fire. In the process of recovery of post-fire species richness and diversity, the time elapsed since the disturbance is an especially relevant factor, 
since it determines the recovery of the vegetation until the conditions prevailing before the perturbation have been restored. This signals the need to explore the possible effects that a new fire interrupting such recovery might have in the early stages of recovery.

The existence of unburnt patches (formed by tilled vineyards, among others) is important in the sense that these offer refuges for the populations of the insects during fires. Accordingly, the maintenance of traditional land uses could reduce the advance of flames and provide a haven that would allow the survival of these insects and that could serve as a source when conditions meet the requirements for recolonization.

Finally, the differences between the analyses carried out with the samples obtained with both capture methods reveals evident differences in their mode of action and in the information they provide concerning insect communities. Despite the different sampling efforts performed with both methods, it is clear that there is a need to use them jointly when performing a study of this type since they complement each other and may reflect more precisely the responses to fire and the composition of the communities of Spheciformes, which would otherwise remain hidden.

\section{Acknowledgements}

This work was funded through a specific collaborative agreement between the Environmental Agency of the Regional Government of Castile and Leon and the University of Salamanca for the analysis of the diversity of the entomological fauna of the network of Natural Spaces in Castile and Leon, by means of the use of bioindicator wasps. The authors acknowledge the collaboration of people who helped with field work. Our thanks are also due to Nicholas Skinner (Languages Central Service of the University of Salamanca) for the translation of this text. 
Appendix A: Results, by traps, of the indices and parameters used in the community analysis. MT: Malaise trap;

YPT: Yellow pan traps.

\begin{tabular}{|c|c|c|c|c|c|c|}
\hline & MT samples independiently & $\mathbf{N}$ & $\mathbf{S}$ & $\mathbf{H}^{\prime}$ & 1-D' & $\mathbf{J}^{\prime}$ \\
\hline \multirow{21}{*}{ FIRE } & MT1_1 & 628 & 41 & 2.727 & 0.894 & 0.734 \\
\hline & MT1_2 & 429 & 48 & 2.958 & 0.925 & 0.764 \\
\hline & MT1_3 & 811 & 53 & 2.877 & 0.913 & 0.725 \\
\hline & MT2_1 & 255 & 44 & 3.012 & 0.914 & 0.796 \\
\hline & MT2_2 & 141 & 36 & 2.901 & 0.919 & 0.809 \\
\hline & MT2_3 & 205 & 40 & 2.964 & 0.916 & 0.803 \\
\hline & MT3_1 & 214 & 36 & 2.825 & 0.893 & 0.788 \\
\hline & MT3_2 & 68 & 14 & 2.197 & 0.854 & 0.832 \\
\hline & MT3_3 & 111 & 36 & 3.093 & 0.942 & 0.863 \\
\hline & MT4_1 & 301 & 32 & 2.103 & 0.753 & 0.607 \\
\hline & MT4_2 & 203 & 32 & 2.257 & 0.770 & 0.651 \\
\hline & MT4_3 & 160 & 33 & 2.611 & 0.865 & 0.747 \\
\hline & MT5_1 & 97 & 26 & 2.862 & 0.932 & 0.878 \\
\hline & MT5_2 & 85 & 31 & 2.978 & 0.934 & 0.867 \\
\hline & MT5_3 & 108 & 35 & 3.151 & 0.942 & 0.886 \\
\hline & MT7_1 & 241 & 37 & 3.012 & 0.933 & 0.834 \\
\hline & MT7_2 & 540 & 46 & 2.934 & 0.918 & 0.766 \\
\hline & MT7_3 & 331 & 39 & 2.903 & 0.916 & 0.792 \\
\hline & MT9_1 & 247 & 51 & 3.021 & 0.896 & 0.768 \\
\hline & MT9_2 & 293 & 52 & 3.246 & 0.945 & 0.822 \\
\hline & MT9_3 & 350 & 49 & 3.023 & 0.921 & 0.777 \\
\hline \multirow{9}{*}{ CONTROL } & MT13-1 & 345 & 44 & 2.971 & 0.918 & 0.785 \\
\hline & MT13-2 & 379 & 39 & 2.833 & 0.908 & 0.773 \\
\hline & MT13-3 & 218 & 34 & 2.882 & 0.918 & 0.817 \\
\hline & MT14-1 & 201 & 46 & 3.360 & 0.958 & 0.878 \\
\hline & MT14-2 & 209 & 51 & 3.421 & 0.957 & 0.870 \\
\hline & MT14-3 & 457 & 47 & 2.875 & 0.904 & 0.747 \\
\hline & MT15-1 & 99 & 32 & 3.194 & 0.958 & 0.922 \\
\hline & MT15-2 & 179 & 57 & 3.549 & 0.959 & 0.878 \\
\hline & MT15-3 & 386 & 55 & 3.381 & 0.957 & 0.844 \\
\hline & MT samples grouped by Site and SY & $\mathbf{N}$ & $\mathbf{S}$ & $\mathbf{H}^{\prime}$ & 1-D' & $\mathbf{J}^{\prime}$ \\
\hline \multirow{7}{*}{ FIRE } & MT1 & 1868 & 63 & 2.916 & 0.913 & 0.704 \\
\hline & MT2 & 601 & 63 & 3.157 & 0.921 & 0.762 \\
\hline & MT3 & 393 & 52 & 3.047 & 0.915 & 0.771 \\
\hline & MT4 & 664 & 52 & 2.443 & 0.792 & 0.618 \\
\hline & MT5 & 290 & 49 & 3.318 & 0.950 & 0.853 \\
\hline & MT7 & 1112 & 61 & 3.092 & 0.932 & 0.752 \\
\hline & MT9 & 890 & 81 & 3.322 & 0.937 & 0.756 \\
\hline \multirow{3}{*}{ CONTROL } & MT13 & 941 & 58 & 3.207 & 0.940 & 0.790 \\
\hline & MT14 & 867 & 70 & 3.404 & 0.946 & 0.801 \\
\hline & MT15 & 664 & 78 & 3.629 & 0.963 & 0.833 \\
\hline & YPT samplesgrouped by Site and SY & $\mathbf{N}$ & $\mathbf{S}$ & $\mathbf{H}^{\prime}$ & 1-D' & $\mathbf{J}^{\prime}$ \\
\hline \multirow{7}{*}{ FIRE } & YPT1 & 315 & 38 & 2.684 & 0.893 & 0.738 \\
\hline & YPT2 & 255 & 35 & 2.542 & 0.837 & 0.715 \\
\hline & YPT3 & 210 & 19 & 2.004 & 0.798 & 0.681 \\
\hline & YPT4 & 182 & 33 & 2.708 & 0.896 & 0.775 \\
\hline & YPT5 & 219 & 19 & 1.977 & 0.794 & 0.671 \\
\hline & YPT7 & 264 & 35 & 2.420 & 0.853 & 0.681 \\
\hline & YPT9 & 398 & 33 & 1.948 & 0.718 & 0.557 \\
\hline \multirow{4}{*}{ CONTROL } & YPT13 & 264 & 36 & 2.666 & 0.892 & 0.744 \\
\hline & YPT14 & 301 & 35 & 2.433 & 0.855 & 0.684 \\
\hline & $\begin{array}{r}\text { YPT15 } \\
\end{array}$ & 198 & 27 & 2.449 & 0.874 & 0.743 \\
\hline & $\begin{array}{c}\text { MT and YPT samples grouped by Site } \\
\text { and SY }\end{array}$ & $\mathbf{N}$ & $\mathbf{S}$ & $\mathbf{H}^{\prime}$ & 1-D' & $\mathbf{J}^{\prime}$ \\
\hline \multirow{7}{*}{ FIRE } & 1 & 2183 & 78 & 3.042 & 0.921 & 0.698 \\
\hline & 2 & 856 & 74 & 3.202 & 0.919 & 0.744 \\
\hline & 3 & 603 & 56 & 2.960 & 0.907 & 0.735 \\
\hline & 4 & 846 & 68 & 2.842 & 0.863 & 0.674 \\
\hline & 5 & 509 & 52 & 3.033 & 0.914 & 0.768 \\
\hline & 7 & 1376 & 69 & 3.121 & 0.929 & 0.737 \\
\hline & 9 & 1288 & 89 & 3.104 & 0.901 & 0.691 \\
\hline \multirow{3}{*}{ CONTROL } & 13 & 1205 & 69 & 3.281 & 0.944 & 0.775 \\
\hline & 14 & 1168 & 82 & 3.481 & 0.951 & 0.790 \\
\hline & 15 & 862 & 85 & 3.610 & 0.960 & 0.813 \\
\hline
\end{tabular}


Appendix B: Abundances of the species collected. Classificatión acording to Pulawski, 2009: www.calcademy.com/research/entomolgy/Entomology_Resources/Hymenoptera/sphecidae.

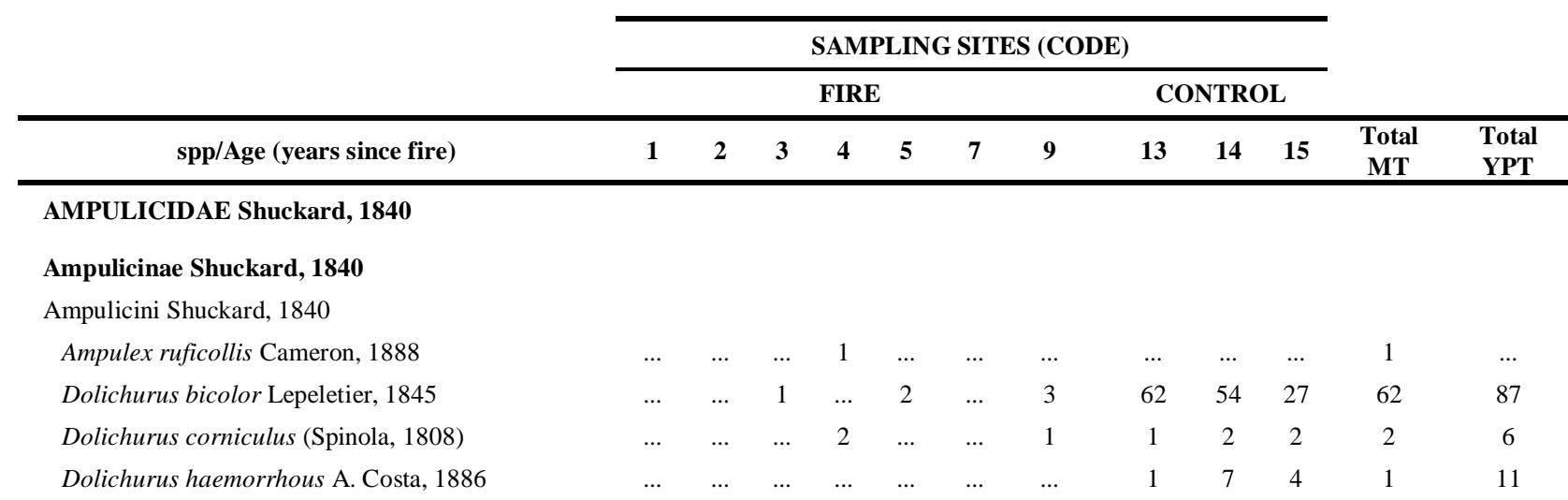

\section{SPHECIDAE Latreille, 1802}

Sceliphrinae Ashmead, 1899

Sceliphrini Ashmead, 1899

Chalybion femoratum (Fabricius, 1781)

Sceliphron destillatorium (Illiger, 1807)

Sphecinae Latreille, 1802

Sphecini Latreille, 1802

Sphex atropilosus Kohl, 1885

Sphex flavipennis Fabricius, 1793

Sphex funerarius Gussakovskij, 1934

Sphex leuconotus Brullé, 1833

Pryonichini Bohart \& Menke, 1963

Palmodes melanarius (Mocsáry, 1883)

Palmodes occitanicus (Roth, 1963)

Chilosphex argyrius (Brullé, 1833)

Prionyx kirbii (Van der Linden, 1827)

Prionyx subfuscatus (Dahlbom, 1845)

Prionyx viduatus (Christ, 1791)

Ammophilinae André, 1886

Ammophilini André, 1886

Ammophila campestris Latreille, 1809

Ammophila heydeni Dahlbom, 1845

Ammophila hungarica Mocsáry, 1883

Ammophila laevicollis André, 1886

Ammophila sabulosa (Linnaeus, 1758)

Podalonia hirsuta (Scopoli, 1763)

CRABRONIDAE Latreille, 1802

Pemphredoninae Dahlbom, 1835

Psenini Costa, 1858

Psenulus fuscipennis (Dahlbom, 1843)

Mimesa grandii Maidl, 1933

Pemphredonini Dahlbom, 1835

Diodontus insidiosus Spooner, 1938

Pemphredon lethifer (Shuckard, 1837)

Pemphredon lugens Dahlbom, 1842

Pemphredon mortifer Valkeila, 1972

Passaloecus gracilis (Curtis, 1834)

$\begin{array}{ccccccccccc}25 & 4 & 3 & 37 & 1 & 4 & \ldots & 7 & 28 & 1 & 110 \\ 4 & \ldots & \ldots & 4 & 5 & 6 & \ldots & 6 & \ldots & \ldots & 25 \\ 102 & 32 & 23 & 100 & 28 & 71 & 30 & 98 & 84 & 32 & 600 \\ 122 & 72 & 11 & 279 & 19 & 36 & 4 & 56 & 129 & 10 & 738 \\ & & & & & & & & & & \\ 3 & 1 & \ldots & \ldots & \ldots & \ldots & 1 & 12 & 5 & 1 & 23 \\ 2 & 1 & 2 & 8 & 3 & \ldots & 5 & 5 & 6 & 6 & 38 \\ 9 & 8 & 5 & 13 & 1 & 1 & 2 & 1 & 1 & 3 & 44 \\ 22 & 17 & 1 & 9 & \ldots & 13 & 2 & 3 & 5 & 4 & 62 \\ 7 & \ldots & \ldots & \ldots & \ldots & \ldots & \ldots & \ldots & \ldots & \ldots & 7 \\ 2 & \ldots & \ldots & \ldots & \ldots & 3 & \ldots & \ldots & \ldots & \ldots & 5\end{array}$

$\begin{array}{cccccccccccc}13 & 8 & 6 & 27 & 9 & 19 & 6 & \ldots & 13 & 17 & 117 & 1 \\ 11 & 24 & 12 & 7 & \ldots & 10 & 8 & 8 & 26 & 41 & 133 & 14 \\ 6 & 2 & 1 & 10 & 7 & 2 & 2 & 1 & 1 & \ldots & 31 & 1 \\ 3 & 1 & 1 & \ldots & \ldots & \ldots & \ldots & \ldots & 2 & 1 & 7 & 1 \\ \ldots & \ldots & \ldots & 1 & \ldots & \ldots & 1 & 2 & 4 & 1 & 4 & 5 \\ 1 & \ldots & \ldots & \ldots & 2 & \ldots & \ldots & \ldots & 2 & 2 & 7 & \ldots\end{array}$

$\begin{array}{cccccccccccc}4 & 10 & 25 & 1 & 8 & 1 & 12 & 3 & 11 & 23 & 98 & \ldots \\ \ldots & \ldots & 1 & \ldots & \ldots & \ldots & 5 & \ldots & 4 & \ldots & 10 & \ldots \\ & & & & & & & & & & & \\ 30 & 55 & 12 & 28 & 20 & 14 & 21 & 19 & 19 & 24 & 201 & 41 \\ \ldots & 2 & 1 & 6 & 5 & \ldots & 3 & \ldots & 1 & 3 & 16 & 5 \\ \ldots & \ldots & 1 & \ldots & 2 & \ldots & 1 & \ldots & \ldots & 1 & 5 & \ldots \\ \ldots & \ldots & 1 & \ldots & 1 & \ldots & \ldots & \ldots & \ldots & \ldots & 2 & \ldots \\ \ldots & 1 & 3 & \ldots & 2 & \ldots & 5 & 3 & 1 & 4 & 19 & \ldots \\ & & & & & & & & & & & \text { Continúa }\end{array}$


SAMPLING SITES (CODE)

FIRE

CONTROL

\begin{tabular}{|c|c|c|c|c|c|c|c|c|c|c|c|c|}
\hline spp/Age (years since fire) & 1 & 2 & 3 & 4 & 5 & 7 & 9 & 13 & 14 & 15 & $\begin{array}{c}\text { Total } \\
\text { MT } \\
\end{array}$ & $\begin{array}{l}\text { Total } \\
\text { YPT } \\
\end{array}$ \\
\hline Passaloecus pictus Ribaut, 1952 & 1 & 7 & 9 & 1 & 2 & 1 & 29 & $\ldots$ & 3 & 2 & 55 & $\ldots$ \\
\hline Passaloecus vandeli Ribaut, 1952 & $\ldots$ & $\ldots$ & $\ldots$ & $\ldots$ & $\ldots$ & $\ldots$ & 2 & $\ldots$ & $\ldots$ & 1 & 3 & $\ldots$ \\
\hline Ammoplanus ceballosi Giner Marí, 1943 & 19 & 20 & 25 & 5 & 1 & 12 & 5 & $\ldots$ & 26 & 9 & 122 & $\ldots$ \\
\hline Ammoplanus gegen Tsuneki, 1972 & $\ldots$ & $\ldots$ & $\ldots$ & $\ldots$ & $\ldots$ & $\ldots$ & $\ldots$ & $\ldots$ & 1 & $\ldots$ & 1 & $\ldots$ \\
\hline Ammoplanus perrisi Giraud, 1869 & 3 & $\ldots$ & $\ldots$ & $\ldots$ & $\ldots$ & $\ldots$ & $\ldots$ & $\ldots$ & $\ldots$ & $\ldots$ & 3 & $\ldots$ \\
\hline Ammoplanus torresi Gayubo, 1991 & $\ldots$ & 1 & $\ldots$ & $\ldots$ & $\ldots$ & $\ldots$ & $\ldots$ & $\ldots$ & 2 & $\ldots$ & 3 & $\ldots$ \\
\hline \multicolumn{13}{|l|}{ Astatinae Lepeletier, 1845} \\
\hline \multicolumn{13}{|l|}{ Astatini Lepeletier, 1845} \\
\hline Astata apostata Mercet, 1910 & 1 & $\ldots$ & $\ldots$ & $\ldots$ & $\ldots$ & 1 & 1 & $\ldots$ & $\ldots$ & 1 & 3 & 1 \\
\hline Astata boops (Schranck, 1871) & $\ldots$ & $\ldots$ & $\ldots$ & 1 & $\ldots$ & $\ldots$ & 1 & $\ldots$ & $\ldots$ & $\ldots$ & 1 & 1 \\
\hline Astata cobosi Giner Marí, 1946 & $\ldots$ & 11 & 1 & 6 & $\ldots$ & $\ldots$ & 15 & 2 & 2 & $\ldots$ & 30 & 7 \\
\hline Astata costae A. Costa, 1867 & $\ldots$ & $\ldots$ & $\ldots$ & $\ldots$ & $\ldots$ & $\ldots$ & 2 & 2 & $\ldots$ & 1 & 5 & $\ldots$ \\
\hline Astata gallica Beaumont, 1942 & 1 & $\ldots$ & $\ldots$ & 1 & $\ldots$ & $\ldots$ & $\ldots$ & $\ldots$ & 2 & $\ldots$ & 3 & 1 \\
\hline Astata kashmirensis Nurse, 1909 & 1 & $\ldots$ & $\ldots$ & $\ldots$ & $\ldots$ & $\ldots$ & $\ldots$ & $\ldots$ & $\ldots$ & $\ldots$ & 1 & $\ldots$ \\
\hline Astata miegii Dufour, 1861 & $\ldots$ & $\ldots$ & $\ldots$ & $\ldots$ & $\ldots$ & $\ldots$ & 1 & $\ldots$ & $\ldots$ & $\ldots$ & 1 & $\ldots$ \\
\hline Dryudella tricolor (Van der Linden, 1829) & 14 & $\ldots$ & 6 & $\ldots$ & 8 & $\ldots$ & 3 & $\ldots$ & $\ldots$ & 1 & 31 & 1 \\
\hline
\end{tabular}

\section{Dinetinae Fox, 1895}

Dinetini Fox, 1895

Dinetus pictus (Fabricius, 1793)

\section{Crabroninae Latreille, 1802}

Larrini Latreille, 1810

Larra anathema (Rossi, 1790)

Liris niger (Fabricius, 1775)

Larropsis europaea Mercet, 1910

Larropsis punctulata (Kohl, 1884)

Tachytes freygessneri Kohl, 1881

Tachytes obsoletus (Rossi, 1792)

Tachytes panzeri (Dufour, 1841)

Tachysphex adjunctus Kohl, 1885

Tachysphex brevipennis Mercet, 1909

Tachysphex consocius Kohl, 1892

Tachysphex costae (De Stefani, 1882)

Tachysphex fugax (Radoszkowski, 1877)

Tachysphex fulvitarsis (A. Costa, 1867)

Tachysphex incertus (Radoszkowski, 1877)

Tachysphex julliani Kohl, 1883

Tachysphex mediterraneus Kohl, 1883

Tachysphex nitidior Beaumont, 1940

Tachysphex obscuripennis (Schenck, 1857)

Tachysphex panzeri (Van der Linden, 1829)

Tachysphex plicosus (A. Costa, 1867)

Tachysphex pompiliformis (Panzer, 1805)

Tachysphex psammobius (Kohl, 1880)

Tachysphex pseudopanzeri Beaumont, 1955

Tachysphex tarsinus (Lepeletier, 1845)

Tachysphex unicolor (Panzer, 1809)

Prosopigastra handlirschi Morice, 1897

Prosopigastra kohli Mercet, 1907

\begin{tabular}{|c|c|c|c|c|c|c|c|c|c|c|c|}
\hline 2 & 2 & $\ldots$ & $\ldots$ & $\ldots$ & 11 & 1 & $\ldots$ & 1 & $\ldots$ & 16 & 1 \\
\hline 2 & 14 & 1 & 8 & 2 & 1 & $\ldots$ & 1 & 9 & 2 & 1 & 39 \\
\hline$\ldots$ & $\ldots$ & $\ldots$ & $\ldots$ & $\ldots$ & $\ldots$ & 1 & $\ldots$ & $\ldots$ & $\ldots$ & $\ldots$ & 1 \\
\hline 1 & 4 & $\ldots$ & $\ldots$ & $\ldots$ & $\ldots$ & $\ldots$ & $\ldots$ & $\ldots$ & $\ldots$ & $\ldots$ & 5 \\
\hline$\ldots$ & $\ldots$ & $\ldots$ & 1 & $\ldots$ & $\ldots$ & $\ldots$ & $\ldots$ & 1 & $\ldots$ & $\ldots$ & 2 \\
\hline 1 & $\ldots$ & $\ldots$ & $\ldots$ & $\ldots$ & $\ldots$ & $\ldots$ & 1 & $\ldots$ & $\ldots$ & 1 & 1 \\
\hline 113 & 16 & 13 & 1 & 2 & 58 & 37 & 28 & 62 & 32 & 349 & 12 \\
\hline$\ldots$ & 1 & 3 & 3 & $\ldots$ & $\ldots$ & 2 & 2 & 11 & 3 & 24 & 1 \\
\hline 1 & 1 & $\ldots$ & $\ldots$ & $\ldots$ & $\ldots$ & $\ldots$ & $\ldots$ & $\ldots$ & $\ldots$ & $\ldots$ & 2 \\
\hline 14 & 3 & 1 & 1 & $\ldots$ & 25 & 6 & 9 & 7 & 3 & 65 & 4 \\
\hline$\ldots$ & $\ldots$ & $\ldots$ & $\ldots$ & 1 & 1 & 2 & 2 & 5 & 4 & 12 & 3 \\
\hline 1 & $\ldots$ & $\ldots$ & $\ldots$ & $\ldots$ & 2 & $\ldots$ & $\ldots$ & $\ldots$ & $\ldots$ & 2 & 1 \\
\hline 27 & 6 & 11 & 11 & 7 & 79 & 34 & 54 & 31 & 28 & 276 & 12 \\
\hline 334 & 22 & 23 & 20 & 10 & 142 & 30 & 144 & 46 & 15 & 764 & 22 \\
\hline$\ldots$ & $\ldots$ & $\ldots$ & 2 & 3 & 24 & 5 & 28 & 8 & 5 & 74 & 1 \\
\hline 1 & 3 & $\ldots$ & $\ldots$ & $\ldots$ & 2 & 4 & 4 & 3 & 1 & 3 & 15 \\
\hline 10 & 16 & 1 & 6 & 4 & 24 & 8 & 16 & 5 & 2 & 53 & 39 \\
\hline 16 & 7 & 6 & 32 & 18 & 35 & 23 & 73 & 134 & 83 & 166 & 261 \\
\hline 59 & 2 & 1 & 1 & $\ldots$ & 18 & 2 & 18 & 11 & 5 & 116 & 2 \\
\hline$\ldots$ & 1 & $\ldots$ & $\ldots$ & $\ldots$ & $\ldots$ & $\ldots$ & 1 & $\ldots$ & $\ldots$ & $\ldots$ & 2 \\
\hline 2 & $\ldots$ & 3 & 2 & $\ldots$ & 6 & 4 & 4 & 12 & 7 & 26 & 14 \\
\hline 1 & 3 & $\ldots$ & 2 & $\ldots$ & $\ldots$ & 3 & 1 & $\ldots$ & 1 & 8 & 3 \\
\hline 256 & 5 & 3 & 3 & $\ldots$ & 111 & 5 & 38 & 8 & 3 & 418 & 14 \\
\hline 11 & 9 & $\ldots$ & 1 & $\ldots$ & 3 & 6 & 3 & 1 & 2 & 23 & 13 \\
\hline 4 & $\ldots$ & $\ldots$ & $\ldots$ & $\ldots$ & 2 & 1 & 3 & 1 & $\ldots$ & 4 & 7 \\
\hline$\ldots$ & 1 & $\ldots$ & $\ldots$ & $\ldots$ & $\ldots$ & $\ldots$ & $\ldots$ & $\ldots$ & $\ldots$ & 1 & $\ldots$ \\
\hline$\ldots$ & $\ldots$ & $\ldots$ & $\ldots$ & $\ldots$ & $\ldots$ & 1 & $\ldots$ & $\ldots$ & $\ldots$ & 1 & $\ldots$ \\
\hline
\end{tabular}


SAMPLING SITES (CODE)

FIRE

CONTROL

\begin{tabular}{|c|c|c|c|c|c|c|c|c|c|c|c|c|}
\hline spp/Age (years since fire) & 1 & 2 & 3 & 4 & 5 & 7 & 9 & 13 & 14 & 15 & $\begin{array}{c}\text { Total } \\
\text { MT }\end{array}$ & $\begin{array}{l}\text { Total } \\
\text { YPT }\end{array}$ \\
\hline Prosopigastra punctatissima A. Costa, 1867 & 1 & $\ldots$ & $\ldots$ & $\ldots$ & $\ldots$ & 1 & 4 & 2 & $\ldots$ & 2 & 7 & 3 \\
\hline \multicolumn{13}{|l|}{ Miscophini Fox, 1895} \\
\hline Solierella compedita (Piccioli, 1869) & 54 & 135 & 92 & 64 & 91 & 126 & 327 & 144 & 75 & 58 & 477 & 689 \\
\hline Solierella pisonoides (Saunders, 1873) & 15 & 8 & 16 & 2 & 9 & 6 & 35 & 9 & 24 & 10 & 13 & 121 \\
\hline Solierella seabrai Andrade, 1950 & 2 & 6 & 8 & 13 & 22 & 6 & 9 & 2 & $\ldots$ & 2 & 4 & 66 \\
\hline Miscophus albufeirae Andrade, 1952 & $\ldots$ & $\ldots$ & $\ldots$ & 1 & $\cdots$ & $\ldots$ & $\ldots$ & $\cdots$ & 1 & $\ldots$ & $\cdots$ & 2 \\
\hline Miscophus bicolor Jurine, 1807 & 9 & 9 & $\ldots$ & 5 & 11 & 23 & 12 & 32 & 24 & 10 & 128 & 7 \\
\hline Miscophus eatoni Saunders, 1903 & 8 & 5 & 1 & 4 & 3 & 7 & 3 & 6 & 2 & 2 & 23 & 18 \\
\hline Miscophus helveticus Kohl, 1883 & $\ldots$ & $\ldots$ & $\ldots$ & $\ldots$ & $\ldots$ & $\ldots$ & $\ldots$ & 1 & $\ldots$ & $\ldots$ & 1 & $\ldots$ \\
\hline Miscophus lusitanicus Andrade, 1952 & $\cdots$ & $\cdots$ & $\ldots$ & $\cdots$ & $\cdots$ & 1 & $\ldots$ & $\cdots$ & $\cdots$ & $\cdots$ & 1 & $\ldots$ \\
\hline Miscophus nicolai Ferton, 1896 & 53 & 14 & 5 & 10 & 10 & 36 & 8 & 66 & 31 & 15 & 82 & 166 \\
\hline Miscophus niger Dahlbom, 1844 & 2 & 1 & $\ldots$ & 1 & $\ldots$ & 2 & $\ldots$ & 3 & $\ldots$ & $\ldots$ & 6 & 3 \\
\hline Nitela lucens Gayubo \& Felton, 2000 & 3 & 1 & 2 & 4 & 2 & 2 & 12 & 12 & 34 & 28 & 98 & 2 \\
\hline Nitela truncata Gayubo \& Felton, 2000 & $\ldots$ & $\ldots$ & $\ldots$ & $\ldots$ & 1 & 1 & 11 & $\ldots$ & 1 & 6 & 19 & 1 \\
\hline \multicolumn{13}{|l|}{ Trypoxylini Lepeletier, 1845} \\
\hline Pison atrum (Spinola, 1808) & 1 & 1 & $\cdots$ & $\ldots$ & $\cdots$ & 1 & 1 & $\cdots$ & $\ldots$ & 2 & 3 & 3 \\
\hline Trypoxylon attenuatum F. Smith, 1851 & 84 & 23 & 86 & 23 & 94 & 20 & 154 & 9 & 4 & 62 & 290 & 269 \\
\hline Trypoxylon clavicerum Lepeletier \& Serville, 1828 & $\cdots$ & $\ldots$ & 4 & 4 & 3 & 2 & 9 & 1 & 8 & 13 & 43 & 1 \\
\hline Trypoxylon figulus (Linnaeus, 1758) & 1 & $\ldots$ & $\ldots$ & $\ldots$ & $\cdots$ & $\ldots$ & 2 & $\ldots$ & $\cdots$ & $\ldots$ & 2 & 1 \\
\hline Trypoxylon minus Beaumont, 1945 & $\ldots$ & $\ldots$ & 1 & $\cdots$ & $\cdots$ & $\ldots$ & 2 & $\cdots$ & $\cdots$ & $\ldots$ & $\cdots$ & 3 \\
\hline Trypoxylon scutatum Chevrier, 1867 & 268 & 168 & 119 & 30 & 47 & 107 & 112 & 46 & 46 & 65 & 802 & 206 \\
\hline \multicolumn{13}{|l|}{ Oxybelini Leach, 1815} \\
\hline Belomicrus odontophorus (Kohl, 1892) & $\ldots$ & $\ldots$ & $\ldots$ & $\ldots$ & $\ldots$ & $\ldots$ & 4 & $\ldots$ & $\ldots$ & $\ldots$ & 3 & 1 \\
\hline Oxybelomorpha steckii (Kohl, 1923) & 1 & $\cdots$ & $\cdots$ & $\cdots$ & $\cdots$ & $\cdots$ & $\ldots$ & $\cdots$ & 1 & $\cdots$ & 2 & $\ldots$ \\
\hline Oxybelus hastatus Fabricius, 1804 & 2 & $\ldots$ & $\ldots$ & $\ldots$ & $\ldots$ & $\ldots$ & $\ldots$ & $\ldots$ & $\ldots$ & $\ldots$ & 2 & $\ldots$ \\
\hline Oxybelus mисronatus (Fabricius, 1793) & $\cdots$ & 1 & 1 & 2 & $\cdots$ & $\cdots$ & $\cdots$ & $\cdots$ & 1 & 1 & 2 & 4 \\
\hline Oxybelus quattuordecimnotatus Jurine, 1807 & 46 & 10 & 19 & 5 & 12 & 11 & 44 & 47 & 37 & 43 & 228 & 46 \\
\hline Oxybelus subspinosus Klug, 1835 & 6 & $\ldots$ & $\ldots$ & 1 & $\cdots$ & 1 & $\ldots$ & $\ldots$ & 1 & $\ldots$ & 7 & 2 \\
\hline \multicolumn{13}{|l|}{ Crabronini Latreille, 1802} \\
\hline Encopognathus braunsi Mercet, 1915 & 6 & $\ldots$ & $\ldots$ & $\cdots$ & $\ldots$ & 3 & $\ldots$ & $\ldots$ & $\ldots$ & $\ldots$ & 9 & $\ldots$ \\
\hline Entomognathus brevis (Van der Linden, 1829) & $\ldots$ & $\cdots$ & 1 & $\ldots$ & $\ldots$ & 2 & $\ldots$ & $\ldots$ & $\ldots$ & 1 & 4 & $\ldots$ \\
\hline Lindenius albilabris (Fabricius, 1793) & $\cdots$ & 1 & $\cdots$ & $\cdots$ & $\ldots$ & $\cdots$ & $\ldots$ & $\cdots$ & $\ldots$ & $\cdots$ & 1 & $\cdots$ \\
\hline Lindenius ibericus Kohl, 1905 & 9 & $\ldots$ & $\ldots$ & 1 & $\ldots$ & 1 & $\ldots$ & 1 & 2 & 2 & 16 & $\ldots$ \\
\hline Lindenius pygmaeus (Rossi, 1794) & $\ldots$ & $\cdots$ & $\cdots$ & $\cdots$ & $\cdots$ & $\cdots$ & 1 & $\cdots$ & 2 & 1 & 3 & 1 \\
\hline Crossocerus elongatulus (Van der Linden, 1829) & $\ldots$ & $\cdots$ & $\ldots$ & $\ldots$ & $\cdots$ & $\cdots$ & $\cdots$ & $\ldots$ & 1 & 2 & 3 & $\ldots$ \\
\hline Crossocerus quadrimaculatus (Fabricius, 1793) & $\ldots$ & $\cdots$ & $\cdots$ & $\cdots$ & $\cdots$ & $\cdots$ & 1 & $\cdots$ & $\cdots$ & $\cdots$ & $\cdots$ & 1 \\
\hline Tracheliodes quinquenotatus (Jurine, 1807) & $\ldots$ & 1 & $\ldots$ & 3 & 3 & 1 & 4 & 2 & 4 & 2 & 17 & 3 \\
\hline Ectemnius cephalotes (Olivier, 1792) & $\cdots$ & 1 & 2 & $\cdots$ & 2 & 2 & $\cdots$ & $\cdots$ & 1 & 4 & 12 & $\ldots$ \\
\hline Ectemnius continuus (Fabricius, 1804) & $\ldots$ & $\cdots$ & $\cdots$ & 1 & $\cdots$ & $\ldots$ & $\ldots$ & $\ldots$ & $\ldots$ & 2 & 1 & 2 \\
\hline Ectemnius crassicornis (Spinola, 1808) & 1 & 2 & $\ldots$ & 1 & 1 & 1 & 4 & 5 & 9 & 8 & 30 & 2 \\
\hline Ectemnius rugifer (Dahlbom, 1845) & $\ldots$ & $\ldots$ & $\ldots$ & $\ldots$ & $\ldots$ & $\ldots$ & $\ldots$ & $\ldots$ & $\ldots$ & 2 & 2 & $\ldots$ \\
\hline Lestica clypeata (Schreber, 1759) & $\ldots$ & $\ldots$ & $\ldots$ & 1 & $\ldots$ & 1 & 1 & 1 & $\ldots$ & 1 & 3 & 2 \\
\hline \multicolumn{13}{|l|}{ Mellininae Latreille, 1802} \\
\hline \multicolumn{13}{|l|}{ Mellinini Latreille, 1802} \\
\hline Mellinus arvensis (Linnaeus, 1758) & $\cdots$ & 2 & $\ldots$ & 1 & $\ldots$ & $\cdots$ & $\cdots$ & 3 & $\ldots$ & 1 & 1 & 6 \\
\hline \multicolumn{13}{|l|}{ Bembicinae Latreille, 1802} \\
\hline \multicolumn{13}{|l|}{ Nyssonini Latreille, 1804} \\
\hline \multirow[t]{2}{*}{ Nysson dusmeti Mercet, 1909} & $\cdots$ & 3 & $\ldots$ & 1 & $\cdots$ & $\ldots$ & $\cdots$ & 1 & $\cdots$ & $\ldots$ & $\cdots$ & 5 \\
\hline & & & & & & & & & & & & Continúa \\
\hline
\end{tabular}




\begin{tabular}{|c|c|c|c|c|c|c|c|c|c|c|c|c|}
\hline \multirow[b]{4}{*}{ spp/Age (years since fire) } & \multirow{2}{*}{\multicolumn{10}{|c|}{ SAMPLING SITES (CODE) }} & \multirow{4}{*}{$\begin{array}{c} \\
\text { Total } \\
\text { MT } \\
\end{array}$} & \multirow{4}{*}{$\begin{array}{l} \\
\text { Total } \\
\text { YPT } \\
\end{array}$} \\
\hline & & & & & & & & & & & & \\
\hline & \multicolumn{5}{|c|}{ FIRE } & \multicolumn{5}{|c|}{ CONTROL } & & \\
\hline & 1 & 2 & 3 & 4 & 5 & 7 & 9 & 13 & 14 & 15 & & \\
\hline Nysson maculosus (Gmelin, 1790) & 5 & 1 & $\ldots$ & $\ldots$ & $\ldots$ & $\ldots$ & 3 & $\ldots$ & 2 & 1 & 2 & 10 \\
\hline Nysson monachus Mercet, 1909 & $\ldots$ & $\ldots$ & 1 & $\ldots$ & 1 & $\ldots$ & 1 & $\ldots$ & $\ldots$ & $\ldots$ & $\ldots$ & 3 \\
\hline Nysson parietalis Mercet, 1909 & $\ldots$ & $\ldots$ & $\ldots$ & $\ldots$ & $\ldots$ & $\ldots$ & 1 & $\ldots$ & $\ldots$ & 1 & 1 & 1 \\
\hline Nysson pratensis Mercet, 1909 & 2 & $\ldots$ & $\ldots$ & $\ldots$ & 1 & $\ldots$ & $\ldots$ & 2 & $\ldots$ & $\ldots$ & $\ldots$ & 5 \\
\hline Nysson variabilis (Chevrier, 1867) & 1 & $\ldots$ & $\ldots$ & $\ldots$ & $\ldots$ & $\ldots$ & $\ldots$ & $\ldots$ & $\ldots$ & 1 & $\ldots$ & 2 \\
\hline Brachystegus scalaris (Illiger, 1807) & $\ldots$ & $\ldots$ & $\ldots$ & $\ldots$ & $\ldots$ & 3 & 1 & $\ldots$ & $\ldots$ & $\ldots$ & 2 & 2 \\
\hline \multicolumn{13}{|l|}{ Bembicini Latreille, 1802} \\
\hline Gorytes quinquefasciatus (Panzer, 1798) & $\ldots$ & $\ldots$ & $\ldots$ & $\ldots$ & $\ldots$ & $\ldots$ & $\ldots$ & 6 & 2 & 5 & 13 & $\ldots$ \\
\hline Gorytes sulcifrons (A. Costa, 1869) & $\ldots$ & 1 & $\ldots$ & 4 & $\ldots$ & 3 & 12 & 4 & 3 & 3 & 28 & 2 \\
\hline Harpactus alvaroi Gayubo, 1992 & 2 & 5 & 5 & 3 & 5 & 2 & 5 & 13 & 9 & 16 & 27 & 38 \\
\hline Harpactus formosus (Jurine, 1807) & 4 & 10 & $\ldots$ & 5 & 3 & 8 & 1 & 6 & 8 & 1 & 39 & 7 \\
\hline Harpactus laevis (Latreille, 1792) & $\ldots$ & $\ldots$ & $\ldots$ & $\ldots$ & 1 & $\ldots$ & 2 & $\ldots$ & $\ldots$ & 19 & 21 & 1 \\
\hline Harpactus elegans (Lepeletier, 1832) & $\ldots$ & $\ldots$ & $\ldots$ & $\ldots$ & $\ldots$ & 2 & $\ldots$ & $\ldots$ & $\ldots$ & $\ldots$ & 1 & 1 \\
\hline Harpactus morawitzi (Snoflak, 1943) & 31 & 14 & 5 & 9 & 2 & 1 & 2 & $\ldots$ & $\ldots$ & $\ldots$ & 62 & 2 \\
\hline Harpactus tumidus (Panzer, 1801) & $\ldots$ & $\ldots$ & 1 & $\ldots$ & $\ldots$ & $\ldots$ & $\ldots$ & $\ldots$ & $\ldots$ & $\ldots$ & 1 & $\ldots$ \\
\hline Lestiphorus bicinctus (Rossi, 1794) & $\ldots$ & 1 & $\ldots$ & $\ldots$ & $\ldots$ & $\ldots$ & $\ldots$ & $\ldots$ & $\ldots$ & $\ldots$ & 1 & $\ldots$ \\
\hline Sphecius nigricornis (Dufour, 1838) & 1 & 1 & $\ldots$ & $\ldots$ & $\ldots$ & $\ldots$ & $\ldots$ & $\ldots$ & 2 & $\ldots$ & 4 & $\ldots$ \\
\hline Bembecinus carpetanus (Mercet, 1906) & 4 & 1 & $\ldots$ & $\ldots$ & $\ldots$ & 3 & 1 & 1 & 2 & 2 & 13 & 1 \\
\hline Bembecinus pulchellus (Mercet, 1906) & 254 & 12 & 11 & $\ldots$ & $\ldots$ & 228 & 105 & 43 & 5 & 7 & 456 & 209 \\
\hline Bembecinus tridens (Fabricius, 1781) & $\ldots$ & $\ldots$ & $\ldots$ & $\ldots$ & $\ldots$ & $\ldots$ & 1 & $\ldots$ & $\ldots$ & $\ldots$ & $\ldots$ & 1 \\
\hline Stizus hispanicus Mocsáry, 1883 & $\ldots$ & $\ldots$ & $\ldots$ & $\ldots$ & $\ldots$ & 1 & $\ldots$ & $\ldots$ & $\ldots$ & $\ldots$ & 1 & $\ldots$ \\
\hline Stizoides tridentatus (Fabricius, 1775) & $\ldots$ & $\ldots$ & $\ldots$ & 1 & $\ldots$ & $\ldots$ & $\ldots$ & $\ldots$ & $\ldots$ & $\ldots$ & 1 & $\ldots$ \\
\hline Bembix bidentata Van der Linden, 1829 & 4 & 1 & 2 & $\ldots$ & $\ldots$ & $\ldots$ & 1 & 1 & 2 & 1 & 12 & $\ldots$ \\
\hline Bembix oculata Panzer, 1801 & 3 & 1 & 1 & $\ldots$ & 2 & 1 & 1 & $\ldots$ & 2 & 1 & 12 & $\ldots$ \\
\hline Bembix zonata Klug, 1835 & 27 & 7 & $\ldots$ & 1 & 5 & 12 & 29 & 1 & 12 & 4 & 96 & 2 \\
\hline \multicolumn{13}{|l|}{ Philanthinae Latreille, 1802} \\
\hline \multicolumn{13}{|l|}{ Philanthini Latreille, 1802} \\
\hline Philanthus triangulum (Fabricius, 1775) & 2 & $\ldots$ & $\ldots$ & 1 & $\ldots$ & $\ldots$ & $\ldots$ & 2 & 2 & $\ldots$ & 6 & 1 \\
\hline \multicolumn{13}{|l|}{ Cercerini Lepeletier, 1845} \\
\hline Cerceris arenaria (Linnaeus, 1758) & $\ldots$ & 4 & 2 & 1 & 1 & 2 & 7 & 11 & 3 & 30 & 60 & 1 \\
\hline Cerceris ibericella Leclercq, 1979 & $\ldots$ & 1 & $\ldots$ & $\ldots$ & $\ldots$ & $\ldots$ & $\ldots$ & $\ldots$ & $\ldots$ & $\ldots$ & 1 & $\ldots$ \\
\hline Cerceris quadricincta (Panzer, 1799) & $\ldots$ & 2 & $\ldots$ & 1 & $\ldots$ & $\ldots$ & $\ldots$ & $\ldots$ & $\ldots$ & 2 & 5 & $\ldots$ \\
\hline Cerceris rybyensis (Linnaeus, 1771) & $\ldots$ & 1 & $\ldots$ & $\ldots$ & $\ldots$ & $\ldots$ & 3 & $\ldots$ & 1 & $\ldots$ & 4 & 1 \\
\hline Cerceris sabulosa (Panzer, 1799) & $\ldots$ & 2 & 1 & $\ldots$ & $\cdots$ & $\ldots$ & 1 & $\ldots$ & 5 & 1 & 8 & 2 \\
\hline TOTAL INDIVIDUALS & 2183 & 856 & 603 & 846 & 509 & 1376 & 1288 & 1205 & 1168 & 862 & 8290 & 2606 \\
\hline TOTAL SPECIES & 78 & 74 & 56 & 68 & 52 & 69 & 89 & 69 & 82 & 85 & 129 & 94 \\
\hline
\end{tabular}


Appendix C: Exclusive species sampled with Malaise and yellow pan traps.

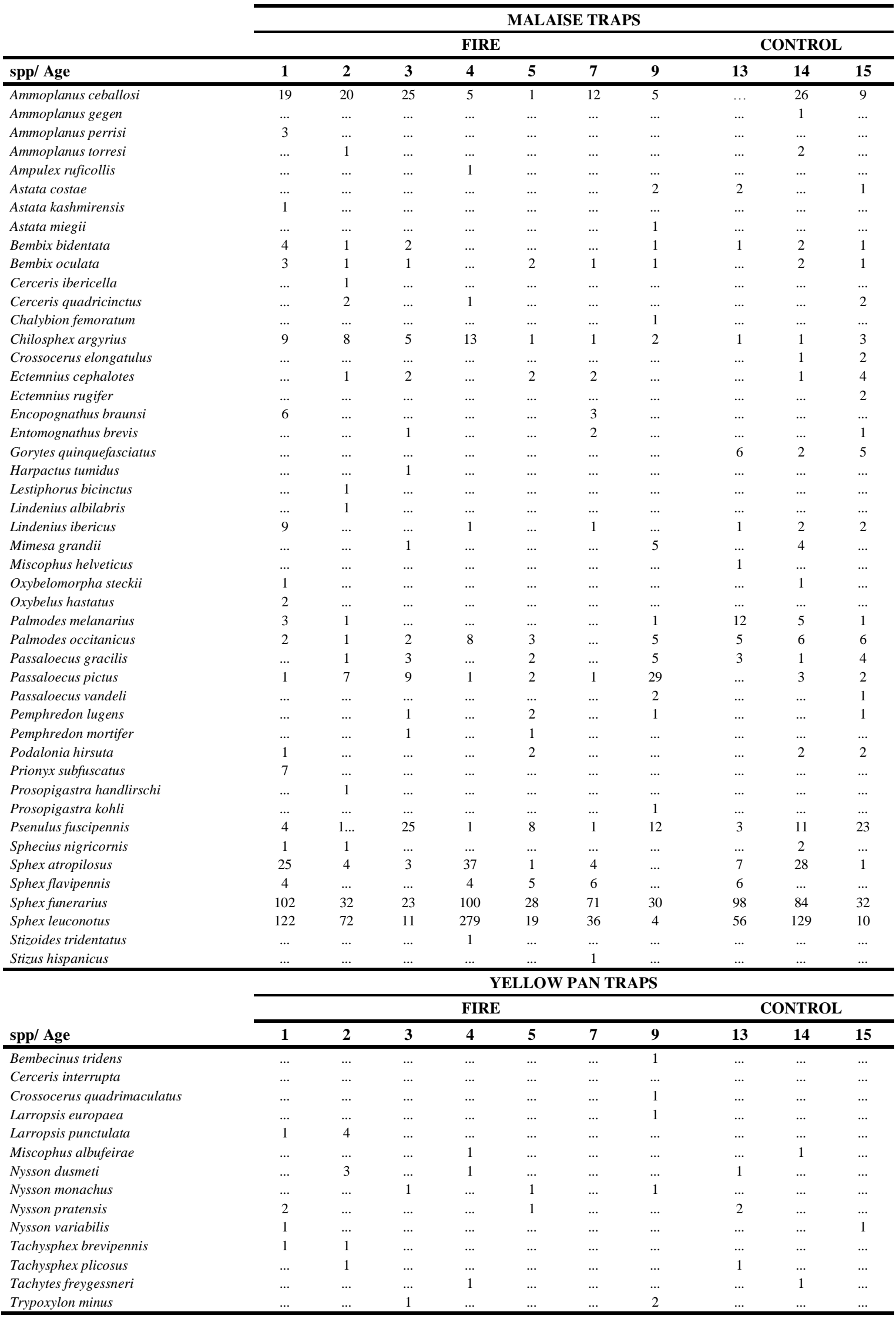




\section{References}

Andersen, A. N. \& Müller, W. J. 2000. Arthropod responses to experimental fire regimes in an Australian tropical savannah: ordinal-level analysis. Austral Ecology 25: 199-209.

Arnan, X., Rodrigo, A. \& Retana, J., 2006. Post-fire recovery of Mediterranean ground ant communities follows vegetation and dryness gradients. J. Biogeography 33 (7): 1246-1258.

Baños-Picón, L., Asís, J. D., Gayubo, S. F. \& Tormos, J. 2009. Analyzing Insect Community Structure through the Application of Taxonomic Distinctness Measures. Zoological Studies 48 (3): 298314.

Bartolomé, C., Álvarez Jiménez, J., Vaquero, J., Costa, M., Casermeiro, M. A., Giraldo, J. \& Zamora, J. 2005. Los tipos de hábitats de interés comunitario de España. Guía Básica. Ministerio de Medio Ambiente. Dirección General para la Biodiversidad. 287 pp.

Breece, C.R., Kolb, T.E., Dickson, B.G., Mc Millin, J.D., Clancy, K.M. 2008. Prescribed fire effects on bark beetle activity and tree mortality in southwestern ponderosa pine forests. Forest Ecol Manag 255: 119-128.

Bond, W. J. \& van Wilgen, B. W. 1996. Fire and Plants. Chapman \& Hall, Londres.

Brown, V. K. 1991. The effects of changes in habitat structure during succession in terrestrial communities. In: Bell, S. S., McCoy, E. D. \& Mushinsky, H. R. (Eds), Habitat structure: the physical arrangement of objects in space. Chapman and Hall, pp: 141-168.

Calonge-Cano, G. 1990. La excepcionalidad climática de los Arribes del Duero. Ería 21: 45-59.

Calvo, L., Tárrega, R. \& Luis-Calabuig, E. 1991. Regeneration in Quercus pyrenaica ecosystems after surface fires. Int. J. Wildland Fire 1 (4): 205-210

Calvo, L., Tárrega, R. \& Luis-Calabuig, E. 1999. Post-fire succession in two Quercus pyrenaica communities with different disturbance histories. Ann. For. Sci. 56: 441-447.

Campbell, J. W., Hannula, J. L. \& Waldrop, T. A. 2007. Effects of prescribed fire and fire surrogates on floral visiting insects of the blue ridge province in North Carolina. Biological Conservation 134: 393-494.

Clarke K. R. \& Warwick RM. 2001a. A further biodiversity index applicable to species lists: variation in taxonomic distinctness. Marine Ecology Progress Series 216: 265-278.

Clarke, K. R. \& Warwick, R. M. 2001b. Change in marine communities: An Approach to Statistical Analysis and Interpretation. $2^{\text {nd }}$ edition. PRIMER-E, Plymouth. $171 \mathrm{pp}$.

Costa Tenorio, M., Morla, C. \& Sainz, H (eds). 2005. Los Bosques Ibéricos. Una interpretación Geobotánica. Ed. Planeta. Barcelona.598 pp.

DeBano, L. F., Neary, D. G. \& Ffolliott, P. F. 1998. Fire's effects on ecosystems. Wiley. New York. 352 pp.

Escudero Alcántara, A., Olano, J. M., García, R., Bariego, P., Molina, C., Arranz, J. A., Molina, J. I. \& Ezquerra, F. J. 2008. Guía básica para la interpretación de los hábitats de interés comunitario de Castilla y León. Junta de Castilla y León. Consejería de Medio Ambiente. Valladolid. 432 pp.

Evans, E. W. 1988. Grasshopper (Insecta: Orthoptera: Acrididae) assemblages of tallgrass prairie: influences of fire frequency, topography, and vegetation. Canadian J. Zoology 66: 1495-1501.

Evans, H. E. \& O’Neill, K. M. 2007 The Sand Wasps: Natural History and Behavior. Harvard University Press, Cambridge, Massachusetts.

Fellows, D. P. \& Newton, W. E. 1999. Prescribed fire effects on biological control of leafy spurge. $J$. Range Management, 52: 489-493.

Fye, R. E. 1972. The effect of forest disturbances on populations of wasps and bees in northwestern Ontario (Hymenoptera: Aculeata). Can. Entomol. 104: 1623-1633. 
García-Feced, C., Escribano, R. \& Elena, R. 2007. Comparación de la estructura de los paisajes en Parques Naturales fronterizos: Arribes del Duero versus Douro Internacional. Montes 91: 8-14.

García-Villanueva, J., Ena, V., Tárrega, R. \& Mediavilla, G. 1998. Recolonization of two burned Quercus pyrenaica ecosystems by Coleoptera. Int. J. Wildland Fire 8: 21-27.

Gathmann A. \& Tscharntke, T. 2002. Foraging ranges of solitary bees. J. Anim. Ecol. 71:757-764.

Gayubo, S. F., González, J. A., Asís, J. D. \& Tormos, J. 2005. Conservation of European environments: The Spheciformes wasps as biodiversity indicators (Hymenoptera: Apoidea: Ampulicidae, Sphecidae and Crabronidae). J. Natural History 39 (29): 2705-2714.

Gibb, H. \& Hjältén, J. 2007. Effects of low severity burning after clear-cutting on mid-boreal ant communities in the two years after fire. J. Insect Conservation 11: 169-175.

González, J.A., Gayubo, S.F., Asís, J.D. \& Tormos, J. 2009. Diversity and Biogeographical Significance of Solitary Wasps (Chrysididae, Eumeninae and Spheciformes) at the Arribes del Duero Natural Park, Spain: Their Importance for Insects Diversity Conservation in the Mediterranean Region. Environ. Entomol. 38 (3): 608-626.

Grafen, A. \& Hails, R. 2002. Modern Statistics for the Life Sciences. Oxford University Press. 351 pp.

Hall, S.P. \& D.F. Schweitzer. 1992. A survey of the moths, butterflies, and grasshoppers of four Nature Conservancy preserves in southeastern North Carolina. Rept. to Nature Conservancy, North Carolina Chapter, Carrboro, NC. 122 pp.

Hansen, J. D. 1988. Trapping methods for rangeland insects in burned and unburned sites: A comparison. Great Basin Naturalist 48 (3): 383-387.

Harmon, J. P., Hladilek E. E., Hinton, J. L., Stodola, T. J. \& Andow, D. A. 2003. Herbivore response to vegetational diversity: spatial interaction of resources and natural enemies. Popul Ecol 45:75-81.

Harper, M. G., Dietrich, C. H., Larimore, R. L. \& Tessene, P. A. 2000. Effects of prescribed fire on prairie arthropods: An enclosure study. Natural Areas J. 20 (4): 325-335.

Haydon, D.T., Friar, J. K., \& Pianka, E. R. 2000. Fire-driven dynamic mosaics in the Great Victoria Desert, Australia. II. A spatial \& temporal landscape model. Landsc. Ecol. 15:407-423.

Hirowatari, T., Makihara, H., \& Sugiarto. 2007. Effects of fires on butterfly assemblages in lowland dipterocarp forest in East Kalimantan. Entomological Science 10 (2): 113-127.

Huber, J. T. 2009 Biodiversity of Hymenoptera. In: Foottit RG, Adler PH, (eds.) Insect Biodiversity: Science and Society. Blackwell Publishing Ltd, Oxford, UK

Izhaki, I., Levey, D.J. \& Silva, W. 2003. Effects of prescribed fire on an ant community in Florida pine savanna. Ecological Entomoogy. 28: 439-448.

Knight, T. M. \& Holt, R. D. 2005 Fire Generates Spatial Gradients in Herbivory: An Example from a Florida Sandhill Ecosystem. Ecology 86 (3): 587-593.

Lamotte, M. 1975. The structure and function of a tropical savanna ecosystem. En: Tropical Ecological Systems: Trends in Terrestrial and Aquatic Research (Golley, F. B. \& Medina, E. eds.), pp 179222. Springer-Verlag, Berlin.

LaSalle, J. \& Gauld, I. D. (eds.) 1993. Hymenoptera and Biodiversity. CAB International. The Natural History Museum, Wallingford, UK. xi +348 pp.

Lassau, S. A. \& Hochuli, D. F. 2005. Wasp community responses to habitat complexity in Sydney sandstone forests. Austral Ecology 30:179-187.

Lockwood, J. A., Shaw, S. R. \& Struttmann, J. M. 1996. Biodiversity of wasp species (Insecta: Hymenoptera) in burned and unburned habitats of Yellowstone National Park, Wyoming, USA. J. Hymenoptera Research, 5: 1-15.

Luis-Calabuig, E. (Coord.) 2008. Arribes del Duero. Guía de la Naturaleza. Edilesa. León. 224 pp. 
Luis-Calabuig, E. \& Tarrega, R. 1993. Studies on post-fire regeneration in Quercus pyrenaica ecosystems in Leon Province (NW Spain). Pages 209-219. In: Trabaud, L. \& Prodon, R. (eds). Fire in Mediterranean ecosystems. ECSC-EEC-EAEC, Brussels-Luxembourg.

Magurran, A. E. 2004. Measuring Biological Diversity. Blackwell Science Publishing. Oxford.

Makihara H, Kinuura H, Yahiro K., \& Soeyamto, C., 2000. The effects of droughts and fires on Coleopteran insects in lowland dipterocarp forests in Bukit Soeharto, East Kalimantan. In: Guhardja E, Futawi M, Sutisna M, Ohta S (eds) Rainforest Ecosystems of East Kalimantan. Ecological Studies, 140, pp 153-163. Springer, Tokyo.

Moreno, J. M. 2007. Cambio global e incendios forestales: Una visión desde España. Proceding of $4^{\mathrm{a}}$ Conferencia Internacional sobre Incendios Forestales. Sevilla, España. 13-14 Mayo. 2007.

Moreno, J. M., Vázquez, A. \& Vélez, R. 1998. Recent history of forest fires in Spain. En: Moreno, J. M. (Ed.) Large Fires, Backhuys Publishers, Leiden. Pp.: 159-185.

Moretti, M. \& S. Barbalat. 2004. The effects of wildfires on wood-eating beetles in deciduous forests on the southern slope of the Swiss Alps. Forest Ecol Manag 187 (1): 85-103.

Moretti, M.; Duelli, P. \& Obrist, M. K. 2006. Biodiversity and resilience of arthropod communities after fire disturbance in temperate forests. Oecologia 149: 312-327.

Moretti, M.; Obrist, M. K. \& Duelli, P. 2004. Arthropod biodiversity after forest fires: winners and losers in the winter fire regime of the Southern Alps. Ecography 27 (2): 173-186.

Moretti, M., Conedera, M., Duelli, P. \& Edwards, P. J. 2002a. The effects of wildfire on ground-active spiders in deciduous forests on the Swiss Southern slope of the Alps. J. Applied Ecology 39 (2): 321-336.

Moretti, M., Zanini, M. \& Conedera, M. 2002b. Faunistic and floristic post-fire succession in southern Switzerland: an integrated analysis with regard to fire frequency and time since the last fire. In: Wiegas, D. X. (ed.), Forest Fire Research and Wildland Fire Safety. Millpress, Rotterdam. CDRom.

Mouillot, D., Gaillard, S., Aliaume, C., Verlaque, M., Belsher, T., Troussellier, M. \& Do Chi, T.2005. Ability of taxonomic diversity indices to discriminate coastal lagoon environments based on macrophyte communities. Ecol. Indicat. 5: 1-17.

Naveh, Z. 1975. The evolutionary significance of fire in the Mediterranean region. Vegetatio 29: 199-208.

Naveh, Z. 1990. Fire in the Mediterranean-landscape ecological perspective. En: Fire in Ecosystems Dynamics (Goldammer, J. G. \& Jenkins, M. J. eds.). S.P.B. Academic Publishing. The Hague: 120.

Ne'eman, G., Dafni, A. \& Potts, S. G. 2000. The effect of fire on flower visitation rate and fruit set in four core-species in east Mediterranean scrubland. Plant Ecol. 146: 97-104.

Niwa, C.G. \& Peck, R.W. 2002. Influence of prescribed fire on carabid beetle (Carabidae) and spider (Araneae) assemblages in forest litter in southwestern Oregon. Environ. Entomol. 31: 785-796.

Nunes, L., Leather, S. \& Rego, F. 2000. Effects of fire on insects and other invertebrates. A review with particular reference to fire indicator species. Silva Lusitana (8), 1: 15-32.

Ortiz-Sánchez, F.J. \& A. Aguirre-Segura.1993. Efecto del color sobre las capturas de abejas mediante trampas Moericke en el sur de España (Hymenoptera, Apoidea). Graellsia 49: 63-71.

Panzer, R. 2003. Importance of in situ survival, recolonization, and habitat gaps in the postfire recovery of fire-sensitive prairie insects species. Natural Areas J. 23: 14-21.

Parr, C. L., Robertson, H. G., Biggs, H. C. \& Chown, S. L., 2004. Response of African savanna ants to long-term fire regimes. J. App. Ecology 41: 630-642.

Pausas, J. G. 2004. Changes in fire and climate in the eastern Iberian Peninsula (Mediterranean Basin). Climatic Change 63 (3): 337-350. 
Pickett, S. T. A. 1989. Space for time substitution as an alternative for long studies. In: Likens, E. G. (ed.), Long-term studies in ecology: approaches and alternatives. Springer, pp. 112-135.

Potts, S. G., Dafni, A. \& Ne'eman, G. 2001. Pollination of a core flowering shrub species in Mediterranean phrygana: variation in pollinator diversity, abundance and effectiveness in response to fire. Oikos 92: 71-80.

Potts, S. G., Vulliamy, B., Dafni, A., Ne'eman, G., O’Toole, C., Roberts, S. \& Willmer, P.G. 2003. Response of plant-pollinator communities to fire: changes in diversity, abundance and floral reward structure. Oikos 101 (1): 103-12.

Potts, S.G., Vulliamy, B., Roberts, S., Roberts, S., O’Toole, C., Dafni, A., Ne'eman, G. \& Willmer, P., 2005. Role of nesting resources in organising diverse bee communities in a Mediterranean landscape. Ecol Entomol 30: 78-85.

Ramos, M. A., Lobo, J. M. \& Esteban, M. 2001. Ten years inventorying the Iberian fauna: results and perspectives. Biodivers. Conserv. 10: 19-28.

Rodrigo, A., Sardá-Palomera, F., Bosch, J. \& Retana, J. 2008. Changes of dominant ground beetles in black pine forest with fire severity and sucesional age. EcoScience 15 (4): 442-452.

Saint-Germain, M., Drapeau, P. \& Hébert, C. 2004. Comparison of Coleoptera assemblages from a recently burned and unburned black spruce forests of northeastern North America. Biological Conservation 118: 583-592.

Schoonhoven, L. M, van Loon, J. J. A. \& Dicke, M. 2005. Insect-Plant Biology. $2^{\text {nd }}$ edition. Oxford University Press. Oxford. 421 pp.

Smith, J. K., ed. 2000. Wildland fire in ecosystems: effects of fire on fauna. Gen. Tech. Rep. RMRSGTR-42-vol. 1. Ogden, UT: U.S. Department of Agriculture, Forest Service, Rocky Mountain Research Station. 83 pp.

Spence, J. R. \& J. K. Niemela. 1994. Sampling carabid assemblages with pitfall traps: the madness and the method. Can. Entomol. 126: 881-894.

Steffan-Dewenter, I., 2002, Landscape context affects trap-nesting bees, wasp, and their natural enemies. Ecological Entomology 27: 631-637.

Steffan-Dewenter, I. \& Leschke, K. 2003. Effects of habitat management on vegetation and above-ground nesting bees and wasps of orchard meadows in Central Europe. Biodivers. Conserv. 12: 19531968.

Steffan-Dewenter, I., Münzenberg, U. \& Tscharntke, T. 2001. Pollination, seed set and seed predation on a landscape scale. Proc. R. Soc. Lond. B. 268: 1685-1690.

Steffan-Dewenter, I., Münzenberg, U., Bürger, C., Carsten, T. \& Tscharntke, T. 2002. Scale dependent effects of landscape context on three pollinator guilds. Ecology 83: 1421-1432.

Stein, J. S., Price, P. W.; Abrahmson, W. G. \& Sacchi, C. F. 1992. The effect of fire on stimulating willow regrowth and subsequent attack by grasshoppers and elk. Oikos 65: 190-196.

Swengel, A. B. 2001. A literature review of insect responses to fire, compared to other conservation managements of open habitat. Biodivers. Conserv. 10 (7): 1141-1169.

Swengel, A. B. \& Swengel, S. R. 2007. Benefit of permanent non-fire refugia for Lepidoptera conservation in fire-managed sites. J. Insect. Conserv. 11: 263-279.

Taki H., Viana, B.F., Kevan, P.G., Silva, F.O., \& Buck, M. 2008. Does forest loss affect the communities of trap-nesting wasps (Hymenoptera: Aculeata) in forests? Landscape vs. local habitat conditions. J. Insect Conservation 12 (1): 15-21.

Trabaud, L. \& Prodon, R. 1993. Fire in Mediterranean ecosystems. - ECSC-EEC-EAEC, BrusselsLuxembourg.

Westphal, C., Bommarco, R., Carre, G., Lamborn, E., Morison, N., Petanidou, T., Potts, S. G., Roberts, S. P. M., Szentgyorgyi, H., Tscheulin, T., Vaissiere, B. E., Woyciechowski, M., Biesmeijer, J. C., 
Kunin, W. E., Settele, T. \& Steffan-Dewenter, I., 2008. Measuring Bee Diversity in Different European Habitats. Ecological Monographs, 78 (4): 653-671.

Whelan, R. J. 1995. The Ecology of Fire. Cambridge University Press, Cambridge. 346 pp.

Wilson, E. O. 1992. The diversity of life. Harvard University Press, Cambridge. 410 pp.

Wright, M. G. \& Samways, M. J. 1998. Insect species richness tracking plant species richness in a diverse flora: gall-insects in the Cape Floristic Region, South Africa. Oecologia, 115: 427-433.

York, A. 1996. Long-term effect of repeated prescribed burning on forest invertebrates: Management implications for the conservation of biodiversity. Consultancy report to the Department of the Environment and Heritage. Final report. April. 


\section{3}

Efecto de los incendios forestales sobre la estructura de la comunidad de avispas

Spheciformes: importancia de las condiciones locales del hábitat.

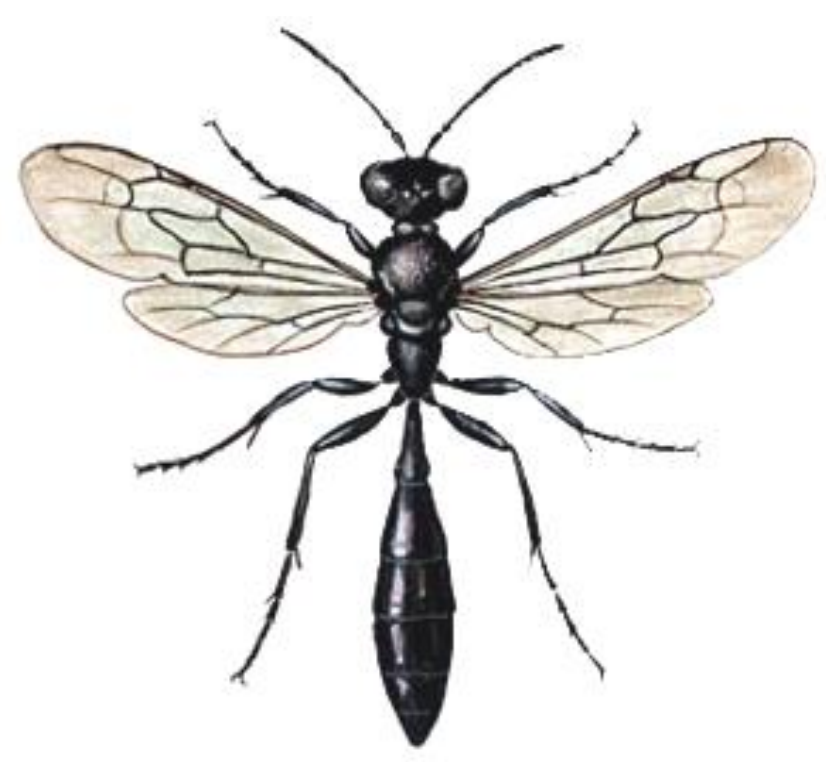




\title{
Efecto de los incendios forestales sobre la estructura de la comunidad \\ de avispas Spheciformes: importancia de las condiciones locales del
}

\section{hábitat.}

\begin{abstract}
Se analiza la estructura de una comunidad de avispas Spheciformes (Hymenoptera: Apoidea) a lo largo de quince años de recuperación tras un incendio en un agroecosistema Mediterraneo, las especies que más contribuyen a determinar dicha estructura, los cambios de dominancia producidos entre las especies más abundantes, la variación en la estructura gremial de la comunidad con el paso del tiempo desde el incendio, y qué variables ambientales contribuyen a estructurar dicha comunidad. Las comunidades de Spheciformes fueron muy resistentes al fuego. Los años de muestreo, representativos de diferentes condiciones climatológicas, y los años transcurridos desde que el fuego tuviera lugar, fueron las principales variables que influyeron en la variación de la comunidad. La variación en las condiciones locales del hábitat tuvo mayor importancia en la estructura de la comunidad que el impacto directo del fuego, mostrando una gran relación entre estos insectos y la estructura del hábitat. Estas condiciones locales (mayor o menor presencia de recursos tróficos, de nidificación y de presas para alimentar a las larvas) dependen de las condiciones climatológicas y del paso del tiempo desde el impacto. Existieron variaciones en los valores de dominancia mostrados por las especies más abundantes, así como desplazamientos entre especies, dentro de un mismo género, en función de las condiciones locales del hábitat, recursos existentes y los años desde el fuego. El cambio en la estructura de la comunidad no puede atribuirse de manera concluyente al efecto del fuego, ya que estuvo más afectado por las condiciones de tipo climático o ambiental.
\end{abstract}

Palabras clave: Hymenoptera, Spheciformes, fuego, estructura de la comunidad, bosques de Quercus pyrenaica. 


\section{Introducción}

Son muchos los ecosistemas forestales que pueden considerarse dependientes del fuego o influidos por este. Entre ellos cabe destacar los bosques mediterráneos (Naveh, 1975; Whelan, 1995; Bond \& van Wilgen, 1996), especialmente propensos al fuego debido a los cambios en los usos del suelo, a la predisposición a quemarse de la vegetación mediterránea y al clima predominante (Pausas, 2004; Moreno, 2007).

El fuego, como factor de perturbación que provoca una pérdida de individuos o biomasa de forma súbita o episódica y que genera espacios que pueden ser colonizados por individuos supervivientes de la misma o de otras especies, juega un importante papel en el mantenimiento de la diversidad biológica de las comunidades mediterráneas, ya sean vegetales (Pausas \& Vallejo, 1999; Ojeda-Copete, 2001) o animales (Potts et al., 2001, 2003, 2005), lo que hace que muchas especies dependan de la existencia de esas perturbaciones periódicas para su existencia (Begon et al., 2006).

Los efectos del fuego sobre la fauna son muy variados y el análisis de las respuestas ofrecidas por los distintos grupos de insectos al fuego presenta resultados variables de unos estudios a otros. Esto es debido a la enorme variedad de especies, comportamientos y biología que presentan, así como al tipo de hábitat y los diferentes componentes del régimen de incendios bajo los que actue el fuego (Whelan, 1995; Nunes et al., 2000; Swengel, 2001). Todos estos parámetros hacen que las respuestas estén reguladas por factores intrínsecos y específicos de cada especie (Buddle et al., 2000; Moretti et al., 2004, 2006). Así, algunas especies se ven favorecidas por la presencia de este tipo de perturbaciones y las alteraciones que provocan en el hábitat (Moretti et al., 2002a; Hanula \& Wade, 2003; Saint-Germain et al., 2004; Campbell et al., 2007; Hirowatari et al., 2007), mientras que otras se ven perjudicadas (Potts et al., 2001; Panzer, 2003; Cleary \& Grill, 2004) o no se ven afectadas (Bock \& Bock, 1991; Siemann et al., 1997).

Los resultados de muchos estudios de campo evidencian que la variación de especies y el cambio del medio físico tras un fuego tienen como resultado la formación de comunidades diferentes en zonas quemadas (Nunes et al., 2000; Swengel, 2001; Fernández \& Salgado, 2004; Saint-Germain et al., 2004; Knight \& Holt, 2005). De este modo, podemos encontrar muchos casos en la literatura en los que determinadas especies características de espacios abiertos aumentan tras el fuego, mientras que otras 
especies pertenecientes a closed forest disminuyen en zonas quemadas (Lockwood et al., 1996; Buddle et al., 2000; Fernández \& Salgado, 2004; Moretti et al., 2004, 2006; Rodrigo \& Retana, 2006; Rodrigo et al., 2008).

A pesar de la gran cantidad de grupos analizados (Swengel, 2001), entre los que se encuentran los Hymenoptera (e.g. Lockwood et al., 1996; Potts et al., 2001, 2003; 2005; Campbell, 2007), apenas hay estudios específicos sobre el efecto del fuego en el grupo de los Spheciformes (Cruz-Sánchez et al., 2009, in prep.), propuestos como grupo indicador de biodiversidad (Gayubo et al., 2005). Se trata de un grupo capaz de colonizar y exploart diferentes hábitats, y que alcanza un alto grado de diversificación debido a lo variado de su comportamiento y morfología. Los individuos adultos se alimentan preferentemente de néctar, mientras que sus larvas son entomófagas, de manera que las hembras son depredadoras y capturan otros insectos (o arañas en algunos casos) para alimentarlas. Los nidos son construidos en el suelo, en huecos o en galerías excavadas en madera, o son construidos con barro (en casos excepcionales también se emplean fibras vegetales) (O’Neill, 2001). Todas estas características hacen de los Spheciformes un grupo muy dependiente de la estructura del hábitat (SteffanDewenter, 2002; Taki et al., 2008) y potencialmente vulnerable a las alteraciones que este pudiera sufrir, ya que influirían en su comportamiento nidificador y en la disponibilidad de recursos tróficos y de presas para alimentar a las larvas.

El objetivo de este estudio es caracterizar la comunidad de avispas Spheciformes tras sufrir un incendio y determinar qué variables ambientales son las que contribuyen a la estructura de dicha comunidad. Se pretende analizar si cambian las abundancias relativas de las especies que componen la comunidad y el sentido en el que lo hacen, así como conocer cuáles son las especies más resistentes ante este tipo de perturbaciones. Se analiza también cómo varía la composición gremial de la comunidad a medida que pasa el tiempo desde el momento del incendio y a medida que avanza el periodo de recuperación del hábitat.

\section{Material y Métodos}

\section{Área de estudio}

El estudio se realizó dentro del Parque Natural de Arribes del Duero (Salamanca, España), en dos localidades vecinas (Villarino de los Aires y Pereña de la Ribera) muy 
afectadas por este tipo de perturbación (Plan Municipal de Prevención de los Incendios Forestales en Villarino de los Aires y Plan 42, Junta de Castilla y León). Dicho Espacio Natural es muy interesante por su diversidad entomológica y significado biogeográfico, a nivel peninsular y europeo (González et al., 2009).

Ubicada en la penillanura y fruto del abandono de las actividades agrícolas intensivas y una mayor tendencia a la ganadería extensiva, el área afectada se caracteriza por su naturalidad y la posesión de un elevado porcentaje de vegetación arbustiva (García-Feced et al., 2007). Se trata de la mayor zona del territorio con representación de los bosques galaico-portugueses con Quercus pyrenaica Willd, especie dotada de una gran capacidad de resistencia debido a la presión constante sufrida a lo largo del tiempo a través de fuego, tala y pastoreo, y cuyas comunidades contienen muchas especies "rebrotadoras", que les proporcionan una gran capacidad de resiliencia (Tárrega \& Luis-Calabuig, 1989; Luis-Calabuig \& Tárrega, 1993; Calvo et al., 1991, 1999; Luis- Calabuig et al., 2001). Estos bosques se recogen en la lista de hábitats de interés comunitario de la UE (Bartolomé et al., 2005: 230-231) siendo característicos de la zona centro y noroccidental de la Península Ibérica en altitudes iguales o superiores a los $700 \mathrm{~m}$ (Costa Tenorio et al., 2005). En el área analizada aparecen adehesados y empobrecidos florísticamente (Escudero Alcántara et al., 2008: 366; Luis-Calabuig, 2008). La zona se caracteriza por presentar una temperatura media anual suave y unas ciertas condiciones de humedad (precipitación media en torno a los 700 mm/año) (Calonge-Cano, 1990) que confieren a esta región un carácter de mesoclima mediterráneo. Solamente existen leptosoles como suelos representativos.

Los incendios de la zona analizada son incendios de superficie, rápidos, de bajamedia intensidad, en su mayoría de origen antrópico (mayoritariamente intencionados) (Plan 42, Junta de Castilla y León) y producidos en verano. La presencia de grandes superficies de roca madre desnuda dispersa, pequeños viñedos labrados o prados delimitados por muros de piedra que actúan como cortafuegos ante el avance de las llamas, hacen que el fuego no queme de manera uniforme, permitiendo la existencia de zonas sin quemar dentro de la propia área incendiada. 


\section{Método y técnicas de muestreo empleados}

La recolección de ejemplares se realizó mediante trampa Malaise (en adelante MT) de color blanco y platos amarillos (en adelante YPT) (22 cm de diámetro y $3 \mathrm{~cm}$ de profundidad). El estudio se basó en una "sustitución de espacio por tiempo" (Picket, 1989) mediante el análisis de tres incendios, de características similares, ocurridos en los años 2004, 2002 y 1998, es decir, uno, tres y siete años antes del comienzo del estudio, que se inició en 2005. Su muestreo repetido (ver Tabla I) permitió establecer una sucesión cronológica que comprendió el periodo de recuperación que va de uno a tres años para el primer incendio, los años 4 y 5 para el segundo, y siete y nueve años para el ocurrido en 1998. Todas las zonas muestreadas están próximas entre sí y pertenecen a áreas de composición vegetal y características físicas, geológicas y edafológicas semejantes. Las características de las localidades muestreadas, año del incendio, extensión y época de los mismos, años de muestreo de cada incendio, número de MT and YPT empleados en cada uno de ellos y tiempo transcurrido desde el incendio se muestran en la Tabla I.

Tabla I: Resumen de las principales características de las zonas estudiadas. SY = Año de muestreo; Age = tiempo desde el incendio (en años); MT = Trampa Malaise; YPT = Platos amarillos; F= Fuego; $\mathrm{C}=\mathrm{Control}$. * Nótese que en las localidades $2 \mathrm{~F}$ y $3 \mathrm{~F}$ sólo se muestrearon 2 años.

\begin{tabular}{|c|c|c|c|c|c|c|c|c|}
\hline & Localidad & $\begin{array}{c}\text { Año del } \\
\text { incendio }\end{array}$ & Extensión & $\begin{array}{c}\text { Fecha } \\
\text { del } \\
\text { incendio }\end{array}$ & SY (Jun.-Sept.) & $\begin{array}{l}\text { Age (Años } \\
\text { post-fuego) }\end{array}$ & MT/SY & YPT/SY \\
\hline \multirow{3}{*}{ 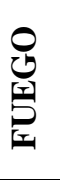 } & $1 \mathrm{~F}$ & 2004 & 120 ha & Agosto & 2005, 2006, 2007 & $1,2,3$ & 3 & 240 \\
\hline & $2 \mathrm{~F}$ & 2002 & 452 ha & Octubre & 2006,2007 & 4,5 & 3 & 240 \\
\hline & $3 F$ & 1998 & 110 ha & Agosto & 2005,2007 & 7,9 & 3 & 240 \\
\hline \multirow{2}{*}{ 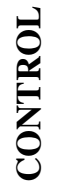 } & $1 \mathrm{C}$ & $\ldots$ & $\ldots$ & $\ldots$ & 2005, 2006, 2007 & $13,14,15$ & 2 & 160 \\
\hline & $2 \mathrm{C}$ & $\ldots$ & $\ldots$ & $\ldots$ & 2005, 2006, 2007 & & 1 & 80 \\
\hline
\end{tabular}

Las zonas Control son zonas recuperadas y representativas del área estudiada aunque, debido a la presencia histórica del fuego en el área analizada, se consideran representativas de un fuego ocurrido 13 años antes de comenzar el estudio. 
Se instalaron 3 MT en el interior de cada una de las tres zonas quemadas y de los dos Controles, por cada año de muestro (Table I), sumando 30 trampas en total (Tabla II). Las trampas se colocaron entre $150 \mathrm{~m}$ y $320 \mathrm{~m}$ del borde más cercano sin quemar, encontrándose las tres trampas de cada zona lo suficientemente alejadas entre sí (80 m de distancia media) como para no considerar interferencias entre ellas a la hora de realizar las capturas. Alrededor de cada MT se delimitó una parcela de 10 m x 10 m en la que se colocaron 20 YPT, cinco en cada lateral. La separación entre cada uno de ellos fue de $2 \mathrm{~m}$ aproximadamente, condicionado por la presencia de vegetación y sustrato adecuado para su colocación. Los YPT se enterraron en el suelo hasta su borde superior, rellenándose casi en su totalidad de agua jabonosa con sal, que actuó como conservante. Para facilitar su localización, dificultada por la frondosidad vegetal existente en determinadas zonas, su posición se señaló con una pequeña estaca de color anaranjado. La elección del color amarillo se debió fundamentalmente a que: 1) es el color que mejor resultado ofrece para los himenópteros y más concretamente para la familia Apoidea (Ortiz-Sánchez \& Aguirre-Segura, 1993); y 2) es el color más habitual entre las flores existentes en el área estudiada y de las que se alimentan los adultos del grupo analizado, por lo que su resultado debería ser óptimo (Toler et al., 2005; Campbell et al., 2007; Westphal et al., 2008). La suma total de YPT empleados fue de 2.400 (Tabla II). Ambos métodos de captura ya han sido empleados con éxito, conjunta o independientemente, en el análisis de comunidades de insectos afectadas por el fuego (Ej. Cancelado \& Yonke, 1970; Hansen, 1986, 1988; Lockwood et al., 1996; Makihara et al., 2000; Campbell et al., 2007; Hirowatari et al., 2007).

Tabla II: Número global y parcial de trampas empleadas en el estudio, por localidad y por año de muestreo (SY).

\begin{tabular}{|c|c|c|c|c|c|c|}
\hline \multirow[b]{3}{*}{ Localidad } & \multicolumn{6}{|c|}{ Año de muestreo \& Método de captura } \\
\hline & \multicolumn{3}{|c|}{ MT } & \multicolumn{3}{|c|}{ YPT } \\
\hline & 2005 & 2006 & 2007 & 2005 & 2006 & 2007 \\
\hline $1 F$ & 3 & 3 & 3 & 240 & 240 & 240 \\
\hline $2 \mathbf{F}$ & $\ldots$ & 3 & 3 & $\ldots$ & 240 & 240 \\
\hline $3 \mathbf{F}$ & 3 & $\ldots$ & 3 & 240 & $\ldots$ & 240 \\
\hline $1 C+2 C$ & 3 & 3 & 3 & 240 & 240 & 240 \\
\hline Total MT/SY & 9 & 9 & 12 & 720 & 720 & 960 \\
\hline Trampas totales & & 30 & & & 2400 & \\
\hline
\end{tabular}

MT = Trampa Malaise; YPT = Platos amarillos; F = Fuego; $\mathrm{C}=$ Control. 
La recogida de muestras se realizó en los meses de junio a septiembre (ambos inclusive) durante los tres años consecutivos que duró el muestreo. Las capturas pertenecientes a cada MT se recogieron quincenalmente, mientras que las correspondientes a los YPT (colocadas el día 15 de cada mes), se recogieron mensualmente, tras permanecer activos durante 48 horas. En los casos en que parte de la muestra se perdió por climatología desfavorable, el muestreo se repitió dos días más tarde, hasta obtener una muestra de YPT por mes y área muestreada. A pesar de ello, la muestra correspondiente al mes de junio de 2005 no pudo obtenerse debido a las condiciones climatológicas adversas y al impacto provocado por rebaños de ganado doméstico y/o de la fauna de mamíferos salvajes. Las muestras se trasladaron al laboratorio para la adecuada preparación de los individuos colectados, procediéndose a la identificación de los ejemplares hasta nivel específico y a su análisis cuantitativo. El material recogido se halla depositado en la colección entomológica del Área de Zoología del Departamento de Biología Animal, Ecología, Parasitología y Química Agrícola de la Universidad de Salamanca.

Tabla III: Resumen de los valores de cobertura media obtenidos para los diferentes estratos vegetales (arbóreo, arbustivo, herbáceo) y de suelo desnudo (en \%). Altura media del estrato arbustivo (en cm.). F = Fuego; C = Control.

\begin{tabular}{cccccccc}
\hline Localidad & $\begin{array}{c}\text { Age (Años } \\
\text { post-fuego) }\end{array}$ & SY & Arbórea & Arbustiva & Herbácea & $\begin{array}{c}\text { Suelo } \\
\text { desnudo }\end{array}$ & $\begin{array}{c}\text { Altura } \\
\text { arbustiva }\end{array}$ \\
\hline 1F & 1 & 2005 & 7,24 & 4,68 & 44,28 & 69,88 & 31,24 \\
$1 \mathrm{~F}$ & 2 & 2006 & 3,08 & 2,2 & 68,68 & 38,24 & 30,88 \\
1F & 3 & 2007 & 14,76 & 16,36 & 40,36 & 36,6 & 36,54 \\
2F & 4 & 2006 & 8,8 & 16,44 & 32,72 & 43,48 & 36,86 \\
2F & 5 & 2007 & 12,64 & 34,6 & 51,16 & 31,12 & 57,7 \\
$3 \mathrm{~F}$ & 7 & 2005 & 14,8 & 48,72 & 46,32 & 2,88 & 97 \\
$3 \mathrm{~F}$ & 9 & 2007 & 8,8 & 46,12 & 65,6 & 0,56 & 106,85 \\
\hline $1 \mathrm{C}-2 \mathrm{C}$ & 13 & 2005 & 34,52 & 57,56 & 37,64 & 8.00 & 124,54 \\
$1 \mathrm{C}-2 \mathrm{C}$ & 14 & 2006 & 21,48 & 63,48 & 41,76 & 4,92 & 91,77 \\
$1 \mathrm{C}-2 \mathrm{C}$ & 15 & 2007 & 21,36 & 52,84 & 29 & 9,08 & 86,43 \\
\hline
\end{tabular}

En cada una de las áreas analizadas se obtuvo mediante estimación visual el porcentaje cobertura arbórea, matorral y de herbáceas. Igualmente se midió la altura arbustiva (en centímetros), y el porcentaje de duelo desnudo, debido a la importancia que tiene la disponibilidad de este recurso para la nidificación de muchas especies de Spheciformes. Para ello se realizó un muestreo por año y localidad a finales del mes de mayo, previo a la colocación de las trampas. Cada uno de los muestreos consistió en 
realizar 5 grupos de 5 transectos paralelos de $5 \mathrm{~m}$ cada uno, con una separación de $5 \mathrm{~m}$. Cada grupo de transectos ocupó una superficie de $100 \mathrm{~m}^{2}$, realizándose en diferentes zonas representativas de la vegetación existente en cada una de las localidades, alrededor de las MT. Los valores medios de cada una de las variables muestreadas, junto con el resto de las variables consideradas en el estudio, se muestran en la Tabla III.

\section{Análisis estadístico}

Las capturas obtenidas mediante MT y YPT por cada una de las localidades y años de muestreo, fueron consideradas como una única muestra.

Se examinó la relación entre la composición de Spheciformes y la estructura del hábitat. El Análisis de Correspondencia (DCA) de las species, mostró que los métodos de ordenación lineal eran los más apropiados, por lo que se realizaron un Análisis de Componentes Principales (PCA) y un Análisis de Redundancia (RDA) (Lepš \& Šmilauer, 2003). Utilizamos PCA con los datos de frecuencia de especies para obtener una idea global de la estructura de la composición de especies en las muestras. Las variables ambientales se añadieron al análisis como variables suplementarias para facilitar la interpretación del PCA, pero no ejercen ninguna influencia sobre la ordenación. Fuego y Control fueron codificadas como variables dummy (Lepš \& Šmilauer, 2003).

Para analizar la influencia de los distintos parámetros-variables ambientales (cobertura, altura arbustiva, suelo desnudo, año de muestreo, localización -Fuego y Control- y edad post-fuego) sobre la comunidad de Spheciformes, se realizó un RDA. Las variables ambientales fueron seleccionadas autómaticamente (automatic forward selected) (ter Braak \& Šmilauer, 1998). Se realizó el test de Monte Carlo (p <0.05; 499 permutaciones) para analizar la significación de la correlación entre las variables ambientales y la distribución de especies. En el modelo sólo se incluyeron las variables significativas

Para calcular el PCA y el RDA se empleó el programa CANOCO 4.0 (ter Braak \& Šmilauer, 1998). Para calcularlos se consideraron sólo las 94 especies que sumaron al menos 5 individuos muestreados en total. Para estos análisis se realizó una 
transformación logarítmica de las especies, con el fin de reducir el peso de las muy abundantes. Para el resto de análisis se utilizó el paquete XLSTAT 2009.

Estos cálculos se complementaron con un análisis de dominancia de las especies para cada una de las muestras obtenidas, siguiendo el criterio de Haeseler (1972), que clasifica a las especies como: eudominantes (> 15\% del total de las capturas), dominantes $(5 \%$ - 15\%), subdominantes $(1 \%$ - 5\%) y subordinadas $(<1 \%)$. Igualmente se llevó a cabo el estudio de la composición gremial de la comunidad.

Para valorar posibles desviaciones en la composición gremial de la comunidad, se compararon los valores obtenidos en cada muestra con el patrón global existente para las especies encontradas en la Península Ibérica. Según la bibliografía existente (Bitsch \& Leclercq, 1993; Bitsch et al., 1997, 2007) se establecieron diversas categorías en función de: (1) el tipo de sustrato utilizado en la nidificación, y (2) el tipo de dieta pedotrófica (presas capturadas para alimentar a las larvas). En el primer caso (sustrato utilizado en la nidificación), diferenciamos entre sustrato terrestre y vegetal, de modo que las agrupaciones resultantes vendrían de la suma de las especies Terrícolas (TE) (que excavan nidos en distintos tipos de terreno, preferentemente arenoso) y Ocupantes de Cavidades Terrestres (OCt) (que nidifican en huecos y galerías, excavados por otros artrópodos), por un lado, y la suma de las Ocupantes de Cavidades Vegetales (OCv) (nidifican en huecos y galerías excavados por otros artrópodos en sustratos vegetales) y Xilícolas-Rubícolas (XR) (que excavan sus nidos en madera muerta o en médula de ramas) por otro. La baja frecuencia de capturas de especies de otras categorías (Parasitoides y Amasadoras) nos llevó a eliminarlas. En segundo lugar, atendiendo al orden a que pertenecían las presas capturadas por cada especie de avispa, se establecieron 7 categorías diferentes (Anexo I). Las categorías establecidas fueron: 1) Araneida; 2) Orthoptera; 3) Homoptera; 4) Heteroptera; 5) Larvas de Lepidoptera ; 6) Diptera; 7) "Otros" (Blattodea, Mantodea, Psocoptera, Thysanoptera, Coleoptera e Hymenoptera -adultos y larvas-). El porcentaje resultante excede de 100 debido a que existen especies que pertenecen a varias categorías al mismo tiempo (Anexo I). La clasificación seguida fue la de Pulawski (2009) - $\underline{\text { ANEXO I-- }}$ 


\section{Resultados}

Se capturaron un total de 10.896 individuos pertenecientes a 141 especies (Anexo I). De ellas, 47 especies $(33,33 \%$ del total) estuvieron representadas por < 5 individuos, 18 especies (12,76\%) por uno sólo (singletons) y 23 (16,3\%) se muestrearon únicamente en una localidad.

El número de especies fue mayor en la zona quemada que en las zonas Control, $y$, al igual que la diversidad de especies (índice de Shannon), mostró una respuesta curvilínea en la que tras presentar valores elevados el primer año tras el fuego, se produjo un descenso continuado hasta alcanzar el mínimo en el cuarto-quinto año, iniciándose entonces una recuperación; los valores iniciales sólo se superaron a partir del octavo-noveno año post-fuego (Cruz-Sánchez et al., 2009, en prep.).

Los 4 primeros ejes del PCA explicaron un 75,6\% de la varianza total de las especies en la comunidad, encontrándose la mayor parte de la misma representada en los ejes 1 y 2 (Tabla IV).

Tabla IV: Análisis de Componentes Principales (PCA).

\begin{tabular}{lccccc}
\hline & Eje 1 & Eje 2 & Eje 3 & Eje 4 & $\begin{array}{c}\text { Varianza } \\
\text { Total }\end{array}$ \\
\hline Eigenvalores: & 0.291 & 0.228 & 0.14 & 0.097 & 1 \\
$\begin{array}{l}\text { Porcentaje de varianza acumulada para los datos de } \\
\text { las especies }\end{array}$ & 29.1 & 51.9 & 66 & 75.6 & \\
\begin{tabular}{l} 
Suma de todos los eigenvalores: \\
\hline
\end{tabular} & & & & & \\
\hline
\end{tabular}

El primer eje se encuentra relacionado con las condiciones climatológicas, año de muestreo, mientras que el segundo está determinado por la estructura del hábitat y su grado de recuperación, años post-fuego (Age). Este segundo eje captura también parte de la variación introducida por las variables cobertura arbórea, arbustiva, herbácea, altura arbustiva y suelo desnudo. La diferenciación de las zonas Control, no perturbadas, y la de mayor tiempo de recuperación (9 años post-fuego), con las zonas más recientemente quemadas fue la principal característica que definió la comunidad. Igualmente destacó la diferenciación observada del primer año después del fuego con el resto de comunidades. 
Las variables seleccionadas mediante la selección automática de Montecarlo (forward selection) fueron año de muestreo ( $25 \%$ de variación explicada, $\mathrm{F}=2,68, p=$ $0,002)$ y Age -años post-fuego- (22\% de variación explicada, $\mathrm{F}=2,97, p=0,004$ ) (Tabla V). El diagrama de ordenación correspondiente al RDA empleando las variables ambientales y las especies (con un fit range $\geq 50 \%$ ) está representado en la Fig. 1. Las dos variables consiguieron explicar un $47,4 \%$ de la varianza total de especies en la comunidad y el $100 \%$ de la varianza acumulada procedente de la relación entre las especies y el medio. El primer eje muestra una elevada correlación con la variable año de тиеstreo, mientras que el segundo está correlacionado con los años post-fuego (Age). Tanto el primer eje $(\mathrm{F}=2.348, p=0.008)$, como todos los ejes canónicos juntos $(\mathrm{F}=3.158, p=0.002)$ fueron significativos (test de Montecarlo, $\mathrm{p}=0.05)$.

Tabla V: Análisis de Redundancia (RDA).

\begin{tabular}{lccccc}
\hline & Eje 1 & Eje 2 & Eje 3 & Eje 4 & $\begin{array}{c}\text { Varianza } \\
\text { Total }\end{array}$ \\
\hline Eigenvalores: & 0.251 & 0.223 & 0.175 & 0.099 & 1 \\
Correlación entre las especies y el medio & 0.962 & 0.992 & 0 & 0 & \\
$\begin{array}{l}\text { Porcentaje de varianza acumulada para los datos } \\
\text { de las especies }\end{array}$ & 25.1 & 47.4 & 64.9 & 74.9 & \\
para la relación de las especies con el medio & 52.9 & 100 & 0 & 0 & \\
$\begin{array}{l}\text { Suma de todos los eigenvalores } \\
\text { Suma de todos los eigenvalores canónicos }\end{array}$ & & & & & 1 \\
\hline
\end{tabular}

La distribución de las especies, con un fit range $\geq 50 \%$ (Fig. 1), a lo largo de los ejes muestra una relación positiva entre las especies depredadoras de pulgones (Homoptera), que utilizan sustratos vegetales para nidificar, y la variable climática año de тиеstreo, frente a las nidificadoras en sustrato terrestre (terrícolas y ocupantes de cavidade terrestres -OCt-) y cazadoras de Orthoptera, que no guarda tanta relación con dicha variable. Las especies cazadoras de Blattodea y Mantodea se encuentran más relacionadas con Age (años post-fuego). 


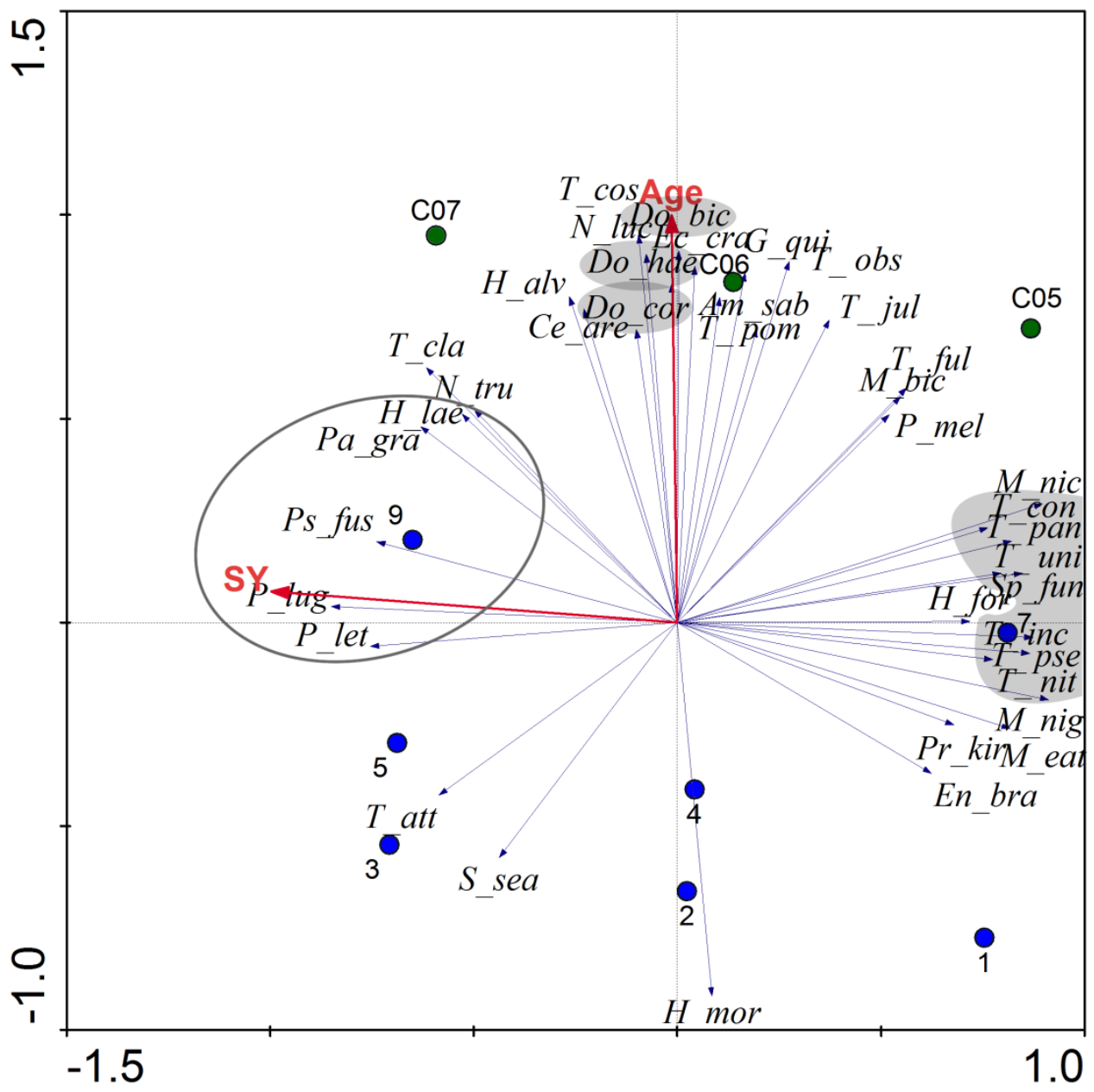

Fig. 1: Diagrama triplot, obtenido del Análisis de Redundancia (RDA), mostrando la correlación entre especies (fit range $\geq 50 \%$ ), localidades muestreadas y variables ambientales. En verde las muestras pertenecientes a los controles y en azul las muestras de las áreas quemadas. La longitud de las flechas indica la correlación entre las variables ambientales y los ejes de ordenación. Las flechas de color rojo representan las variables ambientales significativas y las líneas azules representan las especies. Rodeadas por una línea continua: Especies nidificadoras en sustratos vegetales y cazadoras de homópteros; Coloreadas de gris: Parte superior, especies depredadoras de blatodeos; Parte derecha, especies nidificadoras es sustratos terrestres (terrícolas y ocupantes de cavidades terrestres) y cazadoras de ortópteros. Las abreviaturas de las species son: H_mor, Harpactus morawitchi; S_sea, Solierella seabrai; T_att, Trypoxylon attenuatum; P_let, Pemphredon lethifer; P_lug, Pemphredon lugens; Ps_fus, Psenulus fuscipennis; Pa_gra, Passaloecus gracilis; H_lae, Harpactus laevis; $N \_t r u$, Nitela truncata; $T \_c l a, T r y p o x y l o n ~ c l a v i c e r u m ;$ Ce_are, Cerceris arenaria; H_alv, Harpactus alvaroi; Do_cor, Dolichurus corniculus; Do_hae, Dolichurus haemorrhous; N_luc, Nitela lucens; Do_bic, Dolichurus bicolor; T_cos_Tachysphex costae; Ec_cra, Ectemnius crassicornis; G_qui, Gorytes quinquefasciatus; T_obs, Tachysphex obscuripennis; Am_sab, Ammophila sabulosa; T_jul, Tachysphex julliani; T_pom, Tachysphex pompiliformis; T_ful, Tachysphex fulvitarsis; M_bic, Miscophus bicolor; P_mel, Palmodes melanarius; M_nic, Miscophus nicolai; T_con, Tachysphex consocius; T_pan; Tachysphex panzer; T_uni, Tachysphex unicolor; Sp_fun, Sphex funerarius; $H \_$for, Harpactus formosus; T_inc, Tachysphex incertus; T_pse, Tachysphex pseudopanzeri; T_nit, Tachysphex nitidior; M_nig, Miscophus niger; M_eat, Miscophus eatoni; Pr_kir, Prionyx kirbii; En_bra, Encopognathus braunsi.

\section{Dominancias}

En la Tabla VI se muestra la relación de especies eudominantes y dominantes para cada una de las muestras. 
Tabla VI.- Relación de las especies eudominantes, $\mathrm{N}>15 \%$ (casillas con el fondo gris) y dominantes, $\mathrm{N}=5 \%-15$ $\%$ (en negrita), y número de individuos de dichas especies (entre paréntesis) capturados en cada localidad. Se añade también el número de singletons (especies con un individuo) por muestra.

\begin{tabular}{|c|c|c|c|c|c|c|c|c|c|c|}
\hline \multirow[b]{3}{*}{ ESPECIES } & \multicolumn{10}{|c|}{ AÑOS POST-FUEGO } \\
\hline & \multicolumn{7}{|c|}{ FUEGO } & \multicolumn{3}{|c|}{ CONTROLES } \\
\hline & 1 & 2 & 3 & 4 & 5 & 7 & 9 & 13 & 14 & 15 \\
\hline Dolichurus bicolor & $\ldots$ & $\ldots$ & $0,17(1)$ & $\ldots$ & $0,39(2)$ & $\ldots$ & $0,23(3)$ & $5,15(62)$ & $4,62(54)$ & $3,13(27)$ \\
\hline Sphex funerarius & $4,67(102)$ & $3,74(32)$ & $3,81(23)$ & $11,82(100)$ & $5,5(28)$ & $5,16(71)$ & $2,33(30)$ & $8,13(98)$ & $7,19(84)$ & $3,71(32)$ \\
\hline Sphex leuconotus & $5,59(122)$ & $8,41(72)$ & $1,82(11)$ & 32,98 (279) & $3,73(19)$ & $2,62(36)$ & $0,31(4)$ & $4,65(56)$ & $11,04(129)$ & $1,16(10)$ \\
\hline Diodontus insidiosus & $1,37(30)$ & $6,43(55)$ & $2(12)$ & $3,31(28)$ & $3,93(20)$ & $1,02(14)$ & $1,63(21)$ & $1,58(19)$ & $1,63(19)$ & $2,78(28)$ \\
\hline Tachytes panzeri & $5,18(113)$ & $1,87(16)$ & $2,16(13)$ & $0,12(1)$ & $0,39(2)$ & $4,22(58)$ & $2,87(37)$ & $2,32(28)$ & $5,31(67)$ & $3,71(32)$ \\
\hline Tachysphex fulvitarsis & $1,24(27)$ & $0,7(6)$ & $1,82(11)$ & $1,3(11)$ & $1,38(7)$ & $5,74(79)$ & $2,64(34)$ & $4,48(54)$ & $2,65(31)$ & $3,25(28)$ \\
\hline Tachysphex incertus & $15,3(334)$ & $2,57(22)$ & $3,81(23)$ & $2,36(20)$ & $1,96(10)$ & $10,32(147)$ & $2,33(30)$ & $11,95(144)$ & $3,94(46)$ & $1,74(15)$ \\
\hline Tachysphex obscuripennis & $0,73(16)$ & $0,82(7)$ & $1(6)$ & $3,78(32)$ & $3,54(18)$ & $2,54(35)$ & $1,79(23)$ & $6,06(73)$ & $11,47(134)$ & $9,63(83)$ \\
\hline Tachysphex pseudopanzeri & $11,73(256)$ & $0,58(5)$ & $0,5(3)$ & $0,35(3)$ & $\ldots$ & $8,07(111)$ & $0,39(5)$ & $3,15(38)$ & $0,68(8)$ & $0,35(3)$ \\
\hline Solierella compedita & $2,47(54)$ & $15,77(135)$ & $15,26(92)$ & $7,57(64)$ & $17,88(91)$ & $9,16(126)$ & $25,39(327)$ & $11,95(144)$ & $6,42(75)$ & $6,73(58)$ \\
\hline Miscophus nicolai & $2,43(53)$ & $1,64(14)$ & $0,83(5)$ & $1,18(10)$ & $1,96(10)$ & $2,62(36)$ & $0,62(8)$ & $5,48(66)$ & $2,65(31)$ & $1,74(15)$ \\
\hline Trypoxylon attenuatum & $3,85(84)$ & $2,69(23)$ & $14,26(86)$ & $2,72(23)$ & $18,47(94)$ & $1,45(20)$ & $11,96(154)$ & $0,75(9)$ & $0,34(4)$ & $7,19(62)$ \\
\hline Trypoxylon scutatum & $12,28(268)$ & $19,63(168)$ & 19,73 (119) & $3,55(30)$ & $9,23(47)$ & $7,78(107)$ & $8,7(112)$ & $3,82(46)$ & 3,94 (46) & $7,54(65)$ \\
\hline Bembecinus pulchellus & $11,64(254)$ & $1,4(12)$ & $1,82(11)$ & $\ldots$ & $\ldots$ & $16,57(228)$ & $8,15(105)$ & $3,57(43)$ & $0,43(5)$ & $0,81(7)$ \\
\hline Singletons & 19 & 25 & 21 & 26 & 11 & 18 & 25 & 16 & 17 & 23 \\
\hline
\end{tabular}

Seis de las 15 especies que fueron eudominantes o dominantes en alguna de las muestras, contribuyeron a definir la comunidad según el RDA mostrado previamente (Fig. 1).

De las 78 especies capturadas el primer año tras el fuego, sólo 6 (nidificadoras en sustrato terrestre y cazadoras de Orthoptera en su mayoría) fueron eudominantes o dominantes, y cuatro de ellas perdieron esta categoría, o desaparecieron, hasta recuperarla el quinto año después del fuego, e incluso más tarde.

Tachysphex incertus fue la única especie eudominante el primer año. En los años posteriores sólo llegó a ser dominante a los siete años después del fuego y en el Control equivalente al año trece. De las cuatro especies capturadas del género Sphex, sólo dos alcanzaron posiciones de dominancia: S. leuconotus y S. funerarius, aunque generalmente a distintas edades post-fuego. Trypoxylon attenuatum y Trypoxylon scutatum también presentaron diferencias en cuanto a sus valores de dominancia en función de las edades post-fuego. Solierella compedita fue la única especie que se mostró dominante durante toda la fase de recuperación post-fuego, a excepción del primer año.

Tres de las cuatro especies dominantes en el Control equivalente al año quince después del fuego, son depredadoras de Araneida o Blattodea. 
Existieron tres especies, depredadoras de Araneida o Blattodea, que solamente expresaron valores de dominancia en zonas Control: Dolichurus bicolor, Miscophus nicolai y Tachysphex obscuripennis, siendo esta última la única que mantuvo su dominancia en los tres años en que se muestrearon las zonas Control (Tabla VI).

Se capturaron 34 especies exclusivas de áreas quemadas y 6 de zonas sin quemar (Anexo II), si bien ninguna de ellas sobrepasó la categoría de subdominante.

\section{Composición gremial de la comunidad}

Considerando el número de especies pertenecientes a los diferentes gremios, no se encontraron diferencias significativas ni para el tipo de sustrato de nidificación (Test de Chi-cuadrado, $\left.\mathrm{X}_{9}^{2}=6.7, p=0,672\right)$ ni para el tipo de presas capturadas para alimentar a la progenie (Test de Chi-cuadrado, $\mathrm{X}^{2}{ }_{54}=28,03, p=0,999$ ).

Respecto al número de individuos se observó: 1) Mayor abundancia de individuos pertenecientes a especies que nidifican en el suelo el primer año después del fuego, y menor de las nidificantes en sustratos vegetales; 2) Aumento casi generalizado de nidificantes en la vegetación durante los años posteriores al fuego, a excepción de los años 4 y 7, donde abundaron más los nidificadores en sustratos terrestres; 3) menor presencia, en las zonas Control, de individuos pertenecientes a especies que utilizan sustratos vegetales para nidificar, a excepción del correspondiente al año 15 tras el fuego; 4) mayor número de individuos que depredan sobre Orthoptera el primer año después del incendio, frente al descenso de las que lo hacen sobre el resto de grupos analizados; 5) atendiendo al número de depredadores sobre Orthoptera y Araneida, estos reflejaron los resultados obtenidos para el tipo de nidificación, puesto que la mayor parte de las especies que depredan sobre los primeros nidifican en el suelo, y las que lo hacen sobre Araneida lo hacen sobre la vegetación 6) bajo número de individuos depredadores de Heteroptera durante los primeros años post-fuego y en las zonas Control, frente a un mayor número en fases intermedias; 7) el grupo denominado “Otros” presentó valores positivos únicamente en las zonas recuperadas (Control). 
Tabla VII. - Resultados del análisis Chi-cuadrado para el tipo de sustrato de nidificación y presas capturadas (Age: Años post-fuego; NS: no significativo, (-): menos de los esperados, (+): más de los esperados, ${ }^{*} \mathrm{p}<0,05, * * \mathrm{p}<0,01$, *** $\mathrm{p}<0,001$; valor crítico de z corregidos siguiendo a Legendre \& Legendre (1998) para evitar el problema de comparaciones múltiples). VII a: Tipo de nidificación. VII b: Tipos de presas

a) $\mathbf{N}^{\circ}$ Individuos y tipo de nidificación

\begin{tabular}{lccc} 
& Age & TE + OCt & OCv + XR \\
\hline \multirow{4}{*}{ FUEGO } & $\mathbf{1}$ & $(+)^{* * *}$ & $(-)^{* * *}$ \\
& $\mathbf{2}$ & $\mathrm{NS}$ & $(+)^{* * *}$ \\
& $\mathbf{3}$ & $(-)^{* * *}$ & $(+)^{* * *}$ \\
& $\mathbf{4}$ & $(+)^{* * *}$ & $(-)^{* * *}$ \\
& $\mathbf{5}$ & $(-)^{* * *}$ & $(+)^{* * *}$ \\
& $\mathbf{7}$ & $(+)^{* *}$ & $(-)^{* * *}$ \\
CONTROL & $\mathbf{9}$ & $(-)^{* * *}$ & $(+)^{* * *}$ \\
& $\mathbf{1 3}$ & $(+)^{* *}$ & $(-)^{* * *}$ \\
& $\mathbf{1 4}$ & $\mathrm{NS}$ & $(-)^{* * *}$ \\
\hline
\end{tabular}

TE: Terricolas; OCt: Ocupantes de Cavidades terrestres; OCv: Ocupantes de Cavidades Vegetales; XR: Xilícolas y Rubícolas.

b) $\mathbf{N}^{\circ}$ Individuos y tipo de presas capturadas

\begin{tabular}{|c|c|c|c|c|c|c|c|c|}
\hline & Age & Ar & Or & Ho & He & Lel & Di & Otros \\
\hline \multirow{7}{*}{ FUEGO } & 1 & NS & $(+)^{* * *}$ & NS & $(-)^{* * *}$ & $(-)^{*}$ & NS & $(-)^{* * *}$ \\
\hline & 2 & $(+)^{* * *}$ & $(-)^{* *}$ & NS & $(-)^{* *}$ & NS & NS & $(-)^{* * *}$ \\
\hline & 3 & $(+)^{* * *}$ & $(-)^{* * *}$ & NS & $(-)^{* * *}$ & NS & NS & NS \\
\hline & 4 & $(-)^{* * *}$ & $(+)^{* * *}$ & $(-)^{* * *}$ & NS & $(+)^{* *}$ & $(-)^{* *}$ & NS \\
\hline & 5 & $(+)^{* * *}$ & $(-)^{* * *}$ & NS & $(+) * * *$ & NS & $\mathrm{NS}$ & NS \\
\hline & 7 & $(-)^{* *}$ & $(+)^{* * *}$ & $(+)^{* * *}$ & NS & NS & $(-)^{* *}$ & $(-)^{* *}$ \\
\hline & 9 & $(-)^{* *}$ & $(-)^{* * *}$ & $(+)^{* *}$ & $(+) * * *$ & NS & NS & $(-)^{* *}$ \\
\hline \multirow{3}{*}{ CONTROL } & 13 & $(-)^{* *}$ & $(+)^{*}$ & $(-)^{* * *}$ & NS & $(-)^{* *}$ & NS & $(+)^{* * *}$ \\
\hline & 14 & $(-)^{* * *}$ & NS & $(-)^{* * *}$ & $(-)^{* * *}$ & NS & NS & $(+)^{* * *}$ \\
\hline & 15 & NS & $(-)^{* * *}$ & NS & $(-)^{* *}$ & $(+)^{* * *}$ & $(-)^{* * *}$ & $(+)^{* * *}$ \\
\hline
\end{tabular}

Ar: Araneida; Or: Orthoptera; Ho: Homoptera; He: Heteroptera; Lel.- Larvas de Lepidoptera, Di.- Diptera; Otros: Blattodea; Ninfas de Mantodea; Psocoptera; Thysanoptera; Coleoptera; Hymenoptera y Larvas de Hymenoptera.

\section{Discusión}

La supervivencia de los insectos al fuego guarda relación con los parámetros que definen el régimen del mismo (Whelan, 1995; Bond \& van Wilgen, 1996), con la localización en la que se encuentran los individuos en el momento en que ocurre el 
suceso perturbador y con su movilidad, dependiente del estado de desarrollo en el que se hallen (huevo, larva o ninfa, pupa, adulto) (Swengel, 2001 y Nunes et al., 2000 para una revisión). En nuestro caso, sin olvidar que nuestras zonas Control también habían estado sometidas a la acción del fuego debido a la gran presencia histórica del mismo, pudieron ser varias las causas por las que se registró un mayor número de especies en las zonas quemadas que en las Control, entre las que destacan: a) una gran supervivencia in situ, debido a la existencia de parches sin quemar (obs. per.) dentro del área perturbada (pequeños viñedos labrados, superficies de roca madre desnuda, pequeños prados rodeados de muros de piedra que ejercieron de cortafuegos ante el avance de las llamas) que actuaron como refugio, en un primer momento, y como fuente de especies para colonizar el área incendiada con posterioridad (Panzer, 2003; SaintGermain et al., 2004; Swengel \& Swengel, 2007); b) la época en que se produjeron los incendios, coincidente con la fase móvil de los adultos, y en pleno proceso de construcción y aprovisionamiento (o finalización) del nido por parte de muchas especies; esto les permitiría huir de las llamas y colonizar el nuevo ambiente con relativa rapidez (Hall \& Schweitzer, 1992; Moretti et al., 2004, 2006), ya que los animales alados son los primeros en recuperarse tras sufrir una perturbación, gracias a su gran capacidad de desplazamiento (Lamotte, 1975 y Moretti et al. 2004, 2006); c) el tipo de incendios (ver Material y Métodos), que permite la supervivencia de las fases inmóviles en el interior de los nidos construidos en el suelo, o en la vegetación existente en los parches sin quemar, como ocurre para otros grupos (Swengel, 2001).

Estos resultados denotan un alto grado de supervivencia y de colonización del nuevo ambiente, además de una gran habilidad de acceso y aprovechamiento de los recursos existentes (tróficos, de espacio o de luz), tras la actuación del fuego, por parte de los Spheciformes. Los nuevos recursos resultan de la alteración sufrida por la cobertura arbórea y arbustiva, de su debilitamiento o eliminación y del aumento de la calidad y diversidad de herbáceas (Harper et al. 2000; Panzer, 2003; Campbell et al, 2007; Breece, 2008), así como de los recursos alimenticios ofrecidos por éstas y por los herbívoros que se alimentan de ellas. Como ya indicaran Potts et al. (2003), el volumen, concentración y calidad de néctar son mayores inmediatamente después del fuego y descienden a lo largo del proceso de recuperación. Se sabe que el fuego también puede afectar indirectamente a las comunidades de artrópodos, cambiando la composición de las especies de plantas, sus características foliares y su fenología (Mitchell 1990). Por 
otro lado, puesto que los nutrientes minerales y el régimen de luz son mejores en las áreas quemadas que en las que no lo han sido, muchos son los autores que dan como resultado un aumento de la magnitud del crecimiento y floración después de un incendio (Rundel, 1981; Moretti, et al., 2002b), así como de las características nutricionales de la vegetación rebrotante tras el fuego (Radho-Toly et al., 2001; Potts et al., 2003), que variará de unas especies a otras en función de sus estrategias para regenerarse (SauraMas \& Lloret, 2009). Todos estos cambios pueden alterar las pautas de alimentación de los herbívoros (Knight \& Holt, 2005), y por consiguiente de sus depredadores, de manera que los primeros se verán atraídos por esa vegetación rebrotante de mayor calidad, mientras que los depredadores se verían a su vez atraídos por los herbívoros. En este caso, al igual que apuntaran Campbell et al. (2007), para zonas sometidas a control mecánico de los arbustos, mas fuego prescrito, el aumento de Spheciformes podría ser debido al aumento de polen y néctar para los adultos y al incremento de presas disponibles para alimentar a las larvas.

El conjunto de habilidades de supervivencia y acceso al nuevo ambiente creado, es lo que determinará el éxito colonizador de cada especie, su abundancia relativa y la estructura de la comunidad tras el impacto. En este caso, la estructura de la comunidad se encuentra muy influida por las variables año de muestreo (SY) and Age (Fig. 1). La primera de ellas está muy relacionada con las condiciones climatológicas existentes en la zona analizada. Dichas condiciones se mostraron muy diferentes de un año a otro, lo que sin duda influyó en la cantidad y estructura de la vegetación y, por consiguiente, en las comunidades de Spheciformes dependientes de ella. Así, con datos del Instituto Nacional de Meteorología, los años 2005 y 2007, con valores de precipitación media de 345,6 y 426,2 mm/año, respectivamente, se calificaron como secos, mientras que el año 2006 (714,8mm/año) fue considerado normal (ver Material \& Métodos); el año 2005 además estuvo precedido por otro año igualmente seco. Estas variaciones climatológicas se manifiestan en el primer eje del RDA (Fig. 1), separando claramente dos grupos: uno muy relacionado con el año de muestreo (SY), constituido fundamentalmente por especies nidificadoras en sustratos vegetales y cazadoras de pulgones (Homoptera), y un grupo más amplio, compuesto por especies ground-nesting y depredadoras de Orthoptera, que se mostraron poco relacionadas con año de muestreo (SY) y "favorecidas" por las condiciones de sequía y xericidad existentes durante el primer año de muestreo (2005). La formación del primer grupo vino determinada por una mayor 
disponibilidad de sustratos vegetales para nidificar, tanto el año 2006 (con una mayor precipitación), como el 2007 (ya que la vegetación del año 2006 acogería los nidos de muchas de las especies capturadas en 2007). Por otro lado, la vegetación que crece en áreas quemadas, habría servido de alimento para sus presas potenciales (áfidos) que llegan a ser muy abundantes tras el fuego (Arnán et al., 2007). El segundo grupo, con especies nidificadoras en sustratos terrestres y depredadoras de Orthoptera, se vio influido probablemente por dos factores:

1) a mayor sequía menor cantidad de vegetación, y por lo tanto mayor disponibilidad de suelo desnudo potencialmente apto para nidificar. El primer año de muestreo (2005) fue también el primer año post-fuego, de modo que las especies que requieren un alto grado de insolación para vivir (O’Neill, 2001), se verían favorecidas también por las condiciones ambientales post-fuego (elevadas temperaturas, xericidad y mayor cantidad de suelo desnudo), acrecentadas por la sequía. Todos estos datos apoyarían la hipótesis de Lamotte (1975), confirmada por Moretti et al. (2006, 2004), según la cual el ambiente post-fuego favorecería a la fauna dependiente del sol, insectos heliófilos y florícolas, como es el caso de los Spheciformes. La gran relación del primer año post-fuego con la formación de este grupo, quedó probada al observar que las tres especies que más contribuyeron a su definición, $S$. funerarius, $T$. incertus y $T$. pseudopanzeri formaban parte de las más abundantes registradas ese mismo año 2005.

2) una mayor presencia de Orthoptera sobre los que depredar. Bock \& Bock (1991) reportaron que, a pesar del descenso de la mayoría de las especies de saltamontes tras el paso del fuego, aquellas que tenían preferencia por el suelo desnudo fueron las más abundantes un año después del fuego. Por lo tanto, los Orthoptera pudieron sobrevivir al fuego (ocurrido en Octubre, Tabla I) en fase de huevo (Evans, 1988), viéndose favorecidos posteriormente por la mayor presencia de suelo desnudo y por la existencia de una vegetación rebrotante de mayor calidad nutritiva (Evans, 1988). Un cambio en el hábitat, que favorezca el aumento de presas, también favorecerá el de sus depredadores, de manera que este podría ser el motivo de hallar más especies cazadoras de Orthoptera en el primer año post-fuego (tal como ya sugirieran Niwa \& Peck (2002) para Araneae y Carabidae, y Campbell et al. (2007) para Sphecidae).

En cualquier caso, estas dos suposiciones deben ser tomadas con precaución, debido a que la mayoría de las especies depredadoras de Orthoptera nidifican en el 
suelo, lo que hace que la significación de los individuos nidificantes en sustratos terrestres sea corroborada por los depredadores de Orthoptera, y viceversa.

El paso de los años de recuperación (Age), a pesar de su importancia en la estructuración de la comunidad, no mostró un patrón definido en cuanto al tipo de nidificación empleado por las especies que la definieron, pero sí en cuanto al tipo de presas capturadas por las mismas. De esta manera, las especies depredadoras de Blattodea parecen verse favorecidas por el paso de los años después del fuego (Fig. 1), seguramente por la preferencia de sus presas por hábitats con una mayor presencia de vegetación.

\section{Dominancia y composición gremial de la comunidad}

Los cambios locales en las condiciones ambientales que siguen a una perturbación, tienden a modificar el balance competitivo entre especies, permitiendo una redistribución de su dominancia (Begon et al., 2006) al alterar tanto su número como su abundancia relativa. Se favorece así a unas especies frente a otras (Niwa \& Peck, 2002; Fernández \& Salgado, 2004; Moretti et al., 2004) en función de sus adaptaciones específicas, y como resultado del equilibrio dinámico entre el desplazamiento competitivo y la perturbación (Huston, 1994).

T. incertus se mostró como la especie más resistente al fuego (o la mejor colonizadora), al registrar el mayor número de individuos el primer año tras el incendio (Tabla VI, Anexo I). Al mismo tiempo, demostró ser una especie con unos requerimientos muy específicos en cuanto a condiciones climatológicas se refiere, ya que únicamente se mostró dominante en las muestras obtenidas el año 2005, llegando incluso a desaparecer en alguna de las pertenecientes a los otros dos años de muestreo. Lo mismo sucedió para la especie Trypoxylon attenuatum, esta vez dominante exclusivamente en las capturas del tercer año de muestreo (2007) (Tabla VI). Ambas especies contribuyeron en el modelo resultante del RDA (Fig.1).

De las cuatro especies capturadas del género Sphex, solamente $S$. funerarius y $S$. leuconotus fueron dominantes, a pesar de que el resto de especies de Sphex presentan requerimientos ecológicos muy similares (Tabla VI, Anexo I). S. leuconotus mostró una mayor capacidad de resistencia al fire (o una habilidad superior para recolonizar o 
adaptarse al nuevo escenario creado), ya que presentó una clara posición de dominancia frente a $S$. funerarius hasta el cuarto año post-fuego, momento a partir del cual, y tras alcanzar la categoría de eudominante, se vio claramente superada por S. funerarius, quien pareció adquirir cierta ventaja sobre ella en las fases intermedias de la recuperación post-fuego.

Al igual que en el caso anterior, dos de las cinco especies capturadas de Trypoxylon dominaron sobre el resto, manifestando también cierta competencia y desplazamientos entre ellas. Así, tras el fuego, T. scutatum desplazó a T. attenuatum, al adquirir cierta ventaja sobre esta última y alcanzar un mayor crecimiento, derivado de la simplificación del hábitat y de su habilidad para ocupar cavidades preexistentes, tanto en sustratos vegetales como terrestres. Estos datos corroboran los obtenidos por CruzSánchez et al., (2009, in prep.) en los que T. attenuatum únicamente manifestó ventaja sobre T. scutatum cuando el hábitat mostraba un alto grado de madurez (bosque cerrado). En este caso, salvo determinadas excepciones (ver Tabla VI), T. scutatum mantuvo siempre valores superiores a $T$. attenuatum, posiblemente debido al tipo de hábitat, abierto y aclarado, que presentaban los Controles, de características muy diferentes a las de un bosque cerrado. Por otro lado, Niwa \& Peck (2002) y Urones \& Majadas (2002), hallaron que tras el fuego, se producía una variación en la comunidad de arañas, de manera que las especies tejedoras de telas, sin lugar donde anclar la tela, eran sustituidas por especies con una caza más activa, favorecidas por la simplificación del hábitat quemado y por una mayor cantidad de hormigas. Esta variación en la composición de la comunidad de arañas tras el fuego, podría ser otra de las causas del cambio de dominancia entre las dos especies de Trypoxylon mencionadas anteriormente. Así, T. scutatum podría estar más especializado en la captura de arañas epigeas, mientras que $T$. attenuatum depredaría preferentemente sobre arañas epífitas y constructoras de telas, más abundantes a medida que avanza el periodo de regeneración y se recupera la vegetación. En este sentido, Asís et al. (1994) reportaron que de hecho, T. attenuatum tenía preferencia por la captura de arañas constructoras de telas (63\% de un total de 231 presas registradas), citando asimismo que una de las familias más abundantes, en cuanto al número de individuos capturados por las hembras de la avispa, era la familia Thomisidae $(26,8 \%)$, que a pesar de no construir telas también pueden ser clasificadas como epífitas, ya que basan su estrategia depredadora en acechar sobre hojas y flores. Por otra parte, Tomé (2006) observó una mayor eficiencia de captura de 
T. attenuatum en trampas de nidificación (cañas), mientras que las capturas de $T$. scutatum se registraban principalmente en trampas Moericke, colocadas en el suelo. Esto podría ser indicativo tanto del tipo de nidificación llevado a cabo, como del tipo de desplazamiento realizado por estas dos especies en busca de sus presas, ya sea sobre la superficie del suelo para arañas epigeas, en el caso de $T$. scutatum, o sobre la vegetación, para las arañas epífitas, en el caso de T. attenuatum.

A medida que avanzó el periodo de recuperación, las especies dominantes pasaron de ser depredadoras de Orthoptera, a depredadoras de Blattodea y ninfas de Mantodea, de manera que para el Control correspondiente al año 15 después del fuego, tres de las cuatro especies dominantes depredaban sobre dichos grupos, generalmente más abundantes en zonas con una mayor cantidad de vegetación y estructura más desarrollada. De ellas, Tachysphex obscuripennis (depredadora de Blattodea), fue la única especie dominante, de manera exclusiva, en las tres muestras pertenecientes a los Controles, con una gran diferencia cuantitativa respecto a las áreas quemadas, lo que denotaría su predilección por fases más tardías de la recuperación. Destacó igualmente el hecho de que Dolichurus bicolor (depredadora de Blattodea), muy relacionada con la variable Age (Fig. 1) y mínimamente representada en las áreas quemadas, fuese dominante el año trece después del fuego, a pesar de perder esta categoría en los años posteriores para convertirse en subdominante.

Solierella compedita, a pesar de ver su número reducido el primer año tras el incendio, demostró ser la especie más adaptada y con mayor capacidad de recuperación ante este tipo de perturbaciones, al mostrarse como eudominante en una gran parte de los años que siguieron al impacto, si bien se apreció un cierto descenso en las últimas fases de recuperación (años 13 y 14 después del fuego). Se trata de una especie nidificante tanto en el suelo como en sustratos vegetales (Anexo I), lo que le habría proporcionado una ventaja sobre el resto de especies, al poder alternar el uso de uno u otro recurso en función de su disponibilidad.

De todas las especies exclusivas, tanto de las zonas quemadas, como de las Control, ninguna de ellas fue dominante en las muestras obtenidas, y solamente Encopognathus braunsi y Harpactus morawitzi participaron en el modelo obtenido por RDA para las especies con un fit range $>50 \%$. 
Potts et al. (2005) mostraron cómo la estructura de la comunidad y la abundancia relativa de especies de abejas está influida por la variación en la disponibilidad de recursos viables para la nidificación a lo largo del periodo de recuperación post-fuego, destacando la disponibilidad de suelo desnudo y potenciales cavidades de nidificación, además de otros factores como la abundancia de plantas con médula y la existencia de cavidades preexistentes, entre otras. Según los datos obtenidos para la composición gremial de la comunidad, el número de especies capturadas siguió el patrón global mostrado por las especies existentes en la Península Ibérica, tanto para el tipo de nidificación como para el de presas capturadas, no detectándose ningún cambio significativo. Sin embargo, no sucedió lo mismo con las abundancias: el primer año tras el incendio, se registró una mayor abundancia de individuos pertenecientes a especies que nidifican en el suelo, y menor de las que lo hacen sobre sustratos vegetales (Tabla VIIa), siendo potenciales nidificadoras en sustratos terrestres las cinco especies dominantes el primer año tras la perturbación (Tabla VI). Estos datos coinciden con los obtenidos por Potts et al. (2005), quienes hallaron la mayor abundancia de abejas nidificadoras en el suelo en las áreas recién quemadas. Esto podría deberse a que, tras el incendio, la cobertura vegetal de herbáceas y arbustos fue eliminada, incrementándose el porcentaje de suelo desnudo.

El aumento casi generalizado del número de nidificantes en la vegetación, a partir del primer año, frente al descenso de individuos nidificantes en sustratos terrestres, puede atribuirse al rebrote y crecimiento de la vegetación, que conllevaría un descenso del porcentaje de suelo desnudo según avanza el proceso de recuperación $\left(F_{1,8}=15,239, \mathrm{R}_{\text {ajustado }}^{2}=0,613, \operatorname{Pr}>F=0,005\right.$ para $\left.\mathrm{P}<0,05\right)$.

Los años 4 y 7 sin embargo, registraron un número más elevado de nidificantes en sustrato terrestre; esto se corresponde con una gran abundancia de especies como $S$. funerarius y S. leuconotus, que sumaron el 44,8\% de las capturas del cuarto año, y de T. incertus, S. compedita, y B. pulchellus, que sumaron el 36,04 \% para el séptimo año. También llama la atención la mayor cantidad de nidificantes en sustrato terrestre en uno de los Controles (13 años post-fuego). Ello pudo deberse de nuevo a la mayor presencia de presas, ya que en esta localidad, solamente 7 especies sumaron el 52,7 \% del total de las capturas, de las que el 11,4\% pertenecieron T. obscuripennis y M. nicolai, cazadoras de Blattodea y Araneida, respectivamente, mientras que el resto correspondieron a cazadores de Orthoptera (S. funerarius, S. leuconotus, T. fulvitarsis, T. incertus -29,3\%- 
) y de Heteroptera (S. compedita -12\%-), cuyas presas serían capturadas en prados cercanos al lugar de colocación de las trampas Malaise.

El aumento de depredores de Orthoptera el primer año post-fuego corrobora la significación de los nidificantes en sustrato terrestre, ya que la mayoría de estas especies depredan sobre Orthoptera. Destaca igualmente la elevada presencia de individuos depredadores de Homoptera y Araneida, debido a la gran abundancia de Bembecinus pulchellus y T. scutatum (Tabla VI, Anexo I).

También llama la atención el hecho de que los individuos pertenecientes al grupo "Otros" presentaran valores superiores a los esperados únicamente en las zonas Control, lo que sin duda se debe a la inclusión en el mismo de los depredadores de Blattodea y ninfas de Mantodea, entre otros (ver Material y Métodos, Anexo I).

\section{Conclusión}

Los resultados obtenidos muestran cómo las comunidades de Spheciformes, que poseen una gran capacidad de supervivencia ante este tipo de perturbaciones en hábitats aclarados mediterráneos, sufren una desestructuración, que se manifiesta en modificaciones de las abundancias relativas de las especies y en variaciones en la abundancia de la estructura de gremios de la comunidad. Se producen desplazamientos de unas especies frente a otras en función de las condiciones locales del hábitat. La variación en estas condiciones se refleja en la mayor o menor presencia de recursos (alimenticios, de nidificación y de presas para alimentar a las larvas) y deriva tanto de las cambiantes condiciones climatológicas, como del paso del tiempo desde el impacto.

El cambio en la estructura de la comunidad no puede ser atribuido de manera concluyente al efecto del fuego, ya otro de los factores analizados, el año de muestreo, parece tener una influencia mayor sobre estas comunidades. 
Anexo 1: Abundancias de las especies capturadas. Clasificación según Pulawski, 2009:

www.calcademy.com/research/entomolgy/Entomology_Resources/Hymenoptera/sphecidae. Tipo de nidificación: TE:

Terricolas; OCt: Ocupantes de Cavidades terrestres; OCv: Ocupantes de Cavidades Vegetales; XR: Xilícolas y Rubícolas. Presas capturadas. Ar: Araneida; Or: Orthoptera; Ho: Homoptera; He: Heteroptera; Lel.- Larvas de

Lepidoptera, Di.- Diptera; Bl: Blattodea; Man: Ninfas de Mantodea; Ps: Psocoptera; Th: Thysanoptera; Co:

Coleoptera; Hy: Hymenoptera; Hyl Larvas de Hymenoptera.

Localidades de muestreo

FUEGO CONTROL

\begin{tabular}{|c|c|c|c|c|c|c|c|c|c|c|c|c|}
\hline spp/Age (Años post-fuego) & 1 & 2 & 3 & 4 & 5 & 7 & 9 & 13 & 14 & 15 & Nidific. & Presas \\
\hline $\begin{array}{l}\text { AMPULICIDAE Shuckard, } 1840 \\
\text { Ampulicinae Shuckard, 1840 } \\
\text { Ampulicini Shuckard, } 1840\end{array}$ & & & & & & & & & & & & \\
\hline Ampulex ruficollis Cameron, 1888 & $\ldots$ & $\ldots$ & $\ldots$ & 1 & $\ldots$ & $\ldots$ & $\ldots$ & $\ldots$ & $\ldots$ & $\ldots$ & $\mathrm{OCv}-\mathrm{XR}$ & $\mathrm{Bl}$ \\
\hline Dolichurus bicolor Lepeletier, 1845 & $\ldots$ & $\ldots$ & 1 & $\ldots$ & 2 & $\ldots$ & 3 & 62 & 54 & 27 & $\mathrm{~T}$ & $\mathrm{Bl}$ \\
\hline Dolichurus corniculus (Spinola, 1808) & $\ldots$ & $\ldots$ & $\ldots$ & 2 & $\ldots$ & $\ldots$ & 1 & 1 & 2 & 2 & $\mathrm{~T}$ & $\mathrm{~B} 1$ \\
\hline Dolichurus haemorrhous A. Costa, 1886 & $\ldots$ & $\ldots$ & $\ldots$ & $\ldots$ & $\ldots$ & $\ldots$ & $\ldots$ & 1 & 7 & 4 & $\mathrm{~T}$ & $\mathrm{~B} 1$ \\
\hline $\begin{array}{l}\text { SPHECIDAE Latreille, } 1802 \\
\text { Sceliphrinae Ashmead, } 1899 \\
\text { Sceliphrini Ashmead, } 1899\end{array}$ & & & & & & & & & & & & \\
\hline Chalybion femoratum (Fabricius, 1781) & $\ldots$ & $\ldots$ & $\ldots$ & $\ldots$ & $\ldots$ & $\ldots$ & 1 & $\ldots$ & $\ldots$ & $\ldots$ & $\mathrm{OCa}$ & $\mathrm{Ar}$ \\
\hline Sceliphron destillatorium (Illiger, 1807) & 1 & 6 & $\ldots$ & 1 & 4 & $\ldots$ & 3 & $\ldots$ & 2 & 4 & A & $\mathrm{Ar}$ \\
\hline \multicolumn{13}{|l|}{ Sphecinae Latreille, 1802} \\
\hline \multicolumn{13}{|l|}{ Sphecini Latreille, 1802} \\
\hline Sphex atropilosus Kohl, 1885 & 25 & 4 & 3 & 37 & 1 & 4 & $\ldots$ & 7 & 28 & 1 & $\mathrm{~T}$ & Or \\
\hline Sphex flavipennis Fabricius, 1793 & 4 & $\ldots$ & $\ldots$ & 4 & 5 & 6 & $\ldots$ & 6 & $\ldots$ & $\ldots$ & $\mathrm{T}$ & Or \\
\hline Sphex funerarius Gussakovskij, 1934 & 102 & 32 & 23 & 100 & 28 & 71 & 30 & 98 & 84 & 32 & $\mathrm{~T}$ & Or \\
\hline Sphex leuconotus Brullé, 1833 & 122 & 72 & 11 & 279 & 19 & 36 & 4 & 56 & 129 & 10 & $\mathrm{~T}$ & Or \\
\hline \multicolumn{13}{|l|}{ Pryonichini Bohart \& Menke, 1963} \\
\hline Palmodes melanarius (Mocsáry, 1883) & 3 & 1 & $\ldots$ & $\ldots$ & $\ldots$ & $\ldots$ & 1 & 12 & 5 & 1 & $\mathrm{~T}$ & Or \\
\hline Palmodes occitanicus (Roth, 1963) & 2 & 1 & 2 & 8 & 3 & $\ldots$ & 5 & 5 & 6 & 6 & $\mathrm{~T}$ & Or \\
\hline Chilosphex argyrius (Brullé, 1833) & 9 & 8 & 5 & 13 & 1 & 1 & 2 & 1 & 1 & 3 & $\mathrm{OCt}$ & Or \\
\hline Prionyx kirbii (Van der Linden, 1827) & 22 & 17 & 1 & 9 & $\ldots$ & 13 & 2 & 3 & 5 & 4 & $\mathrm{~T}$ & Or \\
\hline Prionyx subfuscatus (Dahlbom, 1845) & 7 & $\ldots$ & $\ldots$ & $\ldots$ & $\ldots$ & $\ldots$ & $\ldots$ & $\ldots$ & $\ldots$ & $\ldots$ & $\mathrm{T}$ & Or \\
\hline Prionyx viduatus (Christ, 1791) & 2 & $\ldots$ & $\ldots$ & $\ldots$ & $\ldots$ & 3 & $\ldots$ & $\ldots$ & $\ldots$ & $\ldots$ & $\mathrm{T}$ & Or \\
\hline \multicolumn{13}{|l|}{ Ammophilinae André, 1886} \\
\hline \multicolumn{13}{|l|}{ Ammophilini André, 1886} \\
\hline Ammophila campestris Latreille, 1809 & 13 & 8 & 6 & 27 & 9 & 19 & 6 & $\ldots$ & 13 & 17 & $\mathrm{~T}$ & Hyl-Lel \\
\hline Ammophila heydeni Dahlbom, 1845 & 11 & 24 & 12 & 7 & $\ldots$ & 10 & 8 & 8 & 26 & 41 & $\mathrm{~T}$ & Lel \\
\hline Ammophila hungarica Mocsáry, 1883 & 6 & 2 & 1 & 10 & 7 & 2 & 2 & 1 & 1 & $\ldots$ & $\mathrm{T}$ & Lel \\
\hline Ammophila laevicollis André, 1886 & 3 & 1 & 1 & $\ldots$ & $\ldots$ & $\ldots$ & $\ldots$ & $\ldots$ & 2 & 1 & $\mathrm{~T}$ & Lel \\
\hline Ammophila sabulosa (Linnaeus, 1758) & $\ldots$ & $\ldots$ & $\ldots$ & 1 & $\ldots$ & $\ldots$ & 1 & 2 & 4 & 1 & $\mathrm{~T}$ & Lel \\
\hline Podalonia hirsuta (Scopoli, 1763) & 1 & $\ldots$ & $\ldots$ & $\ldots$ & 2 & $\ldots$ & $\ldots$ & $\ldots$ & 2 & 2 & $\mathrm{~T}$ & Lel \\
\hline $\begin{array}{l}\text { CRABRONIDAE Latreille, } \mathbf{1 8 0 2} \\
\text { Pemphredoninae Dahlbom, } 1835 \\
\text { Psenini Costa, } 1858\end{array}$ & & & & & & & & & & & & \\
\hline Psenulus fuscipennis (Dahlbom, 1843) & 4 & 10 & 25 & 1 & 8 & 1 & 12 & 3 & 11 & 23 & $\mathrm{OCv}$ & Ho \\
\hline Mimesa grandii Maidl, 1933 & $\ldots$ & $\ldots$ & 1 & $\ldots$ & $\ldots$ & $\ldots$ & 5 & $\ldots$ & 4 & $\ldots$ & $\mathrm{T}$ & Ho \\
\hline \multicolumn{13}{|l|}{ Pemphredonini Dahlbom, 1835} \\
\hline Diodontus insidiosus Spooner, 1938 & 30 & 55 & 12 & 28 & 20 & 14 & 21 & 19 & 19 & 24 & $\mathrm{~T}$ & Ho \\
\hline Pemphredon lethifer (Shuckard, 1837) & $\ldots$ & 2 & 1 & 6 & 5 & $\ldots$ & 3 & $\ldots$ & 1 & 3 & $\mathrm{OCv}-\mathrm{XR}$ & Ho \\
\hline Pemphredon lugens Dahlbom, 1842 & $\ldots$ & $\ldots$ & 1 & $\ldots$ & 2 & $\ldots$ & 1 & $\ldots$ & $\ldots$ & 1 & XR & Ho \\
\hline Pemphredon mortifer Valkeila, 1972 & $\ldots$ & $\ldots$ & 1 & $\ldots$ & 1 & $\ldots$ & $\ldots$ & $\ldots$ & $\ldots$ & $\ldots$ & XR & Ho \\
\hline Passaloecus gracilis (Curtis, 1834) & $\ldots$ & 1 & 3 & $\ldots$ & 2 & $\ldots$ & 5 & 3 & 1 & 4 & OCV-XR & Ho \\
\hline Passaloecus pictus Ribaut, 1952 & 1 & 7 & 9 & 1 & 2 & 1 & 29 & $\ldots$ & 3 & 2 & $\mathrm{~T}$ & Ho \\
\hline Passaloecus vandeli Ribaut, 1952 & $\ldots$ & $\ldots$ & $\ldots$ & $\ldots$ & $\ldots$ & $\ldots$ & 2 & $\ldots$ & $\ldots$ & 1 & $\mathrm{OCv}-\mathrm{XR}$ & Ho \\
\hline Ammoplanus ceballosi Giner Marí, 1943 & 19 & 20 & 25 & 5 & 1 & 12 & 5 & $\ldots$ & 26 & 9 & $\mathrm{OCv}-\mathrm{OCt}$ & $\mathrm{Th}$ \\
\hline Ammoplanus gegen Tsuneki, 1972 & $\ldots$ & $\ldots$ & $\ldots$ & $\ldots$ & $\ldots$ & $\ldots$ & $\ldots$ & $\ldots$ & 1 & $\ldots$ & $\mathrm{OCv}-\mathrm{OCt}$ & Th \\
\hline Ammoplanus perrisi Giraud, 1869 & 3 & $\ldots$ & $\ldots$ & $\ldots$ & $\ldots$ & $\ldots$ & $\ldots$ & $\ldots$ & $\ldots$ & $\ldots$ & $\mathrm{OCv}-\mathrm{OCt}$ & Th \\
\hline Ammoplanus torresi Gayubo, 1991 & $\ldots$ & 1 & $\ldots$ & $\ldots$ & $\ldots$ & $\ldots$ & $\ldots$ & $\ldots$ & 2 & $\ldots$ & $\mathrm{OCv}-\mathrm{OCt}$ & $\mathrm{Th}$ \\
\hline \multicolumn{13}{|l|}{ Astatinae Lepeletier, 1845} \\
\hline \multicolumn{13}{|l|}{ Astatini Lepeletier, 1845} \\
\hline Astata apostata Mercet, 1910 & 1 & $\ldots$ & $\ldots$ & $\ldots$ & $\ldots$ & 1 & 1 & $\ldots$ & $\ldots$ & 1 & $\mathrm{~T}$ & $\mathrm{He}$ \\
\hline Astata boops (Schranck, 1871) & $\ldots$ & $\cdots$ & $\ldots$ & 1 & $\ldots$ & $\ldots$ & 1 & $\cdots$ & $\ldots$ & $\ldots$ & $\mathrm{T}$ & $\begin{array}{c}\mathrm{He} \\
\text { Continúa }\end{array}$ \\
\hline
\end{tabular}




\begin{tabular}{|c|c|c|c|c|c|c|c|c|c|c|c|c|}
\hline spp/Age (Años post-fuego) & 1 & 2 & 3 & 4 & 5 & 7 & 9 & 13 & 14 & 15 & Nidific. & Presas \\
\hline Astata cobosi Giner Marí, 1946 & $\ldots$ & 11 & 1 & 6 & $\ldots$ & $\ldots$ & 15 & 2 & 2 & $\ldots$ & $\mathrm{T}$ & $\mathrm{He}$ \\
\hline Astata costae A. Costa, 1867 & $\ldots$ & $\ldots$ & $\ldots$ & $\ldots$ & $\ldots$ & $\ldots$ & 2 & 2 & $\ldots$ & 1 & $\mathrm{~T}$ & $\mathrm{He}$ \\
\hline Astata gallica Beaumont, 1942 & 1 & $\ldots$ & $\ldots$ & 1 & $\ldots$ & $\ldots$ & $\ldots$ & $\ldots$ & 2 & $\ldots$ & $\mathrm{T}$ & $\mathrm{He}$ \\
\hline Astata kashmirensis Nurse, 1909 & 1 & $\ldots$ & $\ldots$ & $\ldots$ & $\ldots$ & $\ldots$ & $\ldots$ & $\ldots$ & $\ldots$ & $\ldots$ & $\mathrm{T}$ & $\mathrm{He}$ \\
\hline Astata miegii Dufour, 1861 & $\ldots$ & $\ldots$ & $\ldots$ & $\ldots$ & $\ldots$ & $\ldots$ & 1 & $\ldots$ & $\ldots$ & $\ldots$ & $\mathrm{T}$ & $\mathrm{He}$ \\
\hline Dryudella tricolor (Van der Linden, 1829) & 14 & $\ldots$ & 6 & $\ldots$ & 8 & $\ldots$ & 3 & $\ldots$ & $\ldots$ & 1 & $\mathrm{~T}$ & $\mathrm{He}$ \\
\hline \multicolumn{13}{|l|}{ Dinetinae Fox, 1895} \\
\hline \multicolumn{13}{|l|}{ Dinetini Fox, 1895} \\
\hline Dinetus pictus (Fabricius, 1793) & 8 & $\ldots$ & $\ldots$ & $\ldots$ & $\ldots$ & 8 & 1 & $\ldots$ & $\ldots$ & $\ldots$ & $\mathrm{T}$ & $\mathrm{He}$ \\
\hline \multicolumn{13}{|l|}{ Crabroninae Latreille, 1802} \\
\hline \multicolumn{13}{|l|}{ Larrini Latreille, 1810} \\
\hline Larra anathema (Rossi, 1790) & 2 & 2 & $\ldots$ & $\ldots$ & $\ldots$ & 11 & 1 & $\ldots$ & 1 & $\ldots$ & $\mathrm{T}$ & Or \\
\hline Liris niger (Fabricius, 1775) & 2 & 14 & 1 & 8 & 2 & 1 & $\ldots$ & 1 & 9 & 2 & $\mathrm{~T}$ & Or \\
\hline Larropsis europaea Mercet, 1910 & $\ldots$ & $\ldots$ & $\ldots$ & $\ldots$ & $\ldots$ & $\ldots$ & 1 & $\ldots$ & $\ldots$ & $\ldots$ & $\mathrm{T}$ & Or \\
\hline Larropsis punctulata (Kohl, 1884) & 1 & 4 & $\ldots$ & $\ldots$ & $\ldots$ & $\ldots$ & $\ldots$ & $\ldots$ & $\ldots$ & $\ldots$ & $\mathrm{T}$ & Or \\
\hline Tachytes freygessneri Kohl, 1881 & $\ldots$ & $\ldots$ & $\ldots$ & 1 & $\ldots$ & $\ldots$ & $\ldots$ & $\ldots$ & 1 & $\ldots$ & $\mathrm{T}$ & Or \\
\hline Tachytes obsoletus (Rossi, 1792) & 1 & $\ldots$ & $\ldots$ & $\ldots$ & $\ldots$ & $\ldots$ & $\ldots$ & 1 & $\ldots$ & $\ldots$ & $\mathrm{T}$ & Or \\
\hline Tachytes panzeri (Dufour, 1841) & 113 & 16 & 13 & 1 & 2 & 58 & 37 & 28 & 62 & 32 & $\mathrm{~T}$ & Or \\
\hline Tachysphex adjunctus Kohl, 1885 & $\ldots$ & 1 & 3 & 3 & $\ldots$ & $\ldots$ & 2 & 2 & 11 & 3 & $\mathrm{~T}$ & Or \\
\hline Tachysphex brevipennis Mercet, 1909 & 1 & 1 & $\ldots$ & $\ldots$ & $\ldots$ & $\ldots$ & $\ldots$ & $\ldots$ & $\ldots$ & $\ldots$ & $\mathrm{T}$ & Or \\
\hline Tachysphex consocius Kohl, 1892 & 14 & 3 & 1 & 1 & $\ldots$ & 25 & 6 & 9 & 7 & 3 & $\mathrm{~T}$ & Or \\
\hline Tachysphex costae (De Stefani, 1882) & $\ldots$ & $\ldots$ & $\ldots$ & $\ldots$ & 1 & 1 & 2 & 2 & 5 & 4 & $\mathrm{~T}$ & Man \\
\hline Tachysphex fugax (Radoszkowski, 1877) & 1 & $\ldots$ & $\ldots$ & $\ldots$ & $\ldots$ & 2 & $\ldots$ & $\ldots$ & $\ldots$ & $\ldots$ & $\mathrm{T}$ & Or \\
\hline Tachysphex fulvitarsis (A. Costa, 1867) & 27 & 6 & 11 & 11 & 7 & 79 & 34 & 54 & 31 & 28 & $\mathrm{~T}$ & Or \\
\hline Tachysphex incertus (Radoszkowski, 1877) & 334 & 22 & 23 & 20 & 10 & 142 & 30 & 144 & 46 & 15 & $\mathrm{~T}$ & Or \\
\hline Tachysphex julliani Kohl, 1883 & $\ldots$ & $\ldots$ & $\ldots$ & 2 & 3 & 24 & 5 & 28 & 8 & 5 & $\mathrm{~T}$ & Man \\
\hline Tachysphex mediterraneus Kohl, 1883 & 1 & 3 & $\ldots$ & $\ldots$ & $\ldots$ & 2 & 4 & 4 & 3 & 1 & $\mathrm{~T}$ & Or \\
\hline Tachysphex nitidior Beaumont, 1940 & 10 & 16 & 1 & 6 & 4 & 24 & 8 & 16 & 5 & 2 & $\mathrm{~T}$ & Or \\
\hline Tachysphex obscuripennis (Schenck, 1857) & 16 & 7 & 6 & 32 & 18 & 35 & 23 & 73 & 134 & 83 & $\mathrm{~T}$ & $\mathrm{Bl}$ \\
\hline Tachysphex panzeri (Van der Linden, 1829) & 59 & 2 & 1 & 1 & $\ldots$ & 18 & 2 & 18 & 11 & 5 & $\mathrm{~T}$ & Or \\
\hline Tachysphex plicosus (A. Costa, 1867) & $\ldots$ & 1 & $\ldots$ & $\ldots$ & $\ldots$ & $\ldots$ & $\ldots$ & 1 & $\ldots$ & $\ldots$ & $\mathrm{OCt}$ & Or \\
\hline Tachysphex pompiliformis (Panzer, 1805) & 2 & $\ldots$ & 3 & 2 & $\ldots$ & 6 & 4 & 4 & 12 & 7 & $\mathrm{~T}$ & Or \\
\hline Tachysphex psammobius (Kohl, 1880) & 1 & 3 & $\ldots$ & 2 & $\ldots$ & $\ldots$ & 3 & 1 & $\ldots$ & 1 & $\mathrm{~T}$ & Or \\
\hline Tachysphex pseudopanzeri Beaumont, 1955 & 256 & 5 & 3 & 3 & $\ldots$ & 111 & 5 & 38 & 8 & 3 & $\mathrm{~T}$ & Or \\
\hline Tachysphex tarsinus (Lepeletier, 1845) & 11 & 9 & $\ldots$ & 1 & $\ldots$ & 3 & 6 & 3 & 1 & 2 & $\mathrm{~T}$ & Or \\
\hline Tachysphex unicolor (Panzer, 1809) & 4 & $\ldots$ & $\ldots$ & $\ldots$ & $\ldots$ & 2 & 1 & 3 & 1 & $\ldots$ & $\mathrm{T}$ & Or \\
\hline Prosopigastra handlirschi Morice, 1897 & $\ldots$ & 1 & $\ldots$ & $\ldots$ & $\ldots$ & $\ldots$ & $\ldots$ & $\ldots$ & $\ldots$ & $\ldots$ & $\mathrm{T}$ & Ho \\
\hline Prosopigastra kohli Mercet, 1907 & $\ldots$ & $\ldots$ & $\ldots$ & $\ldots$ & $\ldots$ & $\ldots$ & 1 & $\ldots$ & $\ldots$ & $\ldots$ & $\mathrm{T}$ & Ho \\
\hline Prosopigastra punctatissima A. Costa, 1867 & 1 & $\ldots$ & $\ldots$ & $\ldots$ & $\ldots$ & 1 & 4 & 2 & $\ldots$ & 2 & $\mathrm{~T}$ & Ho \\
\hline \multicolumn{13}{|l|}{ Miscophini Fox, 1895} \\
\hline Solierella compedita (Piccioli, 1869) & 54 & 135 & 92 & 64 & 91 & 126 & 327 & 144 & 75 & 58 & OCt-OCv-XR & $\mathrm{He}$ \\
\hline Solierella pisonoides (Saunders, 1873) & 15 & 8 & 16 & 2 & 9 & 6 & 35 & 9 & 24 & 10 & OCt-OCv-XR & $\mathrm{He}$ \\
\hline Solierella seabrai Andrade, 1950 & 2 & 6 & 8 & 13 & 22 & 6 & 9 & 2 & $\ldots$ & 2 & $\mathrm{OCt}-\mathrm{OCv}$ & $\mathrm{He}$ \\
\hline Miscophus albufeirae Andrade, 1952 & $\ldots$ & $\ldots$ & $\ldots$ & 1 & $\ldots$ & $\ldots$ & $\ldots$ & $\ldots$ & 1 & $\ldots$ & $\mathrm{T}$ & $\mathrm{Ar}$ \\
\hline Miscophus bicolor Jurine, 1807 & 9 & 9 & $\ldots$ & 5 & 11 & 23 & 12 & 32 & 24 & 10 & $\mathrm{~T}$ & $\mathrm{Ar}$ \\
\hline Miscophus eatoni Saunders, 1903 & 8 & 5 & 1 & 4 & 3 & 7 & 3 & 6 & 2 & 2 & $\mathrm{~T}$ & $\mathrm{Ar}$ \\
\hline Miscophus helveticus Kohl, 1883 & $\ldots$ & $\ldots$ & $\ldots$ & $\ldots$ & $\ldots$ & $\ldots$ & $\ldots$ & 1 & $\ldots$ & $\ldots$ & $\mathrm{T}$ & $\mathrm{Ar}$ \\
\hline Miscophus lusitanicus Andrade, 1952 & $\ldots$ & $\ldots$ & $\ldots$ & $\ldots$ & $\ldots$ & 1 & $\ldots$ & $\ldots$ & $\ldots$ & $\ldots$ & $\mathrm{T}$ & $\mathrm{Ar}$ \\
\hline Miscophus nicolai Ferton, 1896 & 53 & 14 & 5 & 10 & 10 & 36 & 8 & 66 & 31 & 15 & $\mathrm{~T}$ & $\mathrm{Ar}$ \\
\hline Miscophus niger Dahlbom, 1844 & 2 & 1 & $\ldots$ & 1 & $\ldots$ & 2 & $\ldots$ & 3 & $\ldots$ & $\ldots$ & $\mathrm{T}$ & $\mathrm{Ar}$ \\
\hline Nitela lucens Gayubo \& Felton, 2000 & 3 & 1 & 2 & 4 & 2 & 2 & 12 & 12 & 34 & 28 & $\mathrm{OCv}$ & Ps \\
\hline Nitela truncata Gayubo \& Felton, 2000 & $\ldots$ & $\ldots$ & $\ldots$ & $\ldots$ & 1 & 1 & 11 & $\ldots$ & 1 & 6 & $\mathrm{OCv}$ & Ps \\
\hline \multicolumn{13}{|l|}{ Trypoxylini Lepeletier, 1845} \\
\hline Pison atrum (Spinola, 1808) & 1 & 1 & $\ldots$ & $\ldots$ & $\ldots$ & 1 & 1 & $\ldots$ & $\ldots$ & 2 & $\mathrm{OCv}$ & $\mathrm{Ar}$ \\
\hline Trypoxylon attenuatum F. Smith, 1851 & 84 & 23 & 86 & 23 & 94 & 20 & 154 & 9 & 4 & 62 & $\mathrm{OCv}$ & $\mathrm{Ar}$ \\
\hline Trypoxylon clavicerum Lepeletier \& Serville, 1828 & $\ldots$ & $\ldots$ & 4 & 4 & 3 & 2 & 9 & 1 & 8 & 13 & $\mathrm{OCv}$ & $\mathrm{Ar}$ \\
\hline Trypoxylon figulus (Linnaeus, 1758) & 1 & $\ldots$ & $\ldots$ & $\ldots$ & $\ldots$ & $\ldots$ & 2 & $\ldots$ & $\ldots$ & $\ldots$ & $\mathrm{OCv}$ & $\mathrm{Ar}$ \\
\hline Trypoxylon minus Beaumont, 1945 & $\ldots$ & $\ldots$ & 1 & $\ldots$ & $\ldots$ & $\ldots$ & 2 & $\ldots$ & $\ldots$ & $\ldots$ & $\mathrm{OCv}$ & $\mathrm{Ar}$ \\
\hline Trypoxylon scutatum Chevrier, 1867 & 268 & 168 & 119 & 30 & 47 & 107 & 112 & 46 & 46 & 65 & $\mathrm{OCt}-\mathrm{OCv}$ & $\mathrm{Ar}$ \\
\hline \multicolumn{13}{|l|}{ Oxybelini Leach, 1815} \\
\hline Belomicrus odontophorus (Kohl, 1892) & $\ldots$ & $\ldots$ & $\ldots$ & $\ldots$ & $\ldots$ & $\ldots$ & 4 & $\ldots$ & $\cdots$ & $\ldots$ & $\mathrm{T}$ & $\mathrm{He}-\mathrm{Co}$ \\
\hline Oxybelomorpha steckii (Kohl, 1923) & 1 & $\ldots$ & $\ldots$ & $\ldots$ & $\ldots$ & $\ldots$ & $\ldots$ & $\ldots$ & 1 & $\ldots$ & $\mathrm{T}$ & $\mathrm{He}-\mathrm{Co}$ \\
\hline Oxybelus hastatus Fabricius, 1804 & 2 & $\ldots$ & $\ldots$ & $\ldots$ & $\ldots$ & $\ldots$ & $\ldots$ & $\ldots$ & $\ldots$ & $\ldots$ & $\mathrm{T}$ & Di \\
\hline Oxybelus mисronatus (Fabricius, 1793) & $\ldots$ & 1 & 1 & 2 & $\ldots$ & $\ldots$ & $\ldots$ & $\ldots$ & 1 & 1 & $\mathrm{~T}$ & $\begin{array}{c}\text { Di } \\
\text { Continúa }\end{array}$ \\
\hline
\end{tabular}


Localidades de muestreo

FUEGO CONTROL

\begin{tabular}{|c|c|c|c|c|c|c|c|c|c|c|c|c|}
\hline spp/Age (Años post-fuego) & 1 & 2 & 3 & 4 & 5 & 7 & 9 & 13 & 14 & 15 & Nidific. & Presas \\
\hline Oxybelus quattuordecimnotatus Jurine, 1807 & 46 & 10 & 19 & 5 & 12 & 11 & 44 & 47 & 37 & 43 & $\mathrm{~T}$ & $\mathrm{Di}$ \\
\hline Oxybelus subspinosus Klug, 1835 & 6 & $\ldots$ & $\ldots$ & 1 & $\ldots$ & 1 & $\ldots$ & $\ldots$ & 1 & $\ldots$ & $\mathrm{T}$ & Di \\
\hline \multicolumn{13}{|l|}{ Crabronini Latreille, 1802} \\
\hline Encopognathus braunsi Mercet, 1915 & 6 & $\ldots$ & $\ldots$ & $\ldots$ & $\ldots$ & 3 & $\ldots$ & $\ldots$ & $\ldots$ & $\ldots$ & $\mathrm{T}$ & $\mathrm{He}$ \\
\hline Entomognathus brevis (Van der Linden, 1829) & $\ldots$ & $\ldots$ & 1 & $\ldots$ & $\ldots$ & 2 & $\ldots$ & $\ldots$ & $\ldots$ & 1 & $\mathrm{~T}$ & Co \\
\hline Lindenius albilabris (Fabricius, 1793) & $\ldots$ & 1 & $\ldots$ & $\ldots$ & $\ldots$ & $\ldots$ & $\ldots$ & $\ldots$ & $\ldots$ & $\ldots$ & $\mathrm{T}$ & He-Di \\
\hline Lindenius ibericus Kohl, 1905 & 9 & $\ldots$ & $\ldots$ & 1 & $\ldots$ & 1 & $\ldots$ & 1 & 2 & 2 & $\mathrm{~T}$ & He-Di \\
\hline Lindenius pygmaeus (Rossi, 1794) & $\ldots$ & $\ldots$ & $\ldots$ & $\ldots$ & $\ldots$ & $\ldots$ & 1 & $\ldots$ & 2 & 1 & $\mathrm{~T}$ & Hy-Di \\
\hline Crossocerus elongatulus (Van der Linden, 1829) & $\ldots$ & $\ldots$ & $\ldots$ & $\ldots$ & $\ldots$ & $\ldots$ & $\ldots$ & $\ldots$ & 1 & 2 & $\mathrm{~T}$ & Di \\
\hline Crossocerus quadrimaculatus (Fabricius, 1793) & $\ldots$ & $\ldots$ & $\ldots$ & $\ldots$ & $\ldots$ & $\ldots$ & 1 & $\ldots$ & $\ldots$ & $\ldots$ & $\mathrm{T}$ & $\mathrm{Di}$ \\
\hline Tracheliodes quinquenotatus (Jurine, 1807) & $\ldots$ & 1 & $\ldots$ & 3 & 3 & 1 & 4 & 2 & 4 & 2 & $\mathrm{~T}$ & Hy \\
\hline Ectemnius cephalotes (Olivier, 1792) & $\ldots$ & 1 & 2 & $\ldots$ & 2 & 2 & $\ldots$ & $\ldots$ & 1 & 4 & $\mathrm{XR}$ & $\mathrm{Di}$ \\
\hline Ectemnius continuиs (Fabricius, 1804) & $\ldots$ & $\ldots$ & $\ldots$ & 1 & $\ldots$ & $\ldots$ & $\ldots$ & $\ldots$ & $\ldots$ & 2 & $\mathrm{XR}$ & Di \\
\hline Ectemnius crassicornis (Spinola, 1808) & 1 & 2 & $\ldots$ & 1 & 1 & 1 & 4 & 5 & 9 & 8 & $\mathrm{OCv}-\mathrm{XR}$ & $\mathrm{Di}$ \\
\hline Ectemnius rugifer (Dahlbom, 1845) & $\ldots$ & $\ldots$ & $\ldots$ & $\ldots$ & $\ldots$ & $\ldots$ & $\ldots$ & $\ldots$ & $\ldots$ & 2 & XR & Di \\
\hline Lestica clypeata (Schreber, 1759) & $\ldots$ & $\ldots$ & $\ldots$ & 1 & $\ldots$ & 1 & 1 & 1 & $\ldots$ & 1 & $\mathrm{OCv}-\mathrm{XR}$ & Le-Di \\
\hline \multicolumn{13}{|l|}{ Mellininae Latreille, 1802} \\
\hline \multicolumn{13}{|l|}{ Mellinini Latreille, 1802} \\
\hline Mellinus arvensis (Linnaeus, 1758) & $\ldots$ & 2 & $\ldots$ & 1 & $\ldots$ & $\ldots$ & $\ldots$ & 3 & $\ldots$ & 1 & $\mathrm{~T}$ & $\mathrm{Di}$ \\
\hline \multicolumn{13}{|l|}{ Bembicinae Latreille, 1802} \\
\hline \multicolumn{13}{|l|}{ Nyssonini Latreille, 1804} \\
\hline Nysson dusmeti Mercet, 1909 & $\ldots$ & 3 & $\ldots$ & 1 & $\ldots$ & $\ldots$ & $\ldots$ & 1 & $\ldots$ & $\ldots$ & $\mathrm{P}$ & \\
\hline Nysson maculosus (Gmelin, 1790) & 5 & 1 & $\ldots$ & $\ldots$ & $\ldots$ & $\ldots$ & 3 & $\ldots$ & 2 & 1 & $\mathrm{P}$ & \\
\hline Nysson monachus Mercet, 1909 & $\ldots$ & $\ldots$ & 1 & $\ldots$ & 1 & $\ldots$ & 1 & $\ldots$ & $\ldots$ & $\ldots$ & $\mathrm{P}$ & \\
\hline Nysson parietalis Mercet, 1909 & $\ldots$ & $\ldots$ & $\ldots$ & $\ldots$ & $\ldots$ & $\ldots$ & 1 & $\ldots$ & $\ldots$ & 1 & $\mathrm{P}$ & \\
\hline Nysson pratensis Mercet, 1909 & 2 & $\ldots$ & $\ldots$ & $\ldots$ & 1 & $\ldots$ & $\ldots$ & 2 & $\ldots$ & $\ldots$ & $\mathrm{P}$ & \\
\hline Nysson variabilis (Chevrier, 1867) & 1 & $\ldots$ & $\ldots$ & $\ldots$ & $\ldots$ & $\ldots$ & $\ldots$ & $\ldots$ & $\ldots$ & 1 & $\mathrm{P}$ & \\
\hline Brachystegus scalaris (Illiger, 1807) & $\ldots$ & $\ldots$ & $\ldots$ & $\ldots$ & $\ldots$ & 3 & 1 & $\ldots$ & $\ldots$ & $\ldots$ & $\mathrm{P}$ & \\
\hline \multicolumn{13}{|l|}{ Bembicini Latreille, 1802} \\
\hline Gorytes quinquefasciatus (Panzer, 1798) & $\ldots$ & $\ldots$ & $\ldots$ & $\ldots$ & $\ldots$ & $\ldots$ & $\ldots$ & 6 & 2 & 5 & $\mathrm{~T}$ & Ho \\
\hline Gorytes sulcifrons (A. Costa, 1869) & $\ldots$ & 1 & $\ldots$ & 4 & $\ldots$ & 3 & 12 & 4 & 3 & 3 & $\mathrm{~T}$ & Ho \\
\hline Harpactus alvaroi Gayubo, 1992 & 2 & 5 & 5 & 3 & 5 & 2 & 5 & 13 & 9 & 16 & $\mathrm{~T}$ & Ho \\
\hline Harpactus formosus (Jurine, 1807) & 4 & 10 & $\ldots$ & 5 & 3 & 8 & 1 & 6 & 8 & 1 & $\mathrm{~T}$ & Ho \\
\hline Harpactus laevis (Latreille, 1792) & $\ldots$ & $\ldots$ & $\ldots$ & $\ldots$ & 1 & $\ldots$ & 2 & $\ldots$ & $\ldots$ & 19 & $\mathrm{~T}$ & Ho \\
\hline Harpactus elegans (Lepeletier, 1832) & $\ldots$ & $\ldots$ & $\ldots$ & $\ldots$ & $\ldots$ & 2 & $\ldots$ & $\ldots$ & $\ldots$ & $\ldots$ & $\mathrm{T}$ & Ho \\
\hline Harpactus morawitzi (Snoflak, 1943) & 31 & 14 & 5 & 9 & 2 & 1 & 2 & $\ldots$ & $\ldots$ & $\ldots$ & $\mathrm{T}$ & Ho \\
\hline Harpactus tumidus (Panzer, 1801) & $\ldots$ & $\ldots$ & 1 & $\ldots$ & $\ldots$ & $\ldots$ & $\ldots$ & $\ldots$ & $\ldots$ & $\ldots$ & $\mathrm{T}$ & Ho \\
\hline Lestiphorus bicinctus (Rossi, 1794) & $\ldots$ & 1 & $\ldots$ & $\ldots$ & $\ldots$ & $\ldots$ & $\ldots$ & $\ldots$ & $\ldots$ & $\ldots$ & $\mathrm{T}$ & Ho \\
\hline Sphecius nigricornis (Dufour, 1838) & 1 & 1 & $\ldots$ & $\ldots$ & $\ldots$ & $\ldots$ & $\ldots$ & $\ldots$ & 2 & $\ldots$ & $\mathrm{T}$ & Ho \\
\hline Bembecinus carpetanus (Mercet, 1906) & 4 & 1 & $\ldots$ & $\ldots$ & $\ldots$ & 3 & 1 & 1 & 2 & 2 & $\mathrm{~T}$ & Ho \\
\hline Bembecinus pulchellus (Mercet, 1906) & 254 & 12 & 11 & $\ldots$ & $\ldots$ & 228 & 105 & 43 & 5 & 7 & $\mathrm{~T}$ & Ho \\
\hline Bembecinus tridens (Fabricius, 1781) & $\ldots$ & $\ldots$ & $\ldots$ & $\ldots$ & $\ldots$ & $\ldots$ & 1 & $\ldots$ & $\ldots$ & $\ldots$ & $\mathrm{T}$ & Ho \\
\hline Stizus hispanicus Mocsáry, 1883 & $\ldots$ & $\ldots$ & $\ldots$ & $\ldots$ & $\ldots$ & 1 & $\ldots$ & $\ldots$ & $\ldots$ & $\ldots$ & $\mathrm{T}$ & Or \\
\hline Stizoides tridentatus (Fabricius, 1775) & $\ldots$ & $\ldots$ & $\ldots$ & 1 & $\ldots$ & $\ldots$ & $\ldots$ & $\ldots$ & $\ldots$ & $\ldots$ & $\mathrm{P}$ & \\
\hline Bembix bidentata Van der Linden, 1829 & 4 & 1 & 2 & $\ldots$ & $\ldots$ & $\ldots$ & 1 & 1 & 2 & 1 & $\mathrm{~T}$ & $\mathrm{Di}$ \\
\hline Bembix oculata Panzer, 1801 & 3 & 1 & 1 & $\ldots$ & 2 & 1 & 1 & $\ldots$ & 2 & 1 & $\mathrm{~T}$ & Di \\
\hline Bembix zonata Klug, 1835 & 27 & 7 & $\ldots$ & 1 & 5 & 12 & 29 & 1 & 12 & 4 & $\mathrm{~T}$ & $\mathrm{Di}$ \\
\hline \multicolumn{13}{|l|}{ Philanthinae Latreille, 1802} \\
\hline \multicolumn{13}{|l|}{ Philanthini Latreille, 1802} \\
\hline Philanthus triangulum (Fabricius, 1775) & 2 & $\ldots$ & $\ldots$ & 1 & $\ldots$ & $\ldots$ & $\ldots$ & 2 & 2 & $\ldots$ & $\mathrm{T}$ & Hy \\
\hline \multicolumn{13}{|l|}{ Cercerini Lepeletier, 1845} \\
\hline Cerceris arenaria (Linnaeus, 1758) & $\ldots$ & 4 & 2 & 1 & 1 & 2 & 7 & 11 & 3 & 30 & $\mathrm{~T}$ & Co \\
\hline Cerceris ibericella Leclercq, 1979 & $\ldots$ & 1 & $\ldots$ & $\ldots$ & $\ldots$ & $\ldots$ & $\ldots$ & $\ldots$ & $\ldots$ & $\ldots$ & $\mathrm{T}$ & Co-Hy \\
\hline Cerceris quadricincta (Panzer, 1799) & $\ldots$ & 2 & $\ldots$ & 1 & $\ldots$ & $\ldots$ & $\ldots$ & $\ldots$ & $\ldots$ & 2 & $\mathrm{~T}$ & Co \\
\hline Cerceris rybyensis (Linnaeus, 1771) & $\ldots$ & 1 & $\ldots$ & $\ldots$ & $\ldots$ & $\ldots$ & 3 & $\ldots$ & 1 & $\ldots$ & $\mathrm{T}$ & Hy \\
\hline Cerceris sabulosa (Panzer, 1799) & $\ldots$ & 2 & 1 & $\ldots$ & $\ldots$ & $\ldots$ & 1 & $\ldots$ & 5 & 1 & $\mathrm{~T}$ & Hy \\
\hline INDIVIDUOS TOTALES & 2183 & 856 & 603 & 846 & 509 & 1376 & 1288 & 1205 & 1168 & 862 & 8290 & 2606 \\
\hline ESPECIES TOTALES & 78 & 74 & 56 & 68 & 52 & 69 & 89 & 69 & 82 & 85 & 129 & 94 \\
\hline
\end{tabular}


Anexo 2: Especies exclusivas de: 2a) Interior de las áreas quemadas; 2b) Controles

a) Interior de las áreas quemadas

\section{AÑOS POST-FUEGO}

\begin{tabular}{|c|c|c|c|c|c|c|c|}
\hline Especies & 1 & 2 & 3 & 4 & 5 & 7 & 9 \\
\hline Ammoplanus perrisi & 3 & $\cdots$ & $\ldots$ & $\ldots$ & $\cdots$ & $\ldots$ & $\ldots$ \\
\hline Ampulex ruficollis & $\ldots$ & $\ldots$ & $\ldots$ & 1 & $\ldots$ & $\ldots$ & $\ldots$ \\
\hline Astata boops & $\ldots$ & $\ldots$ & $\ldots$ & 1 & $\ldots$ & $\ldots$ & 1 \\
\hline Astata kashmirensis & 1 & $\ldots$ & $\ldots$ & $\ldots$ & $\ldots$ & $\ldots$ & $\ldots$ \\
\hline Astata miegii & $\ldots$ & $\ldots$ & $\ldots$ & $\ldots$ & $\ldots$ & $\ldots$ & 1 \\
\hline Belomicrus odonthophorus & $\ldots$ & $\ldots$ & $\ldots$ & $\ldots$ & $\ldots$ & $\ldots$ & 4 \\
\hline Bembecinus tridens & $\ldots$ & $\ldots$ & $\ldots$ & $\ldots$ & $\ldots$ & $\ldots$ & 1 \\
\hline Brachystegus scalaris & $\ldots$ & $\ldots$ & $\ldots$ & $\ldots$ & $\ldots$ & 3 & 1 \\
\hline Cerceris ibericella & $\ldots$ & 1 & $\ldots$ & $\ldots$ & $\ldots$ & $\ldots$ & $\ldots$ \\
\hline Chalybion femoratum & $\ldots$ & $\ldots$ & $\ldots$ & $\ldots$ & $\ldots$ & $\ldots$ & 1 \\
\hline Crossocerus quadrimaculatus & $\ldots$ & $\ldots$ & $\ldots$ & $\ldots$ & $\ldots$ & $\ldots$ & 1 \\
\hline Dinetus pictus & 8 & $\ldots$ & $\ldots$ & $\ldots$ & $\ldots$ & 8 & 1 \\
\hline Encopognathus braunsi & 6 & $\ldots$ & $\ldots$ & $\ldots$ & $\ldots$ & 3 & $\ldots$ \\
\hline Harpactus elegans & $\ldots$ & $\ldots$ & $\ldots$ & $\ldots$ & $\ldots$ & 2 & $\ldots$ \\
\hline Harpactus morawitzi & 31 & 14 & 5 & 9 & 2 & 1 & 2 \\
\hline Harpactus tumidus & $\ldots$ & $\ldots$ & 1 & $\ldots$ & $\ldots$ & $\ldots$ & $\ldots$ \\
\hline Larropsis europaea & $\ldots$ & $\ldots$ & $\ldots$ & $\ldots$ & $\ldots$ & $\ldots$ & 1 \\
\hline Larropsis punctulata & 1 & 4 & $\ldots$ & $\ldots$ & $\ldots$ & $\ldots$ & $\ldots$ \\
\hline Lestiphorus bicinctus & $\ldots$ & 1 & $\ldots$ & $\ldots$ & $\ldots$ & $\ldots$ & $\ldots$ \\
\hline Lindenius albilabris & $\ldots$ & 1 & $\ldots$ & $\ldots$ & $\ldots$ & $\ldots$ & $\ldots$ \\
\hline Miscophus lusitanicus & $\ldots$ & $\ldots$ & $\ldots$ & $\ldots$ & $\ldots$ & 1 & $\ldots$ \\
\hline Nysson monachus & $\ldots$ & $\ldots$ & 1 & $\ldots$ & 1 & $\ldots$ & 1 \\
\hline Oxybelus hastatus & 2 & $\ldots$ & $\ldots$ & $\ldots$ & $\ldots$ & $\ldots$ & $\ldots$ \\
\hline Pemphredon mortifer & $\ldots$ & $\ldots$ & 1 & $\ldots$ & 1 & $\ldots$ & $\ldots$ \\
\hline Prionyx subfuscatus & 7 & $\ldots$ & $\ldots$ & $\ldots$ & $\ldots$ & $\ldots$ & $\ldots$ \\
\hline Prionyx viduatus & 2 & $\ldots$ & $\ldots$ & $\ldots$ & $\ldots$ & 3 & $\ldots$ \\
\hline Prosopigastra handlirschi & $\ldots$ & 1 & $\ldots$ & $\ldots$ & $\ldots$ & $\ldots$ & $\ldots$ \\
\hline Prosopigastra kohli & $\ldots$ & $\ldots$ & $\ldots$ & $\ldots$ & $\ldots$ & $\ldots$ & 1 \\
\hline Stizoides tridentatus & $\ldots$ & $\ldots$ & $\ldots$ & 1 & $\ldots$ & $\ldots$ & $\ldots$ \\
\hline Stizus hispanicus & $\ldots$ & $\ldots$ & $\ldots$ & $\ldots$ & $\ldots$ & 1 & $\ldots$ \\
\hline Tachysphex brevipennis & 1 & 1 & $\ldots$ & $\ldots$ & $\ldots$ & $\ldots$ & $\ldots$ \\
\hline Tachysphex fugax & 1 & $\ldots$ & $\ldots$ & $\ldots$ & $\ldots$ & 2 & $\ldots$ \\
\hline Trypoxylon figulus & 1 & $\ldots$ & $\ldots$ & $\ldots$ & $\ldots$ & $\ldots$ & 2 \\
\hline Trypoxylon minus & $\ldots$ & $\ldots$ & 1 & $\ldots$ & $\ldots$ & $\ldots$ & 2 \\
\hline
\end{tabular}

b) Controles

\begin{tabular}{lccc}
\cline { 2 - 4 } & \multicolumn{3}{c}{ AÑN POST-FUEGO } \\
\hline Especies & $\mathbf{1 3}$ & $\mathbf{1 4}$ & $\mathbf{1 5}$ \\
\hline Ammoplanus gegen & $\ldots$ & 1 & $\ldots$ \\
Crossocerus elongatulus & $\ldots$ & 1 & 2 \\
Dolichurus haemorrhous & 1 & 7 & 4 \\
Ectemnius rugifer & $\ldots$ & $\ldots$ & 2 \\
Gorytes quinquefasciatus & 6 & 2 & 5 \\
Miscophus helveticus & 1 & $\ldots$ & $\ldots$ \\
\hline
\end{tabular}




\section{Bibliografía}

Arnan, X., Rodrigo, A. \& Retana, J., 2007. Uncoupling the effects of shade and food resources of vegetation on Mediterranean ants: an experimental approach at the community level. Ecography 30: 161-172.

Asís, J. D., Tormos, J. \& Gayubo, S. F. 1994. Biological Observations on Trypoxylon attenuatum and Description of its Mature Larva and its Natural Enemy Trichrysis cyanea (Hymenoptera: Sphecidae, Chrysididae). J. Kansas Entomol. Society 67(2): 199-207.

Bartolomé, C., Álvarez Jiménez, J., Vaquero, J., Costa, M., Casermeiro, M. A., Giraldo, J. \& Zamora, J. 2005. Los tipos de hábitats de interés comunitario de España. Guía Básica. Ministerio de Medio Ambiente. Dirección General para la Biodiversidad. 287 pp.

Begon, M., Townsend, C. R. \& Harper, J. L. 2006. Ecology: from individuals to ecosystems. Blackwell Publishing. Oxford. 738 pp.

Bitsch, J. \& Leclercq, J. 1993. Hyménoptères Sphecidae d'Europe Occidentale vol. 1. Faune de France 79. Fédération Française des Sociétés de Sciences Naturelles, Paris.

Bitsch, J., Barbier, Y., Gayubo, S. F., Schmidt, K. \& Ohl, M. 1997. Hyménoptères Sphecidae d'Europe Occidentale vol. 2. Faune de France 82. Fédération Française des Sociétés de Sciences Naturelles, Paris.

Bitsch, J., Dollfuss, H., Bouček, Z., Schmidt, K., Schmid-Egger, C., Gayubo, S. F., Antropov, A. V. \& Barbier, Y. 2007. Hyménoptères Sphecidae d'Europe Occidentale vol. 3 (seconde édition). Faune de France 86. Fédération Française des Sociétés de Sciences Naturelles, Paris.

Breece, C.R., Kolb, T.E., Dickson, B.G., McMillin, J.D., Clancy, K.M. 2008. Prescribed fire effects on bark beetle activity and tree mortality in southwestern ponderosa pine forests. Forest Ecol Manag 255: 119-128.

Bock, C., Bock, J., 1991. Response of grassoppers (Orthoptera:Acrididae) to wildfire in a Southeastern Arizona Grassland. Notes and Discussion, Am. Midl. Nat.125: 162-167.

Bond, W. J. \& van Wilgen, B. W. 1996. Fire and Plants. Chapman \& Hall, Londres.

Buddle, C. M., J. R. Spence, \& D. W. Langor. 2000. Succession of boreal forest spider assemblages following wildfire and harvesting. Ecography 23 (4): 424-436.

Calonge-Cano, G. 1990. La excepcionalidad climática de los Arribes del Duero. ERIA, 21: 45-59.

Calvo, L., Tárrega, R. \& Luis-Calabuig, E. 1991. Regeneration in Quercus pyrenaica ecosystems after surface fires. Int. J. Wildland Fire 1 (4): 205-210

Calvo, L., Tárrega, R. \& Luis-Calabuig, E. 1999. Post-fire sucesion in two Quercus Pyrenaica communities with different disturbance histories. Ann. For. Sci. 56: 441-447.

Campbell, J. W., Hanula, J. L. \& Waldrop, T. A. 2007. Effects of prescribed fire and fire surrogates on floral visiting insects of the blue ridge province in North Carolina. Biolog Conserv 134: 393-494.

Cancelado, R. \& Yonke, T. R. 1970. Effects of prairie burning on insects populations. J. Kansas Entomological Society 43: 274-281.

Cleary, D. F. R \& Grill, A. 2004. Butterfly response to severe NSO-induced forest fires in Borneo. Ecol Entomol 29: 666-676.

Costa Tenorio, M., Morla, C. \& Sainz, H (Eds). 2005. Los Bosques Ibéricos. Una interpretación Geonotánica. Ed. Planeta. Barcelona.598 pp.

Escudero Alcántara, A., Olano, J. M., García, R., Bariego, P., Molina, C., Arranz, J. A., Molina, J. I. \& Ezquerra, F. J. 2008. Guía básica para la interpretación de los hábitats de interés comunitario de Castilla y León. Junta de Castilla y León. Consejería de Medio Ambiente. Valladolid. 432 pp. 
Evans, E. W. 1988. Grasshopper (Insecta: Orthoptera: Acrididae) assemblages of tallgrass prairie: influences of fire frequency, topography, and vegetation. Canadian J. Zoology 66: 1495-1501.

Fernández, M. M. \& Salgado J. M. 2004. Recolonization of a burn pine forest (Pinus pinaster) by Carabidae (Coleoptera). European J. Soil Biology 40: 47-53.

García-Feced, C., Escribano, R. \& Elena, R. 2007. Comparación de la estructura de los paisajes en Parques Naturales fronterizos: Arribes del Duero versus Douro Internacional. Montes № 91: 814.

Gayubo, S. F., González, J. A., Asís, J. D. \& Tormos, J. 2005. Conservation of European environments: The Spheciformes wasp as biodiversity indicators (Hymenoptera: Apoidea: Ampulicidae, Sphecidae and Crabronidae). J. Natural History, 39 (29): 2705-2714.

González, J.A. 2009; Gayubo, S.F.; Asís, J.D. \& Tormos, J. 2009. Diversity and Biogeographical Significance of Solitary wasp (Chrysididae, Eumeninae and Spheciformes) at the Arribes del Duero Natural Park, Spain: Their Importance for Insects Diversity Conservation in the Mediterranean Region. Environ. Entomol. 38 (3): 608-626.

Haeseler, V. 1972. Anthropogene Biotope (Kahlschlag, Kiesgrube, Stadtgärten) als Refugien für Insekten, untersucht am Beispiel der Hymenoptera Aculeata. Zoologische Jahrbücher (Systematik), 99: 133-212.

Hall, S.P. \& D.F. Schweitzer. 1992. A survey of the moths, butterflies, and grasshoppers of four Nature Conservancy preserves in southeastern North Carolina. Rept. to Nature Conservancy, North Carolina Chapter, Carrboro, NC. 122 pp.

Hansen, J. D. 1986. Comparison of insects from burned and unburned areas after a range fire. Great Basin Naturalist 46 (4): 721-727.

Hansen, J. D. 1988. Trapping methods for rangeland insects in burned and unburned sites: A comparison. Great Basin Naturalist 48 (3): 383-387.

Hanula, J. L. \& Wade, D. D. 2003. Influence of long-term dormant-season burning and fire exclusion on ground-dwelling arthropod populations in longleaf pine flatwoods ecosystems. Forest Ecol Manag 175: 163-184

Harper, M. G., Dietrich, C. H., Larimore, R. L. \& Tessene, P. A. 2000. Effects of prescribed fire on prairie arthropods: An enclosure study. Natural Areas J., 20 (4): 325-335.

Hirowatari, T., Makihara, H., \& Sugiarto. 2007. Effects of fires on butterfly assemblages in lowland dipterocarp forest in East Kalimantan. Entomological Science, Vol. 10, Number 2, June 2007, pp. 113-127.

Huston, M. A., 1994. Biological diversity: the coexistence of species on changing landscapes. Cambridge University Press, Cambridge. 681 pp.

JCyL. Junta de Castilla y León. www.jcyl.es

Knight, T. M. \& Holt, R. D. 2005 Fire Generates Spatial Gradients in Herbivory: An Example from a Florida Sandhill Ecosystem. Ecology (86) 3: 587-593.

Lamotte, M. 1975. The structure and function of a tropical savanna ecosystem. En: Tropical Ecological Systems: Trends in Terrestrial and Aquatic Research (Golley, F. B. \& Medina, E. eds.), pp 179222. Springer-Verlag, Berlin.

Lepš, J., \& P. Šmilauer. 2003. Multivariate analysis of ecological data using CANOCO. Cambridge University Press, Cambridge, United King-dom.

Lockwood, J. A., Shaw, S. R. \& Struttmann, J. M. 1996. Biodiversity of wasp species (Insecta: Hymenoptera) in burned and unburned habitats of Yellowstone National Park, Wyoming, USA. J. Hymenoptera Research, 5: 1-15.

Luis-Calabuig, E. (Coord.) 2008. Arribes del Duero. Guía de la Naturaleza. Edilesa. León. 224 pp. 
Luis-Calabuig, E. \& Tarrega, R. 1993. Studies on post-fire regeneration in Quercus pyrenaica ecosystems in Leon Province (NW Spain). Pages 209-219. In: Trabaud L. \& Prodon, R. (eds). Fire in mediterranean ecosystems. ECSC-EEC-EAEC, Brussels-Luxembourg.

Luis Calabuig, E., Tárrega, M. R., Calvo, L., Valbuena, L., Marcos, E., 2001. Fuego y paisaje en áreas de dominio del Roble Rebollo. Ecosistemas X (1).

Makihara H, Kinuura H, Yahiro K., \& Soeyamto, C., 2000. The effects of droughts and fires on Coleopteran insects in lowland dipterocarp forests in Bukit Soeharto, East Kalimantan. In: Guhardja E, Futawi M, Sutisna M, Ohta S (eds) Rainforest Ecosystems of East Kalimantan. Ecological Studies, 140, pp 153-163. Springer, Tokyo.

Mitchell, R.G. 1990. Effects of prescribed fire on insect pests. In: Walstad, J.D.; Radosevich, S.R.; Sandberg, D.V., (eds). Natural and prescribed fires in Pacific Northwest forests. Corvallis, OR: Oregon State University Press: 111-121.

Moreno, J. M. 2007. Cambio global e incendios forestales: Una visión desde España. Proceding of $4^{\text {a }}$ Conferencia Internacional sobre Incendios Forestales. Sevilla, España. 13-14 Mayo. 2007.

Moretti, M., Duelli, P. \& Obrist, M. K. 2006. Biodiversity and resilience of arthropod communities after fire disturbance in temperate forests. Oecología 149: 312-327.

Moretti, M.; Obrist, M. K. \& Duelli, P. 2004. Arthropod biodiversity after forest fires: winners and losers in the winter fire regime of the Southern Alps. Ecography, 27 (2): 173-186.

Moretti, M., Conedera, M., Duelli, P. \& Edwards, P. J. 2002a. The effects of wildfire on ground-active spiders in deciduous forests on the Swiss Southern slope of the Alps. J. Applied Ecology 39 (2): 321-336.

Moretti, M., Zanini, M. \& Conedera, M. 2002b. Faunistic and floristic post-fire succession in southern Switzerland: an integrated analysis with regard to fire frequency and time since the last fire. In: Wiegas, D. X. (ed.), Forest Fire Research and Wildland Fire Safety. Millpress, Rotterdam. CDRom.

Naveh, Z. (1975). The evolutionary significance of fire in the Mediterranean region. Vegetatio 29: 199208.

Niwa, C. G. \& Peck, R. W. 2002. Influence of prescribed fire on carabid beetle (carabidae) and spider (araneae) assemblages in forest litter in southwestern oregon. Environ. Entomol. 31: 785-796.

Nunes, L., Leather, S. \& Rego, F. 2000. Effects of fire on insects and other invertebrates. A review with particular reference to fire indicator species. Silva Lusitana (8), 1: 15-32.

Ojeda-Copete, F. 2001. El fuego como factor clave en la evolución de plantas mediterráneas. En: Ecosistemas Mediterráneos. Análisis funcional (Zamora Rodríguez, R. \& Pugnaire de Iraola, F. I. eds.). Textos Universitarios. CSIC. Asociación Española de Ecología Terrestre.

O’Neill, K. M. 2001. Solitary wasps: behavior and natural history. Cornell University Press, Ithaca. xiii $+406 \mathrm{pp}$.

Ortiz-Sanchez, F.J. \& A. Aguirre-Segura.1993. Efecto del color sobre las capturas de abejas mediante trampas Moericke en el sur de España (Hymenoptera, Apoidea). Graellsia 49: 63-71.

Panzer, R. 2003. Importance of in situ survival, recolonization, and habitat gaps in the postfire recovery of fire-sensitive prairie insects species. Natural areas J. 23: 14-21

Pausas, J. G. 2004. Changes in fire and climate in the eastern Iberian peninsula (Mediterranean Basin). Climatic Change 63: 337-350.

Pausas, J.G. \&Vallejo, R., 1999. The role of fire in European Mediterranean ecosystems. In: Chuvieco, E. (Ed.), Remote Sensing of Large Forest Fires in the European Mediterranean Basin. Springer, pp. 3-16.

Pickett, S. T. A. 1989. Space for time substitution as an alternative for long studies. In: Likens, E. G. (ed.), Long-term studies in ecology: approaches and alternatives. Springer, pp. 112-135. 
Potts, S. G., Dafni, A. \& Ne'eman, G. 2001. Pollination of a core flowering shrub species in Mediterranean phrygana: variation in pollinator diversity, abundance and effectiveness in response to fire. Oikos 92: 71-80.

Potts, S. G., Vulliamy, B., Dafni, A., Ne'eman, G., O’Toole, C., Roberts, S. \& Willmer, P.G. 2003. Response of plant-pollinator communities to fire: changes in diversity, abundance and floral reward structure. Oikos 101.1: 103-12.

Potts, S.G., Vulliamy, B., Roberts, S., Roberts, S., O’Toole, C., Dafni, A., Ne'eman, G. \& Willmer, P., 2005. Role of nesting resources in organising diverse bee communities in a Mediterranean landscape. Ecol. Entomol. 30:78-85.

Pulawski, W. J. 2009. Family-Group Names and Classification. In : Catalog of Sphecidae sensu lato (= $\begin{array}{llllll}\text { Apoidea } & \text { excluding } & \text { Apidae). } & \text { Cited } & 22 & \text { May }\end{array}$ www.calcademy.com/research/entomolgy/Entomology_Resources/Hymenoptera/sphecidae.

Radho-Toly, S., Majer, J.D. \& Yates, C. 2001. Impact of fire on leaf nutrients, arthropod fauna and herbivory of native and exotic eucalypts in Kings Park, Perth, Western Australia. Austral Ecology 26: 500-506.

Rodrigo, A., \& Retana, J. 2006. Post-fire recovery of ant communities in Submediterranean Pinus nigra forests. Ecography 29: 231-239.

Rodrigo, A., Sardá-Palomera, F., Bosch, J. \& Retana, J. 2008. Changes of dominant ground beteles in black pine forest with fire severity and sucesional age. EcoScience 15 (4): 442-452.

Rundel, P. W. 1981. Fire as an ecological factor. Pp. 501-538. In: Lange, O. L., Nobel, P. S., Osmond, C. B. \& Ziegler, H. (eds), Physiological Plant Ecology I: Responses to the Physical Environment. Springer-Verlag, Berlin.

Saint-Germain, M., Drapeau, P. \& Hébert, C. 2004. Comparison of Coleoptera assemblages from a recently burned and unburned black spruce forests of northeastern North America. Biolog Conserv 118: 583-592.

Saura-Mas, S. \& Lloret, F. 2009. Linking post-fire regenerative strategy and leaf nutrient content in Mediterranean woody plants. Perspect. Plant Ecol. Evol. Systematics. Doi: 10.1016/j.ppees.2009.04.002

Siemann, E. Haarstad, J. \& Tilman, D. 1997. Short-term and long-term effects of burning on Oak Savanna Arthropods. American Midland Naturalist, 137 (2): 349-361.

Steffan-Dewenter, I., 2002, Landscape context affects trap-nesting bees, wasp, and their natural enemies. Ecological Entomology 27: 631-637.

Swengel, A. B. 2001. A literature review of insect responses to fire, compared to other conservation managements of open habitat. Biodivers. Conserv., 10 (7): 1141-1169.

Swengel, A. B. \& Swengel, S. R. 2007. Benefit of permanent non-fire refugia for Lepidoptera conservation in fire-managed sites. J. Insect Conserv. 11: 263-279.

Taki H., Viana, B.F., Kevan, P.G., Silva, F.O., \& Buck, M. 2008. Does forest loss affect the communities of trap-nesting wasps (Hymenoptera: Aculeata) in forests? Landscape vs. local habitat conditions. J. Insect Conservation 12 (1): 15-21.

Tárrega, R. \& Luis-Calabuig, E. 1989. Sucesión post-fuego y mecanismos de supervivencia en comunidades de Quercus pyrenaica de la provincia de León. Options Mediterraneénnes- Serie Seminaires 3: 137-140.

ter Brack, C. J. F. \& Šmilauer, P. 1998. CANOCO Reference Manual and User's Guide to Canoco for Windows : Software for Canonical Community Ordination (version 4). Microcomputer Power, Ithaca, NY. $352 \mathrm{pp}$.

Toler, T. R., Evans, E. W. \& Tepedino. V. J. 2005. Pan-trapping for bees (Hymenoptera : Apiformes) in Utah's West Desert: the importance of color diversity. Pan-Pacific Entomologist 81: 103-113. 
Tomé, M. A., 2006. Ecología de nidificación de aculeados xilícolas, con especial referencia a Trypoxylon attenuatum (Hymenoptera: Aculeata). Tesis Doctoral. Universidad de Salamanca. Salamanca. $258 \mathrm{pp}$.

Urones, C. \& Majadas, A. 2002. Cambios en la comunidad de Araneae durante la sucesión post-fire en matorrales mediterráneos de montaña. Revista Ibérica de Aracnología 5: 19-28.

Westphal, C., Bommarco, R., Carre, G., Lamborn, E., Morison, N., Petanidou, T., Potts, S. G., Roberts, S. P. M., Szentgyorgyi, H., Tscheulin, T., Vaissiere, B. E., Woyciechowski, M., Biesmeijer, J. C., Kunin, W. E., Settele, T. \& Steffan-Dewenter, I., 2008. Measuring Bee Diversity in Different European Habitats. Ecological Monographs 78 (4): 653-671.

Whelan, R. J. 1995. The Ecology of Fire. Cambridge University Press, Cambridge. 


\section{4}

Fuego vs. condiciones ambientales: influencia en la estructuración de comunidades de insectos depredadores.

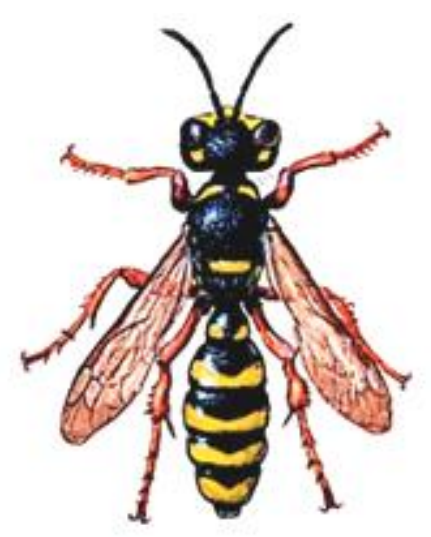




\section{Fuego vs. condiciones ambientales: influencia en la estructuración de comunidades de insectos depredadores.}

\section{Resumen}

Las variaciones, tras un incendio forestal, en la estructura de una comunidad de avispas Spheciformes (Hymenoptera: Apoidea) de un agroecosistema mediterráneo de interés comunitario, dominado por Quercus pyrenaica, se analizaron a lo largo de quince años, empleándose la sustitución de espacio por tiempo. El muestreo se llevó a cabo mediante trampa Malaise y platos amarillos. Las variables más influyentes sobre los cambios en la estructura de la comunidad fueron los años transcurridos desde el incendio y el año y localidad de muestreo. Los resultados evidencian la gran importancia ejercida por las condiciones ambientales sobre dichas comunidades, cuyo efecto superó incluso al ocasionado por el fuego. La trampa Malaise y los platos fueron altamente complementarios, registrándose diferencias importantes en cuanto al tipo de comunidades capturadas por ambos métodos de muestreo, lo que aconseja la necesidad de emplear ambos métodos para realizar estudios de este tipo.

Palabras clave: Bosques de Quercus pyrenaica, avispas Spheciformes, incendio forestal, estructura de la comunidad, Malaise, platos amarillos.

\section{Introducción}

El fuego es el tipo de perturbación natural más frecuente en los ecosistemas mediterráneos (Naveh, 1975; Trabaud \& Prodon, 1993) y es considerado uno de los principales problemas de sus bosques. En las últimas décadas, con sucesos más frecuentes y que afectan a áreas mayores, el fuego ha dejado de ser un fenómeno meramente natural (Moreno et al, 1998). El abandono del medio rural y el cambio de los usos del terreno han favorecido la presencia del fuego en sus términos más catastróficos en cuanto a intensidad y extensión (Pausas 2004; Moreno 2007). Dentro de la Región Mediterránea, considerada uno de los puntos calientes de biodiversidad (Mittermeier et al. 2005), la Península Ibérica en general y España en particular, representa uno de los 
casos más graves. Sin embargo, aún son pocos los estudios llevados a cabo sobre sus efectos, y la mayor parte de ellos se han centrado en la respuesta de distintas especies vegetales o sus comunidades (e.g. Luis-Calabuig \& Tárrega, 1993; De Luis et al. 2006; Capitanio \& Carcaillet 2008). Mucho menores son los datos existentes sobre la influencia del fuego sobre los diferentes grupos de vertebrados en general (e.g. Torre \& Díaz, 2004) e insectos en particular, tanto en la Región Mediterránea (e.g. Potts et al. 2001, 2003, 2005; Ne’eman et al. 2000) como en la Península Ibérica (e.g. García Villanueva et al, 1998; Nunes et al. 2000; Fernández \& Salgado, 2004; Arnan et al. 2006; Rodrigo et al. 2008). El fuego puede afectar a la estructura de muchas comunidades de invertebrados, ya sea mediante el efecto directo de las llamas, el humo y las altas temperaturas, o a través de las modificaciones producidas en el medio tras su paso (Whelan, 1995; York, 2000; Swengel, 2001; Moretti et al. 2004).

El Parque Natural Arribes del Duero (oeste español) es una claro ejemplo de agroecosistema mediterráneo en mosaico, altamente heterogéneo y con una marcada variedad de paisajes y alternancia de usos del terreno (Luis-Calabuig, 2008). Con una gran diversidad entomológica y una elevada importancia desde el punto de vista biogeográfico (González et al. 2009), es a su vez una zona muy afectada por la presencia del fuego (Junta de Castilla y León- www. jcyl.es). El principal objetivo de este estudio es conocer cómo varía la estructura de la comunidad de avispas Spheciformes (Hymenoptera: Apoidea), propuestas como posible grupo indicador de diversidad (Gayubo et al. 2005), a lo largo de quince años tras un incendio superficial y de intensidad baja-media ocurrido en verano. Igualmente se pretende analizar la influencia ejercida sobre dichas comunidades por las condiciones climatológicas reinantes después del suceso perturbador, así como contrastar la información obtenida sobre las comunidades mediante el empleo de dos métodos de muestreo diferentes: trampas Malaise y platos amarillos.

\section{Métodos}

\section{Área de estudio}

El estudio se realizó dentro del Parque Natural de Arribes del Duero (Salamanca, España). Este Espacio Protegido, muy interesante por su diversidad entomológica y significado biogeográfico, tanto a nivel peninsular como europeo (González et al., 
2009), se encuentra especialmente afectado por los incendios forestales. El área analizada, ubicada en la penillanura, comprende la mayor extensión del territorio con representación de bosques galaico-portugueses con Quercus pyrenaica Willd, de interés comunitario para la Unión Europea (Bartolomé et al., 2005: 230-231). Constituida por bosques adehesados (Escudero Alcántara et al., 2008: 366; Luis-Calabuig, 2008), dicha zona se caracteriza por su naturalidad y gran cantidad de vegetación arbustiva (GarcíaFeced et al., 2007), favorecida por el abandono de la agricultura intensiva en favor de la ganadería extensiva. Quercus pyrenaica Willd es una especie adaptada a las perturbaciones, debido a la constante presión ejercida por el hombre a lo largo del tiempo a través del fuego, corta y pastoreo (Luis-Calabuig \& Tárrega, 1993; Calvo et al., 1991, 1999; Luis-Calabuig et al., 2001).

La región posee un mesoclima mediterráneo, con una temperatura media anual suave y precipitaciones medias en torno a los $700 \mathrm{~mm} / \mathrm{año}$ (Calonge-Cano, 1990). Solamente existen leftosoles como suelos representativos.

\section{Características de los incendios}

Los incendios que predominan en el área de estudio son superficiales, rápidos, de intensidad baja-media, en su mayoría de origen antrópico (generalmente intencionados) (Plan 42, JCyL) y producidos en verano. Además, existen algunos factores que favorecen la heterogeneidad del paisaje, permitiendo la existencia de parches sin quemar dentro del área incendiada. Entre estos factores, destacan la presencia de pequeños viñedos labrados, grandes superficies de roca madre desnuda dispersa y prados delimitados por muros de piedra que, en ocasiones, actúan como cortafuegos.

\section{Muestreo de las avispas spheciformes}

Se emplearon dos métodos de muestreo: trampa Malaise (en adelante MT) de color blanco y yellow pan traps (YPT) (22 cm de diámetro y $3 \mathrm{~cm}$ de profundidad).

Se analizaron tres incendios similares ocurridos en los años 2004, 2002 y 1998, es decir, uno, tres y siete años antes de comenzar el estudio (iniciado en 2005). Empleando la "sustitución de espacio por tiempo" propuesta por Picket (1989), se 
estableció una sucesión cronológica que comprendió el periodo de recuperación que va de 1 a 3 años para el primero de ellos, los años 4 y 5 para el segundo incendio, y de 7 a 9 años para el incendio ocurrido en 1998 (ver Tabla I).

Las zonas muestreadas, próximas entre sí, poseían características físicas, geológicas y edafológicas semejantes. Las localidades muestreadas, características de los incendios y tiempo transcurrido tras ellos, así como el número de MT and YPT empleados en cada uno de ellos, se reflejan en la Tabla I.

Tabla I: Resumen de las principales características de las zonas estudiadas. MT = trampa Malaise; YPT = platos; F= Fuego; $\mathrm{C}=$ Control. * Nótese que en las localidades $2 \mathrm{~F}$ y $3 \mathrm{~F}$ sólo se muestrearon dos años.

\begin{tabular}{|c|c|c|c|c|c|c|c|c|}
\hline & Localidad & $\begin{array}{c}\text { Año del } \\
\text { incendio }\end{array}$ & Extensión & $\begin{array}{c}\text { Fecha } \\
\text { del } \\
\text { incendio }\end{array}$ & SY (Jun.-Sept.) & $\begin{array}{l}\text { Age (Años } \\
\text { post-fuego) }\end{array}$ & MT/SY & YPT/SY \\
\hline \multirow{3}{*}{ 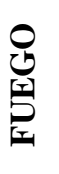 } & $1 \mathrm{~F}$ & 2004 & 120 ha & Agosto & 2005, 2006, 2007 & $1,2,3$ & 3 & 240 \\
\hline & $2 \mathrm{~F}$ & 2002 & 452 ha & Octubre & 2006, 2007 & 4,5 & 3 & 240 \\
\hline & $3 \mathrm{~F}$ & 1998 & $110 \mathrm{ha}$ & Agosto & 2005, 2007 & 7,9 & 3 & 240 \\
\hline \multirow{2}{*}{ 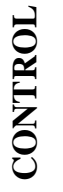 } & $1 \mathrm{C}$ & $\ldots$ & $\ldots$ & $\ldots$ & $2005,2006,2007$ & $13,14,15$ & 2 & 160 \\
\hline & $2 \mathrm{C}$ & $\ldots$ & $\ldots$ & $\ldots$ & 2005, 2006, 2007 & & 1 & 80 \\
\hline
\end{tabular}

Debido a la presencia histórica del fuego en el área analizada, las zonas Control fueron consideradas como representativas de un fuego ocurrido 13 años antes de comenzar el estudio, a pesar de encontrarse recuperadas.

Se instalaron 30 MT en total: 3 MT en el interior de cada una de las tres zonas quemadas y de los dos Controles, por cada año en que fueron muestreadas (Tablas I, II). Las distancias de las trampas al el borde más cercano sin quemar, varió entre los $102 \mathrm{~m}$ y $\operatorname{los} 400 \mathrm{~m}$. Las tres trampas colocadas simultáneamente en una misma zona se encontraban lo suficientemente separadas entre sí ( $80 \mathrm{~m}$ de distancia media) como para considerar la no existencia de interferencias entre ellas en las capturas. Alrededor de cada MT se delimitó una parcela de $10 \mathrm{~m}$ x $10 \mathrm{~m}$ en la que se colocaron 20 YPT, cinco en cada lateral. Los YPT se enterraron en el suelo hasta su borde superior, rellenándose casi en su totalidad de agua jabonosa con sal, que actuó como conservante. La distancia entre YPT fue de $2 \mathrm{~m}$ aproximadamente, condicionado por la presencia de vegetación y 
sustrato adecuado para su colocación. Para facilitar su localización, dificultada por la frondosidad vegetal existente en determinadas zonas, su posición se señalaba con pequeñas estacas de color anaranjado. La elección del color amarillo respondió por una parte a que es el color que mejores resultados ofrece para los himenópteros, y más concretamente para la familia Apoidea (Ortiz-Sánchez \& Aguirre-Segura, 1993), y por otra a que es el color más común entre las flores existentes en el área estudiada (y de las que se alimentan los adultos del grupo analizado), por lo que su resultado debería ser óptimo (Toler et al., 2005; Campbell et al., 2007; Westphal et al., 2008). La suma total de YPT empleados fue de 2.400 (Tabla II). Ambos métodos de captura ya han sido utilizados satisfactoriamente en el análisis de comunidades de insectos afectadas por el fuego (Cancelado \& Yonke, 1970; Hansen, 1988; Lockwood et al., 1996; Makihara et al., 2000; Hirowatari et al., 2007).

Table II: Número global y parcial de trampas empleadas en el estudio, por localidad y por año de muestreo (SY).

\begin{tabular}{|c|c|c|c|c|c|c|}
\hline \multirow[b]{3}{*}{ Localidad } & \multicolumn{6}{|c|}{ Año de muestreo \& Método de captura } \\
\hline & \multicolumn{3}{|c|}{ MT } & \multicolumn{3}{|c|}{ YPT } \\
\hline & 2005 & 2006 & 2007 & 2005 & 2006 & 2007 \\
\hline $\mathbf{1 F}$ & 3 & 3 & 3 & 240 & 240 & 240 \\
\hline $2 F$ & $\ldots$ & 3 & 3 & $\ldots$ & 240 & 240 \\
\hline 3F & 3 & $\ldots$ & 3 & 240 & $\ldots$ & 240 \\
\hline $1 C+2 C$ & 3 & 3 & 3 & 240 & 240 & 240 \\
\hline Total MT/SY & 9 & 9 & 12 & 720 & 720 & 960 \\
\hline Trampas totales & & 30 & & & 2400 & \\
\hline
\end{tabular}

MT = Malaise Trap; YPT= Yellow Pan Traps; F= Fire; $\mathrm{C}=$ Control.

El periodo de captura abarcó los meses de junio a septiembre (ambos inclusive) durante los tres años consecutivos que duró el muestreo. Las capturas pertenecientes a cada MT se recogieron quincenalmente, mientras que las correspondientes a los YPT (colocadas el día 15 de cada mes), se recogieron mensualmente, tras permanecer activas durante 48 horas. Cuando la climatología fue desfavorable, impidiendo la actuación de los YPT, el muestreo se repitió dos días más tarde, hasta obtener una muestra de YPT por mes y área muestreada. A pesar de ello, la muestra correspondiente al mes de junio de 2005 no pudo obtenerse, debido a las adversas condiciones climatológicas y al impacto provocado por rebaños de ganado doméstico y/o de la fauna de mamíferos 
salvajes. Las muestras fueron trasladadas al laboratorio, donde se prepararon e identificaron los ejemplares capturados hasta nivel específico para su análisis cuantitativo. El material recogido se halla depositado en la colección entomológica del Área de Zoología del Departamento de Biología Animal, Ecología, Edafología, Parasitología y Química Agrícola de la Universidad de Salamanca.

\section{Análisis estadístico}

Se empleó el índice de complementariedad de Colwell y Coddington (Colwel \& Coddington, 1994) para comparar los resultados obtenidos, para el global de la comunidad (MT+PL), entre: 1) años post-fuego, atribuyendo una edad de 13 años a las zonas control, en el momento de iniciar el estudio (2005); 2) años de muestreo (SY) (2005, 2006, 2007); 3) áreas quemadas y no quemadas (controles) para cada uno de los años de muestreo y; 4) los dos métodos de muestreo empleados, MT y YPT, a lo largo de todo el periodo sucesional.

Todos los análisis multivariantes de la comunidad se realizaron utilizando la aplicación informática PRIMER v5 (Ver Clarke \& Warwick, 2001). En el estudio de la beta diversidad para las muestras obtenidas, los datos se transformaron logarítmicamente $[\log (\mathrm{x}+1)]$ para reducir el peso de las especies más abundantes. Para analizar la relación entre las distintas muestras se generaron representaciones en dos o tres (para facilitar su interpretación en los casos más complejos) dimensiones mediante la realización de varios Análisis de Escalamiento Multidimensional (MDS), utilizando como medida de proximidad el coeficiente de Bray-Curtis. Los análisis incluyeron las muestras obtenidas de: 1) las 3 MT agrupadas por localidad y año de muestreo; 2) los YPT agrupados por localidad y año de muestreo; 3) la suma de las muestras obtenidas mediante MT y YPT, agrupadas por localidad y año de muestreo y; 4) las muestras independientes de los apartados 1) y 2) (Ver Tabla II). Se realizaron también análisis de similitud (ANOSIM), con 999 permutaciones, sobre las comunidades de Spheciformes muestreadas. ANOSIM es un procedimiento de permutación no paramétrico para valorar las diferencias entre grupos de muestras. Produce un estadístico, R, que compara los rangos de similitud entre las muestras dentro de los grupos con los existentes entre los grupos. $\mathrm{R}$ varía habitualmente entre 0 y 1 , siendo igual a 1 sólo cuando todas las réplicas dentro de los grupos son más similares entre sí que con cualquiera de las 
muestras que no pertenecen al grupo, mientras que $\mathrm{R}$ es aproximadamente igual a 0 cuando las similitudes dentro y entre los grupos son las mismas por término medio. Se examinó si existían diferencias significativas entre: 1) las zonas perturbadas o no;2) los años de muestreo (SY); 3) las localidades de muestreo (incendios analizados y zonas control) y; 4) las zonas de menor y mayor tiempo transcurrido desde el fuego. Dado la rápida recuperación vegetal, observada en la localidad representativa de los años 7 y 9 después del fuego, se llevaron a cabo ANOSIMs con distintas agrupaciones muestrales, para determinar si dicha recuperación vegetal se reflejaba en la comunidad de Spheciformes y si las comunidades de la zona representativa de los años 7 y 9 después del fuego eran más semejantes a las zonas con incendios más recientes (1-5 años postfuego), o a las zonas control (13-15 años post-fuego). Estas agrupaciones fueron: a) 1-5; 7 y 9; 13-15 años post-fuego; b) 1-5; 7, 9 y 13-15 años post-fuego.

\section{Resultados}

Se capturaron un total 10.896 individuos, pertenecientes a 141 especies (Anexo 1). De ellos, 8.290 individuos y 129 especies se colectaron mediante MT, mientras que 2.606 individuos y 92 especies se recogieron con YPT. 49 especies se capturaron sólo con MT, mientras que 13 fueron exclusivas de YPT (ver Anexo 2).

\section{Complementariedad}

Tabla III: Resultados, en porcentajes, obtenidos para el índice de complementariedad calculado entre los años postfuego. Entre paréntesis se indica el número de especies comunes para ambas muestras.

\begin{tabular}{|c|c|c|c|c|c|c|c|c|c|c|}
\hline \multirow[b]{2}{*}{$\begin{array}{l}\text { Edad (años } \\
\text { post-fuego) }\end{array}$} & \multicolumn{7}{|c|}{ FUEGO } & \multicolumn{3}{|c|}{ CONTROL } \\
\hline & 1 & 2 & 3 & 4 & 5 & 7 & 9 & 13 & 14 & 15 \\
\hline 1 & $\ldots$ & & & & & & & & & \\
\hline 2 & $44,9(54)$ & $\ldots$ & & & & & & & & \\
\hline 3 & $58,9(39)$ & $47,1(45)$ & $\ldots$ & & & & & & & \\
\hline 4 & $52,5(48)$ & $44(50)$ & $52,4(40)$ & $\ldots$ & & & & & & \\
\hline 5 & $58,7(37)$ & $55,2(39)$ & $43,5(39)$ & 51,9 (39) & & & & & & \\
\hline 7 & $40,2(55)$ & $49,5(48)$ & $54,7(39)$ & $46,1(48)$ & $50,6(40)$ & $\ldots$ & & & & \\
\hline 9 & $52,2(54)$ & $47,7(56)$ & $50,5(48)$ & $51,9(51)$ & $53,1(44)$ & $46,6(55)$ & $\ldots$ & & & \\
\hline 13 & $50(49)$ & $46,2(50)$ & $56,3(38)$ & $38,8(52)$ & $56(37)$ & $44,9(49)$ & $46,6(55)$ & $\ldots$ & & \\
\hline 14 & $47,6(55)$ & $39,2(59)$ & $48,4(47)$ & $42,1(55)$ & $52,7(43)$ & $47,5(52)$ & $41,7(63)$ & $41,1(56)$ & $\ldots$ & \\
\hline 15 & $50,5(54)$ & $42,6(58)$ & $48,4(48)$ & $45,5(54)$ & $49,5(46)$ & $46(54)$ & $34,3(69)$ & $39,6(58)$ & $33(66)$ & \\
\hline
\end{tabular}


1) Al analizar los valores del índice de complementariedad entre pares de muestras en función de los años post-fuego, se obtuvieron en general valores medios, siendo mayoritarios los valores inferiores al 50\% (Tabla III). Las muestras con un mayor índice de complementariedad (y por lo tanto un menor número de especies en común), con respecto al resto, fueron las correspondientes a los años 1, 3 y 5 después del incendio.

2) Del análisis de las muestras en función de los SY, se observaron valores relativamente bajos de complementariedad, no superándose en ningún caso el $40 \%$ (Tabla IV).

Tabla IV: Resultados, en porcentajes, obtenidos para el índice de complementariedad calculado entre los años de muestreo, para el global de la comunidad. Entre paréntesis especies en común para ambas muestras.

\begin{tabular}{cccc}
\hline & $\mathbf{2 0 0 5}$ & $\mathbf{2 0 0 6}$ & $\mathbf{2 0 0 7}$ \\
\hline $\mathbf{2 0 0 5}$ & $\ldots$ & & \\
$\mathbf{2 0 0 6}$ & $33,6(83)$ & $\ldots$ & \\
$\mathbf{2 0 0 7}$ & $36,6(83)$ & $35,7(83)$ & $\ldots$ \\
\hline
\end{tabular}

3) Los valores de complementariedad de las zonas quemadas, respecto a las zonas no quemadas, en los diferentes SY, mostraron nuevamente la existencia de un número elevado de especies en común. Se observó sin embargo una diferencia entre el primer SY (2005), con un número relativamente inferior de especies en común, y el resto de SY (Tabla V).

Tabla V: Resultados, en porcentajes, del índice de complementariedad calculado entre las muestras pertenecientes a áreas quemadas y áreas control en los respectivos años de muestreo. Entre paréntesis especies en común para ambas muestras.

\begin{tabular}{|c|c|c|c|c|c|c|}
\hline & \multicolumn{2}{|c|}{2005} & \multicolumn{2}{|c|}{2006} & \multirow[t]{2}{*}{2007} & \multirow[b]{2}{*}{ Total $($ FvsC)/SY } \\
\hline & $\mathbf{F}$ & $\mathrm{C}$ & $\mathbf{F}$ & $\mathbf{C}$ & & \\
\hline 2005 & $\ldots$ & $\ldots$ & $\ldots$ & $\ldots$ & $\ldots$ & $46,7(56)$ \\
\hline 2006 & $42,2(67)$ & $41,1(56)$ & $\ldots$ & $\ldots$ & $\ldots$ & $32(70)$ \\
\hline 2007 & $42,6(70)$ & $39,6(58)$ & $43,4(69)$ & $33(67)$ & $\ldots$ & $30,3(76)$ \\
\hline
\end{tabular}


4) Al analizar las muestras obtenidas con MT y YPT, se obtuvieron valores elevados de complementariedad, reflejo de un bajo número de especies en común entre ambos métodos de muestreo (Tabla VI).

Tabla VI: Resultados del valor del índice de complementariedad calculado entre las muestras obtenidas con trampa Malaise y las obtenidas con platos amarillos. Especies capturadas por cada una de las trampas, especies totales y especies en común.

\begin{tabular}{ccccc}
\hline $\begin{array}{c}\text { Edad (años } \\
\text { post-fuego) }\end{array}$ & MT & YPT & $\begin{array}{c}\text { Especies } \\
\text { en común }\end{array}$ & $\begin{array}{c}\text { Índice de } \\
\text { Complementariedad } \\
(\boldsymbol{\%})\end{array}$ \\
\hline $\mathbf{1}$ & 63 & 38 & 23 & 70.5 \\
$\mathbf{2}$ & 63 & 35 & 24 & 67.6 \\
$\mathbf{3}$ & 52 & 19 & 14 & 75.4 \\
$\mathbf{4}$ & 52 & 33 & 16 & 76.8 \\
$\mathbf{5}$ & 49 & 19 & 15 & 71.7 \\
$\mathbf{7}$ & 61 & 35 & 27 & 60.9 \\
$\mathbf{9}$ & 81 & 33 & 25 & 71.9 \\
$\mathbf{1 3}$ & 58 & 36 & 25 & 63.8 \\
$\mathbf{1 4}$ & 70 & 35 & 23 & 72.0 \\
$\mathbf{1 5}$ & 78 & 27 & 20 & 76.5 \\
\hline $\mathbf{N}^{\mathbf{0}}$ especies & $\mathbf{1 2 7}$ & $\mathbf{9 4}$ & $\mathbf{8 0}$ & $\mathbf{4 3 . 3}$ \\
\hline
\end{tabular}

Los valores más bajos del índice de complementariedad se obtuvieron para el año siete y el trece después del fuego, mientras que los más elevados correspondieron a los años cuatro, quince y tres respectivamente (Tabla VI).

\section{MDS y ANOSIM}

1) MT agrupadas por localidad y año de muestreo (Fig. 1) (Tabla II): El MDS bidimensional obtenido refleja similitudes entre muestras obtenidas poco tiempo después del incendio frente a las procedentes de comunidades en fases mediasavanzadas de recuperación (1-5 años y >7 años), así como también mayores similitudes entre las muestras obtenidas en cada uno de los diferentes años de muestreo (2005, 2006, 2007) (Fig. 1). El agrupamiento de muestras en función del tiempo transcurrido desde el incendio, del año de muestreo y de la localidad o incendio analizado (ver Tabla I), revela grupos significativamente definidos al testarlo con ANOSIM. Este análisis muestra el mayor grado de significatividad para el tiempo transcurrido tras el fuego $(\mathrm{R}$ global $=0,452, p=0,008)$. Por otro lado, los valores obtenidos para los incendios 
analizados y los años de muestreo, también significativos, son muy semejantes entre ellos (Tabla VII).
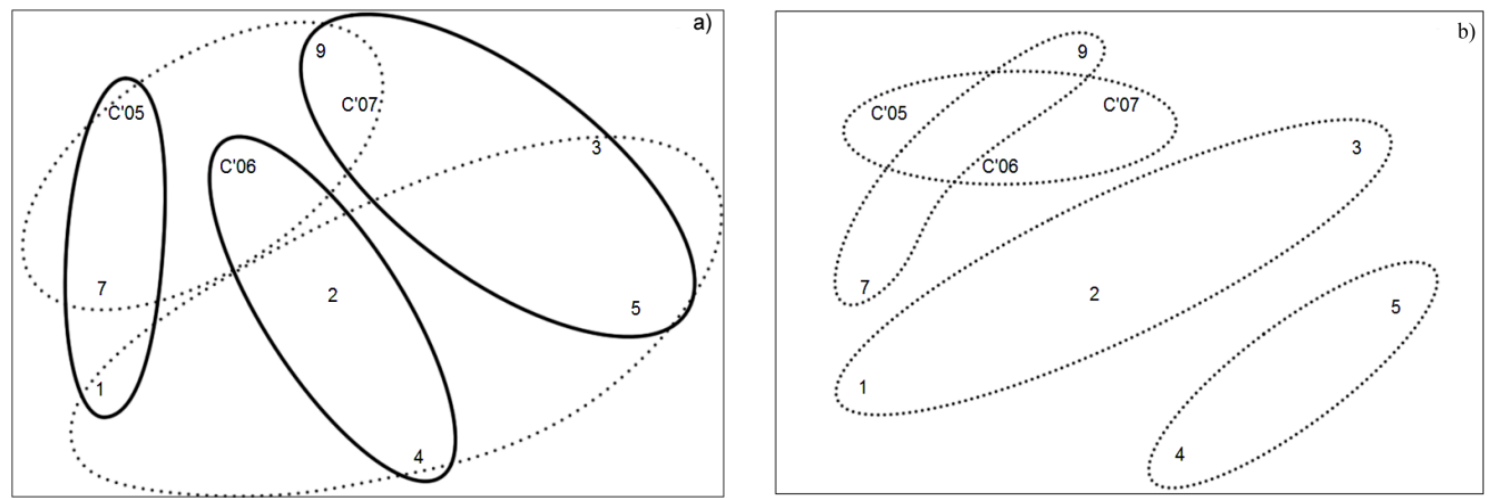

Figura 1: Gráfico MDS para las muestras de trampas Malaise. a) Las muestras recogidas durante el mismo año de muestreo $(2005,2006$ y 2007) aparecen rodeadas con línea continua. Por otra parte, las muestras correspondientes a edades post-fuego tempranas ( 1 a 5 años), y a edades tardías (> 7 años), se muestran rodeadas con línea discontinua.

b) Agrupación de las muestras pertenecientes a los distintos incendios analizados. Stress $=0.1$.

1) YPT agrupados por localidad y año de muestreo (Fig. 2): Las muestras pertenecientes a los controles aparecen agrupadas entre sí, y separadas de las de áreas quemadas. Por otra parte, tanto las muestras de la misma localidad como las correspondientes al mismo año de muestreo muestran mayores similitudes entre sí que con el resto de muestras, tal como revelan los resultados del ANOSIM (Tabla 7).
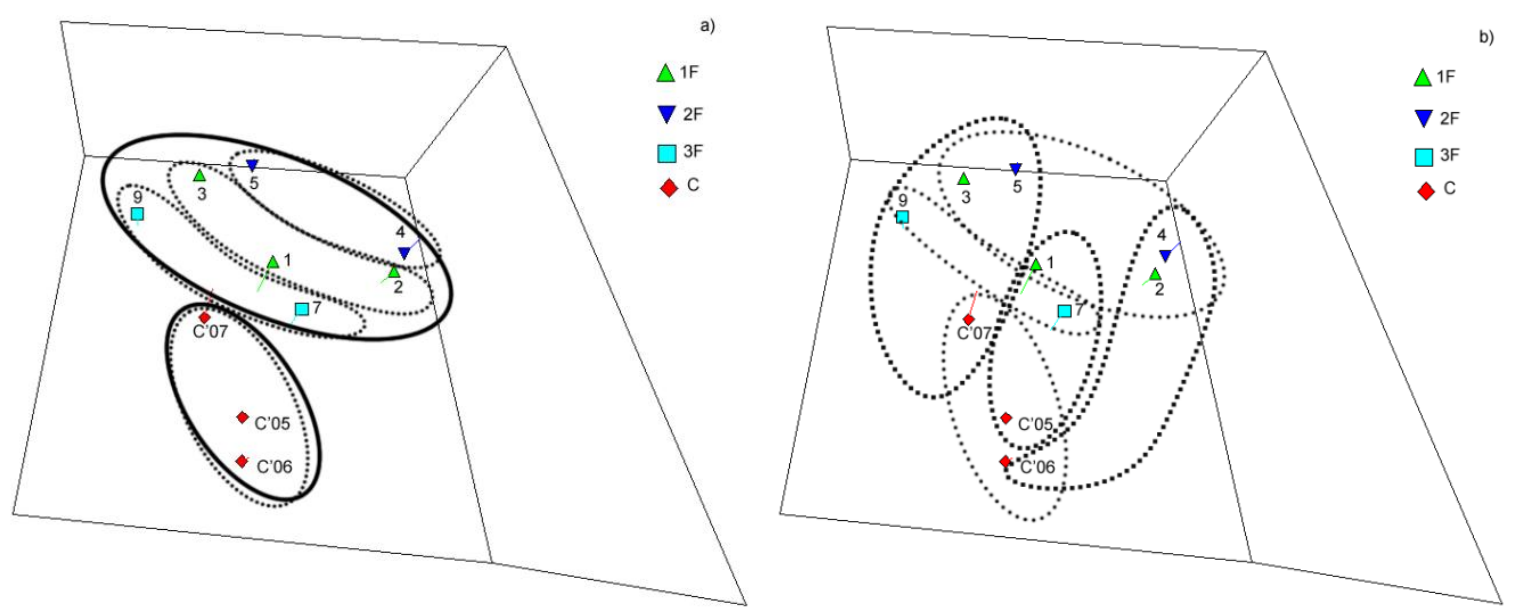

Figura 2: Gráfico MDS, tridimensional, para las muestras de YPT (platos amarillos) agrupados por localidad y año de muestreo. a) Áreas perturbadas y Control rodeados con línea continua; Localidades (incendios) analizados rodeados por línea discontinua. b) Años de muestreo rodeados con línea discontinua de cuadros; Fases temprana, intermedia y final rodeados por línea discontinua de puntos. Stress $=0.16$. 
3) Suma de las muestras obtenidas mediante MT y YPT, agrupadas por localidad y año de muestreo (Fig. 3): El MDS obtenido fue muy similar al llevado a cabo con las MT agrupadas por localidad y año de muestreo, revelándose agrupamientos significativos por año de muestreo, tiempo transcurrido desde el incendio y localidad (Tabla 7).

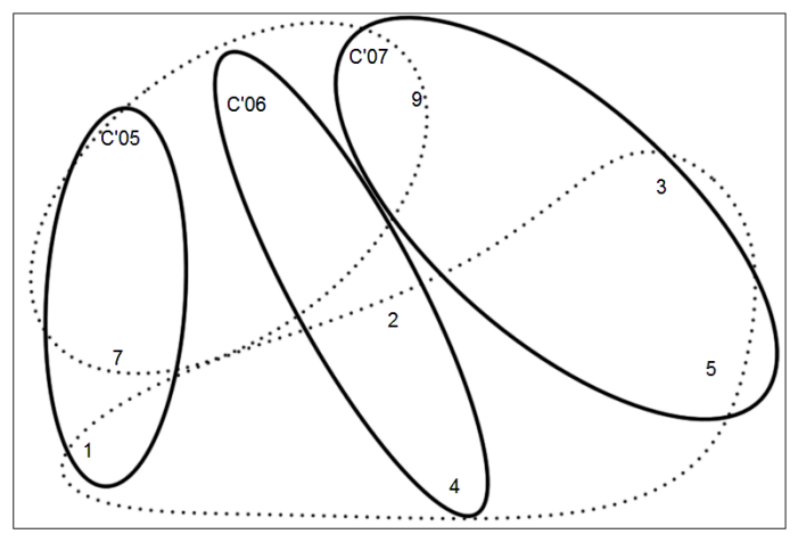

Figura 3: Gráfico MDS para las muestras de trampas Malaise y platos agrupados por localidad y año de muestreo. Años de muestreo rodeados con línea continua. Agrupación de edades post-fuego tempranas y edades tardías rodeados con línea discontinua. Stress $=0,1$.

4) Muestras independientes de las MT y los YPT, agrupadas por localidad y año de muestreo (Fig. 4) (Apartados 1 y 2): Se manifestó una clara separación de las muestras obtenidas con cada uno de los métodos de muestreo, diferencia corroborada por el ANOSIM llevado a cabo $(\mathrm{R}=0.999 ; p=0.001)$.

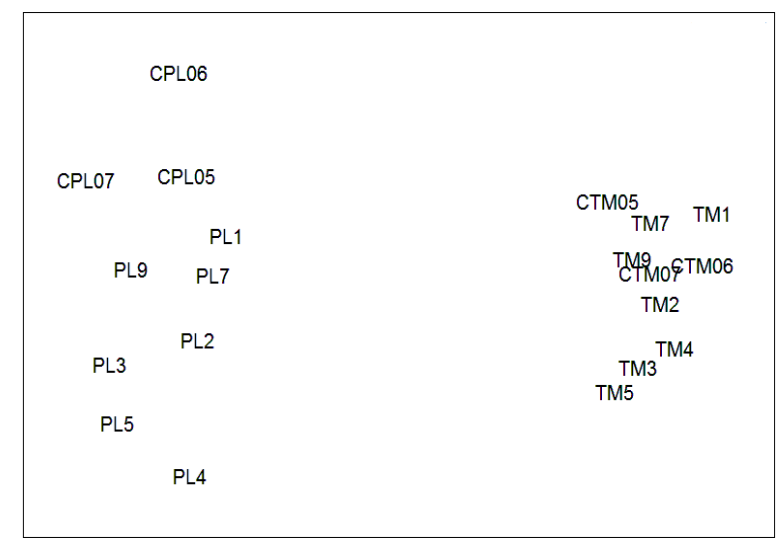

Figura 4: Gráfico MDS para las muestras de trampas Malaise frente a platos amarillos. Stress $=0.1$ MT $=$ trampa Malaise; $\mathrm{PL}=$ Platos. $\mathrm{C}=$ Control. $05=$ año $200506=$ año 2006; $07=$ año 2007. Los números restantes indican el año post-fuego. 
Tabla VII: Resultados de los ANOSIM para cada una de las muestras y agrupaciones empleadas. El valor de R refleja el grado de separación de los grupos comparados, en base a su composición de especies: Si R tiene un valor próximo a 1 los grupos son diferentes, mientras que si es cercano a 0 , los grupos son similares. MT $=$ Trampa

Malaise; YPT $=$ Platos amarillos. $*=p<0.05 ; * *=p<0.01 ; * * *=p<0.001 ; \mathrm{NS}=$ No significativo.

\begin{tabular}{lcccccc}
\hline & $\begin{array}{c}\text { TM agrupadas / } \\
\text { localidad /año de } \\
\text { muestreo } \\
\text { 3 TM = 1 muestra }\end{array}$ & $\begin{array}{c}\text { YPT agrupados / } \\
\text { localidad /año de } \\
\text { muestreo } \\
\text { 240 YPT = 1 } \\
\text { muestra }\end{array}$ & $\begin{array}{c}\text { TM + YPT / localidad / } \\
\text { año de muestreo } \\
\mathbf{3} \text { TM + 240 YPT = 1 } \\
\text { muestra }\end{array}$ \\
\hline & R Global & $\boldsymbol{p}$ & R Global & $\boldsymbol{p}$ & R Global & $\boldsymbol{p}$ \\
\hline Fuego-Control & 0.036 & NS & 0.579 & 0.008 & 0.087 & NS \\
Año de muestreo & 0.444 & 0.017 & 0.46 & 0.018 & 0.51 & 0.008 \\
$\begin{array}{l}\text { Localidad } \\
\text { Agrupación 1: 1-5; 7 y 9; }\end{array}$ & 0.5 & 0.015 & 0.52 & 0.013 & 0.473 & 0.021 \\
$\begin{array}{l}\text { Controles } \\
\text { Agrupación 2: 1-5; 7, 9 y Controles }\end{array}$ & 0.23 & NS & 0.387 & 0.028 & 0.217 & NS \\
\hline
\end{tabular}

\section{Discusión}

Los valores medios de complementariedad (46\% de media) entre las muestras analizadas a lo largo de los años post-fuego, indican que la variación del tipo de especies presentes cada año, aunque importante, no es excesivamente elevada al compararla con los datos obtenidos por Cruz-Sánchez et al. 2009 (in prep.). En dicho trabajo, realizado en el mismo Espacio Protegido para los dos años posteriores a un incendio, se hallaron valores ligeramente superiores a los obtenidos en el presente estudio cuando la comparación se realizaba con un área control (sin quemar) abierta y aclarada, semejante a la actual; sin embargo, cuando se comparaban el primer año postfuego y un área control de bosque maduro y cerrado de $Q$. pyrenaica, la complementariedad alcanzaba el 90\%, demostrándose la respuesta positiva de estas avispas al fuego, y su preferencia por hábitats abiertos, aclarados y muy soleados.

Como era de esperar, los menores valores de complementariedad se obtuvieron al comparar los últimos años de la sucesión analizada (13-15 años), reflejo de comunidades más maduras y estructuradas, ya recuperadas del impacto (Tabla III). Por el contrario, las mayores diferencias, derivadas de la comparación del primer año postfuego con el tercero y quinto respectivamente, podrían indicar la existencia de comunidades inmaduras y en pleno proceso de establecimiento o colonización de los nuevos recursos, espacios y nichos creados por el fuego. Esta diferencia se apreció también en el MDS resultante de analizar el global de la comunidad (MT + YPT), 
donde la muestra perteneciente al año 1, se dispuso separada de las de los años 3 y 5 después del fuego. Este hecho podría atribuirse, además de a la diferencia de edad postfuego, al efecto del año de muestreo, ya que el SY se mostró como un factor muy importante en la configuración de los MDS.

La respuesta de los insectos al fuego depende en gran medida de su capacidad de supervivencia al paso de las llamas, de su habilidad para colonizar el área quemada, de su capacidad de aprovechamiento de los nuevos recursos creados tras la acción del fuego, y/o del tiempo en que estos tarden en recuperar las condiciones previas al impacto (Whelan, 1995; Swengel, 2001). Las comunidades de Q. pyrenaica, especie arbórea dominante en la zona de estudio, se caracterizan por su gran resistencia y rápida capacidad de recuperación ante este tipo de impactos, debido fundamentalmente a la gran historia de fuegos, corta y pastoreo a que se han visto sometidas a lo largo de la historia (Calvo et al., 1991; Luis Calabuig et al., 2001) y que le han proporcionado distintos mecanismos de resistencia ante las perturbaciones. Esto hace suponer que las poblaciones de Spheciformes, así como las del resto de insectos, podrán disponer de nuevo, con relativa rapidez, de algunos de los recursos eliminados por el fuego.

El hecho de que la muestra correspondiente al noveno año post-fuego, mostrase valores menores de complementariedad al compararla con las zonas control (especialmente con la muestra representativa del año quince después del incendio), que con las zonas más recientemente quemadas (Tabla III), refleja que la recuperación de las comunidades de Spheciformes podría ser relativamente rápida, y seguramente asociada a la gran recuperación vegetal experimentada. El MDS llevado a cabo para el global de la comunidad (Fig. 3), en el que las áreas control (agrupadas entre sí y con la muestra del noveno año post-fuego), se disponen claramente alejadas del resto de muestras, corrobora este resultado. Por otra parte, los resultados del ANOSIM muestran agrupamientos significativos al añadir la muestra del año 7 al grupo formado por las muestras del noveno año post-fuego y los controles (Tabla VII). Ello podría estar relacionado con la existencia de un punto de inflexión en el proceso de recuperación de la comunidad que coincidiría aproximadamente con el año 7. Se demostraría así la gran capacidad de recuperación, supervivencia y colonización mostrada por estas avispas, de acuerdo con lo obtenido por Cruz Sánchez et al. (2009, in prep.) quienes, tras un descenso importante de la riqueza de Spheciformes inmediatamente después del incendio $(<2$ meses), registraron valores máximos de riqueza al segundo año tras el 
fuego, encontrando también los mayores valores de riqueza y abundancia en el interior del área quemada (al compararlos con áreas sin quemar), como sucede en el presente estudio.Este tipo de respuesta positiva al fuego ya ha sido obtenido por diferentes autores para otros grupos de artrópodos tales como arañas (Buddle et al., 2000; Moretti et al., 2004), escarabajos (Similä et al., 2000; Moretti et al., 2004; Hyvarinen et al., 2005), sírfidos, abejas y avispas (Moretti et al., 2004) u hormigas (York, 1996; Andersen \& Müller, 2000) entre otros, si bien el tipo de respuesta varía entre especies (Sieman et al., 1997; Swengel, 2001; Hanula \& Wade, 2003).

Debe destacarse también el hecho de que las muestras se agrupasen en función de los SY (Fig. 3), probablemente como consecuencia de las importantes variaciones interanuales que muestran las comunidades de estas avispas (al igual que las de la mayoría de insectos), muy condicionadas por los factores ambientales (en la medida en que estos influyen sobre la vegetación) y por las condiciones locales del medio, de las que dependen para su supervivencia (Tscharntke et al., 1998; Taki et al., 2008; Sobek et $a l .$, 2009). En este caso, 2005 fue un año particularmente seco, al igual que 2007 (este último en menor grado que el primero), mientras que 2006 puede ser considerado como “normal”, en cuanto a los valores medios de precipitación registrados. La sequía del primer SY (2005), habría incrementado las características propias del medio tras un incendio, y que se resumen en un aumento de las condiciones xéricas en general. A pesar de ello, 2005 fue el año en el que se recogió un mayor número de individuos (Anexo 1), reflejo del carácter heliófilo de este grupo y de su preferencia por hábitats abiertos, aclarados y con gran cantidad de luz (O’Neill, 2001). Los resultado obtenidos revelan una importante influencia de las variaciones ambientales interanuales (a través de la variable año de muestreo) y podrían haber determinado también la separación, en el MDS de la muestra del año 7 (correspondiente a 2005) con respecto al año 9 y los controles (Fig. 3).

Se sabe que el fuego puede alterar el crecimiento de las poblaciones y comunidades de insectos (Swengel, 2001), a través del cambio provocado en la estructura del hábitat (York, 2000; Parr et al., 2004), o la disponibilidad de recursos, entre otros (Potts et al., 2001, 2003, 2005). En nuestro estudio, los valores de complementariedad entre las zonas quemadas y no quemadas, en los distintos SY, fueron relativamente bajos (Tabla V). El primer año de muestreo (2005), existieron 
claramente menos especies en común entre las áreas quemadas y no quemadas que en el resto de años (2006 y 2007), en los que se obtuvieron los menores valores de complementariedad (32 \% y $30.3 \%$ respectivamente) (Tabla V). Este resultado probablemente se debe a que fue en 2005 cuando se muestreó el área correspondiente al primer año post-fuego, cuyas características estructurales y microclimáticas eran claramente diferentes a las de las zonas ya recuperadas, y por lo tanto con unas poblaciones de Spheciformes también marcadamente diferentes. Como era de esperar, los valores de complementariedad obtenidos al comparar las áreas quemadas entre sí, en los distintos SY, fueron mayores que los obtenidos para las zonas control, ya recuperadas y por lo tanto más parecidas entre sí (Tabla V).

Muchos de los cambios que ocurren en una comunidad son el resultado de interacciones entre las características del fuego en sí y de los procesos que tienen lugar tras el mismo (como las condiciones climatológicas y la supervivencia y atributos dispersivos de los organismos en relación al fuego), y a los procesos post-fuego (Whelan, 1995). En este caso, el ANOSIM confirmó la existencia de una menor similitud dentro de cada uno de los SY, así como la ausencia de diferencias entre las zonas perturbadas y no perturbadas, para el global de la comunidad (Tabla VII). Estos resultados indicarían que las variaciones climatológicas, causantes en parte de la variación interanual de las comunidades de Spheciformes, podrían ser más importantes para este tipo de insectos que la propia presencia del fuego.

Tras analizar todas las muestras (MT + YPT), según el ANOSIM, las localidades muestreadas -controles, incendio de 2004, 2002 y 1998- presentaron una aparente disimilitud entre ellas (Tabla VI). Esta diferencia, seguramente fue fruto de la variación en la estructura y condiciones locales del hábitat, marcadas generalmente por el mayor o menor desarrollo y cobertura de los diferentes estratos de vegetación (Farji-Brener et al., 2002; Parr et al., 2004), y derivadas de la distinta edad post-fuego representada por cada una de las localidades analizadas. Sin embargo, dichas diferencias entre localidades no tuvieron su reflejo en el gráfico MDS, donde, aparentemente, el mayor peso a la hora de distribuir las muestras vino ejercido por los SY (Fig. 3; Tabla VII). 


\section{Análisis de los diferentes métodos de muestreo}

La mayoría de los variados métodos de captura de insectos se basan en algún aspecto comportamental de los mismos, ya sea para atraerlos o para atraparlos (Leather, 2005). Por lo tanto, la eficiencia de captura depende de un elevado número de factores biológicos, ecológicos y ambientales, a menudo difíciles de determinar. En este caso, mediante la utilización de dos métodos de muestreo diferentes, un método pasivo de interceptación aérea (MT) y otro activo basado en la atracción ejercida por el color YPT), se obtuvo un elevado grado de complementariedad (bajo número de especies comunes a ambos métodos) a lo largo del periodo sucesional post-fuego. Estas diferencias se debieron tanto al método de actuación de cada trampa, como al distinto esfuerzo de muestreo empleado con cada uno de ellos (mucho mayor en el caso de las MT, ver Material y Métodos), lo que se reflejó en la disposición de las muestras en los MDS realizados con las capturas de ambos métodos (Fig. 4).

El hecho de que el MDS resultante de analizar exclusivamente las muestras provenientes de MT (Fig. 1), fuese muy similar al obtenido para el global de la comunidad (Fig. 3), es un reflejo del peso ejercido por el mayor número de capturas llevadas a cabo con este método, muy superiores a las obtenidas con YPT (Anexo 1). En cualquier caso, queda también patente la influencia del factor SY (Fig. 1).

El MDS realizado con las muestras de YPT (Fig. 2) es claramente diferente al obtenido para el global de la comunidad (Fig. 3). Aunque refleja nuevamente la gran influencia ejercida por los SY, revela también la existencia de mayores similitudes entre las muestras de las zonas quemadas por una parte y las procedentes de áreas no quemadas por otra, con dos grupos bien separados. En las zonas control, la vegetación, más densa y de mayor altura (especialmente en su estrato arbustivo), que la de las zonas quemadas, pudo influir negativamente sobre la capacidad de atracción de las YPT, al reducir su visibilidad a grandes distancias. Este hecho determinaría la captura preferente de aquellas especies que se moviesen en sus proximidades.

Considerando estos resultados, así como la cantidad de especies capturadas exclusivamente por cada uno de estos métodos (Anexo 2), parece aconsejable la utilización de ambos tipos de trampas en los estudios en los que se desee analizar la recuperación de poblaciones de Spheciformes tras sufrir un incendio, ya que 
el diferente sesgo introducido en las capturas permitirá registrar un mayor número de especies y proporcionará un mayor grado de conocimiento de las comunidades de Spheciformes presentes en cada una de las fases de recuperación del área impactada. Estos datos se han visto confirmados por el ANOSIM, que revela similitudes muy superiores entre las muestras obtenidas con un mismo método de captura y tiene también su reflejo en el MDS llevado a cabo con las muestras obtenidas por ambos métodos por separado (Fig. 4), si bien debe considerarse que el esfuerzo de muestreo realizado con la trampa Malaise fue muy superior al llevado a cabo con los YPT.

En conclusión, este trabajo muestra la gran capacidad de recuperación que presentan las comunidades de Spheciformes analizadas, destacando la rapidez con la que alcanzan un estado de madurez similar al de las zonas no afectadas por el fuego. Se pone de manifiesto también la gran importancia ejercida por las condiciones ambientales sobre la variación de dichas comunidades, favorecidas por la sequía existente el primer año tras el incendio y las condiciones de xericidad impuestas por el fuego. Los efectos provocados por dichas condiciones ambientales superaron incluso al provocado por la existencia o no de fuego en el área estudiada, condicionando la estructura de las comunidades analizadas. Sin olvidar la diferencia existente en el esfuerzo de muestreo llevado a cabo con MT y YPT, se registraron importantes diferencias en cuanto al tipo de comunidades registradas por ambos métodos, haciendo aconsejable el empleo de ambos en el análisis de la respuesta al fuego por parte de las comunidades de Spheciformes. 
Anexo 1: Valores de abundancia, riqueza y diversidad de las muestras analizadas. MT: Trampa Malaise; SY: Años de muestreo; YPT: Platos amarillos; N: Abundancia; S: Riqueza; H': Índice de diversidad de Shannon.

\begin{tabular}{|c|c|c|c|c|}
\hline & $\begin{array}{c}\text { Muestras de MT agrupadas por } \\
\text { localidad y SY }\end{array}$ & $\mathbf{N}$ & $\mathbf{S}$ & $\mathbf{H}^{\prime}$ \\
\hline \multirow{7}{*}{ FUEGO } & MT1 & 1868 & 63 & 2,916 \\
\hline & MT2 & 601 & 63 & 3,157 \\
\hline & MT3 & 393 & 52 & 3,047 \\
\hline & MT4 & 664 & 52 & 2,443 \\
\hline & MT5 & 290 & 49 & 3,318 \\
\hline & MT7 & 1112 & 61 & 3,092 \\
\hline & MT9 & 890 & 81 & 3,322 \\
\hline \multirow{4}{*}{ CONTROL } & MT13 & 941 & 58 & 3,207 \\
\hline & MT14 & 867 & 70 & 3,404 \\
\hline & MT15 & 664 & 78 & 3,629 \\
\hline & $\begin{array}{c}\text { Muestras de YPT agrupadas } \\
\text { por localidad y SY }\end{array}$ & $\mathbf{N}$ & $\mathbf{S}$ & $\mathbf{H}^{\prime}$ \\
\hline \multirow{7}{*}{ FUEGO } & YPT1 & 315 & 38 & 2,684 \\
\hline & YPT2 & 255 & 35 & 2,542 \\
\hline & YPT3 & 210 & 19 & 2,004 \\
\hline & YPT4 & 182 & 33 & 2,708 \\
\hline & YPT5 & 219 & 19 & 1,977 \\
\hline & YPT7 & 264 & 35 & 2,420 \\
\hline & YРT9 & 398 & 33 & 1,948 \\
\hline \multirow{4}{*}{ CONTROL } & YPT13 & 264 & 36 & 2,666 \\
\hline & YPT14 & 301 & 35 & 2,433 \\
\hline & YPT15 & 198 & 27 & 2,449 \\
\hline & $\begin{array}{c}\text { Muestras de MT y YPT } \\
\text { agrupadas por localidad y SY }\end{array}$ & $\mathbf{N}$ & $\mathbf{S}$ & $\mathbf{H}^{\prime}$ \\
\hline \multirow{7}{*}{ FUEGO } & 1 & 2183 & 78 & 3,042 \\
\hline & 2 & 856 & 74 & 3,202 \\
\hline & 3 & 603 & 56 & 2,960 \\
\hline & 4 & 846 & 68 & 2,842 \\
\hline & 5 & 509 & 52 & 3,033 \\
\hline & 7 & 1376 & 69 & 3,121 \\
\hline & 9 & 1288 & 89 & 3,104 \\
\hline \multirow{3}{*}{ CONTROL } & 13 & 1205 & 69 & 3,281 \\
\hline & 14 & 1168 & 82 & 3,481 \\
\hline & 15 & 862 & 85 & 3,610 \\
\hline
\end{tabular}


Anexo 2: Especies exclusivas, y abundancias, capturadas con cada tipo de trampa.

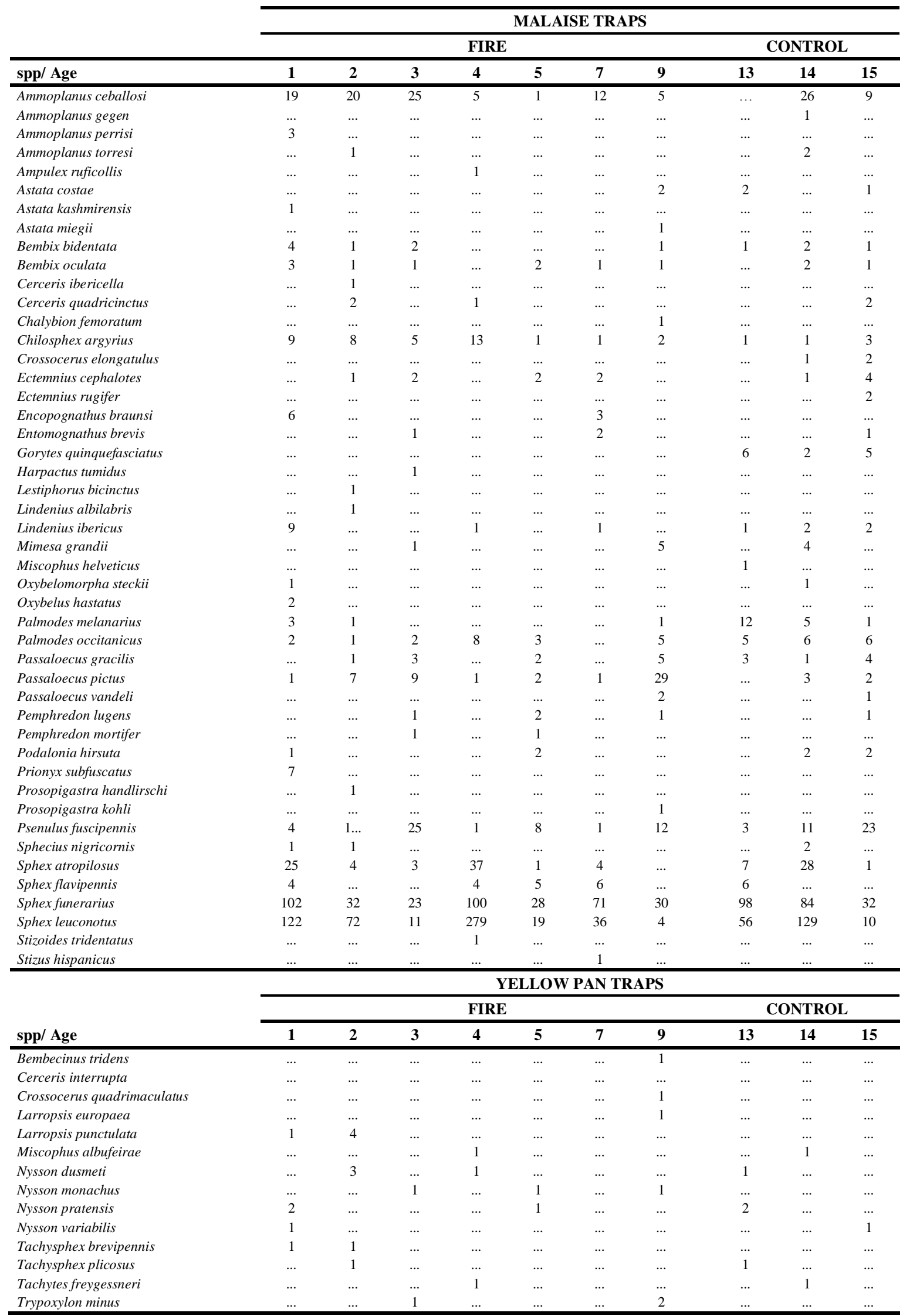




\section{Bibliografía}

Andersen, A. N. \& Müller, W. J. 2000. Arthropod responses to experimental fire regimes in an Australian tropical savannah: ordinal-level analysis. Austral Ecology 25: 199-209

Arnan, X. Rodrigo, A, \& Retana, J. 2006. Post-fire recovery of Mediterranean ground ant communities follows vegetation and dryness gradients. J. Biogeography 33 (7): 1246-1258

Buddle, C. M. Spence, J. R. \& Langor, D. W. 2000. Succession of boreal forest spider assemblages following wildfire and harvesting Ecography 23: 424-436

Calonge-Cano, G. 1990. La excepcionalidad climática de los Arribes del Duero. ERIA 21: 45-59

Calvo, L. Tárrega, R. \& Luis-Calabuig, E. 1991. Regeneration in Quercus pyrenaica ecosystems after surface fires. Int. J. Wildland Fire 1 (4): 205-210

Calvo, L. Tárrega, R. \& Luis-Calabuig. E. 1999. Post-fire succession in two Quercus Pyrenaica communities with different disturbance histories. Ann. For. Sci. 56: 441-447

Campbell, J. W., Hannula, J. L. \& Waldrop, T. A. 2007. Effects of prescribed fire and fire surrogates on floral visiting insects of the blue ridge province in North Carolina. Biolog. Conserv. 134: 393494

Cancelado, R. \& Yonke, T. R. 1970. Effects of prairie burning on insects populations, J. Kansas Entomological Society 43: 274-281

Capitanio, R. \& Carcaillet, C. 2008. Post-fire Mediterranean vegetation dynamics and diversity: A discussion of succession models. Forest Ecol Manag 255: 431-439

Clarke K, R, \& Warwick, R, M, 2001, Change in marine communities: An Approach to Statistical Analysis and Interpretation, $2^{\text {nd }}$ edition, PRIMER-E, Plymouth.

Colwell, R. K. \& Coddington, J. A. 1994. Estimating terrestrial biodiversity through extrapolation. Philosophical Transactions of the Royal Society of London, Series B 345: 101-118

De Luis, M., Raventós, J. \& González-Hidalgo, J. C. 2006. Post-fire vegetation succession in Mediterranean gorse shrublands. Acta Oeclogica 30: 54-61

Escudero Alcántara, A., Olano, J. M., García, R., Bariego, P., Molina, C., Arranz, J, A., Molina, J. I. \& Ezquerra, F. J. 2008. Guía básica para la interpretación de los hábitats de interés comunitario de Castilla y León. Junta de Castilla y León, Consejería de Medio Ambiente, Valladolid, 432 pp.

Farji-Brener, A. G., Corley, J. C., Bettinelli, J. 2002. The effects of fire on ant communities in northwestern Patagonia: the importance of habitat structure and regional context. Divers. Distr. 8: $235-243$

Fernández, M. M. \& Salgado, J. M. 2004. Recolonization of a burn pine forest (Pinus pinaster) by Carabidae (Coleoptera). Eur. J. Soil Biology 40: 47-53

García-Feced, C., Escribano, R. \& Elena, R. 2007. Comparación de la estructura de los paisajes en Parques Naturales fronterizos: Arribes del Duero versus Douro Internacional Montes 91: 8-14

García-Villanueva, J., Ena, V., Tárrega, R. \& Mediavilla, G. 1998. Recolonization of two burned Quercus pyrenaica ecosystems by Coleoptera. Inter. J Wildland Fire 8: 21-27

Gayubo, S. F., González, J. A., Asís, J. D. \& Tormos, J. 2005. Conservation of European environments: The Spheciformes wasp as biodiversity indicators (Hymenoptera: Apoidea: Ampulicidae, Sphecidae \& Crabronidae). J. Nat. History 39 (29): 2705-2714

González, J. A., Gayubo, S. F., Asís, J. D. \& Tormos, J. 2009. Diversity and Biogeographical Significance of Solitary wasp (Chrysididae, Eumeninae and Spheciformes) at the Arribes del Duero Natural Park, Spain: Their Importance for Insects Diversity Conservation in the Mediterranean Region. Environ. Entomol. 38 (3): 608-626 
Hansen, J. D. 1988. Trapping methods for rangeland insects in burned and unburned sites: A comparison, Great Basin Naturalist 48 (3): 383-387

Hanula, J. L. \& Wade, D. D. 2003. Influence of long-term dormant-season burning and fire exclusion on ground-dwelling arthropod populations in longleaf pine flatwoods ecosystems. Forest Ecol. Manag. 175: 163-184

Hirowatari, T., Makihara, H. \& Sugiarto. 2007. Effects of fires on butterfly assemblages in lowland dipterocarp forest in East Kalimantan. Entomological Science 10 (2): 113-127

Hyvarinen, E., Kouki, J., Martikainen, P. \& Lappalainen, H. 2005. Short-term effects of controlled burning and green-tree retention on beetle (Coleoptera) assemblages in manager boreal forests, Forest Ecol. Manag. 212:315-332

Junta de Castilla y León: www.jcyl.es

Leather, S. (ed.) 2005: Insect Sampling in Forest Ecosystems. Blackwell, Oxford, 303 pp.

Lockwood, J. A., Shaw, S. R. \& Struttmann, J. M. 1996. Biodiversity of wasp species (Insecta: Hymenoptera) in burned and unburned habitats of Yellowstone National Park, Wyoming, USA, J. Hym. Research 5: 1-15

Luis-Calabuig, E. (Coord.) 2008. Arribes del Duero. Guía de la Naturaleza. Edilesa. León. 224 pp.

Luis-Calabuig, E. \& Tarrega, R. 1993. Studies on post-fire regeneration in Quercus pyrenaica ecosystems in Leon Province (NW Spain). Pp: 209-219. En: Trabaud, L. \& Prodon, R. (eds.). Fire in Mediterranean ecosystems. ECSC-EEC-EAEC. Brussels-Luxembourg.

Luis-Calabuig, E. Tárrega, M. R., Calvo, L., Valbuena, L., Marcos, E. 2001. Fuego y paisaje en áreas de dominio del Roble Rebollo. Ecosistemas X (1)

Makihara, H., Kinuura, H., Yahiro, K., \& Soeyamto, C. 2000. The effects of droughts \& fires on Coleopteran insects in lowland dipterocarp forests in Bukit Soeharto, East Kalimantan. En: Guhardja, E., Futawi, M., Sutisna, M. \& Ohta, S. (eds.) Rainforest Ecosystems of East Kalimantan. Ecological Studies 140: 153-163. Springer. Tokyo.

Mittermeier, R. A., Gil, P. R., Hoffman, M., Pilgrim, J., Brooks, T., Mittermeier, C. G., Lamoreux, J. \& da Fonseca, G. A. B. 2005. Hotspots revisited: earth's biologically richest and most endangered terrestrial ecoregions. CEMEX-Conservation International, Monterrey, Mexico.

Moreno, J. M. 2007. Cambio global e incendios forestales: Una visión desde España. Proceding of $4^{\mathrm{a}}$ Conferencia Internacional sobre Incendios Forestales. Sevilla, España. 13-14 Mayo, 2007.

Moreno, J. M., Vázquez, A. \& Vélez, R. 1998. Recent history of forest fires in Spain. En: (Moreno, J. M. (ed.). Large Forest Fires. Pp: 159-185. Backhuys, Leiden.

Moretti, M., Obrist, M. K, \& Duelli, P. 2004. Arthropod biodiversity after forest fires: winners and losers in the winter fire regime of the Southern Alps. Ecography 27 (2): 173-186.

Naveh, Z. 1975. The evolutionary significance of fire in the Mediterranean region.Vegetatio 29: 199-208.

Ne'eman, G., Dafni, A. \& Potts, S. G. 2000. The effect of fire on flower visitation rate and fruit set in four core-species in east Mediterranean scrubland. Plant Ecol. 146: 97-104.

Nunes, L., Leather, S. \& Rego, F. 2000. Effects of fire on insects and other invertebrates, A review with particular reference to fire indicator species. Silva Lusitana (8) 1: 15-32.

O’Neill, K. M. 2001. Solitary wasps: behavior and natural history. Cornell University Press.Ithaca, xiii + $406 \mathrm{pp}$.

Ortiz-Sanchez, F. J. \& Aguirre-Segura, A. 1993. Efecto del color sobre las capturas de abejas mediante trampas Moericke en el sur de España (Hymenoptera, Apoidea). Graellsia 49: 63-71.

Parr, C. L., Robertson, H. G., Biggs, H. C. \& Chown, S. L. 2004. Response of African savanna ants to long-term fire regimes. J. Appl. Ecol. 41: 630-642 
Pausas, J. G. 2004. Changes in fire and climate in the eastern Iberian Peninsula (Mediterranean Basin), Climatic Change 63: 337-350.

Pickett, S. T. A. 1989. Space for time substitution as an alternative for long studies, En: Likens, E. G. (ed.). Long-term studies in ecology: approaches and alternatives. Springer. Pp: 112-135.

Potts, S. G., Dafni, A. \& Ne'eman, G. 2001. Pollination of a core flowering shrub species in Mediterranean phrygana: variation in pollinator diversity, abundance and effectiveness in response to fire. Oikos 92: 71-80.

Potts, S. G., Vulliamy, B., Dafni, A., Ne’eman, G., O’Toole, C., Roberts, S. \& Willmer, P. G. 2003. Response of plant-pollinator communities to fire: changes in diversity, abundance and floral reward structure. Oikos 101 (1): 103-12

Potts, S. G., Vulliamy, B., Roberts, S., Roberts, S., O’Toole, C., Dafni, A., Ne'eman, G. \& Willmer, P., 2005. Role of nesting resources in organising diverse bee communities in a Mediterranean landscape. Ecol Entomol. 30:78-85

Rodrigo, A., Sardá-Palomera, F., Bosch, J. \& Retana, J. 2008. Changes of dominant ground beetles in black pine forest with fire severity and sucesional age. EcoScience 15 (4): 442-452

Siemann, E., Haarstad, J. \& Tilman, D. 1997. Short-term and long-term effects of burning on Oak Savanna Arthropods. Am Midland Naturalist 137 (2): 349-361

Similä, M., Kouki, J., Martikainen, P., Uotila, A. 2002. Conservation of beetles in boreal pine forests: the effects of forest age and naturalness on species assemblages. Biol Conserv 106:19-27

Sobek, S., Tscharntke, T., Scherber, C., Schiele, S. \& Steffan-Dewenter, I. 2009. Canopy vs. understory: Does tree diversity affect bee and wasp communities and their natural enemies across forest strata?. Forest Ecol. Manag. 258: 609-615

Swengel, A. B. 2001. A literature review of insect responses to fire, compared to other conservation managements of open habitat. Biodiver Conserv 10 (7): 1141-1169

Taki, H., Viana, B. F., Kevan, P. G., Silva, F. O. \& Buck, M. 2008. Does forest loss affect the communities of trap-nesting wasps (Hymenoptera: Aculeata) in forests? Landscape vs. local habitat conditions. J Insect Conservation 12 (1): 15-21

Toler, T. R., Evans, E. W. \& Tepedino, V. J. 2005. Pan-trapping for bees (Hymenoptera: Apiformes) in Utah's West Desert: the importance of color diversity. Pan-Pacific Entomologist 81: 103-113

Torre, I. \& Díaz, M. 2004. Small mammal abundant in Mediterranean post-fire habitats: a role for predators?. Acta Oecologica 25: 137-143

Trabaud, L. \& Prodon, R. 1993. Fire in Mediterranean ecosystems. - ECSC-EEC-EAEC, BrusselsLuxembourg.

Tscharntke, T., Gathmann, A., Steffan-Dewenter., I. 1998. Bioindication using trap-nesting bees and wasp and their natural enemies: community structure and interactions. J. Applied Ecology 35: 708-719.

Whelan, R. J. 1995. The Ecology of Fire. Cambridge University Press, Cambridge. 346 pp.

Westphal, C., Bommarco, R., Carre, G., Lamborn, E., Morison, N., Petanidou, T., Potts, S. G., Roberts, S. P. M., Szentgyorgyi, H., Tscheulin, T., Vaissiere, B. E., Woyciechowski, M., Biesmeijer, J. C., Kunin, W. E., Settele, T. \& Steffan-Dewenter, I., 2008. Measuring Bee Diversity in Different European Habitats. Ecological Monographs 78 (4): 653-671.

York, A. 1996. Long-term effect of repeated prescribed burning on forest invertebrates: Management implications for the conservation of biodiversity. Consultancy report to the Department of the Environment and Heritage, Final report, April.

York, A. 2000. Long-term effects of frequent low-intensity burning on ant communities in coastal blackbutt forests of southeastern Australia. Austral Ecol 25: 83-98. 


\section{5}

\section{Apartado Faunístico}

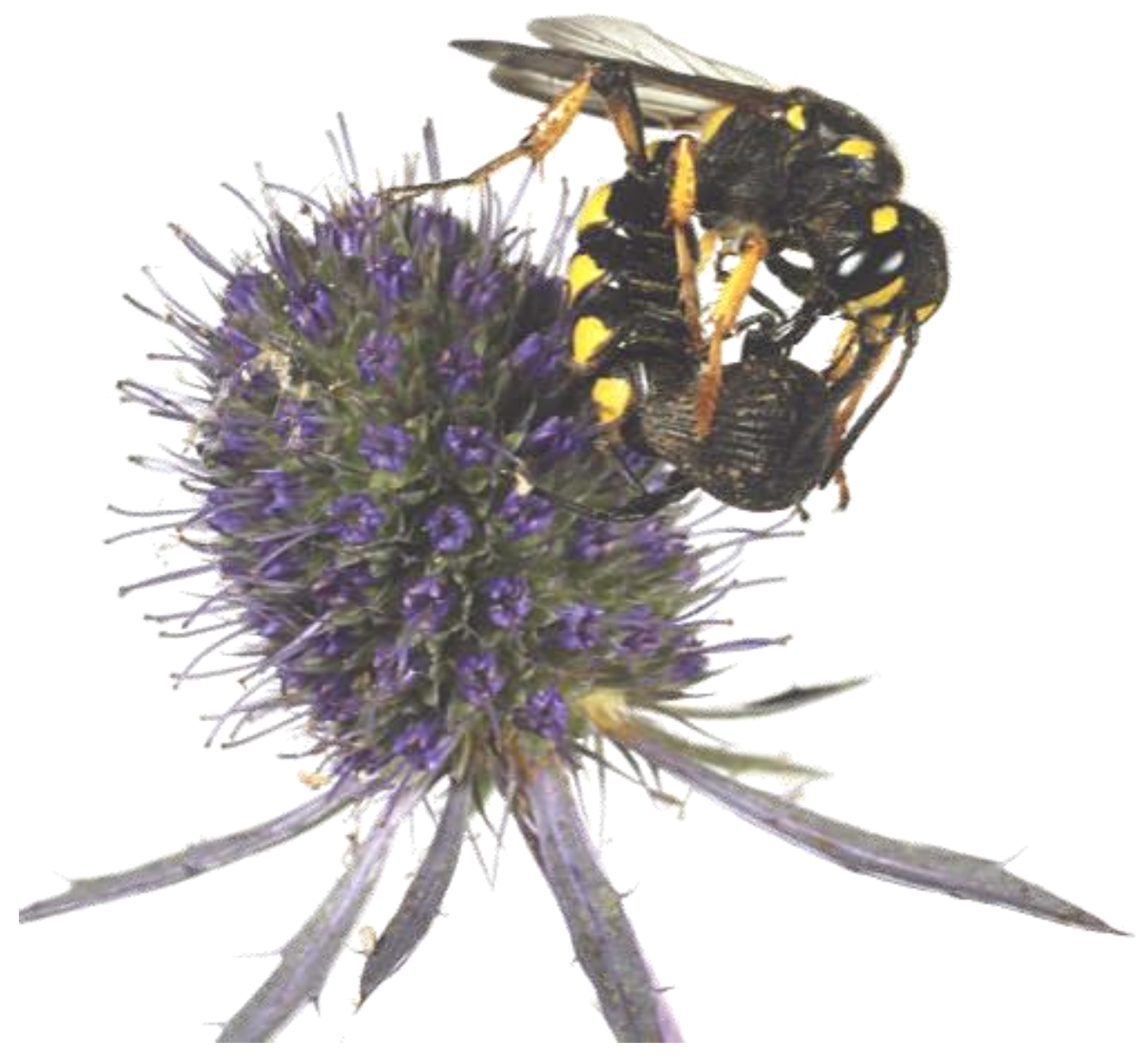


En este apartado se recogen las especies más relevantes e interesantes desde el punto de vista faunístico.

\section{AMPULICIDAE Shuckard, 1840 \\ AMPULICINAE Shuckard, 1840 \\ Ampulicini Shuckard, 1840}

\section{Ampulex ruficollis Cameron, 1888}

Fue descrita originalmente en Gibraltar por CAMERON (1888). Su distribución queda restringida a Marruecos (Tánger) y Península Ibérica (Gibraltar y las provincias de Ávila -Bohoyo, Barco de Ávila-, Cuenca -Tragacete y Valdemeca-, Madrid -Cercedilla-, Cáceres -Malpartida de Plasencia- y Segovia -Lastras de Cuéllar- (GAYUBO et al., 2006), y Salamanca -Linares de Riofrío, San Miguel de Valero, Béjar- (GAYUBO et al., 2007) . Su presencia en Salamanca es, por tanto, el límite occidental actualmente conocido en el solar ibérico, y el primer registro obtenido para el Parque Natural Arribes del Duero.

Material estudiado: Villarino de los Aires 19 (1-15.VII.2006).: Trampa Malaise.

\section{SPHECIDAE Latreille, 1802 \\ SPHECINAE Latreille, 1802 \\ Sphecini Latreille, 1802}

Sphex atropilosus Kohl, 1885

Se trata de una especie muy localizada en la Península Ibérica. Su presencia en Arribes del Duero es muy interesante por la abundancia de los individuos que componen las poblaciones en esta zona occidental del centro español (GONZÁLEZ et al., 2009), destacando en este sentido tanto localidades de la provincia de Zamora -Fariza, Zafara, Fermoselle- como de Salamanca -Villarino de los Aires, Pereña, Mieza- (S. F. Gayubo, com. pers.).

Material estudiado: Pereña de la Ribera $=12 \hat{\jmath}$ y 9 우 $(1-15 . V I .2005) ; 7 \widehat{\jmath}$ y 7 우 (16-30.VI. 2005); 1 ઈ (1-15.VII.2005); 1 ภ y 3 우 (1-15.VI.2006); 1 (16-30.VI. 2006);

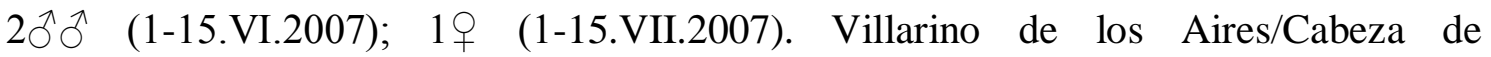

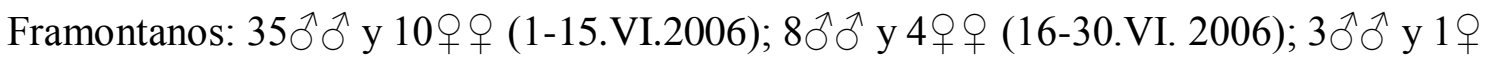

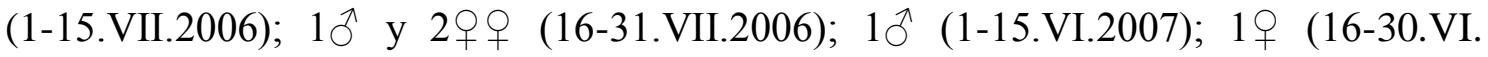
2007).: Trampa Malaise. 
CRABRONIDAE Latreille, 1802

PEMPHREDONINAE Dahlbom, 1835

Pemphredonini Dahlbom, 1835

Ammoplanina Evans, 1959

\section{Ammoplanus bischoffi Maréchal, 1938}

Especie conocida del noroeste de Italia, sur de Francia y Península Ibérica (Vila Boa de Quires -Portugal- y Salamanca -España-) (BOUCEK \& GAYUBO, 2001). Recientemente se ha confirmado se presencia en Salamanca mediante la captura de cuatro individuos uno en Pereña de la Ribera, y tres más en Saucelle, localidades ambas pertenecientes al Parque Natural Arribes del Duero (S. F. Gayubo, com. pers.). (GoNZÁLEZ et al., 2009),

Material estudiado: Pereña de la Ribera 1ठ (16-31.V.2005).: Trampa Malaise.

\section{Ammoplanus gegen Tsuneki, 1972}

Especie originalmente descrita en Mongolia, se conoce actualmente también de la República Checa, Austria, Chipre, Jordania, Turkmenistán y Tajikistán. En la Península Ibérica se ha citado de Zaragoza -Pina de Ebro- (BOUCEK \& GAYUBO, 2001). GAYUBO et al. (2007) la mencionan de Salamanca -Valero y Miranda del Castañar, con uno y seis individuos respectivamente-. Su presencia en la localidad de Pereña de la Ribera amplía considerablemente su distribución y constituye la más occidental de las citas conocidas, siendo la primera en Arribes del Duero.

Material estudiado: Pereña de la Ribera $1 q$ (1-15.VI.2006).: Trampa Malaise.

\section{Ammoplanus torresi Gayubo, 1991}

Especie ibérica, presente tanto en España como en Portugal, aunque con escasas citas. Ya conocida de la provincia de Salamanca -Valdelageve, San Esteban de la Sierra y Montemayor del Río (GAYUBO et al., 2007). , existen tres nuevas citas para Arribes del Duero: Salamanca -Villarino de los Aires y Pereña de la Ribera- y Zamora -Fariza(GONZÁLEZ et al., 2009) (S. F. Gayubo, com. pers.). Las nuevas capturas aportadas en el presente trabajo confirman la presencia preferente de esta especie en zonas del centro occidental español.

Material estudiado: Pereña de la Ribera $1 q$ (1-15.VI.2006), $1 q$ (16-30.VI.2006), $1 q$ (115.VII.2006).. Trampa Malaise. 
CRABRONINAE Latreille, 1802

Larrini Latreille, 1810

Gastrosericina André, 1886

\section{Larropsis europaea (Mercet, 1910)}

GAYUBO et al. (2002) recogen las localidades ibéricas en las que se ha mencionado esta especie. Posteriormente GAYUBO et al. (2006) la mencionan de Salamanca -Herguijuela de la Sierra- y Zamora -Fermoselle-. GonZÁLEZ et al. (2009) mencionan también esta especie para Salamanca, concretamente en Villarino de los Aires y Saucelle (S. F. Gayubo, com. pers.). De las dos especies ibéricas de este género, parece ser la más localizada, estando presente fundamentalmente en Portugal y la zona centro occidental española. Material estudiado: Pereña de la Ribera: $1 \sigma^{\Uparrow}$ (15-IX.2007).: Platos amarillos.

Tachysphex plicosus (A. Costa, 1867)

Especie ampliamente distribuida: Europa, Turquía, India, Sri Lanka, Tailandia, África. En el continente europeo su distribución también es muy amplia (fundamentalmente en áreas de clara influencia mediterránea), excepto en la península Ibérica en donde fue recientemente citada por primera vez en la provincia de Toledo (GAYUBO et al., 2002). Posteriormente se amplió su distribución a tres provincias más: Madrid -Tres Cantos-, Sevilla -Cazalla de la Sierra- y Salamanca -Saucelle- (GAYUBO et al., 2006). El presente trabajo, por tanto, viene a confirmar su presencia en Salamanca y en el Parque Natural Arribes del Duero (GonZÁLEZ et al., 2009), donde ha sido localizada en Saucelle (S. F. Gayubo, com. pers.). Otras dos localidades salmantinas donde también ha sido localizada son Valero y Montemayor del Río (S. F. Gayubo, com. pers.).

Material estudiado: Pereña de la Ribera: $1+$ (15-VIII.2005); $1+$ (15-IX.2006).: Platos amarillos.

Miscophini W. Fox, 1894

Miscophus albufeirae Andrade, 1952

Se trata de una especie muy interesante desde el punto de vista de su distribución, ya que coloniza las zonas más cálidas del cuadrante suroccidental de la Península Ibérica, teniendo su límite septentrional en Arribes del Duero, formando parte del denominado corotipo 1 (GONZÁLEZ et al., 2009), cuya cita pertenece a Salamanca -Villarino de los Aires- (S. F. Gayubo, com. pers.).

Además de las citas españolas de Cádiz -San Roque- y Ciudad Real -La Mestanza-, se suman las de Portugal -Évora, el Algarve- (ver PULAWSKI, 2009). 
Material estudiado: Villarino de los Aires: 19 (15-VIII.2006); Cabeza de Framontanos (Villarino de los Aires) 1 + (15.VII.2006). Platos amarillos.

Crabronini Latreille, 1802

Anacrabronina Ashmead, 1899

Encopognathus braunsi Mercet, 1915

Especie endémica de la Península Ibérica, siendo la única especie del género en Europa. Previamente ha sido citada en las provincias de Salamanca -Alberca- Valladolid Hornillos, Viana de Cega-, Zamora y Cáceres (ver Pulawski, 2009). Más recientemente ha sido citada nuevamente en Salamanca -Miranda del Castañar, Herguijuela de la Sierra- (GonZÁLEZ et al., 2007) Batuecas y Candelario (S. F. Gayubo, com. pers.). GonZÁLEZ et al. (2009) la citan para Arribes del Duero, concretamente para Zamora -Badilla, Fariza, Zafara- y Salamanca -Villarino, Pereña, Mieza- (S. F. Gayubo, com. pers.).

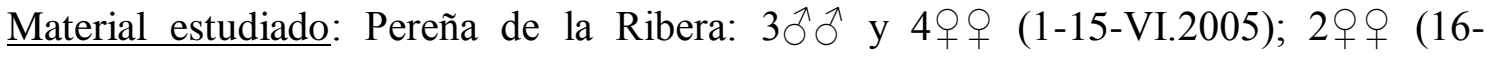
30.VI.2005); 1 q (16-30.VI.2004).: Trampa Malaise.

BEMBICINAE Latreille, 1802

Bembicini Latreille, 1802

Handlirschiina Nemkov \& Lelej, 1996

Sphecius nigricornis (Dufour, 1838)

Los cuatro individuos registrados en el presente trabajo se suman a otros tres obtenidos por González et al. (2009) en Arribes del Duero, concretamente en Villarino de los Aires (S. F. Gayubo, com. pers.). La presencia de esta especie en Arribes es interesante ya que sus capturas son muy raras en la Península Ibérica.

Material estudiado: Pereña de la Ribera: 1 ( 1 -15.VI.2005); 1 ( $(1-15$. VII.2006). Cabeza de Framontanos (Villarino de los Aires): 1 q (16-30.VI.2006); $1 \widehat{\jmath}$ (115.VII.2006).: Trampa Malaise. 


\section{Stizina A. Costa 1859}

\section{Bembecinus pulchelllus (Mercet, 1906)}

Se trata de una especie muy localizada en la Península Ibérica

Los datos el presente estudio, confirman la presencia de poblaciones formadas por un gran número de individuos en la zona de Arribes del Duero (GONZÁlEZ et al., 2009), donde ha sido capturado en Zamora -Formariz, Fermoselle- y Salamanca -Pereña de la Ribera, Saucelle, Trabanca, Villarino de los Aires- (S. F. Gayubo, com. pers.).

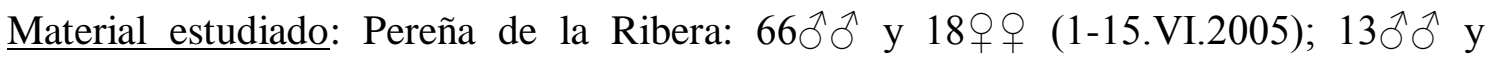
122우 (16-30.VI.2005); 1 ` y 117 우 (1-15.VII.2005); 26 우 (16-31.VIII.2005); 1 우

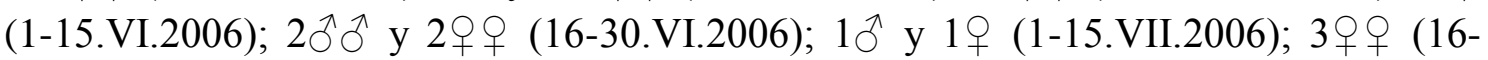
31.VII.2006); 1 우 (1-15.VIII.2006); 32우 (1-15.VII.2007); $1 \delta^{\lambda}$ y 36우 (16-

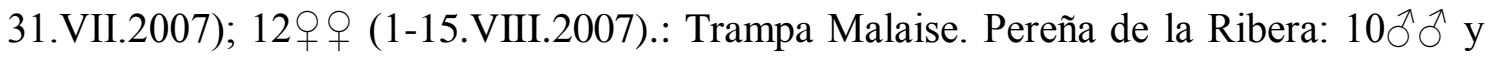
105 우 (1-15.VI.2005); 23 우 (16-30.VI.2005); 1 ㅇ (15.VI.2006); 3 우 (15.VI.2006); 40 우 (15.VII.2007); 2 우 (15.VIII.2007). Cabeza de Framontanos (Villarino de los Aires): $9 \hat{\jmath}$ y 12 우 (15.VI.2005); 2 우 (15.VII.2005) 2 우 (15.IX.2006).: Platos amarillos.
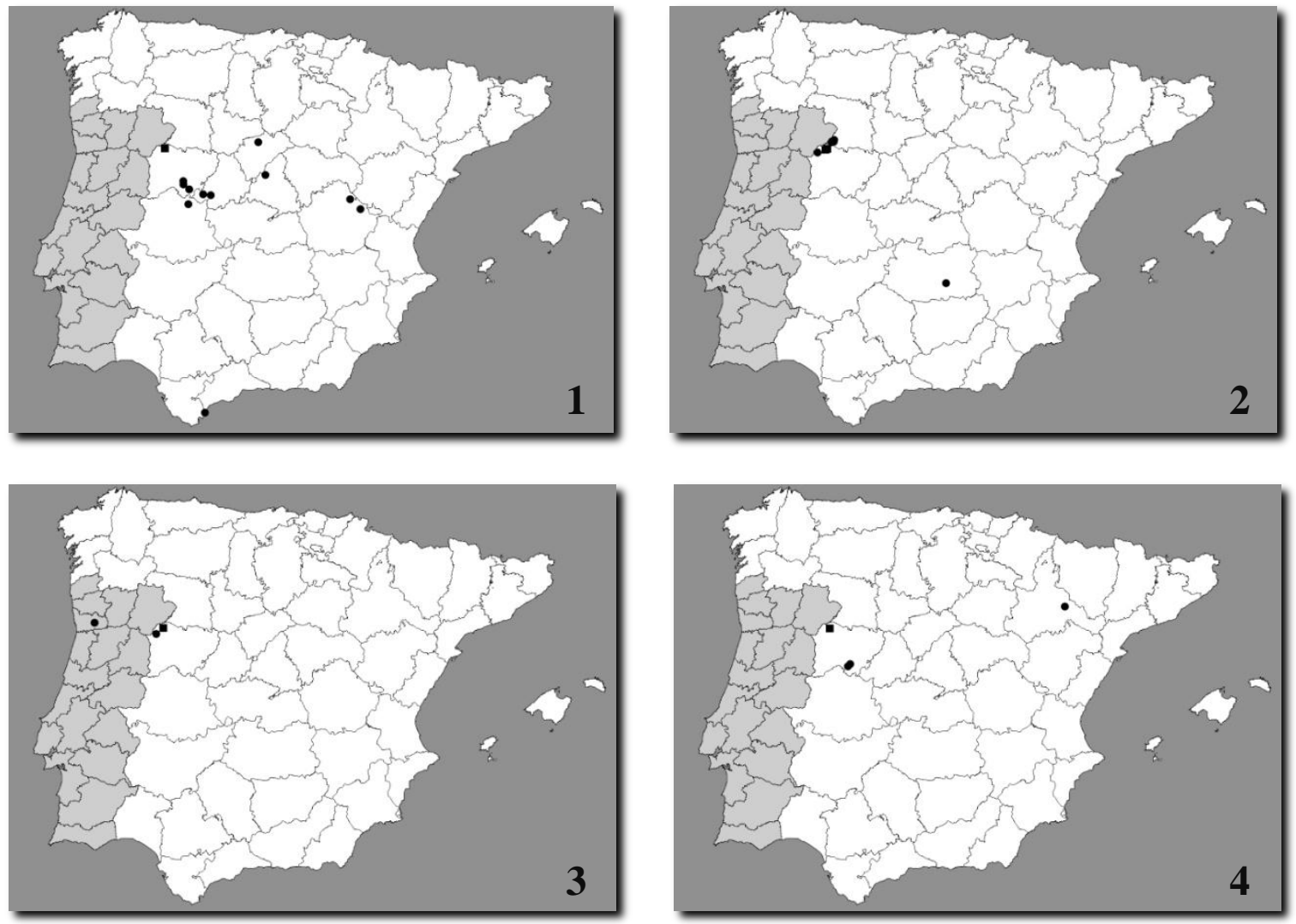

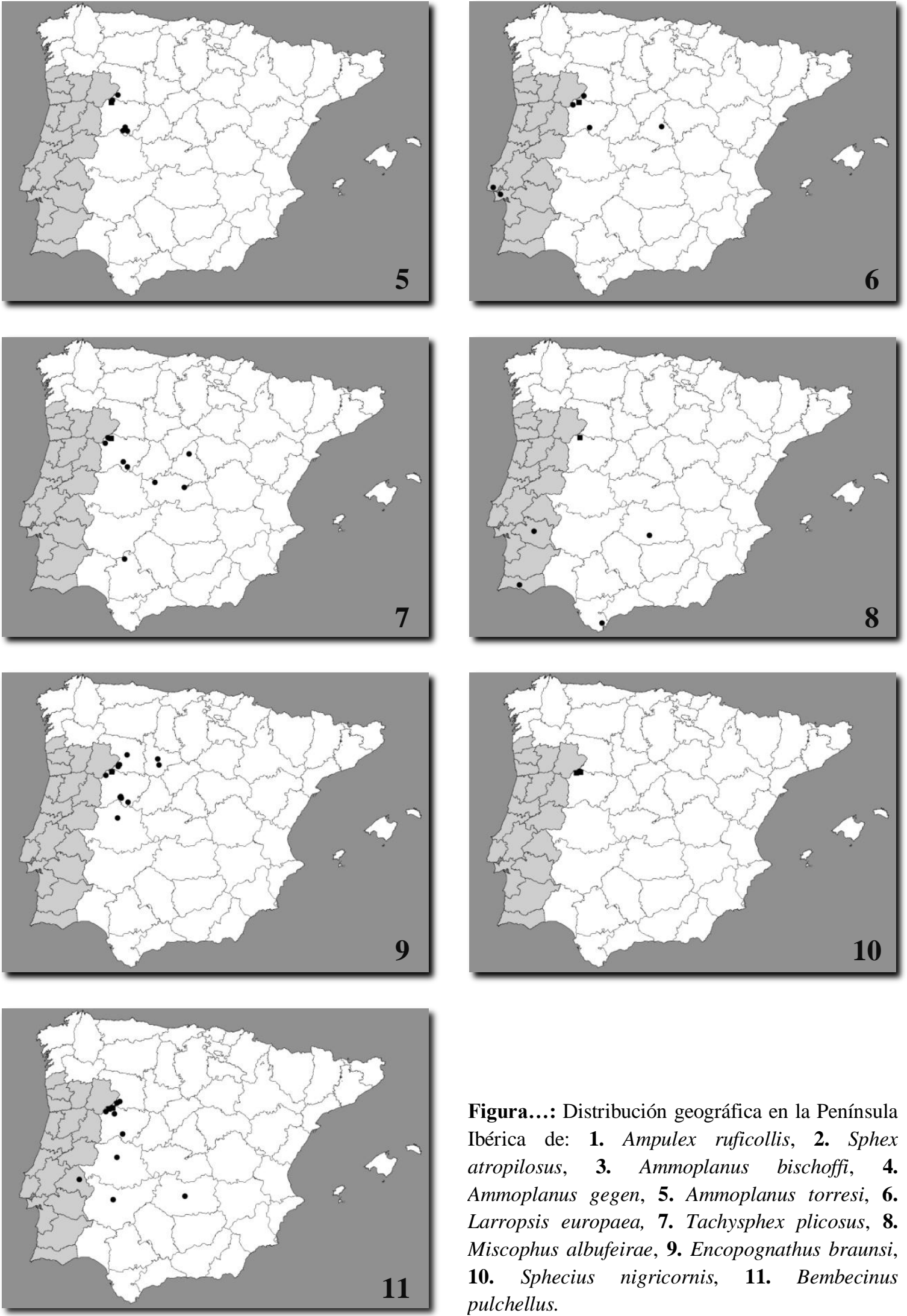

Figura...: Distribución geográfica en la Península Ibérica de: 1. Ampulex ruficollis, 2. Sphex atropilosus, 3. Ammoplanus bischoffi, 4. Ammoplanus gegen, 5. Ammoplanus torresi, 6. Larropsis europaea, 7. Tachysphex plicosus, 8. Miscophus albufeirae, 9. Encopognathus braunsi, 10. Sphecius nigricornis, 11. Bembecinus pulchellus. 


\section{Bibliografía}

Boucek, Z. \& Gayubo, S. F. 2001. The genus Ammoplanus Giraud in the Iberian Peninsula (Hymenoptera: Sphecidae). Entomol. Gaz. 52: 55-66.

CAmeron, P. 1888. Descriptions of twenty-three new species of Hymenoptera. Mem. Proc. Manchester Lit. Phil. Soc. (Series 4) 1: 159-182.

Gayubo, S. F., González, J. A., Tormos, J. \& Asís, J. D. 2002. Especies nuevas o interesantes de esfeciformes para la Península Ibérica (Hymenoptera: Ampulicidae, Sphecidae y Crabronidae). Boletín Sociedad Entomológica Aragonesa 31: 83-92.

Gayubo, S. F., González, J. A., De la Nuez, A., Asís, J. D. \& Tormos, J. 2006. Especies nuevas o interesantes de Spheciformes para Europa y la Península Ibérica (Hymenoptera: Ampulicidae, Sphecidae y Crabronidae). Boletín Sociedad Entomológica Aragonesa 39: 205-212.

Gayubo, S. F., GonzÁlez, J. A. \& Torres, F. 2000. Estudio de una comunidad de esfécidos en la zona natural de "Las Arribes del Duero" (Salamanca, Oeste español) (Hymenoptera, Sphecidae). Fragmenta entomologica 32 (1): 181-209.

Gayubo, S. F., González, J. A., Tormos, J. \& Asís, J. D. 2007. Diversidad de avispas Spheciformes en el Parque Natural de las Batuecas - Sierra de Francia (Salamanca, España) (Hymenoptera: Ampulicidae, Sphecidae y Crabronidae). Nouv Revue. Ent. (N.S.) T.24. Fasc. 2: 131-147.

González, J. A., Gayubo, S. F., Asís, J. D. \& Tormos, J. 2009. Diversity and Biogeographical Significance of Solitary Wasps (Chrysididae, Eumeninae and Spheciformes) at the Arribes del Duero Natural Park, Spain: Their Importance for Insects Diversity Conservation in the Mediterranean Region. Environ. Entomol. 38 (3): 608-626.

PULAWSKI, W. J. 2009. Catalog of Sphecidae sensu lato. www.calcademy.com/research/entomolgy/Entomology_Resources/Hymenoptera/sphecidae. 


\section{CONCLUSIONES}

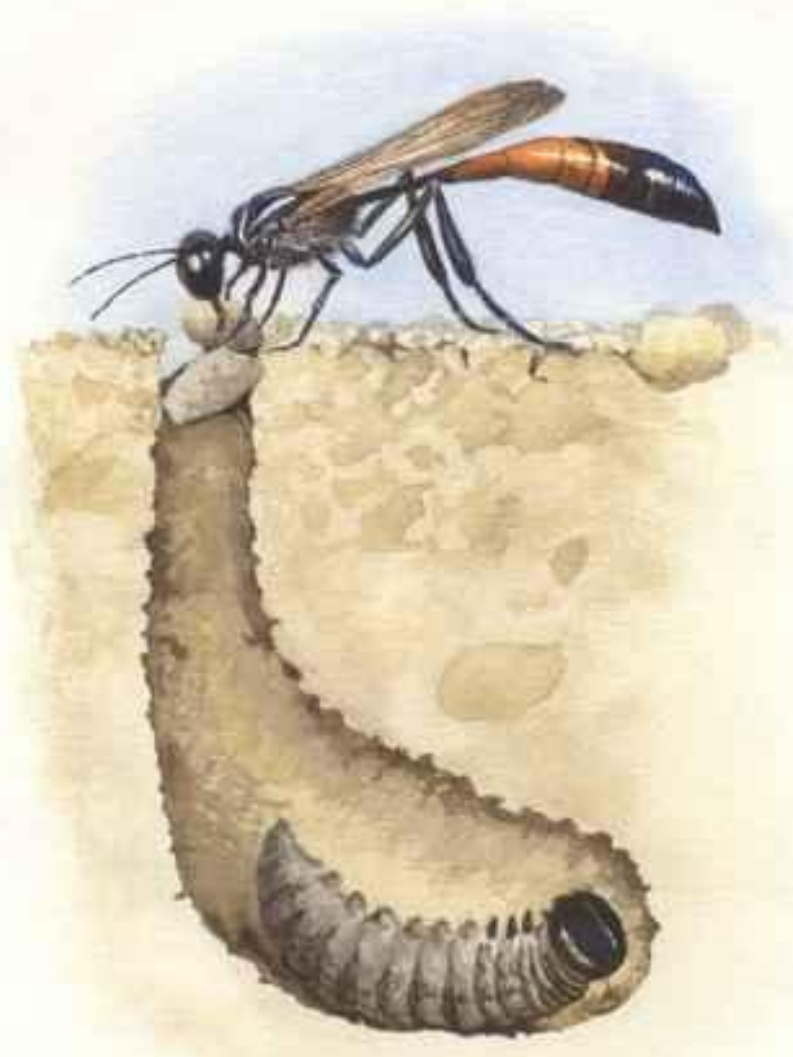


- Primera: Las comunidades de Spheciformes muestran una alta resistencia, viéndose incluso favorecidos, frente a la ocurrencia de incendios estivales, de intensidad baja-media, rápidos y de superficie, lo que se refleja en un mayor número de especies en el interior de las áreas quemadas que en las zonas Control.

- Segunda: Estas comunidades se ven favorecidas por las condiciones xéricas y los espacios abiertos y soleados presentes inmediatamente después del fuego, motivo por el que se hallan más especies exclusivas en el interior de las áreas quemadas que en los Controles.

- Tercera: La respuesta inicial positiva posiblemente se debe a un elevado grado de supervivencia y alto potencial colonizador de los Spheciformes, por su gran capacidad de desplazamiento, que facilitaría la huida de las llamas y la posterior colonización del área incendiada. Igualmente, cabe suponer una elevada supervivencia de las especies que establecen sus nidos en el suelo y cuyas fases inmóviles (huevos, larvas, pupas) se encuentran protegidas de las elevadas temperaturas provocadas por las llamas. Un aumento de la calidad de la vegetación rebrotante y de los recursos tróficos aportados por ésta, también atraerían a los Spheciformes y a sus presas, permitiendo su supervivencia tras el fuego.

- Cuarta: La existencia de parches sin quemar dentro de la propia área incendiada (formados, entre otros, por viñedos labrados), pueden constituir un recurso vital para la supervivencia de estos insectos. Por ello, el mantenimiento de los usos tradicionales del terreno, podría reducir el avance de las llamas y proporcionar un lugar seguro que permita la supervivencia de estos animales y que sirva como fuente a la hora de recolonizar el área quemada.

- Quinta: Los años post-fuego (reflejo del grado de recuperación del hábitat incendiado, cobertura y estructura de la vegetación) y, de manera especial, el año de muestreo (reflejo de las variaciones climatológicas interanuales) se muestran como las principales variables que influyen en la recuperación de las comunidades de Spheciformes. Las condiciones locales del hábitat y las variaciones climatológicas interanuales ejercerían una mayor influencia sobre estas comunidades que la propia perturbación en sí. 
- Sexta: Las comunidades de Spheciformes sufren una desestructuración, que se manifiesta en modificaciones de las abundancias relativas de las especies y en variaciones en la composición de los gremios de la comunidad. La variación en las condiciones locales del hábitat, derivada tanto de las cambiantes condiciones climatológicas, como del paso del tiempo desde que el incendio tuvo lugar, se refleja en la mayor o menor presencia de recursos (alimenticios, de nidificación y de presas para alimentar a las larvas) y produce desplazamientos de unas especies frente a otras.

- Séptima: Los índices de distancia taxonómica no se muestran eficaces en el análisis del impacto provocado por el fuego sobre las comunidades de Spheciformes. Esto podría deberse tanto al fuerte efecto que ejerce el año de muestreo, como al posible hecho de que los índices podrían ser poco sensibles en el análisis de comunidades empleando niveles taxonómicos de nivel bajo (inferior a familia).

- Octava: El elevado grado de complementariedad mostrado por las trampas Malaise y los platos amarillos, y la gran cantidad de especies capturadas exclusivamente por cada uno de estos métodos, aconseja la utilización de ambos tipos de trampas en el análisis de la recuperación de comunidades de Spheciformes tras sufrir un incendio forestal, ya que su diferente método de actuación permitirá registrar un mayor número de especies, y reflejará más fielmente la composición de las comunidades de Spheciformes presentes en cada una de las fases de recuperación del área impactada.

\section{CONCLUSIÓN FINAL}

Las comunidades de Spheciformes son aparentemente muy resistentes ante incendios superficiales, rápidos, de intensidad baja-media y no muy extensos ocurridos en verano en hábitats aclarados de bosque mediterráneo, alcanzando la máxima riqueza de especies en las fases iniciales de recuperación (un año después de sufrir la perturbación) y la mínima durante las fases intermedias (cuatro-cinco años después), completando la recuperación a los ocho o nueve años. Sin embargo, el cambio sufrido en la estructura de la comunidad no puede ser atribuido de manera concluyente al efecto del fuego, ya que las condiciones climatológicas y las condiciones locales del hábitat parecen tener una influencia mayor sobre la evolución de estas comunidades. 


\section{ANEXOS}

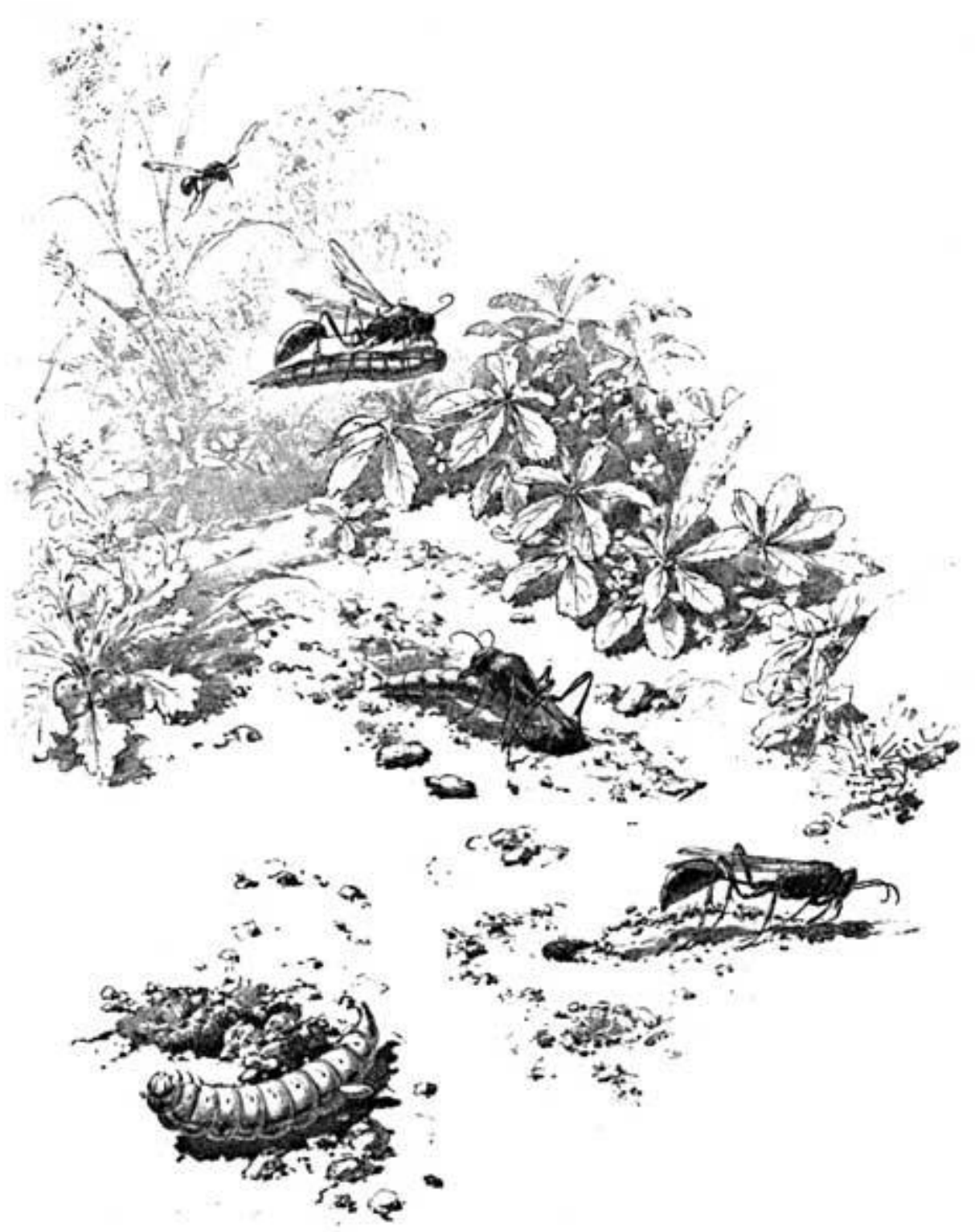


ANEXO I: Clasificación taxonómica para la Península Ibérica del grupo de aculeados estudiado.

Apoidea Latreille, 1802

\section{Ampulicidae Shuckard, 1840}

Ampulicinae Shuckard, 1840

Ampulicini Shuckard, 1840 Ampulex Jurine, 1807

Dolichurus Latreille, 1809

\section{Sphecidae Latreille, 1802}

Sceliphrinae Ashmead, 1899

Sceliphrini Ashmead, 1899

Chalybion Dahlbom, 1843

Sceliphron Klug, 1801

Sphecinae Latreille, 1802

Sphecini Latreille, 1802

Sphex Linnaeus, 1758

Isodontia Patton, 1880

Prionychini Bohart \& Menke, 1963

Palmodes Kohl, 1890

Chilosphex Menke, 1976

Prionyx Vander Linden, 1827

Ammophilinae André, 1886

Ammophilini André, 1886

Hoplammophila Beaumont, 1960

Ammophila W. Kirby, 1798

Podalonia Fernald, 1927

\section{Crabronidae Latreille, 1802}

\section{Pemphredoninae Dahlbom, 1835}

Psenini A. Costa, 1858

Psenulus Kohl, 1897

Psen Latreille, 1796

Pseneo Malloch, 1933

Mimesa Shuckard, 1837

Mimumesa Malloch, 1933

Pemphredonini Dahlbom, 1835

Pemphredonina Dahlbom, 1835

Diodontus Curtis, 1834

Pemphredon Latreille, 1796

Passaloecus Shuckard, 1837

Stigmina Bohart \& Menke, 1976

Stigmus Panzer, 1804

Carinostigmus Tsuneki, 1954

Spilomenina Menke, 1989 Spilomena Shuckard, 1838

Ammoplanina Evans, 1959 Ammoplanus Giraud, 1869

Astatinae Lepeletier, 1845

Astatini Lepeletier, 1845 Astata Latreille, 1797 Dryudella Spinola, 1843

\section{Dinetinae W. Fox, 1895}

Dinetini W. Fox, 1895

Dinetus Panzer, 1806

Crabroninae Latreille, 1802

Larrini Latreille, 1810

Larrina Latreille, 1810

Larra Fabricius, 1793

Liris Fabricius, 1804

Gastrosericina André, 1886

Larropsis Patton, 1892

Tachytes Panzer, 1806

\author{
Tachysphex Kohl, 1883 \\ Prosopigastra A. Costa, 1867 \\ Palarini Schrottky, 1909 \\ Palarus Latreille, 1802 \\ Miscophini W. Fox, 1894 \\ Plenoculus W. Fox, 1893 \\ Solierella Spinola, 1851 \\ Miscophus Jurine, 1807 \\ Nitela Latreille, 1809 \\ Trypoxylini Lepeletier, 1845 \\ Pison Jurine in Spinola, 1808 \\ Trypoxylon Latreille, 1796 \\ Oxybelini Leach, 1815 \\ Belomicrus A. Costa, 1871 \\ Oxybelomorpha Brauns, 1897 \\ Oxybelus Latreille, 1797 \\ Crabronini Latreille, 1802 \\ Anacrabronina Ashmead, 1899 \\ Encopognathus Kohl, 1897 \\ Entomognathus Dahlbom, 1844 \\ Crabronina Latreille, 1802 \\ Lindenius Lepeletier \& Brullé, 1835 \\ Rhopalum Stephens, 1829 \\ Crossocerus Lepelet. \& Brullé, 1835 \\ Tracheliodes A. Morawitz, 1866 \\ Crabro Fabricius, 1775 \\ Ectemnius Dahlbom, 1845 \\ Lestica Billberg, 1820
}

Mellininae Latreille, 1802

Mellinini Latreille, 1802

Mellinus Fabricius, 1790

Bembicinae Latreille, 1802

Nyssonini Latreille, 1804

Nysson Latreille, 1802 (+ Synnevrus) Brachystegus A. Costa, 1859

Alyssontini Dalla Torre, 1897

Alysson Panzer, 1806

Didineis Wesmael, 1852

Bembicini Latreille, 1802

Argogorytina Nemkov \& Lelej, 1996 Argogorytes Ashmead, 1899

Gorytina Lepeletier, 1845 Gorytes Latreille, 1805 Harpactus Shuckard, 1837 Hoplisoides Gribodo, 1884 Lestiphorus Lepeletier, 1832 Oryttus Spinola, 1836 Psammaecius Lepeletier, 1832

Handlirschiina Nemkov \& Lelej, 1996 Ammatomus A. Costa, 1859 Sphecius Dahlbom, 1843

Stizina A. Costa, 1859 Bembecinus A. Costa, 1859 Stizus Latreille, 1802 Stizoides Guérin-Méneville, 1844 Bembicina Latreille, 1802 Bembix Fabricius, 1775

Philanthinae Latreille, 1802

Philanthini Latreille, 1802

Philanthina Latreille, 1802 Philanthus Fabricius, 1790

Philanthinina Menke, 1967 Philanthinus Beaumont, 1949

Pseudoscoliini Menke, 1967

Pseudoscolia Radoszkowski, 1876

Cercerini Lepeletier, 1845

Cerceris Latreille, 1802 
ANEXO II: Lista de especies representadas en cada una de las localidades, años estudiados y trampas empleadas. 


\begin{tabular}{|c|c|c|c|c|c|c|c|c|c|c|c|c|c|c|c|}
\hline \multirow{3}{*}{$\begin{array}{c}\text { Periodos de muestreo } \\
\text { CENIZAS } \\
\text { Villarino (SA) Trampa Malaise } \\
\text { Año } 2005\end{array}$} & \multicolumn{2}{|c|}{1} & \multicolumn{2}{|c|}{2} & \multicolumn{2}{|c|}{3} & \multicolumn{2}{|c|}{4} & \multicolumn{2}{|c|}{5} & \multicolumn{2}{|c|}{6} & & & \\
\hline & \multicolumn{2}{|c|}{ 24-31 VII } & \multicolumn{2}{|c|}{ 1-15 VIII } & \multicolumn{2}{|c|}{ 16-31 VIII } & \multicolumn{2}{|c|}{$1-15 \mathrm{IX}$} & \multicolumn{2}{|c|}{ 16-30 IX } & \multicolumn{2}{|c|}{$1-15 X$} & \multicolumn{2}{|c|}{ Totales } & \\
\hline & $\mathbf{M}$ & $\mathbf{H}$ & M & $\mathbf{H}$ & M & $\mathbf{H}$ & M & $\mathbf{H}$ & $\mathbf{M}$ & $\mathbf{H}$ & $\mathbf{M}$ & $\mathbf{H}$ & M & $\mathbf{H}$ & $\Sigma$ \\
\hline \multicolumn{16}{|l|}{ SPHECIDAE } \\
\hline \multicolumn{16}{|l|}{ SPHECINAE } \\
\hline \multicolumn{16}{|l|}{ SPHECINI } \\
\hline Prionyx viduatus (Christ, 1791) & $\ldots$ & $\ldots$ & $\ldots$ & 2 & $\ldots$ & $\ldots$ & $\ldots$ & $\ldots$ & $\ldots$ & $\ldots$ & $\ldots$ & $\ldots$ & 0 & 2 & 2 \\
\hline Sphex flavipennis Fabricius, 1793 & $\ldots$ & $\ldots$ & 1 & $\ldots$ & $\ldots$ & $\cdots$ & $\ldots$ & $\ldots$ & $\cdots$ & $\ldots$ & $\ldots$ & $\ldots$ & 1 & 0 & 1 \\
\hline Sphex funerarius Gussakovskij, 1934 & 1 & $\ldots$ & $\ldots$ & 2 & 1 & $\ldots$ & $\ldots$ & $\ldots$ & $\ldots$ & $\ldots$ & $\ldots$ & $\ldots$ & 2 & 2 & 4 \\
\hline \multicolumn{16}{|l|}{ AMMOPHILINI } \\
\hline Ammophila heydeni Dahlbom, 1845 & $\ldots$ & $\cdots$ & $\ldots$ & 1 & $\cdots$ & 1 & $\cdots$ & 1 & $\cdots$ & $\ldots$ & $\cdots$ & $\ldots$ & 0 & 3 & 3 \\
\hline \multicolumn{16}{|l|}{ CRABRONIDAE } \\
\hline \multicolumn{16}{|l|}{ PEMPHREDONINAE } \\
\hline PEMPHREDONINI & & & & & & & & & & & & & & & \\
\hline Diodontus insidiosus Spooner, 1938 & $\ldots$ & 1 & $\ldots$ & 1 & $\ldots$ & 5 & 2 & $\ldots$ & $\ldots$ & $\ldots$ & $\ldots$ & $\ldots$ & 2 & 7 & 9 \\
\hline Pemphredon lethifer (Shuckard, 1837) & $\ldots$ & $\ldots$ & $\ldots$ & $\ldots$ & $\ldots$ & $\ldots$ & $\ldots$ & 1 & $\ldots$ & 1 & $\ldots$ & $\ldots$ & 0 & 2 & 2 \\
\hline CRABRONINAE & & & & & & & & & & & & & & & \\
\hline LARRINI & & & & & & & & & & & & & & & \\
\hline Tachysphex fulvitarsis (A. Costa, 1867) & $\ldots$ & $\ldots$ & $\ldots$ & 1 & $\ldots$ & $\ldots$ & $\ldots$ & $\ldots$ & $\ldots$ & $\ldots$ & $\ldots$ & $\ldots$ & 0 & 1 & 1 \\
\hline Tachysphex incertus (Radoszhowski, 1877) & $\ldots$ & 4 & $\ldots$ & 3 & $\ldots$ & $\ldots$ & $\ldots$ & $\ldots$ & $\ldots$ & $\ldots$ & $\ldots$ & $\ldots$ & 0 & 7 & 7 \\
\hline Tachysphex julliani Kohl, 1883 & $\ldots$ & $\ldots$ & $\ldots$ & 1 & $\ldots$ & 1 & $\ldots$ & $\ldots$ & $\ldots$ & $\ldots$ & $\ldots$ & $\ldots$ & 0 & 2 & 2 \\
\hline Tachysphex obscuripennis (Schenck, 1857) & $\ldots$ & 1 & $\ldots$ & 2 & $\ldots$ & 2 & $\ldots$ & $\ldots$ & $\ldots$ & $\ldots$ & $\ldots$ & $\ldots$ & 0 & 5 & 5 \\
\hline Tachysphex panzeri (Van der Linden, 1829) & $\ldots$ & $\ldots$ & $\ldots$ & 2 & $\ldots$ & $\ldots$ & $\ldots$ & $\ldots$ & $\ldots$ & $\ldots$ & $\ldots$ & $\ldots$ & 0 & 2 & 2 \\
\hline Tachysphex tarsinus (Lepeletier, 1845) & $\ldots$ & $\ldots$ & $\ldots$ & 1 & $\ldots$ & $\ldots$ & $\ldots$ & $\ldots$ & $\ldots$ & $\cdots$ & $\cdots$ & $\ldots$ & 0 & 1 & 1 \\
\hline Tachysphex unicolor (Panzer, 1809) & $\ldots$ & $\ldots$ & $\ldots$ & 2 & $\ldots$ & $\ldots$ & $\ldots$ & $\ldots$ & $\cdots$ & $\ldots$ & $\ldots$ & $\ldots$ & 0 & 2 & 2 \\
\hline MISCOPHINI & & & & & & & & & & & & & & & \\
\hline Miscophus bicolor Jurine, 1807 & $\ldots$ & $\ldots$ & $\ldots$ & 1 & $\ldots$ & $\ldots$ & $\ldots$ & $\ldots$ & $\ldots$ & $\ldots$ & $\ldots$ & $\ldots$ & 0 & 1 & 1 \\
\hline Miscophus nicolai Ferton, 1896 & $\ldots$ & $\ldots$ & $\ldots$ & 1 & $\ldots$ & 3 & $\ldots$ & $\ldots$ & $\ldots$ & $\ldots$ & $\ldots$ & $\ldots$ & 0 & 4 & 4 \\
\hline Nitela lucens Gayubo \& Felton, 2000 & $\ldots$ & $\ldots$ & $\ldots$ & $\ldots$ & $\ldots$ & 1 & $\ldots$ & $\ldots$ & $\ldots$ & $\ldots$ & $\ldots$ & $\ldots$ & 0 & 1 & 1 \\
\hline TRYPOXYLINI & & & & & & & & & & & & & & & \\
\hline Trypoxylon clavicerum Lepeletier \& Serville, 1828 & $\ldots$ & $\cdots$ & $\cdots$ & $\ldots$ & $\cdots$ & 2 & $\ldots$ & $\ldots$ & $\cdots$ & $\ldots$ & $\ldots$ & $\ldots$ & 0 & 2 & 2 \\
\hline Trypoxylon scutatum Chevrier, 1867 & $\ldots$ & $\ldots$ & $\cdots$ & $\ldots$ & $\cdots$ & $\ldots$ & $\ldots$ & 1 & $\cdots$ & $\ldots$ & $\cdots$ & $\ldots$ & 0 & 1 & 1 \\
\hline OXYBELINI & & & & & & & & & & & & & & & \\
\hline Oxybelus quattuordecimnotatus Jurine, 1807 & 1 & 1 & $\ldots$ & 1 & 1 & $\ldots$ & $\ldots$ & $\ldots$ & $\ldots$ & $\ldots$ & $\ldots$ & $\cdots$ & 2 & 2 & 4 \\
\hline Oxybelus subspinosus Klug, 1835 & $\ldots$ & $\ldots$ & 1 & 1 & 1 & 1 & $\ldots$ & $\ldots$ & $\ldots$ & $\ldots$ & $\ldots$ & $\ldots$ & 2 & 2 & 4 \\
\hline BEMBICINAE & & & & & & & & & & & & & & & \\
\hline BEMBICINI & & & & & & & & & & & & & & & \\
\hline Harpactus alvaroi Gayubo, 1992 & $\ldots$ & $\ldots$ & $\ldots$ & 2 & $\ldots$ & $\ldots$ & $\ldots$ & $\ldots$ & $\ldots$ & $\ldots$ & $\ldots$ & $\ldots$ & 0 & 2 & 2 \\
\hline Harpactus formosus (Jurine, 1807) & $\cdots$ & $\ldots$ & $\cdots$ & 1 & $\cdots$ & $\ldots$ & $\ldots$ & $\ldots$ & $\ldots$ & $\ldots$ & $\ldots$ & $\ldots$ & 0 & 1 & 1 \\
\hline Bembecinus tridens (Fabricius, 1781) & $\ldots$ & $\ldots$ & $\ldots$ & $\ldots$ & $\ldots$ & 1 & $\ldots$ & $\cdots$ & $\ldots$ & $\ldots$ & $\ldots$ & $\ldots$ & 0 & 1 & 1 \\
\hline Subtotales & 2 & 7 & 2 & 25 & 3 & 17 & 2 & 3 & $\mathbf{0}$ & 1 & $\mathbf{0}$ & $\mathbf{0}$ & 9 & 53 & \\
\hline Total de Ejemplares & & & & & & & & & & & $\mathbf{0}$ & & & 2 & 62 \\
\hline Total de Especies & & & & & & & & & & & $\mathbf{0}$ & & & & 23 \\
\hline
\end{tabular}




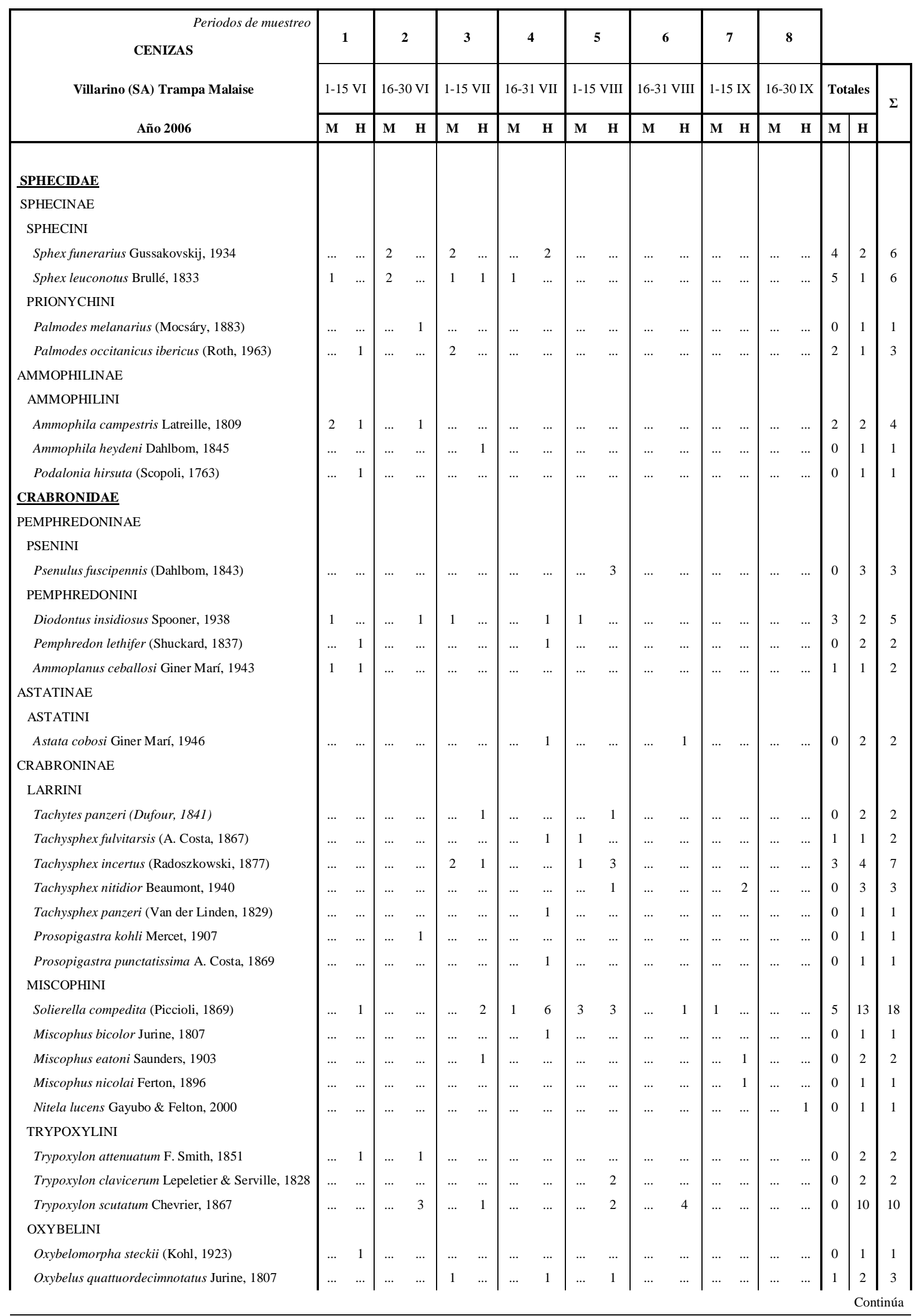




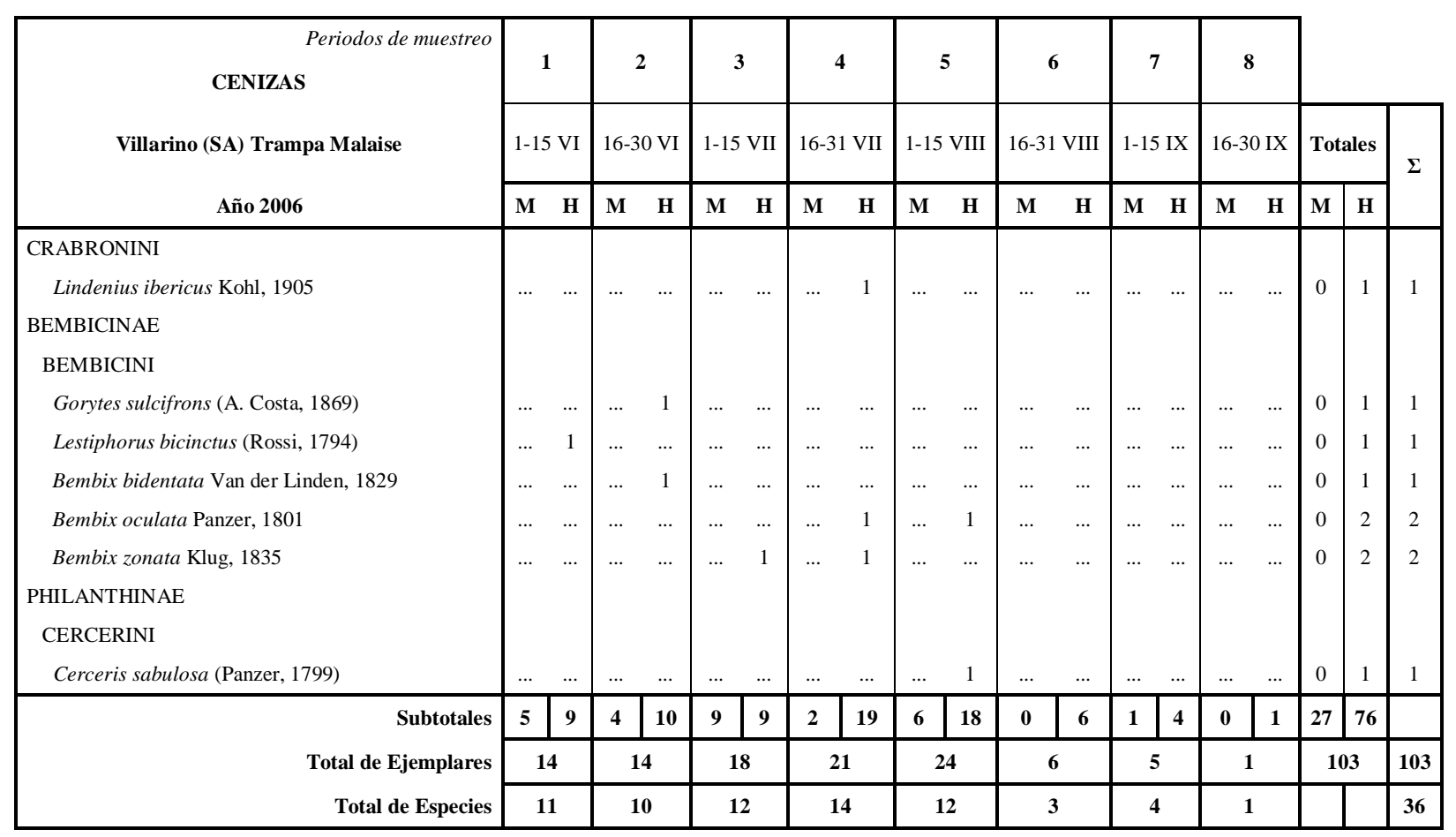




\begin{tabular}{|c|c|c|c|c|c|c|c|c|c|c|c|c|c|c|c|c|c|c|c|}
\hline \multirow{3}{*}{$\begin{array}{c}\text { Periodos de muestreo } \\
\text { CENIZAS } \\
\text { Villarino (SA) Trampa Malaise } \\
\text { Año } 2007\end{array}$} & \multicolumn{2}{|c|}{1} & \multicolumn{2}{|c|}{2} & \multicolumn{2}{|c|}{3} & \multicolumn{2}{|c|}{4} & \multicolumn{2}{|c|}{5} & \multicolumn{2}{|c|}{6} & \multicolumn{2}{|c|}{7} & \multicolumn{2}{|c|}{8} & & & \\
\hline & \multicolumn{2}{|c|}{$\begin{array}{c}1-15 \\
\text { VI }\end{array}$} & \multicolumn{2}{|c|}{$\begin{array}{c}16-30 \\
\text { VI }\end{array}$} & \multicolumn{2}{|c|}{$\begin{array}{l}1-15 \\
\text { VII }\end{array}$} & \multicolumn{2}{|c|}{$\begin{array}{c}16-31 \\
\text { VII }\end{array}$} & \multicolumn{2}{|c|}{$\begin{array}{l}1-15 \\
\text { VIII }\end{array}$} & & & $\begin{array}{c}1- \\
\mathrm{I}\end{array}$ & & $\begin{array}{r}16 \\
\mathrm{I}\end{array}$ & & & ales & $\Sigma$ \\
\hline & $\mathbf{M}$ & $\mathbf{H}$ & $\mathbf{M}$ & $\mathbf{H}$ & $\mathbf{M}$ & $\mathbf{H}$ & $\mathbf{M}$ & $\mathbf{H}$ & $\mathbf{M}$ & $\mathbf{H}$ & $\mathbf{M}$ & $\mathbf{H}$ & M & & $\mathbf{M}$ & & $\mathbf{M}$ & $\mathbf{H}$ & \\
\hline SPHECIDAE & & & & & & & & & & & & & & & & & & & \\
\hline SCELIPHRINAE & & & & & & & & & & & & & & & & & & & \\
\hline SCELIPHRINI & & & & & & & & & & & & & & & & & & & \\
\hline Sceliphron destillatorium (Illiger, 1807) & $\ldots$ & & $\ldots$ & $\ldots$ & & 1 & $\ldots$ & $\ldots$ & $\ldots$ & $\ldots$ & $\ldots$ & $\ldots$ & $\ldots$ & & $\ldots$ & $\ldots$ & 0 & 1 & 1 \\
\hline SPHECINAE & & & & & & & & & & & & & & & & & & & \\
\hline SPHECINI & & & & & & & & & & & & & & & & & & & \\
\hline Sphex flavipennis Fabricius, 1793 & $\ldots$ & $\ldots$ & $\ldots$ & $\ldots$ & $\ldots$ & $\ldots$ & 1 & $\ldots$ & $\ldots$ & $\ldots$ & $\ldots$ & $\ldots$ & $\ldots$ & $\ldots$ & $\ldots$ & $\ldots$ & 1 & 0 & 1 \\
\hline Sphex funerarius Gussakovskij, 1934 & $\ldots$ & $\ldots$ & 1 & $\ldots$ & 3 & 5 & $\ldots$ & 1 & $\ldots$ & 1 & $\ldots$ & $\ldots$ & $\ldots$ & $\ldots$ & $\ldots$ & $\ldots$ & 4 & 7 & 11 \\
\hline Sphex leuconotus Brullé, 1833 & $\ldots$ & $\ldots$ & $\ldots$ & $\ldots$ & 1 & $\cdots$ & 4 & $\ldots$ & $\ldots$ & $\ldots$ & $\ldots$ & $\ldots$ & $\ldots$ & $\ldots$ & $\ldots$ & $\ldots$ & 5 & 0 & 5 \\
\hline PRIONICHYNI & & & & & & & & & & & & & & & & & & & \\
\hline $\begin{array}{l}\text { Palmodes occitanicus occitanicus (Lepeletier \& Serville } \\
\text { 1828) }\end{array}$ & $\cdots$ & $\cdots$ & $\cdots$ & $\cdots$ & $\cdots$ & $\cdots$ & $\cdots$ & 1 & $\ldots$ & $\cdots$ & $\cdots$ & $\cdots$ & $\cdots$ & $\cdots$ & $\cdots$ & $\ldots$ & 0 & 1 & 1 \\
\hline Chilosphex argyrius (Brullé, 1833) & $\ldots$ & $\ldots$ & $\ldots$ & $\ldots$ & $\ldots$ & 1 & ... & 1 & $\ldots$ & $\ldots$ & $\ldots$ & $\cdots$ & $\ldots$ & $\ldots$ & $\cdots$ & $\ldots$ & 0 & 2 & 2 \\
\hline AMMOPHILINAE & & & & & & & & & & & & & & & & & & & \\
\hline AMMOPHILINI & & & & & & & & & & & & & & & & & & & \\
\hline Ammophila campestris Latreille, 1809 & 1 & 1 & $\ldots$ & 1 & $\ldots$ & $\ldots$ & $\ldots$ & $\ldots$ & $\ldots$ & $\ldots$ & $\ldots$ & $\ldots$ & $\ldots$ & $\ldots$ & $\ldots$ & $\ldots$ & 1 & 2 & 3 \\
\hline Ammophila heydeni Dahlbom, 1845 & 2 & $\ldots$ & $\ldots$ & $\ldots$ & $\cdots$ & $\ldots$ & 1 & $\ldots$ & $\ldots$ & $\ldots$ & $\ldots$ & $\ldots$ & $\cdots$ & $\ldots$ & $\ldots$ & $\ldots$ & 3 & 0 & 3 \\
\hline Ammophila Aff. rubriventris & $\ldots$ & $\cdots$ & $\ldots$ & $\ldots$ & $\ldots$ & $\cdots$ & $\cdots$ & $\cdots$ & $\cdots$ & 1 & $\ldots$ & $\ldots$ & $\ldots$ & $\ldots$ & $\ldots$ & $\ldots$ & 0 & 1 & 1 \\
\hline CRABRONIDAE & & & & & & & & & & & & & & & & & & & \\
\hline PEMPHREDONINAE & & & & & & & & & & & & & & & & & & & \\
\hline PSENINI & & & & & & & & & & & & & & & & & & & \\
\hline Psenulus fuscipennis (Dahlbom, 1843) & $\ldots$ & 2 & $\ldots$ & 1 & $\ldots$ & $\ldots$ & $\ldots$ & $\ldots$ & $\ldots$ & $\ldots$ & $\ldots$ & $\ldots$ & $\cdots$ & $\ldots$ & $\ldots$ & $\ldots$ & 0 & 3 & 3 \\
\hline PEMPHREDONINI & & & & & & & & & & & & & & & & & & & \\
\hline Diodontus insidiosus Spooner, 1938 & $\ldots$ & 1 & $\ldots$ & 1 & 1 & 1 & 2 & 2 & 2 & 4 & 1 & $\ldots$ & $\ldots$ & $\ldots$ & $\ldots$ & $\ldots$ & 6 & 9 & 15 \\
\hline Pemphredon lethifer (Shuckard, 1837) & $\ldots$ & 1 & $\ldots$ & 1 & $\ldots$ & $\ldots$ & $\ldots$ & 2 & $\ldots$ & 1 & $\ldots$ & 4 & $\ldots$ & 1 & $\ldots$ & $\ldots$ & 0 & 10 & 10 \\
\hline Passaloecus pictus Ribaut, 1952 & $\ldots$ & $\ldots$ & $\ldots$ & $\ldots$ & $\ldots$ & 1 & $\ldots$ & $\ldots$ & $\ldots$ & $\ldots$ & $\ldots$ & $\ldots$ & $\ldots$ & $\ldots$ & $\ldots$ & $\ldots$ & 0 & 1 & 1 \\
\hline Ammoplanus ceballosi Giner Marí, 1943 & 1 & $\ldots$ & $\ldots$ & $\ldots$ & $\ldots$ & $\ldots$ & $\ldots$ & $\ldots$ & $\ldots$ & $\ldots$ & $\ldots$ & $\ldots$ & $\ldots$ & $\ldots$ & $\cdots$ & $\ldots$ & 1 & 0 & 1 \\
\hline ASTATINAE & & & & & & & & & & & & & & & & & & & \\
\hline ASTATINI & & & & & & & & & & & & & & & & & & & \\
\hline Dryudella tricolor (Van der Linden, 1829) & $\ldots$ & $\ldots$ & $\ldots$ & $\ldots$ & $\ldots$ & $\ldots$ & $\ldots$ & $\ldots$ & $\ldots$ & $\ldots$ & $\ldots$ & 2 & $\ldots$ & $\ldots$ & $\ldots$ & $\ldots$ & 0 & 2 & 2 \\
\hline CRABRONINAE & & & & & & & & & & & & & & & & & & & \\
\hline LARRINI & & & & & & & & & & & & & & & & & & & \\
\hline Tachysphex fulvitarsis (A. Costa, 1867) & $\ldots$ & $\ldots$ & $\ldots$ & $\ldots$ & $\ldots$ & $\ldots$ & $\ldots$ & 1 & $\ldots$ & $\ldots$ & $\ldots$ & $\ldots$ & $\ldots$ & $\ldots$ & $\ldots$ & $\ldots$ & 0 & 1 & 1 \\
\hline Tachysphex nitidior Beaumont, 1940 & $\ldots$ & $\ldots$ & $\ldots$ & $\ldots$ & $\ldots$ & $\ldots$ & $\ldots$ & 1 & $\ldots$ & $\ldots$ & $\ldots$ & $\ldots$ & $\ldots$ & $\ldots$ & $\ldots$ & $\ldots$ & 0 & 1 & 1 \\
\hline MISCOPHINI & & & & & & & & & & & & & & & & & & & \\
\hline Solierella compedita (Piccioli, 1869) & $\ldots$ & $\ldots$ & $\ldots$ & $\ldots$ & $\ldots$ & $\ldots$ & $\ldots$ & $\ldots$ & 2 & 9 & $\ldots$ & 7 & 4 & 11 & $\ldots$ & 1 & 6 & 28 & 34 \\
\hline Solierella seabrai Andrade, 1950 & $\ldots$ & $\ldots$ & $\ldots$ & $\ldots$ & $\ldots$ & $\ldots$ & $\ldots$ & $\ldots$ & $\ldots$ & $\ldots$ & $\ldots$ & 1 & $\ldots$ & $\ldots$ & $\ldots$ & $\ldots$ & 0 & 1 & 1 \\
\hline Miscophus eatoni Saunders, 1903 & $\ldots$ & $\ldots$ & $\ldots$ & $\ldots$ & $\ldots$ & $\ldots$ & $\ldots$ & $\ldots$ & 1 & 1 & $\ldots$ & $\ldots$ & $\ldots$ & $\ldots$ & $\ldots$ & $\ldots$ & 1 & 1 & 2 \\
\hline TRYPOXYLINI & & & & & & & & & & & & & & & & & & & \\
\hline Pison atrum (Spinola, 1808) & $\ldots$ & $\ldots$ & $\ldots$ & $\ldots$ & $\ldots$ & $\ldots$ & $\ldots$ & 1 & $\ldots$ & $\ldots$ & $\ldots$ & $\ldots$ & $\ldots$ & $\ldots$ & $\ldots$ & $\ldots$ & 0 & 1 & 1 \\
\hline Trypoxylon attenuatum F. Smith, 1851 & $\ldots$ & $\ldots$ & $\ldots$ & $\ldots$ & $\ldots$ & 1 & $\ldots$ & 1 & $\ldots$ & 1 & $\ldots$ & $\ldots$ & 1 & 3 & $\ldots$ & 2 & 1 & 8 & 9 \\
\hline Trypoxylon clavicerum Lepeletier \& Serville, 1828 & $\ldots$ & $\ldots$ & $\ldots$ & $\ldots$ & $\ldots$ & $\ldots$ & $\ldots$ & $\ldots$ & $\ldots$ & 1 & $\ldots$ & 1 & $\ldots$ & $\ldots$ & $\ldots$ & $\ldots$ & 0 & 2 & 2 \\
\hline Trypoxylon minus Beaumont, 1945 & $\ldots$ & $\ldots$ & $\ldots$ & $\ldots$ & 1 & $\ldots$ & $\ldots$ & $\ldots$ & $\ldots$ & 1 & $\ldots$ & $\ldots$ & $\ldots$ & $\ldots$ & $\ldots$ & $\ldots$ & 1 & 1 & 2 \\
\hline Trypoxylon scutatum Chevrier, 1867 & $\ldots$ & 2 & $\ldots$ & $\ldots$ & $\ldots$ & 1 & $\ldots$ & 3 & 1 & 5 & $\ldots$ & 2 & $\ldots$ & 5 & $\ldots$ & $\ldots$ & 1 & 18 & 19 \\
\hline OXYBELINI & & & & & & & & & & & & & & & & & & & \\
\hline Oxybelus quattuordecimnotatus Jurine, 1807 & $\ldots$ & $\ldots$ & $\ldots$ & $\ldots$ & 1 & $\ldots$ & $\ldots$ & $\ldots$ & $\ldots$ & $\ldots$ & 2 & 1 & $\ldots$ & $\ldots$ & $\ldots$ & $\ldots$ & 3 & 1 & 4 \\
\hline CRABRONINI & & & & & & & & & & & & & & & & & & & \\
\hline Ectemnius crassicornis (Spinola, 1808) & $\ldots$ & $\ldots$ & $\ldots$ & $\ldots$ & $\ldots$ & 1 & $\ldots$ & $\ldots$ & $\ldots$ & $\ldots$ & $\ldots$ & $\ldots$ & $\ldots$ & $\ldots$ & $\ldots$ & $\ldots$ & 0 & 1 & 1 \\
\hline
\end{tabular}




\begin{tabular}{|c|c|c|c|c|c|c|c|c|c|c|c|c|c|c|c|c|c|c|}
\hline \multirow{3}{*}{$\begin{array}{c}\text { Periodos de muestreo } \\
\text { CENIZAS } \\
\text { Villarino (SA) Trampa Malaise } \\
\text { Año } 2007\end{array}$} & 1 & \multicolumn{2}{|c|}{2} & \multicolumn{2}{|c|}{3} & \multicolumn{2}{|c|}{4} & \multicolumn{2}{|c|}{5} & \multicolumn{2}{|c|}{6} & \multicolumn{2}{|c|}{7} & \multicolumn{2}{|c|}{8} & & & \\
\hline & $\begin{array}{c}1-15 \\
\text { VI }\end{array}$ & \multicolumn{2}{|c|}{$\begin{array}{c}16-30 \\
\text { VI }\end{array}$} & \multicolumn{2}{|c|}{$\begin{array}{l}1-15 \\
\text { VII }\end{array}$} & \multicolumn{2}{|c|}{$\begin{array}{c}16-31 \\
\text { VII }\end{array}$} & \multicolumn{2}{|c|}{$\begin{array}{l}1-15 \\
\text { VIII }\end{array}$} & \multicolumn{2}{|c|}{$\begin{array}{c}16-31 \\
\text { VIII }\end{array}$} & \multicolumn{2}{|c|}{$\begin{array}{c}1-15 \\
\text { IX }\end{array}$} & \multicolumn{2}{|c|}{$\begin{array}{c}16-30 \\
\text { IX }\end{array}$} & \multicolumn{2}{|c|}{ Totales } & \multirow{2}{*}{$\Sigma$} \\
\hline & $\mathbf{M} \mathbf{H}$ & $\mathbf{M}$ & $\mathbf{H}$ & $\mathbf{M}$ & $\mathbf{H}$ & $\mathbf{M}$ & $\mathbf{H}$ & $\mathbf{M}$ & $\mathbf{H}$ & M & $\mathbf{H}$ & $\mathbf{M}$ & $\mathbf{H}$ & $\mathbf{M}$ & $\mathbf{H}$ & $\mathbf{M}$ & $\mathbf{H}$ & \\
\hline \multicolumn{19}{|l|}{ BEMBICINAE } \\
\hline \multicolumn{19}{|l|}{ NYSSONINI } \\
\hline Nysson maculosus (Gmelin, 1790) & $\ldots$ & $\ldots$ & $\ldots$ & $\ldots$ & $\ldots$ & $\ldots$ & 1 & $\ldots$ & $\ldots$ & $\ldots$ & $\ldots$ & $\ldots$ & & $\ldots$ & $\ldots$ & 0 & 1 & 1 \\
\hline \multicolumn{19}{|l|}{ BEMBICINI } \\
\hline Gorytes sulcifrons (A. Costa, 1869) & $\ldots$ & $\ldots$ & $\ldots$ & $\ldots$ & 2 & $\ldots$ & 1 & $\ldots$ & $\ldots$ & $\ldots$ & $\ldots$ & $\ldots$ & & $\ldots$ & $\ldots$ & 0 & 3 & 3 \\
\hline Harpactus formosus (Jurine, 1807) & $\ldots$ & $\ldots$ & $\ldots$ & $\ldots$ & $\ldots$ & $\ldots$ & $\ldots$ & $\ldots$ & $\ldots$ & $\ldots$ & 1 & $\ldots$ & $\ldots$ & $\ldots$ & $\ldots$ & 0 & 1 & 1 \\
\hline Harpactus sp. 2 grimaldensis Gayubo, sp. n. (in lit.) & $\ldots \quad \ldots$ & $\ldots$ & $\ldots$ & $\ldots$ & $\ldots$ & $\ldots$ & $\ldots$ & $\ldots$ & 1 & $\ldots$ & $\ldots$ & $\ldots$ & $\ldots$ & $\ldots$ & $\ldots$ & 0 & 1 & 1 \\
\hline Lestiphorus bicinctus (Rossi, 1794) & $\ldots$ & $\ldots$ & $\ldots$ & $\ldots$ & $\ldots$ & $\ldots$ & $\ldots$ & $\ldots$ & $\ldots$ & $\ldots$ & $\ldots$ & $\ldots$ & 1 & $\ldots$ & $\ldots$ & 0 & 1 & 1 \\
\hline Bembix bidentata Van der Linden, 1829 & $\ldots$ & $\ldots$ & $\ldots$ & $\ldots$ & $\ldots$ & $\ldots$ & 1 & $\ldots$ & $\ldots$ & $\ldots$ & $\ldots$ & $\ldots$ & $\ldots$ & $\ldots$ & $\ldots$ & 0 & 1 & 1 \\
\hline Subtotales & 4 & 1 & 4 & 7 & 14 & 8 & 17 & 6 & 26 & 3 & 19 & 5 & 21 & $\mathbf{0}$ & 3 & 34 & 111 & \\
\hline Total de Ejemplares & 11 & \multicolumn{2}{|c|}{5} & \multicolumn{2}{|c|}{21} & \multicolumn{2}{|c|}{25} & \multicolumn{2}{|c|}{32} & \multicolumn{2}{|c|}{22} & \multicolumn{2}{|c|}{26} & \multicolumn{2}{|c|}{3} & \multicolumn{2}{|c|}{145} & 145 \\
\hline Total de Especies & 7 & & & & & 1 & & & & 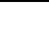 & & 5 & & 2 & & & & 33 \\
\hline
\end{tabular}




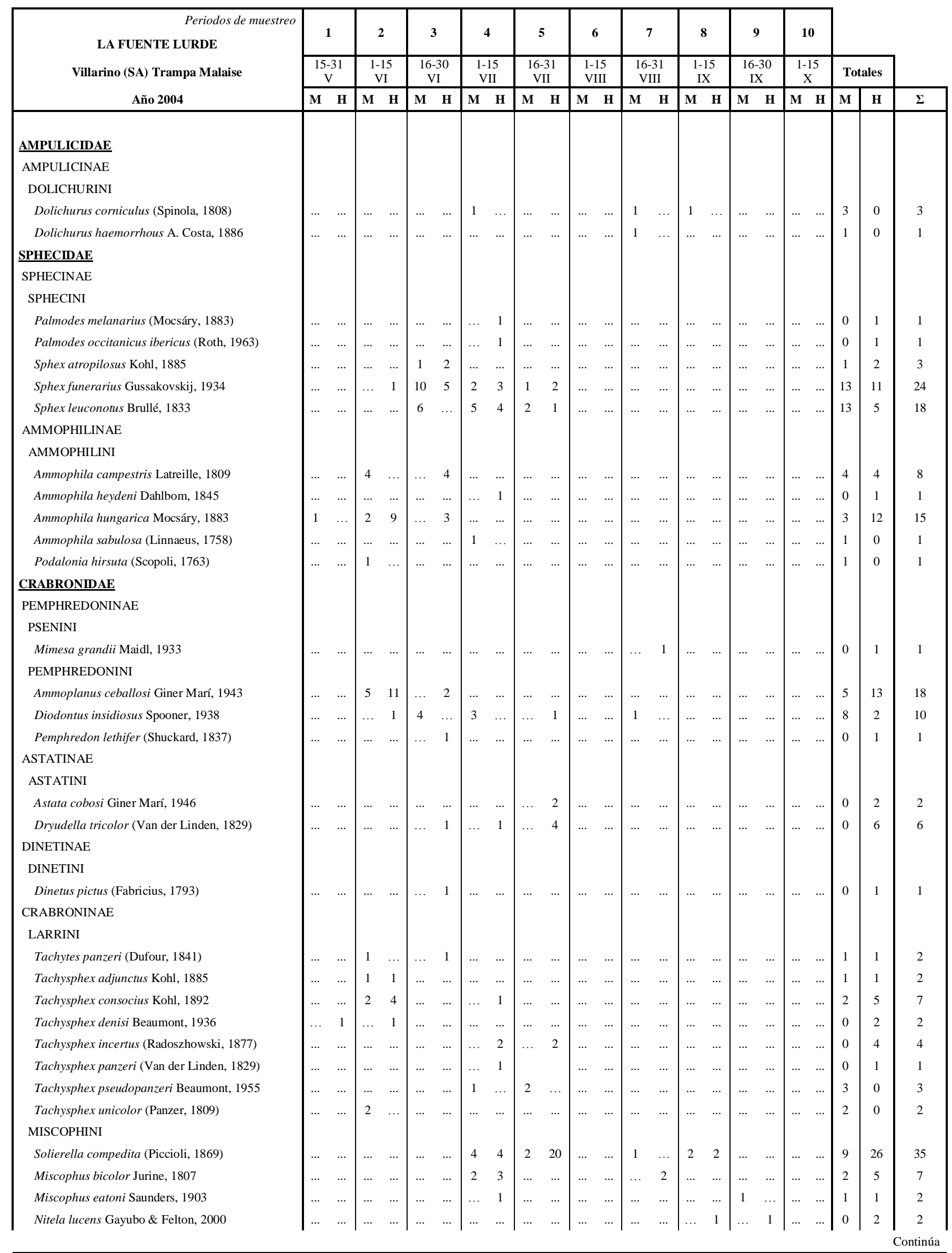




\begin{tabular}{|c|c|c|c|c|c|c|c|c|c|c|c|c|c|c|c|c|c|c|c|c|c|c|c|}
\hline \multirow{3}{*}{$\begin{array}{c}\text { Periodos de muestreo } \\
\text { LA FUENTE LURDE } \\
\text { Villarino (SA) Trampa Malaise } \\
\text { Año } 2004\end{array}$} & \multicolumn{2}{|c|}{1} & \multicolumn{2}{|c|}{2} & \multicolumn{2}{|c|}{3} & \multicolumn{2}{|c|}{4} & \multicolumn{2}{|c|}{5} & \multicolumn{2}{|c|}{6} & \multicolumn{2}{|c|}{7} & \multicolumn{2}{|c|}{8} & \multicolumn{2}{|c|}{9} & \multicolumn{2}{|c|}{10} & & & \\
\hline & \multicolumn{2}{|c|}{$\begin{array}{c}15-31 \\
\mathrm{~V}\end{array}$} & \multicolumn{2}{|c|}{$\begin{array}{c}1-15 \\
\text { VI }\end{array}$} & \multicolumn{2}{|c|}{$\begin{array}{c}16-30 \\
\text { VI }\end{array}$} & \multicolumn{2}{|c|}{$\begin{array}{c}1-15 \\
\text { VII } \\
\end{array}$} & \multicolumn{2}{|c|}{$\begin{array}{c}16-31 \\
\text { VII }\end{array}$} & \multicolumn{2}{|c|}{$\begin{array}{l}1-15 \\
\text { VIII } \\
\end{array}$} & \multicolumn{2}{|c|}{$\begin{array}{c}16-31 \\
\text { VIII }\end{array}$} & \multicolumn{2}{|c|}{$\begin{array}{c}1-15 \\
\text { IX } \\
\end{array}$} & \multicolumn{2}{|c|}{$\begin{array}{c}16-30 \\
\text { IX }\end{array}$} & \multicolumn{2}{|c|}{$\begin{array}{c}1-15 \\
X \\
\end{array}$} & \multicolumn{2}{|c|}{ Totales } & \\
\hline & M & $\mathbf{H}$ & $\mathbf{M}$ & $\mathbf{H}$ & M & $\mathbf{H}$ & $\mathbf{M}$ & $\mathbf{H}$ & $\mathbf{M}$ & $\mathbf{H}$ & $\mathbf{M}$ & $\mathbf{H}$ & $\mathbf{M}$ & $\mathbf{H}$ & M & $\mathbf{H}$ & $\mathbf{M}$ & $\mathbf{H}$ & $\mathbf{M}$ & & $\mathbf{M}$ & $\mathbf{H}$ & $\Sigma$ \\
\hline \multicolumn{24}{|l|}{ TRYPOXYLINI } \\
\hline Trypoxylon attenuatum F. Smith, 1851 & & 2 & $\ldots$ & $\ldots$ & $\ldots$ & 3 & $\ldots$ & 1 & 1 & $\ldots$ & $\ldots$ & $\ldots$ & $\ldots$ & $\ldots$ & $\ldots$ & $\ldots$ & $\ldots$ & $\ldots$ & $\ldots$ & 1 & 1 & 7 & 8 \\
\hline Trypoxylon clavicerum Lepeletier \& Serville, 1828 & $\ldots$ & $\cdots$ & $\ldots$ & $\ldots$ & $\ldots$ & $\cdots$ & $\ldots$ & 1 & $\ldots$ & $\ldots$ & $\ldots$ & $\ldots$ & $\cdots$ & 1 & 2 & $\ldots$ & $\ldots$ & $\ldots$ & $\ldots$ & $\ldots$ & 2 & 2 & 4 \\
\hline Trypoxylon scutatum Chevrier, 1867 & $\ldots$ & $\cdots$ & $\cdots$ & 1 & $\ldots$ & 1 & 1 & 2 & .. & 3 & $\ldots$ & $\cdots$ & 1 & 2 & $\cdots$ & 1 & $\cdots$ & 1 & $\cdots$ & $\ldots$ & 2 & 11 & 13 \\
\hline OXYBELINI & & & & & & & & & & & & & & & & & & & & & & & \\
\hline Belomicrus steckii Kohl, 1923 & $\ldots$ & $\ldots$ & $\cdots$ & 2 & $\ldots$ & $\ldots$ & $\ldots$ & $\ldots$ & $\ldots$ & $\ldots$ & $\cdots$ & $\ldots$ & $\ldots$ & $\cdots$ & $\ldots$ & $\ldots$ & $\ldots$ & $\ldots$ & $\ldots$ & $\ldots$ & 0 & 2 & 2 \\
\hline Oxybelus quattuordecimnotatus Jurine, 1807 & $\ldots$ & $\ldots$ & $\ldots$ & $\ldots$ & $\ldots$ & $\ldots$ & $\ldots$ & 1 & $\ldots$ & 1 & $\ldots$ & $\ldots$ & $\ldots$ & $\ldots$ & $\ldots$ & 3 & $\ldots$ & $\ldots$ & $\ldots$ & $\ldots$ & 0 & 5 & 5 \\
\hline CRABRONINI & & & & & & & & & & & & & & & & & & & & & & & \\
\hline Encopognathus braunsi Mercet, 1915 & $\ldots$ & $\ldots$ & $\ldots$ & $\ldots$ & $\ldots$ & 1 & $\ldots$ & $\ldots$ & $\ldots$ & $\ldots$ & $\cdots$ & $\ldots$ & $\cdots$ & $\ldots$ & $\cdots$ & $\ldots$ & $\cdots$ & $\ldots$ & $\cdots$ & $\ldots$ & 0 & 1 & 1 \\
\hline BEMBICINAE & & & & & & & & & & & & & & & & & & & & & & & \\
\hline NYSSONINI & & & & & & & & & & & & & & & & & & & & & & & \\
\hline Nysson interruptus (Fabricius, 1798) & $\cdots$ & 1 & $\cdots$ & 5 & $\ldots$ & $\ldots$ & $\cdots$ & $\ldots$ & $\cdots$ & $\ldots$ & $\ldots$ & $\ldots$ & $\ldots$ & $\ldots$ & $\ldots$ & $\ldots$ & $\ldots$ & $\ldots$ & $\cdots$ & $\ldots$ & 0 & 6 & 6 \\
\hline BEMBICINI & & & & & & & & & & & & & & & & & & & & & & & \\
\hline Bembix zonata Klug, 1835 & $\ldots$ & $\ldots$ & $\ldots$ & $\cdots$ & $\ldots$ & $\ldots$ & $\cdots$ & 2 & $\ldots$ & 2 & $\ldots$ & $\cdots$ & $\ldots$ & $\ldots$ & $\ldots$ & $\ldots$ & $\ldots$ & $\cdots$ & $\ldots$ & $\ldots$ & 0 & 4 & 4 \\
\hline Harpactus alvaroi Gayubo, 1992 & $\ldots$ & $\cdots$ & $\ldots$ & $\ldots$ & $\cdots$ & $\cdots$ & $\ldots$ & $\ldots$ & $\cdots$ & $\ldots$ & $\cdots$ & $\ldots$ & $\cdots$ & 1 & $\ldots$ & $\ldots$ & $\cdots$ & $\ldots$ & $\cdots$ & $\ldots$ & 0 & 1 & 1 \\
\hline Harpactus formosus (Jurine, 1807) & $\ldots$ & $\ldots$ & $\ldots$ & $\ldots$ & 1 & $\cdots$ & $\ldots$ & 1 & $\ldots$ & $\ldots$ & $\ldots$ & $\ldots$ & $\ldots$ & $\ldots$ & $\ldots$ & $\ldots$ & $\ldots$ & $\ldots$ & $\ldots$ & $\ldots$ & 1 & 1 & 2 \\
\hline Harpactus laevis (Latreille, 1792) & $\ldots$ & $\cdots$ & $\ldots$ & $\cdots$ & $\cdots$ & $\cdots$ & 1 & $\cdots$ & $\ldots$ & $\ldots$ & $\cdots$ & $\ldots$ & $\ldots$ & $\ldots$ & $\cdots$ & 2 & $\cdots$ & 1 & $\cdots$ & $\ldots$ & 1 & 3 & 4 \\
\hline Gorytes sulcifrons (A. Costa, 1869) & $\ldots$ & $\ldots$ & 2 & $\ldots$ & $\ldots$ & 4 & $\ldots$ & $\ldots$ & $\ldots$ & $\ldots$ & $\cdots$ & $\cdots$ & $\cdots$ & $\ldots$ & $\ldots$ & $\ldots$ & $\ldots$ & $\ldots$ & $\cdots$ & $\ldots$ & 2 & 4 & 6 \\
\hline PHILANTHINAE & & & & & & & & & & & & & & & & & & & & & & & \\
\hline CERCERINI & & & & & & & & & & & & & & & & & & & & & & & \\
\hline Cerceris arenaria (Linnaeus, 1758) & $\ldots$ & $\ldots$ & $\ldots$ & $\ldots$ & $\ldots$ & $\ldots$ & $\ldots$ & $\ldots$ & $\cdots$ & 2 & $\ldots$ & $\ldots$ & $\ldots$ & $\ldots$ & $\cdots$ & $\ldots$ & $\ldots$ & $\ldots$ & $\ldots$ & $\ldots$ & 0 & 2 & 2 \\
\hline Cerceris sabulosa (Panzer, 1799) & $\ldots$ & $\ldots$ & $\ldots$ & $\ldots$ & $\ldots$ & $\ldots$ & $\ldots$ & $\ldots$ & $\ldots$ & $\ldots$ & $\ldots$ & $\ldots$ & $\cdots$ & 1 & 1 & $\ldots$ & $\ldots$ & $\ldots$ & $\ldots$ & $\ldots$ & 1 & 1 & 2 \\
\hline Subtotales & 1 & 4 & 20 & 36 & 22 & 29 & 21 & 31 & 8 & 40 & $\mathbf{0}$ & $\mathbf{0}$ & 5 & 8 & 6 & 9 & 1 & 3 & $\mathbf{0}$ & 1 & 84 & 161 & \\
\hline Total de Ejemplares & & & 5 & 6 & & & & & & & & & & & & & 4 & & 1 & & & 15 & 245 \\
\hline Total de Especies & & & 1 & 5 & & & 2 & & & & & & & & & & 4 & & 1 & & & & 45 \\
\hline
\end{tabular}




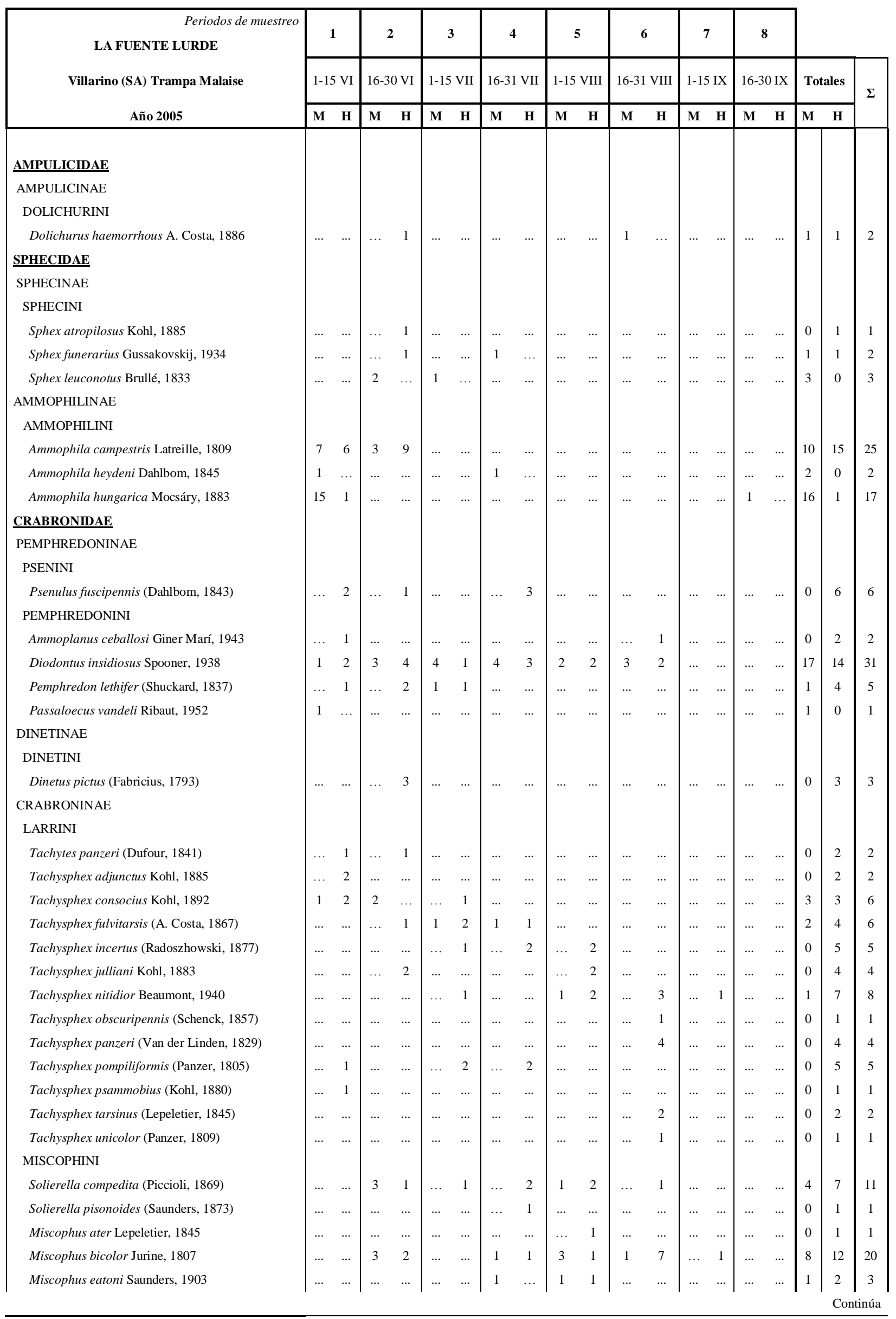




\begin{tabular}{|c|c|c|c|c|c|c|c|c|c|c|c|c|c|c|c|c|c|c|c|}
\hline \multirow{3}{*}{$\begin{array}{c}\text { Periodos de muestreo } \\
\text { LA FUENTE LURDE } \\
\text { Villarino (SA) Trampa Malaise } \\
\text { Año } 2005 \\
\end{array}$} & \multicolumn{2}{|c|}{1} & \multicolumn{2}{|c|}{2} & \multicolumn{2}{|c|}{3} & \multicolumn{2}{|c|}{4} & \multicolumn{2}{|c|}{5} & \multicolumn{2}{|c|}{6} & \multicolumn{2}{|c|}{7} & \multicolumn{2}{|c|}{8} & & & \\
\hline & \multicolumn{2}{|c|}{$1-15 \mathrm{VI}$} & \multicolumn{2}{|c|}{$16-30 \mathrm{VI}$} & \multicolumn{2}{|c|}{ 1-15 VII } & \multicolumn{2}{|c|}{ 16-31 VII } & \multicolumn{2}{|c|}{ 1-15 VIII } & \multicolumn{2}{|c|}{ 16-31 VIII } & \multicolumn{2}{|c|}{ 1-15 IX } & \multicolumn{2}{|c|}{$16-30$ IX } & \multicolumn{2}{|c|}{ Totales } & \multirow{2}{*}{$\Sigma$} \\
\hline & M & & $\mathbf{M}$ & $\mathbf{H}$ & $\mathbf{M}$ & $\mathbf{H}$ & $\mathbf{M}$ & & $\mathbf{M}$ & $\mathbf{H}$ & M & $\mathbf{H}$ & $\mathbf{M}$ & $\mathbf{H}$ & $\mathbf{M}$ & $\mathbf{H}$ & $\mathbf{M}$ & & \\
\hline Miscophus nicolai Ferton, 1896 & $\ldots$ & $\ldots$ & $\ldots$ & $\ldots$ & $\ldots$ & 1 & $\ldots$ & $\ldots$ & $\ldots$ & 5 & $\ldots$ & 1 & $\ldots$ & & $\ldots$ & $\ldots$ & 0 & 7 & 7 \\
\hline Nitela lucens Gayubo \& Felton, 2000 & $\ldots$ & $\ldots$ & $\ldots$ & $\ldots$ & $\ldots$ & $\ldots$ & $\ldots$ & $\ldots$ & $\ldots$ & $\ldots$ & $\ldots$ & $\ldots$ & $\ldots$ & $\ldots$ & $\ldots$ & 1 & 0 & 1 & 1 \\
\hline \multicolumn{20}{|l|}{ TRYPOXYLINI } \\
\hline Trypoxylon attenuatum F. Smith, 1851 & $\ldots$ & 2 & $\ldots$ & 4 & $\ldots$ & 1 & $\ldots$ & $\ldots$ & 2 & 1 & $\ldots$ & $\ldots$ & $\ldots$ & 2 & 1 & ... & 3 & 10 & 13 \\
\hline Trypoxylon clavicerum Lepeletier \& Serville, 1828 & $\ldots$ & 1 & $\ldots$ & $\ldots$ & $\ldots$ & $\ldots$ & 1 & $\ldots$ & $\ldots$ & $\ldots$ & $\ldots$ & $\ldots$ & $\ldots$ & $\ldots$ & $\ldots$ & $\ldots$ & 1 & 1 & 2 \\
\hline Trypoxylon scutatum Chevrier, 1867 & $\cdots$ & $\cdots$ & $\cdots$ & 2 & $\cdots$ & 4 & 1 & 2 & $\cdots$ & 3 & $\cdots$ & 6 & $\cdots$ & $\cdots$ & $\cdots$ & $\ldots$ & 1 & 17 & 18 \\
\hline \multicolumn{20}{|l|}{ OXYBELINI } \\
\hline Belomicrus steckii Kohl, 1923 & .. & 3 & $\ldots$ & $\ldots$ & $\ldots$ & $\ldots$ & $\ldots$ & $\ldots$ & $\ldots$ & $\ldots$ & $\ldots$ & $\ldots$ & $\ldots$ & $\ldots$ & $\ldots$ & $\ldots$ & 0 & 3 & 3 \\
\hline \multicolumn{20}{|l|}{ CRABRONINI } \\
\hline Tracheliodes quinquenotatus (Jurine, 1807) & $\ldots$ & 1 & $\ldots$ & $\ldots$ & $\ldots$ & $\ldots$ & $\ldots$ & 1 & $\ldots$ & $\ldots$ & $\ldots$ & $\ldots$ & $\ldots$ & $\ldots$ & $\ldots$ & $\ldots$ & 0 & 2 & 2 \\
\hline Ectemnius cephalotes (Olivier, 1792) & $\cdots$ & $\cdots$ & $\cdots$ & $\cdots$ & $\cdots$ & $\cdots$ & $\cdots$ & $\cdots$ & $\cdots$ & 1 & $\cdots$ & $\cdots$ & $\cdots$ & $\cdots$ & $\cdots$ & $\cdots$ & 0 & 1 & 1 \\
\hline \multicolumn{20}{|l|}{ BEMBICINAE } \\
\hline NYSSONINI & & & & & & & & & & & & & & & & & & & \\
\hline Nysson interruptus (Fabricius, 1798) & $\cdots$ & 1 & $\cdots$ & $\ldots$ & $\cdots$ & $\cdots$ & $\cdots$ & $\ldots$ & $\ldots$ & $\ldots$ & $\cdots$ & $\ldots$ & $\ldots$ & $\ldots$ & $\ldots$ & $\cdots$ & 0 & 1 & 1 \\
\hline Nysson pratensis Mercet, 1909 & $\ldots$ & $\ldots$ & $\ldots$ & $\ldots$ & $\ldots$ & $\ldots$ & $\ldots$ & $\ldots$ & 1 & $\ldots$ & $\ldots$ & $\ldots$ & $\ldots$ & $\ldots$ & $\ldots$ & $\ldots$ & 1 & 0 & 1 \\
\hline BEMBICINI & & & & & & & & & & & & & & & & & & & \\
\hline Bembix zonata Klug, 1835 & $\ldots$ & $\ldots$ & $\ldots$ & 1 & $\ldots$ & $\ldots$ & $\ldots$ & $\ldots$ & $\ldots$ & $\ldots$ & $\ldots$ & $\ldots$ & $\ldots$ & $\ldots$ & $\ldots$ & $\ldots$ & 0 & 1 & 1 \\
\hline Argogorytes fargeii (Shuckard, 1837) & 1 & 2 & $\cdots$ & $\cdots$ & $\ldots$ & $\ldots$ & $\ldots$ & $\ldots$ & $\ldots$ & $\ldots$ & $\ldots$ & $\ldots$ & $\ldots$ & $\ldots$ & $\ldots$ & $\ldots$ & 1 & 2 & 3 \\
\hline Harpactus formosus (Jurine, 1807) & $\cdots$ & $\ldots$ & $\ldots$ & 1 & $\cdots$ & $\ldots$ & $\ldots$ & $\cdots$ & $\ldots$ & 1 & $\ldots$ & 1 & $\ldots$ & $\ldots$ & $\ldots$ & $\ldots$ & 0 & 3 & 3 \\
\hline Harpactus laevis (Latreille, 1792) & $\ldots$ & $\ldots$ & $\ldots$ & $\ldots$ & $\ldots$ & $\ldots$ & $\ldots$ & $\ldots$ & 3 & $\ldots$ & 5 & 3 & $\ldots$ & $\ldots$ & $\ldots$ & $\ldots$ & 8 & 3 & 11 \\
\hline Harpactus sp. 1 & $\cdots$ & $\cdots$ & $\cdots$ & $\cdots$ & $\cdots$ & $\cdots$ & 1 & $\cdots$ & 3 & $\cdots$ & 2 & $\cdots$ & $\cdots$ & $\cdots$ & $\ldots$ & $\ldots$ & 6 & 0 & 6 \\
\hline Gorytes quinquefasciatus (Panzer, 1798) & $\cdots$ & $\cdots$ & $\cdots$ & $\cdots$ & $\cdots$ & $\cdots$ & $\cdots$ & 1 & $\cdots$ & $\cdots$ & $\cdots$ & $\cdots$ & $\cdots$ & $\cdots$ & $\cdots$ & $\cdots$ & 0 & 1 & 1 \\
\hline Gorytes sulcifrons (A. Costa, 1869) & $\ldots$ & $\ldots$ & $\ldots$ & $\ldots$ & $\ldots$ & 1 & $\ldots$ & $\ldots$ & $\ldots$ & $\ldots$ & $\ldots$ & $\ldots$ & $\ldots$ & $\ldots$ & $\ldots$ & $\ldots$ & 0 & 1 & 1 \\
\hline PHILANTHINAE & & & & & & & & & & & & & & & & & & & \\
\hline CERCERINI & & & & & & & & & & & & & & & & & & & \\
\hline Cerceris arenaria (Linnaeus, 1758) & $\ldots$ & & $\ldots$ & $\ldots$ & $\ldots$ & $\ldots$ & $\ldots$ & $\ldots$ & $\ldots$ & $\ldots$ & 1 & $\ldots$ & $\ldots$ & $\ldots$ & $\ldots$ & $\ldots$ & 1 & 1 & 2 \\
\hline Cerceris quadricincta (Panzer, 1799) & $\cdots$ & $\cdots$ & $\cdots$ & $\ldots$ & $\cdots$ & $\ldots$ & $\cdots$ & $\ldots$ & $\cdots$ & $\cdots$ & $\cdots$ & $\ldots$ & $\cdots$ & 1 & $\cdots$ & $\cdots$ & 0 & 1 & 1 \\
\hline Subtotales & 27 & 31 & 16 & 37 & 7 & 17 & 12 & 19 & 17 & 24 & 13 & 33 & $\mathbf{0}$ & 5 & 2 & 1 & 93 & 168 & \\
\hline Total de Ejemplares & & 8 & & & & & & & & & & & 5 & & 3 & & & 61 & 261 \\
\hline Total de Especies & & 0 & & & & & 1 & & & & & & 2 & & 3 & & & & 50 \\
\hline
\end{tabular}




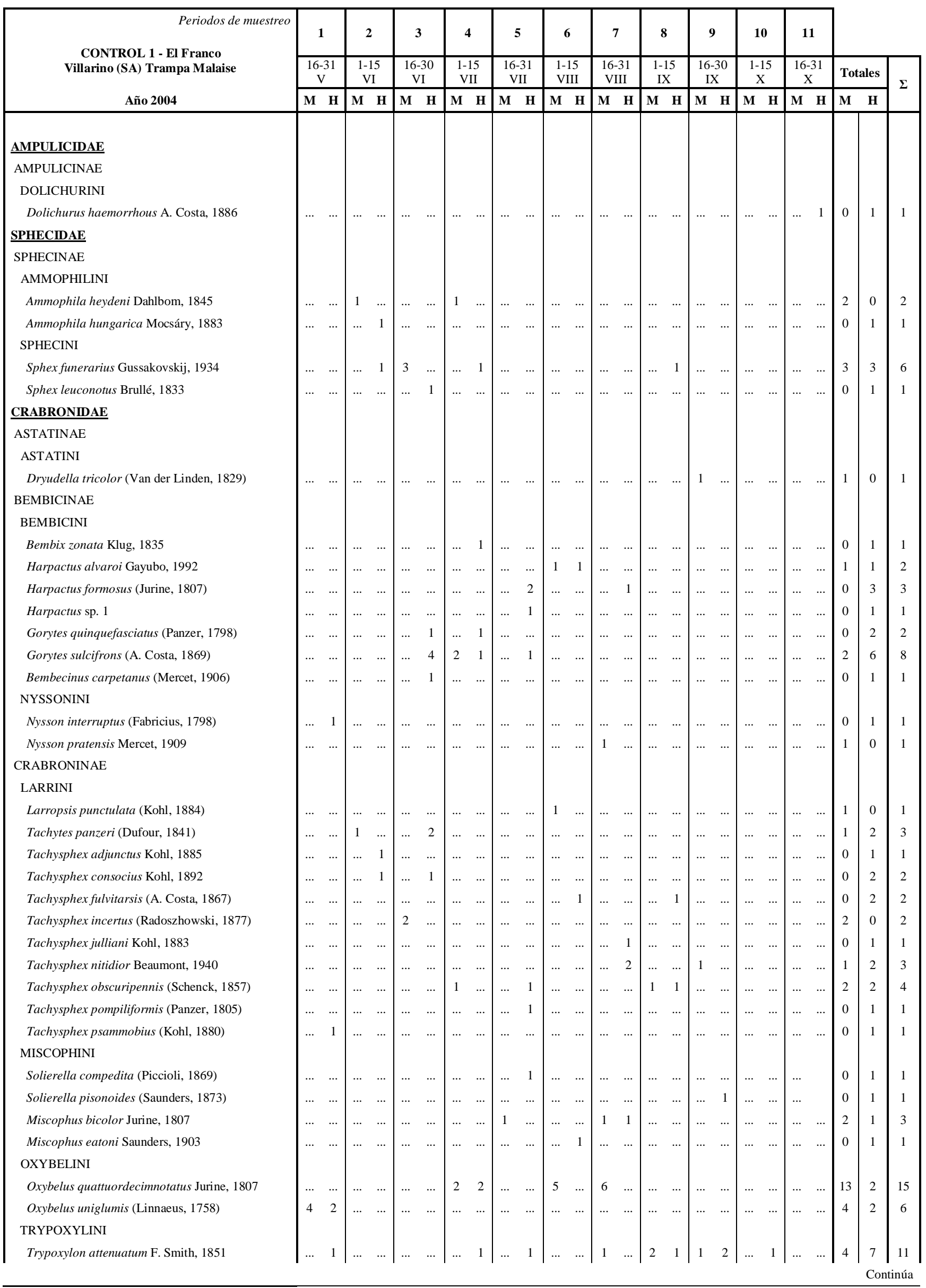




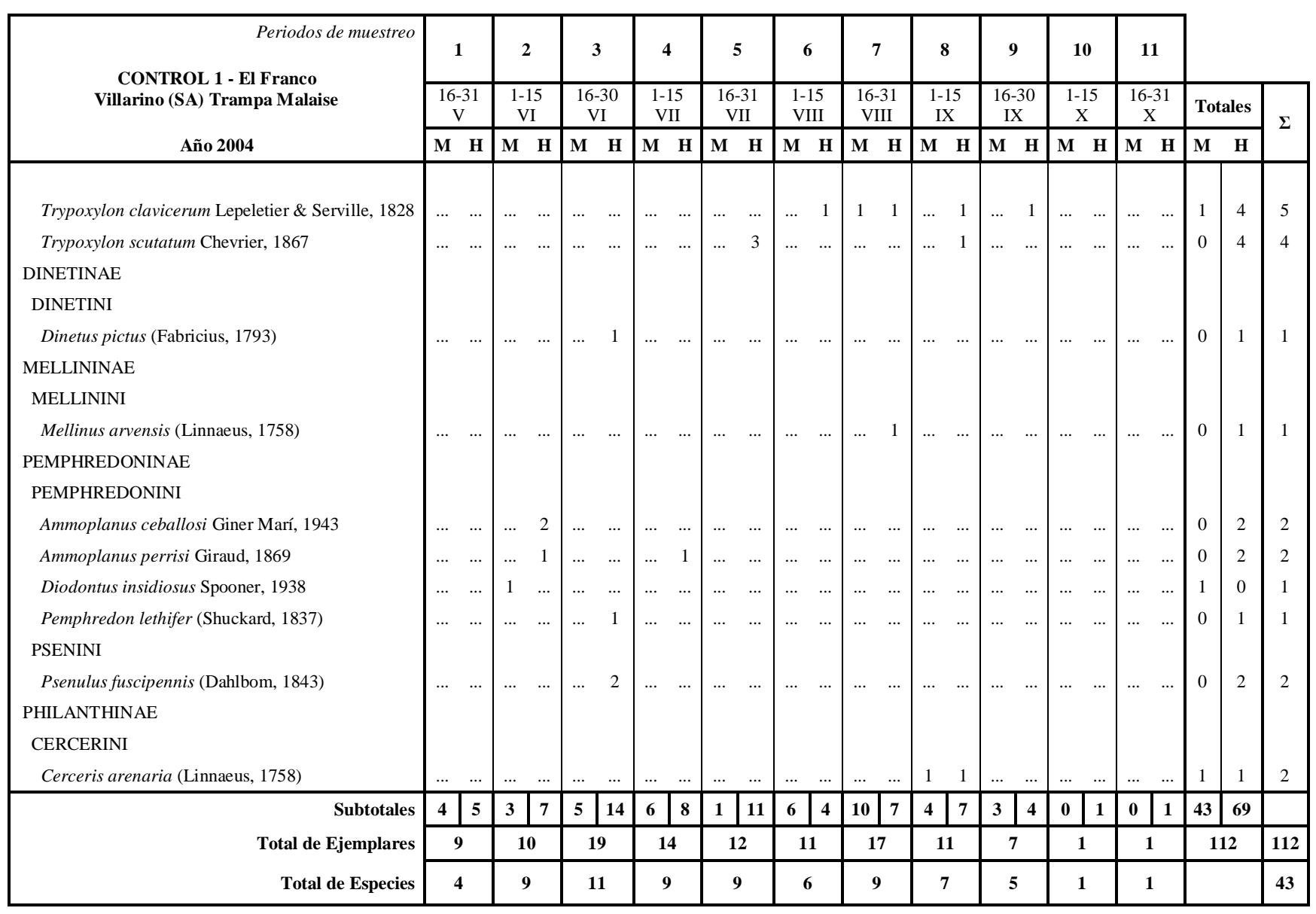




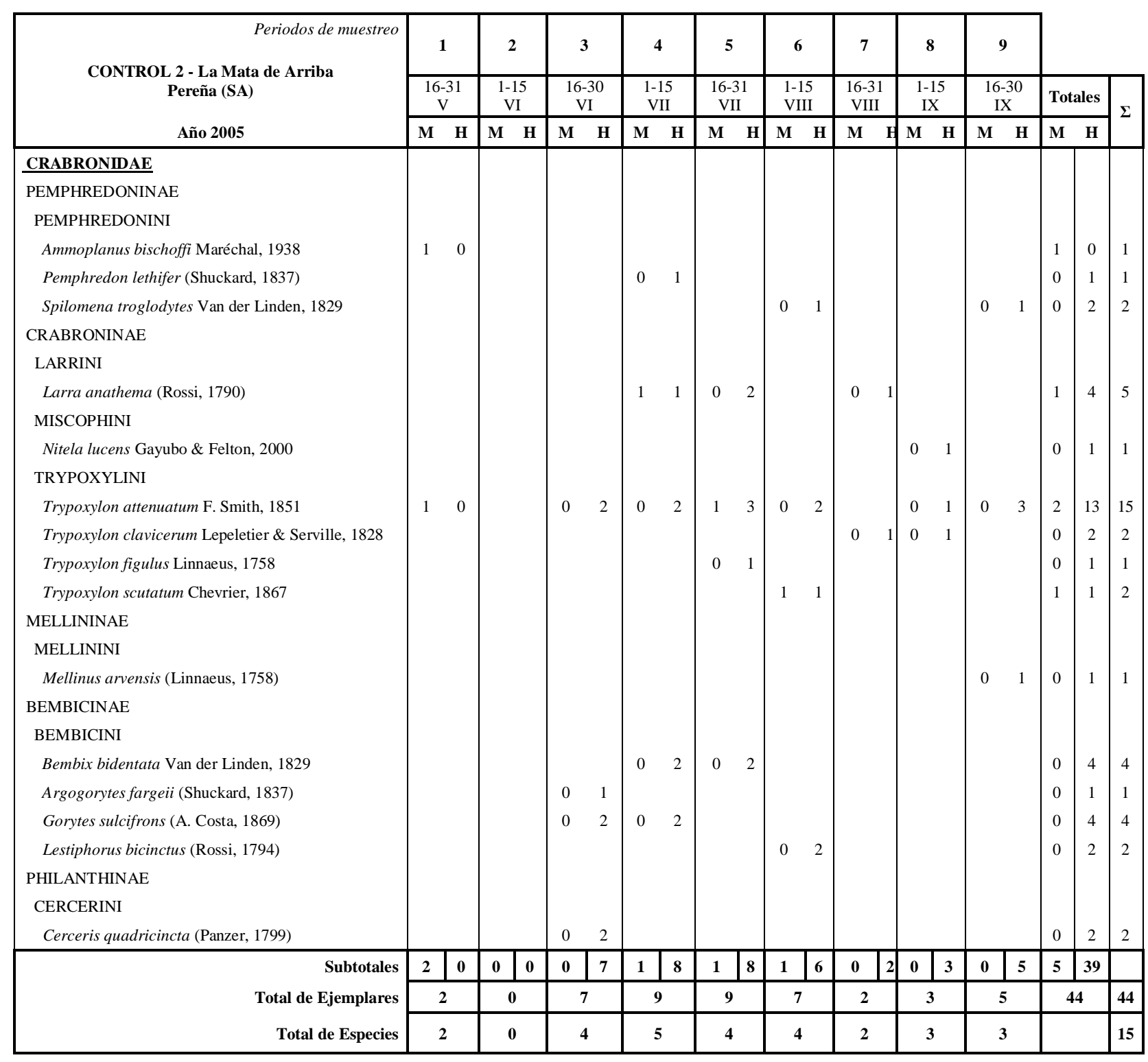




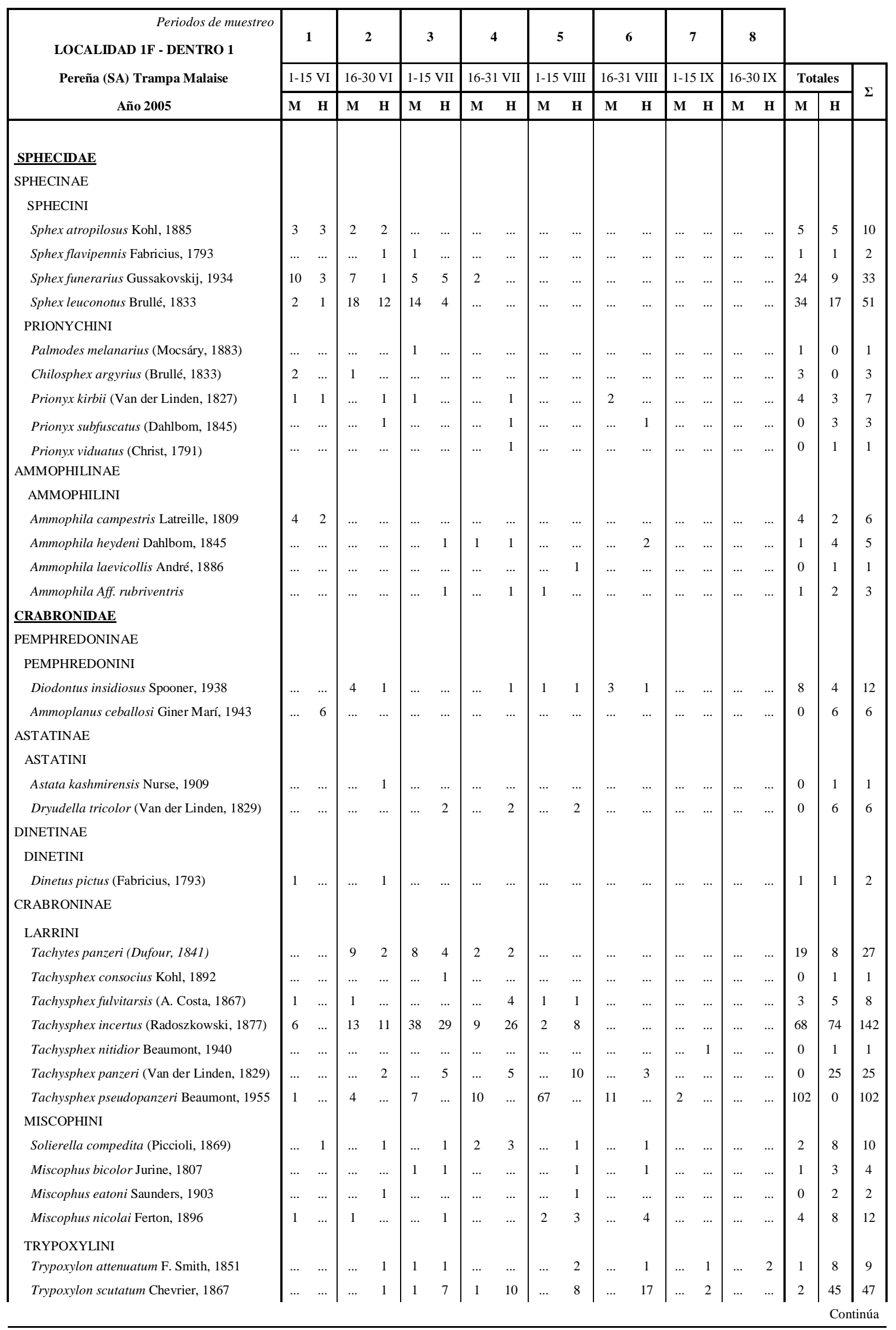




\begin{tabular}{|c|c|c|c|c|c|c|c|c|c|c|c|c|c|c|c|c|c|c|c|}
\hline \multirow{3}{*}{$\begin{array}{r}\text { Periodos de muestreo } \\
\text { LOCALIDAD 1F - DENTRO } 1 \\
\text { Pereña (SA) Trampa Malaise } \\
\text { Año } 2005\end{array}$} & \multicolumn{2}{|c|}{$\mathbf{1}$} & \multicolumn{2}{|c|}{2} & \multicolumn{2}{|c|}{3} & \multicolumn{2}{|c|}{4} & \multicolumn{2}{|c|}{5} & \multicolumn{2}{|c|}{6} & \multicolumn{2}{|c|}{7} & \multicolumn{2}{|c|}{8} & & & \\
\hline & \multicolumn{2}{|c|}{$1-15 \mathrm{VI}$} & \multicolumn{2}{|c|}{$16-30 \mathrm{VI}$} & \multicolumn{2}{|c|}{ 1-15 VII } & \multicolumn{2}{|c|}{$16-31 \mathrm{VII}$} & \multicolumn{2}{|c|}{ 1-15 VIII } & \multicolumn{2}{|c|}{ 16-31 VIII } & \multicolumn{2}{|c|}{$1-15$ IX } & \multicolumn{2}{|c|}{ 16-30 IX } & \multicolumn{2}{|c|}{ Totales } & \multirow{2}{*}{$\Sigma$} \\
\hline & $\mathbf{M}$ & $\mathbf{H}$ & $\mathbf{M}$ & & $\mathbf{M}$ & & $\mathbf{M}$ & $\mathbf{H}$ & $\mathbf{M}$ & & $\mathbf{M}$ & $\mathbf{H}$ & $\mathbf{M}$ & & $\mathbf{M}$ & $\mathbf{H}$ & $\mathbf{M}$ & $\mathbf{H}$ & \\
\hline \multicolumn{20}{|l|}{ OXYBELINI } \\
\hline Oxybelus hastatus Fabricius, 1804 & $\ldots$ & $\ldots$ & $\cdots$ & $\ldots$ & 1 & $\ldots$ & $\ldots$ & $\ldots$ & $\ldots$ & $\ldots$ & $\cdots$ & $\ldots$ & $\ldots$ & $\cdots$ & $\ldots$ & $\ldots$ & 1 & 0 & 1 \\
\hline Oxybelus quattuordecimnotatus Jurine, 1807 & $\ldots$ & $\ldots$ & $\ldots$ & $\ldots$ & 1 & 2 & 1 & $\ldots$ & $\ldots$ & 1 & 2 & $\ldots$ & $\ldots$ & $\ldots$ & $\ldots$ & 1 & 4 & 4 & 8 \\
\hline \multicolumn{20}{|l|}{ CRABRONINI } \\
\hline Encopognathus braunsi Mercet, 1915 & 2 & 2 & $\ldots$ & $\ldots$ & $\ldots$ & $\ldots$ & $\ldots$ & $\ldots$ & $\ldots$ & $\ldots$ & $\ldots$ & $\ldots$ & $\ldots$ & $\ldots$ & $\ldots$ & $\ldots$ & 2 & 2 & 4 \\
\hline Lindenius ibericus Kohl, 1905 & $\ldots$ & $\ldots$ & 1 & $\ldots$ & $\ldots$ & 1 & $\cdots$ & $\ldots$ & $\ldots$ & $\ldots$ & $\ldots$ & $\ldots$ & $\ldots$ & $\ldots$ & $\ldots$ & $\ldots$ & 1 & 1 & 2 \\
\hline \multicolumn{20}{|l|}{ BEMBICINAE } \\
\hline \multicolumn{20}{|l|}{ BEMBICINI } \\
\hline Harpactus formosus (Jurine, 1807) & 1 & $\ldots$ & $\ldots$ & $\ldots$ & $\ldots$ & $\ldots$ & $\ldots$ & $\ldots$ & $\ldots$ & $\ldots$ & $\ldots$ & $\ldots$ & $\ldots$ & $\cdots$ & $\ldots$ & $\ldots$ & 1 & 0 & 1 \\
\hline Harpactur morawitzi (Snoflak, 1943) & $\ldots$ & $\ldots$ & $\ldots$ & $\ldots$ & $\cdots$ & $\ldots$ & $\ldots$ & $\ldots$ & $\ldots$ & $\ldots$ & $\ldots$ & 1 & $\ldots$ & $\ldots$ & $\ldots$ & $\ldots$ & 0 & 1 & 1 \\
\hline Bembecinus carpetanus (Mercet, 1906) & 1 & $\ldots$ & $\ldots$ & 1 & $\ldots$ & $\ldots$ & $\ldots$ & $\ldots$ & $\cdots$ & $\ldots$ & $\cdots$ & $\ldots$ & $\ldots$ & $\ldots$ & $\ldots$ & $\ldots$ & 1 & 1 & 2 \\
\hline Bembecinus pulchelus (Mercet, 1906) & 7 & 5 & 9 & 9 & 1 & 18 & $\ldots$ & 10 & $\ldots$ & $\ldots$ & $\ldots$ & $\ldots$ & $\ldots$ & $\ldots$ & $\ldots$ & $\ldots$ & 17 & 42 & 59 \\
\hline Bembix bidentata Van der Linden, 1829 & $\ldots$ & $\ldots$ & $\ldots$ & 1 & $\ldots$ & $\ldots$ & $\ldots$ & 1 & $\ldots$ & $\ldots$ & $\ldots$ & $\ldots$ & $\ldots$ & $\ldots$ & $\ldots$ & $\ldots$ & 0 & 2 & 2 \\
\hline Bembix oculata Panzer, 1801 & $\ldots$ & $\ldots$ & $\ldots$ & $\ldots$ & $\ldots$ & 1 & $\ldots$ & $\ldots$ & $\ldots$ & $\ldots$ & $\ldots$ & $\ldots$ & $\ldots$ & $\ldots$ & $\ldots$ & 1 & 0 & 2 & 2 \\
\hline Bembix zonata Klug, 1835 & $\ldots$ & $\ldots$ & $\ldots$ & $\ldots$ & 3 & 1 & $\ldots$ & 1 & $\ldots$ & 1 & $\ldots$ & $\ldots$ & $\ldots$ & $\ldots$ & $\ldots$ & $\ldots$ & 3 & 3 & 6 \\
\hline Subtotales & 43 & 24 & 70 & 51 & 84 & 86 & 28 & 70 & 74 & 41 & 18 & 32 & 2 & 4 & $\mathbf{0}$ & 4 & 319 & 312 & \\
\hline Total de Ejemplares & \multicolumn{2}{|c|}{67} & \multicolumn{2}{|c|}{121} & \multicolumn{2}{|c|}{170} & & & & & & & & & & & & & 631 \\
\hline Total de Especies & 1 & & & 4 & & & & & & & & & & & & & & & 42 \\
\hline
\end{tabular}




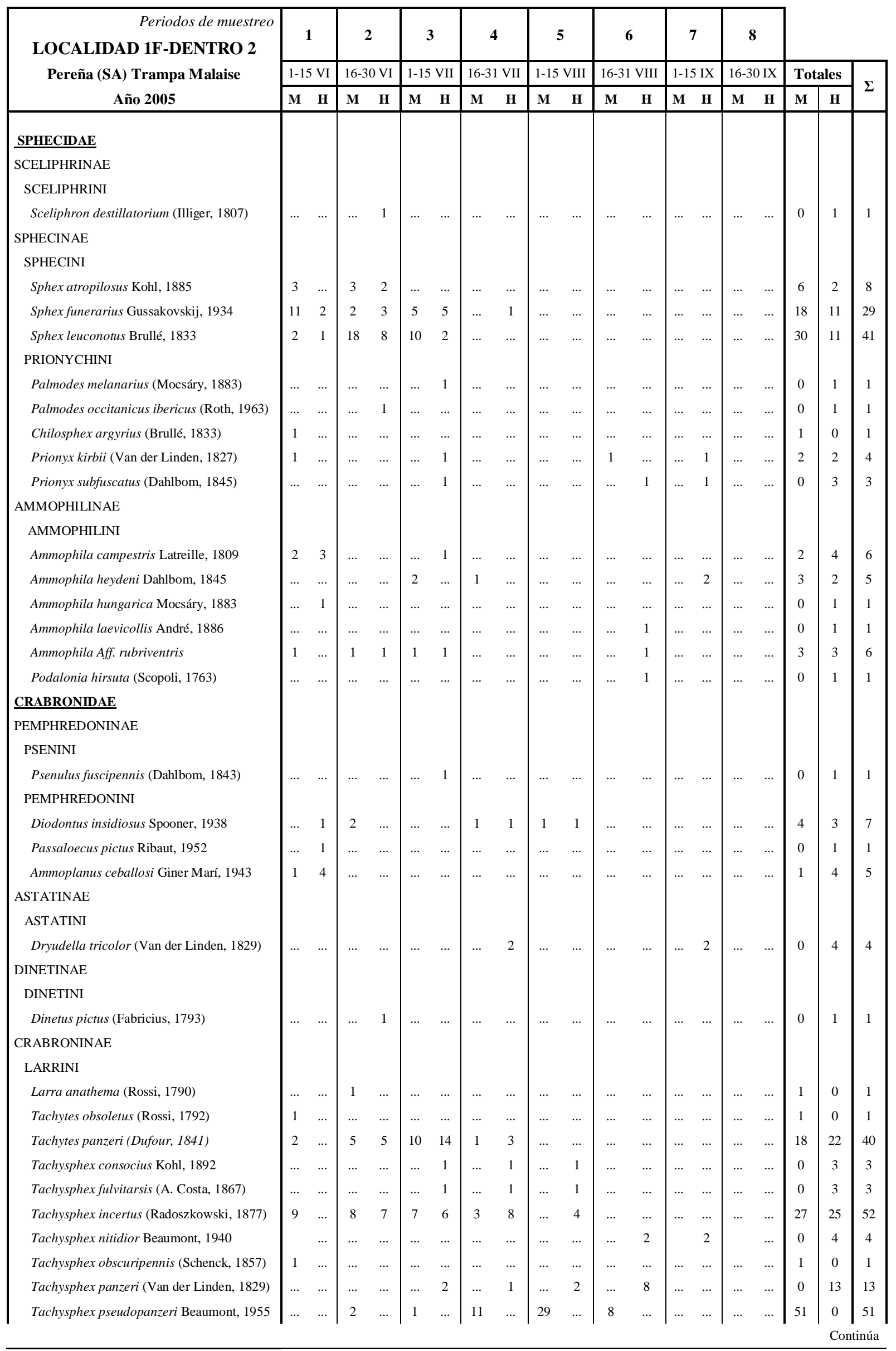




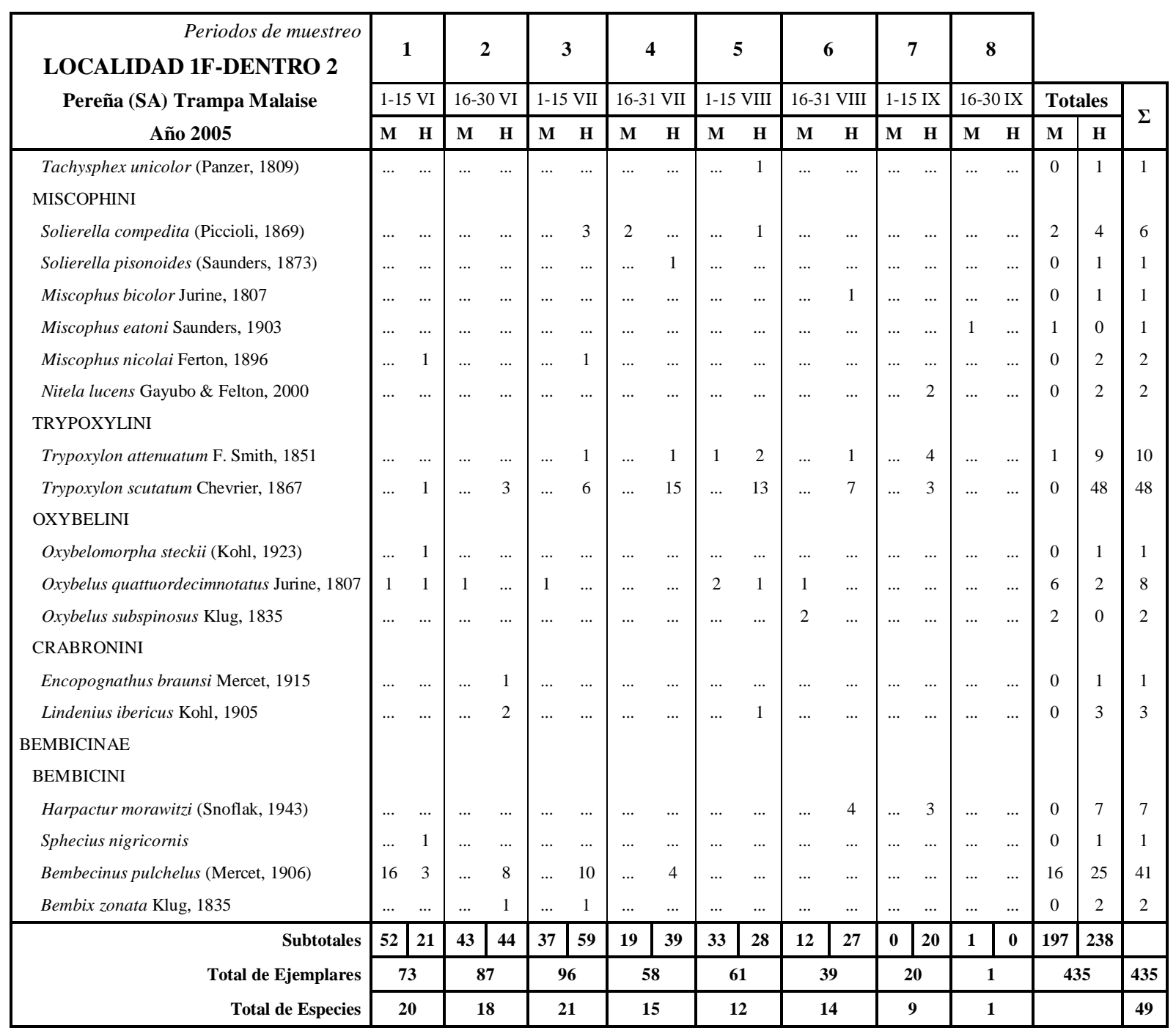




\begin{tabular}{|c|c|c|c|c|c|c|c|c|c|c|c|c|c|c|c|c|c|c|c|}
\hline \multirow{3}{*}{$\begin{array}{r}\text { Periodos de muestreo } \\
\text { LOCALIDAD 1F-DENTRO 3 } \\
\text { Pereña (SA) Trampa Malaise } \\
\text { Año } 2005\end{array}$} & \multicolumn{2}{|c|}{1} & \multicolumn{2}{|c|}{2} & \multicolumn{2}{|c|}{3} & \multicolumn{2}{|c|}{4} & \multicolumn{2}{|c|}{5} & \multicolumn{2}{|c|}{6} & \multicolumn{2}{|c|}{7} & \multicolumn{2}{|c|}{8} & & & \\
\hline & \multicolumn{2}{|c|}{$1-15 \mathrm{VI}$} & \multicolumn{2}{|c|}{$16-30 \mathrm{VI}$} & \multicolumn{2}{|c|}{$1-15 \mathrm{VII}$} & \multicolumn{2}{|c|}{$16-31 \mathrm{VII}$} & \multicolumn{2}{|c|}{ 1-15 VIII } & $16-3$ & VIII & $1-1$ & 5 IX & $16-3$ & 0 IX & TOT & LES & \\
\hline & M & H & M & $\mathbf{H}$ & M & $\mathbf{H}$ & M & H & $\mathbf{M}$ & H & M & H & M & $\mathbf{H}$ & $\mathbf{M}$ & & M & H & 2 \\
\hline$\underline{\text { SPHECIDAE }}$ & & & & & & & & & & & & & & & & & & & \\
\hline SPHECINAE & & & & & & & & & & & & & & & & & & & \\
\hline SPHECINI & & & & & & & & & & & & & & & & & & & \\
\hline Sphex atropilosus Kohl, 1885 & 1 & 4 & 1 & 1 & $\ldots$ & $\ldots$ & $\ldots$ & $\ldots$ & $\ldots$ & $\ldots$ & $\ldots$ & $\ldots$ & $\ldots$ & $\ldots$ & $\ldots$ & $\ldots$ & 2 & 5 & 7 \\
\hline Sphex flavipennis Fabricius, 1793 & $\ldots$ & $\ldots$ & 2 & $\ldots$ & $\ldots$ & $\ldots$ & $\ldots$ & $\ldots$ & $\ldots$ & $\ldots$ & $\ldots$ & $\ldots$ & $\ldots$ & $\ldots$ & $\ldots$ & $\ldots$ & 2 & 0 & 2 \\
\hline Sphex funerarius Gussakovskij, 1934 & 11 & 1 & 1 & 8 & 6 & 3 & 8 & 1 & $\ldots$ & $\ldots$ & 1 & $\ldots$ & $\ldots$ & $\ldots$ & $\ldots$ & $\ldots$ & 27 & 13 & 40 \\
\hline Sphex leuconotus Brullé, 1833 & 1 & $\ldots$ & 17 & 4 & 4 & 3 & 1 & $\ldots$ & $\ldots$ & $\ldots$ & $\ldots$ & $\ldots$ & $\ldots$ & $\ldots$ & $\ldots$ & $\ldots$ & 23 & 7 & 30 \\
\hline PRIONYCHINI & & & & & & & & & & & & & & & & & & & \\
\hline Palmodes melanarius (Mocsáry, 1883) & $\ldots$ & $\ldots$ & $\ldots$ & 1 & $\ldots$ & $\ldots$ & $\ldots$ & $\ldots$ & $\ldots$ & $\ldots$ & $\ldots$ & $\ldots$ & $\ldots$ & $\ldots$ & $\ldots$ & $\ldots$ & 0 & 1 & 1 \\
\hline Palmodes occitanicus ibericus (Roth, 1963) & 1 & $\ldots$ & $\ldots$ & $\ldots$ & $\ldots$ & $\cdots$ & $\ldots$ & $\ldots$ & $\ldots$ & $\ldots$ & $\ldots$ & $\ldots$ & $\ldots$ & $\ldots$ & $\ldots$ & $\ldots$ & 1 & 0 & 1 \\
\hline Chilosphex argyrius (Brullé, 1833) & 2 & $\ldots$ & 1 & 2 & $\ldots$ & $\ldots$ & $\ldots$ & $\ldots$ & $\ldots$ & $\ldots$ & $\ldots$ & $\ldots$ & $\ldots$ & $\ldots$ & $\ldots$ & $\ldots$ & 3 & 2 & 5 \\
\hline Prionyx kirbii (Van der Linden, 1827) & $\ldots$ & $\ldots$ & $\ldots$ & $\ldots$ & $\ldots$ & 3 & $\ldots$ & $\ldots$ & 1 & $\ldots$ & 1 & $\ldots$ & $\ldots$ & $\ldots$ & $\ldots$ & $\ldots$ & 2 & 3 & 5 \\
\hline Prionyx subfuscatus (Dahlbom, 1845) & $\ldots$ & $\ldots$ & $\ldots$ & & $\ldots$ & $\ldots$ & 1 & $\ldots$ & $\ldots$ & $\ldots$ & $\ldots$ & & $\ldots$ & $\ldots$ & $\ldots$ & $\ldots$ & 1 & 0 & 1 \\
\hline Prionyx viduatus (Christ, 1791) & $\ldots$ & $\ldots$ & $\ldots$ & & $\ldots$ & $\ldots$ & 1 & $\ldots$ & $\ldots$ & $\ldots$ & $\ldots$ & & $\ldots$ & $\ldots$ & $\ldots$ & $\ldots$ & 1 & 0 & 1 \\
\hline AMMOPHILINAE & & & & & & & & & & & & & & & & & & & \\
\hline AMMOPHILINI & & & & & & & & & & & & & & & & & & & \\
\hline Ammophila campestris Latreille, 1809 & 1 & $\ldots$ & $\ldots$ & $\ldots$ & $\ldots$ & $\ldots$ & $\ldots$ & $\ldots$ & $\ldots$ & $\ldots$ & $\ldots$ & $\ldots$ & $\ldots$ & $\ldots$ & $\ldots$ & $\ldots$ & 1 & 0 & 1 \\
\hline Ammophila heydeni Dahlbom, 1845 & $\ldots$ & $\ldots$ & $\cdots$ & $\ldots$ & $\ldots$ & $\cdots$ & $\ldots$ & $\ldots$ & $\ldots$ & 1 & $\ldots$ & $\ldots$ & $\ldots$ & $\ldots$ & $\ldots$ & $\ldots$ & 0 & 1 & 1 \\
\hline Ammophila hungarica Mocsáry, 1883 & $\ldots$ & 5 & $\ldots$ & $\ldots$ & $\ldots$ & $\ldots$ & $\ldots$ & $\ldots$ & $\ldots$ & $\ldots$ & $\ldots$ & $\ldots$ & $\ldots$ & $\ldots$ & $\ldots$ & $\ldots$ & 0 & 5 & 5 \\
\hline Ammophila laevicollis André, 1886 & $\ldots$ & $\ldots$ & $\ldots$ & $\ldots$ & 1 & $\ldots$ & $\ldots$ & $\ldots$ & $\ldots$ & $\ldots$ & $\ldots$ & $\ldots$ & $\ldots$ & $\ldots$ & $\ldots$ & $\ldots$ & 1 & 0 & 1 \\
\hline Ammophila Aff. rubriventris & $\ldots$ & 1 & $\ldots$ & $\ldots$ & 1 & $\ldots$ & $\ldots$ & $\ldots$ & 1 & $\ldots$ & $\ldots$ & $\ldots$ & $\ldots$ & $\ldots$ & $\ldots$ & $\ldots$ & 2 & 1 & 3 \\
\hline CRABRONIDAE & & & & & & & & & & & & & & & & & & & \\
\hline PEMPHREDONINAE & & & & & & & & & & & & & & & & & & & \\
\hline PSENINI & & & & & & & & & & & & & & & & & & & \\
\hline Psenulus fuscipennis (Dahlbom, 1843) & $\ldots$ & $\ldots$ & $\ldots$ & $\ldots$ & $\ldots$ & 2 & $\ldots$ & $\ldots$ & $\ldots$ & 1 & $\ldots$ & $\ldots$ & $\ldots$ & $\ldots$ & $\ldots$ & $\ldots$ & 0 & 3 & 3 \\
\hline PEMPHREDONINI & & & & & & & & & & & & & & & & & & & \\
\hline Diodontus insidiosus Spooner, 1938 & $\ldots$ & $\ldots$ & 3 & $\ldots$ & $\ldots$ & 1 & 2 & $\ldots$ & 1 & $\ldots$ & $\ldots$ & $\ldots$ & 1 & $\ldots$ & $\ldots$ & $\ldots$ & 7 & 1 & 8 \\
\hline Ammoplanus ceballosi Giner Marí, 1943 & 2 & 6 & $\ldots$ & $\ldots$ & $\ldots$ & $\ldots$ & $\ldots$ & $\ldots$ & $\cdots$ & $\ldots$ & $\ldots$ & $\ldots$ & $\ldots$ & $\ldots$ & $\ldots$ & $\ldots$ & 2 & 6 & 8 \\
\hline Ammoplanus perrisi Giraud, 1869 & $\ldots$ & 1 & 1 & 1 & $\ldots$ & $\ldots$ & $\ldots$ & $\ldots$ & $\ldots$ & $\ldots$ & $\ldots$ & $\ldots$ & $\ldots$ & $\ldots$ & $\ldots$ & $\ldots$ & 1 & 2 & 3 \\
\hline ASTATINAE & & & & & & & & & & & & & & & & & & & \\
\hline ASTATINI & & & & & & & & & & & & & & & & & & & \\
\hline Astata gallica Beaumont, 1942 & $\cdots$ & $\ldots$ & $\ldots$ & $\ldots$ & $\ldots$ & $\ldots$ & $\ldots$ & $\ldots$ & $\ldots$ & $\ldots$ & $\ldots$ & 1 & $\ldots$ & $\ldots$ & $\ldots$ & $\ldots$ & 0 & 1 & 1 \\
\hline Dryudella tricolor (Van der Linden, 1829) & $\ldots$ & $\ldots$ & $\ldots$ & $\ldots$ & $\ldots$ & 4 & $\ldots$ & $\ldots$ & $\ldots$ & $\ldots$ & $\ldots$ & $\ldots$ & $\ldots$ & $\ldots$ & $\ldots$ & $\ldots$ & 0 & 4 & 4 \\
\hline DINETINAE & & & & & & & & & & & & & & & & & & & \\
\hline DINETINI & & & & & & & & & & & & & & & & & & & \\
\hline Dinetus pictus (Fabricius, 1793) & 1 & 1 & 1 & $\ldots$ & $\ldots$ & $\ldots$ & $\ldots$ & $\ldots$ & $\cdots$ & $\ldots$ & $\cdots$ & $\ldots$ & $\ldots$ & $\ldots$ & $\ldots$ & $\ldots$ & 2 & 1 & 3 \\
\hline CRABRONINAE & & & & & & & & & & & & & & & & & & & \\
\hline LARRINI & & & & & & & & & & & & & & & & & & & \\
\hline Larra anathema (Rossi, 1790) & $\ldots$ & $\ldots$ & $\ldots$ & 1 & $\ldots$ & $\ldots$ & $\cdots$ & $\ldots$ & $\ldots$ & $\ldots$ & $\ldots$ & $\ldots$ & $\ldots$ & $\ldots$ & $\ldots$ & $\ldots$ & 0 & 1 & 1 \\
\hline Tachytes panzeri (Dufour, 1841) & 2 & $\ldots$ & 5 & 2 & 12 & 14 & 4 & 2 & $\ldots$ & 1 & $\ldots$ & $\ldots$ & $\ldots$ & $\ldots$ & $\ldots$ & $\ldots$ & 23 & 19 & 42 \\
\hline Tachysphex consocius Kohl, 1892 & $\ldots$ & $\cdots$ & $\cdots$ & $\cdots$ & $\cdots$ & 1 & $\cdots$ & 1 & 1 & 4 & $\cdots$ & 1 & $\cdots$ & $\cdots$ & $\ldots$ & $\ldots$ & 1 & 7 & 8 \\
\hline Tachysphex fulvitarsis (A. Costa, 1867) & $\ldots$ & $\ldots$ & $\ldots$ & 2 & 1 & $\ldots$ & 3 & 3 & $\ldots$ & 1 & $\ldots$ & 2 & $\ldots$ & $\ldots$ & $\ldots$ & $\ldots$ & 4 & 8 & 12 \\
\hline Tachysphex incertus (Radoszkowski, 1877) & $\ldots$ & 1 & 8 & 3 & 17 & 37 & 4 & 47 & 3 & 12 & 1 & 1 & $\ldots$ & $\ldots$ & $\ldots$ & $\ldots$ & 33 & 101 & 134 \\
\hline Tachysphex obscuripennis (Schenck, 1857) & $\ldots$ & $\cdots$ & $\ldots$ & $\ldots$ & $\cdots$ & 1 & $\cdots$ & $\ldots$ & $\cdots$ & $\cdots$ & $\ldots$ & $\cdots$ & $\ldots$ & $\ldots$ & $\ldots$ & & 0 & 1 & 1 \\
\hline Tachysphex panzeri (Van der Linden, 1829) & $\ldots$ & $\cdots$ & $\ldots$ & $\ldots$ & $\ldots$ & $\cdots$ & $\cdots$ & 3 & $\ldots$ & 8 & $\ldots$ & 10 & $\ldots$ & $\ldots$ & $\ldots$ & $\ldots$ & 0 & 21 & 21 \\
\hline Tachysphex pseudopanzeri Beaumont, 1955 & 1 & $\ldots$ & $\ldots$ & $\ldots$ & 7 & $\ldots$ & 18 & $\ldots$ & 52 & $\ldots$ & 21 & $\ldots$ & 3 & $\ldots$ & $\ldots$ & $\ldots$ & 102 & 0 & 102 \\
\hline Tachysphex pompiliformis (Panzer, 1805) & $\ldots$ & $\ldots$ & $\ldots$ & & $\ldots$ & $\ldots$ & $\ldots$ & $\ldots$ & $\ldots$ & $\ldots$ & $\ldots$ & $\ldots$ & $\ldots$ & 1 & $\ldots$ & $\ldots$ & 0 & 1 & 1 \\
\hline Tachysphex tarsinus (Lepeletier, 1845) & 2 & & 1 & & & $\ldots$ & & $\ldots$ & $\ldots$ & $\ldots$ & $\ldots$ & 3 & & $\ldots$ & $\ldots$ & $\ldots$ & 3 & 3 & 6 \\
\hline
\end{tabular}




\begin{tabular}{|c|c|c|c|c|c|c|c|c|c|c|c|c|c|c|c|c|c|c|c|}
\hline \multirow{3}{*}{$\begin{array}{r}\text { Periodos de muestreo } \\
\text { LOCALIDAD 1F-DENTRO } 3 \\
\text { Pereña (SA) Trampa Malaise } \\
\text { Año } 2005\end{array}$} & \multicolumn{2}{|c|}{1} & \multicolumn{2}{|c|}{2} & \multicolumn{2}{|c|}{3} & \multicolumn{2}{|c|}{4} & \multicolumn{2}{|c|}{5} & \multicolumn{2}{|c|}{6} & \multicolumn{2}{|c|}{7} & \multicolumn{2}{|c|}{8} & & & \\
\hline & \multicolumn{2}{|c|}{$1-15 \mathrm{VI}$} & \multicolumn{2}{|c|}{$16-30 \mathrm{VI}$} & \multicolumn{2}{|c|}{ 1-15 VII } & \multicolumn{2}{|c|}{ 16-31 VII } & \multicolumn{2}{|c|}{$1-15 \mathrm{VIII}$} & \multicolumn{2}{|c|}{ 16-31 VIII } & \multicolumn{2}{|c|}{ 1-15 IX } & \multicolumn{2}{|c|}{ 16-30 IX } & \multicolumn{2}{|c|}{ TOTALES } & \multirow{2}{*}{$\Sigma$} \\
\hline & M & $\mathbf{H}$ & M & $\mathbf{H}$ & M & $\mathbf{H}$ & $\mathbf{M}$ & $\mathbf{H}$ & $\mathbf{M}$ & $\mathbf{H}$ & $\mathbf{M}$ & $\mathbf{H}$ & $\mathbf{M}$ & & $\mathbf{M}$ & $\mathbf{H}$ & $\mathbf{M}$ & $\mathbf{H}$ & \\
\hline $\begin{array}{l}\text { Prosopigastra punctatissima A. Costa, } 1869 \\
\text { MISCOPHINI }\end{array}$ & $\cdots$ & & $\cdots$ & $\cdots$ & $\cdots$ & $\cdots$ & $\cdots$ & $\cdots$ & $\cdots$ & $\cdots$ & $\cdots$ & $\cdots$ & & 1 & $\cdots$ & $\cdots$ & 0 & 1 & 1 \\
\hline Solierella compedita (Piccioli, 1869) & & 2 & $\ldots$ & 2 & 1 & 3 & 3 & 2 & $\ldots$ & $\ldots$ & $\ldots$ & 3 & $\ldots$ & $\ldots$ & $\ldots$ & $\ldots$ & 4 & 12 & 16 \\
\hline Miscophus bicolor Jurine, 1807 & $\ldots$ & $\ldots$ & $\ldots$ & $\ldots$ & $\ldots$ & $\ldots$ & $\ldots$ & $\ldots$ & $\ldots$ & 1 & $\ldots$ & 2 & $\ldots$ & 1 & $\ldots$ & $\cdots$ & .. & 4 & 4 \\
\hline Miscophus eatoni Saunders, 1903 & $\ldots$ & $\ldots$ & 1 & $\ldots$ & $\ldots$ & 1 & $\ldots$ & $\ldots$ & $\ldots$ & $\ldots$ & $\ldots$ & $\ldots$ & $\ldots$ & $\ldots$ & $\ldots$ & $\ldots$ & 1 & 1 & 2 \\
\hline Miscophus nicolai Ferton, 1896 & $\ldots$ & $\ldots$ & $\ldots$ & $\ldots$ & $\ldots$ & $\ldots$ & $\ldots$ & 1 & $\ldots$ & $\ldots$ & $\ldots$ & $\ldots$ & $\ldots$ & $\ldots$ & $\ldots$ & $\ldots$ & 0 & 1 & 1 \\
\hline Nitela lucens Gayubo \& Felton, 2000 & $\ldots$ & $\ldots$ & $\cdots$ & $\ldots$ & $\cdots$ & $\ldots$ & $\cdots$ & $\cdots$ & $\cdots$ & $\cdots$ & $\cdots$ & $\ldots$ & $\ldots$ & 1 & $\cdots$ & $\cdots$ & 0 & 1 & 1 \\
\hline \multicolumn{20}{|l|}{ TRYPOXYLINI } \\
\hline Trypoxylon attenuatum F. Smith, 1851 & $\ldots$ & $\ldots$ & 1 & $\ldots$ & $\ldots$ & 1 & $\ldots$ & 5 & 1 & 14 & 1 & 5 & $\ldots$ & 4 & $\ldots$ & $\ldots$ & 2 & 30 & 32 \\
\hline Trypoxylon scutatum Chevrier, 1867 & $\ldots$ & 1 & 1 & 2 & $\ldots$ & 13 & 3 & 23 & 1 & 35 & 1 & 26 & $\ldots$ & 7 & $\ldots$ & 1 & 6 & 108 & 114 \\
\hline \multicolumn{20}{|l|}{ OXYBELINI } \\
\hline Oxybelus hastatus Fabricius, 1804 & $\ldots$ & $\ldots$ & $\ldots$ & 1 & $\ldots$ & $\ldots$ & $\ldots$ & $\ldots$ & $\ldots$ & $\ldots$ & $\ldots$ & $\ldots$ & $\ldots$ & $\ldots$ & $\ldots$ & $\ldots$ & 0 & 1 & 1 \\
\hline Oxybelus quattuordecimnotatus Jurine, 1807 & 1 & 1 & 3 & 1 & 1 & 3 & 2 & $\ldots$ & 4 & 6 & 3 & 2 & $\cdots$ & $\cdots$ & $\cdots$ & $\cdots$ & 14 & 13 & 27 \\
\hline Oxybelus subspinosus Klug, 1835 & $\ldots$ & $\ldots$ & $\ldots$ & $\ldots$ & $\ldots$ & $\ldots$ & $\ldots$ & 2 & $\ldots$ & $\ldots$ & $\cdots$ & $\ldots$ & $\ldots$ & 1 & $\cdots$ & $\ldots$ & 0 & 3 & 3 \\
\hline Oxybelus sp. & $\ldots$ & $\ldots$ & $\ldots$ & 1 & $\ldots$ & $\cdots$ & $\ldots$ & $\ldots$ & $\ldots$ & $\ldots$ & $\ldots$ & $\cdots$ & $\ldots$ & $\ldots$ & $\ldots$ & $\ldots$ & 0 & 1 & 1 \\
\hline CRABRONINI & & & & & & & & & & & & & & & & & & & \\
\hline Encopognathus braunsi Mercet, 1915 & 1 & $\ldots$ & $\ldots$ & $\ldots$ & $\ldots$ & $\ldots$ & $\ldots$ & $\ldots$ & $\ldots$ & $\ldots$ & $\ldots$ & $\ldots$ & $\ldots$ & $\ldots$ & $\ldots$ & $\cdots$ & 1 & 0 & 1 \\
\hline Lindenius ibericus Kohl, 1905 & $\ldots$ & $\ldots$ & $\ldots$ & 1 & $\ldots$ & 3 & $\ldots$ & $\ldots$ & $\ldots$ & $\ldots$ & $\ldots$ & $\ldots$ & $\ldots$ & $\ldots$ & $\ldots$ & $\ldots$ & 0 & 4 & 4 \\
\hline Ectemnius crassicornis (Spinola, 1808) & $\ldots$ & $\ldots$ & $\ldots$ & $\ldots$ & $\ldots$ & $\ldots$ & $\ldots$ & $\ldots$ & $\ldots$ & $\ldots$ & $\ldots$ & 1 & $\ldots$ & $\ldots$ & $\ldots$ & $\cdots$ & 0 & 1 & 1 \\
\hline BEMBICINAE & & & & & & & & & & & & & & & & & & & \\
\hline BEMBICINI & & & & & & & & & & & & & & & & & & & \\
\hline Harpactus formosus (Jurine, 1807) & $\ldots$ & $\ldots$ & $\ldots$ & $\ldots$ & $\ldots$ & $\ldots$ & 1 & $\ldots$ & $\ldots$ & $\ldots$ & $\ldots$ & 1 & $\ldots$ & $\ldots$ & $\ldots$ & $\ldots$ & 1 & 1 & 2 \\
\hline Harpactus morawitzi (Snoflak, 1943) & $\ldots$ & $\ldots$ & $\ldots$ & $\cdots$ & $\ldots$ & $\cdots$ & $\ldots$ & $\ldots$ & $\cdots$ & $\ldots$ & $\cdots$ & 14 & $\ldots$ & 9 & $\ldots$ & $\ldots$ & 0 & 23 & 23 \\
\hline Bembecinus carpetanus (Mercet, 1906) & 1 & 1 & $\ldots$ & $\ldots$ & $\ldots$ & $\ldots$ & $\ldots$ & $\ldots$ & $\ldots$ & $\cdots$ & $\ldots$ & $\ldots$ & $\ldots$ & $\ldots$ & $\ldots$ & $\ldots$ & 1 & 1 & 2 \\
\hline Bembecinus pulchelus (Mercet, 1906) & 23 & 3 & $\ldots$ & 9 & $\ldots$ & 47 & $\ldots$ & 11 & $\ldots$ & $\ldots$ & $\ldots$ & $\ldots$ & $\ldots$ & $\ldots$ & $\ldots$ & $\ldots$ & 23 & 70 & 93 \\
\hline Bembix bidentata Van der Linden, 1829 & $\ldots$ & $\ldots$ & $\ldots$ & $\ldots$ & $\ldots$ & 1 & $\ldots$ & 1 & $\ldots$ & $\ldots$ & $\ldots$ & $\ldots$ & $\ldots$ & $\ldots$ & $\ldots$ & $\ldots$ & 0 & 2 & 2 \\
\hline Bembix oculata Panzer, 1801 & $\ldots$ & $\ldots$ & $\ldots$ & $\ldots$ & $\ldots$ & 1 & $\ldots$ & $\ldots$ & $\ldots$ & $\ldots$ & $\ldots$ & $\ldots$ & $\ldots$ & $\ldots$ & $\ldots$ & $\ldots$ & 0 & 1 & 1 \\
\hline Bembix zonata Klug, 1835 & $\ldots$ & $\ldots$ & $\ldots$ & $\ldots$ & 3 & 9 & $\ldots$ & 5 & $\cdots$ & 1 & $\ldots$ & 1 & $\ldots$ & $\ldots$ & $\ldots$ & $\ldots$ & 3 & 16 & 19 \\
\hline PHILANTHINAE & & & & & & & & & & & & & & & & & & & \\
\hline PHILANTHINI & & & & & & & & & & & & & & & & & & & \\
\hline Philanthus triangulum (Fabricius, 1775) & $\ldots$ & $\ldots$ & $\ldots$ & $\ldots$ & $\ldots$ & $\cdots$ & $\ldots$ & $\ldots$ & $\cdots$ & $\cdots$ & $\ldots$ & $\ldots$ & $\ldots$ & $\ldots$ & $\ldots$ & 2 & 0 & 2 & 2 \\
\hline Subtotales & 51 & 28 & 47 & 42 & 54 & 151 & 51 & 107 & 65 & 85 & 29 & 73 & 4 & 25 & $\mathbf{0}$ & 3 & 300 & 515 & \\
\hline Total de Ejemplares & & & & & & & & 58 & & & & & 2 & & 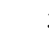 & & & & 815 \\
\hline Total de Especies & & & & & & & & 1 & & & & & 1 & & 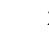 & & & & 55 \\
\hline
\end{tabular}




\begin{tabular}{|c|c|c|c|c|c|c|c|c|c|c|c|}
\hline \multirow{3}{*}{\begin{tabular}{|c} 
Periodos de muestreo \\
LOCALIDAD 1F \\
Pereña (SA) PLATOS \\
Año 2005
\end{tabular}} & \multicolumn{2}{|c|}{1} & \multicolumn{2}{|c|}{2} & \multicolumn{2}{|c|}{3} & \multicolumn{2}{|c|}{4} & & & \\
\hline & \multicolumn{2}{|c|}{ 15-Jun } & \multicolumn{2}{|c|}{ 15-Jul } & \multicolumn{2}{|c|}{ 15-Agos } & \multicolumn{2}{|c|}{ 15-Sep } & \multicolumn{2}{|c|}{ Totales } & \multirow{2}{*}{$\Sigma$} \\
\hline & $\mathbf{M}$ & $\mathbf{H}$ & M & $\mathbf{H}$ & $\mathbf{M}$ & $\mathbf{H}$ & M & $\mathbf{H}$ & M & $\mathbf{H}$ & \\
\hline SPHECIDAE & & & & & & & & & & & \\
\hline SPHECINAE & & & & & & & & & & & \\
\hline PRIONYCHINI & & & & & & & & & & & \\
\hline Prionyx kirbii (Van der Linden, 1827) & $\ldots$ & 1 & $\ldots$ & 1 & 2 & 1 & 1 & $\ldots$ & 3 & 3 & 6 \\
\hline CRABRONIDAE & & & & & & & & & & & \\
\hline PEMPHREDONINAE & & & & & & & & & & & \\
\hline PEMPHREDONINI & & & & & & & & & & & \\
\hline Pemphredonina & & & & & & & & & & & \\
\hline Diodontus insidiosus Spooner, 1938 & $\ldots$ & $\ldots$ & $\ldots$ & $\ldots$ & 1 & $\ldots$ & 1 & 1 & 2 & 1 & 3 \\
\hline ASTATINAE & & & & & & & & & & & \\
\hline ASTATINI & & & & & & & & & & & \\
\hline Astata apostata Mercet, 1910 & $\ldots$ & 1 & $\ldots$ & $\ldots$ & $\ldots$ & $\ldots$ & $\ldots$ & $\ldots$ & 0 & 1 & 1 \\
\hline DINETINAE & & & & & & & & & & & \\
\hline DINETINI & & & & & & & & & & & \\
\hline Dinetus pictus (Fabricius, 1793) & 1 & 1 & $\ldots$ & $\ldots$ & $\ldots$ & $\ldots$ & $\ldots$ & $\ldots$ & 1 & 1 & 2 \\
\hline CRABRONINAE & & & & & & & & & & & \\
\hline LARRINI & & & & & & & & & & & \\
\hline Liris niger (Fabricius, 1775) & $\ldots$ & $\ldots$ & $\ldots$ & $\ldots$ & $\ldots$ & $\ldots$ & 1 & 1 & 1 & 1 & 2 \\
\hline Larropsis punctulata (Kohl, 1884) & $\ldots$ & $\ldots$ & $\ldots$ & $\ldots$ & 1 & $\ldots$ & $\ldots$ & $\ldots$ & 1 & 0 & 1 \\
\hline Tachytes panzeri (Dufour, 1841) & 2 & 1 & 1 & $\ldots$ & $\ldots$ & $\ldots$ & $\ldots$ & $\ldots$ & 3 & 1 & 4 \\
\hline Tachysphex brevipennis Mercet, 1909 & $\ldots$ & $\ldots$ & $\ldots$ & $\ldots$ & 1 & $\ldots$ & $\ldots$ & $\ldots$ & 1 & 0 & 1 \\
\hline Tachysphex consocius Kohl, 1892 & $\ldots$ & 1 & $\ldots$ & $\ldots$ & $\ldots$ & 1 & $\ldots$ & $\ldots$ & 0 & 2 & 2 \\
\hline Tachysphex fugax (Radoszkowski, 1877) & $\ldots$ & $\ldots$ & $\ldots$ & $\ldots$ & $\ldots$ & 1 & $\ldots$ & $\ldots$ & 0 & 1 & 1 \\
\hline Tachysphex fulvitarsis (A. Costa, 1867) & 3 & $\ldots$ & $\ldots$ & $\ldots$ & $\ldots$ & 1 & $\ldots$ & $\ldots$ & 3 & 1 & 4 \\
\hline Tachysphex incertus (Radoszkowski, 1877) & $\ldots$ & 2 & $\ldots$ & 1 & $\ldots$ & 2 & $\ldots$ & 1 & 0 & 6 & 6 \\
\hline Tachysphex mediterraneus Kohl, 1883 & $\ldots$ & $\ldots$ & $\ldots$ & 1 & $\ldots$ & $\ldots$ & $\ldots$ & $\ldots$ & 0 & 1 & 1 \\
\hline Tachysphex nitidior Beaumont, 1940 & $\ldots$ & 1 & 1 & 2 & $\ldots$ & 1 & $\ldots$ & $\ldots$ & 1 & 4 & 5 \\
\hline Tachysphex obscuripennis (Schenck, 1857) & 9 & 1 & $\ldots$ & 4 & $\ldots$ & $\ldots$ & $\ldots$ & $\ldots$ & 9 & 5 & 14 \\
\hline Tachysphex pompiliformis (Panzer, 1805) & 1 & $\ldots$ & $\ldots$ & $\ldots$ & $\ldots$ & $\ldots$ & $\ldots$ & $\ldots$ & 1 & 0 & 1 \\
\hline Tachysphex psammobius (Kohl, 1880) & $\ldots$ & 1 & $\ldots$ & $\ldots$ & $\ldots$ & $\ldots$ & $\ldots$ & $\ldots$ & 0 & 1 & 1 \\
\hline Tachysphex pseudopanzeri Beaumont, 1955 & $\ldots$ & $\ldots$ & $\ldots$ & $\ldots$ & 1 & $\ldots$ & $\ldots$ & $\ldots$ & 1 & 0 & 1 \\
\hline Tachysphex tarsinus (Lepeletier, 1845) & 1 & 1 & $\ldots$ & 1 & $\ldots$ & 1 & $\ldots$ & 1 & 1 & 4 & 5 \\
\hline Tachysphex unicolor (Panzer, 1809) & 1 & $\ldots$ & $\ldots$ & $\ldots$ & $\ldots$ & 1 & $\ldots$ & 1 & 1 & 2 & 3 \\
\hline MISCOPHINI & & & & & & & & & & & \\
\hline Solierella compedita (Piccioli, 1869) & 1 & 5 & 5 & 7 & $\ldots$ & 4 & $\ldots$ & $\ldots$ & 6 & 16 & 22 \\
\hline Solierella pisonoides (Saunders, 1873) & $\ldots$ & 2 & 3 & 6 & 1 & $\ldots$ & 2 & $\ldots$ & 6 & 8 & 14 \\
\hline Solierella seabrai Andrade, 1950 & 1 & $\ldots$ & 1 & $\ldots$ & $\ldots$ & $\ldots$ & $\ldots$ & $\ldots$ & 2 & 0 & 2 \\
\hline Miscophus eatoni Saunders, 1903 & $\ldots$ & $\ldots$ & $\ldots$ & $\ldots$ & $\ldots$ & $\ldots$ & $\ldots$ & 3 & 0 & 3 & 3 \\
\hline Miscophus nicolai Ferton, 1896 & 1 & 6 & 4 & 6 & 6 & 14 & $\ldots$ & 1 & 11 & 27 & 38 \\
\hline Miscophus niger Dahlbom, 1848 & $\ldots$ & $\ldots$ & $\ldots$ & $\ldots$ & $\ldots$ & $\ldots$ & 1 & 1 & 1 & 1 & 2 \\
\hline TRYPOXYLINI & & & & & & & & & & & \\
\hline Pison atrum (Spinola, 1808) & $\ldots$ & $\ldots$ & $\ldots$ & $\ldots$ & $\ldots$ & 1 & $\ldots$ & $\ldots$ & 0 & 1 & 1 \\
\hline Trypoxylon attenuatum F. Smith, 1851 & $\ldots$ & 1 & $\ldots$ & 1 & $\ldots$ & 6 & $\ldots$ & 25 & 0 & 33 & 33 \\
\hline Trypoxylon figulus (Linnaeus, 1758) & $\ldots$ & $\ldots$ & $\cdots$ & 1 & $\ldots$ & $\ldots$ & $\cdots$ & $\ldots$ & 0 & 1 & 1 \\
\hline Trypoxylon scutatum Chevrier, 1867 & $\ldots$ & 3 & $\ldots$ & 11 & $\ldots$ & 17 & 3 & 25 & 3 & 56 & 59 \\
\hline OXYBELINI & & & & & & & & & & & \\
\hline Oxybelus quattuordecimnotatus Jurine, 1807 & $\ldots$ & $\ldots$ & $\ldots$ & $\ldots$ & 2 & $\ldots$ & 1 & $\ldots$ & 3 & 0 & 3 \\
\hline Oxybelus subspinosus Klug, 1835 & 1 & $\ldots$ & $\ldots$ & $\ldots$ & $\ldots$ & $\ldots$ & $\ldots$ & $\ldots$ & 1 & 0 & 1 \\
\hline
\end{tabular}




\begin{tabular}{|c|c|c|c|c|c|c|c|c|c|c|c|}
\hline \multirow{3}{*}{\begin{tabular}{|c} 
Periodos de muestreo \\
LOCALIDAD 1F \\
Pereña (SA) PLATOS \\
Año 2005
\end{tabular}} & \multicolumn{2}{|c|}{1} & \multicolumn{2}{|c|}{2} & \multicolumn{2}{|c|}{3} & \multicolumn{2}{|c|}{4} & & & \\
\hline & \multicolumn{2}{|c|}{ 15-Jun } & \multicolumn{2}{|c|}{ 15-Jul } & \multicolumn{2}{|c|}{ 15-Agos } & \multicolumn{2}{|c|}{ 15-Sep } & \multicolumn{2}{|c|}{ Totales } & \multirow{2}{*}{$\Sigma$} \\
\hline & & & $\mathbf{M}$ & $\mathbf{H}$ & $\mathbf{M}$ & $\mathbf{H}$ & $\mathbf{M}$ & $\mathbf{H}$ & $\mathbf{M}$ & $\mathbf{H}$ & \\
\hline \multicolumn{12}{|l|}{$\begin{array}{l}\text { BEMBICINAE } \\
\text { NYSSONINI }\end{array}$} \\
\hline Nysson maculosus (Gmelin, 1790) & 3 & 2 & $\ldots$ & $\ldots$ & $\ldots$ & $\ldots$ & $\ldots$ & $\ldots$ & 3 & 2 & 5 \\
\hline Nysson pratensis Mercet, 1909 & 1 & 1 & $\ldots$ & $\ldots$ & $\ldots$ & $\ldots$ & $\ldots$ & $\ldots$ & 1 & 1 & 2 \\
\hline Nysson variabilis (Chevrier, 1867) & $\cdots$ & $\cdots$ & $\ldots$ & ... & $\cdots$ & ... & $\ldots$ & 1 & 0 & 1 & 1 \\
\hline \multicolumn{12}{|l|}{ BEMBICINI } \\
\hline Harpactus alvaroi Gayubo, 1992 & $\ldots$ & 1 & & $\ldots$ & & 1 & & & 0 & 2 & 2 \\
\hline Harpactus formosus (Jurine, 1807) & $\ldots$ & $\ldots$ & $\ldots$ & $\ldots$ & $\ldots$ & $\ldots$ & $\ldots$ & 1 & 0 & 1 & 1 \\
\hline Bembecinus pulchelus (Mercet, 1906) & 1 & 39 & $\ldots$ & 21 & $\ldots$ & $\ldots$ & $\ldots$ & $\ldots$ & 1 & 60 & 61 \\
\hline \multirow{3}{*}{$\begin{array}{r}\text { Subtotales } \\
\text { Total de Ejemplares }\end{array}$} & 27 & 71 & 15 & 63 & 15 & 52 & 10 & 62 & 67 & 248 & \\
\hline & \multicolumn{2}{|c|}{98} & \multicolumn{2}{|c|}{78} & \multicolumn{2}{|c|}{67} & \multicolumn{2}{|c|}{72} & \multicolumn{2}{|c|}{315} & 315 \\
\hline & \multicolumn{2}{|c|}{24} & \multicolumn{2}{|c|}{15} & \multicolumn{2}{|c|}{20} & \multicolumn{2}{|c|}{15} & & & 38 \\
\hline
\end{tabular}




\begin{tabular}{|c|c|c|c|c|c|c|c|c|c|c|c|c|c|c|c|c|c|c|c|}
\hline \multirow{3}{*}{\begin{tabular}{|} 
Periodos de muestreo \\
LOCALIDAD 1F - DENTRO 1 \\
Pereña (SA) Trampa Malaise \\
Año 2006
\end{tabular}} & \multicolumn{2}{|c|}{1} & \multicolumn{2}{|c|}{2} & \multicolumn{2}{|c|}{3} & \multicolumn{2}{|c|}{4} & \multicolumn{2}{|c|}{5} & \multicolumn{2}{|c|}{6} & \multicolumn{2}{|c|}{7} & \multicolumn{2}{|l|}{8} & & & \\
\hline & \multicolumn{2}{|c|}{$1-15 \mathrm{VI}$} & \multicolumn{2}{|c|}{$16-30 \mathrm{VI}$} & \multicolumn{2}{|c|}{ 1-15 VII } & \multicolumn{2}{|c|}{ 16-31 VII } & \multicolumn{2}{|c|}{ 1-15 VIII } & $16-3$ & VIII & $1-15$ & & $16-30$ & & & & $\mathbf{\Sigma}$ \\
\hline & M & $\mathbf{H}$ & $\mathbf{M}$ & $\mathbf{H}$ & $\mathbf{M}$ & $\mathbf{H}$ & $\mathbf{M}$ & $\mathbf{H}$ & $\mathbf{M}$ & $\mathbf{H}$ & $\mathbf{M}$ & $\mathbf{H}$ & $\mathbf{M}$ & $\mathbf{H}$ & $\mathbf{M}$ & $\mathbf{H}$ & M & $\mathbf{H}$ & \\
\hline$\underline{\text { SPHECIDAE }}$ & & & & & & & & & & & & & & & & & & & \\
\hline SPHECINAE & & & & & & & & & & & & & & & & & & & \\
\hline SPHECINI & & & & & & & & & & & & & & & & & & & \\
\hline Sphex atropilosus Kohl, 1885 & 1 & $\ldots$ & $\ldots$ & $\ldots$ & $\ldots$ & $\ldots$ & $\ldots$ & $\ldots$ & $\ldots$ & $\ldots$ & $\ldots$ & $\ldots$ & $\ldots$ & $\ldots$ & $\ldots$ & $\ldots$ & 1 & 0 & 1 \\
\hline Sphex funerarius Gussakovskij, 1934 & 5 & 1 & $\ldots$ & 4 & 2 & 4 & $\ldots$ & $\ldots$ & $\ldots$ & 1 & $\ldots$ & $\ldots$ & $\ldots$ & $\ldots$ & $\ldots$ & $\ldots$ & 7 & 10 & 17 \\
\hline Sphex leuconotus Brullé, 1833 & 4 & 1 & 1 & 5 & 7 & 2 & 6 & 3 & 1 & $\ldots$ & $\ldots$ & $\ldots$ & $\ldots$ & $\ldots$ & $\ldots$ & $\ldots$ & 19 & 11 & 30 \\
\hline PRIONYCHINI & & & & & & & & & & & & & & & & & & & \\
\hline Palmodes melanarius (Mocsáry, 1883) & $\ldots$ & $\ldots$ & $\ldots$ & $\ldots$ & ... & $\ldots$ & $\ldots$ & $\ldots$ & $\ldots$ & 1 & $\ldots$ & $\ldots$ & $\ldots$ & $\ldots$ & $\ldots$ & $\ldots$ & 0 & 1 & 1 \\
\hline Chilosphex argyrius (Brullé, 1833) & 2 & 1 & $\ldots$ & 3 & $\ldots$ & $\ldots$ & $\ldots$ & $\ldots$ & $\ldots$ & $\ldots$ & $\ldots$ & $\ldots$ & $\ldots$ & $\ldots$ & $\ldots$ & $\ldots$ & 2 & 4 & 6 \\
\hline Prionyx kirbii (Van der Linden, 1827) & $\ldots$ & 1 & $\ldots$ & $\ldots$ & $\ldots$ & $\ldots$ & $\ldots$ & $\ldots$ & $\ldots$ & 1 & $\ldots$ & 1 & 2 & $\ldots$ & $\ldots$ & $\ldots$ & 2 & 3 & 5 \\
\hline AMMOPHILINAE & & & & & & & & & & & & & & & & & & & \\
\hline AMMOPHILINI & & & & & & & & & & & & & & & & & & & \\
\hline Ammophila campestris Latreille, 1809 & 2 & 2 & $\ldots$ & 1 & 1 & $\ldots$ & $\ldots$ & $\ldots$ & $\ldots$ & $\ldots$ & $\ldots$ & $\ldots$ & $\ldots$ & $\ldots$ & $\ldots$ & $\ldots$ & 3 & 3 & 6 \\
\hline Ammophila heydeni Dahlbom, 1845 & 1 & 1 & $\ldots$ & $\ldots$ & 1 & 1 & 1 & 2 & 1 & 1 & $\ldots$ & 4 & 1 & $\ldots$ & $\ldots$ & $\ldots$ & 5 & 9 & 14 \\
\hline Ammophila laevicollis André, 1886 & $\ldots$ & $\ldots$ & $\ldots$ & $\ldots$ & 1 & $\ldots$ & $\ldots$ & $\ldots$ & $\ldots$ & $\ldots$ & $\ldots$ & $\ldots$ & $\ldots$ & $\ldots$ & $\ldots$ & $\ldots$ & 1 & 0 & 1 \\
\hline CRABRONIDAE & & & & & & & & & & & & & & & & & & & \\
\hline PEMPHREDONINAE & & & & & & & & & & & & & & & & & & & \\
\hline PSENINI & & & & & & & & & & & & & & & & & & & \\
\hline Psenulus fuscipennis (Dahlbom, 1843) & $\ldots$ & $\ldots$ & $\ldots$ & $\ldots$ & $\ldots$ & 1 & $\ldots$ & 2 & $\ldots$ & $\ldots$ & $\ldots$ & 1 & $\ldots$ & $\ldots$ & $\ldots$ & $\ldots$ & 0 & 4 & 4 \\
\hline PEMPHREDONINI & & & & & & & & & & & & & & & & & & & \\
\hline Diodontus insidiosus Spooner, 1938 & $\ldots$ & $\ldots$ & 1 & $\ldots$ & 1 & $\ldots$ & $\ldots$ & 2 & $\ldots$ & $\ldots$ & $\ldots$ & $\ldots$ & $\ldots$ & $\ldots$ & 1 & $\ldots$ & 3 & 2 & 5 \\
\hline Passaloecus pictus Ribaut, 1952 & $\ldots$ & 2 & & & $\ldots$ & $\ldots$ & $\ldots$ & 1 & & $\ldots$ & $\ldots$ & $\ldots$ & $\ldots$ & $\ldots$ & $\ldots$ & & 0 & 3 & 3 \\
\hline Ammoplanus ceballosi Giner Marí, 1943 & $\ldots$ & 5 & $\ldots$ & $\ldots$ & $\ldots$ & $\ldots$ & $\ldots$ & $\ldots$ & $\ldots$ & $\ldots$ & $\ldots$ & $\ldots$ & $\ldots$ & $\ldots$ & $\ldots$ & $\ldots$ & 0 & 5 & 5 \\
\hline Ammoplanus torresi Gayubo, 1991 & $\ldots$ & $\ldots$ & $\ldots$ & 1 & $\ldots$ & $\ldots$ & $\ldots$ & $\ldots$ & $\ldots$ & $\ldots$ & $\ldots$ & $\ldots$ & $\ldots$ & $\ldots$ & $\ldots$ & $\ldots$ & 0 & 1 & 1 \\
\hline ASTATINAE & & & & & & & & & & & & & & & & & & & \\
\hline ASTATINI & & & & & & & & & & & & & & & & & & & \\
\hline Astata cobosi Giner Marí, 1946 & $\ldots$ & $\ldots$ & $\ldots$ & $\ldots$ & $\ldots$ & 1 & $\ldots$ & 1 & $\ldots$ & $\ldots$ & $\ldots$ & $\ldots$ & $\ldots$ & $\ldots$ & $\ldots$ & $\ldots$ & 0 & 2 & 2 \\
\hline CRABRONINAE & & & & & & & & & & & & & & & & & & & \\
\hline LARRINI & & & & & & & & & & & & & & & & & & & \\
\hline Larra anathema (Rossi, 1790) & $\ldots$ & $\ldots$ & $\ldots$ & $\ldots$ & $\ldots$ & $\ldots$ & $\ldots$ & $\ldots$ & $\ldots$ & $\ldots$ & $\ldots$ & $\ldots$ & $\ldots$ & $\ldots$ & 1 & $\ldots$ & 1 & 0 & 1 \\
\hline Tachytes panzeri (Dufour, 1841) & 1 & & $\ldots$ & 1 & $\ldots$ & 1 & $\ldots$ & 1 & & 1 & $\ldots$ & $\ldots$ & $\ldots$ & $\ldots$ & $\ldots$ & $\ldots$ & 1 & 4 & 5 \\
\hline Tachysphex consocius Kohl, 1892 & 1 & & $\ldots$ & $\ldots$ & $\ldots$ & $\ldots$ & $\ldots$ & $\ldots$ & $\ldots$ & $\ldots$ & $\ldots$ & $\ldots$ & $\ldots$ & $\ldots$ & $\ldots$ & $\ldots$ & 1 & 0 & 1 \\
\hline Tachysphex fulvitarsis (A. Costa, 1867) & $\ldots$ & $\ldots$ & $\ldots$ & $\ldots$ & 1 & $\ldots$ & $\ldots$ & 1 & $\ldots$ & 1 & $\ldots$ & 1 & $\ldots$ & $\ldots$ & $\ldots$ & $\ldots$ & 1 & 3 & 4 \\
\hline Tachysphex incertus (Radoszkowski, 1877) & 3 & $\ldots$ & $\ldots$ & $\ldots$ & 4 & 1 & 1 & 1 & 1 & 1 & $\ldots$ & $\ldots$ & $\ldots$ & 1 & $\ldots$ & $\ldots$ & 9 & 4 & 13 \\
\hline Tachysphex nitidior Beaumont, 1940 & $\ldots$ & $\ldots$ & $\ldots$ & $\ldots$ & $\ldots$ & $\ldots$ & $\ldots$ & $\ldots$ & $\ldots$ & 1 & $\ldots$ & $\ldots$ & $\ldots$ & $\ldots$ & $\ldots$ & $\ldots$ & 0 & 1 & 1 \\
\hline Tachysphex obscuripennis (Schenck, 1857) & $\ldots$ & $\ldots$ & $\ldots$ & $\ldots$ & 1 & $\ldots$ & $\ldots$ & $\ldots$ & $\ldots$ & $\ldots$ & $\ldots$ & $\ldots$ & $\ldots$ & $\ldots$ & $\ldots$ & $\ldots$ & 1 & 0 & 1 \\
\hline Tachysphex panzeri (Van der Linden, 1829) & $\ldots$ & & $\ldots$ & $\ldots$ & $\ldots$ & 1 & $\ldots$ & $\ldots$ & $\ldots$ & $\ldots$ & $\ldots$ & $\ldots$ & $\ldots$ & $\ldots$ & $\ldots$ & $\ldots$ & 0 & 1 & 1 \\
\hline Tachysphex psammobius (Kohl, 1880) & $\ldots$ & 1 & $\ldots$ & & $\ldots$ & $\ldots$ & $\ldots$ & $\ldots$ & $\ldots$ & $\ldots$ & $\ldots$ & $\ldots$ & $\ldots$ & $\ldots$ & $\ldots$ & $\ldots$ & 0 & 1 & 1 \\
\hline Tachysphex pseudopanzeri Beaumont, 1955 & $\ldots$ & $\ldots$ & $\ldots$ & $\ldots$ & 1 & $\ldots$ & $\ldots$ & $\ldots$ & 3 & $\ldots$ & $\ldots$ & $\ldots$ & $\ldots$ & $\ldots$ & $\ldots$ & $\ldots$ & 4 & 0 & 4 \\
\hline MISCOPHINI & & & & & & & & & & & & & & & & & & & \\
\hline Solierella compedita (Piccioli, 1869) & $\ldots$ & 1 & $\ldots$ & $\ldots$ & $\ldots$ & 2 & $\ldots$ & $\ldots$ & 1 & 6 & 1 & 1 & 2 & $\ldots$ & $\ldots$ & $\ldots$ & 4 & 10 & 14 \\
\hline Miscophus bicolor Jurine, 1807 & $\ldots$ & $\ldots$ & $\ldots$ & $\ldots$ & $\ldots$ & $\ldots$ & 1 & 2 & $\ldots$ & $\ldots$ & 1 & $\ldots$ & $\ldots$ & 1 & $\ldots$ & $\ldots$ & 2 & 3 & 5 \\
\hline Miscophus eatoni Saunders, 1903 & $\ldots$ & $\ldots$ & $\ldots$ & $\ldots$ & $\ldots$ & $\ldots$ & $\ldots$ & 1 & $\ldots$ & $\ldots$ & $\ldots$ & 1 & $\ldots$ & $\ldots$ & $\ldots$ & $\ldots$ & 0 & 2 & 2 \\
\hline Nitela lucens Gayubo \& Felton, 2000 & $\ldots$ & & & & $\ldots$ & $\ldots$ & $\ldots$ & $\ldots$ & & $\ldots$ & $\ldots$ & $\ldots$ & $\ldots$ & $\ldots$ & $\ldots$ & 1 & 0 & 1 & 1 \\
\hline TRYPOXYLINI & & & & & & & & & & & & & & & & & & & \\
\hline Trypoxylon attenuatum F. Smith, 1851 & $\ldots$ & $\ldots$ & $\ldots$ & 1 & $\ldots$ & 4 & $\ldots$ & 2 & $\ldots$ & 1 & $\ldots$ & 2 & $\ldots$ & 2 & $\ldots$ & $\ldots$ & 0 & 12 & 12 \\
\hline Trypoxylon scutatum Chevrier, 1867 & $\ldots$ & & $\ldots$ & 4 & 1 & 6 & $\ldots$ & 12 & $\ldots$ & 18 & 1 & 11 & 1 & 6 & $\ldots$ & & 3 & 57 & 60 \\
\hline
\end{tabular}




\begin{tabular}{|c|c|c|c|c|c|c|c|c|c|c|c|c|c|c|c|c|c|c|c|}
\hline \multirow{3}{*}{$\begin{array}{r}\text { Periodos de muestreo } \\
\text { LOCALIDAD 1F - DENTRO 1 } \\
\text { Pereña (SA) Trampa Malaise } \\
\text { Año } 2006\end{array}$} & \multicolumn{2}{|c|}{1} & \multicolumn{2}{|c|}{2} & \multicolumn{2}{|c|}{3} & \multicolumn{2}{|c|}{4} & \multicolumn{2}{|c|}{5} & \multicolumn{2}{|c|}{6} & \multicolumn{2}{|c|}{7} & \multicolumn{2}{|c|}{8} & & & \\
\hline & \multicolumn{2}{|c|}{$1-15 \mathrm{VI}$} & \multicolumn{2}{|c|}{$16-30 \mathrm{VI}$} & \multicolumn{2}{|c|}{ 1-15 VII } & \multicolumn{2}{|c|}{ 16-31 VII } & \multicolumn{2}{|c|}{ 1-15 VIII } & \multicolumn{2}{|c|}{ 16-31 VIII } & \multicolumn{2}{|c|}{$1-15$ IX } & \multicolumn{2}{|c|}{ 16-30 IX } & \multicolumn{2}{|c|}{ Totales } & \multirow{2}{*}{$\Sigma$} \\
\hline & & $\mathbf{H}$ & M & $\mathbf{H}$ & M & $\mathbf{H}$ & $\mathbf{M}$ & $\mathbf{H}$ & $\mathbf{M}$ & $\mathbf{H}$ & M & $\mathbf{H}$ & M & $\mathbf{H}$ & M & $\mathbf{H}$ & $\mathbf{M}$ & $\mathbf{H}$ & \\
\hline \multicolumn{20}{|l|}{ OXYBELINI } \\
\hline $\begin{array}{l}\text { Oxybelus quattuordecimnotatus Jurine, } 1807 \\
\text { CRABRONINI }\end{array}$ & & & $\ldots$ & $\ldots$ & $\ldots$ & $\ldots$ & $\ldots$ & 1 & 2 & $\ldots$ & $\ldots$ & 1 & $\ldots$ & $\ldots$ & $\ldots$ & $\ldots$ & 2 & 2 & 4 \\
\hline Tracheliodes quinquenotatus (Jurine, 1807) & $\ldots$ & $\ldots$ & $\ldots$ & $\ldots$ & $\ldots$ & $\ldots$ & $\ldots$ & $\ldots$ & $\ldots$ & 1 & $\ldots$ & $\ldots$ & $\ldots$ & $\ldots$ & $\ldots$ & $\ldots$ & 0 & 1 & 1 \\
\hline Ectemnius crassicornis (Spinola, 1808) & $\ldots$ & & $\cdots$ & $\ldots$ & $\ldots$ & $\ldots$ & $\cdots$ & 1 & $\ldots$ & $\ldots$ & $\cdots$ & $\ldots$ & $\ldots$ & $\cdots$ & $\ldots$ & $\ldots$ & 0 & 1 & 1 \\
\hline \multicolumn{20}{|l|}{ BEMBICINAE } \\
\hline \multicolumn{20}{|l|}{ BEMBICINI } \\
\hline Harpactus formosus (Jurine, 1807) & & 1 & $\ldots$ & $\cdots$ & $\cdots$ & $\ldots$ & $\cdots$ & $\cdots$ & $\cdots$ & $\cdots$ & $\ldots$ & $\cdots$ & 1 & $\ldots$ & $\ldots$ & $\cdots$ & 1 & 1 & 2 \\
\hline Harpactus morawitzi (Snoflak, 1943) & $\ldots$ & & $\ldots$ & $\cdots$ & $\ldots$ & $\ldots$ & $\ldots$ & $\ldots$ & $\ldots$ & 1 & $\ldots$ & 3 & $\cdots$ & 1 & $\ldots$ & $\ldots$ & 0 & 5 & 5 \\
\hline Lestiphorus bicinctus (Rossi, 1794) & $\cdots$ & $\cdots$ & $\ldots$ & 1 & $\cdots$ & $\cdots$ & $\cdots$ & $\ldots$ & $\cdots$ & $\cdots$ & $\ldots$ & $\ldots$ & $\ldots$ & $\cdots$ & $\ldots$ & $\cdots$ & 0 & 1 & 1 \\
\hline Bembecinus carpetanus (Mercet, 1906) & $\ldots$ & $\ldots$ & $\ldots$ & $\ldots$ & $\ldots$ & 1 & $\ldots$ & $\ldots$ & $\ldots$ & $\ldots$ & $\ldots$ & $\ldots$ & $\ldots$ & $\ldots$ & $\ldots$ & $\ldots$ & 0 & 1 & 1 \\
\hline Bembecinus pulchelus (Mercet, 1906) & $\ldots$ & $\ldots$ & 1 & 2 & 1 & $\ldots$ & $\ldots$ & 1 & $\ldots$ & $\ldots$ & $\ldots$ & $\ldots$ & $\ldots$ & $\ldots$ & $\ldots$ & $\ldots$ & 2 & 3 & 5 \\
\hline Bembix zonata Klug, 1835 & $\cdots$ & $\ldots$ & $\ldots$ & $\cdots$ & $\ldots$ & 1 & $\cdots$ & $\ldots$ & $\ldots$ & 1 & $\ldots$ & 1 & $\cdots$ & $\cdots$ & $\ldots$ & $\cdots$ & 0 & 3 & 3 \\
\hline \multicolumn{20}{|l|}{ PHILANTHINAE } \\
\hline \multicolumn{20}{|l|}{ CERCERINI } \\
\hline Cerceris arenaria (Linnaeus, 1758) & $\ldots$ & $\cdots$ & $\cdots$ & $\ldots$ & $\ldots$ & $\ldots$ & $\ldots$ & 1 & $\cdots$ & $\cdots$ & $\ldots$ & $\cdots$ & $\ldots$ & 1 & $\ldots$ & $\ldots$ & 0 & 2 & 2 \\
\hline Cerceris ibericella Leclercq, 1979 & $\cdots$ & $\ldots$ & $\cdots$ & $\cdots$ & $\cdots$ & $\cdots$ & $\cdots$ & $\ldots$ & $\cdots$ & $\cdots$ & $\cdots$ & 1 & $\cdots$ & $\ldots$ & $\ldots$ & $\ldots$ & 0 & 1 & 1 \\
\hline Cerceris quadricinctus (Panzer, 1799) & $\ldots$ & $\ldots$ & $\ldots$ & $\ldots$ & $\ldots$ & $\ldots$ & $\ldots$ & $\ldots$ & $\cdots$ & $\ldots$ & $\ldots$ & 1 & $\ldots$ & $\ldots$ & $\ldots$ & $\ldots$ & 0 & 1 & 1 \\
\hline Cerceris rybyensis (Linnaeus, 1771) & $\ldots$ & $\cdots$ & $\ldots$ & $\ldots$ & $\ldots$ & $\ldots$ & $\ldots$ & 1 & $\ldots$ & $\cdots$ & $\ldots$ & $\cdots$ & $\ldots$ & $\ldots$ & $\cdots$ & $\cdots$ & 0 & 1 & 1 \\
\hline \multirow{2}{*}{$\begin{array}{r}\text { Subtotales } \\
\text { Total de Ejemplares }\end{array}$} & 20 & 17 & 3 & 23 & 22 & 26 & 9 & 36 & 9 & 36 & 3 & 29 & 7 & 12 & 2 & 1 & 75 & 180 & \\
\hline & \multicolumn{2}{|c|}{37} & \multicolumn{2}{|c|}{26} & & & & & & & & & & & & & & 5 & 255 \\
\hline Total de Especies & 1 & & & & & & & & & & & & & & & & & & 44 \\
\hline
\end{tabular}




\begin{tabular}{|c|c|c|c|c|c|c|c|c|c|c|c|c|c|c|c|c|c|c|c|}
\hline \multirow{3}{*}{$\begin{array}{l}\text { Periodos de muestreo } \\
\text { LOCALIDAD 1F - DENTRO } 2 \\
\text { Pereña (SA) Trampa Malaise } \\
\text { Año } 2006\end{array}$} & \multicolumn{2}{|c|}{1} & \multicolumn{2}{|c|}{2} & \multicolumn{2}{|c|}{3} & \multicolumn{2}{|c|}{4} & \multicolumn{2}{|c|}{5} & \multicolumn{2}{|c|}{6} & \multicolumn{2}{|c|}{7} & \multicolumn{2}{|c|}{8} & & & \\
\hline & \multicolumn{2}{|c|}{$1-15 \mathrm{VI}$} & \multicolumn{2}{|c|}{$16-30 \mathrm{VI}$} & \multicolumn{2}{|c|}{$1-15 \mathrm{VII}$} & \multicolumn{2}{|c|}{ 16-31 VII } & \multicolumn{2}{|c|}{ 1-15 VIII } & \multicolumn{2}{|c|}{ 16-31 VIII } & $1-15$ & & $16-30$ & & Tot & ales & \\
\hline & M & H & M & $\mathbf{H}$ & M & $\mathbf{H}$ & $\mathbf{M}$ & $\mathbf{H}$ & M & H & M & $\mathbf{H}$ & $\mathbf{M}$ & & M & $\mathbf{H}$ & M & H & \\
\hline SPHECIDAE & & & & & & & & & & & & & & & & & & & \\
\hline SCELIPHRINAE & & & & & & & & & & & & & & & & & & & \\
\hline SCELIPHRINI & & & & & & & & & & & & & & & & & & & \\
\hline Sceliphron destillatorium (Illiger, 1807) & & 4 & $\ldots$ & $\ldots$ & $\ldots$ & $\ldots$ & $\ldots$ & $\ldots$ & $\ldots$ & $\ldots$ & $\ldots$ & $\ldots$ & $\ldots$ & $\ldots$ & $\ldots$ & $\ldots$ & .. & 4 & 4 \\
\hline SPHECINAE & & & & & & & & & & & & & & & & & & & \\
\hline SPHECINI & & & & & & & & & & & & & & & & & & & \\
\hline Sphex atropilosus Kohl, 1885 & $\ldots$ & 3 & $\ldots$ & $\ldots$ & $\ldots$ & $\ldots$ & $\ldots$ & $\ldots$ & $\ldots$ & $\ldots$ & $\ldots$ & $\ldots$ & $\ldots$ & $\ldots$ & $\ldots$ & $\ldots$ & $\cdots$ & 3 & 3 \\
\hline Sphex funerarius Gussakovskij, 1934 & 1 & 1 & $\ldots$ & $\ldots$ & $\ldots$ & 1 & $\ldots$ & $\ldots$ & $\ldots$ & $\ldots$ & $\ldots$ & 1 & $\ldots$ & $\ldots$ & $\ldots$ & $\ldots$ & 1 & 3 & 4 \\
\hline Sphex leuconotus Brullé, 1833 & 3 & 1 & $\ldots$ & 1 & 2 & 3 & 1 & 2 & 1 & 3 & $\ldots$ & $\ldots$ & $\ldots$ & $\ldots$ & $\ldots$ & $\ldots$ & 7 & 10 & 17 \\
\hline PRIONYCHINI & & & & & & & & & & & & & & & & & & & \\
\hline Chilosphex argyrius (Brullé, 1833) & $\ldots$ & $\ldots$ & $\ldots$ & 1 & $\ldots$ & $\ldots$ & $\ldots$ & $\ldots$ & $\ldots$ & $\ldots$ & $\ldots$ & $\ldots$ & $\ldots$ & $\ldots$ & $\ldots$ & $\ldots$ & $\ldots$ & 1 & 1 \\
\hline AMMOPHILINAE & & & & & & & & & & & & & & & & & & & \\
\hline AMMOPHILINI & & & & & & & & & & & & & & & & & & & \\
\hline Ammophila campestris Latreille, 1809 & $\ldots$ & 1 & $\ldots$ & $\ldots$ & $\ldots$ & $\ldots$ & $\ldots$ & $\ldots$ & $\ldots$ & $\ldots$ & $\ldots$ & $\ldots$ & $\ldots$ & $\ldots$ & $\ldots$ & $\ldots$ & $\ldots$ & 1 & 1 \\
\hline Ammophila heydeni Dahlbom, 1845 & $\ldots$ & $\cdots$ & $\ldots$ & $\ldots$ & $\ldots$ & $\ldots$ & $\ldots$ & 1 & $\ldots$ & $\cdots$ & $\ldots$ & $\ldots$ & $\cdots$ & $\ldots$ & $\ldots$ & $\ldots$ & $\cdots$ & 1 & 1 \\
\hline Ammophila hungarica Mocsáry, 1883 & $\ldots$ & 1 & $\ldots$ & $\ldots$ & $\ldots$ & $\ldots$ & $\ldots$ & $\ldots$ & $\ldots$ & $\ldots$ & $\ldots$ & $\ldots$ & $\ldots$ & $\ldots$ & $\ldots$ & $\ldots$ & $\ldots$ & 1 & 1 \\
\hline CRABRONIDAE & & & & & & & & & & & & & & & & & & & \\
\hline PEMPHREDONINAE & & & & & & & & & & & & & & & & & & & \\
\hline PSENINI & & & & & & & & & & & & & & & & & & & \\
\hline Psenulus fuscipennis (Dahlbom, 1843) & $\ldots$ & $\ldots$ & $\ldots$ & $\ldots$ & $\ldots$ & $\ldots$ & $\ldots$ & 2 & $\ldots$ & $\ldots$ & $\ldots$ & $\ldots$ & $\ldots$ & $\ldots$ & $\ldots$ & $\ldots$ & $\ldots$ & 2 & 2 \\
\hline PEMPHREDONINI & & & & & & & & & & & & & & & & & & & \\
\hline Diodontus insidiosus Spooner, 1938 & 1 & $\ldots$ & $\ldots$ & 1 & $\ldots$ & $\ldots$ & 7 & 3 & 5 & $\ldots$ & 3 & 3 & 1 & 1 & $\ldots$ & $\ldots$ & 17 & 8 & 25 \\
\hline Passaloecus pictus Ribaut, 1952 & $\ldots$ & $\ldots$ & $\ldots$ & $\ldots$ & $\ldots$ & 1 & $\ldots$ & $\ldots$ & $\ldots$ & $\ldots$ & $\ldots$ & $\ldots$ & $\ldots$ & $\ldots$ & $\ldots$ & $\ldots$ & $\ldots$ & 1 & 1 \\
\hline Ammoplanus ceballosi Giner Marí, 1943 & $\ldots$ & 2 & $\ldots$ & $\ldots$ & $\ldots$ & $\ldots$ & $\ldots$ & $\ldots$ & $\ldots$ & $\ldots$ & $\ldots$ & $\ldots$ & $\ldots$ & $\ldots$ & $\ldots$ & $\ldots$ & $\ldots$ & 2 & 2 \\
\hline ASTATINAE & & & & & & & & & & & & & & & & & & & \\
\hline ASTATINI & & & & & & & & & & & & & & & & & & & \\
\hline Astata cobosi Giner Marí, 1946 & $\ldots$ & $\ldots$ & $\ldots$ & $\ldots$ & $\ldots$ & 4 & $\ldots$ & $\ldots$ & $\ldots$ & $\ldots$ & $\ldots$ & $\ldots$ & $\ldots$ & $\cdots$ & $\ldots$ & $\ldots$ & $\cdots$ & 4 & 4 \\
\hline CRABRONINAE & & & & & & & & & & & & & & & & & & & \\
\hline LARRINI & & & & & & & & & & & & & & & & & & & \\
\hline Tachytes panzeri (Dufour, 1841) & 1 & $\ldots$ & $\ldots$ & $\ldots$ & 1 & 2 & $\ldots$ & 1 & $\ldots$ & $\ldots$ & $\ldots$ & $\ldots$ & $\ldots$ & $\ldots$ & $\ldots$ & $\ldots$ & 2 & 3 & 5 \\
\hline Tachysphex adjunctus Kohl, 1885 & $\ldots$ & 1 & $\ldots$ & $\ldots$ & $\ldots$ & $\ldots$ & $\ldots$ & $\ldots$ & $\ldots$ & $\ldots$ & $\ldots$ & $\ldots$ & $\ldots$ & $\ldots$ & $\ldots$ & $\ldots$ & 0 & 1 & 1 \\
\hline Tachysphex fulvitarsis (A. Costa, 1867) & $\ldots$ & $\ldots$ & $\ldots$ & $\ldots$ & $\ldots$ & 1 & $\ldots$ & $\ldots$ & $\ldots$ & $\ldots$ & $\ldots$ & $\ldots$ & $\ldots$ & $\ldots$ & $\ldots$ & $\ldots$ & 0 & 1 & 1 \\
\hline Tachysphex incertus (Radoszkowski, 1877) & $\ldots$ & $\ldots$ & $\ldots$ & $\ldots$ & $\ldots$ & $\ldots$ & $\ldots$ & $\ldots$ & $\ldots$ & 2 & $\ldots$ & $\ldots$ & $\ldots$ & $\ldots$ & $\ldots$ & $\ldots$ & 0 & 2 & 2 \\
\hline Tachysphex mediterraneus Kohl, 1883 & $\ldots$ & $\ldots$ & $\ldots$ & $\ldots$ & $\cdots$ & $\ldots$ & $\ldots$ & $\ldots$ & $\ldots$ & 1 & $\ldots$ & $\ldots$ & $\ldots$ & $\ldots$ & $\ldots$ & $\ldots$ & 0 & 1 & 1 \\
\hline Tachysphex nitidior Beaumont, 1940 & $\ldots$ & $\ldots$ & $\ldots$ & 1 & $\ldots$ & $\ldots$ & $\ldots$ & 1 & $\ldots$ & 1 & $\ldots$ & 2 & $\ldots$ & $\ldots$ & $\ldots$ & $\ldots$ & 0 & 5 & 5 \\
\hline Tachysphex tarsinus (Lepeletier, 1845) & $\ldots$ & $\ldots$ & $\ldots$ & $\ldots$ & $\ldots$ & $\ldots$ & $\ldots$ & $\ldots$ & $\ldots$ & 3 & $\ldots$ & 3 & $\ldots$ & $\ldots$ & $\ldots$ & $\ldots$ & 0 & 6 & 6 \\
\hline Prosopigastra handlirschi Morice, 1897 & $\ldots$ & $\ldots$ & $\ldots$ & $\ldots$ & $\ldots$ & 1 & $\ldots$ & $\ldots$ & $\ldots$ & $\ldots$ & $\ldots$ & $\ldots$ & $\ldots$ & $\ldots$ & $\ldots$ & $\ldots$ & 0 & 1 & 1 \\
\hline MISCOPHINI & & & & & & & & & & & & & & & & & & & \\
\hline Solierella compedita (Piccioli, 1869) & $\ldots$ & $\ldots$ & 1 & $\ldots$ & $\ldots$ & 1 & $\ldots$ & 6 & $\ldots$ & 4 & 1 & 1 & $\ldots$ & $\ldots$ & $\ldots$ & $\ldots$ & 2 & 12 & 14 \\
\hline Miscophus bicolor Jurine, 1807 & $\ldots$ & $\ldots$ & $\ldots$ & $\ldots$ & $\ldots$ & $\ldots$ & $\ldots$ & $\ldots$ & $\ldots$ & $\ldots$ & $\ldots$ & $\ldots$ & $\ldots$ & 1 & $\ldots$ & $\ldots$ & 0 & 1 & 1 \\
\hline Miscophus niger Dahlbom, 1844 & $\ldots$ & $\ldots$ & $\ldots$ & $\ldots$ & $\ldots$ & $\ldots$ & $\ldots$ & $\ldots$ & $\ldots$ & 1 & $\ldots$ & $\ldots$ & $\ldots$ & $\ldots$ & $\ldots$ & $\ldots$ & 0 & 1 & 1 \\
\hline TRYPOXYLINI & & & & & & & & & & & & & & & & & & & \\
\hline Trypoxylon attenuatum F. Smith, 1851 & $\ldots$ & 1 & $\ldots$ & $\ldots$ & $\ldots$ & 1 & $\ldots$ & $\ldots$ & $\ldots$ & 2 & $\ldots$ & $\ldots$ & $\ldots$ & $\ldots$ & $\ldots$ & $\ldots$ & 0 & 4 & 4 \\
\hline Trypoxylon scutatum Chevrier, 1867 & $\ldots$ & $\ldots$ & $\ldots$ & $\ldots$ & $\ldots$ & 4 & $\ldots$ & 3 & $\ldots$ & 7 & 1 & 2 & $\ldots$ & 4 & $\ldots$ & $\ldots$ & 1 & 20 & 21 \\
\hline OXYBELINI & & & & & & & & & & & & & & & & & & & \\
\hline Oxybelus quattuordecimnotatus Jurine, 1807 & 1 & 1 & $\ldots$ & $\ldots$ & $\ldots$ & $\ldots$ & $\cdots$ & $\ldots$ & $\cdots$ & $\ldots$ & $\ldots$ & $\ldots$ & $\ldots$ & $\ldots$ & $\ldots$ & $\ldots$ & 1 & 1 & 2 \\
\hline
\end{tabular}




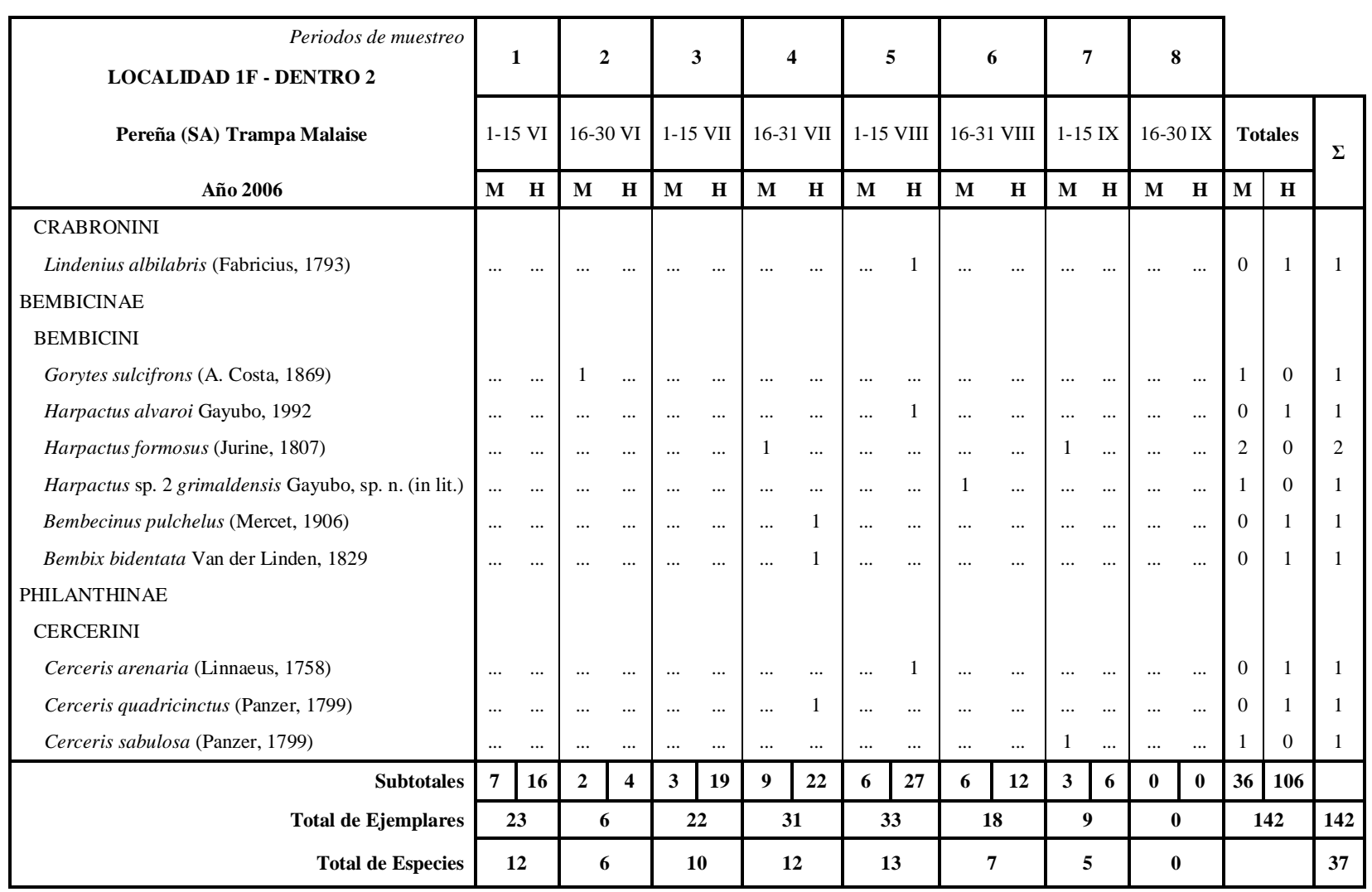




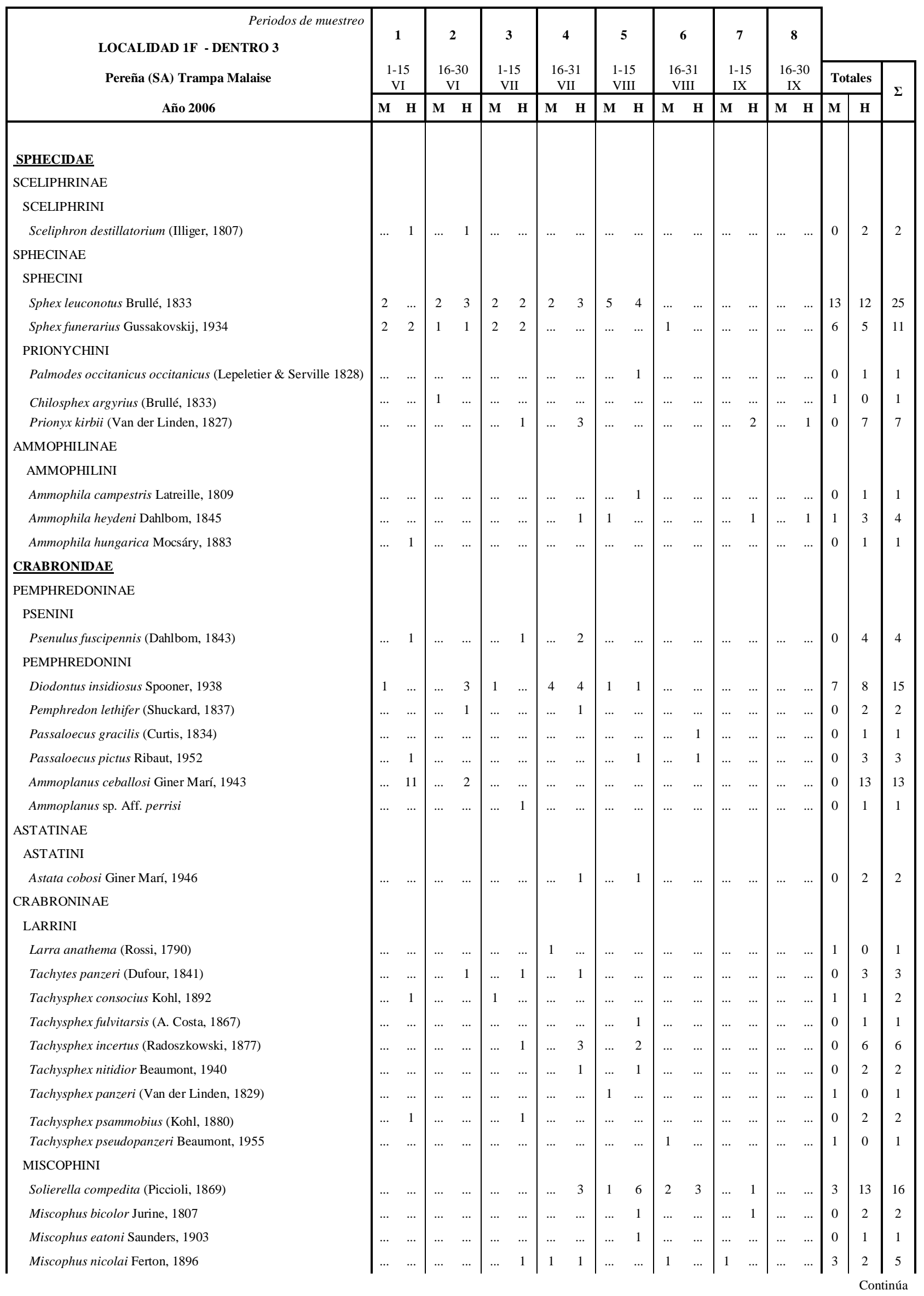




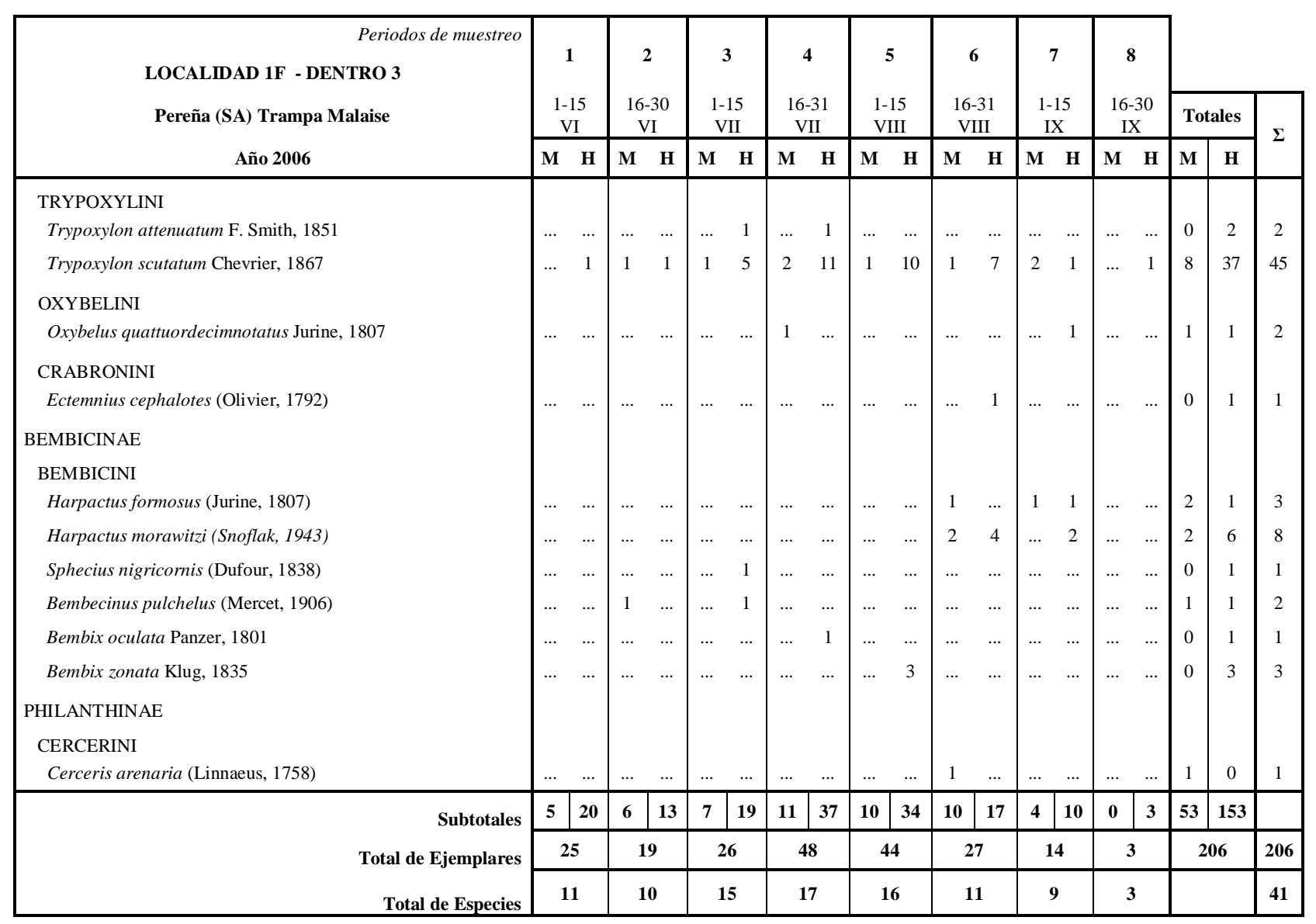




\begin{tabular}{|c|c|c|c|c|c|c|c|c|c|c|c|}
\hline \multirow{3}{*}{$\begin{array}{r}\text { Periodos de muestreo } \\
\text { LOCALIDAD 1F - DENTRO } 1 \\
\text { Pereña (SA) PLATOS } \\
\text { Año 2006 }\end{array}$} & \multicolumn{2}{|c|}{1} & \multicolumn{2}{|c|}{2} & \multicolumn{2}{|c|}{3} & \multicolumn{2}{|c|}{4} & & & \\
\hline & \multicolumn{2}{|c|}{ 15-Jun } & \multicolumn{2}{|c|}{ 15-Jul } & \multicolumn{2}{|c|}{ 15-Agos } & \multicolumn{2}{|c|}{ 15-Sep } & \multicolumn{2}{|c|}{ Totales } & \multirow{2}{*}{$\Sigma$} \\
\hline & $\mathbf{M}$ & $\mathbf{H}$ & $\mathbf{M}$ & $\mathbf{H}$ & $\mathbf{M}$ & $\mathbf{H}$ & $\mathbf{M}$ & $\mathbf{H}$ & $\mathbf{M}$ & $\mathbf{H}$ & \\
\hline \multicolumn{12}{|l|}{ SPHECIDAE } \\
\hline \multicolumn{12}{|l|}{ AMMOPHILINAE } \\
\hline \multicolumn{12}{|l|}{ AMMOPHILINI } \\
\hline Ammophila heydeni Dahlbom, 1845 & $\ldots$ & $\ldots$ & $\ldots$ & $\ldots$ & $\ldots$ & 1 & $\ldots$ & $\ldots$ & 0 & 1 & 1 \\
\hline \multicolumn{12}{|l|}{ CRABRONIDAE } \\
\hline \multicolumn{12}{|l|}{ PEMPHREDONINAE } \\
\hline \multicolumn{12}{|l|}{ PEMPHREDONINI } \\
\hline Diodontus insidiosus Spooner, 1938 & $\ldots$ & 1 & 1 & $\ldots$ & $\ldots$ & $\ldots$ & $\ldots$ & 2 & 1 & 3 & 4 \\
\hline \multicolumn{12}{|l|}{ CRABRONINAE } \\
\hline \multicolumn{12}{|l|}{ LARRINI } \\
\hline Liris niger (Fabricius, 1775) & $\ldots$ & $\ldots$ & 1 & $\ldots$ & $\ldots$ & $\ldots$ & 5 & 2 & 6 & 2 & 8 \\
\hline Larropsis punctulata (Kohl, 1884) & $\ldots$ & $\ldots$ & $\ldots$ & $\ldots$ & $\ldots$ & $\ldots$ & 1 & $\ldots$ & 1 & 0 & 1 \\
\hline Tachysphex nitidior Beaumont, 1940 & $\ldots$ & $\ldots$ & $\ldots$ & $\ldots$ & $\ldots$ & 2 & $\ldots$ & $\ldots$ & 0 & 2 & 2 \\
\hline Tachysphex obscuripennis (Schenck, 1857) & $\ldots$ & $\ldots$ & 1 & 2 & $\ldots$ & $\ldots$ & $\ldots$ & $\ldots$ & 1 & 2 & 3 \\
\hline Tachysphex plicosus (A. Costa, 1877) & $\ldots$ & $\ldots$ & $\ldots$ & $\ldots$ & $\ldots$ & $\ldots$ & $\ldots$ & 1 & 0 & 1 & 1 \\
\hline Tachysphex tarsinus (Lepeletier, 1845) & $\ldots$ & $\ldots$ & $\ldots$ & $\ldots$ & $\ldots$ & 1 & $\ldots$ & $\ldots$ & 0 & 1 & 1 \\
\hline \multicolumn{12}{|l|}{ MISCOPHINI } \\
\hline Solierella compedita (Piccioli, 1869) & $\ldots$ & $\ldots$ & 1 & 1 & $\ldots$ & 4 & 2 & 1 & 3 & 6 & 9 \\
\hline Solierella pisonoides (Saunders, 1873) & $\ldots$ & $\ldots$ & $\ldots$ & $\ldots$ & $\ldots$ & $\ldots$ & 1 & $\ldots$ & 1 & 0 & 1 \\
\hline Miscophus eatoni Saunders, 1903 & $\ldots$ & $\ldots$ & $\ldots$ & $\ldots$ & $\ldots$ & $\ldots$ & 1 & $\ldots$ & 1 & 0 & 1 \\
\hline Miscophus nicolai Ferton, 1896 & 2 & $\ldots$ & $\ldots$ & $\ldots$ & 1 & 2 & 1 & $\ldots$ & 4 & 2 & 6 \\
\hline \multicolumn{12}{|l|}{ TRYPOXYLINI } \\
\hline Trypoxylon scutatum Chevrier, 1867 & 1 & $\ldots$ & $\ldots$ & $\ldots$ & 1 & 1 & $\ldots$ & 5 & 2 & 6 & 8 \\
\hline \multicolumn{12}{|l|}{ OXYBELINI } \\
\hline Oxybelus mucronatus (Fabricius, 1793) & $\ldots$ & $\ldots$ & $\ldots$ & $\ldots$ & $\ldots$ & $\ldots$ & $\ldots$ & 1 & 0 & 1 & 1 \\
\hline Oxybelus quattuordecimnotatus Jurine, 1807 & $\ldots$ & $\ldots$ & $\ldots$ & $\ldots$ & $\ldots$ & $\ldots$ & 1 & $\ldots$ & 1 & 0 & 1 \\
\hline \multicolumn{12}{|l|}{ BEMBICINAE } \\
\hline \multicolumn{12}{|l|}{ BEMBICINI } \\
\hline Harpactus alvaroi Gayubo, 1992 & $\ldots$ & $\ldots$ & $\ldots$ & $\ldots$ & $\ldots$ & $\ldots$ & 1 & 1 & 1 & 1 & 2 \\
\hline Harpactus formosus (Jurine, 1807) & $\ldots$ & $\ldots$ & $\ldots$ & $\ldots$ & $\ldots$ & $\ldots$ & 1 & $\ldots$ & 1 & 0 & 1 \\
\hline Harpactus morawitzi (Snoflak, 1943) & $\ldots$ & $\ldots$ & $\ldots$ & 1 & $\ldots$ & $\ldots$ & $\ldots$ & $\ldots$ & 0 & 1 & 1 \\
\hline Total de Ejemplares & 3 & 1 & 4 & 4 & 2 & 11 & 14 & 13 & 23 & 29 & \\
\hline Total de Ejemplares & & & & & & 3 & & & & & 52 \\
\hline Total de Especies & & & & & & & & & & & 18 \\
\hline
\end{tabular}




\begin{tabular}{|c|c|c|c|c|c|c|c|c|c|c|c|}
\hline \multirow{3}{*}{$\begin{array}{r}\text { Periodos de muestreo } \\
\text { LOCALIDAD - DENTRO } 2 \\
\text { Pereña (SA) PLATOS } \\
\text { Año } 2006\end{array}$} & \multicolumn{2}{|c|}{1} & \multicolumn{2}{|c|}{2} & \multicolumn{2}{|c|}{3} & \multicolumn{2}{|c|}{4} & & & \\
\hline & \multicolumn{2}{|c|}{ 15-Jun } & \multicolumn{2}{|c|}{ 15-Jul } & \multicolumn{2}{|c|}{ 15-Agos } & \multicolumn{2}{|c|}{ 15-Sep } & \multicolumn{2}{|c|}{ Totales } & \multirow{2}{*}{$\Sigma$} \\
\hline & $\mathbf{M}$ & $\mathbf{H}$ & M & $\mathbf{H}$ & M & $\mathbf{H}$ & $\mathbf{M}$ & $\mathbf{H}$ & M & $\mathbf{H}$ & \\
\hline \multicolumn{12}{|l|}{ SPHECIDAE } \\
\hline \multicolumn{12}{|l|}{ SPHECINAE } \\
\hline \multicolumn{12}{|l|}{ PRIONYCHINI } \\
\hline Prionyx kirbii (Van der Linden, 1827) & $\ldots$ & $\ldots$ & 1 & 2 & 1 & $\cdots$ & $\ldots$ & 1 & 2 & 3 & 5 \\
\hline \multicolumn{12}{|l|}{ AMMOPHILINAE } \\
\hline \multicolumn{12}{|l|}{ AMMOPHILINI } \\
\hline Ammophila heydeni Dahlbom, 1845 & $\ldots$ & $\ldots$ & $\ldots$ & $\ldots$ & 1 & $\ldots$ & $\ldots$ & $\ldots$ & 1 & 0 & 1 \\
\hline \multicolumn{12}{|l|}{ CRABRONIDAE } \\
\hline \multicolumn{12}{|l|}{ PEMPHREDONINAE } \\
\hline \multicolumn{12}{|l|}{ PEMPHREDONINI } \\
\hline Diodontus insidiosus Spooner, 1938 & $\ldots$ & 2 & $\ldots$ & $\ldots$ & $\ldots$ & 1 & $\ldots$ & $\ldots$ & 0 & 3 & 3 \\
\hline ASTATINAE & & & & & & & & & & & \\
\hline ASTATINI & & & & & & & & & & & \\
\hline Astata cobosi Giner Marí, 1946 & $\ldots$ & $\ldots$ & $\ldots$ & $\ldots$ & $\ldots$ & 1 & $\ldots$ & $\ldots$ & 0 & 1 & 1 \\
\hline CRABRONINAE & & & & & & & & & & & \\
\hline LARRINI & & & & & & & & & & & \\
\hline Liris niger (Fabricius, 1775) & $\ldots$ & $\ldots$ & $\ldots$ & $\ldots$ & $\ldots$ & 1 & 2 & 1 & 2 & 2 & 4 \\
\hline Larropsis punctulata (Kohl, 1884) & $\cdots$ & $\ldots$ & $\cdots$ & $\cdots$ & $\ldots$ & $\cdots$ & $\ldots$ & 1 & 0 & 1 & 1 \\
\hline Tachytes panzeri (Dufour, 1841) & $\ldots$ & $\ldots$ & 2 & $\ldots$ & $\ldots$ & $\ldots$ & $\ldots$ & $\ldots$ & 2 & 0 & 2 \\
\hline Tachysphex incertus (Radoszkowski, 1877) & $\ldots$ & $\ldots$ & $\ldots$ & 1 & $\ldots$ & $\ldots$ & $\ldots$ & $\ldots$ & 0 & 1 & 1 \\
\hline Tachysphex mediterraneus Kohl, 1883 & $\ldots$ & $\ldots$ & $\ldots$ & $\ldots$ & $\ldots$ & 2 & $\ldots$ & $\ldots$ & 0 & 2 & 2 \\
\hline Tachysphex nitidior Beaumont, 1940 & $\ldots$ & $\ldots$ & $\ldots$ & $\ldots$ & $\ldots$ & 2 & $\ldots$ & 1 & 0 & 3 & 3 \\
\hline Tachysphex obscuripennis (Schenck, 1857) & $\cdots$ & $\ldots$ & $\cdots$ & $\ldots$ & $\ldots$ & 1 & $\ldots$ & 2 & 0 & 3 & 3 \\
\hline Tachysphex tarsinus (Lepeletier, 1845) & $\ldots$ & $\ldots$ & $\ldots$ & $\ldots$ & $\ldots$ & 1 & $\ldots$ & $\ldots$ & 0 & 1 & 1 \\
\hline MISCOPHINI & & & & & & & & & & & \\
\hline Solierella compedita (Piccioli, 1869) & 1 & $\ldots$ & 4 & 18 & 4 & 25 & $\ldots$ & 3 & 9 & 46 & 55 \\
\hline Solierella pisonoides (Saunders, 1873) & $\ldots$ & $\ldots$ & $\ldots$ & $\ldots$ & 1 & 2 & $\ldots$ & 2 & 1 & 4 & 5 \\
\hline Solierella seabrai Andrade, 1950 & $\ldots$ & $\ldots$ & $\ldots$ & $\ldots$ & 1 & $\ldots$ & $\ldots$ & $\ldots$ & 1 & 0 & 1 \\
\hline Miscophus bicolor Jurine, 1807 & 1 & $\ldots$ & $\ldots$ & $\ldots$ & $\ldots$ & $\ldots$ & $\ldots$ & $\ldots$ & 1 & 0 & 1 \\
\hline TRYPOXYLINI & & & & & & & & & & & \\
\hline Pison atrum (Spinola, 1808) & $\ldots$ & $\ldots$ & $\ldots$ & $\ldots$ & $\ldots$ & 1 & $\ldots$ & $\cdots$ & 0 & 1 & 1 \\
\hline Trypoxylon attenuatum $\mathrm{F}$. Smith, 1851 & $\ldots$ & $\ldots$ & $\ldots$ & $\ldots$ & $\ldots$ & $\ldots$ & $\ldots$ & 1 & 0 & 1 & 1 \\
\hline Trypoxylon scutatum Chevrier, 1867 & $\cdots$ & $\ldots$ & $\ldots$ & 3 & $\ldots$ & 8 & $\ldots$ & 4 & 0 & 15 & 15 \\
\hline CRABRONINI & & & & & & & & & & & \\
\hline Ectemnius crassicornis (Spinola, 1808) & $\ldots$ & $\ldots$ & $\ldots$ & $\ldots$ & $\cdots$ & $\ldots$ & $\ldots$ & 1 & 0 & 1 & 1 \\
\hline BEMBICINAE & & & & & & & & & & & \\
\hline NYSSONINI & & & & & & & & & & & \\
\hline Nysson dusmeti Mercet, 1909 & $\ldots$ & $\ldots$ & $\ldots$ & $\ldots$ & $\ldots$ & $\ldots$ & 2 & 1 & 2 & 1 & 3 \\
\hline Nysson maculosus (Gmelin, 1790) & $\ldots$ & $\ldots$ & $\ldots$ & $\ldots$ & $\ldots$ & 1 & $\ldots$ & $\ldots$ & 0 & 1 & 1 \\
\hline BEMBICINI & & & & & & & & & & & \\
\hline Harpactus alvaroi Gayubo, 1992 & $\ldots$ & $\ldots$ & $\ldots$ & $\ldots$ & $\ldots$ & 1 & $\ldots$ & 1 & 0 & 2 & 2 \\
\hline Bembecinus pulchelus (Mercet, 1906) & $\ldots$ & 1 & $\ldots$ & $\ldots$ & $\ldots$ & $\ldots$ & $\ldots$ & $\ldots$ & 0 & 1 & 1 \\
\hline Bembix zonata Klug, 1835 & $\ldots$ & $\ldots$ & 1 & $\ldots$ & $\ldots$ & $\ldots$ & $\ldots$ & $\ldots$ & 1 & 0 & 1 \\
\hline Subtotales & 2 & 3 & 8 & 24 & 8 & 47 & 4 & 19 & 22 & 93 & \\
\hline Total de Ejemplares & & & & & & & & & & & 115 \\
\hline Total de Especies & & & & & & & & & & & 25 \\
\hline
\end{tabular}




\begin{tabular}{|c|c|c|c|c|c|c|c|c|c|c|c|}
\hline \multirow{3}{*}{\begin{tabular}{|} 
Periodos de muestreo \\
LOCALIDAD 1F - DENTRO 3 \\
Pereña (SA) PLATOS \\
Año 2006 \\
\end{tabular}} & \multicolumn{2}{|c|}{1} & \multicolumn{2}{|c|}{2} & \multicolumn{2}{|c|}{3} & \multicolumn{2}{|c|}{4} & & & \\
\hline & \multicolumn{2}{|c|}{ 15-Jun } & \multicolumn{2}{|c|}{ 15-Jul } & \multicolumn{2}{|c|}{ 15-Agos } & \multicolumn{2}{|c|}{ 15-Sep } & \multicolumn{2}{|c|}{ Totales } & \multirow{2}{*}{$\Sigma$} \\
\hline & $\mathbf{M}$ & $\mathbf{H}$ & M & $\mathbf{H}$ & $\mathbf{M}$ & $\mathbf{H}$ & $\mathbf{M}$ & $\mathbf{H}$ & M & $\mathbf{H}$ & \\
\hline \multicolumn{12}{|l|}{ SPHECIDAE } \\
\hline \multicolumn{12}{|l|}{ AMMOPHILINAE } \\
\hline \multicolumn{12}{|l|}{ AMMOPHILINI } \\
\hline Ammophila heydeni Dahlbom, 1845 & $\ldots$ & $\ldots$ & 1 & 2 & $\ldots$ & $\ldots$ & $\ldots$ & $\ldots$ & 1 & 2 & 3 \\
\hline \multicolumn{12}{|l|}{ CRABRONIDAE } \\
\hline \multicolumn{12}{|l|}{ PEMPHREDONINAE } \\
\hline \multicolumn{12}{|l|}{ PEMPHREDONINI } \\
\hline Diodontus insidiosus Spooner, 1938 & $\ldots$ & $\ldots$ & & 2 & $\ldots$ & $\ldots$ & $\ldots$ & $\ldots$ & 0 & 2 & 2 \\
\hline \multicolumn{12}{|l|}{ ASTATINAE } \\
\hline \multicolumn{12}{|l|}{ ASTATINI } \\
\hline Astata cobosi Giner Marí, 1946 & $\ldots$ & $\ldots$ & $\ldots$ & $\ldots$ & 1 & $\ldots$ & 1 & $\ldots$ & 2 & 0 & 2 \\
\hline \multicolumn{12}{|l|}{ CRABRONINAE } \\
\hline \multicolumn{12}{|l|}{ LARRINI } \\
\hline Liris niger (Fabricius, 1775) & $\ldots$ & $\ldots$ & $\ldots$ & $\ldots$ & $\ldots$ & $\ldots$ & 2 & $\ldots$ & 2 & 0 & 2 \\
\hline Larropsis punctulata (Kohl, 1884) & $\ldots$ & $\ldots$ & $\ldots$ & $\ldots$ & $\ldots$ & 1 & 1 & $\ldots$ & 1 & 1 & 2 \\
\hline Tachytes panzeri (Dufour, 1841) & $\ldots$ & $\cdots$ & 1 & $\ldots$ & $\cdots$ & $\ldots$ & $\cdots$ & $\ldots$ & 1 & 0 & 1 \\
\hline Tachysphex brevipennis Mercet, 1909 & $\ldots$ & $\ldots$ & $\ldots$ & $\ldots$ & $\ldots$ & 1 & $\ldots$ & $\ldots$ & 0 & 1 & 1 \\
\hline Tachysphex nitidior Beaumont, 1940 & $\ldots$ & $\ldots$ & $\ldots$ & 3 & $\ldots$ & $\ldots$ & $\ldots$ & $\ldots$ & 0 & 3 & 3 \\
\hline MISCOPHINI & & & & & & & & & & & \\
\hline Solierella compedita (Piccioli, 1869) & $\ldots$ & $\ldots$ & 7 & 11 & 2 & 6 & 1 & $\ldots$ & 10 & 17 & 27 \\
\hline Solierella pisonoides (Saunders, 1873) & $\ldots$ & $\ldots$ & 1 & $\ldots$ & 1 & $\ldots$ & $\ldots$ & $\ldots$ & 2 & 0 & 2 \\
\hline Solierella seabrai Andrade, 1950 & $\ldots$ & $\ldots$ & 1 & 2 & $\ldots$ & 2 & $\ldots$ & $\ldots$ & 1 & 4 & 5 \\
\hline Miscophus eatoni Saunders, 1903 & $\ldots$ & $\ldots$ & $\ldots$ & $\ldots$ & $\ldots$ & $\ldots$ & 1 & $\ldots$ & 1 & 0 & 1 \\
\hline Miscophus nicolai Ferton, 1896 & 1 & $\ldots$ & & $\ldots$ & $\ldots$ & 1 & 1 & $\ldots$ & 2 & 1 & 3 \\
\hline TRYPOXYLINI & & & & & & & & & & & \\
\hline Trypoxylon attenuatum F. Smith, 1851 & $\cdots$ & $\ldots$ & $\ldots$ & $\ldots$ & $\cdots$ & $\ldots$ & 1 & 3 & 1 & 3 & 4 \\
\hline Trypoxylon scutatum Chevrier, 1867 & $\ldots$ & $\ldots$ & $\ldots$ & 9 & $\ldots$ & 8 & $\ldots$ & 2 & 0 & 19 & 19 \\
\hline OXYBELINI & & & & & & & & & & & \\
\hline Oxybelus quattuordecimnotatus Jurine, 1807 & $\ldots$ & $\ldots$ & 1 & $\ldots$ & $\ldots$ & $\ldots$ & $\ldots$ & $\ldots$ & 1 & 0 & 1 \\
\hline MELLININAE & & & & & & & & & & & \\
\hline MELLININI & & & & & & & & & & & \\
\hline Mellinus arvensis (Linnaeus, 1758) & $\ldots$ & $\ldots$ & $\ldots$ & $\ldots$ & $\ldots$ & $\ldots$ & $\ldots$ & 2 & 0 & 2 & 2 \\
\hline BEMBICINAE & & & & & & & & & & & \\
\hline BEMBICINI & & & & & & & & & & & \\
\hline Harpactus formosus (Jurine, 1807) & $\ldots$ & $\ldots$ & 1 & $\ldots$ & $\ldots$ & $\ldots$ & 1 & $\ldots$ & 2 & 0 & 2 \\
\hline Bembecinus pulchelus (Mercet, 1906) & $\ldots$ & $\ldots$ & $\ldots$ & 3 & $\ldots$ & $\ldots$ & $\ldots$ & $\ldots$ & 0 & 3 & 3 \\
\hline PHILANTHINAE & & & & & & & & & & & \\
\hline CERCERINI & & & & & & & & & & & \\
\hline Cerceris sabulosa (Panzer, 1799) & $\ldots$ & $\ldots$ & $\ldots$ & 1 & $\ldots$ & $\ldots$ & $\ldots$ & $\ldots$ & 0 & 1 & 1 \\
\hline Subtotales & 1 & $\mathbf{0}$ & 13 & 33 & 4 & 19 & 9 & 7 & 27 & 59 & \\
\hline Total de Ejemplares & & & & & & 3 & & & & & 86 \\
\hline Total de Especies & & & & & & & & & & & 20 \\
\hline
\end{tabular}




\begin{tabular}{|c|c|c|c|c|c|c|c|c|c|c|c|c|c|c|c|c|c|c|c|}
\hline \multirow{3}{*}{$\begin{array}{r}\text { Periodos de muestreo } \\
\text { LOCALIDAD 1F - DENTRO } 1 \\
\text { Pereña (SA) Trampa Malaise } \\
\text { Año 2007 }\end{array}$} & \multicolumn{2}{|c|}{1} & \multicolumn{2}{|c|}{2} & \multicolumn{2}{|c|}{3} & \multicolumn{2}{|c|}{4} & \multicolumn{2}{|c|}{5} & \multicolumn{2}{|c|}{6} & \multicolumn{2}{|c|}{7} & \multicolumn{2}{|c|}{8} & & & \\
\hline & \multicolumn{2}{|c|}{$1-15 \mathrm{VI}$} & \multicolumn{2}{|c|}{$16-30 \mathrm{VI}$} & \multicolumn{2}{|c|}{ 1-15 VII } & \multicolumn{2}{|c|}{ 16-31 VII } & \multicolumn{2}{|c|}{ 1-15 VIII } & $16-$ & VIII & $1-15$ & IX & $16-3$ & $0 \mathrm{IX}$ & & ales & \\
\hline & $\mathbf{M}$ & & $\mathbf{M}$ & $\mathbf{H}$ & $\mathbf{M}$ & $\mathbf{H}$ & $\mathbf{M}$ & $\mathbf{H}$ & $\mathbf{M}$ & & $\mathbf{M}$ & $\mathbf{H}$ & $\mathbf{M}$ & & $\mathbf{M}$ & & $\mathbf{M}$ & $\mathbf{H}$ & \\
\hline SPHECIDAE & & & & & & & & & & & & & & & & & & & \\
\hline SPHECINAE & & & & & & & & & & & & & & & & & & & \\
\hline SPHECINI & & & & & & & & & & & & & & & & & & & \\
\hline Sphex funerarius Gussakovskij, 1934 & $\ldots$ & & 1 & $\ldots$ & $\ldots$ & 1 & $\ldots$ & $\ldots$ & 1 & $\ldots$ & $\ldots$ & $\ldots$ & $\ldots$ & 2 & $\ldots$ & $\ldots$ & 2 & 3 & 5 \\
\hline Sphex leuconotus Brullé, 1833 & $\ldots$ & $\cdots$ & $\ldots$ & 1 & 1 & $\ldots$ & $\ldots$ & $\ldots$ & $\ldots$ & 1 & $\cdots$ & $\ldots$ & & $\ldots$ & $\ldots$ & $\ldots$ & 1 & 2 & 3 \\
\hline PRIONYCHINI & & & & & & & & & & & & & & & & & & & \\
\hline Palmodes occitanicus ibericus (Roth, 1963) & $\ldots$ & $\ldots$ & $\ldots$ & $\ldots$ & $\ldots$ & $\ldots$ & $\ldots$ & 1 & $\ldots$ & $\ldots$ & $\ldots$ & 1 & $\ldots$ & $\ldots$ & $\ldots$ & $\ldots$ & 0 & 2 & 2 \\
\hline Chilosphex argyrius (Brullé, 1833) & $\ldots$ & $\ldots$ & $\ldots$ & 1 & $\ldots$ & 2 & $\ldots$ & $\ldots$ & $\ldots$ & $\ldots$ & $\ldots$ & $\ldots$ & $\ldots$ & $\ldots$ & $\ldots$ & $\ldots$ & 0 & 3 & 3 \\
\hline Prionyx kirbii (Van der Linden, 1827) & $\ldots$ & $\ldots$ & $\ldots$ & $\ldots$ & $\ldots$ & $\ldots$ & $\ldots$ & $\ldots$ & $\ldots$ & $\ldots$ & $\ldots$ & 1 & $\ldots$ & $\ldots$ & $\ldots$ & $\ldots$ & 0 & 1 & 1 \\
\hline AMMOPHILINAE & & & & & & & & & & & & & & & & & & & \\
\hline AMMOPHILINI & & & & & & & & & & & & & & & & & & & \\
\hline Ammophila campestris Latreille, 1809 & 2 & 1 & $\ldots$ & $\ldots$ & $\ldots$ & 1 & $\ldots$ & $\ldots$ & $\ldots$ & $\ldots$ & $\ldots$ & $\ldots$ & $\ldots$ & $\ldots$ & $\ldots$ & $\ldots$ & 2 & 2 & 4 \\
\hline Ammophila heydeni Dahlbom, 1845 & 1 & 1 & 3 & $\ldots$ & 1 & 1 & $\ldots$ & $\ldots$ & $\ldots$ & 1 & $\ldots$ & 1 & $\ldots$ & 1 & $\ldots$ & $\ldots$ & 5 & 5 & 10 \\
\hline Ammophila Aff. rubriventris & $\ldots$ & $\ldots$ & $\ldots$ & $\ldots$ & $\ldots$ & $\ldots$ & $\ldots$ & $\ldots$ & $\ldots$ & $\ldots$ & 1 & $\ldots$ & $\ldots$ & $\ldots$ & $\ldots$ & $\ldots$ & 1 & 0 & 1 \\
\hline CRABRONIDAE & & & & & & & & & & & & & & & & & & & \\
\hline PEMPHREDONINAE & & & & & & & & & & & & & & & & & & & \\
\hline PSENINI & & & & & & & & & & & & & & & & & & & \\
\hline Psenulus fuscipennis (Dahlbom, 1843) & $\ldots$ & 1 & $\ldots$ & 2 & $\ldots$ & 2 & $\ldots$ & 4 & $\ldots$ & 4 & $\ldots$ & 2 & $\ldots$ & $\ldots$ & $\ldots$ & $\ldots$ & 0 & 15 & 15 \\
\hline Mimesa grandii Maidl, 1933 & $\ldots$ & $\ldots$ & $\ldots$ & $\ldots$ & $\ldots$ & $\ldots$ & $\ldots$ & $\ldots$ & $\ldots$ & $\ldots$ & $\ldots$ & 1 & $\ldots$ & $\ldots$ & $\ldots$ & $\ldots$ & 0 & 1 & 1 \\
\hline PEMPHREDONINI & & & & & & & & & & & & & & & & & & & \\
\hline Diodontus insidiosus Spooner, 1938 & 1 & $\ldots$ & $\ldots$ & $\ldots$ & $\ldots$ & $\ldots$ & $\ldots$ & $\ldots$ & 3 & 1 & $\ldots$ & $\ldots$ & $\ldots$ & $\ldots$ & $\ldots$ & $\ldots$ & 4 & 1 & 5 \\
\hline Pemphredon mortifer Valkeila, 1972 & $\ldots$ & $\cdots$ & $\cdots$ & 1 & $\ldots$ & $\cdots$ & $\ldots$ & $\cdots$ & $\cdots$ & $\cdots$ & $\cdots$ & $\ldots$ & $\cdots$ & $\ldots$ & $\ldots$ & $\cdots$ & 0 & 1 & 1 \\
\hline Passaloecus gracilis (Curtis, 1834) & $\ldots$ & $\ldots$ & $\ldots$ & $\ldots$ & $\ldots$ & $\ldots$ & $\ldots$ & $\ldots$ & $\ldots$ & $\ldots$ & $\ldots$ & $\ldots$ & $\ldots$ & 2 & $\ldots$ & $\ldots$ & 0 & 2 & 2 \\
\hline Passaloecus pictus Ribaut, 1952 & $\ldots$ & $\ldots$ & $\ldots$ & $\ldots$ & $\ldots$ & 1 & $\ldots$ & 3 & $\ldots$ & 2 & $\ldots$ & 1 & $\ldots$ & $\ldots$ & $\ldots$ & 1 & 0 & 8 & 8 \\
\hline Ammoplanus ceballosi Giner Marí, 1943 & $\ldots$ & 2 & $\ldots$ & 2 & $\ldots$ & 2 & $\ldots$ & $\ldots$ & $\ldots$ & $\ldots$ & $\ldots$ & $\ldots$ & $\ldots$ & $\ldots$ & $\ldots$ & $\ldots$ & 0 & 6 & 6 \\
\hline ASTATINAE & & & & & & & & & & & & & & & & & & & \\
\hline ASTATINI & & & & & & & & & & & & & & & & & & & \\
\hline Astata cobosi Giner Marí, 1946 & $\ldots$ & $\ldots$ & $\ldots$ & $\ldots$ & $\ldots$ & $\ldots$ & $\ldots$ & $\ldots$ & $\ldots$ & $\ldots$ & $\ldots$ & $\ldots$ & $\ldots$ & 1 & $\ldots$ & $\ldots$ & 0 & 1 & 1 \\
\hline Dryudella tricolor (Van der Linden, 1829) & $\ldots$ & $\ldots$ & 1 & $\ldots$ & $\ldots$ & $\ldots$ & $\ldots$ & 1 & $\ldots$ & $\ldots$ & $\ldots$ & $\ldots$ & $\ldots$ & $\ldots$ & $\ldots$ & $\ldots$ & 1 & 1 & 2 \\
\hline CRABRONINAE & & & & & & & & & & & & & & & & & & & \\
\hline LARRINI & & & & & & & & & & & & & & & & & & & \\
\hline Liris niger (Fabricius, 1775) & $\ldots$ & $\ldots$ & $\ldots$ & $\ldots$ & $\ldots$ & $\ldots$ & $\ldots$ & $\ldots$ & $\ldots$ & $\ldots$ & 1 & $\ldots$ & $\ldots$ & $\ldots$ & $\ldots$ & $\ldots$ & 1 & 0 & 1 \\
\hline Tachytes panzeri (Dufour, 1841) & $\ldots$ & $\ldots$ & $\ldots$ & 1 & $\ldots$ & $\ldots$ & 1 & $\ldots$ & $\ldots$ & 1 & $\ldots$ & 1 & $\ldots$ & $\ldots$ & $\ldots$ & $\ldots$ & 1 & 3 & 4 \\
\hline Tachysphex adjunctus Kohl, 1885 & 1 & 1 & $\ldots$ & $\ldots$ & $\ldots$ & $\ldots$ & $\ldots$ & $\ldots$ & $\ldots$ & $\ldots$ & $\ldots$ & $\ldots$ & $\ldots$ & $\ldots$ & $\ldots$ & $\ldots$ & 1 & 1 & 2 \\
\hline Tachysphex fulvitarsis (A. Costa, 1867) & $\cdots$ & $\ldots$ & $\ldots$ & $\ldots$ & $\ldots$ & $\ldots$ & $\ldots$ & 3 & $\ldots$ & 3 & $\ldots$ & 1 & $\ldots$ & $\ldots$ & $\ldots$ & $\ldots$ & 0 & 7 & 7 \\
\hline Tachysphex incertus (Radoszkowski, 1877) & $\ldots$ & $\ldots$ & $\ldots$ & $\ldots$ & 1 & $\ldots$ & 1 & 2 & 3 & 4 & 2 & $\ldots$ & $\ldots$ & $\ldots$ & $\ldots$ & $\ldots$ & 7 & 6 & 13 \\
\hline Tachysphex nitidior Beaumont, 1940 & $\ldots$ & $\ldots$ & $\ldots$ & $\ldots$ & $\ldots$ & $\ldots$ & $\ldots$ & $\ldots$ & $\ldots$ & 1 & $\ldots$ & $\ldots$ & $\ldots$ & $\ldots$ & $\ldots$ & $\ldots$ & 0 & 1 & 1 \\
\hline Tachysphex obscuripennis (Schenck, 1857) & $\ldots$ & $\ldots$ & $\ldots$ & $\ldots$ & $\ldots$ & $\cdots$ & $\ldots$ & $\ldots$ & $\ldots$ & 1 & $\ldots$ & $\ldots$ & $\ldots$ & $\ldots$ & $\ldots$ & 1 & 0 & 2 & 2 \\
\hline Tachysphex panzeri (Van der Linden, 1829) & $\cdots$ & $\ldots$ & $\cdots$ & $\ldots$ & $\ldots$ & $\cdots$ & $\ldots$ & $\ldots$ & $\ldots$ & 1 & $\ldots$ & $\ldots$ & $\ldots$ & $\ldots$ & $\ldots$ & $\ldots$ & 0 & 1 & 1 \\
\hline Tachysphex pompiliformis (Panzer, 1805) & $\ldots$ & $\ldots$ & 1 & $\ldots$ & $\ldots$ & $\ldots$ & $\ldots$ & $\ldots$ & $\ldots$ & $\ldots$ & $\ldots$ & $\ldots$ & $\ldots$ & $\ldots$ & $\ldots$ & $\ldots$ & 1 & 0 & 1 \\
\hline Tachysphex pseudopanzeri Beaumont, 1955 & $\ldots$ & $\ldots$ & $\ldots$ & $\ldots$ & $\ldots$ & $\ldots$ & $\ldots$ & $\ldots$ & $\ldots$ & 1 & $\ldots$ & 1 & $\ldots$ & $\ldots$ & $\ldots$ & $\ldots$ & 0 & 2 & 2 \\
\hline MISCOPHINI & & & & & & & & & & & & & & & & & & & \\
\hline Solierella compedita (Piccioli, 1869) & $\ldots$ & $\ldots$ & $\ldots$ & $\ldots$ & $\ldots$ & 1 & 1 & 1 & 2 & 1 & 1 & 3 & 1 & 1 & $\ldots$ & 2 & 5 & 9 & 14 \\
\hline Miscophus eatoni Saunders, 1903 & $\ldots$ & $\ldots$ & $\ldots$ & $\ldots$ & $\ldots$ & $\ldots$ & $\ldots$ & 1 & $\ldots$ & $\ldots$ & $\ldots$ & $\ldots$ & $\ldots$ & $\ldots$ & $\ldots$ & $\ldots$ & 0 & 1 & 1 \\
\hline TRYPOXYLINI & & & & & & & & & & & & & & & & & & & \\
\hline Trypoxylon attenuatum F. Smith, 1851 & $\ldots$ & $\ldots$ & $\ldots$ & $\ldots$ & $\ldots$ & $\ldots$ & 1 & 3 & 1 & $\ldots$ & $\ldots$ & 4 & 3 & 6 & $\ldots$ & 4 & 5 & 17 & 22 \\
\hline Trypoxylon clavicerum Lepeletier \& Serville, 1828 & $\cdots$ & $\cdots$ & $\ldots$ & $\ldots$ & $\ldots$ & $\ldots$ & $\ldots$ & $\ldots$ & $\ldots$ & 2 & $\ldots$ & $\cdots$ & $\ldots$ & $\ldots$ & $\ldots$ & $\ldots$ & 0 & 2 & 2 \\
\hline Trypoxylon scutatum Chevrier, 1867 & $\ldots$ & 1 & $\ldots$ & $\ldots$ & $\ldots$ & 1 & $\ldots$ & 3 & 2 & 16 & $\ldots$ & 14 & $\ldots$ & 22 & $\ldots$ & 1 & 2 & 58 & 60 \\
\hline
\end{tabular}




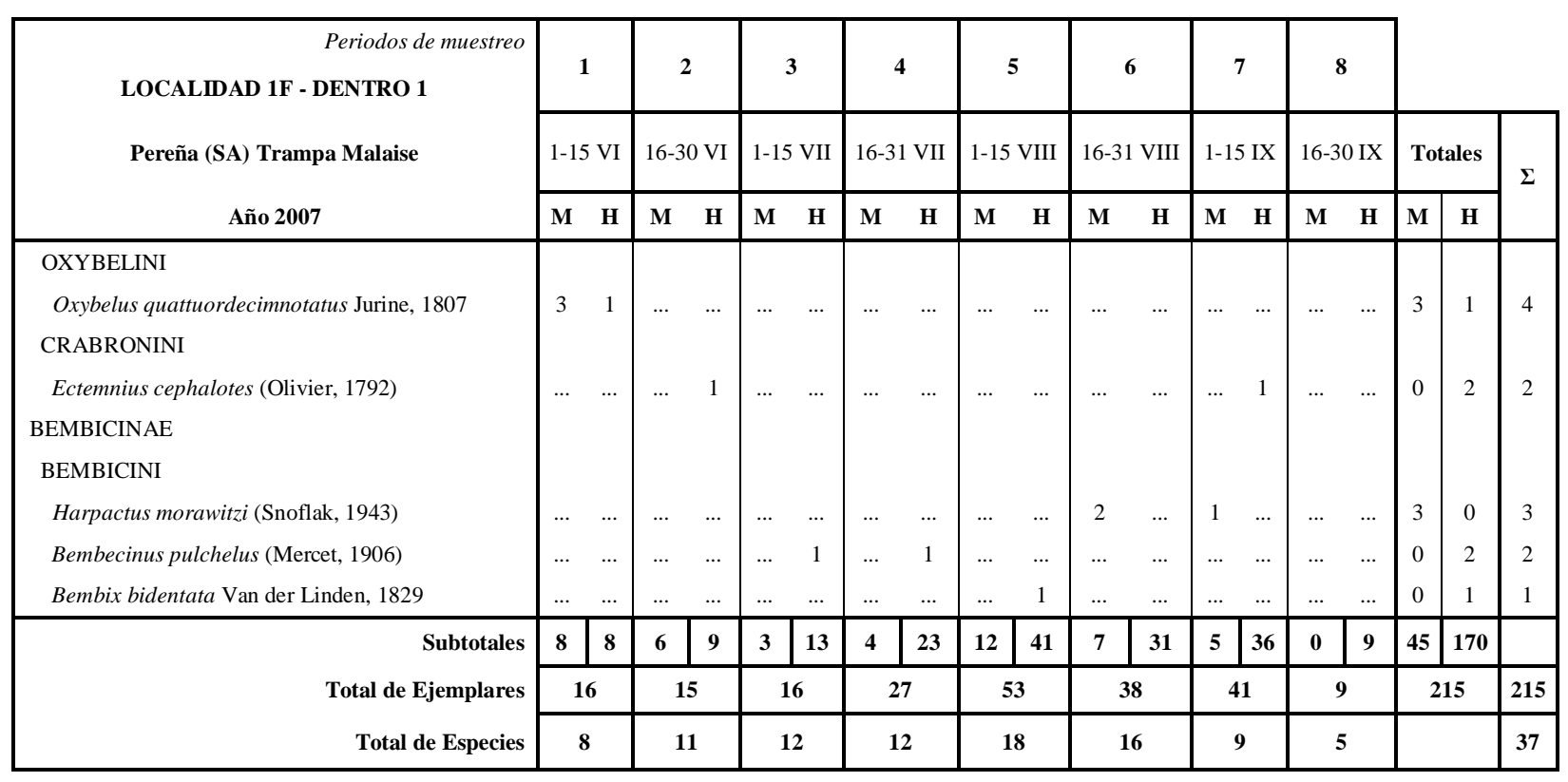




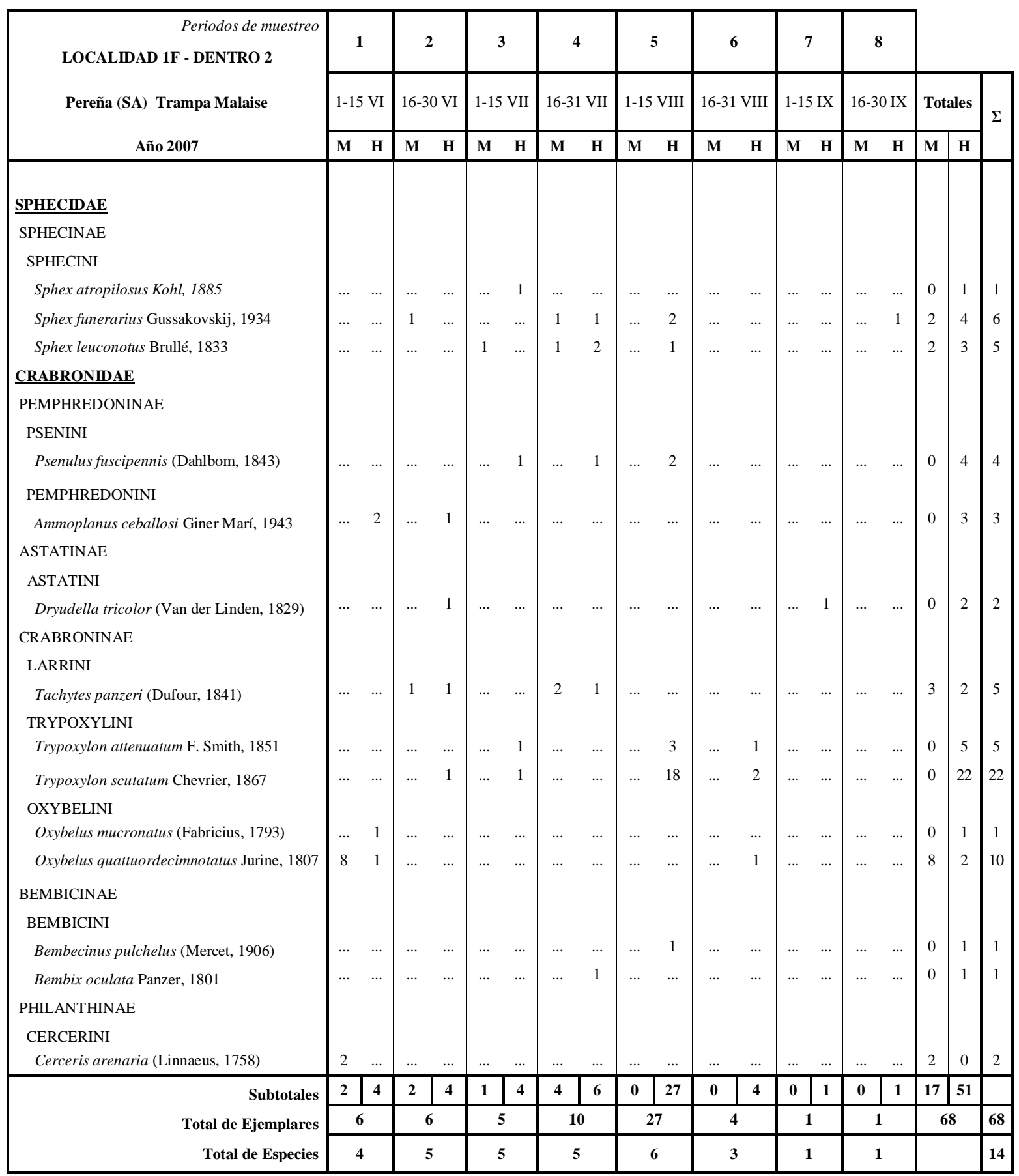




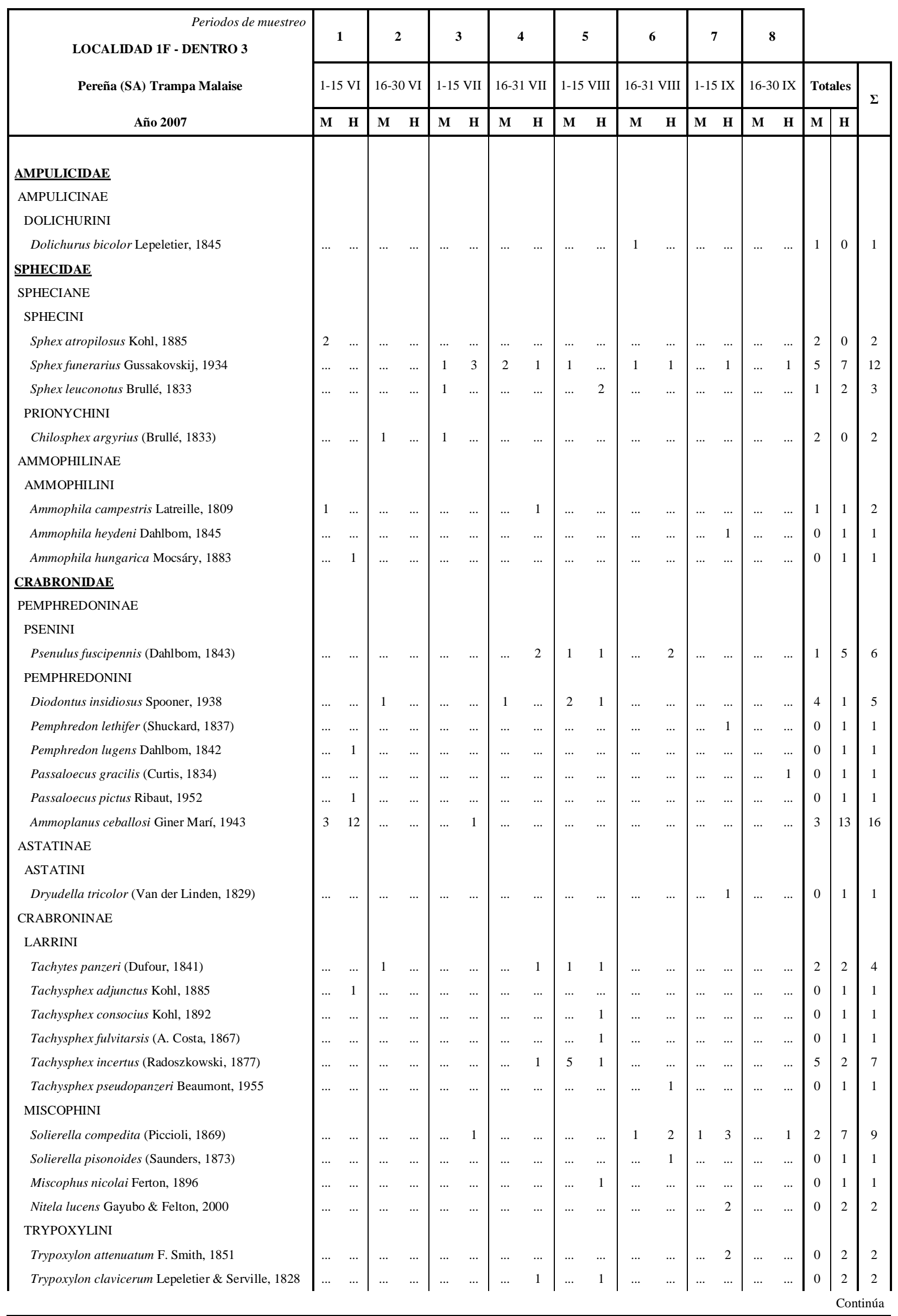




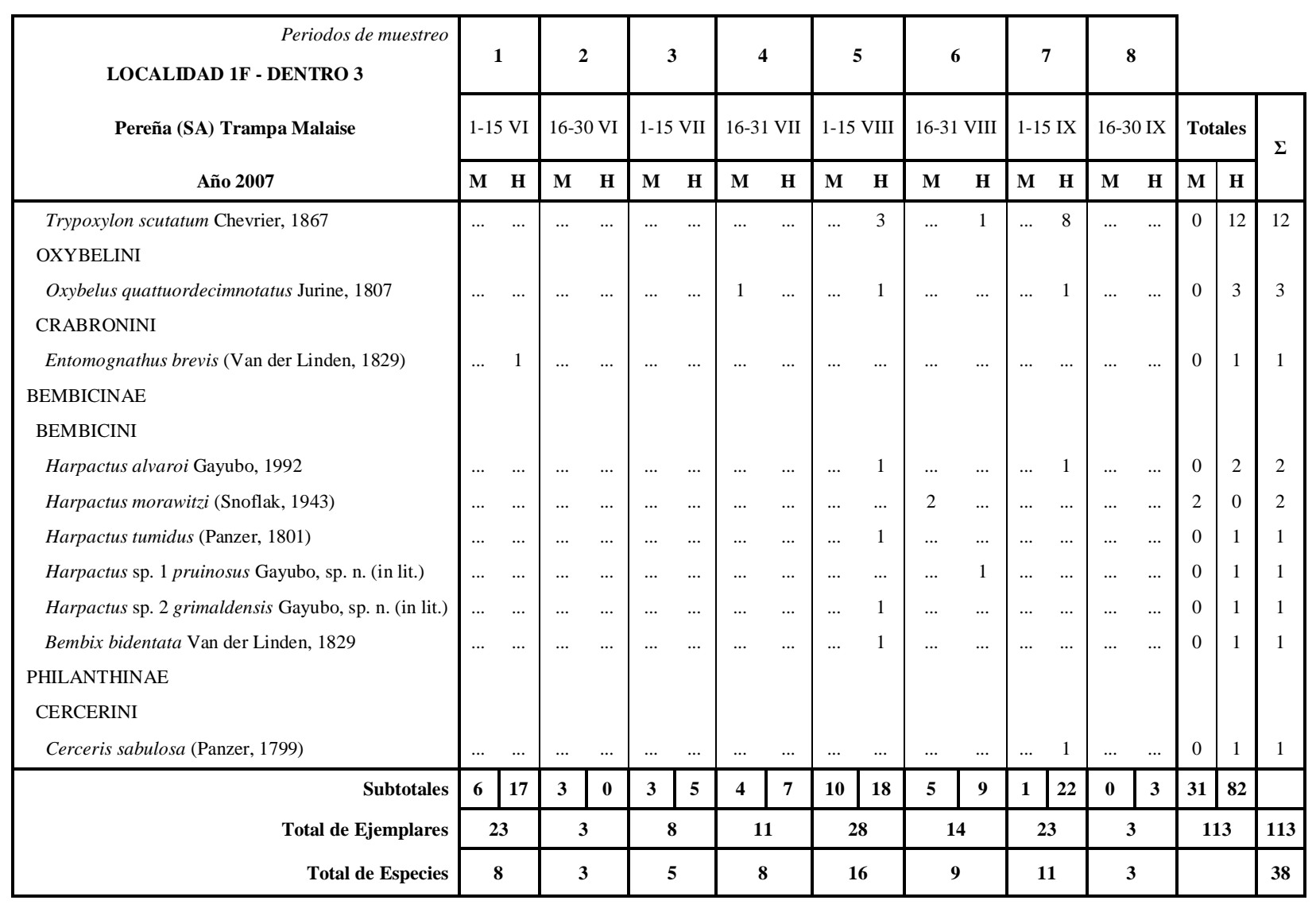




\begin{tabular}{|c|c|c|c|c|c|c|c|c|c|c|c|}
\hline \multirow{3}{*}{$\begin{array}{r}\text { Periodos de muestreo } \\
\text { LOCALIDAD 1F - DENTRO } 1 \\
\text { Pereña (SA) PLATOS } \\
\text { Año 2007 }\end{array}$} & \multicolumn{2}{|c|}{1} & \multicolumn{2}{|c|}{2} & \multicolumn{2}{|c|}{3} & \multicolumn{2}{|c|}{4} & & & \\
\hline & \multicolumn{2}{|c|}{ 15-Jun } & \multicolumn{2}{|c|}{ 15-Jul } & \multicolumn{2}{|c|}{ 15-Agos } & \multicolumn{2}{|c|}{ 15-Sep } & \multicolumn{2}{|c|}{ Totales } & \multirow{2}{*}{$\Sigma$} \\
\hline & & & M & H & M & H & M & $\mathbf{H}$ & M & $\mathbf{H}$ & \\
\hline \multicolumn{12}{|l|}{ CRABRONIDAE } \\
\hline \multicolumn{12}{|l|}{ PEMPHREDONINAE } \\
\hline \multicolumn{12}{|l|}{ PEMPHREDONINI } \\
\hline Diodontus insidiosus Spooner, 1938 & $\ldots$ & $\ldots$ & ... & 1 & $\ldots$ & $\ldots$ & $\ldots$ & $\ldots$ & 0 & 1 & 1 \\
\hline \multicolumn{12}{|l|}{ ASTATINAE } \\
\hline \multicolumn{12}{|l|}{ ASTATINI } \\
\hline Dryudella tricolor (Van der Linden, 1829) & & $\ldots$ & & $\ldots$ & & 1 & & & 0 & 1 & 1 \\
\hline \multicolumn{12}{|l|}{ CRABRONINAE } \\
\hline \multicolumn{12}{|l|}{ LARRINI } \\
\hline Tachysphex fulvitarsis (A. Costa, 1867) & $\ldots$ & $\ldots$ & 1 & $\ldots$ & $\ldots$ & $\cdots$ & $\ldots$ & $\ldots$ & 1 & 0 & 1 \\
\hline Tachysphex incertus (Radoszkowski, 1877) & $\ldots$ & $\ldots$ & 2 & $\ldots$ & $\ldots$ & $\ldots$ & $\ldots$ & $\ldots$ & 2 & 0 & 2 \\
\hline \multicolumn{12}{|l|}{ MISCOPHINI } \\
\hline Solierella compedita (Piccioli, 1869) & $\ldots$ & $\ldots$ & 1 & 1 & 1 & 1 & 9 & 2 & 11 & 4 & 15 \\
\hline Solierella pisonoides (Saunders, 1873) & & $\ldots$ & 5 & $\ldots$ & 3 & $\ldots$ & & & 8 & 0 & 8 \\
\hline Solierella seabrai Andrade, 1950 & $\ldots$ & $\ldots$ & $\ldots$ & 1 & $\ldots$ & 4 & $\ldots$ & $\ldots$ & 0 & 5 & 5 \\
\hline Miscophus nicolai Ferton, 1896 & $\ldots$ & $\ldots$ & $\ldots$ & $\ldots$ & $\ldots$ & 1 & $\ldots$ & $\ldots$ & 0 & 1 & 1 \\
\hline \multicolumn{12}{|l|}{ TRYPOXYLINI } \\
\hline Trypoxylon attenuatum F. Smith, 1851 & $\ldots$ & $\ldots$ & $\ldots$ & $\ldots$ & $\ldots$ & $\ldots$ & 1 & 12 & 1 & 12 & 13 \\
\hline Trypoxylon scutatum Chevrier, 1867 & $\ldots$ & $\ldots$ & $\ldots$ & 1 & $\ldots$ & 1 & 1 & 2 & 1 & 4 & 5 \\
\hline \multicolumn{12}{|l|}{ BEMBICINAE } \\
\hline \multicolumn{12}{|l|}{ NYSSONINI } \\
\hline Nysson monachus Mercet, 1909 & $\ldots$ & $\ldots$ & $\ldots$ & 1 & $\ldots$ & $\ldots$ & $\ldots$ & $\ldots$ & 0 & 1 & 1 \\
\hline \multicolumn{12}{|l|}{ BEMBICINI } \\
\hline Harpactus alvaroi Gayubo, 1992 & $\cdots$ & $\ldots$ & $\ldots$ & $\ldots$ & $\ldots$ & $\ldots$ & $\ldots$ & 1 & 0 & 1 & 1 \\
\hline Bembecinus pulchelus (Mercet, 1906) & $\ldots$ & $\ldots$ & $\ldots$ & 3 & $\ldots$ & 1 & $\ldots$ & $\ldots$ & 0 & 4 & 4 \\
\hline \multirow{2}{*}{$\begin{array}{r}\text { Subtotales } \\
\text { Total de Ejemplares }\end{array}$} & $\mathbf{0}$ & $\mathbf{0}$ & 9 & 8 & 4 & 9 & 11 & 17 & 24 & 34 & 58 \\
\hline & \multicolumn{2}{|c|}{$\mathbf{0}$} & \multicolumn{2}{|c|}{17} & \multicolumn{2}{|c|}{13} & \multicolumn{2}{|c|}{28} & & & 116 \\
\hline Total de Especies & & & & & & & & & & & 13 \\
\hline
\end{tabular}




\begin{tabular}{|c|c|c|c|c|c|c|c|c|c|c|c|}
\hline \multirow{3}{*}{\begin{tabular}{|c|} 
Periodos de muestreo \\
LOCALIDAD 1F - DENTRO 2 \\
Pereña (SA) PLATOS \\
Año 2007 \\
\end{tabular}} & \multicolumn{2}{|c|}{1} & \multicolumn{2}{|c|}{2} & \multicolumn{2}{|c|}{3} & \multicolumn{2}{|c|}{4} & & & \\
\hline & \multicolumn{2}{|c|}{ 15-Jun } & \multicolumn{2}{|c|}{ 15-Jul } & \multicolumn{2}{|c|}{ 15-Agos } & \multicolumn{2}{|c|}{ 15-Sep } & \multicolumn{2}{|c|}{ Totales } & \multirow{2}{*}{$\Sigma$} \\
\hline & $\mathbf{M}$ & & $\mathbf{M}$ & & M & $\mathbf{H}$ & & $\mathbf{H}$ & $\mathbf{M}$ & $\mathbf{H}$ & \\
\hline \multicolumn{12}{|l|}{ SPHECIDAE } \\
\hline \multicolumn{12}{|l|}{ AMMOPHILINAE } \\
\hline \multicolumn{12}{|l|}{ AMMOPHILINI } \\
\hline Ammophila heydeni Dahlbom, 1845 & $\ldots$ & $\ldots$ & $\ldots$ & & $\ldots$ & 1 & $\ldots$ & $\ldots$ & 0 & 1 & 1 \\
\hline Ammophila laevicollis André, 1886 & $\ldots$ & $\ldots$ & $\ldots$ & $\ldots$ & 1 & $\ldots$ & $\ldots$ & $\ldots$ & 1 & 0 & 1 \\
\hline \multicolumn{12}{|l|}{ CRABRONIDAE } \\
\hline \multicolumn{12}{|l|}{ CRABRONINAE } \\
\hline \multicolumn{12}{|l|}{ MISCOPHINI } \\
\hline Solierella compedita (Piccioli, 1869) & $\ldots$ & $\ldots$ & 1 & 1 & 13 & 15 & 8 & 1 & 22 & 17 & 39 \\
\hline Solierella pisonoides (Saunders, 1873) & $\ldots$ & $\ldots$ & $\ldots$ & $\ldots$ & 1 & 2 & 1 & 1 & 2 & 3 & 5 \\
\hline \multicolumn{12}{|l|}{ TRYPOXYLINI } \\
\hline Trypoxylon attenuatum F. Smith, 1851 & $\ldots$ & $\ldots$ & $\ldots$ & $\ldots$ & $\ldots$ & 1 & 8 & 30 & 8 & 31 & 39 \\
\hline Trypoxylon minus Beaumont, 1945 & $\ldots$ & $\ldots$ & $\ldots$ & $\ldots$ & $\ldots$ & 1 & $\ldots$ & $\ldots$ & 0 & 1 & 1 \\
\hline Trypoxylon scutatum Chevrier, 1867 & $\ldots$ & $\ldots$ & $\ldots$ & $\ldots$ & 1 & 3 & 1 & 4 & 2 & 7 & 9 \\
\hline \multirow{2}{*}{$\begin{array}{r}\text { Subtotales } \\
\text { Total de Ejemplares }\end{array}$} & $\mathbf{0}$ & $\mathbf{0}$ & 1 & 1 & 16 & 23 & 18 & 36 & 35 & 60 & 95 \\
\hline & \multicolumn{2}{|c|}{$\mathbf{0}$} & \multicolumn{2}{|c|}{2} & \multicolumn{2}{|c|}{39} & \multicolumn{2}{|c|}{54} & \multicolumn{2}{|c|}{95} & 95 \\
\hline Total de Especies & \multicolumn{2}{|c|}{$\mathbf{0}$} & \multicolumn{2}{|c|}{1} & \multicolumn{2}{|c|}{7} & \multicolumn{2}{|c|}{4} & & & 7 \\
\hline
\end{tabular}




\begin{tabular}{|c|c|c|c|c|c|c|c|c|c|c|c|}
\hline \multirow{3}{*}{\begin{tabular}{|} 
Periodos de muestreo \\
LOCALIDAD 1F - DENTRO 3 \\
Pereña (SA) PLATOS \\
Año 2007
\end{tabular}} & \multicolumn{2}{|c|}{1} & \multicolumn{2}{|c|}{2} & \multicolumn{2}{|c|}{3} & \multicolumn{2}{|c|}{4} & & & \\
\hline & \multicolumn{2}{|c|}{ 15-Jun } & \multicolumn{2}{|c|}{ 15-Jul } & \multicolumn{2}{|c|}{ 15-Aug } & \multicolumn{2}{|c|}{ 15-Sep } & \multicolumn{2}{|c|}{ Totales } & \multirow{2}{*}{$\Sigma$} \\
\hline & M & $\mathbf{H}$ & $\mathbf{M}$ & $\mathbf{H}$ & $\mathbf{M}$ & $\mathbf{H}$ & M & $\mathbf{H}$ & $\mathbf{M}$ & $\mathbf{H}$ & \\
\hline \multicolumn{12}{|l|}{ CRABRONIDAE } \\
\hline \multicolumn{12}{|l|}{ PEMPHREDONINAE } \\
\hline \multicolumn{12}{|l|}{ PEMPHREDONINI } \\
\hline Diodontus insidiosus Spooner, 1938 & $\ldots$ & $\ldots$ & $\ldots$ & 1 & $\ldots$ & $\ldots$ & $\ldots$ & $\ldots$ & 0 & 1 & 1 \\
\hline \multicolumn{12}{|l|}{ CRABRONINAE } \\
\hline \multicolumn{12}{|l|}{ LARRINI } \\
\hline Tachysphex fulvitarsis (A. Costa, 1867) & $\ldots$ & $\ldots$ & $\cdots$ & $\ldots$ & 2 & $\ldots$ & $\ldots$ & $\ldots$ & 2 & 0 & 2 \\
\hline Tachysphex incertus (Radoszkowski, 1877) & $\ldots$ & $\ldots$ & $\ldots$ & $\ldots$ & 1 & $\ldots$ & $\ldots$ & $\ldots$ & 1 & 0 & 1 \\
\hline Tachysphex obscuripennis (Schenck, 1857) & $\ldots$ & $\ldots$ & 2 & 1 & $\ldots$ & $\ldots$ & $\ldots$ & 1 & 2 & 2 & 4 \\
\hline Tachysphex pompiliformis (Panzer, 1805) & $\ldots$ & $\ldots$ & $\ldots$ & 2 & $\ldots$ & $\ldots$ & $\ldots$ & $\ldots$ & 0 & 2 & 2 \\
\hline \multicolumn{12}{|l|}{ MISCOPHINI } \\
\hline Solierella compedita (Piccioli, 1869) & $\ldots$ & $\ldots$ & 1 & 3 & 2 & 4 & 1 & 4 & 4 & 11 & 15 \\
\hline Solierella pisonoides (Saunders, 1873) & $\ldots$ & $\ldots$ & 1 & 1 & $\ldots$ & $\ldots$ & $\ldots$ & $\ldots$ & 1 & 1 & 2 \\
\hline Solierella seabrai Andrade, 1950 & $\ldots$ & $\ldots$ & $\ldots$ & 2 & $\ldots$ & 1 & $\ldots$ & $\ldots$ & 0 & 3 & 3 \\
\hline Miscophus nicolai Ferton, 1896 & $\ldots$ & $\ldots$ & $\cdots$ & 2 & 1 & $\ldots$ & $\ldots$ & $\ldots$ & 1 & 2 & 3 \\
\hline \multicolumn{12}{|l|}{ TRYPOXYLINI } \\
\hline Trypoxylon attenuatum F. Smith, 1851 & $\ldots$ & ... & $\ldots$ & $\ldots$ & $\ldots$ & $\ldots$ & $\ldots$ & 5 & 0 & 5 & 5 \\
\hline Trypoxylon scutatum Chevrier, 1867 & $\ldots$ & $\ldots$ & $\ldots$ & 2 & $\ldots$ & 3 & 2 & 4 & 2 & 9 & 11 \\
\hline \multicolumn{12}{|l|}{ OXYBELINI } \\
\hline Oxybelus quattuordecimnotatus Jurine, 1807 & $\ldots$ & $\ldots$ & $\ldots$ & $\ldots$ & $\ldots$ & $\ldots$ & $\ldots$ & 2 & 0 & 2 & 2 \\
\hline \multicolumn{12}{|l|}{ BEMBICINAE } \\
\hline \multicolumn{12}{|l|}{ BEMBICINI } \\
\hline Harpactus alvaroi Gayubo, 1992 & $\ldots$ & $\ldots$ & $\ldots$ & $\ldots$ & $\cdots$ & $\ldots$ & $\ldots$ & 2 & 0 & 2 & 2 \\
\hline Bembecinus pulchelus (Mercet, 1906) & $\cdots$ & $\ldots$ & $\ldots$ & 4 & $\ldots$ & $\ldots$ & $\ldots$ & $\ldots$ & 0 & 4 & 4 \\
\hline \multirow{2}{*}{$\begin{array}{r}\text { Subtotales } \\
\text { Total de Ejemplares }\end{array}$} & $\mathbf{0}$ & $\mathbf{0}$ & 4 & 18 & 6 & 8 & 3 & 18 & 13 & 44 & \\
\hline & \multicolumn{2}{|c|}{ 0 } & \multicolumn{2}{|c|}{22} & \multicolumn{2}{|c|}{14} & \multicolumn{2}{|c|}{21} & \multicolumn{2}{|c|}{57} & 57 \\
\hline Total de Especies & \multicolumn{2}{|c|}{ 0 } & & & & & & & & & 14 \\
\hline
\end{tabular}




\begin{tabular}{|c|c|c|c|c|c|c|c|c|c|c|c|c|c|c|c|c|c|c|c|}
\hline \multirow{2}{*}{$\begin{array}{c}\text { Periodos de muestreo } \\
\text { LOCALIDAD 2F - DENTRO 1 } \\
\text { Villarino (SA) Trampa Malaise } \\
\text { Año } 2006\end{array}$} & \multicolumn{2}{|c|}{1} & \multicolumn{2}{|c|}{2} & \multicolumn{2}{|c|}{3} & \multicolumn{2}{|c|}{4} & \multicolumn{2}{|c|}{5} & \multicolumn{2}{|c|}{6} & \multicolumn{2}{|c|}{7} & \multicolumn{2}{|c|}{8} & & & \\
\hline & \multicolumn{2}{|c|}{$1-15 \mathrm{VI}$} & \multicolumn{2}{|c|}{$16-30 \mathrm{VI}$} & \multicolumn{2}{|c|}{ 1-15 VII } & \multicolumn{2}{|c|}{ 16-31 VII } & & VIII & $16-$ & VIII & & & $16-$ & IX & & & \\
\hline$\underline{\text { SPHECIDAE }}$ & & & & & & & & & & & & & & & & & & & \\
\hline SPHECINAE & & & & & & & & & & & & & & & & & & & \\
\hline SPHECINI & & & & & & & & & & & & & & & & & & & \\
\hline Sphex atropilosus Kohl, 1885 & 15 & 8 & 1 & 2 & $\ldots$ & $\ldots$ & 1 & 1 & $\ldots$ & $\ldots$ & $\ldots$ & $\ldots$ & $\ldots$ & $\ldots$ & $\ldots$ & $\ldots$ & 17 & 11 & 28 \\
\hline Sphex funerarius Gussakovskij, 1934 & 25 & 5 & 3 & 5 & 3 & 1 & 2 & 2 & $\ldots$ & 1 & $\ldots$ & $\ldots$ & $\ldots$ & $\ldots$ & $\ldots$ & $\ldots$ & 33 & 14 & 47 \\
\hline Sphex leuconotus Brullé, 1833 & 16 & $\ldots$ & 56 & 11 & 38 & 10 & 2 & 3 & 1 & 1 & $\ldots$ & $\ldots$ & $\ldots$ & $\ldots$ & $\ldots$ & $\ldots$ & 113 & 25 & 138 \\
\hline PRIONYCHINI & & & & & & & & & & & & & & & & & & & \\
\hline Palmodes occitanicus ibericus (Roth, 1963) & $\ldots$ & $\ldots$ & 1 & $\ldots$ & $\ldots$ & 1 & $\ldots$ & $\ldots$ & $\ldots$ & $\ldots$ & $\ldots$ & $\ldots$ & $\ldots$ & $\ldots$ & $\ldots$ & $\ldots$ & 0 & 2 & 2 \\
\hline Chilosphex argyrius (Brullé, 1833) & $\ldots$ & $\ldots$ & $\ldots$ & 1 & $\ldots$ & $\ldots$ & $\ldots$ & $\ldots$ & $\ldots$ & $\ldots$ & $\ldots$ & $\ldots$ & $\ldots$ & $\ldots$ & $\ldots$ & $\ldots$ & 0 & 1 & 1 \\
\hline Prionyx kirbii (Van der Linden, 1827) & $\ldots$ & $\ldots$ & $\ldots$ & $\ldots$ & $\ldots$ & $\ldots$ & $\ldots$ & $\ldots$ & $\ldots$ & 1 & $\ldots$ & 2 & $\ldots$ & 4 & $\ldots$ & $\ldots$ & 0 & 7 & 7 \\
\hline AMMOPHILINAE & & & & & & & & & & & & & & & & & & & \\
\hline AMMOPHILINI & & & & & & & & & & & & & & & & & & & \\
\hline Ammophila campestris Latreille, 1809 & 3 & 9 & $\ldots$ & $\ldots$ & $\ldots$ & $\ldots$ & $\ldots$ & $\ldots$ & $\ldots$ & $\ldots$ & $\ldots$ & $\ldots$ & $\ldots$ & $\ldots$ & $\ldots$ & $\ldots$ & 3 & 9 & 12 \\
\hline Ammophila heydeni Dahlbom, 1845 & $\ldots$ & $\ldots$ & $\ldots$ & $\ldots$ & $\ldots$ & $\ldots$ & $\ldots$ & $\ldots$ & $\ldots$ & $\ldots$ & $\ldots$ & $\ldots$ & 1 & $\ldots$ & $\ldots$ & $\ldots$ & 1 & 0 & 1 \\
\hline Ammophila hungarica Mocsáry, 1883 & 1 & 2 & $\ldots$ & $\ldots$ & $\ldots$ & $\ldots$ & $\ldots$ & $\ldots$ & $\ldots$ & $\ldots$ & $\ldots$ & $\ldots$ & $\ldots$ & $\ldots$ & $\ldots$ & $\ldots$ & 1 & 2 & 3 \\
\hline CRABRONIDAE & & & & & & & & & & & & & & & & & & & \\
\hline PEMPHREDONINAE & & & & & & & & & & & & & & & & & & & \\
\hline PEMPHREDONINI & & & & & & & & & & & & & & & & & & & \\
\hline Diodontus insidiosus Spooner, 1938 & 1 & 1 & $\ldots$ & $\ldots$ & 1 & 1 & 1 & $\ldots$ & $\ldots$ & $\ldots$ & $\ldots$ & 1 & 1 & $\ldots$ & $\ldots$ & $\ldots$ & 4 & 3 & 7 \\
\hline Pemphredon lethifer (Shuckard, 1837) & $\ldots$ & $\ldots$ & $\ldots$ & 1 & $\ldots$ & 1 & $\ldots$ & $\ldots$ & $\ldots$ & $\ldots$ & $\ldots$ & $\ldots$ & $\ldots$ & $\ldots$ & $\ldots$ & $\ldots$ & 0 & 2 & 2 \\
\hline Ammoplanus ceballosi Giner Marí, 1943 & $\ldots$ & 2 & $\ldots$ & $\ldots$ & $\ldots$ & $\ldots$ & $\ldots$ & $\ldots$ & $\ldots$ & $\ldots$ & $\ldots$ & $\ldots$ & $\ldots$ & $\ldots$ & $\ldots$ & $\ldots$ & 0 & 2 & 2 \\
\hline CRABRONINAE & & & & & & & & & & & & & & & & & & & \\
\hline LARRINI & & & & & & & & & & & & & & & & & & & \\
\hline Tachysphex adjunctus Kohl, 1885 & $\ldots$ & 1 & $\ldots$ & $\ldots$ & $\ldots$ & $\ldots$ & $\ldots$ & $\ldots$ & $\ldots$ & $\ldots$ & $\ldots$ & $\ldots$ & $\ldots$ & $\ldots$ & $\ldots$ & $\ldots$ & 0 & 1 & 1 \\
\hline Tachysphex consocius Kohl, 1892 & $\ldots$ & 1 & $\ldots$ & $\ldots$ & $\ldots$ & $\ldots$ & $\ldots$ & $\ldots$ & $\ldots$ & $\ldots$ & $\ldots$ & $\ldots$ & $\ldots$ & $\ldots$ & $\ldots$ & $\ldots$ & 0 & 1 & 1 \\
\hline Tachysphex fulvitarsis (A. Costa, 1867) & $\ldots$ & $\ldots$ & 3 & $\ldots$ & $\ldots$ & 1 & $\ldots$ & $\ldots$ & $\ldots$ & 1 & $\ldots$ & $\ldots$ & $\ldots$ & $\ldots$ & $\ldots$ & $\ldots$ & 3 & 2 & 5 \\
\hline Tachysphex incertus (Radoszkowski, 1877) & 3 & $\ldots$ & 2 & 1 & 2 & 1 & $\ldots$ & $\ldots$ & $\ldots$ & 2 & $\ldots$ & 1 & $\ldots$ & $\ldots$ & $\ldots$ & $\ldots$ & 7 & 5 & 12 \\
\hline Tachysphex obscuripennis (Schenck, 1857) & $\ldots$ & $\ldots$ & $\ldots$ & $\ldots$ & $\ldots$ & 1 & $\ldots$ & 1 & $\ldots$ & 1 & $\ldots$ & 2 & $\ldots$ & $\ldots$ & $\ldots$ & $\ldots$ & 0 & 5 & 5 \\
\hline Tachysphex panzeri (Van der Linden, 1829) & $\ldots$ & $\ldots$ & $\ldots$ & $\ldots$ & $\ldots$ & $\ldots$ & $\ldots$ & $\ldots$ & $\ldots$ & 1 & $\ldots$ & $\ldots$ & $\ldots$ & $\ldots$ & $\ldots$ & $\ldots$ & 0 & 1 & 1 \\
\hline Tachysphex psammobius (Kohl, 1880) & $\ldots$ & 1 & $\ldots$ & 1 & $\ldots$ & $\ldots$ & $\ldots$ & $\ldots$ & $\ldots$ & $\ldots$ & $\ldots$ & $\ldots$ & $\ldots$ & $\ldots$ & $\ldots$ & $\ldots$ & 0 & 2 & 2 \\
\hline Tachysphex pseudopanzeri Beaumont, 1955 & $\ldots$ & $\ldots$ & 1 & $\ldots$ & $\ldots$ & $\ldots$ & $\ldots$ & $\ldots$ & $\ldots$ & $\ldots$ & $\ldots$ & $\ldots$ & $\ldots$ & $\ldots$ & $\ldots$ & $\ldots$ & 1 & 0 & 1 \\
\hline MISCOPHINI & & & & & & & & & & & & & & & & & & & \\
\hline Solierella compedita (Piccioli, 1869) & $\ldots$ & $\ldots$ & $\ldots$ & $\ldots$ & $\ldots$ & $\ldots$ & 1 & $\ldots$ & $\ldots$ & 2 & $\ldots$ & 1 & 1 & $\ldots$ & $\ldots$ & $\ldots$ & 2 & 3 & 5 \\
\hline Miscophus bicolor Jurine, 1807 & $\ldots$ & $\ldots$ & $\ldots$ & $\ldots$ & $\ldots$ & 1 & $\ldots$ & $\ldots$ & $\ldots$ & $\ldots$ & $\ldots$ & $\ldots$ & $\ldots$ & 1 & $\ldots$ & $\ldots$ & 0 & 2 & 2 \\
\hline Miscophus eatoni Saunders, 1903 & $\ldots$ & $\ldots$ & $\ldots$ & $\ldots$ & $\ldots$ & $\ldots$ & $\ldots$ & $\ldots$ & $\ldots$ & $\ldots$ & $\ldots$ & $\ldots$ & $\ldots$ & 1 & $\ldots$ & $\ldots$ & 0 & 1 & 1 \\
\hline Miscophus niger Dahlbom, 1844 & $\ldots$ & $\ldots$ & $\ldots$ & 1 & $\ldots$ & $\ldots$ & $\ldots$ & $\ldots$ & $\ldots$ & $\ldots$ & $\ldots$ & $\ldots$ & $\ldots$ & $\ldots$ & $\ldots$ & $\ldots$ & 0 & 1 & 1 \\
\hline Nitela lucens Gayubo \& Felton, 2000 & $\ldots$ & $\ldots$ & $\ldots$ & $\ldots$ & $\ldots$ & $\ldots$ & $\ldots$ & $\ldots$ & $\ldots$ & $\ldots$ & $\ldots$ & $\ldots$ & $\ldots$ & 1 & $\ldots$ & 1 & 0 & 2 & 2 \\
\hline TRYPOXYLINI & & & & & & & & & & & & & & & & & & & \\
\hline Trypoxylon clavicerum Lepeletier \& Serville, 1828 & $\ldots$ & $\ldots$ & $\ldots$ & $\ldots$ & $\ldots$ & $\ldots$ & $\ldots$ & 1 & $\ldots$ & $\ldots$ & $\ldots$ & $\ldots$ & $\ldots$ & $\ldots$ & $\ldots$ & $\ldots$ & 0 & 1 & 1 \\
\hline $\begin{array}{l}\text { Trypoxylon scutatum Chevrier, } 1867 \\
\text { OXYBELINI }\end{array}$ & $\ldots$ & $\ldots$ & $\ldots$ & 1 & $\ldots$ & 1 & $\ldots$ & $\ldots$ & $\ldots$ & $\ldots$ & $\ldots$ & $\ldots$ & $\ldots$ & 1 & $\ldots$ & $\ldots$ & 0 & 3 & 3 \\
\hline Oxybelus quattuordecimnotatus Jurine, 1807 & $\ldots$ & $\ldots$ & $\ldots$ & $\ldots$ & $\ldots$ & $\ldots$ & $\ldots$ & $\ldots$ & $\ldots$ & $\ldots$ & $\ldots$ & $\ldots$ & 1 & $\ldots$ & $\ldots$ & $\ldots$ & 1 & 0 & 1 \\
\hline $\begin{array}{l}\text { BEMBICINAE } \\
\text { BEMBICINI }\end{array}$ & & & & & & & & & & & & & & & & & & & \\
\hline Gorytes sulcifrons (A. Costa, 1869) & $\ldots$ & $\ldots$ & $\ldots$ & $\ldots$ & $\ldots$ & $\ldots$ & $\ldots$ & 1 & $\ldots$ & $\ldots$ & $\ldots$ & $\ldots$ & $\ldots$ & $\ldots$ & $\ldots$ & $\ldots$ & 0 & 1 & 1 \\
\hline Harpactus alvaroi Gayubo, 1992 & $\ldots$ & $\ldots$ & $\ldots$ & $\ldots$ & $\ldots$ & $\ldots$ & $\ldots$ & 1 & $\ldots$ & 1 & $\ldots$ & $\ldots$ & $\ldots$ & $\ldots$ & $\ldots$ & $\ldots$ & 0 & 2 & 2 \\
\hline Harpactus formosus (Jurine, 1807) & $\ldots$ & $\ldots$ & $\ldots$ & $\ldots$ & $\ldots$ & $\ldots$ & $\ldots$ & $\ldots$ & $\ldots$ & $\ldots$ & 1 & $\ldots$ & 2 & $\ldots$ & $\ldots$ & $\ldots$ & 3 & 0 & 3 \\
\hline Stizoides tridentatus (Fabricius, 1775) & 1 & $\ldots$ & $\ldots$ & $\ldots$ & $\ldots$ & $\ldots$ & $\ldots$ & $\ldots$ & $\ldots$ & $\ldots$ & $\ldots$ & $\ldots$ & $\ldots$ & $\ldots$ & $\ldots$ & $\ldots$ & 1 & 0 & 1 \\
\hline Subtotales & 65 & 30 & 67 & 24 & 44 & 19 & 7 & 10 & 1 & 11 & 1 & 7 & 6 & 8 & $\mathbf{0}$ & 1 & 190 & 111 & \\
\hline Total de Ejemplares & & & & & & & & & & & & & & & & & & & 301 \\
\hline Total de Especies & & & & & & & & & & & & & & & & & & & 32 \\
\hline
\end{tabular}




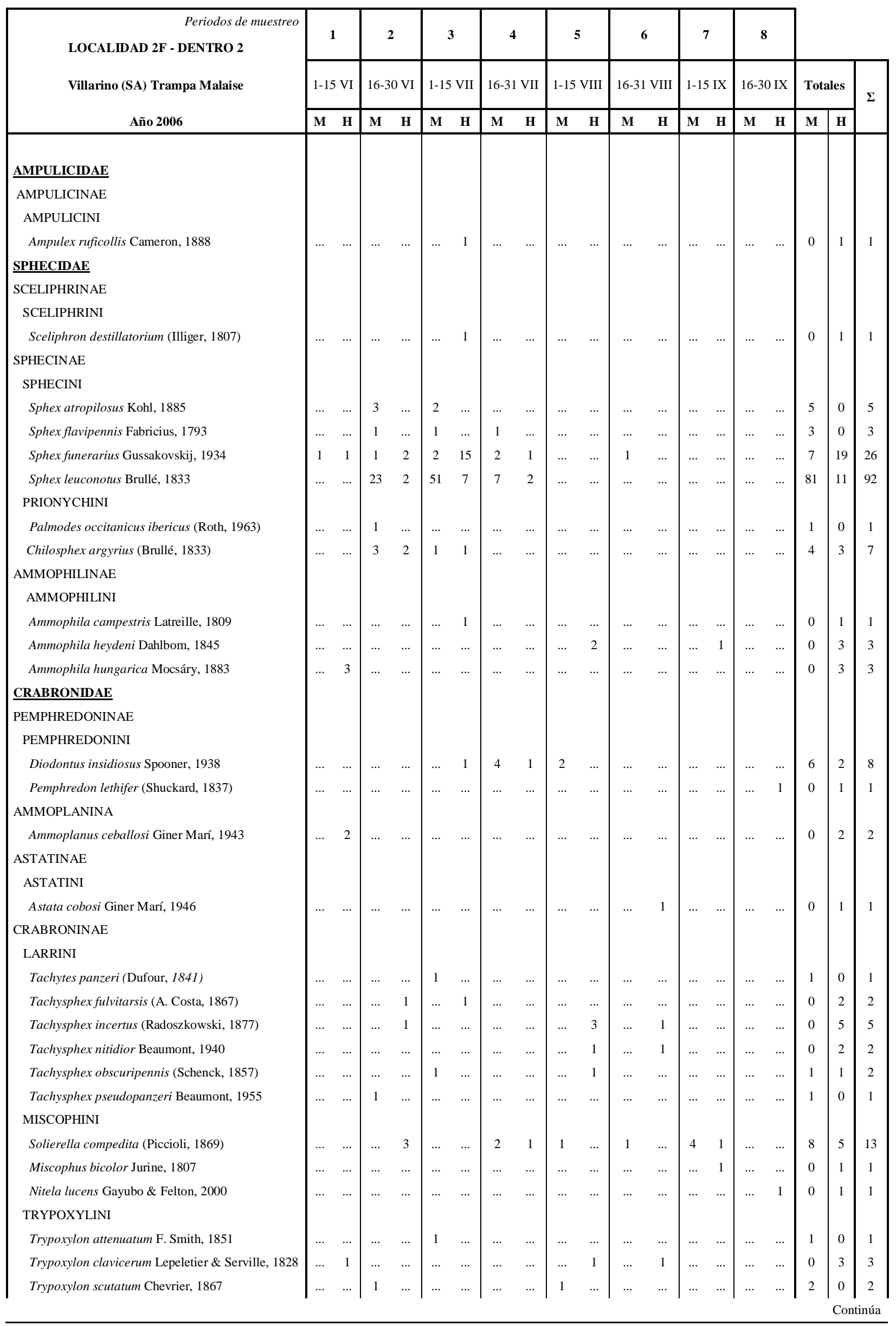




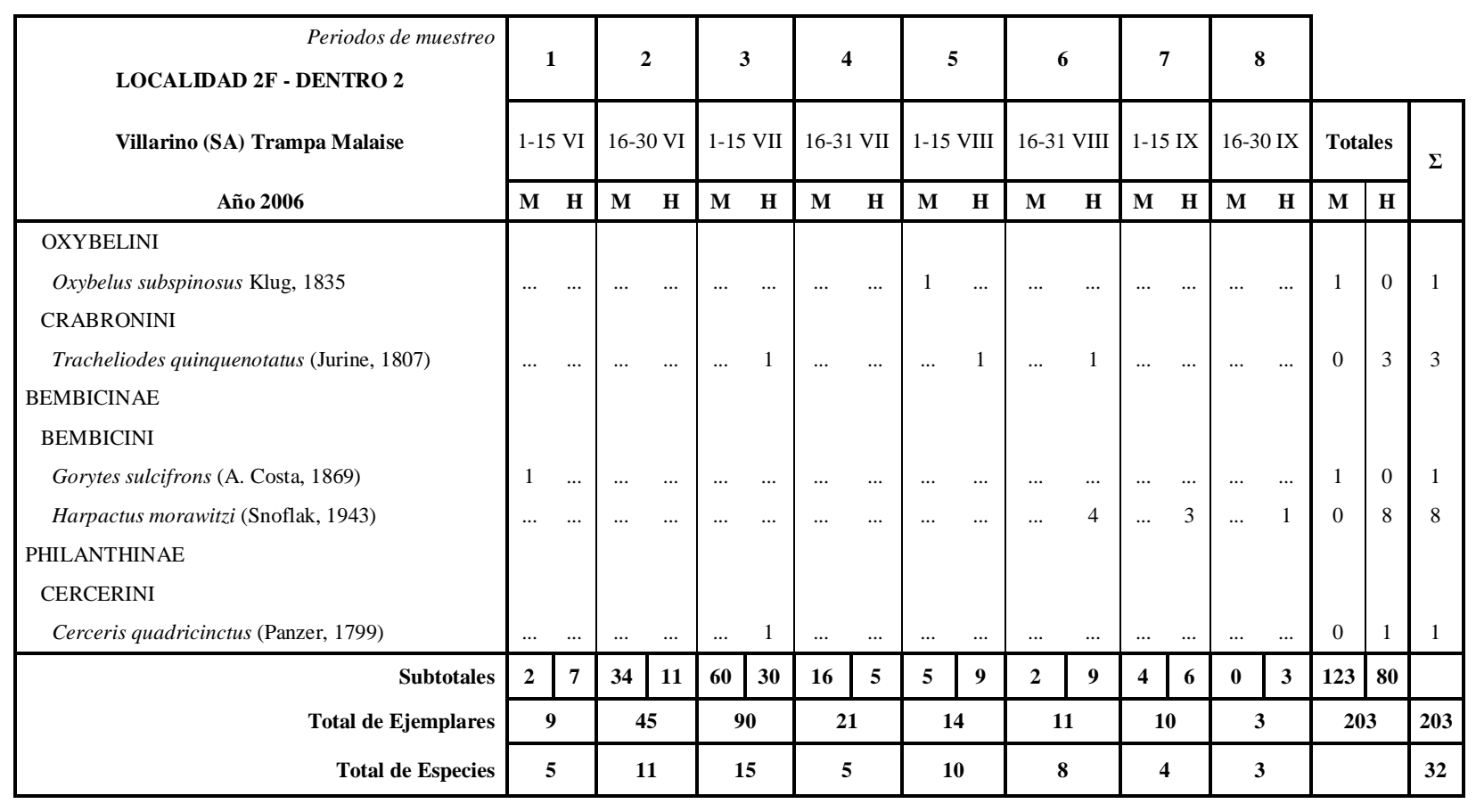




\begin{tabular}{|c|c|c|c|c|c|c|c|c|c|c|c|c|c|c|c|c|c|c|c|}
\hline \multirow{3}{*}{$\begin{array}{c}\text { Periodos de muestreo } \\
\text { LOCALIDAD 2F - DENTRO } 3 \\
\text { Villarino (SA) Trampa Malaise } \\
\text { Año } 2006\end{array}$} & \multicolumn{2}{|c|}{1} & \multicolumn{2}{|c|}{2} & \multicolumn{2}{|c|}{3} & \multicolumn{2}{|c|}{4} & \multicolumn{2}{|c|}{5} & \multicolumn{2}{|c|}{6} & \multicolumn{2}{|c|}{7} & \multicolumn{2}{|c|}{8} & & & \\
\hline & \multicolumn{2}{|c|}{$\begin{array}{c}1-15 \\
\text { VI }\end{array}$} & \multicolumn{2}{|c|}{$\begin{array}{c}16-30 \\
\text { VI }\end{array}$} & \multicolumn{2}{|c|}{$\begin{array}{l}1-15 \\
\text { VII }\end{array}$} & \multicolumn{2}{|c|}{$\begin{array}{c}16-31 \\
\text { VII }\end{array}$} & \multicolumn{2}{|c|}{$\begin{array}{l}1-15 \\
\text { VIII }\end{array}$} & \multicolumn{2}{|c|}{$\begin{array}{c}16-31 \\
\text { VIII }\end{array}$} & \multicolumn{2}{|c|}{$\begin{array}{c}1-15 \\
\text { IX }\end{array}$} & & & Tot & ales & $\Sigma$ \\
\hline & $\mathbf{M}$ & & $\mathbf{M}$ & & $\mathbf{M}$ & & $\mathbf{M}$ & $\mathbf{H}$ & $\mathbf{M}$ & & $\mathbf{M}$ & & & & $\mathbf{M}$ & & $\mathbf{M}$ & $\mathbf{H}$ & \\
\hline SPHECIDAE & & & & & & & & & & & & & & & & & & & \\
\hline $\begin{array}{l}\text { SPHECINAE } \\
\text { SPHECINI }\end{array}$ & & & & & & & & & & & & & & & & & & & \\
\hline Sphex atropilosus Kohl, 1885 & 1 & $\ldots$ & 1 & 1 & 1 & $\ldots$ & $\ldots$ & $\ldots$ & $\ldots$ & $\ldots$ & $\ldots$ & $\ldots$ & $\ldots$ & $\ldots$ & $\ldots$ & $\ldots$ & 3 & 1 & 4 \\
\hline Sphex flavipennis Fabricius, 1793 & $\ldots$ & $\ldots$ & $\ldots$ & $\ldots$ & 1 & $\ldots$ & $\ldots$ & $\ldots$ & $\ldots$ & $\ldots$ & $\ldots$ & $\ldots$ & $\ldots$ & $\ldots$ & $\ldots$ & $\ldots$ & 1 & 0 & 1 \\
\hline Sphex funerarius Gussakovskij, 1934 & 12 & $\ldots$ & 2 & 6 & $\ldots$ & 2 & 2 & $\ldots$ & $\ldots$ & 1 & 1 & 1 & $\ldots$ & $\ldots$ & $\ldots$ & $\ldots$ & 17 & 10 & 27 \\
\hline Sphex leuconotus Brullé, 1833 & 2 & $\ldots$ & 21 & 4 & 15 & 4 & 3 & $\ldots$ & $\cdots$ & $\ldots$ & $\ldots$ & $\ldots$ & $\ldots$ & $\ldots$ & $\ldots$ & $\ldots$ & 41 & 8 & 49 \\
\hline Chilosphex argyrius (Brullé, 1833) & 2 & 1 & 2 & $\ldots$ & $\ldots$ & $\ldots$ & $\ldots$ & $\ldots$ & $\ldots$ & $\ldots$ & $\ldots$ & $\ldots$ & $\ldots$ & $\ldots$ & $\ldots$ & $\ldots$ & 4 & 1 & 5 \\
\hline PRIONYCHINI & & & & & & & & & & & & & & & & & & & \\
\hline *Palmodes occitanicus ibericus (Roth, 1963) & $\ldots$ & $\ldots$ & $\ldots$ & $\ldots$ & $\ldots$ & 1 & $\ldots$ & 2 & $\ldots$ & $\ldots$ & $\ldots$ & $\ldots$ & $\ldots$ & $\ldots$ & $\ldots$ & $\ldots$ & 0 & 3 & 3 \\
\hline *Palmodes occitanicus occitanicus (Lepeletier \& Serville 1828) & $\ldots$ & $\ldots$ & $\ldots$ & $\ldots$ & $\cdots$ & 1 & $\ldots$ & 1 & $\ldots$ & $\ldots$ & $\ldots$ & $\ldots$ & $\ldots$ & $\ldots$ & $\ldots$ & $\ldots$ & 0 & 2 & 2 \\
\hline Prionyx kirbii (Van der Linden, 1827) & $\ldots$ & $\ldots$ & $\ldots$ & $\ldots$ & $\ldots$ & $\ldots$ & $\ldots$ & $\ldots$ & $\ldots$ & $\ldots$ & $\ldots$ & 1 & $\ldots$ & $\ldots$ & $\ldots$ & $\ldots$ & 0 & 1 & 1 \\
\hline $\begin{array}{l}\text { AMMOPHILINAE } \\
\text { AMMOPHILINI }\end{array}$ & & & & & & & & & & & & & & & & & & & \\
\hline Ammophila campestris Latreille, 1809 & 8 & 5 & $\ldots$ & $\ldots$ & $\ldots$ & 1 & $\ldots$ & $\ldots$ & $\ldots$ & $\ldots$ & $\ldots$ & $\ldots$ & $\ldots$ & $\ldots$ & $\ldots$ & $\ldots$ & 8 & 6 & 14 \\
\hline Ammophila hungarica Mocsáry, 1883 & $\ldots$ & 3 & $\ldots$ & $\ldots$ & $\ldots$ & $\ldots$ & $\ldots$ & $\ldots$ & $\ldots$ & $\ldots$ & $\ldots$ & $\ldots$ & $\ldots$ & $\ldots$ & $\ldots$ & $\ldots$ & 0 & 3 & 3 \\
\hline CRABRONIDAE & & & & & & & & & & & & & & & & & & & \\
\hline PEMPHREDONINAE & & & & & & & & & & & & & & & & & & & \\
\hline PSENINI & & & & & & & & & & & & & & & & & & & \\
\hline Psenulus fuscipennis (Dahlbom, 1843) & $\ldots$ & $\ldots$ & $\ldots$ & $\ldots$ & $\ldots$ & $\ldots$ & $\ldots$ & 1 & $\ldots$ & $\ldots$ & $\ldots$ & $\ldots$ & $\ldots$ & $\ldots$ & $\ldots$ & $\ldots$ & 0 & 1 & 1 \\
\hline PEMPHREDONINI & & & & & & & & & & & & & & & & & & & \\
\hline Diodontus insidiosus Spooner, 1938 & $\ldots$ & $\ldots$ & $\ldots$ & $\ldots$ & $\ldots$ & $\ldots$ & $\ldots$ & $\ldots$ & 1 & $\ldots$ & $\ldots$ & $\cdots$ & $\ldots$ & $\cdots$ & $\ldots$ & $\ldots$ & 1 & 0 & 1 \\
\hline Passaloecus pictus Ribaut, 1952 & $\ldots$ & 1 & $\ldots$ & $\ldots$ & $\ldots$ & $\ldots$ & $\ldots$ & $\ldots$ & $\ldots$ & $\ldots$ & $\ldots$ & $\ldots$ & $\ldots$ & $\ldots$ & $\ldots$ & $\ldots$ & 0 & 1 & 1 \\
\hline Ammoplanus ceballosi Giner Marí, 1943 & $\cdots$ & 1 & $\ldots$ & $\ldots$ & $\cdots$ & $\cdots$ & $\ldots$ & $\ldots$ & $\ldots$ & $\cdots$ & $\ldots$ & $\ldots$ & $\ldots$ & $\ldots$ & $\ldots$ & $\ldots$ & 0 & 1 & 1 \\
\hline ASTATINAE & & & & & & & & & & & & & & & & & & & \\
\hline ASTATINI & & & & & & & & & & & & & & & & & & & \\
\hline Astata cobosi Giner Marí, 1946 & $\ldots$ & $\ldots$ & $\ldots$ & $\ldots$ & $\ldots$ & $\ldots$ & $\ldots$ & 1 & $\ldots$ & $\ldots$ & $\ldots$ & $\ldots$ & $\ldots$ & $\ldots$ & $\ldots$ & $\ldots$ & 0 & 1 & 1 \\
\hline CRABRONINAE & & & & & & & & & & & & & & & & & & & \\
\hline LARRINI & & & & & & & & & & & & & & & & & & & \\
\hline Tachysphex adjunctus Kohl, 1885 & $\ldots$ & 2 & $\ldots$ & $\ldots$ & $\ldots$ & $\ldots$ & $\ldots$ & $\ldots$ & $\ldots$ & $\ldots$ & $\ldots$ & $\ldots$ & $\ldots$ & $\ldots$ & $\ldots$ & $\ldots$ & 0 & 2 & 2 \\
\hline Tachysphex fulvitarsis (A. Costa, 1867) & $\ldots$ & $\ldots$ & $\ldots$ & $\ldots$ & $\ldots$ & 1 & $\ldots$ & 2 & $\ldots$ & 1 & $\ldots$ & $\ldots$ & $\ldots$ & $\ldots$ & $\ldots$ & $\ldots$ & 0 & 4 & 4 \\
\hline Tachysphex incertus (Radoszkowski, 1877) & 2 & $\ldots$ & 1 & $\ldots$ & $\ldots$ & $\cdots$ & $\ldots$ & $\ldots$ & $\ldots$ & $\ldots$ & $\ldots$ & $\ldots$ & $\ldots$ & $\ldots$ & $\ldots$ & $\ldots$ & 3 & 0 & 3 \\
\hline Tachysphex julliani Kohl, 1883 & $\ldots$ & $\ldots$ & $\ldots$ & $\ldots$ & $\ldots$ & $\ldots$ & $\ldots$ & $\ldots$ & $\ldots$ & 2 & $\ldots$ & $\ldots$ & $\ldots$ & $\ldots$ & $\ldots$ & $\ldots$ & 0 & 2 & 2 \\
\hline Tachysphex nitidior Beaumont, 1940 & $\ldots$ & 2 & $\ldots$ & $\ldots$ & $\ldots$ & $\ldots$ & $\ldots$ & $\ldots$ & $\ldots$ & $\ldots$ & $\ldots$ & $\cdots$ & $\ldots$ & $\ldots$ & $\ldots$ & $\ldots$ & 0 & 2 & 2 \\
\hline Tachysphex obscuripennis (Schenck, 1857) & $\ldots$ & $\ldots$ & $\ldots$ & $\ldots$ & $\ldots$ & $\ldots$ & $\ldots$ & $\ldots$ & $\ldots$ & 1 & $\ldots$ & 1 & $\ldots$ & 2 & $\ldots$ & $\ldots$ & 0 & 4 & 4 \\
\hline Tachysphex pompiliformis (Panzer, 1805) & $\ldots$ & 1 & $\ldots$ & 1 & $\ldots$ & $\ldots$ & $\ldots$ & $\ldots$ & $\ldots$ & $\ldots$ & $\ldots$ & $\ldots$ & $\ldots$ & $\ldots$ & $\ldots$ & $\ldots$ & 0 & 2 & 2 \\
\hline Tachysphex pseudopanzeri Beaumont, 1955 & $\ldots$ & $\ldots$ & $\ldots$ & $\ldots$ & 1 & $\ldots$ & $\ldots$ & $\ldots$ & $\ldots$ & $\ldots$ & $\ldots$ & $\ldots$ & $\ldots$ & $\ldots$ & $\ldots$ & $\ldots$ & 1 & 0 & 1 \\
\hline Tachysphex tarsinus (Lepeletier, 1845) & $\ldots$ & $\ldots$ & $\ldots$ & $\ldots$ & $\ldots$ & $\ldots$ & $\ldots$ & $\ldots$ & $\ldots$ & $\ldots$ & $\ldots$ & 1 & $\ldots$ & $\ldots$ & $\ldots$ & $\ldots$ & 0 & 1 & 1 \\
\hline MISCOPHINI & & & & & & & & & & & & & & & & & & & \\
\hline Solierella compedita (Piccioli, 1869) & $\ldots$ & $\ldots$ & $\ldots$ & $\ldots$ & $\ldots$ & $\ldots$ & $\ldots$ & 1 & $\ldots$ & $\ldots$ & $\ldots$ & $\ldots$ & $\ldots$ & $\ldots$ & $\ldots$ & $\ldots$ & 0 & 1 & 1 \\
\hline Miscophus bicolor Jurine, 1807 & $\ldots$ & $\ldots$ & $\ldots$ & $\ldots$ & $\ldots$ & 1 & $\ldots$ & 1 & $\ldots$ & $\ldots$ & $\ldots$ & $\ldots$ & $\ldots$ & $\ldots$ & $\ldots$ & $\ldots$ & 0 & 2 & 2 \\
\hline Miscophus nicolai Ferton, 1896 & $\cdots$ & $\ldots$ & 1 & $\ldots$ & $\cdots$ & 1 & $\ldots$ & $\ldots$ & $\ldots$ & $\ldots$ & $\ldots$ & $\ldots$ & 2 & $\cdots$ & $\ldots$ & $\cdots$ & 3 & 1 & 4 \\
\hline Nitela lucens Gayubo \& Felton, 2000 & $\ldots$ & $\ldots$ & $\ldots$ & $\ldots$ & $\ldots$ & $\ldots$ & $\ldots$ & $\ldots$ & $\ldots$ & $\ldots$ & $\ldots$ & $\ldots$ & 1 & $\ldots$ & $\ldots$ & $\ldots$ & 1 & 0 & 1 \\
\hline TRYPOXYLINI & & & & & & & & & & & & & & & & & & & \\
\hline Trypoxylon attenuatum F. Smith, 1851 & $\ldots$ & $\ldots$ & $\ldots$ & $\ldots$ & $\ldots$ & 2 & $\ldots$ & $\ldots$ & $\ldots$ & $\ldots$ & $\ldots$ & $\ldots$ & $\ldots$ & $\ldots$ & $\ldots$ & $\ldots$ & 0 & 2 & 2 \\
\hline Trypoxylon scutatum Chevrier, 1867 & $\ldots$ & 2 & $\ldots$ & 3 & $\ldots$ & 3 & $\ldots$ & 1 & $\ldots$ & $\ldots$ & $\ldots$ & $\ldots$ & $\ldots$ & 1 & $\ldots$ & $\ldots$ & 0 & 10 & 10 \\
\hline
\end{tabular}




\begin{tabular}{|c|c|c|c|c|c|c|c|c|c|c|c|c|c|c|c|c|c|c|c|}
\hline \multirow{3}{*}{$\begin{array}{c}\text { Periodos de muestreo } \\
\text { LOCALIDAD 2F - DENTRO } 3 \\
\text { Villarino (SA) Trampa Malaise } \\
\text { Año } 2006\end{array}$} & \multicolumn{2}{|c|}{1} & \multicolumn{2}{|c|}{2} & \multicolumn{2}{|c|}{3} & \multicolumn{2}{|c|}{4} & \multicolumn{2}{|c|}{5} & \multicolumn{2}{|c|}{6} & \multicolumn{2}{|c|}{7} & \multicolumn{2}{|c|}{8} & & & \\
\hline & \multicolumn{2}{|c|}{$\begin{array}{c}1-15 \\
\text { VI }\end{array}$} & \multicolumn{2}{|c|}{$\begin{array}{c}16-30 \\
\text { VI }\end{array}$} & \multicolumn{2}{|c|}{$\begin{array}{l}1-15 \\
\text { VII }\end{array}$} & \multicolumn{2}{|c|}{$\begin{array}{c}16-31 \\
\text { VII }\end{array}$} & \multicolumn{2}{|c|}{$\begin{array}{l}1-15 \\
\text { VIII }\end{array}$} & \multicolumn{2}{|c|}{$\begin{array}{c}16-31 \\
\text { VIII }\end{array}$} & \multicolumn{2}{|c|}{$\begin{array}{c}1-15 \\
\text { IX }\end{array}$} & \multicolumn{2}{|c|}{$\begin{array}{c}16-30 \\
\text { IX }\end{array}$} & \multicolumn{2}{|c|}{ Totales } & \multirow[t]{2}{*}{$\Sigma$} \\
\hline & & $\mathbf{H}$ & $\mathbf{M}$ & $\mathbf{H}$ & M & $\mathbf{H}$ & M & $\mathbf{H}$ & $\mathbf{M}$ & & M & & M & $\mathbf{H}$ & $\mathbf{M}$ & & $\mathbf{M}$ & $\mathbf{H}$ & \\
\hline \multicolumn{20}{|l|}{ CRABRONINI } \\
\hline Lindenius ibericus Kohl, 1905 & & & $\cdots$ & & & & $\cdots$ & $\cdots$ & $\cdots$ & $\cdots$ & $\cdots$ & $\ldots$ & & & $\cdots$ & & 0 & 1 & 1 \\
\hline Ectemnius crassicornis (Spinola, 1808) & & $\ldots$ & $\ldots$ & $\ldots$ & $\ldots$ & $\ldots$ & $\ldots$ & $\cdots$ & $\ldots$ & $\ldots$ & $\ldots$ & $\cdots$ & $\ldots$ & & $\ldots$ & $\ldots$ & 0 & 1 & 1 \\
\hline \multicolumn{20}{|l|}{ BEMBICINAE } \\
\hline \multicolumn{20}{|l|}{ BEMBICINI } \\
\hline \multirow{3}{*}{$\begin{array}{l}\text { Gorytes sulcifrons (A. Costa, 1869) } \\
\text { Harpactus sp. } 2 \text { grimaldensis Gayubo, sp. n. (in lit.) } \\
\text { Bembix zonata Klug, } 1835\end{array}$} & $\ldots$ & & $\ldots$ & & $\ldots$ & 1 & $\ldots$ & $\ldots$ & $\ldots$ & $\ldots$ & ... & $\ldots$ & ... & $\ldots$ & ... & $\ldots$ & 0 & 2 & 2 \\
\hline & $\ldots$ & $\ldots$ & $\ldots$ & $\ldots$ & $\ldots$ & 1 & $\ldots$ & $\ldots$ & 1 & $\ldots$ & $\ldots$ & $\ldots$ & $\ldots$ & 1 & $\ldots$ & $\ldots$ & 1 & 2 & 3 \\
\hline & & $\ldots$ & $\ldots$ & $\ldots$ & $\cdots$ & $\cdots$ & $\ldots$ & 1 & $\ldots$ & $\ldots$ & $\ldots$ & $\ldots$ & $\ldots$ & ... & $\ldots$ & $\ldots$ & 0 & 1 & 1 \\
\hline Subtotales & 27 & 18 & 28 & 16 & 18 & 20 & 5 & 11 & 2 & 5 & 1 & 4 & 3 & 5 & $\mathbf{0}$ & $\mathbf{0}$ & 84 & 79 & \\
\hline Total de Ejemplares & \multicolumn{2}{|c|}{45} & \multicolumn{2}{|c|}{44} & \multicolumn{2}{|c|}{38} & \multicolumn{2}{|c|}{16} & \multicolumn{2}{|c|}{7} & \multicolumn{2}{|c|}{5} & \multicolumn{2}{|c|}{8} & \multicolumn{2}{|c|}{$\mathbf{0}$} & 10 & & 163 \\
\hline Total de Especies & 1 & & & & & & & & & & & & ( & & & & & & 34 \\
\hline
\end{tabular}

* Subespecies 


\begin{tabular}{|c|c|c|c|c|c|c|c|c|c|c|c|}
\hline \multirow{3}{*}{$\begin{array}{r}\text { Periodos de muestreo } \\
\text { LOCALIDAD 2F - DENTRO } 1 \\
\text { Villarino (SA) PLATOS } \\
\text { Año 2006 }\end{array}$} & \multicolumn{2}{|c|}{1} & \multicolumn{2}{|c|}{2} & \multicolumn{2}{|c|}{3} & \multicolumn{2}{|c|}{4} & & & \\
\hline & \multicolumn{2}{|c|}{ 15-Jun } & \multicolumn{2}{|c|}{ 15-Jul } & \multicolumn{2}{|c|}{ 15-Agos } & \multicolumn{2}{|c|}{ 15-Sep } & \multicolumn{2}{|c|}{ Totales } & \multirow{2}{*}{$\Sigma$} \\
\hline & $\mathbf{M}$ & $\mathbf{H}$ & M & $\mathbf{H}$ & $\mathbf{M}$ & $\mathbf{H}$ & $\mathbf{M}$ & $\mathbf{H}$ & $\mathbf{M}$ & $\mathbf{H}$ & \\
\hline \multicolumn{12}{|l|}{ AMPULICIDAE } \\
\hline \multicolumn{12}{|l|}{ AMPULICINAE } \\
\hline \multicolumn{12}{|l|}{ AMPULICINI } \\
\hline Dolichurus corniculus (Spinola, 1808) & $\ldots$ & $\ldots$ & $\ldots$ & $\ldots$ & $\ldots$ & $\ldots$ & 2 & $\ldots$ & 2 & 0 & 2 \\
\hline \multicolumn{12}{|l|}{ CRABRONIDAE } \\
\hline \multicolumn{12}{|l|}{ PEMPHREDONINAE } \\
\hline \multicolumn{12}{|l|}{ PEMPHREDONINI } \\
\hline \multicolumn{12}{|l|}{ Pemphredonina } \\
\hline Diodontus insidiosus Spooner, 1938 & $\ldots$ & 2 & $\ldots$ & $\ldots$ & 1 & 1 & 1 & 1 & 2 & 4 & 6 \\
\hline Pemphredon lethifer (Shuckard, 1837) & $\ldots$ & $\ldots$ & $\ldots$ & $\ldots$ & $\ldots$ & $\ldots$ & 1 & $\ldots$ & 1 & 0 & 1 \\
\hline \multicolumn{12}{|l|}{ ASTATINAE } \\
\hline \multicolumn{12}{|l|}{ ASTATINI } \\
\hline Astata cobosi Giner Marí, 1946 & $\ldots$ & $\ldots$ & $\ldots$ & $\ldots$ & 1 & 1 & $\ldots$ & $\ldots$ & 1 & 1 & 2 \\
\hline \multicolumn{12}{|l|}{ CRABRONINAE } \\
\hline \multicolumn{12}{|l|}{ LARRINI } \\
\hline Liris niger (Fabricius, 1775) & ... & $\ldots$ & $\ldots$ & $\ldots$ & 1 & $\ldots$ & $\ldots$ & $\ldots$ & 1 & 0 & 1 \\
\hline Tachysphex obscuripennis (Schenck, 1857) & $\ldots$ & $\ldots$ & 5 & 1 & 1 & 5 & $\ldots$ & $\ldots$ & 6 & 6 & 12 \\
\hline MISCOPHINI & & & & & & & & & & & \\
\hline Solierella compedita $($ Piccioli, 1869) & $\ldots$ & 2 & 10 & 3 & 1 & 2 & 1 & 1 & 12 & 8 & 20 \\
\hline Solierella pisonoides (Saunders, 1873) & $\ldots$ & $\ldots$ & $\ldots$ & 1 & $\ldots$ & $\ldots$ & $\ldots$ & $\ldots$ & 1 & 0 & 1 \\
\hline Solierella seabrai Andrade, 1950 & $\ldots$ & $\ldots$ & 3 & 6 & $\ldots$ & 2 & $\ldots$ & 1 & 3 & 9 & 12 \\
\hline Miscophus nicolai Ferton, 1896 & 1 & $\ldots$ & $\ldots$ & $\ldots$ & $\ldots$ & $\ldots$ & $\ldots$ & $\ldots$ & 1 & 0 & 1 \\
\hline TRYPOXYLINI & & & & & & & & & & & \\
\hline Trypoxylon attenuatum F. Smith, 1851 & $\ldots$ & $\ldots$ & $\ldots$ & $\ldots$ & $\ldots$ & $\ldots$ & $\ldots$ & 1 & 0 & 1 & 1 \\
\hline Trypoxylon scutatum Chevrier, 1867 & $\ldots$ & 1 & $\ldots$ & 2 & $\ldots$ & 2 & $\ldots$ & $\ldots$ & 0 & 5 & 5 \\
\hline OXYBELINI & & & & & & & & & & & \\
\hline Oxybelus mucronatus (Fabricius, 1793) & $\ldots$ & $\ldots$ & $\ldots$ & $\ldots$ & $\ldots$ & $\ldots$ & $\ldots$ & 1 & 0 & 1 & 1 \\
\hline Oxybelus quattuordecimnotatus Jurine, 1807 & $\ldots$ & $\ldots$ & $\ldots$ & $\ldots$ & $\ldots$ & $\ldots$ & $\ldots$ & 2 & 0 & 2 & 2 \\
\hline MELLININAE & & & & & & & & & & & \\
\hline MELLININI & & & & & & & & & & & \\
\hline Mellinus arvensis (Linnaeus, 1758) & $\ldots$ & $\ldots$ & $\ldots$ & $\ldots$ & $\ldots$ & 1 & $\ldots$ & $\ldots$ & 0 & 1 & 1 \\
\hline BEMBICINAE & & & & & & & & & & & \\
\hline BEMBICINI & & & & & & & & & & & \\
\hline Harpactus formosus (Jurine, 1807) & & $\ldots$ & & $\ldots$ & 1 & $\ldots$ & & $\ldots$ & 1 & 0 & 1 \\
\hline PHILANTHINAE & & & & & & & & & & & \\
\hline PHILANTHINI & & & & & & & & & & & \\
\hline Philanthus triangulum (Fabricius, 1775) & $\ldots$ & $\ldots$ & $\ldots$ & $\ldots$ & 1 & $\ldots$ & $\ldots$ & $\ldots$ & 1 & 0 & 1 \\
\hline Subtotales & 1 & 5 & 18 & 13 & 7 & 14 & 5 & 7 & 32 & 38 & \\
\hline Total de Ejemplares & & & & & & & & & & & 70 \\
\hline Total de Especies & & & & & & & & & & & 17 \\
\hline
\end{tabular}




\begin{tabular}{|c|c|c|c|c|c|c|c|c|c|c|c|}
\hline \multirow{3}{*}{\begin{tabular}{|c} 
Periodos de muestreo \\
LOCALIDAD 2F - DENTRO 2 \\
Villarino (SA) PLATOS \\
Año 2006
\end{tabular}} & \multicolumn{2}{|c|}{1} & \multicolumn{2}{|c|}{2} & \multicolumn{2}{|c|}{3} & \multicolumn{2}{|c|}{4} & & & \\
\hline & \multicolumn{2}{|c|}{ 15-Jun } & \multicolumn{2}{|c|}{ 15-Jul } & \multicolumn{2}{|c|}{ 15-Agost } & \multicolumn{2}{|c|}{ 15-Sep } & \multicolumn{2}{|c|}{ Totales } & \multirow{2}{*}{$\Sigma$} \\
\hline & M & $\mathbf{H}$ & $\mathbf{M}$ & $\mathbf{H}$ & M & $\mathbf{H}$ & $\mathbf{M}$ & $\mathbf{H}$ & $\mathbf{M}$ & $\mathbf{H}$ & \\
\hline \multicolumn{12}{|l|}{ SPHECIDAE } \\
\hline \multicolumn{12}{|l|}{ AMMOPHILINAE } \\
\hline \multicolumn{12}{|l|}{ AMMOPHILINI } \\
\hline Ammophila heydeni Dahlbom, 1845 & $\ldots$ & $\ldots$ & $\ldots$ & $\ldots$ & $\ldots$ & 1 & $\ldots$ & 2 & 0 & 3 & 3 \\
\hline Ammophila hungarica Mocsáry, 1883 & $\ldots$ & 1 & $\ldots$ & $\ldots$ & $\ldots$ & $\ldots$ & $\ldots$ & $\ldots$ & 0 & 1 & 1 \\
\hline \multicolumn{12}{|l|}{ CRABRONIDAE } \\
\hline \multicolumn{12}{|l|}{ PEMPHREDONINAE } \\
\hline \multicolumn{12}{|l|}{ PEMPHREDONINI } \\
\hline Diodontus insidiosus Spooner, 1938 & $\ldots$ & $\ldots$ & $\ldots$ & $\ldots$ & $\ldots$ & 2 & 2 & $\ldots$ & 2 & 2 & 4 \\
\hline Pemphredon lethifer (Shuckard, 1837) & $\ldots$ & $\ldots$ & $\ldots$ & $\ldots$ & $\ldots$ & $\ldots$ & 1 & 1 & 1 & 1 & 2 \\
\hline \multicolumn{12}{|l|}{ ASTATINAE } \\
\hline \multicolumn{12}{|l|}{ ASTATINI } \\
\hline Astata boops (Schranck, 1871) & $\ldots$ & $\ldots$ & $\ldots$ & $\ldots$ & $\ldots$ & $\ldots$ & 1 & $\ldots$ & 1 & 0 & 1 \\
\hline Astata cobosi Giner Marí, 1946 & $\ldots$ & $\ldots$ & $\ldots$ & $\ldots$ & $\ldots$ & $\ldots$ & 1 & 1 & 1 & 1 & 2 \\
\hline Astata gallica Beaumont, 1942 & $\ldots$ & $\ldots$ & $\ldots$ & $\ldots$ & $\ldots$ & $\ldots$ & $\ldots$ & 1 & 0 & 1 & 1 \\
\hline \multicolumn{12}{|l|}{ CRABRONINAE } \\
\hline LARRINI & & & & & & & & & & & \\
\hline Liris niger (Fabricius, 1775) & $\ldots$ & $\ldots$ & $\ldots$ & $\ldots$ & $\ldots$ & 2 & 3 & $\ldots$ & 3 & 2 & 5 \\
\hline Tachytes freygessneri Kohl, 1881 & $\ldots$ & $\ldots$ & $\ldots$ & $\ldots$ & $\ldots$ & 1 & $\ldots$ & $\ldots$ & 0 & 1 & 1 \\
\hline Tachytes panzeri (Dufour, 1841) & $\ldots$ & $\ldots$ & 1 & $\ldots$ & $\ldots$ & $\ldots$ & $\ldots$ & $\ldots$ & 1 & 0 & 1 \\
\hline Tachysphex nitidior Beaumont, 1940 & $\ldots$ & $\ldots$ & $\ldots$ & 1 & $\ldots$ & 1 & $\ldots$ & $\ldots$ & 0 & 2 & 2 \\
\hline Tachysphex obscuripennis (Schenck, 1857) & $\ldots$ & $\ldots$ & $\ldots$ & $\ldots$ & 2 & 1 & $\ldots$ & $\ldots$ & 2 & 1 & 3 \\
\hline MISCOPHINI & & & & & & & & & & & \\
\hline Solierella compedita (Piccioli, 1869) & $\ldots$ & $\ldots$ & $\ldots$ & 1 & 3 & 4 & 2 & 2 & 5 & 7 & 12 \\
\hline Miscophus albufeirae Andrade, 1952 & $\ldots$ & $\ldots$ & $\ldots$ & $\ldots$ & $\ldots$ & 1 & $\ldots$ & $\ldots$ & 0 & 1 & 1 \\
\hline Miscophus eatoni Saunders, 1903 & $\ldots$ & $\ldots$ & $\ldots$ & $\ldots$ & $\ldots$ & $\ldots$ & 1 & 1 & 1 & 1 & 2 \\
\hline Miscophus nicolai Ferton, 1896 & $\ldots$ & $\ldots$ & $\ldots$ & $\ldots$ & $\ldots$ & $\ldots$ & 1 & $\ldots$ & 1 & 0 & 1 \\
\hline TRYPOXYLINI & & & & & & & & & & & \\
\hline Trypoxylon attenuatum F. Smith, 1851 & $\ldots$ & $\ldots$ & 1 & 10 & $\ldots$ & 1 & $\ldots$ & 6 & 1 & 17 & 18 \\
\hline Trypoxylon scutatum Chevrier, 1867 & $\ldots$ & $\ldots$ & $\ldots$ & 4 & $\ldots$ & 3 & $\ldots$ & $\ldots$ & 0 & 7 & 7 \\
\hline OXYBELINI & & & & & & & & & & & \\
\hline Oxybelus quattuordecimnotatus Jurine, 1807 & $\ldots$ & $\ldots$ & $\ldots$ & $\ldots$ & $\ldots$ & $\ldots$ & 1 & 1 & 1 & 1 & 2 \\
\hline CRABRONINI & & & & & & & & & & & \\
\hline Ectemnius continuus (Fabricius, 1804) & $\ldots$ & $\ldots$ & $\ldots$ & $\ldots$ & $\ldots$ & $\ldots$ & 1 & $\ldots$ & 1 & 0 & 1 \\
\hline BEMBICINAE & & & & & & & & & & & \\
\hline NYSSONINI & & & & & & & & & & & \\
\hline Nysson dusmeti Mercet, 1909 & $\ldots$ & $\ldots$ & $\ldots$ & $\ldots$ & $\ldots$ & $\ldots$ & 1 & $\ldots$ & 1 & 0 & 1 \\
\hline BEMBICINI & & & & & & & & & & & \\
\hline Harpactus alvaroi Gayubo, 1992 & $\ldots$ & $\ldots$ & $\ldots$ & 1 & $\ldots$ & $\ldots$ & $\ldots$ & $\ldots$ & 0 & 1 & 1 \\
\hline Harpactus formosus (Jurine, 1807) & $\ldots$ & $\ldots$ & $\ldots$ & $\ldots$ & $\ldots$ & $\ldots$ & 1 & $\ldots$ & 1 & 0 & 1 \\
\hline Harpactus morawitzi (Snoflak, 1943) & $\ldots$ & $\ldots$ & $\ldots$ & $\ldots$ & $\ldots$ & $\ldots$ & $\ldots$ & 1 & 0 & 1 & 1 \\
\hline Subtotales & $\mathbf{0}$ & 1 & 2 & 17 & 5 & 17 & 16 & 16 & 23 & 51 & \\
\hline Total de Ejemplares & & & & & & & & & & & 74 \\
\hline Total de Especies & & & & & & & & & & & 24 \\
\hline
\end{tabular}




\begin{tabular}{|c|c|c|c|c|c|c|c|c|c|c|c|}
\hline \multirow{3}{*}{\begin{tabular}{|c} 
Periodos de muestreo \\
LOCALIDAD 2F - DENTRO 3 \\
Villarino (SA) PLATOS \\
Año 2006
\end{tabular}} & \multicolumn{2}{|c|}{$\mathbf{1}$} & \multicolumn{2}{|c|}{2} & \multicolumn{2}{|c|}{3} & \multicolumn{2}{|c|}{4} & & & \\
\hline & \multicolumn{2}{|c|}{ 15-Jun } & \multicolumn{2}{|c|}{ 15-Jul } & \multicolumn{2}{|c|}{ 15-Agost } & \multicolumn{2}{|c|}{ 15-Sep } & \multicolumn{2}{|c|}{ Totales } & \multirow{2}{*}{$\Sigma$} \\
\hline & $\mathbf{M}$ & & $\mathbf{M}$ & & $\mathbf{M}$ & $\mathbf{H}$ & $\mathbf{M}$ & $\mathbf{H}$ & $\mathbf{M}$ & $\mathbf{H}$ & \\
\hline \multicolumn{12}{|l|}{ SPHECIDAE } \\
\hline \multicolumn{12}{|l|}{ SPHECINAE } \\
\hline \multicolumn{12}{|l|}{ PRIONYCHINI } \\
\hline Prionyx kirbii (Van der Linden, 1827) & $\ldots$ & $\ldots$ & $\ldots$ & $\ldots$ & $\ldots$ & $\ldots$ & $\ldots$ & 1 & 0 & 1 & 1 \\
\hline \multicolumn{12}{|l|}{ AMMOPHILINAE } \\
\hline \multicolumn{12}{|l|}{ AMMOPHILINI } \\
\hline Ammophila sabulosa (Linnaeus, 1758) & $\ldots$ & 1 & $\ldots$ & $\ldots$ & $\ldots$ & $\ldots$ & $\ldots$ & $\ldots$ & 0 & 1 & 1 \\
\hline \multicolumn{12}{|l|}{ CRABRONIDAE } \\
\hline \multicolumn{12}{|l|}{ PEMPHREDONINAE } \\
\hline \multicolumn{12}{|l|}{ PEMPHREDONINI } \\
\hline Diodontus insidiosus Spooner, 1938 & $\ldots$ & $\ldots$ & $\ldots$ & $\ldots$ & 1 & $\ldots$ & $\ldots$ & 1 & 1 & 1 & 2 \\
\hline \multicolumn{12}{|l|}{ CRABRONINAE } \\
\hline \multicolumn{12}{|l|}{ LARRINI } \\
\hline Liris niger (Fabricius, 1775) & $\ldots$ & $\ldots$ & $\ldots$ & 1 & $\ldots$ & $\ldots$ & $\ldots$ & 1 & 0 & 2 & 2 \\
\hline Tachysphex obscuripennis (Schenck, 1857) & $\ldots$ & $\ldots$ & 1 & 4 & $\ldots$ & $\ldots$ & $\ldots$ & 1 & 1 & 5 & 6 \\
\hline \multicolumn{12}{|l|}{ MISCOPHINI } \\
\hline Solierella compedita (Piccioli, 1869) & 1 & $\ldots$ & 3 & 9 & $\ldots$ & $\ldots$ & $\ldots$ & $\ldots$ & 4 & 9 & 13 \\
\hline Solierella pisonoides (Saunders, 1873) & $\ldots$ & $\ldots$ & $\ldots$ & 1 & $\ldots$ & $\ldots$ & $\ldots$ & $\ldots$ & 0 & 1 & 1 \\
\hline Solierella seabrai Andrade, 1950 & $\ldots$ & $\ldots$ & $\ldots$ & 1 & $\ldots$ & $\ldots$ & $\ldots$ & $\ldots$ & 0 & 1 & 1 \\
\hline Miscophus eatoni Saunders, 1903 & 1 & $\ldots$ & $\ldots$ & $\ldots$ & $\ldots$ & $\ldots$ & $\ldots$ & $\ldots$ & 1 & 0 & 1 \\
\hline Miscophus nicolai Ferton, 1896 & $\ldots$ & $\ldots$ & 2 & 2 & $\ldots$ & $\ldots$ & $\ldots$ & $\ldots$ & 2 & 2 & 4 \\
\hline \multicolumn{12}{|l|}{ TRYPOXYLINI } \\
\hline Trypoxylon attenuatum F. Smith, 1851 & $\ldots$ & $\ldots$ & $\ldots$ & $\ldots$ & $\ldots$ & $\ldots$ & $\ldots$ & 1 & 0 & 1 & 1 \\
\hline Trypoxylon scutatum Chevrier, 1867 & 1 & $\ldots$ & $\ldots$ & 2 & $\ldots$ & $\ldots$ & $\ldots$ & $\ldots$ & 1 & 2 & 3 \\
\hline \multicolumn{12}{|l|}{ OXYBELINI } \\
\hline Oxybelus quattuordecimnotatus Jurine, 1807 & 1 & $\ldots$ & $\ldots$ & $\ldots$ & $\ldots$ & $\ldots$ & $\ldots$ & $\ldots$ & 1 & 0 & 1 \\
\hline Oxybelus mucronatus (Fabricius, 1793) & $\ldots$ & 1 & $\ldots$ & $\ldots$ & $\ldots$ & $\ldots$ & $\ldots$ & $\ldots$ & 0 & 1 & 1 \\
\hline CRABRONINI & & & & & & & & & & & \\
\hline Lestica clypeata (Schreber, 1759) & $\ldots$ & $\ldots$ & $\ldots$ & $\ldots$ & $\ldots$ & $\ldots$ & $\ldots$ & 1 & 0 & 1 & 1 \\
\hline PHILANTHINAE & & & & & & & & & & & \\
\hline CERCERINI & & & & & & & & & & & \\
\hline Cerceris arenaria (Linnaeus, 1758) & $\ldots$ & 1 & $\ldots$ & $\ldots$ & $\ldots$ & $\ldots$ & $\ldots$ & $\ldots$ & 0 & 1 & 1 \\
\hline Subtotales & 4 & 3 & 6 & 20 & 1 & $\mathbf{0}$ & $\mathbf{0}$ & 6 & 11 & 29 & \\
\hline Total de Ejemplares & & & & & & & & & & & 40 \\
\hline Total de Especies & & & & & & & & & & & 16 \\
\hline
\end{tabular}




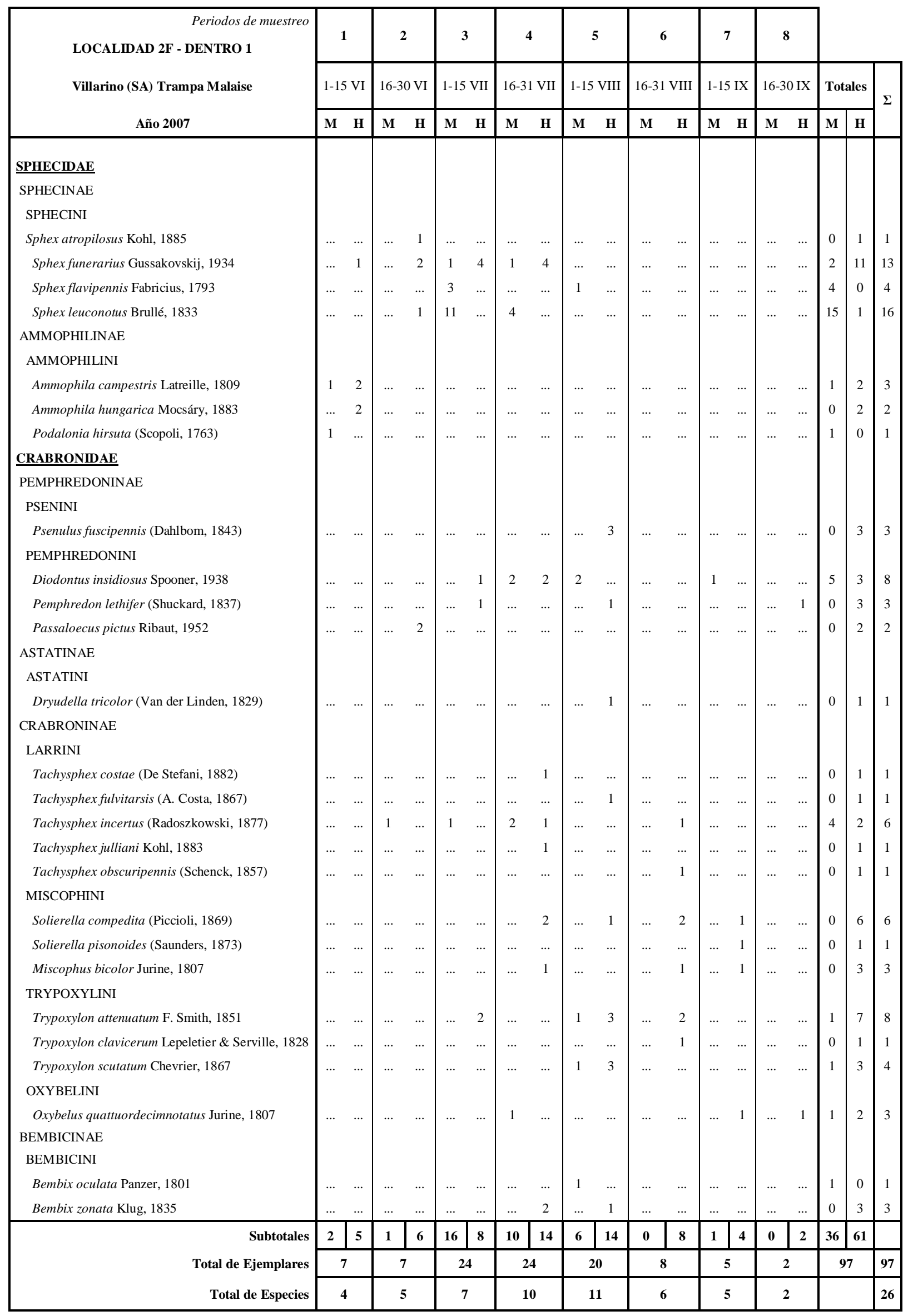




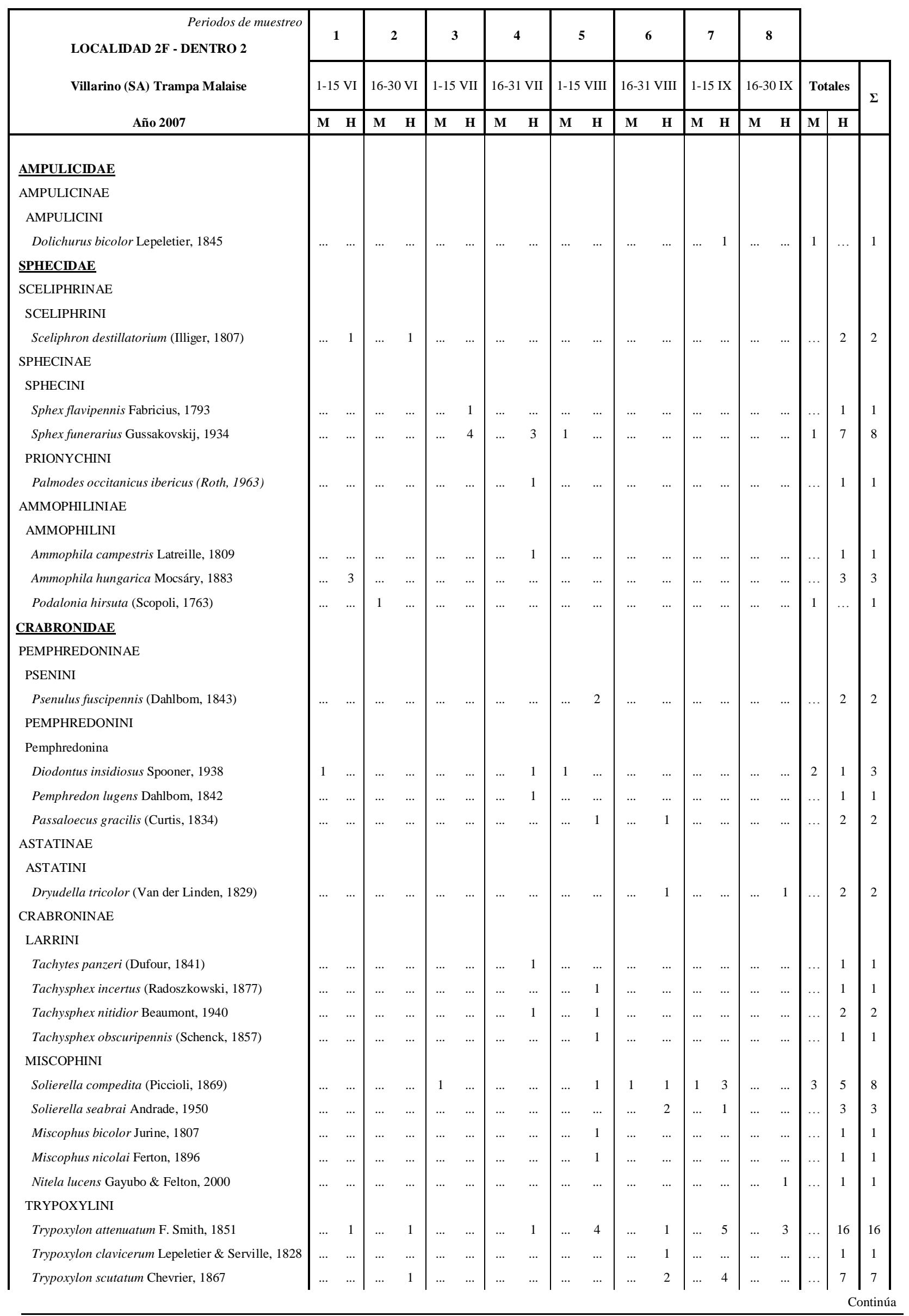




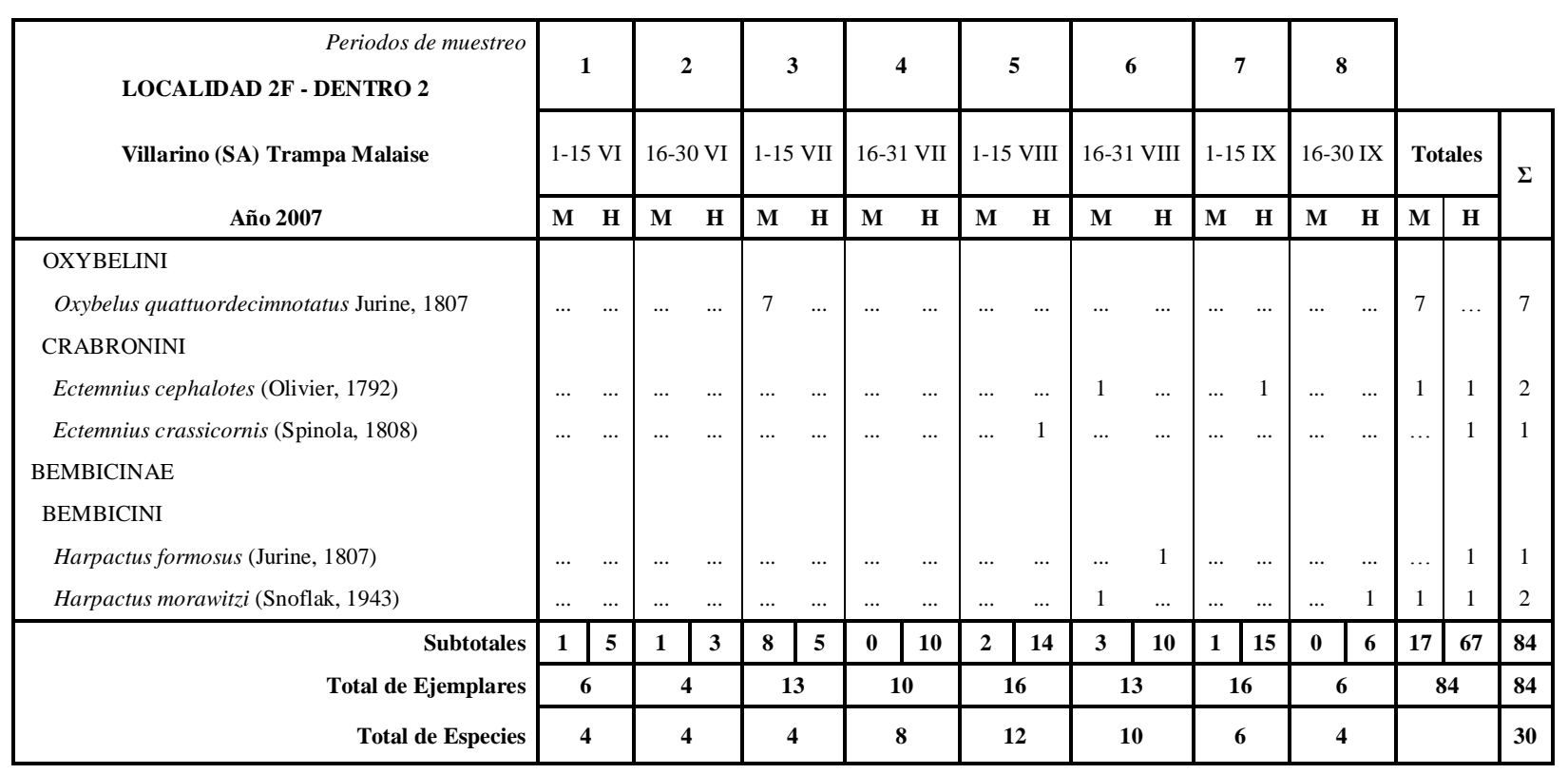




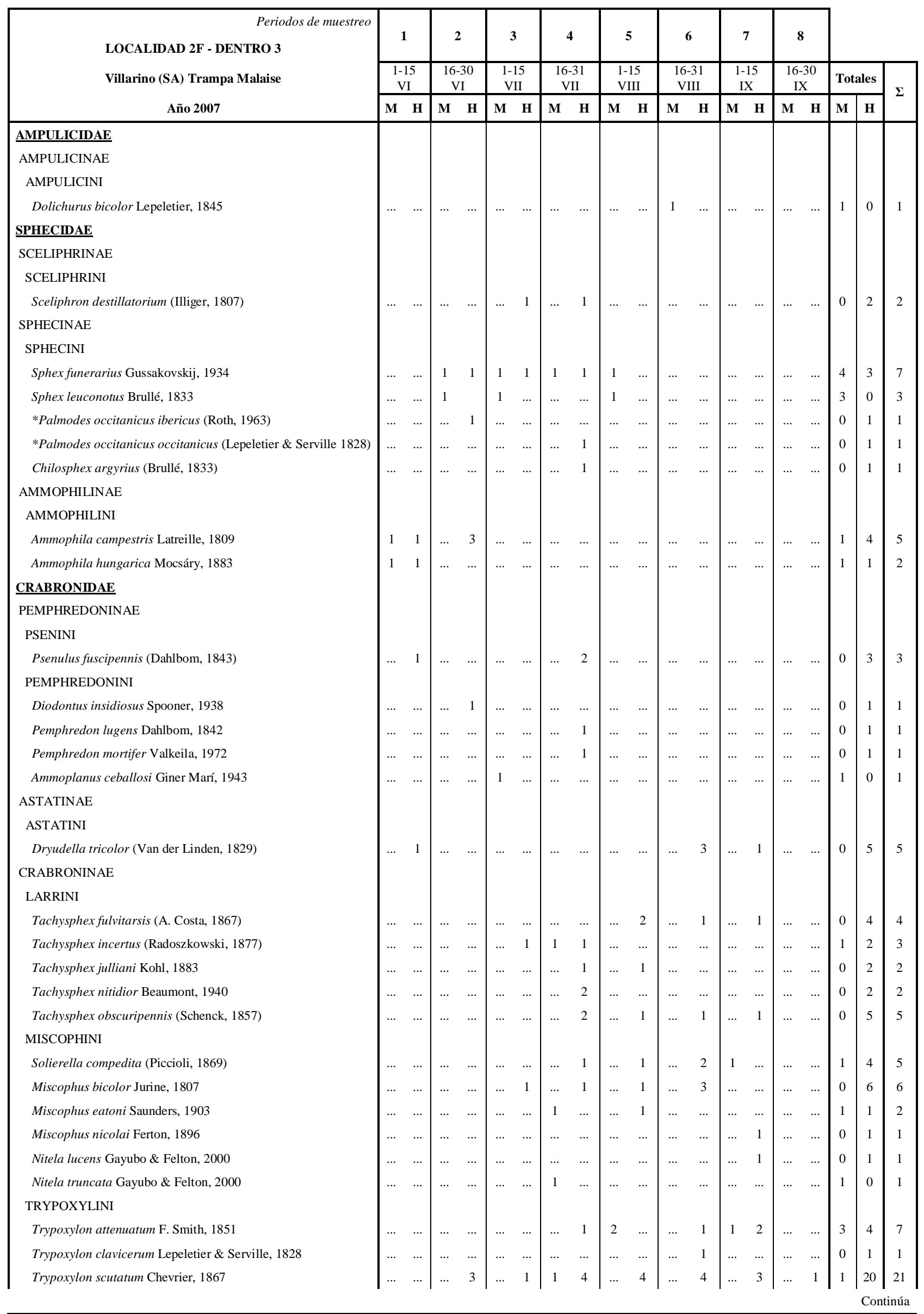




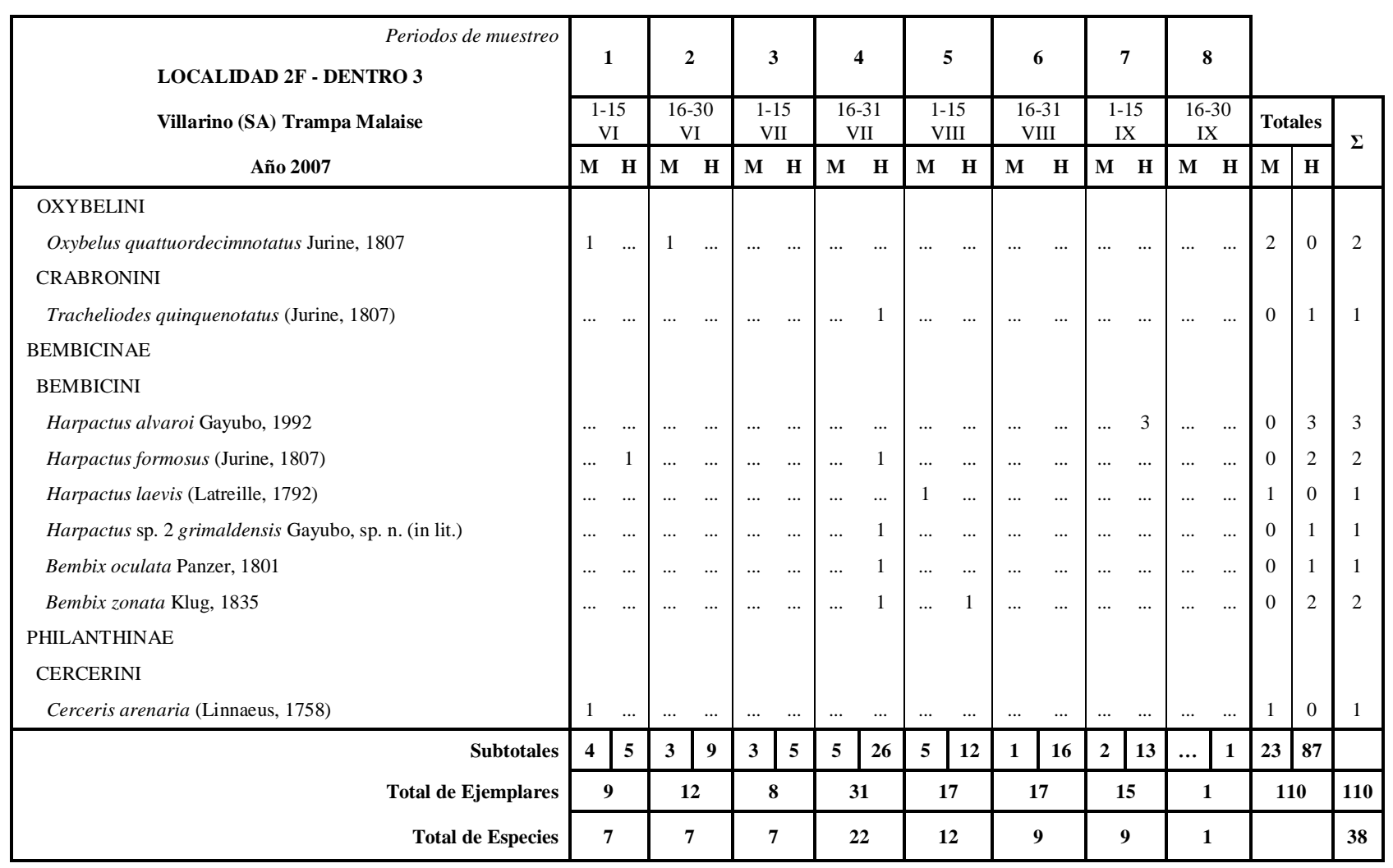

* Subespecies 


\begin{tabular}{|c|c|c|c|c|c|c|c|c|c|c|c|}
\hline \multirow{3}{*}{$\begin{array}{c}\text { Periodos de muestreo } \\
\text { LOCALIDAD 2F - DENTRO 1 } \\
\text { Villarino (SA) PLATOS } \\
\text { Año 2007 }\end{array}$} & \multicolumn{2}{|c|}{1} & \multicolumn{2}{|c|}{2} & \multicolumn{2}{|c|}{3} & \multicolumn{2}{|c|}{4} & & & \\
\hline & \multicolumn{2}{|c|}{ 15-Jun } & \multicolumn{2}{|c|}{ 15-Jul } & \multicolumn{2}{|c|}{ 15-Agos } & \multicolumn{2}{|c|}{ 15-Sep } & \multicolumn{2}{|c|}{ Totales } & \multirow{2}{*}{$\Sigma$} \\
\hline & & & M & $\mathbf{H}$ & M & & & & M & $\mathbf{H}$ & \\
\hline \multicolumn{12}{|l|}{ CRABRONIDAE } \\
\hline \multicolumn{12}{|l|}{ PEMPHREDONINAE } \\
\hline \multicolumn{12}{|l|}{ PEMPHREDONINI } \\
\hline Diodontus insidiosus Spooner, 1938 & $\ldots$ & $\ldots$ & $\ldots$ & 1 & $\ldots$ & $\ldots$ & $\ldots$ & $\ldots$ & 0 & 1 & 1 \\
\hline Pemphredon lethifer (Shuckard, 1837) & $\ldots$ & $\ldots$ & $\ldots$ & $\ldots$ & $\ldots$ & $\ldots$ & 1 & 1 & 1 & 1 & 2 \\
\hline \multicolumn{12}{|l|}{ CRABRONINAE } \\
\hline \multicolumn{12}{|l|}{ LARRINI } \\
\hline Tachysphex obscuripennis (Schenck, 1857) & $\ldots$ & $\ldots$ & 4 & 1 & 1 & 1 & & $\ldots$ & 5 & 2 & 7 \\
\hline \multicolumn{12}{|l|}{ MISCOPHINI } \\
\hline Solierella compedita (Piccioli, 1869) & $\ldots$ & $\ldots$ & 2 & 1 & 10 & 12 & 3 & 1 & 15 & 14 & 29 \\
\hline Solierella pisonoides (Saunders, 1873) & $\cdots$ & $\ldots$ & $\ldots$ & $\ldots$ & $\ldots$ & $\ldots$ & $\ldots$ & 1 & 0 & 1 & 2 \\
\hline Solierella seabrai Andrade, 1950 & $\ldots$ & $\ldots$ & $\ldots$ & 7 & $\ldots$ & 3 & $\ldots$ & $\ldots$ & 0 & 10 & 10 \\
\hline Miscophus eatoni Saunders, 1903 & $\ldots$ & $\ldots$ & $\ldots$ & & $\ldots$ & $\ldots$ & 1 & $\ldots$ & 1 & 0 & 1 \\
\hline Miscophus nicolai Ferton, 1896 & $\ldots$ & $\ldots$ & 2 & 1 & 1 & 1 & $\ldots$ & $\ldots$ & 3 & 2 & 5 \\
\hline \multicolumn{12}{|l|}{ TRYPOXYLINI } \\
\hline Trypoxylon attenuatum F. Smith, 1851 & $\ldots$ & $\ldots$ & $\ldots$ & $\ldots$ & $\ldots$ & 2 & 5 & 6 & 5 & 8 & 13 \\
\hline Trypoxylon scutatum Chevrier, 1867 & $\ldots$ & $\ldots$ & $\ldots$ & $\ldots$ & $\ldots$ & 1 & $\ldots$ & 2 & 0 & 3 & 3 \\
\hline \multicolumn{12}{|l|}{ BEMBICINAE } \\
\hline \multicolumn{12}{|l|}{ BEMBICINI } \\
\hline Harpactus sp. 2 grimaldensis Gayubo, sp. n. (in lit.) & $\ldots$ & $\ldots$ & $\ldots$ & 1 & $\cdots$ & $\ldots$ & $\ldots$ & $\ldots$ & 0 & 1 & 1 \\
\hline \multirow{2}{*}{$\begin{array}{r}\text { Subtotales } \\
\text { Total de Ejemplares }\end{array}$} & $\mathbf{0}$ & $\mathbf{0}$ & 8 & 12 & 12 & 20 & 10 & 11 & 30 & 43 & \\
\hline & \multicolumn{2}{|c|}{0} & \multicolumn{2}{|c|}{20} & \multicolumn{2}{|c|}{32} & \multicolumn{2}{|c|}{21} & \multicolumn{2}{|c|}{74} & 74 \\
\hline Total de Especies & \multicolumn{2}{|c|}{$\mathbf{0}$} & \multicolumn{2}{|c|}{6} & \multicolumn{2}{|c|}{6} & & & & & 11 \\
\hline
\end{tabular}




\begin{tabular}{|c|c|c|c|c|c|c|c|c|c|c|c|}
\hline \multirow{3}{*}{$\begin{array}{c}\text { Periodos de muestreo } \\
\text { LOCALIDAD 2F - DENTRO } 2 \\
\text { Villarino (SA) PLATOS } \\
\text { Año 2007 }\end{array}$} & \multicolumn{2}{|c|}{1} & \multicolumn{2}{|c|}{2} & \multicolumn{2}{|c|}{3} & \multicolumn{2}{|c|}{4} & & & \\
\hline & \multicolumn{2}{|c|}{ 15-Jun } & \multicolumn{2}{|c|}{ 15-Jul } & \multicolumn{2}{|c|}{ 15-Agos } & \multicolumn{2}{|c|}{ 15-Sep } & \multicolumn{2}{|c|}{ Totales } & \multirow{2}{*}{$\Sigma$} \\
\hline & $\mathbf{M}$ & $\mathbf{H}$ & $\mathbf{M}$ & $\mathbf{H}$ & M & & $\mathbf{M}$ & $\mathbf{H}$ & $\mathbf{M}$ & $\mathbf{H}$ & \\
\hline \multicolumn{12}{|l|}{ CRABRONIDAE } \\
\hline \multicolumn{12}{|l|}{ PEMPHREDONINAE } \\
\hline \multicolumn{12}{|l|}{ PEMPHREDONINI } \\
\hline Diodontus insidiosus Spooner, 1938 & $\ldots$ & $\ldots$ & 1 & 4 & $\ldots$ & $\ldots$ & $\ldots$ & $\ldots$ & 1 & 4 & 5 \\
\hline \multicolumn{12}{|l|}{ CRABRONINAE } \\
\hline \multicolumn{12}{|l|}{ LARRINI } \\
\hline Liris niger (Fabricius, 1775) & $\ldots$ & $\ldots$ & $\ldots$ & $\ldots$ & ... & $\ldots$ & 1 & $\ldots$ & 1 & $\ldots$ & 1 \\
\hline Tachytes panzeri (Dufour, 1841) & $\cdots$ & $\ldots$ & ... & 1 & ... & $\ldots$ & $\ldots$ & $\ldots$ & $\ldots$ & 1 & 1 \\
\hline Tachysphex fulvitarsis (A. Costa, 1867) & $\ldots$ & $\ldots$ & $\ldots$ & $\ldots$ & 1 & $\ldots$ & $\ldots$ & $\ldots$ & 1 & $\ldots$ & 1 \\
\hline \multicolumn{12}{|l|}{ MISCOPHINI } \\
\hline Solierella compedita (Piccioli, 1869) & $\ldots$ & $\ldots$ & $\ldots$ & $\ldots$ & $\ldots$ & 6 & 6 & 6 & 6 & 12 & 18 \\
\hline Solierella seabrai Andrade, 1950 & $\cdots$ & $\cdots$ & $\cdots$ & ... & ... & 3 & $\cdots$ & $\cdots$ & $\ldots$ & 3 & 3 \\
\hline \multicolumn{12}{|l|}{ TRYPOXYLINI } \\
\hline Trypoxylon attenuatum F. Smith, 1851 & $\ldots$ & $\ldots$ & $\ldots$ & $\ldots$ & ... & 10 & 3 & 23 & 3 & 33 & 36 \\
\hline Trypoxylon scutatum Chevrier, 1867 & $\ldots$ & $\ldots$ & $\ldots$ & $\ldots$ & $\ldots$ & 2 & $\ldots$ & 7 & $\ldots$ & 9 & 9 \\
\hline \multicolumn{12}{|l|}{ CRABRONINI } \\
\hline Tracheliodes quinquenotatus (Jurine, 1807) & $\ldots$ & $\cdots$ & $\ldots$ & $\ldots$ & ... & 1 & $\ldots$ & $\ldots$ & $\ldots$ & 1 & 1 \\
\hline \multicolumn{12}{|l|}{ BEMBICINAE } \\
\hline \multicolumn{12}{|l|}{ BEMBICINI } \\
\hline Harpactus alvaroi Gayubo, 1992 & $\cdots$ & $\ldots$ & $\ldots$ & $\ldots$ & ... & 1 & $\ldots$ & 1 & $\ldots$ & 2 & 2 \\
\hline Subtotales & $\mathbf{0}$ & $\mathbf{0}$ & 1 & 5 & 1 & 23 & 10 & 37 & 12 & 65 & \\
\hline Total de Ejemplares & \multicolumn{2}{|c|}{$\mathbf{0}$} & \multicolumn{2}{|c|}{6} & \multicolumn{2}{|c|}{24} & \multicolumn{2}{|c|}{47} & \multicolumn{2}{|c|}{77} & 77 \\
\hline Total de Especies & \multicolumn{2}{|c|}{$\mathbf{0}$} & \multicolumn{2}{|c|}{2} & \multicolumn{2}{|c|}{6} & & & & & 10 \\
\hline
\end{tabular}




\begin{tabular}{|c|c|c|c|c|c|c|c|c|c|c|c|}
\hline $\begin{array}{l}\text { Periodos de muestreo } \\
\text { P }\end{array}$ & \multicolumn{2}{|c|}{1} & \multicolumn{2}{|c|}{2} & \multicolumn{2}{|c|}{3} & \multicolumn{2}{|c|}{4} & & & \\
\hline Villarino (SA) PLATOS & \multicolumn{2}{|c|}{ 15-Jun } & \multicolumn{2}{|c|}{ 15-Jul } & \multicolumn{2}{|c|}{ 15-Agos } & \multicolumn{2}{|c|}{ 15-Sep } & \multicolumn{2}{|c|}{ Totales } & \multirow{2}{*}{$\Sigma$} \\
\hline Año 2007 & M & $\mathbf{H}$ & M & $\mathbf{H}$ & $\mathbf{M}$ & $\mathbf{H}$ & $\mathbf{M}$ & & M & $\mathbf{H}$ & \\
\hline \multicolumn{12}{|l|}{ CRABRONIDAE } \\
\hline \multicolumn{12}{|l|}{ PEMPHREDONINAE } \\
\hline \multicolumn{12}{|l|}{ PEMPHREDONINI } \\
\hline Diodontus insidiosus Spooner, 1938 & $\ldots$ & $\ldots$ & $\cdots$ & $\cdots$ & $\ldots$ & 1 & 1 & $\ldots$ & 1 & 1 & 2 \\
\hline \multicolumn{12}{|l|}{ CRABRONINAE } \\
\hline \multicolumn{12}{|l|}{ LARRINI } \\
\hline Liris niger (Fabricius, 1775) & $\ldots$ & $\ldots$ & $\cdots$ & $\cdots$ & $\ldots$ & $\ldots$ & 1 & $\ldots$ & 1 & 0 & 1 \\
\hline Tachysphex fulvitarsis (A. Costa, 1867) & $\ldots$ & $\ldots$ & $\cdots$ & 1 & $\ldots$ & $\ldots$ & $\ldots$ & $\ldots$ & 0 & 1 & 1 \\
\hline Tachysphex obscuripennis (Schenck, 1857) & $\ldots$ & $\ldots$ & $\cdots$ & $\ldots$ & 2 & 2 & $\ldots$ & $\ldots$ & 2 & 2 & 4 \\
\hline \multicolumn{12}{|l|}{ MISCOPHINI } \\
\hline Solierella compedita (Piccioli, 1869) & $\ldots$ & $\ldots$ & $\cdots$ & 1 & 3 & 16 & 1 & 4 & 4 & 21 & 25 \\
\hline Solierella pisonoides (Saunders, 1873) & $\ldots$ & $\ldots$ & 1 & $\ldots$ & 3 & 2 & $\ldots$ & 1 & 4 & 3 & 7 \\
\hline Solierella seabrai Andrade, 1950 & $\ldots$ & $\ldots$ & $\ldots$ & 2 & $\ldots$ & 3 & $\ldots$ & 1 & 0 & 6 & 6 \\
\hline Miscophus bicolor Jurine, 1807 & $\ldots$ & $\ldots$ & $\cdots$ & $\cdots$ & $\ldots$ & 1 & $\ldots$ & $\ldots$ & 0 & 1 & 1 \\
\hline Miscophus nicolai Ferton, 1896 & $\ldots$ & $\ldots$ & 1 & $\ldots$ & 2 & $\ldots$ & $\cdots$ & $\ldots$ & 3 & 0 & 3 \\
\hline \multicolumn{12}{|l|}{ TRYPOXYLINI } \\
\hline Trypoxylon attenuatum F. Smith, 1851 & $\ldots$ & $\ldots$ & $\ldots$ & $\ldots$ & $\ldots$ & $\ldots$ & 1 & 13 & 1 & 13 & 14 \\
\hline Trypoxylon scutatum Chevrier, 1867 & $\ldots$ & $\ldots$ & $\cdots$ & $\ldots$ & $\ldots$ & 1 & $\ldots$ & 2 & 0 & 3 & 3 \\
\hline \multicolumn{12}{|l|}{ BEMBICINAE } \\
\hline \multicolumn{12}{|l|}{ NYSSONINI } \\
\hline Nysson monachus Mercet, 1909 & $\ldots$ & $\ldots$ & $\ldots$ & $\ldots$ & $\ldots$ & 1 & $\ldots$ & $\ldots$ & 0 & 1 & 1 \\
\hline Nysson pratensis Mercet, 1909 & $\ldots$ & $\ldots$ & $\ldots$ & $\ldots$ & $\ldots$ & $\ldots$ & 1 & $\ldots$ & 1 & 0 & 1 \\
\hline \multirow{2}{*}{$\begin{array}{r}\text { Subtotales } \\
\text { Total de Ejemplares }\end{array}$} & $\mathbf{0}$ & $\mathbf{0}$ & 2 & 4 & 10 & 27 & 5 & 21 & 17 & 52 & \\
\hline & \multicolumn{2}{|c|}{$\mathbf{0}$} & \multicolumn{2}{|c|}{6} & \multicolumn{2}{|c|}{37} & \multicolumn{2}{|c|}{26} & \multicolumn{2}{|c|}{69} & 69 \\
\hline Total de Especies & \multicolumn{2}{|c|}{ 0 } & \multicolumn{2}{|c|}{5} & \multicolumn{2}{|c|}{9} & \multicolumn{2}{|c|}{8} & & & 13 \\
\hline
\end{tabular}




\begin{tabular}{|c|c|c|c|c|c|c|c|c|c|c|c|c|c|c|c|c|c|c|c|}
\hline \multirow{3}{*}{\begin{tabular}{|c|} 
Periodos de muestreo \\
LOCALODAD 3F - DENTRO 1 \\
Pereña(SA) Trampa Malaise \\
Año 2005
\end{tabular}} & \multicolumn{2}{|c|}{1} & \multicolumn{2}{|c|}{2} & \multicolumn{2}{|c|}{3} & \multicolumn{2}{|c|}{4} & \multicolumn{2}{|c|}{5} & \multicolumn{2}{|c|}{6} & \multicolumn{2}{|c|}{7} & \multicolumn{2}{|c|}{8} & & & \\
\hline & \multicolumn{2}{|c|}{$1-15 \mathrm{VI}$} & \multicolumn{2}{|c|}{$16-30 \mathrm{VI}$} & \multicolumn{2}{|c|}{$1-15 \mathrm{VII}$} & \multicolumn{2}{|c|}{ 16-31 VII } & \multicolumn{2}{|c|}{$1-15$ VIII } & \multicolumn{2}{|c|}{$16-31 \mathrm{VIII}$} & $1-15$ & & $16-3$ & 0 IX & Tot & ales & \\
\hline & M & $\mathbf{H}$ & M & $\mathbf{H}$ & $\mathbf{M}$ & $\mathbf{H}$ & M & $\mathbf{H}$ & $\mathbf{M}$ & $\mathbf{H}$ & M & $\mathbf{H}$ & M & $\mathbf{H}$ & M & $\mathbf{H}$ & $\mathbf{M}$ & $\mathbf{H}$ & \\
\hline SPHECIDAE & & & & & & & & & & & & & & & & & & & \\
\hline SPHECINAE & & & & & & & & & & & & & & & & & & & \\
\hline SPHECINI & & & & & & & & & & & & & & & & & & & \\
\hline Sphex atropilosus Kohl, 1885 & 1 & & $\ldots$ & $\ldots$ & $\ldots$ & $\ldots$ & $\ldots$ & $\ldots$ & $\ldots$ & $\ldots$ & $\ldots$ & $\ldots$ & $\ldots$ & $\ldots$ & $\ldots$ & $\ldots$ & 1 & 0 & 1 \\
\hline Sphex flavipennis Fabricius, 1793 & $\ldots$ & $\ldots$ & $\ldots$ & $\ldots$ & 1 & $\ldots$ & $\ldots$ & 1 & $\ldots$ & $\ldots$ & $\ldots$ & $\ldots$ & $\ldots$ & $\ldots$ & $\ldots$ & $\ldots$ & 1 & 1 & 2 \\
\hline Sphex funerarius Gussakovskij, 1934 & 1 & & 1 & 6 & 1 & 3 & 2 & 4 & $\ldots$ & 1 & 1 & $\ldots$ & $\ldots$ & $\ldots$ & $\ldots$ & $\ldots$ & 6 & 15 & 21 \\
\hline Sphex leuconotus Brullé, 1833 & $\ldots$ & $\ldots$ & 4 & 2 & 2 & $\ldots$ & $\ldots$ & $\ldots$ & $\ldots$ & $\ldots$ & $\ldots$ & $\ldots$ & $\ldots$ & $\ldots$ & $\ldots$ & $\ldots$ & 6 & 2 & 8 \\
\hline PRIONYCHINI & & & & & & & & & & & & & & & & & & & \\
\hline Chilosphex argyrius (Brullé, 1833) & $\ldots$ & $\ldots$ & $\ldots$ & 1 & $\ldots$ & $\ldots$ & $\ldots$ & $\ldots$ & $\ldots$ & $\ldots$ & $\ldots$ & $\ldots$ & $\ldots$ & $\ldots$ & $\ldots$ & $\ldots$ & 0 & 1 & 1 \\
\hline Prionyx viduatus (Christ, 1791) & $\ldots$ & $\ldots$ & $\ldots$ & $\ldots$ & $\ldots$ & $\ldots$ & $\ldots$ & $\ldots$ & $\ldots$ & $\ldots$ & $\ldots$ & 2 & $\ldots$ & $\ldots$ & $\ldots$ & $\ldots$ & 0 & 2 & 2 \\
\hline AMMOPHILINAE & & & & & & & & & & & & & & & & & & & \\
\hline AMMOPHILINI & & & & & & & & & & & & & & & & & & & \\
\hline Ammophila campestris Latreille, 1809 & 1 & $\ldots$ & $\ldots$ & 3 & $\ldots$ & $\ldots$ & $\ldots$ & $\ldots$ & $\ldots$ & $\ldots$ & $\ldots$ & $\ldots$ & $\ldots$ & $\ldots$ & $\ldots$ & $\ldots$ & 1 & 3 & 4 \\
\hline Ammophila heydeni Dahlbom, 1845 & 1 & $\ldots$ & $\ldots$ & $\ldots$ & $\ldots$ & $\ldots$ & $\ldots$ & $\ldots$ & 1 & $\ldots$ & $\ldots$ & $\ldots$ & $\ldots$ & $\ldots$ & $\ldots$ & $\ldots$ & 2 & 0 & 2 \\
\hline CRABRONIDAE & & & & & & & & & & & & & & & & & & & \\
\hline PEMPHREDONINAE & & & & & & & & & & & & & & & & & & & \\
\hline PEMPHREDONINI & & & & & & & & & & & & & & & & & & & \\
\hline Diodontus insidiosus Spooner, 1938 & & $\ldots$ & $\ldots$ & & & $\ldots$ & 1 & & & & 1 & & $\ldots$ & $\ldots$ & & $\ldots$ & 2 & 0 & 2 \\
\hline Ammoplanus ceballosi Giner Marí, 1943 & 2 & 2 & $\ldots$ & $\ldots$ & $\ldots$ & $\ldots$ & $\ldots$ & $\ldots$ & $\ldots$ & $\ldots$ & $\ldots$ & & $\ldots$ & $\ldots$ & $\ldots$ & $\ldots$ & 2 & 2 & 4 \\
\hline CRABRONINAE & & & & & & & & & & & & & & & & & & & \\
\hline Tachytes panzeri (Dufour, 1841) & 1 & 1 & 3 & 3 & 4 & 2 & $\ldots$ & $\ldots$ & $\ldots$ & $\ldots$ & $\ldots$ & $\ldots$ & $\ldots$ & $\ldots$ & $\ldots$ & $\ldots$ & 8 & 6 & 14 \\
\hline Tachysphex consocius Kohl, 1892 & 2 & 2 & $\ldots$ & 1 & $\ldots$ & $\ldots$ & $\ldots$ & $\ldots$ & $\ldots$ & $\ldots$ & $\ldots$ & $\ldots$ & $\ldots$ & $\ldots$ & $\ldots$ & $\ldots$ & 2 & 3 & 5 \\
\hline Tachysphex fulvitarsis (A. Costa, 1867) & 1 & $\ldots$ & 2 & $\ldots$ & $\ldots$ & 3 & $\ldots$ & $\ldots$ & $\ldots$ & $\ldots$ & $\ldots$ & $\ldots$ & $\ldots$ & $\ldots$ & $\ldots$ & $\ldots$ & 3 & 3 & 6 \\
\hline Tachysphex incertus (Radoszkowski, 1877) & $\ldots$ & $\ldots$ & 1 & $\ldots$ & 2 & 12 & $\ldots$ & 7 & $\ldots$ & 1 & $\ldots$ & $\ldots$ & $\ldots$ & $\ldots$ & $\ldots$ & $\ldots$ & 3 & 20 & 23 \\
\hline Tachysphex julliani Kohl, 1883 & $\ldots$ & $\ldots$ & $\ldots$ & 4 & $\ldots$ & 3 & $\ldots$ & 5 & $\ldots$ & $\ldots$ & $\ldots$ & 1 & $\ldots$ & $\ldots$ & $\ldots$ & $\ldots$ & 0 & 13 & 13 \\
\hline Tachysphex nitidior Beaumont, 1940 & $\ldots$ & $\ldots$ & $\ldots$ & $\ldots$ & $\ldots$ & $\ldots$ & $\ldots$ & 2 & $\ldots$ & 1 & $\ldots$ & 1 & $\ldots$ & $\ldots$ & $\ldots$ & $\ldots$ & 0 & 4 & 4 \\
\hline Tachysphex obscuripennis (Schenck, 1857) & $\ldots$ & $\ldots$ & $\ldots$ & 2 & 1 & 1 & $\ldots$ & 2 & $\ldots$ & $\ldots$ & $\ldots$ & $\ldots$ & $\ldots$ & $\ldots$ & $\ldots$ & $\ldots$ & 1 & 5 & 6 \\
\hline Tachysphex panzeri (Van der Linden, 1829) & & $\ldots$ & $\ldots$ & $\ldots$ & $\ldots$ & 1 & $\ldots$ & $\ldots$ & $\ldots$ & 2 & & 1 & $\ldots$ & $\ldots$ & & $\ldots$ & 0 & 4 & 4 \\
\hline Tachysphex pseudopanzeri Beaumont, 1955 & 1 & $\ldots$ & 2 & $\ldots$ & $\ldots$ & $\ldots$ & $\ldots$ & $\ldots$ & 1 & $\ldots$ & $\ldots$ & $\ldots$ & $\ldots$ & $\ldots$ & $\ldots$ & $\ldots$ & 4 & 0 & 4 \\
\hline Tachysphex tarsinus (Lepeletier, 1845) & $\ldots$ & $\ldots$ & $\ldots$ & 1 & $\ldots$ & $\ldots$ & $\ldots$ & $\ldots$ & $\ldots$ & $\ldots$ & $\ldots$ & $\ldots$ & $\ldots$ & $\ldots$ & $\ldots$ & $\ldots$ & 0 & 1 & 1 \\
\hline MISCOPHINI & & & & & & & & & & & & & & & & & & & \\
\hline Solierella compedita (Piccioli, 1869) & 1 & $\ldots$ & $\ldots$ & $\ldots$ & 2 & 4 & $\ldots$ & 3 & 5 & 2 & 5 & 11 & $\ldots$ & $\ldots$ & $\ldots$ & $\ldots$ & 13 & 20 & 33 \\
\hline Miscophus bicolor Jurine, 1807 & $\ldots$ & $\ldots$ & $\ldots$ & 1 & $\ldots$ & $\ldots$ & $\ldots$ & 2 & $\ldots$ & $\ldots$ & $\ldots$ & & $\ldots$ & $\ldots$ & $\ldots$ & $\ldots$ & 0 & 3 & 3 \\
\hline Miscophus eatoni Saunders, 1903 & & $\ldots$ & $\ldots$ & & & 1 & $\ldots$ & $\ldots$ & $\ldots$ & $\ldots$ & $\ldots$ & & $\ldots$ & $\ldots$ & & $\ldots$ & 0 & 1 & 1 \\
\hline Miscophus lusitanicus Andrade, 1952 & $\ldots$ & $\ldots$ & $\ldots$ & $\ldots$ & $\ldots$ & $\ldots$ & $\ldots$ & $\ldots$ & $\ldots$ & 1 & $\ldots$ & $\ldots$ & $\ldots$ & $\ldots$ & $\ldots$ & $\ldots$ & 0 & 1 & 1 \\
\hline Miscophus nicolai Ferton, 1896 & $\ldots$ & $\ldots$ & $\ldots$ & $\ldots$ & $\ldots$ & 1 & $\ldots$ & $\ldots$ & $\ldots$ & 1 & $\ldots$ & $\ldots$ & $\ldots$ & $\ldots$ & $\ldots$ & $\ldots$ & 0 & 2 & 2 \\
\hline Miscophus niger Dahlbom, 1848 & $\ldots$ & $\ldots$ & $\ldots$ & $\ldots$ & $\ldots$ & 1 & $\ldots$ & $\ldots$ & $\ldots$ & $\ldots$ & $\ldots$ & $\ldots$ & $\ldots$ & $\ldots$ & $\ldots$ & $\ldots$ & 0 & 1 & 1 \\
\hline Nitela lucens Gayubo \& Felton, 2000 & $\ldots$ & $\ldots$ & $\ldots$ & $\ldots$ & $\ldots$ & $\ldots$ & $\ldots$ & $\ldots$ & $\ldots$ & $\ldots$ & $\ldots$ & $\ldots$ & $\ldots$ & $\ldots$ & $\ldots$ & 2 & 0 & 2 & 2 \\
\hline TRYPOXYLINI & & & & & & & & & & & & & & & & & & & \\
\hline Trypoxylon attenuatum F. Smith, 1851 & $\ldots$ & 2 & $\ldots$ & 1 & $\ldots$ & 1 & 1 & $\ldots$ & $\ldots$ & $\ldots$ & $\ldots$ & $\ldots$ & $\ldots$ & 1 & $\ldots$ & 2 & 1 & 7 & 8 \\
\hline Trypoxylon scutatum Chevrier, 1867 & 1 & 1 & $\ldots$ & 1 & $\ldots$ & 4 & $\ldots$ & 4 & $\ldots$ & 4 & $\ldots$ & 1 & $\ldots$ & 3 & $\ldots$ & $\ldots$ & 1 & 18 & 19 \\
\hline OXYBELINI & & & & & & & & & & & & & & & & & & & \\
\hline Oxybelus quattuordecimnotatus Jurine, 1807 & & 1 & $\ldots$ & 1 & $\ldots$ & $\ldots$ & $\ldots$ & $\ldots$ & $\ldots$ & $\ldots$ & $\ldots$ & $\ldots$ & $\ldots$ & $\ldots$ & $\ldots$ & $\ldots$ & 0 & 2 & 2 \\
\hline CRABRONINI & & & & & & & & & & & & & & & & & & & \\
\hline Encopognathus braunsi Mercet, 1915 & $\ldots$ & 1 & $\ldots$ & $\ldots$ & $\ldots$ & $\ldots$ & $\ldots$ & $\ldots$ & $\ldots$ & $\ldots$ & $\ldots$ & $\ldots$ & $\ldots$ & $\ldots$ & $\ldots$ & $\ldots$ & 0 & 1 & 1 \\
\hline Entomognathus brevis (Van der Linden, 1829) & $\ldots$ & 1 & $\ldots$ & $\ldots$ & $\ldots$ & $\ldots$ & $\ldots$ & 1 & $\ldots$ & $\ldots$ & $\ldots$ & $\ldots$ & $\ldots$ & $\ldots$ & $\ldots$ & $\ldots$ & 0 & 2 & 2 \\
\hline
\end{tabular}




\begin{tabular}{|c|c|c|c|c|c|c|c|c|c|c|c|c|c|c|c|c|c|c|}
\hline \multirow{3}{*}{$\begin{array}{r}\text { Periodos de muestreo } \\
\text { LOCALODAD 3F - DENTRO } 1 \\
\text { Pereña(SA) Trampa Malaise } \\
\text { Año } 2005\end{array}$} & 1 & \multicolumn{2}{|c|}{2} & \multicolumn{2}{|c|}{3} & \multicolumn{2}{|c|}{4} & \multicolumn{2}{|c|}{5} & \multicolumn{2}{|c|}{6} & \multicolumn{2}{|c|}{7} & \multicolumn{2}{|c|}{8} & & & \\
\hline & 1-15 VI & \multicolumn{2}{|c|}{$16-30 \mathrm{VI}$} & \multicolumn{2}{|c|}{ 1-15 VII } & \multicolumn{2}{|c|}{ 16-31 VII } & \multicolumn{2}{|c|}{ 1-15 VIII } & \multicolumn{2}{|c|}{ 16-31 VIII } & \multicolumn{2}{|c|}{ 1-15 IX } & \multicolumn{2}{|c|}{ 16-30 IX } & \multicolumn{2}{|c|}{ Totales } & \multirow{2}{*}{$\Sigma$} \\
\hline & M H & M & & $\mathbf{M}$ & $\mathbf{H}$ & M & & $\mathbf{M}$ & & M & H & M & & $\mathbf{M}$ & & M & $\mathbf{H}$ & \\
\hline \multirow{2}{*}{\multicolumn{19}{|c|}{$\begin{array}{l}\text { BEMBICINAE } \\
\text { BEMBICINI }\end{array}$}} \\
\hline & & & & & & & & & & & & & & & & & & \\
\hline Gorytes sulcifrons (A. Costa, 1869) & $\ldots$ & $\ldots$ & & 1 & $\ldots$ & $\ldots$ & $\ldots$ & $\ldots$ & $\ldots$ & $\ldots$ & $\ldots$ & & & $\ldots$ & $\ldots$ & 1 & 0 & 1 \\
\hline Harpactus formosus (Jurine, 1807) & $\ldots$ & $\ldots$ & & $\ldots$ & 1 & $\ldots$ & $\ldots$ & & $\ldots$ & $\ldots$ & $\ldots$ & & 1 & $\ldots$ & & 0 & 2 & 2 \\
\hline Bembecinus pulchelus (Mercet, 1906) & 1 & 1 & 17 & ... & 9 & $\ldots$ & 1 & $\ldots$ & $\ldots$ & $\ldots$ & $\ldots$ & $\ldots$ & $\ldots$ & $\ldots$ & $\ldots$ & 3 & 28 & 31 \\
\hline Bembix zonata Klug, 1835 & $\ldots$ & $\ldots$ & 1 & 1 & 1 & $\ldots$ & $\ldots$ & $\ldots$ & 1 & $\ldots$ & ... & & $\ldots$ & $\ldots$ & $\ldots$ & 1 & 3 & 4 \\
\hline \multicolumn{19}{|l|}{ PHILANTHINAE } \\
\hline \multicolumn{19}{|l|}{ CERCERINI } \\
\hline Cerceris arenaria (Linnaeus, 1758) & $\ldots$ & $\ldots$ & ... & ... & $\ldots$ & $\ldots$ & $\ldots$ & $\ldots$ & ... & $\ldots$ & $\ldots$ & ... & 1 & $\ldots$ & $\ldots$ & 0 & 1 & 1 \\
\hline \multirow{2}{*}{$\begin{array}{r}\text { Subtotales } \\
\text { Total de Ejemplares }\end{array}$} & $15 \mid 13$ & 14 & 45 & 15 & 48 & 4 & 32 & 7 & 14 & 7 & 17 & $\mathbf{0}$ & 6 & 0 & 4 & 62 & 179 & \\
\hline & 28 & \multicolumn{2}{|c|}{59} & \multicolumn{2}{|c|}{63} & \multicolumn{2}{|c|}{36} & \multicolumn{2}{|c|}{21} & \multicolumn{2}{|c|}{24} & \multicolumn{2}{|c|}{6} & \multicolumn{2}{|c|}{4} & 24 & & 241 \\
\hline Total de Especies & 16 & 1 & & 1 & & & & & & & & 4 & & 2 & & & & 37 \\
\hline
\end{tabular}




\begin{tabular}{|c|c|c|c|c|c|c|c|c|c|c|c|c|c|c|c|c|c|c|c|}
\hline \multirow{3}{*}{$\begin{array}{r}\text { Periodos de muestreo } \\
\text { LOCALIDAD 3F - DENTRO } 2 \\
\text { Pereña(SA) Trampa Malaise } \\
\text { Año } 2005\end{array}$} & \multicolumn{2}{|c|}{1} & \multicolumn{2}{|c|}{2} & \multicolumn{2}{|c|}{3} & \multicolumn{2}{|c|}{4} & \multicolumn{2}{|c|}{5} & \multicolumn{2}{|c|}{6} & \multicolumn{2}{|c|}{7} & \multicolumn{2}{|c|}{8} & & & \\
\hline & \multicolumn{2}{|c|}{$1-15 \mathrm{VI}$} & \multicolumn{2}{|c|}{$16-30 \mathrm{VI}$} & \multicolumn{2}{|c|}{$1-15 \mathrm{VII}$} & \multicolumn{2}{|c|}{ 16-31 VII } & $1-15$ & VIII & $16-3$ & VIII & $1-1$ & & $16-$ & IX & Tot & & $\Sigma$ \\
\hline & & $\mathbf{H}$ & M & & $\mathbf{M}$ & $\mathbf{H}$ & M & & M & $\mathbf{H}$ & M & $\mathbf{H}$ & & $\mathbf{H}$ & $\mathbf{M}$ & & $\mathbf{M}$ & $\mathbf{H}$ & \\
\hline$\underline{\text { SPHECIDAE }}$ & & & & & & & & & & & & & & & & & & & \\
\hline SPHECINAE & & & & & & & & & & & & & & & & & & & \\
\hline SPHECINI & & & & & & & & & & & & & & & & & & & \\
\hline Sphex atropilosus Kohl, 1885 & 2 & $\ldots$ & $\ldots$ & $\ldots$ & 1 & $\ldots$ & $\ldots$ & $\ldots$ & $\ldots$ & $\ldots$ & $\ldots$ & $\ldots$ & $\ldots$ & $\ldots$ & $\ldots$ & $\ldots$ & 3 & 0 & 3 \\
\hline Sphex flavipennis Fabricius, 1793 & $\ldots$ & $\ldots$ & $\ldots$ & $\ldots$ & 2 & $\ldots$ & $\ldots$ & $\ldots$ & $\ldots$ & $\ldots$ & $\ldots$ & $\ldots$ & $\ldots$ & $\ldots$ & $\ldots$ & $\ldots$ & 2 & 0 & 2 \\
\hline Sphex funerarius Gussakovskij, 1934 & 2 & 2 & 4 & 4 & 2 & 3 & 4 & 8 & 2 & $\ldots$ & $\ldots$ & $\ldots$ & $\cdots$ & $\ldots$ & $\ldots$ & $\ldots$ & 14 & 17 & 31 \\
\hline Sphex leuconotus Brullé, 1833 & $\ldots$ & $\ldots$ & 8 & 5 & 11 & 1 & $\cdots$ & $\ldots$ & $\cdots$ & $\cdots$ & $\ldots$ & $\ldots$ & $\cdots$ & $\cdots$ & $\ldots$ & $\cdots$ & 19 & 6 & 25 \\
\hline PRIONYCHINI & & & & & & & & & & & & & & & & & & & \\
\hline Prionyx kirbii (Van der Linden, 1827) & $\ldots$ & $\ldots$ & $\ldots$ & 1 & $\cdots$ & $\ldots$ & $\ldots$ & 1 & 1 & $\ldots$ & 2 & 2 & $\cdots$ & $\cdots$ & $\ldots$ & $\cdots$ & 3 & 4 & 7 \\
\hline Prionyx viduatus (Christ, 1791) & ... & $\ldots$ & $\cdots$ & $\cdots$ & $\cdots$ & $\cdots$ & $\ldots$ & $\ldots$ & $\ldots$ & $\ldots$ & $\ldots$ & 1 & $\ldots$ & $\ldots$ & $\ldots$ & $\ldots$ & 0 & 1 & 1 \\
\hline AMMOPHILINAE & & & & & & & & & & & & & & & & & & & \\
\hline AMMOPHILINI & & & & & & & & & & & & & & & & & & & \\
\hline Ammophila campestris Latreille, 1809 & 3 & 5 & 2 & 1 & $\ldots$ & $\cdots$ & $\ldots$ & $\ldots$ & $\ldots$ & $\ldots$ & $\ldots$ & $\ldots$ & $\ldots$ & $\ldots$ & $\ldots$ & $\ldots$ & 5 & 6 & 11 \\
\hline Ammophila hungarica Mocsáry, 1883 & $\ldots$ & 2 & $\cdots$ & $\ldots$ & $\cdots$ & $\cdots$ & $\cdots$ & $\ldots$ & $\ldots$ & $\cdots$ & $\ldots$ & $\ldots$ & $\ldots$ & $\ldots$ & $\ldots$ & $\cdots$ & 0 & 2 & 2 \\
\hline CRABRONIDAE & & & & & & & & & & & & & & & & & & & \\
\hline PEMPHREDONINAE & & & & & & & & & & & & & & & & & & & \\
\hline PEMPHREDONINI & & & & & & & & & & & & & & & & & & & \\
\hline Diodontus insidiosus Spooner, 1938 & $\ldots$ & 1 & $\cdots$ & $\ldots$ & 1 & 1 & $\ldots$ & $\cdots$ & 1 & $\cdots$ & $\ldots$ & $\ldots$ & $\cdots$ & $\cdots$ & $\ldots$ & $\cdots$ & 2 & 2 & 4 \\
\hline Ammoplanus ceballosi Giner Marí, 1943 & $\ldots$ & 4 & $\cdots$ & $\cdots$ & $\cdots$ & $\cdots$ & $\ldots$ & $\cdots$ & $\ldots$ & $\ldots$ & $\ldots$ & $\ldots$ & $\cdots$ & $\ldots$ & $\ldots$ & $\cdots$ & 0 & 4 & 4 \\
\hline DINETINAE & & & & & & & & & & & & & & & & & & & \\
\hline DINETINI & & & & & & & & & & & & & & & & & & & \\
\hline Dinetus pictus (Fabricius, 1793) & 1 & 2 & 2 & $\ldots$ & $\cdots$ & $\ldots$ & $\cdots$ & $\ldots$ & $\cdots$ & $\cdots$ & $\ldots$ & $\ldots$ & $\cdots$ & $\cdots$ & $\cdots$ & $\cdots$ & 3 & 2 & 5 \\
\hline CRABRONINAE & & & & & & & & & & & & & & & & & & & \\
\hline LARRINI & & & & & & & & & & & & & & & & & & & \\
\hline Larra anathema (Rossi, 1790) & $\ldots$ & $\ldots$ & 7 & $\ldots$ & $\ldots$ & $\ldots$ & $\ldots$ & $\ldots$ & 1 & $\ldots$ & $\ldots$ & $\ldots$ & 1 & $\ldots$ & $\ldots$ & $\cdots$ & 9 & 0 & 9 \\
\hline Gastrosericina & & & & & & & & & & & & & & & & & & & \\
\hline Tachytes panzeri (Dufour, 1841) & 2 & $\ldots$ & 11 & 5 & 4 & 6 & 1 & 1 & $\ldots$ & $\ldots$ & 1 & $\ldots$ & $\ldots$ & $\ldots$ & $\ldots$ & $\ldots$ & 19 & 12 & 31 \\
\hline Tachysphex consocius Kohl, 1892 & $\ldots$ & 5 & $\ldots$ & 1 & $\ldots$ & 1 & $\ldots$ & $\ldots$ & $\cdots$ & $\ldots$ & $\ldots$ & $\ldots$ & $\ldots$ & $\ldots$ & $\ldots$ & $\ldots$ & 0 & 7 & 7 \\
\hline Tachysphex costae (De Stefani, 1882) & $\ldots$ & 1 & $\ldots$ & $\ldots$ & $\ldots$ & $\cdots$ & $\ldots$ & $\cdots$ & $\cdots$ & $\ldots$ & $\cdots$ & $\cdots$ & $\cdots$ & $\cdots$ & $\ldots$ & $\ldots$ & 0 & 1 & 1 \\
\hline Tachysphex fugax (Radoszkowski, 1877) & 2 & $\ldots$ & $\ldots$ & $\ldots$ & $\ldots$ & $\ldots$ & $\ldots$ & $\ldots$ & $\ldots$ & $\ldots$ & $\ldots$ & $\ldots$ & $\ldots$ & $\ldots$ & $\ldots$ & $\ldots$ & 2 & 0 & 2 \\
\hline Tachysphex fulvitarsis (A. Costa, 1867) & 6 & 3 & 4 & 4 & 2 & 2 & 2 & 7 & 1 & $\ldots$ & $\ldots$ & $\ldots$ & $\ldots$ & $\ldots$ & $\ldots$ & $\ldots$ & 15 & 16 & 31 \\
\hline Tachysphex incertus (Radoszkowski, 1877) & 2 & 2 & 3 & 11 & 7 & 27 & 3 & 21 & 7 & 4 & $\ldots$ & $\ldots$ & $\ldots$ & $\ldots$ & $\ldots$ & $\ldots$ & 22 & 65 & 87 \\
\hline Tachysphex julliani Kohl, 1883 & $\ldots$ & $\ldots$ & $\ldots$ & 2 & $\cdots$ & 2 & $\ldots$ & $\ldots$ & $\cdots$ & $\ldots$ & $\ldots$ & $\ldots$ & $\cdots$ & $\ldots$ & $\ldots$ & $\ldots$ & 0 & 4 & 4 \\
\hline Tachysphex nitidior Beaumont, 1940 & $\ldots$ & $\ldots$ & $\ldots$ & 1 & $\ldots$ & 2 & $\ldots$ & 1 & $\ldots$ & $\ldots$ & 1 & 2 & $\ldots$ & $\ldots$ & $\ldots$ & $\ldots$ & 1 & 6 & 7 \\
\hline Tachysphex obscuripennis (Schenck, 1857) & 1 & $\ldots$ & $\ldots$ & $\ldots$ & $\ldots$ & $\ldots$ & $\ldots$ & 1 & $\ldots$ & $\ldots$ & $\ldots$ & $\ldots$ & $\ldots$ & $\ldots$ & $\ldots$ & $\ldots$ & 1 & 1 & 2 \\
\hline Tachysphex panzeri (Van der Linden, 1829) & $\ldots$ & 1 & $\ldots$ & $\ldots$ & $\ldots$ & 1 & $\ldots$ & $\ldots$ & $\ldots$ & 4 & & 5 & $\ldots$ & $\ldots$ & $\ldots$ & $\ldots$ & 0 & 11 & 11 \\
\hline Tachysphex pseudopanzeri Beaumont, 1955 & $\ldots$ & $\ldots$ & $\ldots$ & $\ldots$ & 2 & $\ldots$ & 11 & $\ldots$ & 54 & $\ldots$ & 21 & $\ldots$ & 2 & $\ldots$ & $\ldots$ & $\ldots$ & 88 & 2 & 90 \\
\hline Tachysphex tarsinus (Lepeletier, 1845) & 1 & $\ldots$ & $\ldots$ & $\ldots$ & $\cdots$ & $\ldots$ & $\ldots$ & $\ldots$ & $\ldots$ & $\ldots$ & $\cdots$ & $\ldots$ & $\cdots$ & $\ldots$ & $\ldots$ & $\ldots$ & 1 & 0 & 1 \\
\hline Tachysphex unicolor (Panzer, 1809) & $\ldots$ & $\ldots$ & $\ldots$ & $\ldots$ & $\cdots$ & $\ldots$ & $\cdots$ & $\ldots$ & $\ldots$ & 1 & $\ldots$ & $\ldots$ & $\ldots$ & $\ldots$ & $\ldots$ & $\ldots$ & 0 & 1 & 1 \\
\hline Prosopigastra punctatissima A. Costa, 1869 & $\ldots$ & $\ldots$ & $\ldots$ & $\ldots$ & $\ldots$ & $\ldots$ & $\ldots$ & 1 & $\ldots$ & $\ldots$ & $\ldots$ & $\ldots$ & $\ldots$ & $\ldots$ & $\ldots$ & $\ldots$ & 0 & 1 & 1 \\
\hline MISCOPHINI & & & & & & & & & & & & & & & & & & & \\
\hline Solierella compedita (Piccioli, 1869) & $\ldots$ & 1 & $\ldots$ & 3 & 2 & $\ldots$ & 1 & 5 & $\ldots$ & 4 & 2 & 4 & $\ldots$ & $\ldots$ & $\ldots$ & $\ldots$ & 5 & 17 & 22 \\
\hline Miscophus bicolor Jurine, 1807 & $\ldots$ & $\cdots$ & $\ldots$ & 1 & $\cdots$ & 3 & $\ldots$ & $\ldots$ & $\ldots$ & 1 & $\ldots$ & 3 & $\ldots$ & 1 & $\ldots$ & $\ldots$ & 0 & 9 & 9 \\
\hline Miscophus eatoni Saunders, 1903 & $\ldots$ & $\ldots$ & $\ldots$ & 1 & $\ldots$ & $\ldots$ & $\ldots$ & $\ldots$ & $\ldots$ & $\ldots$ & $\ldots$ & $\ldots$ & $\cdots$ & $\ldots$ & 1 & $\ldots$ & 1 & 1 & 2 \\
\hline Miscophus nicolai Ferton, 1896 & $\ldots$ & $\ldots$ & $\ldots$ & $\ldots$ & $\ldots$ & 2 & $\ldots$ & 1 & $\ldots$ & 1 & $\ldots$ & 1 & $\ldots$ & $\ldots$ & $\ldots$ & $\ldots$ & 0 & 5 & 5 \\
\hline TRYPOXYLINI & & & & & & & & & & & & & & & & & & & \\
\hline Trypoxylon attenuatum F. Smith, 1851 & $\ldots$ & $\ldots$ & $\ldots$ & $\ldots$ & $\ldots$ & $\ldots$ & $\ldots$ & $\ldots$ & $\ldots$ & $\ldots$ & $\ldots$ & 2 & $\ldots$ & $\ldots$ & $\ldots$ & $\ldots$ & 0 & 2 & 2 \\
\hline Trypoxylon clavicerum Lepeletier \& Serville, 1828 & $\ldots$ & 1 & $\cdots$ & $\cdots$ & 1 & $\ldots$ & $\cdots$ & $\cdots$ & $\cdots$ & $\cdots$ & $\cdots$ & $\ldots$ & $\cdots$ & $\cdots$ & $\ldots$ & $\cdots$ & 1 & 1 & 2 \\
\hline Trypoxylon scutatum Chevrier, 1867 & $\ldots$ & 2 & 1 & 1 & $\ldots$ & 4 & 1 & 6 & 1 & 7 & 1 & 9 & $\ldots$ & $\ldots$ & $\ldots$ & 1 & 4 & 30 & 34 \\
\hline
\end{tabular}




\begin{tabular}{|c|c|c|c|c|c|c|c|c|c|c|c|c|c|c|c|c|c|c|c|}
\hline $\begin{array}{l}\text { Periodos de muestreo } \\
\text { P }\end{array}$ & \multicolumn{2}{|c|}{1} & \multicolumn{2}{|c|}{2} & \multicolumn{2}{|c|}{3} & \multicolumn{2}{|c|}{4} & \multicolumn{2}{|c|}{5} & \multicolumn{2}{|c|}{6} & \multicolumn{2}{|c|}{7} & \multicolumn{2}{|c|}{8} & & & \\
\hline Pereña(SA) Trampa Malaise & \multicolumn{2}{|c|}{$1-15 \mathrm{VI}$} & \multicolumn{2}{|c|}{$16-30 \mathrm{VI}$} & \multicolumn{2}{|c|}{ 1-15 VII } & \multicolumn{2}{|c|}{ 16-31 VII } & \multicolumn{2}{|c|}{ 1-15 VIII } & \multicolumn{2}{|c|}{ 16-31 VIII } & \multicolumn{2}{|c|}{ 1-15 IX } & \multicolumn{2}{|c|}{$16-30 \mathrm{IX}$} & \multicolumn{2}{|c|}{ Totales } & \multirow{2}{*}{$\Sigma$} \\
\hline Año 2005 & $\mathbf{M}$ & $\mathbf{H}$ & $\mathbf{M}$ & $\mathbf{H}$ & $\mathbf{M}$ & & $\mathbf{M}$ & & $\mathbf{M}$ & & $\mathbf{M}$ & & $\mathbf{M}$ & & $\mathbf{M}$ & & $\mathbf{M}$ & $\mathbf{H}$ & \\
\hline \multicolumn{20}{|l|}{ OXYBELINI } \\
\hline Oxybelus quattuordecimnotatus Jurine, 1807 & 2 & 1 & $\cdots$ & 2 & $\ldots$ & $\cdots$ & $\ldots$ & $\ldots$ & $\cdots$ & 2 & $\ldots$ & $\ldots$ & $\cdots$ & $\cdots$ & $\cdots$ & $\ldots$ & 2 & 5 & 7 \\
\hline \multicolumn{20}{|l|}{ CRABRONINI } \\
\hline Encopognathus braunsi Mercet, 1915 & $\ldots$ & $\ldots$ & $\ldots$ & 1 & $\ldots$ & $\ldots$ & $\cdots$ & $\ldots$ & $\cdots$ & $\ldots$ & $\cdots$ & $\ldots$ & $\ldots$ & $\cdots$ & $\cdots$ & $\ldots$ & 0 & 1 & 1 \\
\hline Lindenius ibericus Kohl, 1905 & $\ldots$ & $\ldots$ & $\ldots$ & 1 & $\ldots$ & $\cdots$ & $\ldots$ & $\ldots$ & $\ldots$ & $\ldots$ & $\ldots$ & $\ldots$ & $\ldots$ & $\ldots$ & $\ldots$ & $\ldots$ & 0 & 1 & 1 \\
\hline Ectemnius cephalotes (Olivier, 1792) & $\ldots$ & $\ldots$ & $\cdots$ & $\ldots$ & $\ldots$ & $\ldots$ & $\ldots$ & $\cdots$ & $\ldots$ & 1 & $\ldots$ & $\cdots$ & $\cdots$ & $\ldots$ & $\ldots$ & $\ldots$ & 0 & 1 & 1 \\
\hline \multicolumn{20}{|l|}{ BEMBICINAE } \\
\hline \multicolumn{20}{|l|}{ BEMBICINI } \\
\hline Gorytes sulcifrons (A. Costa, 1869) & 1 & $\ldots$ & 1 & $\ldots$ & $\ldots$ & $\ldots$ & $\ldots$ & $\ldots$ & $\cdots$ & $\ldots$ & $\ldots$ & $\ldots$ & $\ldots$ & $\cdots$ & $\ldots$ & $\ldots$ & 2 & 0 & 2 \\
\hline Harpactus alvaroi Gayubo, 1992 & $\ldots$ & $\ldots$ & $\cdots$ & 1 & $\ldots$ & $\cdots$ & $\ldots$ & $\ldots$ & $\cdots$ & $\ldots$ & $\ldots$ & $\ldots$ & $\ldots$ & $\cdots$ & $\cdots$ & $\ldots$ & 0 & 1 & 1 \\
\hline Harpactus formosus (Jurine, 1807) & 3 & 3 & $\ldots$ & $\ldots$ & $\ldots$ & $\ldots$ & $\cdots$ & $\ldots$ & $\cdots$ & $\ldots$ & $\cdots$ & $\ldots$ & $\ldots$ & $\ldots$ & $\ldots$ & $\ldots$ & 3 & 3 & 6 \\
\hline Harpactus morawitzi (Snoflak, 1943) & $\ldots$ & $\ldots$ & $\ldots$ & $\ldots$ & $\ldots$ & $\ldots$ & $\ldots$ & $\ldots$ & $\ldots$ & $\ldots$ & $\ldots$ & 1 & $\ldots$ & $\ldots$ & $\ldots$ & $\ldots$ & 0 & 1 & 1 \\
\hline Bembecinus pulchelus (Mercet, 1906) & 11 & 5 & $\ldots$ & 27 & $\ldots$ & 10 & $\ldots$ & $\ldots$ & $\ldots$ & $\ldots$ & $\ldots$ & $\ldots$ & $\cdots$ & $\cdots$ & $\cdots$ & $\ldots$ & 11 & 42 & 53 \\
\hline Stizus hispanicus Mocsáry, 1883 & 1 & $\ldots$ & $\ldots$ & $\ldots$ & $\ldots$ & $\ldots$ & $\ldots$ & $\ldots$ & $\cdots$ & $\ldots$ & $\ldots$ & $\ldots$ & $\ldots$ & $\ldots$ & $\ldots$ & $\ldots$ & 1 & 0 & 1 \\
\hline Bembix zonata Klug, 1835 & $\ldots$ & $\ldots$ & $\ldots$ & 2 & 2 & 3 & $\ldots$ & $\ldots$ & $\cdots$ & $\ldots$ & $\cdots$ & $\ldots$ & $\ldots$ & 1 & $\ldots$ & $\ldots$ & 2 & 6 & 8 \\
\hline \multicolumn{20}{|l|}{ CERCERINI } \\
\hline Cerceris arenaria (Linnaeus, 1758) & 1 & $\ldots$ & $\ldots$ & $\ldots$ & $\ldots$ & $\ldots$ & $\ldots$ & $\ldots$ & $\ldots$ & $\ldots$ & $\ldots$ & $\ldots$ & $\ldots$ & $\ldots$ & $\ldots$ & $\ldots$ & 1 & 0 & 1 \\
\hline \multirow{2}{*}{$\begin{array}{r}\text { Subtotales } \\
\text { Total de Ejemplares }\end{array}$} & 41 & 41 & 43 & 75 & 37 & 68 & 23 & 53 & 68 & 25 & 28 & 30 & 3 & 2 & 1 & 1 & 242 & 297 & \\
\hline & \multicolumn{2}{|c|}{82} & \multicolumn{2}{|c|}{119} & \multicolumn{2}{|c|}{105} & & & & & & & 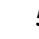 & & 2 & & & & 540 \\
\hline Total de Especies & & 5 & & & & & 1 & & & & & & 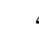 & & 2 & & & & 46 \\
\hline
\end{tabular}




\begin{tabular}{|c|c|c|c|c|c|c|c|c|c|c|c|c|c|c|c|c|c|c|c|}
\hline \multirow{3}{*}{\begin{tabular}{|} 
Periodos de muestreo \\
LOCALIDAD 3F - DENTRO 3 \\
Pereña (SA) Trampa Malaise \\
Año 2005
\end{tabular}} & \multicolumn{2}{|c|}{1} & \multicolumn{2}{|c|}{2} & \multicolumn{2}{|c|}{3} & \multicolumn{2}{|c|}{4} & \multicolumn{2}{|c|}{5} & \multicolumn{2}{|c|}{6} & \multicolumn{2}{|c|}{7} & \multicolumn{2}{|c|}{8} & & & \\
\hline & \multicolumn{2}{|c|}{$\begin{array}{c}1-15 \\
\text { VI }\end{array}$} & \multicolumn{2}{|c|}{$\begin{array}{c}16-30 \\
\text { VI }\end{array}$} & \multicolumn{2}{|c|}{$\begin{array}{l}1-15 \\
\text { VII }\end{array}$} & \multicolumn{2}{|c|}{$\begin{array}{c}16-31 \\
\text { VII }\end{array}$} & \multicolumn{2}{|c|}{ 1-15 VIII } & & VIII & $\begin{array}{c}1- \\
\mathrm{I}\end{array}$ & & & & & & $\Sigma$ \\
\hline & & $\mathbf{H}$ & $\mathbf{M}$ & $\mathbf{H}$ & $\mathbf{M}$ & $\mathbf{H}$ & $\mathbf{M}$ & $\mathbf{H}$ & $\mathbf{M}$ & $\mathbf{H}$ & $\mathbf{M}$ & $\mathbf{H}$ & $\mathbf{M}$ & $\mathbf{H}$ & $\mathbf{M}$ & $\mathbf{H}$ & $\mathbf{M}$ & $\mathbf{H}$ & \\
\hline SPHECIDAE & & & & & & & & & & & & & & & & & & & \\
\hline SPHECINAE & & & & & & & & & & & & & & & & & & & \\
\hline SPHECINI & & & & & & & & & & & & & & & & & & & \\
\hline Sphex flavipennis Fabricius, 1793 & $\ldots$ & $\ldots$ & $\cdots$ & $\ldots$ & ... & 1 & $\ldots$ & $\ldots$ & 1 & $\ldots$ & $\ldots$ & $\ldots$ & $\ldots$ & $\ldots$ & $\ldots$ & $\ldots$ & 1 & 1 & 2 \\
\hline Sphex funerarius Gussakovskij, 1934 & 2 & $\ldots$ & 2 & 6 & ... & 4 & $\ldots$ & 3 & 1 & 1 & $\ldots$ & $\ldots$ & $\ldots$ & $\ldots$ & $\ldots$ & $\ldots$ & 5 & 14 & 19 \\
\hline Sphex leuconotus Brullé, 1833 & $\ldots$ & $\ldots$ & 1 & $\ldots$ & 1 & $\cdots$ & 1 & $\ldots$ & $\ldots$ & $\ldots$ & $\ldots$ & $\ldots$ & $\ldots$ & $\ldots$ & $\ldots$ & $\ldots$ & 3 & 0 & 3 \\
\hline PRIONYCHINI & & & & & & & & & & & & & & & & & & & \\
\hline Prionyx kirbii (Van der Linden, 1827) & 1 & $\ldots$ & $\ldots$ & $\ldots$ & $\ldots$ & 1 & $\ldots$ & 1 & 1 & $\ldots$ & $\ldots$ & 1 & $\ldots$ & $\ldots$ & $\ldots$ & $\ldots$ & 2 & 3 & 5 \\
\hline AMMOPHILINAE & & & & & & & & & & & & & & & & & & & \\
\hline AMMOPHILINI & & & & & & & & & & & & & & & & & & & \\
\hline Ammophila campestris Latreille, 1809 & 1 & 1 & $\ldots$ & 1 & $\ldots$ & $\cdots$ & $\ldots$ & $\ldots$ & $\ldots$ & $\ldots$ & $\ldots$ & $\ldots$ & $\ldots$ & $\ldots$ & $\ldots$ & $\ldots$ & 1 & 2 & 3 \\
\hline Ammophila heydeni Dahlbom, 1845 & 1 & $\ldots$ & 2 & 2 & $\ldots$ & $\cdots$ & $\ldots$ & $\ldots$ & 1 & $\ldots$ & $\ldots$ & $\ldots$ & $\ldots$ & $\ldots$ & $\ldots$ & $\ldots$ & 4 & 2 & 6 \\
\hline CRABRONIDAE & & & & & & & & & & & & & & & & & & & \\
\hline PEMPHREDONINAE & & & & & & & & & & & & & & & & & & & \\
\hline PSENINI & & & & & & & & & & & & & & & & & & & \\
\hline Psenulus fuscipennis (Dahlbom, 1843) & $\ldots$ & 1 & $\cdots$ & $\cdots$ & $\ldots$ & $\cdots$ & $\ldots$ & $\ldots$ & $\ldots$ & $\ldots$ & $\ldots$ & $\ldots$ & $\ldots$ & $\ldots$ & $\ldots$ & $\ldots$ & 0 & 1 & 1 \\
\hline PEMPHREDONINI & & & & & & & & & & & & & & & & & & & \\
\hline Diodontus insidiosus Spooner, 1938 & $\ldots$ & $\ldots$ & 1 & $\ldots$ & 1 & 1 & $\ldots$ & $\ldots$ & $\ldots$ & ... & 1 & $\ldots$ & $\ldots$ & $\ldots$ & $\ldots$ & $\ldots$ & 3 & 1 & 4 \\
\hline Passaloecus pictus Ribaut, 1952 & $\ldots$ & $\ldots$ & $\cdots$ & $\ldots$ & $\ldots$ & $\cdots$ & $\ldots$ & $\ldots$ & $\ldots$ & $\ldots$ & $\ldots$ & $\ldots$ & $\ldots$ & $\ldots$ & 1 & $\ldots$ & 1 & 0 & 1 \\
\hline Ammoplanus ceballosi Giner Marí, 1943 & $\ldots$ & 4 & $\cdots$ & $\cdots$ & ... & $\cdots$ & $\cdots$ & $\ldots$ & $\ldots$ & $\cdots$ & $\cdots$ & $\cdots$ & $\cdots$ & $\cdots$ & $\cdots$ & $\cdots$ & 0 & 4 & 4 \\
\hline ASTATINAE & & & & & & & & & & & & & & & & & & & \\
\hline ASTATINI & & & & & & & & & & & & & & & & & & & \\
\hline Astata apostata Mercet, 1910 & $\ldots$ & $\ldots$ & $\ldots$ & 1 & $\ldots$ & $\ldots$ & $\ldots$ & $\ldots$ & $\ldots$ & $\ldots$ & $\ldots$ & $\ldots$ & $\ldots$ & $\ldots$ & $\ldots$ & $\ldots$ & 0 & 1 & 1 \\
\hline DINETINAE & & & & & & & & & & & & & & & & & & & \\
\hline DINETINI & & & & & & & & & & & & & & & & & & & \\
\hline Dinetus pictus (Fabricius, 1793) & $\ldots$ & 1 & $\ldots$ & 1 & $\ldots$ & $\ldots$ & $\cdots$ & $\ldots$ & $\ldots$ & $\ldots$ & $\ldots$ & $\ldots$ & $\ldots$ & $\ldots$ & $\ldots$ & $\ldots$ & 0 & 2 & 2 \\
\hline CRABRONINAE & & & & & & & & & & & & & & & & & & & \\
\hline LARRINI & & & & & & & & & & & & & & & & & & & \\
\hline Larra anathema (Rossi, 1790) & $\ldots$ & $\ldots$ & $\cdots$ & $\ldots$ & $\ldots$ & $\ldots$ & $\ldots$ & $\ldots$ & $\ldots$ & 1 & $\ldots$ & $\cdots$ & $\ldots$ & $\ldots$ & $\ldots$ & $\ldots$ & 0 & 1 & 1 \\
\hline Tachytes panzeri (Dufour, 1841) & $\ldots$ & $\ldots$ & 1 & 6 & 1 & 2 & $\ldots$ & 1 & $\ldots$ & $\ldots$ & $\ldots$ & $\ldots$ & $\ldots$ & $\ldots$ & $\ldots$ & $\ldots$ & 2 & 9 & 11 \\
\hline Tachysphex consocius Kohl, 1892 & 1 & 2 & 1 & 4 & $\ldots$ & 3 & $\ldots$ & 1 & 1 & $\ldots$ & $\ldots$ & $\ldots$ & $\ldots$ & $\ldots$ & $\ldots$ & $\ldots$ & 3 & 10 & 13 \\
\hline Tachysphex fulvitarsis (A. Costa, 1867) & 8 & $\ldots$ & 8 & 7 & 9 & 3 & 3 & 1 & $\ldots$ & 2 & $\ldots$ & 1 & $\ldots$ & $\ldots$ & $\ldots$ & $\ldots$ & 28 & 14 & 42 \\
\hline Tachysphex incertus (Radoszkowski, 1877) & 2 & 2 & 2 & 3 & 1 & 13 & $\ldots$ & 4 & 3 & $\ldots$ & $\ldots$ & $\ldots$ & $\ldots$ & $\ldots$ & $\ldots$ & $\ldots$ & 8 & 22 & 30 \\
\hline Tachysphex julliani Kohl, 1883 & $\ldots$ & $\ldots$ & $\ldots$ & 4 & $\ldots$ & 3 & $\ldots$ & $\ldots$ & $\ldots$ & $\ldots$ & $\ldots$ & $\ldots$ & $\ldots$ & $\ldots$ & $\ldots$ & $\ldots$ & 0 & 7 & 7 \\
\hline Tachysphex nitidior Beaumont, 1940 & $\ldots$ & $\ldots$ & $\cdots$ & $\ldots$ & $\ldots$ & 1 & $\ldots$ & $\ldots$ & 1 & 3 & $\ldots$ & 1 & $\ldots$ & $\ldots$ & $\ldots$ & $\ldots$ & 1 & 5 & 6 \\
\hline Tachysphex obscuripennis (Schenck, 1857) & 1 & $\ldots$ & $\ldots$ & 2 & 1 & 2 & $\ldots$ & 1 & $\ldots$ & 1 & $\ldots$ & $\ldots$ & $\ldots$ & $\ldots$ & $\ldots$ & $\ldots$ & 2 & 6 & 8 \\
\hline Tachysphex panzeri (Van der Linden, 1829) & $\ldots$ & $\ldots$ & $\ldots$ & $\ldots$ & $\ldots$ & 1 & $\ldots$ & $\ldots$ & $\ldots$ & 1 & 1 & $\ldots$ & $\ldots$ & $\ldots$ & $\ldots$ & $\ldots$ & 1 & 2 & 3 \\
\hline Tachysphex pompiliformis (Panzer, 1805) & 2 & $\ldots$ & 2 & $\cdots$ & $\ldots$ & $\ldots$ & $\ldots$ & $\ldots$ & $\ldots$ & $\ldots$ & $\ldots$ & $\ldots$ & $\ldots$ & $\ldots$ & $\ldots$ & $\ldots$ & 4 & 0 & 4 \\
\hline Tachysphex pseudopanzeri Beaumont, 1955 & $\ldots$ & $\ldots$ & $\ldots$ & $\ldots$ & 2 & $\ldots$ & $\ldots$ & $\ldots$ & 5 & $\ldots$ & 3 & $\ldots$ & 1 & $\ldots$ & $\ldots$ & $\ldots$ & 11 & 0 & 11 \\
\hline MISCOPHINI & & & & & & & & & & & & & & & & & & & \\
\hline Solierella compedita (Piccioli, 1869) & $\ldots$ & 1 & $\ldots$ & 3 & $\ldots$ & 1 & $\ldots$ & 3 & 1 & 1 & 4 & 7 & $\ldots$ & 1 & $\ldots$ & $\ldots$ & 5 & 17 & 22 \\
\hline Miscophus bicolor Jurine, 1807 & $\ldots$ & $\ldots$ & 1 & 1 & 1 & 2 & 1 & 1 & $\ldots$ & $\ldots$ & $\ldots$ & 3 & $\ldots$ & 1 & $\ldots$ & $\ldots$ & 3 & 8 & 11 \\
\hline Miscophus eatoni Saunders, 1903 & $\ldots$ & $\ldots$ & 1 & $\ldots$ & $\ldots$ & $\ldots$ & $\ldots$ & $\ldots$ & $\ldots$ & $\ldots$ & $\ldots$ & $\ldots$ & $\ldots$ & 1 & $\ldots$ & $\ldots$ & 1 & 1 & 2 \\
\hline Miscophus nicolai Ferton, 1896 & $\ldots$ & $\cdots$ & $\ldots$ & $\ldots$ & $\ldots$ & $\ldots$ & $\cdots$ & 2 & $\ldots$ & $\cdots$ & $\ldots$ & 1 & $\ldots$ & $\ldots$ & $\ldots$ & $\ldots$ & 0 & 3 & 3 \\
\hline Nitela truncata Gayubo \& Felton, 2000 & $\ldots$ & $\ldots$ & $\ldots$ & $\ldots$ & $\ldots$ & $\ldots$ & $\ldots$ & $\ldots$ & $\ldots$ & $\ldots$ & 1 & $\ldots$ & $\ldots$ & $\ldots$ & $\ldots$ & $\ldots$ & 1 & 0 & 1 \\
\hline TRYPOXYLINI & & & & & & & & & & & & & & & & & & & \\
\hline Trypoxylon attenuatum F. Smith, 1851 & $\ldots$ & $\ldots$ & $\ldots$ & 2 & 2 & $\ldots$ & 1 & $\ldots$ & $\ldots$ & 1 & $\ldots$ & $\ldots$ & $\ldots$ & $\ldots$ & $\ldots$ & $\ldots$ & 3 & 3 & 6 \\
\hline Trypoxylon scutatum Chevrier, 1867 & $\ldots$ & $\ldots$ & 1 & $\ldots$ & $\ldots$ & 2 & $\ldots$ & 5 & $\ldots$ & 6 & $\ldots$ & 8 & $\ldots$ & 1 & $\ldots$ & 1 & 1 & 23 & 24 \\
\hline
\end{tabular}




\begin{tabular}{|c|c|c|c|c|c|c|c|c|c|c|c|c|c|c|c|c|c|c|c|}
\hline \multirow{3}{*}{\begin{tabular}{|c} 
Periodos de muestreo \\
LOCALIDAD 3F - DENTRO 3 \\
Pereña (SA) Trampa Malaise \\
Año 2005
\end{tabular}} & \multicolumn{2}{|c|}{1} & \multicolumn{2}{|c|}{2} & \multicolumn{2}{|c|}{3} & \multicolumn{2}{|c|}{4} & \multicolumn{2}{|c|}{5} & \multicolumn{2}{|c|}{6} & \multicolumn{2}{|c|}{7} & \multicolumn{2}{|c|}{8} & & & \\
\hline & \multicolumn{2}{|c|}{$\begin{array}{c}1-15 \\
\text { VI }\end{array}$} & \multicolumn{2}{|c|}{$\begin{array}{c}16-30 \\
\text { VI }\end{array}$} & \multicolumn{2}{|c|}{$\begin{array}{c}1-15 \\
\text { VII }\end{array}$} & \multicolumn{2}{|c|}{$\begin{array}{c}16-31 \\
\text { VII }\end{array}$} & \multicolumn{2}{|c|}{ 1-15 VIII } & \multicolumn{2}{|c|}{ 16-31 VIII } & \multicolumn{2}{|c|}{$\begin{array}{c}1-15 \\
\text { IX }\end{array}$} & \multicolumn{2}{|c|}{$\begin{array}{c}16-30 \\
\text { IX }\end{array}$} & \multicolumn{2}{|c|}{ Totales } & \multirow{2}{*}{$\Sigma$} \\
\hline & & $\mathbf{H}$ & & $\mathbf{H}$ & $\mathbf{M}$ & $\mathbf{H}$ & M & $\mathbf{H}$ & M & $\mathbf{H}$ & $\mathbf{M}$ & $\mathbf{H}$ & $\mathbf{M}$ & & $\mathbf{M}$ & $\mathbf{H}$ & $\mathbf{M}$ & $\mathbf{H}$ & \\
\hline \multicolumn{20}{|l|}{ OXYBELINI } \\
\hline Oxybelus quattuordecimnotatus Jurine, 1807 & & & $\ldots$ & $\ldots$ & $\ldots$ & $\ldots$ & $\ldots$ & $\ldots$ & $\ldots$ & $\ldots$ & $\ldots$ & $\ldots$ & $\ldots$ & $\ldots$ & $\ldots$ & & 0 & 1 & 1 \\
\hline \multicolumn{20}{|l|}{ CRABRONINI } \\
\hline Encopognathus braunsi Mercet, 1915 & & 1 & $\cdots$ & $\cdots$ & $\cdots$ & $\ldots$ & $\ldots$ & $\ldots$ & $\ldots$ & $\ldots$ & $\ldots$ & $\cdots$ & $\ldots$ & $\ldots$ & $\cdots$ & $\ldots$ & 0 & 1 & 1 \\
\hline Ectemnius cephalotes (Olivier, 1792) & $\ldots$ & $\ldots$ & $\ldots$ & $\ldots$ & $\ldots$ & $\ldots$ & $\ldots$ & $\ldots$ & $\ldots$ & $\ldots$ & $\ldots$ & $\ldots$ & $\ldots$ & $\ldots$ & $\ldots$ & 1 & 0 & 1 & 1 \\
\hline Ectemnius crassicornis (Spinola, 1808) & $\ldots$ & $\ldots$ & $\cdots$ & $\cdots$ & 1 & $\ldots$ & $\ldots$ & $\ldots$ & $\ldots$ & $\ldots$ & $\ldots$ & $\ldots$ & $\ldots$ & $\ldots$ & $\ldots$ & $\ldots$ & 1 & 0 & 1 \\
\hline \multicolumn{20}{|l|}{ BEMBICINAE } \\
\hline \multicolumn{20}{|l|}{ NYSSONINI } \\
\hline Brachystegus scalaris (Illiger, 1807) & 1 & $\cdots$ & $\ldots$ & $\cdots$ & $\ldots$ & $\ldots$ & $\cdots$ & $\ldots$ & $\ldots$ & $\cdots$ & $\ldots$ & $\cdots$ & $\cdots$ & $\cdots$ & $\cdots$ & $\ldots$ & 1 & 0 & 1 \\
\hline \multicolumn{20}{|l|}{ BEMBICINI } \\
\hline Harpactus elegans (Lepeletier, 1832) & 1 & $\ldots$ & $\cdots$ & $\cdots$ & $\cdots$ & $\ldots$ & $\cdots$ & $\ldots$ & $\ldots$ & $\cdots$ & $\ldots$ & $\cdots$ & $\ldots$ & $\ldots$ & $\ldots$ & $\ldots$ & 1 & 0 & 1 \\
\hline Harpactus sp. 2 grimaldensis Gayubo, sp. n. (in lit.) & 1 & $\ldots$ & $\cdots$ & $\ldots$ & $\ldots$ & $\ldots$ & $\ldots$ & $\ldots$ & $\ldots$ & $\ldots$ & $\ldots$ & $\ldots$ & $\ldots$ & $\ldots$ & $\ldots$ & $\cdots$ & 1 & 0 & 1 \\
\hline Bembecinus carpetanus (Mercet, 1906) & $\ldots$ & $\ldots$ & $\ldots$ & $\ldots$ & $\ldots$ & 1 & $\ldots$ & $\ldots$ & $\ldots$ & $\ldots$ & $\ldots$ & $\ldots$ & $\ldots$ & $\ldots$ & $\ldots$ & $\ldots$ & 0 & 1 & 1 \\
\hline Bembecinus pulchelus (Mercet, 1906) & 3 & $\ldots$ & $\ldots$ & 45 & $\ldots$ & 19 & $\cdots$ & $\ldots$ & $\ldots$ & $\cdots$ & $\ldots$ & $\ldots$ & $\cdots$ & $\ldots$ & $\ldots$ & $\ldots$ & 3 & 64 & 67 \\
\hline Bembix oculata Panzer, 1801 & $\ldots$ & $\ldots$ & $\ldots$ & $\ldots$ & $\ldots$ & $\ldots$ & $\ldots$ & $\ldots$ & $\ldots$ & $\cdots$ & $\ldots$ & $\ldots$ & $\ldots$ & 1 & $\ldots$ & $\ldots$ & 0 & 1 & 1 \\
\hline Subtotales & 25 & 14 & 23 & 88 & 20 & 60 & 6 & 23 & 15 & 17 & 10 & 22 & 1 & 5 & 1 & 2 & 101 & 231 & \\
\hline Total de Ejemplares & \multicolumn{2}{|c|}{39} & \multicolumn{2}{|c|}{111} & \multicolumn{2}{|c|}{80} & \multicolumn{2}{|c|}{29} & & & & & & & & & & 32 & 332 \\
\hline Total de Especies & 1 & & & & & & & & & & & & & & & & & & 40 \\
\hline
\end{tabular}




\begin{tabular}{|c|c|c|c|c|c|c|c|c|c|c|c|}
\hline \multirow{3}{*}{\begin{tabular}{|c} 
Periodos de muestreo \\
LOCALIDAD 3F \\
Pereña (SA) PLATOS \\
Año 2005
\end{tabular}} & \multicolumn{2}{|c|}{1} & \multicolumn{2}{|c|}{2} & \multicolumn{2}{|c|}{3} & \multicolumn{2}{|c|}{4} & & & \\
\hline & \multicolumn{2}{|c|}{ 15-Jun } & \multicolumn{2}{|c|}{ 15-Jul } & \multicolumn{2}{|c|}{ 15-Agos } & \multicolumn{2}{|c|}{ 15-Sep } & \multicolumn{2}{|c|}{ Totales } & \multirow{2}{*}{$\Sigma$} \\
\hline & M & & & & $\mathbf{M}$ & & $\mathbf{M}$ & & $\mathbf{M}$ & $\mathbf{H}$ & \\
\hline \multicolumn{12}{|l|}{ SPHECIDAE } \\
\hline \multicolumn{12}{|l|}{ SPHECINAE } \\
\hline \multicolumn{12}{|l|}{ PRIONYCHINI } \\
\hline Prionyx kirbii (Van der Linden, 1827) & $\ldots$ & $\ldots$ & $\ldots$ & $\ldots$ & $\ldots$ & $\ldots$ & $\ldots$ & 1 & 0 & 1 & 1 \\
\hline \multicolumn{12}{|l|}{ AMMOPHILINAE } \\
\hline \multicolumn{12}{|l|}{ AMMOPHILINI } \\
\hline Ammophila campestris Latreille, 1809 & $\ldots$ & 1 & $\ldots$ & $\ldots$ & $\ldots$ & $\ldots$ & $\ldots$ & $\ldots$ & 0 & 1 & 1 \\
\hline Ammophila heydeni Dahlbom, 1845 & $\ldots$ & $\ldots$ & $\ldots$ & $\ldots$ & 1 & 1 & $\ldots$ & $\ldots$ & 1 & 1 & 2 \\
\hline \multicolumn{12}{|l|}{ CRABRONIDAE } \\
\hline \multicolumn{12}{|l|}{ PEMPHREDONINAE } \\
\hline \multicolumn{12}{|l|}{ PEMPHREDONINI } \\
\hline Diodontus insidiosus Spooner, 1938 & $\ldots$ & $\ldots$ & $\ldots$ & $\ldots$ & 1 & 2 & $\ldots$ & 1 & 1 & 3 & 4 \\
\hline DINETINAE & & & & & & & & & & & \\
\hline DINETINI & & & & & & & & & & & \\
\hline Dinetus pictus (Fabricius, 1793) & $\ldots$ & 1 & $\ldots$ & $\ldots$ & $\ldots$ & $\ldots$ & $\ldots$ & $\ldots$ & 0 & 1 & 1 \\
\hline CRABRONINAE & & & & & & & & & & & \\
\hline LARRINI & & & & & & & & & & & \\
\hline Larra anathema (Rossi, 1790) & $\ldots$ & $\ldots$ & $\ldots$ & $\ldots$ & 1 & $\ldots$ & $\ldots$ & $\ldots$ & 1 & 0 & 1 \\
\hline Liris niger (Fabricius, 1775) & $\ldots$ & $\ldots$ & $\ldots$ & $\ldots$ & $\ldots$ & 1 & $\ldots$ & $\ldots$ & 0 & 1 & 1 \\
\hline Tachytes panzeri (Dufour, 1841) & $\ldots$ & $\ldots$ & $\ldots$ & 1 & $\cdots$ & $\ldots$ & $\ldots$ & $\ldots$ & 0 & 1 & 1 \\
\hline Tachysphex incertus (Radoszkowski, 1877) & 1 & 1 & $\cdots$ & $\ldots$ & $\cdots$ & $\ldots$ & $\cdots$ & $\ldots$ & 1 & 1 & 2 \\
\hline Tachysphex mediterraneus Kohl, 1883 & $\ldots$ & $\ldots$ & $\ldots$ & 2 & $\ldots$ & $\ldots$ & $\ldots$ & $\ldots$ & 0 & 2 & 2 \\
\hline Tachysphex nitidior Beaumont, 1940 & $\ldots$ & 1 & $\ldots$ & $\ldots$ & $\cdots$ & 6 & $\cdots$ & $\ldots$ & 0 & 7 & 7 \\
\hline Tachysphex obscuripennis (Schenck, 1857) & 4 & 2 & 7 & 2 & $\ldots$ & 3 & 1 & $\ldots$ & 12 & 7 & 19 \\
\hline Tachysphex panzeri (Van der Linden, 1829) & $\ldots$ & $\ldots$ & $\ldots$ & $\ldots$ & $\cdots$ & 1 & $\ldots$ & $\ldots$ & 0 & 1 & 1 \\
\hline Tachysphex pompiliformis (Panzer, 1805) & 1 & 1 & $\ldots$ & $\ldots$ & $\ldots$ & $\ldots$ & $\ldots$ & $\ldots$ & 1 & 1 & 2 \\
\hline Tachysphex pseudopanzeri Beaumont, 1955 & $\ldots$ & $\ldots$ & $\cdots$ & $\ldots$ & 6 & $\ldots$ & $\ldots$ & $\ldots$ & 6 & 0 & 6 \\
\hline Tachysphex tarsinus (Lepeletier, 1845) & $\ldots$ & $\ldots$ & $\ldots$ & $\ldots$ & $\ldots$ & 1 & $\ldots$ & $\ldots$ & 0 & 1 & 1 \\
\hline Tachysphex unicolor (Panzer, 1809) & $\ldots$ & $\ldots$ & $\ldots$ & 1 & $\ldots$ & $\ldots$ & $\ldots$ & $\ldots$ & 0 & 1 & 1 \\
\hline MISCOPHINI & & & & & & & & & & & \\
\hline Solierella compedita (Piccioli, 1869) & $\ldots$ & 19 & 5 & 10 & 8 & 6 & $\ldots$ & 1 & 13 & 36 & 49 \\
\hline Solierella pisonoides (Saunders, 1873) & 2 & 3 & 1 & $\ldots$ & $\cdots$ & $\ldots$ & $\ldots$ & $\ldots$ & 3 & 3 & 6 \\
\hline Solierella seabrai Andrade, 1950 & $\ldots$ & 4 & 1 & $\ldots$ & $\ldots$ & 1 & $\ldots$ & $\ldots$ & 1 & 5 & 6 \\
\hline Miscophus eatoni Saunders, 1903 & $\ldots$ & $\ldots$ & 1 & $\ldots$ & $\ldots$ & $\ldots$ & $\ldots$ & 1 & 1 & 1 & 2 \\
\hline Miscophus nicolai Ferton, 1896 & 3 & 3 & 1 & 5 & 5 & 9 & $\ldots$ & $\ldots$ & 9 & 17 & 26 \\
\hline Miscophus niger Dahlbom, 1848 & $\ldots$ & $\ldots$ & $\ldots$ & $\ldots$ & $\ldots$ & 1 & $\ldots$ & $\ldots$ & 0 & 1 & 1 \\
\hline TRYPOXYLINI & & & & & & & & & & & \\
\hline Pison atrum (Spinola, 1808) & $\ldots$ & 1 & $\ldots$ & $\ldots$ & $\ldots$ & $\ldots$ & $\cdots$ & $\ldots$ & 0 & 1 & 1 \\
\hline Trypoxylon attenuatum F. Smith, 1851 & $\ldots$ & $\ldots$ & $\ldots$ & $\ldots$ & $\ldots$ & 2 & $\ldots$ & 2 & 0 & 4 & 4 \\
\hline Trypoxylon scutatum Chevrier, 1867 & $\ldots$ & 1 & $\ldots$ & 7 & $\cdots$ & 15 & $\ldots$ & 7 & 0 & 30 & 30 \\
\hline OXYBELINI & & & & & & & & & & & \\
\hline Oxybelus quattuordecimnotatus Jurine, 1807 & $\ldots$ & 1 & $\ldots$ & $\ldots$ & $\ldots$ & $\ldots$ & $\ldots$ & $\ldots$ & 0 & 1 & 1 \\
\hline Oxybelus subspinosus Klug, 1835 & $\cdots$ & $\ldots$ & $\ldots$ & $\ldots$ & $\ldots$ & 1 & $\cdots$ & $\ldots$ & 0 & 1 & 1 \\
\hline CRABRONINI & & & & & & & & & & & \\
\hline Tracheliodes quinquenotatus (Jurine, 1807) & $\cdots$ & $\ldots$ & 1 & $\ldots$ & $\ldots$ & $\ldots$ & $\ldots$ & $\ldots$ & 1 & 0 & 1 \\
\hline Lestica clypeata (Schreber, 1759) & $\ldots$ & $\ldots$ & $\ldots$ & 1 & $\ldots$ & $\ldots$ & $\ldots$ & $\ldots$ & 0 & 1 & 1 \\
\hline
\end{tabular}




\begin{tabular}{|c|c|c|c|c|c|c|c|c|c|c|c|}
\hline \multirow{3}{*}{\begin{tabular}{|c|} 
Periodos de muestreo \\
LOCALIDAD 3F \\
Pereña (SA) PLATOS \\
Año 2005 \\
\end{tabular}} & \multicolumn{2}{|c|}{1} & \multicolumn{2}{|c|}{2} & \multicolumn{2}{|c|}{3} & \multicolumn{2}{|l|}{4} & & & \\
\hline & \multicolumn{2}{|c|}{ 15-Jun } & \multicolumn{2}{|c|}{ 15-Jul } & \multicolumn{2}{|c|}{ 15-Agos } & \multicolumn{2}{|c|}{ 15-Sep } & \multicolumn{2}{|c|}{ Totales } & \multirow{2}{*}{$\Sigma$} \\
\hline & M & & M & & M & H & M & & M & H & \\
\hline \multicolumn{12}{|l|}{ BEMBICINAE } \\
\hline \multicolumn{12}{|l|}{ NYSSONINI } \\
\hline Brachystegus scalaris (Illiger, 1807) & 1 & & & $\ldots$ & $\ldots$ & $\ldots$ & $\ldots$ & $\ldots$ & 1 & 1 & 2 \\
\hline \multicolumn{12}{|l|}{ BEMBICINI } \\
\hline Harpactus alvaroi Gayubo, 1992 & $\ldots$ & $\ldots$ & $\ldots$ & $\ldots$ & $\ldots$ & 1 & $\ldots$ & $\ldots$ & 0 & 1 & 1 \\
\hline Harpactus elegans (Lepeletier, 1832) & 1 & $\ldots$ & $\ldots$ & $\ldots$ & $\ldots$ & $\ldots$ & $\ldots$ & $\ldots$ & 1 & 0 & 1 \\
\hline Bembecinus carpetanus (Mercet, 1906) & & 1 & $\ldots$ & $\ldots$ & $\ldots$ & ... & $\ldots$ & $\ldots$ & 0 & 1 & 1 \\
\hline Bembecinus pulchelus (Mercet, 1906) & 9 & 66 & $\ldots$ & 2 & $\ldots$ & $\ldots$ & $\ldots$ & $\ldots$ & 9 & 68 & 77 \\
\hline Subtotales & 22 & 107 & 17 & 31 & 22 & 51 & 1 & 13 & 62 & 202 & \\
\hline Total de Ejemplares & \multicolumn{2}{|c|}{129} & \multicolumn{2}{|c|}{48} & \multicolumn{2}{|c|}{73} & \multicolumn{2}{|c|}{14} & \multicolumn{2}{|c|}{264} & 264 \\
\hline Total de Especies & \multicolumn{2}{|c|}{17} & \multicolumn{2}{|c|}{13} & \multicolumn{2}{|c|}{17} & \multicolumn{2}{|l|}{7} & & & 35 \\
\hline
\end{tabular}




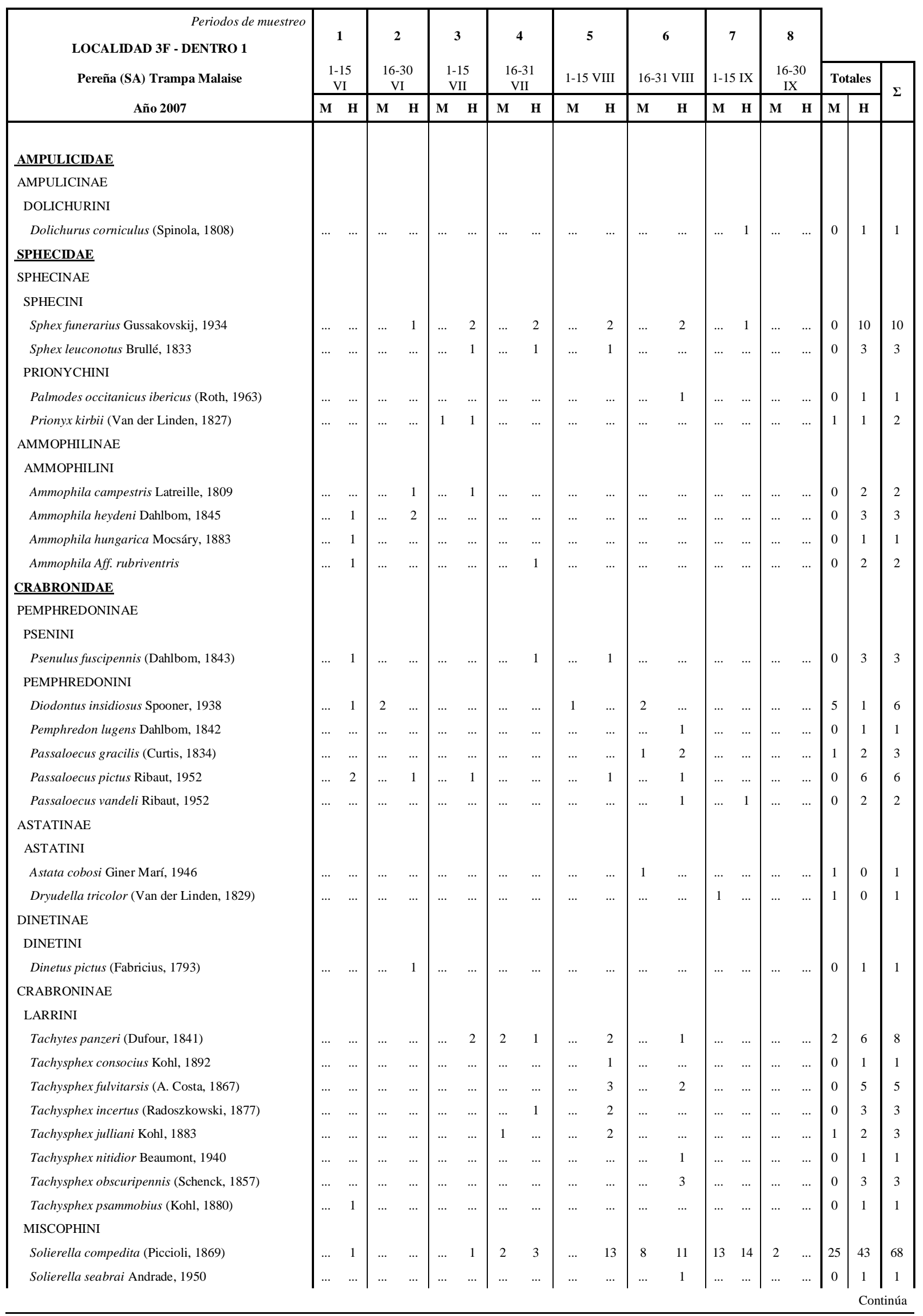




\begin{tabular}{|c|c|c|c|c|c|c|c|c|c|c|c|c|c|c|c|c|c|c|c|}
\hline \multirow{3}{*}{$\begin{array}{r}\text { Periodos de muestreo } \\
\text { LOCALIDAD 3F - DENTRO } 1 \\
\text { Pereña (SA) Trampa Malaise } \\
\text { Año } 2007\end{array}$} & \multirow{2}{*}{\multicolumn{2}{|c|}{$\begin{array}{c}1 \\
\\
1-15 \\
\text { VI } \\
\end{array}$}} & \multirow{2}{*}{\multicolumn{2}{|c|}{$\begin{array}{c}2 \\
16-30 \\
\text { VI }\end{array}$}} & \multirow{2}{*}{\multicolumn{2}{|c|}{$\begin{array}{c}3 \\
\\
1-15 \\
\text { VII }\end{array}$}} & \multirow{2}{*}{\multicolumn{2}{|c|}{$\begin{array}{c}4 \\
16-31 \\
\text { VII }\end{array}$}} & \multirow{2}{*}{\multicolumn{2}{|c|}{$\begin{array}{c}5 \\
1-15 \text { VIII }\end{array}$}} & \multirow{2}{*}{\multicolumn{2}{|c|}{$\begin{array}{c}6 \\
16-31 \mathrm{VIII}\end{array}$}} & \multirow{2}{*}{\multicolumn{2}{|c|}{$\begin{array}{c}7 \\
1-15 \text { IX }\end{array}$}} & \multirow{2}{*}{\multicolumn{2}{|c|}{$\begin{array}{c}8 \\
16-30 \\
\text { IX }\end{array}$}} & \multirow{3}{*}{\multicolumn{3}{|c|}{ Tot }} \\
\hline & & & & & & & & & & & & & & & & & & & \\
\hline & & $\mathbf{H}$ & M & & $\mathbf{M}$ & & $\mathbf{M}$ & & $\mathbf{M}$ & $\mathbf{H}$ & M & $\mathbf{H}$ & M & & & & & & \\
\hline Miscophus bicolor Jurine, 1807 & & $\ldots$ & $\ldots$ & $\ldots$ & ... & $\ldots$ & $\ldots$ & $\ldots$ & $\ldots$ & 1 & 1 & 1 & 2 & & $\ldots$ & $\ldots$ & 3 & 2 & 5 \\
\hline Miscophus eatoni Saunders, 1903 & $\ldots$ & $\ldots$ & $\ldots$ & $\ldots$ & $\ldots$ & $\ldots$ & $\ldots$ & $\ldots$ & $\ldots$ & $\ldots$ & $\ldots$ & $\ldots$ & 1 & $\ldots$ & $\ldots$ & $\ldots$ & 1 & 0 & 1 \\
\hline Miscophus nicolai Ferton, 1896 & $\ldots$ & $\ldots$ & $\ldots$ & $\ldots$ & $\ldots$ & $\ldots$ & $\ldots$ & $\ldots$ & $\ldots$ & $\ldots$ & $\ldots$ & 2 & $\ldots$ & $\ldots$ & $\ldots$ & $\ldots$ & 0 & 2 & 2 \\
\hline Nitela lucens Gayubo \& Felton, 2000 & $\ldots$ & $\ldots$ & $\ldots$ & $\ldots$ & .. & $\ldots$ & $\ldots$ & $\cdots$ & $\cdots$ & $\ldots$ & $\ldots$ & 3 & $\ldots$ & 1 & $\ldots$ & 1 & 0 & 5 & 5 \\
\hline Nitela truncata Gayubo \& Felton, 2000 & $\ldots$ & $\ldots$ & $\ldots$ & $\ldots$ & 1 & 1 & $\ldots$ & 1 & $\ldots$ & $\ldots$ & $\ldots$ & 1 & $\ldots$ & $\ldots$ & 3 & $\ldots$ & 4 & 3 & 7 \\
\hline \multicolumn{20}{|l|}{ TRYPOXYLINI } \\
\hline Pison atrum (Spinola, 1808) & $\ldots$ & $\ldots$ & $\ldots$ & $\ldots$ & ... & $\ldots$ & $\ldots$ & 1 & $\ldots$ & $\ldots$ & $\ldots$ & $\ldots$ & $\ldots$ & $\ldots$ & $\ldots$ & $\ldots$ & 0 & 1 & 1 \\
\hline Trypoxylon attenuatum F. Smith, 1851 & $\ldots$ & $\ldots$ & $\ldots$ & $\ldots$ & $\ldots$ & $\ldots$ & $\ldots$ & $\ldots$ & 1 & 1 & 1 & 2 & $\ldots$ & 2 & $\ldots$ & $\ldots$ & 2 & 5 & 7 \\
\hline Trypoxylon clavicerum Lepeletier \& Serville, 1828 & $\cdots$ & 1 & $\cdots$ & $\cdots$ & $\cdots$ & $\cdots$ & $\cdots$ & $\cdots$ & $\cdots$ & $\ldots$ & $\ldots$ & 1 & $\ldots$ & $\ldots$ & $\ldots$ & $\ldots$ & 0 & 2 & 2 \\
\hline Trypoxylon scutatum Chevrier, 1867 & $\ldots$ & 2 & $\ldots$ & 1 & $\ldots$ & $\ldots$ & $\ldots$ & 1 & 1 & 10 & 2 & 6 & $\ldots$ & 9 & $\ldots$ & 1 & 3 & 30 & 33 \\
\hline \multicolumn{20}{|l|}{ OXYBELINI } \\
\hline Belomicrus odonthophorus (Kohl, 1892) & $\ldots$ & $\ldots$ & $\ldots$ & $\ldots$ & $\ldots$ & $\cdots$ & $\ldots$ & $\ldots$ & $\ldots$ & 1 & $\ldots$ & $\ldots$ & $\ldots$ & $\ldots$ & $\ldots$ & $\ldots$ & 0 & 1 & 1 \\
\hline Oxybelus quattuordecimnotatus Jurine, 1807 & 2 & $\ldots$ & $\ldots$ & 1 & 1 & $\ldots$ & $\ldots$ & $\ldots$ & $\ldots$ & $\ldots$ & $\ldots$ & $\ldots$ & 1 & $\ldots$ & $\ldots$ & 1 & 4 & 2 & 6 \\
\hline \multicolumn{20}{|l|}{ CRABRONINI } \\
\hline Lindenius pygmaeus (Rossi, 1794) & $\ldots$ & $\ldots$ & $\cdots$ & $\ldots$ & $\ldots$ & $\ldots$ & $\ldots$ & $\ldots$ & $\ldots$ & $\ldots$ & $\ldots$ & $\ldots$ & $\ldots$ & 1 & $\ldots$ & $\ldots$ & 0 & 1 & 1 \\
\hline Ectemnius crassicornis (Spinola, 1808) & $\ldots$ & $\ldots$ & $\ldots$ & $\ldots$ & $\ldots$ & $\cdots$ & $\ldots$ & $\ldots$ & $\ldots$ & $\ldots$ & $\ldots$ & $\ldots$ & $\ldots$ & 2 & $\ldots$ & $\ldots$ & 0 & 2 & 2 \\
\hline \multicolumn{20}{|l|}{ BEMBICINAE } \\
\hline \multicolumn{20}{|l|}{ NYSSONINI } \\
\hline Nysson maculosus (Gmelin, 1790) & $\ldots$ & $\ldots$ & $\cdots$ & $\ldots$ & ... & $\cdots$ & $\ldots$ & 1 & $\cdots$ & $\cdots$ & $\cdots$ & $\cdots$ & $\cdots$ & $\cdots$ & $\ldots$ & $\ldots$ & 0 & 1 & 1 \\
\hline Nysson parietalis Mercet, 1909 & $\ldots$ & $\ldots$ & $\cdots$ & $\ldots$ & $\ldots$ & $\ldots$ & $\ldots$ & $\ldots$ & $\cdots$ & 1 & $\cdots$ & $\ldots$ & $\cdots$ & $\ldots$ & $\ldots$ & $\cdots$ & 0 & 1 & 1 \\
\hline \multicolumn{20}{|l|}{ BEMBICINI } \\
\hline Harpactus formosus (Jurine, 1807) & $\ldots$ & $\ldots$ & $\cdots$ & ... & ... & $\cdots$ & $\ldots$ & 1 & $\ldots$ & $\cdots$ & $\cdots$ & $\cdots$ & $\cdots$ & $\ldots$ & $\ldots$ & $\cdots$ & 0 & 1 & 1 \\
\hline Harpactus laevis (Latreille, 1792) & $\ldots$ & $\ldots$ & $\cdots$ & $\ldots$ & $\ldots$ & $\cdots$ & $\ldots$ & $\cdots$ & $\ldots$ & 1 & $\cdots$ & $\cdots$ & $\cdots$ & $\ldots$ & $\ldots$ & $\ldots$ & 0 & 1 & 1 \\
\hline Harpactus morawitzi (Snoflak, 1943) & $\ldots$ & $\ldots$ & $\ldots$ & $\ldots$ & ... & $\cdots$ & ... & $\ldots$ & $\ldots$ & $\ldots$ & $\ldots$ & 1 & $\ldots$ & $\ldots$ & $\ldots$ & $\ldots$ & 0 & 1 & 1 \\
\hline Harpactus sp. 2 grimaldensis Gayubo, sp. n. (in lit.) & $\ldots$ & $\ldots$ & $\cdots$ & $\ldots$ & $\ldots$ & $\cdots$ & $\ldots$ & $\cdots$ & $\ldots$ & $\cdots$ & $\cdots$ & $\cdots$ & $\cdots$ & 1 & $\ldots$ & $\cdots$ & 0 & 1 & 1 \\
\hline Bembecinus carpetanus (Mercet, 1906) & $\ldots$ & $\ldots$ & $\ldots$ & $\ldots$ & $\ldots$ & 1 & $\ldots$ & $\ldots$ & $\ldots$ & $\ldots$ & $\ldots$ & $\ldots$ & $\ldots$ & $\ldots$ & $\ldots$ & $\ldots$ & 0 & 1 & 1 \\
\hline Bembecinus pulchelus (Mercet, 1906) & $\ldots$ & $\ldots$ & $\ldots$ & $\ldots$ & ... & 12 & $\ldots$ & 2 & $\ldots$ & 1 & $\ldots$ & $\ldots$ & $\ldots$ & $\ldots$ & $\ldots$ & $\ldots$ & 0 & 15 & 15 \\
\hline Bembix bidentata Van der Linden, 1829 & $\ldots$ & $\ldots$ & $\ldots$ & $\ldots$ & $\ldots$ & $\ldots$ & $\ldots$ & 1 & $\ldots$ & $\ldots$ & $\ldots$ & $\ldots$ & $\ldots$ & $\ldots$ & $\ldots$ & $\ldots$ & 0 & 1 & 1 \\
\hline Bembix zonata Klug, 1835 & $\ldots$ & $\ldots$ & $\ldots$ & $\ldots$ & $\ldots$ & $\ldots$ & $\ldots$ & $\ldots$ & $\ldots$ & 1 & $\ldots$ & 2 & $\ldots$ & $\ldots$ & $\ldots$ & $\ldots$ & 0 & 3 & 3 \\
\hline \multicolumn{20}{|l|}{ PHILANTHINAE } \\
\hline \multicolumn{20}{|l|}{ CERCERINI } \\
\hline Cerceris arenaria (Linnaeus, 1758) & 1 & $\ldots$ & 1 & $\ldots$ & 1 & $\ldots$ & 1 & $\ldots$ & 2 & $\ldots$ & 1 & $\ldots$ & $\ldots$ & $\ldots$ & $\ldots$ & $\ldots$ & 7 & 0 & 7 \\
\hline Cerceris rybyensis (Linnaeus, 1771) & 1 & $\ldots$ & $\ldots$ & $\ldots$ & $\ldots$ & $\ldots$ & $\ldots$ & $\ldots$ & $\ldots$ & $\ldots$ & $\ldots$ & $\ldots$ & $\ldots$ & $\ldots$ & $\ldots$ & $\ldots$ & 1 & 0 & 1 \\
\hline \multirow{2}{*}{$\begin{array}{r}\text { Subtotales } \\
\text { Total de Ejemplares }\end{array}$} & 4 & 12 & 3 & 8 & 4 & 23 & 6 & 18 & 5 & 45 & 17 & 46 & 18 & 33 & 5 & 3 & 62 & 188 & 250 \\
\hline & & & & & & & & & & & & & & & & & & 50 & \\
\hline Total de Especies & & & & & & & & & & & & & & & & & & & 53 \\
\hline
\end{tabular}




\begin{tabular}{|c|c|c|c|c|c|c|c|c|c|c|c|c|c|c|c|c|c|c|c|}
\hline \multirow{3}{*}{$\begin{array}{c}\text { Periodos de muestreo } \\
\text { LOCALIDAD 3F - DENTRO } 2 \\
\text { Pereña (SA) Trampa Malaise } \\
\text { Año 2007 }\end{array}$} & \multicolumn{2}{|c|}{1} & \multicolumn{2}{|c|}{2} & \multicolumn{2}{|c|}{3} & \multicolumn{2}{|c|}{4} & \multicolumn{2}{|c|}{5} & \multicolumn{2}{|c|}{6} & \multicolumn{2}{|c|}{7} & \multicolumn{2}{|c|}{8} & & & \\
\hline & \multicolumn{2}{|c|}{$1-15 \mathrm{VI}$} & \multicolumn{2}{|c|}{$\begin{array}{c}16-30 \\
\text { VI }\end{array}$} & \multicolumn{2}{|c|}{$\begin{array}{c}1-15 \\
\text { VII }\end{array}$} & \multicolumn{2}{|c|}{$\begin{array}{c}16-31 \\
\text { VII }\end{array}$} & \multicolumn{2}{|c|}{$\begin{array}{l}1-15 \\
\text { VIII }\end{array}$} & & & & & $\begin{array}{r}16- \\
\text { IV }\end{array}$ & & & les & $\Sigma$ \\
\hline & M & $\mathbf{H}$ & M & & $\mathbf{M}$ & $\mathbf{H}$ & $\mathbf{M}$ & $\mathbf{H}$ & $\mathbf{M}$ & $\mathbf{H}$ & $\mathbf{M}$ & $\mathbf{H}$ & $\mathbf{M}$ & $\mathbf{H}$ & $\mathbf{M}$ & $\mathbf{H}$ & $\mathbf{M}$ & $\mathbf{H}$ & \\
\hline$\underline{\text { SPHECIDAE }}$ & & & & & & & & & & & & & & & & & & & \\
\hline SCELIPHRINAE & & & & & & & & & & & & & & & & & & & \\
\hline SCELIPHRINI & & & & & & & & & & & & & & & & & & & \\
\hline Sceliphron destillatorium (Illiger, 1807) & $\ldots$ & & $\ldots$ & $\ldots$ & & & $\ldots$ & $\ldots$ & $\ldots$ & 1 & $\ldots$ & $\ldots$ & $\ldots$ & $\ldots$ & $\ldots$ & $\ldots$ & 0 & 2 & 2 \\
\hline SPHECINAE & & & & & & & & & & & & & & & & & & & \\
\hline SPHECINI & & & & & & & & & & & & & & & & & & & \\
\hline Sphex funerarius Gussakovskij, 1934 & $\ldots$ & $\ldots$ & $\ldots$ & $\ldots$ & $\ldots$ & 1 & 1 & 1 & $\ldots$ & $\ldots$ & $\ldots$ & $\ldots$ & $\ldots$ & $\cdots$ & $\ldots$ & $\ldots$ & 1 & 2 & 3 \\
\hline Sphex leuconotus Brullé, 1833 & $\ldots$ & $\ldots$ & $\ldots$ & 1 & $\ldots$ & $\ldots$ & $\ldots$ & $\ldots$ & $\ldots$ & $\ldots$ & $\ldots$ & $\ldots$ & $\ldots$ & $\cdots$ & $\ldots$ & $\ldots$ & 0 & 1 & 1 \\
\hline PRIONYCHINI & & & & & & & & & & & & & & & & & & & \\
\hline Palmodes melanarius (Mocsáry, 1883) & $\ldots$ & $\ldots$ & $\ldots$ & $\ldots$ & $\ldots$ & $\ldots$ & $\ldots$ & $\ldots$ & $\ldots$ & 1 & $\ldots$ & $\ldots$ & $\ldots$ & $\ldots$ & $\ldots$ & $\ldots$ & 0 & 1 & 1 \\
\hline *Palmodes occitanicus ibericus (Roth, 1963) & $\ldots$ & $\ldots$ & $\cdots$ & $\cdots$ & $\cdots$ & $\cdots$ & $\cdots$ & 1 & $\cdots$ & 1 & $\ldots$ & $\ldots$ & $\ldots$ & $\cdots$ & $\ldots$ & $\ldots$ & 0 & 2 & 2 \\
\hline *Palmodes occitanicus occitanicus (Lepeletier \& Serville 1828) & $\ldots$ & $\ldots$ & $\cdots$ & $\ldots$ & $\ldots$ & $\ldots$ & $\ldots$ & $\ldots$ & $\ldots$ & 1 & $\ldots$ & $\ldots$ & $\ldots$ & $\ldots$ & $\ldots$ & $\ldots$ & 0 & 1 & 1 \\
\hline Chilosphex argyrius (Brullé, 1833) & $\ldots$ & $\ldots$ & $\ldots$ & $\ldots$ & $\ldots$ & 2 & $\ldots$ & $\ldots$ & $\ldots$ & $\ldots$ & $\ldots$ & $\ldots$ & $\ldots$ & $\ldots$ & $\ldots$ & $\ldots$ & 0 & 2 & 2 \\
\hline AMMOPHILINAE & & & & & & & & & & & & & & & & & & & \\
\hline AMMOPHILINI & & & & & & & & & & & & & & & & & & & \\
\hline Ammophila campestris Latreille, 1809 & 1 & $\ldots$ & $\ldots$ & 1 & $\ldots$ & $\ldots$ & $\ldots$ & $\ldots$ & & $\cdots$ & & $\ldots$ & $\ldots$ & $\ldots$ & $\ldots$ & $\ldots$ & 1 & 1 & 2 \\
\hline Ammophila heydeni Dahlbom, 1845 & 1 & $\ldots$ & $\cdots$ & $\ldots$ & $\ldots$ & $\ldots$ & $\cdots$ & $\ldots$ & $\cdots$ & $\ldots$ & $\ldots$ & $\ldots$ & $\ldots$ & $\cdots$ & $\ldots$ & $\ldots$ & 1 & 0 & 1 \\
\hline Ammophila hungarica Mocsáry, 1883 & $\ldots$ & 1 & $\ldots$ & $\ldots$ & $\ldots$ & $\ldots$ & $\ldots$ & $\ldots$ & $\cdots$ & $\ldots$ & $\ldots$ & $\ldots$ & $\ldots$ & $\ldots$ & $\ldots$ & $\ldots$ & 0 & 1 & 1 \\
\hline CRABRONIDAE & & & & & & & & & & & & & & & & & & & \\
\hline PEMPHREDONINAE & & & & & & & & & & & & & & & & & & & \\
\hline PSENINI & & & & & & & & & & & & & & & & & & & \\
\hline Psenulus fuscipennis (Dahlbom, 1843) & $\ldots$ & $\ldots$ & $\ldots$ & $\ldots$ & $\ldots$ & $\ldots$ & $\ldots$ & $\ldots$ & $\ldots$ & 4 & $\ldots$ & 2 & $\ldots$ & $\ldots$ & $\ldots$ & $\ldots$ & 0 & 6 & 6 \\
\hline Mimesa grandii Maidl, 1933 & $\ldots$ & $\ldots$ & $\ldots$ & $\ldots$ & $\ldots$ & $\ldots$ & $\ldots$ & 1 & $\ldots$ & 1 & $\ldots$ & 1 & $\ldots$ & 2 & $\ldots$ & $\ldots$ & 0 & 5 & 5 \\
\hline PEMPHREDONINI & & & & & & & & & & & & & & & & & & & \\
\hline Diodontus insidiosus Spooner, 1938 & 1 & 1 & 2 & 2 & $\ldots$ & $\ldots$ & $\ldots$ & $\ldots$ & 1 & 4 & 1 & $\ldots$ & $\ldots$ & $\ldots$ & $\ldots$ & $\ldots$ & 5 & 7 & 12 \\
\hline Pemphredon lethifer (Shuckard, 1837) & $\ldots$ & $\ldots$ & $\ldots$ & $\ldots$ & $\ldots$ & $\ldots$ & $\ldots$ & $\ldots$ & $\cdots$ & $\ldots$ & $\cdots$ & $\ldots$ & $\ldots$ & 1 & $\ldots$ & $\ldots$ & 0 & 1 & 1 \\
\hline Passaloecus gracilis (Curtis, 1834) & $\ldots$ & $\ldots$ & $\ldots$ & $\ldots$ & $\ldots$ & $\ldots$ & $\ldots$ & $\ldots$ & $\ldots$ & $\ldots$ & $\ldots$ & $\ldots$ & 1 & $\ldots$ & $\ldots$ & $\ldots$ & 1 & 0 & 1 \\
\hline Passaloecus pictus Ribaut, 1952 & $\ldots$ & 1 & $\ldots$ & 5 & $\ldots$ & 1 & $\ldots$ & 1 & $\ldots$ & $\ldots$ & $\ldots$ & 1 & $\ldots$ & $\ldots$ & $\ldots$ & $\ldots$ & 0 & 9 & 9 \\
\hline Ammoplanus ceballosi Giner Marí, 1943 & $\ldots$ & 2 & $\ldots$ & $\ldots$ & $\ldots$ & $\cdots$ & $\ldots$ & $\ldots$ & $\cdots$ & $\ldots$ & $\ldots$ & $\ldots$ & $\ldots$ & $\ldots$ & $\ldots$ & $\ldots$ & 0 & 2 & 2 \\
\hline ASTATINAE & & & & & & & & & & & & & & & & & & & \\
\hline ASTATINI & & & & & & & & & & & & & & & & & & & \\
\hline Astata cobosi Giner Marí, 1946 & $\ldots$ & $\ldots$ & $\ldots$ & $\ldots$ & $\ldots$ & 1 & $\ldots$ & $\ldots$ & $\cdots$ & 2 & $\ldots$ & 1 & $\ldots$ & $\ldots$ & $\ldots$ & $\ldots$ & 0 & 4 & 4 \\
\hline Astata costae A. Costa, 1867 & $\cdots$ & $\ldots$ & $\cdots$ & $\ldots$ & $\cdots$ & $\cdots$ & $\cdots$ & $\cdots$ & $\cdots$ & $\ldots$ & $\cdots$ & 1 & $\ldots$ & $\cdots$ & $\cdots$ & $\cdots$ & 0 & 1 & 1 \\
\hline Astata miegii Dufour, 1861 & $\ldots$ & $\ldots$ & $\ldots$ & $\ldots$ & $\ldots$ & $\ldots$ & 1 & $\ldots$ & $\ldots$ & $\ldots$ & $\ldots$ & $\ldots$ & $\ldots$ & $\ldots$ & $\ldots$ & $\ldots$ & 1 & 0 & 1 \\
\hline CRABRONINAE & & & & & & & & & & & & & & & & & & & \\
\hline LARRINI & & & & & & & & & & & & & & & & & & & \\
\hline Larra anathema (Rossi, 1790) & $\ldots$ & $\ldots$ & $\ldots$ & $\ldots$ & $\ldots$ & $\ldots$ & $\ldots$ & $\ldots$ & $\ldots$ & $\ldots$ & 1 & $\ldots$ & $\ldots$ & $\ldots$ & $\ldots$ & $\ldots$ & 1 & 0 & 1 \\
\hline Tachytes panzeri (Dufour, 1841) & $\ldots$ & $\ldots$ & $\ldots$ & $\ldots$ & $\ldots$ & 1 & 7 & 4 & 1 & 4 & $\ldots$ & $\ldots$ & $\ldots$ & $\ldots$ & $\ldots$ & $\ldots$ & 8 & 9 & 17 \\
\hline Tachysphex consocius Kohl, 1892 & $\ldots$ & 1 & $\ldots$ & 3 & $\ldots$ & $\ldots$ & $\ldots$ & $\ldots$ & $\ldots$ & $\ldots$ & $\ldots$ & $\ldots$ & $\ldots$ & $\ldots$ & $\ldots$ & $\ldots$ & 0 & 4 & 4 \\
\hline Tachysphex costae (De Stefani, 1882) & $\ldots$ & $\ldots$ & $\ldots$ & $\ldots$ & $\ldots$ & $\ldots$ & 2 & $\ldots$ & $\ldots$ & $\ldots$ & $\ldots$ & $\ldots$ & $\ldots$ & $\ldots$ & $\ldots$ & $\ldots$ & 2 & 0 & 2 \\
\hline Tachysphex fulvitarsis (A. Costa, 1867) & $\ldots$ & $\ldots$ & $\ldots$ & 1 & $\ldots$ & $\ldots$ & 1 & $\ldots$ & 1 & $\ldots$ & $\cdots$ & $\ldots$ & 1 & $\ldots$ & $\ldots$ & $\ldots$ & 3 & 1 & 4 \\
\hline Tachysphex incertus (Radoszkowski, 1877) & $\ldots$ & $\ldots$ & $\ldots$ & $\ldots$ & $\ldots$ & $\ldots$ & 4 & 5 & 5 & 4 & $\ldots$ & 1 & $\ldots$ & $\ldots$ & $\ldots$ & $\ldots$ & 9 & 10 & 19 \\
\hline Tachysphex nitidior Beaumont, 1940 & $\cdots$ & $\ldots$ & $\ldots$ & $\ldots$ & $\ldots$ & $\ldots$ & $\ldots$ & $\cdots$ & $\cdots$ & $\ldots$ & $\ldots$ & 2 & $\ldots$ & 2 & $\ldots$ & $\ldots$ & 0 & 4 & 4 \\
\hline Tachysphex obscuripennis (Schenck, 1857) & $\ldots$ & $\ldots$ & $\ldots$ & $\ldots$ & $\ldots$ & $\ldots$ & $\ldots$ & $\ldots$ & $\cdots$ & $\ldots$ & $\ldots$ & 1 & $\ldots$ & $\ldots$ & $\ldots$ & $\ldots$ & 0 & 1 & 1 \\
\hline Tachysphex panzeri (Van der Linden, 1829) & $\ldots$ & $\ldots$ & $\cdots$ & $\ldots$ & $\ldots$ & $\ldots$ & $\ldots$ & $\ldots$ & $\ldots$ & $\ldots$ & $\ldots$ & $\ldots$ & $\ldots$ & $\ldots$ & $\ldots$ & 1 & 0 & 1 & 1 \\
\hline Tachysphex pompiliformis (Panzer, 1805) & $\ldots$ & $\ldots$ & $\ldots$ & $\ldots$ & 1 & 1 & $\ldots$ & $\ldots$ & $\ldots$ & $\ldots$ & 1 & $\ldots$ & $\ldots$ & $\ldots$ & $\cdots$ & $\ldots$ & 2 & 1 & 3 \\
\hline Tachysphex psammobius (Kohl, 1880) & $\cdots$ & $\ldots$ & 1 & $\ldots$ & $\ldots$ & $\ldots$ & $\cdots$ & $\cdots$ & $\cdots$ & $\ldots$ & $\ldots$ & $\ldots$ & $\ldots$ & $\ldots$ & $\ldots$ & $\ldots$ & 1 & 0 & 1 \\
\hline Tachysphex pseudopanzeri Beaumont, 1955 & $\ldots$ & $\ldots$ & $\ldots$ & $\ldots$ & $\ldots$ & $\ldots$ & $\ldots$ & $\ldots$ & $\ldots$ & 2 & $\ldots$ & 1 & $\ldots$ & $\ldots$ & $\ldots$ & $\ldots$ & 0 & 3 & 3 \\
\hline
\end{tabular}




\begin{tabular}{|c|c|c|c|c|c|c|c|c|c|c|c|c|c|c|c|c|c|c|c|}
\hline \multirow{3}{*}{$\begin{array}{c}\text { Periodos de muestreo } \\
\text { LOCALIDAD 3F - DENTRO } 2 \\
\text { Pereña (SA) Trampa Malaise } \\
\text { Año } 2007\end{array}$} & \multicolumn{2}{|c|}{1} & \multicolumn{2}{|c|}{2} & \multicolumn{2}{|c|}{3} & \multicolumn{2}{|c|}{4} & \multicolumn{2}{|c|}{5} & \multicolumn{2}{|c|}{6} & \multicolumn{2}{|c|}{7} & \multicolumn{2}{|c|}{8} & & & \\
\hline & \multicolumn{2}{|c|}{$1-15 \mathrm{VI}$} & \multicolumn{2}{|c|}{$\begin{array}{c}16-30 \\
\text { VI }\end{array}$} & \multicolumn{2}{|c|}{$\begin{array}{c}1-15 \\
\text { VII }\end{array}$} & \multicolumn{2}{|c|}{$\begin{array}{c}16-31 \\
\text { VII }\end{array}$} & \multicolumn{2}{|c|}{$\begin{array}{l}1-15 \\
\text { VIII }\end{array}$} & \multicolumn{2}{|c|}{$\begin{array}{c}16-31 \\
\text { VIII }\end{array}$} & \multicolumn{2}{|c|}{$\begin{array}{c}1-15 \\
\text { IX }\end{array}$} & \multicolumn{2}{|c|}{$\begin{array}{c}16-30 \\
\text { IX }\end{array}$} & \multicolumn{2}{|c|}{ Totales } & \multirow[t]{2}{*}{$\Sigma$} \\
\hline & $\mathbf{M}$ & $\mathbf{H}$ & $\mathbf{M}$ & $\mathbf{H}$ & $\mathbf{M}$ & $\mathbf{H}$ & M & $\mathbf{H}$ & $\mathbf{M}$ & $\mathbf{H}$ & M & $\mathbf{H}$ & M & $\mathbf{H}$ & M & $\mathbf{H}$ & M & $\mathbf{H}$ & \\
\hline Tachysphex tarsinus (Lepeletier, 1845) & $\ldots$ & $\ldots$ & $\ldots$ & $\ldots$ & $\ldots$ & $\ldots$ & $\ldots$ & $\ldots$ & $\ldots$ & 1 & $\ldots$ & & $\ldots$ & & $\ldots$ & $\ldots$ & 0 & 1 & 1 \\
\hline Tachysphex unicolor (Panzer, 1809) & $\ldots$ & $\ldots$ & $\ldots$ & $\ldots$ & $\ldots$ & $\ldots$ & $\ldots$ & $\ldots$ & $\ldots$ & 1 & $\ldots$ & $\ldots$ & $\ldots$ & $\ldots$ & $\ldots$ & $\ldots$ & 0 & 1 & 1 \\
\hline Prosopigastra punctatissima A. Costa, 1870 & $\ldots$ & $\ldots$ & $\ldots$ & $\ldots$ & 1 & $\ldots$ & $\cdots$ & $\ldots$ & 1 & $\ldots$ & $\ldots$ & $\cdots$ & $\ldots$ & $\ldots$ & $\ldots$ & $\ldots$ & 2 & 0 & 2 \\
\hline \multicolumn{20}{|l|}{ MISCOPHINI } \\
\hline Solierella compedita (Piccioli, 1869) & $\ldots$ & $\ldots$ & $\ldots$ & $\cdots$ & $\ldots$ & $\ldots$ & $\ldots$ & 2 & 1 & 10 & 1 & 2 & 5 & 2 & 1 & $\ldots$ & 8 & 16 & 24 \\
\hline Solierella pisonoides (Saunders, 1873) & $\ldots$ & $\ldots$ & $\ldots$ & $\ldots$ & $\ldots$ & $\ldots$ & $\ldots$ & $\ldots$ & $\ldots$ & $\ldots$ & $\ldots$ & 1 & $\ldots$ & 2 & $\ldots$ & $\ldots$ & 0 & 3 & 3 \\
\hline Miscophus bicolor Jurine, 1807 & $\ldots$ & $\ldots$ & $\ldots$ & $\ldots$ & $\ldots$ & $\ldots$ & $\ldots$ & $\ldots$ & 2 & $\ldots$ & $\ldots$ & 1 & $\ldots$ & 2 & $\ldots$ & $\ldots$ & 2 & 3 & 5 \\
\hline Nitela truncata Gayubo \& Felton, 2000 & $\ldots$ & 1 & $\ldots$ & $\ldots$ & $\ldots$ & $\ldots$ & $\ldots$ & $\ldots$ & $\ldots$ & $\ldots$ & $\ldots$ & $\ldots$ & $\ldots$ & $\ldots$ & $\ldots$ & $\ldots$ & 0 & 1 & 1 \\
\hline \multicolumn{20}{|l|}{ TRYPOXYLINI } \\
\hline Trypoxylon attenuatum F. Smith, 1851 & $\ldots$ & 3 & $\ldots$ & $\ldots$ & $\ldots$ & $\ldots$ & $\ldots$ & $\ldots$ & 1 & 6 & 4 & 1 & 2 & 1 & $\ldots$ & 3 & 7 & 14 & 21 \\
\hline Trypoxylon clavicerum Lepeletier \& Serville, 1828 & $\ldots$ & $\ldots$ & $\ldots$ & $\ldots$ & $\ldots$ & $\ldots$ & $\ldots$ & $\ldots$ & $\ldots$ & 2 & $\cdots$ & $\ldots$ & $\ldots$ & $\ldots$ & $\ldots$ & $\ldots$ & 0 & 2 & 2 \\
\hline Trypoxylon scutatum Chevrier, 1867 & $\ldots$ & 2 & $\ldots$ & 1 & $\ldots$ & 2 & $\ldots$ & 1 & 1 & 3 & $\ldots$ & 7 & $\ldots$ & 8 & $\ldots$ & $\ldots$ & 1 & 24 & 25 \\
\hline \multicolumn{20}{|l|}{ OXYBELINI } \\
\hline Belomicrus odonthophorus (Kohl, 1892) & $\ldots$ & $\ldots$ & $\ldots$ & $\ldots$ & $\ldots$ & $\ldots$ & $\ldots$ & $\ldots$ & $\ldots$ & 2 & $\ldots$ & $\ldots$ & $\ldots$ & $\ldots$ & $\ldots$ & $\ldots$ & 0 & 2 & 2 \\
\hline Oxybelus quattuordecimnotatus Jurine, 1807 & 1 & 2 & 4 & $\ldots$ & 4 & $\ldots$ & 10 & $\ldots$ & 8 & 1 & 1 & $\ldots$ & $\ldots$ & $\ldots$ & $\ldots$ & $\ldots$ & 28 & 3 & 31 \\
\hline CRABRONINI & & & & & & & & & & & & & & & & & & & \\
\hline Tracheliodes quinquenotatus (Jurine, 1807) & $\ldots$ & $\ldots$ & $\ldots$ & $\ldots$ & $\ldots$ & $\ldots$ & $\ldots$ & $\ldots$ & $\ldots$ & 1 & $\ldots$ & 1 & $\ldots$ & $\ldots$ & $\ldots$ & $\ldots$ & 0 & 2 & 2 \\
\hline Ectemnius crassicornis (Spinola, 1808) & $\ldots$ & $\ldots$ & $\ldots$ & $\ldots$ & $\ldots$ & $\ldots$ & $\ldots$ & $\ldots$ & $\ldots$ & 1 & $\ldots$ & $\ldots$ & $\ldots$ & $\ldots$ & $\ldots$ & $\ldots$ & 0 & 1 & 1 \\
\hline Lestica clypeata (Schreber, 1759) & $\cdots$ & $\ldots$ & $\cdots$ & $\ldots$ & $\ldots$ & $\ldots$ & $\ldots$ & $\ldots$ & $\ldots$ & $\ldots$ & $\ldots$ & $\ldots$ & $\ldots$ & 1 & $\ldots$ & $\ldots$ & 0 & 1 & 1 \\
\hline BEMBICINAE & & & & & & & & & & & & & & & & & & & \\
\hline NYSSONINI & & & & & & & & & & & & & & & & & & & \\
\hline Brachystegus scalaris (Illiger, 1807) & $\ldots$ & $\ldots$ & $\ldots$ & $\ldots$ & $\ldots$ & $\ldots$ & $\ldots$ & $\ldots$ & $\ldots$ & 1 & $\ldots$ & $\cdots$ & $\ldots$ & $\ldots$ & $\ldots$ & $\ldots$ & 0 & 1 & 1 \\
\hline BEMBICINI & & & & & & & & & & & & & & & & & & & \\
\hline Gorytes sulcifrons (A. Costa, 1869) & $\ldots$ & $\cdots$ & $\ldots$ & $\ldots$ & $\ldots$ & $\ldots$ & 1 & $\ldots$ & 1 & $\ldots$ & $\ldots$ & $\ldots$ & $\ldots$ & $\ldots$ & $\cdots$ & $\cdots$ & 0 & 2 & 2 \\
\hline Harpactus alvaroi Gayubo, 1992 & $\ldots$ & $\cdots$ & $\ldots$ & $\ldots$ & $\ldots$ & $\ldots$ & $\ldots$ & $\ldots$ & $\ldots$ & 1 & $\ldots$ & $\ldots$ & $\ldots$ & 1 & $\ldots$ & $\ldots$ & 0 & 2 & 2 \\
\hline Harpactus sp. 2 grimaldensis Gayubo, sp. n. (in lit.) & $\cdots$ & $\cdots$ & $\ldots$ & $\ldots$ & $\cdots$ & $\ldots$ & $\ldots$ & 1 & $\cdots$ & $\ldots$ & $\cdots$ & $\ldots$ & $\ldots$ & $\ldots$ & $\ldots$ & $\ldots$ & 0 & 1 & 1 \\
\hline Bembecinus pulchelus (Mercet, 1906) & $\ldots$ & $\ldots$ & $\ldots$ & $\ldots$ & $\ldots$ & 4 & 1 & 19 & $\ldots$ & 8 & $\ldots$ & $\ldots$ & $\ldots$ & $\ldots$ & $\ldots$ & $\ldots$ & 1 & 31 & 32 \\
\hline Bembix oculata Panzer, 1801 & $\ldots$ & $\ldots$ & $\ldots$ & $\ldots$ & $\ldots$ & $\ldots$ & $\ldots$ & 1 & $\ldots$ & $\ldots$ & $\cdots$ & $\ldots$ & $\ldots$ & $\ldots$ & $\ldots$ & $\ldots$ & 0 & 1 & 1 \\
\hline Bembix zonata Klug, 1835 & $\ldots$ & $\ldots$ & $\ldots$ & $\ldots$ & $\ldots$ & $\ldots$ & 1 & 4 & $\ldots$ & 9 & $\ldots$ & 1 & $\cdots$ & $\ldots$ & $\ldots$ & $\ldots$ & 1 & 14 & 15 \\
\hline Subtotales & 4 & 14 & 7 & 14 & 6 & 14 & 29 & 41 & 23 & 72 & 9 & 25 & 9 & 22 & 1 & 4 & 86 & 208 & \\
\hline Total de Ejemplares & & & & & & & 7 & & & & & 4 & & & 5 & & & 94 & 294 \\
\hline Total de Especies & & & & & & & 1 & & & & & $\mathbf{0}$ & 1 & & 3 & & & & 53 \\
\hline
\end{tabular}




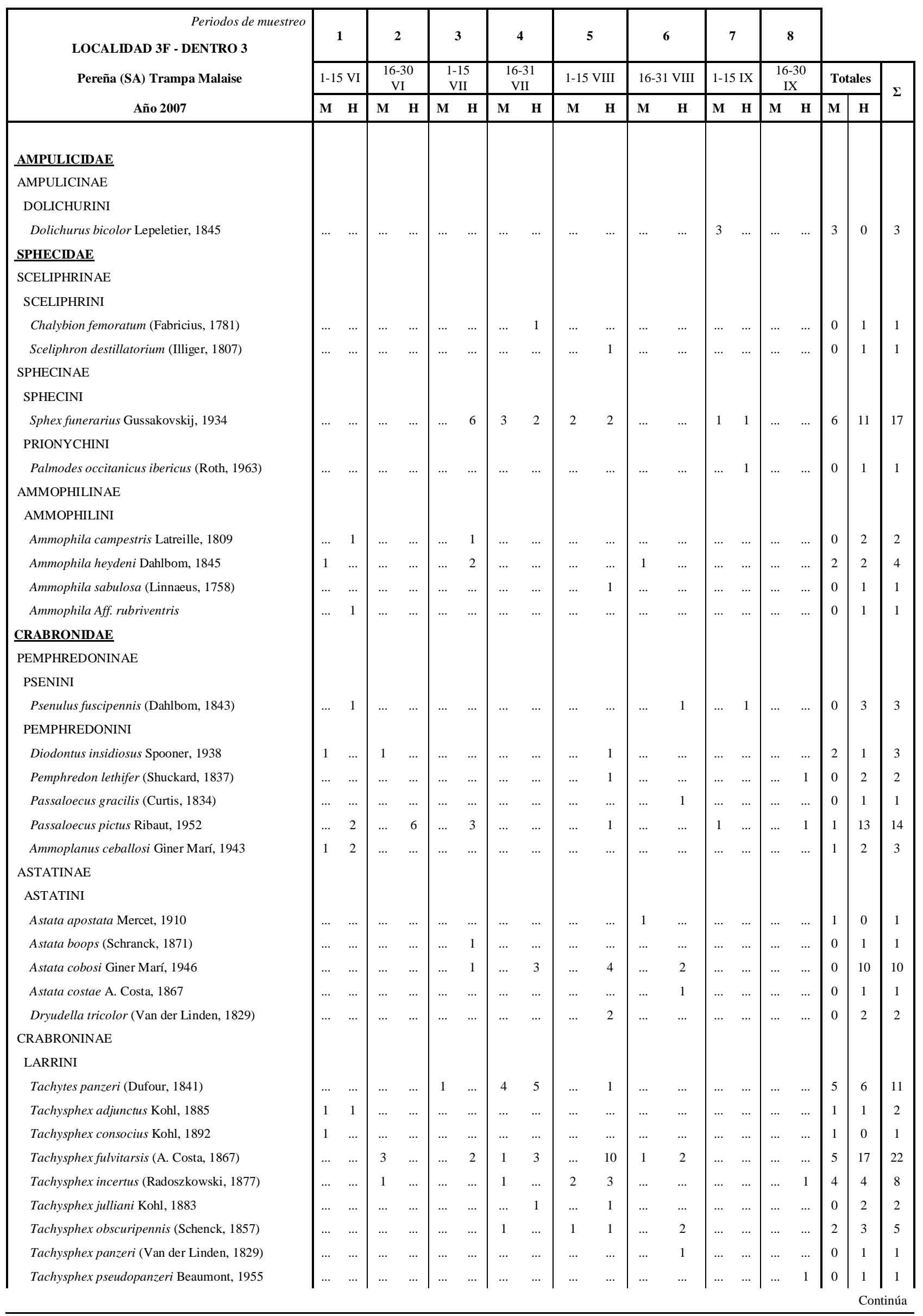




\begin{tabular}{|c|c|c|c|c|c|c|c|c|c|c|c|c|c|c|c|c|c|c|c|}
\hline \multirow{3}{*}{$\begin{array}{l}\text { Periodos de muestreo } \\
\text { LOCALIDAD 3F - DENTRO 3 } \\
\text { Pereña (SA) Trampa Malaise } \\
\text { Año } 2007\end{array}$} & \multicolumn{2}{|c|}{1} & \multicolumn{2}{|c|}{2} & \multicolumn{2}{|c|}{3} & \multicolumn{2}{|c|}{4} & \multicolumn{2}{|c|}{5} & \multicolumn{2}{|c|}{6} & \multicolumn{2}{|c|}{7} & \multicolumn{2}{|c|}{8} & & & \\
\hline & \multicolumn{2}{|c|}{$1-15 \mathrm{VI}$} & \multicolumn{2}{|c|}{$\begin{array}{c}16-30 \\
\text { VI } \\
\end{array}$} & \multicolumn{2}{|c|}{$\begin{array}{l}1-15 \\
\text { VII } \\
\end{array}$} & \multicolumn{2}{|c|}{$\begin{array}{c}16-31 \\
\text { VII }\end{array}$} & \multicolumn{2}{|c|}{ 1-15 VIII } & \multicolumn{2}{|c|}{ 16-31 VIII } & \multicolumn{2}{|c|}{$1-15 \mathrm{IX}$} & \multicolumn{2}{|c|}{$\begin{array}{c}16-30 \\
\text { IX } \\
\end{array}$} & \multicolumn{2}{|c|}{ Totales } & \multirow{2}{*}{$\Sigma$} \\
\hline & & $\mathbf{H}$ & & $\mathbf{H}$ & M & & & $\mathbf{H}$ & $\mathbf{M}$ & $\mathbf{H}$ & $\mathbf{M}$ & $\mathbf{H}$ & M & $\mathbf{H}$ & M & & $\mathbf{M}$ & $\mathbf{H}$ & \\
\hline Tachysphex tarsinus (Lepeletier, 1845) & $\ldots$ & & $\ldots$ & $\ldots$ & $\ldots$ & $\ldots$ & $\ldots$ & $\ldots$ & 2 & $\ldots$ & $\ldots$ & $\ldots$ & $\ldots$ & $\ldots$ & $\ldots$ & $\ldots$ & 2 & 0 & 2 \\
\hline Prosopigastra kohli Mercet, 1907 & $\ldots$ & $\ldots$ & $\ldots$ & $\ldots$ & $\ldots$ & $\ldots$ & $\ldots$ & $\ldots$ & $\ldots$ & 1 & $\ldots$ & $\ldots$ & $\ldots$ & $\ldots$ & $\ldots$ & $\ldots$ & 0 & 1 & 1 \\
\hline Prosopigastra punctatissima A. Costa, 1870 & $\ldots$ & $\ldots$ & $\ldots$ & $\ldots$ & $\ldots$ & $\ldots$ & $\ldots$ & $\ldots$ & $\ldots$ & $\ldots$ & $\ldots$ & 1 & $\ldots$ & $\ldots$ & $\ldots$ & $\ldots$ & 0 & 1 & 1 \\
\hline \multicolumn{20}{|l|}{ MISCOPHINI } \\
\hline Solierella compedita (Piccioli, 1869) & $\ldots$ & $\ldots$ & $\ldots$ & $\ldots$ & $\ldots$ & 1 & $\ldots$ & 3 & 2 & 9 & 2 & 5 & 8 & 4 & 1 & 2 & 13 & 24 & 37 \\
\hline Solierella pisonoides (Saunders, 1873) & $\ldots$ & $\ldots$ & $\ldots$ & $\ldots$ & $\ldots$ & $\ldots$ & $\ldots$ & $\ldots$ & $\ldots$ & $\ldots$ & $\ldots$ & 1 & 1 & 2 & $\ldots$ & $\ldots$ & 1 & 3 & 4 \\
\hline Miscophus bicolor Jurine, 1807 & $\ldots$ & $\ldots$ & $\ldots$ & $\ldots$ & $\ldots$ & 1 & $\ldots$ & $\ldots$ & 1 & $\ldots$ & $\ldots$ & $\ldots$ & $\ldots$ & $\ldots$ & $\ldots$ & $\ldots$ & 1 & 1 & 2 \\
\hline Nitela lucens Gayubo \& Felton, 2000 & $\ldots$ & $\ldots$ & $\ldots$ & 1 & $\ldots$ & $\ldots$ & $\ldots$ & $\ldots$ & $\ldots$ & 1 & $\ldots$ & $\ldots$ & 1 & $\ldots$ & $\ldots$ & 2 & 1 & 4 & 5 \\
\hline Nitela truncata Gayubo \& Felton, 2000 & $\ldots$ & $\ldots$ & $\ldots$ & $\ldots$ & $\ldots$ & $\ldots$ & $\ldots$ & $\ldots$ & $\ldots$ & $\ldots$ & $\ldots$ & $\ldots$ & 1 & $\ldots$ & 1 & $\ldots$ & 2 & 0 & 2 \\
\hline \multicolumn{20}{|l|}{ TRYPOXYLINI } \\
\hline Trypoxylon attenuatum F. Smith, 1851 & $\ldots$ & 1 & $\ldots$ & $\ldots$ & $\ldots$ & 1 & $\ldots$ & 2 & 2 & 7 & 5 & 14 & 8 & 14 & 2 & 10 & 17 & 49 & 66 \\
\hline Trypoxylon clavicerum Lepeletier \& Serville, 1828 & 1 & $\ldots$ & $\ldots$ & $\ldots$ & $\ldots$ & $\ldots$ & $\ldots$ & 1 & 1 & $\ldots$ & $\ldots$ & 1 & $\ldots$ & 1 & $\ldots$ & $\ldots$ & 2 & 3 & 5 \\
\hline Trypoxylon figulus (Linnaeus, 1758) & $\ldots$ & 2 & $\ldots$ & $\ldots$ & $\ldots$ & $\ldots$ & $\ldots$ & $\ldots$ & $\ldots$ & $\ldots$ & $\ldots$ & $\ldots$ & $\ldots$ & $\ldots$ & $\ldots$ & $\ldots$ & 2 & 0 & 2 \\
\hline Trypoxylon scutatum Chevrier, 1867 & $\ldots$ & 2 & $\ldots$ & 2 & $\ldots$ & 2 & $\ldots$ & 2 & 1 & 12 & $\ldots$ & 13 & 1 & 8 & $\ldots$ & $\ldots$ & 2 & 41 & 43 \\
\hline OXYBELINI & & & & & & & & & & & & & & & & & & & \\
\hline Oxybelus quattuordecimnotatus Jurine, 1807 & 1 & $\ldots$ & $\ldots$ & $\ldots$ & $\ldots$ & 1 & 2 & $\ldots$ & $\ldots$ & 1 & $\ldots$ & $\ldots$ & $\ldots$ & $\ldots$ & $\ldots$ & $\ldots$ & 3 & 2 & 5 \\
\hline CRABRONINI & & & & & & & & & & & & & & & & & & & \\
\hline Tracheliodes quinquenotatus (Jurine, 1807) & $\ldots$ & $\ldots$ & $\ldots$ & $\ldots$ & $\ldots$ & 1 & $\ldots$ & $\ldots$ & $\ldots$ & 1 & $\ldots$ & $\ldots$ & $\ldots$ & $\ldots$ & $\ldots$ & $\ldots$ & 0 & 2 & 2 \\
\hline Ectemnius crassicornis (Spinola, 1808) & $\ldots$ & $\ldots$ & $\ldots$ & $\ldots$ & $\cdots$ & $\ldots$ & $\ldots$ & $\ldots$ & 1 & $\ldots$ & $\ldots$ & $\ldots$ & $\ldots$ & $\cdots$ & $\ldots$ & $\ldots$ & 1 & 0 & 1 \\
\hline BEMBICINAE & & & & & & & & & & & & & & & & & & & \\
\hline BEMBICINI & & & & & & & & & & & & & & & & & & & \\
\hline Gorytes sulcifrons (A. Costa, 1869) & $\ldots$ & $\ldots$ & $\ldots$ & $\ldots$ & $\ldots$ & $\ldots$ & 1 & 2 & 3 & 2 & $\ldots$ & $\ldots$ & $\ldots$ & $\ldots$ & $\ldots$ & $\ldots$ & 4 & 4 & 8 \\
\hline Harpactus alvaroi Gayubo, 1992 & $\ldots$ & $\ldots$ & $\ldots$ & $\ldots$ & $\ldots$ & $\ldots$ & $\ldots$ & $\ldots$ & $\ldots$ & 1 & $\ldots$ & $\ldots$ & $\ldots$ & $\ldots$ & $\ldots$ & $\ldots$ & 0 & 1 & 1 \\
\hline Harpactus laevis (Latreille, 1792) & $\ldots$ & $\ldots$ & $\ldots$ & $\ldots$ & $\ldots$ & $\ldots$ & $\ldots$ & $\ldots$ & $\ldots$ & 1 & $\ldots$ & $\ldots$ & $\ldots$ & $\ldots$ & $\ldots$ & $\ldots$ & 0 & 1 & 1 \\
\hline Harpactus morawitzi (Snoflak, 1943) & $\ldots$ & $\ldots$ & $\ldots$ & $\ldots$ & $\ldots$ & $\ldots$ & $\cdots$ & $\ldots$ & $\ldots$ & $\ldots$ & $\ldots$ & $\ldots$ & 1 & $\ldots$ & $\ldots$ & $\ldots$ & 1 & 0 & 1 \\
\hline Harpactus sp. 2 grimaldensis Gayubo, sp. n. (in lit.) & $\ldots$ & $\ldots$ & $\ldots$ & $\ldots$ & $\ldots$ & $\ldots$ & $\cdots$ & $\ldots$ & $\ldots$ & $\ldots$ & $\ldots$ & $\ldots$ & 1 & $\ldots$ & $\ldots$ & $\ldots$ & 1 & 0 & 1 \\
\hline Bembecinus pulchelus (Mercet, 1906) & $\ldots$ & $\ldots$ & $\ldots$ & $\ldots$ & $\ldots$ & 12 & $\ldots$ & 14 & $\ldots$ & 2 & $\ldots$ & $\ldots$ & $\ldots$ & $\ldots$ & $\ldots$ & $\ldots$ & 0 & 28 & 28 \\
\hline Bembix zonata Klug, 1835 & $\ldots$ & $\ldots$ & $\ldots$ & $\ldots$ & $\ldots$ & $\ldots$ & $\ldots$ & 4 & $\ldots$ & 5 & $\ldots$ & 1 & $\ldots$ & $\ldots$ & $\ldots$ & $\ldots$ & 0 & 10 & 10 \\
\hline PHILANTHINAE & & & & & & & & & & & & & & & & & & & \\
\hline Cercerini & & & & & & & & & & & & & & & & & & & \\
\hline Cerceris rybyensis (Linnaeus, 1771) & $\ldots$ & $\ldots$ & $\ldots$ & $\ldots$ & $\ldots$ & 1 & $\ldots$ & $\ldots$ & $\ldots$ & $\ldots$ & $\ldots$ & $\ldots$ & $\ldots$ & 1 & $\ldots$ & $\ldots$ & 0 & 2 & 2 \\
\hline Subtotales & 7 & 13 & 5 & 9 & 1 & 36 & 13 & 43 & 18 & 72 & 10 & 46 & 27 & 33 & 4 & 18 & 87 & 268 & \\
\hline Total de Ejemplares & & 20 & & & & & & & & & & & & & & & & 55 & 355 \\
\hline Total de Especies & & 14 & & & & & & & & & & & & & & & & & 52 \\
\hline
\end{tabular}




\begin{tabular}{|c|c|c|c|c|c|c|c|c|c|c|c|}
\hline \multirow{3}{*}{$\begin{array}{c}\text { Periodos de muestreo } \\
\text { LOCALIDAD 3F - DENTRO } 1 \\
\text { Pereña (SA) PLATOS } \\
\text { Año 2007 }\end{array}$} & \multicolumn{2}{|c|}{$\mathbf{1}$} & \multicolumn{2}{|c|}{2} & \multicolumn{2}{|c|}{3} & \multicolumn{2}{|c|}{4} & & & \\
\hline & \multicolumn{2}{|c|}{ 15-Jun } & \multicolumn{2}{|c|}{ 15-Jul } & \multicolumn{2}{|c|}{ 15-Agos } & \multicolumn{2}{|c|}{ 15-Sep } & \multicolumn{2}{|c|}{ Totales } & \multirow{2}{*}{$\boldsymbol{\Sigma}$} \\
\hline & $\mathbf{M}$ & $\mathbf{H}$ & $\mathbf{M}$ & $\mathbf{H}$ & $\mathbf{M}$ & $\mathbf{H}$ & $\mathbf{M}$ & & $\mathbf{M}$ & $\mathbf{H}$ & \\
\hline \multicolumn{12}{|l|}{ CRABRONIDAE } \\
\hline \multicolumn{12}{|l|}{ CRABRONINAE } \\
\hline \multicolumn{12}{|l|}{ LARRINI } \\
\hline Tachysphex mediterraneus Kohl, 1883 & $\ldots$ & $\ldots$ & $\ldots$ & $\ldots$ & $\ldots$ & 4 & $\ldots$ & $\ldots$ & 0 & 4 & 4 \\
\hline Tachysphex nitidior Beaumont, 1940 & $\ldots$ & $\ldots$ & $\ldots$ & $\ldots$ & 1 & $\ldots$ & $\ldots$ & $\ldots$ & 1 & 0 & 1 \\
\hline Tachysphex obscuripennis (Schenck, 1857) & $\ldots$ & $\ldots$ & $\ldots$ & $\ldots$ & 8 & $\ldots$ & $\ldots$ & $\ldots$ & 8 & 0 & 8 \\
\hline Tachysphex pseudopanzeri Beaumont, 1955 & $\ldots$ & $\ldots$ & $\ldots$ & $\ldots$ & $\ldots$ & 1 & $\ldots$ & $\ldots$ & 0 & 1 & 1 \\
\hline Tachysphex tarsinus (Lepeletier, 1845) & $\ldots$ & $\ldots$ & $\ldots$ & $\ldots$ & 3 & $\ldots$ & $\ldots$ & $\ldots$ & 3 & 0 & 3 \\
\hline \multicolumn{12}{|l|}{ MISCOPHINI } \\
\hline Solierella compedita (Piccioli, 1869) & $\ldots$ & $\ldots$ & $\ldots$ & $\ldots$ & 35 & 33 & 11 & 6 & 46 & 39 & 85 \\
\hline Solierella pisonoides (Saunders, 1873) & $\ldots$ & $\ldots$ & 1 & $\ldots$ & 12 & 8 & 1 & 2 & 14 & 10 & 24 \\
\hline Solierella seabrai Andrade, 1950 & $\ldots$ & $\ldots$ & $\ldots$ & $\ldots$ & $\cdots$ & 3 & $\cdots$ & $\ldots$ & 0 & 3 & 3 \\
\hline Miscophus nicolai Ferton, 1896 & $\ldots$ & $\ldots$ & $\ldots$ & $\ldots$ & 2 & 3 & $\ldots$ & $\ldots$ & 2 & 3 & 5 \\
\hline Nitela lucens Gayubo \& Felton, 2000 & $\ldots$ & $\ldots$ & $\ldots$ & $\ldots$ & $\ldots$ & $\ldots$ & $\ldots$ & 1 & 0 & 1 & 1 \\
\hline Nitela truncata Gayubo \& Felton, 2000 & $\ldots$ & $\ldots$ & $\ldots$ & $\ldots$ & $\ldots$ & $\ldots$ & $\ldots$ & 1 & 0 & 1 & 1 \\
\hline \multicolumn{12}{|l|}{ TRYPOXYLINI } \\
\hline Trypoxylon attenuatum F. Smith, 1851 & $\ldots$ & $\ldots$ & $\ldots$ & $\ldots$ & $\ldots$ & 4 & 8 & 8 & 8 & 12 & 20 \\
\hline Trypoxylon minus Beaumont, 1945 & $\ldots$ & $\ldots$ & $\ldots$ & $\ldots$ & $\ldots$ & $\ldots$ & ... & 2 & 0 & 2 & 2 \\
\hline Trypoxylon scutatum Chevrier, 1867 & $\ldots$ & $\ldots$ & $\ldots$ & $\ldots$ & $\ldots$ & 2 & 1 & 1 & 1 & 3 & 4 \\
\hline \multicolumn{12}{|l|}{ OXYBELINI } \\
\hline Belomicrus odonthophorus (Kohl, 1892) & $\ldots$ & $\ldots$ & $\ldots$ & $\ldots$ & $\ldots$ & 1 & $\ldots$ & $\ldots$ & 0 & 1 & 1 \\
\hline Oxybelus quattuordecimnotatus Jurine, 1807 & $\ldots$ & $\ldots$ & $\ldots$ & $\ldots$ & 1 & $\ldots$ & $\ldots$ & $\ldots$ & 1 & 0 & 1 \\
\hline \multicolumn{12}{|l|}{ BEMBICINAE } \\
\hline \multicolumn{12}{|l|}{ BEMBICINI } \\
\hline Harpactus alvaroi Gayubo, 1992 & $\ldots$ & $\ldots$ & $\ldots$ & $\ldots$ & $\ldots$ & 1 & $\ldots$ & $\ldots$ & 0 & 1 & 1 \\
\hline Bembecinus pulchelus (Mercet, 1906) & $\ldots$ & $\ldots$ & $\ldots$ & 2 & $\ldots$ & 1 & $\ldots$ & $\ldots$ & 0 & 3 & 3 \\
\hline Bembecinus tridens (Fabricius, 1781) & $\ldots$ & $\ldots$ & ... & $\ldots$ & $\ldots$ & $\ldots$ & $\ldots$ & 1 & 0 & 1 & 1 \\
\hline Bembix zonata Klug, 1835 & $\cdots$ & $\ldots$ & $\ldots$ & $\ldots$ & $\cdots$ & 1 & $\ldots$ & $\ldots$ & 0 & 1 & 1 \\
\hline \multirow{2}{*}{$\begin{array}{r}\text { Subtotales } \\
\text { Total de Ejemplares }\end{array}$} & $\mathbf{0}$ & 0 & 1 & 2 & 62 & 62 & 21 & 22 & 84 & 86 & \\
\hline & \multicolumn{2}{|c|}{$\mathbf{0}$} & \multicolumn{2}{|c|}{3} & \multicolumn{2}{|c|}{124} & \multicolumn{2}{|c|}{43} & \multicolumn{2}{|c|}{170} & 170 \\
\hline Total de Especies & \multicolumn{2}{|c|}{ 0 } & & & & & & & & & 20 \\
\hline
\end{tabular}




\begin{tabular}{|c|c|c|c|c|c|c|c|c|c|c|c|}
\hline \multirow{3}{*}{\begin{tabular}{|} 
Periodos de muestreo \\
LOCALIDAD 3F - DENTRO 2 \\
Pereña (SA) PLATOS \\
Año 2007
\end{tabular}} & \multicolumn{2}{|c|}{1} & \multicolumn{2}{|c|}{2} & \multicolumn{2}{|c|}{3} & \multicolumn{2}{|c|}{4} & & & \\
\hline & \multicolumn{2}{|c|}{ 15-Jun } & \multicolumn{2}{|c|}{ 15-Jul } & \multicolumn{2}{|c|}{ 15-Agos } & \multicolumn{2}{|c|}{ 15-Sep } & \multicolumn{2}{|c|}{ Totales } & \multirow{2}{*}{$\Sigma$} \\
\hline & $\mathbf{M}$ & $\mathbf{H}$ & M & $\mathbf{H}$ & $\mathbf{M}$ & $\mathbf{H}$ & $\mathbf{M}$ & $\mathbf{H}$ & $\mathbf{M}$ & $\mathbf{H}$ & \\
\hline \multicolumn{12}{|l|}{ CRABRONIDAE } \\
\hline \multicolumn{12}{|l|}{ CRABRONINAE } \\
\hline \multicolumn{12}{|l|}{ LARRINI } \\
\hline Larropsis europaea Mercet, 1910 & $\ldots$ & $\ldots$ & $\ldots$ & $\ldots$ & $\ldots$ & $\ldots$ & 1 & $\ldots$ & 1 & 0 & 1 \\
\hline Tachytes panzeri (Dufour, 1841) & $\ldots$ & $\ldots$ & 1 & $\ldots$ & $\ldots$ & $\ldots$ & $\ldots$ & $\ldots$ & 1 & 0 & 1 \\
\hline Tachysphex fulvitarsis (A. Costa, 1867) & $\ldots$ & $\ldots$ & ... & 1 & $\ldots$ & $\ldots$ & $\ldots$ & $\ldots$ & 0 & 1 & 1 \\
\hline Tachysphex nitidior Beaumont, 1940 & $\ldots$ & $\ldots$ & $\ldots$ & $\ldots$ & $\ldots$ & 2 & $\ldots$ & $\ldots$ & 0 & 2 & 2 \\
\hline Tachysphex obscuripennis (Schenck, 1857) & $\ldots$ & $\ldots$ & 1 & $\cdots$ & $\ldots$ & $\ldots$ & $\ldots$ & 2 & 1 & 2 & 3 \\
\hline Tachysphex pompiliformis (Panzer, 1805) & $\ldots$ & $\ldots$ & 1 & $\ldots$ & $\ldots$ & $\ldots$ & $\ldots$ & $\ldots$ & 1 & 0 & 1 \\
\hline Tachysphex psammobius (Kohl, 1880) & $\ldots$ & $\ldots$ & $\ldots$ & 1 & $\ldots$ & $\ldots$ & $\ldots$ & $\ldots$ & 0 & 1 & 1 \\
\hline Prosopigastra punctatissima A. Costa, 1870 & $\ldots$ & $\ldots$ & ... & $\cdots$ & 1 & $\ldots$ & $\ldots$ & $\ldots$ & 1 & 0 & 1 \\
\hline \multicolumn{12}{|l|}{ MISCOPHINI } \\
\hline Solierella compedita (Piccioli, 1869) & $\ldots$ & $\ldots$ & 1 & 4 & 21 & 17 & 21 & 5 & 43 & 26 & 69 \\
\hline Solierella pisonoides (Saunders, 1873) & $\ldots$ & $\ldots$ & 1 & $\ldots$ & 1 & $\ldots$ & 1 & $\ldots$ & 3 & 0 & 3 \\
\hline \multicolumn{12}{|l|}{ TRYPOXYLINI } \\
\hline Trypoxylon attenuatum F. Smith, 1851 & $\ldots$ & $\ldots$ & ... & $\ldots$ & $\ldots$ & $\ldots$ & 5 & 17 & 6 & 17 & 23 \\
\hline Trypoxylon scutatum Chevrier, 1867 & $\ldots$ & $\ldots$ & $\cdots$ & $\ldots$ & $\ldots$ & 1 & $\ldots$ & 2 & 0 & 3 & 3 \\
\hline \multicolumn{12}{|l|}{ BEMBICINAE } \\
\hline \multicolumn{12}{|l|}{ NYSSONINI } \\
\hline Nysson maculosus (Gmelin, 1790) & $\ldots$ & $\ldots$ & $\ldots$ & $\ldots$ & $\ldots$ & 1 & $\ldots$ & $\ldots$ & 0 & 1 & 1 \\
\hline \multicolumn{12}{|l|}{ BEMBICINI } \\
\hline Gorytes sulcifrons (A. Costa, 1869) & $\ldots$ & $\ldots$ & 2 & $\ldots$ & $\ldots$ & $\ldots$ & $\ldots$ & $\ldots$ & 2 & 0 & 2 \\
\hline Harpactus alvaroi Gayubo, 1992 & $\ldots$ & $\ldots$ & $\ldots$ & $\ldots$ & $\ldots$ & 1 & $\ldots$ & $\ldots$ & 0 & 1 & 1 \\
\hline Bembecinus pulchelus (Mercet, 1906) & $\ldots$ & $\ldots$ & ... & 20 & $\ldots$ & $\ldots$ & $\ldots$ & $\ldots$ & 0 & 20 & 20 \\
\hline \multicolumn{12}{|l|}{ PHILANTHINAE } \\
\hline \multicolumn{12}{|l|}{ CERCERINI } \\
\hline Cerceris sabulosa (Panzer, 1799) & $\ldots$ & $\ldots$ & $\cdots$ & $\ldots$ & $\ldots$ & $\ldots$ & $\ldots$ & 1 & 0 & 1 & 1 \\
\hline Total de Ejemplares & $\mathbf{0}$ & $\mathbf{0}$ & 7 & 26 & 23 & 22 & 28 & 27 & 59 & 75 & \\
\hline Total de Ejemplares & \multicolumn{2}{|c|}{$\mathbf{0}$} & \multicolumn{2}{|c|}{33} & \multicolumn{2}{|c|}{55} & \multicolumn{2}{|c|}{55} & \multicolumn{2}{|c|}{134} & 134 \\
\hline Total de Especies & & & & & & & & & & & 17 \\
\hline
\end{tabular}




\begin{tabular}{|c|c|c|c|c|c|c|c|c|c|c|c|}
\hline \multirow{3}{*}{$\begin{array}{c}\text { Periodos de muestreo } \\
\text { LOCALIDAD 3F - DENTRO 3 } \\
\text { Pereña (SA) PLATOS } \\
\text { Año 2007 }\end{array}$} & \multicolumn{2}{|c|}{1} & \multicolumn{2}{|c|}{2} & \multicolumn{2}{|c|}{3} & \multicolumn{2}{|c|}{4} & & & \\
\hline & \multicolumn{2}{|c|}{ 15-Jun } & \multicolumn{2}{|c|}{ 15-Jul } & \multicolumn{2}{|c|}{ 15-Agos } & \multicolumn{2}{|c|}{ 15-Sep } & \multicolumn{2}{|c|}{ Totales } & \multirow{2}{*}{$\Sigma$} \\
\hline & $\mathbf{M}$ & $\mathbf{H}$ & M & & M & & $\mathbf{M}$ & $\mathbf{H}$ & $\mathbf{M}$ & $\mathbf{H}$ & \\
\hline \multicolumn{12}{|l|}{ CRABRONIDAE } \\
\hline \multicolumn{12}{|l|}{ CRABRONINAE } \\
\hline \multicolumn{12}{|l|}{ LARRINI } \\
\hline Tachysphex fulvitarsis (A. Costa, 1867) & $\ldots$ & $\ldots$ & $\ldots$ & $\ldots$ & 2 & $\ldots$ & $\ldots$ & $\ldots$ & 2 & 0 & 2 \\
\hline Tachysphex obscuripennis (Schenck, 1857) & $\ldots$ & $\ldots$ & $\ldots$ & $\ldots$ & 2 & $\ldots$ & 1 & $\ldots$ & 3 & 0 & 3 \\
\hline \multicolumn{12}{|l|}{ MISCOPHINI } \\
\hline Solierella compedita (Piccioli, 1869) & $\ldots$ & $\ldots$ & 2 & 1 & 5 & 8 & 24 & 4 & 31 & 13 & 44 \\
\hline Solierella pisonoides (Saunders, 1873) & $\ldots$ & $\cdots$ & 1 & $\cdots$ & $\cdots$ & $\cdots$ & $\cdots$ & $\cdots$ & 1 & 0 & 1 \\
\hline Solierella seabrai Andrade, 1950 & $\cdots$ & $\ldots$ & $\ldots$ & 4 & $\cdots$ & 1 & $\cdots$ & $\ldots$ & 0 & 5 & 5 \\
\hline Miscophus eatoni Saunders, 1903 & $\ldots$ & $\ldots$ & $\cdots$ & $\ldots$ & $\ldots$ & $\ldots$ & $\ldots$ & 2 & 0 & 2 & 2 \\
\hline Miscophus nicolai Ferton, 1896 & $\ldots$ & $\ldots$ & 1 & $\ldots$ & $\ldots$ & $\ldots$ & $\ldots$ & $\ldots$ & 1 & 0 & 1 \\
\hline Nitela lucens Gayubo \& Felton, 2000 & $\ldots$ & $\ldots$ & $\ldots$ & $\ldots$ & $\cdots$ & $\ldots$ & $\ldots$ & 1 & 0 & 1 & 1 \\
\hline \multicolumn{12}{|l|}{ TRYPOXYLINI } \\
\hline Trypoxylon attenuatum F. Smith, 1851 & $\ldots$ & $\ldots$ & $\ldots$ & $\ldots$ & $\ldots$ & $\ldots$ & 11 & 7 & 11 & 7 & 18 \\
\hline Trypoxylon scutatum Chevrier, 1867 & $\cdots$ & $\ldots$ & $\cdots$ & $\ldots$ & $\ldots$ & 2 & $\ldots$ & 2 & 0 & 4 & 4 \\
\hline \multicolumn{12}{|l|}{ OXYBELINI } \\
\hline Oxybelus quattuordecimnotatus Jurine, 1807 & $\ldots$ & $\ldots$ & $\ldots$ & $\ldots$ & $\ldots$ & $\ldots$ & $\ldots$ & 1 & 0 & 1 & 1 \\
\hline CRABRONINI & & & & & & & & & & & \\
\hline Crossocerus quadrimaculatus (Fabricius, 1793) & $\ldots$ & $\ldots$ & $\ldots$ & $\ldots$ & $\ldots$ & $\ldots$ & 1 & $\ldots$ & 1 & 0 & 1 \\
\hline \multicolumn{12}{|l|}{ BEMBICINAE } \\
\hline \multicolumn{12}{|l|}{ NYSSONINI } \\
\hline Nysson monachus Mercet, 1909 & $\ldots$ & $\ldots$ & $\ldots$ & $\ldots$ & $\ldots$ & 1 & $\ldots$ & $\ldots$ & 0 & 1 & 1 \\
\hline \multicolumn{12}{|l|}{ BEMBICINI } \\
\hline Bembecinus pulchelus (Mercet, 1906) & $\ldots$ & $\ldots$ & $\ldots$ & 7 & $\ldots$ & $\ldots$ & $\ldots$ & $\ldots$ & 0 & 7 & 7 \\
\hline Subtotales & $\mathbf{0}$ & $\mathbf{0}$ & 4 & 12 & 9 & 12 & 37 & 17 & 50 & 41 & \\
\hline Total de Ejemplares & \multicolumn{2}{|c|}{ 0 } & \multicolumn{2}{|c|}{16} & \multicolumn{2}{|c|}{21} & \multicolumn{2}{|c|}{54} & \multicolumn{2}{|c|}{91} & 91 \\
\hline Total de Especies & \multicolumn{2}{|c|}{ 0 } & \multicolumn{2}{|c|}{5} & \multicolumn{2}{|c|}{6} & & & & & 14 \\
\hline
\end{tabular}




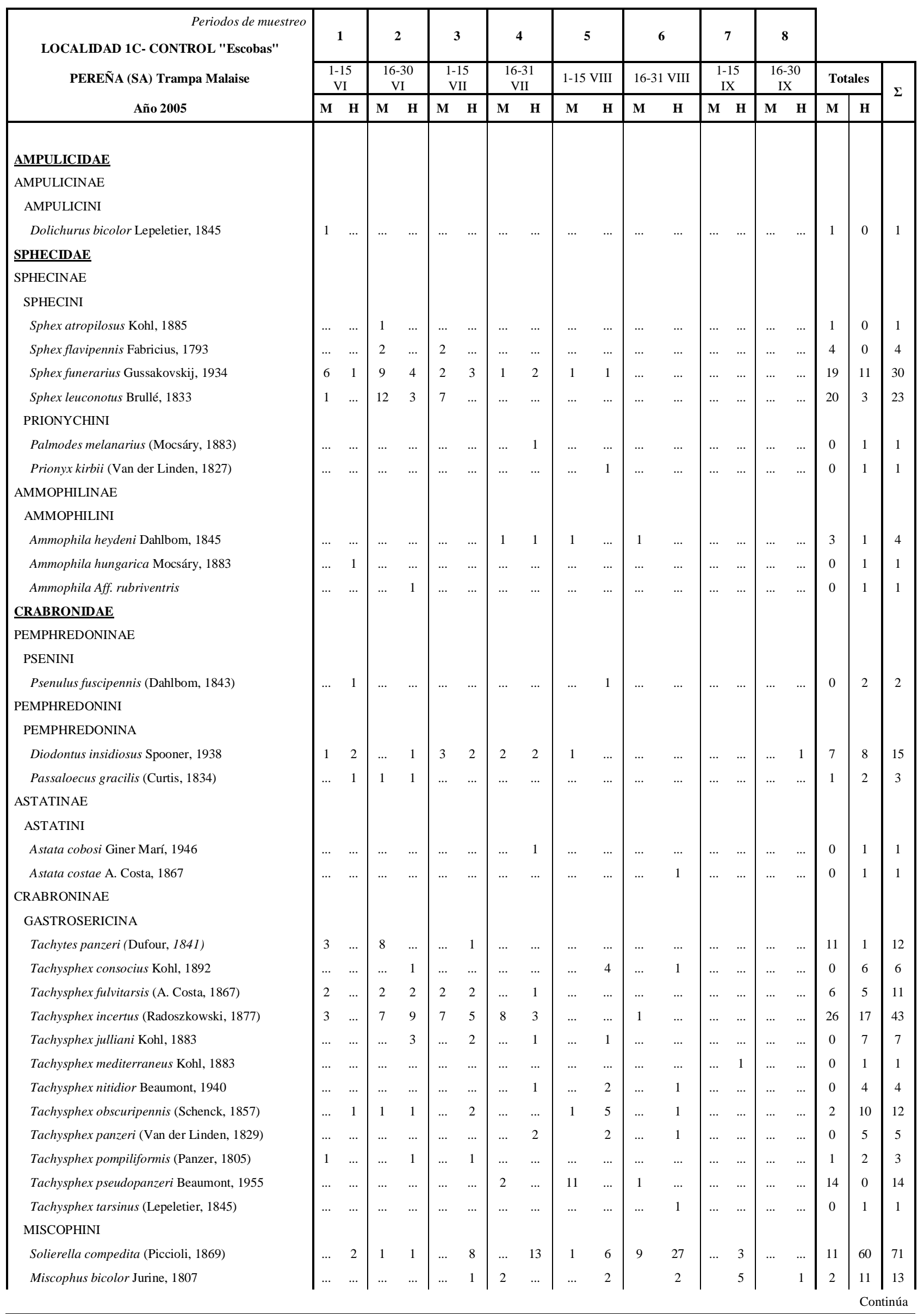




\begin{tabular}{|c|c|c|c|c|c|c|c|c|c|c|c|c|c|c|c|c|c|c|c|}
\hline \multirow{3}{*}{\begin{tabular}{|} 
Periodos de muestreo \\
LOCALIDAD 1C- CONTROL "Escobas" \\
PEREÑN (SA) Trampa Malaise \\
Año 2005
\end{tabular}} & \multicolumn{2}{|c|}{1} & \multicolumn{2}{|c|}{2} & \multicolumn{2}{|c|}{3} & \multicolumn{2}{|c|}{4} & \multicolumn{2}{|c|}{5} & \multicolumn{2}{|c|}{6} & \multicolumn{2}{|c|}{7} & \multicolumn{2}{|c|}{8} & & & \\
\hline & \multicolumn{2}{|c|}{$\begin{array}{c}1-15 \\
\text { VI }\end{array}$} & \multicolumn{2}{|c|}{$\begin{array}{c}16-30 \\
\text { VI } \\
\end{array}$} & \multicolumn{2}{|c|}{$\begin{array}{l}1-15 \\
\text { VII } \\
\end{array}$} & \multicolumn{2}{|c|}{$\begin{array}{c}16-31 \\
\text { VII } \\
\end{array}$} & \multicolumn{2}{|c|}{ 1-15 VIII } & \multicolumn{2}{|c|}{ 16-31 VIII } & \multicolumn{2}{|c|}{$\begin{array}{c}1-15 \\
\text { IX } \\
\end{array}$} & \multicolumn{2}{|c|}{$\begin{array}{c}16-30 \\
\text { IX } \\
\end{array}$} & \multicolumn{2}{|c|}{ Totales } & \multirow{2}{*}{$\Sigma$} \\
\hline & & $\mathbf{H}$ & $\mathbf{M}$ & & & $\mathbf{H}$ & $\mathbf{M}$ & & $\mathbf{M}$ & & $\mathbf{M}$ & & M & & & & $\mathbf{M}$ & $\mathbf{H}$ & \\
\hline Miscophus eatoni Saunders, 1903 & & & $\ldots$ & $\ldots$ & $\ldots$ & & $\ldots$ & 1 & $\ldots$ & $\ldots$ & $\ldots$ & $\ldots$ & $\ldots$ & & $\ldots$ & $\ldots$ & 0 & 1 & 1 \\
\hline Miscophus helveticus Kohl, 1883 & $\ldots$ & & $\ldots$ & $\ldots$ & $\ldots$ & 1 & $\ldots$ & $\ldots$ & $\ldots$ & $\ldots$ & $\ldots$ & $\ldots$ & $\ldots$ & & $\ldots$ & $\ldots$ & 0 & 1 & 1 \\
\hline Miscophus nicolai Ferton, 1896 & $\ldots$ & $\ldots$ & $\ldots$ & $\ldots$ & $\ldots$ & 1 & $\ldots$ & 2 & $\ldots$ & $\ldots$ & $\ldots$ & 1 & $\ldots$ & $\ldots$ & $\ldots$ & $\ldots$ & 0 & 4 & 4 \\
\hline Nitela lucens Gayubo \& Felton, 2000 & $\ldots$ & 1 & $\ldots$ & $\ldots$ & $\ldots$ & $\ldots$ & $\ldots$ & $\ldots$ & $\ldots$ & 1 & $\ldots$ & 1 & $\ldots$ & 1 & $\ldots$ & $\ldots$ & 0 & 4 & 4 \\
\hline \multicolumn{20}{|l|}{ TRYPOXYLINI } \\
\hline Trypoxylon attenuatum F. Smith, 1851 & $\ldots$ & $\ldots$ & $\ldots$ & $\ldots$ & $\ldots$ & $\ldots$ & $\ldots$ & $\ldots$ & $\ldots$ & 1 & $\ldots$ & 1 & $\ldots$ & $\ldots$ & $\ldots$ & $\ldots$ & 0 & 2 & 2 \\
\hline Trypoxylon scutatum Chevrier, 1867 & $\ldots$ & $\ldots$ & $\ldots$ & 1 & $\ldots$ & 7 & 2 & 2 & 1 & 2 & $\ldots$ & 2 & $\ldots$ & 1 & $\ldots$ & $\ldots$ & 3 & 15 & 18 \\
\hline \multicolumn{20}{|l|}{ OXYBELINI } \\
\hline Oxybelus quattuordecimnotatus Jurine, 1807 & 1 & $\ldots$ & $\ldots$ & $\ldots$ & $\ldots$ & $\ldots$ & $\ldots$ & $\ldots$ & $\ldots$ & 1 & $\ldots$ & $\ldots$ & $\ldots$ & $\ldots$ & $\ldots$ & $\ldots$ & 1 & 1 & 2 \\
\hline \multicolumn{20}{|l|}{ CRABRONINI } \\
\hline \multicolumn{20}{|l|}{ CRABRONINA } \\
\hline Lindenius ibericus Kohl, 1905 & $\ldots$ & $\ldots$ & $\ldots$ & 1 & $\ldots$ & $\ldots$ & $\ldots$ & $\ldots$ & $\ldots$ & $\ldots$ & $\ldots$ & $\ldots$ & $\ldots$ & $\ldots$ & $\ldots$ & $\ldots$ & 0 & 1 & 1 \\
\hline Tracheliodes quinquenotatus (Jurine, 1807) & $\ldots$ & $\ldots$ & $\ldots$ & 1 & $\ldots$ & 1 & $\ldots$ & $\ldots$ & $\ldots$ & $\ldots$ & $\ldots$ & $\ldots$ & $\ldots$ & $\ldots$ & $\cdots$ & $\ldots$ & 0 & 2 & 2 \\
\hline Ectemnius crassicornis (Spinola, 1808) & $\ldots$ & $\ldots$ & $\ldots$ & 1 & $\ldots$ & $\cdots$ & $\cdots$ & $\ldots$ & $\ldots$ & $\ldots$ & $\cdots$ & $\ldots$ & $\ldots$ & $\cdots$ & $\ldots$ & $\ldots$ & 0 & 1 & 1 \\
\hline \multicolumn{20}{|l|}{ MELLININAE } \\
\hline MELLININI & & & & & & & & & & & & & & & & & & & \\
\hline Mellinus arvensis (Linnaeus, 1758) & $\ldots$ & $\ldots$ & $\ldots$ & $\ldots$ & $\ldots$ & $\ldots$ & $\cdots$ & $\cdots$ & $\ldots$ & $\ldots$ & $\ldots$ & $\ldots$ & $\ldots$ & 1 & $\ldots$ & $\ldots$ & 0 & 1 & 1 \\
\hline BEMBICINAE & & & & & & & & & & & & & & & & & & & \\
\hline BEMBICINI & & & & & & & & & & & & & & & & & & & \\
\hline Gorytes sulcifrons (A. Costa, 1869) & $\ldots$ & $\ldots$ & $\ldots$ & $\ldots$ & $\ldots$ & 1 & $\ldots$ & $\ldots$ & $\ldots$ & $\ldots$ & $\ldots$ & $\ldots$ & $\ldots$ & $\ldots$ & $\ldots$ & $\ldots$ & 0 & 1 & 1 \\
\hline Harpactus alvaroi Gayubo, 1992 & $\ldots$ & $\ldots$ & $\ldots$ & $\ldots$ & $\ldots$ & $\ldots$ & $\ldots$ & $\ldots$ & $\ldots$ & 2 & $\ldots$ & $\ldots$ & $\ldots$ & $\ldots$ & $\ldots$ & $\ldots$ & 0 & 2 & 2 \\
\hline Harpactus formosus (Jurine, 1807) & $\ldots$ & 1 & $\ldots$ & $\ldots$ & $\ldots$ & $\ldots$ & $\ldots$ & $\ldots$ & $\ldots$ & $\ldots$ & $\ldots$ & $\ldots$ & $\ldots$ & $\ldots$ & $\ldots$ & $\ldots$ & 0 & 1 & 1 \\
\hline Harpactus sp. 2 grimaldensis Gayubo, sp. n. (in lit.) & $\ldots$ & 1 & $\ldots$ & 1 & $\ldots$ & $\cdots$ & $\ldots$ & $\ldots$ & 1 & 1 & $\ldots$ & $\ldots$ & $\ldots$ & $\ldots$ & $\ldots$ & $\ldots$ & 1 & 3 & 4 \\
\hline Bembecinus carpetanus (Mercet, 1906) & & & & 1 & & & & & & & & & & & & & 0 & 1 & 1 \\
\hline Bembecinus pulchelus (Mercet, 1906) & 4 & $\ldots$ & 1 & 6 & $\ldots$ & 1 & $\ldots$ & $\ldots$ & $\ldots$ & $\ldots$ & $\ldots$ & $\ldots$ & $\ldots$ & $\ldots$ & $\ldots$ & $\ldots$ & 5 & 7 & 12 \\
\hline Subtotales & 23 & 12 & 45 & 40 & 23 & 39 & 18 & 33 & 18 & 33 & 12 & 40 & $\mathbf{0}$ & 12 & $\mathbf{0}$ & 2 & 139 & 211 & 350 \\
\hline Total de Ejemplares & 3 & & & & & & & & & & & & & 2 & & & & 5 & \\
\hline Total de Especies & 1 & & & & & & & & & & & & & 5 & & & & & 46 \\
\hline
\end{tabular}




\begin{tabular}{|c|c|c|c|c|c|c|c|c|c|c|c|c|c|c|c|c|c|c|c|}
\hline \multirow{3}{*}{$\begin{array}{r}\text { Periodos de muestreo } \\
\text { LOCALIDAD 1C - CONTROL "Prado" } \\
\text { PEREÑA (SA) Trampa Malaise } \\
\text { Año } 2005\end{array}$} & \multicolumn{2}{|c|}{1} & \multicolumn{2}{|c|}{2} & \multicolumn{2}{|c|}{3} & \multicolumn{2}{|c|}{4} & \multicolumn{2}{|c|}{5} & \multicolumn{2}{|c|}{6} & \multicolumn{2}{|c|}{7} & \multicolumn{2}{|c|}{8} & & & \\
\hline & \multicolumn{2}{|c|}{$\begin{array}{c}1-15 \\
\text { VI }\end{array}$} & \multicolumn{2}{|c|}{$\begin{array}{c}16-30 \\
\text { VI }\end{array}$} & \multicolumn{2}{|c|}{$\begin{array}{c}1-15 \\
\text { VII }\end{array}$} & \multicolumn{2}{|c|}{$\begin{array}{c}16-31 \\
\text { VII }\end{array}$} & \multicolumn{2}{|c|}{$\begin{array}{l}1-15 \\
\text { VIII } \\
\end{array}$} & & & $\begin{array}{r}1- \\
\mathrm{I}\end{array}$ & & $\begin{array}{r}16 \\
\mathrm{I}\end{array}$ & & & & $\Sigma$ \\
\hline & $\mathbf{M}$ & $\mathbf{H}$ & M & & M & $\mathbf{H}$ & $\mathbf{M}$ & & $\mathbf{M}$ & $\mathbf{H}$ & $\mathbf{M}$ & & M & & $\mathbf{M}$ & & $\mathbf{M}$ & $\mathbf{H}$ & \\
\hline$\underline{\text { SPHECIDAE }}$ & & & & & & & & & & & & & & & & & & & \\
\hline SPHECINAE & & & & & & & & & & & & & & & & & & & \\
\hline SPHECINI & & & & & & & & & & & & & & & & & & & \\
\hline Sphex atropilosus Kohl, 1885 & 2 & 2 & $\ldots$ & 2 & $\ldots$ & $\ldots$ & $\ldots$ & $\ldots$ & $\ldots$ & $\ldots$ & $\ldots$ & $\ldots$ & $\ldots$ & $\ldots$ & $\ldots$ & $\ldots$ & 2 & 4 & 6 \\
\hline Sphex flavipennis Fabricius, 1793 & $\ldots$ & $\ldots$ & 2 & $\ldots$ & $\ldots$ & $\ldots$ & $\ldots$ & $\ldots$ & $\ldots$ & $\ldots$ & $\ldots$ & $\ldots$ & $\ldots$ & $\ldots$ & $\ldots$ & $\ldots$ & 2 & 0 & 2 \\
\hline Sphex funerarius Gussakovskij, 1934 & 13 & 4 & 29 & 6 & 2 & 2 & 1 & 2 & $\ldots$ & $\ldots$ & $\ldots$ & 2 & $\ldots$ & $\ldots$ & $\ldots$ & $\ldots$ & 45 & 16 & 61 \\
\hline Sphex leuconotus Brullé, 1833 & 9 & $\ldots$ & 12 & 1 & 5 & 1 & 1 & 1 & $\ldots$ & $\ldots$ & $\ldots$ & $\ldots$ & $\ldots$ & $\ldots$ & $\ldots$ & $\ldots$ & 27 & 3 & 30 \\
\hline PRIONYCHINI & & & & & & & & & & & & & & & & & & & \\
\hline Palmodes melanarius (Mocsáry, 1883) & $\ldots$ & $\ldots$ & 3 & 2 & $\ldots$ & 4 & $\ldots$ & $\ldots$ & $\ldots$ & 1 & $\ldots$ & $\ldots$ & $\ldots$ & $\ldots$ & $\ldots$ & $\ldots$ & 3 & 7 & 10 \\
\hline *Palmodes occitanicus ibericus (Roth, 1963) & 1 & $\ldots$ & $\ldots$ & 1 & $\ldots$ & $\ldots$ & $\ldots$ & $\ldots$ & $\ldots$ & $\ldots$ & $\ldots$ & $\ldots$ & $\ldots$ & $\ldots$ & $\ldots$ & $\ldots$ & 1 & 1 & 2 \\
\hline *Palmodes occitanicus occitanicus (Lepeletier \& Serville 1828) & $\ldots$ & $\ldots$ & $\ldots$ & $\ldots$ & $\ldots$ & 1 & $\ldots$ & $\ldots$ & $\ldots$ & $\ldots$ & $\ldots$ & $\ldots$ & $\ldots$ & $\ldots$ & $\ldots$ & $\ldots$ & 0 & 1 & 1 \\
\hline Chilosphex argyrius (Brullé, 1833) & 1 & $\ldots$ & $\ldots$ & $\ldots$ & $\ldots$ & $\ldots$ & $\ldots$ & $\ldots$ & $\ldots$ & $\ldots$ & $\ldots$ & $\ldots$ & $\ldots$ & $\ldots$ & $\ldots$ & $\ldots$ & 1 & 0 & 1 \\
\hline Prionyx kirbii (Van der Linden, 1827) & $\ldots$ & $\ldots$ & $\ldots$ & $\ldots$ & $\ldots$ & 1 & $\ldots$ & $\ldots$ & $\ldots$ & 1 & $\ldots$ & $\ldots$ & $\ldots$ & $\ldots$ & $\ldots$ & $\ldots$ & 0 & 2 & 2 \\
\hline AMMOPHILINAE & & & & & & & & & & & & & & & & & & & \\
\hline AMMOPHILINI & & & & & & & & & & & & & & & & & & & \\
\hline Ammophila heydeni Dahlbom, 1845 & $\ldots$ & $\ldots$ & $\ldots$ & $\ldots$ & $\ldots$ & 1 & $\ldots$ & $\ldots$ & 1 & $\ldots$ & $\ldots$ & $\ldots$ & $\ldots$ & $\ldots$ & $\ldots$ & $\ldots$ & 1 & 1 & 2 \\
\hline Ammophila Aff. rubriventris & $\ldots$ & $\ldots$ & $\ldots$ & $\ldots$ & $\ldots$ & $\ldots$ & $\ldots$ & $\ldots$ & $\ldots$ & 1 & $\ldots$ & $\ldots$ & $\ldots$ & $\ldots$ & $\ldots$ & $\ldots$ & 0 & 1 & 1 \\
\hline CRABRONIDAE & & & & & & & & & & & & & & & & & & & \\
\hline PEMPHREDONINAE & & & & & & & & & & & & & & & & & & & \\
\hline PSENINI & & & & & & & & & & & & & & & & & & & \\
\hline Psenulus fuscipennis (Dahlbom, 1843) & $\ldots$ & $\ldots$ & $\ldots$ & 1 & $\ldots$ & $\ldots$ & $\ldots$ & $\ldots$ & $\ldots$ & $\ldots$ & $\ldots$ & $\ldots$ & $\ldots$ & $\ldots$ & $\ldots$ & $\ldots$ & 0 & 1 & 1 \\
\hline ASTATINAE & & & & & & & & & & & & & & & & & & & \\
\hline ASTATINI & & & & & & & & & & & & & & & & & & & \\
\hline Astata costae A. Costa, 1867 & $\ldots$ & 1 & $\ldots$ & $\ldots$ & $\ldots$ & $\ldots$ & $\ldots$ & $\ldots$ & $\ldots$ & $\ldots$ & $\ldots$ & $\ldots$ & $\ldots$ & $\ldots$ & $\ldots$ & $\ldots$ & 0 & 1 & 1 \\
\hline CRABRONINAE & & & & & & & & & & & & & & & & & & & \\
\hline LARRINI & & & & & & & & & & & & & & & & & & & \\
\hline Tachytes panzeri (Dufour, 1841) & 1 & $\ldots$ & 5 & 2 & 1 & 1 & 1 & $\ldots$ & $\ldots$ & $\ldots$ & $\ldots$ & $\ldots$ & $\ldots$ & $\ldots$ & $\ldots$ & $\ldots$ & 8 & 3 & 11 \\
\hline Tachysphex costae (De Stefani, 1882) & $\ldots$ & $\ldots$ & $\ldots$ & 1 & $\ldots$ & $\ldots$ & $\ldots$ & $\ldots$ & $\ldots$ & $\ldots$ & $\ldots$ & $\ldots$ & $\ldots$ & $\ldots$ & $\ldots$ & $\ldots$ & 0 & 1 & 1 \\
\hline Tachysphex fulvitarsis (A. Costa, 1867) & 1 & 6 & 1 & 3 & 4 & 6 & 2 & 6 & $\ldots$ & 7 & $\ldots$ & $\ldots$ & $\ldots$ & $\ldots$ & $\ldots$ & $\ldots$ & 8 & 28 & 36 \\
\hline Tachysphex incertus (Radoszkowski, 1877) & 6 & 4 & 10 & 8 & 12 & 16 & 4 & 13 & 2 & 2 & $\ldots$ & $\ldots$ & $\ldots$ & $\ldots$ & $\ldots$ & $\ldots$ & 34 & 43 & 77 \\
\hline Tachysphex julliani Kohl, 1883 & $\ldots$ & $\ldots$ & $\ldots$ & 2 & $\ldots$ & 7 & $\ldots$ & 6 & $\ldots$ & 3 & $\ldots$ & $\ldots$ & $\ldots$ & $\ldots$ & $\ldots$ & $\ldots$ & 0 & 18 & 18 \\
\hline Tachysphex obscuripennis (Schenck, 1857) & $\ldots$ & $\ldots$ & $\ldots$ & 2 & $\ldots$ & $\ldots$ & $\ldots$ & $\ldots$ & $\ldots$ & 1 & $\ldots$ & $\ldots$ & $\ldots$ & $\ldots$ & $\ldots$ & $\ldots$ & 0 & 3 & 3 \\
\hline Tachysphex panzeri (Van der Linden, 1829) & $\ldots$ & $\ldots$ & $\ldots$ & 2 & $\ldots$ & 1 & $\ldots$ & 3 & $\ldots$ & 4 & $\ldots$ & 2 & $\ldots$ & 1 & $\ldots$ & $\ldots$ & 0 & 13 & 13 \\
\hline Tachysphex pseudopanzeri Beaumont, 1955 & $\ldots$ & $\ldots$ & $\ldots$ & $\ldots$ & 2 & $\ldots$ & 1 & $\ldots$ & 13 & $\ldots$ & 3 & $\ldots$ & 1 & $\ldots$ & $\ldots$ & $\ldots$ & 20 & 0 & 20 \\
\hline Tachysphex unicolor (Panzer, 1809) & $\ldots$ & $\ldots$ & $\ldots$ & $\ldots$ & $\ldots$ & $\ldots$ & $\ldots$ & 1 & $\ldots$ & $\ldots$ & $\ldots$ & $\ldots$ & $\ldots$ & $\ldots$ & $\ldots$ & $\ldots$ & 0 & 1 & 1 \\
\hline MISCOPHINI & & & & & & & & & & & & & & & & & & & \\
\hline Solierella compedita (Piccioli, 1869) & $\ldots$ & $\ldots$ & $\ldots$ & $\ldots$ & $\ldots$ & 2 & 1 & 2 & $\ldots$ & $\ldots$ & $\ldots$ & 4 & 1 & $\ldots$ & $\ldots$ & $\ldots$ & 2 & 8 & 10 \\
\hline Miscophus bicolor Jurine, 1807 & $\ldots$ & $\ldots$ & $\ldots$ & $\ldots$ & $\ldots$ & $\ldots$ & $\ldots$ & $\ldots$ & $\ldots$ & 3 & $\ldots$ & 5 & $\ldots$ & $\ldots$ & $\ldots$ & $\ldots$ & 0 & 8 & 8 \\
\hline Miscophus eatoni Saunders, 1903 & $\ldots$ & $\ldots$ & $\ldots$ & $\ldots$ & $\ldots$ & $\ldots$ & $\ldots$ & $\ldots$ & $\ldots$ & 1 & $\ldots$ & $\ldots$ & $\ldots$ & $\ldots$ & $\ldots$ & $\ldots$ & 0 & 1 & 1 \\
\hline Miscophus nicolai Ferton, 1896 & $\ldots$ & $\ldots$ & $\ldots$ & 1 & 1 & 5 & & 2 & $\ldots$ & 5 & 1 & $\ldots$ & $\ldots$ & $\ldots$ & $\ldots$ & $\ldots$ & 2 & 13 & 15 \\
\hline Nitela lucens Gayubo \& Felton, 2000 & $\ldots$ & $\ldots$ & $\ldots$ & $\ldots$ & $\ldots$ & $\ldots$ & $\ldots$ & $\ldots$ & $\ldots$ & $\ldots$ & $\ldots$ & $\ldots$ & $\ldots$ & $\ldots$ & $\ldots$ & 4 & 0 & 4 & 4 \\
\hline TRYPOXYLINI & & & & & & & & & & & & & & & & & & & \\
\hline Trypoxylon attenuatum F. Smith, 1851 & $\ldots$ & $\ldots$ & $\ldots$ & 1 & $\ldots$ & 1 & $\ldots$ & $\ldots$ & $\ldots$ & $\ldots$ & $\ldots$ & $\ldots$ & $\ldots$ & $\ldots$ & $\ldots$ & $\ldots$ & 0 & 2 & 2 \\
\hline Trypoxylon clavicerum Lepeletier \& Serville, 1828 & $\ldots$ & $\ldots$ & $\ldots$ & $\ldots$ & $\ldots$ & 1 & $\ldots$ & $\ldots$ & $\ldots$ & $\cdots$ & $\ldots$ & $\cdots$ & $\ldots$ & $\ldots$ & $\ldots$ & $\ldots$ & 0 & 1 & 1 \\
\hline Trypoxylon scutatum Chevrier, 1867 & $\ldots$ & $\ldots$ & $\ldots$ & 2 & 1 & 1 & $\ldots$ & 4 & $\ldots$ & 4 & $\ldots$ & 1 & $\ldots$ & $\ldots$ & $\ldots$ & $\ldots$ & 1 & 12 & 13 \\
\hline OXYBELINI & & & & & & & & & & & & & & & & & & & \\
\hline Oxybelus quattuordecimnotatus Jurine, 1807 & $\ldots$ & $\ldots$ & $\ldots$ & $\ldots$ & $\ldots$ & $\ldots$ & $\ldots$ & 1 & $\ldots$ & 1 & $\ldots$ & $\ldots$ & $\ldots$ & $\ldots$ & $\ldots$ & $\ldots$ & 0 & 2 & 2 \\
\hline
\end{tabular}




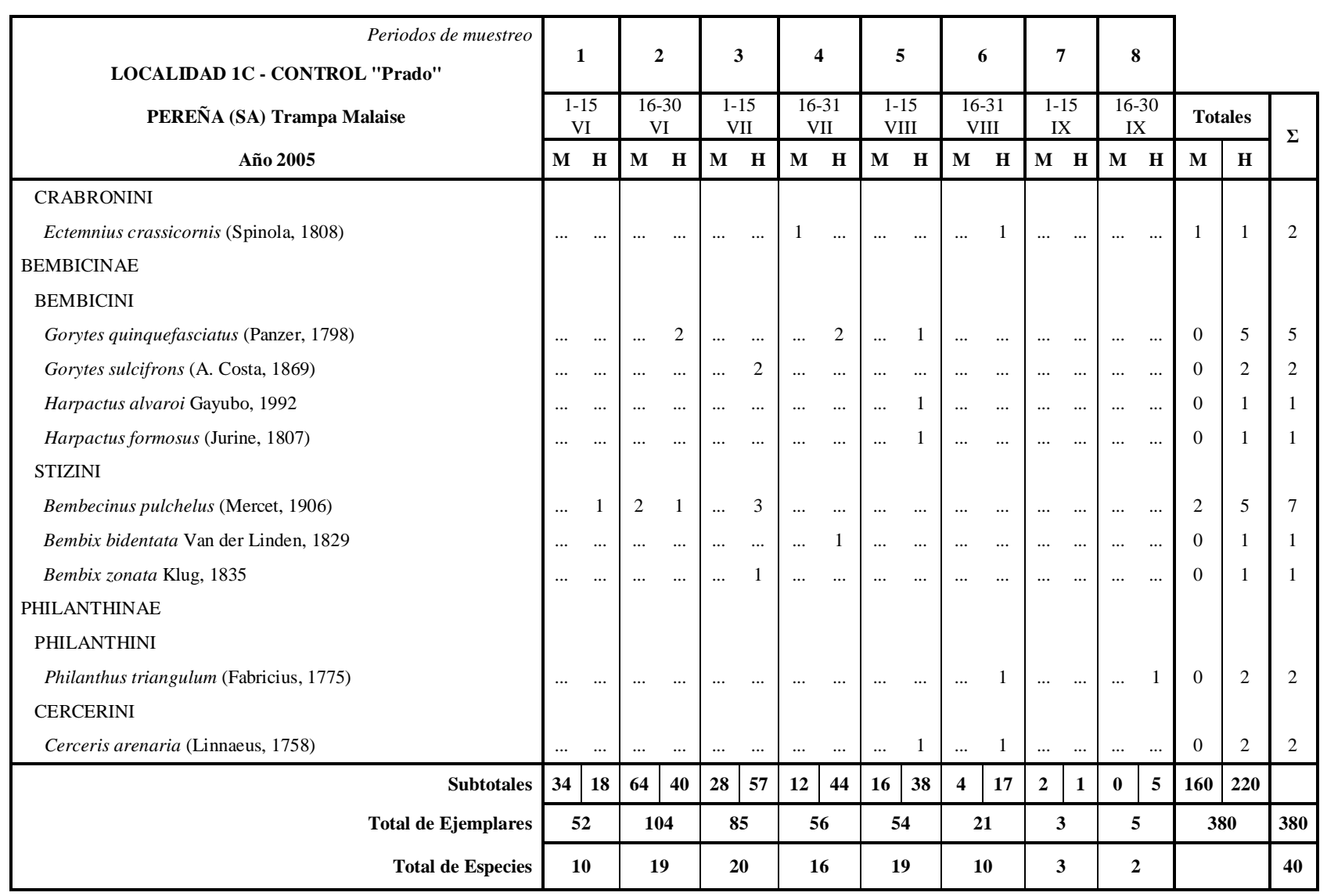

* Subespecies 


\begin{tabular}{|c|c|c|c|c|c|c|c|c|c|c|c|}
\hline \multirow{3}{*}{$\begin{array}{l}\text { Periodos de muestreo } \\
\text { LOCALIDAD 1C - (Escobas+Prado) } \\
\text { Pereña (SA) PLATOS } \\
\text { Año 2005 }\end{array}$} & \multicolumn{2}{|c|}{1} & \multicolumn{2}{|c|}{2} & \multicolumn{2}{|c|}{3} & \multicolumn{2}{|c|}{4} & & & \\
\hline & \multicolumn{2}{|c|}{ 15-Jun } & \multicolumn{2}{|c|}{ 15-Jul } & \multicolumn{2}{|c|}{ 15-Agos } & \multicolumn{2}{|c|}{ 15-Sep } & \multicolumn{2}{|c|}{ Totales } & \multirow{2}{*}{$\Sigma$} \\
\hline & $\mathbf{M}$ & $\mathbf{H}$ & $\mathbf{M}$ & & $\mathbf{M}$ & $\mathbf{H}$ & $\mathbf{M}$ & $\mathbf{H}$ & $\mathbf{M}$ & $\mathbf{H}$ & \\
\hline \multicolumn{12}{|l|}{ AMPULICIDAE } \\
\hline \multicolumn{12}{|l|}{ AMPULICINAE } \\
\hline \multicolumn{12}{|l|}{ AMPULICINI } \\
\hline Dolichurus haemorrhous A. Costa, 1886 & $\ldots$ & $\ldots$ & $\ldots$ & $\ldots$ & $\ldots$ & $\ldots$ & $\ldots$ & 1 & 0 & 1 & 1 \\
\hline \multicolumn{12}{|l|}{ CRABRONIDAE } \\
\hline \multicolumn{12}{|l|}{ PEMPHREDONINAE } \\
\hline \multicolumn{12}{|l|}{ PEMPHREDONINI } \\
\hline Diodontus insidiosus Spooner, 1938 & $\ldots$ & 2 & $\ldots$ & $\ldots$ & $\ldots$ & $\ldots$ & $\ldots$ & $\ldots$ & 0 & 2 & 2 \\
\hline \multicolumn{12}{|l|}{ CRABRONINAE } \\
\hline Tachysphex incertus (Radoszkowski, 1877) & 4 & $\ldots$ & $\ldots$ & 3 & $\ldots$ & $\ldots$ & $\ldots$ & $\ldots$ & 4 & 3 & 7 \\
\hline Tachysphex mediterraneus Kohl, 1883 & $\ldots$ & $\ldots$ & $\ldots$ & 1 & $\ldots$ & 2 & $\ldots$ & $\ldots$ & 0 & 3 & 3 \\
\hline Tachysphex nitidior Beaumont, 1940 & $\ldots$ & 1 & $\ldots$ & 4 & $\ldots$ & 2 & $\ldots$ & $\ldots$ & 0 & 7 & 7 \\
\hline Tachysphex obscuripennis (Schenck, 1857) & 2 & 6 & 6 & 3 & 1 & 2 & $\ldots$ & 1 & 9 & 12 & 21 \\
\hline Tachysphex plicosus (A. Costa, 1867) & $\ldots$ & $\ldots$ & $\ldots$ & $\ldots$ & $\ldots$ & 1 & $\ldots$ & $\ldots$ & 0 & 1 & 1 \\
\hline Tachysphex pompiliformis (Panzer, 1805) & 1 & $\ldots$ & $\ldots$ & $\ldots$ & $\ldots$ & $\ldots$ & $\ldots$ & $\ldots$ & 1 & 0 & 1 \\
\hline Tachysphex psammobius (Kohl, 1880) & $\ldots$ & 1 & $\ldots$ & $\ldots$ & $\ldots$ & $\ldots$ & $\ldots$ & $\ldots$ & 0 & 1 & 1 \\
\hline Tachysphex pseudopanzeri Beaumont, 1955 & $\ldots$ & $\ldots$ & $\ldots$ & $\ldots$ & 2 & $\ldots$ & $\ldots$ & $\ldots$ & 2 & 0 & 2 \\
\hline Prosopigastra punctatissima A. Costa, 1869 & 1 & $\ldots$ & $\ldots$ & $\ldots$ & $\ldots$ & $\ldots$ & $\ldots$ & $\ldots$ & 1 & 0 & 1 \\
\hline \multicolumn{12}{|l|}{ MISCOPHINI } \\
\hline Solierella compedita (Piccioli, 1869) & $\ldots$ & 1 & 6 & 24 & 18 & 3 & 1 & 3 & 25 & 31 & 56 \\
\hline Solierella pisonoides (Saunders, 1873) & 1 & $\ldots$ & 2 & 3 & $\ldots$ & $\ldots$ & $\ldots$ & $\ldots$ & 3 & 3 & 6 \\
\hline Solierella seabrai Andrade, 1950 & $\cdots$ & 1 & $\ldots$ & $\ldots$ & 1 & $\cdots$ & $\ldots$ & $\ldots$ & 1 & 1 & 2 \\
\hline Miscophus bicolor Jurine, 1807 & $\ldots$ & $\ldots$ & $\ldots$ & $\ldots$ & 1 & $\ldots$ & $\ldots$ & $\ldots$ & 1 & 0 & 1 \\
\hline Miscophus eatoni Saunders, 1903 & $\ldots$ & $\ldots$ & $\ldots$ & 2 & $\ldots$ & $\ldots$ & $\ldots$ & 1 & 0 & 3 & 3 \\
\hline Miscophus nicolai Ferton, 1896 & 2 & 5 & 1 & 8 & 2 & 18 & $\ldots$ & $\ldots$ & 5 & 31 & 36 \\
\hline \multicolumn{12}{|l|}{ TRYPOXYLINI } \\
\hline Trypoxylon attenuatum F. Smith, 1851 & $\ldots$ & $\ldots$ & $\ldots$ & $\ldots$ & $\ldots$ & $\ldots$ & $\ldots$ & 1 & 0 & 1 & 1 \\
\hline Trypoxylon scutatum Chevrier, 1867 & $\ldots$ & 1 & $\ldots$ & 1 & $\ldots$ & $\ldots$ & $\ldots$ & $\ldots$ & 0 & 2 & 2 \\
\hline \multicolumn{12}{|l|}{ BEMBICINAE } \\
\hline \multicolumn{12}{|l|}{ NYSSONINI } \\
\hline Nysson pratensis Mercet, 1909 & $\ldots$ & 1 & $\ldots$ & $\ldots$ & $\ldots$ & $\ldots$ & $\ldots$ & $\ldots$ & 0 & 1 & 1 \\
\hline \multicolumn{12}{|l|}{ BEMBICINI } \\
\hline Harpactus alvaroi Gayubo, 1992 & $\ldots$ & $\ldots$ & $\ldots$ & $\ldots$ & $\ldots$ & 2 & $\ldots$ & $\ldots$ & 0 & 2 & 2 \\
\hline Harpactus sp. 2 grimaldensis Gayubo, sp. n. (in lit.) & 1 & $\ldots$ & $\ldots$ & $\ldots$ & $\ldots$ & $\ldots$ & $\ldots$ & 1 & 1 & 1 & 2 \\
\hline Subtotales & 12 & 19 & 15 & 49 & 25 & 30 & 1 & 8 & 53 & 106 & \\
\hline Total de Ejemplares & & & & & & & & & & & 159 \\
\hline Total de Especies & & & & & & & & & & & 22 \\
\hline
\end{tabular}




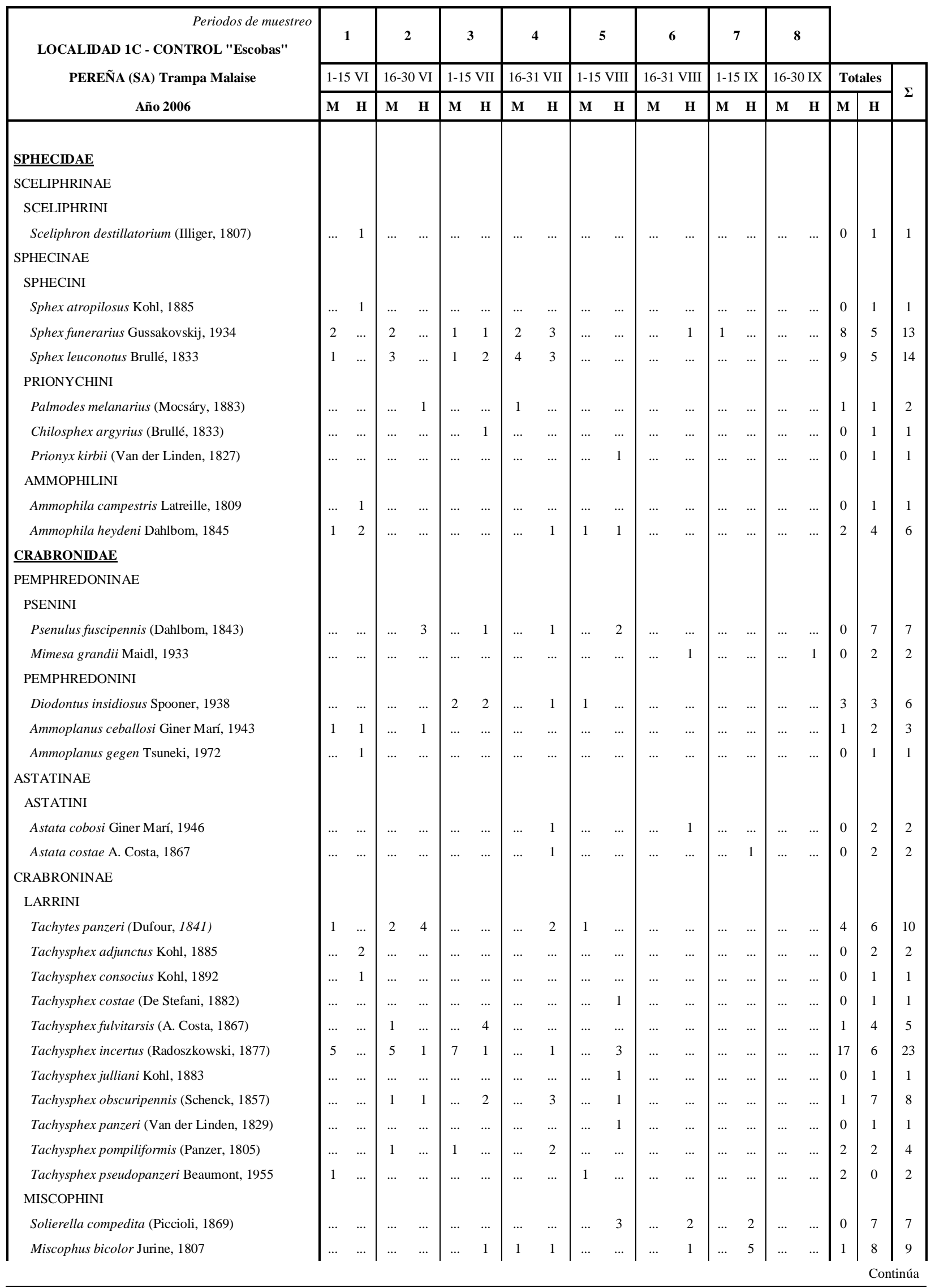




\begin{tabular}{|c|c|c|c|c|c|c|c|c|c|c|c|c|c|c|c|c|c|c|c|}
\hline \multirow{3}{*}{$\begin{array}{r}\text { Periodos de muestreo } \\
\text { LOCALIDAD 1C - CONTROL "Escobas" } \\
\text { PEREÑA (SA) Trampa Malaise } \\
\text { Año } 2006\end{array}$} & \multicolumn{2}{|c|}{1} & \multicolumn{2}{|c|}{2} & \multicolumn{2}{|c|}{3} & \multicolumn{2}{|c|}{4} & \multicolumn{2}{|c|}{5} & \multicolumn{2}{|c|}{6} & \multicolumn{2}{|c|}{7} & \multicolumn{2}{|c|}{8} & & & \\
\hline & \multicolumn{2}{|c|}{$1-15 \mathrm{VI}$} & \multicolumn{2}{|c|}{$16-30 \mathrm{VI}$} & \multicolumn{2}{|c|}{$1-15 \mathrm{VII}$} & \multicolumn{2}{|c|}{$16-31 \mathrm{VII}$} & \multicolumn{2}{|c|}{ 1-15 VIII } & \multicolumn{2}{|c|}{ 16-31 VIII } & \multicolumn{2}{|c|}{ 1-15 IX } & \multicolumn{2}{|c|}{ 16-30 IX } & \multicolumn{2}{|c|}{ Totales } & \multirow{2}{*}{$\Sigma$} \\
\hline & $\mathbf{M}$ & $\mathbf{H}$ & $\mathbf{M}$ & & $\mathbf{M}$ & & $\mathbf{M}$ & & $\mathbf{M}$ & & $\mathbf{M}$ & & $\mathbf{M}$ & & $\mathbf{M}$ & $\mathbf{H}$ & M & $\mathbf{H}$ & \\
\hline Miscophus nicolai Ferton, 1896 & $\ldots$ & $\ldots$ & $\ldots$ & $\ldots$ & $\ldots$ & $\ldots$ & $\ldots$ & $\ldots$ & $\ldots$ & 1 & $\ldots$ & $\ldots$ & $\ldots$ & 1 & $\ldots$ & $\ldots$ & 0 & 2 & 2 \\
\hline Nitela lucens Gayubo \& Felton, 2000 & $\ldots$ & $\ldots$ & $\ldots$ & $\ldots$ & $\ldots$ & $\ldots$ & $\ldots$ & 2 & $\ldots$ & 2 & $\ldots$ & 4 & 1 & 2 & $\ldots$ & 3 & 1 & 13 & 14 \\
\hline \multicolumn{20}{|l|}{ TRYPOXYLINI } \\
\hline Trypoxylon clavicerum Lepeletier \& Serville, 1828 & $\ldots$ & $\ldots$ & $\ldots$ & $\ldots$ & $\ldots$ & $\ldots$ & $\ldots$ & $\ldots$ & $\ldots$ & $\ldots$ & $\ldots$ & 2 & $\ldots$ & 2 & $\ldots$ & $\ldots$ & 0 & 4 & 4 \\
\hline Trypoxylon scutatum Chevrier, 1867 & $\ldots$ & 1 & $\ldots$ & 1 & $\ldots$ & $\ldots$ & $\ldots$ & 2 & $\ldots$ & 3 & $\ldots$ & 4 & $\ldots$ & 1 & $\ldots$ & $\ldots$ & 0 & 12 & 12 \\
\hline \multicolumn{20}{|l|}{ OXYBELINI } \\
\hline Oxybelus quattuordecimnotatus Jurine, 1807 & $\ldots$ & $\ldots$ & 1 & $\ldots$ & $\ldots$ & $\ldots$ & $\ldots$ & 2 & 1 & 2 & $\ldots$ & 1 & $\ldots$ & $\ldots$ & $\ldots$ & $\ldots$ & 2 & 5 & 7 \\
\hline Oxybelus subspinosus Klug, 1835 & $\ldots$ & $\ldots$ & $\ldots$ & $\ldots$ & $\ldots$ & $\ldots$ & $\cdots$ & 1 & $\ldots$ & $\ldots$ & $\ldots$ & $\ldots$ & $\ldots$ & $\ldots$ & $\ldots$ & $\ldots$ & 0 & 1 & 1 \\
\hline \multicolumn{20}{|l|}{ CRABRONINI } \\
\hline Lindenius pygmaeus (Rossi, 1794) & $\ldots$ & $\ldots$ & $\ldots$ & $\ldots$ & $\ldots$ & $\ldots$ & $\ldots$ & $\ldots$ & $\ldots$ & $\ldots$ & $\ldots$ & $\ldots$ & $\ldots$ & 1 & $\ldots$ & $\ldots$ & 0 & 1 & 1 \\
\hline Tracheliodes quinquenotatus (Jurine, 1807) & $\ldots$ & $\ldots$ & $\ldots$ & $\ldots$ & $\ldots$ & 1 & $\ldots$ & 1 & $\cdots$ & $\ldots$ & $\ldots$ & $\ldots$ & $\ldots$ & $\ldots$ & $\ldots$ & $\ldots$ & 0 & 2 & 2 \\
\hline Ectemnius crassicornis (Spinola, 1808) & $\ldots$ & $\ldots$ & $\ldots$ & $\ldots$ & $\ldots$ & $\ldots$ & 1 & $\ldots$ & $\ldots$ & $\ldots$ & $\ldots$ & $\ldots$ & $\ldots$ & $\ldots$ & $\ldots$ & $\ldots$ & 1 & 0 & 1 \\
\hline \multicolumn{20}{|l|}{ BEMBICINAE } \\
\hline \multicolumn{20}{|l|}{ BEMBICINI } \\
\hline Bembecinus carpetanus (Mercet, 1906) & 1 & $\ldots$ & $\ldots$ & $\ldots$ & $\ldots$ & $\ldots$ & $\ldots$ & $\ldots$ & $\cdots$ & $\ldots$ & $\ldots$ & $\ldots$ & $\ldots$ & $\ldots$ & $\ldots$ & $\ldots$ & 1 & 0 & 1 \\
\hline Bembecinus pulchelus (Mercet, 1906) & $\ldots$ & $\ldots$ & $\ldots$ & $\ldots$ & $\ldots$ & $\ldots$ & $\ldots$ & 1 & $\ldots$ & 1 & $\ldots$ & $\ldots$ & $\ldots$ & $\ldots$ & $\ldots$ & $\ldots$ & 0 & 2 & 2 \\
\hline Bembix bidentata Van der Linden, 1829 & $\ldots$ & $\ldots$ & $\ldots$ & $\ldots$ & $\ldots$ & 1 & $\ldots$ & $\ldots$ & $\ldots$ & $\ldots$ & $\ldots$ & $\ldots$ & $\ldots$ & $\ldots$ & $\ldots$ & $\ldots$ & 0 & 1 & 1 \\
\hline Bembix oculata Panzer, 1801 & $\cdots$ & $\ldots$ & $\ldots$ & $\ldots$ & $\ldots$ & 1 & $\ldots$ & $\ldots$ & $\ldots$ & $\ldots$ & $\ldots$ & $\ldots$ & $\ldots$ & $\ldots$ & $\ldots$ & $\ldots$ & 0 & 1 & 1 \\
\hline Bembix zonata Klug, 1835 & $\ldots$ & $\ldots$ & $\ldots$ & $\ldots$ & $\ldots$ & $\ldots$ & 1 & 4 & $\ldots$ & 2 & $\ldots$ & $\ldots$ & $\ldots$ & $\ldots$ & $\ldots$ & $\ldots$ & 1 & 6 & 7 \\
\hline PHILANTHINAE & & & & & & & & & & & & & & & & & & & \\
\hline PHILANTHINI & & & & & & & & & & & & & & & & & & & \\
\hline Philanthus triangulum (Fabricius, 1775) & $\ldots$ & $\ldots$ & $\ldots$ & $\ldots$ & $\ldots$ & $\ldots$ & $\ldots$ & $\ldots$ & 1 & $\ldots$ & $\ldots$ & $\ldots$ & $\ldots$ & $\ldots$ & $\ldots$ & 1 & 1 & 1 & 2 \\
\hline CERCERINI & & & & & & & & & & & & & & & & & & & \\
\hline Cerceris arenaria (Linnaeus, 1758) & $\ldots$ & $\ldots$ & $\ldots$ & $\ldots$ & $\ldots$ & $\ldots$ & $\ldots$ & $\ldots$ & $\ldots$ & $\ldots$ & 1 & $\ldots$ & $\ldots$ & $\ldots$ & $\ldots$ & $\ldots$ & 1 & 0 & 1 \\
\hline Cerceris sabulosa (Panzer, 1799) & $\ldots$ & $\ldots$ & $\ldots$ & $\ldots$ & $\ldots$ & $\ldots$ & $\ldots$ & $\ldots$ & 2 & 1 & 2 & $\ldots$ & $\ldots$ & $\ldots$ & $\ldots$ & $\ldots$ & 4 & 1 & 5 \\
\hline Subtotales & 13 & 11 & 16 & 12 & 12 & 18 & 10 & 33 & 8 & 26 & 3 & 17 & 2 & 15 & $\mathbf{0}$ & 5 & 64 & 137 & \\
\hline Total de Ejemplares & 2 & & & & & & & & & & & & 1 & & & & & 01 & 201 \\
\hline Total de Especies & 1 & & & & & & & & & & & & Sala & & & & & & 46 \\
\hline
\end{tabular}




\begin{tabular}{|c|c|c|c|c|c|c|c|c|c|c|c|c|c|c|c|c|c|c|c|}
\hline $\begin{array}{l}\text { Periodos de muestreo } \\
\text { Pe" }\end{array}$ & 1 & & 2 & & 3 & & & & & & & & 7 & 7 & 8 & 3 & & & \\
\hline PEREÑA (SA) Trampa Malaise & $1-15$ & $5 \mathrm{VI}$ & $16-3$ & $0 \mathrm{VI}$ & $1-15$ & VII & & VII & & & & VIII & $1-15$ & 5 IX & $16-3$ & $0 \mathrm{IX}$ & Tot & ales & \\
\hline Año 2006 & M & $\mathbf{H}$ & M & $\mathbf{H}$ & M & $\mathbf{H}$ & M & $\mathbf{H}$ & $\mathbf{M}$ & $\mathbf{H}$ & $\mathbf{M}$ & $\mathbf{H}$ & M & & M & $\mathbf{H}$ & $\mathbf{M}$ & $\mathbf{H}$ & 2 \\
\hline SPHECIDAE & & & & & & & & & & & & & & & & & & & \\
\hline SPHECINAE & & & & & & & & & & & & & & & & & & & \\
\hline SPHECINI & & & & & & & & & & & & & & & & & & & \\
\hline Sphex funerarius Gussakovskij, 1934 & $\ldots$ & 1 & 1 & 2 & $\ldots$ & 2 & $\ldots$ & 1 & ... & 2 & $\ldots$ & 2 & $\ldots$ & $\ldots$ & $\ldots$ & $\ldots$ & 1 & 10 & 11 \\
\hline Sphex leuconotus Brullé, 1833 & $\ldots$ & 1 & 3 & $\ldots$ & 1 & 1 & 2 & 1 & $\ldots$ & 1 & $\ldots$ & $\ldots$ & $\ldots$ & $\ldots$ & $\ldots$ & $\ldots$ & 6 & 4 & 10 \\
\hline PRIONYCHINI & & & & & & & & & & & & & & & & & & & \\
\hline Palmodes melanarius (Mocsáry, 1883) & $\ldots$ & 1 & $\ldots$ & $\ldots$ & $\ldots$ & ... & $\ldots$ & 1 & $\ldots$ & $\ldots$ & $\ldots$ & $\ldots$ & $\ldots$ & $\ldots$ & $\ldots$ & $\ldots$ & 0 & 2 & 2 \\
\hline Prionyx kirbii (Van der Linden, 1827) & $\ldots$ & $\ldots$ & $\ldots$ & $\ldots$ & $\ldots$ & $\ldots$ & $\ldots$ & $\ldots$ & $\ldots$ & 1 & $\ldots$ & $\ldots$ & $\ldots$ & $\ldots$ & $\ldots$ & 1 & 0 & 2 & 2 \\
\hline AMMOPHILINAE & & & & & & & & & & & & & & & & & & & \\
\hline AMMOPHILINI & & & & & & & & & & & & & & & & & & & \\
\hline Ammophila campestris Latreille, 1809 & 1 & 6 & $\ldots$ & $\ldots$ & $\ldots$ & ... & $\ldots$ & $\ldots$ & $\ldots$ & $\ldots$ & $\ldots$ & $\ldots$ & $\ldots$ & $\ldots$ & $\ldots$ & $\ldots$ & 1 & 6 & 7 \\
\hline Ammophila heydeni Dahlbom, 1845 & $\ldots$ & 2 & $\ldots$ & $\ldots$ & 1 & $\ldots$ & $\ldots$ & $\ldots$ & ... & 1 & $\ldots$ & 1 & $\ldots$ & $\ldots$ & $\ldots$ & $\ldots$ & 1 & 4 & 5 \\
\hline Ammophila laevicollis André, 1886 & $\ldots$ & 1 & ... & $\ldots$ & $\ldots$ & .. & $\ldots$ & $\ldots$ & $\ldots$ & $\ldots$ & $\ldots$ & $\ldots$ & $\ldots$ & $\ldots$ & $\ldots$ & $\ldots$ & 0 & 1 & 1 \\
\hline Ammophila sabulosa (Linnaeus, 1758) & $\ldots$ & $\ldots$ & $\ldots$ & $\ldots$ & ... & .. & 1 & $\ldots$ & $\ldots$ & $\ldots$ & $\ldots$ & $\ldots$ & $\ldots$ & $\ldots$ & $\ldots$ & $\ldots$ & 1 & 0 & 1 \\
\hline Podalonia hirsuta (Scopoli, 1763) & 1 & $\ldots$ & $\ldots$ & $\ldots$ & $\ldots$ & $\ldots$ & $\ldots$ & $\ldots$ & $\ldots$ & $\ldots$ & $\ldots$ & $\ldots$ & $\ldots$ & $\ldots$ & $\ldots$ & $\ldots$ & 1 & 0 & 1 \\
\hline CRABRONIDAE & & & & & & & & & & & & & & & & & & & \\
\hline PEMPHREDONINAE & & & & & & & & & & & & & & & & & & & \\
\hline PSENINI & & & & & & & & & & & & & & & & & & & \\
\hline Psenulus fuscipennis (Dahlbom, 1843) & $\ldots$ & $\ldots$ & ... & $\ldots$ & $\ldots$ & 1 & $\ldots$ & $\ldots$ & $\ldots$ & $\ldots$ & $\ldots$ & $\ldots$ & $\ldots$ & $\ldots$ & $\ldots$ & $\ldots$ & 0 & 1 & 1 \\
\hline Mimesa grandii Maidl, 1933 & $\ldots$ & $\ldots$ & ... & $\ldots$ & $\ldots$ & $\ldots$ & 1 & $\ldots$ & $\ldots$ & 1 & $\ldots$ & $\ldots$ & $\ldots$ & $\ldots$ & $\ldots$ & $\ldots$ & 1 & 1 & 2 \\
\hline PEMPHREDONINI & & & & & & & & & & & & & & & & & & & \\
\hline Diodontus insidiosus Spooner, 1938 & $\ldots$ & 1 & $\ldots$ & 4 & 1 & $\ldots$ & $\ldots$ & 1 & $\ldots$ & 1 & 1 & $\ldots$ & $\ldots$ & $\ldots$ & $\ldots$ & $\ldots$ & 2 & 7 & 9 \\
\hline Passaloecus gracilis (Curtis, 1834) & $\ldots$ & $\ldots$ & $\ldots$ & 1 & $\ldots$ & $\ldots$ & $\ldots$ & $\ldots$ & $\ldots$ & $\ldots$ & $\ldots$ & $\ldots$ & $\ldots$ & $\ldots$ & $\ldots$ & $\ldots$ & 0 & 1 & 1 \\
\hline Passaloecus pictus Ribaut, 1952 & $\ldots$ & $\ldots$ & ... & 2 & $\ldots$ & $\ldots$ & $\ldots$ & $\ldots$ & $\ldots$ & $\ldots$ & $\ldots$ & $\ldots$ & $\ldots$ & $\ldots$ & $\ldots$ & 1 & 0 & 3 & 3 \\
\hline Ammoplanus ceballosi Giner Marí, 1943 & 3 & 20 & ... & $\ldots$ & $\ldots$ & $\ldots$ & $\ldots$ & $\ldots$ & $\ldots$ & $\ldots$ & $\ldots$ & $\ldots$ & $\ldots$ & $\ldots$ & $\ldots$ & $\ldots$ & 3 & 20 & 23 \\
\hline Ammoplanus torresi Gayubo, 1991 & $\ldots$ & 1 & $\ldots$ & $\ldots$ & $\ldots$ & 1 & $\ldots$ & $\ldots$ & $\ldots$ & $\ldots$ & $\ldots$ & $\ldots$ & $\ldots$ & $\ldots$ & $\ldots$ & $\ldots$ & 0 & 2 & 2 \\
\hline Ammoplanus sp. Aff. perrisi & $\ldots$ & 1 & $\ldots$ & $\ldots$ & $\ldots$ & $\ldots$ & $\ldots$ & $\ldots$ & $\ldots$ & $\ldots$ & $\ldots$ & $\ldots$ & $\ldots$ & $\ldots$ & $\ldots$ & $\ldots$ & 0 & 1 & 1 \\
\hline CRABRONINAE & & & & & & & & & & & & & & & & & & & \\
\hline LARRINI & & & & & & & & & & & & & & & & & & & \\
\hline Larra anathema (Rossi, 1790) & $\ldots$ & $\ldots$ & $\ldots$ & $\ldots$ & $\ldots$ & $\ldots$ & $\ldots$ & 1 & ... & $\ldots$ & $\ldots$ & $\ldots$ & $\ldots$ & $\ldots$ & $\ldots$ & $\ldots$ & 0 & 1 & 1 \\
\hline Tachytes panzeri (Dufour, 1841) & $\ldots$ & $\ldots$ & 1 & $\ldots$ & 1 & 2 & $\ldots$ & $\ldots$ & $\ldots$ & $\ldots$ & $\ldots$ & $\ldots$ & $\ldots$ & $\ldots$ & $\ldots$ & $\ldots$ & 2 & 2 & 4 \\
\hline Tachysphex consocius Kohl, 1892 & $\ldots$ & 1 & $\ldots$ & 2 & $\ldots$ & $\ldots$ & $\ldots$ & $\ldots$ & $\ldots$ & $\ldots$ & $\ldots$ & $\ldots$ & $\ldots$ & $\ldots$ & $\ldots$ & $\ldots$ & 0 & 3 & 3 \\
\hline Tachysphex costae (De Stefani, 1882) & $\ldots$ & $\ldots$ & ... & $\ldots$ & $\ldots$ & 1 & $\ldots$ & $\ldots$ & ... & $\ldots$ & $\ldots$ & $\ldots$ & $\ldots$ & $\ldots$ & $\ldots$ & $\ldots$ & 0 & 1 & 1 \\
\hline Tachysphex fulvitarsis (A. Costa, 1867) & 1 & 1 & 1 & 4 & 2 & 1 & $\ldots$ & 2 & $\ldots$ & 1 & $\ldots$ & 4 & $\ldots$ & $\ldots$ & $\ldots$ & $\ldots$ & 4 & 13 & 17 \\
\hline Tachysphex incertus (Radoszkowski, 1877) & 3 & 5 & 2 & 1 & 2 & 1 & $\ldots$ & 1 & $\ldots$ & $\ldots$ & $\ldots$ & 1 & $\ldots$ & $\ldots$ & $\ldots$ & $\ldots$ & 7 & 9 & 16 \\
\hline Tachysphex julliani Kohl, 1883 & $\ldots$ & $\ldots$ & $\ldots$ & $\ldots$ & $\ldots$ & $\ldots$ & $\ldots$ & $\ldots$ & $\ldots$ & 3 & $\ldots$ & 1 & $\ldots$ & $\ldots$ & $\ldots$ & $\ldots$ & 0 & 4 & 4 \\
\hline Tachysphex obscuripennis (Schenck, 1857) & $\ldots$ & $\ldots$ & $\ldots$ & $\ldots$ & $\ldots$ & 1 & $\ldots$ & 1 & $\ldots$ & 2 & $\ldots$ & $\ldots$ & $\ldots$ & $\ldots$ & $\ldots$ & $\ldots$ & 0 & 4 & 4 \\
\hline Tachysphex panzeri (Van der Linden, 1829) & $\ldots$ & $\ldots$ & $\ldots$ & 1 & $\ldots$ & $\ldots$ & $\ldots$ & 1 & $\ldots$ & 2 & $\ldots$ & 2 & $\ldots$ & $\ldots$ & $\ldots$ & $\ldots$ & 0 & 6 & 6 \\
\hline Tachysphex pompiliformis (Panzer, 1805) & $\ldots$ & $\ldots$ & 1 & $\ldots$ & $\ldots$ & $\ldots$ & $\ldots$ & 1 & $\ldots$ & $\ldots$ & $\ldots$ & $\ldots$ & $\ldots$ & $\ldots$ & $\ldots$ & $\ldots$ & 1 & 1 & 2 \\
\hline MISCOPHINI & & & & & & & & & & & & & & & & & & & \\
\hline Solierella compedita (Piccioli, 1869) & $\ldots$ & $\ldots$ & $\ldots$ & 1 & $\ldots$ & $\ldots$ & $\ldots$ & $\ldots$ & 2 & $\ldots$ & $\ldots$ & $\ldots$ & $\ldots$ & $\ldots$ & $\ldots$ & $\ldots$ & 2 & 1 & 3 \\
\hline Solierella pisonoides (Saunders, 1873) & $\ldots$ & $\ldots$ & $\ldots$ & $\ldots$ & $\ldots$ & $\ldots$ & $\ldots$ & $\ldots$ & $\ldots$ & $\ldots$ & $\ldots$ & 1 & $\ldots$ & $\ldots$ & $\ldots$ & $\ldots$ & 0 & 1 & 1 \\
\hline Miscophus bicolor Jurine, 1807 & $\ldots$ & $\ldots$ & $\ldots$ & 1 & $\ldots$ & 2 & $\ldots$ & 2 & $\ldots$ & $\ldots$ & $\ldots$ & 2 & $\ldots$ & $\ldots$ & $\ldots$ & $\ldots$ & 0 & 7 & 7 \\
\hline Miscophus nicolai Ferton, 1896 & 1 & $\ldots$ & $\ldots$ & 3 & $\ldots$ & $\ldots$ & $\ldots$ & 1 & $\ldots$ & 1 & $\ldots$ & $\ldots$ & $\ldots$ & $\ldots$ & $\ldots$ & $\ldots$ & 1 & 5 & 6 \\
\hline Nitela lucens Gayubo \& Felton, 2000 & $\ldots$ & $\ldots$ & 1 & $\ldots$ & $\ldots$ & $\ldots$ & $\ldots$ & 1 & $\ldots$ & $\ldots$ & 1 & 1 & $\ldots$ & $\ldots$ & $\ldots$ & $\ldots$ & 2 & 2 & 4 \\
\hline Nitela truncata Gayubo \& Felton, 2000 & $\ldots$ & $\ldots$ & $\ldots$ & $\ldots$ & $\ldots$ & & $\ldots$ & $\ldots$ & $\ldots$ & $\ldots$ & $\ldots$ & 1 & $\ldots$ & $\ldots$ & $\ldots$ & $\ldots$ & 0 & 1 & 1 \\
\hline
\end{tabular}




\begin{tabular}{|c|c|c|c|c|c|c|c|c|c|c|c|c|c|c|c|c|c|c|c|}
\hline \multirow{3}{*}{$\begin{array}{r}\text { Periodos de muestreo } \\
\text { LOCALIDAD 1C - CONTROL "Prado" } \\
\text { PEREÑA (SA) Trampa Malaise } \\
\text { Año } 2006\end{array}$} & \multicolumn{2}{|c|}{1} & \multicolumn{2}{|c|}{2} & \multicolumn{2}{|c|}{3} & \multicolumn{2}{|c|}{4} & & \multicolumn{2}{|c|}{6} & \multicolumn{2}{|l|}{7} & \multicolumn{2}{|c|}{8} & & & \\
\hline & \multicolumn{2}{|c|}{$1-15 \mathrm{VI}$} & \multicolumn{2}{|c|}{$16-30 \mathrm{VI}$} & \multicolumn{2}{|c|}{$1-15 \mathrm{VII}$} & \multicolumn{2}{|c|}{ 16-31 VII } & \multicolumn{2}{|c|}{ 1-15 VIII } & \multicolumn{2}{|c|}{ 16-31 VIII } & \multicolumn{2}{|c|}{$1-15$ IX } & \multicolumn{2}{|c|}{ 16-30 IX } & \multicolumn{2}{|c|}{ Totales } & \multirow{2}{*}{$\Sigma$} \\
\hline & M & & $\mathbf{M}$ & $\mathbf{H}$ & M & & M & $\mathbf{H}$ & M & $\mathbf{H}$ & $\mathbf{M}$ & & M & & M & $\mathbf{H}$ & $\mathbf{M}$ & $\mathbf{H}$ & \\
\hline \multicolumn{20}{|l|}{ TRYPOXYLINI } \\
\hline Trypoxylon attenuatum F. Smith, 1851 & $\ldots$ & & $\ldots$ & $\ldots$ & $\ldots$ & & $\ldots$ & $\ldots$ & 1 & 1 & $\ldots$ & $\ldots$ & $\ldots$ & $\ldots$ & $\ldots$ & $\ldots$ & 1 & 1 & 2 \\
\hline Trypoxylon clavicerum Lepeletier \& Serville, 1828 & $\ldots$ & $\ldots$ & $\ldots$ & $\ldots$ & $\ldots$ & & $\ldots$ & 1 & $\ldots$ & 1 & $\ldots$ & 1 & $\ldots$ & $\ldots$ & $\ldots$ & $\ldots$ & 0 & 3 & 3 \\
\hline Trypoxylon scutatum Chevrier, 1867 & $\ldots$ & $\ldots$ & $\ldots$ & $\ldots$ & $\ldots$ & 2 & 1 & 6 & $\ldots$ & 5 & $\ldots$ & 4 & $\ldots$ & $\ldots$ & $\ldots$ & $\ldots$ & 1 & 17 & 18 \\
\hline \multicolumn{20}{|l|}{ OXYBELINI } \\
\hline Oxybelus mucronatus (Fabricius, 1793) & $\ldots$ & $\ldots$ & $\ldots$ & $\ldots$ & $\ldots$ & $\ldots$ & $\ldots$ & $\ldots$ & $\ldots$ & $\ldots$ & $\ldots$ & 1 & $\ldots$ & $\ldots$ & $\ldots$ & $\ldots$ & 0 & 1 & 1 \\
\hline Oxybelus quattuordecimnotatus Jurine, 1807 & $\ldots$ & $\ldots$ & $\ldots$ & $\ldots$ & $\ldots$ & $\ldots$ & $\ldots$ & 2 & $\ldots$ & $\ldots$ & $\ldots$ & $\ldots$ & $\ldots$ & $\ldots$ & $\ldots$ & $\ldots$ & 0 & 2 & 2 \\
\hline Oxybelomorpha steckii (Kohl, 1923) & $\ldots$ & 1 & $\ldots$ & $\ldots$ & $\ldots$ & $\ldots$ & $\ldots$ & $\ldots$ & $\ldots$ & $\ldots$ & $\ldots$ & $\ldots$ & $\ldots$ & $\ldots$ & $\ldots$ & $\ldots$ & 0 & 1 & 1 \\
\hline \multicolumn{20}{|l|}{ CRABRONINI } \\
\hline Crossocerus elongatulus (Van der Linden, 1829) & $\ldots$ & $\ldots$ & $\ldots$ & $\ldots$ & $\ldots$ & ... & $\ldots$ & $\ldots$ & $\ldots$ & $\ldots$ & $\ldots$ & $\ldots$ & $\ldots$ & $\ldots$ & $\ldots$ & 1 & 0 & 1 & 1 \\
\hline Tracheliodes quinquenotatus (Jurine, 1807) & $\ldots$ & $\ldots$ & $\ldots$ & $\ldots$ & $\ldots$ & $\ldots$ & $\ldots$ & $\ldots$ & $\ldots$ & $\ldots$ & $\ldots$ & $\ldots$ & $\ldots$ & $\ldots$ & $\ldots$ & 1 & 0 & 1 & 1 \\
\hline Ectemnius crassicornis (Spinola, 1808) & $\ldots$ & $\ldots$ & $\ldots$ & $\ldots$ & $\ldots$ & $\ldots$ & $\ldots$ & $\ldots$ & $\ldots$ & $\ldots$ & $\ldots$ & 1 & $\ldots$ & $\ldots$ & $\ldots$ & 1 & 0 & 2 & 2 \\
\hline \multicolumn{20}{|l|}{ BEMBICINAE } \\
\hline BEMBICINI & & & & & & & & & & & & & & & & & & & \\
\hline Gorytes quinquefasciatus (Panzer, 1798) & $\ldots$ & $\ldots$ & $\ldots$ & $\ldots$ & $\ldots$ & $\ldots$ & $\ldots$ & 1 & $\ldots$ & $\ldots$ & $\ldots$ & $\ldots$ & $\ldots$ & $\ldots$ & $\ldots$ & $\ldots$ & 0 & 1 & 1 \\
\hline Gorytes sulcifrons (A. Costa, 1869) & $\ldots$ & $\ldots$ & $\ldots$ & $\ldots$ & $\ldots$ & $\ldots$ & $\ldots$ & 1 & $\ldots$ & $\ldots$ & $\ldots$ & $\ldots$ & $\ldots$ & $\ldots$ & $\ldots$ & $\ldots$ & 0 & 1 & 1 \\
\hline Harpactus alvaroi Gayubo, 1992 & $\ldots$ & $\ldots$ & $\ldots$ & $\ldots$ & $\ldots$ & $\ldots$ & 1 & $\ldots$ & $\ldots$ & $\ldots$ & 1 & 2 & $\ldots$ & $\ldots$ & $\ldots$ & $\ldots$ & 2 & 2 & 4 \\
\hline Harpactus formosus (Jurine, 1807) & $\ldots$ & $\ldots$ & $\ldots$ & 1 & $\ldots$ & $\ldots$ & $\ldots$ & $\ldots$ & $\ldots$ & 1 & $\ldots$ & $\ldots$ & $\ldots$ & $\ldots$ & $\ldots$ & $\ldots$ & 0 & 2 & 2 \\
\hline Bembecinus carpetanus (Mercet, 1906) & $\ldots$ & $\ldots$ & $\ldots$ & $\ldots$ & $\ldots$ & 1 & $\ldots$ & $\ldots$ & $\ldots$ & $\ldots$ & $\ldots$ & $\ldots$ & $\ldots$ & $\ldots$ & $\ldots$ & $\ldots$ & 0 & 1 & 1 \\
\hline Bembecinus pulchelus (Mercet, 1906) & $\ldots$ & 1 & $\ldots$ & $\ldots$ & $\ldots$ & $\ldots$ & $\ldots$ & $\ldots$ & $\ldots$ & $\ldots$ & $\ldots$ & $\ldots$ & $\ldots$ & $\ldots$ & $\ldots$ & $\ldots$ & 0 & 1 & 1 \\
\hline Bembix bidentata Van der Linden, 1829 & $\ldots$ & $\ldots$ & $\ldots$ & $\ldots$ & $\ldots$ & $\ldots$ & $\ldots$ & 1 & $\ldots$ & $\ldots$ & $\ldots$ & $\ldots$ & $\ldots$ & $\ldots$ & $\ldots$ & $\ldots$ & 0 & 1 & 1 \\
\hline Bembix zonata Klug, 1835 & $\ldots$ & $\ldots$ & $\ldots$ & 1 & $\ldots$ & $\ldots$ & $\ldots$ & $\ldots$ & $\ldots$ & $\ldots$ & $\ldots$ & 2 & $\ldots$ & $\ldots$ & $\ldots$ & 1 & 0 & 4 & 4 \\
\hline PHILANTHINAE & & & & & & & & & & & & & & & & & & & \\
\hline PHILANTHINI & & & & & & & & & & & & & & & & & & & \\
\hline Philanthus triangulum (Fabricius, 1775) & $\ldots$ & $\ldots$ & $\ldots$ & $\ldots$ & $\ldots$ & $\ldots$ & $\ldots$ & $\ldots$ & $\ldots$ & $\ldots$ & $\ldots$ & $\ldots$ & $\ldots$ & $\ldots$ & $\ldots$ & 1 & 0 & 1 & 1 \\
\hline CERCERINI & & & & & & & & & & & & & & & & & & & \\
\hline Cerceris arenaria (Linnaeus, 1758) & $\ldots$ & $\ldots$ & $\ldots$ & $\ldots$ & $\ldots$ & $\ldots$ & $\ldots$ & $\ldots$ & $\ldots$ & $\ldots$ & 1 & $\ldots$ & $\ldots$ & $\ldots$ & $\ldots$ & $\ldots$ & 1 & 0 & 1 \\
\hline Subtotales & 10 & 44 & 10 & 24 & 8 & 16 & 6 & 27 & 3 & 24 & 4 & 27 & $\mathbf{0}$ & $\mathbf{0}$ & 0 & 7 & 41 & 169 & \\
\hline Total de Ejemplares & 5 & & 3 & 4 & & 4 & & & & & 3 & & 0 & & 7 & & & 10 & \\
\hline Total de Especies & 17 & & $\begin{array}{llll}1 & & & \\
\end{array}$ & 7 & & 4 & & & & & 1 & & 0 & & 7 & & & & 52 \\
\hline
\end{tabular}




\begin{tabular}{|c|c|c|c|c|c|c|c|c|c|c|c|}
\hline \multirow{3}{*}{\begin{tabular}{|c} 
Periodos de muestreo \\
LOCALIDAD 1C -CONTROL "Escobas" \\
Pereña (SA) PLATOS \\
Año 2006
\end{tabular}} & \multicolumn{2}{|c|}{1} & \multicolumn{2}{|c|}{2} & \multicolumn{2}{|c|}{3} & \multicolumn{2}{|c|}{4} & & & \\
\hline & \multicolumn{2}{|c|}{ 15-Jun } & \multicolumn{2}{|c|}{ 15-Jul } & \multicolumn{2}{|c|}{ 15-Agos } & \multicolumn{2}{|c|}{ 15-Sep } & \multicolumn{2}{|c|}{ Totales } & \multirow{2}{*}{$\Sigma$} \\
\hline & $\mathbf{M}$ & $\mathbf{H}$ & M & & M & & M & $\mathbf{H}$ & $\mathbf{M}$ & $\mathbf{H}$ & \\
\hline \multicolumn{12}{|l|}{ AMPULICIDAE } \\
\hline \multicolumn{12}{|l|}{ AMPULICINAE } \\
\hline \multicolumn{12}{|l|}{ AMPULICINI } \\
\hline Dolichurus haemorrhous A. Costa, 1886 & $\ldots$ & $\ldots$ & $\ldots$ & 2 & $\ldots$ & $\ldots$ & $\ldots$ & $\ldots$ & 0 & 2 & 2 \\
\hline \multicolumn{12}{|l|}{ CRABRONIDAE } \\
\hline \multicolumn{12}{|l|}{ CRABRONINAE } \\
\hline \multicolumn{12}{|l|}{ LARRINI } \\
\hline Liris niger (Fabricius, 1775) & $\ldots$ & $\ldots$ & $\ldots$ & & $\ldots$ & & $\ldots$ & 3 & 0 & 3 & 3 \\
\hline Tachysphex mediterraneus Kohl, 1883 & $\ldots$ & $\ldots$ & $\ldots$ & 1 & $\ldots$ & & $\ldots$ & $\ldots$ & 0 & 1 & 1 \\
\hline Tachysphex obscuripennis (Schenck, 1857) & $\ldots$ & $\ldots$ & 2 & 2 & 1 & 2 & $\ldots$ & $\ldots$ & 3 & 4 & 7 \\
\hline Tachysphex pompiliformis (Panzer, 1805) & $\ldots$ & $\ldots$ & 1 & $\ldots$ & $\ldots$ & $\ldots$ & $\ldots$ & $\ldots$ & 1 & 0 & 1 \\
\hline \multicolumn{12}{|l|}{ MISCOPHINI } \\
\hline Solierella compedita (Piccioli, 1869) & $\ldots$ & $\ldots$ & $\ldots$ & $\ldots$ & 2 & 2 & $\ldots$ & $\ldots$ & 2 & 2 & 4 \\
\hline Solierella pisonoides (Saunders, 1873) & $\ldots$ & $\ldots$ & 1 & 1 & 2 & 2 & $\ldots$ & 1 & 3 & 4 & 7 \\
\hline Miscophus eatoni Saunders, 1903 & & $\ldots$ & & 1 & $\ldots$ & & $\ldots$ & & 0 & 1 & 1 \\
\hline Miscophus nicolai Ferton, 1896 & $\ldots$ & $\ldots$ & 1 & 1 & 5 & 2 & 1 & 1 & 7 & 4 & 11 \\
\hline \multicolumn{12}{|l|}{ OXYBELINI } \\
\hline Oxybelus quattuordecimnotatus Jurine, 1807 & & $\ldots$ & $\ldots$ & 4 & $\ldots$ & & $\ldots$ & & 0 & 4 & 4 \\
\hline \multicolumn{12}{|l|}{ BEMBICINAE } \\
\hline \multicolumn{12}{|l|}{ BEMBICINI } \\
\hline Harpactus alvaroi Gayubo, 1992 & $\ldots$ & $\ldots$ & $\ldots$ & $\ldots$ & 1 & $\ldots$ & $\ldots$ & $\ldots$ & 1 & 0 & 1 \\
\hline \multicolumn{12}{|l|}{ PHILANTHINAE } \\
\hline \multicolumn{12}{|l|}{ CERCERINI } \\
\hline Cerceris rybyensis (Linnaeus, 1771) & & & $\ldots$ & & & & & 1 & 0 & 1 & 1 \\
\hline \multirow{2}{*}{$\begin{array}{r}\text { Subtotales } \\
\text { Total de Ejemplares }\end{array}$} & $\mathbf{0}$ & $\mathbf{0}$ & 5 & 12 & 11 & 8 & 1 & 6 & 17 & 26 & \\
\hline & \multicolumn{2}{|c|}{$\mathbf{0}$} & \multicolumn{2}{|c|}{17} & \multicolumn{2}{|c|}{19} & \multicolumn{2}{|c|}{7} & & & 43 \\
\hline Total de Especies & & & & & & & & & & & 12 \\
\hline
\end{tabular}




\begin{tabular}{|c|c|c|c|c|c|c|c|c|c|c|c|}
\hline \multirow{3}{*}{\begin{tabular}{|} 
Periodos de muestreo \\
LOCALIDAD 1C - CONTROL "Prado" \\
Pereña (SA) PLATOS \\
Año 2006
\end{tabular}} & \multicolumn{2}{|c|}{1} & \multicolumn{2}{|c|}{2} & \multicolumn{2}{|c|}{3} & \multicolumn{2}{|c|}{4} & & & \\
\hline & \multicolumn{2}{|c|}{ 15-Jun } & \multicolumn{2}{|c|}{ 15-Jul } & \multicolumn{2}{|c|}{ 15-Agos } & \multicolumn{2}{|c|}{ 15-Sep } & \multicolumn{2}{|c|}{ Totales } & \multirow{2}{*}{$\Sigma$} \\
\hline & M & $\mathbf{H}$ & M & $\mathbf{H}$ & M & & $\mathbf{M}$ & & $\mathbf{M}$ & $\mathbf{H}$ & \\
\hline \multicolumn{12}{|l|}{ AMPULICIDAE } \\
\hline \multicolumn{12}{|l|}{ AMPULICINAE } \\
\hline \multicolumn{12}{|l|}{ AMPULICINI } \\
\hline Dolichurus haemorrhous A. Costa, 1886 & $\ldots$ & $\ldots$ & $\ldots$ & $\ldots$ & $\ldots$ & $\ldots$ & 1 & $\ldots$ & 1 & 0 & 1 \\
\hline \multicolumn{12}{|l|}{ SPHECIDAE } \\
\hline \multicolumn{12}{|l|}{ SPHECINAE } \\
\hline \multicolumn{12}{|l|}{ PRIONYCHINI } \\
\hline Prionyx kirbii (Van der Linden, 1827) & $\ldots$ & $\ldots$ & $\ldots$ & $\ldots$ & 1 & $\ldots$ & $\ldots$ & $\ldots$ & 1 & 0 & 1 \\
\hline \multicolumn{12}{|l|}{ AMMOPHILINAE } \\
\hline \multicolumn{12}{|l|}{ AMMOPHILINI } \\
\hline Ammophila heydeni Dahlbom, 1845 & $\ldots$ & $\ldots$ & $\ldots$ & $\ldots$ & $\ldots$ & $\ldots$ & $\ldots$ & 1 & 0 & 1 & 1 \\
\hline Ammophila sabulosa (Linnaeus, 1758) & $\ldots$ & $\ldots$ & & $\ldots$ & $\ldots$ & $\ldots$ & 1 & $\ldots$ & 1 & 0 & 1 \\
\hline Ammophila Aff. rubriventris & $\ldots$ & $\ldots$ & & $\ldots$ & 1 & & $\ldots$ & $\ldots$ & 1 & 0 & 1 \\
\hline \multicolumn{12}{|l|}{ CRABRONIDAE } \\
\hline \multicolumn{12}{|l|}{ CRABRONINAE } \\
\hline \multicolumn{12}{|l|}{ LARRINI } \\
\hline Liris niger (Fabricius, 1775) & $\ldots$ & $\ldots$ & $\ldots$ & 2 & $\ldots$ & 1 & 1 & 2 & 1 & 5 & 6 \\
\hline Tachytes panzeri (Dufour, 1841) & 1 & $\ldots$ & $\ldots$ & $\ldots$ & $\ldots$ & $\ldots$ & $\ldots$ & $\ldots$ & 1 & 0 & 1 \\
\hline Tachysphex julliani Kohl, 1883 & $\ldots$ & $\ldots$ & 1 & $\ldots$ & $\ldots$ & $\ldots$ & $\ldots$ & $\ldots$ & 1 & 0 & 1 \\
\hline Tachysphex mediterraneus Kohl, 1883 & $\ldots$ & $\ldots$ & $\ldots$ & 1 & $\ldots$ & $\ldots$ & $\ldots$ & $\ldots$ & 0 & 1 & 1 \\
\hline Tachysphex obscuripennis (Schenck, 1857) & $\ldots$ & $\ldots$ & $\ldots$ & $\ldots$ & 1 & 1 & $\ldots$ & 1 & 1 & 2 & 3 \\
\hline Tachysphex panzeri (Van der Linden, 1829) & $\ldots$ & $\ldots$ & & 1 & $\ldots$ & $\ldots$ & $\ldots$ & $\ldots$ & 0 & 1 & 1 \\
\hline \multicolumn{12}{|l|}{ MISCOPHINI } \\
\hline Solierella compedita (Piccioli, 1869) & $\ldots$ & $\ldots$ & $\ldots$ & 3 & $\ldots$ & 1 & $\ldots$ & $\ldots$ & 0 & 4 & 4 \\
\hline Solierella pisonoides (Saunders, 1873) & $\ldots$ & $\ldots$ & $\ldots$ & 1 & $\ldots$ & 5 & $\ldots$ & $\ldots$ & 0 & 6 & 6 \\
\hline Miscophus eatoni Saunders, 1903 & $\ldots$ & $\ldots$ & $\ldots$ & $\ldots$ & $\ldots$ & $\ldots$ & $\ldots$ & 1 & 0 & 1 & 1 \\
\hline Miscophus nicolai Ferton, 1896 & $\ldots$ & $\ldots$ & $\ldots$ & $\ldots$ & 1 & $\ldots$ & $\ldots$ & 3 & 1 & 3 & 4 \\
\hline \multicolumn{12}{|l|}{ TRYPOXYLINI } \\
\hline Trypoxylon scutatum Chevrier, 1867 & $\ldots$ & $\ldots$ & & $\ldots$ & & 1 & $\ldots$ & $\ldots$ & 0 & 1 & 1 \\
\hline OXYBELINI & & & & & & & & & & & \\
\hline Oxybelus quattuordecimnotatus Jurine, 1807 & $\ldots$ & $\ldots$ & $\ldots$ & 1 & $\ldots$ & $\ldots$ & $\ldots$ & $\ldots$ & 0 & 1 & 1 \\
\hline CRABRONINI & & & & & & & & & & & \\
\hline Lindenius pygmaeus (Rossi, 1794) & $\ldots$ & $\ldots$ & $\ldots$ & ... & $\ldots$ & $\ldots$ & 1 & $\ldots$ & 1 & 0 & 1 \\
\hline Subtotales & 1 & $\mathbf{0}$ & 1 & 9 & 4 & 9 & 4 & 8 & 10 & 26 & \\
\hline Total de Ejemplares & & & & & & & & & & & 36 \\
\hline Total de Especies & & & & & & & & & & & 18 \\
\hline
\end{tabular}




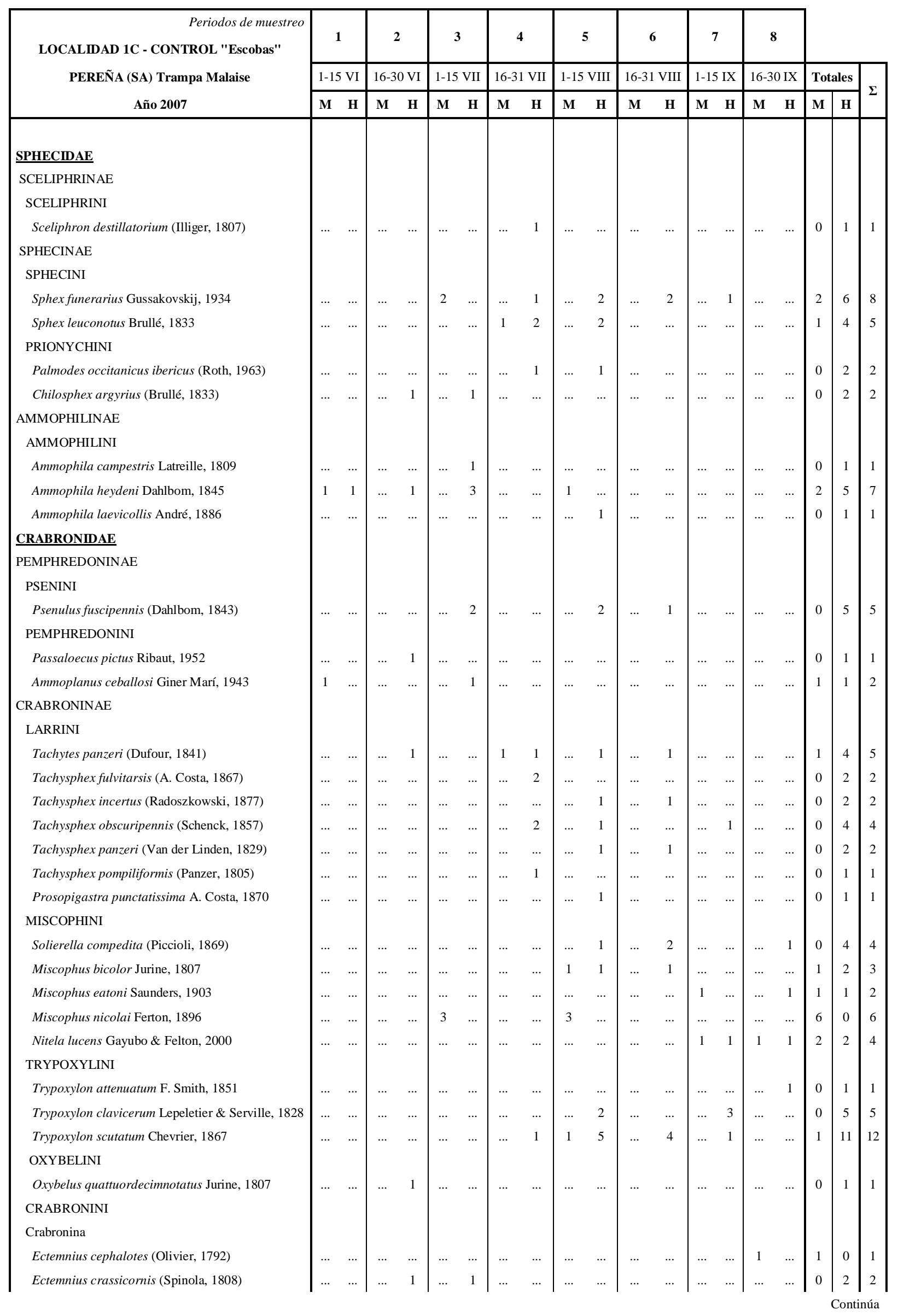




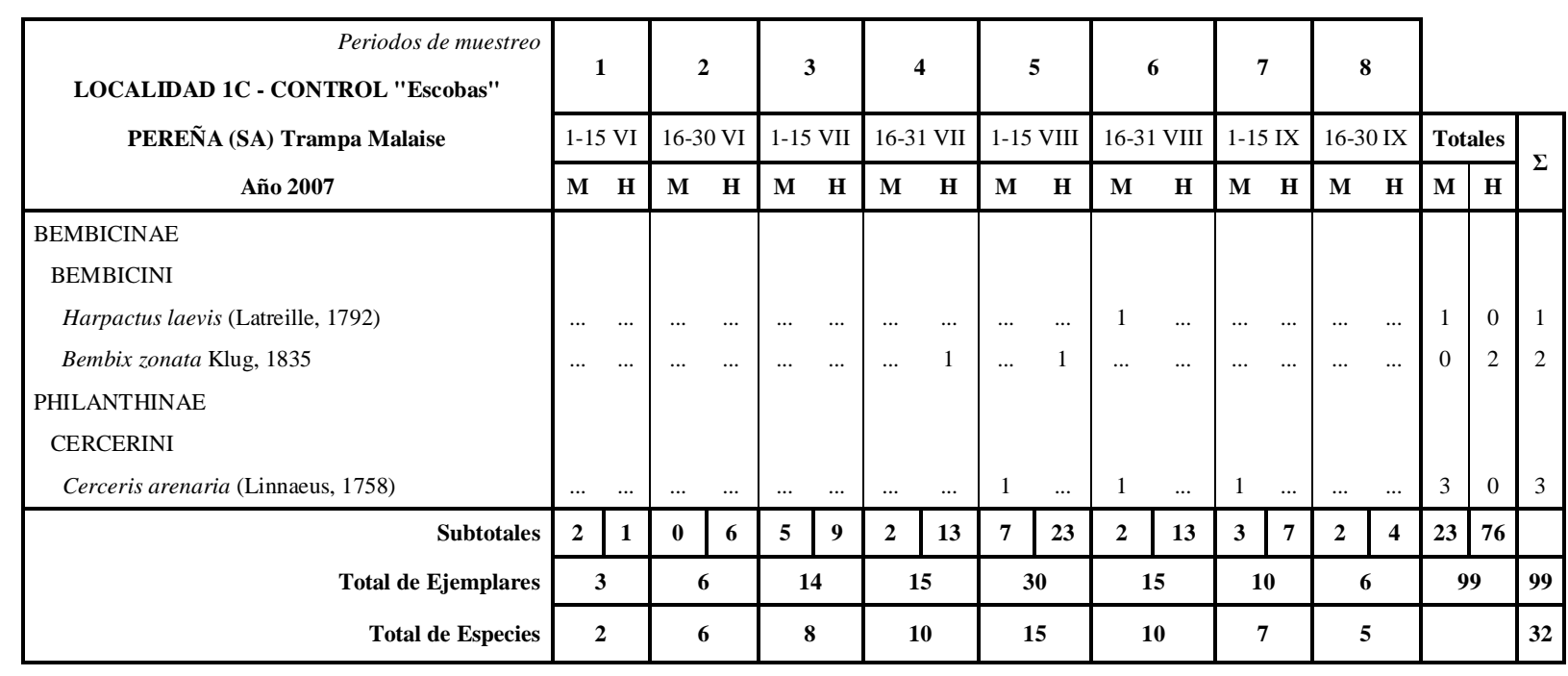




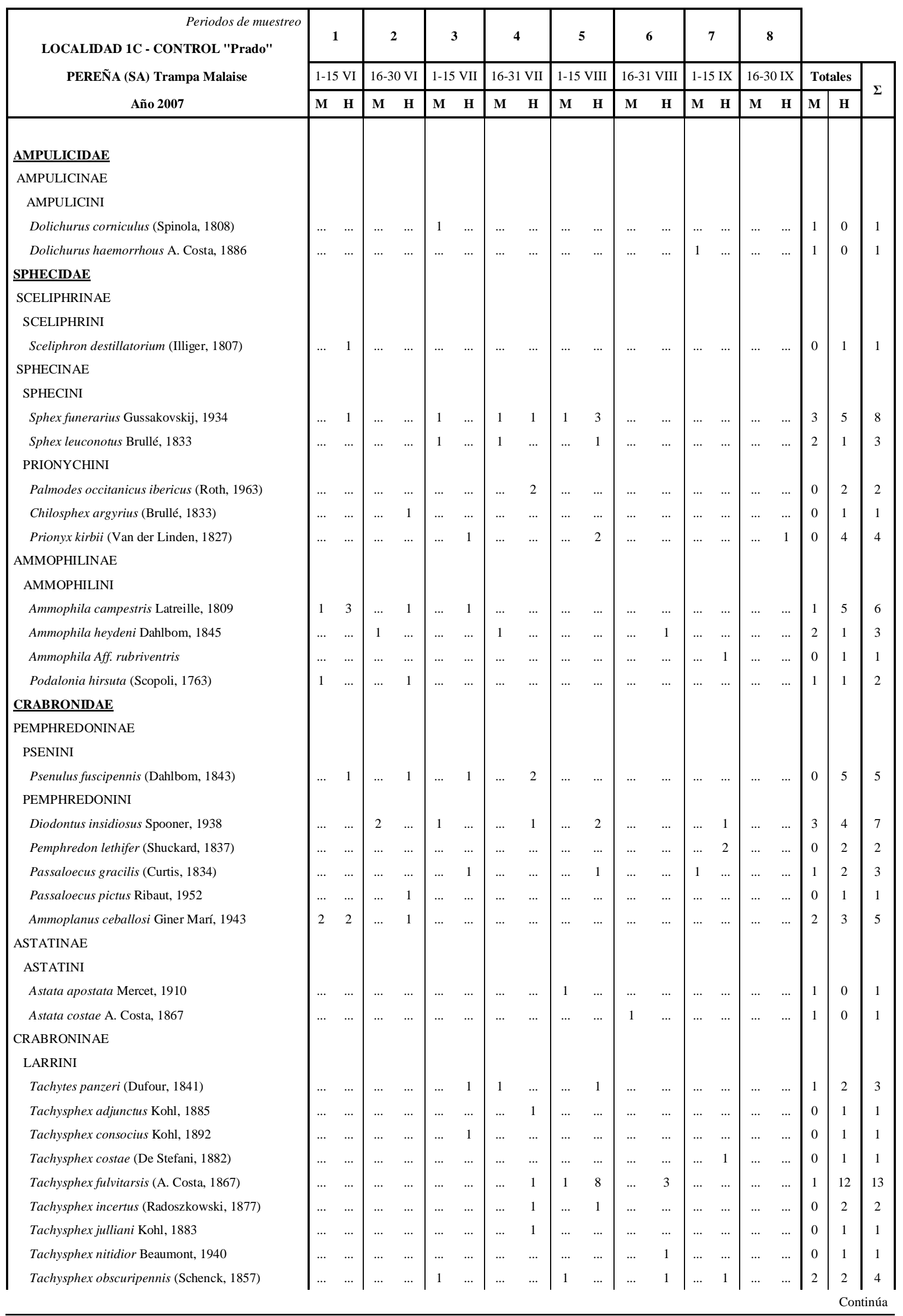




\begin{tabular}{|c|c|c|c|c|c|c|c|c|c|c|c|c|c|c|c|c|c|c|c|}
\hline \multirow{3}{*}{$\begin{array}{r}\text { Periodos de muestreo } \\
\text { LOCALIDAD 1C - CONTROL "Prado" } \\
\text { PEREÑA (SA) Trampa Malaise } \\
\text { Año } 2007\end{array}$} & \multicolumn{2}{|c|}{1} & \multicolumn{2}{|c|}{2} & \multicolumn{2}{|c|}{3} & \multicolumn{2}{|c|}{4} & & \multicolumn{2}{|c|}{0} & \multicolumn{2}{|c|}{7} & \multicolumn{2}{|c|}{8} & & & \\
\hline & \multicolumn{2}{|c|}{$1-15 \mathrm{VI}$} & \multicolumn{2}{|c|}{$16-30 \mathrm{VI}$} & \multicolumn{2}{|c|}{$1-15 \mathrm{VII}$} & \multicolumn{2}{|c|}{$16-31 \mathrm{VII}$} & \multicolumn{2}{|c|}{ 1-15 VIII } & \multicolumn{2}{|c|}{ 16-31 VIII } & \multicolumn{2}{|c|}{ 1-15 IX } & \multicolumn{2}{|c|}{ 16-30 IX } & \multicolumn{2}{|c|}{ Totales } & \\
\hline & $\mathbf{M}$ & $\mathbf{H}$ & $\mathbf{M}$ & & $\mathbf{M}$ & & $\mathbf{M}$ & & $\mathbf{M}$ & & $\mathbf{M}$ & & & & $\mathbf{M}$ & & M & $\mathbf{H}$ & \\
\hline Tachysphex panzeri (Van der Linden, 1829) & $\ldots$ & $\ldots$ & $\ldots$ & $\ldots$ & $\ldots$ & $\ldots$ & $\ldots$ & $\ldots$ & $\ldots$ & $\ldots$ & $\ldots$ & $\ldots$ & $\ldots$ & 1 & $\ldots$ & $\ldots$ & 0 & 1 & 1 \\
\hline Tachysphex pompiliformis (Panzer, 1805) & $\ldots$ & $\ldots$ & $\ldots$ & $\ldots$ & $\ldots$ & $\ldots$ & 1 & $\ldots$ & $\ldots$ & $\ldots$ & $\ldots$ & $\ldots$ & $\ldots$ & $\ldots$ & $\ldots$ & $\ldots$ & 1 & 0 & 1 \\
\hline Tachysphex psammobius (Kohl, 1880) & $\ldots$ & 1 & $\ldots$ & $\ldots$ & $\ldots$ & $\ldots$ & $\ldots$ & $\ldots$ & $\ldots$ & $\ldots$ & $\ldots$ & $\ldots$ & $\ldots$ & $\ldots$ & $\ldots$ & $\ldots$ & 0 & 1 & 1 \\
\hline Tachysphex pseudopanzeri Beaumont, 1955 & $\ldots$ & $\ldots$ & $\ldots$ & $\ldots$ & $\ldots$ & $\ldots$ & $\ldots$ & $\ldots$ & $\ldots$ & 1 & $\ldots$ & $\ldots$ & $\ldots$ & $\ldots$ & $\ldots$ & $\ldots$ & 0 & 1 & 1 \\
\hline MISCOPHINI & & & & & & & & & & & & & & & & & & & \\
\hline Solierella compedita (Piccioli, 1869) & $\ldots$ & $\ldots$ & $\ldots$ & $\ldots$ & $\ldots$ & $\ldots$ & $\ldots$ & $\ldots$ & $\ldots$ & $\ldots$ & 1 & 2 & $\ldots$ & 3 & $\ldots$ & $\ldots$ & 1 & 5 & 6 \\
\hline Solierella pisonoides (Saunders, 1873) & $\ldots$ & $\ldots$ & $\ldots$ & $\ldots$ & $\ldots$ & $\ldots$ & $\ldots$ & $\ldots$ & $\ldots$ & $\ldots$ & $\ldots$ & $\ldots$ & $\ldots$ & 1 & $\ldots$ & $\ldots$ & 0 & 1 & 1 \\
\hline Miscophus bicolor Jurine, 1807 & $\ldots$ & $\ldots$ & $\ldots$ & $\ldots$ & $\ldots$ & $\ldots$ & $\ldots$ & 1 & $\ldots$ & $\ldots$ & $\ldots$ & $\ldots$ & $\ldots$ & 1 & $\ldots$ & $\ldots$ & 0 & 2 & 2 \\
\hline Miscophus nicolai Ferton, 1896 & $\ldots$ & $\ldots$ & $\ldots$ & $\ldots$ & $\ldots$ & $\ldots$ & 1 & 1 & 1 & 1 & $\ldots$ & $\ldots$ & $\ldots$ & $\ldots$ & $\ldots$ & $\ldots$ & 2 & 2 & 4 \\
\hline Nitela lucens Gayubo \& Felton, 2000 & $\ldots$ & $\ldots$ & $\ldots$ & $\ldots$ & $\ldots$ & $\ldots$ & $\ldots$ & $\ldots$ & $\ldots$ & $\ldots$ & $\ldots$ & 2 & 1 & 2 & 1 & $\ldots$ & 2 & 4 & 6 \\
\hline Nitela truncata Gayubo \& Felton, 2000 & $\ldots$ & $\ldots$ & $\ldots$ & $\ldots$ & $\ldots$ & $\ldots$ & $\ldots$ & 1 & $\cdots$ & $\ldots$ & 2 & $\ldots$ & $\ldots$ & 1 & $\ldots$ & $\ldots$ & 2 & 2 & 4 \\
\hline TRYPOXYLINI & & & & & & & & & & & & & & & & & & & \\
\hline Pison atrum (Spinola, 1808) & $\ldots$ & $\ldots$ & $\ldots$ & $\ldots$ & $\ldots$ & $\ldots$ & $\ldots$ & 1 & $\ldots$ & $\ldots$ & $\ldots$ & $\ldots$ & $\ldots$ & 1 & $\ldots$ & $\ldots$ & 0 & 2 & 2 \\
\hline Trypoxylon attenuatum $\mathrm{F}$. Smith, 1851 & $\ldots$ & $\ldots$ & $\ldots$ & $\ldots$ & $\ldots$ & $\ldots$ & $\ldots$ & 1 & 1 & 1 & 2 & 1 & $\ldots$ & 2 & $\ldots$ & 5 & 3 & 10 & 13 \\
\hline Trypoxylon clavicerum Lepeletier \& Serville, 1828 & $\ldots$ & $\ldots$ & $\ldots$ & $\ldots$ & $\ldots$ & $\ldots$ & $\ldots$ & $\ldots$ & $\cdots$ & $\ldots$ & $\ldots$ & 2 & 1 & 3 & $\ldots$ & $\ldots$ & 1 & 5 & 6 \\
\hline Trypoxylon scutatum Chevrier, 1867 & $\ldots$ & 1 & $\ldots$ & 2 & $\ldots$ & 1 & $\ldots$ & 3 & $\ldots$ & 2 & $\ldots$ & 9 & 2 & 6 & $\ldots$ & $\ldots$ & 2 & 24 & 26 \\
\hline OXYBELINI & & & & & & & & & & & & & & & & & & & \\
\hline Oxybelus quattuordecimnotatus Jurine, 1807 & $\ldots$ & $\ldots$ & 1 & 1 & $\ldots$ & $\ldots$ & $\ldots$ & $\ldots$ & $\ldots$ & $\ldots$ & $\ldots$ & $\ldots$ & $\ldots$ & $\ldots$ & $\ldots$ & $\ldots$ & 1 & 1 & 2 \\
\hline CRABRONINI & & & & & & & & & & & & & & & & & & & \\
\hline Lindenius pygmaeus (Rossi, 1794) & $\ldots$ & $\ldots$ & $\ldots$ & $\cdots$ & $\ldots$ & $\ldots$ & $\ldots$ & $\ldots$ & $\cdots$ & $\ldots$ & $\ldots$ & 1 & $\ldots$ & $\ldots$ & $\ldots$ & $\ldots$ & 0 & 1 & 1 \\
\hline Tracheliodes quinquenotatus (Jurine, 1807) & $\ldots$ & 1 & $\ldots$ & $\ldots$ & $\ldots$ & 1 & $\ldots$ & $\ldots$ & $\ldots$ & $\ldots$ & $\ldots$ & $\ldots$ & $\ldots$ & $\ldots$ & $\ldots$ & $\ldots$ & 0 & 2 & 2 \\
\hline Ectemnius crassicornis (Spinola, 1808) & $\ldots$ & $\ldots$ & $\ldots$ & $\ldots$ & $\ldots$ & $\ldots$ & $\ldots$ & $\ldots$ & 1 & $\ldots$ & $\ldots$ & $\ldots$ & $\ldots$ & $\ldots$ & $\ldots$ & $\ldots$ & 1 & 0 & 1 \\
\hline BEMBICINAE & & & & & & & & & & & & & & & & & & & \\
\hline BEMBICINI & & & & & & & & & & & & & & & & & & & \\
\hline Gorytes quinquefasciatus (Panzer, 1798) & $\ldots$ & $\ldots$ & $\ldots$ & $\ldots$ & $\ldots$ & $\ldots$ & $\cdots$ & $\ldots$ & $\cdots$ & 1 & $\cdots$ & $\ldots$ & $\ldots$ & $\ldots$ & $\ldots$ & $\ldots$ & 0 & 1 & 1 \\
\hline Harpactus formosus (Jurine, 1807) & $\ldots$ & $\ldots$ & $\ldots$ & $\ldots$ & $\ldots$ & $\ldots$ & $\ldots$ & $\ldots$ & $\ldots$ & $\ldots$ & $\ldots$ & $\ldots$ & $\ldots$ & $\ldots$ & $\ldots$ & 1 & 0 & 1 & 1 \\
\hline Harpactus laevis (Latreille, 1792) & $\ldots$ & $\ldots$ & $\ldots$ & $\ldots$ & $\ldots$ & $\ldots$ & $\cdots$ & 1 & $\cdots$ & $\ldots$ & $\ldots$ & $\ldots$ & $\ldots$ & $\ldots$ & $\ldots$ & $\ldots$ & 0 & 1 & 1 \\
\hline Bembecinus carpetanus (Mercet, 1906) & $\ldots$ & $\ldots$ & 1 & 1 & $\ldots$ & $\ldots$ & $\ldots$ & $\ldots$ & $\cdots$ & $\ldots$ & $\cdots$ & $\cdots$ & $\ldots$ & $\ldots$ & $\ldots$ & $\ldots$ & 1 & 1 & 2 \\
\hline Bembecinus pulchelus (Mercet, 1906) & $\ldots$ & $\ldots$ & $\ldots$ & $\ldots$ & $\ldots$ & 3 & $\ldots$ & $\ldots$ & $\ldots$ & $\ldots$ & $\ldots$ & $\ldots$ & $\ldots$ & $\ldots$ & $\ldots$ & $\ldots$ & 0 & 3 & 3 \\
\hline Bembix bidentata Van der Linden, 1829 & $\ldots$ & $\ldots$ & $\ldots$ & $\cdots$ & $\ldots$ & $\ldots$ & $\ldots$ & $\ldots$ & $\cdots$ & 1 & $\ldots$ & $\ldots$ & $\ldots$ & $\ldots$ & $\ldots$ & $\ldots$ & 0 & 1 & 1 \\
\hline Bembix oculata Panzer, 1801 & $\ldots$ & $\ldots$ & $\ldots$ & $\ldots$ & $\ldots$ & $\ldots$ & $\ldots$ & $\ldots$ & $\cdots$ & $\ldots$ & $\ldots$ & $\ldots$ & $\ldots$ & 1 & $\ldots$ & $\ldots$ & 0 & 1 & 1 \\
\hline Bembix zonata Klug, 1835 & $\ldots$ & $\ldots$ & $\ldots$ & $\ldots$ & $\ldots$ & $\ldots$ & $\ldots$ & $\ldots$ & $\ldots$ & $\ldots$ & $\ldots$ & $\ldots$ & $\ldots$ & 2 & $\ldots$ & $\ldots$ & 0 & 2 & 2 \\
\hline PHILANTHINAE & & & & & & & & & & & & & & & & & & & \\
\hline CERCERINI & & & & & & & & & & & & & & & & & & & \\
\hline Cerceris arenaria (Linnaeus, 1758) & $\ldots$ & $\ldots$ & $\ldots$ & $\ldots$ & $\ldots$ & $\ldots$ & $\ldots$ & $\ldots$ & $\ldots$ & $\ldots$ & 1 & $\ldots$ & $\ldots$ & $\ldots$ & $\ldots$ & $\ldots$ & 1 & 0 & 1 \\
\hline Cerceris quadricinctus (Panzer, 1799) & $\ldots$ & $\ldots$ & $\ldots$ & $\ldots$ & $\ldots$ & 1 & $\ldots$ & $\ldots$ & $\cdots$ & $\ldots$ & $\ldots$ & $\ldots$ & $\ldots$ & $\ldots$ & $\ldots$ & $\ldots$ & 0 & 1 & 1 \\
\hline Cerceris sabulosa (Panzer, 1799) & $\ldots$ & $\ldots$ & $\ldots$ & $\ldots$ & $\ldots$ & $\ldots$ & $\ldots$ & $\ldots$ & $\ldots$ & $\ldots$ & $\ldots$ & $\ldots$ & $\ldots$ & 1 & $\ldots$ & $\ldots$ & 0 & 1 & 1 \\
\hline Subtotales & 4 & 11 & 5 & 10 & 5 & 12 & 6 & 19 & 7 & 26 & 7 & 23 & 6 & 31 & 1 & 7 & 41 & 139 & \\
\hline Total de Ejemplares & & 5 & & & & & & & & & & & 3 & & & & & 80 & 180 \\
\hline Total de Especies & & 9 & & & & & & & & & & & 2 & & 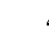 & & & & 58 \\
\hline
\end{tabular}




\begin{tabular}{|c|c|c|c|c|c|c|c|c|c|c|c|}
\hline \multirow{3}{*}{\begin{tabular}{|c} 
Periodos de muestreo \\
LOCALIDAD 1C- CONTROL "Escobas" \\
Pereña (SA) PLATOS \\
Año 2007
\end{tabular}} & \multicolumn{2}{|c|}{1} & \multicolumn{2}{|c|}{2} & \multicolumn{2}{|c|}{3} & \multicolumn{2}{|c|}{4} & & & \\
\hline & \multicolumn{2}{|c|}{ 15-Jun } & \multicolumn{2}{|c|}{ 15-Jul } & \multicolumn{2}{|c|}{ 15-Agos } & \multicolumn{2}{|c|}{ 15-Sep } & \multicolumn{2}{|c|}{ Totales } & \multirow{2}{*}{$\Sigma$} \\
\hline & M & $\mathbf{H}$ & M & & M & $\mathbf{H}$ & $\mathbf{M}$ & $\mathbf{H}$ & $\mathbf{M}$ & $\mathbf{H}$ & \\
\hline \multicolumn{12}{|l|}{ CRABRONIDAE } \\
\hline \multicolumn{12}{|l|}{ CRABRONINAE } \\
\hline \multicolumn{12}{|l|}{ LARRINI } \\
\hline Tachysphex incertus (Radoszkowski, 1877) & $\ldots$ & $\ldots$ & $\ldots$ & $\ldots$ & 1 & $\ldots$ & $\ldots$ & $\ldots$ & 1 & 0 & 1 \\
\hline Tachysphex obscuripennis (Schenck, 1857) & $\ldots$ & $\ldots$ & 7 & $\ldots$ & 12 & 3 & $\ldots$ & $\ldots$ & 19 & 3 & 22 \\
\hline Tachysphex pompiliformis (Panzer, 1805) & $\ldots$ & $\ldots$ & 1 & 1 & $\ldots$ & 1 & $\ldots$ & $\ldots$ & 1 & 2 & 3 \\
\hline \multicolumn{12}{|l|}{ MISCOPHINI } \\
\hline Solierella compedita (Piccioli, 1869) & $\ldots$ & $\ldots$ & 2 & $\ldots$ & 4 & 6 & 2 & 2 & 8 & 8 & 16 \\
\hline Solierella pisonoides (Saunders, 1873) & $\ldots$ & $\ldots$ & $\ldots$ & $\ldots$ & 2 & 1 & $\ldots$ & & 2 & 1 & 3 \\
\hline Solierella seabrai Andrade, 1950 & $\ldots$ & $\ldots$ & $\ldots$ & 1 & $\ldots$ & 1 & $\ldots$ & $\ldots$ & 0 & 2 & 2 \\
\hline Miscophus nicolai Ferton, 1896 & $\ldots$ & $\ldots$ & $\ldots$ & $\ldots$ & $\ldots$ & 4 & $\ldots$ & $\ldots$ & 0 & 4 & 4 \\
\hline \multicolumn{12}{|l|}{ TRYPOXYLINI } \\
\hline Trypoxylon attenuatum F. Smith, 1851 & $\ldots$ & $\ldots$ & $\ldots$ & $\ldots$ & $\ldots$ & $\ldots$ & $\ldots$ & 3 & 0 & 3 & 3 \\
\hline Trypoxylon clavicerum Lepeletier \& Serville, 1828 & $\ldots$ & $\ldots$ & $\ldots$ & $\ldots$ & $\ldots$ & $\ldots$ & $\ldots$ & 1 & 0 & 1 & 1 \\
\hline Trypoxylon scutatum Chevrier, 1867 & $\ldots$ & & $\ldots$ & 1 & & 1 & 1 & & 1 & 2 & 3 \\
\hline OXYBELINI & & & & & & & & & & & \\
\hline Oxybelus quattuordecimnotatus Jurine, 1807 & $\ldots$ & $\ldots$ & $\ldots$ & $\ldots$ & $\ldots$ & $\ldots$ & $\ldots$ & 1 & 0 & 1 & 1 \\
\hline \multicolumn{12}{|l|}{ MELLININAE } \\
\hline \multicolumn{12}{|l|}{ MELLININI } \\
\hline Mellinus arvensis (Linnaeus, 1758) & $\ldots$ & $\ldots$ & $\ldots$ & $\ldots$ & $\ldots$ & $\ldots$ & $\ldots$ & 1 & 0 & 1 & 1 \\
\hline \multicolumn{12}{|l|}{ BEMBICINAE } \\
\hline \multicolumn{12}{|l|}{ BEMBICINI } \\
\hline Harpactus alvaroi Gayubo, 1992 & $\ldots$ & $\ldots$ & $\ldots$ & $\ldots$ & 3 & $\ldots$ & $\ldots$ & $\ldots$ & 3 & 0 & 3 \\
\hline Bembecinus pulchelus (Mercet, 1906) & $\ldots$ & & & 4 & & $\ldots$ & $\ldots$ & & 0 & 4 & 4 \\
\hline \multirow{2}{*}{$\begin{array}{r}\text { Subtotales } \\
\text { Total de Ejemplares }\end{array}$} & $\mathbf{0}$ & $\mathbf{0}$ & 10 & 7 & 22 & 17 & 3 & 8 & 35 & 32 & \\
\hline & \multicolumn{2}{|c|}{$\mathbf{0}$} & \multicolumn{2}{|c|}{17} & \multicolumn{2}{|c|}{39} & \multicolumn{2}{|c|}{11} & \multicolumn{2}{|c|}{67} & 67 \\
\hline Total de Especies & \multicolumn{2}{|c|}{$\mathbf{0}$} & \multicolumn{2}{|c|}{6} & & & & & & & 14 \\
\hline
\end{tabular}




\begin{tabular}{|c|c|c|c|c|c|c|c|c|c|c|c|}
\hline \multirow{3}{*}{\begin{tabular}{|} 
Periodos de muestreo \\
LOCALIDAD 1C - CONTROL "Prado" \\
Pereña (SA) PLATOS \\
Año 2007
\end{tabular}} & \multicolumn{2}{|c|}{1} & \multicolumn{2}{|c|}{2} & \multicolumn{2}{|c|}{3} & \multicolumn{2}{|c|}{4} & & & \\
\hline & \multicolumn{2}{|c|}{ 15-Jun } & \multicolumn{2}{|c|}{ 15-Jul } & \multicolumn{2}{|c|}{ 15-Agos } & \multicolumn{2}{|c|}{ 15-Sep } & \multicolumn{2}{|c|}{ Totales } & \multirow{2}{*}{$\Sigma$} \\
\hline & M & $\mathbf{H}$ & M & $\mathbf{H}$ & M & $\mathbf{H}$ & & $\mathbf{H}$ & M & $\mathbf{H}$ & \\
\hline \multicolumn{12}{|l|}{ AMPULICIDAE } \\
\hline \multicolumn{12}{|l|}{ AMPULICINAE } \\
\hline \multicolumn{12}{|l|}{ DOLICHURINI } \\
\hline Dolichurus corniculus (Spinola, 1808) & $\ldots$ & $\ldots$ & $\ldots$ & $\ldots$ & 1 & $\ldots$ & $\ldots$ & $\ldots$ & 1 & 0 & 1 \\
\hline Dolichurus haemorrhous A. Costa, 1886 & $\ldots$ & $\ldots$ & $\ldots$ & $\ldots$ & $\ldots$ & $\ldots$ & 3 & $\ldots$ & 3 & 0 & 3 \\
\hline \multicolumn{12}{|l|}{ SPHECIDAE } \\
\hline \multicolumn{12}{|l|}{ AMMOPHILINAE } \\
\hline \multicolumn{12}{|l|}{ AMMOPHILINI } \\
\hline Ammophila sabulosa (Linnaeus, 1758) & $\ldots$ & $\ldots$ & $\ldots$ & $\ldots$ & & $\ldots$ & & 1 & 0 & 1 & 1 \\
\hline \multicolumn{12}{|l|}{ CRABRONIDAE } \\
\hline \multicolumn{12}{|l|}{ CRABRONINAE } \\
\hline \multicolumn{12}{|l|}{ LARRINI } \\
\hline Liris niger (Fabricius, 1775) & $\ldots$ & $\ldots$ & $\ldots$ & $\ldots$ & & $\ldots$ & $\ldots$ & 2 & 0 & 2 & 2 \\
\hline Tachysphex obscuripennis (Schenck, 1857) & $\ldots$ & $\ldots$ & $\ldots$ & $\ldots$ & 1 & $\ldots$ & $\ldots$ & $\ldots$ & 1 & 0 & 1 \\
\hline \multicolumn{12}{|l|}{ MISCOPHINI } \\
\hline Solierella compedita $($ Piccioli, 1869) & $\ldots$ & $\ldots$ & $\ldots$ & $\ldots$ & & 9 & 1 & 1 & 1 & 10 & 11 \\
\hline Solierella pisonoides (Saunders, 1873) & $\ldots$ & $\ldots$ & $\ldots$ & $\ldots$ & 4 & $\ldots$ & $\ldots$ & $\ldots$ & 4 & 0 & 4 \\
\hline \multicolumn{12}{|l|}{ TRYPOXYLINI } \\
\hline Trypoxylon attenuatum F. Smith, 1851 & $\ldots$ & $\ldots$ & & $\ldots$ & & $\ldots$ & 2 & 3 & 2 & 3 & 5 \\
\hline Trypoxylon scutatum Chevrier, 1867 & $\ldots$ & $\ldots$ & $\ldots$ & $\ldots$ & $\ldots$ & $\ldots$ & $\ldots$ & 1 & 0 & 1 & 1 \\
\hline \multicolumn{12}{|l|}{ BEMBICINAE } \\
\hline \multicolumn{12}{|l|}{ NYSSONINI } \\
\hline Nysson parietalis Mercet, 1909 & $\ldots$ & $\ldots$ & $\ldots$ & $\ldots$ & & $\ldots$ & $\ldots$ & 1 & 0 & 1 & 1 \\
\hline Nysson variabilis (Chevrier, 1867) & $\ldots$ & $\ldots$ & $\ldots$ & $\ldots$ & 1 & $\ldots$ & $\ldots$ & $\ldots$ & 1 & 0 & 1 \\
\hline \multicolumn{12}{|l|}{ BEMBICINI } \\
\hline Harpactus alvaroi Gayubo, 1992 & ... & $\ldots$ & $\ldots$ & $\ldots$ & 1 & 1 & 2 & ... & 3 & 1 & 4 \\
\hline \multirow{2}{*}{$\begin{array}{r}\text { Subtotales } \\
\text { Total de Ejemplares }\end{array}$} & $\mathbf{0}$ & $\mathbf{0}$ & $\mathbf{0}$ & $\mathbf{0}$ & 8 & 10 & 8 & 9 & 16 & 19 & \\
\hline & & & & & & & & & & & 35 \\
\hline Total de Especies & & & & & & & & & & & 12 \\
\hline
\end{tabular}




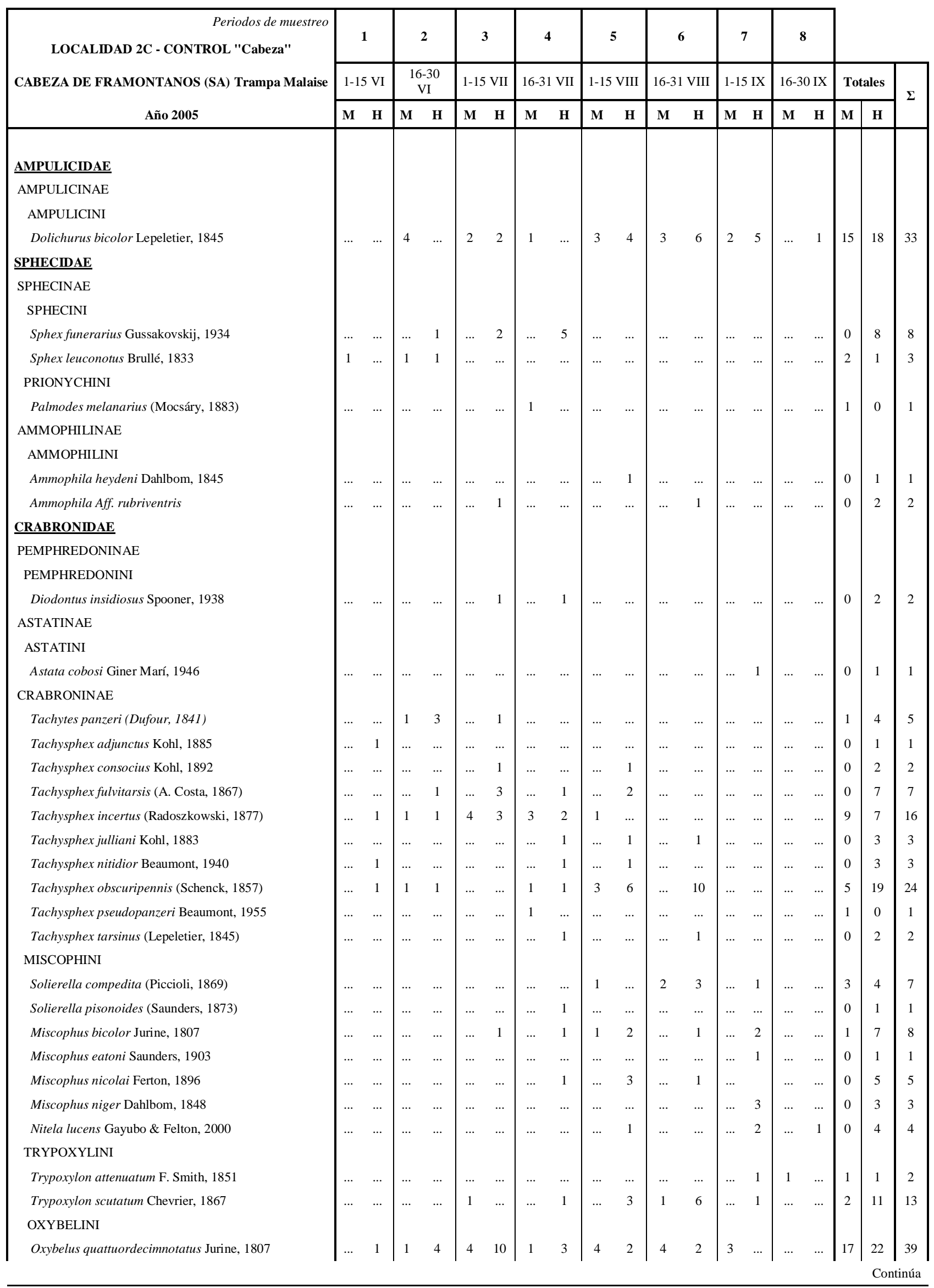




\begin{tabular}{|c|c|c|c|c|c|c|c|c|c|c|c|c|c|c|c|c|c|c|}
\hline \multirow{3}{*}{$\begin{array}{l}\text { Periodos de muestreo } \\
\text { LOCALIDAD 2C - CONTROL "Cabeza" } \\
\text { CABEZA DE FRAMONTANOS (SA) Trampa Malaise } \\
\text { Año } 2005\end{array}$} & 1 & \multicolumn{2}{|c|}{2} & \multicolumn{2}{|c|}{3} & \multicolumn{2}{|c|}{4} & \multicolumn{2}{|c|}{5} & \multicolumn{2}{|c|}{6} & \multicolumn{2}{|c|}{7} & \multicolumn{2}{|c|}{8} & & & \\
\hline & $1-15 \mathrm{VI}$ & \multicolumn{2}{|c|}{$\begin{array}{c}16-30 \\
\text { VI }\end{array}$} & \multicolumn{2}{|c|}{$1-15 \mathrm{VII}$} & \multicolumn{2}{|c|}{$16-31 \mathrm{VII}$} & \multicolumn{2}{|c|}{ 1-15 VIII } & \multicolumn{2}{|c|}{ 16-31 VIII } & \multicolumn{2}{|c|}{ 1-15 IX } & \multicolumn{2}{|c|}{ 16-30 IX } & \multicolumn{2}{|c|}{ Totales } & \multirow{2}{*}{$\Sigma$} \\
\hline & M H & $\mathbf{M}$ & $\mathbf{H}$ & & $\mathbf{H}$ & $\mathbf{M}$ & & $\mathbf{M}$ & & M & & $\mathbf{M}$ & & $\mathbf{M}$ & & M & $\mathbf{H}$ & \\
\hline \multicolumn{19}{|l|}{ CRABRONINI } \\
\hline Ectemnius crassicornis (Spinola, 1808) & $\ldots$ & $\ldots$ & $\ldots$ & $\ldots$ & $\ldots$ & $\ldots$ & 1 & $\ldots$ & $\ldots$ & $\ldots$ & 1 & $\ldots$ & & $\ldots$ & $\ldots$ & 0 & 2 & 2 \\
\hline Lestica clypeata (Schreber, 1759) & $\ldots \quad \ldots$ & $\ldots$ & $\ldots$ & 1 & $\ldots$ & $\ldots$ & $\ldots$ & $\ldots$ & $\ldots$ & $\ldots$ & $\ldots$ & $\ldots$ & $\ldots$ & $\ldots$ & $\ldots$ & 1 & 0 & 1 \\
\hline \multicolumn{19}{|l|}{ BEMBICINAE } \\
\hline \multicolumn{19}{|l|}{ BEMBICINI } \\
\hline Gorytes quinquefasciatus (Panzer, 1798) & $\ldots \quad \ldots$ & $\ldots$ & $\ldots$ & $\ldots$ & $\ldots$ & $\ldots$ & 1 & $\ldots$ & $\ldots$ & ... & $\ldots$ & $\ldots$ & & $\ldots$ & $\ldots$ & 0 & 1 & 1 \\
\hline Gorytes sulcifrons (A. Costa, 1869) & $\ldots$ & $\ldots$ & $\ldots$ & $\ldots$ & 1 & $\ldots$ & $\ldots$ & $\ldots$ & $\ldots$ & $\ldots$ & $\ldots$ & $\ldots$ & $\ldots$ & $\ldots$ & $\ldots$ & 0 & 1 & 1 \\
\hline Harpactus alvaroi Gayubo, 1992 & $\ldots$ & $\ldots$ & 1 & $\ldots$ & $\ldots$ & $\ldots$ & $\ldots$ & $\ldots$ & 1 & $\ldots$ & $\ldots$ & 1 & 2 & $\ldots$ & $\ldots$ & 1 & 4 & 5 \\
\hline Harpactus formosus (Jurine, 1807) & $\ldots$ & $\ldots$ & $\ldots$ & $\ldots$ & 1 & $\ldots$ & $\ldots$ & $\ldots$ & 2 & $\ldots$ & $\ldots$ & $\ldots$ & $\ldots$ & $\ldots$ & $\ldots$ & 0 & 3 & 3 \\
\hline Harpactus sp. 2 grimaldensis Gayubo, sp. n.(in lit.) & $\cdots$ & $\cdots$ & $\cdots$ & $\ldots$ & $\ldots$ & $\ldots$ & $\ldots$ & 2 & 2 & 1 & $\ldots$ & 1 & $\ldots$ & $\cdots$ & $\ldots$ & 4 & 2 & 6 \\
\hline \multicolumn{19}{|l|}{ PHILANTHINAE } \\
\hline \multicolumn{19}{|l|}{ CERCERINI } \\
\hline Cerceris arenaria (Linnaeus, 1758) & $\ldots$ & 1 & $\ldots$ & $\ldots$ & $\ldots$ & 1 & $\ldots$ & $\ldots$ & 1 & 4 & $\ldots$ & 2 & $\ldots$ & $\ldots$ & $\ldots$ & 8 & 1 & 9 \\
\hline \multirow{2}{*}{$\begin{array}{r}\text { Subtotales } \\
\text { Total de Ejemplares }\end{array}$} & 5 & 10 & 13 & 12 & 27 & 9 & 22 & 15 & 33 & 15 & 33 & 9 & 19 & 1 & 2 & 72 & 154 & \\
\hline & 6 & \multicolumn{2}{|c|}{23} & \multicolumn{2}{|c|}{39} & \multicolumn{2}{|c|}{31} & & & & & 2 & & & & & 26 & 226 \\
\hline Total de Especies & 6 & & 0 & & & & & & & & & 1 & & & & & & 36 \\
\hline
\end{tabular}




\begin{tabular}{|c|c|c|c|c|c|c|c|c|c|c|c|}
\hline \multirow{3}{*}{$\begin{array}{c}\text { Periodos de muestreo } \\
\text { LOCALIDAD 2C - CONTROL "Cabeza" } \\
\text { Cabeza de Framontanos (SA) PLATOS } \\
\text { Año } 2005\end{array}$} & \multicolumn{2}{|c|}{1} & \multicolumn{2}{|c|}{2} & \multicolumn{2}{|c|}{3} & \multicolumn{2}{|c|}{4} & & & \\
\hline & \multicolumn{2}{|c|}{ 15-Jun } & \multicolumn{2}{|c|}{ 15-Jul } & \multicolumn{2}{|c|}{ 15-Agos } & \multicolumn{2}{|c|}{ 15-Sep } & \multicolumn{2}{|c|}{ Totales } & \multirow{2}{*}{$\Sigma$} \\
\hline & M & $\mathbf{H}$ & $\mathbf{M}$ & $\mathbf{H}$ & $\mathbf{M}$ & $\mathbf{H}$ & $\mathbf{M}$ & $\mathbf{H}$ & M & $\mathbf{H}$ & \\
\hline \multicolumn{12}{|l|}{ AMPULICIDAE } \\
\hline \multicolumn{12}{|l|}{ AMPULICINAE } \\
\hline \multicolumn{12}{|l|}{ AMPULICINI } \\
\hline Dolichurus bicolor Lepeletier, 1845 & $\ldots$ & $\ldots$ & 3 & 3 & 13 & 4 & $\cdots$ & 5 & 16 & 12 & 28 \\
\hline Dolichurus corniculus (Spinola, 1808) & $\cdots$ & $\ldots$ & .. & $\cdots$ & $\cdots$ & $\cdots$ & $\cdots$ & 1 & $\cdots$ & 1 & 1 \\
\hline \multicolumn{12}{|l|}{ SPHECIDAE } \\
\hline \multicolumn{12}{|l|}{ AMMOPHILINAE } \\
\hline \multicolumn{12}{|l|}{ AMMOPHILINI } \\
\hline Ammophila heydeni Dahlbom, 1845 & $\ldots$ & $\ldots$ & $\ldots$ & 1 & $\ldots$ & $\ldots$ & $\ldots$ & $\cdots$ & 0 & 1 & 1 \\
\hline Ammophila sabulosa (Linnaeus, 1758) & $\ldots$ & $\ldots$ & $\ldots$ & $\ldots$ & $\ldots$ & $\ldots$ & $\ldots$ & 2 & 0 & 2 & 2 \\
\hline \multicolumn{12}{|l|}{ CRABRONIDAE } \\
\hline CRABRONINAE & & & & & & & & & & & \\
\hline LARRINI & & & & & & & & & & & \\
\hline Liris niger (Fabricius, 1775) & $\cdots$ & $\cdots$ & $\cdots$ & $\cdots$ & $\cdots$ & 1 & $\cdots$ & ... & 0 & 1 & 1 \\
\hline Tachytes obsoletus (Rossi, 1792) & 1 & $\ldots$ & $\cdots$ & $\ldots$ & $\ldots$ & $\cdots$ & .. & ... & 1 & 0 & 1 \\
\hline Tachysphex adjunctus Kohl, 1885 & $\ldots$ & 1 & $\ldots$ & $\ldots$ & $\ldots$ & $\ldots$ & $\ldots$ & $\ldots$ & 0 & 1 & 1 \\
\hline Tachysphex consocius Kohl, 1892 & 1 & $\ldots$ & $\ldots$ & $\ldots$ & $\ldots$ & $\ldots$ & $\ldots$ & $\ldots$ & 1 & 0 & 1 \\
\hline Tachysphex costae (De Stefani, 1882) & $\ldots$ & $\ldots$ & $\cdots$ & $\ldots$ & $\ldots$ & 1 & $\ldots$ & $\ldots$ & 0 & 1 & 1 \\
\hline Tachysphex incertus (Radoszkowski, 1877) & $\ldots$ & $\ldots$ & $\ldots$ & 1 & $\ldots$ & & $\ldots$ & $\ldots$ & 0 & 1 & 1 \\
\hline Tachysphex nitidior Beaumont, 1940 & .. & $\ldots$ & $\ldots$ & .. & 1 & 1 & .. & $\ldots$ & 1 & 1 & 2 \\
\hline Tachysphex obscuripennis (Schenck, 1857) & 1 & 5 & 3 & $\ldots$ & 2 & 1 & $\ldots$ & 1 & 6 & 7 & 13 \\
\hline Tachysphex pseudopanzeri Beaumont, 1955 & $\ldots$ & $\ldots$ & $\ldots$ & $\ldots$ & 2 & & $\ldots$ & $\ldots$ & 2 & 0 & 2 \\
\hline Tachysphex unicolor (Panzer, 1809) & & 1 & $\ldots$ & $\ldots$ & $\cdots$ & 1 & .. & .. & 0 & 2 & 2 \\
\hline Prosopigastra punctatissima A. Costa, 1869 & $\ldots$ & 1 & $\ldots$ & $\ldots$ & $\ldots$ & $\ldots$ & $\ldots$ & $\ldots$ & 0 & 1 & 1 \\
\hline MISCOPHINI & & & & & & & & & & & \\
\hline Solierella pisonoides (Saunders, 1873) & $\ldots$ & $\ldots$ & 1 & $\ldots$ & $\ldots$ & 1 & $\ldots$ & $\ldots$ & 1 & 1 & 2 \\
\hline Miscophus bicolor Jurine, 1807 & $\ldots$ & $\ldots$ & $\ldots$ & $\ldots$ & $\ldots$ & 2 & $\ldots$ & $\ldots$ & 0 & 2 & 2 \\
\hline Miscophus nicolai Ferton, 1896 & $\cdots$ & $\ldots$ & $\ldots$ & $\cdots$ & 1 & 5 & $\ldots$ & $\ldots$ & 1 & 5 & 6 \\
\hline TRYPOXYLINI & & & & & & & & & & & \\
\hline Trypoxylon attenuatum F. Smith, 1851 & $\ldots$ & $\ldots$ & 1 & $\ldots$ & $\ldots$ & $\ldots$ & 1 & $\ldots$ & 2 & 0 & 2 \\
\hline Trypoxylon scutatum Chevrier, 1867 & $\ldots$ & $\ldots$ & $\ldots$ & 1 & $\ldots$ & $\ldots$ & $\ldots$ & $\ldots$ & 0 & 1 & 1 \\
\hline OXYBELINI & & & & & & & & & & & \\
\hline Oxybelus quattuordecimnotatus Jurine, 1807 & 1 & $\ldots$ & $\ldots$ & 1 & $\ldots$ & 1 & $\ldots$ & 1 & 1 & 3 & 4 \\
\hline MELLININAE & & & & & & & & & & & \\
\hline MELLININI & & & & & & & & & & & \\
\hline Mellinus arvensis (Linnaeus, 1758) & $\ldots$ & $\ldots$ & $\cdots$ & $\cdots$ & $\cdots$ & $\ldots$ & $\ldots$ & 2 & 0 & 2 & 2 \\
\hline BEMBICINAE & & & & & & & & & & & \\
\hline NYSSONINI & & & & & & & & & & & \\
\hline Nysson dusmeti Mercet, 1909 & $\ldots$ & 1 & $\ldots$ & $\ldots$ & $\ldots$ & $\ldots$ & $\ldots$ & $\ldots$ & 0 & 1 & 1 \\
\hline Nysson pratensis Mercet, 1909 & $\cdots$ & 1 & $\cdots$ & $\ldots$ & $\ldots$ & $\ldots$ & $\cdots$ & $\ldots$ & 0 & 1 & 1 \\
\hline BEMBICINI & & & & & & & & & & & \\
\hline Harpactus alvaroi Gayubo, 1992 & $\ldots$ & $\ldots$ & $\ldots$ & $\ldots$ & 2 & 1 & $\ldots$ & $\ldots$ & 2 & 1 & 3 \\
\hline Harpactus formosus (Jurine, 1807) & $\ldots$ & $\ldots$ & $\ldots$ & $\ldots$ & 1 & $\ldots$ & $\ldots$ & $\ldots$ & 1 & 0 & 1 \\
\hline Harpactus sp. 2 grimaldensis Gayubo, sp. n. (in lit.) & $\ldots$ & $\ldots$ & $\ldots$ & $\ldots$ & 4 & $\ldots$ & $\ldots$ & $\ldots$ & 4 & 0 & 4 \\
\hline Bembecinus pulchelus (Mercet, 1906) & 9 & 12 & $\ldots$ & 2 & $\ldots$ & $\ldots$ & $\cdots$ & $\ldots$ & 9 & 14 & 23 \\
\hline Subtotales & 13 & 22 & 8 & 9 & 26 & 19 & 1 & 12 & 48 & 62 & \\
\hline Total de Ejemplares & & & & & & & & & & & 110 \\
\hline Total de Especies & & & & & & & & & & & 28 \\
\hline
\end{tabular}




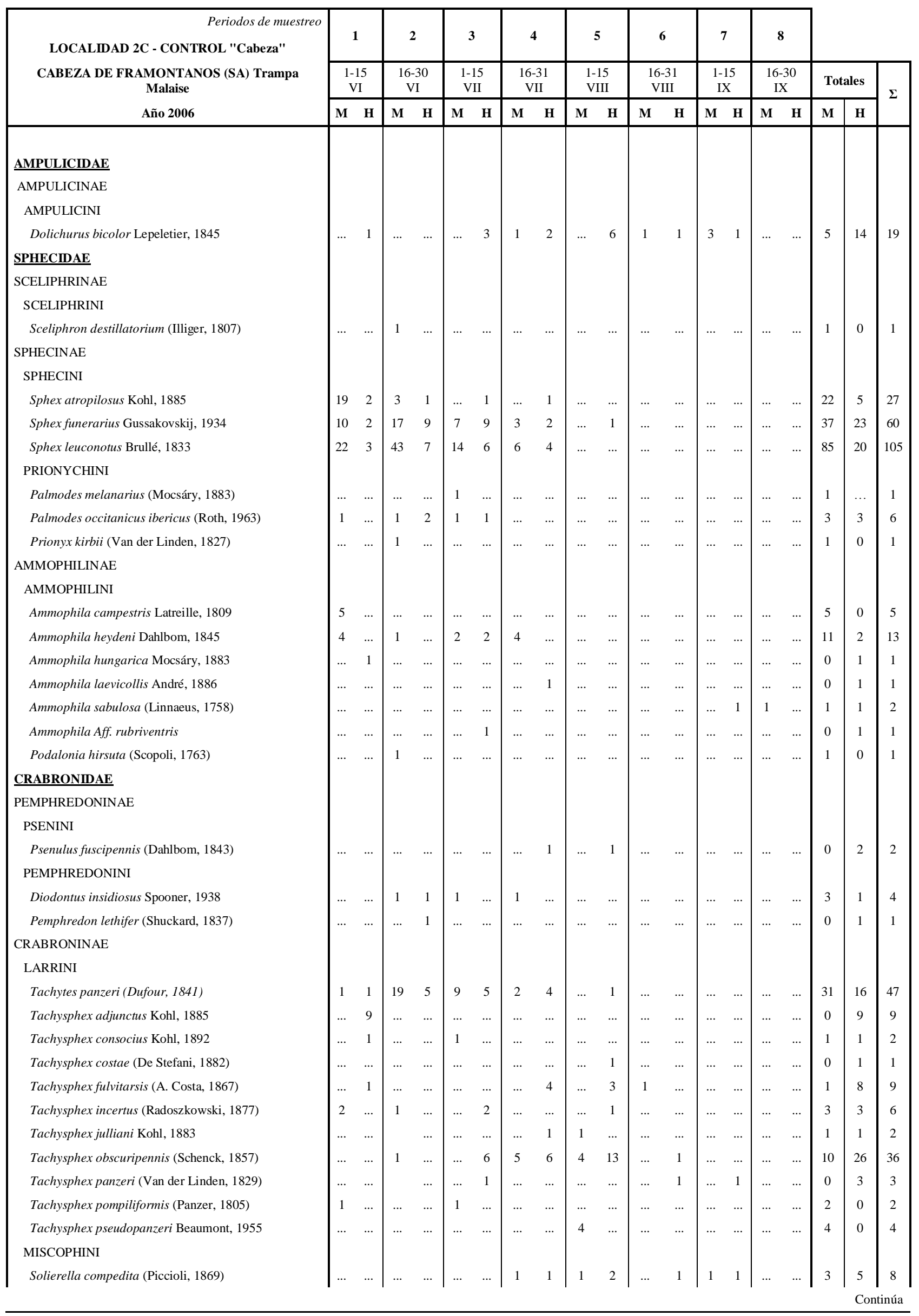




\begin{tabular}{|c|c|c|c|c|c|c|c|c|c|c|c|c|c|c|c|c|c|c|c|}
\hline \multirow{3}{*}{$\begin{array}{l}\text { Periodos de muestreo } \\
\text { LOCALIDAD 2C - CONTROL "Cabeza" } \\
\text { CABEZA DE FRAMONTANOS (SA) Trampa } \\
\text { Malaise } \\
\text { Año } 2006\end{array}$} & \multicolumn{2}{|c|}{1} & \multicolumn{2}{|c|}{2} & \multicolumn{2}{|c|}{3} & \multicolumn{2}{|c|}{4} & \multicolumn{2}{|c|}{5} & \multicolumn{2}{|c|}{6} & \multicolumn{2}{|c|}{7} & \multicolumn{2}{|c|}{8} & & & \\
\hline & \multicolumn{2}{|c|}{$\begin{array}{c}1-15 \\
\text { VI }\end{array}$} & \multicolumn{2}{|c|}{$\begin{array}{c}16-30 \\
\text { VI }\end{array}$} & \multicolumn{2}{|c|}{$\begin{array}{c}1-15 \\
\text { VII }\end{array}$} & \multicolumn{2}{|c|}{$\begin{array}{c}16-31 \\
\text { VII }\end{array}$} & \multicolumn{2}{|c|}{$\begin{array}{l}1-15 \\
\text { VIII }\end{array}$} & \multicolumn{2}{|c|}{$\begin{array}{c}16-31 \\
\text { VIII }\end{array}$} & \multicolumn{2}{|c|}{$\begin{array}{c}1-15 \\
\text { IX }\end{array}$} & \multicolumn{2}{|c|}{$\begin{array}{c}16-30 \\
\text { IX }\end{array}$} & \multicolumn{2}{|c|}{ Totales } & \multirow{2}{*}{$\Sigma$} \\
\hline & & $\mathbf{H}$ & $\mathbf{M}$ & & $\mathbf{M}$ & & M & & $\mathbf{M}$ & & $\mathbf{M}$ & & M & $\mathbf{H}$ & $\mathbf{M}$ & & $\mathbf{M}$ & $\mathbf{H}$ & \\
\hline Miscophus bicolor Jurine, 1807 & $\ldots$ & & $\ldots$ & $\ldots$ & 1 & 1 & 1 & ... & $\ldots$ & 4 & $\ldots$ & $\ldots$ & $\ldots$ & & $\ldots$ & $\ldots$ & 2 & 5 & 7 \\
\hline Miscophus nicolai Ferton, 1896 & $\cdots$ & $\cdots$ & $\ldots$ & $\cdots$ & $\ldots$ & $\ldots$ & $\ldots$ & $\ldots$ & $\ldots$ & 1 & $\ldots$ & $\ldots$ & $\cdots$ & $\cdots$ & $\cdots$ & $\ldots$ & 0 & 1 & 1 \\
\hline Nitela lucens Gayubo \& Felton, 2000 & & 2 & $\ldots$ & $\ldots$ & $\ldots$ & 1 & $\ldots$ & 2 & $\ldots$ & 1 & 1 & 6 & 1 & 2 & $\ldots$ & $\ldots$ & 2 & 14 & 16 \\
\hline \multicolumn{20}{|l|}{ TRYPOXYLINI } \\
\hline Trypoxylon attenuatum F. Smith, 1851 & $\ldots$ & $\cdots$ & $\ldots$ & $\ldots$ & $\ldots$ & 1 & $\ldots$ & $\ldots$ & $\cdots$ & 1 & $\cdots$ & $\cdots$ & $\cdots$ & $\cdots$ & $\ldots$ & $\ldots$ & 0 & 2 & 2 \\
\hline Trypoxylon clavicerum Lepeletier \& Serville, 1828 & $\cdots$ & $\cdots$ & $\cdots$ & $\cdots$ & $\cdots$ & $\ldots$ & $\ldots$ & $\ldots$ & $\ldots$ & $\ldots$ & $\ldots$ & 1 & $\cdots$ & $\cdots$ & $\cdots$ & $\ldots$ & 0 & 1 & 1 \\
\hline Trypoxylon scutatum Chevrier, 1867 & $\ldots$ & $\ldots$ & $\ldots$ & 2 & 1 & 1 & $\ldots$ & 4 & 2 & 2 & $\ldots$ & $\ldots$ & $\ldots$ & 2 & $\ldots$ & $\ldots$ & 3 & 11 & 14 \\
\hline \multicolumn{20}{|l|}{ OXYBELINI } \\
\hline Oxybelus quattuordecimnotatus Jurine, 1807 & $\cdots$ & $\ldots$ & 1 & 1 & $\cdots$ & 4 & 2 & 1 & 2 & $\ldots$ & $\ldots$ & 2 & $\ldots$ & $\cdots$ & $\ldots$ & $\ldots$ & 5 & 8 & 13 \\
\hline \multicolumn{20}{|l|}{ CRABRONINI } \\
\hline Lindenius ibericus Kohl, 1905 & $\ldots$ & $\ldots$ & $\ldots$ & $\cdots$ & $\ldots$ & $\ldots$ & $\ldots$ & 2 & $\ldots$ & $\ldots$ & $\ldots$ & $\cdots$ & $\ldots$ & $\ldots$ & $\ldots$ & $\ldots$ & 0 & 2 & 2 \\
\hline Ectemnius cephalotes (Olivier, 1792) & $\ldots$ & $\ldots$ & $\ldots$ & $\ldots$ & $\ldots$ & $\ldots$ & $\ldots$ & $\ldots$ & $\cdots$ & $\ldots$ & $\ldots$ & $\ldots$ & $\ldots$ & $\cdots$ & 1 & $\ldots$ & 1 & 0 & 1 \\
\hline Ectemnius crassicornis (Spinola, 1808) & $\ldots$ & $\ldots$ & 1 & $\cdots$ & 2 & $\ldots$ & 2 & $\ldots$ & $\ldots$ & $\ldots$ & 1 & $\cdots$ & $\ldots$ & $\ldots$ & $\cdots$ & $\ldots$ & 6 & 0 & 6 \\
\hline \multicolumn{20}{|l|}{ BEMBICINAE } \\
\hline BEMBICINI & & & & & & & & & & & & & & & & & & & \\
\hline Gorytes quinquefasciatus (Panzer, 1798) & $\cdots$ & $\cdots$ & $\ldots$ & $\cdots$ & $\cdots$ & 1 & $\ldots$ & $\ldots$ & $\cdots$ & $\ldots$ & $\ldots$ & $\cdots$ & $\ldots$ & $\ldots$ & $\ldots$ & $\ldots$ & 0 & 1 & 1 \\
\hline Gorytes sulcifrons (A. Costa, 1869) & $\cdots$ & $\cdots$ & $\cdots$ & $\ldots$ & $\ldots$ & 1 & $\ldots$ & 1 & $\cdots$ & $\ldots$ & $\ldots$ & $\cdots$ & $\cdots$ & $\cdots$ & $\cdots$ & $\ldots$ & 0 & 2 & 2 \\
\hline Harpactus alvaroi Gayubo, 1992 & $\ldots$ & $\ldots$ & $\cdots$ & $\ldots$ & $\ldots$ & $\cdots$ & $\ldots$ & $\ldots$ & $\ldots$ & 1 & $\ldots$ & $\cdots$ & $\cdots$ & $\ldots$ & $\ldots$ & $\ldots$ & 0 & 1 & 1 \\
\hline Harpactus formosus (Jurine, 1807) & $\ldots$ & $\ldots$ & $\cdots$ & $\cdots$ & 1 & $\ldots$ & 3 & $\ldots$ & $\cdots$ & 1 & 1 & $\cdots$ & $\cdots$ & $\cdots$ & $\cdots$ & $\ldots$ & 5 & 1 & 6 \\
\hline Harpactus sp. 2 grimaldensis Gayubo, sp. $n$. (in lit.) & $\ldots$ & $\cdots$ & 2 & $\ldots$ & 1 & 2 & $\ldots$ & $\cdots$ & 1 & 1 & 1 & 1 & $\cdots$ & $\cdots$ & $\cdots$ & $\ldots$ & 5 & 4 & 9 \\
\hline Sphecius nigricornis (Dufour, 1838) & $\ldots$ & $\ldots$ & $\ldots$ & 1 & 1 & $\ldots$ & $\cdots$ & $\ldots$ & $\ldots$ & $\ldots$ & $\ldots$ & $\ldots$ & $\cdots$ & $\ldots$ & $\ldots$ & $\ldots$ & 1 & 1 & 2 \\
\hline Bembix oculata Panzer, 1801 & $\ldots$ & $\ldots$ & $\ldots$ & $\ldots$ & $\ldots$ & $\ldots$ & $\ldots$ & $\ldots$ & $\ldots$ & $\ldots$ & $\ldots$ & $\cdots$ & $\cdots$ & $\cdots$ & $\cdots$ & 1 & 0 & 1 & 1 \\
\hline Bembix zonata Klug, 1835 & $\cdots$ & $\cdots$ & $\ldots$ & $\cdots$ & $\cdots$ & $\cdots$ & $\cdots$ & 1 & $\ldots$ & $\ldots$ & $\cdots$ & $\ldots$ & $\cdots$ & $\cdots$ & $\cdots$ & $\ldots$ & 0 & 1 & 1 \\
\hline PHILANTHINAE & & & & & & & & & & & & & & & & & & & \\
\hline CERCERINI & & & & & & & & & & & & & & & & & & & \\
\hline Cerceris arenaria (Linnaeus, 1758) & $\ldots$ & $\ldots$ & $\ldots$ & $\cdots$ & $\ldots$ & $\ldots$ & $\ldots$ & $\ldots$ & 1 & $\ldots$ & $\ldots$ & $\ldots$ & $\ldots$ & $\cdots$ & $\ldots$ & $\ldots$ & 1 & 0 & 1 \\
\hline Subtotales & 65 & 23 & 94 & 30 & 44 & 49 & 31 & 38 & 16 & 41 & 6 & 14 & 5 & 8 & 2 & 1 & 263 & 204 & \\
\hline Total de Ejemplares & & & & & 9 & & & & & & & & & & 3 & & & & 467 \\
\hline Total de Especies & & & & & 2 & & & & & & & & & & 3 & & & & 49 \\
\hline
\end{tabular}




\begin{tabular}{|c|c|c|c|c|c|c|c|c|c|c|c|}
\hline \multirow{3}{*}{\begin{tabular}{|} 
Periodos de muestreo \\
LOCALIDAD 2C - CONTROL "Cabeza" \\
Cabeza de Framontanos (SA) PLATOS \\
Año 2006
\end{tabular}} & \multicolumn{2}{|c|}{1} & \multicolumn{2}{|c|}{2} & \multicolumn{2}{|c|}{3} & \multicolumn{2}{|c|}{4} & & & \\
\hline & \multicolumn{2}{|c|}{ 15-Jun } & \multicolumn{2}{|c|}{ 15-Jul } & \multicolumn{2}{|c|}{ 15-Agos } & \multicolumn{2}{|c|}{ 15-Sep } & \multicolumn{2}{|c|}{ Totales } & \multirow{2}{*}{$\Sigma$} \\
\hline & M & $\mathbf{H}$ & M & $\mathbf{H}$ & M & $\mathbf{H}$ & $\mathbf{M}$ & $\mathbf{H}$ & M & $\mathbf{H}$ & \\
\hline \multicolumn{12}{|l|}{ AMPULICIDAE } \\
\hline \multicolumn{12}{|l|}{ AMPULICINAE } \\
\hline \multicolumn{12}{|l|}{ AMPULICINI } \\
\hline Dolichurus bicolor Lepeletier, 1845 & $\ldots$ & $\ldots$ & 25 & 4 & 6 & $\ldots$ & $\ldots$ & $\ldots$ & 31 & 4 & 35 \\
\hline Dolichurus corniculus (Spinola, 1808) & $\ldots$ & $\ldots$ & 2 & $\ldots$ & $\ldots$ & $\ldots$ & $\ldots$ & $\ldots$ & 2 & 0 & 2 \\
\hline Dolichurus haemorrhous A. Costa, 1886 & $\ldots$ & $\ldots$ & $\ldots$ & $\ldots$ & $\ldots$ & 4 & $\ldots$ & $\ldots$ & 0 & 4 & 4 \\
\hline \multicolumn{12}{|l|}{ SPHECIDAE } \\
\hline \multicolumn{12}{|l|}{ AMMOPHILINAE } \\
\hline \multicolumn{12}{|l|}{ AMMOPHILINI } \\
\hline Ammophila heydeni Dahlbom, 1845 & $\ldots$ & $\ldots$ & 1 & $\ldots$ & $\ldots$ & $\ldots$ & $\ldots$ & $\ldots$ & 1 & 0 & 1 \\
\hline \multicolumn{12}{|l|}{ CRABRONIDAE } \\
\hline CRABRONINAE & & & & & & & & & & & \\
\hline LARRINI & & & & & & & & & & & \\
\hline Tachytes freygessneri Kohl, 1881 & $\ldots$ & $\ldots$ & $\ldots$ & 1 & $\ldots$ & $\ldots$ & $\ldots$ & $\ldots$ & 0 & 1 & 1 \\
\hline Tachysphex consocius Kohl, 1892 & & $\ldots$ & & 1 & $\ldots$ & & & $\ldots$ & 0 & 1 & 1 \\
\hline Tachysphex costae (De Stefani, 1882) & $\ldots$ & $\ldots$ & $\ldots$ & $\ldots$ & $\ldots$ & 2 & $\ldots$ & $\ldots$ & 0 & 2 & 2 \\
\hline Tachysphex incertus (Radoszkowski, 1877) & $\ldots$ & $\ldots$ & $\ldots$ & 1 & $\ldots$ & $\ldots$ & $\ldots$ & $\ldots$ & 0 & 1 & 1 \\
\hline Tachysphex mediterraneus Kohl, 1883 & $\ldots$ & $\ldots$ & $\ldots$ & 1 & $\ldots$ & $\ldots$ & $\ldots$ & $\ldots$ & 0 & 1 & 1 \\
\hline Tachysphex nitidior Beaumont, 1940 & $\ldots$ & $\ldots$ & 2 & 2 & $\ldots$ & $\ldots$ & $\ldots$ & 1 & 2 & 3 & 5 \\
\hline Tachysphex obscuripennis (Schenck, 1857) & $\ldots$ & $\ldots$ & 49 & 14 & 6 & 7 & $\ldots$ & $\ldots$ & 55 & 21 & 76 \\
\hline Tachysphex pompiliformis (Panzer, 1805) & $\ldots$ & $\ldots$ & 1 & 2 & $\ldots$ & $\ldots$ & $\ldots$ & $\ldots$ & 1 & 2 & 3 \\
\hline Tachysphex pseudopanzeri Beaumont, 1955 & $\ldots$ & $\ldots$ & $\ldots$ & $\ldots$ & $\ldots$ & $\ldots$ & $\ldots$ & 2 & 0 & 2 & 2 \\
\hline Tachysphex tarsinus (Lepeletier, 1845) & $\ldots$ & $\ldots$ & $\ldots$ & $\ldots$ & $\ldots$ & $\ldots$ & $\ldots$ & 1 & 0 & 1 & 1 \\
\hline Tachysphex unicolor (Panzer, 1809) & $\ldots$ & $\ldots$ & $\ldots$ & $\ldots$ & $\ldots$ & $\ldots$ & $\ldots$ & 1 & 0 & 1 & 1 \\
\hline MISCOPHINI & & & & & & & & & & & \\
\hline Solierella compedita (Piccioli, 1869) & $\ldots$ & $\ldots$ & 12 & 18 & 3 & 6 & 1 & 9 & 16 & 33 & 49 \\
\hline Solierella pisonoides (Saunders, 1873) & $\ldots$ & $\ldots$ & 3 & 2 & 4 & 1 & $\ldots$ & $\ldots$ & 7 & 3 & 10 \\
\hline Miscophus albufeirae de Andrade, 1952 & $\ldots$ & $\ldots$ & $\ldots$ & 1 & $\ldots$ & $\ldots$ & $\ldots$ & $\ldots$ & 0 & 1 & 1 \\
\hline Miscophus bicolor Jurine, 1807 & $\ldots$ & $\ldots$ & 1 & $\ldots$ & $\ldots$ & $\ldots$ & $\ldots$ & $\ldots$ & 1 & 0 & 1 \\
\hline Miscophus nicolai Ferton, 1896 & $\ldots$ & $\ldots$ & 2 & $\ldots$ & 1 & 1 & $\ldots$ & 3 & 3 & 4 & 7 \\
\hline TRYPOXYLINI & & & & & & & & & & & \\
\hline Trypoxylon scutatum Chevrier, 1867 & $\ldots$ & $\ldots$ & $\ldots$ & $\ldots$ & $\ldots$ & $\ldots$ & $\ldots$ & 1 & 0 & 1 & 1 \\
\hline OXYBELINI & & & & & & & & & & & \\
\hline Oxybelus quattuordecimnotatus Jurine, 1807 & $\ldots$ & $\ldots$ & 1 & 8 & 1 & $\ldots$ & $\ldots$ & $\ldots$ & 2 & 8 & 10 \\
\hline CRABRONINI & & & & & & & & & & & \\
\hline Tracheliodes quinquenotatus (Jurine, 1807) & $\ldots$ & $\ldots$ & $\ldots$ & $\ldots$ & $\ldots$ & $\ldots$ & 1 & $\ldots$ & 1 & 0 & 1 \\
\hline BEMBICINAE & & & & & & & & & & & \\
\hline NYSSONINI & & & & & & & & & & & \\
\hline Nysson maculosus (Gmelin, 1790) & $\ldots$ & $\ldots$ & $\ldots$ & 1 & $\ldots$ & $\ldots$ & $\ldots$ & 1 & 0 & 2 & 2 \\
\hline Nysson pratensis Mercet, 1909 & $\ldots$ & $\ldots$ & $\ldots$ & $\ldots$ & 1 & $\ldots$ & $\ldots$ & $\ldots$ & 1 & 0 & 1 \\
\hline BEMBICINI & & & & & & & & & & & \\
\hline Harpactus alvaroi Gayubo, 1992 & $\ldots$ & $\ldots$ & 1 & 1 & $\ldots$ & 1 & $\ldots$ & $\ldots$ & 1 & 2 & 3 \\
\hline Harpactus sp. 2 grimaldensis Gayubo, sp. $\mathrm{n}$. (in lit.) & $\ldots$ & $\ldots$ & $\ldots$ & $\ldots$ & 5 & $\ldots$ & $\ldots$ & $\ldots$ & 5 & 0 & 5 \\
\hline Bembecinus pulchelus (Mercet, 1906) & $\ldots$ & $\ldots$ & $\ldots$ & $\ldots$ & $\ldots$ & $\ldots$ & $\ldots$ & 2 & 0 & 2 & 2 \\
\hline Subtotales & $\mathbf{0}$ & $\mathbf{0}$ & 100 & 57 & 27 & 22 & 2 & 21 & 129 & 100 & \\
\hline Total de Ejemplares & & & & & & & & & & & 229 \\
\hline Total de Especies & & & 1 & & & & & & & & 28 \\
\hline
\end{tabular}




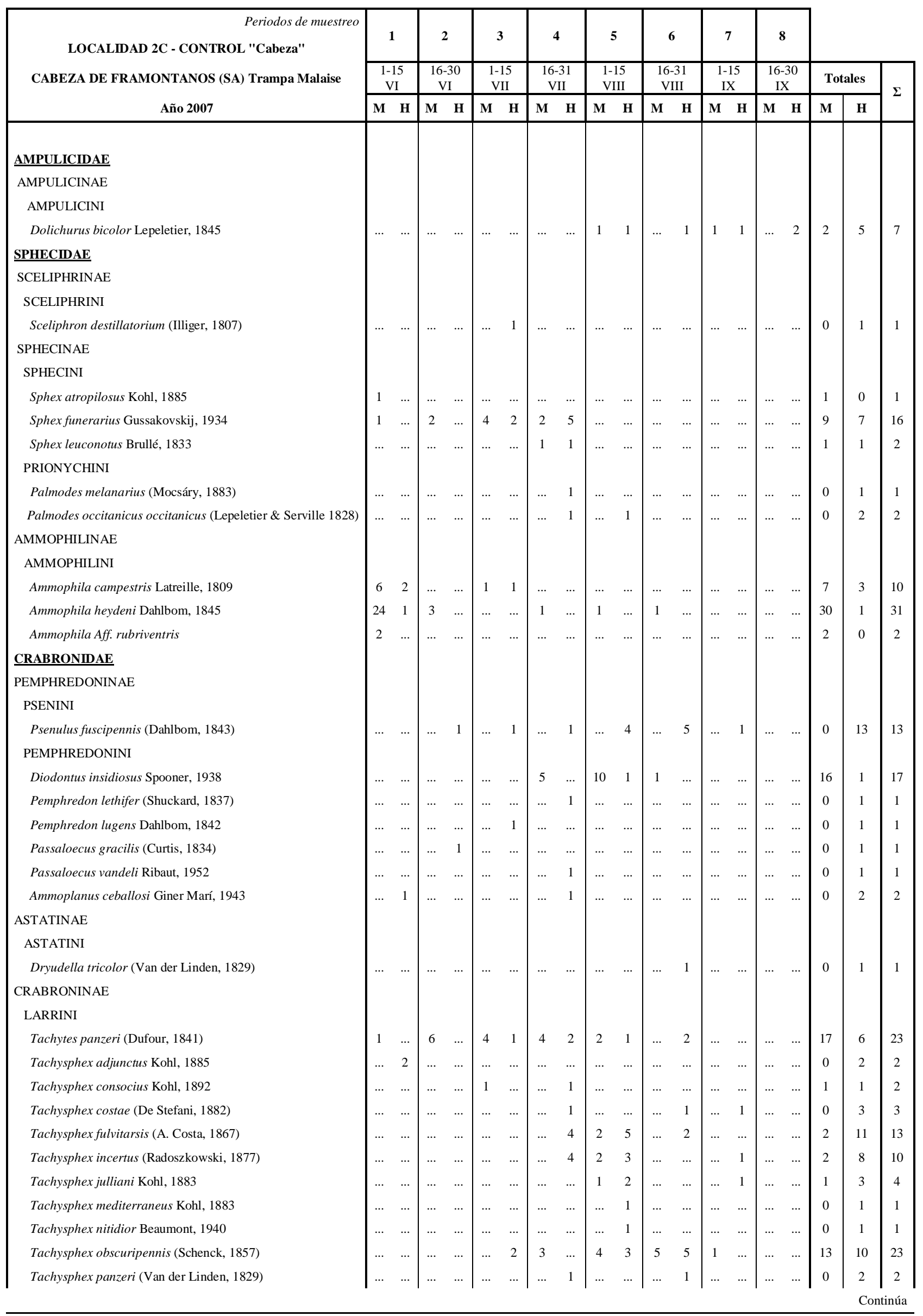




\begin{tabular}{|c|c|c|c|c|c|c|c|c|c|c|c|c|c|c|c|c|c|c|c|}
\hline \multirow{3}{*}{$\begin{array}{l}\text { CABEZA DE FRAMONTANOS (SA) Trampa Malaise } \\
\qquad \text { Año } 2007\end{array}$} & \multicolumn{2}{|c|}{1} & \multicolumn{2}{|c|}{2} & \multicolumn{2}{|c|}{3} & \multicolumn{2}{|c|}{4} & \multicolumn{2}{|c|}{5} & \multicolumn{2}{|c|}{6} & \multicolumn{2}{|c|}{7} & \multicolumn{2}{|c|}{8} & & & \\
\hline & \multicolumn{2}{|c|}{$\begin{array}{c}1-15 \\
\text { VI } \\
\end{array}$} & \multicolumn{2}{|c|}{$\begin{array}{c}16-30 \\
\mathrm{VI} \\
\end{array}$} & \multicolumn{2}{|c|}{$\begin{array}{l}1-15 \\
\text { VII } \\
\end{array}$} & \multicolumn{2}{|c|}{$\begin{array}{c}16-31 \\
\text { VII } \\
\end{array}$} & \multicolumn{2}{|c|}{$\begin{array}{l}1-15 \\
\text { VIII } \\
\end{array}$} & \multicolumn{2}{|c|}{$\begin{array}{c}16-31 \\
\text { VIII } \\
\end{array}$} & \multicolumn{2}{|c|}{$\begin{array}{c}1-15 \\
\text { IX } \\
\end{array}$} & \multicolumn{2}{|c|}{$\begin{array}{c}16-30 \\
\text { IX }\end{array}$} & \multicolumn{2}{|c|}{ Totales } & $\Sigma$ \\
\hline & & $\mathbf{H}$ & $\mathbf{M}$ & & M & & $\mathbf{M}$ & $\mathbf{H}$ & M & & $\mathbf{M}$ & & & & M & & $\mathbf{M}$ & $\mathbf{H}$ & \\
\hline Tachysphex pompiliformis (Panzer, 1805) & & $\ldots$ & $\ldots$ & & $\ldots$ & $\ldots$ & 1 & & 1 & & $\ldots$ & $\ldots$ & $\ldots$ & & $\ldots$ & & 2 & 0 & 2 \\
\hline Tachysphex pseudopanzeri Beaumont, 1955 & $\ldots$ & $\ldots$ & $\ldots$ & $\ldots$ & $\ldots$ & $\ldots$ & $\ldots$ & $\ldots$ & 1 & $\ldots$ & $\ldots$ & 1 & $\ldots$ & $\ldots$ & $\ldots$ & $\ldots$ & 1 & 1 & 2 \\
\hline Tachysphex tarsinus (Lepeletier, 1845) & $\ldots$ & $\ldots$ & $\ldots$ & $\ldots$ & 1 & $\ldots$ & $\ldots$ & $\ldots$ & $\ldots$ & $\ldots$ & $\ldots$ & 1 & $\ldots$ & $\ldots$ & $\ldots$ & $\ldots$ & 1 & 1 & 2 \\
\hline Prosopigastra punctatissima A. Costa, 1870 & $\ldots$ & $\ldots$ & $\ldots$ & $\ldots$ & $\ldots$ & $\ldots$ & $\ldots$ & 1 & $\ldots$ & $\ldots$ & $\ldots$ & $\ldots$ & $\ldots$ & $\ldots$ & $\ldots$ & $\ldots$ & 0 & 1 & 1 \\
\hline MISCOPHINI & & & & & & & & & & & & & & & & & & & \\
\hline Solierella compedita (Piccioli, 1869) & $\ldots$ & $\ldots$ & $\ldots$ & $\ldots$ & $\ldots$ & $\ldots$ & $\ldots$ & $\ldots$ & $\ldots$ & 1 & $\ldots$ & 9 & $\ldots$ & 7 & $\ldots$ & 1 & 0 & 18 & 18 \\
\hline Miscophus bicolor Jurine, 1807 & $\ldots$ & $\ldots$ & $\ldots$ & $\ldots$ & $\ldots$ & $\ldots$ & $\ldots$ & $\ldots$ & $\ldots$ & 1 & $\ldots$ & $\ldots$ & 2 & 2 & $\ldots$ & $\ldots$ & 2 & 3 & 5 \\
\hline Nitela lucens Gayubo \& Felton, 2000 & 1 & 1 & 1 & 2 & $\ldots$ & $\ldots$ & $\ldots$ & $\ldots$ & 1 & $\ldots$ & 2 & 6 & 2 & 1 & 1 & $\ldots$ & 8 & 10 & 18 \\
\hline Nitela truncata Gayubo \& Felton, 2000 & $\ldots$ & $\ldots$ & $\ldots$ & $\ldots$ & $\ldots$ & $\ldots$ & 1 & 1 & $\ldots$ & $\ldots$ & $\ldots$ & $\ldots$ & $\ldots$ & $\ldots$ & $\ldots$ & $\ldots$ & 1 & 1 & 2 \\
\hline TRYPOXYLINI & & & & & & & & & & & & & & & & & & & \\
\hline Trypoxylon attenuatum F. Smith, 1851 & $\ldots$ & $\ldots$ & $\ldots$ & $\ldots$ & $\ldots$ & 1 & $\ldots$ & $\ldots$ & 2 & 5 & 3 & 5 & $\ldots$ & 4 & 3 & 1 & 8 & 16 & 24 \\
\hline Trypoxylon clavicerum Lepeletier \& Serville, 1828 & $\ldots$ & $\ldots$ & $\ldots$ & $\ldots$ & $\ldots$ & $\ldots$ & $\ldots$ & $\ldots$ & $\ldots$ & $\ldots$ & $\ldots$ & 1 & $\ldots$ & $\ldots$ & $\ldots$ & $\ldots$ & 0 & 1 & 1 \\
\hline Trypoxylon scutatum Chevrier, 1867 & 1 & 1 & 1 & 2 & $\ldots$ & 2 & $\ldots$ & $\ldots$ & 2 & 1 & 4 & $\ldots$ & 4 & 5 & $\ldots$ & $\ldots$ & 12 & 11 & 23 \\
\hline OXYBELINI & & & & & & & & & & & & & & & & & & & \\
\hline Oxybelus quattuordecimnotatus Jurine, 1807 & 1 & 1 & 1 & 1 & 2 & $\ldots$ & 1 & 4 & $\ldots$ & 12 & $\ldots$ & 3 & $\ldots$ & 1 & $\ldots$ & $\ldots$ & 5 & 22 & 27 \\
\hline CRABRONINI & & & & & & & & & & & & & & & & & & & \\
\hline Entomognathus brevis (Van der Linden, 1829) & 1 & $\ldots$ & $\ldots$ & $\ldots$ & $\ldots$ & $\cdots$ & $\ldots$ & $\cdots$ & $\cdots$ & $\cdots$ & $\cdots$ & $\ldots$ & $\cdots$ & $\ldots$ & $\ldots$ & $\ldots$ & 1 & 0 & 1 \\
\hline Lindenius ibericus Kohl, 1905 & $\ldots$ & $\ldots$ & $\ldots$ & $\ldots$ & $\ldots$ & $\ldots$ & $\ldots$ & $\ldots$ & $\ldots$ & 1 & $\ldots$ & 1 & $\ldots$ & $\ldots$ & $\ldots$ & $\ldots$ & 0 & 2 & 2 \\
\hline Crossocerus elongatulus (Van der Linden, 1829) & $\ldots$ & $\ldots$ & $\cdots$ & $\ldots$ & $\ldots$ & $\ldots$ & $\cdots$ & $\cdots$ & $\cdots$ & $\ldots$ & 1 & $\ldots$ & $\ldots$ & 1 & $\ldots$ & $\ldots$ & 1 & 1 & 2 \\
\hline Ectemnius cephalotes (Olivier, 1792) & $\ldots$ & $\ldots$ & $\ldots$ & $\ldots$ & $\ldots$ & $\ldots$ & $\ldots$ & 1 & 1 & $\ldots$ & $\ldots$ & $\ldots$ & $\ldots$ & 1 & $\ldots$ & $\ldots$ & 1 & 2 & 3 \\
\hline Ectemnius continuus (Fabricius, 1804) & $\ldots$ & $\ldots$ & $\ldots$ & $\ldots$ & $\ldots$ & $\ldots$ & $\ldots$ & $\cdots$ & $\ldots$ & $\ldots$ & 1 & $\ldots$ & $\ldots$ & $\ldots$ & $\ldots$ & $\ldots$ & 1 & $\cdots$ & 1 \\
\hline Ectemnius crassicornis (Spinola, 1808) & 1 & $\ldots$ & $\ldots$ & $\ldots$ & 1 & 1 & $\ldots$ & $\ldots$ & $\ldots$ & $\ldots$ & 1 & $\ldots$ & $\ldots$ & $\cdots$ & $\ldots$ & $\ldots$ & 3 & 1 & 4 \\
\hline Ectemnius rugifer (Dahlbom, 1845) & $\ldots$ & $\ldots$ & $\ldots$ & $\ldots$ & $\ldots$ & $\ldots$ & $\ldots$ & $\ldots$ & 1 & $\ldots$ & 1 & $\ldots$ & $\ldots$ & $\ldots$ & $\ldots$ & $\ldots$ & 2 & 0 & 2 \\
\hline Lestica clypeata (Schreber, 1759) & 1 & $\ldots$ & $\ldots$ & $\ldots$ & $\ldots$ & $\ldots$ & $\ldots$ & $\ldots$ & $\cdots$ & $\ldots$ & $\ldots$ & $\ldots$ & $\ldots$ & $\ldots$ & $\ldots$ & $\ldots$ & 1 & 0 & 1 \\
\hline BEMBICINAE & & & & & & & & & & & & & & & & & & & \\
\hline NYSSONINI & & & & & & & & & & & & & & & & & & & \\
\hline Nysson maculosus (Gmelin, 1790) & $\cdots$ & $\ldots$ & $\ldots$ & $\ldots$ & $\ldots$ & 1 & $\ldots$ & $\ldots$ & $\cdots$ & $\ldots$ & $\ldots$ & $\ldots$ & $\ldots$ & $\ldots$ & $\ldots$ & $\ldots$ & 0 & 1 & 1 \\
\hline BEMBICINI & & & & & & & & & & & & & & & & & & & \\
\hline Gorytes quinquefasciatus (Panzer, 1798) & $\ldots$ & $\ldots$ & $\ldots$ & $\ldots$ & $\ldots$ & $\ldots$ & $\ldots$ & $\ldots$ & $\cdots$ & 4 & $\ldots$ & $\ldots$ & $\ldots$ & $\ldots$ & $\ldots$ & $\ldots$ & 0 & 4 & 4 \\
\hline Gorytes sulcifrons (A. Costa, 1869) & $\ldots$ & $\ldots$ & $\ldots$ & $\ldots$ & $\ldots$ & $\ldots$ & $\ldots$ & $\cdots$ & $\ldots$ & 3 & $\ldots$ & $\ldots$ & $\ldots$ & $\ldots$ & $\ldots$ & $\ldots$ & 0 & 3 & 3 \\
\hline Harpactus alvaroi Gayubo, 1992 & $\ldots$ & $\ldots$ & $\ldots$ & $\ldots$ & $\ldots$ & $\ldots$ & $\ldots$ & 2 & $\ldots$ & $\ldots$ & $\cdots$ & $\ldots$ & $\ldots$ & $\cdots$ & $\ldots$ & $\ldots$ & 0 & 2 & 2 \\
\hline Harpactus laevis (Latreille, 1792) & $\ldots$ & $\ldots$ & $\ldots$ & $\ldots$ & 1 & $\ldots$ & 5 & 2 & 3 & 3 & 1 & 1 & $\ldots$ & $\ldots$ & $\ldots$ & $\ldots$ & 10 & 6 & 16 \\
\hline Harpactus sp. 2 grimaldensis Gayubo, sp. n. (in lit.) & $\ldots$ & $\ldots$ & $\ldots$ & $\ldots$ & $\ldots$ & $\ldots$ & $\ldots$ & $\ldots$ & 1 & 1 & 5 & $\ldots$ & $\ldots$ & $\ldots$ & 1 & $\ldots$ & 7 & 1 & 8 \\
\hline PHILANTHINAE & & & & & & & & & & & & & & & & & & & \\
\hline CERCERINI & & & & & & & & & & & & & & & & & & & \\
\hline Cerceris arenaria (Linnaeus, 1758) & 3 & $\ldots$ & 1 & $\ldots$ & $\ldots$ & $\ldots$ & 1 & 1 & 7 & 1 & 4 & 1 & 4 & $\ldots$ & $\ldots$ & 3 & 20 & 6 & 26 \\
\hline Cerceris quadricinctus (Panzer, 1799) & $\ldots$ & $\ldots$ & $\ldots$ & $\ldots$ & $\ldots$ & 1 & $\ldots$ & $\ldots$ & $\ldots$ & $\ldots$ & $\ldots$ & $\ldots$ & $\ldots$ & $\ldots$ & $\ldots$ & $\ldots$ & 0 & 1 & 1 \\
\hline Subtotales & 44 & 9 & 15 & 7 & 15 & 15 & 25 & 37 & 43 & 56 & 30 & 47 & 14 & 27 & 5 & 7 & 191 & 205 & \\
\hline Total de Ejemplares & 5 & & & & & & & & & 9 & 7 & & & & & & & & 396 \\
\hline Total de Especies & 1 & & & & & & & & & 8 & 2 & & 1 & & & & & & 57 \\
\hline
\end{tabular}




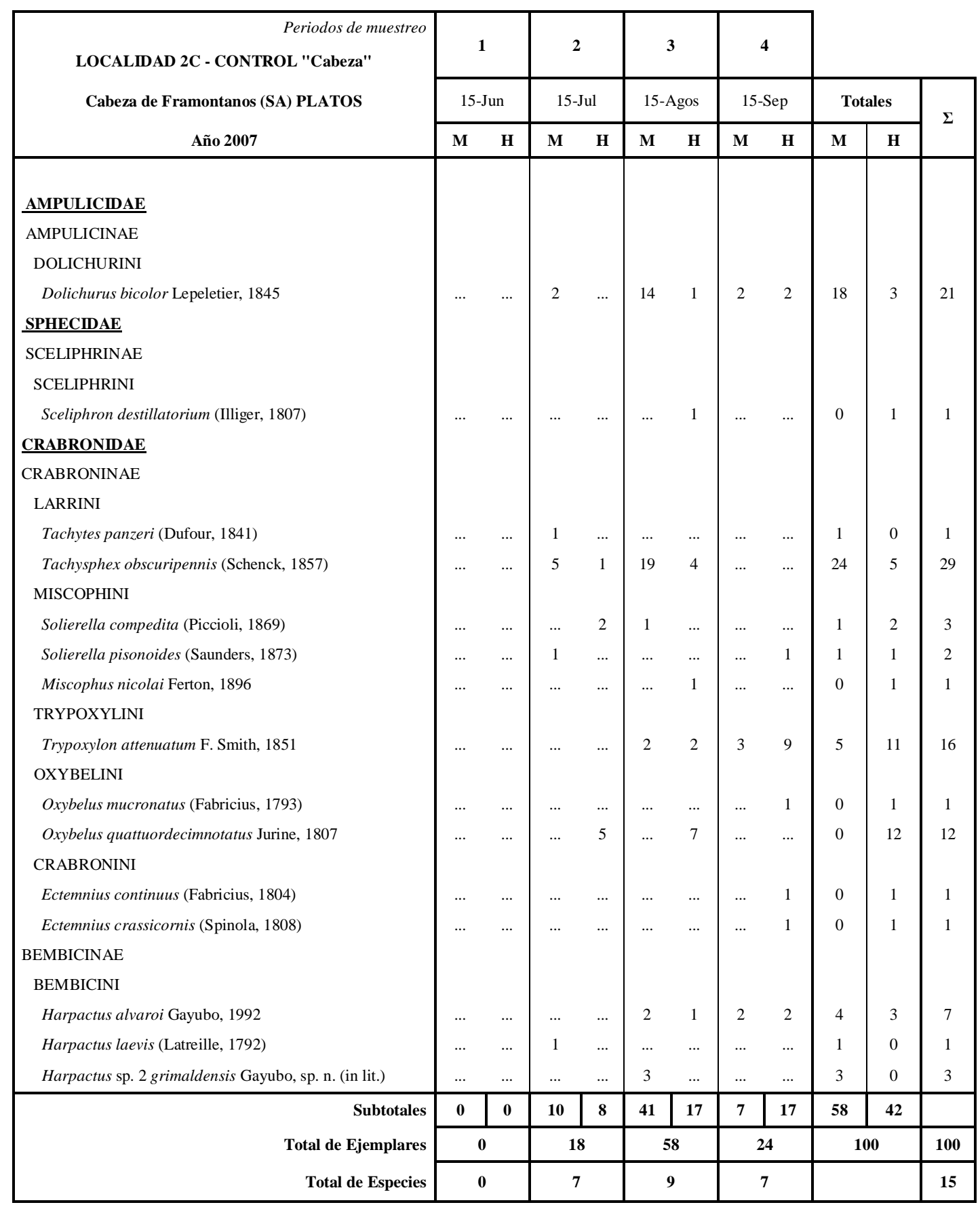




ANEXO III: Master list de las especies de Spheciformes presentes en la Península Ibérica




\begin{tabular}{|c|c|c|c|c|}
\hline Especies & Géneros & Tribus & Subfamilias & Familias \\
\hline Ampulex fasciata & Ampulex & Ampulicini & Ampulicinae & Ampulicidae \\
\hline Ampulex ruficollis & Ampulex & Ampulicini & Ampulicinae & Ampulicidae \\
\hline Dolichurus bicolor & Dolichurus & Ampulicini & Ampulicinae & Ampulicidae \\
\hline Dolichurus corniculus & Dolichurus & Ampulicini & Ampulicinae & Ampulicidae \\
\hline Dolichurus haemorrhous & Dolichurus & Ampulicini & Ampulicinae & Ampulicidae \\
\hline Chalybion femoratum & Chalybion & Sceliphrini & Sceliphrinae & Sphecidae \\
\hline Chalybion flebile & Chalybion & Sceliphrini & Sceliphrinae & Sphecidae \\
\hline Sceliphron caementarium & Sceliphron & Sceliphrini & Sceliphrinae & Sphecidae \\
\hline Sceliphron curvatum & Sceliphron & Sceliphrini & Sceliphrinae & Sphecidae \\
\hline Sceliphron destillatorium & Sceliphron & Sceliphrini & Sceliphrinae & Sphecidae \\
\hline Sceliphron madraspartanum tubifex & Sceliphron & Sceliphrini & Sceliphrinae & Sphecidae \\
\hline Sceliphron spirifex & Sceliphron & Sceliphrini & Sceliphrinae & Sphecidae \\
\hline Sphex atropilosus & Sphex & Sphecini & Sphecinae & Sphecidae \\
\hline Sphex flavipennis & Sphex & Sphecini & Sphecinae & Sphecidae \\
\hline Sphex funerarius & Sphex & Sphecini & Sphecinae & Sphecidae \\
\hline Sphex leuconotus & Sphex & Sphecini & Sphecinae & Sphecidae \\
\hline Sphex pruinosus & Sphex & Sphecini & Sphecinae & Sphecidae \\
\hline Isodontia mexicana & Isodontia & Sphecini & Sphecinae & Sphecidae \\
\hline Isodontia paludosa & Isodontia & Sphecini & Sphecinae & Sphecidae \\
\hline Isodontia splendidula & Isodontia & Sphecini & Sphecinae & Sphecidae \\
\hline Palmodes melanarius & Palmodes & Prionychini & Sphecinae & Sphecidae \\
\hline Palmodes occitanicus & Palmodes & Prionychini & Sphecinae & Sphecidae \\
\hline Palmodes strigulosus & Palmodes & Prionychini & Sphecinae & Sphecidae \\
\hline Chilosphex argyrius & Chilosphex & Prionychini & Sphecinae & Sphecidae \\
\hline Prionyx kirbii & Prionyx & Prionychini & Sphecinae & Sphecidae \\
\hline Prionyx lividocincta & Prionyx & Prionychini & Sphecinae & Sphecidae \\
\hline Prionyx niveatus & Prionyx & Prionychini & Sphecinae & Sphecidae \\
\hline Prionyx nudatus & Prionyx & Prionychini & Sphecinae & Sphecidae \\
\hline Prionyx subfuscatus & Prionyx & Prionychini & Sphecinae & Sphecidae \\
\hline Prionyx viduatus & Prionyx & Prionychini & Sphecinae & Sphecidae \\
\hline Hoplammophila armata & Hoplammophila & Ammophilini & Ammophilinae & Sphecidae \\
\hline Hoplammophila clypeata & Hoplammophila & Ammophilini & Ammophilinae & Sphecidae \\
\hline Ammophila albotomentosa & Ammophila & Ammophilini & Ammophilinae & Sphecidae \\
\hline Ammophila campestris & Ammophila & Ammophilini & Ammophilinae & Sphecidae \\
\hline Ammophila heydeni & Ammophila & Ammophilini & Ammophilinae & Sphecidae \\
\hline Ammophila holosericea & Ammophila & Ammophilini & Ammophilinae & Sphecidae \\
\hline Ammophila hungarica & Ammophila & Ammophilini & Ammophilinae & Sphecidae \\
\hline Ammophila laevicollis & Ammophila & Ammophilini & Ammophilinae & Sphecidae \\
\hline Ammophila leclercqi & Ammophila & Ammophilini & Ammophilinae & Sphecidae \\
\hline Ammophila modesta & Ammophila & Ammophilini & Ammophilinae & Sphecidae \\
\hline Ammophila sabulosa & Ammophila & Ammophilini & Ammophilinae & Sphecidae \\
\hline Ammophila striata & Ammophila & Ammophilini & Ammophilinae & Sphecidae \\
\hline Ammophila terminata mocsaryi & Ammophila & Ammophilini & Ammophilinae & Sphecidae \\
\hline Podalonia affinis & Podalonia & Ammophilini & Ammophilinae & Sphecidae \\
\hline Podalonia alpina & Podalonia & Ammophilini & Ammophilinae & Sphecidae \\
\hline Podalonia hirsuta & Podalonia & Ammophilini & Ammophilinae & Sphecidae \\
\hline Podalonia luffii & Podalonia & Ammophilini & Ammophilinae & Sphecidae \\
\hline Podalonia merceti & Podalonia & Ammophilini & Ammophilinae & Sphecidae \\
\hline Podalonia rothi & Podalonia & Ammophilini & Ammophilinae & Sphecidae \\
\hline Podalonia tydei & Podalonia & Ammophilini & Ammophilinae & Sphecidae \\
\hline
\end{tabular}




\begin{tabular}{|c|c|c|c|c|}
\hline Especies & Géneros & Tribus & Subfamilias & Familias \\
\hline Psenulus berlandi & Psenulus & Psenini & Pemphredoninae & Crabronidae \\
\hline Psenulus concolor & Psenulus & Psenini & Pemphredoninae & Crabronidae \\
\hline Psenulus fulvicornis & Psenulus & Psenini & Pemphredoninae & Crabronidae \\
\hline Psenulus fuscipennis & Psenulus & Psenini & Pemphredoninae & Crabronidae \\
\hline Psenulus hidalgo & Psenulus & Psenini & Pemphredoninae & Crabronidae \\
\hline Psenulus laevigatus & Psenulus & Psenini & Pemphredoninae & Crabronidae \\
\hline Psenulus meridionalis & Psenulus & Psenini & Pemphredoninae & Crabronidae \\
\hline Psenulus pallipes & Psenulus & Psenini & Pemphredoninae & Crabronidae \\
\hline Psenulus schencki & Psenulus & Psenini & Pemphredoninae & Crabronidae \\
\hline Psen ater & Psen & Psenini & Pemphredoninae & Crabronidae \\
\hline Pseneo exaratus & Pseneo & Psenini & Pemphredoninae & Crabronidae \\
\hline Mimesa bicolor & Mimesa & Psenini & Pemphredoninae & Crabronidae \\
\hline Mimesa crassipes & Mimesa & Psenini & Pemphredoninae & Crabronidae \\
\hline Mimesa equestris & Mimesa & Psenini & Pemphredoninae & Crabronidae \\
\hline Mimesa grandii & Mimesa & Psenini & Pemphredoninae & Crabronidae \\
\hline Mimesa lutaria & Mimesa & Psenini & Pemphredoninae & Crabronidae \\
\hline Mimumesa atratina & Mimumesa & Psenini & Pemphredoninae & Crabronidae \\
\hline Mimumesa dahlbomi & Mimumesa & Psenini & Pemphredoninae & Crabronidae \\
\hline Mimumesa unicolor & Mimumesa & Psenini & Pemphredoninae & Crabronidae \\
\hline Diodontus bejarensis & Diodontus & Pemphredonini & Pemphredoninae & Crabronidae \\
\hline Diodontus crassicornis & Diodontus & Pemphredonini & Pemphredoninae & Crabronidae \\
\hline Diodontus hyalipennis & Diodontus & Pemphredonini & Pemphredoninae & Crabronidae \\
\hline Diodontus insidiosus & Diodontus & Pemphredonini & Pemphredoninae & Crabronidae \\
\hline Diodontus luperus & Diodontus & Pemphredonini & Pemphredoninae & Crabronidae \\
\hline Diodontus medius & Diodontus & Pemphredonini & Pemphredoninae & Crabronidae \\
\hline Diodontus minutus & Diodontus & Pemphredonini & Pemphredoninae & Crabronidae \\
\hline Diodontus tristis & Diodontus & Pemphredonini & Pemphredoninae & Crabronidae \\
\hline Pemphredon austriaca & Pemphredon & Pemphredonini & Pemphredoninae & Crabronidae \\
\hline Pemphredon baltica & Pemphredon & Pemphredonini & Pemphredoninae & Crabronidae \\
\hline Pemphredon inornata & Pemphredon & Pemphredonini & Pemphredoninae & Crabronidae \\
\hline Pemphredon lethifer & Pemphredon & Pemphredonini & Pemphredoninae & Crabronidae \\
\hline Pemphredon lugens & Pemphredon & Pemphredonini & Pemphredoninae & Crabronidae \\
\hline Pemphredon lugubris & Pemphredon & Pemphredonini & Pemphredoninae & Crabronidae \\
\hline Pemphredon morio & Pemphredon & Pemphredonini & Pemphredoninae & Crabronidae \\
\hline Pemphredon mortifer & Pemphredon & Pemphredonini & Pemphredoninae & Crabronidae \\
\hline Pemphredon rugifer & Pemphredon & Pemphredonini & Pemphredoninae & Crabronidae \\
\hline Passaloecus australis & Passaloecus & Pemphredonini & Pemphredoninae & Crabronidae \\
\hline Passaloecus borealis & Passaloecus & Pemphredonini & Pemphredoninae & Crabronidae \\
\hline Passaloecus brevilabris & Passaloecus & Pemphredonini & Pemphredoninae & Crabronidae \\
\hline Passaloecus corniger & Passaloecus & Pemphredonini & Pemphredoninae & Crabronidae \\
\hline Passaloecus eremita & Passaloecus & Pemphredonini & Pemphredoninae & Crabronidae \\
\hline Passaloecus gracilis & Passaloecus & Pemphredonini & Pemphredoninae & Crabronidae \\
\hline Passaloecus insignis & Passaloecus & Pemphredonini & Pemphredoninae & Crabronidae \\
\hline Passaloecus monilicornis & Passaloecus & Pemphredonini & Pemphredoninae & Crabronidae \\
\hline Passaloecus pictus & Passaloecus & Pemphredonini & Pemphredoninae & Crabronidae \\
\hline Passaloecus singularis & Passaloecus & Pemphredonini & Pemphredoninae & Crabronidae \\
\hline Passaloecus turionum & Passaloecus & Pemphredonini & Pemphredoninae & Crabronidae \\
\hline Passaloecus vandeli & Passaloecus & Pemphredonini & Pemphredoninae & Crabronidae \\
\hline Stigmus pendulus & Stigmus & Pemphredonini & Pemphredoninae & Crabronidae \\
\hline Stigmus solskyi & Stigmus & Pemphredonini & Pemphredoninae & Crabronidae \\
\hline
\end{tabular}




\begin{tabular}{|c|c|c|c|c|}
\hline Especies & Géneros & Tribus & Subfamilias & Familias \\
\hline Carinostigmus hispanicus & Carinostigmus & Pemphredonini & Pemphredoninae & Crabronidae \\
\hline Spilomena beata & Spilomena & Pemphredonini & Pemphredoninae & Crabronidae \\
\hline Spilomena curruca & Spilomena & Pemphredonini & Pemphredoninae & Crabronidae \\
\hline Spilomena maghrebensis & Spilomena & Pemphredonini & Pemphredoninae & Crabronidae \\
\hline Spilomena mocsaryi & Spilomena & Pemphredonini & Pemphredoninae & Crabronidae \\
\hline Spilomena troglodytes & Spilomena & Pemphredonini & Pemphredoninae & Crabronidae \\
\hline Ammoplanus bischoffi & Ammoplanus & Pemphredonini & Pemphredoninae & Crabronidae \\
\hline Ammoplanus blascoi & Ammoplanus & Pemphredonini & Pemphredoninae & Crabronidae \\
\hline Ammoplanus ceballosi & Ammoplanus & Pemphredonini & Pemphredoninae & Crabronidae \\
\hline Ammoplanus dusmeti & Ammoplanus & Pemphredonini & Pemphredoninae & Crabronidae \\
\hline Ammoplanus gegen & Ammoplanus & Pemphredonini & Pemphredoninae & Crabronidae \\
\hline Ammoplanus insularis & Ammoplanus & Pemphredonini & Pemphredoninae & Crabronidae \\
\hline Ammoplanus kaszabi & Ammoplanus & Pemphredonini & Pemphredoninae & Crabronidae \\
\hline Ammoplanus kohlii & Ammoplanus & Pemphredonini & Pemphredoninae & Crabronidae \\
\hline Ammoplanus marathroicus & Ammoplanus & Pemphredonini & Pemphredoninae & Crabronidae \\
\hline Ammoplanus nanus & Ammoplanus & Pemphredonini & Pemphredoninae & Crabronidae \\
\hline Ammoplanus perrisi & Ammoplanus & Pemphredonini & Pemphredoninae & Crabronidae \\
\hline Ammoplanus rhodesianus & Ammoplanus & Pemphredonini & Pemphredoninae & Crabronidae \\
\hline Ammoplanus torresi & Ammoplanus & Pemphredonini & Pemphredoninae & Crabronidae \\
\hline Astata affinis & Astata & Astatini & Astatinae & Crabronidae \\
\hline Astata apostata & Astata & Astatini & Astatinae & Crabronidae \\
\hline Astata boops & Astata & Astatini & Astatinae & Crabronidae \\
\hline Astata cobosi & Astata & Astatini & Astatinae & Crabronidae \\
\hline Astata costae & Astata & Astatini & Astatinae & Crabronidae \\
\hline Astata gallica & Astata & Astatini & Astatinae & Crabronidae \\
\hline Astata kashmirensis & Astata & Astatini & Astatinae & Crabronidae \\
\hline Astata lusitanica & Astata & Astatini & Astatinae & Crabronidae \\
\hline Astata miegii & Astata & Astatini & Astatinae & Crabronidae \\
\hline Astata minor & Astata & Astatini & Astatinae & Crabronidae \\
\hline Astata rufipes & Astata & Astatini & Astatinae & Crabronidae \\
\hline Dryudella aquitana & Dryudella & Astatini & Astatinae & Crabronidae \\
\hline Dryudella bifasciata & Dryudella & Astatini & Astatinae & Crabronidae \\
\hline Dryudella erythrosoma & Dryudella & Astatini & Astatinae & Crabronidae \\
\hline Dryudella monticola & Dryudella & Astatini & Astatinae & Crabronidae \\
\hline Dryudella stigma & Dryudella & Astatini & Astatinae & Crabronidae \\
\hline Dryudella tricolor & Dryudella & Astatini & Astatinae & Crabronidae \\
\hline Dinetus pictus & Dinetus & Dinetini & Dinetinae & Crabronidae \\
\hline Larra anathema & Larra & Larrini & Crabroninae & Crabronidae \\
\hline Liris atratus & Larra & Larrini & Crabroninae & Crabronidae \\
\hline Liris festinans praetermissus & Liris & Larrini & Crabroninae & Crabronidae \\
\hline Liris haemorrhoidalis & Liris & Larrini & Crabroninae & Crabronidae \\
\hline Liris micans & Liris & Larrini & Crabroninae & Crabronidae \\
\hline Liris niger & Liris & Larrini & Crabroninae & Crabronidae \\
\hline Liris nigricans & Liris & Larrini & Crabroninae & Crabronidae \\
\hline Larropsis europaea & Larropsis & Larrini & Crabroninae & Crabronidae \\
\hline Larropsis punctulata & Larropsis & Larrini & Crabroninae & Crabronidae \\
\hline Tachytes etruscus & Tachytes & Larrini & Crabroninae & Crabronidae \\
\hline Tachytes freygessneri & Tachytes & Larrini & Crabroninae & Crabronidae \\
\hline Tachytes matronalis & Tachytes & Larrini & Crabroninae & Crabronidae \\
\hline Tachytes obsoletus & Tachytes & Larrini & Crabroninae & Crabronidae \\
\hline
\end{tabular}

Continúa 


\begin{tabular}{|c|c|c|c|c|}
\hline Especies & Géneros & Tribus & Subfamilias & Familias \\
\hline Tachytes panzeri & Tachytes & Larrini & Crabroninae & Crabronidae \\
\hline Tachytes procerus & Tachytes & Larrini & Crabroninae & Crabronidae \\
\hline Tachysphex adjunctus & Tachysphex & Larrini & Crabroninae & Crabronidae \\
\hline Tachysphex albocincta & Tachysphex & Larrini & Crabroninae & Crabronidae \\
\hline Tachysphex blattivorus & Tachysphex & Larrini & Crabroninae & Crabronidae \\
\hline Tachysphex brevipennis & Tachysphex & Larrini & Crabroninae & Crabronidae \\
\hline Tachysphex brullii & Tachysphex & Larrini & Crabroninae & Crabronidae \\
\hline Tachysphex carli & Tachysphex & Larrini & Crabroninae & Crabronidae \\
\hline Tachysphex consocius & Tachysphex & Larrini & Crabroninae & Crabronidae \\
\hline Tachysphex coriaceus & Tachysphex & Larrini & Crabroninae & Crabronidae \\
\hline Tachysphex costae & Tachysphex & Larrini & Crabroninae & Crabronidae \\
\hline Tachysphex denisi & Tachysphex & Larrini & Crabroninae & Crabronidae \\
\hline Tachysphex descendentis & Tachysphex & Larrini & Crabroninae & Crabronidae \\
\hline Tachysphex erythropus & Tachysphex & Larrini & Crabroninae & Crabronidae \\
\hline Tachysphex excelsus & Tachysphex & Larrini & Crabroninae & Crabronidae \\
\hline Tachysphex fugax & Tachysphex & Larrini & Crabroninae & Crabronidae \\
\hline Tachysphex fulvitarsis & Tachysphex & Larrini & Crabroninae & Crabronidae \\
\hline Tachysphex gracilitarsis & Tachysphex & Larrini & Crabroninae & Crabronidae \\
\hline Tachysphex helveticus & Tachysphex & Larrini & Crabroninae & Crabronidae \\
\hline Tachysphex incertus & Tachysphex & Larrini & Crabroninae & Crabronidae \\
\hline Tachysphex julliani & Tachysphex & Larrini & Crabroninae & Crabronidae \\
\hline Tachysphex mediterraneus & Tachysphex & Larrini & Crabroninae & Crabronidae \\
\hline Tachysphex mocsaryi & Tachysphex & Larrini & Crabroninae & Crabronidae \\
\hline Tachysphex nitidior & Tachysphex & Larrini & Crabroninae & Crabronidae \\
\hline Tachysphex nitidus & Tachysphex & Larrini & Crabroninae & Crabronidae \\
\hline Tachysphex obscuripennis & Tachysphex & Larrini & Crabroninae & Crabronidae \\
\hline Tachysphex panzeri & Tachysphex & Larrini & Crabroninae & Crabronidae \\
\hline Tachysphex plicosus & Tachysphex & Larrini & Crabroninae & Crabronidae \\
\hline Tachysphex pompiliformis & Tachysphex & Larrini & Crabroninae & Crabronidae \\
\hline Tachysphex psammobius & Tachysphex & Larrini & Crabroninae & Crabronidae \\
\hline Tachysphex pseudopanzeri & Tachysphex & Larrini & Crabroninae & Crabronidae \\
\hline Tachysphex saundersi & Tachysphex & Larrini & Crabroninae & Crabronidae \\
\hline Tachysphex schmiedeknechti & Tachysphex & Larrini & Crabroninae & Crabronidae \\
\hline Tachysphex tarsinus & Tachysphex & Larrini & Crabroninae & Crabronidae \\
\hline Tachysphex unicolor & Tachysphex & Larrini & Crabroninae & Crabronidae \\
\hline Prosopigastra handlirschi & Prosopigastra & Larrini & Crabroninae & Crabronidae \\
\hline Prosopigastra kohli & Prosopigastra & Larrini & Crabroninae & Crabronidae \\
\hline Prosopigastra punctatissima & Prosopigastra & Larrini & Crabroninae & Crabronidae \\
\hline Prosopigastra zalinda & Prosopigastra & Larrini & Crabroninae & Crabronidae \\
\hline Palarus almeriensis & Palarus & Palarini & Crabroninae & Crabronidae \\
\hline Palarus variegatus & Palarus & Palarini & Crabroninae & Crabronidae \\
\hline Plenoculus beaumonti & Plenoculus & Miscophini & Crabroninae & Crabronidae \\
\hline Solierella compedita & Solierella & Miscophini & Crabroninae & Crabronidae \\
\hline Solierella insidiosa & Solierella & Miscophini & Crabroninae & Crabronidae \\
\hline Solierella pisonoides & Solierella & Miscophini & Crabroninae & Crabronidae \\
\hline Solierella seabrai & Solierella & Miscophini & Crabroninae & Crabronidae \\
\hline Solierella verhoeffi & Solierella & Miscophini & Crabroninae & Crabronidae \\
\hline Miscophus albufeirae & Miscophus & Miscophini & Crabroninae & Crabronidae \\
\hline Miscophus andradei & Miscophus & Miscophini & Crabroninae & Crabronidae \\
\hline Miscophus ater & Miscophus & Miscophini & Crabroninae & Crabronidae \\
\hline
\end{tabular}

Continúa 


\begin{tabular}{|c|c|c|c|c|}
\hline Especies & Géneros & Tribus & Subfamilias & Familias \\
\hline Miscophus benidormicus & Miscophus & Miscophini & Crabroninae & Crabronidae \\
\hline Miscophus bicolor & Miscophus & Miscophini & Crabroninae & Crabronidae \\
\hline Miscophus bonifaciensis & Miscophus & Miscophini & Crabroninae & Crabronidae \\
\hline Miscophus concolor & Miscophus & Miscophini & Crabroninae & Crabronidae \\
\hline Miscophus eatoni & Miscophus & Miscophini & Crabroninae & Crabronidae \\
\hline Miscophus gineri & Miscophus & Miscophini & Crabroninae & Crabronidae \\
\hline Miscophus helveticus & Miscophus & Miscophini & Crabroninae & Crabronidae \\
\hline Miscophus lusitanicus & Miscophus & Miscophini & Crabroninae & Crabronidae \\
\hline Miscophus merceti & Miscophus & Miscophini & Crabroninae & Crabronidae \\
\hline Miscophus nevesi & Miscophus & Miscophini & Crabroninae & Crabronidae \\
\hline Miscophus nicolai & Miscophus & Miscophini & Crabroninae & Crabronidae \\
\hline Miscophus niger & Miscophus & Miscophini & Crabroninae & Crabronidae \\
\hline Miscophus portoi & Miscophus & Miscophini & Crabroninae & Crabronidae \\
\hline Miscophus spurius & Miscophus & Miscophini & Crabroninae & Crabronidae \\
\hline Miscophus verhoeffi & Miscophus & Miscophini & Crabroninae & Crabronidae \\
\hline Nitela blascoi & Nitela & Miscophini & Crabroninae & Crabronidae \\
\hline Nitela borealis & Nitela & Miscophini & Crabroninae & Crabronidae \\
\hline Nitela fallax & Nitela & Miscophini & Crabroninae & Crabronidae \\
\hline Nitela lucens & Nitela & Miscophini & Crabroninae & Crabronidae \\
\hline Nitela spinolae & Nitela & Miscophini & Crabroninae & Crabronidae \\
\hline Nitela truncata & Nitela & Miscophini & Crabroninae & Crabronidae \\
\hline Pison atrum & Pison & Trypoxylini & Crabroninae & Crabronidae \\
\hline Trypoxylon albipes & Trypoxylon & Trypoxylini & Crabroninae & Crabronidae \\
\hline Trypoxylon attenuatum & Trypoxylon & Trypoxylini & Crabroninae & Crabronidae \\
\hline Trypoxylon beaumonti & Trypoxylon & Trypoxylini & Crabroninae & Crabronidae \\
\hline Trypoxylon clavicerum & Trypoxylon & Trypoxylini & Crabroninae & Crabronidae \\
\hline Trypoxylon deceptorium & Trypoxylon & Trypoxylini & Crabroninae & Crabronidae \\
\hline Trypoxylon figulus & Trypoxylon & Trypoxylini & Crabroninae & Crabronidae \\
\hline Trypoxylon fronticorne & Trypoxylon & Trypoxylini & Crabroninae & Crabronidae \\
\hline Trypoxylon kolazyi & Trypoxylon & Trypoxylini & Crabroninae & Crabronidae \\
\hline Trypoxylon latilobatum & Trypoxylon & Trypoxylini & Crabroninae & Crabronidae \\
\hline Trypoxylon medium & Trypoxylon & Trypoxylini & Crabroninae & Crabronidae \\
\hline Trypoxylon minus & Trypoxylon & Trypoxylini & Crabroninae & Crabronidae \\
\hline Trypoxylon scutatum & Trypoxylon & Trypoxylini & Crabroninae & Crabronidae \\
\hline Belomicrus gataensis & Belomicrus & Oxybelini & Crabroninae & Crabronidae \\
\hline Belomicrus italicus & Belomicrus & Oxybelini & Crabroninae & Crabronidae \\
\hline Belomicrus odonthophorus & Belomicrus & Oxybelini & Crabroninae & Crabronidae \\
\hline Oxybelomorpha steckii & Oxybelomorpha & Oxybelini & Crabroninae & Crabronidae \\
\hline Oxybelus argentatus & Oxybelus & Oxybelini & Crabroninae & Crabronidae \\
\hline Oxybelus aurantiacus & Oxybelus & Oxybelini & Crabroninae & Crabronidae \\
\hline Oxybelus bipunctatus & Oxybelus & Oxybelini & Crabroninae & Crabronidae \\
\hline Oxybelus diphyllus & Oxybelus & Oxybelini & Crabroninae & Crabronidae \\
\hline Oxybelus dissectus & Oxybelus & Oxybelini & Crabroninae & Crabronidae \\
\hline Oxybelus dusmeti & Oxybelus & Oxybelini & Crabroninae & Crabronidae \\
\hline Oxybelus fischeri & Oxybelus & Oxybelini & Crabroninae & Crabronidae \\
\hline Oxybelus haemorrhoidalis & Oxybelus & Oxybelini & Crabroninae & Crabronidae \\
\hline Oxybelus hastatus & Oxybelus & Oxybelini & Crabroninae & Crabronidae \\
\hline Oxybelus lamellatus andalusiacus & Oxybelus & Oxybelini & Crabroninae & Crabronidae \\
\hline Oxybelus latro & Oxybelus & Oxybelini & Crabroninae & Crabronidae \\
\hline Oxybelus lineatus & Oxybelus & Oxybelini & Crabroninae & Crabronidae \\
\hline
\end{tabular}




\begin{tabular}{|c|c|c|c|c|}
\hline Especies & Géneros & Tribus & Subfamilias & Familias \\
\hline Oxybelus mandibularis & Oxybelus & Oxybelini & Crabroninae & Crabronidae \\
\hline Oxybelus mucronatus & Oxybelus & Oxybelini & Crabroninae & Crabronidae \\
\hline Oxybelus occitanicus & Oxybelus & Oxybelini & Crabroninae & Crabronidae \\
\hline Oxybelus quattuordecimnotatus & Oxybelus & Oxybelini & Crabroninae & Crabronidae \\
\hline Oxybelus spectabilis & Oxybelus & Oxybelini & Crabroninae & Crabronidae \\
\hline Oxybelus subspinosus & Oxybelus & Oxybelini & Crabroninae & Crabronidae \\
\hline Oxybelus trispinosa & Oxybelus & Oxybelini & Crabroninae & Crabronidae \\
\hline Oxybelus uniglumis & Oxybelus & Oxybelini & Crabroninae & Crabronidae \\
\hline Oxybelus variegatus & Oxybelus & Oxybelini & Crabroninae & Crabronidae \\
\hline Encopognathus braunsi & Encopognathus & Crabronini & Crabroninae & Crabronidae \\
\hline Entomognathus brevis & Entomognathus & Crabronini & Crabroninae & Crabronidae \\
\hline Entomognathus dentifer & Entomognathus & Crabronini & Crabroninae & Crabronidae \\
\hline Entomognathus fortuitus & Entomognathus & Crabronini & Crabroninae & Crabronidae \\
\hline Lindenius aegyptius & Lindenius & Crabronini & Crabroninae & Crabronidae \\
\hline Lindenius albilabris & Lindenius & Crabronini & Crabroninae & Crabronidae \\
\hline Lindenius cabrerae & Lindenius & Crabronini & Crabroninae & Crabronidae \\
\hline Lindenius ceballosi & Lindenius & Crabronini & Crabroninae & Crabronidae \\
\hline Lindenius hannibal & Lindenius & Crabronini & Crabroninae & Crabronidae \\
\hline Lindenius ibericus & Lindenius & Crabronini & Crabroninae & Crabronidae \\
\hline Lindenius luteiventris & Lindenius & Crabronini & Crabroninae & Crabronidae \\
\hline Lindenius major & Lindenius & Crabronini & Crabroninae & Crabronidae \\
\hline Lindenius melinopus & Lindenius & Crabronini & Crabroninae & Crabronidae \\
\hline Lindenius merceti & Lindenius & Crabronini & Crabroninae & Crabronidae \\
\hline Lindenius mesopleuralis & Lindenius & Crabronini & Crabroninae & Crabronidae \\
\hline Lindenius panzeri & Lindenius & Crabronini & Crabroninae & Crabronidae \\
\hline Lindenius peninsularis & Lindenius & Crabronini & Crabroninae & Crabronidae \\
\hline Lindenius pygmaeus & Lindenius & Crabronini & Crabroninae & Crabronidae \\
\hline Lindenius sierrae & Lindenius & Crabronini & Crabroninae & Crabronidae \\
\hline Lindenius spilostomus & Lindenius & Crabronini & Crabroninae & Crabronidae \\
\hline Lindenius subaeneus & Lindenius & Crabronini & Crabroninae & Crabronidae \\
\hline Rhopalum clavipes & Rhopalum & Crabronini & Crabroninae & Crabronidae \\
\hline Rhopalum coarctatum & Rhopalum & Crabronini & Crabroninae & Crabronidae \\
\hline Rhopalum gracile & Rhopalum & Crabronini & Crabroninae & Crabronidae \\
\hline Crossocerus acanthophorus & Crossocerus & Crabronini & Crabroninae & Crabronidae \\
\hline Crossocerus annulipes & Crossocerus & Crabronini & Crabroninae & Crabronidae \\
\hline Crossocerus assimilis & Crossocerus & Crabronini & Crabroninae & Crabronidae \\
\hline Crossocerus barbipes & Crossocerus & Crabronini & Crabroninae & Crabronidae \\
\hline Crossocerus binotatus & Crossocerus & Crabronini & Crabroninae & Crabronidae \\
\hline Crossocerus capitosus & Crossocerus & Crabronini & Crabroninae & Crabronidae \\
\hline Crossocerus cetratus & Crossocerus & Crabronini & Crabroninae & Crabronidae \\
\hline Crossocerus denticrus & Crossocerus & Crabronini & Crabroninae & Crabronidae \\
\hline Crossocerus dimidiatus & Crossocerus & Crabronini & Crabroninae & Crabronidae \\
\hline Crossocerus distinguendus & Crossocerus & Crabronini & Crabroninae & Crabronidae \\
\hline Crossocerus elongatulus & Crossocerus & Crabronini & Crabroninae & Crabronidae \\
\hline Crossocerus leucostoma & Crossocerus & Crabronini & Crabroninae & Crabronidae \\
\hline Crossocerus megacephalus & Crossocerus & Crabronini & Crabroninae & Crabronidae \\
\hline Crossocerus nigritus & Crossocerus & Crabronini & Crabroninae & Crabronidae \\
\hline Crossocerus ovalis & Crossocerus & Crabronini & Crabroninae & Crabronidae \\
\hline Crossocerus podagricus & Crossocerus & Crabronini & Crabroninae & Crabronidae \\
\hline Crossocerus quadrimaculatus & Crossocerus & Crabronini & Crabroninae & Crabronidae \\
\hline
\end{tabular}




\begin{tabular}{|c|c|c|c|c|}
\hline Especies & Géneros & Tribus & Subfamilias & Familias \\
\hline Crossocerus styrius & Crossocerus & Crabronini & Crabroninae & Crabronidae \\
\hline Crossocerus tarsatus & Crossocerus & Crabronini & Crabroninae & Crabronidae \\
\hline Crossocerus toledensis & Crossocerus & Crabronini & Crabroninae & Crabronidae \\
\hline Crossocerus vagabundus & Crossocerus & Crabronini & Crabroninae & Crabronidae \\
\hline Crossocerus varus & Crossocerus & Crabronini & Crabroninae & Crabronidae \\
\hline Crossocerus wesmaeli & Crossocerus & Crabronini & Crabroninae & Crabronidae \\
\hline Tracheliodes quinquenotatus & Tracheliodes & Crabronini & Crabroninae & Crabronidae \\
\hline Crabro alpinus & Crabro & Crabronini & Crabroninae & Crabronidae \\
\hline Crabro cribrarius & Crabro & Crabronini & Crabroninae & Crabronidae \\
\hline Crabro korbi & Crabro & Crabronini & Crabroninae & Crabronidae \\
\hline Crabro lapponicus & Crabro & Crabronini & Crabroninae & Crabronidae \\
\hline Crabro peltarius & Crabro & Crabronini & Crabroninae & Crabronidae \\
\hline Crabro peltatus & Crabro & Crabronini & Crabroninae & Crabronidae \\
\hline Crabro pugillator & Crabro & Crabronini & Crabroninae & Crabronidae \\
\hline Ectemnius borealis & Ectemnius & Crabronini & Crabroninae & Crabronidae \\
\hline Ectemnius cavifrons & Ectemnius & Crabronini & Crabroninae & Crabronidae \\
\hline Ectemnius cephalotes & Ectemnius & Crabronini & Crabroninae & Crabronidae \\
\hline Ectemnius confinis & Ectemnius & Crabronini & Crabroninae & Crabronidae \\
\hline Ectemnius continuus & Ectemnius & Crabronini & Crabroninae & Crabronidae \\
\hline Ectemnius crassicornis & Ectemnius & Crabronini & Crabroninae & Crabronidae \\
\hline Ectemnius dives & Ectemnius & Crabronini & Crabroninae & Crabronidae \\
\hline Ectemnius fossorius & Ectemnius & Crabronini & Crabroninae & Crabronidae \\
\hline Ectemnius guttatus & Ectemnius & Crabronini & Crabroninae & Crabronidae \\
\hline Ectemnius hispanicus & Ectemnius & Crabronini & Crabroninae & Crabronidae \\
\hline Ectemnius hypsae & Ectemnius & Crabronini & Crabroninae & Crabronidae \\
\hline Ectemnius kriechbaumeri & Ectemnius & Crabronini & Crabroninae & Crabronidae \\
\hline Ectemnius lapidarius & Ectemnius & Crabronini & Crabroninae & Crabronidae \\
\hline Ectemnius lituratus & Ectemnius & Crabronini & Crabroninae & Crabronidae \\
\hline Ectemnius massiliensis & Ectemnius & Crabronini & Crabroninae & Crabronidae \\
\hline Ectemnius meridionalis & Ectemnius & Crabronini & Crabroninae & Crabronidae \\
\hline Ectemnius nigritarsus & Ectemnius & Crabronini & Crabroninae & Crabronidae \\
\hline Ectemnius palamosi & Ectemnius & Crabronini & Crabroninae & Crabronidae \\
\hline Ectemnius rubicola & Ectemnius & Crabronini & Crabroninae & Crabronidae \\
\hline Ectemnius ruficornis & Ectemnius & Crabronini & Crabroninae & Crabronidae \\
\hline Ectemnius rugifer & Ectemnius & Crabronini & Crabroninae & Crabronidae \\
\hline Ectemnius sexcinctus & Ectemnius & Crabronini & Crabroninae & Crabronidae \\
\hline Lestica alata & Lestica & Crabronini & Crabroninae & Crabronidae \\
\hline Lestica clypeata & Lestica & Crabronini & Crabroninae & Crabronidae \\
\hline Lestica pluschtschevskyi & Lestica & Crabronini & Crabroninae & Crabronidae \\
\hline Lestica subterranea & Lestica & Crabronini & Crabroninae & Crabronidae \\
\hline Mellinus arvensis & Mellinus & Mellinini & Mellininae & Crabronidae \\
\hline Mellinus crabroneus & Mellinus & Mellinini & Mellininae & Crabronidae \\
\hline Nysson alicantinus & Nysson & Nyssonini & Bembicinae & Crabronidae \\
\hline Nysson castellanus & Nysson & Nyssonini & Bembicinae & Crabronidae \\
\hline Nysson dimidiatus & Nysson & Nyssonini & Bembicinae & Crabronidae \\
\hline Nysson dusmeti & Nysson & Nyssonini & Bembicinae & Crabronidae \\
\hline Nysson fraternus & Nysson & Nyssonini & Bembicinae & Crabronidae \\
\hline Nysson fulvipes & Nysson & Nyssonini & Bembicinae & Crabronidae \\
\hline Nysson ibericus & Nysson & Nyssonini & Bembicinae & Crabronidae \\
\hline Nysson interruptus & Nysson & Nyssonini & Bembicinae & Crabronidae \\
\hline
\end{tabular}




\begin{tabular}{|c|c|c|c|c|}
\hline Especies & Géneros & Tribus & Subfamilias & Familias \\
\hline Nysson konowi & Nysson & Nyssonini & Bembicinae & Crabronidae \\
\hline Nysson laufferi & Nysson & Nyssonini & Bembicinae & Crabronidae \\
\hline Nysson maculosus & Nysson & Nyssonini & Bembicinae & Crabronidae \\
\hline Nysson miegi & Nysson & Nyssonini & Bembicinae & Crabronidae \\
\hline Nysson militaris & Nysson & Nyssonini & Bembicinae & Crabronidae \\
\hline Nysson monachus & Nysson & Nyssonini & Bembicinae & Crabronidae \\
\hline Nysson parietalis & Nysson & Nyssonini & Bembicinae & Crabronidae \\
\hline Nysson pratensis & Nysson & Nyssonini & Bembicinae & Crabronidae \\
\hline Nysson spinosus & Nysson & Nyssonini & Bembicinae & Crabronidae \\
\hline Nysson tridens & Nysson & Nyssonini & Bembicinae & Crabronidae \\
\hline Nysson trimaculatus & Nysson & Nyssonini & Bembicinae & Crabronidae \\
\hline Nysson varelai & Nysson & Nyssonini & Bembicinae & Crabronidae \\
\hline Nysson variabilis & Nysson & Nyssonini & Bembicinae & Crabronidae \\
\hline Brachystegus scalaris & Brachystegus & Nyssonini & Bembicinae & Crabronidae \\
\hline Alysson spinosus & Alysson & Alyssontini & Bembicinae & Crabronidae \\
\hline Alysson tricolor & Alysson & Alyssontini & Bembicinae & Crabronidae \\
\hline Didineis crassicornis & Didineis & Alyssontini & Bembicinae & Crabronidae \\
\hline Didineis hispanica & Didineis & Alyssontini & Bembicinae & Crabronidae \\
\hline Didineis lunicornis & Didineis & Alyssontini & Bembicinae & Crabronidae \\
\hline Argogorytes fargeii & Argogorytes & Bembicini & Bembicinae & Crabronidae \\
\hline Argogorytes hispanicus & Argogorytes & Bembicini & Bembicinae & Crabronidae \\
\hline Argogorytes mystaceus & Argogorytes & Bembicini & Bembicinae & Crabronidae \\
\hline Gorytes africanus & Gorytes & Bembicini & Bembicinae & Crabronidae \\
\hline Gorytes albidulus & Gorytes & Bembicini & Bembicinae & Crabronidae \\
\hline Gorytes fallax & Gorytes & Bembicini & Bembicinae & Crabronidae \\
\hline Gorytes foveolatus dichrous & Gorytes & Bembicini & Bembicinae & Crabronidae \\
\hline Gorytes laticinctus & Gorytes & Bembicini & Bembicinae & Crabronidae \\
\hline Gorytes nigrifacies & Gorytes & Bembicini & Bembicinae & Crabronidae \\
\hline Gorytes planifrons & Gorytes & Bembicini & Bembicinae & Crabronidae \\
\hline Gorytes pleuripunctatus & Gorytes & Bembicini & Bembicinae & Crabronidae \\
\hline Gorytes procrustes & Gorytes & Bembicini & Bembicinae & Crabronidae \\
\hline Gorytes quadrifasciatus & Gorytes & Bembicini & Bembicinae & Crabronidae \\
\hline Gorytes quinquecinctus & Gorytes & Bembicini & Bembicinae & Crabronidae \\
\hline Gorytes quinquefasciatus & Gorytes & Bembicini & Bembicinae & Crabronidae \\
\hline Gorytes sulcifrons & Gorytes & Bembicini & Bembicinae & Crabronidae \\
\hline Harpactus alvaroi & Harpactus & Bembicini & Bembicinae & Crabronidae \\
\hline Harpactus elegans & Harpactus & Bembicini & Bembicinae & Crabronidae \\
\hline Harpactus exiguus & Harpactus & Bembicini & Bembicinae & Crabronidae \\
\hline Harpactus formosus & Harpactus & Bembicini & Bembicinae & Crabronidae \\
\hline Harpactus laevis & Harpactus & Bembicini & Bembicinae & Crabronidae \\
\hline Harpactus morawitzi & Harpactus & Bembicini & Bembicinae & Crabronidae \\
\hline Harpactus quadrisignatus & Harpactus & Bembicini & Bembicinae & Crabronidae \\
\hline Harpactus tumidus & Harpactus & Bembicini & Bembicinae & Crabronidae \\
\hline Hoplisoides craverii & Hoplisoides & Bembicini & Bembicinae & Crabronidae \\
\hline Hoplisoides latifrons & Hoplisoides & Bembicini & Bembicinae & Crabronidae \\
\hline Hoplisoides punctuosus & Hoplisoides & Bembicini & Bembicinae & Crabronidae \\
\hline Lestiphorus bicinctus & Lestiphorus & Bembicini & Bembicinae & Crabronidae \\
\hline Oryttus concinnus & Oryttus & Bembicini & Bembicinae & Crabronidae \\
\hline Psammaecius punctulatus & Psammaecius & Bembicini & Bembicinae & Crabronidae \\
\hline Ammatomus coarctatus & Ammatomus & Bembicini & Bembicinae & Crabronidae \\
\hline
\end{tabular}




\begin{tabular}{|c|c|c|c|c|}
\hline Especies & Géneros & Tribus & Subfamilias & Familias \\
\hline Sphecius nigricornis & Sphecius & Bembicini & Bembicinae & Crabronidae \\
\hline Bembecinus carpetanus & Bembecinus & Bembicini & Bembicinae & Crabronidae \\
\hline Bembecinus crassipes & Bembecinus & Bembicini & Bembicinae & Crabronidae \\
\hline Bembecinus hungaricus & Bembecinus & Bembicini & Bembicinae & Crabronidae \\
\hline Bembecinus pulchellus & Bembecinus & Bembicini & Bembicinae & Crabronidae \\
\hline Bembecinus tridens & Bembecinus & Bembicini & Bembicinae & Crabronidae \\
\hline Stizus aestivalis & Stizus & Bembicini & Bembicinae & Crabronidae \\
\hline Stizus continuus & Stizus & Bembicini & Bembicinae & Crabronidae \\
\hline Stizus fasciatus & Stizus & Bembicini & Bembicinae & Crabronidae \\
\hline Stizus hispanicus & Stizus & Bembicini & Bembicinae & Crabronidae \\
\hline Stizus perrisi ibericus & Stizus & Bembicini & Bembicinae & Crabronidae \\
\hline Stizus pubescens & Stizus & Bembicini & Bembicinae & Crabronidae \\
\hline Stizus ruficornis & Stizus & Bembicini & Bembicinae & Crabronidae \\
\hline Stizoides crassicornis & Stizoides & Bembicini & Bembicinae & Crabronidae \\
\hline Stizoides tridentatus & Stizoides & Bembicini & Bembicinae & Crabronidae \\
\hline Bembix bidentata & Bembix & Bembicini & Bembicinae & Crabronidae \\
\hline Bembix flavescens bolivari & Bembix & Bembicini & Bembicinae & Crabronidae \\
\hline Bembix merceti & Bembix & Bembicini & Bembicinae & Crabronidae \\
\hline Bembix oculata & Bembix & Bembicini & Bembicinae & Crabronidae \\
\hline Bembix olivacea & Bembix & Bembicini & Bembicinae & Crabronidae \\
\hline Bembix rostrata & Bembix & Bembicini & Bembicinae & Crabronidae \\
\hline Bembix sinuata & Bembix & Bembicini & Bembicinae & Crabronidae \\
\hline Bembix tarsata & Bembix & Bembicini & Bembicinae & Crabronidae \\
\hline Bembix zonata & Bembix & Bembicini & Bembicinae & Crabronidae \\
\hline Philanthus coronatus ibericus & Philanthus & Philanthini & Philanthinae & Crabronidae \\
\hline Philanthus dufourii & Philanthus & Philanthini & Philanthinae & Crabronidae \\
\hline Philanthus pulchellus & Philanthus & Philanthini & Philanthinae & Crabronidae \\
\hline Philanthus sculpturatus & Philanthus & Philanthini & Philanthinae & Crabronidae \\
\hline Philanthus triangulum & Philanthus & Philanthini & Philanthinae & Crabronidae \\
\hline Philanthus venustus & Philanthus & Philanthini & Philanthinae & Crabronidae \\
\hline Pseudoscolia martinezi & Pseudoscolia & Pseudoscoliini & Philanthinae & Crabronidae \\
\hline Cerceris abdominalis & Cerceris & Cercerini & Philanthinae & Crabronidae \\
\hline Cerceris albofasciata & Cerceris & Cercerini & Philanthinae & Crabronidae \\
\hline Cerceris arenaria & Cerceris & Cercerini & Philanthinae & Crabronidae \\
\hline Cerceris bellona & Cerceris & Cercerini & Philanthinae & Crabronidae \\
\hline Cerceris bicincta & Cerceris & Cercerini & Philanthinae & Crabronidae \\
\hline Cerceris boetica & Cerceris & Cercerini & Philanthinae & Crabronidae \\
\hline Cerceris bupresticida & Cerceris & Cercerini & Philanthinae & Crabronidae \\
\hline Cerceris circularis dacica & Cerceris & Cercerini & Philanthinae & Crabronidae \\
\hline Cerceris dusmeti & Cerceris & Cercerini & Philanthinae & Crabronidae \\
\hline Cerceris eryngii & Cerceris & Cercerini & Philanthinae & Crabronidae \\
\hline Cerceris fimbriata & Cerceris & Cercerini & Philanthinae & Crabronidae \\
\hline Cerceris flavicornis & Cerceris & Cercerini & Philanthinae & Crabronidae \\
\hline Cerceris flavilabris & Cerceris & Cercerini & Philanthinae & Crabronidae \\
\hline Cerceris flaviventris & Cerceris & Cercerini & Philanthinae & Crabronidae \\
\hline Cerceris hortivaga & Cerceris & Cercerini & Philanthinae & Crabronidae \\
\hline Cerceris ibericella & Cerceris & Cercerini & Philanthinae & Crabronidae \\
\hline Cerceris interrupta & Cerceris & Cercerini & Philanthinae & Crabronidae \\
\hline Cerceris lunata & Cerceris & Cercerini & Philanthinae & Crabronidae \\
\hline Cerceris media & Cerceris & Cercerini & Philanthinae & Crabronidae \\
\hline
\end{tabular}




\begin{tabular}{|l|l|l|l|l|}
\hline Especies & Géneros & Tribus & Subfamilias & Familias \\
\hline Cerceris quadricincta & Cerceris & Cercerini & Philanthinae & Crabronidae \\
\hline Cerceris quadrifasciatus & Cerceris & Cercerini & Philanthinae & Crabronidae \\
\hline Cerceris quinquefasciatus & Cerceris & Cercerini & Philanthinae & Crabronidae \\
\hline Cerceris rubida & Cerceris & Cercerini & Philanthinae & Crabronidae \\
\hline Cerceris ruficornis & Cerceris & Cercerini & Philanthinae & Crabronidae \\
\hline Cerceris rufiventris & Cerceris & Cercerini & Philanthinae & Crabronidae \\
\hline Cerceris rutila lindenii & Cerceris & Cercerini & Philanthinae & Crabronidae \\
\hline Cerceris rybyensis & Cerceris & Cercerini & Philanthinae & Crabronidae \\
\hline Cerceris sabulosa & Cerceris & Cercerini & Philanthinae & Crabronidae \\
\hline Cerceris specularis & Cerceris & Cercerini & Philanthinae & Crabronidae \\
\hline Cerceris tenuivittata & Cerceris & Cercerini & Philanthinae & Crabronidae \\
\hline Cerceris tuberculata & Cerceris & Cercerini & Philanthinae & Crabronidae \\
\hline
\end{tabular}


